\title{
DIE KAUSIA
}

Symbolik und Funktion der makedonischen Kleidung

Dissertation

zur Erlangung des Doktorgrades (Dr. Phil.)

an der Philosophischen Fakultät

der Georg-August-Universität zu Göttingen

vorgelegt von

Eric Janssen

aus Emden

Göttingen 2007 
D 7 - Göttinger philosophische Dissertationen

1. Gutachterin Prof. Dr. Marianne Bergmann

2. Gutachter Prof. Dr. Hartmut Döhl

Tag der mündlichen Prüfung: 05.02.2003 


\section{Inhaltsverzeichnis}

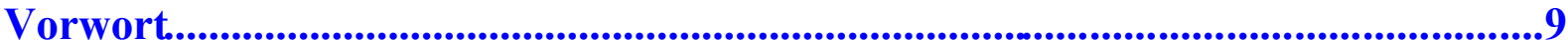

Abkürzungsverzeichnis.......................................................................................................10

1. Einleitung......................................................................................................................................13

1.1 Forschungsgeschichte und Forschungsstand........................................................................15

1.2 Kleidungsforschung in Archäologie und Ethnologie..................................................18

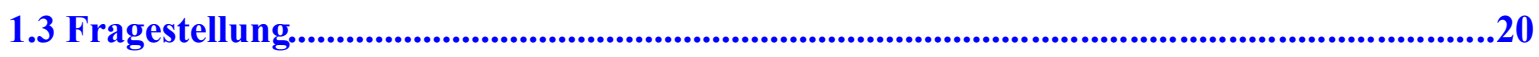

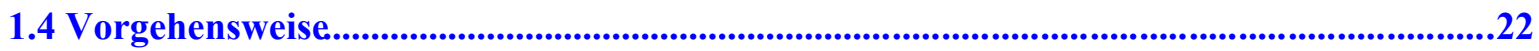

1.5 Die „Makedones“ - eine „ethnische“ Gruppe?......................................................................23

2. Die Kausia...............................................................................................................................29

2.1 Identifizierung......................................................................................................................................29

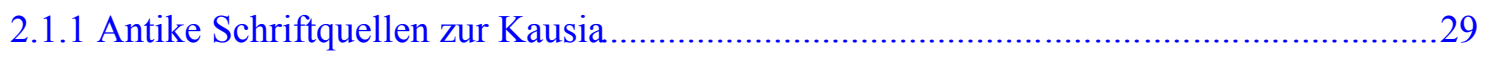

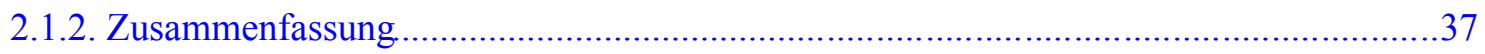

2.2 Aussehen der Kausia........................................................................................................................39

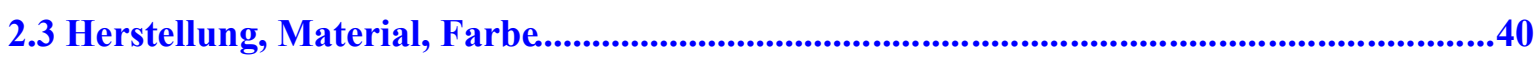

2.4 Herkunft und Verbreitung................................................................................................................43

3. Die Kausia in den archäologischen Quellen................................................................46

3.1 Szenische Darstellungen und die Kausia diadematophoros..................................................47

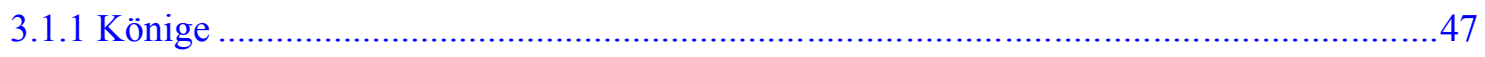

3.1.1.1 Die Kausia diadematophoros als Kopfbedeckung der Könige............................47

3.1.1.2 Die Kausia diadematophoros als Beizeichen auf Münzen.....................................67

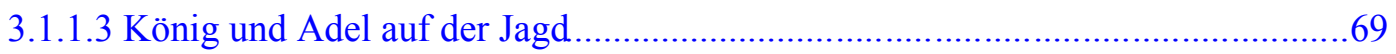

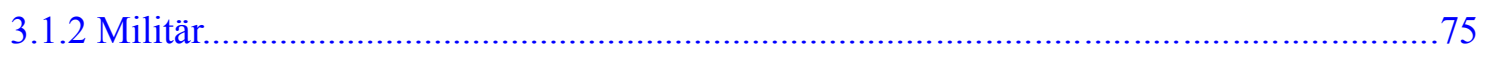

3.1.2.1 Die Kausia als Kopfbedeckung makedonischer Soldaten.................................. 75

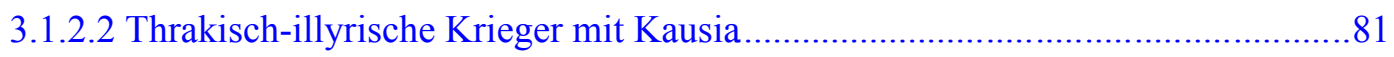

3.1.2.3 Unterschiedliche Nutzung der Kausia im militärischen Bereich..........................84

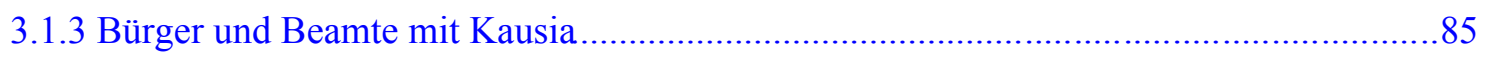

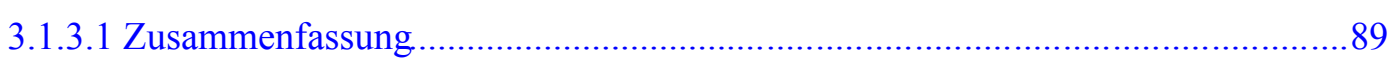

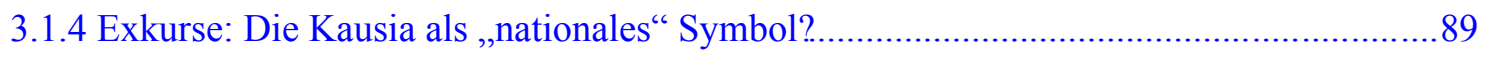

Exkurs: Die „Kausia“ im illyrisch-thrakischen Bereich...................................................8

Exkurs: Kausia und Rundschild als ,nationale Symbole“?............................................ 92

Exkurs: Personifikationen mit Kausia....................................................................... 94

3.2 Grabbeigaben und Weihungen: Statuetten aus Ton und Stein........................................97

Exkurs: Thematische und typologische Bindung der Statuetten mit Kausia............................98

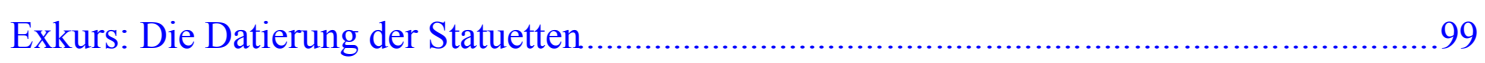




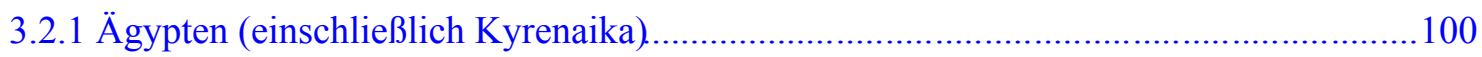

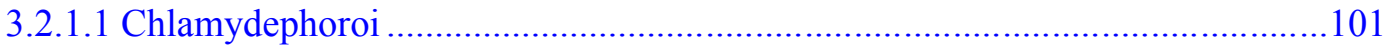

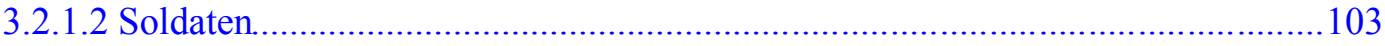

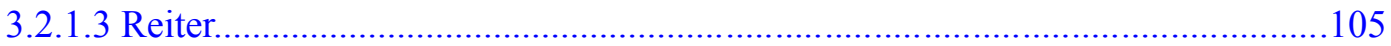

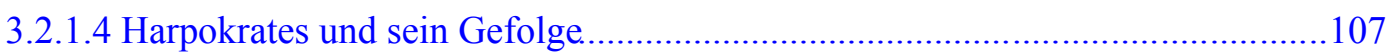

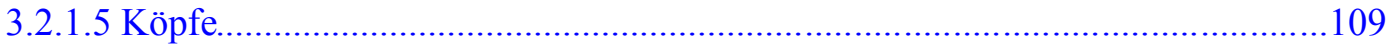

3.2.1.6 Zusammenfassung: Kleinformatige Statuetten mit Kausia aus Ägypten.............109

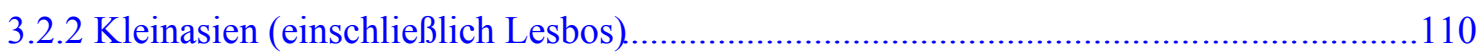

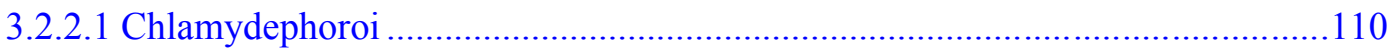

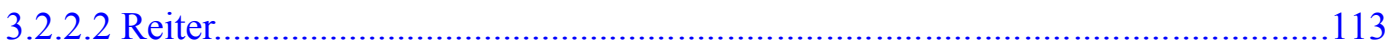

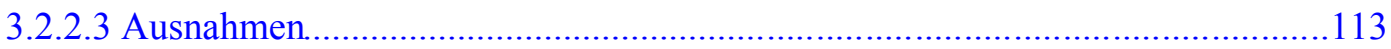

3.2.2.4 Zusammenfassung: Terrakotten mit Kausia aus Kleinasien..............................113

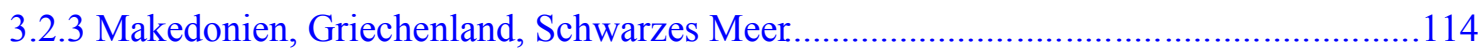

3.2.3.1 Makedonien (in den Grenzen von 359 v. Chr.).................................................115

3.2.3.2 Nordgriechische Poleis (von Philipp II. zwischen 359 und 340 v.Chr. erobert) 117

3.2.3.3 Griechische Poleis am Schwarzen Meer unter makedonischer Kontrolle..........121

3.2.3.4 Griechische Poleis im „Korinthischen Bund“....................................................122

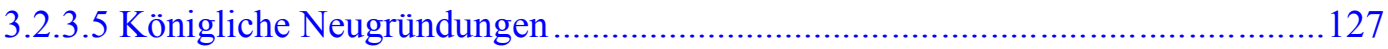

3.2.3.6 Griechische Poleis auf der Krim / Bosporanisches Reich.................................133

3.2.3.7 Zusammenfassung: Terrakotten mit Kausia auf der Balkanhalbinsel..................133

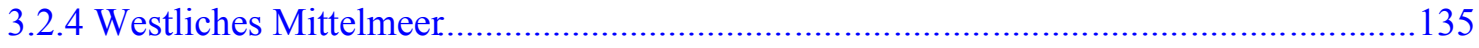

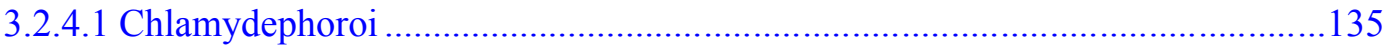

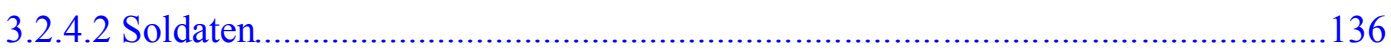

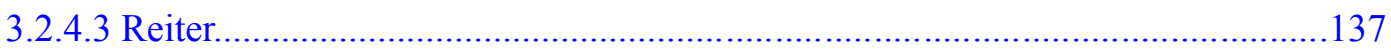

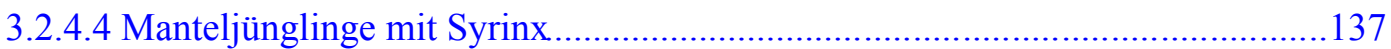

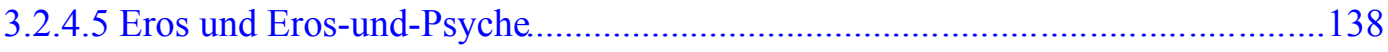

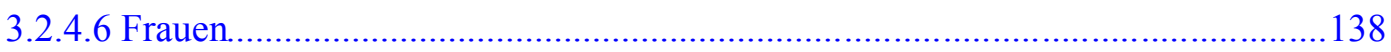

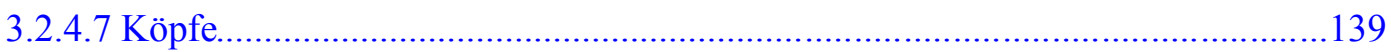

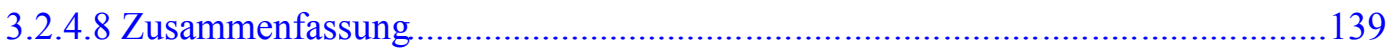

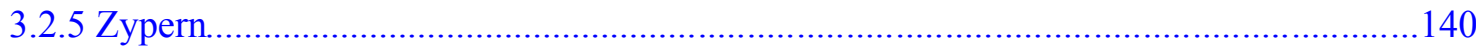

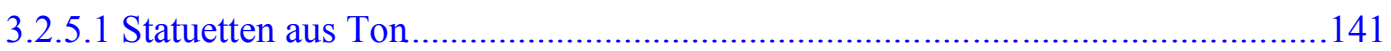

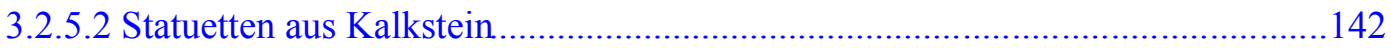

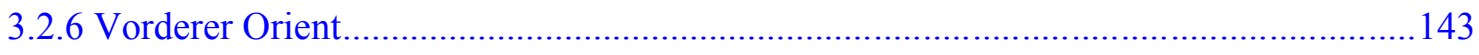

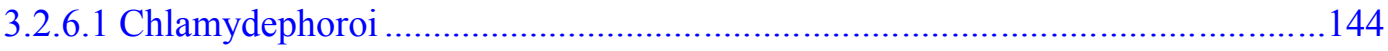

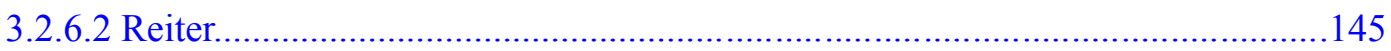

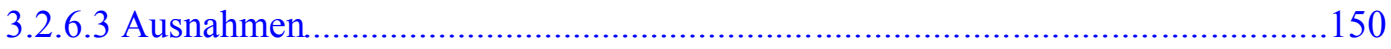

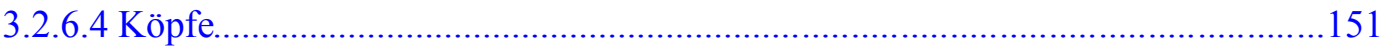

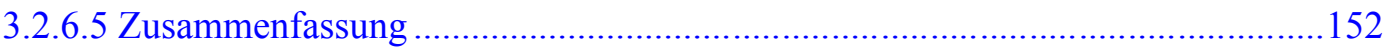

3.2.7 Zusammenfassung: Verbreitung von Statuetten mit Kausia.........................................152 
3.2.7.1 Verbreitung von Statuetten ohne Kausia am Beispiel der Chlamydephoren......153

3.2.7.2 Das Gesamtverbreitungsgebiet von Statuetten mit Kausia.................................157

3.3 Fundorte und Fundkontexte von Statuetten..............................................................................158

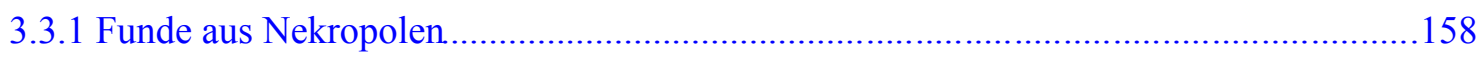

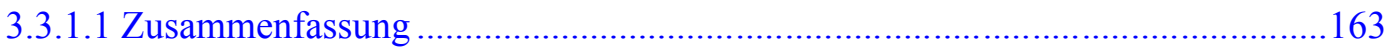

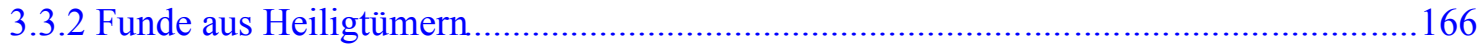

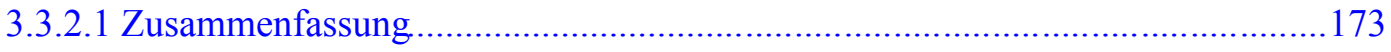

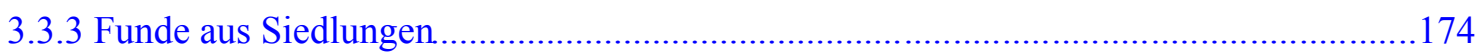

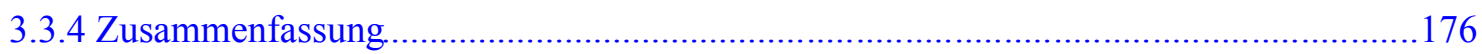

Exkurs: Nicht-koroplastische Wiedergaben aus Nekropolen und Heiligtümern.....................177

3.4 Die koroplastischen Typen und ihr kulturelles Umfeld.............................................................177

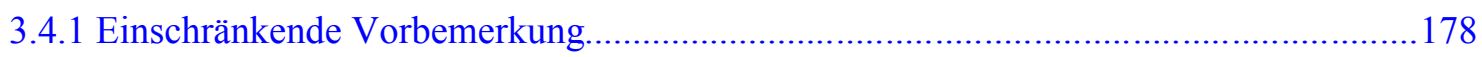

3.4.2 Chlamydephoroi: Paides, Epheboi und Neoi und das Gymnasion................................179

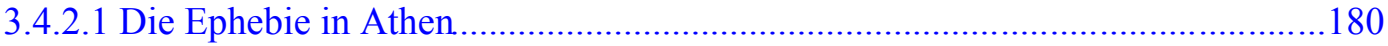

3.4.2.2 Erziehung und Ephebie in hellenistischer Zeit.................................................181

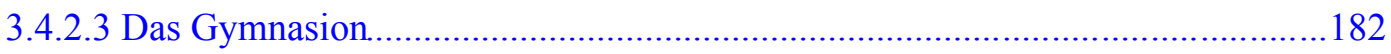

3.4.2.4 Bedeutung von Ephebie und Gymnasion in hellenistischer Zeit........................183

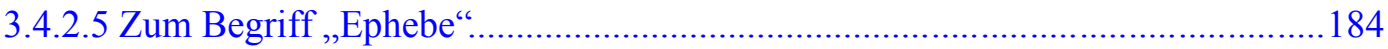

3.4.2.6 Zur Benennung der Chlamydephorenstatuetten................................................ 185

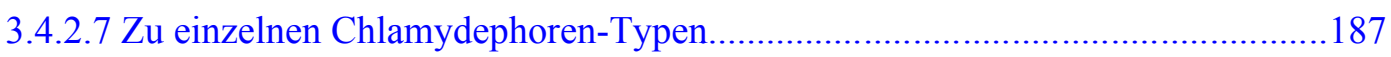

3.4.2.8 Zur primär-synchronen Funktion von Chlamydephoren-Statuetten................... 189

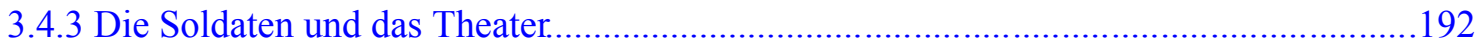

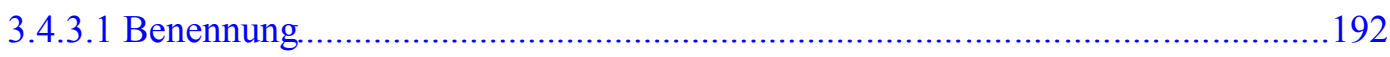

3.4.3.2 Bedeutung von Heer und Theater...................................................................... 194

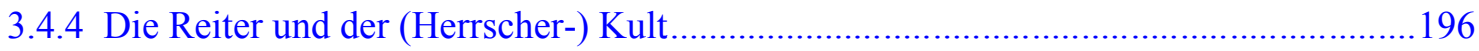

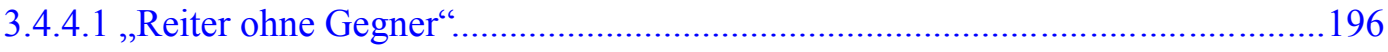

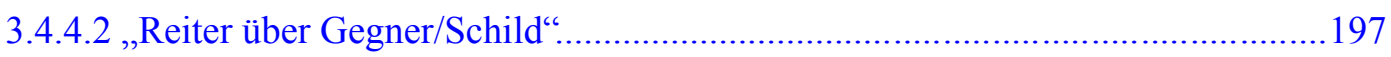

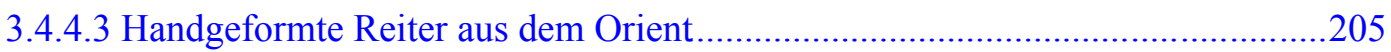

\section{Unterschiedliche Häufigkeit von Darstellungen in einzelnen Regionen und}

Gattungen................................................................................................................................210

4.1 Die Verbreitung in den einzelnen Regionen.........................................................................210

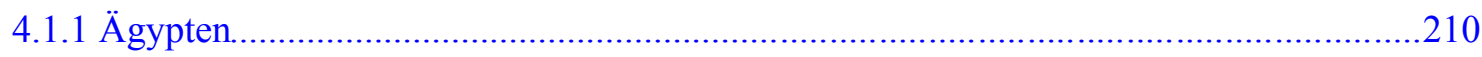

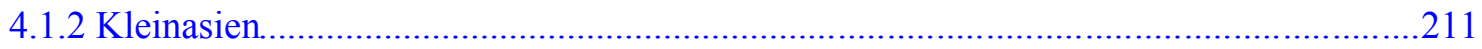

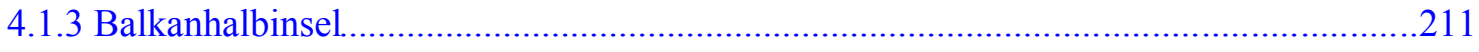

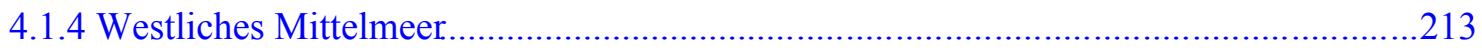

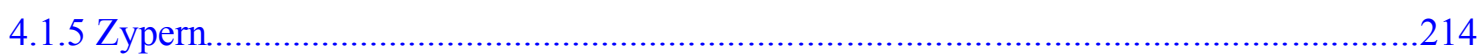

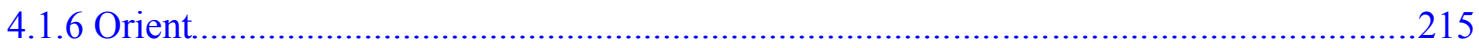

4.1.7 Exkurs: Eine kausiaähnliche Mütze im zypriotisch-phönizisch-punischen Raum..........216 


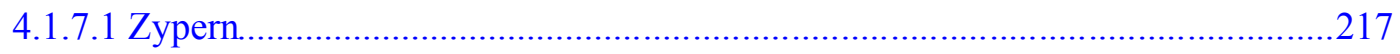

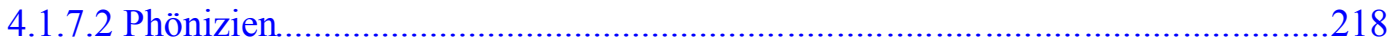

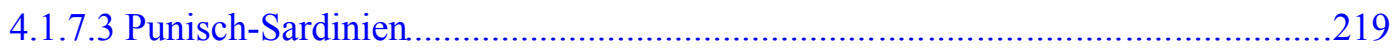

4.2 Die Kausia in unterschiedlichen Bildgattungen........................................................219

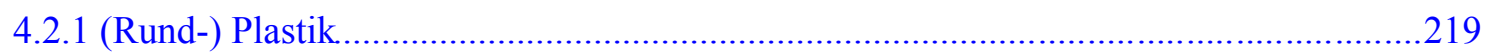

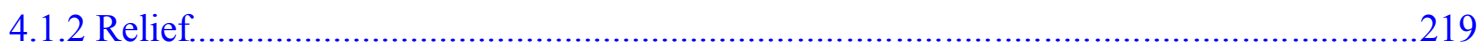

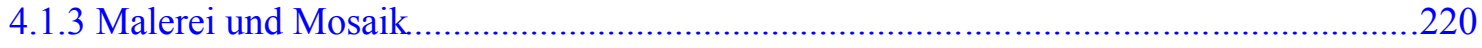

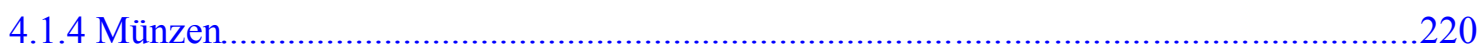

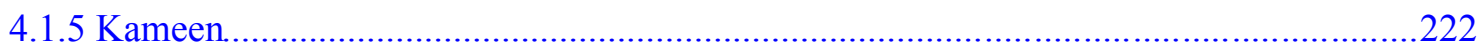

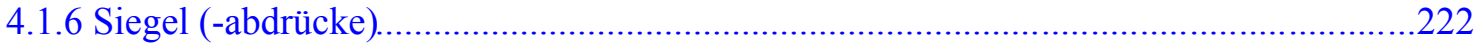

4.3 Zusammenfassung der Besonderheiten in Regionen und Gattungen................................226

4.3.1 Besonderheiten der Symbolik und Funktion in einzelnen Regionen.............................226

4.3.2 Besonderheiten der Symbolik und Funktion in einzelnen Gattungen............................227

5. Die Kausia als Kopfbedeckung bestimmter Personengruppen ...........................228

5.1 Vorbemerkung und Forschungsgeschichte..................................................................................228

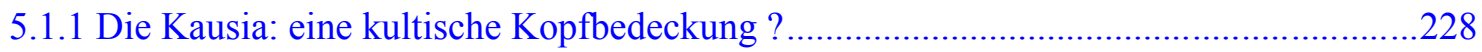

5.1.2 Die Kausia: eine Kopfbedeckung ausschließlich der basilikoi paides? .........................230

5.2 Personengruppen mit Kausia in den literarischen Quellen....................................................236

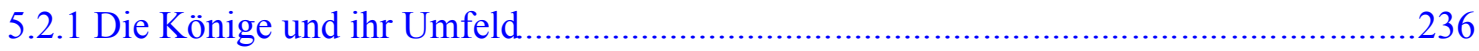

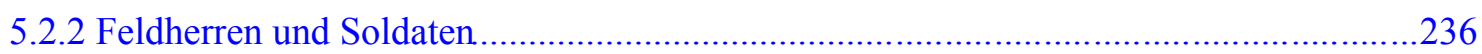

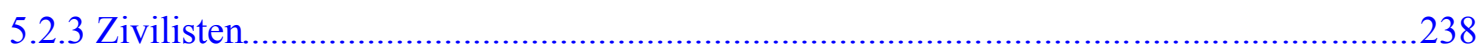

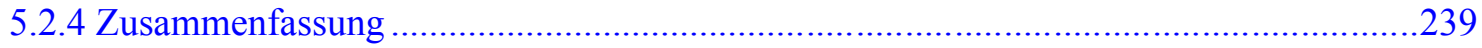

5.3 Personengruppen mit Kausia in den archäologischen Quellen............................................240

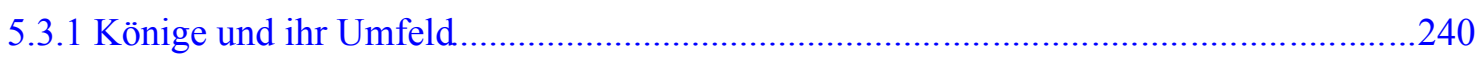

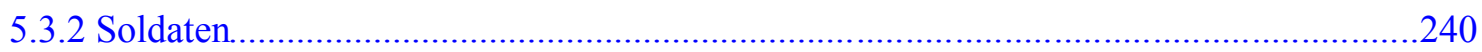

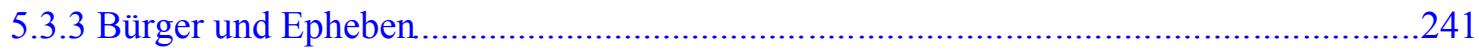

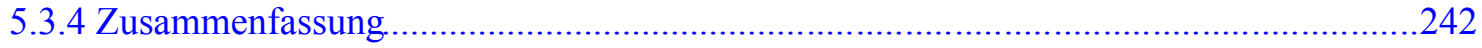

5.4 Literarische und archäologische Quellen im Vergleich - eine Zusammenfassung..........242

6. Symbolik und Funktion........................................................................................244

6.1 Symbolik und Funktion in szenischen Darstellungen..........................................................244

6.1.1 Symbolik und Funktion der Kausia im herrschaftlichen Bereich..................................244

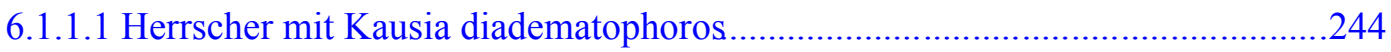

6.1.1.2 Die isolierte Kausia diadematophoros..........................................................245

6.1.1.3 Königliche Jagdgesellschaften: Herrscher mit einfacher Kausia?.......................245

6.1.2 Symbolik und Funktion der Kausia im militärischen Bereich.......................................246

6.1.3 Symbolik und Funktion der Kausia im bürgerlichen Bereich.......................................246

6.1.4 Symbolik und Funktion der Kausia von Personifikationen..........................................247

6.2 Symbolik und Funktion der Statuetten in Kult und Gesellschaft...................................248 


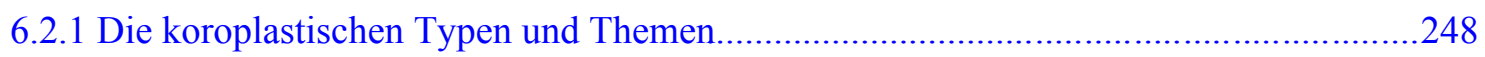

6.2.1.1 Die Reiter: Könige, Soldaten und Epheben?..................................................248

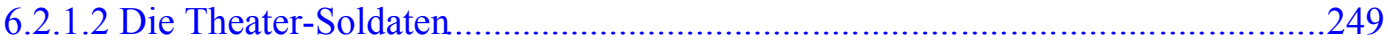

6.2.1.3 Chlamydephoren: Paides, Epheben, Neoi und Soldaten?.................................250

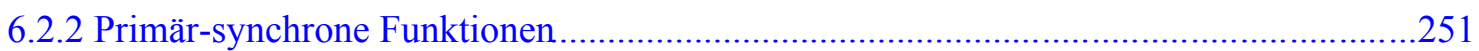

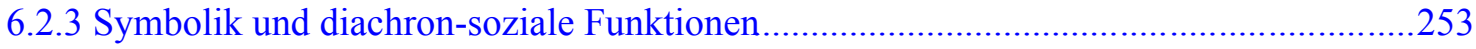

7. Zusammenfassung................................................................................................................259

7.1 Die Kausia als Realie.................................................................................................................259

7.2 Primär-synchrone Funktionen der Kausia als realem Bestandteil der makedonischen

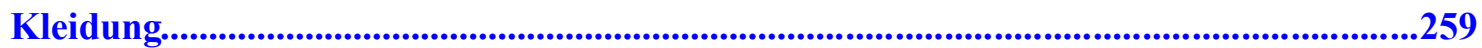

7.3 Symbolik und diachron-soziale Funktion der Kausia als Realie und in bildlichen

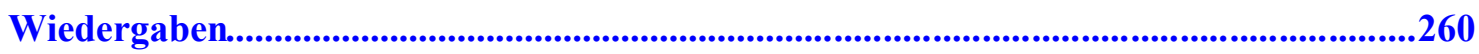

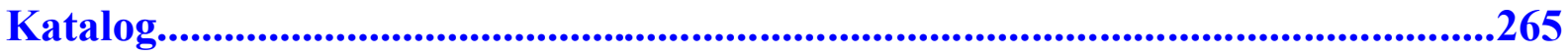

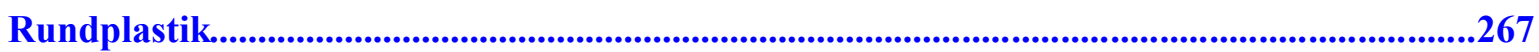

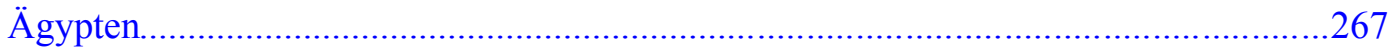

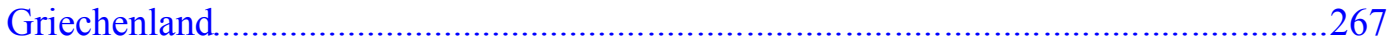

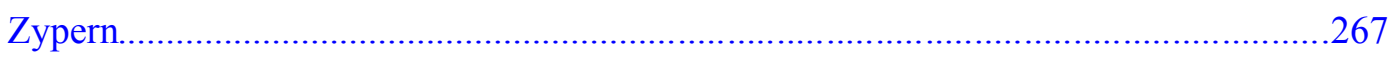

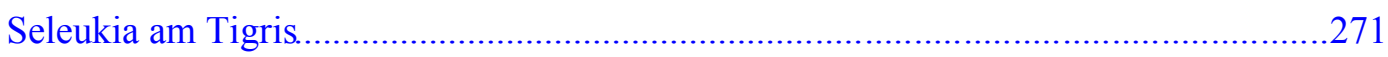

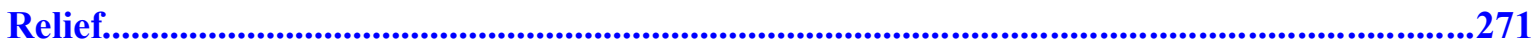

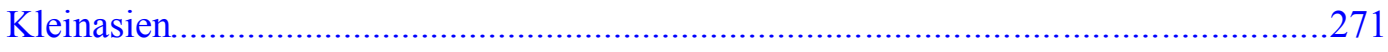

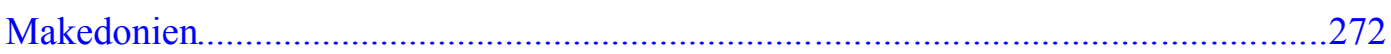

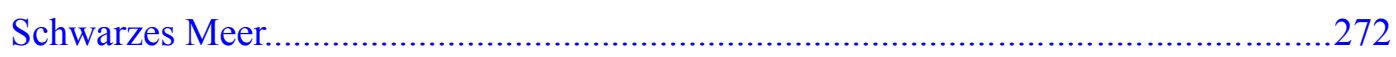

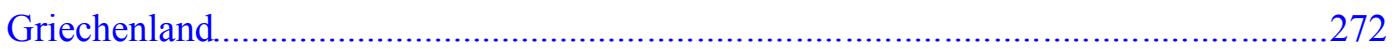

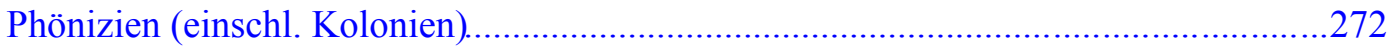

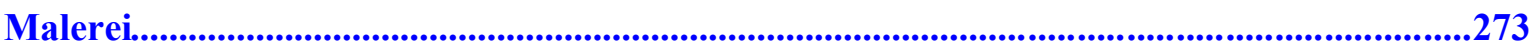

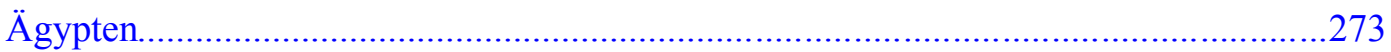

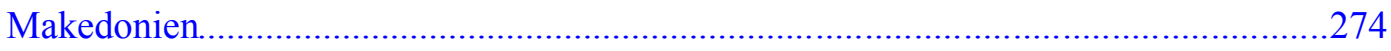

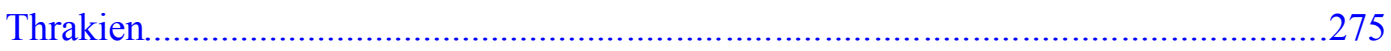

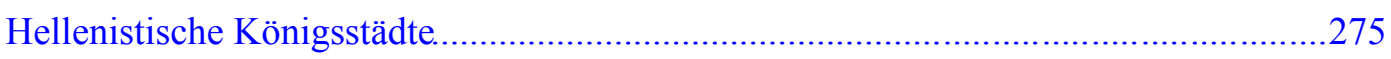

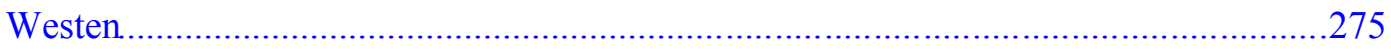

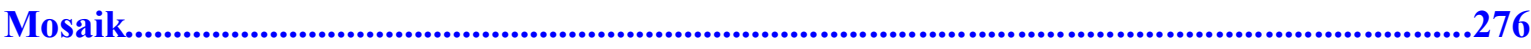

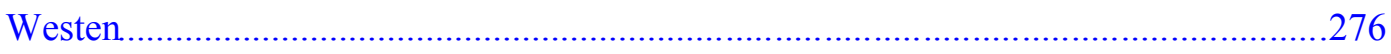

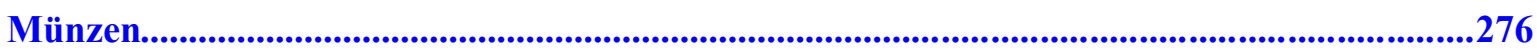

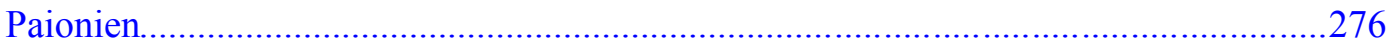

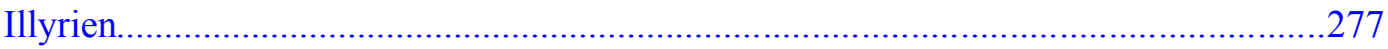

Makedonische Reichsprägestätte Amphipolis........................................................27

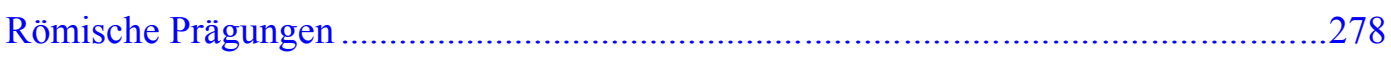

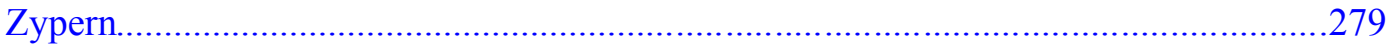




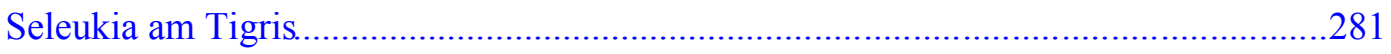

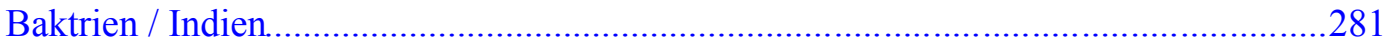

Kameen...................................................................................................................................................284

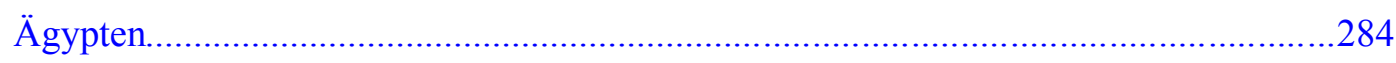

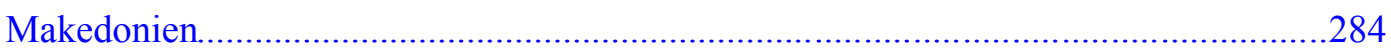

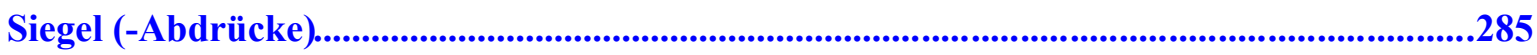

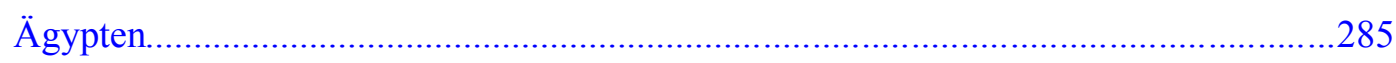

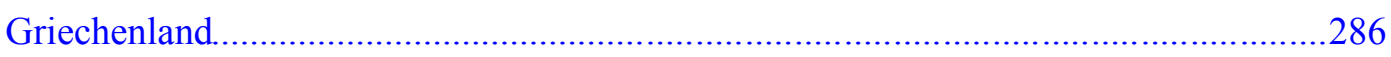

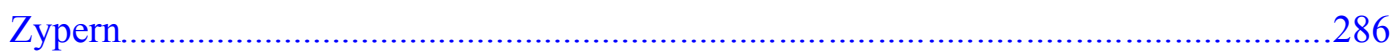

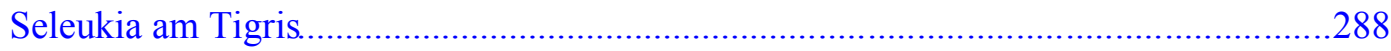

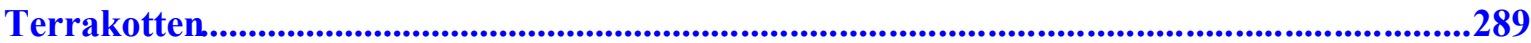

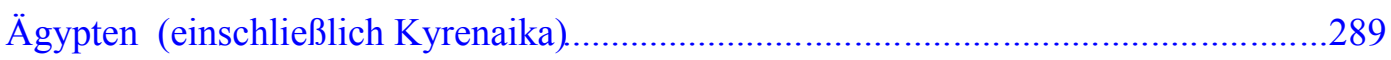

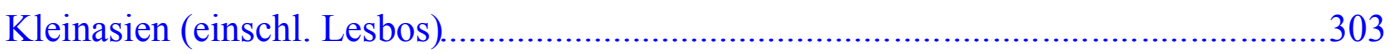

Griechenland, Makedonien und Schwarzes Meer........................................................310

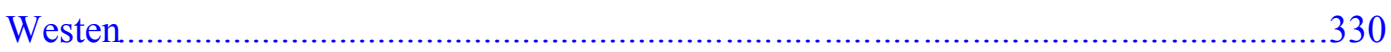

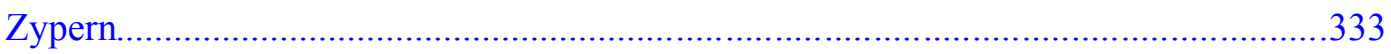

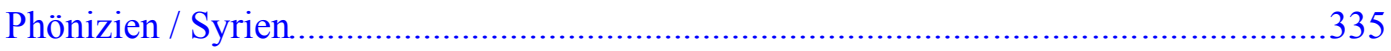

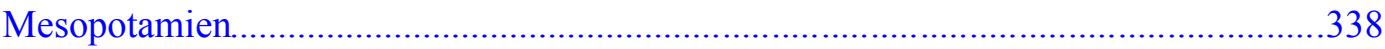

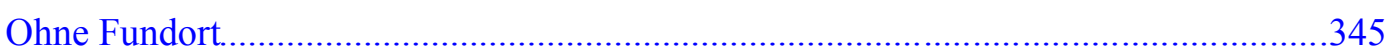

Literaturverzeichnis............................................................................................347

Abbildungsnachweis.......................................................................................361

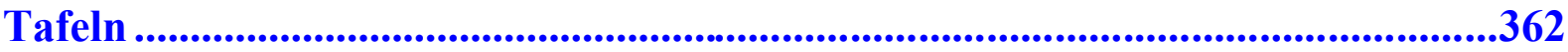




\section{Vorwort}

Bei der vorliegenden Publikation handelt es sich um die überarbeitete Fassung einer Arbeit, die im Sommersemester 2002 von der philosophischen Fakultät der Georg-August-Universität Göttingen als Dissertation angenommen wurde.

Direkt im Anschluss nahm ich parallel zur Vorbereitung der Disputation im Februar 2003 im Wintersemester 2002/03 ein Studium der Evangelischen Theologie auf, das ich im Juni 2007 abschloss. Aus diesem Grund erscheint diese Arbeit erst jetzt.

Die seit 2002 erschienene Literatur konnte nur noch teilweise eingearbeitet werden.

Im Abbildungsteil wird das archäologische Material in der Regel in Strichzeichnungen wiedergegeben. Dies liegt in der Methodik dieser Arbeit begründet: Relevant ist die Erkennbarkeit der Typologie; eine Untersuchung stilistischer Merkmale, die die Verwendung von Photographien geboten hätte, tritt zurück. Die Korrektheit der Zeichnungen kann gegebenenfalls anhand der im Katalog verzeichneten Publikationen überprüft werden.

Mein besonderer Dank gilt Frau Prof. Dr. M. Bergmann, die mich zur Beschäftigung mit dem Thema anregte und mir in allen Stadien der Arbeit mit Rat und Kritik zu Seite stand. Ferner bin ich Herrn Prof. Dr. Döhl für das Korreferat zu Dank verpflichtet. Zu danken ist auch allen anderen Mitarbeiterinnen und Mitarbeitern des Archäologischen Instituts der Universität Göttingen sowie allen Personen im In- und Ausland, die mich durch Hinweise und Ratschläge unterstützten. Nicht vergessen seien auch die Studierenden in Göttingen, die maßgeblich zu einer guten Arbeitsatmosphäre beitrugen, sowie M. Rosenau M.A. (Theologisches Stift), der mir bei der Erstellung der Druckvorlage half.

$\mathrm{Zu}$ danken habe ich ferner dem Land Niedersachsen, das mir ein Graduiertenstipendium gewährte.

Abschließend gilt mein Dank meinen Eltern, ohne deren uneingeschränkte Unterstützung diese Arbeit nicht hätte entstehen können.

Göttingen, im Dezember 2007 


\section{Abkürzungsverzeichnis}

Außer den in der Archäologischen Bibliographie 1988, S. X ff., im Archäologischen Anzeiger 1989, 721 ff. und im Kleinen Pauly I (1964) S. XXI ff. (antike Autoren und Werke) angegebenen werden folgende Abkürzungen verwendet:

Adriani, Annuaire III

Arvanitopoulos, Demetrias

Bayer-Niemeier, Frankfurt

Besques, Paris III

Besques, Paris IV-I

Besques, Paris IV-II

Breccia, Sciatbi

Breccia, Alexandria II 1

Breccia, Alexandria II 2

Burr-Thompson, Troy

Burckhardt, Bürger und Soldaten
A. Adriani, Annuaire du Musée Gréco-Romaine 1940-50, 1952

A. Arvanitopoulos, $\Gamma \rho \alpha \pi \tau \alpha \hat{\imath} \quad \Sigma \tau \eta \hat{\lambda} \alpha \iota \quad \Delta \eta \mu \eta \tau \rho\llcorner\alpha ́ \delta o \varsigma$ $\Pi \alpha \gamma \alpha \sigma \omega \hat{\nu}$ (1928)

E. Bayer-Niemeier, Griechisch-römische Terrakotten. Bildwerke der Sammlung Kaufmann, Band 1. Liebieghaus-Museum Alter Plastik. Frankfurt am Main (1988)

S. Besques, Musée National du Louvre. Catalogue raisonnée des figurines et reliefs en terre-cuite grecs, étrusques et romaines III-I. Epoques hellénistique et romaine. Grèce et Asie Mineure (1972)

S. Besques, Musée National du Louvre. Catalogue raisonnée des figurines et reliefs en terre-cuite grecs, étrusques et romaines IV-I. Epoques hellénistique et romaine. Italie méredionale - Sicile - Sardaigne (1986)

S. Besques, Musée National du Louvre. Catalogue raisonnée des figurines et reliefs en terre-cuite grecs, étrusques et romaines IV-II. Epoques hellénistique et romaine. Cyrénaique, Égypte ptolémaique et romaine, Afrique du Nord et Proche Orient (1992)

E. Breccia, La necropoli di Sciatbi (1912)

E. Breccia, Terrecotte figurate greche e greco-egizie del Museo di Alessandria. Monuments de 1'Égypte gréco-romaine II 1 (1930)

E. Breccia, Terrecotte figurate greche e greco-egizie del Museo di Alessandria. Monuments de l'Égypte grécoromaine II 2 (1934)

D. Burr-Thompson, Troy III. The Terracotta Figurines of the Hellenistic Period (1963)

L. Burckhardt, Bürger und Soldaten. Aspekte der politischen und militärischen Rolle athenischer Bürger im 
Canarache, Kallatis

Chéhab, Kharayeb

Dintsis, Helme

Dunand, Paris

Dusenbery, Samothrake

Fischer, Slg. Sieglin/Schreiber

Hesberg, Gymnasion

Hornung-Bertemes, Demetrias

Ingen, Seleukia

Leyenaar-Plaisier, Leiden

Marrou, Erziehung

Mollard-Besques, Paris II

Nilsson, Schule

Pingiatoglou, Benaki
Kriegswesen des 4. Jahrhunderts v.Chr., Historia Einzelschriften 101 (1996)

V. Canarache, Masken und Tanagra-Figuren aus Werkstätten von Callatis-Mangalia (1969)

M. H. Chéhab, Les terres cuites de Kharayeb (1951/52, 1953/54)

P. Dintsis, Hellenistische Helme (1986)

F. Dunand, Terres cuites gréco-romaine d'Égypte. Musée du Louvre, Département des Antiquites Égytiennes (1990)

E. B. Dusenbery, Samothrace - The Necropoleis, Samothrace 11 (Hrsgg.: K. Lehmann/Ph. Williams Lehmann) (1998)

J. Fischer, Griechisch-römische Terrakotten aus Ägypten.

Die Sammlungen Sieglin und Schreiber. DresdenLeipzig-Stuttgart- Tübingen (1994)

H. von Hesberg, Das griechische Gymnasion im 2. Jh. v.Chr., in: M. Wörrle/P. Zanker (Hrsgg.), Stadtbild und Bürgerbild im Hellenismus (Kolloquium München 1993) (1995) $13 \mathrm{ff}$.

K. Hornung-Bertemes, Die „Kausia“-Darstellungen aus Demetrias, in: A. Muller (Hrsg.), Le moulage en terre cuite dans l'antiquité: creation et production derivée, fabrication et diffusion (Kolloquium Lille 1995) (1997/99) 181206

W. van Ingen, Figurines from Seleucia on the Tigris (1939)

P. G. Leyenaar-Plaisier, Les terres cuites gréques et romaines I-III. Catalogue de la Collection du Musée National des Antiquites a Leiden (1979)

H. I. Marrou, Geschichte der Erziehung im Klassischen Altertum (1977 [= Taschenbuchauflage nach der 7. Aufl.]) (franz. Erstaufl. 1948)

S. Mollard-Besques, Musée National du Louvre. Catalogue raisonnée des figurines et reliefs en terre-cuite grecs, étrusques et romaines II. Myrina (1963)

M. P. Nilsson, Die hellenistische Schule (1955)

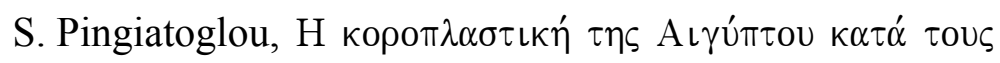

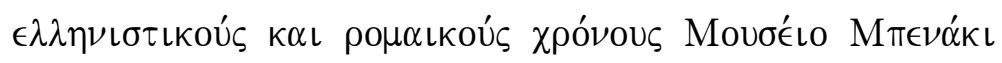

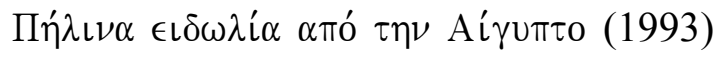


Saatsoglou-Paliadeli, Costume

Schubert, Kleidung

Schürmann, Karlsruhe

Weber, Berlin

Winter, Typen II
Ch. Saatsoglou-Paliadeli, Aspects of Ancient Macedonian Costume, JHS 113, 1993, 122 ff.

G. Schubert, Kleidung als Zeichen. Kopfbedeckungen im Donau-Balkanraum, Balkanologische Veröffentlichungen 20 (1993 [Habilitationsschrift, FU Berlin, 1991])

W. Schürmann, Katalog der antiken Terrakotten im badischen Landesmuseum Karlsruhe (1989)

W. Weber, Die ägyptisch-griechischen Terrakotten. Königliche Museen zu Berlin. Mitteilungen aus der Ägyptischen Sammlung II (1914)

R. Kekulé von Stradonitz (Hrsg.), Die antiken Terrakotten III. F. Winter, Die Typen der figürlichen Terrakotten II (1903) 


\section{Einleitung}

Die Kausia wird in der antiken Literatur als flache Mütze beschrieben, die in erster Linie von Makedonen, insbesondere makedonischen Königen und ihrem Gefolge, getragen wurde. Meist wird sie mit einer barettartigen Kopfbedeckung identifiziert, wie sie auf zahlreichen antiken Denkmälern wiedergegeben ist. Im Aussehen entspricht die betreffende Kopfbedeckung in etwa einer Matrosen- oder Baskenmütze. Insbesondere eine im afghanisch-pakistanischen Grenzgebiet getragene Kopfbedeckung namens Chitrali weist bis in die Details hinein große Ähnlichkeit mit der Kausia auf, ohne dass deshalb die eine das Vorbild der anderen gewesen sein muss.

Es sind - meines Wissens - rund 30 Erwähnungen der Kausia in der antiken Literatur sowie mehr als 740 bildliche Wiedergaben erhalten. ${ }^{1}$ Die Darstellungen verteilen sich auf verschiedene Kunstgattungen. Es finden sich Beispiele in der Rundplastik und im Relief, in der Koroplastik, in der Malerei und im Mosaik, auf Münzen, Kameen und Siegelabdrücken. Diese entstammen Gebieten zwischen Frankreich im Westen, Pakistan im Osten, der Krim im Norden und Mittelägypten im Süden und Zeiträumen zwischen dem mittleren 4. Jahrhundert v.Chr. und dem 3. Jahrhundert n.Chr.

Die thematischen Schwerpunkte der literarischen und der archäologischen Quellen weichen von einander $a b$, wie auch die bildlich dargestellten Themen von Gattung zu Gattung variieren und es innerhalb einzelner Gattungen je nach Region und Zeitabschnitt zu unterschiedlichen Gewichtungen thematischer und typologischer Art kommen kann.

Während die Kausia beispielsweise im archäologischen Material selten als Kopfbedeckung hellenistischer Herrscher erscheint, ist sie in der schriftlichen Überlieferung typisch für Alexander und die auf diesen folgenden Könige. So zeigt nur ein einziges rundplastisches Herrscherporträt einen Ptolemäerkönig mit Kausia. Das ganz in ägyptisierendem Stil gehaltene Beispiel stellt jedoch aus verschiedenen Gründen die Ausnahme dar. Auch auf hellenistischen Münzen, deren Vorderseiten regelmäßig das Bildnis des Herrschers bieten, wird der König nur auf den Prägungen der ganz am Rande der hellenistischen Welt liegenden baktrischen und indo-griechischen Reiche mit Kausia wiedergegeben. Dagegen werden auf Siegeln und Kameen gelegentlich Vertreter aller großen hellenistischen Dynastien mit der Kausia dargestellt (Ptolemäer, Seleukiden, Antigoniden).

Neben einigen Personengruppen (z.B. Soldaten), die sowohl in den Schrift- als auch den Bildquellen mit der Kausia erscheinen, finden sich im archäologischen Material Hunderte von Darstellungen von Knaben und jungen Männern, die neben der Kausia meist mit Chlamys, Chiton und Stiefeln bekleidet sind. Es handelt sich um Statuetten aus Ton und vereinzelt auch

\footnotetext{
${ }^{1}$ Es handelt sich hierbei um mindestens 624 Terrakotten, 35 rundplastische Werke aus Stein, neun Reliefs, 13 Beispiele aus Malerei und Mosaik, 37 numismatische Darstellungen, drei Kameen und 20 Siegelabdrücke (vgl. Katalog).
} 
aus Stein. Eine Deutung dieser kleinformatigen Figuren ist allein auf der Grundlage literarischer Quellen bisher nicht möglich.

Die in der literarischen und der materiellen Überlieferung unterschiedliche Beschreibung des Kreises der Träger der Kausia mag teilweise in den griechischen Darstellungskonventionen begründet liegen. So wurde vor allem in der Rundplastik die Kleidung oft nur in Auswahl wiedergegeben. Der Kreis der Träger der Kausia wird auch aufgrund des eingeschränkten Spektrums der in der antiken Literatur der Überlieferung für wert befundenen Themen zu eng umschrieben sein.

Diese Auswahlkriterien allein erklären jedoch nicht das geographisch, chronologisch und gattungsmäßig sehr unterschiedliche Auftreten von Darstellungen von Personen mit Kausia: Sie begründen weder, warum die Kausia regelmäßig die Münzbildnisse indo-baktrischer Könige ziert, im antigonidischen, seleukidischen oder ptolemäischen Bereich jedoch nie als Kopfbedeckung des Herrschers auftritt, noch die gattungsübergreifende Konzentration von Darstellungen des Königs mit Kausia auf bestimmte Zeiten. Auch die Unterschiede zwischen verschiedenen Regionen, so das Auftreten unterschiedlicher Themen und hiermit verbunden das Vorkommen bestimmter Gattungen in einzelnen Gebieten, bedürfen anderer Deutungen. So werden in Makedonien Könige, Soldaten, Jäger, Männer auf dem Weg zum Symposion sowie Knaben und junge Männer mit Kausia wiedergegeben und zwar auf Kameen, in der Grabmalerei und auf gemalten oder reliefierten Grabstelen sowie vereinzelt in Form von Terrakottastatuetten. In Kleinasien dagegen ist das Spektrum weitestgehend auf Statuetten junger, männlicher Personen (in zunächst unklarem Kontext) beschränkt. Auch das zeitliche Auftreten und Verschwinden bestimmter Gattungen schwankt regional: So endet die Produktion von Terrakotten mit Kausia in einigen Gebieten (z.B. Makedonien/Griechenland und Ägypten) mit dem politischen Ende des Hellenismus, während sie in anderen Regionen (Kleinasien, Mesopotamien) nach der Eroberung durch die Römer bzw. Parther wahrscheinlich noch Jahrhunderte andauert. Während einerseits in bestimmten Regionen nur bestimmte Typen von Statuetten auftreten (in Kleinasien fast ausschließlich Chlamydephoren, in Ägypten Chlamydephoren, Reiter und Soldaten, im nördlichen Mesopotamien Reiter und Chlamydephoren, in südlichen Mesopotamien ausschließlich Reiter), stimmt das Typenspektrum in demographisch und politisch ähnlich strukturierter Ortschaften (z.B. den königlichen Neugründungen Demetrias [Thessalien], Alexandria [Ägypten], Seleukia am Tigris) regionsübergreifend überein (vorwiegend Chlamydephoren). In Makedonien schließlich, dem Mutterland der Kausia, fehlen koroplastische Darstellungen der Kausia weitgehend, während diese Kopfbedeckung dort in anderen Gattungen relativ häufig erscheint.

Diese und andere Eigenarten der geographischen, chronologischen, gattungsmäßigen und typologischen Verteilung der bildlichen Darstellungen von Personen mit Kausia sind auf ihre Bedeutung hin zu befragen. Den Gründen für die Streuung entsprechender Wiedergaben eines zentralen Elements der makedonischen Selbstdarstellung nachzugehen, ist eines der Ziele dieser Arbeit. 


\subsection{Forschungsgeschichte und Forschungsstand}

Es sind rund 740 Darstellungen der Kausia allein oder kausiatragender Personen publiziert. Die Zahl der Erwähnungen in der Literatur (meist Grabungsberichte und Museums- bzw. Ausstellungskataloge) ist entsprechend hoch. Ich werde mich im Rahmen dieser Forschungsübersicht darauf beschränken, diejenigen Untersuchungen anzusprechen, die sich in grundlegender Weise zu Problemen geäußert haben, die in Zusammenhang mit der Erforschung der Kausia diskutiert wurden.

Die Anfänge der Erforschung der Kausia reichen bis ins 19. Jahrhundert zurück. Seit dieser Zeit wird die Kausia in altertumswissenschaftlichen Nachschlagewerken sowie Zeitschriften mit kleineren Artikeln bedacht. Zu nennen sind hier besonders die Lexikonartikel von L. Heu$z^{2}{ }^{2}$ und von A. von Netoliczka ${ }^{3}$ aus den Jahren 1896 und 1921 sowie ein Aufsatz von E. Wuescher-Becchi ${ }^{4}$ aus dem Jahre 1904. Gemeinsam war diesen frühen Versuchen, dass sie sich in erster Linie auf die damals zum größten Teil schon bekannten schriftlichen Quellen stützten. Sie referierten korrekt die dort gegebenen Informationen, nach denen es sich bei der Kausia um eine flache Mütze handelt, die von Makedonen getragen wurde, insbesondere auch makedonisch-hellenistischen Königen, die sie mit einem Diadem umwanden. Die anschließenden Bemühungen, diese Ergebnisse auf das archäologische Material zu übertragen und bildliche Wiedergaben der Kausia zu identifizieren, verliefen jedoch wenig erfolgreich. Meist wurden fälschlich Darstellungen des Petasos oder des böotischen Helmes als solche der Kausia bezeichnet. ${ }^{5}$

Neue Impulse gingen nach dem 2. Weltkrieg von primär am archäologischen Material orien-

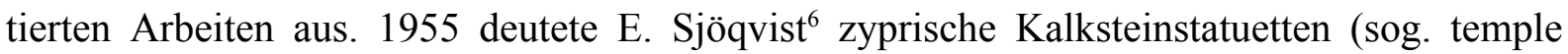
boys) und Tonfiguren, die eine flache Kopfbedeckung tragen, in der er die Kausia erkennen wollte, als Darstellungen von Tempeldienern oder gar männlichen Tempelprostituierten im zyprischen Aphrodite-Kult und sprach der Kausia selbst eine kultische Bedeutung zu.

Dieser ganz an den Verhältnissen auf Zypern orientierten Sichtweise widersprach D. BurrThompson ${ }^{7}$ im Rahmen der Publikation der hellenistischen Terrakotten aus Troja, unter denen sich auch koroplastische Wiedergaben junger männlicher Personen mit Kausia finden. Sie sprach die betreffende Kopfbedeckung als makedonische Kausia an, erkannte den Statuetten, die sich auch in Troja in Heiligtümern weiblicher Gottheiten fanden, jedoch ebenfalls Votivcharakter zu und sah in den Dargestellten Anhänger der Göttin.

\footnotetext{
2 Daremberg-Saglio I, 2 (1896) 975 f. s.v. Causia (L. Heuzey).

${ }^{3}$ RE XI (1921) 89-93 s.v. k $\alpha v \sigma i ́ \alpha$ (A. v. Netoliczka).

${ }^{4}$ E. Wuescher-Becchi, Petasus e Causia, BullCom 32, 1904, 93-110.

${ }^{5}$ So finden sich unter den sechs bei L. Heuzey (Daremberg-Saglio I 2 [1886] 975 f. s.v. Causia) abgebildeten Kopfbedeckungen zwei Petasoi, drei Helme und nur eine Kausia.

${ }^{6}$ E. Sjöqvist, A Cypriot Temple Atttendant, AJA 59, 1955, 47.

${ }^{7}$ D. Burr-Thompson, Troy III. The Terracotta Figurines of the Hellenistic Period (1963).
} 
Anfang der 80er Jahre schlug B. M. Kingsley ${ }^{8}$ vor, nicht mehr, wie bisher, Makedonien als Ursprungsgebiet der Kausia anzusehen, sondern Afghanistan. Dort wird noch heute eine in Aussehen und Machart identische Mütze („Chitrali“) getragen. Ihrer Meinung nach sollten die Soldaten des Alexanderheeres einen antiken Vorläufer dieser Kopfbedeckung nach Westen gebracht haben. Diese These gilt mittlerweile als überholt, da sich, wie die Forschungen der folgenden Jahre gezeigt haben, die Kausia im mediterranen Raum schon vor Beginn der Eroberung des Perserreiches nachweisen lässt. Die Untersuchung bietet dennoch weiterhin die einzig sinnvolle Rekonstruktion der Herstellungsweise einer Kausia.

Eine 1982 eingereichte und 1986 erschienene Dissertation von P. Dintsis ${ }^{9}$ über die Helme hellenistischer Zeit beschäftigt sich im fünfzehnten und letzten Kapitel mit der Kausia. Anhand der Schriftquellen untersucht diese Arbeit nochmals allgemeine Fragen zu deren Aussehen, Herstellung, Verbreitung und Verwendung. Darüber hinaus geht das Werk entsprechend seiner Gesamtausrichtung auf Aspekte der Kausia als einem militärischen Ausrüstungsgegenstand hellenistischer Heere ein. Der angeschlossene Katalog umfasst 20 Darstellungen, die die Kausia in einem mehr oder weniger militärischen Umfeld zeigen. Es handelt sich hierbei um die bisher umfangreichste gattungsübergreifende Zusammenstellung von bildlichen Wiedergaben der Kausia.

In den Jahren zwischen 1986 und 1993 erschien eine Reihe von Aufsätzen, deren Ausgangspunkt meist die Untersuchung des sog. Philippsgrabes bei Vergina war. Auf dem Fries an der Fassade dieses Grabes werden einige der dort dargestellten Jäger mit Kausien wiedergegeben. $\mathrm{Zu}$ nennen sind insbesondere die Beiträge von A. M. Prestianni-Giallombardo ${ }^{10}$ und Ch. Saatsoglou-Paliadeli ${ }^{11}$, die die Diskussion vorerst abschließen. ${ }^{12}$ Als Materialgrundlage dienen beiden Autorinnen die antiken Schriftquellen sowie der Katalog bei Dintsis ${ }^{13}$. Darüber hinaus führen sie nur eine sehr begrenzte Anzahl neuer Darstellungen der Kausia an.

\footnotetext{
${ }^{8}$ B. M. Kingsley, The Cap that Survived Alexander, AJA 85, 1981, 39-46. Vgl. auch dies., The „Chitrali“. A Macedonian Import to the West, Afghanistan Journal 8, 1981, 90-93 .- dies., The Kausia Diadematophoros, AJA 88, 1984, 66 ff. .- dies., Alexander's Kausia and Macedonian Tradition, ClAnt 10, 1991, $59-76$.

${ }^{9}$ P. Dintsis, Hellenistische Helme (1986) 183-198. 304-312 Nr. 281-301. Dintsis berücksichtigt die Arbeiten von B.M. Kingsley noch nicht.

${ }^{10}$ A.M. Prestianni-Giallombardo, Un Copricapo dell' equipaggiamento militare macedone: la kausia, NumAntCl 22, 1993, 61 ff. Vgl. auch A.M. Prestianni-Giallombardo, Recenti testimonianze iconografiche sulla kausia in Macedonia e la datazione del fregio della caccia della II tomba reale di Vergina, DialHistAnc 17, 1991, 257-304. ${ }^{11}$ Ch. Saatsoglou-Paliadeli, Aspects of the Ancient Macedonian Costume, JHS 113, 1993, $122 \mathrm{ff}$.

${ }^{12}$ Vgl. jetzt auch J. Fischer, Ein triumphierender Makedonenreiter - Zeugnis eines ptolemäischen Siegesdenkmals?, StädelJb 19, 2004, 487-492. J. Fischer bearbeitet in ihrem Aufsatz, der parallel zu dieser Arbeit entstand, in erster Linie die Terrakotten vom Typus „Reiter über Gegner“. In der Deutung dieses Statuettentypus' stimmen J.Fischer und der Verfasser weitgehend überein (s.u.). Den Kreis der Träger der Kausia beschreibt J.Fischer (S. 490 mit Anm. 57-58) dagegen in Anlehnung an A.M. Prestianni-Giallombardo (s. nachfolgende Anm.).

${ }^{13}$ Vgl. die Hinweise bei A. M. Prestianni-Giallombardo, Un copricapo dell' equipaggiamento militare macedone: la kausia, NumAntCl 22, 1993, 61 und Saatsoglou-Paliadeli, Costume, 122 f. („His [Dintsis] almost full catalogue of relevant representations...").
} 
Der Artikel von A. M. Prestianni-Giallombardo ${ }^{14}$ stellt eine Rezension zu P. Dintsis dar. Als Materialgrundlage dient dessen Katalog, der kritisch besprochen wird. Die Fragestellung (Kausia als Militärmütze) orientiert sich ebenfalls an Dintsis bzw. den antiken Schriftquellen. Auf die Einarbeitung neuer Erkenntnisse wird bewusst verzichtet. ${ }^{15}$

Ch. Saatsoglou-Paliadeli ${ }^{16}$ baut in ihrem Beitrag ebenfalls auf P. Dintsis' Katalog auf. Darüber hinaus sind ihr einige Terrakottafiguren mit Kausia, die bei Dintsis mit einer Ausnahme fehlen, bekannt. Weiterhin führt sie den Fries vom sog. Philippsgrab in Vergina, das letztlich den Ausgangspunkt ihrer Untersuchung bildet, in die Diskussion ein. Infolge der Einbeziehung bisher nicht beachteter literarischer Quellen sind ihr neue Erkenntnisse zu Gebrauch, Material und Herstellung sowie zur Benennung der Kausia zu verdanken.

Das Hauptinteresse beider Aufsätze richtet sich allerdings auf die Eingrenzung des Kreises der Träger der Kausia. Dieser ist nach Auffassung der Verfasserinnen weitgehend auf Militärangehörige ${ }^{17}$ sowie die makedonischen Könige und Personen aus deren engstem Umfeld (das sog. Pagenkorps $)^{18}$ zu beschränken.

Dieses Ergebnis ist darauf zurückzuführen, dass die literarischen Quellen, die letztlich die Deutung bestimmen, nur einen Ausschnitt der Wirklichkeit spiegeln, und die Auswahl der herangezogenen bildlichen Wiedergaben von den Ergebnissen der Auswertung der Schriftquellen und der sich daran anschließenden Fragestellungen beeinflusst wurde.

Eine einseitige Auswahl bzw. Überbewertung bestimmter literarischer Quellen, kombiniert mit einer ebenso selektiven Zusammenstellung von bildlichen Wiedergaben führt insbesondere Ch. Saatsoglou-Paliadeli zu dem Schluss, dass es sich bei Darstellungen barettartiger Mützen nur dann um Kausien handelt, wenn diese sich auf dem Kopf eines makedonischen Königs oder auf dem eines Angehörigen seines Pagenkorps befinden.

Wie ein Blick auf die Geschichte der Erforschung der Kausia gezeigt hat, leidet diese darunter, dass auf der einen Seite nur ein verschwindend geringer Teil der zu Hunderten publizierten Darstellungen herangezogen wird und dass anderseits die Untersuchungen von den in den Schriftquellen gemachten Angaben bzw. den davon abhängigen Fragestellungen beherrscht werden. Dies führt im günstigsten Fall zu einer korrekten „Bebilderung“ der schriftlichen Überlieferung. Das archäologische Material wird jedoch nicht als eigenständige Quelle herangezogen und leistet entsprechend auch keinen Beitrag zur Verbesserung des Kenntnisstandes. Im Extrem kann die Verbindung einer durch eine bestimmte Fragestellung bedingten Auswahl

\footnotetext{
${ }^{14}$ A.M. Prestianni-Giallombardo, Un Copricapo dell' equipaggiamento militare macedone: la kausia, NumAntCl 22, 1993, $61 \mathrm{ff}$.

${ }^{15}$ A.M. Prestianni-Giallombardo lag das Manuskript des nachfolgend besprochenen Aufsatzes von Ch. Saatsoglou-Paliadeli vor (Vgl. Ch. Saatsoglou-Paliadeli, Aspects of the Ancient Macedonian Costume, JHS 113, 1993, 146.), dessen Ergebnisse jedoch nicht berücksichtigt werden.

${ }^{16}$ Saatsoglou-Paliadeli, Costume, $122 \mathrm{f}$.

${ }^{17}$ A.M. Prestianni-Giallombardo, Un Copricapo dell' equipaggiamento militare macedone: la kausia, NumAntCl 22, 1993, $81 \mathrm{ff}$.

${ }^{18}$ Saatsoglou-Paliadeli, Costume, 140.
} 
der in ihrer Thematik ohnehin stark eingeschränkten literarischen Überlieferung mit ebenfalls voreingenommen ausgewählten archäologischen Quellen sogar dazu führen, dass z.B. die Verbreitung der Kausia und der Kreis derjenigen Personen, die sie getragen haben, verengter dargestellt werden, als es allein die schriftliche Überlieferung vorgegeben hätte. ${ }^{19}$

Die Folge ist, dass trotz relativ intensiver Forschungen gerade in den letzten zwei Jahrzehnten derzeit keine Einigkeit darin besteht, welche Darstellungen flacher Kopfbedeckungen als Kausia bezeichnet werden dürfen. Die geographische und zeitliche Verbreitung der Kausia sowie der Kreis derjenigen Personen, die diese Mütze trugen, werden je nach herangezogenem Material und Fragestellung sehr unterschiedlich beschrieben und stets stark verengt wiedergegeben.

Da die antike Literatur zwar real getragene Kausien erwähnt, nicht jedoch bildliche Wiedergaben der Kausia, beschäftigte sich die schriftquellenbezogene Forschung ebenfalls nicht mit solchen Darstellungen. Die am archäologischen Material orientierten Grabungs- und Museumspublikationen wiederum gehen von einzelnen Fundorten bzw. einzelnen Objekten aus und können eine übergreifende Bearbeitung des Themas nicht erbringen. Eine Abhandlung, die sowohl die schriftliche Überlieferung zur Kausia als auch möglichst alle Darstellungen behandelt, existiert nicht. Ebenfalls ein Desiderat der Forschung ist die Einbeziehung der in anderen Disziplinen, die sich ebenfalls mit der Erforschung von Kleidung beschäftigen, geläufigen Fragestellungen und Ergebnisse. So gehen ethnologische Studien in stärkerem Umfang, als dies bei Untersuchungen aus dem Bereich der - insbesondere Klassischen - Archäologie der Fall ist, auf den Symbolgehalt, die Funktion und den gesellschaftlichen Kontext von Kleidungsstücken ein.

\subsection{Kleidungsforschung in Archäologie und Ethnologie}

Meist beschränkt sich die Beschäftigung mit Elementen der antiken Bekleidung in klassischarchäologischen Veröffentlichungen auf einzelne Bemerkungen im Rahmen der Bearbeitung einzelner Monumente. Im späten 19. und frühen 20. Jahrhundert erschienen darüber hinaus verschiedene kleinere Artikel zu einzelnen Kleidungsstücken teils in Zeitschriften ${ }^{20}$ und insbesondere in den großen Lexika ${ }^{21}$ der Zeit. Ebenfalls noch im frühen 20. Jahrhundert entstanden einige Werke, die einen Überblick über die antike Kleidung vermitteln wollten. ${ }^{22}$ Monographische Arbeiten zu einzelnen Bekleidungselementen, die versuchen, sämtliche bildlichen Wiedergaben eines bestimmten Kleidungsstückes oder zumindest eine repräsentative Anzahl entsprechender Darstellungen zu erfassen und diese möglichst umfassend zu deuten, sind da-

\footnotetext{
${ }^{19}$ So geschehen bei Saatsoglou-Paliadeli, Costume, 140.

${ }^{20}$ z.B. F. B. Tarbell, The Form of the Chlamys, ChPh 1, 1906, 283-89.

${ }^{21}$ z.B. Daremberg-Saglio I, 2 (1896) 975 f. s.v. Causia (L. Heuzey) und RE XI (1921) 89-93 s.v. kausiva (A. v. Netoliczka).

${ }^{22}$ Vgl. z.B. L. Heuzey, Histoire de la costume antique (1922) und davon abhängig M. Bieber, Griechische Kleidung (1928).
} 
gegen selten. Die wenigen in den letzten Jahren erschienenen Monographien zu einzelnen Kleidungsstücken entsprangen zudem nur indirkt der Beschäftigung mit der Bekleidung an sich, sondern wurden durch die Bearbeitung bestimmter Materialgruppen (z.B. des römischen Porträts, der Saatsreliefs) angeregt. Entsprechend orientieren sich die Fragestellungen dieser Werke zunächst an den im betreffenden Forschungsgebiet relevanten Fragen. ${ }^{23}$ Darüber hinaus wird aber auch hier nach der Beziehung bestimmter Bekleidungselemente zu bestimmten Statusgruppen der (römischen) Gesellschaft gefragt. ${ }^{24}$

Wirft man einen Blick auf die Nachbardisziplinen, stellt man fest, dass die Erforschung der Kleidung eines der Hauptaufgabengebiete ethnologischer Fächer - auf Europa bezogen der „Volkskunde“ bzw. „Europäischen Ethnologie“ - ist. Nachdem das Augenmerk lange dem Sammeln, Beschreiben und Typisieren von Kleidungsstücken galt, wird in der volkskundlichen Forschung in jüngerer Zeit verstärkt nach den Menschen gefragt, die sich dieser Bekleidung in einer bestimmten Weise bedienen. ${ }^{25}$

Diese ,strukturalistisch-funktionale“ Betrachtungsweise wurde ursprünglich von Petr Bogatyrev $^{26}$ in der Kleidungsforschung eingeführt und in neuerer Zeit insbesondere von Gabriella Schubert ${ }^{27}$ aufgegriffen.

Gabriella Schubert geht davon aus, dass die Kleidung zwar auch zur materiellen Kultur gehört, jedoch ,,primär ... ein Ergebnis der Fähigkeiten des denkenden Menschen sowie einer interagierenden Gesellschaft ${ }^{‘ 28}$ sei. Die ,,allgemeine Aufgabe einer zeitgemäßen ethnologischen Forschung“ sei es „kulturelle Phänomene kontextuell zu untersuchen, d.h. danach zu fragen, für wen, aus welchen Bedürfnissen heraus, auf welchen Grundlagen und mit welchem Nutzen

\footnotetext{
${ }^{23}$ So geht H. R. Goette, Studien zu römischen Togadarstellungen (1990) kurz auf antiquarische Probleme (Herkunft, Drapierung, Größe, Farbe) ein, ordnet die einzelnen Togati anhand der Drapierung zu Typen und datiert diese mit Hilfe äußerlich datierter Monumente. Das Ziel der Monographie ist letztlich eine datierte Typologie, die der Datierung sowohl der gesammelten Togadarstellungen als auch anderer Monumente dienen kann. Weitergehende Fragestellungen z.B. zur Symbolik oder (diachronen) Funktion werden nicht bearbeitet.

${ }^{24}$ Vgl. z.B. H.Gabelmann, Antike Audienz- und Tribunalszenen (1984) .- Th.Schäfer, Imperii Insignia. Zur Repräsentation römischer Magistrate (1989) .- H. R.Goette, Studien zu römischen Togadarstellungen (1990) .- B.Scholz, Untersuchungen zur Tracht der römischen matrona (1992).

${ }^{25}$ Vgl. zur Entwicklung der volkskundlich-ethnologischen Kleidungsforschung: G. Böth, Kleidungsforschung, in: R.W. Brednich, Grundriß der Volkskunde. Eine Einführung in die Forschungsfelder der Europäischen Ethno$\operatorname{logie}^{3}(2001)$ 221-238.

${ }^{26}$ P. G. Bogatyrev, Funkcie kroja na Moravskom Slovensku (1937). Das Werk wurde ursprünglich in slowakischer Sprache publiziert. 1971 erschienen eine russische und eine englische Fassung (P. G. Bogatyrev, The Funktion of Folk Costume in Moravian Slovacia, Approaches to Semiotics 5 [1971]). - G. Böth, Kleidungsforschung, in: R.W. Brednich, Grundriß der Volkskunde ${ }^{3}$ (2001) 226 f. weist darauf hin, dass dieser Weg kurz zuvor bereits von Mathilde Hain, Das Lebensbild eines oberhessischen Trachtendorfes. Von bäuerlicher Tracht und Gemeinschaft, Forschungen zur deutschen Volkskunde 1 (1936) beschritten wurde. Die Rezeption setzte jedoch erst Jahrzehnte später ein.

${ }^{27}$ G. Schubert, Kleidung als Zeichen. Kopfbedeckungen im Donau-Balkanraum, Balkanologische Veröffentlichungen 20 (1993 [= Habilitationsschrift, FU Berlin, 1991]).

${ }^{28}$ Schubert, Kleidung, 4. Vgl. auch B. Jacobs, Kleidung als Symbol. Das Beispiel der Altgläubigen Südsibiriens im 19. und beginnenden 20. Jahrhundert, Kölner ethnologische Studien 21 (1992) 15: „Die Kleidung ist nicht nur ein Sachgut, sondern Ausdrucksmedium seines Trägers und dessen Gesellschaft.“
} 
sie funktionieren“29. Entsprechend sei es die Aufgabe der Kleidungsforschung „Kleidung synchron - in ihren funktionalen Relationen zum Menschen sowie - diachron - in ihrem sozialen und kulturellen Stellenwert zu untersuchen. ${ }^{\text {“30 } ~ „ V o r d e r g r u ̈ n d i g ~ i n t e r e s s i e r e n “ ~ d e m g e m a ̈ ß ~}$ „Fragestellungen - wie nach der Funktion von Kleidung, nach dem Verhältnis des Trägers zu seiner Kleidung bzw. nach den sozialen, kulturellen und politischen Tatbeständen und Entwicklungen, die sich in der Kleidung ausdrücken. Sich kleiden bedeutet nämlich zugleich: sich einordnen in ein soziales Gefüge; sich anziehen heißt zugleich: sich im Rahmen dieser generellen Einordnung der jeweils gegebenen, aktuellen Situation anzupassen.“31 „Kleidung weist“ daher „über sich selbst hinaus auf andere Erscheinungen, besitzt Zeichencharakter, ist,

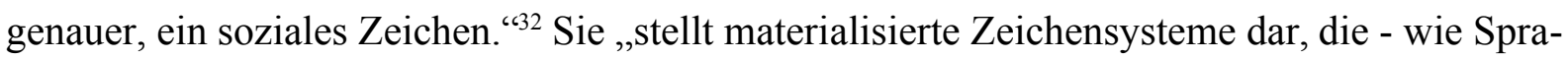
che - der Kommunikation dienen, nämlich der non-verbalen, mit Hilfe von visuellen, vestimentären Zeichen.“33 Als solche dient sie ,,als Symbol für soziale Identifikation und für Solidarität der Mitglieder“34.

\subsection{Fragestellung}

G. Schubert ${ }^{35}$ differenziert zwischen dem „Ausdruck“ und dem „Inhalt“ eines Gegenstandes (z.B. einer Kopfbedeckung). Unter „Ausdruck“ versteht sie die optisch wahrnehmbaren Merkmale (Farbe, Material, Form, Musterung etc.), unter „Inhalt“ Gegebenheiten, die aus den natürlichen und klimatischen Verhältnissen und den persönlichen Bedürfnissen eines Menschen resultieren sowie aus Normierungen (Geschlecht, Alter, Stand, Anlass, Gruppen- und Schichtzugehörigkeit). Der Inhalt ergibt sich demnach einerseits aus der (synchronen) Funktion (z.B. Schutz vor Sonne) und andererseits kennzeichnet er eine bestimmte soziale Gruppe (z.B. Frauen, Jugendliche, Schüler). Die verschiedenen genannten Ebenen, die man als eine

\footnotetext{
${ }^{29}$ Schubert, Kleidung, 4.

${ }^{30}$ Schubert, Kleidung, 4.

${ }^{31}$ Schubert, Kleidung, 5.

${ }^{32}$ Schubert, Kleidung, 7. Vgl. auch B. Jacobs, Kleidung als Symbol. Das Beispiel der Altgläubigen Südsibiriens im 19. und beginnenden 20. Jahrhundert, Kölner ethnologische Studien 21 (1992) 4: ,..., denn Kleidung kann als ein materialisiertes Zeichensystem formuliert werden, das verschlüsselt die sozio-religiöse Realität der Mitglieder einer Gesellschaft repräsentiert.“ Ähnlich auch I. Petrascheck-Heim, Die Sprache der Kleidung. Wesen und Wandel von Tracht, Mode, Kostüm und Uniform (2. neubearb. Aufl. 1988) 4. 5 f. 106.

${ }^{33}$ Schubert, Kleidung, 37. Vgl. L. Schneider, B. Fehr, K.-H. Meyer, Zeichen - Kommunikation - Interaktion, Hephaistos 1, 1979, 7 ff. .- Dass Kommunikation auch auf non-verbalem Wege stattfinden kann, ist auch in anderen Disziplinen erkannt worden; vgl. z.B. D. Stollberg, Wahrnehmen und Annehmen. Seelsorge in Theologie und Praxis (1978) 21: „Die Kommunikation bedient sich verschiedener Ausdrucksmöglichkeiten (Kommunikationsformen)... Es gibt verbale und nichtverbale Kommunikationsformen. Die nichtverbalen sind, entwicklungspsychologisch gesehen, ursprünglicher. ... Die Grundelemente der Kommunikation sind Erfahrungswerte repräsentierende Symbole verbaler und nichtverbaler Art... Als Kommunikationsmodi im eigentlichen Sinne bezeichnen wir Ausdrucksformen der Gemeinschaft, z.B. ... das Gespräch und die Darstellung (Kunst, Kultus)." Der Autor ist Theologe und Psychotherapeut.

${ }^{34}$ Schubert, Kleidung, 65. So auch B. Jacobs, Kleidung als Symbol. Das Beispiel der Altgläubigen Südsibiriens im 19. und beginnenden 20. Jahrhundert, Kölner ethnologische Studien 21 (1992) 17.

${ }^{35}$ Schubert, Kleidung, $37 \mathrm{f}$.
} 
optische, eine synchron-funktionale und eine soziale (oder diachron-funktionale) bezeichnen könnte, sind eng miteinander verbunden und bedingen sich teils. Inhalt und Ausdruck ergeben ein Zeichensystem, in dem sich auch die politische, kulturelle und soziale Ordnung spiegelt, in der diese Zeichen wiederum eine Funktion erfüllen.

Auch im Rahmen dieser Untersuchung soll in Anlehnung an die oben zitierten ethnologischen Arbeiten nach den optischen Eigenschaften (dem Aussehen) der Kausia, ihrer synchronen Funktion und den mit dieser verbundenen Tätigkeiten und Personengruppen sowie dem sozialen Rahmen und der diachronen Funktion der Kausia als Symbol in einem bestimmten gesellschaftlichen Umfeld gefragt werden.

Im Unterschied zur Ethnologie, die sich meist mit zeitgenössischen oder zumindest neuzeitlichen Phänomenen beschäftigt, hat es die (Klassische) Archäologie mit der Hinterlassenschaft „toter“ Völkern zu tun. Dies erschwert den Umgang mit dem erhaltenen Material und führt zu einer Verschiebung der Fragestellung.

So existiert keine mündliche Überlieferung zur Kausia noch ist auch nur eine einzige reale Kausia erhalten. Das Material besteht stattdessen aus Erwähnungen in den antiken Schriftquellen sowie bildlichen Wiedergaben der Kopfbedeckung. Die erste Aufgabe besteht entsprechend in der Verbindung der schriftlich belegten „Kausia“ mit einer der vielen bildlich überlieferten Kopfbedeckungen. Danach können - jeweils anhand literarischer Quellen und bildlicher Darstellungen - das Aussehen und die Herstellung der Kausia sowie ihre zeitliche und geographische Verbreitung geklärt werden. Weiter sind die Funktion der Kausia in den dargestellten Szenen und der Kreis derjenigen Personen und Personengruppen, die mit der Kausia dargestellt wurden, einzugrenzen. Neben der Funktion der Kausia an sich ist auch diejenige entsprechender bildlicher Wiedergaben zu umschreiben. Am Ende der Bearbeitung der Darstellungen steht die Frage nach einem ihnen innewohnenden Zeichensystem und der Einordnung dieses Systems in das politische, kulturelle und soziale Umfeld. Schließlich ist zu überprüfen, ob und in welchem Umfang die auf der Grundlage der schriftlichen und bildlichen Quellen gewonnen Ergebnisse auf die reale Kausia übertragen werden können. Insbesondere ist zu hinterfragen, inwieweit Aussagen verallgemeinert werden können, die durch in der antiken Literatur übliche Themenschwerpunkte, die Darstellungskonventionen der griechisch-römischen Kunst oder die Gattung bedingt werden. Die primär-synchrone Funktion der realen Kausia, der Kreis ihrer Träger sowie die symbolische Bedeutung ${ }^{36}$ und deren gesellschaftlicher Kontext und eine daraus resultierende diachrone Funktion in der Gesellschaft sind entsprechend zu bestimmen.

\footnotetext{
${ }^{36}$ Unter „symbolischer Bedeutung“ (bzw. „Symbolik“, „Symbol“ u.ä.) wird hier diejenige Aussage verstanden, die der Kausia und insbesondere den Darstellungen dieser Kopfbedeckung nicht direkt innewohnt, die die Kausia jedoch angenommen hat (Vgl. zu Konnotationen und Subcodes L. Schneider, B. Fehr, K.-H. Meyer, Zeichen - Kommunikation - Interaktion, Hephaistos 1, 1979, 21 f.). In der symbolischen Bedeutung liegt die gesellschaftliche Funktion der Kausia selbst und der Darstellungen der Kausia begründet, und sie ist die Voraussetzung für die gezielte Verwendung bildlicher Wiedergaben der Kausia.
} 


\subsection{Vorgehensweise}

Die Voraussetzung für die Beschäftigung mit der Kausia ist es, diese unter den verschiedenen jeweils nur in bildlichen Wiedergaben und nicht im Original erhaltenen Gruppen antiker Kopfbedeckungen zu identifizieren. Diese Identifizierung erfolgt auf der Grundlage der literarischen Überlieferung. Es werden daher zunächst die rund 30 antiken Erwähnungen im Original und in Übersetzung geboten und kurz zusammengefasst. In diesem Zusammenhang wird auch auf Form, Material und Farbe der Kausia sowie Fragen der Herstellung eingegangen. Weiter wird unter Einbeziehung der archäologischen wie der literarischen Quellen ein erster Überblick über die zeitliche und räumliche Verbreitung der Kausia gegeben, um deren Herkunft zu klären.

Der Hauptteil dient der Klärung der primär-synchronen Funktion und einer möglichen Symbolik und sekundär-diachronen Funktion der Kausia selbst sowie der bildlichen Wiedergaben der Kausia in ihrem jeweiligen Kontext. Entsprechend der Struktur des archäologischen Materials sowie den unterschiedlichen Möglichkeiten, sich diesem zu nähern, gliedert sich dieser Teil in drei Unterabschnitte.

Der erste Abschnitt behandelt diejenigen bildlichen Wiedergaben der Kausia, die in einem Zusammenhang dargestellt sind, der Rückschlüsse auf die Deutung zulässt. Ein solcher Kontext - meist eine Szene, in der mehrere Personen erscheinen - ermöglicht die Identifizierung dieser Personen und eine Bestimmung der Tätigkeiten, bei denen diese Kopfbedeckung jedenfalls im Bild getragen wurde, sowie des politischen, kulturellen oder sozialen Rahmens, in dem dies geschah. Aus diesen Angaben können einerseits die primäre Funktion der Kausia und andererseits eine mögliche Symbolik der Darstellung und der Kausia in dieser sowie eine gesellschaftliche Funktion erschlossen werden. Das beschriebene Verfahren lässt sich auf eine große Anzahl von Darstellungen aus den unterschiedlichsten Gattungen (Rundplastik, Relief, Malerei, Mosaik, Münzen, Kameen, Siegel) anwenden.

Der zweite Abschnitt geht auf diejenigen Darstellungen ein, die nicht in einem klar erkennbaren Kontext auftreten. Es handelt sich hierbei um meist kleinformatige Einzelfiguren aus Ton oder Stein, die abgesehen von der Kausia und einem gewöhnlich mit dieser kombinierten Mantel (Chlamys) in der Regel keine weiteren „Attribute“ aufweisen. Entsprechend fehlen eindeutige Hinweise auf die wiedergegebene Person, die ausgeübte Tätigkeit und das soziale Umfeld. Um diese Informationen zu erlangen, wird von der aus dem Fundort und dem Fundkontext erschließbaren Funktion der Statuetten ausgegangen. Aus der Funktion - es handelt sich meist um Weihungen oder Grabbeigaben - lässt sich in Verbindung mit weiteren Hinweisen, die sich beispielsweise aus dem Charakter eines Heiligtums und den dort ausgeübten Riten bzw. den sonstigen Grabbeigaben ergeben sowie aus dem demographischen und politischen Verhältnissen und der Ikonographie erschließbar sind, auf den dargestellten Personenkreis, dessen gesellschaftliche Stellung und das kulturelle Umfeld schließen.

Im dritten Abschnitt wird das Gesamtmaterial noch einmal unter einem anderen Gesichtspunkt bearbeitet. Statt von einzelnen Darstellungen auszugehen, werden die archäologischen 
Funde zuerst nach Regionen und dann nach Gattungen zusammengefasst behandelt. Einerseits wird so die Untersuchung der Symbolik und Funktion der Kausia durch einen Vergleich der sehr unterschiedlichen Verteilung und Gewichtung bestimmter Gattungen und Themen in den einzelnen Regionen mit den politischen und kulturellen Strukturen der betreffenden Gebiete vorbereitet. Andererseits kann die Funktion einer Gattung in einem bestimmten Kontext auf den Symbolgehalt und die Funktion einer Darstellung der Kausia oder der Kausia selbst verweisen.

Nachdem die Schriftquellen vorgestellt und das archäologische Material aufbereitet worden ist, wird die in den letzten Jahren viel diskutierte Frage des Umfanges des Kreises der Träger der Kausia in einer Synopse der schriftlichen und archäologischen Überlieferung geklärt.

Abschließend wird auf die synchrone Funktion, die Symbolik und die diachrone Funktion sowohl einzelner Materialgruppen als auch der Gesamtmaterials eingegangen. Dies geschieht einerseits mit Blick auf die bildlichen Wiedergaben der Kausia und andererseits auf die Kausia als realem Bekleidungsstück.

Schließlich werden noch einmal alle Ergebnisse kurz zusammengefasst.

\subsection{Die „Makedones“ - eine „ethnische“ Gruppe?}

Es wird sich zeigen, ${ }^{37}$ dass die Kausia aus Makedonien stammt und Bestandteil der Bekleidung der dort ansässigen Bevölkerung war. Da andere Elemente der makedonischen Kleidung (Chlamys, Chiton, Krepides) auch von benachbarten Volksgruppen (z.B. den Thessalern) getragen wurden, blieb als „typisch makedonisches“ Kleidungsstück nur die Kausia. In der antiken literarischen Überlieferung wird die Kausia in der Regel als „makedonische“ Kopfbedeckung bezeichnet. Die namentlich bekannten Träger sind meist makedonischer Herkunft oder es werden allgemein „Makedonen“ als Träger der Kausia genannt. Die Kausia konnte sich schließlich zu einem Symbol Makedoniens entwickeln. Personen, die mit dieser Kopfbedeckung dargestellt worden sind, werden daher auch in der modernen Literatur oft als „Makedonen" angesprochen.

In den nachfolgenden Kapiteln wird daher des Öfteren von den „Makedonen“ die Rede sein. Der Begriff ist jedoch interpretationsbedürftig.

Überprüfen lässt sich Zuweisung der Kausia an die „Makedonen“ nur anhand einer relativ geringen Anzahl von bildlichen Wiedergaben der Kausia bzw. entsprechenden Erwähnungen in den antiken Schriftquellen. Bei den dort als Träger der Kausia dargestellten oder erwähnten und namentlich bekannten Personen handelt es sich meist um Herrscher. Diese stammen überwiegend aus alten makedonischen Familien (Argeaden, Lagiden, Seleukiden, Antigoniden). Vereinzelt erscheinen jedoch auch Könige nicht-makedonischer Abstammung, so die wohl griechisch-stämmigen Könige Baktriens.

\footnotetext{
${ }^{37}$ Die Nachweise der hier vorab angestellten Behauptungen werden in den nachfolgenden Kapiteln erbracht.
} 
Die große Mehrheit der dargestellten Personen bleibt für uns jedoch anonym. Insbesondere die in Massenproduktion hergestellten Statuetten stehen letztlich nicht für bestimmte Einzelpersonen, sondern für Gruppen von Personen. ${ }^{38}$ Diejenigen Individuen, die diese Figuren kauften und als Votiv oder am Grab verwendeten, bleiben wiederum namenlos. Dennoch werden auch die Vorbilder dieser Statuetten und ihre Käufer im Zweifelsfall als „Makedonen“ angesprochen, denn nur bei diesen lässt sich das Tragen der Kausia bzw. die Darstellung mit dieser begründen.

Das Beispiel der baktrischen Könige, die nicht makedonischer Abstammung waren und trotzdem mit der Kausia, dem Symbol Makedoniens, wiedergegeben wurden, zeigt, dass ,,makedonisch" sich nicht zwangsläufig oder ausschließlich auf die Herkunft im biologischen Sinne beziehen muss, sondern auch „,in der Tradition des makedonischen Heeres stehend“ oder ,in der Nachfolge des Makedonenkönigs Alexander regierend“ bedeuten kann.

Ähnliches ist auch in anderen Fällen nicht auszuschließen. Eine Überprüfung ist jedoch mangels ausreichenden Quellengrundlage bezogen auf den Einzelfall fast nie und auch für bestimmte Regionen, Zeitabschnitte und Gattungen nur eingeschränkt möglich.

Sowohl für den ptolemäischen als auch für den seleukidischen Bereich gibt es Hinweise darauf, dass ethnische Bezeichnungen wie „Makedone“ (oder auch „Hellene“ oder „Perser“) sich nicht unbedingt an der Abstammung orientieren müssen. ${ }^{39}$ So führten einerseits ganze Einheiten der ptolemäischen Armee Bezeichnungen, die auf die „Makedonen“ verwiesen (z.B. „die Makedonen“ für die Leibwache der Ptolemäerkönige in Alexandria oder eine ptolemäische Reitertruppe namens „Hipparchie der Makedonen“) ${ }^{40}$ andererseits wurden einzelne Kleruchen als „Makedonen“ bezeichnet. ${ }^{41}$ Diese Benennungen bezogen sich jedoch günstigenfalls auf die Herkunft der Soldaten zum Zeitpunkt der Aufstellung der betreffenden Truppenteile. Sehr früh wurden diese Einheiten mit Soldaten unterschiedlichster - meist griechisch-thraki-

\footnotetext{
${ }^{38}$ Zur engen Bindung von Zeichen (Konnotationen, Subcodes) an Gruppen und deren Interessen vgl. L. Schneider, B. Fehr, K.-H. Meyer, Zeichen - Kommunikation - Interaktion, Hephaistos 1, 1979, $21 \mathrm{f}$.

${ }^{39}$ Zum Thema „Ethnizität" allg. vgl. S. Jones, The Archaeology of Ethnicity (1997). Die Autorin bietet einen Überblick über die Forschungsgeschichte, stellt verschiedene Definitionen des Begriffes vor und versucht Möglichkeiten zu entwickeln, die unterschiedlichen Ansätze zu verbinden. - Zur „Ethnizität“ und zum Zusammenleben von Makedonen/Griechen und Einheimischen in den hellenistischen Reichen und insbesondere dem ptolemäischen Ägypten vgl. F. Uebel, Die Kleruchen Ägyptens unter den ersten sechs Ptolemäern, AbhBerlin (Klasse f. Sprache, Literatur u. Kunst), 1968, Nr. 3 .- N. Lewis, Greeks in Ptolemaic Egypt (1986) .- K. Goudriaan, Ethnicity in Ptolemaic Egypt, Dutch Monographs on Ancient History and Archaeology 5 (1988) -- A.K. Bowman, Egypt after the Pharaohs (1989) 121 ff. .- P. Bilde, T. Engberg-Pedersen, L. Hannestad (Hrsgg.), Ethnicity in Hellenistic Egypt, Studies in Hellenistic Civilisation 3 (1992) .- Alexandria and Alexandrianism (Symposium, Malibu, 22.-25.04.1993) (1996) .- I. Malkin (Hrsg.), Ancient Perceptions of Greek Identity, Center of Hellenic Studies colloquia 5 (2001).

${ }^{40}$ Vgl. z.B.: P.M. Fraser, Ptolemaic Alexandria I (1972) 80. 88 .- D.J. Thompson, Hellenistic Hellenes. The Case of Ptolemaic Egypt, in: I. Malkin (Hrsg.), Ancient Perceptions of Greek Identity, Center of Hellenic Studies colloquia 5 (2001) 306. Zur seleukidischen „Phalanx der Makedonen“ vgl. F.W. Walbank, Die hellenistische Welt (1983) 134 mit Verweis auf Appian, Syriake 32, 161.

${ }^{41}$ F. Uebel, Die Kleruchen Ägyptens unter den ersten sechs Ptolemäern, AbhBerlin (K1. f. Sprache, Literatur u. Kunst), 1968/3, 32 ff. Nr. 7, 20-21, 28, $91-92$ u.ö. (Auflistung S. 420 s.v. M $\alpha \kappa \in \delta \omega ́ v)$ ).
} 
scher, teils auch ägyptisch-orientalischer - Herkunft aufgefüllt. ${ }^{42}$ Die Angehörigen dieser Kontingente trugen jedoch weiterhin das Ethnikon M $\alpha \kappa \epsilon \delta \omega \nu .{ }^{43}$ Der Begriff „Makedone“ wurde von einer Stammesbezeichnung zu einem militärtechnischen Ausdruck, der auf eine bestimmte Bewaffnung und Kampftechnik verwies. ${ }^{44}$

Heiraten zwischen „Makedonen“ - seien es solche makedonischer, griechischer, orientalischer oder ägyptischer Herkunft - und einheimischen Frauen (im Ptolemäerreich Ägypterinnen, im Seleukidenreich Angehörigen verschiedener asiatischer Völker) und der Eintritt der Söhne aus solchen Verbindungen in die Einheiten der Väter führten zu einer weiteren Veränderung der „Ethnizität“ der „Makedonen“ im abstammungsmäßigen Sinne. Im Ergebnis konnten diese „Makedonen“ sich je nach Kontext einerseits als Teil der makedonisch-griechischen und andererseits der (z.B.) ägyptischen Kultur geben und neben einen makedonisch-griechischen einen ägyptischen Namen annehmen. ${ }^{45}$

Im Falle der zivilen makedonischstämmigen Siedler ist ebenfalls einerseits von einer Vermischung mit der einheimischen Bevölkerung durch Heirat insbesondere in ländlichen Gebieten auszugehen, andererseits ist insbesondere in den griechisch geprägten Städten ein weitgehendes Aufgehen in der übrigen griechischsprachigen Bevölkerung zu beobachten. Dies ist auf zwei Gründe zurückzuführen: Einerseits war der Anteil der aus Makedonien stammenden Bevölkerung auch in den neu gegründeten Königsstädten, wie z.B. Alexandria ${ }^{46}$ oder Demetri$\mathrm{as}^{47}$, nur relativ gering, während die große Mehrheit der Vollbürger dieser Städte aus allen Teilen der griechischen Welt einwanderte. Andererseits ist eine Bevorzugung makedonischer Einwanderer durch die hellenistischen Herrscher nicht festzustellen. ${ }^{48}$ Die Könige der Diadochenreiche förderten zwar den Zuzug fremder Bevölkerungsgruppen. Bestimmte Vorrechte, die Teilen der Bevölkerung gewährt wurden, waren jedoch nicht abhängig von der Abstammung, sondern von bestimmten Fähigkeiten. Diese Fähigkeiten waren kultureller Art und ihre

\footnotetext{
${ }^{42}$ P.M. Fraser, Ptolemaic Alexandria I (1972) 129 .- D. Delia, „All Army Boots and Uniforms?“ Ethnicity in Ptolemaic Egypt, in: Alexandria and Alexandrianism (Symposium Malibu 1993) (1996) 45. Für den seleukidischen Bereich vgl. F.W. Walbank, Die helenistische Welt (1983) 134.

${ }^{43}$ Zur Nomenklatur der Soldatennamen vgl. F. Uebel, Die Kleruchen Ägyptens unter den ersten sechs Ptolemäern, AbhBerlin (Kl. f. Sprache, Literatur u. Kunst), 1968/3,11 ff. und D.J. Thompson, Hellenistic Hellenes. The Case of Ptolemaic Egypt, in: I. Malkin (Hrsg.), Ancient Perceptions of Greek Identity, Center of Hellenic Studies colloquia 5 (2001) $304 \mathrm{f}$.

${ }^{44}$ Vgl. V. Ehrenberg, Der Staat derGriechen ${ }^{2}$ (1965) 180.

${ }^{45}$ D.J. Thompson, Hellenistic Hellenes. The Case of Ptolemaic Egypt, in: I. Malkin (Hrsg.), Ancient Perceptions of Greek Identity, Center of Hellenic Studies colloquia 5 (2001) 315 f. Vgl. auch F.W. Walbank, Die hellenistische Welt (1983) $119 \mathrm{f}$.

${ }^{46}$ Zur Herkunft der Bevölkerung Alexandrias vgl. D. Delia, „All Army Boots and Uniforms?“ Ethnicity in Ptolemaic Egypt, in: Alexandria and Alexandrianism (Symposium Malibu 1993) (1996) 41-53 bes. 45 mit Anm. 27 (zivile Einwanderer) und Anm. 32 (Soldaten). Vgl. auch L. Koenen, Eine agonistische Inschrift aus Ägypten und frühptolemäische Königsfeste, Beiträge zur Klassischen Philologie 56 (1977) 4 f. 23 ff. .- D.J. Thompson, Hellenistic Hellenes. The Case of Ptolemaic Egypt, in: I. Malkin (Hrsg.), Ancient Perceptions of Greek Identity, Center of Hellenic Studies colloquia 5 (2001) 303.

${ }^{47}$ Die Bevölkerung von Demetrias stammte aus über 100 (meist griechischen) Städten (C. Wolters, Die Anthemien-Ornamente der Grabstelen von Demetrias [Diss. Heidelberg 1969/70] 21).

${ }^{48}$ P.M. Fraser, Ptolemaic Alexandria I (1972) 53 f.
} 
Beherrschung abhängig von einer gewissen Vertrautheit mit der griechischen Kultur. Entsprechend kamen in den Genuss dieser Vorrechte zwar vorzugsweise Griechen und Makedonen und in geringerem Umfang auch andere Zuwanderer (Araber, Juden, „Perser“), aber auch einheimische Ägypter bzw. Orientalen. Wichtig für die Gewährung von Vorrechten durch den König oder den Zugang zu den Ämtern der kommunalen Selbstverwaltung und den damit verbundenen Möglichkeiten der Einflussnahme war nicht die Herkunft aus Tarent, Athen, Pella oder Milet, sondern die Kenntnis der griechischen Sprache und Kultur. ${ }^{49}$

Diejenige Personengruppe, die den einheimischen Ägyptern im ptolemäischen Reich gegenüber stand, waren entsprechend nicht die Makedonen, die Einwanderer aus Syrakus, Athen oder Kreta und nicht die Alexandriner, sondern eine „die Hellenen“ genannte Gruppe. ${ }^{50}$ Der Begriff ist - ähnlich wie „die Makedonen“ - mehrdeutig: Er umfasste die griechischen Einwanderer, zu denen trotz einer gewissen Sonderstellung nach Sprache und Kultur auch der nordgriechische Stamm der Makedonen gehörte.

„Die Hellenen“ konnte, wie „die Makedonen“ auch, im militärtechnischen Sinne verstanden werden, wobei in den entsprechenden Einheiten wiederum auch Nichtgriechen dienten. ${ }^{51}$

Die „Hellenen“ waren aber auch eine steuerrechtliche Gruppe. Ausländischen Zuwanderern wurden unter den Ptolemäern steuerliche Vorteile gewährt. In den Steuerlisten stellten „die Hellenen“ die größte Gruppe der Bevorrechtigten. Bei den genannten Personen handelte es sich überwiegend um Griechen. In geringerem Umfang werden aber auch kleinasiatische, thrakische und jüdische Siedler genannt. Vereinzelt erscheinen Ägypter, die durch ihre Mitarbeit in der regionalen Verwaltung dem ptolemäischen Herrschaftssystem verbunden waren. ${ }^{52}$ Diese „Hellenen“ waren von der sog. Obolensteuer befreit und genossen infolge dieser Einstufung weitere Vorteile (z.B. Freistellung von Deichinstandhaltungsarbeiten). ${ }^{53}$ Gemeinsam war diesen Personen, dass sie die griechische Sprache und Schrift beherrschten und dass sie das Land im Auftrag und zum Nutzen der Ptolemäerkönige erschlossen und verwalteten. Innerhalb „der Hellenen“ nahm eine kleine Gruppe eine Sonderstellung ein. Die Angehörigen dieser Gruppe waren zusätzlich auch von der sog. Salzsteuer befreit. Es handelt sich um Lehrer, Trainer, siegreiche Athleten und Schauspieler. ${ }^{54}$ Diesen Personen ist gemeinsam, dass sie

\footnotetext{
${ }^{49}$ D.J. Thompson, Hellenistic Hellenes. The Case of Ptolemaic Egypt, in: I. Malkin (Hrsg.), Ancient Perceptions of Greek Identity, Center of Hellenic Studies colloquia 5 (2001) 307. 310. $311 \mathrm{f}$.

${ }^{50}$ D.J. Thompson, Hellenistic Hellenes. The Case of Ptolemaic Egypt, in: I. Malkin (Hrsg.), Ancient Perceptions of Greek Identity, Center of Hellenic Studies colloquia 5 (2001) $301 \mathrm{ff}$. Vgl. A. Mehl, Erziehung zum Hellenen. Erziehung zum Weltbürger. Bemerkungen zum Gymnasion im hellenistischen Osten, Nikephoros 5, 1992, 65.

${ }^{51}$ Vgl. z.B. F. Uebel, Die Kleruchen Ägyptens unter den ersten sechs Ptolemäern, AbhBerlin (K1. f. Sprache, Literatur u. Kunst), 1968/3, 109 (Nr. 301). 111 (Nr. 312): „Thraker“ und „Makedone“ in der „Hipparchie der Thessaler und der anderen Hellenen“".

${ }^{52}$ D.J. Thompson, Hellenistic Hellenes. The Case of Ptolemaic Egypt, in: I. Malkin (Hrsg.), Ancient Perceptions of Greek Identity, Center of Hellenic Studies colloquia 5 (2001) 308-311.

${ }^{53}$ Vgl. D.J. Thompson, Hellenistic Hellenes. The Case of Ptolemaic Egypt, in: I. Malkin (Hrsg.), Ancient Perceptions of Greek Identity, Center of Hellenic Studies colloquia 5 (2001) $306 \mathrm{ff}$.

${ }^{54}$ D.J. Thompson, Hellenistic Hellenes. The Case of Ptolemaic Egypt, in: I. Malkin (Hrsg.), Ancient Perceptions of Greek Identity, Center of Hellenic Studies colloquia 5 (2001) 307. Vgl. auch dies., Language and Literacy in Early Ptolemaic Egypt, in: P. Bilde, T. Engberg-Pedersen, L. Hannestad (Hrsgg.), Ethnicity in Hellenistic Egypt,
} 
Berufe ausübten, die eng mit dem Gymnasion und dem Theater verbunden waren, denjenigen Institutionen, in denen griechische Bildung und Kultur vermittelt und verbreitet wurden.

Gefördert wurden demnach nicht „ethnische“ Gruppen im Sinne gemeinsamer Abstammung, sondern die Gruppe der „Hellenen“, deren Mitgliedern gemeinsam war, dass sie - im Gegensatz zu den „Ägyptern“ - bestimmte kulturelle Praktiken beherrschten, die geeignet waren, Ägypten zum Nutzen aller „Hellenen“ - das sind der König, die Soldaten und Beamten, die Vollbürger in den Städten und die Kleruchen auf dem Lande - zu bewirtschaften.

Der Bedarf an „Hellenen“ und die Vorteile, die es mit sich brachte „Hellene“ zu sein, führten zur zunehmenden Verschmelzung von Makedonen und Griechen und anderen Volksgruppen. Die Frage ist, ob dieser Vorgang als weitgehend spurloses Aufgehen kleinerer Gruppen (darunter der Makedonen) in der griechischen Bevölkerung zu sehen ist oder ob eine wirkliche Verschmelzung stattfand, die zur Folge hatte, dass - auf griechischer Grundlage - eine neue Gruppe entstand, zu deren Kultur sowohl Griechen als auch Makedonen und andere einen Beitrag leisteten. Eine solche neue Gruppierung hätte auch Bestandteile der materiellen Kultur Makedoniens wie die Kausia in den Gesamtbestand „hellenischer“ Kulturerscheinungen aufnehmen können. Entsprechend müsste die Kausia nicht ausschließlich den „Makedonen“ (im abstammungsmäßigen wie militärtechnischen Sinne) zugeordnet werden, sondern könnte in hellenistischer Zeit zur typischen Kopfbedeckung der „Hellenen“ der neuen Reiche geworden sein.

Diese Möglichkeit lässt sich anhand der anonym überlieferten Darstellungen von Personen, die die Kausia tragen, nicht verbindlich überprüfen. Es existieren jedoch Indizien, die in diese Richtung deuten: So fehlen in Regionen, in denen in großen Zahl Chlamydephoren-Statuetten mit Kausia gefunden wurden, entsprechende Figuren mit dem Petasos, dem griechischen Gegenstück, weitgehend. Wenn, wie versucht wird zu belegen, diese Statuetten mit dem Gymnasion und der Ephebie in Verbindung zu bringen sind und entsprechende Figuren mit dem Petasos als Kopfbedeckung in Griechenland (z.B. Athen) ebenfalls im Grabkult und als Votiv Ver wendung fanden und einen Bezug zum Gymnasion und zur Ephebie aufwiesen, das Gymnasion und die Ephebie aber in Ägypten und anderen Regionen der hellenistischen Welt eine vorrangige Stellung im gesellschaftlichen Leben der „Hellenen“ einnahmen, ist erklärungsbedürftig, warum nur „Makedonen“ als Chlamydephoren dargestellt wurden und nicht auch Griechen. Eine Möglichkeit der Deutung ist, dass die Kausia zur Kopfbedeckung der „Hellenen“ geworden war, sowohl von „Makedonen“ als auch Griechen getragen wurde und alle „Hellenen“ mit der Kausia wiedergegeben werden konnten. Für eine Einordnung der Kausia als der typischen Kopfbedeckung aller Besucher der Gymnasien und Theater, d.h. der „Hellenen“, in den neuen Reichen spricht auch, dass die Kausia als Mütze Alexanders und der auf ihn folgenden Könige sowie der „makedonischen“ Soldaten als Symbol der obersten Macht und ihrer Hauptstütze diente, während der Petasos eher für ein veraltetes politisches System und ein griechisches Mutterland, dessen Bedeutung abnahm, stand.

Studies in Hellenistic Civilisation 3 (1992) 48. 
Wenn demnach in dieser Arbeit Personen, die mit der Kausia wiedergegeben werden, als „Makedonen“ (meist in Anführungsstrichen) angesprochen werden, handelt es sich bei diesen nur zum geringeren Teil um Makedonen im abstammungsmäßigen oder auch nur militärtechnischen Sinne. Der Begriff „Makedone“ ist demnach nur in der Anfangsphase streng ethnisch im Sinne einer Abstammung von makedonischen Eltern und/oder einer Herkunft aus Makedonien zu verstehen.

Insbesondere diejenigen Darstellungen aus den Zentren hellenistischer Siedlungstätigkeit, das sind die neugegründeten Königsstädte (Alexandria, Seleukia am Tigris, Demetrias) und die Gebiete, in denen in größerem Umfang mit Militärkolonisten (Kleruchen, Katoiken) zu rechnen ist (Ägypten, Westkleinasien, Syrien, Mesopotamien/Susiane), werden in der Regel „Hellenen“ zeigen, unter denen sich eher zufällig auch „echte“ Makedonen befunden haben können. 


\section{Die Kausia}

\subsection{Identifizierung}

Die Grundlage der Identifizierung der seit rund 1700 Jahren nicht mehr nachweisbaren Kausia sind die Erwähnungen in antiken Schriftquellen. Diese werden nachfolgend im Urtext und in Übersetzung angeführt. Auf eine Kommentierung wurde hier weitgehend verzichtet. Die Interpretation erfolgt erst nach Vorstellung des archäologischen Materials am Ende der Arbeit.

\subsubsection{Antike Schriftquellen zur Kausia}

\section{Q 1 Antipatros von Thessaloniki}

(um Christi Geburt)

\section{Anthologia palatina 6, 335:}

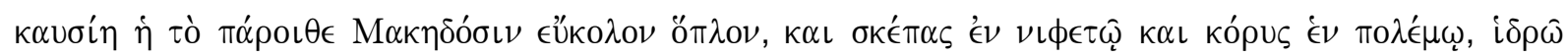

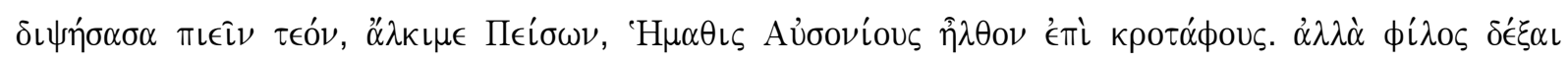

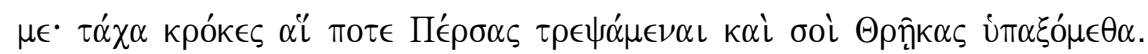

War ich, die Kausia, einst Makedonen guter/leichter Ausrüstungsgegenstand, während des Schneiens ein Hut, während des Krieges ein Helm, heute komme ich zu dir aus Emathia, tapferer [C. Calpurnius] Piso, dir vom ausonischen Haupt durstig zu schlürfen den Schweiß. Darum empfange mich als Freund. Hat dieses Gewebe die Perser einst geschlagen, sie macht dir auch die Thraker zum Knecht. ${ }^{5}$

\section{Q 2 Aristobulos}

(ca. 380 - nach 301 v.Chr.)

FGrHist 139, 55 (= Arrian, Anabasis 7, 22, 2):

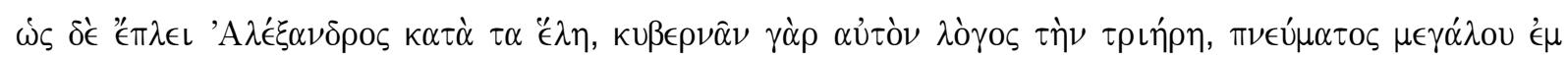

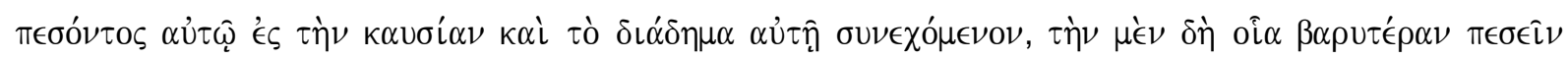

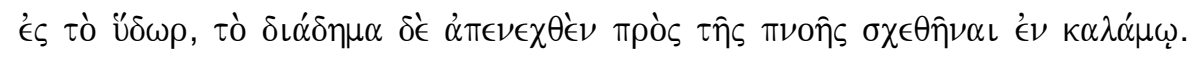

Als Alexander auf der Fahrt durch das Sumpfland ${ }^{56}$ selbst am Steuer der Triere stand, habe ein heftiger Wind seine Kausia mit dem Diadem, das daran befestigt war, erfasst und sie, weil sie schwerer war, in das Wasser geschleudert, während das Diadem durch den Wind davon geweht wurde und im Schilf hängen blieb. ${ }^{57}$

\footnotetext{
${ }^{55}$ Übersetzung nach: H. Beckby (Hrsg.), Anthologia Graeca. Buch I-VI (2. Ausgabe, o.J. [Erstausgabe 1957]) 641.

${ }^{56}$ Die Fahrt auf dem Euphrat fand 323 v.Chr. statt.

${ }^{57}$ Übersetzung nach: G. Wirth - O. v. Hinüber (Hrsgg.), Flavius Arrianus, Der Alexanderzug. Indische Geschichte (1985) 593.
} 


\section{Q 3 Duris von Samos}

Frgt. 14 (= Athenaios 12, 535 f.):

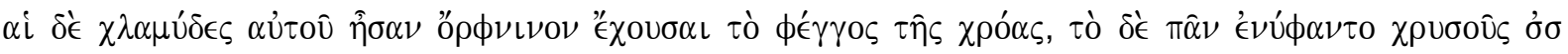

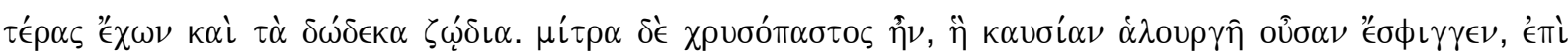

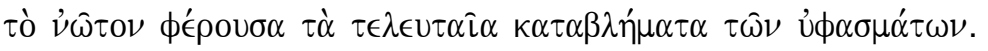

Seine [des Demetrios Poliorketes] Chlamyden waren dunkelrot, hatten aber das Leuchten der Farbe, und das Weltall mit den goldenen Sternen und den zwölf Tierkreiszeichen waren darin eingewebt. Die Mitra, die die purpurfarbene Kausia umfing, war goldgestickt und führte die herabhängenden Endstücke der gewebten Bänder in den Nacken.

\section{Q 4 Ephippos von Olynth}

(E. 4. Jh. v.Chr.)

FGrHist 126, 5 (= Athenaios 12, 537 e):

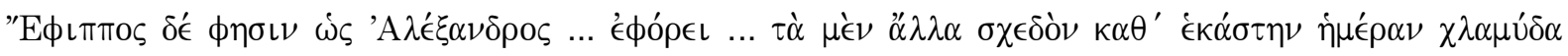

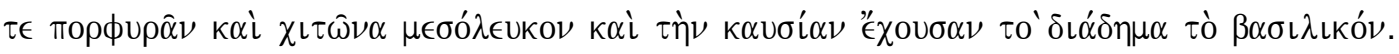

Ephippos sagt, dass Alexander [...] trug [...] zu anderen Gelegenheiten aber fast täglich eine purpurne Chlamys und einen weißgestreiften Chiton und die Kausia mit dem königlichen Diadem.

\section{Q 5 Eustathios von Thessaloniki}

(1115 - 1195/97 n.Chr.)

\section{a) Kommentar zu Ilias B $461(255,1)$ :}

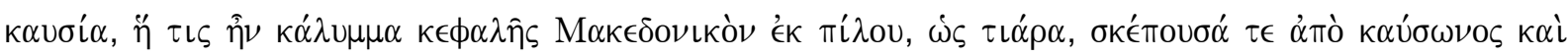

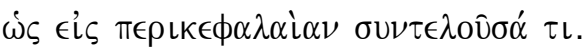

Die Kausia [ist] eine makedonische Kopfbedeckung aus Filz, wie eine Tiara, sie schützt vor der Sonnenhitze und vollendet etwas wie eine Kopfbedeckung.

\section{b) Kommentar zur Odyssee A 122 (1399, 3-6)}

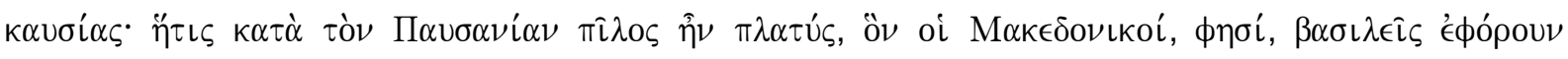

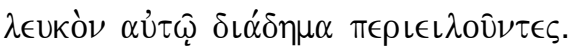

Die Kausia war nach Pausanias ${ }^{58}$ eine flache/breite Filzmütze, die die makedonischen Könige, sagt man, umgeben von einem weißen Diadem trugen.

\section{Q 6 Herakleides (Heraclides Ponticus)}

(4. Jh. v.Chr.)

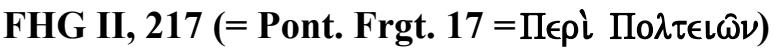

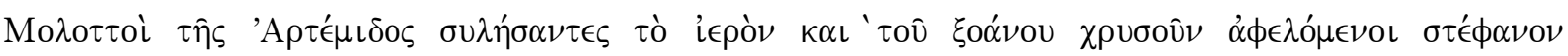

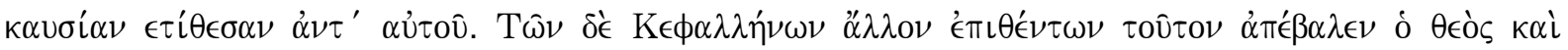

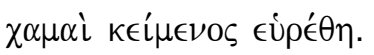

\footnotetext{
${ }^{58}$ Pausanias war ein Lexikograph hadrianischer Zeit. Vgl. Ritter, Diadem, 33.
} 
Nachdem die Molosser das Heiligtum der Artemis geplündert und den goldenen Kranz des Kultbildes geraubt hatten, setzten sie ihm stattdessen eine Kausia ${ }^{59}$ auf. Nachdem die Kephallenier ihm den anderen [Kranz] daraufgesetzt hatten, warf die Gottheit diese [Kausia] ab und sie wurde am Boden liegend gefunden.

\section{Q 7 Herodian}

(um 180 - 238 n.Chr.)

\section{a) 1, 3, 3:}

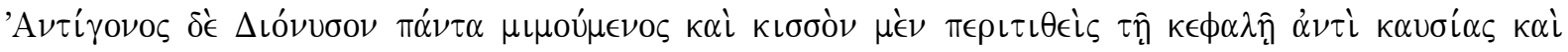

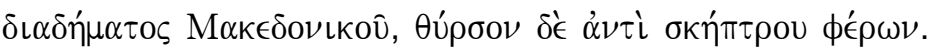

Antigonos $^{60}$ aber ahmte in allen Dingen Dionysos nach, und trug statt der makedonischen Kausia und des Diadems einen Kranz, statt des Zepters einen Thyrsos.

b) 4, 8, 1-2:

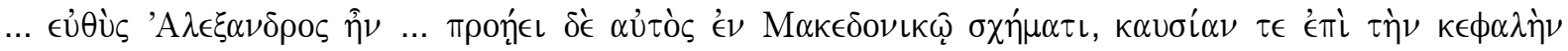

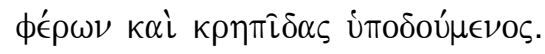

Dort war er [Caracalla] Alexander... Er rückte in makedonischer Kleidung vor, trug eine Kausia auf dem Kopf und Krepides als Schuhe.

\section{Q 8 Martial}

(ca. 40 - 103/4 n.Chr.)

\section{Epigramme 14, 29:}

\section{Causea}

In Pompeiano tecum spectabo theatro.

Mandatus (oder: nam ventus, nam flatus) ${ }^{61}$ populo vela negare solet.

Kausia

Im Pompeius-Theater werde ich mit dir (das Schauspiel) ansehen.

Mandatus (oder: Denn der Wind) versagt dem Volk häufig das Schutzsegel.

\section{Q 9 Menander}

(342/1-291/0 v.Chr.)

Frgt. 281 (331) (= Misogynes) ${ }^{62}$ :

... $\chi \lambda \alpha \mu u^{\prime} \delta \alpha, \kappa \alpha \nu \sigma i \alpha \nu, \ldots$

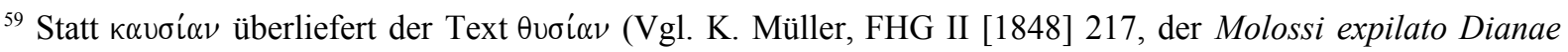
fano, quum ex statua eius coronam auream spoliassent, sacrificium pro ea obtulerunt. Cephallenes autem quum aliam coronam imposuissent, reiecit eam dea humique iacens inventa est. übersetzt.). Für „Kausia“ sprechen sich u.a. O. Hoffmann, Die Makedonen, ihre Sprache und ihr Volkstum (1906) 56 mit Anm. 39 und Dintsis, Helme 188 mit Anm. 39 aus.

${ }^{60}$ Nach Ritter, Diadem, 33 könnten Antigonos Monophthalmos, Antigonos Gonatas oder Antigonos Doson gemeint sein.

${ }^{61}$ Vgl. W.C.A. Ker; Martial. Epigrams II (1968) 450 Anm. 2.

${ }^{62} \mathrm{Vgl}$. A. Koerte, Menandri quae supersunt II (1953) $105 \mathrm{f}$.
} 
Q 10 Onesikritos von Astypalaia ${ }^{63}$

(um 325

\section{v.Chr.)}

FGrHist 134, 17 A (= Strabo 15, 1, 64):

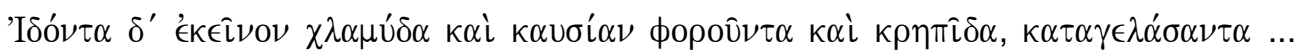

Aber als er [der indische Gymnosophist Kalanos] jenen [Onesikritos] Chlamys und Kausia und Krepides tragen sah, lachte er ...64

\section{Q 11 Philon von Byzanz}

( M. 3. Jh. v.Chr.)

Mechanike Syntaxis VII. VIII. (IV, 77 f.; p. 102) :

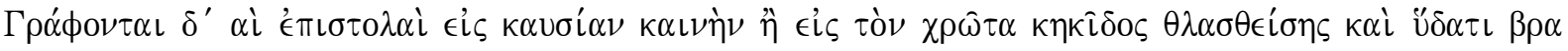

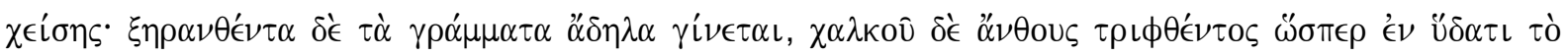

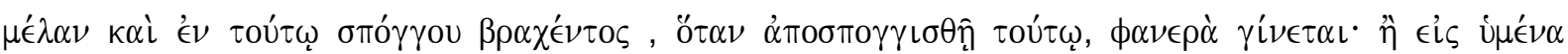

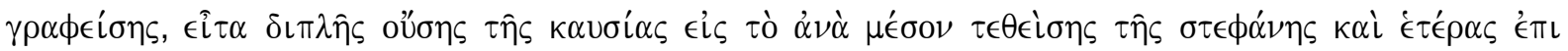

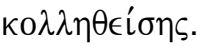

Man schreibt diese Briefe in eine neue Kausia oder in die [menschliche] Haut mit zerquetschten und mit Wasser versetzten Galläpfeln. Ist die Schrift getrocknet, wird sie unsichtbar; zerreibt man aber Vitriol wie die Tusche im Wasser und benetzt damit einen Schwamm, so tritt diese, wenn sie damit abge waschen wird, deutlich hervor. Oder man schreibt auf dünnes Pergament; dieses wird, da die Kausia doppelt ist, in die Mitte der Kappe/des Kappenrandes (Stephane) ${ }^{65}$ gelegt und mit dem anderen zusammengeleimt. ${ }^{66}$

\section{Q 12 Photios}

(um 810 - um 893 n.Chr.)

\section{Lexikon $^{67}$ :}

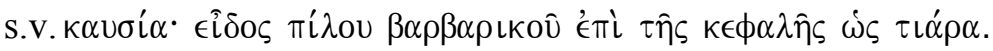

Kausia: Begriff für eine barbarische Filzmütze auf dem Kopf wie die Tiara.

\footnotetext{
${ }^{63}$ Onesikritos nahm an Alexanders Indienzug teil.

${ }^{64}$ Die Begegnung fand 326 v.Chr. statt.

${ }^{65}$ Stephane kann alles bezeichnen, was den Kopf umgibt (z.B. einen Helm oder Hut insgesamt), aber auch den

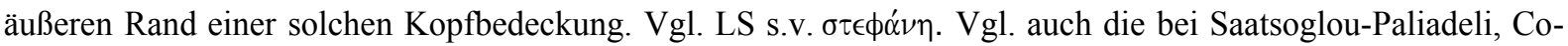
stume 147 ohne Nennung des Übersetzers zitierte französische Übersetzung: „ou bien on les écrit sur une membrane, que l'on place à la partie supérieure d'un chapeau à deux fonds collés l'un à l'autre.“

${ }^{66}$ Übersetzung nach H. Diels, E. Schramm, Exzerpte aus Philons Mechanik B. VII und VIII (Vulgo fünftes Buch), Abh. der Preussischen Akademie der Wissenschaften, Phil.-Hist. Klasse, 1919 Nr. 12 (1920) 79.

${ }^{67}$ Ch. Theodoridis (Hrsg.), Photii Patriarchae Lexicon II (1998) 385 Nr. 506.
} 


\section{Q 13 Plautus}

(ca. 250 - nach 184 v.Chr.)

a) Miles gloriosus ${ }^{68} 1178-1181(\mathrm{IV}, 4)$ :

...ibi tu ilico facito uti venias ornatu huc ad nos nauclerico. causeam habeas ferrugineam, et scutulam ob oculos laneam, palliolum habeas ferrugineam (nam is colos thalasiust),...: atque apud hunc senem omnia haec sunt, nam piscatores habet.

...kommst du [Pleusikles, ein junger Athener in Ephesos] ${ }^{69}$ sogleich in der Kleidung eines Kapitäns hierher. Hast du (trage) eine rostfarbene Kausia, und auch eine wollene Rolle ${ }^{70}$ über den Augen, trage einen rostfarbenen Mantel (denn das ist die Farbe des Meeres), [...]: Bei dem Alten findest du alles, denn er hält ja Fischer sich. ${ }^{71}$

\section{b) Persa 155 (I, 3):}

cape tunicam atque zonam, et chlamydem adferto et causeam, quam ille habeat qui hanc lenoni huic vendat.

Nimm Tunica und Gürtel, und bringe herbei Chlamys und Kausia, was jener ${ }^{72}$ haben muss, der an den Kuppler sie verkauft. ${ }^{73}$

\section{Q 14 Plutarch von Chaironeia}

(ca. 50 - nach 120 n.Chr.)

\section{a) Antonius 54, 5:}

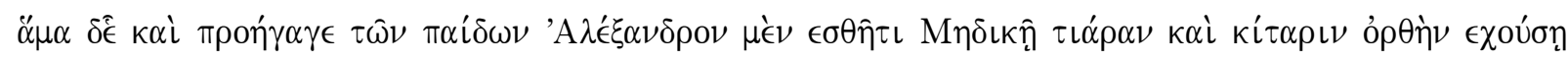

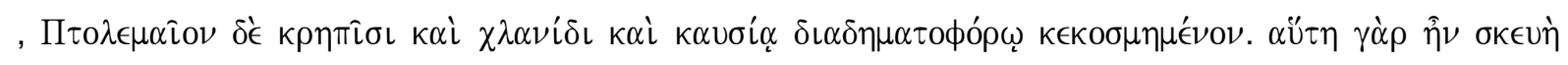

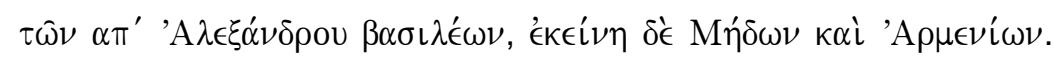

Zugleich aber ließ er [Antonius] von den Jungen Alexander in medischer Kleidung, zu der Tiara und aufrechte Kitaris gehörten, den Ptolemaios aber in Krepides und Chlanis und einer Kausia, um die ein

\footnotetext{
${ }^{68}$ Plautus schrieb den „Miles gloriosus“ vermutlich in enger Anlehnung an den „Alazon“ des Alexis von Thurioi (376/72-270 v.Chr.). Das Stück wurde wahrscheinlich zwischen 299 und 295 v.Chr. uraufgeführt und richtete sich gegen Demetrios Poliorketes. Vgl. L. Schaaf, Der Miles gloriosus des Plautus und sein griechisches Original, Studia et Testimonia Antiqua 18 (1977) 353 ff.

${ }^{69}$ Es handelt sich um einen jungen Athener, der als Schiffskapitän verkleidet in Ephesos auftreten soll. Vgl. auch nachfolgende Anm.

${ }^{70}$ B.M. Kingsley, Alexander's Kausia and Macedonian Tradition, ClAnt 10, 1991, 62 mit Anm. 21 sieht in der Rolle einen Bestandteil der Kausia. Dies scheint mir aus dem Text nicht eindeutig hervorzugehen.

${ }^{71}$ Vgl. W. Ludwig, Plautus/Terenz. Antike Komödien I (1974 [Nachdruck]) 572 (Neubearbeitung der Übersetzung von W. Binder, 1864 ff.): ,....kommst du [Pleusikles, junger Athener] sogleich in der Kleidung eines Kapitäns hierher, mit dunkelbrauner Kausia, einer Wollbinde vor den Augen, einem braunen Mäntelchen (Denn das ist die Seemannsfarbe) auf der Schulter links hinaufgeknüpft, mit bloßem Arm, die Kleidung hochgerafft, und stellst dich so, als ob du der Kommandant des Schiffes wärst. Bei dem Alten findest du alles, denn er hält ja Fischer sich.“ - P. Nixon, Plautus III (1970) 251 übersetzt: „,wear a broad-brimmed, rust-coloured hat, a woolen patch over your eyes, and a short, rust-coloured cloak“".

${ }^{72}$ Angeblich auswärtiger (peregrinus [Plaut. Persa 157]) Sklavenhändler, der die als Perserin bzw. Araberin (Plaut. Persa 541) verkleidete Tochter eines athenischen Parasiten zum Schein zum Kauf anbieten soll. Der „Sklavenhändler“ wird später als Mann in persischer Kleidung mit Tiara statt Kausia als Kopfbedeckung beschrieben (Plaut. Persa $463=$ IV,2).

${ }^{73}$ Übersetzung in Anlehnung an P. Nixon, Plautus III (1970) 437.
} 
Diadem gewunden war, auftreten. Denn dies war die Kleidung der auf Alexander folgenden Könige, jenes die der medischen und armenischen. ${ }^{74}$

\section{b) Demetrios 41, 6:}

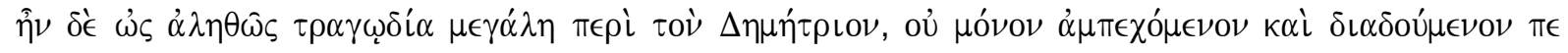

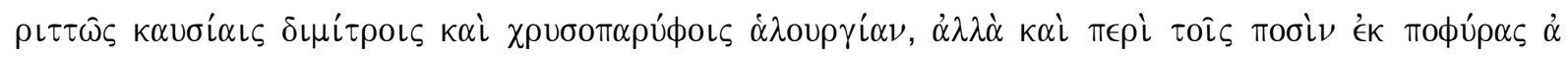

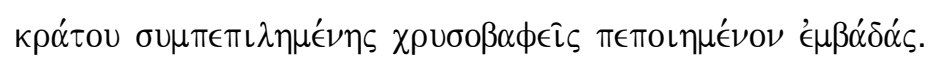

Es war aber in der Tat eine große Tragödie um Demetrios [Poliorketes], der nicht allein ein mit doppelter Mitra umwundene Kausia und ein purpurnes, goldbesetztes Gewand trug, sondern auch an seinen Füßen Schuhe, die aus purpurnem Filz gemacht und mit Gold bestickt waren. ${ }^{75}$

\section{c) Eumenes 6, 1:}

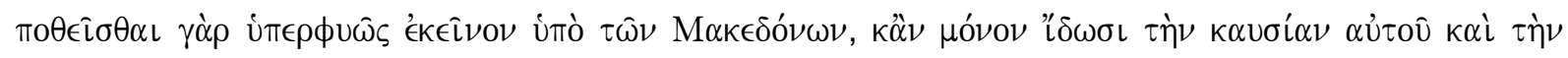

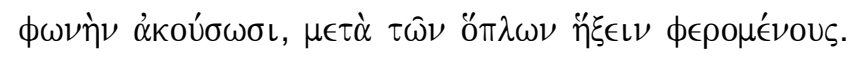

Denn nach ihm [Krateros] hätten die Makedonen eine wahre Sehnsucht, und wenn sie nur seine Kausia sähen und seine Stimme hörten, würden sie zu ihm überlaufen. ${ }^{76}$

\section{d) Eumenes 8, 7:}

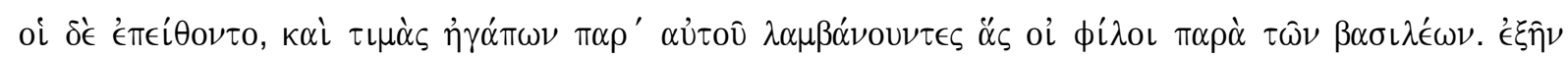

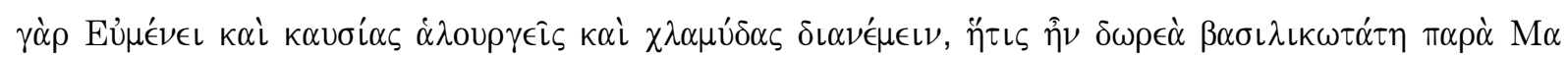
$\kappa \in \delta o ́ \sigma l$.

Sie fügten sich darein und waren erfreut von ihm die gleiche Ehrengabe zu erhalten wie die Freunde (Philoi) von den Königen. Denn Eumenes [von Kardia] hatte das Recht, auch purpurne Kausien und Chlamyden zu verleihen, die höchste Königsgabe bei den Makedonen. ${ }^{77}$

\section{e) Pyrrhos 11, 6:}

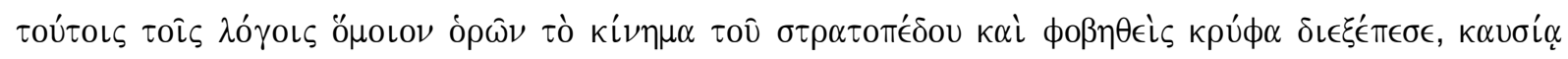

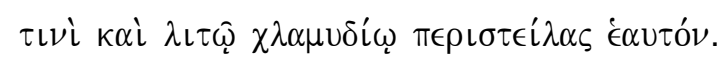

\footnotetext{
${ }^{74}$ Das Zitat lautet im Zusammenhang (in der Übersetzung K. Ziegler [Hrsg.], Plutarch. Große Griechen und Römer V [1960] 355 f.): „Er [Antonius] ließ nämlich das Volk sich im Gymnasion versammeln, auf einer silbernen Bühne zwei goldene Thronsessel aufstellen, den einen für sich, den anderen für Kleopatra, und dazu niedrigere für die Söhne, und erklärte erstens Kleopatra als Königin von Ägypten, Kypros, Libyen und Koile-Syrien unter Mitherrschaft von Kaisarion, welcher als Sohn des älteren Caesar galt, der Kleopatra schwanger zurückgelassen hatte; zweitens ernannte er seine Söhne von Kleopatra zu „Königen der Könige“ und wies dem Alexander Armenien, Medien und das Partherreich (sobald er es erobert haben würde), dem Ptolemaios Phoinikien, Syrien und Kilikien zu. Zugleich ließ er Alexander in medischer Tracht mit Tiara und aufrechtem Turban (Kitaris), den Ptolemaios in Stiefeln (Krepides) und Mantel (Chlanis) und diademgeschmückter Mütze (Kausia) auftreten; dies war nämlich die Tracht der Nachfolgerkönige Alexanders, jenes die der medischen und armenischen Könige; und während die Söhne ihre Eltern begrüßten, umstand den einen eine Leibwache von Armeniern, den anderen eine solche von Makedonen.“

${ }^{75}$ Vgl. die Übersetzung von K. Ziegler (Hrsg.), Plutarch. Große Griechen und Römer V (1960) 286: „Tatsächlich umgab sich Demetrios mit einem gewaltigen Theaterprunk. Er trug nicht nur auf dem Haupt einen mit doppelten Binden prächtig geschmückten Makedonenhut und kleidete sich in goldumsäumte Purpurgewänder, sondern hatte auch für seine Füße Schuhe aus reinem Purpurfilz mit Goldstickerei machen lassen.“

${ }^{76}$ Übersetzung nach K. Ziegler (Hrsg.), Plutarch. Große Griechen und Römer V (1960) 219.

${ }^{77}$ Übersetzung nach K. Ziegler (Hrsg.), Plutarch. Große Griechen und Römer V (1960) 223 f.
} 
Da er [Demetrios Poliorketes] bemerkte, dass die Vorgänge im Lager [der Makedonen] diesen Reden völlig entsprachen, geriet er in Furcht und machte sich, mit irgendeiner Kausia und einer schlechten Chlamys bekleidet, heimlich davon. ${ }^{78}$

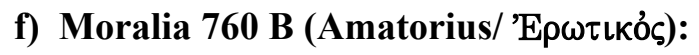

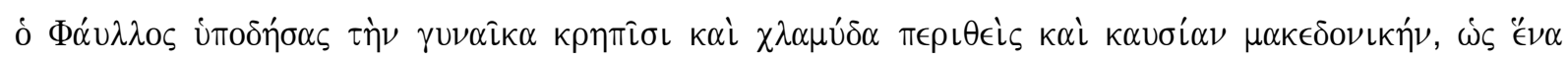

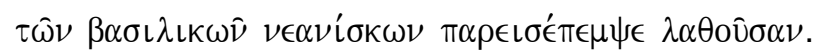

Phayllos band seiner Frau Krepides unter und legte ihr eine Chlamys und eine makedonische Kausia an, und so blieb sie unbemerkt und wurde als einer der königlichen Pagen eingelassen. ${ }^{79}$

\section{Q 15 Polyainos von Makedonien}

(2. H. 2. Jh. n.Chr.)

\section{Strategemata 5, 44, 5:}

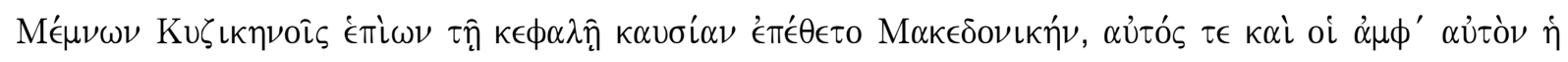

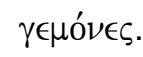

Als Memnon [rhodischer Söldnerführer] die Kyzikener [die ein makedonisches Entsatzheer erwarteten] angriff, setze er sich die makedonische Kausia auf den Kopf, er selbst und auch die Unterführer um ihn herum. ${ }^{80}$

\section{Q 16 Polybios von Megalopolis}

(ca. 200 - ca. 120 v.Chr.)

\section{4, 4, 5:}

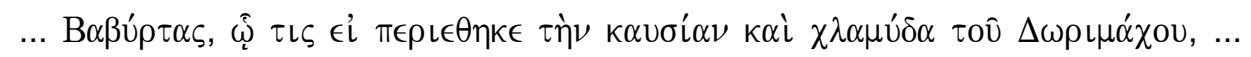

... Babyrtas, dem man nur die Kausia und Chlamys des Dorimachos ${ }^{81}$ hätte anzulegen brauchen,... ${ }^{82}$

\section{Q 17 Pollux (Iulius Polydeukes) von Naukratis}

(2. H. 2. Jh. n.Chr.)

\section{Onomastikon 10, 162:}

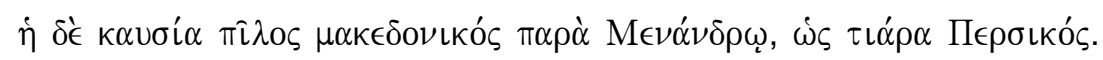

\footnotetext{
${ }^{78}$ Vgl. die Übersetzung von K. Ziegler (Hrsg.), Plutarch. Große Griechen und Römer VI (1965) 20: „, Da er nun auch eine diesen Worten entsprechende Bewegung im Lager bemerkte, erschrak er und machte sich heimlich davon, einen makedonischen Hut auf dem Kopf und in einen schlichten Mantel gehüllt.“

${ }^{79}$ Philipp V. (221-179 v.Chr.) hält sich in Argos auf. Der Argiver Phayllos möchte dem König seine schöne Frau zuführen, um Einfluss zu gewinnen. Nikostratos, ein Gegner des Phayllos, versucht dies zu verhindern. Phayllos wendet darauf die oben beschriebene List an. Vgl. Plutarch, Moralia 760 B.

${ }^{80}$ Der rhodische Söldnerführer Memnon kämpfte 336/5 v.Chr. im Auftrag des Perserkönigs Darios III. gegen die mit Philipp II. von Makedonien verbündeten Städte in Kleinasien, darunter Kyzikos. Die Kyzikener erwarteten ein makedonisches Entsatzheer unter Kallas. Vgl. auch Diodor 17, 7, 3. Vgl. zu Kleitarch als zeitgenössischer Quelle des Polyainos und Diodor: E. A. Fredricksmeyer, Alexander the Great and the Macedonian Kausia, TransactAmPhilAss 116, 1986, 219.

${ }^{81}$ Dorimachos leitete den aitolischen Angriff auf Messene (220 v.Chr.) und war mehrfach Stratege des Aitolischen Bundes im Krieg gegen Philipp V. von Makedonien.

82 Übersetzung nach H. Drexler, Polybios. Geschichte I (1961) 325. Die Textstelle lautet im Kontext: „Damals lebte in Messene ein übler Mensch, einer von denen, die in jeder Beziehung den Anspruch verloren hatten, ein Mann zu heißen, namens Babyrtas, dem man nur die Kausia und Chlamys des Dorimachos hätte anzulegen brauchen, so hätte man die beiden nicht unterscheiden können.“
} 
Die Kausia aber [ist] nach Menander eine makedonische Filzmütze, wie die Tiara eine persische.

\section{Q 18 Suda (byzantinisches Lexikon)}

(10. Jh. n.Chr.)

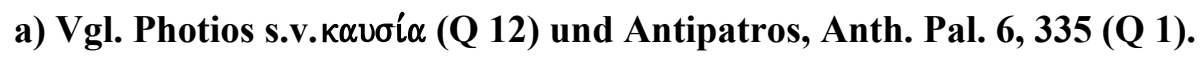

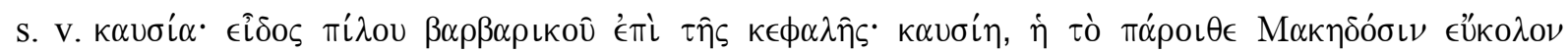

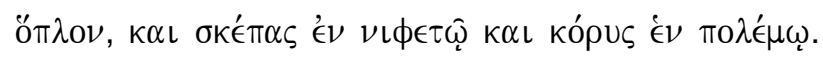

Kausia: Begriff für eine barbarische Mütze aus Filz auf dem Kopf: Kausia, einst den Makedonen guter/leichter Ausrüstungsgegenstand, während des Schneiens ein Hut, während des Krieges ein Helm.

b) Vgl. Antipatros, Anth. Pal. 6, 335 (Q 1).

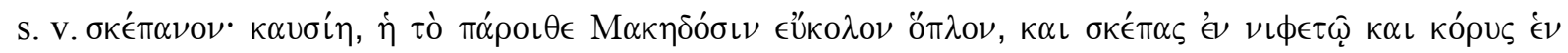
$\pi \mathrm{N} \epsilon^{\prime} \mu \omega$.

Bedeckung: Kausia, einst den Makedonen guter/leichter Ausrüstungsgegenstand, während des Schnei ens ein Hut, während des Krieges ein Helm.

\section{Q 19 Valerius Maximus}

( um 30 n.Chr.)

\section{Facta et dicta memorabilia 5, 1, ext. 4:}

humo caput sublatum causea, qua velatum caput suum more Macedonum habeat, texit corporique pyrri redditum honoratissime cremandum curavit.

Er [Antigonos Gonatas] nahm den [abgeschlagenen] Kopf [des Pyrrhos] vom Boden auf, bedeckte ihn mit der Kausia, die er nach makedonischem Brauch auf dem eigenen Kopf trug, setzte ihn auf den Körper des Pyrrhos ${ }^{83}$ und sorgte dafür, dass der wiederhergestellte [Körper] mit höchsten Ehren verbrannt wurde.

\section{Q 20 Xanthos, Inschrift am Eingang zum Letoon}

(um 200 v.Chr.)

\section{SEG XXXVI 1221 (vgl.: Chr. Le Roy, RA, 1986, 279 ff.):}

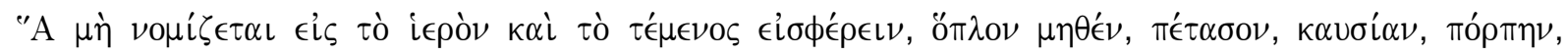

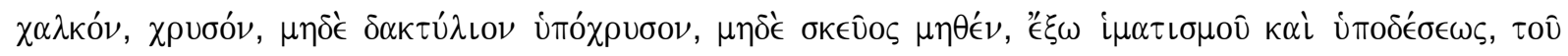

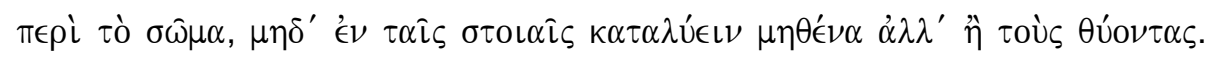

Es gilt als Gesetz, diese Dinge nicht in das Heiligtum und den heiligen Bezirk hineinzubringen: nicht eine Waffe, einen Petasos, eine Kausia, eine Spange, Bronze, Gold, auch nicht einen goldhaltigen Fingerring, noch auch Bekleidung, außer Bekleidung und Schuhwerk, die [sich] auf dem Körper [befinden], auch nicht beim Rasten in den Wandelhallen, niemand außer den Opfernden.

\footnotetext{
${ }^{83}$ Pyrrhos starb 272 v.Chr.
} 


\section{Q 21 Zenon von Kaunos (Privatarchiv in Philadelphia/Ägypten)}

\section{Zenon Papyrus Kairo 59633:}

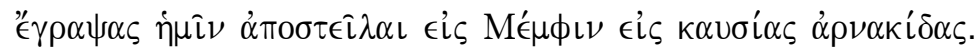

Du hast geschrieben, uns zu schicken nach Memphis in (nach?) Kausien aus Schaffell.

\subsubsection{Zusammenfassung}

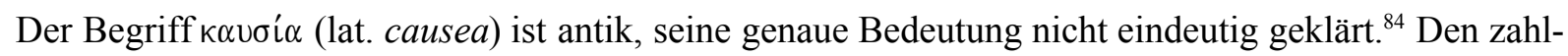
reichen Erwähnungen in der griechischen und lateinischen Literatur lässt sich Folgendes entnehmen: Die Kausia wird als flache (oder breite?) Mütze ${ }^{85}$ beschrieben $^{86}$. Sie bestand aus Wollstoff bzw. Filz ${ }^{87}$ oder Leder ${ }^{88}$ oder einer Kombination aus beiden ${ }^{89}$. Ihre Träger waren in der Regel Makedonen oder

\footnotetext{
${ }^{84} \kappa \alpha v \sigma i \alpha$ lässt sich wahrscheinlich auf $\kappa \alpha i \omega$ (brennen) zurückführen. Der Name weist vermutlich entweder auf

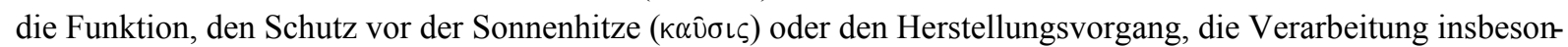
dere von Leder in heißem Zustand, hin. Vgl. Dintsis, Helme, 183 Anm. 1 und besonders zur letztgenannten Deutung Saatsoglou-Paliadeli, Costume, $126 \mathrm{f}$.

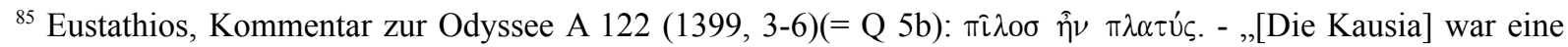
flache/breite Filzmütze."

${ }^{86}$ Nach Dintsis, Helme, 183 Anm. 3. 185 und Saatsoglou-Paliadeli, Costume, 127 ff. liegt bei Plaut. Trin. 851 (Pol hic quidem fungino generest: capite se totum tegit. - „Dieser hier gehört gewiss zur Pilzfamilie: durch den Kopf wird er ganz bedeckt.“) eine weitere Beschreibung der Kausia vor. Dintsis und Saatsoglou-Paliadeli erwähnen nicht, dass von der Kausia nirgends die Rede ist, und sie verzichten darauf, den nachfolgenden Vers (Hilurica facies videtur hominis, eo ornatu advenit. - „Das Aussehen des Mannes scheint illyrisch zu sein, in dieser Ausstattung kommt er daher.") zu zitieren, in dem der Betreffende, es handelt sich um einen Athener, aufgrund seiner Kleidung als Illyrier angesprochen wird. Es könnte bei Plautus demnach auch ein Petasos oder eine regionale illyrische Kopfbedeckung gemeint sein. Aus diesem Grunde halte ich die Verwendung der Textstelle für unzulässig.

${ }^{87}$ Für Filz/Wollstoff sprechen sich aus: Daremberg-Saglio I 2 (1896) 975 s.v. Causia (L. Heuzey) .- RE XI (1921) 89 ff. s.v. kausiva (A. v. Netoliczka) .- C. Schneider, Kulturgeschichte des Hellenismus II (1969) 32 .- T. Hölscher, Historienbilder des 4. - 5. Jh. v. Chr. (1973) 135 .- A. Kähler, Der große Fries von Pergamon (1948) 138 Anm. 73 .- B. M. Kingsley, The Cap that survived Alexander, AJA 85, 1981, 42 .-Dintsis, Helme, 183 Anm. 4. Begründet wird dies meist unter Hinweis auf Antipatros, Anth. pal. VI, 335 (= Q 1): кро́кєৎ - „Gewebe“ und

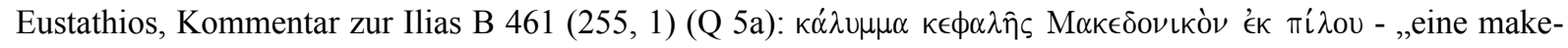
donische Kopfbedeckung aus Filz“.

${ }^{88}$ Vgl. E. Wuescher-Becchi, Petasus e causia, BullCom 32, 1904, 104. Vgl. Zenon Papyrus Kairo 59633 (= Q 21): $\dot{\alpha} \rho \nu \alpha \kappa\llcorner\dot{\delta} \delta \alpha \varsigma$ - „Schaffell““.

${ }^{89}$ Die Neuinterpretation altbekannter Texte (Antipatros, Anth. Pal. VI, 335 [= Q 1]; Eustathios, Kommentar zur Ilias B 461 [= Q 5a]) und die Heranziehung weiterer Texte (Philon von Byzanz, Mech. Syn. 77 f. [= Q 11]:

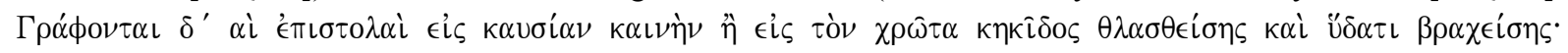

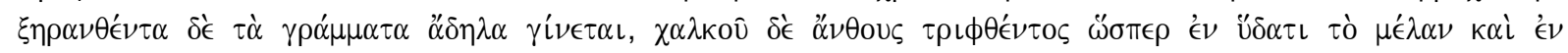

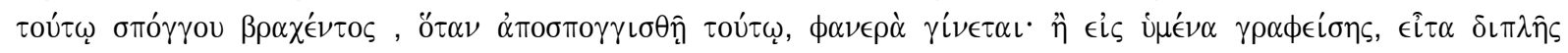

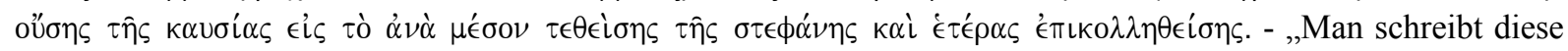
Briefe in eine neue Kausia oder in die [menschliche] Haut mit zerquetschten und mit Wasser versetzten Galläpfeln. Ist die Schrift getrocknet, wird sie unsichtbar; zerreibt man aber Vitriol wie die Tusche im Wasser und benetzt damit einen Schwamm, so tritt diese, wenn sie damit abgewaschen wird, deutlich hervor. Oder man schreibt auf dünnes Pergament; dieses wird, da die Kausia doppelt ist, in die Mitte der Kappe/des Kappenrandes (Stephane) gelegt und mit dem anderen zusammengeleimt." und Zenon Papyrus 59633 [= Q 21]) lassen es am wahrscheinlichsten erscheinen, dass die Kausia teilweise aus Stoff/Filz und teilweise aus (Lamm-) Leder bestehen konnte (z.B. außen Leder, innen Stoff oder Saum aus Stoff, Rest aus Leder). Vgl. Saatsoglou-Paliadeli, Costume, $123 \mathrm{ff}$.
} 
Personen, die als solche erscheinen wollten. ${ }^{90}$ Genannt werden insbesondere Könige. ${ }^{91}$ Sie trugen die Kausia in Kombination mit Mantel $\left(\chi \lambda \alpha \mu \nu v^{92}\right.$ oder $\left.\chi \lambda \alpha \nu^{\prime} \iota^{93}\right)$ und Stiefeln $\left(\kappa \rho \eta \pi i ́ \delta \in \varsigma^{94}\right)$. In dieser Kombination wurde sie auch von Angehörigen hellenistischer Heere getragen. ${ }^{95}$ Das erste in der antiken Literatur genannte Ereignis, in dem die Kausia eine Rolle spielte, fällt in das Jahr 336/5 v. Chr. ${ }^{96}$, das letzte in die Zeit Caracallas ${ }^{97}$. Die Masse der Erwähnungen konzentriert sich in dem Zeitraum, in dem hellenistische Heere aktiv waren, d.h. in die Zeit von Alexander bis Kleopatra.

Nach den Schriftquellen handelt es sich bei der Kausia also um eine seit spätklassischer Zeit für make donische Herrscher und Soldaten in Makedonien bzw. makedonisch beeinflussten Gebieten in Kombination mit Chlamys und Krepides bezeugte flache Mütze aus Stoff und/oder Leder.

Diese Angaben zu Material und Aussehen, Verbreitungsgebiet, Trägerkreis und Zeitstellung der Kausia lassen sich gut mit einer von Hunderten von Terrakottastatuetten getragenen Kopfbedeckung vereinbaren, die darüber hinaus auch auf Münzen, Kameen und Siegelabdrücken sowie in der Malerei und Plastik überliefert ist.

${ }^{90}$ Antipatros, Anth. Pal. VI, 335 (Q 1) .- Eustathios, Kommentar zur Ilias B $461(255,1)$ (Q 5a) .- Eustathios, Kommentar zur Odyssee A 122 (1399, 3-6) (Q 5b) .- Herodian, 1, 3, 3 (Q 7a) .- Herodian 4, 8, 1-2 (Q 7b) .- Plutarch, Eumenes 6, 1. 7, 8 (Q 14c/d) .- Plutarch, Moralia 760 B (Q 14f) .- Polyainos 5, 44, 4f. (Q 15) .- Pollux X,

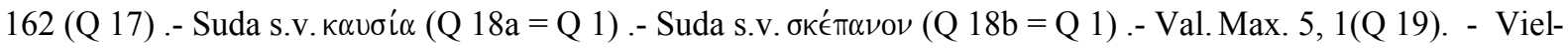
leicht im Zuge der Verbreitung über die gesamte hellenistische Welt werden auch einzelne Angehörige anderer Völker als Träger genannt: Molosser: Herakleides, Pont. Frgt. 17 (= FGrHist 2,217) (Q 6); Aitoler: Polybios IV,

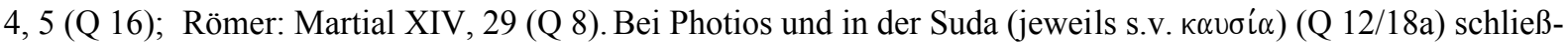

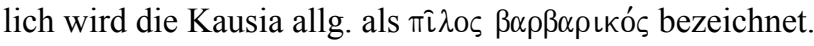

${ }^{91}$ Aristobulos, FGrHist 139, 55 (= Arrian, Anabasis 7, 22, 2) (Q 2): Alexander .- Ephippos, FGrHist 126, 5 (Q 4): Alexander .- Duris, Frgt. 14 (= Athenaios 12, 536) (Q 3): Demetrios Poliorketes .- Plutarch, Demetrios 41, 6 (Q 14b): Demetrios Poliorketes .- Val. Max. 5, 1 (Q 19): Antigonos Gonatas (und Pyrrhos) .- Plutarch, Antonius 54, 4 (Q 14a): alle Könige von Alexander bis in späthellenistische Zeit .- Eustathios, Kommentar zur Odyssee A 122 (1399, 3-6) (Q 5b): die makedonischen Könige .- Herodian 1, 3, 3 (Q 7a): Antigonos im Gegensatz zu anderen nicht. Vgl. auch Plutarch, Eumenes 8, 7 (Q 14d): königliches Geschenk schon zur Zeit des Eumenes von Kardia (321/0 v.Chr.) .- Herodian 4, 8 (Q 7b): Caracalla in Anlehnung an Alexander während einer MakedonienReise.

${ }^{92}$ Duris, Frgt. 14 (= Athenaios 12, 535 f.) (Q 3) .- Ephippos, FGrHist 126, 5 (= Athenaios 12, 537 e) (Q 4) .Menander, Frgt. 281 (331) (Q 9) .- Onesikritos, FGrHist. 134, 17 A (= Strabo 15, 1, 64) (Q 10) .- Plautus, Persa 155 (Q 13b) .- Plutarch, Eumenes 8, 7 (Q 14d) .- Plutarch, Pyrrhos 11, 6 (Q 14e) .- Plutarch, Moralia 760 B (Q 14f) .- Polybios 4, 4, 5 (Q 16). Als Untergewand werden Chiton (Ephippos) bzw. Tunica (Plautus) genannt.

${ }^{93}$ Plutarch, Antonius 54, 4 (Q 14a).

${ }^{94}$ Herodian 4, 8 (Q 7b) .- Onesikritos, FGrHist. 134, 17 A (= Strabo 15, 1, 64) (Q 10) .- Plutarch, Antonius 54, 4 (Q 14a) .- Plutarch, Mor 760 B (Q 14f).

${ }^{95}$ Antipatros, Anth. Pal. VI, 335 (Q 1) .- Plutarch, Eumenes 8, 7 (Q 14d) .- Plutarch, Pyrrhos 11, 6 (Q 14e) .- Polyainos, Strategemata 5, 44, 4-5 (Q 15) .- Polybios 4, 4, 5 (Q 16). Bei den meisten der in den vorhergehenden Anmerkungen genannten Personen (Makedonen, Könige) handelt es sich um Offiziere bzw. Könige in der Funktion des Feldherren, d.h. ebenfalls um Soldaten.

${ }^{96}$ Polyainos 5, 44, 5 (Q 15). Der Bericht über den Angriff des rhodischen Söldnerführers Memnon, der mit Hilfe einer Kausia als der makedonische General Kallas erscheinen wollte, auf Kyzikos, von dem in stark gekürzter Form auch Diodor 17, 7, 3 berichtet, geht wahrscheinlich auf Kleitarchos (Ende 4. Jh. v.Chr.) zurück. Zur Evidenz vgl. E.A. Fredricksmeyer, Alexander the Great and the Macedonian Kausia, TAPhA 116, 1986, 219. (Gegen eine Beweiskraft der Textstelle spricht sich jedoch weiterhin B. M. Kingsley, Alexander's Kausia and Macedonian Tradition, ClAnt 10, 1991, 59-76 aus.)

${ }^{97}$ Herodian, Antoninus Caracalla 4, 8 (Q 7b). 


\subsection{Aussehen der Kausia}

In der Vergangenheit ist die Trennlinie zwischen Petasos und Kausia nicht eindeutig gezogen worden $^{98}$, und es ist bis in die jüngste Zeit zu Verwechslungen gekommen ${ }^{99}$. Infolge dessen möchte ich im Folgenden das Aussehen von Petasos und Kausia definieren.

Der Petasos $^{\mathbf{1 0 0}}$ (Taf. 1 Abb. 3) besteht aus zwei Bestandteilen: der Kopfform ${ }^{101}$ und der Krempe. Die Kopfform, eine gewölbte Erhebung über dem Loch der Krempe, kann in ihrer Größe beträchtlich schwanken. Manchmal umschließt sie fast halbkugelförmig den oberen Teil des Kopfes, manchmal ist sie zu einer knopfähnlichen Erhebung in der Mitte der scheibenförmigen Krempe verkümmert. Die Krempe, ein meist rundes Stück Filz oder Leder mit einem Loch von unterschiedlichem Durchmesser in der Mitte, kann verschieden breit sein. Sie wird auch hochgeklappt oder nach unten hängend dargestellt. Beide Bestandteile (Krempe und Kopfform) kann man sich auch aus einem Stück gearbeitet vorstellen. Befestigt wird der Petasos am Kopf durch Kinn- und/oder Nackenbänder.

Die Kausia (Taf. 1 Abb. 2, Taf. 2 ff. Abb. 4 ff.) besteht aus zwei Teilen ${ }^{102}$ : dem Schirm, einer kreisrunden Scheibe, die leicht gewölbt sein kann und deren Durchmesser meist den größten Umfang der Mütze angibt, und einem zu einer Röhre zusammengenähten Streifen. Der Durchmesser der Röhre muss dem des Schirmes (rund $30 \mathrm{~cm}$ ) entsprechen, da das obere Ende der Röhre mit dem Schirm zusammengenäht wird, so dass der Schirm die Röhre an einem Ende verschließt. Je nach Höhe der Röhre entsteht entweder eine flache Binde oder eine wulstartige Rolle. Eine etwa $10 \mathrm{~cm}$ hohe Röhre bildet eine flache Binde als unteren Abschluss (entspricht im Aussehen der Matrosen- oder Baskenmütze); wird eine $30 \mathrm{~cm}$ hohe Röhre zweimal umgeschlagen bzw. aufgerollt, entsteht eine Mütze vom Aussehen der afghanischpakistanischen Chitrali. Um den unteren röhrenförmigen Teil der Kausia kann sich bei Herrschern das Diadem winden. Der untere Durchmesser der Binde bzw. der Wulstrolle ist mit Hilfe von Abnähungen an die Kopfweite des Trägers angepasst und dient so unter anderem der Befestigung der Kausia auf dem Kopf.

Wenn der untere Teil der Kausia nicht erkennbar ist, ${ }^{103}$ ist für die Identifizierung entscheidend, dass die Kausia im Gegensatz zum Petasos weder Kopfform noch Sturmbänder ${ }^{104}$ aufweisen

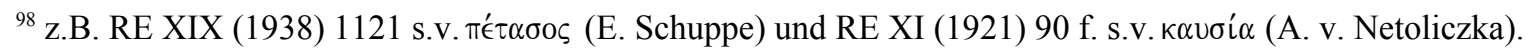

${ }^{99}$ z.B. Dintsis, Helme, Nr. 281. 282. 294 .- Saatsoglou-Paliadeli, Costume, 140 (mit Anm. 189).

${ }^{100}$ Vgl. allg.: RE XIX (1938) 1121 s.V. $\pi \epsilon ́ \tau \alpha \sigma o \varsigma$ (E. Schuppe) und Saatsoglou-Paliadeli, Costume, $128 \mathrm{f}$.

${ }^{101}$ Den Begriff „Kopfform“ habe ich aus dem in vorhergehender Anm. genannten RE-Artikel übernommen. Vgl.

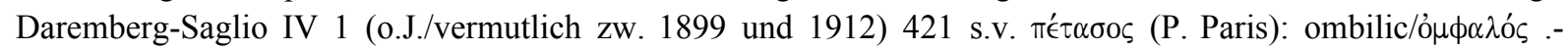
Saatsoglou-Paliadeli, Costume, 129: knob.

${ }^{102}$ Die Herstellung der Kausia ist umstritten. Vgl. zur Diskussion das Kapitel „Herstellung, Material, Farbe“.

${ }^{103}$ Dies kann der Fall sein, wenn die Krempe oder ein überdurchschnittlich großer Schirm den unteren Teil verdecken, wenn die Kopfbedeckung in Draufsicht gezeigt wird oder die Darstellung von geringer Größe ist.

${ }^{104}$ H. Biesantz, Die thessalischen Grabreliefs (1965) 79 behauptet, dass die Kausia mit einem Kinnriemen, der Petasos mit einem Nackenriemen befestigt wurde. Dies stimmt nicht. Alle eindeutig als Kausia identifizierbaren Kopfbedeckungen weisen keine Riemen auf (vgl. Katalog), der Petasos wird durch Kinn- und/oder Nackenbän-
} 
darf. Der Petasos ist in der Regel größer als die Kausia. Da jedoch die Größe beider Kopfbedeckungen stark schwankt, ist dies kein sicheres Unterscheidungsmerkmal.

Es existieren verschiedene Varianten der Kausia. Der Schirm kann flach, leicht gewölbt oder konisch sein. Der Übergang zwischen Schirm und unteren Teil ist teilweise scharf, teilweise fließend. Die Rolle kann groß oder klein sein, manchmal ist sie flachgedrückt, manchmal fehlt sie bzw. ist zum Stirnband verkümmert. Der Schirm kann den unteren Abschnitt überragen und umgekehrt. Alle Variationen sind möglich, sie lassen sich jedoch alle mit der Grundform (runder Schirm mit unterschiedlich langer Röhre, die zur Rolle geformt sein kann) vereinbaren. Eine unterschiedliche Bedeutung einzelner Varianten anzunehmen, ${ }^{105}$ scheint mir durch das Material jedoch nicht gerechtfertigt. Zeitlich, regional und typologisch zusammengehörende Terrakottastatuetten, wie die Chlamydephoroi aus Lesbos (Tk 180-184), die aus einer geschlossenen, münzdatierten Nekropole stammen und teilweise formgleich sind, oder die Soldaten (Tk 3-8, 50-53, 99-100, 109-112, 125-126) und die Reiter (Tk 9-24, 58-64, 95-97, 102, 105-107) aus Ägypten weisen jeweils diverse Kausiaformen auf. Zusammenfassend lässt sich sagen, dass es verschiedene Varianten der Kausia gab, deren Besonderheiten sich, wie künstlerisch hochwertige Darstellungen, z.B. an der Fassade des Grabes bei Agios Athanasios (Ma 6, Taf. 10 Abb. 48-49), zeigen, nicht auf mangelnde Fähigkeiten der Künstler zurückführen lassen. Alle Varianten sind jedoch auf das oben beschriebene Schnittmuster zurückführbar. Sie lassen sich weder zeitlich noch regional ordnen, noch sind sie auf einzelne Teile der makedonischen Bevölkerung beschränkt.

\subsection{Herstellung, Material, Farbe}

Auch wenn die Kausia nicht aus Afghanistan stammt, so bietet es sich an, sich für die Herstellung an einer modernen afghanisch-pakistanischen Mütze („Chitrali“) zu orientieren, da diese im Aussehen bis hin zu Details wie den Abnähungen auf der Rolle mit der Kausia übereinstimmt $^{106}$ (Taf. 1 Abb. 1-2).

Die Chitrali genannte Mütze besteht aus einem kreisrunden Stoffstück von etwa $30 \mathrm{~cm}$ Durchmesser, dem Schirm, und aus einem viereckigen Stück (ca. 95×30 cm), das zu einer Röhre zusammengenäht wird. Durch das Abnähen ${ }^{107}$ lässt sich diese Röhre gegebenenfalls an bestimm-

der gehalten (vgl. z.B. Daremberg-Saglio IV 1 [o.J.] 421 s.v. T⿱㇒́ $\tau \alpha \sigma o \varsigma$ [P. Paris]). Das bei Biesantz genannte Beispiel (Stele von Aiane) zeigt Kinn- und Nackenband (so schon E. Wuescher-Becchi, Petasus e Causia, BullCom 32, 1904, 98), so dass es auch nach Biesantz' Definition nicht als Kausia bestimmbar wäre (es ist im Übrigen eine knopfartige Kopfform zu erkennen).

${ }^{105} \mathrm{Vgl}$. Ch. Saatsoglou-Paliadeli, Aspects of Ancient Macedonian Costume, JHS 113, 1993, $122 \mathrm{ff}$.

${ }^{106}$ B. M. Kingsley, The Cap that survived Alexander, AJA 85, 1981, 39 Abb. 1 Taf. 6 .- B. M. Kingsley, The Kausia Diadematophoros, AJA 88, 1984, 66 Taf. 24, 2.

${ }^{107}$ So entstehen auch die charakteristischen Nähte auf der Rolle, die sich sowohl auf der afghanisch-pakistanischen Mütze (Chitrali) (s. vorherige Anm.) als auch auf den Kausien einiger Terrakotten (Tk 180, 294 f.) finden. 
ten Stellen verengen. Schlägt man sie zweimal um oder rollt sie auf, so entsteht die wulstartige Rolle ${ }^{108}$.

Aus dieser Grundform lassen sich die diversen Unterformen der Kausia ableiten: Verwendet man statt einer kreisrunden Scheibe für den Schirm ein Kreissegment ${ }^{109}$, so entsteht ein konischer Schirm. Eine Kausia ohne Rolle erhält man, indem die Röhre auf etwa $10 \mathrm{~cm}$ verkürzt und das untere Ende dem Kopfumfang entsprechend abgenäht wird. Diese Variante ist, wie verschiedene Zwischenformen mit teilweise gekürzter und nur im unteren Bereich aufgerollter Röhre, besonders geeignet, in Kombination mit dem königlichen Diadem getragen zu werden.

In älteren ${ }^{110}$ Rekonstruktionsversuchen wird meist von drei Bestandteilen ausgegangen: einer Scheibe (bzw. einem Kreissegment) für den Schirm und zwei Streifen statt einer Röhre. Dies ist problematisch. P. Dintsis bietet denn auch gleich zwei Rekonstruktionsversuche an: Im ersten wird der auf die Scheibe folgende Streifen von einem lang gestreckten Trapez gebildet, an das unten ein - wie auch immer entstandener - kleiner Wulst angenäht wird; im zweiten Versuch wird an die Scheibe ein Streifen von undefinierbarer Form und an diesen ein weiterer langrechteckiger Streifen angenäht. ${ }^{111}$ Beide Vorschläge wirken etwas gekünstelt-theoretisch. Die Kausia mit großer Rolle lässt sich so überhaupt nicht erklären, bzw. es müsste zu weiteren Hilfskonstruktionen gegriffen werden (ein dicker Wulst wird nachträglich an der Kausia befestigt und gehört eigentlich nicht dazu). Dass eine an vielen Kausien zu beobachtende Raffung nur durch einen zweiten engeren Streifen zu erzielen ist, ${ }^{112}$ trifft nicht zu. Die Raffung lässt sich genauso durch das Aufrollen des unteren Teiles der Röhre erreichen.

Die Chitrali genannte Mütze aus dem Hindukusch eignet sich demnach am besten als Schnittmustervorlage für alle erdenklichen Formen der antiken Kausia, obwohl beide Kopfbedeckungen sehr wahrscheinlich unabhängig voneinander entstanden.

\footnotetext{
${ }^{108}$ Plautus, Miles gloriosus 1178 ff. (= Q 13a) erwähnt nebeneinander eine rostfarbene Kausia, eine wollene Rolle über den Augen und eine rostfarbenen Mantel (causeam habeas ferrugineam, et scutulam ob oculos laneam, palliolum habeas ferrugineam...). B.M. Kingsley, Alexander's Kausia and Macedonian Tradition, ClAnt 10, 1991, 62 mit Anm. 21 geht davon aus, dass die Rolle Bestandteil der Kausia ist (,It [the kausia]... had a roll of wool above the eyes that could be serve as a sweatband."). Der antike Name der Rolle/Röhre wäre demnach scutula (griech. $\sigma \kappa \cup \tau \alpha \dot{\lambda} \lambda \eta)$. Ich übersetzte jedoch „Hast du (trage) eine rostfarbene Kausia, und auch eine wollene Rolle über den Augen, hast du (trage) einen rostfarbenen Mantel...". Bei der Rolle muss es sich entsprechend nicht zwingend um einen Teil der Kausia handeln, sondern es kann sich auch um ein getrennt von der Kausia gearbeitetes und unabhängig von dieser zu tragendes Kleidungsstück handeln, das entsprechend nicht zur Beschreibung der Kausia herangezogen werden kann.

${ }^{109}$ Vgl. E. Wuescher-Becchi, Petasus e Causia, BullCom 32, 1904, 104 Abb. 8 .- Dintsis, Helme, Beil. 14 unten.

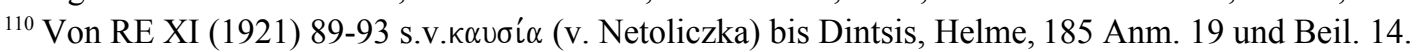

${ }^{111}$ Dintsis, Helme, 185 erwähnt im Text nur eine Variante (Scheibe mit zwei Streifen) und illustriert diese durch zwei voneinander abweichende Zeichnungen (Dintsis, Helme, Beil. 14).

${ }^{112}$ So Dintsis, Helme, 185 Anm. 17. Er nennt als Beispiel die Kausia vom Waffenfries aus Pergamon (hier Re 1). Bezeichnenderweise weist diese keinen unteren Streifen auf, sondern eine kleine Rolle.
} 
Als Material kommen - wie oben ${ }^{113}$ angesprochen - Stoff oder Leder bzw. eine Kombination aus beiden in Frage.

Die Farbe variiert. Die in den antiken Schriftquellen genannten Kausien sind purpurfarben. ${ }^{114}$ Dies ist darauf zurückzuführen, dass dort ausschließlich vom Herrscher getragene oder von diesem verschenkte Kausien beschrieben werden und dass Purpur die Farbe der Könige war. Farbige bildliche Wiedergaben sind selten. ${ }^{115}$ Die Darstellung eines hellenistischen Königs, der eindeutig als solcher identifiziert werden kann und eine purpurfarbene, mit einem Diadem umwundene Kausia trägt, ist nicht überliefert. Stellvertretend kann hier nur die „Makedonia“ (im Sinne einer Personifikation des makedonisch-hellenistischen Königtums) an einer Wand der Villa von Boscoreale genannt werden, die eine violette Kausia (diadematophoros?) aufweist (Ma 11). Erscheint die Kausia in der Malerei in alltäglichen Zusammenhängen, wird sie in verschiedenen weiß-grauen, ocker-gelben oder braunen Farbtönen wiedergegeben. ${ }^{116}$ Diese könnten für die Farben des ungefärbten oder nur mit einfachen Naturfarben gefärbten Materials (Leder/Stoff) stehen.

Bei Terrakotten erscheinen neben gelblichen Farbtönen (z.B. Tk 360) auch bläuliche (Tk 47, 61, 71, 74, 77, 79-83, 85, 90, 302) und rötliche (Tk 12, 46, 102, 123, 145, 155, 169, 185, 353, 363) Kausien. An Reiterstatuetten vom Typus „Reiter über Gegner“ (Tk 12 aus „Ägypten“; Tk 102 aus Naukratis), hinter denen sich vielleicht Darstellungen Alexanders oder eines Ptolemäerkönigs verbergen, sind vereinzelt rote Farbspuren zu beobachtenden. Diese werden von J. Fischer mit der Purpurfarbe der königlichen Kausien in Verbindung gebracht. ${ }^{117}$ Da jedoch auch andere Typen (z.B. Chlamydephoren [Tk 46, 123, 145, 353]), die sicher nicht den König zeigen, rote Kausien aufweisen können, ist die rote Farbgebung nicht grundsätzlich mit dem königlichen Purpur zu identifizieren. Die Farbigkeit der Kausien der Terrakottafiguren orientiert sich möglicherweise weniger an der Realität, als am Spektrum der in der hellenistischen Koroplastik üblichen Modefarben (insbesondere rosa-rot und [hell-] blau).

\footnotetext{
${ }^{113}$ Vgl. Kapitel „Identifizierung“ mit Hinweisen auf entsprechende Bemerkungen in den antiken Quellen (Anti-

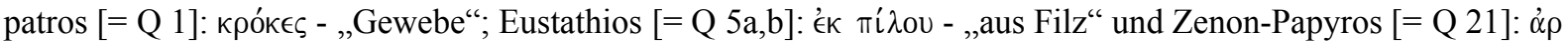
$\nu \alpha \kappa i \delta \alpha \varsigma_{-}$, ,aus Schaffell“; Philon von Byzanz, Mech. Syn. 77 f. [= Q 11]) und auf die Sekundärliteratur (besonders Saatsoglou-Paliadeli, Costume, $123 \mathrm{ff}$.).

${ }^{114}$ Duris, Frgt. 14 (= Athenaios 12, 535 f.): $\dot{\alpha} \lambda$ oup $\gamma \hat{\eta}$ (= Q 3); Plutarch, Eumenes 8, 7: $\dot{\alpha} \lambda$ oup $\gamma \epsilon \hat{i} \varsigma$ (= Q 14d).

${ }^{115}$ Münzen, Siegel (-abdrücke) und Kameen sind gattungsbedingt nicht farbig gestaltet. Darstellungen der Kausia in der Koroplastik, steinernen Rundplastik sowie im Relief waren in der Antike zwar meist farbig gefasst, entsprechende Farbspuren haben sich aber in der Regel nicht erhalten. Es bleiben die bildlichen Wiedergaben in der Malerei und im Mosaik. Diese sind selten, und oft ist die ursprüngliche Farbgebung unklar, oder es handelt sich nur um weitgehend farblose Strichzeichnungen.

${ }^{116}$ Vgl. Ma 4 (Alexandria, Architrav des Grabes 1 der Mustafa-Pascha-Nekropole: gelbe Kausia [?] eines opfernden Kavalleristen), Ma 5 (Vergina, Architrav des,,Philippsgrabes“: Kausien der Jäger in rötlich, gelb-ocker und bräunlich), Ma 6 (Grab von Ag. Athanasios [bei Thessaloniki]: braune Kausien bewaffneter Festteilnehmer auf dem Architrav, weiße Kausien der „Grabwächter“/Soldaten auf der Wand neben dem Eingang), Ma 7 (Dromos des Grabes von Kasanlak: gelbe Kausia eines Soldaten

117 J. Fischer, Ein triumphierender Makedonenreiter - Zeugnis eines ptolemäischen Siegesdenkmals?, StädelJb 19, 2004, 487 und insbesondere 492.
} 


\subsection{Herkunft und Verbreitung}

Im Mittelmeerraum und im Vorderen Orient finden sich seit frühgeschichtlicher Zeit Darstellungen von kausiaähnlichen Mützen. ${ }^{118}$ Auch im etruskisch-italischen Bereich ${ }^{119}$ und auf Zypern $^{120}$ erscheinen seit archaischer Zeit ähnliche Kopfbedeckungen. Eine Verbindung zwischen diesen Mützen und der makedonischen Kausia ist nicht belegbar. ${ }^{121}$

Die Herkunft der Kausia war zeitweilig umstritten. B.M. Kingsley ${ }^{122}$ hat versucht, sie auf die postulierten Vorläufer einer modernen afghanisch-pakistanischen Mütze namens Chitrali zurückzuführen. Diese hätten die Soldaten Alexanders übernommen und im Westen verbreitet. Diese Auffassung kann seit den Arbeiten von E.A. Fredricksmeyer ${ }^{123}$ und Ch. Saatsoglou-Paliadeli ${ }^{124}$, die zeigen, dass die Kausia schon in vorhellenistischer Zeit im mediterranen Raum vereinzelt nachweisbar ist, als widerlegt gelten. Die Kausia stammt demnach aus Makedonien und verbreitete sich von hieraus. ${ }^{125}$

\footnotetext{
${ }^{118}$ Vgl. z.B. eine minoische Bronzestatuette (G. v. Horn, Eine minoische Bronze in Leiden, JdI 30, 1915, 65 ff.), die Schnittervase aus Agia Triada in Iraklion (M. P. Nilsson, The Minoan-Mycenaean Religion and ist Survivals in Greek Religion [1955] 161 Abb. 66) oder einen Terrakottakopf aus Susa in Teheran (A. Spycket, Les figurines de Suse, MDAI 52 [1992] 195 Nr. 1215 Taf. 140).

${ }^{119}$ Vgl. z.B. L. Bonfante, Etruscan Dress (1975) 81 .- G. Camporeale, in: Die Etrusker und Europa, Ausst.-Kat. Berlin 1993, 81 f. .- M. Christofani, I Bronzi degli Etruschi (1985) 162 .- A. Ferri, Il Museo Archeologico di Bologna (1974) 32 f. .- G. Lilliu, Scultura Sardegna Nuragica (1966) 51. 266. 268.

${ }^{120}$ Vgl. z.B. E. Sjöqvist, The Swedish Cyprus Expedition II (1935) Nr. 259. 1219. 1369. 1796 .- ders., A Cypriote Temple Attendant, AJA 59, 1955, 47 Nr. 13-17 .- J.H. Young - S.H. Young, Terracota Figurines from Kourion in Cyprus (1955) 163 Nr. 3016 Taf. 62; 163 Nr. 3021 Taf. 62; 164 Nr. 3030 Taf. 67; 102 Mold 11A. Zum Problem der kausiaähnlichen Kopfbedeckungen siehe unten den „Exkurs: Eine kausiaähnliche Mütze im zypriotisch-phönizisch-punischen Raum“.

${ }^{121}$ Entsprechend werden Darstellungen kausiaähnlicher Kopfbedeckungen aus diesen Bereichen - insbesondere auch aus dem kaiserzeitlichen Italien (z.B. Wandgemälde mit Meleager [mit kausiaähnlicher Kopfbedeckung] und Atalante aus der Casa del Centauro in Pompeji [Dintsis, Helme, 312 Nr. 300]) - hier nicht behandelt, soweit nicht der Kontext eindeutig auf eine makedonische Kausia hinweist (wie z.B. bei der Makedonia aus der Villa von Boscoreale [Ma 11]). Verunklärend wirkt auch, dass der Begriff „causea“ im lateinischen Sprachraum nicht mehr exklusiv für die makedonische Kausia verwendet wurde, sondern auch ähnliche Kopfbedeckungen nicht unbedingt makedonischer Herkunft bezeichnen konnte, wie die „causea“, die Martial (Epigramme 14, 29; Q 8) im Theater trägt, und die „causea“ eines Schiffers bei Plautus, Miles gloriosus 1178 (Q 13a) andeuten.

${ }^{122}$ B. M. Kingsley, The Cap that Survived Alexander, AJA 85, 1981, 39 ff. .- dies., Alexander's Kausia and Macedonian Tradition, ClAnt 10, 1991, 59-76.

${ }^{123}$ E. A. Fredricksmeyer, Alexander the Great and the Macedonian Kausia, TransactAmPhilAss 116, 1986, 215 ff.

${ }^{124}$ Ch. Saatsoglou-Paliadeli, Aspects of Ancient Macedonian Costume, JHS 113, 1993, $122 \mathrm{ff}$.

${ }^{125} \mathrm{Zu}$ einem erweiterten Ursprungsgebiet (Illyrien, Thrakien, Makedonien) der dann illyrisch-thrakisch-makedonischen Kausia und/oder ähnlichen Mützen im illyrisch-thrakischen Raum vgl. u. „Exkurs: Die ,Kausia“ im illyrisch-thrakischen Bereich“.
} 
Nachweisen lässt sich die Kausia erst relativ spät ${ }^{126}$ : Sieht man von den unterschiedlich interpretierbaren Darstellungen auf den Grabreliefs der Achämenidenkönige ${ }^{127}$, dem Graffito auf einer Schale aus Berezen (um 500 v.Chr.) ${ }^{128}$ und einen vielleicht zu einem Choregen-Monument gehörenden Relief der Zeit um 340 v.Chr. aus Athen, das komische Tänzer, die einen Stock und eine kleine dosenförmige Mütze tragen und versuchsweise als tanzende makedonische Soldaten mit Speer und Kausia gedeutet worden sind, ${ }^{129}$ ab, ist die Kausia mit Hilfe des archäologischen Materials erst seit etwa dem letzten Drittel des 4. Jahrhunderts v.Chr. nachweisbar. ${ }^{130}$ In der literarischen Überlieferung wird sie erstmals für ein Ereignis des Jahres 336/5 v.Chr. erwähnt. ${ }^{131}$ Damals sollen der in persischen Diensten stehende Söldnerführer

\footnotetext{
${ }^{126}$ Der Grund für das weitgehende Fehlen von Darstellungen und Erwähnungen in den archäologischen und literarischen Quellen der vorhellenistischen Zeit ist nicht in der Nicht-Existenz der Kausia zu suchen, sondern in der allgemein geringen Zahl von Relikten und Nachrichten aus dem vorhellenistischen Makedonien und darin, dass die wenigen Zeugnisse zum Makedonien dieser Zeit weniger der Betonung eines eigenständigen Volkscharakters als der Zugehörigkeit zum Griechentum dienten. Dies änderte sich erst zur Zeit Philipps II. und Alexanders, als Makedonien vom Randgebiet zur Vormacht Griechenlands aufstieg. Jetzt konnten auch makedonische Bekleidungselemente gezeigt werden, die nun nicht mehr die Zugehörigkeit zu einer rückständigen, sondern zur herrschenden Gruppe symbolisierten.

${ }^{127}$ Vgl. z.B. das Grabmal des Königs Dareios I. (gestorben 486 v.Chr.) von Naks-i-Rustem (F. H. Weisbach, Die Keilinschriften der Achämeniden [1911] 86 ff. .- G. Walser, Die Völkerschaften auf den Reliefs von Persepolis, TeherF 2 [1966] 33 ff. Taf. 5 und Nachzeichnung auf Falttafel Nr. 1). Das Grabrelief zeigt unter dem Thron Personifikationen der tributpflichtigen Völker (jeweils in der Landestracht dargestellt). Diese sind durch Beischriften unter den Figuren sowie die Grabinschrift identifizierbar. Als Nummer 23, 25 und 26 erscheinen die (kleinasiatischen) Ionier (= Griechen), die Skudra (= Thraker) und die (balkanischen) „Ionier (= Griechen), die Schilde auf ihren Köpfen (= schildförmige Kopfbedeckungen) tragen“. Im Relief werden kleinasiatische Griechen, Thraker und Griechen auf dem Balkan einheitlich mit einer am ehesten an den Petasos erinnernden Kopfbedeckung gezeigt. Hinter den zuletzt genannten „Ioniern“ verbergen sich die Bewohner der Griechenstädte an der nördlichen Küste der Ägäis, die Makedonen oder die Thessaler. Da die Kopfbedeckung nur für die balkanischen „Ionier" eigens erwähnt wird, obwohl auch die kleinasiatischen Griechen und die Thraker mit Hut dargestellt werden, ist dieser Kopfbedeckung eine besondere Bedeutung zugesprochen und die Vermutung geäußert worden, dass es sich entweder um den thessalischen Petasos oder die makedonische Kausia handeln könnte (F. H. Weisbach, Die Keilinschriften der Achämeniden [1911] 89 f. Anm. p). Es ist jedoch weder die Identifizierung der Volksgruppe noch die der Kopfbedeckung eindeutig, und daher können Relief und Inschriften nicht den Beweis einer Existenz der Kausia in vorhellenistischer Zeit erbringen.

${ }^{128}$ Vgl. Saatsoglou-Paliadeli, Costume, 141, die die Scherbe in Form einer Strichzeichnung publiziert hat. Die fragmentierte Schale befindet sich im Archäologischen Museum von Odessa (Inv. A 43950+23759). Der Schrift-

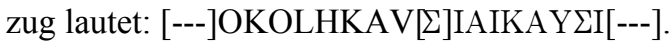

${ }^{129}$ Athen, Agora S 1025 und 1586. Vgl. T.B.L. Webster, Greek Dramatic Monuments from the Athenian Agora and Pnyx, Hesperia 29, 1960, 263 ff. Taf. 66 .- B.M. Kingsley, Alexander's Kausia and Macedonian Tradition, ClAnt 10, 1991, 62 mit Anm. 18 und Abb. 7.

${ }^{130}$ Vereinzelt könnten bildliche Wiedergaben der Kausia schon vor dem Beginn des Alexanderzuges entstanden sein (so ein Grabrelief aus Vergina [Re 2] oder einige Terrakottastatuetten aus dem Bereich Attika/Böotien [Tk 289 ff.]). Das Material lässt sich jedoch meist nicht mit ausreichender Genauigkeit datieren. Verbindlich nachzuweisen sind Darstellungen in großem Umfang rund um das Mittelmeer und in verschiedenen Gattungen für die Zeit seit dem letzten Viertel des 4. Jh. v.Chr. (Vgl. z.B. Tk 39 ff.; 5 ff., Ma 7 f., Nu 1 ff. 4 ff.).

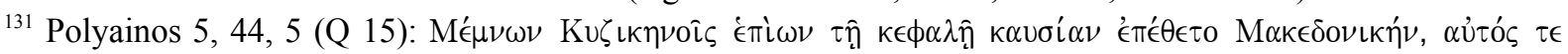

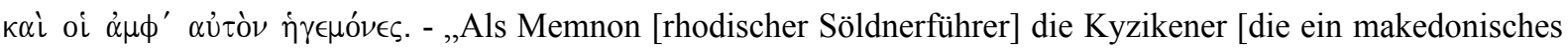
Entsatzheer erwarteten] angriff, setze er sich die makedonische Kausia auf den Kopf, er selbst und auch die Unterführer um ihn herum.“ - Der Bericht über den Angriff auf Kyzikos (Vgl. Diodor 17, 7, 3.) geht wahrscheinlich auf Kleitarchos (Ende 4. Jh. v.Chr.) zurück. Vgl. E. A. Fredricksmeyer, Alexander the Great and the Macedonian Kausia, TransactAmPhilAss 116, 1986, 219 f.
} 
Memnon und seine Offiziere die Kausia getragen haben. Memnon wollte den Bewohnern der mit Makedonien verbündeten Stadt Kyzikos als Befehlshaber eines Entsatzheeres unter dem Makedonen Kallas erscheinen.

Mit der Ausdehnung des makedonischen Einflusses in der Folge des Alexanderfeldzuges verbreitete sich die Kausia in allen Gebieten, in denen in hellenistischer Zeit Makedonen, Griechen oder hellenisierte Barbaren lebten. Die Kausia findet sich von Sizilien bis Baktrien und von der Krim bis Ägypten (Karte 1 ff.).

Das schwerpunktmäßige Vorkommen der Kausia in Makedonien und makedonisch beherrschten Gebieten, der Zeitpunkt ihres vermehrten Auftretens sehr kurz nach dem Alexanderfeldzug und die Tatsache, dass die Kausia von Alexander und zumindest Teilen seines Heeres getragen wurde, legen es nahe, in den Soldaten des Alexanderheeres und nachrückenden Siedlern die Verbreiter der Kausia zu sehen. 


\section{Die Kausia in den archäologischen Quellen}

Das archäologische Material lässt sich in zwei Gruppen aufteilen:

1. Bildliche Wiedergaben der Kausia bzw. von Personen mit Kausia, die in einen szenischen Zusammenhang eingebunden oder mit einem bestimmten Attribut (dem Diadem) verbunden sind. In beiden Fällen erlaubt es die Einordnung in einen Kontext, die betreffenden Darstellungen weitgehend aus sich heraus zu deuten.

Der ersten Untergruppe, den meist mehrfigurigen szenischen Darstellungen, gehören in der Regel Beispiele aus den Bereichen Relief oder Malerei an. Den betreffenden Szenen ist zu entnehmen, in Kombination mit welchen weiteren Trachtbestandteilen die Kausia bei welchen Tätigkeiten getragen wurde. Das Alter und Geschlecht und teils auch der Name, der Beruf oder die gesellschaftliche Stellung des Trägers der Kausia können bestimmt werden. Aus dem Fundort und dem Fundkontext sowie der Datierung eines Denkmals lassen sich weitere Angaben entnehmen (u.a. zur geographischen und zeitlichen Verbreitung).

Der zweiten Untergruppe, den Darstellungen der mit einem Diadem umwundenen Kausia, fehlt der szenische Zusammenhang im engeren Sinne meist, da es sich in der Regel um Münzen, Siegelabdrücke oder Kameen handelt, die nur das Porträt oder die Büste einer Person mit der Kausia diadematophoros zeigen. Da jedoch das Diadem nur von einer klar definierten Gruppe (dem König und wenigen ihm nahe stehenden Personen) getragen wurde, sind auch in diesen Darstellungen Alter und Geschlecht sowie der „Beruf“ und der soziale Status des Trägers der Kausia bekannt. Münzen, die den Namen des Herrschers meist in der Legende nennen, ermöglichen darüber hinaus die Identifizierung bestimmter Personen. Präge- und Fundorte können zudem Auskunft über die Verbreitung der Kausia geben.

2. Statuetten meist kleineren Formats und aus gebranntem Ton, vereinzelt auch aus Stein. Diese zeigen fast ausschließlich Knaben und junge Männer. Sie sind überwiegend bekleidet mit einer Art von Standardtracht, bestehend aus Kausia, Chlamys, Chiton und Stiefeln, und weisen daneben meist keine weiteren Attribute auf, die zur Deutung beitragen könnten. Statt des durch den szenischen Zusammenhang oder das Attribut erschließbaren Kontextes können bei diesen Figuren, die zu Hunderten in Gebieten zwischen Südfrankreich und dem Iran gefunden wurden, Regelmäßigkeiten, die sich bei der Auswertung der Fundorte bzw. Fundkontexte ergeben, einen Beitrag zur Interpretation leisten. Entsprechende Statuetten wurden - soweit nachweisbar - ausschließlich in Nekropolen und in Heiligtümern entdeckt. Der Grabkontext bzw. der Charakter bestimmter Heiligtümer ermöglichen unter Umständen Rückschlüsse auf die dort bestatteten oder bestattenden Personen bzw. die Weihenden und den Anlass der Weihung.

Die relativ große Anzahl der Statuetten sowie das konzentrierte Auftreten bestimmter Typen zu bestimmten Zeiten in begrenzten Gebieten erlauben es nicht nur, allgemeine Angaben über 
die geographische und chronologische Verbreitung der Kausia zu machen. Mit Einschränkungen sind auch Angaben zur Demographie einzelner Regionen oder zur Bedeutung bestimmter Personengruppen und Institutionen möglich.

\subsection{Szenische Darstellungen und die Kausia diadematophoros}

Diejenigen bildlichen Wiedergaben der Kausia bzw. von Personen mit Kausia, die durch die Einbindung in eine Szene oder die Kombination mit dem Diadem bestimmten Kontexten zugeordnet werden können, lassen sich drei Gruppen von Personen zuweisen: den Königen, den Soldaten sowie den Bürgern und (bürgerlichen) Beamten.

Neben den genannten realen Personengruppen können auch Personifikationen ${ }^{132}$ Makedoniens die Kausia tragen.

\subsubsection{Könige}

Bei den meisten der in diesem Abschnitt besprochenen Darstellungen handelt es sich um solche, die nur begrenzt als „szenisch“ bezeichnet werden können: die Porträts hellenistischer Herrscher mit Kausia diadematophoros. Im Anschluss an die genannten Darstellungen gehe ich auf isoliert erscheinende Wiedergaben der Kausia diadematophoros ein. Diese sind, auch wenn die Träger der Kopfbedeckung selbst nicht gezeigt werden, dennoch in einem königlichen Kontext zu sehen, da das Diadem ausschließlich vom König getragen wurde.

Die wenigen szenischen Darstellungen, in denen der König und sein Gefolge auftreten, zeigen (königliche) Jagden, deren Teilnehmer teils die Kausia tragen - jedoch ohne Diadem.

\subsubsection{Die Kausia diadematophoros als Kopfbedeckung der Könige}

Bei der Kausia diadematophoros handelt es sich um eine purpurfarbene ${ }^{133}$ und mit einem Diadem umwundene Kausia. Während die einfache Kausia - wie zu zeigen sein wird - von allen Makedonen getragen werden konnte, waren die Farbe Purpur ${ }^{134}$ und das Diadem dem König vorbehalten. In einer Person, die in hellenistischer Zeit ein Diadem und so auch eine mit einem Diadem umwundene Kausia trägt, ist demnach grundsätzlich ein Herrscher $^{135}$ zu sehen.

\footnotetext{
${ }^{132} \mathrm{Zu}$ den Personifikationen vgl. unten den „Exkurs: Personifikationen mit Kausia“.

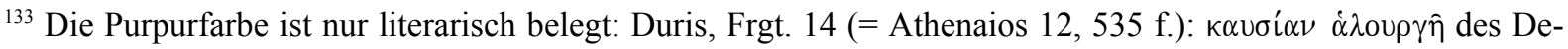

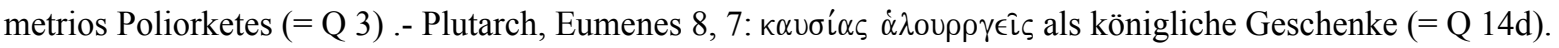

${ }^{134}$ Das Recht, Purpur zu tragen, konnte vom König an verdiente Personen verliehen werden. Vgl. Plutarch, Eumenes 8, 7, der berichtet, dass Eumenes von Kardia (als Stellvertreter des toten Königs) 1000 purpurne Kausien

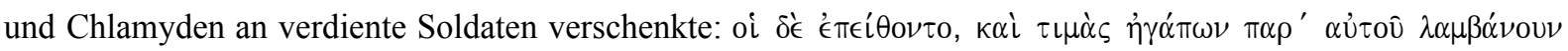

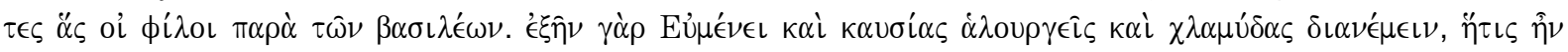

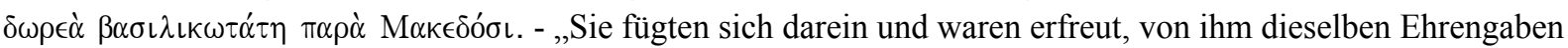
zu erhalten, wie die Freunde (philoi) von den Königen. Denn Eumenes hatte das Recht auch purpurne Kausien und Chlamyden zu verleihen, die höchste Königsgabe bei den Makedonen." (Übersetzung in Anlehnung an K. Ziegler, Plutarch. Große Griechen und Römer V [1960] 223 f.) Vgl. auch die vermutete Kausia des potentiellen Ptolemaios auf dem Alexandermosaik (Mo 1).
} 
Ich gehe zunächst auf diejenigen Beispiele ein, die die Kausia diadematophoros als Kopfbedeckung einer Person - meist eines namentlich bekannten Königs - zeigen.

Anschließend werden die isolierten Darstellungen der Kausia diadematophoros besprochen.

\section{Philipp II., Philipp V. oder Perseus ?}

Ein Kameo in Paris (Ka 3, Taf. 2 Abb. 4) zeigt die Rückenbüste eines bärtigen Mannes. Das Porträt ist im Profil nach links wiedergegeben. Bekleidet ist die Person (abgesehen von einer Kausia) nur mit einer über der linken Schulter hängenden Ägis. Hinter der rechten Schulter ist eine Hand zu erkennen, die waagerecht einen Speer hält. Die linke Hand ist nicht zu sehen. Auf dem Kopf des Mannes befindet sich eine konische Kausia. Der untere Rand des Schirmes der Kausia ist mit einer Wellenranke verziert. Auf dem oberen Abschnitt des Schirmes ist eine Kampfszene wiedergegeben: Ein bogenschießender Kentaur bewegt sich von rechts auf einen knienden unbekleideten Kämpfer mit Rundschild (und weiterer Waffe?) zu. An der Spitze der Kausia befindet sich eine kreisförmige Verzierung, die vielleicht eine Öffnung andeuten soll. Der untere Abschnitt der Kausia ist mit einer in Nacken verknoteten Binde umwunden, deren lange Enden im Rücken herabhängen. Derjenige Teil der Binde, der die Kausia umwindet, ist efeubestickt.

Die Kopfbedeckung macht einen sehr steifen und scharfkantigen Eindruck. Dies hat zu der Vermutung geführt, dass es sich bei ihr um eine metallbeschlagene Form der Kausia oder gar um einen ganz aus Metall bestehenden Helm namens $\kappa \hat{\omega} \nu \varsigma_{\zeta}$ handeln könnte. ${ }^{136}$ Solche Erwägungen sind wenig überzeugend. Die Kopfbedeckung auf der Pariser Kamee weist alle Bestandteile (Schirm, darunter Binde) der Kausia auf. Mit der Kausia unvereinbare Elemente, z.B. einem Kinnriemen, wie er zur Befestigung eines Helmes notwendig wäre, treten nicht auf. Die Mütze sitzt direkt mit der Binde auf dem Kopf auf. Dies deutet auf ein weiches, sich dem Kopfumfang anpassendes Material (Stoff, Leder) hin, nicht auf starres Metall. Die Verzierungen werden auf der Kamee in Relief angegeben. Dies ist jedoch auf die Technik der Steinschneiderei zurückzuführen, nicht auf das Material des Vorbildes. Die Kampfszenen und Ornamente können auf der realen Kausia in Malerei, Stickerei oder durch Einprägen in Leder angegeben gewesen sein. Auch die steife Form ist nicht zwangsläufig auf Metall als Material zu beziehen, denn durch die Verwendung von gestärktem Stoff und insbesondere von Leder ist eine ähnliche Wirkung zu erzielen.

\footnotetext{
${ }^{135}$ Der Kreis der Diademträger unter den Herrschern lässt sich noch weiter eingrenzen. Das Diadem trugen Alexander, die Seleukiden und Ptolemäer, verschiedene Kleinkönige in Kleinasien, am Schwarzen Meer, im Vorderen und Mittleren Orient, in Arabien und Nordafrika und auf Sizilien sowie einige der Antigoniden (H.-W. Ritter, Diadem und Königsherrschaft [1965] 31 ff. 79 ff. 128 ff.). In der Anfangsphase trugen jedoch diejenigen Könige, deren Herrschaft auf Makedonien beschränkt war (Kassander bis Demetrios II./Antigonos Dosen?), das Diadem nicht. Erst Antigonos Doson, Philipp V. und Perseus zeigten sich mit Diadem (Vgl. die teils widersprüchlichen Angaben bei H.-W. Ritter, Diadem und Königsherrschaft [1965] 33 f. 155 f.).

${ }^{136}$ Saatsoglou-Paliadeli, Costume, 132.
} 
Der oben beschriebenen Binde ist aufgrund der Form ${ }^{137}$ ihrer Enden und der auf ihr befindlichen Stickerei bzw. ihrer potentiellen Farbgebung ${ }^{138}$ teilweise eine Identifizierung als Diadem abgesprochen worden. Als Diadem darf eine Binde nur dann angesprochen werden, wenn es sich um ein flaches Stoffband handelt, dessen im Nacken herabhängende Enden gerade abgeschnitten und meist mit Fransen versehen sind. ${ }^{139}$ Das Diadem war zudem weiß-purpurn gestreift oder weiß. ${ }^{140}$ Die in sich gedrehte Binde auf dem Kameo weist jedoch abgerundete Enden auf, an deren Enden sich kleine Quasten befinden. ${ }^{141}$ Es kann sich daher beispielsweise auch um eine Siegerbinde handeln. ${ }^{142}$ Wie erwähnt, ist darüber hinaus derjenige Teil der Binde, der die Kausia umwindet, efeubestickt. Auf Grund der abgerundeten Enden der Binde und der Verzierung handelt es sich nicht um die übliche Form des Diadems. Ausnahmen sind jedoch zumindest bezüglich der Verzierung auch in anderen Fällen zu beobachten. ${ }^{143}$

Aus der antiken Literatur geht hervor, dass Demetrios Poliorketes, um die anderen Könige zu übertrumpfen, anstatt des Diadems eine goldbestickte Mitra bzw. Doppelmitra trug. ${ }^{144}$ Diese war nicht nur bestickt, sondern kann auch in der Form (z.B. den Enden) vom typischen Diadem abgewichen haben. Andererseits muss diese bestickte Mitra dem Diadem soweit geglichen haben, dass sie wie ein Diadem um den Kopf bzw. die Kausia getragen werden konnte. Es könnte sich daher auf dem Kameo um eine bestickte Mitra handeln, wie sie von Demetrios Poliorketes alternativ zum Diadem getragen wurde.

Die dargestellte Person ist versuchsweise als Philipp II. (359-336 v.Chr.), Philipp V. (221-179 v.Chr.) oder Perseus (179-168 v.Chr.) bezeichnet worden. ${ }^{145}$ Die Basis dieser Zuweisungen ist

${ }^{137}$ H. Kyrieleis, Der Kameo Gonzaga, BJB 171, 1971, 166 f. mit Anm. 23, 16 .- M. Bergmann, Die Strahlen der Herrscher (1998) 115.

${ }^{138}$ H. Kyrieleis, Der Kameo Gonzaga, BJB 171, 1971, 166 f. mit Anm. 23, 16.

${ }^{139}$ Zur Form des Diadems und zur Art der Darstellung in einzelnen Gattungen vgl. M. Bergmann, Die Strahlen der Herrscher (1998) $114 \mathrm{f}$.

${ }^{140}$ H. Kyrieleis, Der Kameo Gonzaga, BJB 171, 1971, 166 f. mit Anm. 23, 16 (mit Verweis auf A. Krug, Binden in der griechischen Kunst [1968] 118 f.).

${ }^{141}$ Es ist auf dem Kameo nur ein Bindenende zu sehen, da das andere von der Ägis verdeckt wird.

${ }^{142}$ Vgl. zur Typologie und Verwendung verschiedener griechischer Binden A. Krug, Binden in der griechischen Kunst (1968).

${ }^{143}$ Vgl. Münzporträts Ptolemaios V., die den König mit einem mit einer Ähre verzierten Diadem (H. Kyrieleis, Bildnisse der Ptolemäer, AF 2 [1975] 52 Taf. 40, 1-2 .- ders., Die Porträtmünzen Ptolemaios‘ V., JdI 88, 1973, 224-235 Abb. 5, 8-11, 17-19, 29 [Silber-Tetradrachmen und Gold-Oktadrachmen]) bzw. mit einem Flechtbandmuster auf dem Diadem (H. Kyrieleis, Die Porträtmünzen Ptolemaios' V., JdI 88, 1973, 217 Abb. 2 [Tetradrachmon]) zeigen, sowie vielleicht eine Bronzebüste Ptolemaios XII. Auletes (?) mit einer Kranzbinde, die „nicht mit Sicherheit als Diadem zu erkennen" ist (H. Kyrieleis, Bildnisse der Ptolemäer, AF 2 [1975] 77 Taf. 68, 6-7 [I 2]).

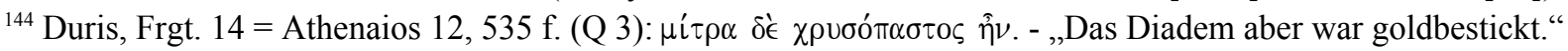

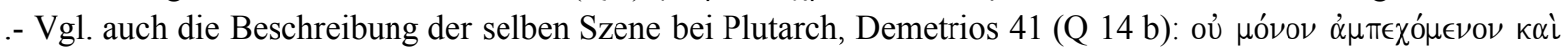

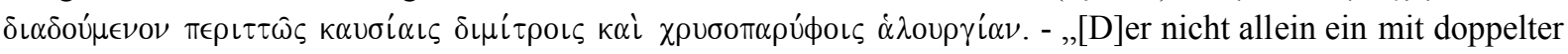
Mitra umwundene Kausia und ein purpurnes, goldbesetztes Gewand trug,...“

${ }^{145}$ Für Philipp II. spricht sich H. Kyrieleis, Der Kameo Gonzaga, BJB 171, 1971, 166 f. mit Anm. 23, 16 aus. Für Philipp V.z.B. G.M.A. Richter, The Portraits of the Greeks III (1965) 256 f. (mit Literatur) und Dintsis, Helme, 309 Nr. 292 (mit Literatur). Die alte Deutung als Perseus vertreten z.B. E. Babelon, Catalogue des Camées antiques et modernes de la Bibliothèque Nationale (1897) 103 Nr. 228 Taf. 22 und jetzt wieder: M.-L. Vollenweider, Camées et intailles I. Les Portraits grecs du Cabinet des médailles. Catalogue raisonné (1995) 184 f. Nr. 201 (mit Literatur). 
wohl darin zu sehen, dass - wegen der Kausia - ein makedonischer Herrscher gesucht wurde, von dem Wiedergaben mit Bart bekannt ${ }^{146}$ oder für den aufgrund allgemeiner Überlegungen solche Darstellungen zu fordern sind ${ }^{147}$. Keine dieser Deutungen lässt sich eindeutig belegen. Unterstützen lässt sich jedoch die Zuweisung an einen hellenistischen König, da die Kombination von verschiedenen göttlichen Attributen, wie Ägis (Zeus, Apollon, Athena) und Efeu (Dionysos ${ }^{148}$ ), und die Verbindung mit einem mythologischen Thema (Kentauromachie) typisch für diese war. ${ }^{149}$ Es muss sich zudem um einen Herrscher handeln, der sowohl mit Kausia als auch mit Bart wiedergegeben werden konnte. Dies trifft jedoch für weitaus mehr als die drei genannten Könige zu. Denn es muss sich nicht unbedingt um einen in Makedonien herrschenden König handeln, sondern es kommen auch Angehörige anderer aus Makedonien stammender Dynastien (z.B. Seleukiden und Ptolemäer) in Frage und darüber hinaus auch nicht-makedonischstämmige Herrscher, die in der Tradition des Makedonenkönigs Alexander stehen (z.B. die baktrischen Könige). Mit Bart lassen sich von diesen auf Münzen z.B. die Seleukidenkönige Seleukos II. Kallinikos (246-226/5 v.Chr.), Antiochos Hierax (246-228 v.Chr.), Achaios (220-214 v.Chr. [Usurpator]), Seleukos IV. Philopator (187-175 v.Chr.), Demetrios II. Nikator (145-139/8 und 129-125 v.Chr.), Antiochos IX. Kyzikenos (115-95 v.Chr.), Demetrios III. Philopator (95-88 v.Chr.) und Antiochos XII. Dionysos (87-84 v.Chr.) darstellen. ${ }^{150}$ Problematisch ist auch, dass zur Ermittlung der Gruppe der bärtigen Könige ausschließlich Münzen herangezogen werden. Denn in anderen Gattungen werden Herrscherbildnisse teils variationsreicher gestaltet. So werden Ptolemäerkönige auf Münzen immer bartlos und ohne Kausia wiedergegeben, können auf den eng mit den Kameen verwandten Siegeln jedoch Bart und Kausia tragen. ${ }^{151}$

\footnotetext{
${ }^{146}$ Vgl. z.B. G.M.A. Richter, The Portraits of the Greeks III (1965) 256 f. Abb. 1746 (Philipp V.); 257 Abb. 1749 (Perseus) .- N. Davis/C. M. Kraay, The Hellenistic Kingdoms. Portrait Coins and History (1973) Abb. 123. 127 (Philipp V.); Abb. 125. 128 (Perseus).

${ }^{147}$ Von Philipp II. sind (u.a. da er keine Münzen mit seinem Porträt prägen ließ) keine gesicherten zeitgenössischen Bildnisse bekannt (Vgl. G.M.A. Richter, The Portraits of the Greeks III [1965] 253 mit Abb. 1706, 1708). Eine Barttracht ist jedoch wahrscheinlich, da diese in der Mitte des 4. Jahrhunderts v.Chr. bei reiferen Männern allgemein üblich war.

${ }^{148}$ R.R.R. Smith, Hellenistic Royal Portraits (1988) 37, der das hellenistische Herrscherdiadem nicht aus der orientalischen Königsikonographie ableitet, sondern mit Dionysos in Verbindung bringt, sieht in der Darstellung des Efeus, der heiligen Pflanze dieses Gottes, auf der Binde einen Hinweis auf den Ursprung des Diadems.

${ }^{149}$ Vgl. D. Svenson, Darstellungen hellenistischer Könige mit Götterattributen (1995).

${ }^{150}$ Vgl. z.B. R. Fleischer, Studien zur seleukidischen Kunst 1. Herrscherbildnisse (1991) Taf. 14 d-e (Seleukos II.), Taf. 15 b (Antiochos Hierax), Taf. 19 g (Achaios), Taf. 33 e. 42 d-e (Demetrios II.), Taf. 46 b-c (Antiochos IX.), Taf. 49 c (Seleukos VI.), Taf. 51 a-c, e (Demetrios III.), Taf. 52 d (Antiochos XII.) .- G.M.A. Richter, The Portraits of the Greeks III (1965) 270-272 Abb. 1874. 1895. 1902. 1906. Darüber hinaus werden auch im 2. und 1. Jh. v.Chr. regierende Könige verschiedener kleinasiatischer, pontischer und nordafrikanischer Reiche(Bithynien, Pontos, Kappadokien, Parthien, Numidien, Mauretanien) mit Bart dargestellt (G.M.A. Richter a.a.O. 274 Abb. 1922 ff.), deren Herrschaft jedoch meist überwiegend in einheimischer (persischer oder afrikanischer) Tradition steht.

${ }^{151}$ Vgl. Si 14 (Ptolemaios XV. Kaisarion?) aus Nea Paphos/Zypern. Vgl. auch ein rundplastisches Porträt mit Bart, das vielleicht den „subptolemäischen“ König Ptolemaios von Mauretanien zeigt (G.M.A. Richter, The Portraits of the Greeks III [1965] 281 Abb. 2012).
} 
Nicht vorgeschlagen wurde bisher eine Deutung als Porträt der Demetrios Poliorketes mit Kausia und der literarisch überlieferten verzierten diademartigen Mitra. Dies dürfte darauf zurückzuführen sein, dass bärtige (Münz-) Bildnisse dieses Herrschers nicht bekannt sind.

Solange der dargestellte Herrscher nicht anhand des Porträts oder der Attribute eindeutig zu identifizieren ist, lässt sich nur feststellen, dass es sich entweder um ein posthumes Porträt Philipps II. oder um das Porträt eines auf die eine oder andere Art in makedonischer Tradition stehenden Königs des wahrscheinlich späteren 3. bis 1. Jahrhunderts v.Chr. handelt - darunter auch Demetrios Poliorketes.

\section{Ptolemäer}

\section{Ein rundplastisches Porträt aus dem Faijum}

Der leicht unterlebensgroße Kopf (P 1, Taf. 2 Abb. 5) stammt vermutlich aus dem Faijum und zeigt das Porträt eines jungen Mannes im ägyptischen Stil. Dieser trägt eine mit einem Diadem umwundene Kausia. Daran befindet sich über der Stirn eine Uräusschlange, deren „Schwanz“ sich bis zum Scheitelpunkt der Mütze schlängelt. Aufgrund von Diadem und Uräus muss es sich um einen König handeln. Kausia und Diadem weisen auf einen makedonischhellenistischen Herrscher hin, das Haar ist im griechischen Stil gehalten. Das Porträt ist von R.S. Bianchi als das Alexanders des Großen (336-23 v.Chr.) gedeutet worden. ${ }^{152}$ B. von Bothmer hat aus stilistischen Gründen eine Datierung des Kopfes in die Mitte des 1. Jahrhunderts v.Chr. vorgeschlagen. ${ }^{153}$ G. Grimm bringt das Bildnis versuchsweise mit Ptolemaios XV. Kaisarion (44-31 v.Chr.) in Verbindung. ${ }^{154}$

Es handelt sich um das einzige annähernd lebensgroße Porträt, das einen hellenistischen Herrscher mit der Kausia zeigt. Auf den ersten Blick überrascht dies, da antike Schriftquellen berichten, dass viele oder gar alle hellenistischen Könige mit Kausia auftraten, und entsprechende Darstellungen in anderen Gattungen (Münzen, Siegeln) auch überliefert sind. Bestimmte Bereiche und Gattungen der antiken Kunst waren jedoch bestimmten Darstellungskonventionen verpflichtet. Gemäß diesen Konventionen wurde bei großplastischen hellenistischen Königsporträts auf Attribute und Kopfbedeckungen in der Regel verzichtet. Der Kopf des Königs wird nur mit dem Diadem umwunden dargestellt. Dass das hier besprochene Porträt dennoch eine Kausia aufweist, ist darauf zurückzuführen, dass es in einem ägyptisierenden Stil gehalten ist und es ägyptischer Konvention entspricht, den Pharao mit königlicher Kopfbedeckung darzustellen. Sollte die Datierung in die spätptolemäische Zeit zutreffen, könnte die Entstehungszeit die Herstellung dieser ungewöhnlichen Darstellung begünstigt haben: Der

\footnotetext{
${ }^{152}$ R. S. Bianchi, Alexander the Great as a Kausia Diadematophoros from Egypt, in: The Intellectual Heritage of Egypt, FS Lásló Kakosy, Studia Aegytiaca 14 (1992) 69-75 Taf. 2-3.

${ }^{153}$ B.v. Bothmer, Hellenistic Elements in Egyptian Sculpture of the Ptolemaic Period, in: Alexandria and Alexandrianism, Symposium Malibu 1993 (1996) 220 .- So auch J.A. Josephson, Egyptian Royal Sculpture of the Late Period. 400-246 B.C. (1997) 19-21.

${ }^{154}$ G. Grimm, Alexandria. Die erste Königsstadt der hellenistischen Welt (1998) 143.
} 
Kopf steht ganz am Ende der Geschichte des hellenistischen Königsporträts, was das Hervortreten ägyptisch-griechischer Mischformen vielleicht erleichterte. Und das Porträt entstand zu einer Zeit, zu der die ptolemäische Propaganda ${ }^{155}$ im Kampf gegen Rom auf die Person Alexanders des Großen und im Zusammenhang damit auf die Kausia als der königlich-makedonischen Kopfbedeckung zurückgriff.

\section{Kameen}

Zwei Kameen aus Glas in London (Ka 1, Taf. 3 Abb. 12; Fundort unbekannt) und Neapel (Ka 2 [o. Abb.]; in Herculaneum gefunden) zeigen jeweils eine männliche Porträtbüste im Profil nach rechts. Die dargestellte Person ist in beiden Fällen mit einem Panzer, einer Chlamys und der Kausia bekleidet. Das Exemplar in London weist ein Diadem auf, bei der Kamee in Neapel ist dieses aufgrund der schlechten Qualität nicht eindeutig zu erkennen. Die massigen Gesichter beider Männer weisen jedoch große Ähnlichkeit auf. Dies spricht dafür, dass es sich um die gleiche Person handelt. Die Kausia diadematophoros und auch der Brustpanzer kennzeichnen den Mann als König, die Züge des Porträts sind als die eines späten Ptolemäers, vielleicht Ptolemaios IX. Soter II. (116-107 und 88-81 v. Chr.) oder Ptolemaios X. Alexander (107-88 v. Chr.), gedeutet worden. ${ }^{156}$

\section{Siegelabdrücke}

Aus einem rund 650 Siegelabdrücke umfassenden Fund aus Edfu' ${ }^{157}$ (Oberägypten) stammen vier Abdrücke (Si 1, Taf. 3 Abb. 6; Si 2-4 [o. Abb.]), die jeweils ein männliches Porträt im Profil nach rechts mit Kausia und Chlamys zeigen. Bei den Abdrücken Si 1 und Si 2 ist die Kausia mit einem Diadem umwunden, die beiden anderen Abdrücke sind zu flau, um Details zu erkennen. Si 1 zeigt das Porträt Ptolemaios I. Soter. Das Siegel stammt jedoch nicht aus der Zeit des ersten Ptolemäers, sondern ist wie der gesamte Hortfund in den Zeitraum von 200-30 v.Chr. zu datieren. Die Porträts auf den beiden Siegeln ohne klar erkennbares Diadem (Si 3-4) weisen ebenfalls das charakteristische Kinn Ptolemaios' I. auf. Si 2 zeigt eine andere Person, infolge des Diadems wird es sich ebenfalls um einen (ptolemäischen) König handeln.

\footnotetext{
${ }^{155}$ Vgl. Plutarch, Antonius 54, 4 (Q 14a). Ptolemaios Philadelphos (der Sohn des Marcus Antonius und der Kleopatra) tritt in Kausia diadematophoros (sowie Krepides und Chlanis) auf, ,denn dies war die Tracht der auf Alex-

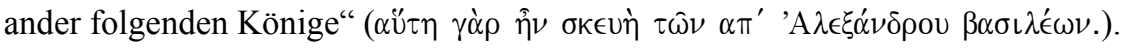

${ }^{156}$ Vgl. D. Plantzos, Ptolemaic Cameos of the 2nd and 1st Centuries B.C., OJA 15, 1996, 44.

157317 Siegelabdrücke in Amsterdam sowie 330 Abdrücke in Toronto gehören vermutlich zu einem gemeinsamen Hortfund, der 1905-6 in Edfu entdeckt wurde. Sie stammen möglicherweise aus dem Archiv des Tempels von Philae. Datiert wird der Fund in die Zeit von Ptolemaios V. Epiphanes bis Kleopatra VII. Vgl. D. Plantzos, Female portrait types from the Edfu hoard of clay seal impressions, in: Archivi e Sigilli nel mondo ellenistico, Symposion Turin 1993, BCH Suppl. 29 (1996) 307 ff. Nr. 1 Taf. 48.
} 
$\mathrm{Zu}$ einem mehrere tausend Abdrücke umfassenden Fund aus Nea Paphos ${ }^{158}$ (Zypern) gehören auch mindestens sechs Siegelabdrücke, die verschiedene Herrscher mit Kausia diadematophoros darstellen. Sie geben vermutlich Ptolemaios X. Alexander I. (Si 10-12, Taf. 3 Abb. 9-11), Ptolemaios XV. Kaisarion (Si 13-14, Taf. 4 Abb. 14-15) und einen weiteren ptolemäischen König (Si 15, Taf. 3 Abb. 13) wieder.

Die Siegelabdrücke mit Bildnissen des Ptolemaios X. Alexander I. (Si 10-12) zeigen die Büste des Herrschers im Profil nach rechts, bekleidet mit Chlamys und Kausia diadematophoros. Sie weisen teils verschiedene Attribute bzw. Beizeichen auf: In einem Fall (Si 11) befindet sich auf der Seite der Kausia ein Komposit Symbol der Isis (Sonnenscheibe zwischen geschwungenen Kuhhörner, zwei aufrechte Federn). ${ }^{159}$ Über der Stirn des Königs erscheinen zwei (Dioskuren-) Sterne als Beizeichen. Ein anderes Exemplar (Si 10) zeigt auf der Kausia einen Makedonenstern. Das dritte Siegel (Si 12) weist weder Beizeichen noch Verzierung auf. Die Siegel des Ptolemaios XV. Kaisarion zeigen die Büste des Königs einmal nach links (Si 13) und einmal nach rechts (Si 14) gewendet. Gekleidet ist er jeweils in Chlamys und Kausia diadematophoros. Während der Herrscher auf einem Siegel unbärtig erscheint (Si 13), wird er auf dem anderen mit Bart wiedergegeben (Si 14). Auf dem Abdruck mit Bart erscheint Ptolemaios zudem mit einem geschulterten Kerykeion (Hermesstab) sowie einer kleinen ägyptischen Atef-Krone am Diadem über der Stirn. ${ }^{160}$

Siegelabdruck Si 15 ist nur fragmentarisch erhalten. Es sind nur der obere Teil des Gesichtes und die vordere obere Hälfte der Kausia vorhanden. Diademenden sind entsprechend nicht nachweisbar. Die Kausia ist mit einem Makedonenstern versehen. Ein präziser Identifizierungsvorschlag wurde bisher nicht unterbreitet, es dürfte sich jedoch wie bei den anderen Abdrücken aus Nea Paphos um das Bildnis eines ptolemäischen Königs handeln.

\footnotetext{
${ }^{158}$ Nea Paphos war ab 192/1 v.Chr. Sitz der ptolemäischen Verwaltung von Zypern (G. Hölbl, Geschichte des Ptolemäerreiches [1994] 126). Die hier zu besprechenden Siegelabdrücke stammen aus einem etwa 11000 Tonbullen umfassenden Depotfund. Die Bullen zeigen u.a. ca. 1200 Porträtsiegelabdrücke. Gefunden wurden sie in sekundärer „Verwendung“ unter dem Mosaikfußboden des „Hauses des Dionysos“. Der ursprünglich Ort und Umfang des Archivs sind nicht bekannt. Die ältesten datierbaren Siegel fallen in die Zeit des Ptolemaios VIII. (seit 145 v.Chr.), die jüngsten Abdrücke zeigen Kleopatra VII., Ptolemaios XV. Kaisarion sowie Octavian. Das Ende des Archivs wird mit einem Erdbeben des Jahres 15 v.Chr. in Verbindung gebracht(H. Kyrieleis, Ptolemäische Porträts auf Siegelabrücken aus Nea Paphos [Zypern], in: Archives et Sceaux du monde hellenistique, BCH Suppl. 29 [Symposium Turin 1993] [Hrsgg.: M.-F. Boussac, A. Invernizzi] [1996] 315 ff. 319 Taf. 59 Abb. 6).

${ }^{159}$ Zur Deutung vgl. jetzt. H.Kyrieleis, Ägyptische Bildelemente auf Siegelabdrücken aus Nea Paphos (Zypern), StädelJb 19, 2004, 111ff. Abb. 11: Kompositkrone als Hinweis auf Isis, als dessen Inkarnation sich ptolemäische Königinnen (insbesondere Kleopatra III.) darstellen ließen, doppelter Makedonenstern als Verweis auf die gemeinsame Herrschaftsausübung durch König und Königinmutter, insgesamt Betonung der besonderen Stellung der für ihre unmündigen Kinder herrschende Königinmutter.

${ }^{160}$ Vgl. H. Kyrieleis, Bildnisse des Kaisarion. Zu den Siegelabdrücken aus Nea Paphos, in: Akten des XIII. Internationalen Kongresses für Klassische Archäologie, Berlin 1988 [1990] 457 f. Taf. 67 e .- ders.; Ptolemäische Porträts auf Siegelabdrücken aus Nea Paphos [Zypern], in: Archivi e Sigilli nel mondo ellenistico, Symposion Turin 1993 [= BCH Suppl. 29] [1996] 315 ff. 318 Taf. 55 Abb. 2) .- ders., Ägyptische Bildelemente auf Siegelabdrücken aus Nea Paphos (Zypern), StädelJb 19, 2004, 111 Abb. 8. - Ein rundplastisches Porträt (P 1), das vermutlich ebenfalls Ptolemaios XV. Kaisarion zeigt, weist am Diadem über der Stirn eine Uräus-Schlange auf.
} 
Im Papyrosarchiv der aitolischen Stadt Kallipolis/Kallion fanden sich Hunderte von Siegelabdrücken. Sie werden in den Zeitraum von etwa 230 bis 160 v. Chr. datiert ${ }^{161}$. Einige der Abdrücke zeigen Köpfe im Profil nach rechts mit Kausia (Si 5-6, Taf. 3 Abb. 7-8). Zu nennen sind Porträts des Ptolemaios III. Euergetes (246-221 v. Chr.) und des Ptolemaios IV. Philopator (221-205 v. Chr.). ${ }^{162}$

\section{Seleukiden und Usurpatoren}

\section{Münzähnlicher Gegenstand aus Ton}

Die einzige „Münze“ aus dem seleukidischen Bereich, die eindeutig ein Herrscherporträt mit Kausia zeigt, ist nur als (antikes) „Tonmodell“ (Nu 25, Taf. 5 Abb. 18) erhalten. Die Tonmünze zeigt auf der Vorderseite ein Porträt nach rechts mit Kausia diadematophoros und auf der Rückseite eine stehende nackte männliche Figur, die sich mit dem linken Arm auf einen Pfeiler, Baumstamm oder ähnliches stützt. Der rechte Arm ist im Bogen über den leicht nach links zum Pfeiler gewandten Kopf geführt. Die Beine sind überkreuzt, wobei das linke (Spiel-) Bein sich vor dem rechten (Stand-) Bein befindet. Die unleserliche Legende bildet rechts und links der Stützfigur je zwei Kolumnen, es dürfte sich demnach um einen vierteiligen Titel gehandelt haben. Das Tonmodell wird aufgrund von Überlegungen zur Stratigraphie in die Zeit kurz vor der Eroberung Mesopotamiens durch die Parther, d.h. um 150 v.Chr., datiert. ${ }^{163}$

Da Darstellungen der Kausia auf Münzen regulärer seleukidischer Könige nicht bekannt sind, vermutete man die Prägung eines Usurpators. Versuchsweise wurde die Tonmünze mit einem abtrünnigen seleukidischen Gouverneur namens Timarchos in Verbindung gebracht. ${ }^{164}$ Dieser war ursprünglich Satrap von Medien, ließ sich um 162 v.Chr. unter Ausnutzung innerseleukidischer Thronstreitigkeiten zum König ausrufen, paktierte mit dem König von Baktrien und dem ebenfalls nach Unabhängigkeit strebenden Satrapen von Armenien und konnte sein Herr-

\footnotetext{
${ }^{161}$ Die Siegelabdrücke stammen aus Haus IV („Archiv-Haus“) der ostaitolischen Stadt. Diese wurde 279 v.Chr. von den Kelten zerstört. P. Themelis, Ausgrabungen in Kallipolis 1977-78, AAA 12/2, 1979, 245-279 zog dieses Ereignis zur der Datierung der Siegel heran und sah im Jahr 279 v. Chr. einen terminus ante quem. Dieser Datierungsansatz wird heute nicht mehr vertreten. Die Stadt wurde bis in spätantike Zeit weiterbesiedelt, die Siegelabdrücke gehören in die Zeit vom letzten Drittel des 3. Jahrhunderts v. Chr. bis zum Anfang des 2. Jahrhunderts

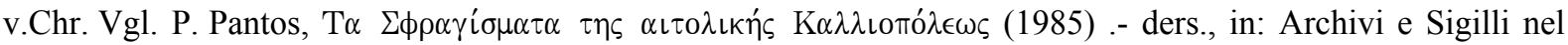
mondo ellenistico, Symposium Turin 1993, BCH Suppl. 29 (1996) 184-94. - Kallipolis gehörte weder zum ptolemäischen noch zum seleukidischen Reich. Ob die Siegel mit den Porträts der betreffenden Herrscher von Personen aus der Stadt, die sich diesen Königen verbunden fühlten, verwendet wurden oder mit schon versiegelte Dokumente aus den Machtbereichen hellenistischer Könige nach Kallipolis gelangten, ist unklar.

${ }^{162}$ In Kallipolis wurden auch Abdrücke entdeckt, die vermutlich den Seleukiden Antiochos III. zeigen (Si 7), sowie Abdrücke (Si 8-9), die nur teilweise abgedrückt bzw. erhalten sind und bei denen ein auf dem Siegel vielleicht vorhandenes Diadem nicht mehr erkennbar ist. Ob es sich um die Porträts von Herrschern oder Privatleuten handelt, ist daher nicht zu entscheiden.

${ }^{163}$ R.H. McDowell, Stamped and Inscribed Objects from Seleucia on the Tigris (1935) $214 \mathrm{f}$.

${ }^{164}$ R.H. McDowell, Stamped and Inscribed Objects from Seleucia on the Tigris (1935) $214 \mathrm{ff} .249 \mathrm{f}$.
} 
schaftsgebiet zeitweilig über weite Teile der Ostprovinzen einschließlich der Gegend um Seleukia ausbreiten, bis Demetrios I. ihn 160 v.Chr. schlug. ${ }^{165}$

Die Könige von Baktrien hatten erreicht, was Timarchos anstrebte, den Aufstieg vom seleukidischen Satrapen zum unabhängigen König in der Nachfolge Alexanders. Timarchos lehnte sich in seiner Münzprägung und Titulatur eng an die gleichzeitig regierenden baktrischen Könige Eukratides I. und Apollodotos I. an. ${ }^{166}$

Problematisch an dieser Zuweisung ist, dass zwar die Vorderseite (Königsporträt mit Kausia diadematophoros) baktrischen Vorbildern entspricht, nicht aber die Rückseite. Diese zeigt nämlich nicht einen sich selbst bekränzenden Herakles, ${ }^{167}$ wie er häufig auf baktrischen Prägungen erscheint, ${ }^{168}$ sondern die oben beschriebene Stützfigur mit überkreuzten Beinen.

Versucht man, die auf der Tonmünze wiedergegebene Figur zu identifizieren, ergibt sich folgendes: Aus dem Bereich der Großplastik ist ein an einen Stamm gelehnter Silenknabe mit überkreuzten Beinen im Stand- und Stützmotiv vergleichbar, der allerdings Querflöte spielt und insofern abweicht. ${ }^{169}$ Die Armhaltung und das Stützmotiv der Tonmünze finden sich auch bei verschiedenen spätklassisch-frühhellenistischen Apollontypen ${ }^{170}$, die jedoch nur in Ausnahmefällen mit überkreuzten Beinen dargestellt werden. ${ }^{171}$ Eine vollständige Übereinstimmung besteht nur zwischen dem Tonmodell aus Seleukia und einer Prägung des Kaisers Commodus aus dem Jahr 190/91 n.Chr. Diese trägt die Beischrift APOLLINI MONETAE und gibt wahrscheinlich eine in oder vor der Münze in Rom stehende Apollon-Statue wieder. ${ }^{172}$

165 A. Kneppe, Timarchos von Milet - ein Usurpator im Seleukidenreich, in: Migratio et commutatio (FS T. Pekáry) (1989) $37 \mathrm{ff}$.

${ }^{166}$ Vgl. die Münzen des Timarchos, die auf der Vorderseite ein Porträt nach rechts mit Helm und auf der Rückseite die Dioskuren zeigen (A. Houghton, Timarchus as King in Babylonia, RevNum 21, 1979, 214), mit den Prägungen des baktrischen Königs Eukratides I. (O. Bopeorachchi, Monnaies gréco-bactriennes et indo-grecques [1991] 202 ff. Taf. 16 ff. Serie 4 ff. Nr. 25 ff.). Nicht nur die Ikonographie, sondern auch die Legende (BA II $\Lambda$ E $\Omega \Sigma$ MEГА $\Lambda$ OY TIMAPXOY bzw. EYKPATI $\Delta O Y$ ) und deren Platzierung auf den Münzen verbinden Timarchos und den gleichzeitig in Baktrien regierenden Eukratides I. (Vgl. A. Kneppe, Timarchos von Milet - ein Usurpator im Seleukidenreich, in: Migratio et commutatio [FS T. Pekáry] [1989] 44 f.). Der Titel eines Großkönigs wurde jedoch auch von den Seleukiden getragen und ist letztlich der des achämenidischen Herrschers (Vgl. RE III [1897] 80 f. s.v. Basileus [1] [v. Schoeffer]).

${ }^{167}$ So R.H. McDowell, Stamped and Inscribed Objects from Seleucia on the Tigris (1935) $249 \mathrm{f}$.

${ }^{168}$ Vgl. z.B. O. Bopeorachchi, Monnaies gréco-bactriennes et indo-grecques (1991) Taf. 4 Serie 1 ff. Nr. 1 ff. (Demetrios I.). Ähnliche Stempel werden auch von verschiedenen nachfolgenden Königen verwendet (u.a. Euthydemos I., Euthydemos II., Agathokles, Zoilos I., Lysias). Ein nackter stehender Herakles bekränzt sich mit der rechten Hand und hält in der Linken eine Keule und ein Gewand. Der Herakles überkreuzt die Beine nicht und stützt sich auch nicht auf die Keule oder etwas anderes.

${ }^{169}$ LIMC VIII Suppl. (1997) 1130 s.v. Silenoi Nr. 216 (E. Simon): Paris, Louvre MA 595; Kopie nach Original um 300 v. Chr.

${ }^{170}$ Vgl. zum Apollon Sauroktonos LIMC II (1985) 199 s.v. Apollon Nr. 81 (W. Lambrinudakis u.a.) bzw. LIMC II (1985) 378 s.v. Apollon/Apollo Nr. 53 (E. Simon) und zum Apollon Lykeios LIMC II (1985) 193 s.v. Apollon Nr. 39 (W. Lambrinudakis u.a.) bzw.LIMC II (1985) 379 s.v. Apollon/Apollo Nr. 54 (E. Simon).

${ }^{171}$ Vgl. LIMC II (1985) s.v. Apollon Nr. 81a (W. Lambrinudakis u.a.): Ringstein aus Glaspaste in Den Haag .LIMC II (1985) 407 s.v. Apollon/Apollo Nr. 307a (E. Simon): zwei Bronzestatuetten in Bologna und Paris mit überkreuzten Beinen (Pfeiler o.ä. und Attribut fehlen).

${ }^{172} \mathrm{Ph}$. Hill, The Temples and Statues of Apollo in Rom, NumChron 2, 1962, 135 f. Taf. 10, 10 .- LIMC II (1985) s.v. Apollon/Apollo Nr. 23 Nr. 210. Theoretisch könnte es sich bei diesem Apollon um eine nach hellenistischem Vorbild kopierte Statue handeln oder um ein Original, das z.B. mit der pergamenischen Erbschaft in den römi- 
Auch wenn sich kein exaktes Vorbild ausmachen lässt, das in hellenistischer Zeit nachweisbar im Orient bekannt war, weist vieles auf eine Apollon-Darstellung hin. Dieser Gott erscheint vereinzelt auf baktrischen Münzen ${ }^{173}$ und als Schutzgottheit und Ahnherr der Seleukiden regelmäßig auf deren Prägungen. ${ }^{174}$

Gegen einen Bezug der Tonmünze auf Timarchos spricht meines Erachtens die vierzeilige Le-

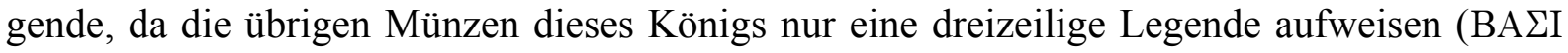
$\Lambda$ E $\Omega \Sigma$ МЕГА $\Lambda$ OY TIMAPXOY). ${ }^{175}$ Aus vier Kolumnen bestehende Beischriften wurden zur entsprechenden Zeit jedoch von den seleukidischen Königen Antiochos IV. Epiphanes (176/5165/4 v.Chr.), Alexander I. Balas (150-145 v.Chr.) und Demetrios II. Nikator (145-139/8 v.Chr.) verwendet. ${ }^{176}$ Von keinem der genannten Könige sind Münzen mit Kausiadarstellungen bekannt. Alexander I. Balas prägte jedoch Bronzen, auf denen das Porträt eines König mit einem makedonisch-böotischen ${ }^{177}$ Helm, wie ihn auch die baktrischen Könige tragen, erscheint. Eine Anlehnung an die Ikonographie der baktrischen Könige ist im Falle des Alexander Balas auszuschließen. Dieser war zwar ein Usurpator, jedoch einer, der großen Wert darauf legte, als Sohn Antiochos IV. zu gelten, ${ }^{178}$ und der deshalb kein Interesse daran gehabt haben kann, mit einer auswärtigen Macht in Verbindung gebracht zu werden. Der Helm muss demnach eine andere Bedeutung aufweisen. Die Propaganda des Alexander Balas zielte einerseits auf die Abstammung von Antiochos IV. ab. ${ }^{179}$ Anderseits bezog er sich auf Alexander den Großen. Dessen Namen nahm er an, und er prägte neben den Münzen, die ihn (oder Alexander den Großen?) mit Helm und Anastole zeigen, auch ebenfalls aus Bronze bestehende Münzen, auf denen ein König mit Löwenskalp zu sehen ist. Unklar ist, ob auf diesen Alexander der Großen mit Zügen des Alexander Balas oder dieser in der Art Alexanders des Großen

schen Staatsschatz gelangte. Ein solches Standbild hätte das direkte Vorbild für die Figur auf der Tonmünze abgeben können. Nachweisen lässt sich dies jedoch nicht.

${ }^{173}$ Apollon stehend (im Kontrapost, Standbein rechts, Spielbein links), nackt, in der rechten Hand einen Pfeil, in der Linken einen Bogen (auf den Boden aufsetzend). Vgl. O. Bopeorachchi, Monnaies gréco-bactriennes et indogrecques (1991) Taf. 12, Série 6 Nr. 73 ff. (Apollodotos I., 180-60 v.Chr.), Taf. 22 Série 1 ff. Nr. 1 ff. (Eukratides II., $145-40$ v.Chr.).

${ }^{174}$ Vgl. z.B. E. Newell, The Seleucid Mint of Antioch (1917 [Nachdruck 1978]) Taf. 1 Nr. 1: Apollon stehend, an Dreifuß gelehnt, mit Pfeil und Bogen (aber ohne überkreuzte Beine, mit anderer Blickrichtung und Armhaltung) (Seleukos II.); Taf. 1 Nr. 3 ff.: Apollon auf Omphalos sitzend, mit überkreuzten Beinen, mit Pfeil und Bogen (Seleukos III., Antiochos III.) .- A. Houghton, Coins of the Seleucid Empire from the Collection of Arthur Houghton (1983) Taf. 3 Nr. 47 ff.: Apollon stehend mit Pfeil in der rechten Hand, in der Linken einen auf den Boden aufsetzenden Bogen (Antiochos II.). Der gleiche Apollon-Typus findet sich in der baktrischen Münzprägung seit Apollodotos I. Vgl. O. Bopeorachchi, Monnaies gréco-bactriennes et indo-grecques (1991) Taf. 12 ff. Série 6 Nr. 73 ff.

${ }^{175}$ Vgl. A. Houghton, Timarchus as King in Babylonia, RevNum 21, 1979, 214.

176 Vgl. z.B. E. Newell, The Seleucid Mint of Antioch (1917 [Nachdruck 1978]) 22 Taf. 3 f. Nr. 54 ff.

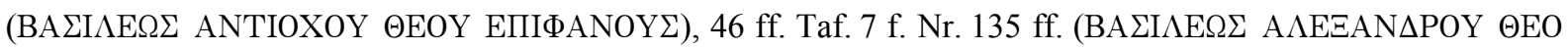

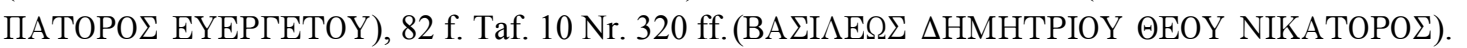

${ }^{177}$ A. Houghton, Coins of the Seleucid Empire from the Collection of Arthur Houghton (1983) 12 Nr. 200 spricht von einem makedonischen Helm. Sonst wird dieser meist als „böotisch“ bezeichnet. Vgl. z.B. R. Fleischer, Studien zur seleukidischen Kunst 1. Herrscherbildnisse [1991] 62.

${ }^{178}$ Vgl. R. Fleischer, Studien zur seleukidischen Kunst 1. Herrscherbildnisse (1991) 60 mit Anm. 495 (Literatur).

${ }^{179}$ Vgl. R. Fleischer, Studien zur seleukidischen Kunst 1. Herrscherbildnisse (1991) $60 \mathrm{f}$. 
dargestellt ist. ${ }^{180}$ Sieht man in den seleukidischen Münzen mit Helm eine Bezugnahme nicht auf die baktrischen Herrscher, ${ }^{181}$ sondern auf Alexander den Großen und parallelisiert die Darstellungen der Königsporträts mit Helm mit denen mit Kausia, so ergibt sich in beiden Fällen eine Angleichung an Alexander den Großen, dessen Sieghaftigkeit und dessen Königtum. ${ }^{182}$

Sieht man in dem Tonmodell die relativ exakte Nachahmung einer echten Münze, so ist an erster Stelle von einer Prägung Alexander I. Balas auszugehen. Dieser regierte im entsprechenden Zeitraum, verwendete Apollondarstellungen als Rückseitenmotiv ${ }^{183}$, bezog sich in der Münzprägung auf Alexander den Großen und führte einen aus vier Wörtern bestehenden Titel.

Dennoch lässt sich nicht ausschließen, dass die Tonmünze eine freie Neuschöpfung unter Verwendung von teils im numismatischen Bereich, teils in anderen Gattungen belegten Motiven ist. Hierfür sprechen das Nichtvorhandensein einer metallischen Version und der abgewandelte „Apollon“-Typus. Andererseits kann das scheinbare Fehlen einer echten Münze dieser Serie auch auf eine nur geringe Anzahl von ausgeprägten Münzen zurückzuführen sein, während die genaue Wiedergabe des Statuentypus bei einer Tonausfertigung möglicherweise von untergeordneter Bedeutung war.

Die Verwendung solcher „Münzen“ ist unklar. Die Tonmünze könnte als Spielstein oder als Votiv gedient haben.

\footnotetext{
${ }^{180}$ Vgl. R. Fleischer, Studien zur seleukidischen Kunst 1. Herrscherbildnisse (1991) 61.

${ }^{181}$ Die Bezugnahme auf Baktrien ist auch insofern problematisch, als entsprechende Darstellungen im seleukidischen Bereich und in Baktrien weitgehend zeitgleich zum ersten Mal auftreten: Der erste „Seleukide“, der mit Helm dargestellt wird, ist Timarchos (162-160 v.Chr.), in Baktrien wird als erster König Eukratides (um 170-145 v.Chr.) so gezeigt (Vgl. z.B. A. Houghton, Timarchus as King in Babylonia, RevNum 21, 1979, 213 ff. .- O. Bopeorachchi, Monnaies gréco-bactriennes et indo-grecques [1991] Taf. 16 Série 4 Nr. 25 ff.). Folgt man in Fragen der Datierung M. Mitchiner (M. Mitchiner, Indo-Greek and Indo-Scytian Coinage 1. The Early Indo-Greeks and their Antecedants [1975] 68 Taf. 10), prägte Eukratides I. Münzen mit behelmtem Königsporträt erst ab ca. 160 v.Chr., d.h. genau zeitgleich mit Timarchos. Im Übrigen trägt die Klärung der Abhängigkeit nur begrenzt zur Beantwortung der Frage nach der eigentlichen Bedeutung bei.

${ }^{182}$ Auf eine Deutung der baktrischen Königsporträts mit Kausia als Anspielung auf das Königtum Alexanders des Großen und dessen Sieghaftigkeit gehe ich im Zusammenhang mit der Besprechung der graeco-baktrischen und indo-griechischen Münzen näher ein.

${ }^{183}$ Vgl. O. Mørkholm, Sculpture and Coins: The Portrait of Alexander Balas of Syria, NumAntCl 10, 1981, 235 ff. Taf. 2 Nr. 11 ff. (Apollon sitzend auf Omphalos) .- A. Houghton, Coins of the Seleucid Empire from the Collection of Arthur Houghton (1983) 13 Taf. 12 Nr. 204 (Apollon stehend mit Pfeil und auf den Boden aufsetzendem Bogen).
} 


\section{Siegelabdrücke}

Aus Archiven in Seleukia am Tigris ${ }^{184}$ sind fünf Siegelabdrücke mit Wiedergaben der Kausia bekannt (Si 16-20). Nur einer dieser Abdrücke (Si 16, Taf. 4 Abb. 17) lässt sich eindeutig mit einem bestimmten Herrscher in Verbindung bringen. Es handelt sich um das Porträt eines bärtigen Mannes im Profil nach rechts mit Kausia diadematophoros. Dieses wird als Bildnis des Demetrios II. Nikator aus dessen zweiter Regierungszeit (129-25 v.Chr.) angesprochen, ${ }^{185}$ da dieser damals Münzen mit einem bärtigen Porträt prägte. ${ }^{186} \mathrm{Zu}$ dieser Zeit gehörte Seleukia noch einmal kurzfristig zum Seleukidenreich, nach dem es 143/2 v.Chr. erstmals von den Parthern erobert worden war.

Siegelabdruck Si 19 zeigt einen männlichen Kopf im Profil nach links mit Kausia. Ein Diadem ist nicht zu erkennen. Da jedoch der hintere untere Bereich mit den potentiellen Diademenden nicht mit abgedrückt ist, lässt sich nicht eindeutig bestimmen, ob es sich um ein Herrscherporträt (mit Diadem) oder um das eines Privatmannes handelt. Das Siegel wurde früher als das des Timarchos (antiseleukidischer Usurpator 162-60 v.Chr.) gedeutet. ${ }^{187}$ Eine Ähnlichkeit des Siegelporträts mit gesicherten Porträts des Timarchos auf Münzen besteht jedoch

${ }^{184}$ Die Siegelabdrücke aus Seleukia entstammen einer amerikanischen und einer italienischen Grabung. Beide Ausgrabungen fanden im Gebiet des Tell 'Umar am südöstlichen Rande Seleukias statt. Die Amerikaner förderten 203 Abdrücke zutage (publiziert in: R.H. McDowell, Stamped and Inscribed Objects from Seleucia on the Tigris [1935]). Die Siegel wurden in zwei Räumen („Archiv A und B“) eines „great house“ genannten Gebäudes gefunden und werden in die Zeit von 295/89 bis 141/25 v.Chr. bzw. 188 bis 152/1 v.Chr. datiert (R.H. McDowell a.a.O. 11 ff.). Bei italienischen Grabungen wurde seit 1963 u.a. das „Stadtarchiv“ mit ca. 30000 Tonbullen (mit zum Teil je mehreren Siegelabdrücken) gefunden (Literaturübersicht in: EAA V 2. Suppl. 1974-94 [1997] $210 \mathrm{ff}$. 212 s.v. Seleucia sull Tigri [A. Invernizzi]). Publiziert wurden bisher nur wenig mehr als ein Dutzend Abdrücke (A. Invernizzi), diese dafür vielfach.

${ }^{185} \mathrm{Vgl}$. A. Invernizzi, Arte seleucide in Mesopotamia, in: Akten des XIII. Internationalen Kongresses für Klassische Archäologie. Berlin 1988 (1990) 20 Taf. 3,3 .- ders., RA 1991, 180 ff. .- u.ö. (Im vermutlich ebenfalls von A. Invernizzi stammenden Text des Ausstellungskataloges „La terra tra i due fiumi“ [Florenz 1986] $176 \mathrm{Nr} .4$ wird noch eine Datierung zwischen 250 und 150 v. Chr. vorgeschlagen.) sowie R. Fleischer, Studien zur seleukidischen Kunst I: Herrscherbildnisse (1991) 71 Taf. 42 d-f und T. Moreno, Scultura ellenistica I (1994) 244 Abb. 313 S. 248.

${ }^{186}$ Auch an dieser Stelle sei wie im Falle der Kamee (Ka 3) in Paris (s.o.) darauf hingewiesen, dass auch andere Seleukidenkönige (z.B. Seleukos II. [246-26 v.Chr.]; vgl. die Tetradrachme bei R. Fleischer, Studien zur seleukidischen Kunst I: Herrscherbildnisse [1991] 26 Taf. 14e) bärtig dargestellt werden können und dass auch Herrscher, die auf Münzen nie mit Bart wiedergegeben werden, auf Siegeln mit einem solchen erscheinen können (Vgl. z.B. H. die Siegelabdrücke mit bärtigen Porträts ptolemäischer Könige, die auf Münzen nie mit Bart erscheinen [Kyrieleis, Ptolemäische Porträts auf Siegelabrücken aus Nea Paphos [Zypern], in: Archives et Sceaux du monde hellenistique [Symposium Turin 1993] [Hrsgg.: M.-F. Boussac, A. Invernizzi] [= BCH Suppl. 29] [1996] 315 ff. Taf. 55 f./Abb. 2 f. [Ptolemaios XV.]; Taf. 62/Abb. 9 [Ptolemaios IX. ?].). Entsprechend muss auch Si 16 nicht zwangsläufig als Porträt Demetrios' II. angesehen werden.

${ }^{187}$ So R.H. McDowell, Stamped and Inscribed Objects from Seleucia on the Tigris (1935) 46 f. 214-20 Taf. 1,10. Die Zuweisung beruht in erster Linie darauf, dass reguläre seleukidische Herrscher nur selten mit Kausia dargestellt werden (Demetrios II. ist eine Ausnahme und lebte etwa eine Generation später.), baktrische Könige in der Münzprägung zwar häufig mit Kausia wiedergegeben werden, ihre Porträts in Seleukia aber nicht unbedingt zu erwarten sind und Timarchos ein Usurpator ist, dessen Münzprägung Parallelen zur baktrischen aufweist. Gegen eine Identifizierung mit Timarchos hat sich u.a. R. Fleischer, Studien zur seleukidischen Kunst 1. Herrscherbildnisse (1991) 108 (mit älterer Literatur) ausgesprochen. 
nicht. Auch Identifizierungsversuche mit verschiedenen baktrischen Königen (Euthydemos, Apollodotos) bleiben hypothetisch. ${ }^{188}$

Ebenfalls als Porträt des Timarchos wurde ursprünglich Abdruck Si 20 (Porträt im Profil nach rechts mit flacher Kopfbedeckung) interpretiert. ${ }^{189}$ Das Bildnis ist jedoch so schlecht erhalten, dass Details der Gesichtszüge nicht erkennbar sind und auch die flache Kopfbedeckung nicht eindeutig als Kausia zu identifizieren ist.

Ein unvollständig abgedrücktes Siegel (Si 17) zeigt ein männliches Porträt im Profil nach rechts. Zu sehen ist nur ein Teil des Gesichtes (von der Mitte des Kinns aufwärts) und der Schirm einer Kopfbedeckung. ${ }^{190}$ Ein Identifizierungsversuch liegt meines Wissens nicht vor, das Porträt hat jedoch Ähnlichkeit mit dem des Timarchos auf Tetradrachmen, die diesen Herrscher mit makedonisch-böotischem Helm zeigen. ${ }^{191}$ Die Ähnlichkeit beschränkt sich jedoch nicht nur auf die Gesichtszüge (markante Nase und Nasolabialfalte). Auch der Schirm ist vielleicht nicht der einer Kausia, sondern der eines böotisch-makedonischen Helmes.

Alle Siegelabdrücke werden in die Zeit der seleukidischen Herrschaft über Seleukia (295-141 und 138-129 v.Chr.) datiert. ${ }^{192}$ Gesichert scheint mir dies nur, wenn Si 16 Demetrios II. Nikator (129-25 v.Chr. [2. Regierungszeit]) zeigt, wenn die Datierung der Schichten (295/80141/25 v.Chr. bzw. 188-153/2 v.Chr.), in denen Si 19-20 gefunden wurden, noch dem heutigen Forschungsstand ${ }^{193}$ entspricht, und wenn auf Abdruck Si 17 (Porträt mit Kausia oder Helm?) Timarchos (162-160 v.Chr.) dargestellt sein sollte. Grundsätzlich ist eine Datierung von Darstellungen der Kausia auch in nachseleukidische Zeit nicht auszuschließen, da Kausiadarstellungen in der Koroplastik auch für die parthische Zeit belegt sind.

Wie schon erwähnt wurde, fanden sich im Papyrosarchiv der aitolischen Stadt Kallipolis/Kallion Hunderte von Siegelabdrücke, die in den Zeitraum von etwa 230 bis 160 v. Chr. datiert werden. ${ }^{194}$ Die Abdrücke zeigen jeweils Köpfe im Profil nach rechts mit Kausia. Neben den Porträts ptolemäischer Könige (Si 5-6: Ptolemaios III. Euergetes [246-221 v.Chr.], Ptolemaios IV. Philopator [221-205 v. Chr.]) und nicht näher bestimmbarer Personen (Si 8-9) erscheint

\footnotetext{
${ }^{188}$ Vgl. R. Fleischer, Studien zur seleukidischen Kunst 1. Herrscherbildnisse (1991) 108 (mit Literatur).

${ }^{189}$ R.H. McDowell, Stamped and Inscribed Objects from Seleucia on the Tigris (1935) 67. 214-20.

${ }^{190}$ Diese Kopfbedeckung wird von A. Invernizzi, La terra tra i due fiumi [Ausstellungskatalog Florenz 1986] 125 Nr. 106 als „beretto“ bezeichnet, womit in diesem Zusammenhang nur die Kausia gemeint sein kann.

${ }^{191}$ Abgebildet z.B. bei R. Fleischer, Studien zur seleukidischen Kunst 1. Herrscherbildnisse (1991) Taf. 31a.

${ }^{192}$ Vgl. R.H. McDowell, Stamped and Inscribed Objects from Seleucia on the Tigris (1935) 214-20 .- A. Invernizzi, La terra tra i due fiumi (Ausstellungskatalog Florenz 1986) 125 Nr. 104, 106, 109.

${ }^{193}$ Fast zeitgleich mit R.H. McDowell, Stamped and Inscribed Objects from Seleucia on the Tigris (1935) erschien W. van Ingen, Figurines from Seleucia on the Tigris (1939). Die dort gegebene Datierungen der Terrakotten bzw. der Schichten, aus denen diese stammen, hat sich mittlerweile um 100 bis 200 Jahre in Richtung der Parther- bzw. Römerzeit verschoben (Vgl. K. Karvonen-Kaunas, The Seleucid and Parthian Terracotta Figurines from Babylon [1995] 37 Anm. 109 [mit Verweis auf A. Invernizzi, Mesopotamia 5-6, 1970-71, 33 ff.].). D. Plantzos, Hellenistic Engraved Gems (1999) 31 zweifelt die Datierung nach R.H. McDowell jedoch nicht an.

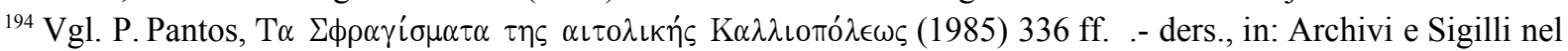
mondo ellenistico, BCH Suppl. 29 (Symposium Turin 1993) (1996) 184-94 und P. Themelis, Ausgrabungen in Kallipolis 1977-78, AAA 12/2, 1979, 245- 79 mit überholter Datierung (s.o.).
} 
auch ein vermutlich als Bildnis Antiochos' III. (223-187 v.Chr.) zu identifizierender Abdruck (Si 7, Taf. 4 Abb. 16a-c) ${ }^{195}$ mit Kausia diadematophoros.

\section{Baktrische und indo-griechische Könige: Die Kausia diadematophoros in Randgebieten}

Sämtliche Kausiadarstellungen aus Gebieten östlich des Irans treten in Verbindung mit Porträts baktrischer bzw. indo-griechischer Könige auf Münzen (Nu 26-36, Taf. 6 Abb. 25-30) auf. Die Häufung von Königsporträts mit Kausia diadematophoros ist sicher kein Zufall - entsprechende Darstellungen finden sich auf den Prägungen anderer hellenistischer Herrscher fast nie ${ }^{196}$ - und bedarf der näheren Betrachtung. Das Fehlen von Wiedergaben dieser Kopfbedeckung in anderen Gattungen in Baktrien und Indien dürfte zumindest teilweise auf den Forschungsstand bzw. ungünstige Überlieferungsbedingungen an diesem äußersten Ende der hellenistischen Welt zurückzuführen sein. Denn grundsätzlich ist auch in Baktrien und den angrenzenden Gebieten mit ähnlichen Erscheinungen der griechisch-hellenistischen Kultur zu rechnen, wie in anderen Gegenden des ehemaligen Alexanderreiches. ${ }^{197}$

Mit Kausia diadematophoros lassen sich darstellen: Antimachos I. Theos (185-170 v.Chr.) und Apollodotos I. Soter (180-160 v.Chr.) sowie Lysias Aniketos (120-110 v.Chr.), Antialkidas I. Nikephoros (115-95 v.Chr.), Demetrios III. Aniketos ( 100 v.Chr.) und Amyntas Nikator (95-90 v.Chr.). ${ }^{198}$

a) Antimachos I. Theos (185-70 v.Chr.) beherrschte das eigentliche Baktrien (Afghanistan) sowie die östlich und südöstlich angrenzenden Gebiete (Paropamisade, Arachosien). Er prägte Obolen (Nu 29), Diobolen oder Hemidrachmen ( $\mathrm{Nu} 28$ ), Drachmen ( $\mathrm{Nu} 27)$ und Tetradrachmen $(\mathrm{Nu} 26)$ jeweils mit seinem Porträt nach rechts (mit Kausia diadematophoros) auf der Vorderseite und Poseidon sowie der Legende auf der Rückseite. Der Münzfuß ist attisch, die Legende (BA $\Sigma \mathrm{I} \Lambda \mathrm{E} \Omega \Sigma$ OEOY ANTIMAXOY) ist griechisch.

b) Apollodotos I. Soter (180-60 v.Chr.) regierte teilweise zeitgleich mit Antimachos, jedoch nicht in Baktrien, sondern den östlich angrenzenden Gebieten Pakistans und Indiens (Paropamisade, Arachosien, Gandhara, Punjab). Unter seiner Herrschaft wurden Tetradrachmen ( $\mathrm{Nu}$ 30) attischen Standards mit griechischer Legende (BA $\Sigma \Lambda \Lambda \mathrm{E} \Omega \Sigma$ AПO $\Lambda \Lambda \mathrm{O} \Delta \mathrm{OTOY}$ ) geprägt.

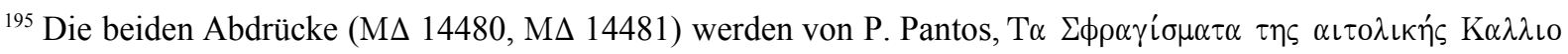
mó $\lambda \in \omega \varsigma$ (1985) Taf. 41 .- ders., in: Archivi e Sigilli nel mondo ellenistico, BCH Suppl. 29 (Symposium Turin 1993) (1996) Taf. 38, 4 als Abdrücke eines Siegels (Nr. 283) angesehen. Dies trifft nicht zu.

${ }^{196}$ Eine Ausnahme bildet eine nur als Tonmodell (Nu 25) überlieferte Münze (?), die vielleicht mit dem Seleukiden Alexander Balas zu verbinden ist und möglicherweise dem Vorbild Alexanders des Großen und/oder der baktrischen Könige folgt.

${ }^{197}$ Vgl. z.B. W. Posch, Baktrien zwischen Griechen und Kuschan (1995) 23 ff.

${ }^{198}$ Die exakte Chronologie, die Zuordnung von Münzen zu Königen gleichen Namens (z.B. Demetrios I.-III.) sowie die Zuweisung einzelner (Teil-) Könige zu bestimmten Reichsteilen sind im Detail umstritten (Vgl. z.B. M. Mitchiner, Indo-Greek and Indo-Scythian Coinage 1-3 [1975] und O. Bopearachchi, Monnaies gréco-bactriennes et indo-greques. Catalogue raisonné [1991].). Die hier gegebenen Jahreszahlen, Zuordnungen und Gebietszuweisungen sind entnommen: O. Bopearachchi, Monnaies gréco-bactriennes et indo-greques. Catalogue raisonné (1991) 453 Taf. 5.
} 
Die Vorderseite zeigt das Porträt des Königs nach rechts mit Kausia diadematophoros, die Rückseite eine sitzende Athena und die Legende. Einige Tetradrachmen (mit Kausia) des Antimachos I. und des Apollodotos I. sowie teils auch Tetradrachmen (ohne Kausia) des Eukratides I. weisen ein identisches Monogramm als Beizeichen auf. ${ }^{199}$ Dies könnte auf einen für alle drei Könige arbeitenden Münzbeamten und vielleicht auf eine gemeinsame Münzprägeanstalt und eine zeitgleiche Entstehung hinweisen. Die Regierungszeiten der Könige (185-170 [Antimachos I.], 180-160 [Apollodotos I.] und 170-145 v.Chr. [Eukratides I.]) überschneiden sich um das Jahr 170 v.Chr.

c) Lysias Aniketos (120-110 v.Chr.) herrschte über Paropamisade und Arachosien. Er prägte Silbermünzen $(\mathrm{Nu}$ 31) mit indischem Münzfuß (so genannte indische Drachmen zu ca. 2,45 g). Auf der Vorderseite ist wiederum das Porträt des Königs nach rechts mit Kausia diadematophoros sowie der griechischen Legende (BA $\Sigma \mathrm{I} \Lambda \mathrm{E} \Omega \Sigma$ ANIKETOY $\Lambda$ Y $\Sigma \mathrm{IOY}$ ) zu sehen, auf der Rückseite ein stehender, sich bekränzender Herakles sowie die Legende im indischen Kharoshthi-Dialekt (Maharajasa apadihatasa Lisikasa bzw. Lisiasa).

d) Antialkidas I. Nikephoros (115-95 v.Chr.) regiert in Paropamisade und Arachosien. Er prägte Drachmen $(\mathrm{Nu} 33)$ und Tetradrachmen $(\mathrm{Nu}$ 32) mit attischem Münzfuß, die auf der Vorderseite das Porträt nach rechts mit Kausia diadematophoros und auf Rückseite einen sitzenden Zeus mit Elefantenprotome davor zeigen, sowie ,indische Drachmen“ ( $\mathrm{Nu} 34)$, deren Vorderseiten das Porträt nach rechts mit Kausia diadematophoros zeigen, während auf den Rückseiten Zeus und eine Löwenprotome erscheinen. Bei den Münzen nach attischem Standard erscheint die Legende nur auf der Rückseite und zwar in griechischer Schrift und Sprache (BA $\Sigma \mathrm{I} \Lambda \mathrm{E} \Omega \Sigma$ NIKHФOPOY ANTIA $\Lambda$ KI $\Delta \mathrm{OY}$ ), bei den ,indischen Drachmen“ findet sich die griechische Legende auf der Vorderseite und die entsprechende indische (Maharajasa jayadharasa Amtialkidasa) auf der Rückseite.

e) Demetrios III. Aniketos ( 100 v.Chr.) herrschte über Gandhara. Er prägte Münzen (Nu 35) indischen Gewichts („Tetradrachmen“). Auf der Vorderseite ist das Porträt des Königs mit Kausia diadematophoros zu sehen, auf der Rückseite ein stehender Zeus. Die Legende ist, wie bei allen Münzen mit indischem Gewichtsstandard, auf der Vorderseite in griechischer (BA $\Sigma \mathrm{I}$ $\Lambda$ E $\Omega \Sigma$ ANIKETOY $\Delta$ HMHTPIOY), auf der Rückseite in indischer Schrift und Sprache (Maharajasa aparajitasa Dimetriyasa) angegeben.

f) Der letzte indo-griechische König, der auf seinen Münzen das Königsporträt mit Kausia diadematophoros verwendete, war Amyntas Nikator. Er regierte von ca. 95-90 v.Chr. über Gandhara. Geprägt wurden ,indische Drachmen“ ( $\mathrm{Nu} 36)$ mit einem sitzenden Zeus auf der Rückseite. Die Legende erscheint auf der Vorderseite wiederum in griechischer Sprache (BA $\Sigma \mathrm{I} \Lambda \mathrm{E} \Omega \Sigma$ NIKATOPO $\Sigma$ AMYNTOY) und auf der Rückseite im Kharoshthi-Dialekt (Maharajasa jayadharasa Amitasa).

\footnotetext{
199 Vgl. O. Bopearachchi, Monnaies gréco-bactriennes et indo-greques. Catalogue raisonné (Bibliotèque nationale) (1991) Taf. 9 Série 1, 1 = Nu 26 (Antimachos I.), Taf. 11 Série 1, A = Nu 30 (Apollodotos I.), Taf. 17 Série 6, 28-30 (Eukratides).
} 
Das Material lässt sich in zwei zeitlich getrennte Blöcke einteilen: Die Münzen der Könige Antimachos und Apollodotos (185-160 v.Chr.) und die der Zeit von 120 bis 90 v.Chr. (Lysias, Antialkidas I., Demetrios III., Amyntas). Der Einteilung in zwei chronologisch getrennte Blöcke entsprechen im Großen und Ganzen der Übergang vom attischen zum indischen Münzfuß, die Einführung zweisprachiger Legenden, die Verlagerung des Herrschaftsbereiches von Baktrien (Afghanistan) in Richtung Südosten (Pakistan/„Indien“) sowie völlig veränderte außenpolitische Rahmenbedingungen. Es erscheint demnach sinnvoll, die Münzprägungen der baktrischen und der indo-griechischen Könige in zwei Abschnitten zu behandeln. ${ }^{200}$

Zuvor sei jedoch angemerkt, dass es - neben der unten ausführlich besprochenen Bezugnahme auf Alexander den Großen und dessen Sieghaftigkeit - zwei weitere Deutungsmöglichkeiten für die Darstellung eines Königs mit Kopfbedeckung gibt:

1. H.-W. Ritter hat vorgeschlagen, die Wiedergaben baktrischer Könige mit der Kausia darauf zurückzuführen, dass im Orient die Darstellung asiatischer Könige mit einer Kopfbedeckung im Gegensatz zu griechischen Gepflogenheiten - die Regel war. ${ }^{201}$ In der Prägung von Münzen durch baktrische und indo-griechische Könige, die den Herrscher mit Kausia (oder Helm) zeigen, wäre entsprechend eine Orientalisierung zu sehen.

2. In modernen Staaten, die im 19. und 20. Jahrhundert unter europäischer Kolonialherrschaft standen, halten sich gerade im militärischen Bereich (Zeremoniell, Uniformen) oft Elemente, die der Tradition der auf kriegerischem Wege vertriebenen ehemaligen Herren entstammen. Ähnlich könnte sich auch in den baktrischen und indo-griechischen Reichen mit ihrer weniger makedonischen als griechisch-iranisch-indischen Bevölkerung trotz einer teils negativen Einstellung zu Makedonien die Kausia als Bestandteil der makedonischen Tracht und der Ausrüstung der Soldaten des Alexanderheeres erhalten haben.

\section{Baktrien (Nu 26-30)}

Die Münzen der baktrischen Könige Antimachos (185-170 v.Chr.) und Apollodotos (180-160 v.Chr.) bzw. die propagandistische Zielrichtung ihrer Prägungen richteten sich nach Ausweis des verwendeten Münzfußes und der Schrift und Sprache der Legende an ein griechisches oder griechisch geprägtes Publikum. ${ }^{202}$ In Frage kommen einerseits die griechische oder gräzisierte Bevölkerung Baktriens selbst, andererseits die Bewohner des Seleukidenreiches. Dieses grenzte damals noch direkt an Baktrien an und dürfte wichtiger Handelspartner und vielleicht auch Rekrutierungsgebiet für Söldner gewesen sein.

\footnotetext{
${ }^{200}$ Vgl. allg. zum Unterschied zwischen graeco-baktrischer und indo-griechischer Kunst und Numismatik: K. Karttunen, India and the Hellenistic World, StOr 83 (1997) $300 \mathrm{f}$.

${ }^{201}$ Vgl. H.-W. Ritter, Diadem und Königsherrschaft (1965) 60.

${ }^{202}$ Dies bezieht sich im Falle des Apollodotos, der die östlichen Teile des baktrischen Reiches beherrschte, nur auf die hier zu besprechende Münze mit Kausiadarstellung. Bei den übrigen Münzen handelt es sich um meist zweisprachige Prägungen von quadratischer Form, auf denen gerne Elefanten und Buckelrinder dargestellt wurden (Vgl. O. Bopearachchi, Monnaies gréco-bactriennes et indo-grecques [1991] $188 \mathrm{ff}$. Serie $2 \mathrm{ff}$. Taf. $11 \mathrm{ff}$.). Diese Münzen dürften eher für indische Bevölkerungsteile oder den Indienhandel bestimmt gewesen sein.
} 
Die übliche Grundbedeutung einer Kausiadarstellung im Sinne eines Hinweises auf das Makedonentum kann in Baktrien nicht oder nur in eingeschränkter Form gemeint sein. Die Bevölkerung Baktriens stammte, abgesehen von den einheimischen (baktrisch-iranischen) Einwohnern, überwiegend aus Griechenland und nicht aus Makedonien, ${ }^{203}$ und auch die Könige waren Griechen. ${ }^{204}$

Den Schlüssel zur Deutung liefert vielleicht ein Blick auf die baktrische Münzprägung in ihrer Gesamtheit. Bis etwa 185 v.Chr. folgt diese ganz den auch in anderen hellenistischen Reichen üblichen Strömungen. In Bezug auf die Ikonographie von Herrscherdarstellungen bedeutet dies, dass das Porträt des Königs im Profil und mit Diadem wiedergegeben wurde. ${ }^{205}$ Dies ändert sich seit der Zeit des Antimachos I. (185-170 v.Chr.) bzw. des Eukratides I. (170-145 v. Chr.): Die Könige wurden jetzt häufig mit realen Kopfbedeckungen gezeigt. Seit Antimachos I. mit Kausia, seit Eukratides auch mit dem makedonisch-böotischen Helm, ${ }^{206}$ der in der Folgezeit typisch für die Bildnisse baktrischer Könige werden sollte. Gleichzeitig erscheint der makedonisch-böotische Helm im seleukidischen Bereich auf Prägungen des Usurpators Timarchos. ${ }^{207}$ Dieser stammte aus Milet, war also wie die baktrischen Könige kein Makedone.

Beiden Kopfbedeckungen ist gemeinsam, dass sie mit Makedonien bzw. Alexander in Verbindung gebracht wurden. Auf die Beziehung der Kausia zu Makedonien muss an dieser Stelle nicht noch einmal eingegangen werden. Im Falle des betreffenden Helmes ist der Zusammenhang weniger eindeutig, dennoch kann auch er als „makedonisch“ bezeichnet werden. ${ }^{208}$ In der modernen Forschung wird dieser Helm in Anlehnung an eine Stelle in Xenophons Werk über die Reitkunst meist als „böotischer Helm“ angesprochen. ${ }^{209}$ Dies heißt jedoch nicht, dass er ursprünglich oder ausschließlich aus Böotien stammen muss. Seit klassischer Zeit lässt er sich in weiten Teilen insbesondere des nördlichen Griechenlands nachweisen, was zur Folge

\footnotetext{
${ }^{203}$ Das genaue Zahlenverhältnis von Makedonen und Griechen in Baktrien lässt sich nicht ermitteln. Es wird jedoch von einem starken Übergewicht der griechischstämmigen Bevölkerung schon seit der Zeit Alexanders (und der antimakedonischen Söldneraufstände [Diodor 18, 7, 1]) ausgegangen. Vgl. E. Will, Histoire politique du monde hellénistique (1979) 28 f. .- F.L. Hol, Alexander the Great and Bactria, Mnemosyne Suppl. 104 (1988) 88 f. .- W. Posch, Baktrien zwischen Griechen und Kuschan (1995) 11 ff.

${ }^{204}$ Schon Stasanor, der erste Satrap nach der Niederschlagung des griechischen Aufstandes in Baktrien, war Grieche aus Zypern (RE 2. Reihe III [1929] 2152 f. s.v. Stasanor [Honigmann]). Die Herkunft Diodotos I., der die Ablösung Baktriens vom Seleukidenreich einleitete, ist nicht bekannt (RE V [1905] 714 f. s.v. Diodotos [7] [Willrich]). Euthydemos, der Diodotos II. stürzte und von dem u.a. Antimachos, der erste König, der sich mit Kausia darstellen lässt, abstammt, kam aus Magnesia (RE VI [1909] 1503 f. s.v. Euthydemos [9] [Willrich]).

${ }^{205} \mathrm{Vgl}$. O. Bopearachchi, Monnaies gréco-bactriennes et indo-grecques (1991) 147-182 Taf. 1-9 oben. Eine Ausnahme bilden Darstellungen des Demetrios I. mit Elefantenskalp (O. Bopearachchi, Monnaies grécobactriennes et indo-grecques [1991] 164 ff. Taf. 4). Es handelt sich hierbei jedoch einerseits um eine irreale Kopfbedeckung, die sich andererseits ebenfalls auf Alexander und die Sieghaftigkeit (in diesem Falle mit Hilfe von Kriegselefanten) beziehen dürfte.

${ }^{206}$ Vgl. O. Bopearachchi, Monnaies gréco-bactriennes et indo-grecques (1991) 183 ff. Taf. 9 ff. bzw. 202 ff. Série $4 \mathrm{ff}$. Taf. $16 \mathrm{ff}$.

${ }^{207}$ Vgl. A. Houghton, Timarchus as King in Babylonia, RevNum 21, 1979, 214 .- A. Kneppe, Timarchos von Milet - ein Usurpator im Seleukidenreich, in: Migratio et commutatio (FS T. Pekáry) (1989) $37 \mathrm{ff}$.

${ }^{208}$ So bei A. Houghton, Coins of the Seleucid Empire from the Collection of Arthur Houghton (1983) $12 \mathrm{Nr}$. 200.

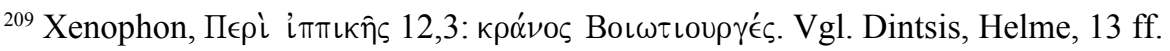


hat, dass unter anderem auch ein thessalischer, illyrischer oder makedonischer Ursprung diskutiert worden ist. ${ }^{210}$ Während die Herkunft nicht mehr genau zu ermitteln ist, besteht kein Zweifel daran, dass die große Beliebtheit dieses Reiterhelmes in den hellenistischen Reichen darauf zurückzuführen ist, dass er im Heer Alexanders des Großen weit verbreitet war. In der Folgezeit ist er der Standardhelm insbesondere der Reitereinheiten hellenistischer Armeen, ${ }^{211}$ und diese waren zumindest dem Selbstverständnis nach makedonisch. Es ist daher sehr wahrscheinlich, dass die Menschen der hellenistischen Zeit diesen Helm nicht mit dem damals weitgehend bedeutungslosen Böotien, sondern mit dem Alexanderheer und dem auf militärischem Gebiet führenden Makedonien verbanden.

Ein weiterer Schritt ist es, in der Kausia und im makedonisch-böotischen Helm einen Hinweis speziell auf Alexander zu sehen, und dies in einem in gewissem Sinne fast schon antimakedonischen Zusammenhang. Alexander der Große ist in der antiken Kunst nie mit Kausia oder Helm dargestellt worden. Dies ist jedoch nicht verwunderlich. Erstens entspricht es allgemeinen antiken Darstellungskonventionen und zweitens wurden Attribute nie willkürlich verwendet, sondern nur wenn sie einen Aspekt des Dargestellten beleuchteten, der im einfachen Porträt noch nicht vorhanden war. Im Falle Alexanders bedeutete das, dass auf seine makedonische Herkunft und andere menschliche Qualitäten nicht mittels Attributen hingewiesen werden musste. Wollte man seine über das Menschliche hinausgehenden Komponenten betonen, geschah dies durch Attribute aus dem göttlichen Bereich.

Wenn die griechischstämmigen baktrischen Könige sich, trotz einer antimakedonischen Grundhaltung der Griechen Baktriens, die nach mehreren Aufständen zur Abspaltung vom makedonisch-seleukidischen Herrschaftsbereich führte, auf ihren Münzen mit Kausia wiedergeben ließen, kann es sich hierin im Ausschlussverfahren nur um eine Anspielung auf Alexander handeln. Dem entspricht, dass die baktrischen Könige auch auf anderen Ebenen versuchten, an das Königtum Alexanders des Großen anzuschließen. Dies geschah unter anderen durch die Propagierung einer (fiktiven) Abstammung der baktrischen Dynastien von Alexander und Roxane ${ }^{212}$ und das Prägen von Alexandermünzen ${ }^{213}$.

Analog hierzu ist die Wiedergabe mit makedonisch-böotischem Helm zu verstehen, die kurz nach dem Einsetzen der ersten Kausiadarstellungen in der Münzprägung Baktriens aufkam. Auch in ihm kann keine direkte Anspielung auf Makedonien gesehen werden. Es bleibt eine solche auf Alexander und das Alexanderheer. Einen indirekten Beleg gibt es in der seleukidischen Prägetätigkeit, in der, wie erwähnt, die Darstellung des Königs mit Helm zur gleichen

\footnotetext{
${ }^{210} \mathrm{Vgl}$. Dintsis, Helme, 11 f. (mit älterer Literatur).

${ }^{211}$ Vgl. Dintsis, Helme, $17 \mathrm{ff}$.

${ }^{212}$ Vgl. den Stammbaum bei W.W.Tarn, The Greeks in Bactria and India (1951) Beilage.

${ }^{213}$ Vgl. Tetradrachmen des Agathokles (190-80 v.Chr.) mit Vorderseite Herakles-Alexander mit Löwenskalp und

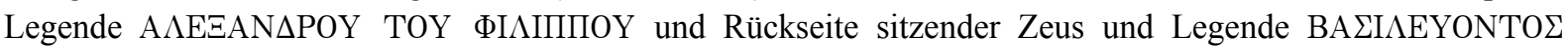

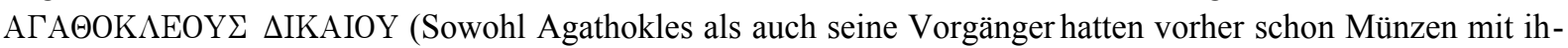
rem Porträt und unter Nennung des eigenen Namens und des Königstitels [BA $\Sigma I \Lambda E \Omega \Sigma . .$.$] geprägt. Agathokles$ ließ auch Münzen zum Gedächtnis anderer Vorgänger schlagen [Antiochos II.; Diodotos Soter, Diodotos Theos, Euthydemos I., Demetrios I., Pantaleon].). Vgl. O. Bopearachchi, Monnaies gréco-bactriennes et indo-grecques (1991) 177 Taf. 8 Serie 12 Nr. 22 f.
} 
Zeit einsetzt wie in Baktrien. Der seleukidische König Alexander I. Balas (150-145 v.Chr.), der sich auch sonst, wie schon aus dem von ihm angenommenen Namen hervorgeht, an den großen Makedonen anlehnte, ließ eine Serie von Bronzemünzen schlagen, ${ }^{214}$ bei denen nicht eindeutig ist, ob Alexander Balas oder Alexander der Große dargestellt ist. ${ }^{215}$ Einige Münzen zeigen auf der Vorderseite einen Kopf mit Löwenskalp (Herakles/Alexander?) und auf der Rückseite Apollon. Sie verweisen damit sowohl auf den Ausgangspunkt aller hellenistischen Königsmacht (Alexander [und dessen Ahnherrn Herakles]) als auch auf die eigene Dynastie (Apollon als mythischer Urvater der Seleukiden). Andere Bronzen bieten ein Porträt mit makedonisch-böotischem Helm sowie auf der Rückseite eine Nike. Ob hier wieder Alexander der Große gemeint ist, bleibt offen. Auch die Beischrift ist zweideutig. Genannt wird jeweils nicht - wie sonst üblich - der vollständige Titel des Alexander Balas im Genitiv (BA $\Sigma \mathrm{I} \Lambda \mathrm{E} \Omega \Sigma$

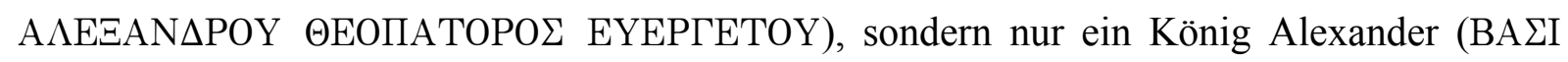
$\Lambda \mathrm{E} \Omega \Sigma$ A $\Lambda \mathrm{E} \Xi \mathrm{AN} \Delta \mathrm{POY})$. Diese Kürzung des Titels kann nicht auf die geringen Maße der Münzen zurückgeführt werden, da die noch kleineren Drachmen des Königs den vollen Titel nennen. ${ }^{216}$ Es wird demnach vielleicht bewusst mit der Zweideutigkeit der Legende gespielt, die offen lässt, welcher Alexander gemeint ist. Denkbar ist, dass hier zwar Alexander Balas dargestellt ist, jedoch bewusst innerhalb einer Serie, in der auch Alexander der Große erscheint, mit unklarer Beischrift und mit einer Kopfbedeckung, die auf Alexander den Großen anspielt. In Kombination mit der Nike auf der Rückseite könnte man einen in der Art Alexanders des Großen dargestellten Alexander Balas erkennen, der wie sein Vorbild siegreich ist. ${ }^{217}$ Wie in der Wiedergabe des Königs mit Kausia ist demnach auch in derjenigen mit makedonisch-böotischem Helm im Ausschlussverfahren und aufgrund entsprechender Anspielungen in der gleichzeitigen seleukidischen Münzprägung mit einiger Wahrscheinlichkeit ein Hinweis auf Alexander den Großen zu sehen. Hinter Alexander schließlich verbirgt sich in diesem Fall nicht der Verweis auf eine makedonische Abstammung, sondern derjenige auf besondere Eigenschaften, die Alexander III. mit dem jeweils prägenden baktrischen oder seleukidischen König verbinden: ein unabhängiges Königtum in der quasi direkten Nachfolge Alexanders des Großen sowie Sieghaftigkeit. ${ }^{218}$

\footnotetext{
${ }^{214}$ BMC, Greek Coins. The Seleucid Kings of Syria (1878) Taf. 16, 10-11 .- A. Houghton, Coins of the Seleucid Empire from the Collection of Arthur Houghton (1983) 12 f. 200-204 Taf. 12 .- R. Fleischer, Studien zur seleukidischen Kunst 1. Herrscherbildnisse (1991) 61 f. Taf. 31 f, h.

${ }^{215}$ Vgl. R. Fleischer, Studien zur seleukidischen Kunst 1. Herrscherbildnisse (1991) $61 \mathrm{f}$.

${ }^{216}$ Vgl. A Houghton, Coins of the Seleucid Empire from the Collection of Arthur Houghton (1983) 11 Nr. 185 ff. Taf. 11.

${ }^{217}$ Vgl. auch oben das Tonmodell einer Münze (Nu 25), das einen König mit Kausia zeigt, hinter dem sich meiner Meinung nach im Zweifelsfall Alexander Balas verbirgt.

${ }^{218}$ Das Königtum Alexanders des Großen unterschied sich von fast allen früheren Formen monarchischer Machtausübung darin, dass es nicht an ein bestimmtes Territorium oder Volk gebunden war, sondern an die Person des Königs. Dieser herrschte in erster Linie aufgrund persönlicher Fähigkeiten (insbesondere derjenigen zu siegen) über ein Gemisch verschiedener Völker und Territorien mit unterschiedlichen Traditionen. H.-J. Gehrke nennt dies eine „personal-victoriale Königsherrschaft“ (H.-J. Gehrke, Geschichte des Hellenismus [Oldenbourg Grundriß der Geschichte 1A] [1995] 165 f. [mit Literaturverweisen]). In dieser Tradition standen zumindest diejenigen hellenistischen Herrscher, die ein größeres, multiethnisches Gebiet regierten (Antigoniden, Seleukiden,
} 
Das Ziel der Verwendung der Kausia (bzw. des makedonisch-böotischen Helmes) war bei den baktrischen (und einigen seleukidischen) Königen demnach nicht oder nicht nur, an makedonische Traditionen anzuschließen, sondern die Art der Herrschaftsausübung gegenüber äußeren Gegnern (insbesondere gegenüber den Seleukiden) und vielleicht den eigenen Untertanen $\mathrm{zu}$ legitimieren und darüber hinaus auf eine ebenfalls aus der Alexandernachfolge resultierende Sieghaftigkeit hinzuweisen.

\section{Indien (Nu 31-36)}

Die Münzprägung der indo-griechischen Könige Lysias (120-110 v.Chr.), Antialkidas I. (11595 v.Chr.), Demetrios III. ( 100 v.Chr.) und Amyntas (95-90 v. Chr.) orientiert sich fast ausschließlich am indischen Münzfuß und weist dann regelmäßig zweisprachige Legenden auf. Es ist demnach an einen indisch geprägten Wirtschaftsraum und eine teilweise indisch sprechende Bevölkerung als Zielgruppe zu denken.

Dies entspricht den veränderten außenpolitischen Rahmenbedingungen, nachdem um etwa 150/135 v.Chr. das eigentliche Baktrien von den Kuschan und die östlichen Provinzen des Seleukidenreiches von den Parthern erobert worden waren. Ein Konkurrenzverhältnis zwischen den indo-griechischen Königen und den Seleukiden kann infolge der unterbrochenen Landverbindung zwischen den griechischen Reichen auf dem indischen Subkontinent und den übrigen hellenistischen Staaten nicht mehr bestanden haben. Ein Versuch der Legitimierung der ursprünglich usurpierten Macht gegenüber den Seleukiden durch Bezugnahme auf Alexander den Großen scheidet demnach aus.

Möglich wäre, dass die Kausia (und der böotisch-makedonische Helm) aus traditionellen Gründen auch im indo-griechischen Bereich weiterhin dargestellt wurden, ohne dass die ursprüngliche Bezugnahme auf Alexander noch eine Rolle spielte. Dem widerspricht, dass die Kausia zwischen 160 und 120 v.Chr. keine Verwendung in der Münzprägung fand. ${ }^{219}$

Andererseits gab es weiterhin Gruppen, gegenüber denen der Bezug auf Alexander von Vorteil war. Zu nennen sind einerseits die griechischstämmige Bevölkerung, die auf Alexander zurückgehende Traditionen positiv bewertet haben könnte, andererseits die indischen Bewohner sowohl der indo-griechischen Reiche als auch der indischen Nachbarstaaten. Alexander genoss bei diesen einmal die Anerkennung eines legitimen Oberherrschers und ist vielleicht ähnlich wie im koptischen und persisch-islamischen Bereich ${ }^{220}$ auch im indischen Denken zum idealen König verklärt worden. Der zweite Aspekt der Imitatio Alexandri, die Betonung

\footnotetext{
Ptolemäer, baktrische Könige). Im Besonderen aber gilt dies für die Usurpatoren, denn sie sprengten zusätzlich den auch im Hellenismus vorhandenen Gedanken der Legitimierung durch Zugehörigkeit zu einer Dynastie. Nicht zufällig handelt es sich bei einem Großteil der hier genannten Könige um Usurpatoren (Eukratides I., Timarchos, Alexander I. Balas).

${ }^{219}$ Vgl. O. Bopearachchi, Monnaies gréco-bactriennes et indo-grecques (1991) 195-256 Taf. 14-37 (ohne Kausia).

${ }^{220}$ Vgl. z.B. Alessandro Magno. Storia e mito (Ausstellungskatalog Rom 1995/96) (1995) 161-193. 294 ff. 334 ff.
} 
der Sieghaftigkeit ${ }^{221}$, wurde bezeichnenderweise ebenfalls von denjenigen Königen gepflegt, die sich mit der Kausia darstellen ließen. Sie alle verweisen im Rahmen ihrer Königstitulatur

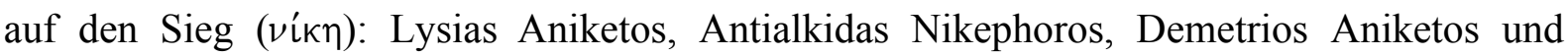
Amyntas Nikator. 222

\subsubsection{Die Kausia diadematophoros als Beizeichen auf Münzen}

Die Kausia diadematophoros erscheint auf makedonischen und ptolemäischen Prägungen vereinzelt als Beizeichen. Die Person des Herrschers ist in den betreffenden Fällen nicht wiedergegeben. Da es sich jedoch beim Diadem um ein königliches Symbol handelt, muss wiederum eine direkte oder indirekte Verbindung zum Königtum bestehen.

\section{Makedonische Reichsprägungen aus Amphipolis}

Amphipolis ist 357 v.Chr. von Philipp II. erobert worden und beherbergte in der Folgezeit eine der makedonischen Reichsprägestätten. Zwischen 323/2 und 316/15 v.Chr. wurden dort Tetradrachmen, „Fünftel-Tetradrachmen ${ }^{\bullet 223}$ und Goldstatere geprägt, die die Kausia diadematophoros als Beizeichen aufweisen.

Die Tetradrachmen (Nu 6a, Taf. 7 Abb. 31) zeigen auf der Vorderseite einen bärtigen Kopf mit Lorbeerkranz (Zeus?) und auf der Rückseite einen Reiter (mit Petasos ${ }^{224}$ ), als Beizeichen eine Kausia diadematophoros und den Schriftzug ФІ $\Lambda$ IППОY. Auf den „Fünftel-Tetradrachmen“ (Nu 6b, Taf. 7 Abb. 32) ist vorne ein Kopf ohne Bart mit Lorbeerkranz zu sehen, hinten erscheinen wiederum der Reiter, das Beizeichen Kausia diadematophoros und ФІ Die Goldstatere $(\mathrm{Nu}$ 7, Taf. 7 Abb. 33) weisen auf der Vorderseite einen unbärtigen Kopf ebenfalls mit Lorbeerkranz (Apollon) auf, auf der Rückseite erscheint eine Biga, die Kausia diadematophoros sowie im Abschnitt ФІ $\Lambda$ IППОY.

\section{Ptolemäische Prägungen aus Zypern}

Ptolemäische Tetradrachmen mit einer Kausia diadematophoros als Beizeichen wurden auf Zypern in Salamis (Nu 14-21, Taf. 7 Abb. 35-38, 41) und Kition (Nu 22-23, Taf. 7 Abb. 3940, 42) geprägt. Die Münzstätte in Salamis gab entsprechende Münzen in drei Schüben her-

\footnotetext{
${ }^{221}$ Zur Verwendung der Bezeichnung „Theos aniketos“ für Alexander vgl. A. Stewart, Faces of Power (1993) 95 ff.

${ }^{222}$ Vgl. O. Bopearachchi, Monnaies gréco-bactriennes et indo-grecques (1991) 266 ff. Taf. 38 f.; 271 ff. Taf. 39 ff.; 288 Taf. 43; 299 ff. Taf. 46 f.

${ }^{223}$ So bezeichnet bei G. Le Rider, Le Monnayage d'Argent et d'Or de Philippe II. - Frappé en Macédoinie de 359 á 294 (1977) 122. Die Münzen wiegen 2,36-2,55 g. Es ist zu überlegen, ob die Prägungen nicht, statt als „Fünftel-Tetradrachmen" nach attischem Gewichtsstandard, besser als „Drachmen“ nach chalkidischem Standard anzusprechen sind. Chalkidische Tetradrachmen ( 12,5 g.) prägte zeitgleich der paionische König Patraos (Vgl. Nu 1-3.).

${ }^{224}$ Die Kopfbedeckung des Reiters auf den Münzen Philipps II./III. wird häufig als Kausia bezeichnet (Vgl. z.B. G. LeRider, Le Monnayage d'Argent et d'Or de Philippe II. - Frappé en Macédoinie de 359 á 294 [1977] 5 Taf. 1 ff.). Dies trifft nicht zu. Trotz der makedonischen Herkunft der Prägungen handelt es sich bei dieser Kopfbedeckung, da besser erhaltene Exemplare einen Knopf auf dem Hut erkennen lassen, um einen Petasos.
} 
aus: 182/1 bis 175/4, 150/49 und 122/1 v. Chr. In den Jahren 150/49 und 122/1 wurden auch Tetradrachmen mit dem Ethnikon KI (Kition) und der Kausia diadematophoros als Beizeichen emittiert, was darauf hindeutet, dass Beizeichen für alle Prägeorte einheitlich vorgegeben wurden oder dass die Beamten, die diese verwendeten, identisch gewesen sind. ${ }^{225}$

Darüber hinaus entstanden auf Zypern an einem nicht näher bekannten Ort vermutlich ebenfalls im 2. Jahrhundert v. Chr. Didrachmen mit einer Kausia diadematophoros als Beizeichen (Nu 24, Taf. 7 Abb. 34).

Die Prägungen zeigen auf der Vorderseite jeweils das Porträt des ptolemäischen Königs nach rechts und auf der Rückseite einen Adler mit Blitzbündel, die Legende ПTO $\Lambda \mathrm{E} \Omega \Sigma$, Angaben zum Jahr und zum Ort der Prägung sowie als Beizeichen eine Kausia diadematophoros und teilweise weitere Beizeichen. 226

Sowohl bei den auf Zypern als auch den in Amphipolis geschlagenen Münzen handelt es sich jeweils um die einzigen ptolemäischen bzw. makedonischen Prägungen, die eine Kausia zeigen.

\section{Zur Deutung der isolierten Kausia diadematophoros}

Wie auf den ptolemäischen Münzen Zyperns erscheint die Kausia diadematophoros auch auf den in Amphipolis geprägten makedonischen Münzen nicht als Kopfbedeckung in Verbindung mit dem Herrscherporträt, sondern als Beizeichen. Die Beizeichen dienten vermutlich der Unterscheidung einzelner Münzserien, die auf diesem Wege bestimmten, verantwortlichen Beamten zugewiesen werden konnten.

Die für die Prägung zuständigen Beamten waren in der Wahl der von ihnen verwendeten Beizeichen anscheinend relativ frei, wie die große Zahl ständig wechselnder Symbole zeigt. Es liegt nahe, hinter den Beizeichen einen Hinweis auf die sie auswählende Personengruppe zu suchen.

Da als Beizeichen nie die einfache Kausia verwendet wird, sondern immer die mit dem Diadem umwundene, spiegelt sich in der Wahl des maßgeblichen Bestandteiles der makedonischen Kleidung als persönlichem Zeichen nicht allein die Bedeutung Makedoniens für den Prägenden, z.B. im Sinne eines Verweises auf die makedonische Herkunft, wider. Denn die Kausia diadematophoros steht einerseits für Makedonien (Kausia), andererseits aber für das Königtum (Diadem). Die Verwendung dieses Symbols enthält demnach einen Hinweis auf den König.

\footnotetext{
${ }^{225}$ Soweit nicht auf Beizeichen verzichtet wurde, was in Paphos meistens, in Kition manchmal der Fall war, wurden in den drei zyprischen Münzstätten in der Regel zeitgleich die gleichen Beizeichen verwendet (Vgl. O. Mørkholm/A. Kromann, The Ptolemaic Silver Coinage on Cyprus 192/1-164/3 B.C., Chiron 14, 1984, $150 \mathrm{ff}$. $155 \mathrm{ff}$.). - Als Vorderseiten-Stempel einer Münze aus Kition (Nu 22) diente ein Stempel, der im Vorjahr noch in Salamis Verwendung fand (Vgl. BMC, Greek Coins. The Ptolemies [1883] 90 Nr. 19, 91 Nr. 38), was auf den Austausch von Stempeln hinweist, vielleicht auch auf eine zentrale Prägestätte.

${ }^{226}$ Die Didrachmen ( $\left.\mathrm{Nu} 24\right)$ weichen von den oben beschriebenen Tetradrachmen (Nu 14-23) insofern ab, als sie auf der Vorderseite statt des Porträts des Ptolemaios I. mit Diadem eines des Ptolemaios IV. (?) als Dionysos zeigen und auf der Rückseite die Angaben zu Ort und Jahr der Prägung fehlen.
} 
Welcher Art dieser Hinweis sein könnte, ist mangels weiterer Indizien unklar. In Frage kommen verschiedene Varianten.

Die einfachste und zugleich unwahrscheinlichste Möglichkeit ist, dass der König selbst für die Prägung der betreffenden Münzen zuständig war und die Kausia diadematophoros als Beizeichen auf diesen Umstand hinweisen sollte. Denn eine nur allgemeine Oberaufsicht der Herrscher über die Reichsprägung und großer Teile der städtischen Edelmetallprägung in ihrem Machtbereich kann nicht gemeint sein. In diesem Fall müsste ein Großteil der hellenistischen Münzen ein entsprechendes Beizeichen aufweisen bzw. wäre dies überflüssig, da die Oberherrschaft des Königs schon durch dessen Porträt auf der Münze verdeutlicht würde. Eine direkte Kontrolle der Münzprägung durch den Herrscher kann ebenfalls nicht gemeint sein, da der König nicht gleichzeitig an verschiedenen, oft weit auseinander liegenden Orten die Emission von Münzen überwacht haben kann und daher diese Aufgabe delegiert haben muss.

Im Falle der zyprischen Prägungen mit Kausia diadematophoros hielten sich gerade in den Zeitabschnitten, in denen diese Münzen geschlagen wurden, keine zum ptolemäischen Herrscherhaus gehörenden Strategen oder (Teil-) Könige auf der Insel auf. ${ }^{227}$

Es bleibt die Möglichkeit, dass eine Person, die selbst nicht zum Kreis der Diademträger gehörte, die Kausia diadematophoros als Beizeichen wählte, um ein besonderes Verhältnis zum König zum Ausdruck zu bringen.

Welcher Art dieses Nahverhältnis war, lässt sich nicht nachweisen. Möglich ist ein eher allgemeines und die Wahl der Kausia diadematophoros als Beizeichen im Sinne einer allgemeinen Ehrerbietung oder Danksagung an den König. Zu Dank und Ehrerbietung verpflichtet waren dem Herrscher gegenüber jedoch alle königlichen Beamten. Es ist daher nur schwer nachzuvollziehen, warum nur wenige dies auch zum Ausdruck brachten.

\subsubsection{König und Adel auf der Jagd}

Personen mit Kausia erscheinen zweimal im Rahmen von Jagdszenen: auf dem Fries des sog. Philippsgrabes in Vergina und auf der Basis mit dem Löwenjagdrelief aus Messene.

\section{Löwenjagdrelief Messene}

Das Löwenjagdrelief aus Messene (Re 5, Taf. 8 Abb. 43) befindet sich auf dem Block einer Rundbasis. Es zeigt (von links nach rechts) einen heranpreschenden Reiter, einen nach rechts schreitenden Löwen, der den Kopf nach hinten, d.h. zum Reiter wendet, und vor dem Löwen einen stehenden Mann, der eine Doppelaxt schwingt und mit einem stark bestoßenen Umhang bekleidet ist, der meist als Löwenfell gedeutet wird. Weiterhin sind zwei Jagdhunde wiedergegeben: der eine greift den Löwen an, der andere befindet sich unter den Vordertatzen des Lö-

\footnotetext{
${ }^{227}$ Die Kausia diadematophoros erscheint als Beizeichen: 182-174, 150/49 und 122/1 v.Chr. Ptolemäer halten sich auf Zypern als Strategen oder (Teil-) Könige zwischen 117 und 58 v.Chr. auf.
} 
wen. Es kann nicht ausgeschlossen werden, dass auf der Basis weitere Personen oder Tiere dargestellt waren, da nur ein Teil der Rundbasis erhalten ist. ${ }^{228}$ Die Szene wird von der Forschung in Anlehnung an literarische Quellen ${ }^{229}$ und an eine nach Delphi geweihte Skulpturengruppe $^{230}$ vielfach als eine Wiedergabe des reitenden Krateros, der dem mit einem Löwen kämpfenden Alexander, während einer Löwenjagd bei Sidon, zu Hilfe kommt, gedeutet. ${ }^{231}$

Der Reiter (Krateros) trägt (neben Chiton und Chlamys) eine flache Kopfbedeckung. Diese ist meist als Kausia gedeutet worden. ${ }^{232}$ Aufgrund der starken Beschädigungen sind jedoch weder die typischen Merkmale eines Petasos (Kopfform/Knopf, Riemen) noch die der Kausia (Rolle o.ä. am unteren Rand) eindeutig identifizierbar. Der archäologische Befund ist also nicht eindeutig. Die schriftliche Überlieferung ${ }^{233}$, die Krateros als einen Mann beschreibt, den man an seiner Kausia erkennen konnte, spricht für die Rekonstruktion mit Kausia.

Die Entstehung der Basis wird in Anlehnung an die Deutung (Alexander und Krateros) an das Ende des 4. Jahrhunderts v.Chr. datiert. ${ }^{234}$

\section{„Philippsgrab“ und Krateros-Monument}

Im oberen Bereich der Fassade des so genannten „Philippsgrabes“ in Vergina (Ma 5, Taf. 8 Abb. 44) befindet sich ein gemalter Fries ${ }^{235}$. Dieser zeigt in dicht gedrängter Abfolge Jagdszenen: Von links nach rechts sind eine Jagd auf Hirsche, eine Eberjagd, eine Löwenjagd sowie eine Bärenjagd zu sehen. In der Mitte des Frieses (zwischen Eber- und Löwenjagd) ist ein einzelner Reiter dargestellt, der durch die zentrale Stellung, aber auch seine Kleidung ${ }^{236}$ und den Umstand, dass er zwar wie die meisten anderen Jäger mit einem Speer bewaffnet ist, aber letztlich keiner der Szenen zugeordnet werden kann, hervorgehoben wird. ${ }^{237}$

Von den zehn dargestellten Personen sind drei mit Kausien wiedergegeben. Diese verteilen sich auf zwei der Jagdgruppen: Beide Teilnehmer der Bärenjagd tragen Kausien. Der dritte Kausiaträger gehört zu den drei Männern, die Jagd auf den Löwen machen.

Zur Bärenjagdgruppe gehört ein Mann in Krepides (Schnürstiefeln), Chlamys und Kausia. Dieser trägt kein Untergewand (Chiton), der Körper ist weitgehend entblößt wiedergegeben.

\footnotetext{
${ }^{228}$ Vgl. T. Hölscher, Griechische Historienbilder des 5. und 4. Jahrhunderts v. Chr. (1973) 183.

${ }^{229}$ Die antiken Quellen (Plinius h.n. 34, 64 .- Plutarch, Alexander 40, 4-5 .- Weihinschrift in Delphi) sind bei A. Stewart, Faces of Power (1993) 390 ff. (mit Literatur) zusammengetragen. Vgl. auch T. Hölscher, Griechische Historienbilder des 5. und 4. Jahrhunderts v. Chr. (1973) $181 \mathrm{ff}$.

${ }^{230}$ F. Courby, FdD II. Laterrasse du temple (1927) $237 \mathrm{ff}$.

${ }^{231}$ T. Hölscher, Griechische Historienbilder des 5. und 4. Jahrhunderts v. Chr. (1973) 181 f. 183 ff. Taf. 15, 3.

${ }^{232} \mathrm{Vgl}$. Dintsis, Helme, 306 Nr. 285.

${ }^{233}$ Vgl. Plutarch, Eumenes 6, 1 (= Q 14c).

${ }^{234}$ T. Hölscher, Griechische Historienbilder des 5. und 4. Jahrhunderts v. Chr. (1973) 183 ff. 294 mit Anm. 1121.

${ }^{235}$ Großformatige Abbildungen fehlen. Kleinere Photographien sowie Strichzeichnungen und Aquarelle sind u.a. publiziert in M. Andronicos, Vergina. The Royal Tombs and the Ancient City (1984) 100-116 Abb. 56-71.

${ }^{236}$ Der zentrale Reiter trägt einen rötlichen Chiton sowie einen Kranz auf dem Kopf. Die übrigen Personen sind (bis auf zwei Ausnahmen, die anders zu erklären sind; vgl. unten) in „heroischer Nacktheit“" dargestellt.

${ }^{237}$ M. Andronicos, Vergina. The Royal Tombs and the Ancient City (1984) 108 f. mit Abb. 65 f. sieht in dem Reiter Alexander den Großen. Diese Deutung ist jedoch von der Zuweisung des Grabes an dessen Vater Philipp II. abhängig.
} 
Dieses muss nicht der realen Tracht entsprechen, sondern kann gemäß griechischer Darstellungskonvention der Charakterisierung der Person dienen („heroische Nacktheit" ${ }^{\text {‘238) }}$ ). Der Jäger wird von einem Hund begleitet und zielt mit einem kurzen Wurfspeer auf einen Bären, der, schon von anderen Speeren getroffen, etwas oberhalb auf einem Felsen liegt. Neben dem Jäger steht ganz am Rande des Frieses eine Person, die ebenfalls Krepides und die Kausia trägt, jedoch in Kombination mit einem Fellumhang anstelle der Chlamys sowie einem Chiton. Dieser Mann ist mit dem Ordnen eines Wurfnetzes beschäftigt. Die Kausien der beiden unterscheiden sich stark. Auf dem Kopf des „heroischen“ Jägers befindet sich eine Kausia, die relativ hoch, weich und voluminös erscheint und unten mit einer Wulstrolle abschließt, die den größten Umfang der Mütze angibt. ${ }^{239}$ Die Kopfbedeckung des Netzträgers besteht, soweit erkennbar, hauptsächlich aus einem ausladenden, flachen Schirm. ${ }^{240}$ Es handelt sich dennoch in beiden Fällen um Kausien, da beide Varianten auch sonst auftreten und beide die grundlegenden Merkmale der Kausia aufweisen. ${ }^{241}$

Der dritte Kausiaträger gehört zur Löwenjagdgruppe (Taf. 8 Abb. 44). Er trägt eine Kopfbedeckung, die der des oben beschriebenen Bärenjägers gleicht, und ist wie dieser in „heroischer Nacktheit" dargestellt: das Untergewand und in diesem Fall auch die Stiefel fehlen. Der Mann wird von einem Hund begleitet und richtet seine Stoßlanze auf die Kehle des Löwen. Zur Gruppe gehören weiterhin ein Mann der ausschließlich mit einem zurückgeschlagenen Umhang bekleidet ist und beidhändig eine Doppelaxt über dem Kopf schwingt, sowie ein Reiter auf einem sich aufbäumenden Pferd, der von hinten mit einer Lanze auf den Löwen einsticht. Dieser Reiter ist vollständig bekleidet mit Chiton, Chlamys und Krepides und trägt vermutlich einen Bart, der ihn als älteren Mann charakterisieren könnte. Im Zentrum der Gruppe befindet sich der Löwe. Dieser wendet den Kopf nach hinten zum angreifenden Reiter. Ein Jagdhund fällt den Löwen währenddessen von der Seite an, ein weiterer wird von den Vordertatzen des Löwen zu Boden gedrückt. Bemerkenswert ist, dass es sich bei der Löwenjagdgruppe auf dem Fries in Vergina um eine -seitenverkehrte - Wiedergabe der Gruppe auf der Basis aus Messene (Vgl. Re 5 und Ma 5 auf Taf. 9 Abb. 45-46) handelt. ${ }^{242}$ Die Gruppe in Vergina ist jedoch um

${ }^{238}$ Zum Fehlen einzelner Trachtbestandteile vgl. N. Himmelmann, Ideale Nacktheit in der griechischen Kunst (1990) 53 mit Rez. T. Hölscher, Gnomon 65, 1993, 519-28 .- Th. Schäfer, Andres Agathoi (1997) 38 ff. 147 ff. 149 ff. $158 \mathrm{ff}$.

239 Ähnliche Kausien finden sich auch auf dem Fries der Fassade des Grabes von Ag. Athanasios (Ma 6) und der Grabstele aus Vergina (Re 2).

${ }^{240}$ Vgl. die Kausien der „Grabwächter“/Soldaten rechts und links des Eingangs zum Grab bei Ag. Athanasios (Ma 6) oder die des „Krateros“ auf der Löwenjagdbasis aus Messene (Re 5).

${ }^{241}$ Auf die Ausführungen Ch. Saatsoglou-Paliadelis (Saatsoglou-Paliadeli, Costume, 135), die nur in den Kopfbedeckungen der heroischen Jäger makedonische Kausien, die ihrer Meinung nach ausschließlich von den Königen und den „Pagen“ getragen wurden, sehen möchte und die die Mütze des Netzträgers als ein Barett der Unterschicht ansieht, gehe ich unten im Kapitel 5. 1. „Die Kausia als Kopfbedeckung bestimmter Personengruppen.

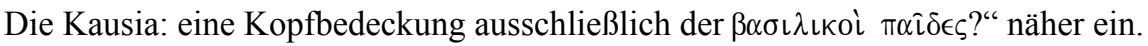

${ }^{242}$ Das Relief aus Messene zeigt von links nach rechts: den Reiter (Krateros) - einen Löwen nach rechts, der den Kopf zum Reiter wendet - einen Jagdhund unter den Vordertatzen des Löwen - den Mann mit Löwenfell und Doppelaxt (Alexander), parallel dahinter einen weiteren Hund. Der Kern der Löwenjagdgruppe in Vergina zeigt (wiederum von li. n. re.): den Mann mit der Doppelaxt, parallel davor einen Jagdhund - den Hund unter den Vordertatzen des Löwen - den Löwen selbst (nach links) mit nach rechts (zum Reiter) gedrehtem Kopf - den Reiter. 
zwei Figuren (den Jäger mit Kausia sowie den Hund, der den Löwen von der Seite anfällt) erweitert, die in Messene fehlen. ${ }^{243}$ Darüber hinaus weichen beide Darstellungen nur in geringfügigen Trachtunterschieden ${ }^{244}$ voneinander $a b$ sowie in der künstlerischen Umsetzung des vermuteten dreidimensionalen Vorbildes (Statuengruppe in Delphi) in ein zweidimensionales Medium (Relief, Malerei) ${ }^{245}$. Grundsätzlich stimmen die Löwenjagden in Messene und Vergina jedoch überein, und dies auch im Vergleich mit anderen Darstellungen der Jagd auf einen Löwen. ${ }^{246}$ Es ist daher von einem gemeinsamen Vorbild auszugehen. Als Vorbild der Basis von Messene wird in der Forschung ${ }^{247}$ das Krateros-Monument in Delphi (Taf. 9 Abb. 47) angenommen. ${ }^{248}$ Entsprechend ist in Vergina in dem Mann mit Doppelaxt Alexander zu sehen,

${ }^{243}$ Der Fries in Vergina erweitert die Gruppe um den Jäger in Chlamys und Kausia mit Stoßlanze sowie einen dritten Hund. Für die Teilnahme von mehr als zwei Personen an der Löwenjagd bei Sidon sprechen bildliche Darstellungen (z.B. die Rückseite des „Alexandersarkophargs“ aus Sidon in Istanbul), sowie die literarischen Quellen zu diesem Ereignis (Vgl. T. Hölscher, Griechische Historienbilder des 5. und 4. Jahrhunderts v. Chr. [1973] 181 ff. .- A. Stamatiou, Alexander the Great as a Lion Hunter, in: Praktika tou XII Diethnous synedriou klasikes archaiologias, Athen 1983, Bd. 2 [1988] 209 ff. .- W. Fuchs, Die Skulptur der Griechen [1993] 363 Abb. 402 f.) aber auch ein überliefertes Verbot Alexanders, ihm während einer Jagd zu Hilfe zu kommen (Curtius Rufus 8, 1, 18; vgl. T. Hölscher, Griechische Historienbilder des 5. und 4. Jahrhunderts v. Chr. [1973] 184). Für die Rekonstruktion des Krateros-Monumentes in Delphi ziehen die Bearbeiter, die (möglicherweise unvollständige) Gruppe auf der Reliefbasis aus Messene heran, erweitern diese jedoch um weitere Statuen, vermutlich um den vorhandenen Raum (15,27 x 6,35 m) besser füllen zu können (F. Courby, FdD II. La terrasse du temple [1927] Abb. 189-191 [nach S. 240]).

${ }^{244} \mathrm{Da}$ der Erhaltungszustand der Malerei nicht sehr gut und die Größe der publizierten Photographien zu gering ist, sind Einzelheiten der Kleidung oft nicht zu erkennen. Die Detailtreue von Strichzeichnungen (schwarz/weiß) und farbigen Aquarellen, wie sie u.a. bei M. Andronicos, Vergina. The Royal Tombs and the Ancient City (1984) 100-116 Abb. 56-71 erscheinen, lässt sich nicht überprüfen. Soweit dies auf der genannten Grundlage feststellbar ist, trägt der Mann mit der Doppelaxt (Alexander?) in Vergina keinen Löwenfellumhang, sondern eine einfache Chlamys. Der Fellumhang ist jedoch auch in Messene nicht eindeutig zu erkennen. Der Reiter (Krateros?) weist in Vergina anders als in Messene vermutlich keine Kopfbedeckung auf.

${ }^{245}$ Auf dem Fries in Vergina wird durch die Staffelung der Figuren und durch Verkürzungen räumliche Tiefe sug geriert. Das Relief auf der Basis aus Messene zeigt die einzelnen Figuren neben einander aufgereiht. Überschneidungen der Figuren sind selten bzw. treten nur in Zusammenhang mit den kleinen Hunden auf. Auf räumliche Verkürzungen wird weitgehend verzichtet. Die Größenverhältnisse entsprechen nicht der Realität (Der stehende Mann mit Doppelaxt ist genau so hoch wie der Reiter [samt Pferd].). Das Relief wirkt wie eine vereinfachte, in die Fläche gedrückte Wiedergabe einer dreidimensionalen Gruppe, während der gemalte Fries den Anschein der räumlichen Tiefe beibehält.

${ }^{246}$ Vgl. das Mosaik in Pella, die B-Seite des „Alexandersarkopharges“ von Sidon oder das Mosaik in Neapel (T. Hölscher, Griechische Historienbilder des 5. und 4. Jahrhunderts v. Chr. [1973] 186 ff. 189 ff. .- A. Stamatiou, Alexander the Great as a Lion Hunter, in: Praktika tou XII Diethnous synedriou klasikes archaiologias, Athen 1983, Bd. 2 [1988] 211-217 .- W. Fuchs, Die Skulptur der Griechen ～[1993] 363 Abb. 402 f.). Die Übereinstimmungen beschränken sich darauf, dass eine Löwenjagd wiedergegeben wird. Eine vergleichbare Gruppe (Mann mit Doppelaxt und Hund - Löwe, der sich umdreht, mit Hund unter den Vordertatzen - Reiter) findet sich aufdiesen Darstellungen auch dann nicht, wenn dieselbe Löwenjagd bei Sidon gemeint ist (wie auf dem Alexandersarkopharg aus Sidon).

${ }^{247}$ Vgl. T. Hölscher, Griechische Historienbilder des 5. und 4. Jahrhunderts v. Chr. (1973) 181 ff. 185 .- A. Stamatiou, Alexander the Great as a Lion Hunter, in: Praktika tou XII Diethnous synedriou klasikes archaiologias, Athen 1983, Bd. 2 (1988) 213.

${ }^{248}$ Die Statuen des Krateros-Monuments in Delphi wurden von Lysipp und Leochares geschaffen (T. Hölscher, Griechische Historienbilder des 5. und 4. Jahrhunderts v. Chr. [1973] 181 ff.). M. Andronicos, Vergina. The Royal Tombs and the Ancient City (1984) 113, der keinen Zusammenhang zwischen dem Fries von Vergina, der Rundbasis aus Messene und dem Krateros-Monument annimmt, bemerkt dennoch, dass einige der Personen auf dem Fries Statuen des Leochares ähnlich sehen. 
im Reiter wahrscheinlich Krateros ${ }^{249}$ und in der Person mit Kausia ein weiterer Jagdteilnehmer aus dem Umfeld Alexanders des Großen. ${ }^{250}$

Das Grab wird von seinem Ausgräber (M. Andronikos) als dasjenige Philipps II. von Makedonien angesprochen. ${ }^{251}$ Philipp II. wurde 336 v.Chr. ermordet, der Grabhügel müsste kurze Zeit später entstanden sein. Die Zuweisung des Grabes an den Vater Alexanders des Großen sowie die Gleichsetzung des modernen Ortes Vergina mit Aigai, der antiken Hauptstadt Makedoniens, ist jedoch umstritten und u.a. aufgrund des nicht abschließend publizierten Fundmaterials nur schwer zu überprüfen. Gehen jedoch das Relief aus Messene und die Darstellung auf der Fassade des Grabes in Vergina auf das gleiche Urbild zurück und handelt es sich hierbei um die von Krateros bzw. dessen gleichnamigen Sohn nach Delphi geweihte Statuengruppe, so können das Relief und die Grabfassade nicht vor der Statuengruppe entstanden sein. Diese wurde jedoch erst zwischen 323 und 300 v.Chr. ${ }^{252}$ aufgestellt, d.h. rund 15 - 35 Jahre nach dem Tode Philipps II. Es kann sich beim „Philippsgrab“ demnach nicht um das Grab Philipps II. handeln. ${ }^{253}$

\section{Interpretation der Jagdszenen}

Den Jagddarstellungen ist gemeinsam, dass sie nicht oder nicht in erster Linie der Nahrungsgewinnung dienen. Jagdobjekte sind vielmehr Löwen und Bären. Die Teilnehmer sind Alexander, Krateros und weitere Personen aus dem Umfeld des Königs. Es handelt sich entsprechend um Veranstaltungen, die der standesgemäßen Selbstdarstellung, der Nachahmung heroischer Vorbilder (Herakles) oder auch dem Vergnügen dienen.

Die auf dem Fries in Vergina mit der Kausia wiedergegebenen Personen lassen sich anhand der Bekleidung und der ausgeübten Tätigkeiten verschiedenen gesellschaftlichen Gruppen zu-

${ }^{249}$ Der Reiter auf dem Fries in Vergina ist mit Bart dargestellt, was auf einen Mann reiferen Alters hindeutet (Vgl. M. Andronicos, Vergina. The Royal Tombs and the Ancient City [1984] 100-116 Abb. 56-71, der im Reiter Philipp II. erkennen will.). Im reiferen Alter der dargestellten Person könnte auch begründet liegen, dass dieser nicht mehr in „heroischer Nacktheit“ gezeigt wird. Das Geburtsjahr des Krateros scheint nicht bekannt zu sein. Eine Angabe hierzu fehlt zumindest in den einschlägigen Lexika (z.B. RE Suppl. IV [1924] 1038 ff. s.v. Krateros [1a] [Geyer]) und bei H. Berve, Das Alexanderreich auf prosopographischer Grundlage II (1926) 220 ff. Nr. 446. ${ }^{250}$ An der Löwenjagd zu Sidon nahmen neben Alexander und seinen Vertrauten (u.a. Lysimachos, der ebenfalls einen Löwen erlegte) auch Abdalonymos, der König von Sidon, und Gefolge teil (Vgl. T. Hölscher, Griechische Historienbilder des 5. und 4. Jahrhunderts v. Chr. [1973] 189 ff.). Der Mann mit Kausia ist ein namentlich nicht näher bestimmbarer Makedone aus dem Umfeld Alexanders. Es ist nicht vollständig auszuschließen, dass es sich bei ihm (und nicht bei dem Reiter) um Krateros handelt, da in den das Denkmal in Delphi beschreibenden antiken Quellen (vgl. diese bei A. Stewart, Faces of Power [1993] 390 ff.) nicht erwähnt wird, dass Krateros als Reiter wiedergegeben worden sei.

${ }^{251}$ M. Andronicos, Vergina. The Royal Tombs and the Ancient City (1984) $97 \mathrm{ff}$.

${ }^{252} \mathrm{Zu}$ Krateros (gestorben 321 v.Chr.) als dem ursprünglich Weihenden und seinem gleichnamigen Sohn (*321 v.Chr.) oder seiner Frau Phila als den letztlich Ausführenden sowie den hiermit zusammenhängenden Datierungsansätzen vgl. T. Hölscher, Griechische Historienbilder des 5. und 4. Jahrhunderts v. Chr.(1973) 182 f.

${ }^{253}$ Die Löwenjagdszenen auf dem Grab von Vergina und der Basis aus Messene werden auch von P. Moreno, Elementi di pittura ellenistica, in: L'Italie méridionale et les premières expériences de la peinture hellenistique, Collection de l'école française de Rome 244 (Actes... Rome 18.02.1994) (1998), 19 ff. Abb. 9-10 miteinander verglichen. P. Moreno betont jedoch die Unterschiede (drei Jäger in Vergina gegenüber zwei Jägern in Messene und einer Hervorhebung Alexanders) und hält an der Zuweisung an Philipp II. bzw. Krateros/Alexander III. fest. 
ordnen: Einerseits zwei Männer, die neben der Kausia nur die Chlamys und Stiefel tragen, jedoch kein Untergewand (Chiton) aufweisen und entsprechend zum Großteil nackt erscheinen. Sie stoßen mit ihren Lanzen auf einen Löwen ein bzw. werfen einen Speer auf einen Bären. Andererseits ein Netzträger, der neben einer Kausia, einem Chiton und Stiefeln statt der Chlamys einen Fellumhang trägt. Die Vertreter der ersten Gruppe sind als die eigentlichen Jäger dargestellt. Ihre Jagdobjekte sind zudem so herausragende Tiere wie der Bär und insbesondere der Löwe. Das Fehlen des Untergewandes muss nicht der realen Bekleidungssitte entsprechen, sondern kann mit in der griechischen Kunst wirkenden Darstellungskonventionen in Verbindung gebracht werden (einzelne Kleidungs- oder Bewaffnungselemente stehen stellvertretend für die gesamte Bekleidung oder Bewaffnung). Die (teils) unbekleidete Wiedergabe herausgehobener Personen kann zudem der Betonung körperlicher Vorzüge dienen. Die dritte Person wird durch das Netz als Helfer charakterisiert, der Fellumhang könnte den untergeordneten Status der betreffenden Person betonen.

Bei der Untersuchung der Kleidung der dargestellten Personen ist $\mathrm{zu}$ unterscheiden zwischen solchen, die in real während der Jagd getragener Tracht gezeigt werden, und solchen, bei denen die Bekleidung bzw. das Fehlen der Bekleidung der Verdeutlichung anderer Aspekte dient. Zur zuletzt genannten Gruppe zählen der potentielle Alexander mit dem Löwenfell sowie die ohne Untergewand und teils auch ohne Schuhwerk wiedergegebenen Jäger. Die Bekleidung dieser Personen dient der Kenntlichmachung der Person bzw. der Unterstreichung ihres heroischen Charakters. In realer Jagdbekleidung sind einerseits die Reiter dargestellt. Deren Tracht (Chiton, Krepides, Chlamys und teilweise Kausia) dürfte der realen Bekleidung der Jäger aus der Oberschicht entsprechen. Andererseits erscheint der Netzträger in einer Kleidung (Chiton, Krepides, Fellumhang, Kausia), die ebenfalls der realen Bekleidung entsprochen haben dürfte, jedoch nicht der der „heroischen“ Jäger (König und Gefolge), sondern derjenigen der Jagdhelfer, d.h. der nicht zur Oberschicht gehörenden Teilnehmer an der Jagd. Jäger mit Kausia treten in den - wenigen - überlieferten Darstellungen nur im Rahmen königlicher Jagdgesellschaften auf. Dies hat zu der Vermutung geführt, dass nur der König und eine

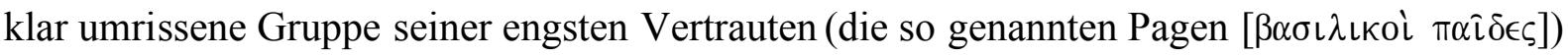
die Kausia tragen durften. ${ }^{254}$ Dies trifft jedoch nicht zu, wie sowohl der Netzträger auf dem Fries in Vergina als auch zahlreiche andere Darstellungen von Kausiaträgern aus dem unterschiedlichsten gesellschaftlichen Bereichen belegen. Das auf königliche Jagden beschränkte Auftreten von Jägern mit Kausia in der darstellenden Kunst ist vielmehr darauf zurückzuführen, dass in der antiken (Hoch-) Kunst wie auch in der Literatur - entsprechend dem Kreis der Auftraggeber bzw. der Zielgruppe - vorzugsweise herrschaftlichen Jagdgesellschaften dargestellt und beschrieben wurden..$^{255}$

In der Realität wird der Kreis der Träger der Kausia sowohl bei Jagden als auch bei anderen im Freien ablaufenden Tätigkeiten alle Teile der makedonischer Bevölkerung umfasst haben,

\footnotetext{
${ }^{254}$ Vgl. Saatsoglou-Paliadeli, Costume, 135 ff. 139 f. 142.

${ }^{255}$ Vgl. unten Kap. „Die Kausia: eine Kopfbedeckung ausschließlich der basilikoi; pai deß?“.
} 
wie dies der Netzträger mit Kausia andeutet und es weitere Bespiele aus anderen Bereichen zeigen werden.

\subsubsection{Militär}

Darstellungen der Kausia in einem militärischen Zusammenhang finden sich sowohl im Bereich Makedoniens ${ }^{256}$ und der ostmediterranen Nachfolgestaaten ${ }^{257}$ des Alexanderreiches als auch in den nördlich an Makedonien angrenzenden illyrisch-thrakischen Gebieten ${ }^{258}$.

Da nicht eindeutig geklärt ist, ob sich hinter der barettartigen Mütze der Illyrer und Thraker die makedonische Kausia oder eine regionale Variante verbirgt und diese Kopfbedeckung im illyrisch-thrakischen Raum vermutlich etwas anders genutzt wurde als in Makedonien und den Diadochenreichen, werden die entsprechenden Beispiele zunächst getrennt bearbeitet.

\subsubsection{Die Kausia als Kopfbedeckung makedonischer Soldaten}

Unter „makedonischen Soldaten“ verstehe ich in diesem Zusammenhang die Soldaten des Alexanderheeres und der Armeen der entsprechenden Nachfolgestaaten. ${ }^{259}$

„Makedonische Soldaten“ in diesem Sinne werden mit der Kausia als Kopfbedeckung auf folgenden Denkmälern dargestellt: in Malerei auf der Fassade des makedonischen Grabes bei Agios Athanasios, auf drei bemalten Grabstelen und auf einem ebenfalls gemalten Fries einer Grabfassade in Alexandria sowie auf zwei Darstellungen in Pompeji, die vermutlich auf ostmediterran-hellenistische Vorbilder zurückgehen (Wandmalerei mit Theaterszene, Alexandermosaik). Ein Fries aus Pergamon zeigt die Kausia zusammen mit anderen „Beutewaffen“.

\section{Agios Athanasios}

Auf der Fassade des noch nicht abschließend publizierten makedonischen Grabes bei Agios Athanasios (Ma 6, Taf. 10 Abb. 48-49) erscheinen Kausiaträger sowohl im Figurenfries über dem Eingang als auch in Form lebensgroßer Figuren links und rechts neben der Tür. Der Fries über dem Eingang zeigt in der Mitte eine Symposionsszene und zu beiden Seiten daran anschließend Personen, die zum Gelage ziehen. Unter diesen befinden sich mindestens fünf Männer, die Kausien tragen, welche relativ eng am Kopf anliegen. Die Männer sind zusätzlich mit Chiton, Chlamys und Krepides bekleidet. Speere und (in drei Fällen) Brustpanzer kennzeichnen sie als Krieger. Auch die neben ihnen stehenden Personen sind durch Helme, Speere und makedonische Schilde als Krieger gekennzeichnet. ${ }^{260}$

\footnotetext{
${ }^{256}$ Ma 6 (Grab bei Ag. Athanasios).

${ }^{257}$ Ma 1-3 (Grabstelen Alexandria), Ma 4 (Architrav in alexandrinischer Nekropole). Ma 12 (Pompeii, Theaterszene) geht vermutlich auf ein ostmediterranes (ptolemäisches?) Vorbild zurück (Vgl. die dickbäuchigen Theater-Soldaten-Terrakotten aus Ägypten.). Mo 1 (Alexandermosaik Pompeii) stammt je nach Deutung (s.u.) entweder aus Makedonien oder geht auf ein ptolemäisches oder ostmediterranes Original zurück.

${ }^{258} \mathrm{Nu}$ 1-3 (Münzen des paionischen Königs Patraos), Ma 7 (Grab von Kasanlak).

${ }^{259}$ Vgl. hierzu das Kapitel „Die ,Makedones“ - eine ,ethnische“ Gruppe?““

${ }^{260}$ Vgl. M. Tsimbidou-Avloniti, AErgMak 10A, 1996, 427-442 Abb. 5 und jetzt dies., Revealing a painted Macedonian tomb near Thessaloniki, in: A. Pontrandolfo (Hrsg.), La pittura parietale in Macedonia e Magna Grecia,
} 
Die großen Figuren links und rechts der Tür des Grabes sind bekleidet mit Chlamys, Chiton und Krepides sowie weit ausladenden flachen weißen Kausien. Bewaffnet sind sie mit langen Lanzen. Über ihren Köpfen hängen Rundschilde.

Das Grab wird von seiner Ausgräberin in die letzten Jahrzehnte des 4. Jahrhunderts v.Chr. datiert.

Die zum Symposion ziehenden Krieger auf dem Fries sind - soweit die wenigen publizierten Abbildungen Aussagen hierzu zulassen - jeweils unterschiedlich gekleidet und bewaffnet. Diese Variationsbreite wird u.a. durch eine unvollständige Wiedergabe der Bewaffnung erzielt: So wird ein Krieger mit Helm, Schild und Speer gezeigt, ein anderer nur mit Schild und Speer. Die Kausiaträger sind teils mit Speer und Brustpanzer bewaffnet, teils nur mit einem Speer. Sämtliche Speere (oder Lanzen?) sind nur etwa mannshoch, es handelt sich demnach formal nicht um die überlangen typisch-makedonischen Sarissen. Die Länge bzw. Kürze kann jedoch in der geringen Höhe des Frieses bedingt sein.

Die großen Figuren rechts und links neben dem Eingang zum Grab, die wie Wachsoldaten wirken, stützen sich auf Lanzen, deren Länge im Verhältnis zu den Körpern der Männer etwa 3,5 m betragen dürfte. Auch ihre Länge wird durch den auf der Fassade vorhandenen Platz beschränkt. Zumindest in diesen Lanzen dürfen die langen makedonischen Sarissen ${ }^{261}$ erkannt werden. Die über den Köpfen der Soldaten hängenden Rundschilde vervollständigen deren Bewaffnung. In diesem Fall werden demnach Kausia und Chlamys mit Sarisse und (makedonischem) Schild kombiniert. Da die beiden „Wachsoldaten“ gleich gekleidet und bewaffnet sind, eine unterschiedlich vollständige Ausrüstung also nicht der Variation dient, ist es wahrscheinlich, dass die Bekleidung und die Bewaffnung dieser Soldaten vollständig und der Realität entsprechend zusammengestellt sind.

\section{Grabstelen Alexandria}

Die Grabstelen geben jeweils einen Soldaten in Begleitung eines Dieners wieder: Grabstele Ma 1 (Taf. 13 Abb. 53) zeigt einen stehenden Mann in Chlamys, Chiton, Krepides und Kausia. Daneben steht ein kleinerer Diener, der die Speere trägt. Auf der Stele des Nikanor (Ma 2, Taf. 11 Abb. 50) ist ein Reiter in Chlamys, Brustpanzer und Kausia auf seinem Pferd zu sehen. Am Schwanz des Tieres hält sich ein Diener fest, der wiederum die Waffen trägt. Die Stele Ma 3 (Taf. 11 Abb. 51) zeigt ebenfalls einen Reiter auf einem sich aufbäumenden Pferd. Er ist ebenfalls mit Chlamys, Panzer und Kausia gekleidet und hält den Speer schon in der rechten Hand, während er mit der linken Hand einen Helm entgegennimmt, den ihm ein Diener reicht.

Atti del Convegno Internazionale di Studi in ricordo di Mario Napoli, Salerno-Paestum 1996 (2002) 37-42 mit Taf. 6-7. Auch dort ist der Fries jedoch nur in Ausschnitten wiedergegeben.

${ }^{261}$ Vgl. RE 2. Reihe I,2 (1920) 2515 ff. s.v. Sarisse (Lammert). 
Die Stele des Nikanor (Ma 2) nennt nicht nur den Namen des Toten, sondern bezeichnet diesen auch ausdrücklich als „Makedonen“6262. Für die beiden anderen Männer ist aufgrund der Bekleidung gleiches anzunehmen.

Entstanden sind die drei Grabstelen in frühptolemäischer Zeit (Ende 4. bis Mitte 3. Jahrhundert v.Chr.).

Den Darstellungen ist zu entnehmen, dass die Kausia sowohl zur Ausrüstung von Fußsoldaten (Ma 1) als auch von Kavalleristen (Ma 2-3) gehörte. Sie wird bei dem Infanteristen kombiniert mit Chlamys und Speeren, die Reiter tragen zusätzlich einen Panzer. Neben der Wiedergabe mit Kausia belegt die Inschrift auf der Stele des Nikanor, die diesen als Makedonen bezeichnet, dass es sich um „makedonische“ Soldaten des ptolemäischen Heeres handelt. Die „Makedonen“ stellten den Kern des Heeres, insbesondere auch die im Ansehen über der Infanterie eingestufte Reiterei. Der Status der Soldaten wird überdies durch den sowohl dem Fußsoldaten als auch den Reitern beigegeben Diener, der die Waffen zu tragen hatte, verdeutlicht.

Die Grabstelen geben einen Hinweis auf die Art der Verwendung der Kausia innerhalb des militärischen Alltags. Der kausiatragende Reiter auf der Stele Ma 3, der den Speer schon in der Hand hält, lässt sich von seinem Diener einen Helm reichen. Die Kausia, die als weiche Mütze aus Stoff oder Leder keinerlei Schutz gegen Verwundungen bot, wurde offenbar nur vor dem eigentlichen Kampf (z.B. auf dem Marsch) getragen und rechtzeitig vor der Schlacht gegen einen Helm ausgetauscht. Dass neben der Kausia ein Metallhelm zur Standardausrüstung eines makedonischen Soldaten gehörte, legt auch der gehobene Status der „Makedonen“ nahe, der einer zu leichten „Bewaffnung“ widerspricht. ${ }^{263}$

\section{Reitersoldaten aus der Mustapha-Pascha-Nekropole}

Eine Malerei (Ma 4 , Taf. 12 Abb. 52) auf einem Architrav vor dem Hauptgrab im Peristyl des Grabes Nr. 1 der Mustafa-Pascha-Nekropole in Alexandria zeigt drei Reiter auf sich aufbäumenden Pferden, die sich auf den Betrachter zuzubewegen scheinen. Rechts und links des mittleren Reiters befinden sich stehende weibliche Gestalten, zwischen dem mittleren Reiter und der rechten Frau zusätzlich ein Altar. Alle drei Reiter halten - wie auch die beiden Frauen - Phialen in Händen, es handelt sich demnach um eine Opferszene. Der rechte Reiter trägt einen Helm, ist also als Soldat charakterisiert. ${ }^{264}$ Der mittlere und der linke Reiter tragen flache Kopfbedeckungen, die des Mittleren ist etwas ausladender. Wie diese zu deuten sind, ist umstritten. ${ }^{265}$ Sollte es sich bei einer dieser Kopfbedeckungen um eine Kausia handeln, dann am ehesten bei der des linken Reiters. Da Einzelheiten (z.B. Sturmbänder, die für einen Peta-

\footnotetext{
${ }^{262}$ Die verstümmelte Inschrift lautet: NIKAN $\Omega$ P MAKE[...]IO[.].

${ }^{263}$ Die Zuordnung bestimmter Bewaffnungsarten zu einzelnen Teilen des makedonischen Heeres (z.B. den Hypaspisten) ist umstritten. Vgl. die Diskussion bei Dintsis, Helme, 192 ff. mit Anm. 68 ff. (dort weitere Literatur).

${ }^{264}$ Alle Reiter sollen Brustpanzer tragen (B. R. Brown, Ptolemaic Paintings and Mosaics and The Alexandrian Style [1957] 52 f. .- Dintsis, Helme, 307 f. Nr. 289), diese sind jedoch ähnlich wie die Kopfbedeckungen nur schwer zu erkennen.
} 
sos sprechen würden) jedoch nicht zu erkennen sind, lässt sich dies nicht verbindlich entscheiden.

Da der rechte Reiter einen Helm trägt und vermutlich alle drei mit einem Brustpanzer ausgerüstet sind, ist auch die potentielle Kausia in einem militärischen Kontext zu sehen. Die Bewaffnung ist wiederum unvollständig wiedergegeben, es fehlen sowohl ein Schild als auch sämtliche Angriffswaffen (z.B. Speer/Lanze, Schwert). Dargestellt sind zudem möglicherweise nicht lebende Menschen, sondern diejenigen, denen die beiden Frauen opfern (Verstorbene, Heroen oder Götter ${ }^{266}$ ).

\section{Soldat Pompeii (Theaterszene)}

Aus der Casa della Fontana grande in Pompeii ist eine heute verlorene Wandmalerei (Ma 12, Taf. 13 Abb. 54) bekannt, die in drei Zeichnungen überliefert ist. Dargestellt ist jeweils ein Mann mit Kausia, Chlamys und Chiton, der sich mit der rechten Hand auf eine Lanze stützt, eine Theatermaske trägt und von weiteren Schauspielern und sonstigem Bühnenpersonal umgeben ist. ${ }^{267}$ Es handelt sich also um einen Schauspieler in der Rolle eines Soldaten. ${ }^{268} \mathrm{Zu}$ denken ist hier an eine Figur ähnlich der des Polemon aus Menanders Perikeiromene oder des Pyrgopolynikes aus dem Miles gloriosus des Plautus.

Dass der Soldat mit Kausia dargestellt wurde, kann zwei Gründe haben. Einerseits ist es möglich, dass dieser spezielle Soldat als von makedonischer Abkunft gekennzeichnet werden sollte. Andererseits gehörte die Kausia wahrscheinlich neben anderen Kopfbedeckungen zur Standardausrüstung hellenistischer Soldaten in den Diadochenreichen, auch wenn diese nicht aus Makedonien stammten. Es könnte demnach - insbesondere in einem westmediterranen Zusammenhang - auch allgemein auf einen Soldaten ostmediterraner Herkunft verwiesen werden.

\section{Alexandermosaik Pompeii}

Das Alexandermosaik (Mo 1, Taf. 14 Abb. 55) aus der Casa del Fauno in Pompeii gibt eine Schlacht zwischen Alexander dem Großen und dem Perserkönig Dareios und den jeweiligen Heeren wieder. Links neben dem Unterarm des reitenden Makedonenkönigs erscheint der Kopf einer laufenden, männlichen Person. Die Darstellung ist an dieser Stelle stark beschä-

\footnotetext{
${ }^{265}$ B. R. Brown, Ptolemaic Paintings and Mosaics and The Alexandrian Style (1957) 52 f. äußert sich nur zur Kopfbedeckung des linken Reiters und bezeichnet diese als Petasos. Dintsis, Helme, 307 Nr. 289 sieht in den Mützen des mittleren und des linken Reiters Kausien. Saatsoglou-Paliadeli, Costume, 130 hält die Kopfbedeckungen beider Reiter (wie auch die auf den oben genannten Grabstelen) für Petasoi. N. Secunda, Seleucid and Ptolemaic Reformed Armies 168-145 B.C. II. The Ptolemaic Army (1995) Abb. 108 f. rekonstruiert den mittleren Reiter mit Petasos und den linken mit Kausia.

${ }^{266} \mathrm{Zu}$ opfernden Göttern vgl. N. Himmelmann, Spendende Götter, in: Minima archaeologia (1996) 54-61.

${ }^{267}$ Die gesamte Szene ist abgebildet in A. Mau, Pompeji (1908) 584 Abb. 307, die drei überlieferten Zeichnungen des Soldaten in C. Robert, Die Masken der neueren attischen Komoedie, 25. HallWPr (1911) 5 Abb. 7-9.

${ }^{268}$ Vgl. J. Overbeck, A. Mau, Pompeji (1884) 584 .- Weber, Berlin, 202 Anm. 3 .- C. Robert, Die Masken der neueren attischen Komoedie, 25. HallWPr (1911) 5 .- M. Bieber, AJA 60, 1956, 171 f. .- M. Bieber, History of Greek and Roman Theater (1961) (1. Aufl. 1939) 99.
} 
digt. Erkennbar sind Teile des Gesichtes im Profil, der Ansatz einer Chlamys und das vordere Stück einer purpurnen Kopfbedeckung. Bei dieser könnte es sich um eine Kausia handeln. Die wiedergegebene Person wird u.a. als Alexanders General Ptolemaios ${ }^{269}$, der später Herrscher über Ägypten wurde, und als Seleukos I. Nikator ${ }^{270}$ gedeutet.

Das Mosaik ist wiederum keine pompejanische Neuschöpfung, sondern eine vermutlich leicht gestauchte, beschnittene und vereinfachte Kopie nach einem hellenistischen Vorbild. Bei dieser Vorlage handelt es sich wahrscheinlich um ein Tafelbild ${ }^{271}$ ostmediterraner Herkunft. Die Herkunft und Datierung des Originals sind umstritten. Es wurde entweder um 316 v.Chr. von Philoxenos aus Eretria im Auftrag Kassanders geschaffen ${ }^{272}$ oder geht auf ein ptolemäisches Urbild $^{273}$ zurück, das sich unter anderem aufgrund antiquarischer Details ins späte 3. bis frühe 2. Jahrhundert datieren lassen soll. ${ }^{274}$ Neuerdings schlägt B.Andrae als Entstehungsort Antiochia am Orontes und als Künstler Eutychides (von Sikyon?)vor, der das Werk kurz nach der Schlacht bei Ipsos (301) geschaffen hätte. ${ }^{275}$

Eine detaillierte Deutung des Mannes mit Kausia (wie auch der Gesamtkonzeption) ist aufgrund des fragmentierten Zustandes, der nur indirekten Überlieferung durch Kopien, der ungesicherten Herkunft der Originalvorlage und entsprechend auch des historischen Zusammenhanges nicht möglich. Es bleibt vorerst nur die Feststellung, dass die Kausia auf einen Makedonen hinweist und die Darstellung einer Alexanderschlacht in allen in der Alexandernachfolge stehenden Reichen, d.h. in allen Diadochenreichen, möglich war.

Trifft Andreaes Deutung zu, der im Profil des Fußsoldaten mit Kausia das Porträt des Seukos Nikator erkennt, diesen als Hauptperson des Mosaiks bzw. der Vorlage in Malerei bezeichnet und ihn entsprechend als der Auftraggeber ansieht, so könnte der Anlass der Entstehung der Sieg in der Schlacht bei Ipsos 301 gewesen sein. Da Seleukos in der antiken Literatur (Appian, Arrian) als Fußsoldat (Stratiotes) bzw.Kommandeur der königlichen Fußgarde (Hyaspisten) beschrieben wird, hätte er sich deshalb auf dem Alexanderschlachtgemälde nicht zu Pferd, sondern als Pezhetairos darstellen lassen. ${ }^{276}$

\footnotetext{
${ }^{269}$ Vgl. die Diskussion bei M. Pfrommer, Untersuchungen zur Chronologie und Komposition des Alexandermosaiks auf antiquarischer Grundlage (1998) 101 ff., der offen lässt, ob es sich um eine Kausia oder ein breites spätptolemäisches Diadem handelt, das den Dargestellten als Ptolemaios I. als König und den Auftraggeber als einen seiner Nachfolger kennzeichnen würde.

${ }^{270}$ B.Andreae, Seleukos Nikator als Pezhétairos im Alexandermosaik, RM 111, 2004, 69-82 .- ders., Antike Bildmosaiken (2003) 14-17, 62-77, 114-115.

${ }^{271}$ Vgl. T. Hölscher, Griechische Historienbilder des 5. und 4. Jahrhunderts v.Chr. (1973) 158 ff. .- M. Pfrommer, Untersuchungen zur Chronologie und Komposition des Alexandermosaiks auf antiquarischer Grundlage (1998) 159 f. 219. -- M. Donderer, Das pompejanische Alexandermosaik - Ein östliches Importstück, in: Das antike Rom und der Osten (FS Parlasca) (1990) 19 ff. geht im Gegensatz hierzu von der Verlegung eines aus einem ostmediterranen Palast erbeuteten Mosaiks der 1. Hälfte des 2. Jahrhunderts in Pompeii aus.

${ }^{272}$ T. Hölscher, Griechische Historienbilder des 5. und 4. Jahrhunderts v.Chr. (1973) 159-162.

${ }^{273}$ Vgl. M. Pfrommer, Untersuchungen zur Chronologie und Komposition des Alexandermosaiks auf antiquarischer Grundlage (1998) 218.

${ }^{274}$ Vgl. M. Pfrommer, Untersuchungen zur Chronologie und Komposition des Alexandermosaiks auf antiquarischer Grundlage (1998) 216.

${ }^{275}$ B.Andreae, Seleukos Nikator als Pezhétairos im Alexandermosaik, RM 111, 2004, 69-82.

${ }^{276}$ B.Andreae, Seleukos Nikator als Pezhétairos im Alexandermosaik, RM 111, 2004, 69-82.
} 
Nur in dieser Darstellung wird die Kausia als eine in der Schlacht selbst getragene Kopfbedeckung gezeigt. Dieses muss nicht der Realität entsprechen. Denn Alexander, die Hauptperson des Mosaiks, wird in ebenfalls unrealistischer Weise ohne Helm wiedergegeben. Zurückzuführen ist dies auf ein bestimmtes Herrscherideal und damit zusammenhängende Darstellungskonventionen. Entsprechend könnte auch der Mann mit Kausia z.B. als potentieller Auftraggeber ohne Helm, aber mit Kausia dargestellt worden sein, um ihn in einer bestimmten Weise zu kennzeichnen.

\section{Waffenfries aus Pergamon}

Der Fries (Re 1, Taf. 14 Abb. 56) von der Balustrade der Nordhalle des Athenaheiligtums auf dem Burgberg von Pergamon zeigt neben verschiedenen anderen militärischen Ausrüstungsgegenständen (u.a. Brustpanzer, Beinschienen, Schilde [rund und oval], Schwert in Scheide, Lanzen) auch eine Kausia. Es handelt sich um erbeutete Gegenstände, die mit verschiedenen Gegnern (u.a. den Galliern) in Verbindung zu bringen sind. ${ }^{277}$ Die Nordhalle stammt aus der Zeit Eumenes II. (197-159 v.Chr.).

Das Relief zeigt die Kausia in einem militärischen Kontext, ohne dass eine Zuordnung zu einem bestimmten Heer oder zu einer bestimmten Gesamtbekleidung oder -bewaffnung möglich wäre.

\section{Zusammenfassung}

In Makedonien und den Diadochenreichen findet die Kausia demnach zwar im militärischen Bereich Verwendung: Sie gehörte zur Ausrüstung sowohl von Infanteristen ${ }^{278}$ als auch von Kavalleristen $^{279}$. Es ist jedoch keine realistische Darstellung überliefert, in der ein Soldat die Kausia in der Schlacht trägt. Stattdessen erscheinen Personen auf dem Marsch bzw. dem Weg zum Gelage oder in „Ruhestellung“. Die Kausia gehörte daher im Falle der makedonischen Soldaten nicht zur eigentlichen Kampfbekleidung, sondern wurde von diesen auf dem Marsch, außerhalb des „Dienstes“ oder während der Wache getragen. Waren Kampfhandlungen zu erwarten, die einen Kopfschutz sinnvoll machten, wurde die Stoffmütze gegen einen Metallhelm ausgetauscht, wie dies auf einer Grabstele aus Alexandria (Ma 3) gezeigt wird.

Neben den hier besprochenen Darstellungen makedonischer Soldaten existiert eine Reihe von kleinformatigen Statuetten aus Ton bzw. Stein (Tk 3-8, 54-57, 99-100, 109-112, 113, 125-126, 165, 361, P 2; vgl. Taf. 28-29 Abb. 102-110), die ebenfalls Angehörige makedonischer bzw. hellenistischer Heere mit Kausia zeigen. Ich werde auf diese im Rahmen der Bearbeitung der Weihungen und Grabbeigaben näher eingehen. Es handelt sich um Darstellungen bestimmter

\footnotetext{
${ }^{277}$ Vgl. Dintsis, Helme, 191 f. (mit Anm. 65). 195 .- W. Radt, Pergamon (1988) 180 ff.

${ }^{278}$ Infanteristen (bzw. stehende Soldaten) zeigen: Ma 1 (Grabstele Alexandria), Ma 6 (makedonisches Grab bei Ag. Athanasios), Ma 12 (Theaterszene aus Pompeii), Mo 1 (Alexandermosaik, Pompeii).

${ }^{279}$ Kavalleristen zeigen: Ma 2-3 (Grabstelen in Alexandria), Ma 4 (Grabfassade Alexandria).
} 
Charaktere des Theaterbetriebes. Auch sie stellen den Soldaten nicht in der Schlacht, sondern im Privatleben dar.

\subsubsection{Thrakisch-illyrische Krieger mit Kausia}

Im illyrisch-thrakischen Raum werden Personen mit einer Kopfbedeckung, bei der es sich entweder um die makedonische Kausia oder um eine im Aussehen identische regionale Mütze handelt, im militärischen Zusammenhang auf paionischen Münzen sowie in Malerei im Grabmal von Kasanlak dargestellt.

\section{„Soldat" auf paionischer Münze}

Zwischen 331 und 315 v. Chr. geprägte Tetradrachmen(Nu 1-3, Taf. 15 Abb. 57-59) des paionischen Königs Patraos, dessen Reich nördlich an Makedonien grenzte, zeigen auf der Rückseite einen Reiter mit Helm, Panzer und Lanze, der einen Fußsoldaten, bewaffnet mit Speer und makedonischem Schild und bekleidet mit Kausia, Chiton und (meistens) Hosen, niederreitet sowie die Legende ПАТРАOY. Auf den Vorderseiten sind männliche Bildnisse im Profil nach rechts zu sehen, die unterschiedliche Attribute aufweisen: Es erscheinen bartlose ${ }^{280}$ Porträts ohne Attribut ( $\mathrm{Nu}$ 1), mit Binde ( $\mathrm{Nu}$ 2) sowie Bildnisse mit Lorbeerkranz ( $\mathrm{Nu} 3$ ).

Die Szene auf der Rückseite wurde bisher als verkürzte Wiedergabe einer historischen Schlacht gedeutet: Der siegreiche Reiter ${ }^{281}$ ist jeweils der Paione, in dem unterlegenen Infanteristen wurde früher ein Perser ${ }^{282}$ in Hosen und mit orientalischer Kopfbedeckung gesehen. In

\footnotetext{
${ }^{280}$ Diejenigen Bildnisse, die bisher als Porträts des Patraos gedeutet wurden (Nu 1-2), weisen eine im Bereich der Mundwinkel auffällig nach unten gezogene „Oberlippe“ auf, die an einen Schnurrbart erinnert.

${ }^{281}$ Die Tracht und Körperhaltung des Reiters können wie die des Infanteristen auf den unterschiedlichen Prägungen leicht variieren. Der Brustpanzer kann relativ stark gewölbt sein (z.B. H. Gaebler, Die antiken Münzen von Makedonia und Paionia [Die antiken Münzen Nord-Griechenlands III 2] [1935] Taf. XXXVII, 15 f.), vereinzelt verläuft eine Linie diagonal von der linken Schulter zur rechten Hüfte (H. Gaebler a.a.O. Taf. XXXVII, 17). Dies könnte auf einen (weiblichen) Busen unter dem Panzer bzw. eine die rechte Brust freilassende Exomis hindeuten. Die reitende Person wäre dann als Amazone anzusprechen. Hiergegen spricht, dass sich auf einigen Prägungen weibliche Merkmale eindeutig nicht finden (so auf der in 4,5-facher Vergrößerung bei Chr. Le Roy, Un règlement religieux au Létôon du Xanthos, RA, 1986, 279 ff. Abb. 8 abgebildeten Münze in Paris, Bibliothèque nationale, Cabinet des Médailles). Auch ist die isolierte Darstellung einer einen Infanteristen niederreitenden Amazone unüblich (Vgl. LIMC I,2 [1981] 440 ff. s.v. Amazones.) und ist ein Amazonen-Kult zumindest in römischer Zeit im makedonisch-paionischen Raum nicht mehr nachweisbar (Vgl. S. Düll, Die Götterkulte Nordmakedoniens [1977].). Im Gegenzug kann der betonte Brustpanzer damit erklärt werden, dass der Oberkörper des Reiters nicht wie sonst üblich von der Seite, sondern in 3/4-Ansicht wiedergegeben wird. Bei der nur in einem Fall auftretenden diagonalen Linie kann es sich auch um eine Beschädigung des Stempels oder der Münze handelt. Selbst wenn es sich um eine Exomis handeln sollte, ist diese nicht auf Amazonen beschränkt, sondern wird z.B. auch von einem reitenden Dionysos auf einer (kaiserzeitlichen) Stele aus der Region getragen (S. Düll, Die Götterkulte Nordmakedoniens [1977] 322 Nr. 98 Abb. 34) sowie von einigen Kriegern auf dem Fries von Kasanlak (vgl. Literatur zu Ma 7). - Vgl. auch A. Pekridou-Gorecki, Mode im antiken Griechenland (1989) 87 mit Abb. 60, die die Exomis (und den Heteromaschalos) als Bekleidung von Männern anspricht.

${ }^{282}$ So H. Gaebler, Die antiken Münzen von Makedonia und Paionia (Die antiken Münzen Nord-Griechenlands III 2) (1935) 201 f. Nr. 2 ff.
} 
der neueren Forschung wird dieser als Makedone ${ }^{283}$ mit Kausia und makedonischem Rundschild angesprochen.

Von den Bildnissen auf den Vorderseiten wurde dasjenige mit dem Lorbeerkranz $(\mathrm{Nu} 3)$ als Kopf des Gottes Apollon gedeutet, diejenigen ohne Attribut bzw. mit Binde dagegen als Porträts des paionischen Königs Patraos ${ }^{284}$.

Sowohl die Deutung der Rückseite als Wiedergabe eines historischen Ereignisses, als auch die der Vorderseite als Königsporträt ist abzulehnen.

Die Deutung als Porträt des Patraos beruht auf der Identifizierung der Binde mit dem Dia$\mathrm{dem}^{285}$. Ein Diadem ist jedoch ein am Hinterkopf verknotetes, flaches Stoffband, dessen Enden in den Nacken herabhängen. ${ }^{286}$ Dies trifft auf die Binde des angeblichen Patraos eindeutig nicht zu. Es handelt sich eher um eine Wulstbinde (Strophion), wie sie auch von Denkern, Athleten, Heroen und Gottheiten getragen wird. Gegen eine Deutung als Patraos-Porträt spricht auch, dass es unwahrscheinlich ist, dass ein sonst weitgehend unbekannter Kleinkönig noch vor den Diadochenkönigen das Diadem Alexanders anlegte und Münzen mit dem eigenen Bild prägte. ${ }^{287}$ Wesentlich wahrscheinlicher ist es, dass das Bildnis - wie dies auf fast allen gleichzeitigen und früheren Münzen der Fall ist - einen Gott, vielleicht eine regionale, dem Apollon vergleichbare Gottheit, zeigt.

Die Kampfszene auf der Rückseite ist nicht als Reflex einer historischen Schlacht zu lesen. Denn einige Münzen, die auf der Vorderseite den Apollonkopf (mit Lorbeer) aufweisen, zeigen auf der Rückseite nur eine Pferdeprotome (Taf. 15 Abb. 60). ${ }^{288}$ Diese kann als Symbol für einen (Reiter-) Heros gedeutet werden, und in dieses Schema passt sich auch die Reiterkampfszene ein.

Dargestellt ist demnach auf der Vorderseite der Kopf eines Gottes, auf der Rückseite ein Reiterheros, der einen Gegner niederreitet.

Die Kleidung und Bewaffnung sowohl des Reiters als auch des Infanteristen werden auf den einzelnen Prägungen weitgehend einheitlich wiedergegeben. Der Reiter ist mit einem Helm, einem Panzer mit lamellenartigem Schurz (pteryges), einer Lanze und, soweit erkennbar, langen Hosen dargestellt. Der Fußsoldat trägt die Kausia, einen gegürteten knielangen Chiton

\footnotetext{
${ }^{283}$ Vgl. Dintsis, Helme, 190 (mit Anm. 57) .- K. Liampi, Der makedonische Schild (1998) 136 (mit Anm. 378).

${ }^{284}$ Vgl. H. Gaebler, Die antiken Münzen von Makedonia und Paionia (Die antiken Münzen Nord-Griechenlands III 2) (1935) 201 f. Nr. 2 ff. .- K. Liampi, Der makedonische Schild (1998) 134.

${ }^{285}$ Als „Diadem“ wird die Binde zuletzt bezeichnet bei K. Liampi, Der makedonische Schild (1998) $134 \mathrm{f}$.

${ }^{286}$ Vgl. z.B. H. Kyrieleis, Bildnisse der Ptolemäer (1975) Taf. 1, 2. Taf. 8, 1-3 u.ö. .- M. Bergmann, Die Strahlen der Herrscher (1998) 115.

${ }^{287}$ Antigonos Monophthalmos nahm 306 v.Chr. den Königstitel an und legte sich in der Nachfolge Alexanders das Diadem um. Die anderen Diadochen folgten in den darauf folgenden Jahren (H.-J. Gehrke, Geschichte des Hellenismus $^{2}$ [1995] 38). 305/4 v.Chr. begann Ptolemaios I. als erster König Münzen mit dem eigenen Porträt zu prägen (Vgl. H. Kyrieleis, Bildnisse der Ptolemäer [1975] 4 Taf. 1,2.). Der paionische Regionalkönig Patraos lebte zu diesem Zeitpunkt schon seit rund zehn Jahren nicht mehr. - Vgl. hierzu auch die Bemerkungen H.-W. Ritters zu den angeblich auf vorhellenistischen Münzen gezeigten Bildnissen von Königen mit Diadem (H.-W. Ritter, Diadem und Königsherrschaft [1965] 39 f.).

${ }^{288}$ Vgl. Gaebler a.a.O. 201 Nr. 1 Taf. XXXVII, 19.
} 
und in der Regel eine lange Hose. Bewaffnet ist er mit einem Speer und einem in makedonischer Art verzierten Rundschild. Das Fehlen oft angewandter Stilmittel (Variation durch wechselnde Teilbewaffnung, Verdeutlichung bestimmter Qualitäten durch Darstellung in „heroische Nacktheit" u.ä.) und die in sich sinnvolle Kombinationen aus Schutz- und Angriffsbewaffnung (Helm, Panzer, Lanze bzw. Schild und Speer) deuten auf eine vollständige und der Realität entsprechende Bekleidung und Bewaffnung beider Gegner hin. Die Darstellung sowohl des Kavalleristen als auch des Fußkämpfers in langen Hosen sprechen für die Wiedergabe einer regionalen (paionischen) Art der Bekleidung, da Hosen im griechisch-makedonischen Raum unüblich waren.

In Kausia, Chiton und (teils) Hosen sowie Rundschild und Speer sind daher die übliche Bekleidung und Bewaffnung eines leichtbewaffneten paionischen Fußsoldaten zu erkennen. Dass dieser auch die Kausia und den makedonischen Rundschild benutzte, muss nicht überraschen, da das direkt an Makedonien grenzende Paionien seit Philipp II. von diesem abhängig war und in hellenistischer Zeit weitgehend in Makedonien aufging und es sich bei der betreffenden Tracht (und Bewaffnung) - wie anfangs schon erwähnt wurde - vermutlich um eine im gesamten illyrisch-thrakisch-makedonischen Raum verbreitete Bekleidung handelt.

\section{Thrakischer Krieger (Kasanlak)}

Im Vorraum (Dromos) des Grabes von Kasanlak (Ma 7, Taf. 15 Abb. 61) befinden sich auf den beiden Längsseiten gemalte Friese, die je zwei aufeinander zulaufende Gruppen von Kriegern, die sich in der Mitte treffen, zeigen. Diese Gruppen bestehen aus Reitern (mit Chlamys, Helm, Panzer und Speer) und Fußsoldaten. Die Infanteristen sind durchweg ohne Panzer dargestellt und mit Exomis oder kurzem Chiton nur leicht bekleidet. Sie tragen teilweise Kopfbedeckungen (meist Helme), teils sind sie barhäuptig wiedergegeben. Bewaffnet sind sie in der Regel mit einem Krummsäbel, einem ovalen Schild und mehreren kurzen Speeren. Das Fehlen von Brustpanzern und teils auch Helmen kennzeichnet sie als Leichtbewaffnete. Diese Form der Bewaffnung wird in der antiken Literatur als typisch thrakisch beschrieben. ${ }^{289}$

Auf dem Ostfries befindet sich unter den beiden im Zentrum aufeinander treffenden Fußsoldaten einer, der eine Kausia und eine Chlamys trägt. Bewaffnet ist er wie die meisten anderen Fußkämpfer auch mit Krummsäbel, ovalem Schild und zwei Speeren.

Das Grab von Kasanlak ist mit der etwa $5 \mathrm{~km}$ entfernt gelegenen thrakisch-odrysischen Königsstadt Seuthopolis ${ }^{290}$ in Verbindung zu bringen. Thrakien war seit 342 v.Chr. von Makedonien abhängig gewesen. Zur Zeit der Gründung von Seuthopolis und der Anlage des Grabes (spätes 4. - frühes 3. Jahrhundert v.Chr.) waren die Odrysen schon nicht mehr makedonisch

\footnotetext{
${ }^{289}$ Vgl. RE XIX (1938) 403-406 s.v. Peltastai (F. Lammert) mit Literatur (Thukydides, Xenophon u.a.). - Die Details der thrakischen Tracht und Bewaffnung sind meines Wissens nicht ausreichend erforscht (so die mögliche Identität des genannten „Krummsäbels“ mit der Kopis und die Verbreitung dieser Waffe[n]).

${ }^{290} \mathrm{Zu}$ Seuthopolis vgl. R. F. Hoddinott, Bulgaria in Antiquity (1975) 92 ff.
} 
beherrscht, sondern führten Krieg gegen Lysimachos, der Thrakien seit Alexanders Tod, den die Odrysen als Anlass zum Abfall nahmen, verwaltete.

\section{Zusammenfassung}

Auf den paionischen Münzen und in Kasanlak wird die Kausia jeweils als Kopfbedeckung leichtbewaffneter und leicht bekleideter Personen gezeigt. Diese tragen die Kausia im Gegensatz zu den Makedonen in der eigentlichen „Schlacht“.

\subsubsection{Unterschiedliche Nutzung der Kausia im militärischen Bereich}

Sowohl in Makedonien (und den Diadochenreichen) als auch in den nördlich angrenzenden Gebieten Illyriens und Thrakiens ist die Kausia als Kopfbedeckung bewaffneter Personen bekannt. $\mathrm{Ob}$ es sich in beiden Fällen um die makedonische Kausia handelt, die von Thrakern und Illyrern von den Makedonen übernommen wurde, oder auch bei den Thrakern und Illyrern seit langem eine im Aussehen der Kausia entsprechende Mütze verbreitet war bzw. die Kausia letztlich keine speziell makedonische Kopfbedeckung ist, sondern eine bei verschiedenen Völkern der Region übliche, kann aufgrund der eingeschränkten Informationen zur typischen Kleidung der betreffenden Völker derzeit nicht beantwortet werden. Eine Bemerkung bei Strabon, der berichtet, dass sich Makedonen, Epiroten und Illyrer anhand der Kleidung die Kopfbedeckungen erwähnt er jedoch nicht ausdrücklich - nicht unterscheiden ließen, spricht für große Ähnlichkeiten in der Tracht. ${ }^{291}$

Während demnach sowohl Makedonen als auch Thraker und Illyrer die Kausia oder eine im Aussehen identische Kopfbedeckung trugen, gibt es einen Unterschied in der Nutzung, der wahrscheinlich in der Art der Kriegführung bzw. der Art der üblicherweise aufgestellten Truppen begründet liegt. Den Kern des makedonischen Heeres bildete die Phalanx. Diese unterschied sich in Details von der klassischen griechischen Phalanx (Durchmesser des Schildes, Länge der Lanze), grundsätzlich ist jedoch auch der makedonische Phalangit ein gepanzerter Hoplit, dessen Ausrüstung auch einen Helm umfasste. Dagegen stellten die Angehörigen der nördlich angrenzenden Völker (insbesondere die Thraker) seit mindestens dem 5. Jahrhundert v.Chr. traditionell die leichtbewaffneten Kämpfer (Peltastes, Akontistai). Diese waren nur mit (meist mehreren) Speeren und einem leichten Schild bewaffnet und trugen in der Regel weder Panzer noch Helm.

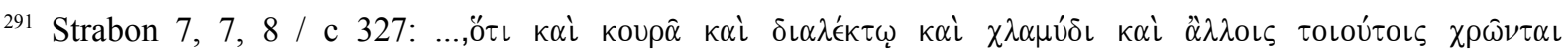

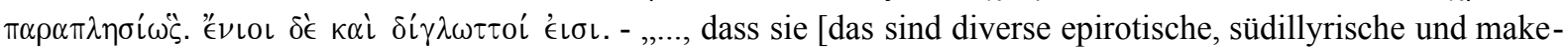
donische Teilstämme] sich sowohl in der Haartracht, als auch der Sprache, als auch der Chlamys, als auch anderen Dingen solcher Art fast ebenso berührten. Einige sind aber auch zweier Sprachen kundig.“ - Zur großen Ähnlichkeit der Bekleidung der Makedonen und der benachbarten Stämme vgl. auch die Diskussion (s.u.) zu den Münzen des Königs Gentios und der illyrischen Labeaten $(\mathrm{Nu} 4-5)$, den Weihreliefs aus Mesambria $(\operatorname{Re} 3-4)$ und eine Bemerkung zur Kausia bei den Mollossern (Herakleides, FHG II, 217 [Pont. Frgt. 17] [= Q 6]).
} 
Dieser Unterschied in der Art der Bewaffnung bzw. Kriegführung spiegelt sich in den Denkmälern. Der makedonische Hoplit trägt die Kausia nur außerhalb der Schlacht, der thrakischillyrische Leichtbewaffnete auch während des Kampfes. ${ }^{292}$

\subsubsection{Bürger und Beamte mit Kausia}

Personen, die nicht als Militärangehörige oder Herrscher identifiziert werden können, erscheinen mit der Kausia auf Grabstelen aus Vergina (Re 2) und Demetrias (Ma 8-10) sowie auf Weihreliefs aus Mesambria (Re 3-4). Darüber hinaus könnten sich hinter einigen Siegelbildnissen von Personen, die nicht eindeutig als Herrscher gekennzeichnet sind, ebenfalls Wiedergaben von Privatpersonen verbergen (Si 8-9 [Kallipolis], Si 17-20 [Seleukia/Tigris]). Gleiches gilt für ein unvollendetes Porträt aus Thasos (P 4).

\section{Grabrelief Vergina}

Ein Grabrelief (Re 2, Taf. 16 Abb. 62) aus Vergina zeigt einen stehenden Mann in Chlamys, Chiton und Kausia. Er reicht einer sitzenden Frau die Hand (Dexiosis). Zwischen beiden befindet sich ein Kind. Das Relief wird in die Zeit um 350-325 v. Chr. datiert und gehört damit zu den frühesten Darstellungen der Kausia.

\section{Grabstelen Demetrias}

Aus Demetrias sind drei bemalte Grabstelen mit Darstellungen der Kausia bekannt: Eine zeigt einen stehenden Mann, der einer rechts von ihm sitzenden Frau die Hand reicht (Ma 8, Taf. 16 Abb. 63). Auf einer weiteren Stele ist das gleiche Motiv (Dexiosis) seitenverkehrt zu sehen und durch einen stehenden Knaben erweitert (Ma 9 [o. Abb.]). Die dritte (nur fragmentarisch erhaltene) Grabstele bietet den Oberkörper eines liegenden Mannes mit Kantharos. Es handelt sich wahrscheinlich um eine Bankettszene (Ma 10, Taf. 16 Abb. 64). Die Männer sind jeweils mit Chlamys, Chiton, Stiefeln und Kausia bekleidet. Die Stelen werden in die 2. Hälfte des 3. Jahrhunderts v.Chr. bzw. die Zeit von 293-194/191 v.Chr. datiert.

Die bemalten Grabstelen aus Demetrias stehen ganz in der Tradition der attischen Grabreliefs des späten 4. Jahrhunderts v.Chr. und wurden vermutlich von Werkstätten hergestellt, die aus Athen ausgewandert sind. ${ }^{293}$ Auch die Grabstele in Vergina orientiert sich an attischen bzw. gemeingriechischen Vergleichsstücken. So entspricht auch die Ikonographie der Grabstelen

\footnotetext{
${ }^{292}$ Es sei hier nicht verschwiegen, dass die Art und Weise der Bewaffnung einzelner makedonischer Heeresabteilungen sowie die Zuweisung der überlieferten Bezeichnungen zu diesen Gruppen umstritten sind (Vgl. Dintsis, Helme, 192 ff. mit Anm. 68-75.) und dass im makedonischen Heer (zumindest in vorhellenistischer Zeit) vermutlich auch leichtbewaffnete makedonische Soldaten kämpften (vielleicht die Hypaspisten, so RE XIX (1938) 403-406 s.v. Peltastai [F. Lammert]). Demnach könnte es auch im makedonischen Heer leichtbewaffnete Makedonen gegeben haben, die mangels schwerer Schutzbewaffnung die Kausia auch während der Schlacht trugen.

${ }^{293}$ Vgl. C. Wolters, Die Anthemien-Ornamente der Grabstelen von Demetrias (Diss. Heidelberg 1969/70) 21 f. .V. von Graeve, Die bemalten Grabstelen von Demetrias, in: La Thessalie, Collection de la Maison de 1'Orient Méditerranéen 6, Série Archeologique 5 (Actes Lyon) (1979) 113.
} 
weitgehend der der attischen Vorbilder ${ }^{294}$. Von diesen unterscheiden sie sich nur in der wiedergegebenen Bekleidung. Diese wird durch den Zusatz der Kausia an die Alltagsbekleidung der makedonischen bzw. sich makedonisch gebenden ${ }^{295}$ Kunden angepasst. Darüber hinaus wird aber auch das Himation, das attische Bürgergewand, durch die Chlamys ersetzt. Dies ist darauf zurückzuführen, dass die Kausia grundsätzlich in Kombination mit der Chlamys (und Chiton und Krepides) getragen wird und Kausia und Chlamys letztlich zwei Elemente einer Gesamttracht darstellen. In der Verwendung der Chlamys spiegelt sich möglicherweise aber nicht nur ein ethnischer Unterschied. Denn die auch in Athen bekannte (und dort in Kombination mit dem Petasos getragene) Chlamys steht dort für die außerstädtischen Aktivitäten des Bürgers (Krieg, Militärdienst, Handel, Reise). Das Himation dagegen steht für die innerstädtischen Aspekte des Polisbürgers (z.B. Teilnahme am politischen und kulturellen Leben). In der Verwendung der Chlamys als makedonischem Bürgergewand im Rahmen der Selbstdarstellung spiegelt sich daher vielleicht auch ein anderes Bürgerverständnis.

\section{Weihrelief Mesambria}

In die um 50 v.Chr. errichtete Stadtmauer von Mesambria (Nesebar) sind u.a. eine Reihe so genannter Strategenreliefs als Spolien verbaut worden. Diese zeigen jeweils die sechs Strategen und den Schreiber der Stadt sowie weitere Beifiguren (meist Kinder) um ein Heroengrab bzw. einen Altar versammelt. Die einzelnen Personen sind durch Inschriften benannt. Auf zweien dieser Reliefs (Re 3, Taf. 17 Abb. 65; Re 4 [o. Abb.]) sind sowohl die Strategen als auch der Schreiber mit Kausia, Chlamys und Chiton bekleidet dargestellt. Datieren lassen sich die Weihreliefs anhand epigraphischer, ikonographischer und historischer Überlegungen sowie des Fundortes (terminus ante quem) in die Zeit von 200-50 v.Chr. (Re 3) bzw. in die Zeit um 100 v.Chr. (Re 4).

Mesambria stand, wie andere westpontische Griechenstädte auch, nur relativ kurz unter makedonischer Oberhoheit (ca. 340-280 v.Chr.). Danach war es bis zur Eingliederung in das Römische Reich im frühen 1. Jahrhundert n.Chr. eine freie, wenn auch zeitweilig von thrakischen und keltischen Stämmen bedrängte Stadt. ${ }^{296}$ Es ist nur schwer vorstellbar, dass die nur kurze und zwangsweise makedonische Herrschaft zur Folge gehabt haben sollte, dass die Kausia noch 200 Jahre später demonstrativ gezeigt wurde. Bei den Dargestellten handelt es sich zudem nicht um einzelne Privatpersonen, hinter denen sich zufällig Makedonen verbergen könnten, sondern um jeweils sieben Beamte, die durchweg mit Kausia wiedergegeben werden. Die Verwendung der Kausia auf den militärischen Charakter des Strategenamtes zurückzuführen,

\footnotetext{
${ }^{294}$ Vgl. zu Ma 8: A. Scholl, Die attischen Bildfeldstelen des 4. Jhs. v.Chr. (1996) Taf. 4,5 Nr. 187, Taf. 6,1 Nr. 292, Taf. 6,2 Nr. 396 u.ö. .- J. Bergemann, Demos und Thanatos (1997) Taf. 109,3; zu Ma 9: A. Scholl, Die attischen Bildfeldstelen des 4. Jhs. v.Chr. (1996) Taf. 11,4 Nr. 398 u.ö.; zu Ma10: A. Scholl, Die attischen Bildfeldstelen des 4. Jhs. v.Chr. (1996) Taf. 40,3 Nr. 421, Taf.41,6 Nr. 136 u.ö.

${ }^{295}$ Aus den Inschriften der Grabstelen von Demetrias geht hervor, dass die Einwanderer aus über 100 Städten stammten (C. Wolters, Die Anthemien-Ornamente der Grabstelen von Demetrias [Diss. Heidelberg 1969/70] 21). ${ }^{296}$ Vgl. V. Velkov, Mesambria Pontica, in: W. Schuller (Hrsg.), Die bulgarische Schwarzmeerküste im Altertum, Xenia 16 (1985) $30 \mathrm{ff}$.
} 
ist nicht möglich, da diese Kopfbedeckung keine rein militärische war. Es kommt hinzu, dass auch der Schreiber, der nicht derjenige der Strategen, sondern derjenige der Boule, also ein ziviler Beamter, war, ebenfalls die Kausia trägt.

Auch hier stellt sich wieder die Frage, ob die Kausia nicht auch bei den Thrakern verbreitet gewesen ist. Mesambria war zwar immer eine griechisch dominierte Stadt, ein Einsickern thrakischer Bevölkerungsteile, Sitten und Realien lässt sich jedoch sowohl archäologisch als auch epigraphisch belegen. ${ }^{297}$ Nimmt man eine Verbreitung der Kausia nicht nur bei den Makedonen, sondern auch bei den Illyrern und Thrakern an, ${ }^{298}$ ergibt sich die Möglichkeit, dass die Kausia von dort nach Mesambria (und in andere Poleis am Schwarzen Meer) eindrang. ${ }^{299}$ Wenn aber die griechischen Mesambrier die Kausia von den Thrakern übernahmen und dies bis in die Tracht ihrer Beamten hinein, so lässt dies Schlüsse auf das Verhältnis der Mesambrier zu den Thrakern und/oder zur Konnotation der Kausia zu. Entweder gab es keinen griechisch-thrakischen Gegensatz bzw. waren die Thraker aus diesem schon als eindeutige Sieger hervorgegangen, was nicht der vorherrschenden Meinung der Forschung entspricht, oder es war den Griechen in Mesambria möglich, einen Trachtbestandteil von den Thrakern zu übernehmen, ohne dass darin die Übernahme eines typisch thrakischen und damit feindlichen Elementes gesehen worden wäre. Die Kausia wäre dann nicht als typisch thrakisch angesehen worden oder ein Denken in nationalen Kategorien unbekannt gewesen.

\section{Siegel}

Im Papyrosarchiv der aitolischen Stadt Kallipolis/Kallion fanden sich Hunderte von Siegelabdrücken, die in den Zeitraum von etwa 230 bis 160 v. Chr. datiert werden. ${ }^{300}$ Einige der Abdrücke zeigen Köpfe im Profil nach rechts mit Kausia. Neben Herrscherporträts, die Ptolemaios III., Ptolemaios IV. und vermutlich Antiochos III. mit Kausia diadematophoros zeigen, geben zwei Abdrücke Bildnisse nicht identifizierter Personen mit Kausia wieder. Bei Abdruck Si 8 (Taf. 5 Abb. 21) fehlt der hintere Teil des Kopfes und der Kausia, Diademenden sind entsprechend nicht erkennbar. Ob es sich um das Porträt eines Herrschers oder eines Privatmannes handelt, ist nicht zu entscheiden. Si 9 (Taf. 5 Abb. 24) zeigt ein Porträt mit Kausia. Ein Diadem ist vermutlich nicht vorhanden. Es handelt sich demnach eher um eine nicht-königliche Person. Da die Kausia in hellenistischer Zeit möglicherweise auch bei den Aitolern ver-

\footnotetext{
${ }^{297}$ Vgl. P. Delev, Bevölkerung und Siedlungssystem an der bulgarischen Schwarzmeerküste, in: W. Schuller (Hrsg.), Die bulgarische Schwarzmeerküste im Altertum, Xenia 16 (1985) 17.

${ }^{298}$ Eine Verbreitung der Kausia auch bei Illyrern und Thrakern deuten u.a. an: Nu 4-5 (Münze des illyrischen Königs Genthios/der Labeaten), Nu 1-3 (Münzen des paionischen Königs Patraos, mit unterlegenem Kausiaträger), Ma 7 (Grab von Kasanlak, mit thrakischem Krieger mit Kausia) sowie die Bemerkung des Strabon, dass sich Makedonen, Epiroten und Illyrer anhand der Tracht nicht unterscheiden lassen (Strabon 7, 7, 8 / c 327).

${ }^{299}$ Dies bezieht sich nur auf den realen Gebrauch der Kausia und entsprechende Darstellungen. Die Wiedergaben in der Koroplastik (Tk 283 ff.) folgen typologisch so eindeutig griechisch-hellenistischen Vorbildern, dass eine Übernahme von den Thrakern auszuschließen ist.

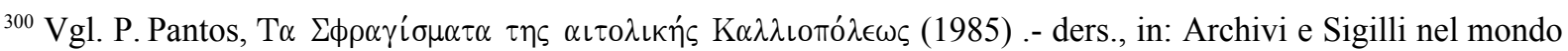
ellenistico, BCH Suppl. 29 (Symposium Turin 1993) (1996) 184-94. Vgl. auch P. Themelis, Ausgrabungen in Kallipolis 1977-78, AAA 12/2, 1979, 245- 79 (mit überholter Datierung).
} 
breitet war, ${ }^{301}$ könnte es sich bei den vermuteten Privatporträts um Bildnisse von Einheimischen handeln.

Der vollständig erhaltener Siegelabdruck Si 18 (Taf. 5 Abb. 23) aus Seleukia am Tigris zeigt ein männliches Porträt im Profil nach rechts. Die dargestellte Person trägt ein sehr flaches Barett $^{302}$, bei dem es sich vermutlich um eine Kausia handelt. Ein Diadem ist eindeutig nicht vorhanden. Es kann sich daher um die Wiedergabe einer Privatperson handeln.

Die nur unvollständig abgedrückten oder schlecht erhaltenen Siegelabdrücke Si 17, 19 und Si 20 (Taf. 5 Abb. 22, 19-20) sind verschiedentlich als Porträts seleukidischer Herrscher gedeutet worden (s.o.). Da jedoch ein Diadem jeweils nicht oder nicht eindeutig zu erkennen ist, können auch Privatpersonen dargestellt sein.

Alle Siegelabdrücke aus Seleukia werden in die Zeit der seleukidischen Herrschaft über die Stadt (295-141 und 138-129 v.Chr.) datiert. ${ }^{303}$ Grundsätzlich ist jedoch das Vorkommen von Darstellungen der Kausia auch in nachseleukidischer Zeit nicht auszuschließen, wie die große Anzahl von Terrakotten mit Kausia aus parthischer Zeit deutlich macht. Insbesondere ist dies bei Privatporträts (wie Si 18) möglich.

Die genannten Siegelbildnisse aus Kallipolis und Seleukia weisen keine (erkennbaren) Diademe auf. Es kann sich daher um Porträts von Bürgern oder Beamten handeln. Dies muss jedoch nicht zwangsläufig der Fall sein. Möglich ist auch eine Darstellung des Herrschers ohne Diadem oder die Wiedergabe der Personifikation Makedoniens.

\section{Plastik}

Aus dem Bereich der Agora (hinter der Grundmauer der Nord-Portikus) von Thasos stammt ein etwa lebensgroßer (marmorner?) Kopf (P 4, Taf. 17 Abb. 66). Das Stück ist unfertig, das Gesicht ist nur in groben Zügen angelegt, die Ober- und Rückseite sind weitgehend unbearbeitet. Gedeutet wird der Kopf von J. Pouilloux ${ }^{304}$ als weiblicher Kopf mit Schleier. Die Interpretation als Frauenkopf beruht auf der Ansprache einer Bossierung unter dem rechten Ohr als Ohrring. Die Profilansicht zeigt jedoch an der entsprechenden Stelle nur eine abgeschrägte, grob behauene Fläche. Es handelt sich daher mit großer Wahrscheinlichkeit um einen männlichen Kopf mit Kausia. Die Deutung als Privatporträt aufgrund des Fehlens eines Diadems ist hypothetisch, da die Rückseite mit den potentiellen Diademenden noch nicht angelegt worden ist.

\footnotetext{
${ }^{301}$ Polybios 4, 4, 5 (= Q 16) berichtet, dass Dorimachos, Stratege des Aitolischen Bundes um 220 v. Chr., Kausia

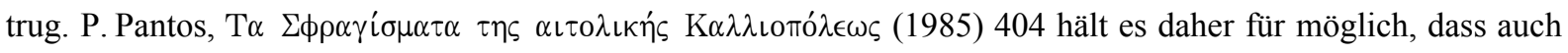
die Aitoler die Kausia trugen.

${ }^{302}$ A. Invernizzi, La terra tra i due fiumi (Ausstellungskatalog Florenz 1986) 125 Nr. 109 Abb. S. 178: „,beretto basso".

${ }^{303}$ Vgl. R.H. McDowell, Stamped and Inscribed Objects from Seleucia on the Tigris (1935) 214-20 .- A. Invernizzi, La terra tra i due fiumi (Ausstellungskatalog Florenz 1986) 125 Nr. 104, 106, 109.

${ }^{304}$ J. Pouilloux u.a., Chroniques des fouilles en 1951. Thasos, BCH 76, 1952, 269 Abb. 63 f. (S. 265).
} 


\subsubsection{Zusammenfassung}

Bürger und Beamte, die im klassischen Athen im Himation und ohne Kopfbedeckung wiedergegeben wurden, konnten in makedonisch (und vielleicht auch thrakisch) geprägten Städten mit Chlamys und Kausia dargestellt werden. Wie schon erwähnt, drückt sich hierin möglicherweise nicht nur die unterschiedliche Stammeszugehörigkeit aus, sondern auch ein anderes bürgerliches Selbstverständnis. Dieses könnte darin bestanden haben, dass weniger die Teilnahme an der Beratung und Entscheidung politischer Fragen im Rahmen einer Volksversammlung auf der Agora oder im Theater das Wesen des Bürgers bestimmten, als vielmehr der Besuch des Gymnasions sowie die militärischen Strukturen der Neuen Reiche. Ähnliches bahnte sich auch im spätklassischen Athen mit der Neuordnung der Ephebie als einer allgemeinen Wehrpflichtorganisation und Voraussetzung für die Wahrnehmung des vollen Bürgerrechtes an. ${ }^{305}$ Während diese Entwicklung in Athen durch die militärischen Niederlagen gegen Makedonien abgebrochen wurde und man statt dessen ungeachtet der veränderten außenpolitischen Lage in der Pflege klassischer Traditionen verharrte, bildete sich in Makedonien und in den Diadochenreichen ein neues Bürgerverständnis heraus. Für dieses war die Beziehung zum König, dessen Macht in erster Linie auf dem Oberbefehl über das Heer beruhte, oft wichtiger, als die alten Polisstrukturen. Diese bestanden gerade in den neuen Königsstädten und den Militärkolonien, in denen Kausia und Chlamys eine besondere Rolle spielten, nicht oder nur rudimentär. Ersetzt wurden sie durch andere Institutionen (z.B. das Gymnasion und die Ephebie), die als Stätten der paramilitärischen Ausbildung den geeigneteren Hintergrund bildeten für den „Bürger in Uniform“. 306

\subsubsection{Exkurse: Die Kausia als „,nationales“ Symbol?}

\section{Exkurs: Die „Kausia“ im illyrisch-thrakischen Bereich}

Aus den nördlich an Makedonien angrenzenden Regionen stammt - wie schon in den vorhergehenden Kapiteln angedeutet wurde - eine Reihe von bildlichen Wiedergaben von Personen, die eine Kopfbedeckung tragen, welche der makedonischen Kausia im Aussehen gleicht. Es handelt sich bei den dargestellten Personen jedoch nicht um Makedonen, sondern um Einheimische (Illyrer, Paionen, Thraker). Dies wirft die Frage auf, ob die makedonische Kausia auch von den Bewohnern der nördlich angrenzenden Gebiete getragen wurde und ob die Kausia (oder eine sehr ähnliche Mütze) letztlich keine makedonische, sondern eine im makedonisch-

\footnotetext{
${ }^{305}$ Vgl. hierzu das Aufkommen von Terrakottastatuetten, die Chlamys und Petasos (das griechische Äquivalent zur makedonischen Kausia) tragen, im spätklassischen Athen (z.B. R. Higgins, Tanagra and the Figurines [1986] 148 ff. Abb. 179 ff. und 150 ff. Abb. 186 ff.).

${ }^{306}$ In diesem Zusammenhang sei auf die große Anzahl von Tonfiguren, die Jungen und junge Männer mit Kausia und Chlamys zeigen, hingewiesen, die seit frühhellenistischer Zeit vorzugsweise im ostmediterranen Raum in den Hochburgen makedonischer Siedlungstätigkeit auftreten (Tk 1 f. 39 ff. u.ö. [„Chlamydephoren“]; Diskussion s.u. im Rahmen der Besprechung der Weihungen und Grabbeigaben). Bei diesen handelt es sich zwar nicht um Darstellungen von Bürgern, aber vermutlich um solch von Anwärtern auf das Bürgerrecht.
} 
illyrisch-thrakischen Raum allgemein verbreitete Kopfbedeckung war, die heute nur deshalb als „makedonisch“ bezeichnet wird, weil sich die Makedonen zum (militärisch) führenden Volk entwickelten und von der Umwelt entsprechend beachtet wurden. Es stellt sich weiter die Frage, ob die Kausia (oder eine äußerlich identische Kopfbedeckung) auch als Erkennungsmerkmal eines nicht-makedonischen Stammes dienen konnte.

An bildlichen Wiedergaben der „Kausia“ aus Illyrien, Paionien und Thrakien sind zunächst einige schon besprochene Beispiele zu nennen:

Die zwischen 331 und 315 geschlagenen Prägungen (Nu 1-3, Taf. 15 Abb. 57-59, Taf. 21 Abb. 80) des paionischen Königs Patraos, die auf der Rückseite wahrscheinlich einen Reiterheros zeigen, der einen Paionen niederreitet. Bekleidet ist der Paione mit „Kausia“, kurzem Chiton und (meist) langen Hosen, bewaffnet mit Speer und „makedonischem“ Rundschild.

An der Decke des Grabes von Kasanlak (beim antiken Seuthopolis/Thrakien) aus dem späten 4. oder frühen 3. Jahrhundert v.Chr. werden mehrere Kampfszenen wiedergegeben. Sie zeigen u.a. einen Krieger, der neben einer „Kausia“ eine Chlamys trägt und mit Speeren, einem länglichen Schild sowie einem Krummsäbel bewaffnet ist (Ma 7, Taf. 21 Abb. 79). Die Bekleidung und insbesondere die Bewaffnung kennzeichnen ihn als Thraker.

Zwei Weihreliefs (Re 3, Taf. 17 Abb. 65 [200-50 v.Chr.], Re 4 [um 100 v.Chr.]) aus der ursprünglich griechischen Polis Mesambria an der thrakischen Schwarzmeerküste mit sowohl griechischem als auch thrakischem Bevölkerungsanteil zeigen jeweils die sechs Strategen der Stadt und den Schreiber der Boule mit „Kausia“ und Chlamys.

Hinzu kommen einige noch nicht angesprochenen illyrische Prägungen. Sowohl der illyrische König Genthios (181-168 v.Chr.) als auch das Koinon der Labeaten, einer der Nachfolgestaaten des illyrischen Königreiches nach dessen Zerschlagung durch die Römer im Jahre 168 v.Chr., prägten Bronzemünzen, auf denen die „Kausia“ als Kopfbedeckung erscheint (Nu 4-5, Taf. 21 Abb. 77-78). Die Rückseiten zeigen ein Schiff und den Namen des Königs bzw. des Ethnikons, die Vorderseiten einen männlichen Kopf im Profil mit flacher Mütze.

Die Kopfbedeckung ist auch als thessalischer Petasos ${ }^{307}$ gedeutet worden. Dies ist darauf zurückzuführen, dass in erster Linie ein ausladender Schirm zu sehen ist. Der untere Abschluss ist unklar, eine Binde oder Rolle nicht eindeutig erkennbar. Eine solche könnte jedoch der summarischen Darstellung zum Opfer gefallen sein bzw. sich unter dem Schirm verbergen. Eindeutig nicht vorhanden sind jedoch unverzichtbare Bestandteile des Petasos (Kopfform/Knopf, Riemen). Da aber entweder Kinn-/Nackenriemen oder eine Binde am unteren Rand zu fordern sind, weil eine ausladende Kopfbedeckung anders nicht zu befestigen ist und ein Riemen bei keiner der über Jahrzehnte geprägten Münzserien zu sehen ist, die Nichtsichtbarkeit der Binde dagegen durch Verdecken oder ähnliches erklärt werden kann, handelt es sich bei der Kopfbedeckung mit großer Wahrscheinlichkeit um eine Mütze vom Aussehen der Kausia.

\footnotetext{
${ }^{307}$ O. Hoffmann, Die Makedonen (1906) 56.
} 
Der Kopf zeigt jedoch nicht das Porträt des Genthios ${ }^{308}$, da auszuschließen ist, dass die von Rom abhängigen Labeaten nach der Gefangennahme des Königs noch Münzen mit dessen Bildnis prägten. Entsprechend verwundert es auch nicht, dass kein königliches Diadem zu sehen ist. Dargestellt ist vielmehr eine Gottheit, vorgeschlagen wurde der illyrische Meeresgott Redon $^{309}$.

Zu klären ist jetzt, ob es sich bei der Mütze des Redon um eine erst in historischer Zeit aus Makedonien übernommene makedonische Kausia handelt oder um eine regionale in Illyrien seit langer Zeit verbreitete Kopfbedeckung. Gegen eine Übernahme aus Makedonien spricht, dass es sich bei der dargestellten Person nicht um einen König handelt, dessen Auftreten in der für hellenistische Herrscher üblichen Kleidung nicht überraschen würde, sondern um einen Gott. Für diesen ist ein Wechsel der Bekleidung je nach tagespolitischem Geschehen jedoch nicht anzunehmen. Gegen eine speziell makedonische Kausia spricht auch, dass diese Kopfbedeckung auch nach der Zerschlagung Makedoniens und des mit diesem verbündeten Illyrerreiches weiterhin auf den Münzen des mit Rom verbündeten bzw. von diesem abhängigen Stammes erscheint. Die weitere Verwendung dieser Mütze ist nur möglich, wenn ihre Wiedergabe nicht zwangsläufig als makedonisches und damit romfeindliches Symbol gedeutet werden musste, sondern auch die Interpretation als Kopfbedeckung einer regionalen Bevölkerungsgruppe, z.B. der seefahrenden Labeaten und ihres Gottes Redon, möglich war. Nicht auszuschließen ist allerdings eine Übernahme in vorgeschichtlicher Zeit oder ein gemeinsamer Ursprung der Kopfbedeckungen der Illyrer und Makedonen. Dies würde bedeuten, dass das illyrische Barett und die makedonische Kausia letztlich identisch ${ }^{310}$ sind und die Kausia kein so exklusiv makedonischer Trachtbestandteil war, wie es die Masse der literarischen und archäologischen Quellen suggeriert.

Es spricht demnach einiges dafür, dass die Kausia oder eine im Aussehen weitgehend identische und entwicklungsgeschichtlich vielleicht verwandte Mütze zumindest in spätklassischhellenistischer Zeit auch im illyrisch-thakischem Raum verbreitet war. Diese „Kausia“ konnte - wie insbesondere das Beispiel des Münzbildnis des illyrischen Gottes Redon mit dieser Kopfbedeckung zeigt - auch zur Kennzeichnung nicht-makedonischer „Personen“ und Volksgruppen dienen.

\footnotetext{
${ }^{308}$ Porträt des Königs wird angenommen z.B. von Dintsis, Helme, 311 Nr. 297.

${ }^{309}$ Vgl. Albanien. Schätze aus dem Land der Skipetaren, Ausstellungskatalog Hildesheim (1988) 272.

${ }^{310}$ Vgl. auch Strabon, der berichtet, dass sich Makedonen, Epiroten und Illyrer anhand der Kleidung - die Kopfbedeckungen erwähnt er jedoch nicht ausdrücklich - nicht unterscheiden ließen (Strabon 7, 7, 8 / c 327: ..., ö ๘

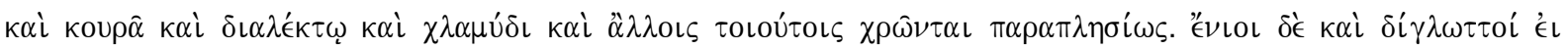
бᄂ. - ,,..., dass sie [das sind diverse epirotische, südillyrische und makedonische Teilstämme] sich sowohl in der Haartracht, als auch der Sprache, als auch der Chlamys, als auch anderen Dingen solcher Art fast ebenso berührten. Einige sind aber auch zweier Sprachen kundig."). - Vgl. auch die Berichte von den (epirotisch-) molossichen Kriegern, die dem Kultbild der Artemis von Kephallenia eine Kausia aufsetzen (Herakleides, FHG II, 217 [Pont. Frgt. 17] [= Q 6]), und über Dorimachos, den Feldherrn des Aitolischen Bundes, der im Krieg gegen Makedonien eine Kausia trägt (Polybios 4, 4, 5 [= Q 16]).
} 


\section{Exkurs: Kausia und Rundschild als ,nationale Symbole“?}

Vor kurzem ist Katerini Liampi ${ }^{311}$ der Frage nachgegangen, ob im makedonischen Schild ein nationales Symbol gesehen werden kann. Bezugnehmend auf die Darstellungen des 5. und frühen 4. Jahrhunderts kommt sie zu folgendem Ergebnis: „In der makedonischen Münzprägung ist der Schild anfänglich als Darstellung der realen Waffe ein Motiv mit begrenztem Aussagewert. “312 Später lasse sich in der Zeit Philipps II. und Alexanders III. der „Übergang von der Wiedergabe des Schildes als Waffe zum symbolischen Gebrauch“‘313 beobachten. Den Schlüssel zur Deutung bietet für K. Liampi jedoch nicht die Münzprägung der makedonischen Herrscher, sondern die des paionischen Königs Patraos. Diese zeige auf der Rückseite einen Kavalleristen, der einen Fußsoldaten mit makedonischen Schild und Kausia niederreitet $(\mathrm{Nu}$ 1-3). Zu sehen seien ein Paione zu Pferd und ein makedonischer Infanterist. „Diese Darstellung bezeugt, dass der Schild als typisch makedonische Bewaffnung, nationalen' Charakter hat und den Gegner als Makedonen kennzeichnet. “314 Diese Deutung ist jedoch aus zweierlei Gründen abzulehnen. Einerseits handelt es sich - wie oben herausgearbeitet wurde - wohl nicht um die verkürzte Illustration einer historischen Schlacht zwischen Paionen und Makedonen, sondern um die Darstellung eines Reiterheros und seines dann ebenfalls mythischen Gegners. Andererseits ist es durchaus fraglich, ob die Herkunft des sog. makedonischen Schildes ausschließlich auf Makedonien zu beschränken ist oder ob dieser nicht, ähnlich wie dies für die Kausia vermutet wurde, in einem größeren makedonisch-illyrischen Raum beheimatet war und nur aufgrund der überragenden Bedeutung Makedoniens als „,makedonisch“ in die Geschichte einging. ${ }^{315}$

In den folgenden 200 Jahren erscheint der Schild in Makedonien und teilweise auch anderen Diadochenreichen häufiger als ein die gesamte Vorderseite einer Münze ausfüllendes Motiv. „Die weite Zirkulation des makedonischen Geldes förderte die Bekanntheit des makedonischen Schildes und seine Gleichsetzung mit dem makedonischen Heer, den Makedonen und ihrem König. "316 Diese Aussage ist zwar zutreffend, sie deutet aber auch an, dass der Schild nicht von Anfang an infolge seiner außerordentlichen nationalen Symbolik gezielt als Münzbild verwendet wurde, sondern dass er diese Bedeutung erst nach und nach erlangte und zwar u.a. durch die Nutzung im Münzwesen.

\footnotetext{
${ }^{311}$ K. Liampi, Der makedonische Schild (1998) 44-47.

${ }^{312}$ K. Liampi a.a.O. 45.

${ }^{313}$ K. Liampi a.a.O. 45.

${ }^{314}$ K. Liampi a.a.O. 45.

${ }^{315}$ Die Zweifel (z.B. albanischer Archäologen) an Makedonien als ausschließlichem Ursprungsgebiet des makedonischen Schildes sind auch K. Liampi bekannt (K. Liampi, Der makedonische Schild [1998] 47 mit Anm. 174). Sie weist diese Zweifel unter Hinweis auf methodische Fehler der Gegenseite zurück. Eine unvoreingenommene Untersuchung des von ihr gesammelten Materials unterbleibt jedoch. Stattdessen schließt sie eine Verbreitung des „,makedonischen“ Schildes auch im illyrischen Raum von vornherein aus und deutet in Illyrien gefundene Wiedergaben entsprechend. So muss es sich bei der Darstellung eines Kriegers mit entsprechendem Schild auf einer Grabstele aus Idumenai (heute Republik Mazedonien) schon deshalb um einen Makedonen handeln, da die Stele außerhalb Makedoniens aufgestellt wurde (K. Liampi a.a.O. 67: „Der ,nationale“ Charakter des Schildes ist daraus ersichtlich, dass die Stele außerhalb Makedoniens aufgestellt wurde.“).

${ }^{316}$ K. Liampi a.a.O. 46.
} 
In der Spätphase dann ,dokumentiert [der makedonische Schild] den Willen des makedonischen Königreiches, sich gegenüber dem Vordringen der Römer zu behaupten“6317. Dies ist jedoch der Endpunkt einer mehrhundertjährigen Entwicklung, in deren Verlauf sich der Schild des makedonischen Heeres von „der realen Waffe ... mit begrenztem Aussagewert“ erst zu einem Erkennungsmerkmal und schließlich zu einem Symbol des Widerstandes heranbilden konnte. Aber auch in der Spätzeit des politischen Hellenismus wirkte der Schild als ,nationales' Symbol in erster Linie im Innern als Identifikationselement und besaß nur insofern eine abgrenzende Wirkung nach außen, als eine solche eine Folge der inneren Selbstbezogenheit sein kann. ${ }^{318}$

Mit der Kausia verhält es sich ähnlich. Sie wird seit alters die reale Kopfbedeckung der Makedonen sowohl im zivilen als auch im militärischen Bereich gewesen sein. In bildlichen Wiedergaben erscheint die Kausia, seit (Selbst-) Darstellungen von Makedonen, die auf regionale Besonderheiten Rücksicht nehmen, in verstärktem Umfang auftreten, d.h. seit dem 4. Jahrhundert v.Chr. Wie gerade die frühen Darstellungen aus dem makedonischen Mutterland zeigen, sind in den bildlichen Wiedergaben der Kausia anfangs eher zufällige Reflexe der realen Kleidung - ohne Anspruch auf eine nationale Symbolik oder auch nur eine näher bestimmbare Symbolik oder Funktion - zu sehen. Mit dem Ausgreifen der makedonischen Macht auf fremde Gebiete musste sich dies ändern. Jetzt lebten Makedonen in relativ geschlossenen Gruppen (z.B. von Garnisonssoldaten oder Militärkolonisten) umgeben von Nicht-Makedonen außerhalb Makedoniens. Optisch waren die einzelnen Personengruppen am einfachsten anhand der Kleidung zu unterscheiden. Das markanteste Merkmal der makedonischen Regionalbekleidung aber ist die Kausia. Diese diente sowohl den Makedonen als auch den unterworfenen Griechen, Ägyptern und Orientalen gegenüber als Erkennungsmerkmal.

Was die Kausia von anderen Kopfbedeckungen mit ähnlicher Funktion unterscheidet, ist es, dass diese Mütze nicht die irgendeines unbedeutenden Stammes war, sondern die der Makedonen und damit die der Beherrscher der hellenistischen Welt. Die Kausia war zudem nicht nur die Kopfbedeckung der Makedonen im allgemeinen, sondern sie wurde insbesondere von bestimmten Personen und Personengruppe im Rahmen „staatstragender“ Tätigkeiten genutzt. So war sie die Kopfbedeckung der jungen Makedonen im Gymnasion, die dort auf ihre Funktion in Staat und Gesellschaft vorbereitet wurden und für die die Absolvierung der wehrpflichtähnlichen Ephebie zumindest in römischer Zeit die Voraussetzung für die Aufnahme in die Bürgerschaft war. Die Kausia war Bestandteil der „Uniform“ der Angehörigen makedonischer Heere. Schließlich trugen Alexander und die auf ihn folgenden Könige die Kausia. Ent-

\footnotetext{
${ }^{317}$ K. Liampi a.a.O. 46.

${ }^{318}$ Vgl. G. Schubert, Kleidung als Zeichen. Kopfbedeckungen im Donau-Balkanraum, Balkanologische Veröffentlichungen 20 (1993) 67: , Kleidung als Symbol der Zugehörigkeit zu einer Gruppe kann zugleich ein Symbol für Exklusion von Nichtmitgliedern sein. Denn Identifikation mit einer Gruppe kann im Interesse des Fortbestandes der Gruppe mit der Ablehnung von Zielen und Symbolen einer anderen Gruppe verbunden sein. Aus denselben Gründen kann die Gruppenkleidung zur Separierung und Abschottung dieser Gruppe gegenüber anderen dienen.“
} 
sprechend entwickelte sich die Kausia zu einem ethnischen ${ }^{319}$ Erkennungszeichen, das identitätsstiftend und innerhalb der Gruppe solidarisierend wirkte, und so der gemeinsamen Durchsetzung gemeinsamer Interessen diente.

\section{Exkurs: Personifikationen mit Kausia}

Eine in diesem Zusammenhang interessante Untergruppe bilden Szenen, die nicht wie die Masse der Darstellungen reale Personen zeigen, sondern Personifikationen der „Makedonia“ mit der Kausia. Diese Wiedergaben können beitragen zu klären, ob und in welcher Form in der Kausia ein „nationales Symbol“ Makedoniens zu sehen ist.

Personifikationen, die als Kopfbedeckung die makedonische Kausia tragen, erscheinen in Malerei auf einer Wand der Villa des P. Fannius Synistor in Boscoreale sowie in der römischen Münzprägung und möglicherweise auf Siegelabdrücken.

\section{„Makedonia“" Boscoreale}

Auf einem der Abschnitte der Westwand des Festsaales der Villa des P. Fannius Synistor in Boscoreale bei Pompeii sind zwei weibliche Personen dargestellt (Ma 11, Taf. 18 Abb. 67). Die eine, etwas erhöht auf einem Felsen sitzende Frau ist in Chiton und Mantel gekleidet und trägt eine Kausia. Sie hält einen Stab, den man als Schaft einer Sarisse deuten kann, zu ihren Füßen lehnt ein makedonischer Schild. Die Gestalt kann aufgrund der makedonischen Kleidung (Kausia) und Bewaffnung (Sarisse, Schild) als Personifikation Makedoniens angesprochen werden. Ihr gegenüber, am unteren rechten Rand des Bildes sitzt, getrennt durch eine Meerenge, eine weitere weibliche Gestalt, die als „Asia“ gedeutet wird. ${ }^{320}$

Es handelt sich bei der Wandmalerei um eine römische Kopie (um 40/30 v.Chr.) nach einem hellenistischen Original aus dem ostmediterranen Raum, vielleicht aus Alexandria ${ }^{321}$ oder Makedonien $^{322}$. Die Deutung ist letztlich vom genauen Entstehungsort des Originals und den entsprechenden historischen Rahmenbedingungen abhängig. Solange diese nicht eindeutig geklärt sind, lässt sich nur sagen, dass die Kausia und andere typisch makedonische Realien (Sa-

\footnotetext{
${ }^{319}$ Der Begriff „ethnisch“ ist insoweit zu relativieren, als die Makedonen mit den „Hellenen“ verschmolzen und die „Hellenen“ eine eher sprachlich-funktional als ethnisch (im Sinne von biologisch-abstammungsmäßig) definierte Gruppe waren (s.o.).

${ }^{320}$ Zur Deutung auf „Makedonia“ und „Asia“ vgl. zuletzt M. Pfrommer, Göttliche Fürsten in Boscoreale, 12. MWPr (1992) 38 ff. (mit Literatur). Diese Deutung wird auch von K. Fittschen (Vortrag Göttingen 15.06.1999) akzeptiert. Anspielungen auf Ptolemaios III. und den 3. Syrischen Krieg bzw. eine Zweitverwendung unter Kleopatra VII. lehnt Fittschen ab.

${ }^{321}$ So M. Pfrommer, Göttliche Fürsten in Boscoreale, 12. MWPr (1992) 16 ff. .- G. Grimm, Alexandria. Die erste Königsstadt der hellenistischen Welt (1998) 136 ff.

${ }^{322}$ Die Personifikation der „Makedonia“ ist in der Vergangenheit u.a. auch als Darstellung bestimmter makedonischer Könige gedeutet worden (so Dintsis, Helme, 307 Nr. 287 [mit älterer Literatur]; vgl. auch den Überblick über „Forschungsstand und Deutungsvarianten“ bei M. Pfrommer, Göttliche Fürsten in Boscoreale, 12. MWPr (1992) 55 ff.). Auch wenn eine Deutung als König abzulehnen ist, so kann die Personifikation der Makedonia mit Kausia diadematophoros doch überall dort entstanden sein, wo ein Bezug zu Makedonien und zum Königtum Alexanders vorlagen, d.h. sowohl am antigonidischen als auch seleukidischen oder ptolemäischen Hof.
} 
risse, Schild) als geeignet erachtet wurden, die Personifikation Makedoniens kenntlich zu machen.

Die Kausia der Makedonia wird in Form zweier übereinander liegender Wülste wiedergegeben. Den oberen schwarzen Wulst bildet der am Rand abgerundete Schirm, den unteren eine Rolle, die hellblau gefärbt ist. Diese Form lässt sich verschiedentlich nachweisen. ${ }^{323}$ Ungewöhnlich sind zwei flache Bänder, die über dem rechten Ohr der Personifikation aus der Rolle hervortreten und auf die Schulter herabhängen. Die Bänder erscheinen wie die Rolle hellblau und enden mit einem geraden schwarzen Abschnitt (Fransen?). Diese Bänder sind als Enden eines Diadems gedeutet worden. ${ }^{324}$ Dargestellt worden wäre demnach nicht die einfache Kausia, die als Hinweis auf Makedonien ausreichen würde, sondern die mit dem Diadem umwundene, königliche Kausia. Diese Identifizierung ist jedoch problematisch: Die Bänder hängen nicht wie üblich hinten im Nacken herab, sondern an der rechten Seite. Es ist nicht erkennbar, dass das Band um die Kausia gewunden ist, sondern die Enden treten anscheinend aus einem Schlitz der Rolle hervor. ${ }^{325}$ Die Farbe (grau-hellblau) weicht zumindest in der heute erhaltenen Form von der für das Königsdiadem überlieferten ab (weiß bzw. rot-weiß). Diese Abweichungen könnten mit dem Bedürfnis begründet werden, die Diademenden, die am Hinterkopf weitgehend unsichtbar gewesen wären, durch eine seitliche Anbringung hervorzuheben. Um dieses zu erreichen, hätten die langen Diademenden jedoch auch vom Nacken über die Schultern nach vorne geführt werden können. Weitere Begründungen wären das Unvermögen des Kopisten oder ein Missverständnis. Die Deutung der Bänder als Diadem des Königs bleibt dennoch unsicher. Entsprechend ist auf eine Betonung des herrschaftlichen Kontextes durch die ungewöhnliche Art der Darstellung des Diadems nur unter Vorbehalt zu verweisen. Gleiches gilt für vermeintliche Hinweise auf das makedonische Königtum oder einen bestimmten königlichen Auftraggeber.

\section{Römische Prägungen mit Provinz „Macedonia“}

Römische Denare der Jahre 54 und 43 v.Chr. zeigen auf der Vorderseite die Büste der Macedonia mit Kausia und den Umschriften CN PLANCIVS AED CVR S C (Nu 8, Taf. 19 Abb. 68) bzw. C ANTONIVS M F PROCOS (Nu 9, Taf. 19 Abb. 69). Auf der Rückseite sind Köcher, Bogen und kretische Ziege $(\mathrm{Nu} 8)$ bzw. Kultgeräte und der Schriftzug PONTIFEX $(\mathrm{Nu}$ 9) dargestellt.

\footnotetext{
${ }^{323}$ Vgl. z.B. Tk 21 („Reiter über Schild“, Ägypten), Tk 50 (stehender Chlamydephoros, Alexandria?), Tk 158 (stehender Chlamydephoros, Myrina), Tk 166 (sitzender Chlamydephoros, ionische Küste), Tk 175 (EphebenSoldat, Xanthos) u.ö.

${ }^{324}$ Dintsis, Helme, 307 Nr. 287 (mit Literatur) vermutet die Darstellung eines Königs (Antigonos Gonatas?).

${ }^{325}$ Die Deutung der unteren Rolle als (Metall-) Reif, der mit dem Diadem identisch ist oder zu dessen Befestigung dient (Vgl. M. Andronicos, Vergina. The Royal Tombs and the Ancient City [1984] 171-175 mit Abb. 138139 [S. 174] .- Dintsis, Helme, 307 Nr. 287.), lehne ich mit H. W. Ritter, Zum so genannten Diadem des Philippsgrabes, AA 1984, 105-11 ab.
} 
Cn. Plancius wirkte von 62 bis 57 v.Chr. als Tribun in Makedonien. ${ }^{326}$ Die Münzen, die er 54 v.Chr. als curulischer Ädil in Rom schlagen ließ, erinnerten an diese Tätigkeit und dort erworbene Verdienste.

C. Antonius war in den Wirren nach Caesars Tod mit Hilfe seines Bruders Marcus Antonius gegen den Willen des Senats Proconsul von Makedonien geworden. Er wurde noch vor Erreichen seines Amtsbezirkes von Brutus in Apollonia (Illyria) festgesetzt und später getötet. C. Antonius erreichte Makedonien also nie. Die Münzen wurden auf dem Marsch von Rom nach Makedonien geprägt. ${ }^{327}$ Ihre Botschaft („C. Antonius wird Proconsul in Makedonien!“) zielte auf ein römisches Publikum, vielleicht die Legionäre seiner Kohorten, ab.

Hadrian ließ im Rahmen einer Politik, in der er als Restitutor der Provinzen auftrat, verschiedene Silber- und Bronzemünzen prägen, auf denen die Personifikation der jeweiligen Provinz zu sehen ist ( $\mathrm{Nu}$ 10, 12, Taf. 19 Abb. 70-71 [Nu 11, 13 o. Abb.]). Diese zeigen auf der Vorderseite das Porträt des Kaisers (mit Beischrift HADRIANUS AUG COS III PP) ${ }^{328}$. Auf den Rückseiten erscheinen stehende oder kniende weibliche Gestalten, die durch die Kopfbedeckung (Kausia) sowie die Beischrift (RESTITUTORI MACEDONIAE bzw. ADVENTUI AUG MACEDONIAE SC) als Personifikationen der Provinz Macedonia gekennzeichnet sind. Die Münzen wurden in Rom geprägt. Entsprechende Prägungen gibt es auch mit Darstellungen anderer Provinzen, die jeweils durch passende Kopfbedeckungen oder Symbole kenntlich gemacht werden (z.B. Sicilia mit Triskelis, Africa mit Elefantenskalp).

Die Münzen des Cn. Plantius und des C. Antonius sowie Kaiser Hadrians sind ein Beleg dafür, dass die Kausia auch von Nicht-Makedonen, in diesem Fall von Römern, als maßgeblicher Bestandteil der für die Provinz Makedonien typischen Bekleidung angesehen wurde und dieses bis weit in die Kaiserzeit hinein. ${ }^{329}$

\section{Siegelbildnisse mit Kausia diadematophoros und einfacher Kausia}

Die Siegelabdrücke mit Wiedergaben der Kausia lassen sich in solche, die ein Porträt mit Kausia diadematophoros ${ }^{330}$ aufweisen, und solche mit einfacher Kausia ${ }^{331}$ aufteilen - soweit sie in ausreichendem Maße erhalten sind. ${ }^{332}$ Während diejenigen Siegel mit Kausia diadematophoros als Porträts oft namentlich benennbarer Herrscher angesprochen werden können, kann es sich bei denen mit einfacher Kausia (auch) um Privatporträts handeln. Grundsätzlich

\footnotetext{
${ }^{326}$ Vgl. RE XX (1950) 2013 ff. s.v. Plancius (4) (F. Münzer) .- M. H. Crawford, Roman Republican Coinage (2 Bde.) (1974) 455.

${ }^{327}$ Vgl. RE I (1894) 2582 s.v. Antonius (20) (Klebs) .- M. H. Crawford, Roman Republican Coinage (2 Bde.) (1974) 496.

${ }^{328}$ Hadrian, Kaiser 117-138 n. Chr., trat sein drittes und letztes Konsulat 119 an.

${ }^{329} \mathrm{Vgl}$. auch Caracalla mit Kausia auf Makedonienreise: Herodian 4, 8, 1f. (= Q 7b).

${ }^{330}$ Si 1-2, (3-4 ?) aus Edfu, Si 5-7 aus Kallipolis, Si 10-14, (15 ?) aus Nea Paphos und Si 16, (17 ?) aus Seleukia am Tigris.

${ }^{331}$ Si 9 (Kallipolis) und Si 18 (Seleukia/Tigris).

${ }^{332}$ Unklar bzw. umstritten ist die Zuweisung der Siegelabdrücke Si 3-4 (Edfu), Si 8 (Kallipolis), Si 15 (Nea Paphos) und Si 17, 19-20 (Seleukia/T.).
} 
besteht daneben die Möglichkeit, dass sich sowohl hinter den Bildnissen mit einfacher Kausia als auch hinter denen mit Kausia diadematophoros Personifikationen Makedoniens verbergen. Mangels entsprechender Beischriften o.ä. lässt sich dies jedoch nicht eindeutig belegen. ${ }^{333}$

\subsection{Grabbeigaben und Weihungen: Statuetten aus Ton und Stein}

Die bisher besprochenen Wiedergaben der Kausia konnten aufgrund der Einbindung in einen szenischen Zusammenhang oder der Verbindung mit anderen Attributen bestimmten Kontexten zugeordnet werden. Es bestand zudem oft ein Bezug zu einem bestimmten Fundort. Diese Voraussetzungen ermöglichten eine Deutung und lassen Aussagen zum Symbolgehalt und zur Funktion der Kausia zu.

Dies ist im Fall der kleinformatigen Statuetten von Kausiaträgern aus Ton oder Stein grundlegend anders. Der szenische Zusammenhang fehlt weitgehend, auch Attribute kommen nur selten vor. Die teils nur in Auswahl wiedergegebene Standardtracht (Kausia, Chlamys, Chiton, Krepides) der meist jugendlichen, männlichen Personen lässt verschiedene Deutungsmöglichkeiten zu. Im Gegensatz zu den meisten szenischen Darstellungen handelt es sich bei den Statuetten nicht um Einzelstücke. Stattdessen tritt eine sehr geringe Anzahl von Typen in dutzend- oder mehrhundertfacher Ausführung auf. Dabei finden sich typologisch weitgehend identische Figuren an den unterschiedlichsten Orten verteilt über weite Teile der hellenistischen Welt.

Aufgrund der genannten Beschaffenheit des Materials werden die Ton- und Steinstatuetten daher zu größeren Gruppen zusammengefasst bearbeitet. Hierbei wird in mehren Schritten vorgegangen, in deren Verlauf die Figuren jeweils unter bestimmten Gesichtspunkten zusammengestellt werden.

1. Zunächst wird das Material nach Regionen und innerhalb dieser nach Themen und Typen geordnet vorgestellt.

2. Darauf wird näher auf diejenigen Statuetten eingegangen, zu denen detailiertere Angaben zur Art des Fundortes (Nekropole, Heiligtum, Siedlungsareal) oder zum Fundkontext (z.B. Beifunde) vorliegen.

3. Abschließend wird versucht, die Statuetten in den betreffenden politischen, gesellschaftlichen und kulturellen Kontext einzuordnen.

Das Ziel der einzelnen Untersuchungen ist es, auf verschiedenen Wegen und Umwegen zu klären, welche Personengruppen die Kausia trugen und welche mit der Kausia dargestellt wurden, warum dies geschah und in welchen politischen und kulturellen Rahmen dies zu verstehen ist. Weiter sind der symbolische Gehalt und die Funktion von bildlichen Wiedergaben der Kausia zu klären.

\footnotetext{
${ }^{333}$ Eine Deutung als Personifikation könnte die auf einigen Abdrücken zu beobachtende Anbringung des Makedonensternes unterstützen (Si 10: mit Diadem und Makedonenstern, „Ptolemaios X.“; Si 15: mit Makedonenstern, Diadem nicht erkennbar, Ptolemäerkönig?).
} 


\section{Exkurs: Thematische und typologische Bindung der Statuetten mit Kausia}

Rund 90\% der etwa 624 Ton- und 35 Steinfiguren mit Kausia lassen sich vier Themen, die sich in eine begrenzte Anzahl von Typen untergliedern, zuordnen: den Chlamydephoroi, Soldaten, Reitern und hockenden Knaben (,temple boys“").

Die Chlamydephoroi (Taf. 23-27 Abb. 87-101) zeigen junge, männliche Personen (vom Kleinkind bis zum jungen Erwachsenen), die im Idealfall, d.h., soweit der Erhaltungszustand dies noch erkennen lässt bzw. die Figuren mit ausreichender Sorgfalt ausgearbeitet sind, mit der Kausia, einem Chiton (kann manchmal fehlen ${ }^{334}$ ) und einer auf der rechten Schulter geschlossenen und me und meist längeren Chlamys gekleidet sind. Zur vollständigen Bekleidung dürften Krepides (Schnürschuhe) gehört haben, die jedoch nur ausnahmsweise wiedergegeben sind. ${ }^{335}$ Die Chlamydephoren können stehend oder auf einem Felsen sitzend dargestellt werden.

Als Soldaten (Taf. 28-29 Abb. 102-110) werden Statuetten dickbäuchiger, meist bartloser männlicher Personen bezeichnet, die mit einer Kausia, einem Chiton, einer auf der rechten Schulter oder vor der Brust verschlossenen, über beide Schultern zurückgeworfenen, meist kürzeren Chlamys und Krepides bekleidet sind. Sie sind meist still stehend, manchmal schreitend dargestellt und können in der linken Hand einen Beutel oder ein Schwert halten.

Die Reiter-Statuetten (Taf. 30-33 Abb. 111-114, 118-130) treten in verschiedenen Typen von meist nur regionaler Verbreitung auf. Sie lassen sich in eine mediterran-ptolemäische und mehrere orientalische Gruppen einteilen, die ich, wie auch die einzelnen Typen, weiter unten näher beschreiben werde. Ihnen ist letztlich nur gemeinsam, dass ein Reiter mit Kausia auf einem Pferd wiedergegeben wird.

Die Statuetten hockender Knaben (Taf. 34-35 Abb. 131-139) zeigen Kleinkinder, die am Boden kauern, meist unbekleidet oder nur teilweise bekleidet sind (nur Chlamys oder nur Chiton) und überwiegend mit einem Attribut (Gefäß, Wasservogel) dargestellt werden.

Im Folgenden werde ich die Statuetten nach Gebieten geordnet vorstellen und dabei auf regional und zeitlich begrenzt auftretende Typen und Besonderheiten eingehen. ${ }^{336}$ Beginnen werde ich mit Ägypten. Nur in dieser Region finden sich alle Themen (Clamydephoroi, Soldaten, Reiter, hockende Knaben) sowie fast alle im mediterranen Raum vorkommenden Typen. Es eignet sich daher am besten zur erstmaligen Vorstellung des Materials. Anschließend werden der Reihe nach die Figuren aus den übrigen mediterranen Regionen vorgestellt: Kleinasien, Balkanhalbinsel (Griechenland, Makedonien, Thrakien, Küste des Schwarzen Meeres), Wes-

\footnotetext{
${ }^{334}$ Zum Fehlen einzelner Trachtbestandteile vgl. N. Himmelmann, Ideale Nacktheit in der griechischen Kunst (1990) 53 mit Rez. T. Hölscher, Gnomon 65, 1993, 519 ff. .- Th. Schäfer, Andres Agathoi (1997) 38 ff. 147 ff. $149 \mathrm{ff} .158 \mathrm{ff}$.

${ }^{335}$ z.B. Tk 292, 294.

${ }^{336}$ Die Deutung des Materials erfolgt in der Regel getrennt von der Materialvorstellung in den nachfolgenden Kapiteln. Abweichend hiervon wird die Deutung der Ausnahmen und jener Gebiete mit geringer Fundkonzentration, auf die ich in späteren Abschnitten nur noch begrenzt zurückkommen werde, direkt in Anschluss an die Vorstellung des Materials vorgenommen.
} 
ten (Italien/Sizilien). Zuletzt werden von Westen nach Osten die Statuetten aus dem Orient behandelt: Zypern, Levante, Nordsyrien/Nordmesopotamien, Südmesopotamien.

\section{Exkurs: Die Datierung der Statuetten}

Eine Grundvoraussetzung der Deutung der Statuetten ist deren Datierung. Nur diese ermöglicht es, die Figuren in einen bestimmten politischen oder kulturellen Zusammenhang einzuordnen und ihre Bedeutung, ihren symbolischen Gehalt und ihre Funktion in diesem zu bestimmen.

Die Mehrzahl der hier bearbeiteten Figuren befindet sich seit dem 19. oder frühen 20. Jahrhundert in Museen und Sammlungen. Die Angaben zum Fundort beschränken sich in der Regel auf die Nennung einer Stadt, teils auch nur einer Region. Nähere Angaben zum Fundort oder gar zum Fundkontext, zu Beifunden o.ä., sind die Ausnahme. Aber auch die aus neueren Grabungen stammenden Statuetten sind oft in einer Art und Weise ergraben und/oder publiziert, die die Datierung der Funde erschwert.

Eine Datierung aufgrund von Beifunden oder stratigraphischen Überlegungen ist daher die Ausnahme ${ }^{337}$. Vereinzelt ist es möglich, größere Komplexe, z.B. eine Nekropole ${ }^{338}$, zeitlich einzuordnen. In der Regel orientiert sich die Datierung einzelner Statuetten jedoch an den Grenzen des Bestehens der Siedlung oder des Heiligtums, in denen diese gefunden wurden. Dies ist insbesondere dann sinnvoll, wenn es sich um Orte handelt, die nur einen begrenzten Zeitraum bestanden haben und bei denen das Datum der Gründung (meist im Frühhellenismus) und der Zerstörung (durch Römer oder Parther in mittel- bis späthellenistischer Zeit) überliefert ist ${ }^{339}$. Schließlich lehnen sich die Überlegungen zur Datierung der Statuetten in einem gewissen Umfang an den zeitlichen Rahmen des Bestehens desjenigen politischen oder kulturellen Umfeldes an, das für die Existenz von bildliche Wiedergaben von Makedonen außerhalb Makedoniens als Voraussetzung angesehen wird. Neben dem relativ einheitlichen Datum des Beginns ist hier besonders der Zeitpunkt des Endes des politischen oder kulturellen Hellenismus von Bedeutung, da dieser regional variiert.

Auf diesem Wege lassen sich rund 25\% der Statuetten mehr oder weniger genau in einen groben chronologischen Rahmen einpassen. Eine Untersuchung der stilistischen Merkmale dieser äußerlich datierten Darstellungen ermöglicht es, Tendenzen der Stilentwicklung festzustellen. Die äußerlich nicht datierten Figuren können den ihnen stilistisch nahe stehenden zugeordnet und entsprechend datiert werden. Chronologisch auswertbare Entwicklungen sind auch auf anderen Gebieten zu beobachten: So ist ein zeitlich fixierbarer Wechsel zwischen Kurz- und Langhaarfrisuren wahrzunehmen sowie ein zeitlich begrenztes Auftreten bestimmter Typen. Diese Phänomene können ergänzend oder bestätigend zur Datierung beitragen.

\footnotetext{
${ }^{337}$ Vgl. z.B. die Terrakotten aus Mytilene (Tk 180 ff.) und Seleukia am Tigris (Tk 406 ff.).

${ }^{338}$ Vgl. z.B. die Terrakotten aus Sciatbi und Hadra (Tk 39 ff.).

${ }^{339}$ Demetrias z.B. wurde 293 v.Chr. vom makedonischen König Demetrios Poliorketes auf erobertem thessalischem Gebiet gegründet und musste 196 v.Chr. auf römischen Druck an Thessalien zurückgegeben werden.
} 
Dieser auf der Verknüpfung einer absoluten und einer relativen Chronologie beruhende Datierungsansatz ermöglicht eine zumindest grobe zeitliche Einordnung der meisten Statuetten. Es treten jedoch auch Ungenauigkeiten und Probleme auf:

So können die Statuetten meist nur einem Zeitraum von rund 100 Jahren zugewiesen werden. Eine genauere Datierung ist nur selten möglich, teilweise muss der zeitliche Rahmen noch weiter gefasst werden. ${ }^{340}$

Die Datierung erfolgt je nach Zeitstellung, Region und Typus mit unterschiedlicher Verlässlichkeit. So ist die Anzahl der der Chronologie zugrunde liegenden Daten für das späte 4. und das 3. Jahrhundert v.Chr. relativ groß. Danach nimmt sie ab, für das 1.-2. nachchristliche Jahrhundert fehlen Angaben aus dem mediterranen Raum vollständig. Aus bestimmten Regionen (z.B. Ägypten) liegen verhältnismäßig viele Angaben zur äußeren Datierung vor. Andere Gebiete (z.B. Kleinasien) sind unterrepräsentiert. In Regionen, die durch große Distanzen getrennt sind (z.B. Italien und Mesopotamien), kann es zu unterschiedlichen Entwicklungen oder zeitlichen Verschiebungen gekommen sein. Dies macht die Übertragung von Datierungsansätzen über weite Strecken problematisch. Während zu den Chlamydephoren-Statuetten, insbesondere zu den stehenden Chlamydephoren von „Normaltypus“, wiederum viele Angaben vorliegen, sieht dies für die verschiedenen Nebentypen und Varianten meist anders aus. Im Fall bestimmter seltener und oft nur regional auftretender Typen, z.B. der meisten ReiterTypen, ist die zeitliche Einordnung des gesamten Typus oft von einzelnen, äußerlich datierten Exemplaren abhängig. Einzelne Themen (z.B. die Soldaten) werden im Rahmen eines Vergleiches mit thematisch abweichenden Statuetten im Ausschlussverfahren datiert. Dieses setzt u.a. eine identische Funktion von Statuetten unterschiedlicher Thematik voraus.

\subsection{1 Ägypten (einschließlich Kyrenaika)}

Aus Ägypten stammen 132 Terrakottastatuetten (Tk 1-126) ${ }^{341}$ sowie zwei kleinformatige Steinfiguren (P 2-3) von Kausiaträgern. Nach Abzug der Köpfe verteilen sie sich zu 100\% auf die vier oben beschriebenen Themen (Chlamydephoroi, Soldaten, Reiter, hockende Knaben). ${ }^{342}$ Vermutlich gehören alle Figuren der ptolemäischen Epoche an. Im Folgenden werden die Terrakotten der Übersichtlichkeit halber typologisch geordnet vorgestellt.

\footnotetext{
${ }^{340}$ Dies macht es z.B. unmöglich zu klären, ob aus dem westlichen Kleinasien des 3. Jahrhunderts v.Chr. stammende Chlamydephoren-Statuetten noch mit dem Seleukiden- oder schon mit dem Attalidenreich in Verbindung zu bringen sind. Auch ist es nicht möglich zu klären, ob z.B. entlang der Süd- und Westküste Kleinasiens gefundene Statuetten aus dem 3. Jh. v.Chr. mit ptolemäischem Einfluss zu verbinden sind, da diese Gebiete zwar zur Mitte des Jahrhunderts unter ptolemäischer Kontrolle standen, zu Beginn und Ende des Jahrhunderts jedoch nicht und eine Datierung der Figuren nicht mit ausreichender Genauigkeit möglich ist.

${ }^{341}$ Hinter einer Katalognummer verbirgt sich in der Regel eine einzelne Darstellung. In meist durch die Art der (Erst-) Publikation begründeten Ausnahmefällen werden gelegentlich mehrere bildliche Wiedergaben in einer Nummer vereinigt. Dies hat im Fall der Terrakotten aus Ägypten zur Folge, dass Tk 1-126 für 132 Exemplare stehen.

${ }^{342}$ Von den 134 Statuetten aus Ton und Stein mit Kausia lassen sich 88 Exemplare einem Thema zuordnen: Es handelt sich um 26 Chlamydephoroi, 20 Soldaten, 36 Reiter und sechs hockende Knaben (Harpokrates?). Es bleiben 45 Köpfe, die anteilig auf diese Themen zu verteilen sind.
} 


\subsubsection{Chlamydephoroi}

Die Chlamydephoros-Statuetten (26 Exemplare) lassen sich in Ägypten in zwei Typen (sitzend/stehend $)^{343}$ und einige Varianten aufteilen.

\section{Typus des sitzenden Chlamydephoren (Taf. 23 Abb. 84)}

Dieser Typus zeigt einen auf einem Felsen sitzenden Jungen/Jüngling in knöchel- bis bodenlanger, auf der rechten Schulter zusammengesteckter Chlamys, sowie Chiton und Kausia. Das Gesicht ist rundlich-pausbäckig, das Haar schulterlang und gelockt oder gewellt. Der rechte Arm hängt herab, die Hand liegt in die Chlamys gehüllt auf dem rechten Oberschenkel. Der linke Arm ist vor der Brust spitz angewinkelt, die Hand befindet sich unterhalb des Kinns unter der Chlamys. Soweit erkennbar, greifen beide Hände in das Gewand. Die Beine sind parallel gestellt.

Von den acht erhaltenen Exemplaren stammen je zwei aus den alexandrinischen Nekropolen von Sciatbi (Tk 39-40) und Hadra (Tk 41-42), drei weitere aus „Alexandria“ (Tk 43-45) und eines aus der Kyrenaika (Tk 122).

Ebenfalls aus Ägypten stammt eine Variante (Tk 1, Taf. 23 Abb. 83) des Typus sitzender Chlamydephoros. Die junge männliche Person trägt kein Untergewand, ist also weitgehend entblößt (d.h. ohne Chiton und mit zurückgeschlagener Chlamys) dargestellt. Darüber hinaus hält die Statuette in der rechten Hand vermutlich eine Strigilis.

\section{Typus des stehenden Chlamydephoren (Taf. 24 Abb. 87)}

Die stehenden Chlamydephoroi des „Normaltypus“ unterscheiden sich von den sitzenden Typen darin, dass der Felsensitz fehlt und die Jünglinge aufrecht stehend dargestellt werden. Kleidung, Frisur, Gesichtsformen, Arm- und Beinhaltung stimmen weitgehend überein. Eine Ausnahme bildet Tk 48 aus Hadra. Hier sind die Haare (schon) kurz und ist das Gesicht eher länglich. Alle stehenden Chlamysträger wurden in Alexandria entdeckt: Eine Statuette stammt aus Sciatbi (Tk 46), eine aus Sciatbi oder Hadra (Tk 51), drei aus Hadra (Tk 47-49), eine aus Ibrahimieh (Tk 52) und zwei aus „Alexandria“ (Tk 50, 53).

Darüber hinaus sind sieben Oberkörperfragmente von Chlamydephoroi erhalten, von denen sich nicht eindeutig sagen lässt, ob sie sitzen oder stehen. Sie stammen aus „Alexandria“ (Tk 36, 78-79, 94), Tanis (Tk 98), Athribis (Tk 104) und der Kyrenaika (Tk 124).

An Varianten ist ein stehender Chlamydephoros aus der Kyrenaika (Tk 123) zu nennen, der sich die Chlamys vor das Kinn zieht. Diese Variante ist in erster Linie im (nord-) ägäisch nordwestkleinasiatischen Raum nachweisbar ${ }^{344}$ und tritt dort überwiegend in der Zeit vom späten 4. bis zum 2. Jahrhundert v.Chr. auf (Taf. 25 Abb. 90-93).

\footnotetext{
${ }^{343}$ Die sitzenden Chlamydephoren treten überwiegend in frühhellenistischer Zeit auf und werden in der Folge immer seltener. Sie werden daher vor den stehenden Typen behandelt.
} 
Ohne Parallele ist ein aus „Ägypten“ stammender Chlamydephoros, der sich in „praxitelischer" Weise mit dem linken Arm auf einen Pfeiler lehnt, während sich die rechte Hand auf die Hüfte stützt und die Beine übereinander geschlagen sind (Tk 2 [o. Abb.]).

\section{Datierung $^{345}$}

Die Chlamydephoroi lassen sich in Ägypten chronologisch relativ gut einordnen, da neun der 26 Exemplare aus den alexandrinischen Nekropolen von Sciatbi und Hadra stammen. ${ }^{346}$ Diese werden in die Zeit von 325 - 240 bzw. 280 - 180 v.Chr. datiert. ${ }^{347}$

In Sciatbi überwiegt der sitzende Typus (2:1), in Hadra der stehende (3:2). Es kann daher vermutet werden, dass der sitzende Typus vor der Mitte des 3. Jahrhunderts beliebt war, der stehende nach diesem Zeitpunkt. Hiermit stimmen ähnliche Beobachtungen aus anderen Regionen überein.

Weiter ist zu beobachten, dass die dem späten 4. und dem 3. Jahrhundert entstammenden Statuetten aus Sciatbi (und überwiegend auch diejenigen aus Hadra) längeres lockiges Haar und rundliche Gesichtsformen aufweisen. Dies entspricht einer allgemein zu beobachtenden Entwicklung der Frisuren und Gesichtsformen von kurzhaarig (bis zweites Drittel 4. Jh. v.Chr.) über lockig-langhaarig und pausbäckig (spätes 4. und 3. Jh. v.Chr.) über kurzhaarig und verhältnismäßig schmalgesichtig (2. -1. Jh. v.Chr.) zu lockig-langhaarig-,,dädalisch“ (1. Jh. v. - 2. Jh. n.Chr.) (Taf. 22 Abb. 81). Diese unterschiedlichen Gesichtsformen und insbesondere Frisuren sind nicht mit bestimmten Altersklassen (im Sinne von lockig-pausbäckig gleich Knabe und kurzhaarig gleich junger Mann) zu verbinden. Denn in diesem Fall wäre zu erklären, warum - bei sonst gleich bleibender Verwendung und Funktion der Statuetten - im frühen 4. Jahrhundert v.Chr. und im 2.-1. Jahrhundert v.Chr. nur kurzhaarige und im späten 4. und im 3. Jahrhundert v.Chr. und dann wieder vom 1. vorchristlichen bis zum 2. nachchristlichen Jahrhundert nur langhaarig-lockige und pausbäckige Chlamydephoren dargestellt wurden. Für eine Deutung als Frisurentyp bzw. Zeitgesicht spricht auch, dass es Gruppen gibt, die einen älteren (langhaarigen, pausbäckigen) Jugendlichen zeigen, der einen kleinen Jungen (mit Kurzhaarfrisur) auf den Schultern trägt (Taf. 22 Abb. 82). ${ }^{348}$

Die nach Kurzhaarfrisur und magerer Gesichtsform jüngste Statuette (Tk 48) stammt entsprechend aus der jüngeren Nekropole von Hadra und gehört dem stehenden, d.h. tendenziell jün-

\footnotetext{
${ }^{344}$ Vgl. Tk 135-139 (Troja/Troas), Tk 158-159 (Myrina), Tk 181-184 (Mytilene), Tk 188 (Pydna), Tk 197-198 b (Amphipolis), Tk 240, 249-260 (Samothrake), Tk 294-296 (Attika/Böotien), Tk 307-309 (Demetrias), Tk 334 (Kassandreia) und vielleicht Tk 368 (Lipari).

${ }^{345}$ Die Abschnitte zur Datierung sind ungleichmäßig in den Text des Materialkapitels eingestreut. Dies ist auf unterschiedliche Datierungsgrundlagen (Fundort, Stil etc.) zurückzuführen, die eine entsprechende Gliederung des Materials erfordern.

${ }^{346}$ Diejenigen nicht aufgrund des Fundortes datierbaren ägyptischen Chlamydephoroi-Statuetten lassen sich denen aus Sciatbi und Hadra bis auf Ausnahmen anhand stilistischer Merkmale gut zuordnen.

${ }^{347}$ Zur Datierung von Sciatbi und Hadra vgl. W. D. E. Coulson, Chatby reconsidered, JEA 73, 1987, 234-6 .- Fischer, Slg. Sieglin/Schreiber, 38 f. (mit Anm. 17-22).

${ }^{348}$ Vgl. Chéhab, Kharayeb, 34 Nr. 234-241 Taf. 35.
} 
geren, Typus an. Da die Belegungszeit der Hadra-Nekropole um 180 v.Chr. endet, ist der Wechsel von Lang- zu Kurzhaarfrisur vorher (vielleicht um 200 v.Chr.) anzusetzen.

\subsubsection{Soldaten}

Die in Ägypten durch 20 Exemplare ${ }^{349}$ vertretenen Soldaten (Taf. 28-29 Abb. 102-107, 109110) bilden, abgesehen von vier für die Deutung wichtigen Statuetten, eine weitgehend homogene Gruppe:

Der Normaltypus (16 Exemplare: Tk 3-8, 54-57, 99-100, 110-112, 126) des Soldaten zeigt eine stehende, männliche Person, bekleidet mit Kausia, knielangem, gegürteten Chiton $^{350}$ und einer kürzeren, d.h. ebenfalls nur bis zum Knie reichenden Chlamys, die vor der Brust oder auf der rechten Schulter zusammengehalten wird und über beide Schultern zurückgeschlagen ist. Schuhwerk ist nicht erkennbar, was auf den schlechten Erhaltungszustand bzw. die einfache Qualität der Figuren zurückgeführt werden kann. Die Haare sind kurz oder leicht gelockt (Tk [5-6], 7), das Gesicht rundlich bis länglich-oval und bartlos. Die Soldaten weisen durchweg einen dicken Bauch auf, der ganze Körperbau wirkt gedrungen.

Die Arme hängen meist leicht angewinkelt am Körper herab. Die rechte Hand kann dabei in den Saum des Mantels greifen ${ }^{351}$ und diesen leicht nach vorne ziehen (Tk 3-5, [7], 8, 54-56, [99, 109], 111-112, [126]). In der linken Hand halten die Statuetten teilweise Attribute (Tk 36, [7], 8, 54-56, 99, 109-112). Die Beschreibung der Hand- und Armhaltung und die Identifizierung des Objektes in der linken Hand werden durch den schlechten Erhaltungszustand (starke Verreibung) erschwert. Sind Details erkennbar, so ist entweder ein runder, bauchiger Gegenstand dargestellt (Tk [4-5, 7], 8, 54-56, [111-112]) $)^{352}$, der als Beutel gedeutet wird, oder ein länglicher, flacher (Tk 3, [110] ${ }^{353}$; vgl. u. Tk 109), hinter dem (in Anlehnung an Tk 359) ein Schwert vermutet werden kann.

Bei den Vertretern der ersten vom Normaltypus abweichenden Variante handelt es sich um zwei bärtige - d.h. eindeutig erwachsen dargestellte - Figuren (Tk 109, 125; Taf. 29 Abb. 106107). Die eine stammt aus dem Faijum (Tk 109) und ist mit nur $6,2 \mathrm{~cm}$ Höhe die kleinste Soldaten-Statuette (der Durchschnitt liegt bei etwa $10 \mathrm{~cm}$ ). Sie hält in der linken Hand wohl ein

\footnotetext{
${ }^{349}$ Tk 3-8 (Ägypten), Tk 54-57 (,Alexandria“), Tk 99-100 (Tanis), Tk 109-113 (Faijum), Tk 125-126 (Kyrenaika), P 2 (Koptos?). Nur ein bis zwei Exemplare fanden sich außerhalb Ägyptens und der Kyrenaika: Tk 359 (Tarent) und wohl Tk 457 (ohne FO; Soldat oder Silen).Vgl. auch die Soldat-und-Hetäre-Gruppen (Tk 354-355 aus Capua).

${ }^{350}$ Der über der Gürtung befindliche Teil des Chiton erinnert manchmal an einen Brustpanzer (z.B. Tk 7, 95-96). Da jedoch teilweise Falten auf dem Bauch erkennbar sind (Tk 3-5, 54, 125), dürfte es sich dennoch um einen durch den Bauch aufgeblähten Chiton handeln.

${ }^{351}$ So Fischer, Slg. Sieglin/Schreiber 162 zu Nr. 200 (= Tk 54). - Der von der Hand schräg nach hinten verlaufende Mantelbausch erweckt teilweise den Eindruck, dass der Soldat (unter dem Mantel) ein Schwert hält. Es ist jedoch keine Statuette erhalten, die eindeutig ein Schwert in der rechten Hand trägt: Ein Schwert wäre auch eher an der linken Seite zu erwarten, damit es mit der Rechten gezogen werden kann.

${ }^{352}$ Der Beutel ist am besten erkennbar bei Tk 54 und Tk 8 (s. Farbtafel).

${ }^{353}$ Tk 110 hält ein Schwert nach Bayer-Niemeier, Frankfurt, 68 Nr. 25.
} 
Schwert. ${ }^{354}$ Die zweite Terrakotte kommt aus der Kyrenaika (Tk 125). Der Chiton und die mit einer Rundfibel auf der Brust verschlossene Chlamys sind überdurchschnittlich kurz. Die frei gearbeiteten Arme fehlen. Die ebenfalls (anders als bei allen anderen Soldatenstatuetten) frei gearbeiteten Beine sind oberhalb die Knie gebrochen. Die verbleibende Höhe der Statuette beträgt rund 12,5 cm, was auf eine ursprüngliche Gesamthöhe von ca. 16-17 cm schließen lässt. Die Figur ist damit die größte unter den Soldaten. Der Soldat aus der Kyrenaika ist sehr qualitätvoll gearbeitet, was nicht auf die Größe zurückgeführt werden muss, wie der ebenfalls recht gut gearbeitete, kleine bärtige Soldat (Tk 109) zeigt, sondern z.B. auf eine frühe Entstehung hinweisen könnte.

Die zweite Variante wird in Ägypten ebenfalls durch nur zwei Exemplare repräsentiert: Tk 113 und P 2 (Taf. 29 Abb. 109-110) Diese Variante zeichnet sich dadurch aus, dass die Chlamys nicht über beide Schultern zurückgeschlagen ist, sondern Bauch und Brust verdeckt. Eine vielleicht aus dem Faijum stammende Terrakotte (Tk 113) zeigt einen bartlosen Mann mit kurzen Haaren. Er trägt Kausia, Chiton und eine auf der rechten Schulter zusammengesteckte Chlamys. Unter der sehr rechtwinklig gestalteten Chlamys ist ein leichter Bauchansatz erkennbar. Der Unterkörper fehlt. Attribute sind nicht sichtbar. Das zweite Beispiel bildet eine nur sechs Zentimeter hohe Steatitfigur aus der Gegend von Koptos im Museum von Kairo (P 2).

Diese Statuetten lassen sich mit dem Oberkörperfragment einer Terrakottafigur aus Tarent(Tk 359; Taf. 29 Abb. 108) vergleichen. Während die ägyptischen Exemplare weitgehend identisch gestaltet sind und belegen, dass der Typus zwar selten ist, aber in verschiedenen Gattungen vorkommt, bietet die Terrakotte aus Tarent einen Hinweis auf die Deutung: Tk 359 hält in der linken Hand eindeutig ein in der Scheide befindliches Schwert. Dargestellt ist demnach ein Soldat. Das Gesicht weist eine ausgeprägte Mimik auf. Diese Mimik, die vielleicht eine Maske andeuten soll, könnte auf das Theater verweisen. ${ }^{355}$

\section{Datierung}

Die Soldaten werden (mit Ausnahme von Tk 125) ins 2.-1. Jahrhundert datiert. ${ }^{356}$ Dies beruht jedoch nicht auf der Bindung an einen datierten Fundort, wie im Falle der Chlamydephoroi, sondern auf Vergleichen mit (älteren) ägyptischen Terrakotten (z.B. Chlamydephoroi) und stratigraphisch datierbaren Terrakottastatuetten des 2.-1. Jahrhunderts aus anderen Landschaften (Kleinasien, Samothrake). Flächige Gewandgestaltung, Kurzhaarfrisuren, längliche Gesichtsformen (soweit dies im Rahmen der allgemeinen Fettleibigkeit möglich ist) und schlech-

\footnotetext{
${ }^{354}$ Weber, Berlin, 201 f. äußert sich nicht zur Bewaffnung von Tk 109. Auf der Abbildung Weber, Berlin, Taf. 32 Nr. 341 ist ein Schwert nicht eindeutig zu erkennen. Die Statuette weist jedoch einen von der re. Schulter zur li. Hüfte verlaufenden Riemen auf, der zur Befestigung einer Schwertscheide gedient haben könnte (vgl. den reitenden Alexander auf dem Alexandermosaik [Mo 1]). Sicher weist eine Soldatenstatuette in Göttingen ein Schwert auf (Tk 8).

${ }^{355}$ Vgl. auch Tk 457 (Fundort unbekannt; Soldat oder Silen, mit Theatermaske, ohne Schwert).

${ }^{356}$ Vgl. Fischer, Slg. Sieglin/Schreiber, 161 f. Nr. 199 f.
} 
te Qualität unterscheiden sie von den älteren alexandrinischen Terrakotten und nähern sie denen des 2.-1. Jahrhunderts aus anderen Gebieten an. Problematisch ist, dass die zum Vergleich herangezogenen Stücke aus verschiedenen Gründen nur begrenzt vergleichbar sind, wodurch das Ergebnis verfälscht worden sein könnte: Sie gehören alle nicht dem ausschließlich in Ägypten vorkommenden Soldaten vom Normaltypus an. Auf die Datierung der Soldaten hat sicher auch Einfluss, dass diese in den Nekropolen von Sciatbi und Hadra nicht vorkommen. Dies ist jedoch nur relevant, wenn sowohl die Chlamydephoren- als auch die Soldatenstatuetten im sepulkralen Bereich Verwendung fanden. Erfüllten die Soldatenfiguren jedoch eine Funktion im Kult (Votiv), kann ihr Fehlen in den alexandrinischen Nekropolen keinen Beitrag zur chronologischen Einordnung liefern. Als terminus ante quem scheint die Eroberung Ägyptens durch die Römer eine Rolle zu spielen, nach der man nicht mehr mit der Produktion von Darstellungen makedonischer Soldaten rechnen möchte.

Trotz aller Unsicherheiten halte ich eine Datierung der Soldaten ins 2.-1. Jahrhundert v.Chr. dennoch für die wahrscheinlichste.

Wie man sich einen im 3. Jh. v.Chr. produzierten Soldaten vorzustellen hat, zeigt die, wenn auch nur stilistisch in dieses Jahrhundert datierte, Statuette aus der Kyrenaika (Tk 125). Die Soldaten stellen vermutlich einen Charakter der Komödie bzw. des Mimos dar. Diese Charaktere wurden dem Alltagsleben entnommen. Im Alltag spielten makedonische Soldaten nach der römischen Eroberung Ägyptens keine Rolle mehr.

\subsubsection{Reiter}

Von den insgesamt 42 erhaltenen Reitern aus dem mediterranen Raum ${ }^{357}$ stammen 36 aus Ägypten ${ }^{358}$. Die Reiter stellen ähnlich wie die Soldaten ein typisch ptolemäisches Thema dar. Die sechs nicht aus Ägypten stammenden Reiter sind in ihrem Umfeld völlig isoliert. ${ }^{359}$ Sie spiegeln vielleicht den ptolemäischen Einfluss im 3. Jh. wieder.

Es lassen sich drei Typen herausarbeiten:

\section{Typus des Reiters ohne Gegner (Taf. 30 Abb. 111-112)}

Die „Reiter ohne Gegner“ (Tk 58-61, 105) zeigen einen Reiter, der nach rechts zum Betrachter blickt. Er ist bekleidet mit Kausia, Chiton und Chlamys. Schuhwerk ist nicht erkennbar, was wiederum an der schlechten Ausarbeitung oder Erhaltung liegen kann. ${ }^{360}$ Bei der Chla-

\footnotetext{
${ }^{357}$ Nicht mitgezählt sind hier die aus dem mesopotamischen Bereich stammenden Reiter. Diese folgen ikonographisch und teilweise auch handwerklich größtenteils orientalischen Traditionen. Vgl. die nachfolgenden Kapitel. ${ }^{358}$ Tk 9-24 (Ägypten), Tk 58-64 (Alexandria), Tk 95-96 (Sais), Tk 97 a/b (Thmuis), Tk 102 a/b (Naukratis), Tk 105-107 (Athribis), Tk 114-116 (Faijum), Tk 118-119 (Kom-el-Ahdar).

${ }^{359}$ Tk 138 (Troas), Tk 185 (Lesbos?), Tk 305-306 (Korinth, mit Kausia?), Tk 370 (Voiron/franz. Alpen), Tk 392 (Ibn Hani, ptolemäische Garnison bei Seleucia-ad-Mare/Syrien).

${ }^{360}$ Details können hier wie auch bei allen anderen Terrakotten in Malerei angeben gewesen sein. Vgl. jetzt J.Fischer, Ein triumphierender Makedonenreiter. Zeugnis eines ptolemäischen Siegesdenkmals?, in: P.C.Bol - G.Kaminski - C.Maderna (Hrsg.), Fremdheit - Eigenheit. Ägypten, Griechenland und Rom. Austausch und Verständnis, StädelJb 19, 2004, 487 mit Anm. 1.
} 
mys handelt es sich, soweit erkennbar, wie bei den „Soldaten“ um eine kürzere Form. Sie ist auf der rechten Schulter zusammengeheftet und bedeckt die linke obere Hälfte der Brust, die linke Schulter samt Arm und den Rücken. Das rechte untere Ende ist durch das zwischen Körper und rechtem, angewinkelten Arm entstehende Loch gezogen. Das Pferd trabt nach rechts. Der Ton zwischen der Standfläche, den Pferdebeinen und der Unterseite des Pferderumpfes ist stehengelassen. Die Darstellung wirkt hierdurch reliefartig.

Die in Ägypten gefundenen „Reiter ohne Gegner“ stammen größtenteils aus der Nekropole von Sciatbi (Tk 58-61) und lassen sich entsprechend dem Zeitraum von 325 bis 240 v.Chr. zuordnen. Eine Statuette aus Athribis (Tk 105) wird anhand des Fundkontextes ins 3. Jahrhundert v.Chr. datiert.

Für den Reiter (Tk 392) aus Ibn Hani (ptolemäische Garnison bei Seleukia ad Mare in Syrien) wird aufgrund der historischen Rahmenbedingungen eine Datierung um die Mitte des 3. Jahrhunderts v.Chr. angenommen. Die wenigen nicht in Ägypten gefundenen Statuetten vom Typus des Reiters ohne Gegner (Tk 138, 185, 307-308) werden ebenfalls ins 3. Jahrhundert v.Chr. datiert.

\section{Typus des Reiters über Gegner (Taf. 30-31 Abb. 113, 118)}

Der Typus des Reiters über Gegner (Tk 9-20, 62-64, 95-96, 97 a/b, 102 a/b, 105-107, 114116, 118-119) zeigt einen wie oben beschrieben gekleideten Reiter, dessen Pferd über einen knienden, ebenfalls nach rechts blickenden Gegner hinweggaloppiert. Die über beide Schultern des Reiters zurückgeworfene Chlamys flattert infolge der schnellen Fortbewegung des Pferdes nach hinten. Ein weiteres Unterscheidungsmerkmal ist, dass beim „Reiter über Gegner" der Ton zwischen der Standfläche, den Beinen und dem Rumpf des Pferdes nicht stehengelassen ist. Es handelt sich bei den Statuetten vom Typus „Reiter über Gegner“ um rundplastische Werke, bei denen auch die Rückseite ausgearbeitet ist. ${ }^{361}$ Dennoch wirken auch diese Figuren - wie alle ptolemäischen Reiterstatuetten - etwas einansichtig-reliefartig.

Die Statuetten vom Typus „Reiter über Gegner“ wurden bisher in erster Linie aufgrund von Überlegungen zum Stil (insbesondere in der deutschen Forschung) in die Kaiserzeit oder die

\footnotetext{
${ }^{361}$ Zur Rückseite (d.h. den linken Körperhälften von Pferd und Reiter) der „Reiter über Gegner“ vgl. Taf. 31 Abb. 118 (Tk 14) und jetzt J. Fischer, Ein triumphierender Makedonenreiter - Zeugnis eines ptolemäischen Siegesdenkmals?, StädelJb 19, 2004, 489 Abb. 2 (Tk 12). J.Fischer bietet auch eine detaillierte Beschreibung des Typus (S. 488).
} 
Spätantike (1. - 2. bzw. 3. - 4. Jahrhundert n. Chr.) datiert. ${ }^{362}$ Seit den Grabungen in Athribis ${ }^{363}$ lässt sich aufgrund des stratigraphischen Befundes nachweisen, dass die Statuetten in frühhellenistischer Zeit (Ende 4. - Anfang 3. Jh. v.Chr.) entstanden. ${ }^{364}$

\section{Typus des Reiters über Schild (Taf. 30 Abb. 114)}

Die Vertreter dieses Typus (Tk 21-24) verbindet die eng anliegende, nicht flatternde Chlamys und die nicht durchbrochene Fläche zwischen der Standlinie und dem Pferd mit dem Typus des Reiters ohne Gegner. Mit dem Typus des Reiters über Gegner stimmt die Aussage überein: Der Rundschild, über dem sich das Pferd aufbäumt, dürfte für den Gegner stehen.

Wie die „Reiter über Gegner“ wurden auch die Vertreter des Typus „Reiter über Schild“ bisher meist dem 3.-4. Jahrhundert n.Chr. zugeordnet. ${ }^{365}$ Näheres zum Fundkontext ist zu keiner dieser Statuetten bekannt. Da jedoch sowohl die „Reiter ohne Gegner“ als auch die „Reiter über Gegner“ nachweisbar in (früh-) hellenistische Zeit zu datieren sind, ist auch für die „Reiter über Schild“, die dem gleichen kulturellen Kontext zugewiesen werden müssen und ähnlich wie die „Reiter über Gegner“ zu deuten sind, ein zeitlicher Ansatz in hellenistischer Zeit anzunehmen. Tk 21 ist aufgrund stilistischer Merkmale vermutlich in die späthellenistische Zeit zu datieren.

\subsubsection{Harpokrates und sein Gefolge}

Bei den wenigen Statuetten, die sich nicht einem der Chlamydephoren-, Soldaten- oder Reiter-Typen zuordnen lassen, handelt es sich um Darstellungen männlicher Kleinkinder (Taf. 34 Abb. 131-136), die meist hocken und mit Kausia und über die Schulter nach hinten zurückgeschlagener Chlamys bekleidet sind (Tk 25-27 [aus „Ägypten“], 65 [Alexandria], 117 [Faijum]). Eine Variante bildet ein stehender Knabe mit am Rücken herabgerutschen Himation (Tk 28 [,Ägypten“]). Alle diese tragen kein Untergewand und wirken daher von vorne gesehen weitgehend nackt. Im Arm halten sie jeweils ein Gefäß (Topf, Rhyton/Füllhorn, Schale)

\footnotetext{
${ }^{362}$ In römische oder spätantike Zeit datieren: H. Philipp, Terrakotten aus Ägypten im Ägyptischen Museum Berlin (1972) 31 Nr. 43 (300 n.Chr.) .- Bayer-Niemeier, Frankfurt, 223 f. Nr. 514 f. (3.- 4. Jh. n.Chr.) .- Schürmann, Karlsruhe, 304 Nr. 1144 (3. Jh. n.Chr.) .- Fischer, Slg. Sieglin/Schreiber, 387 Nr. 995 ff. (1.- 2. Jh. n.Chr.) .- M. Fjeldhagen Graeco-roman Terracottas from Egypt. Ny Carlsberg Glyptotek (1995) 131 Nr. 114 (1.- 4. Jh. n.Chr.) .- Dunand, Paris, 214 f. Nr. 581 (römisch). Eine Datierung in hellenistische Zeit wurde schon früher in Teilen der französischen Forschung angenommen: A. Reinach, Les Galates dans l'Art Alexandrin, MontPiot 18, 1910, 103 und 104 mit Anm. 1 (hellenistisch) .- Besques, Paris VI-II, 121 D 4520 f. (späthellenistisch).

${ }^{363} \mathrm{~K}$. Mysliwiec, Fruchtbarkeitskult und erotische Kunst im ptolemäischen Athribis (Unterägypten), in: H. Felber - S. Pfisterer-Haas (Hrsgg.), Ägypter-Griechen-Römer, Kanobos 1 (1999) 79 .- K. Mysliwiec - Moattameda Bakr Said, Polish-Egyptian Excavations at Tell Atrib in 1994-1995, EtTrav 17, 1999, 191. Vgl. jetzt: J. Fischer, Ein triumphierender Makedonenreiter - Zeugnis eines ptolemäischen Siegesdenkmals?, StädelJb 19, 2004, 488 C. Maderna, Zum Feindbild der Ptolemäer, in: Ägypten Griechenland Rom. Abwehr und Berührung, Ausstellung Städelsches Kunstinstitut und Städtische Gallerie Frankfurt, 2005/06, 258-266, 584f. Nr. 157.

${ }^{364}$ Auch der ursprünglich aus dem ptolemäischen Ägypten stammende „Reiter über Gegner“ (Tk 370) aus Voiron (französische Alpen) ist entsprechend zu datieren.

${ }^{365}$ Bayer-Niemeier, Frankfurt, 223 Nr. 513 .- Schürmann, Karlsruhe, 303 f. Nr. 1142 f.
} 
und/oder einen überdimensionalen Phallos. ${ }^{366}$ Bei diesen Attributen (Topf [mit fruchtbarmachendem Nilwasser], Füllhorn, Phallos) handelt es sich jeweils um Fruchtbarkeitssymbole.

Die hockenden Figuren lassen sich am besten mit einer Gruppe von Terrakotten vergleichen, die bei J. Fischer ${ }^{367}$ unter der Überschrift „Harpokrates, kauernd, mit Topf“ geführt wird: Diese Gruppe besteht meist aus weitgehend nackten Knaben, die größtenteils - aber nicht immer als Harpokrates gekennzeichnet sind (Krone, Horuslocke), mehrheitlich den rechten (Zeige-) Finger in den Mund stecken und ein Gefäß oder ähnliches im linken Arm halten bzw. links neben sich stehen haben.

Im Sitzmotiv sind die kauernden Knaben auch mit den so genannten „temple boys“ aus Zypern vergleichbar (P 5-9, Taf. 35 Abb. 138-139). Diese sind aus Kalkstein gearbeitet, tragen Kausia und Chiton (sind also weitgehend bekleidet ${ }^{368}$ ), weisen jedoch keine Horus-Attribute auf und werden aufgrund ihres Fundortes als Votive an Aphrodite und Adonis gedeutet.

Die schon erwähnte stehende Variante (Tk 28, aus „Ägypten“) zeigt eine jugendliche Person mit schulterlangen, gewellten Haaren. Auf dem Kopf trägt sie Kausia und Kranz. Darüber hinaus ist sie nur mit einem von den Schultern gerutschten, am Rüchen herabhängenden Mantel bekleidet. Die Statuette trägt kein Untergewand. In der rechten Hand hält sie eine Schale. Der überdimensionale Phallos reicht bis zum Kopf und wird wie ein Füllhorn im linken Arm gehalten.

Die Terrakotte weist dieselben Attribute (Gefäß, überdimensionaler Phallos/Füllhorn) auf wie die hockenden Knaben (Tk 25-27, 65, 117). Es bietet sich an, in ihr ebenfalls einem Harpokrates (bzw. eine Person aus dessen Gefolge) zu sehen. Hierfür spricht auch, dass sich stehende Figuren, die mit Schale und Phallos dargestellt werden und durch die Horuslocke eindeutig benennbar sind, nachweisen lassen. ${ }^{369}$ Es handelt sich letztlich um eine stehende Variante der hockenden Knaben.

Jutta Fischer ${ }^{370}$ deutet eine Gruppe von Statuetten, zu der u.a. Kinder und Zwerge gehören, die mit Gefäßen und Phalloi dargestellt werden, als Kultdiener oder Angehörige des Gefolges des Harpokrates. Dieser entwickelte sich seit dem 6./5. Jahrhundert v.Chr. - vermutlich schon unter griechischem Einfluss - von einem Kinder- und Königsgott zu einem Gott der Fruchtbarkeit. Seit vorhellenistischer Zeit und in verstärktem Umfang seit dem Hellenismus wurde die

\footnotetext{
${ }^{366}$ Tk 65 ist mit einem Topf (?) im rechten Arm dargestellt. Tk 25 hält im linken Arm ein Füllhorn (Vgl. Dunand, Paris, 213 .- Weber, Berlin, 115 hielt das Rhyton noch für einen Phallos.). Tk 26 und Tk 117 halten im linken Arm ein Füllhorn, während um den rechten Arm jeweils ein Phallos geschlungen ist. Tk 27 weist vermutlich zwei Phalloi auf, von denen einer vielleicht aus einem Füllhorn entstanden ist. Der stehende Knabe Tk 28 hält im linken Arm einen riesigen Phallos und in der rechten Hand eine Schale.

${ }^{367}$ Fischer, Slg. Sieglin/Schreiber, 267 ff. Nr. 573. 574. 578-90 Taf. 57 ff.

${ }^{368}$ Es gibt jedoch auch weniger bekleidete „temple boys“ (ohne Kausia). Vgl. C. Beer, Temple Boys (1994).

${ }^{369}$ Dunand, Paris, 108 Nr. 252 .- Vgl. auch: J. Fischer, Der Zwerg, der Phallos und Harpokrates, in: H. Felber - S. Fisterer-Haas (Hrsgg.), Ägypter - Griechen - Römer. Begegnungen der Kulturen, Kanobos 1 (1999) 39 f. Abb. 6. 370 J. Fischer, Der Zwerg, der Phallos und Harpokrates, in: H. Felber - S. Fisterer-Haas (Hrsgg.), Ägypter - Griechen - Römer. Begegnungen der Kulturen, Kanobos 1 (1999) 27-45, besonders 34 ff.
} 
Ikonographie des Harpokrates derjenigen vergleichbarer griechischer jugendlicher Fruchtbarkeitsgottheiten (Dionysos, Triptolemos, Ploutos, Priapos) angeglichen. Entsprechende Figuren fanden Verwendung als Votive im Kult dieser Gottheiten. ${ }^{371}$

$\mathrm{Zu}$ den genauen Fundorten der hier besprochen Terrakotten liegen keine Angaben vor. Entsprechend lässt sich nicht verbindlich sagen, ob auch sie im Kult eines für Fruchtbarkeit, Familie und Vegetation zuständigen Gottes genutzt wurden. Denkbar ist auch eine Verwendung im Totenkult oder als Grabbeigabe, da der Fruchtbarkeits- und Phalloskult eng mit der Wiedergeburt verbunden war und Harpokrates der auferstandene Gott ist. ${ }^{372}$

Die Datierung der Statuetten ist mangels Angaben zu den Fundorten unklar. Grundsätzlich erscheinen solche Statuetten aber seit frühptolemäischer Zeit (z.B. in Athribis). Da keine so enge Bindung an das ptolemäische Staatswesen besteht, wie dies beispielsweise für die Soldatenstatuetten anzunehmen ist, könnte die Produktion das Ende des Ptolemäerreiches überdauert haben.

\subsubsection{Köpfe}

Bisher unerwähnt blieb die große Anzahl von Tonköpfen (45 Exemplare: Tk 29-35, 37-38, 66-77, 80-93, 101, 103, 108, 120-121 a-f). Sie sind alle bartlos, das Aussehen der Gesichter, Frisuren etc. schwankt. Bei den Köpfen handelt es sich um Fragmente von Figuren ${ }^{373}$, die sich anteilig auf die vier genannten Themen (Chlamydephoroi, Soldaten, Reiter, Harpokrates) verteilen dürften.

Schließlich wurde in Memphis (Mit Rahineh) ein nur zwei Zentimeter großes Köpfchen (P 3) aus gelbem Kalkstein gefunden. Es entzieht sich mangels erhaltenem Körper oder bekannter Fundumstände einer Deutung.

\subsubsection{Zusammenfassung: Kleinformatige Statuetten mit Kausia aus Ägypten}

Alle aus Ägypten stammenden Terrakottastatuetten mit Kausia, die so weit erhalten sind, dass sie sich einem Typus oder zumindest Thema zuweisen lassen, verteilen sich auf nur vier Themen: Chlamydephoros (29,5\%), Soldat (22,7\%), Reiter (40,9\%) und Harpokrates (6,8\%). Sämtliche anderen im hellenistisch-römischen Ägypten in großer Zahl vorkommendem Themen und Typen von Terrakotten werden niemals mit der Kausia kombiniert.

Dies bedeutet, dass die Kausia nicht willkürlich dargestellt wurde, sondern bildliche Wiedergaben dieser Kopfbedeckung nur in bestimmten Kontexten Verwendung fanden.

\footnotetext{
${ }^{371}$ Vgl. J. Fischer, Der Zwerg, der Phallos und Harpokrates, in: H. Felber - S. Fisterer-Haas (Hrsgg.), Ägypter Griechen - Römer. Begegnungen der Kulturen, Kanobos 1 (1999) 39 .- K. Mysliwiec, Fruchtbarkeitskult und erotische Kunst im ptolemäischen Athribis (Unterägypten), in: H. Felber - S. Pfisterer-Haas (Hrsgg.), ÄgypterGriechen-Römer, Kanobos 1 (1999) 55 ff.

${ }^{372}$ Vgl. J. Fischer, Der Zwerg, der Phallos und Harpokrates, in: H. Felber - S. Fisterer-Haas (Hrsgg.), Ägypter Griechen - Römer. Begegnungen der Kulturen, Kanobos 1 (1999) 38.

${ }^{373}$ Die zugehörigen Körperfragmente „finden“ sich wesentlich seltener. Dies ist darauf zurückzuführen, dass Köpfe bis heute bevorzugt aufgesammelt, inventarisiert und bearbeitet werden. Eine Deutung wird durch diese Art der „Materialaufnahme“ weitgehend unmöglich gemacht.
} 
Der Beginn und das Ende der Herstellung und Verwendung von Tonfiguren mit Kausia fallen in Ägypten mit der Begründung und dem Untergang des Ptolemäerreiches weitgehend zusammen - soweit sie äußerlich datierbar sind. Es lässt sich jedoch nicht ausschließen, dass Typen, die mit Institutionen (Gymnasion, Ephebie) oder Kulten (Harpokrates) in Verbindung standen, die das Ende des Ptolemäerreiches überdauerten, weiterhin hergestellt wurden.

\subsubsection{Kleinasien (einschließlich Lesbos)}

Die 60 aus Kleinasien stammenden Statuetten mit Kausia (Tk 127-185) gehören fast alle dem „Typus stehender Chlamydephoros“ an. ${ }^{374}$ Andere Chlamydephorentypen sowie Reiter sind selten, Soldaten erscheinen überhaupt nicht. Die Figuren werden in der Forschung in den Zeitraum vom 3. Jahrhundert v. Chr. bis zum 2. Jahrhundertn. Chr. datiert.

\subsubsection{Chlamydephoroi}

\section{„Typus sitzender Chlamydephoros“}

Sitzende Chlamydephoren kommen in Kleinasien nur fünfmal vor. Sie sind wie die ägyptischen Vertreter dieses Typus mit Kausia, Chlamys und Chitonbekleidet.

Ein Exemplar (Tk 166) mit der Fundortbezeichnung „ionische Küste“ ist in Denkerpose dargestellt (Taf. 23 Abb. 85). Das Kinn ist auf den rechten Arm gestützt, der linke Arm liegt auf dem Oberschenkel.

Die Armhaltung der übrigen vier, aus Lesbos (Mytilene) stammenden Terrakotten (Tk 180183, Taf. 23 Abb. 86) schwankt. Während der rechte Arm jeweils auf dem rechten Oberschenkel liegt und in einigen Fällen in den Mantel gehüllt ist, kann der linke Arm unter dem Mantel vor den Oberkörper gelegt sein oder neben dem Körper auf dem Felsen aufliegen. Die Beine (Unterschenkel) sind bei allen mytilenischen Chlamydephoren gekreuzt wiedergegeben (beim „ionischen“ und allen ägyptischen sitzenden Chlamydephoren sind die Beine parallel gestellt). Aus dem rechten hinteren Bereich der Felsensitze sämtlicher mytilenischer, sitzender Chlamydephoren erwächst eine Herme. Diese ist bei anderen sitzenden Chlamydephoren nie nachweisbar.

Der ,ionische“ Denker (Tk 166) wird aus stilistischen Gründen in den Zeitraum vom Ende des vierten bis zum Anfang des dritten Jahrhunderts datiert. Die mytilenischen Chlamydephoren (Tk 180-183) stammen aus einem Gräberfeld bei Mytilene, das Ende der achtziger Jahre ordentlich gegraben wurde. Sie können unter anderem aufgrund von mitgefundenen Münzen in die Zeit nach 250 v. Chr. datiert werden. Dem entsprechen auch Gewandgestaltung und Frisur.

\footnotetext{
${ }^{374}$ Nach Abzug von 16 Köpfen lassen sich 44 Statuetten einem Typus zuweisen. Es handelt sich um 41 Chlamydephoroi bzw. Fragmente vom solchen (93\%), zwei Reiter (5\%) und eine Ausnahme (Affe mit Schild, Schwert und Kausia).
} 
Die weitgehende typologische und zeitliche Übereinstimmung zwischen den mytilenischen und den ägyptischen sitzenden Chlamydephoren ist auffallend. Das zeitliche Zusammenfallen der Verbreitung der sitzenden Chlamydephoren mit dem Zeitpunkt der größten ptolemäischen Machtentfaltung ${ }^{375}$ im ägäischen Raum könnte Zufall sein - zumal die Materialbasis recht gering ist - könnte aber auch ptolemäischen Einfluss reflektieren. Dem widerspricht teilweise, dass sich mit Tk 182 formgleiche ${ }^{376}$ Statuetten (ohne Kausia) in Tanagra fanden. ${ }^{377}$ Dies könnte auf eine Bindung der mytilenischen Variante an den attisch-böotischen Raum, vielleicht auch eine dortige Produktion, hinweisen, die sich jedoch wiederum an der Nachfrage auf einem ptolemäisch dominierten Markt orientiert haben könnte.

\section{„Typus stehender Chlamydephoros“6}

Die Statuetten stehender Chlamydephoren zeigen eine männliche Person, die mit Kausia, Chiton und auf der rechten Schulter zusammengesteckter, ganz überwiegend längerer ${ }^{378}$ Chlamys bekleidet sind. Der rechte Arm hängt locker herab und ist meist in den Mantel gehüllt, der Linke befindet sich angewinkelt unter der Chlamys und liegt auf der Brust auf. Dieser Normaltypus (vgl. Taf. 24 Abb. 88-89) kann dahingehend variiert werden, dass die Chlamys mit der rechten unter dem Mantel liegenden Hand vor das Gesicht (in der Regel nur vor das Kinn) gezogen wird (vgl. Taf. 25 Abb. 91-93). Dieser Variante gehören in Kleinasien acht Exemplare (Tk 135-137 a-b, 139 [?], 158-159, 184) an (hierbei sind Fragmente und Köpfe, bei denen dieser Gestus erkennbar ist, mitgezählt). Stehende Chlamydephoren mit nicht vor das Kinn gezogener Chlamys treten 27-mal auf (Tk 127-134, 144-154, 157, 164, 167-168, 172-174, 176), Köpfe sind hier nicht mitgezählt.

\section{Typus „Ephebensoldat“}

Dem in der gesamten hellenistischen Welt relativ seltenen Typus des „Ephebensoldaten“379 gehören zwei Statuetten (Tk 175 [Xanthos], 179 [Lykien/Pamphylien?]) aus dem südwestlichen Kleinasien an (vgl. Taf. 27 Abb. 98-101). Wie die Vertreter der übrigen Chlamydephoren-Typen zeigen auch die „Ephebensoldaten“ männliche Personen in Chlamys und Chiton. Der Unterschied zwischen den Typen besteht in der Drapierung und der Länge der Gewänder sowie im scheinbaren Alter der dargestellten Personen. Während die Chlamys der Chlamydephoren vom „Normaltypus“ meist mindestens knöchellang ist und den Körper weitgehend verhüllt, ist die auf der rechten Schulter zusammengesteckte Chlamys der „Ephebensoldaten“ meist kürzer - wie die der „Soldaten“ - und wird mit Hilfe der in die Taille gestützten Arme

\footnotetext{
${ }^{375}$ Vgl. G. Hölbl, Geschichte des Ptolemäerreiches (1994) 46 ff. und Karte 1.

376 „Formgleichheit“ bezieht sich bei Terrakotten meist nicht auf die Kopfbedeckungen. Diese wurden oft erst nachträglich angesetzt.

${ }^{377}$ Winter, Typen II, 256 Nr. 3.

${ }^{378}$ Knie- bis knöchellang, teilweise bis auf den Boden fallend.

379 Die wenigen weiteren Vertreter dieses Typus stammen aus Kallatis (Tk 284 [formgleich mit Tk 292]), Athen/Böotien (Tk 292-293), Zypern (Tk 371-372, 374), Kharayeb (Tk 380 a-b) und Uruk (Tk 437 a-b).
} 
diagonal zurückgehalten. Die Folge ist, dass der Körper und das Untergewand, ein kurzer Chiton, zum Vorschein kommen. Infolge der Kürze der Gewänder sind bei den „Ephebensoldaten" die Stiefel, die sonst oft verdeckt sind, meist erkennbar. Bei den dargestellten Personen handelt es sich eindeutig um junge Männer, während die anderen Chlamydephoren-Typen oft den Anschein erwecken, Jugendliche oder Knaben zu zeigen.

Eine Statuette stammt aus dem Letoon von Xanthos (Tk 175). Die Figur wurde in einem Bothros des Heiligtums gefunden, ist also als Votiv verwendet worden. Die übrigen Funde aus diesem Bothros, der zwischen 98 und 102 n.Chr. überbaut wurde, werden ins 6. - 1. Jahrhundert v.Chr. datiert. Die Langhaarfrisur deutet in frühhellenistische Zeit, die Figur ist jedoch von schlechter Qualität oder stark verrieben, was eine stilistische Einordnung erschwert.

Die zweite Figur befindet sich in Antalya (Tk 179) und dürfte aus der Umgebung der Stadt stammen (Lykien/Pamphylien). Nähere Angaben zum Fundort liegen jedoch nicht vor.

\section{Datierung der Chlamydephoren-Typen}

Die Datierung wird durch die unklaren Fundumstände der meisten Statuetten, die sich größtenteils seit dem 19. Jahrhundert in westeuropäischen Museen befinden, erschwert. Aufgrund des Fundzusammenhanges lassen sich nur wenige Stücke datieren ${ }^{380}: \mathrm{Zu}$ nennen sind hier die mytilenischen Tonfiguren (Tk 180-182, 184), die durch mitgefundene Münzen in die Zeit kurz nach 250 v. Chr. datiert werden, und die trojanischen Terrakotten (Tk 135-136, 139-142), für die sich aus dem stratigraphischen Befund ein terminus ante quem von 85 bzw. 22 v. Chr. ergibt. Die Exemplare aus Limyra (Tk 176-178) stammen aus hellenistischen und späthellenistischen Schichten. Eine Terrakottafigur aus dem Letoon von Xanthos (Tk 175) muss vor 102 n. Chr. in den Boden gelangt sein.

Diese wenigen und weitauseinander liegender Daten, die zusätzlich dadurch in ihrer Aussagekraft geschwächt werden, dass jeweils nur der terminus ante oder post quem, nie jedoch beide vorliegen, bilden die Grundlage. Hinzu kommen Erkenntnisse zur Chronologie anderer Kunstlandschaften, die mit einiger Vorsicht auch zur Datierung kleinasiatischer Terrakotten herangezogen werden können.

Verbindet man die relative chronologische Ordnung der in Kleinasien gefundenen Statuetten mit den halbwegs gesicherten absoluten Daten, ergibt sich, dass in dieser Region Chlamydephoros-Statuetten mit Kausia vom 3. Jahrhundert v.Chr. ${ }^{381}$ bis ins 2. Jahrhundert n.Chr. ${ }^{382}$ produziert wurden.

\footnotetext{
${ }^{380}$ Zur Verbreiterung werden hier auch einige Köpfe (Tk 139-142, 177-178) zur Datierung des Typus Chlamydephoros herangezogen, da es sich bei den in Kleinasien nachgewiesenen Terrakotten mit Kausia fast ausschließlich um Chlamydephoren handelt und deshalb auch die Köpfe mit großer Wahrscheinlichkeit entsprechend zu ergänzen sind.

${ }^{381}$ Die frühesten Exemplare sind Tk 166 (sitzender Chlamydephoros von der ,ionischen Küste“) und Tk 180-183 (sitzende und stehende Chlamydephoren aus Lesbos).

${ }^{382}$ Vermutlich erst ins zweite nachchristliche Jahrhundert gehören: Tk 152-156 („südliche Aiolis“), Tk 164 (Kyme), Tk 172 (ionische Küste/Smyrna). Vgl. hierzu jedoch unten die Problematik der Datierung der stilistisch ähnlichen Statuetten aus Delos (Tk 302-303).
} 


\subsubsection{Reiter}

In Kleinasien wurden nur zwei Reiter (Tk 138, 185) gefunden. Beide sind mit dem ptolemäischen Typus „Reiter ohne Gegner“ (Taf. 30 Abb. 111-112) vergleichbar.

Der Reiter Tk 138 stammt vermutlich aus der Troas. Pferd und Reiter bewegen sich im Gegensatz zu allen anderen Reiterterrakotten nach links. Der Reiter trägt langes, gewelltes Haar, gleiches gilt auch für die nachfolgend beschriebene Statuette Tk 185 (aus Lesbos?). Die Langhaarfrisur verbindet die kleinasiatischen Reiter mit den typologisch und stilistisch sehr ähnlichen „Reitern ohne Gegner“ (Tk 58-60) aus der alexandrinischen Nekropole von Sciatbi, die in die Zeit von 320 - 240 v.Chr. datiert werden.

In der Literatur ${ }^{383}$ wird als Fundort des Reiters ohne Gegner Tk 185 „Kleinasien“ oder „Myrina?“ genannt. Dies beruht höchst wahrscheinlich auf der Tendenz, kleinasiatische Terrakotten mit nicht näher bestimmbarem Fundort im Zweifelsfall Myrina zuzuordnen. Vergleichbare Terrakotten aus Myrina existieren in diesem Fall jedoch nicht. Heute befindet sich die Reiterstatuette in Leipzig, wohin sie 1901 als Geschenk Peter Warrens gelangte. Vorher gehörte das Stück einer Sammlung auf Lesbos an. Für Lesbos auch als Fundort spricht neben dem früheren Aufbewahrungsort, dass alle mytilenischen Terrakotten sich - wie dieser Reiter - an ptolemäische bzw. mutterländische Typen anschließen lassen.

Von den bisherigen Bearbeitern wird die Reiterstatuette Tk 185 in hellenistische Zeit bzw. ins 2. Jahrhundert v. Chr. datiert. Aufgrund der Langhaarfrisur, der runden Gesichtsform und des Typus' würde ich eher zu einer früheren zeitlichen Einordnung (3. - bis Anfang 2. Jahrhundert v. Chr.) tendieren. ${ }^{384}$

\subsubsection{Ausnahmen}

Die einzige Terrakottafigur mit Kausia aus dieser Region, die weder einen Chlamydephoren noch einen Reiter wiedergibt, zeigt einen Affen mit Rundschild und gezücktem Schwert. Die Statuette (Tk 165) wurde in Larisa am Hermos gefunden und entstammt einer Zerstörungsschicht, die von den Ausgräbern ${ }^{385}$ in die Zeit um 300 v.Chr. datiert wird.

\subsubsection{Zusammenfassung: Terrakotten mit Kausia aus Kleinasien}

Betrachtet man die Verteilung der kausiatragenden Terrakottastatuetten über Kleinasien (Karten 3, 5), stellt man fest, dass diese sich fast ausschließlich an der Westküste finden und auch hier sehr ungleichmäßig verteilt sind. Die ionische Küste mit den alten Zentren griechischer Kultur in Kleinasien fällt fast vollständig aus. Stattdessen lässt sich eine Konzentration an der Nordwestküste (Aiolis, Troas) feststellen. Dies könnte darauf zurückzuführen sein, dass diese Gebiete erst in hellenistischer Zeit in stärkerem Maße hellenisiert wurden und sowohl make-

\footnotetext{
${ }^{383}$ E. Paul, Antike Welt in Ton (o. J. [spätestens 1968]) 86: Kleinasien, hellenistisch .- S. Fisterer-Haas, Antike Terrakotten (1996) 48: Myrina ?, 2. Jh. v.Chr.

${ }^{384}$ Vgl. z.B. die Figuren aus Sciatbi und Hadra (Tk 39-42, 46-47, 58-59).

${ }^{385}$ J. Boehlau, K. Schefold (Hrsgg.), Larisa am Hermos. Die Ergebnisse der Ausgrabungen 1902-34. Bd. 3: Die Kleinfunde (1942) 44 Taf. 9, 16.
} 
donischer Einfluss als auch entsprechende identitäts- und gemeinschaftsstiftende Symbole hier, wie in Ägypten, von besonderer Bedeutung waren.

Problematisch ist, dass der allergrößte Teil der kleinasiatischen Terrakotten aus dem Kunsthandel stammt und Fundortbezeichnungen wie „südliche Aiolis“ und „ionische Küste“ eher vage und unsichere Hinweise liefern. ${ }^{386}$

Die unklare bzw. nicht nachvollziehbare Herkunft vieler Terrakotten erschwert auch die geographische Eingrenzung des Verbreitungszentrums derjenigen Chlamydephoren, die das Gewand vor den unteren Bereich des Gesichts ziehen. Nachweisen lässt sich diese Variante in Troja (Tk 135-137 a-b, 139 [?]), auf Lesbos (Tk 181-84) und in Myrina (Tk 158-159). Im Rest Kleinasiens (einschließlich der „südlichen Aiolis“) ist sie unbekannt. Die das Gesicht verhüllenden Chlamydephoren scheinen typisch zu sein für den nordägäischen Raum, denn vergleichbare Exemplare finden sich auch auf Samothrake sowie in Amphipolis, Kassandreia, Pydna und Demetrias ${ }^{387}$. In anderen Regionen erscheint diese Variante nur sporadisch. ${ }^{388}$

Der chronologische Rahmen weicht von dem in Ägypten gegebenen ab. Wenn die genannten Datierungsansätze zutreffen, hielt die Produktion von Statuetten mit Kausia in Kleinasien vom 4./3. Jahrhundert v.Chr. bis ins 2. nachchristliche Jahrhundert an. Die Figuren überdauerten demnach das politische Ende des Hellenismus in Kleinasien und behielten ihre Funktion und Bedeutung auch unter römischer Oberherrschaft bei. ${ }^{389}$ Dies steht im Gegensatz zu den Verhältnissen in Ägypten, wo das Ende der Herstellung von Terrakotten mit Kausia - soweit nachweisbar - mit dem politischen Untergang des Ptolemäerreiches zusammenfiel, obwohl eine hellenistisch geprägte Kultur auch in Ägypten noch jahrhundertelang weiter bestand.

Während Kleinasien in chronologischer Hinsicht über Ägypten hinausgreift, erweist sich das thematische Spektrum als stark verengt: Es erscheinen fast ausschließlich Chlamydephoren $(\sim 93 \%)$.

\subsubsection{Makedonien, Griechenland, Schwarzes Meer}

Die Balkanhalbinsel und die angrenzenden westlichen und nördlichen Küstenregionen des Schwarzen Meeres bilden geographisch ein zusammenhängendes, relativ kompaktes Gebiet.

Die Region weist dennoch eine starke sowohl ethnische als auch politische Differenzierung auf, die ihren Niederschlag in einer entsprechenden Vielschichtigkeit des Fundmaterials findet. Für die vorliegende Untersuchung macht dies eine Untergliederung einerseits nach Volksgruppen (Griechen, Makedonen, Illyrer, Thraker), andererseits nach politischen Verhältnissen,

\footnotetext{
${ }^{386}$ Auch der Fundort „Smyrna“ ist problematisch, da Smyrna im 19. und frühen 20. Jahrhundert das Zentrum des „Kunsthandels“ war.

387 Tk 240, 249-260 (Samothrake), Tk 197-198 a-b (Amphipolis), Tk 188 (Pydna [formgleich mit Tk 294-295 aus Athen/Böotien]), Tk 334 (Kassandreia), Tk 307-309 (Demetrias).

${ }^{388}$ Tk 123 (Kyrenaika), Tk 294-296 (Athen/Böotien, ab frühem 3. Jahrhundert!), Tk 368 (Lipari).

389 Ähnliches ist in Mesopotamien zu beobachten, wo bis weit in parthische Zeit Terrakotten mit Kausia Verwendung fanden (Vgl. unten).
} 
das heißt in diesem Zusammenhang meist nach Form und Beginn der Abhängigkeit einer Polis oder eines Stammes von Makedonien, notwendig.

Das Ergebnis ist eine Unterteilung in folgende Gebiete:

a) Makedonien (in den Grenzen von 359 v.Chr.), b) nordgriechische Poleis, die von Philipp II. zwischen 359 und 340 v.Chr. an Makedonien angeschlossen wurden, c) griechische Poleis an der Küste des Schwarzen Meeres, die seit Philipp II. unter makedonische Herrschaft oder makedonischen Einfluss gerieten, d) griechische Poleis, die nach der Schlacht von Chaironeia (338 v.Chr.) in Abhängigkeit von Makedonien gerieten (Korinthischer Bund) und teilweise makedonische Garnisonen aufnehmen mussten, e) königlich-makedonische Neugründungen, f) griechische Poleis auf der Krim/Bosporanisches Reich.

Diese Einteilung ist in erster Linie im Rahmen der Untersuchung der Terrakotten zweckmäBig. Bildliche Wiedergaben, die anderen Gattungen (Plastik, Relief, Malerei, Münzen, Kameen, Siegel) entstammen, entziehen sich u.a. aufgrund der wesentlich geringeren Anzahl der Darstellungen meist einer solchen Untergliederung.

\subsubsection{Makedonien (in den Grenzen von 359 v. Chr.)}

„Makedonien“ meint an dieser Stelle diejenigen meist ländlichen Gebiete, die schon vor dem Beginn der großen Expansion unter Philipp II. von Makedonen bewohnt und von makedonischen Königen beherrscht wurden. Nicht zu „Makedonien“ gehören in diesem Sinne selbst Städte, die in hellenistisch-römischer Zeit eng mit der Geschichte Makedoniens verbunden waren, wie z.B. Pydna, das bis 357 v.Chr. als unabhängige Polis dem Attischen Seebund angehörte.

Das Ziel einer solch rigiden Eingrenzung ist der Versuch, die makedonische Selbstdarstellung auf ,urmakedonischem“ Boden, d.h. in einem Gebiet, in dem Makedonen nicht in Konkurrenz oder einem anderen Spannungsverhältnis zu weiteren Volksgruppen(z.B. Griechen, Ägyptern, Mesopotamiern) standen, zu erfassen, um das Ergebnis mit dem anderer Gebiete vergleichen zu können, in denen Makedonen - meist als Minderheit - mit anderen Bevölkerungsgruppen zusammenlebten.

Sämtliche bekannten Tonfiguren mit Kausia aus Makedonien stammen aus zwei Kammergräbern bei Pella. Es handelt sich um fünf formgleiche Statuetten (Taf. 40 Abb. 158) von Knaben in Chlamys, Chiton und Kausia, die auf Ziegenböcken reiten (Tk 186 a-e, aus Grab $\Theta$ ), und einen weiteren Knaben (in Chlamys, Endromides und Kausia) auf einem Ziegenbock (Tk 187) aus einem Grab auf dem Grundstück Zotakis. ${ }^{390}$

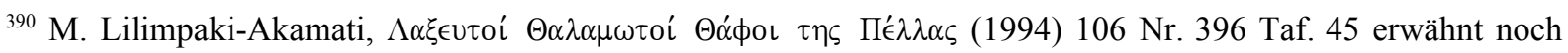
fünf Eroten mit Kausia im gleichen Grab. Das einzig abgebildete Exemplar trägt jedoch keine (erkennbare) Kopfbedeckung. Die für die Kopfbedeckung angegebenen Vergleichsstücke (Leyenaar-Plaisier, Leiden, 110. 515 Taf. 38 Nr. 221; Taf. 192 Nr. 1505 .- E. Paul, Tanagrafiguren [1962] Taf. 30 .- Besques, Paris III, 31 Taf. 38 Nr. 167) tragen durchweg einen Petasos.
} 
Anhand des Fundkontextes lassen sich der Knabe Tk 187 (Grab Zotakis) in die Zeit um 225200, die Ziegenreiter aus Grab $\Theta$ (Tk 186 a-e) in die Mitte des 2. Jahrhunderts v.Chr. datieren.

Der reitende Knabe wird von der Ausgräberin als Harpokrates gedeutet. ${ }^{391}$ Dies ist darauf zurückzuführen, dass Harpokrates (eindeutig gekennzeichnet durch Krone und Finger im Mund) in der alexandrinischen Koroplastik als auf Tieren (u.a. dem Ziegenbock) reitend dargestellt werden kann. ${ }^{392}$ Da auf verschiedenen Tieren reitende Kinder aber auch z.B. in Myrina ${ }^{393}$ vorkommen, ist die Deutung auf Horus als Kind nicht zwingend. Es könnten auch andere kindliche Götter (z.B. Eros, Dionysos) gemeint sein. Die Ziegenreiter aus Pella unterscheiden sich von den meisten anderen reitenden Kindern dahingehend, dass es sich bei ihnen um Chlamydephoroi handelt. Dies kann einerseits darauf zurückgeführt werden, dass es sich bei Chlamys und Kausia um die in Makedonien allgemein übliche Bekleidung handelt und Chlamys und Kausia immer in Kombination miteinander getragen werden. Andererseits weicht die Bekleidung von Kindern in der Regel von der der Erwachsenen ab. Die Darstellung der kindlichen Reiter in einer für Jugendliche und (junge) Männer üblichen Kleidung könnte daher auf eine den Chlamydephoren vergleichbare Deutung hinweisen. ${ }^{394}$

Makedonien gehört zwar nicht zu den Zentren der Herstellung und Verwendung von Tonfiguren, diese erscheinen hier jedoch durchaus in nennenswertem Umfang. ${ }^{395}$ Die geringe Anzahl von Terrakotten mit Kausia ausgerechnet im Ursprungsgebiet dieser Kopfbedeckung lässt sich demnach nicht mit der geringen Anzahl von Tonfiguren allgemein erklären. Auffällig ist auch, dass nicht nur die Zahl koroplastischer Wiedergaben der Kausia im makedonischen Kernland gering ist, sondern auch die sonst in makedonisch dominierten Landschaften regelmäßig in Kombination mit der Kausia auftretenden stehenden und sitzenden Chlamydephoren-Typen vollständig fehlen. Im weitgehenden Fehlen dieser Chlamydephoren-Statuetten (sowohl mit Kausia, aber auch mit Petasos oder barhäuptig!) ist demnach der Grund für das geringe Vorkommen von Darstellungen der Kausia in der Koroplastik zu sehen.

Das Nichtvorhandensein der Chlamydephoren-Typen wiederum kann nicht auf eine geringe Bedeutung derjenigen Institutionen oder Personengruppen (Gymnasion/Epheben, aber auch Soldaten u.a.) zurückgeführt werden, die in den neuen hellenistischen Reichen mit einiger Sicherheit mit diesen zu verbinden sind. Gymnasion und Ephebie sind auch für Makedonien nachweisbar, und auch militärische Aspekte spielten, wie die Ephebenordnungen zeigen, eine besondere Rolle. ${ }^{396}$ Auch die zugehörigen Kulte müssen existiert haben, in diesen herrschten

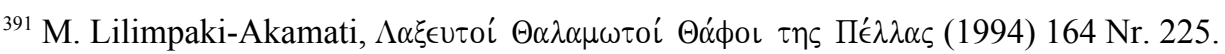

${ }^{392}$ Vgl. z.B. Fischer, Slg. Sieglin/Schreiber, Nr. 616-28.

${ }^{393}$ Auf sie und nicht die alexandrinischen Stücke beruft sich M. Lilimpaki-Akamati a.a.O. 168 Nr. 225.

${ }^{394}$ Auf die Deutung, Symbolik und Funktion von Chlamydephoren wird unten eingegangen.

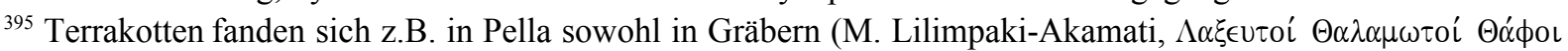

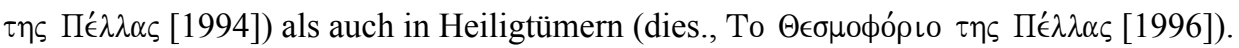

${ }^{396} \mathrm{Vgl}$. z.B. M. B. Hatzopoulos, Macedonian Institutions under the Kings, Meletemata 22 (1996) $87 \mathrm{f.} 131 \mathrm{ff}$. 150 ff. 182. 209 (mit Anm. 1). 381. 387. 393. 397. 405. 409 ff.
} 
jedoch möglicherweise andere Kultpraktiken vor, z.B. die Weihung bzw. Opferung von vergänglichen Materialien oder die Weihung nicht von Wiedergaben des Gottes oder des Weihenden, sondern von Darstellungen des Opfertieres. ${ }^{397}$

Darstellungen der Kausia fehlen demnach in der Koroplastik Makedoniens nicht, weil diese Kopfbedeckung in der Realität nicht getragen wurde, sondern da die Kausia in bildlichen Wiedergaben ausschließlich in Verbindung mit der Chlamys gezeigt wurde. Ob Chlamysträger dargestellt wurden, hing wiederum nicht nur von der Bedeutung bestimmter Institutionen sowie der mit ihnen verbundenen Kulte ab, sondern auch von variierenden Ritualen im Kult und Totenkult. Spielten hier Chlamydephoren-Figuren keine Rolle, erscheinen auch die an diese gebundenen Wiedergaben der Kausia nicht.

\subsubsection{Nordgriechische Poleis (von Philipp II. zwischen 359 und 340 v.Chr. erobert)}

Die hier behandelten Poleis (Pydna, Amphipolis, Samothrake) liegen in an Makedonien angrenzenden Gebieten und wurden schon zu Beginn der makedonischen Expansion dem Argeadenreich bei weitgehendem Verlust ihrer Unabhängigkeit einverleibt.

Die älteste Figur aus dieser Region wurde in einem Grab bei Pydna (Südnekropole, kleines Kistengrab, Tk 188) entdeckt und wird an das Ende des 4. Jahrhunderts v.Chr. datiert. Sie zeigt einen stehenden Chlamydephoros mit Kausia, Chlamys, Chiton und ausnahmsweise einmal gut erkennbaren Krepides (vgl. Taf. 25 Abb. 90). Die sehr qualitätvolle Statuette ist formgleich mit zwei weiteren Exemplaren in London und New York (Tk 294, 295) und dürfte wie diese attischen Ursprungs sein, während die nachfolgend beschriebenen Tonfiguren aus Amphipolis und Samothrake eher einheimischer Produktion entstammen.

Aus Amphipolis, und soweit bekannt, ${ }^{398}$ wiederum aus Nekropolen (Tk 189-200), kommt eine größere Anzahl von Chlamydephoroi verschiedener Typen. Es handelt sich um die Statuette eines sitzenden Chlamydephoren in „Denkerpose“ (Tk 189, vgl. Taf. 23 Abb. 85), sieben sitzende Chlamydephoren-Statuetten, in zurückgeschlagener Chlamys und Kausia, aber ohne Chiton, d.h. weitgehend entblößt (Tk 190-196, vgl. Taf. 23 Abb. 83), drei stehende vollbekleidete Chlamydephoren, die das Kinn bzw. den unteren Bereich des Gesichtes mit der Chlamys verhüllen (Tk 197-198 a-b, Taf. 25 Abb. 91) sowie um einen stehenden Jüngling im Mantel (Chlamys oder Himation) ohne Chiton (Tk 199 [o. Abb.]) und einen stehenden jungen Mann mit am Rücken herabgerutschtem Mantel, ohne Chiton, das heißt weitgehend nackt (Tk 200 [o. Abb.]).

\footnotetext{
${ }^{397}$ Vgl. z.B. die Darstellung eines Widders aus Grab Q in Pella (M. Lilimpaki-Akamati, $\Lambda \alpha \xi \in \in$ coó $\Theta \alpha \lambda \alpha \mu \omega \tau o i ́$

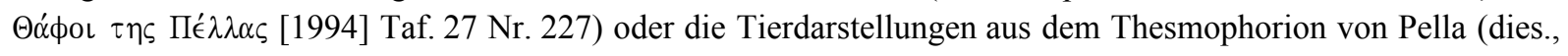

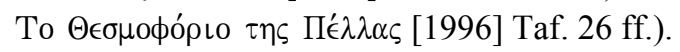

${ }^{398}$ Die Statuetten aus Amphipolis stammen meist aus alten Grabungen bzw. sind nur im Rahmen kurzer Vorberichte publiziert worden.
} 
Nachtrag: In den Jahren 1999-2000 wurden bei Notgrabungen anlässlich von Straßenbaumaßnahmen (Via Egnatia) mehrere Nekropolen mit teils hunderten von Gräbern aufgedeckt. Die Ergebnisse sind bisher nur in kurzen Vorberichten publiziert: Stehende Chlamydephoren vom Normaltypus mit Kausia wurden jedoch sowohl in der Ost-Nekropole ${ }^{399}$ von Amphipolis als auch bei Nea Kerdyllia (Grabung Modi ${ }^{400}$ ), ebenfalls in der Nähe von Amphipolis gelegen, gefunden.

Von der Insel Samothrake waren bis vor kurzem nur drei Terrakottastatuetten mit Kausia bekannt. ${ }^{401}$ Die Publikation der Funde aus den Nekropolen der Insel ließ diese Zahl um weitere 45 Exemplare anwachsen. ${ }^{402}$ Aufgrund von Formkoppelungen konnte im Anschluss an diese Veröffentlichung darüber hinaus ein Komplex von Tonfiguren im Louvre, der u.a. 32 Statuetten mit Kausia beinhaltet und bisher als ,aiolisch“ angesehen wurde, ${ }^{403}$ der Insel Samothrake zugeschrieben werden. ${ }^{404}$ Die Gesamtzahl der auf Samothrake nachweisbaren koroplastischen Darstellungen von Kausiaträgern beträgt damit mindestens ${ }^{405} 80$. Diese für einen einzelnen Ort überaus hohe Anzahl - es ist die nach Alexandria höchste - ist weniger auf die Bedeutung der Insel bzw. der Statuetten mit Kausia auf ihr zurückzuführen, als darauf, dass hier einmal Fundmaterial in großer Zahl und nicht nur in Auswahl publiziert wurde. Hierfür spricht auch, dass die Figuren aus einer nur geringen Anzahl von Formen stammen.

Da die Art der Veröffentlichung im Falle der Terrakotten aus Samothrake von Bedeutung ist, werde ich das Material nach Publikationsort und -zeitpunkt untergliedert vorstellen:

$\mathrm{Zu}$ den drei schon lange publizierten Stücken zählt ein Kopf mit Kausia (Tk 248 x [o. Abb.]), der sich im Vorhof zum Propylon des Heiligtums der Großen Götter fand. Er gehört, wie ähnliche Fragmente sowie Bruchstücke von Frauenfiguren mit Hydria, zu Schuttmassen, die den Hang zwischen Stadt und Heiligtum herabgerutscht sind und in keinem Zusammenhang zum Heiligtum der Großen Götter stehen. Wie sich aus der Zusammensetzung des Schuttes (Chlamydephoroi mit Kausia, Hydrophoren) ergibt, befand sich am Hang oberhalb des Heiligtums

\footnotetext{
${ }^{399}$ P. Malama, AErgMak 14, 2000, 55-70 (bes. 58 Plan 3, 65, 70 Abb. 20): Schnitt A, Grab 43 enthält neben einem stehenden Chlamydephoros weitere Terrakotten (zwei stehende weibliche Figuren in Chiton und Mantel, mit Krone und in der Hand Diptychon[?], aufgestützter nackter Eros, nackter Mann in Hüftmantel mit Langschild [Standmotiv wie „Thermenherrscher“]) und Keramik (hauptsächlich Pyxiden). Die Nekropole wurde vom 5. Jh. v.Chr - 1. Jh. n.Chr. genutzt, das Grab wird in die hellenistische Zeit datiert.

${ }^{400}$ P. Malama/M. Christopoulou/K. Ntarkis, AErgMak 14, 2000, $71-85$ (bes. 72 Plan 1, 74, 82 Abb. 4): Grab 13 (3.-1. Jh. v.Chr.) enthält neben zwei stehenden Chlamydephoroi mit Kausia, einen Chlamydephoros ohne Kopfbedeckung, zwei kleine Reiter sowie eine Vase und Schmuck

${ }^{401}$ Tk 244, 246 (Vgl. BCH 80, 1956, 321. 325 Abb. 6.). Tk 248 x. Vgl. J. R. McCredie, Hesperia 34, 1965,120 f. Taf. 38c.

${ }^{402}$ Tk 201-243, 245, 247. Vgl. E. B. Dusenbery, Samothrace - The Necropoleis, Samothrace 11 (Hrsgg.: K. Lehmann, Ph. Williams Lehmann) (1998).

${ }^{403}$ Tk 249-280. Vgl. Besques, Paris III, $114 \mathrm{ff}$.

${ }^{404}$ Vgl. Dusenbery, Samothrake, 867 ff. Anm. 14.

${ }^{405}$ Hinweise auf weitere Statuetten finden sich bei J. R. McCredie, Hesperia 34, 1965, 120 f. (Vgl. Tk 248 x.) und Besques, Paris III, 117 f. D 762-770 Taf. 145 f. (Vgl. Tk 281 x.).
} 
vermutlich ein anderes Heiligtum, vielleicht eines der Demeter oder einer ähnlichen Gottheit. $^{406}$

Im Jahre 1998 erschien die Publikation der Funde aus den Nekropolen von Samothrake. ${ }^{407}$ Für die 47 dort veröffentlichten Exemplare werden als Fundorte Nekropolen zwischen der Stadt und dem Heiligtum der Großen Götter angegeben. Dies täuscht darüber hinweg, dass die meisten der Terrakotten mit dem sepulkralen Bereich nicht oder nur mittelbar in Verbindung zu bringen sind. Auch eine Verbindung mit dem Kult der Großen Götter ist fraglich.

Zum Fundmaterial gehören folgende Figuren: Ein auf einem Felsen sitzender Chlamydephoros in Denkerpose in Kausia, Chlamys, und Chiton (Tk 201), zwölf ebenso gekleidete stehende Chlamydephoroi (Tk 205, 209, 218-219, 243-247; die Hälfte hiervon nur fragmentarisch erhalten) sowie 34 Köpfe (Tk 202-204, 206-209, 211-217, 220-239). 37 der 47 Statuetten stammen aus nur vier verschiedenen Formen. Dies vermindert zwar den quantitativen Aussagewert des Materials - die hohe Zahl von Einzelstücken ist auf das nur selten übliche Veröffentlichen von formgleichen Terrakotten zurückzuführen - ermöglicht es aber 25 der 34 Köpfe sicher zu stehenden Chlamydephoroi zu ergänzen. Da auf Samothrake Kausiadarstellungen nur in Verbindung mit Chlamydephoros-Typen nachgewiesen werden können, sind vermutlich alle Köpfe entsprechend zu ergänzen.

E.B. Dusenbery schlägt für die meisten Figuren eine Datierung ins 3. Jahrhundert v.Chr. vor, insbesondere in die Zeit um 275 v.Chr. Da jedoch die zur chronologischen Einordnung herangezogenen Fund- und Befundzusammenhänge durchweg gestört sind, ${ }^{408}$ die Art der Publikation eine Überprüfung der Ergebnisse unmöglich macht ${ }^{409}$ und es Hinweise darauf gibt, dass schon bei der Fund- und Befundaufnahme im Rahmen der Grabung nicht immer systematisch

${ }^{406}$ Vgl. J. R. McCredie, Hesperia 34, 1965, 120 Taf. 38c.

407 E. B. Dusenbery, Samothrace - The Necropoleis, Samothrace 11 (Hrsgg.: K. Lehmann, Ph. Williams Lehmann) (1998). Die Publikation besteht aus zwei Bänden (The Necropoleis and Catalogues of Burials sowie Catalogues of Objects by Categories). Die doppelte Darstellung des Materials sowohl nach Fundzusammenhängen/Befunden als auch nach Gattungen ist positiv zu bewerten, da eine Dokumentation geschlossener Funde und Befunde Voraussetzung für die Beantwortung derzeit üblicher Fragestellungen ist. Die praktische Ausführung (u.a. der Verzicht auf jegliches Kartenmaterial) macht jedoch teilweise den Eindruck, dass ursprünglich nur unzureichend dokumentiertes Fundgut nachträglich (zwischen Grabung und Publikation liegen 35-45 Jahre!) an moderne Publikationskonzepte angepasst wurde. (Vgl. zu Details auch die nachfolgenden Anmerkungen.)

${ }^{408}$ E.B. Dusenbery teilt den größeren Teil der in den Nekropolen von Samothrake gefundenen Terrakotten in die „types I-IV“ ein (Dusenbery, Samothrake, 867 ff.). Unter „type“ versteht sie die Herstellung aus derselben Form. Typologisch - im Sinne meiner Typologie der Chlamydephoren-Typen - stimmen ,type I-IV“ völlig überein (stehende Chlamydephoroi in Kausia, Chlamys und Chiton).

Terrakotten des „type I“ aus dem gestörten Grab S (=Südnekropole) 130 werden anhand der Beifunde ins 3. Jahrhundert bzw. die Zeit von 275-50 v.Chr. datiert, Vertreter des ,type I“ aus dem ebenfalls gestörten Fundzusammenhang TCDS (= Terrakottadeposit in der Südnekropole) in die Jahre 300-275 v.Chr.

„Type II“ wird ebenfalls aufgrund der Beifunde aus den gestörten Fundzusammenhängen S 130 und TCDS ins 3. Jahrhundert bzw. die Zeit von 300-275 bzw. 275-50 v.Chr. datiert.

Für ,type III“ ist Datierungsgrundlage S 131 (ebenfalls gestört) und TCDS. Ergebnis ist wiederum 275-50 bzw. 300-275 v.Chr.

„Type IV“ (ohne genauen Fundort und ohne Beifunde) wird ohne Angabe von Gründen „probably“ 3. Jahrhundert datiert.

Der sitzende Chlamydephoros aus Grab S 125 wird infolge eines Beifundes (ein Unguentarium) um 300 v.Chr. datiert, alle übrigen Figuren auf ähnlich wackeliger Basis in die Zeit von 300-275 v.Chr. 
vorgegangen wurde, ${ }^{410}$ ist die zeitliche Einordnung teilweise problematisch. Die Statuetten lassen sich mit Hilfe datierter Terrakotten anderer Fundorte, stilistischer Merkmale sowie der Frisurentypen dem Zeitraum vom ausgehenden 4. Jahrhundert bis zum 1. Jahrhundert v.Chr. zuweisen. $^{411}$

Ein Fundkomplex im Louvre enthält neben Hydrophoren und anderen Terrakotten auch Statuetten mit Kausia. Bisher wurden diese Figuren von S. Besques aufgrund stilistischer Merkmale, des verwendeten Tones und von Überlegungen, wie die Stücke in den Louvre gelangt sein könnten, als ,aiolisch“ eingestuft. ${ }^{412}$ E.B. Dusenbery erkannte, dass diese Tonfiguren anhand von Formkoppelungen Samothrake zugewiesen werden können. Sie sind wahrscheinlich 1866 bei französischen Grabungen am Rande des Heiligtums der Großen Götter gefunden worden und können vermutlich - wie das Köpfchen aus dem Bereich des Propylons - mit einem Heiligtum der Demeter verbunden werden, das sich zwischen der Stadtmauer und dem Heiligtum der Theoi Megaloi am Hang befand. ${ }^{413}$

Es handelt sich um 31 Köpfe bzw. Oberkörperfragmente mit Kausia. Diese lassen sich in zwei Gruppen aufteilen. Einerseits Köpfe sowie Oberkörperfragmente mit Kausia und vor das untere Gesicht bzw. Kinn gezogener Chlamys (12 Exemplare; Tk 249-260, Taf. 25 Abb. 92), an-

\footnotetext{
${ }^{409}$ Die Publikation enthält keine Pläne: Weder wird ein Übersichtsplan beigegeben, aus dem die Lage der einzelnen Nekropolen und ihr Verhältnis zu Stadt und Heiligtum zu entnehmen wären, noch gibt es Pläne einzelner Nekropolen, die z.B. die Lage einzelner Gräber oder Konzentrationen von Terrakotten erkennen ließen, noch sind Pläne oder Schnittzeichnungen einzelner Gräber publiziert, was sich insbesondere in Anbetracht der stark gestörten Grabzusammenhänge positiv ausgewirkt hätte. - Für die Gräber der Südnekropole sind „,sections“ angegeben, die einen Fundort näher eingrenzen könnten. Mangels Plänen oder Beschreibungen im Text können jedoch weder die Lage noch der Umfang dieser ,sections“ ermittelt werden. Auch die Angabe der Tiefe unter der Oberfläche (für einzelne Gräber) ist unbrauchbar, solange das Verhältnis von antiker zu moderner Oberfläche sowie Unebenheiten in der Oberflächengestalt, Hanglagen u.ä. nicht beschrieben werden. Auch hier wären Zeichnungen der Schnitte und Plana von Vorteil gewesen.

${ }^{410}$ Das Fehlen von Schnitt- und Flächenzeichnungen deutet darauf hin, dass diese nicht oder nur in unbrauchbarer Form existieren. E.B. Dusenbery ist seit 1954 mit der Bearbeitung der Terrakotten aus den Nekropolen betraut. Aus den Inventarnummern (diese beginnen jeweils mit einer Jahreszahl) ergibt sich, dass zwischen 1955 und 1964 inventarisiert wurde. Es fällt auf, dass aus ein und demselben Grab stammende Stücke mehrere Jahre auseinander liegende Inventarnummern tragen können (so weisen z.B. die Funde aus Grab S 130 Inventarnummern der Jahre 1957, 1959 und 1960 auf) und dass 22 der 39 in der Südnekropole gefundenen Figuren mit Kausia über keinen genauer bekannten Fundort verfügen, sondern eine mit XS (= irgendwo aus der Südnekropole) beginnende Katalognummer tragen. Dies deutet auf eine nachträgliche und zeitlich zerrissene Inventarisierung und Katalogisierung des Materials sowie Mängel im Rahmen der Grabungstätigkeit und/oder Fundaufnahme hin. ${ }^{411}$ „Type I“ lässt sich aufgrund stilistischer Merkmale und der Langhaarfrisuren mit Figuren aus der Nekropole von Sciatbi (Alexandria) aus der Zeit von 320-200 v.Chr. vergleichen.

„Type II“ erinnert an spätklassisch-attische bzw. klassizistische Vergleichstücke. Die Beifunde aus dem - allerdings gestörten - Grab S 130 werden ins 4. Jahrhundert v.Chr. datiert. Warum E.B. Dusenbery die ihrer Meinung nach zugehörigen Terrakotten ins 3. Jahrhundert datiert, ist unklar.

„Type III“" gehört nach Stil und Langhaarfrisur ins 3. Jahrhundert v.Chr.

„Type IV“ (Dusenbery: „probably“ 3. Jahrhundert) lässt sich schwer einordnen. Lange auf den Schultern aufliegende Haare, aufgedunsene Gesichter und schlechte Qualität erinnern am ehesten an Beispiele aus dem 1. Jahrhundert v.Chr. (z.B. Tk 146-150, aus der „südlichen Aiolis“ [Vgl. Leyenaar-Plaisier, Leiden, 406 f.]). Andererseits weist S. Besques dem ausgehenden 2. und beginnenden 1. Jahrhundert v.Chr. kurzhaarige, eher klassizistisch wirkende Statuetten aus Samothrake (Vgl. Tk 268 ff.) zu.

${ }^{412} \mathrm{Vgl}$. Besques, Paris III, $114 \mathrm{ff}$.

${ }^{413} \mathrm{Vgl}$. Dusenbery, Samothrake, 867 ff. Anm. 14.
} 
dererseits solche mit nicht vor das Kinn gezogenem Gewand (Tk 261-280, vgl. Taf. 24 Abb. 87-89). Drei der Köpfe aus dem Louvre (Tk 277-279) sind formgleich mit solchen aus den Nekropolen von Samothrake (samothrakischer „type I“" nach Dusenbery: Tk 202, 205-210, 218-221, 242 [?], 247). Die drei Köpfe aus dem Louvre sind anhand der entsprechenden Stücke aus Samothrake sicher als stehende Chlamydephoroi zu ergänzen. Für die anderen Köpfe und Oberkörperfragmente dürfte aufgrund der im Hals- und Schulterbereich ansatzweise erkennbaren Gewänder sowie mitgefundener Gewand- und Unterkörperfragmente ebenfalls eine Rekonstruktion zu meist stehenden Chlamydephoroi-Typen wahrscheinlich sein. Datieren lassen sich die Statuetten mit Hilfe von Vergleichsmaterial aus den Nekropolen von Samothrake sowie aufgrund stilistischer Merkmalen in die Zeit vom 4. - 2./1. Jahrhundert v.Chr. ${ }^{414}$

\section{Zusammenfassung}

In den unter Philipp II. eroberten Städten treten in (spätklassisch-) hellenistischer Zeit Terrakotten mit Kausia ähnlich häufig auf wie z.B. im ptolemäischen Ägypten. Fast alle Terrakotten mit Kausia lassen sich den Chlamydephoroi-Typen zuordnen. Während auf Samothrake nur Vertreter des stehenden „Normaltypus“ (einschließlich der den unteren Teil des Gesichtes verhüllenden Variante) gefunden wurden, erscheinen in Amphipolis jedoch fast ausschließlich verschiedene (häufig sitzende) Varianten und Sonderformen.

Die Verhältnisse in den 359 bis 340 v.Chr. eroberten griechischen Pokis sind demnach, soweit sich dies an den Kausiadarstellungen ablesen lässt, denen in den von Alexander und seinen Nachfolgern eroberten Gebieten z.B. im nordwestlichen Kleinasien oder Ägypten vergleichbar. Hier wie dort erscheinen Chlamydephoren mit Kausia seit etwa 325/300 v.Chr. Die Gründe für die Wiedergabe der Kausia in bestimmten Gattungen sind also nicht in der Nähe zum makedonischen Kernland oder in einem bestimmten Zeitpunkt der Eroberung zu suchen. Vielmehr müssen in den eroberten und in unterschiedlichem Umfang makedonisch besiedelten Städten, unabhängig davon, ob diese noch von Philipp oder erst von Alexander erobert wurden, Verhältnisse geherrscht haben, die zur Herstellung und Verwendung von Chlamydephoren-Statuetten mit Kausia führten.

\subsubsection{Griechische Poleis am Schwarzen Meer unter makedonischer Kontrolle}

Die griechischen Poleis entlang der westlichen Küste des Schwarzen Meeres verbindet mit den zuvor besprochenen Städten entlang der nordwestlichen Ägäisküste, dass sie schon vor Beginn des Alexanderzuges unter makedonische Kontrolle gerieten. Diese war jedoch lockerer und endete schon mit dem Tode des Lysimachos 281 v.Chr. Im Anschluss wurde die Ge-

\footnotetext{
${ }^{414}$ Es sei hier darauf hingewiesen, dass die Statuetten vom „type I nach Dusenbery“ von E.B. Dusenbery aufgrund (gestörter) Fundzusammenhänge in die Zeit um 300-250 v.Chr., vom Verfasser unter Hinweis auf ähnliche Stücke aus Sciatbi/Alexandria in den Zeitraum von 320-200 v.Chr. und von S. Mollard-Besques aufgrund des Stiles an den Anfang des 2. Jahrhunderts. v.Chr. datiert werden.
} 
schichte dieser Region weniger durch Makedonien als den sowohl friedlichen als auch kriegerischen Kontakt zu den Bewohnern des Hinterlandes (Thraker, Kelten) geprägt.

Aus Odessos (Varna) stammt ein schreitender Chlamydephoros (Tk 282, Taf. 26 Abb. 97). Der rechte Arm hängt leicht angewinkelt am Körper herab und greift ins Gewand, die linke Hand befindet sich wie beim Normaltypus unter der Chlamys vor der Brust. Die Statuette wurde in einer Werkstatt gefunden, entstammt also sicher lokaler Produktion. Die Figur wird ins 2. Jahrhundert v.Chr. datiert. ${ }^{415}$ Da sie noch eine Langhaarfrisur aufweist, ist eine Entstehungszeit um 200 v.Chr. am wahrscheinlichsten.

Aus Kallatis (Mangalia) kommen die Oberkörperfragmente zweier Statuetten vom Typus des stehenden Chlamydephoros (Tk 285-286, vgl. Taf. 24 Abb. 87-89) und ein auf einem Felsen sitzender Chlamydephoros in Denkerpose (Tk 283, vgl. Taf. 23 Abb. 85). Die zwei Terrakotten stehender Figuren dürften aufgrund der ungewöhnlich scharfkantigen Gestaltung von Gewand und Haaren ebenfalls in der Region hergestellt worden sein. Zu den Statuetten aus Kallatis liegen keine Angaben zur Datierung vor. Da sie wie die Figuren aus Odessos lange Locken aufweisen und diese Frisur in Alexandria um 200 v.Chr. ausläuft, ist eine Datierung ins 3. Jahrhundert v.Chr. möglich.

Eine Besonderheit unter den Terrakotten aus Kallatis ist ein noch ins Ende des 4. Jahrhunderts zu datierender „Ephebensoldat“ (Tk 284), der aus der gleichen Form stammt, wie eine Statuette aus „Böotien“ in Boston (Tk 292, Taf. 27 Abb. 98). Es dürfte sich um ein Importstück aus dem attisch-böotischen Raum oder um ein aus einer exportierten Form gearbeitetes Exemplar handeln.

Weiterhin wurden in Kallatis noch zwei Köpfe mit Kausia gefunden (Tk 287-288).

In der Koroplastik der Städte am Schwarzen Meer finden sich - wie in anderen von Philipp eroberten Poleis - Kausiadarstellungen nur in Verbindung mit Chlamydephoros-Typen. Obwohl die makedonische Herrschaft schon 281 v.Chr. mit dem Tode des Lysimachos endet, werden Terrakotten mit Kausia möglicherweise bis ins 3./2. Jahrhundert v.Chr. produziert. ${ }^{416}$

\subsubsection{Griechische Poleis im „Korinthischen Bund“}

Bei den hier besprochenen Städten handelt es sich meist um die großen alten Poleis des mittleren und südlichen Griechenlands. Diese wurden zwar nicht wie die meisten Städte an der nordägäischen Küste dem makedonischen Königreich einverleibt, mussten sich jedoch nach der Schlacht von Chaironeia (338 v.Chr.) im „Korinthischen Bund“ zusammenschließen, des-

\footnotetext{
${ }^{415}$ Vgl. S. Dremisizova, Anticni Terakoti ot Bulgaria (1971) 66, 121 Nr. 83.

${ }^{416}$ Vgl. auch die Strategenreliefs (Re 3-4) aus Mesambria aus dem 2.-1. Jh. v.Chr., auf denen örtliche Beamte mit Kausia dargestellt werden. Vgl. auch oben die Überlegungen im Kapitel „Exkurs: Die ,Kausia‘ im illyrisch-thrakischen Bereich“.
} 
sen Hegemon der makedonische König war. Teilweise bzw. zeitweilig wurden in diese Städte makedonische Garnisonen gelegt (z.B. Chalkis, Athen/Piräus, Korinth).

Terrakottafiguren mit Kausia stammen aus Delos (Tk 302-304), Chalkis (Tk 301) und Korinth (Tk 305-306) sowie aus dem Bereich Attika/Böotien (Tk 289-300).

Zwischen Athen/Attika und Tanagra/Böotien wird hier und im Katalog nicht unterschieden, weil die in Böotien gefundenen Exemplare entweder ebenfalls aus Athen stammen oder zumindest maßgeblich von dort beeinflusst wurden. ${ }^{417}$ Zudem stammen die meisten der betreffenden Figuren aus dem „Kunsthandel“, so dass die Fundortangabe entsprechend unsicher ist. Bei den aus Athen und Böotien stammenden Statuetten handelt es sich um zwei Terrakottafiguren sitzender Chlamydephoren, die kein Untergewand (Chiton), sondern nur eine Chlamys und die Kausia tragen, so dass weite Teile des Körpers nicht bedeckt sind (Tk 289-290, vgl. Taf. 23 Abb. 83), eine Gipsform zur Herstellung sitzender Chlamydephoroi in Chlamys, Chiton und Kausia (Tk 291, vgl. Taf. 23 Abb. 84), zwei stehende Chlamydephoren-Statuetten vom Typus „Epheben-Soldat“ (Tk 292-293, Taf. 27 Abb. 98), drei stehende ChlamydephorenStatuetten in Chlamys, Chiton und Kausia, die ein Stück der Chlamys vor den unteren Teil des Gesichtes ziehen (Tk 294-296, vgl. Taf. 25 Abb. 90-93), einen stehenden Chlamydephoros in Chlamys, Chiton und Kausia vom „Normaltypus“ (Tk 297, vgl. Taf. 24 Abb. 87-89), eine Statuette, die einen voll bekleideten stehenden Chlamydephoros zeigt, der an einem Pfeiler lehnt (Tk 298 [o. Abb.]) sowie um zwei weitgehend nackte Knaben in heruntergerutschten Mänteln (und Kausien?) mit einem Apfel bzw. einer Theatermaske in der rechten Hand (Tk 299-300 [o. Abb.]).

Die Figuren aus Attika/Böotien sind durchweg sehr früh zu datieren ${ }^{418}$ : Die „Epheben-Soldaten" sowie der an einen Pfeiler gelehnte Chlamydephoros gehören in die Zeit um $330 \mathrm{v}$. Chr. ${ }^{419}$, alle übrigen Chlamydephoroi und Knaben ins 4. - 3. Jh. v. Chr. ${ }^{420}$

Sowohl die Thematik (Ephebie) als auch die Vorlagen sämtlicher Typen von Chlamydephoren-Statuetten haben ihren Ursprung in Athen. Athen ist die erste Polis, in der sich die Ephebie $^{421}$ in der reformierten Fassung, in der sie später in verschiedenen Varianten in fast allen hellenistischen Städten erkennbar ist, belegen lässt. Alle Chlamydephorentypen sind seit spätklassischer Zeit, d.h. seit der Begründung der straff durchorganisierten Form der Ephebie, in

\footnotetext{
${ }^{417}$ Vgl. D. Burr-Thompson, The Origin of the Tanagras, AJA 70, 1966, $51 \mathrm{ff}$.

${ }^{418}$ Vgl. die Literatur zu Tk 289-300.

${ }^{419}$ Stil und Kurzhaarfrisuren gehören noch der ausgehenden Spätklassik an. Es sind im Gegensatz zu den meisten hellenistischen Beispielen nicht scheinbar kindliche oder jugendliche Personen, sondern junge Männer dargestellt. Dies entspricht dem Alter der Epheben in spätklassisch-frühhellenistischer Zeit (18-20 Jahre). Die spätklassischen Figuren unterscheiden sich auch im Format von den hellenistischen. Sie sind mit 20-30 cm größer als die rund $15 \mathrm{~cm}$ hohen hellenistischen Chlamydephoroi. Ob sich hierin auch eine veränderte Funktion spiegelt, ist unklar.

${ }^{420}$ Stil und Langhaarfrisuren entsprechen denen der Statuetten aus den alexandrinischen Nekropolen von Sciatbi (325-240 v. Chr.) und Hadra (280-180 v. Chr.) (Vgl. Tk 39 ff.,46 ff.).

${ }^{421}$ Zur Entstehung und Bedeutung der Ephebie vgl. u. das Kapitel „Die koroplastischen Typen und ihr kulturelles Umfeld“.
} 
Athen nachweisbar. Dies gilt insbesondere auch für den Typus „Epheben-Soldat“, jenen Typus, in dem sich die nur kurzfristig bestehende, spätklassische Form der Ephebie (als Wehrpflichtorganisation) spiegelt, und der entsprechend auch vorzugsweise im letzten Drittel des 4. Jahrhunderts dargestellt wurde.

Der frühen Datierung der attischen Tonfiguren entspricht die große Bedeutung, die Athen auf politischem, kulturellem und wirtschaftlichem Gebiet im 4. und 3. Jahrhundert noch besaß. Vorbildfunktion besaßen vermutlich sowohl die attische Form der Ephebie als auch die in Athen üblichen koroplastischen Typen. Es ist mit einem Export von attischen Tonfiguren oder von Formen zur Herstellung solcher Statuetten ${ }^{422}$ bzw. der Auswanderung attischer Koroplasten zu rechnen. Hierauf weisen z.B. hin, dass sich aus einer Form stammende Chlamydephoros-Figuren mit Kausia sowohl in Athen (Tk 294-295) als auch Pydna (Tk 188) fanden, formgleiche Statuetten vom Typus „Chlamydephoros, sitzend, mit Herme“ in Tanagra ${ }^{423}$ ohne und in Mytilene (Tk 182-183) mit Kausia erscheinen und eine in Athen gefundene Form (Tk 291) geeignet ist, Figuren zu produzieren, die sich bestens unter die sitzenden Chlamydephoroi aus den frühhellenistischen Nekropolen Alexandrias (Tk 39 ff.) einreihen ließen. ${ }^{424}$ Auf das Vorkommen formgleicher „Ephebensoldaten“ in Athen/Böotien (Tk 292) und Kallatis (Tk 284) wurde schon hingewiesen.

In Verbindung mit der Kausia treten in Athen auch weitgehend nackte Knaben in heruntergerutschtem Mantel auf. Während sich die Chlamydephoroi in der nachfolgenden Zeit in erster Linie im Bereich der (makedonisierten) Diadochenreiche größerer Beliebtheit erfreuten, finden sich nackte Knaben auch in nur schwach makedonisch beeinflussten Gebieten wie Italien und der Krim.

Die attischen Koroplasten verfügten über ein umfangreiches Repertoire von Typen (z.B. Chlamydephoroi, nackte Knaben/Eroten, „Tanagräerinnen“), das sich ursprünglich an den politischen, gesellschaftlichen und religiösen Bedürfnissen der eigenen Polis orientiert haben dürfte. Teile dieses Bestandes wurden im erweiterten Verbreitungsgebiet den neuen Verhältnissen angepasst. Die Chlamydephoros-Typen, die unter Bezugnahme auf die attische Ephebie entwickelt und in Athen in der Regel mit dem Petasos kombiniert wurden, konnten für den Export in makedonisierte Bereiche mit Kausien versehen bzw. dort in der Folgezeit entsprechend nachgeahmt werden.

Im Laufe des Hellenismus ging die Bedeutung Athens in Folge des Aufstieges der hellenistischen Reiche und der kleinasiatischen Städte zurück. ${ }^{425}$ Athen sandte keine neuen Impulse mehr aus, die alten attischen Typen wurden jedoch noch jahrhundertelang weitgehend unverändert regional reproduziert.

\footnotetext{
${ }^{422}$ Durch Abformen von Tonfiguren aus Athen konnten auch in anderen Teilen der hellenistischen Welt auf einfache Art neue Formen zur Herstellung ,attischer" Statuetten gewonnen werden.

${ }^{423}$ Winter, Typen II, 256,3.

${ }^{424}$ Vgl. zur Herkunft der alexandrinischen Koroplastik z.B. J. B. Connelly, Hellenistic Alexandria, in: J. P. Uhlenbrock (Hrsg.), The Coroplast's Art (FS D. Burr Thompson) (1990) $89 \mathrm{ff}$.

${ }^{425}$ Vgl. M. Rostovtzeff, Die hellenistische Welt. Gesellschaft und Wirtschaft II (1955) 811.
} 
Aus der Nekropole der euböischen Stadt Chalkis stammt ein Chlamydephoros in Chlamys, Chiton und Kausia (Tk 301), der nicht stehend, sondern schreitend ${ }^{426}$ dargestellt ist (vgl. Taf. 26 Abb. 97). Dieses „Stand“-Motiv ist unter den Hunderten von Chlamydephorenstatuetten nur ein weiteres Mal zu beobachten. ${ }^{427}$ Die „Kausia“ hat Ähnlichkeit mit einem runden Kissen. Der abweichende Typus und die ungewöhnliche Form der Kausia deuten darauf hin, dass der Typus des stehenden Chlamydephoros mit Kausia auf Euböa nicht üblich war und versucht worden ist, unter Verwendung eines ähnlichen Typus, dem nachträglicheine Kausia aufgesetzt wurde, eine entsprechende Statuette zu imitieren. Die Figur wird aufgrund des Kontextes der zweiten Hälfte des 3. Jahrhunderts v.Chr. zugeordnet. ${ }^{428}$ Als Auftraggeber bzw. Abnehmer kann ein Angehöriger der makedonischen Garnison in Chalkis vermutet werden.

Auf der Insel Delos wurden zwei Köpfe bzw. Oberkörperfragmente von vermutlich stehenden Chlamydephoren (Tk 302-303) und ein Kopf mit bärtiger Theatermaske (Tk 304; Taf. 40 Abb. 156) gefunden (Soldaten-Typus?).

Die zwei delischen Chlamydephorenfragmente (Tk 302-303) lassen sich nach Stil und Frisur mit Figuren aus der „südlichen Aiolis“ (Tk 152 ff.) in Verbindung bringen (Taf. 24 Abb. 89). Diese werden ins 1.-2. Jahrhundert n. Chr. datiert. In hellenistischer Zeit wäre das Auftreten von Chlamydephoren-Statuetten auf Delos, dem Zentrum des internationalen Handels mit multiethnischer Bevölkerung, unter der sich sicher auch Makedonen, Alexandriner und Bewohner anderer makedonisierter Regionen befanden, nicht überraschend gewesen. In diesen Rahmen lässt sich vielleicht das Köpfchen mit bärtiger Theatermaske und Kausia (Tk 304) einordnen. Will man jedoch nicht vom Zufall ausgehen, lässt sich nur schwer erklären, wie die Chlamydephoros-Fragmente Jahrhunderte nach den Zerstörungen von 88 und 69 v. Chr. auf die in der Kaiserzeit weitgehend entvölkerte Insel gelangt sein könnten. Eine Erklärungsmöglichkeit wäre, dass Delos nach den verheerenden Plünderungen nicht so vollständig unbewohnt gewesen wäre, wie gerne angenommen wird. ${ }^{429}$ Die zweite Möglichkeit ist, dass die Datierung der Figuren aus der „südlichen Aiolis ${ }^{6430}$ nicht zutrifft. Nimmt man letzteres an,

\footnotetext{
${ }^{426}$ Im Gegensatz zu den „stehenden Chlamydephoren“, deren Beine weitgehend parallel und eng zusammenstehend gezeigt werden, weist der Jüngling aus Chalkis eine weit ausschreitende Beinstellung mit rechten Standund linken Spielbein (nur die Zehenspitzen berühren den Boden) auf.

${ }^{427} \mathrm{Tk} 282$ aus Odessos/Varna (sog. Orator).

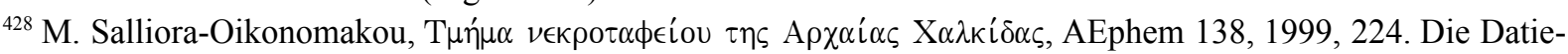
rung ist jedoch mit einem Fragezeichen versehen. Im vermutlich zugehörigen Grab 4 fand sich u.a. ein Bronzekranz des späten 4. bis frühen 3. Jahrhunderts v.Chr. Weitere in der Umgebung gefundene Terrakotten entstammen dem 3. bzw. frühen 3. Jh. v.Chr.

${ }^{429}$ Das Abbrechen der Besiedlung von Delos ist einer der wenigen Fixpunkte, an denen sich die Chronologie der materiellen Hinterlassenschaft des Hellenismus orientiert.

${ }^{430}$ Diese befinden sich heute in Leiden. Die Datierung beruht auf der Analyse des Stiles. Gekauft wurden die Figuren in den 1880er Jahren im „Kunsthandel“ in Smyrna. Der vermutete Fundort („,üdliche Aiolis“) orientiert sich am Ort des Kaufes.
} 
müsste man die gesamte Chronologie koroplastischer Chlamydephorendarstellungen um fast 200 Jahre verkürzen ${ }^{431}$ oder von der Gleichzeitigkeit sehr verschiedener Stile ausgehen. ${ }^{432}$

Die Reiter aus Korinth (Tk 305-306) gehören einem Depotfund (unbekannter Bestimmung) an, der sich durch Beifunde in die Zeit um 250 v. Chr. datieren lässt. Chronologisch und typologisch sind diese mit den ptolemäischen Reitern aus Sciatbi (Tk 58 ff., vgl. Taf. 30 Abb. 111112) vergleichbar. Da in Korinth zwar weitere Reiterstatuetten gefunden wurden, ${ }^{433}$ diese jedoch alle keine Kausia tragen und Reiter mit Kausia sonst nur im ptolemäischen Einflussbereich auftreten, stellt sich die Frage, ob die Statuetten für einen korinthischen Bürger produziert wurden. Korinth war bis 243 makedonisch besetzt und wurde dann von Arat mit ptolemäischer Hilfe dem Achäischen Bund angeschlossen. ${ }^{434}$ Daher würde sich auch ein makedonischer bzw. ptolemäischer Soldat oder Söldner als Verwender anbieten.

\section{Zusammenfassung}

Auf dem Gebiet des Korinthischen Bundes finden sich Terrakotten mit Kausia relativ selten. Bis auf wenige Ausnahmen ${ }^{435}$ handelt es sich um Chlamydephoren-Statuetten ${ }^{436}$, im Gegensatz zu den bisher besprochenen Regionen jedoch meist nicht um Vertreter des Normaltypus، (stehend, vollständig bekleidet mit Kausia, Chlamys, Chiton). Stattdessen treten verschiedene Varianten auf (z.B. schreitende oder nur teilweise bekleidete Chlamydephoren, „Ephebensoldaten“, stehende Chlamydephoren mit verhülltem Gesicht/Kinn). Die Figuren sind in der Regel $^{437}$ sehr früh zu datieren (4.-3. Jh. v.Chr.).

Die Poleis des Korinthischen Bundes - insbesondere der Raum Athen/Böotien - sind das Ursprungsgebiet sämtlicher Chlamydephoren-Typen. ${ }^{438}$ Diese wurden hier in spätklassischer Zeit entwickelt. Die dargestellten Personen wurden mit Petasos, Kranz oder barhäuptig gezeigt, die Kausia ist die Ausnahme. Seit frühhellenistischer Zeit verbreiteten sich dann bestimmte

\footnotetext{
${ }^{431}$ Dies hätte u.a. zur Folge, dass sich die Kausia in der Koroplastik der Kaiserzeit nicht mehr nachweisen ließe, nachdem schon die Datierung der „Reiter über Gegner“ aus tetrachisch-konstantinischer Zeit in den frühen Hellenismus vorverlegt werden musste (s.o.).

${ }^{432}$ Das Chlamydephorenfragment Tk 302 wurde am Hang unterhalb des Heiligtums der Kabiren/Götter von Samothrake gefunden. Sowohl der Fundort als auch das häufige Auftreten von Chlamydephorenfiguren auf Samothrake und in ähnlichen Heiligtümern legen eine Verbindung von Statuette und Heiligtum nahe. Auch hier ist zu fragen, ob das Heiligtum noch im 2. Jh. n. Chr. genutzt wurde, die Terrakotte ins 1. Jh. v. Chr. zu datieren ist oder mit zwei gleichzeitigen Stilkreisen - Samothrake-Athen-Alexandria auf der einen, „Südliche Aiolis“-Delos auf der anderen Seite - zu rechnen ist.

${ }^{433}$ G. Davidson, A Hellenistic Deposit at Corinth, Hesperia 11, 1942, 111 Abb. 3

${ }^{434}$ Vgl. Der Kleine Pauly III (1969) 302 s.v. Korinthos (E. Meyer) .- Der Kleine Pauly I (1964) 487 f. s.v. Arat (2) (H. Volkmann).

${ }^{435}$ Vgl. die vermutlich kausiatragenden Reiter aus der Garnisonsstadt Korinth (Tk 305-306) und den bärtigen Kopf aus Delos/Mykonos (Tk 304).

${ }^{436}$ Tk 289-300 (Athen/Böotien), Tk 301 (Chalkis), Tk 302 (Delos).

${ }^{437}$ Eine Ausnahme bilden nur die vermutlich kaiserzeitlich zu datierenden Terrakotten aus Delos (Tk 302 [Chlamydephoros?], Tk 303 [Kopf]).

${ }^{438}$ Auf den Ursprung der Chlamydephoren-Typen und der vermutlich hinter ihnen stehenden Institutionen (Ephebie, Gymnasion) gehe ich später ausführlich ein.
} 
Varianten (z.B. der „stehende Normaltypus“) in den makedonisch dominierten Gebieten der östlichen Mittelmeerwelt und wurden dort regelmäßig mit der Kausia kombiniert. In den zentralgriechischen Poleis blieb dies die Ausnahme, die wenigen Beispiele waren vielleicht für den Export oder für Angehörige der makedonischen Minderheit (z.B. Garnisonssoldaten) bestimmt.

In den südlich angrenzenden Gebieten Griechenlands (Sparta, südliche Kykladen, Sporaden, Rhodos, Kreta), die nicht, erst sehr spät oder nur kurzfristig von Makedonien abhängig waren, wurden bisher keine Terrakotten mit Kausia entdeckt.

\subsubsection{Königliche Neugründungen}

Zur Gründung von Städten durch makedonische Könige kam es nicht nur in den von Alexander und seinen Nachfolgern in Asien und Nordafrika beherrschten Gebieten, sondern auch am

Rande des makedonischen Kernlandes (Thessaloniki) und in den Nachbarregionen (Demetrias [Thessalien] und Kassandreia [Chalkidike]). 
Aus Demetrias sind mindestens ${ }^{439} 61$ Tonfiguren mit Kausia bekannt (Tk 307-329). Es handelt sich durchweg um Darstellungen stehender, männlicher, jugendlicher Personen. Meist sind es Vertreter des Chlamydephoren-Normaltypus (Tk 310-321 a-h, vgl. Taf. 24 Abb. 87$89)^{440}$. Drei Statuetten zeigen stehende Chlamydephoren mit verhülltem Kinn (Tk 307-309, vgl. Taf. 25 Abb. 90-93) $)^{441}$. Hinzu kommen zehn weitere nur fragmentarisch erhaltene Chlamydephoren-Statuetten (Tk 329 a-j), die sich infolge der schlechten Abbildungsqualität keinem „Typus“ nach K. Hornung-Bertemes zuweisen lassen. Vier (oder mehr) ${ }^{442}$ Figuren (Tk 322-325, Taf. 26 Abb. 94-96) bereichern den Typus durch eine Syrinx und/oder ein Lagobo-

${ }^{439}$ Die bei den Ausgrabungen unter der Leitung von A. Arvanitopoulos am Anfang des 20. Jahrhunderts gefun-

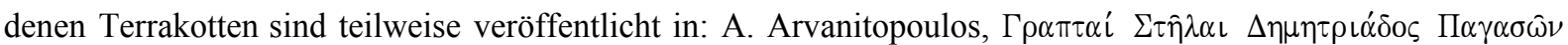
(1928) 46 f. Abb. $52-55$ (Die Abbildungen geben jeweils eine sehr große Anzahl von Statuetten in Form sehr kleiner Sammelaufnahmen wieder. So zeigt Abb. 5261 Figuren auf einer Fläche von 7,5 x 10,5 cm!). Darstellungen der Kausia finden sich auf: Abb. 52, 3. Reihe Nr. 2, 5-6, 15-16; 4. Reihe Nr. 2-4, 9-10, 12, 14-15, 19; Abb. 53, 1. Reihe Nr. 4-5; 2. Reihe Nr. 1-17; 3. Reihe Nr. 1-4; Abb. 54, 4. Reihe Nr. 9; Abb. 55, re. Hälfte, 2. Reihe Nr. 5. Die Figuren Abb. 53, 1. Reihe Nr. 3, 6-14 (= 10 Exemplare) gehen vermutlich auf die gleiche Form zurück wie diejenigen auf Abb. 53, 3. Reihe Nr. 1-4 (u.a.). Ob sie ebenfalls Kausia tragen, lässt sich aufgrund der geringen Größe und der schlechten Qualität der Abbildungen nicht mit Sicherheit sagen (Abb. 52 und 53 wurden von A. Arvanitopoulos erstmals publiziert in: Prakt 1912, 204 ff. Abb. 16 f.). - Einige bei neueren deutschen Grabungen entdeckte Statuetten sind publiziert in: V. Milojcic, Bericht über die deutschen archäologischen Ausgrabungen in Thessalien, ADelt 28B'2, 1973, 347 f. Abb. 309c (2 Statuetten) .- J.-P. Michaud, Chronique, BCH 97, 1973, 335 ff. Abb. 176 (Grabungsfoto mit Statuetten in situ) 177 f. (2 Statuetten) .- V. Milojcic, D. Theocharis (Hrsgg.), Demetrias III, BAM 19 (1980) Taf. 7, 2 (Grabungsfoto). Neben zwei einzeln abgebildeten Statuetten (Tk 322 f., mit Syrinx) wird jeweils ein Grabungsfoto wiedergegeben, das eine größere Anzahl von Figuren in situ, d.h. noch teilweise im Boden steckend, auf der Seite liegend etc., zeigt. Dies erschwert es, genaue Angaben zu Zahl und Aussehen der Statuetten zu machen. - Im Rahmen einer Dissertation bereitet K. Hornung-Bertemes (Saarbrücken) eine Neuveröffentlichung der Terrakotten von Demetrias vor. Grundlage bilden die bisher publizierten Exemplare sowie die Bestände des Museums von Volos und des Depots der deutschen Grabung. Vorweg erschien ein Aufsatz (K. Hornung-Bertemes, Die „Kausia“-Darstellungen aus Demetrias, in: A. Muller [Hrsg.], Le moulage en terre cuite dans l'antiquité: creation et production dérivée, fabrication et diffusion [Kolloquium Lille 1995] [1997/99] 181-206). In diesem wird die Zahl der Terrakotten mit Kausia einerseits mit nur 40 Exemplaren beziffert (Hornung-Bertemes, Demetrias, 182, 188 und Konkordanzliste S. 201 f.), andererseits werden bei der Behandlung der Fundorte jedoch 48 bzw. 49 Figuren besprochen (Hornung-Bertemes, Demetrias, 185-88). Abgebildet werden im betreffenden Artikel zehn Statuetten. Es ist jedoch nur in Einzelfällen möglich, diese Terrakotten mit bestimmten Fundorten innerhalb von Demetrias in Verbindung zu bringen, da entsprechende Hinweise im Text oder in den Bildunterschriften nicht gegeben werden. Weiter ist es in den meisten Fällen nicht möglich, zu klären, in welchem Umfang die bei K. Hornung-Bertemes gezeigten Statuetten mit den schon bei A. Arvanitopoulos publizierten identisch sind, weil entsprechende Angaben fehlen und Größe und Qualität der Abbildungen bei Arvanitopoulos meist nicht ausreichen, um entsprechende Vergleiche selbst anzustellen. Da sich jedoch diejenigen Figuren, die anhand von Brüchen relativ leicht zu identifizieren sind, bei Arvanitopoulos größtenteils noch nicht finden, ergibt sich, dass K. Hornung-Bertemes teilweise auch neues Material publiziert hat. - Es lässt sich zusammenfassen, dass auf Grundlage des derzeitigen Publikationsstandes in Demetrias mindestens 61 - sollte es sich bei den bei Arvanitopoulos, Demetrias, Abb. 53, 1. Reihe Nr. 3, 6-14 gezeigten Figuren um solche mit Kausia handeln - sogar 71 Statuetten (vgl. Tk 307-329) mit Kausia nachzuweisen sind.

${ }^{440}$ „Typen“ B und C nach Hornung-Bertemes. Vgl. Tk 310-321 a-h (= 36 [+10? = 46?] Exemplare): stehend, in Chlamys, Chiton und Kausia, rechter Arm am Körper herabhängend, teilweise ins Gewand greifend, linker Arm unter der Chlamys vor die Brust gelegt.

${ }^{441}$ „Typus“ A nach Hornung-Bertemes.

${ }^{442}$ Alle Darstellungen mit Syrinx und/oder Lagobolon stammen aus dem sog. Demeter-Heiligtum auf Höhe 35: Tk 323 mit Syrinx, Tk 322 vermutlich mit Syrinx (V. Milojcic, BCH 97, 1973, 338 Abb. 177, 178); auf dem Grabungsfoto BCH 97, 1973, 338 Abb. 176 sieht man darüber hinaus einen weiteren Chlamydephoros (Tk 324) mit 
lon ( $\lambda \alpha \gamma \omega \beta$ ó $\lambda \mathrm{ov}$, lat.: pedum), ein gekrümmtes Wurfholz, in der rechten Hand. Zwei Terrakotten zeigen männliche Jugendliche mit Kausia, aber ohne Chiton und mit herabgerutschter Chlamys, d.h. weitgehend nackt (Tk 327-328 [o. Abb.]).

Eine Bestimmung der Fundorte einzelner Statuetten innerhalb der Stadt ist anhand der Publikationen (s. vorhergehende Anmerkungen) nur teilweise möglich. Der größte Teil der Figuren stammt aus dem Pasikrata-(= Artemis?)-Heiligtum, ${ }^{443}$ darunter die zwei weitgehend nackten Knaben (Tk 327-328) und mindestens ${ }^{444} 27$ Vertreter des Chlamydephoren-Normaltypus. Aus einem Bothros auf Höhe 35 (am östlichen Rand der Stadt) stammen mindestens 13 weitere Figuren mit Kausia (u.a. Tk 308, 322-326 a-e). ${ }^{445}$ Davon zeigt mindestens sechs Statuetten einen Chlamydephoros im Normaltypus (u.a. Tk 308), mindestens drei Terrakotten geben Chlamydephoren mit Syrinx und/oder Lagobolon wieder (Tk 322-325, 326 [?]). Das Heiligtum wird bisher aufgrund der dort gefundenen Tonfiguren (Chlamydephoroi sowie Frauen, teilweise mit Tieren) und einer in der Nähe ans Tageslicht gelangten Inschrift als eines der Demeter, der Kore und des Pluton gedeutet. ${ }^{446}$ Syrinx und Lagobolon in den Händen der männlichen Statuetten sprechen für ein Hirtenheiligtum. Eine weitere Statuette mit Kausia fand sich im 293 v. Chr. mit Demetrias vereinigtem Hafenort Néleia (Pefkakia). Für Néleia ist inschriftlich ein

Kausia und Lagobolon (der untere Teil der Figur ist noch von Erde bedeckt, eine möglicherweise vorhandene Syrinx deshalb nicht zu erkennen), fünf weitere Statuetten (Tk 326), von denen nur die Köpfe/Oberkörper aus dem Boden ragen bzw. nur die Beine erhalten sind, und bei denen Aussagen zum Vorhandensein von Syrinx und Lagobolon ebenfalls nicht möglich sind, sowie eine Statuette ohne Kopf und damit auch ohne Kausia, jedoch vom gleichen Typus, die in der rechten Hand sowohl Lagobolon als auch Syrinx (viereckiger Rahmen, durch Streifen gegliedert) hält (Tk 325).

${ }^{443}$ Eine genaue Bestimmung der Anzahl der Statuetten aus dem Pasikrata-Heiligtum ist auf Grundlage der derzeit publizierten Vorberichte (z.B. BCH 97, 1973, 335 ff. Abb. 176 f.) nicht möglich (vgl. in der Anm. oben den Abschnitt zur deutschen Grabung). Laut A. Arvanitopoulos, Demetrias, 46 f. 52 ff. stammen alle dort publizierten 39 (+10?) Terrakotten mit Kausia aus dem Pasikrata-Heiligtum. In den Inventarbüchern des Museums von Volos erscheint diese Fundortbezeichnung jedoch nur selten, meist wird nur allg. „Demetrias“ genannt (so Hornung-Bertemes, Demetrias, 186). K. Hornung-Bertemes behandelt die genannten Statuetten teilweise als aus dem Pasikrata-Heiligtum stammend (Hornung-Bertemes, Demetrias, 186), teilweise als Funde unklarer Herkunft (Hornung-Bertemes, Demetrias, 205 Abb. 5), ohne dass erkennbar wäre, welche der bei A. Arvanitopoulos abgebildeten Exemplare nachweisbar aus dem Heiligtum stammen.

Das Pasikrata-Heiligtum befindet sich im Vorfeld des Stelenturmes V auf dem Gebiet der späteren Südnekropole. Die Figuren stammen teils aus Gruben teils aus Grabverfüllungen. A. Arvanitopoulos geht jedoch davon aus, dass alle Statuetten dem Heiligtum zuzuordnen sind und erst nachträglich teilweise in die Gräber gelangten (Arvanitopoulos, Demetrias, 44 ff.). Heute lässt sich der Kultbezirk infolge von Änderungen im Küstenverlauf nicht mehr nachweisen (vgl. P. Marzoff, in: V. Milojcic, D. Theocharis [Hrsgg.], Demetrias III, BAM 19 [1980] 9 Anm. 7 .- Hornung-Bertemes, Demetrias, 185 f.). - Welchen Charakter die Gottheit besaß, die dort verehrt wurde, ist nicht eindeutig geklärt. A. Arvanitopoulos, Prakt 1920, 22 ff. vermutet Aphrodite. F. Stählin, E. Meyer, A. Heidner, Pagasai und Demetrias (1934) 188 mit Anm. 2 sehen eher ein Heiligtum der Artemis als Weggottheit (Enodia) und vielleicht des Hermes (Enodios).

${ }^{444} \mathrm{Zu}$ den bei Arvanitopoulos, Demetrias, 44 Abb. 52 ff. publizierten Statuetten, die eindeutig den Normaltypus zeigen, kommen noch zehn Exemplare hinzu, bei denen nicht klar erkennbar ist, ob sie Kausia tragen (Arvanitopoulos, Demetrias, 44 Abb. 53, 1. Reihe Nr. 3, 6-14), sowie Fragmente von zehn weiteren Figuren, deren Typus nicht zweifelsfrei bestimmbar ist (Arvanitopoulos, Demetrias, 44 Abb. 52, 3. Reihe Nr. 9; 4. Reihe Nr. 2-4, 9-10, $12,14-15,18)$.

${ }^{445}$ Vgl. Hornung-Bertemes, Demetrias, 186 f. 202.

${ }^{446}$ F. Stählin, E. Meyer, A. Heidner, Pagasai und Demetrias (1934) 124, 187 .- Hornung-Bertemes, Demetrias, $186 \mathrm{f}$. 
Aphrodite-Heiligtum belegt, mit dem die Figur in Verbindung stehen könnte. ${ }^{447}$ Acht Terrakotten wurden in Goritza, einer spätklassischen Stadt am Golf von Volos gegenüber von Demetrias gefunden. Die Zahl der zivilen Bewohner dieser Stadt war in hellenistischer Zeit zwar rückläufig, sie wurde aber weiterhin militärisch genutzt. ${ }^{448}$ Eine nicht näher bestimmbare Anzahl (vielleicht 10-20 Figuren) lässt sich anhand der ungenügenden Publikationslage keinem genauen Fundort zuweisen, stammt aber vermutlich aus Demetrias. ${ }^{449}$

Für die Datierung wichtig ist ein Fragment (Tk 314), das sich in der Fundamentierung des Anaktorons fand. Es lässt sich zweifelsfrei zu einem Chlamydephoros der Serie „Typus B nach Hornung-Bertemes“ (= Normaltypus) ergänzen. ${ }^{450}$ Die Fundamentschicht wird in die Zeit um 220-200 v. Chr. datiert. Die Figuren der Serie B („Typus B nach Hornung-Bertemes“; Tk 310-316 a-r) werden entsprechend im Verlauf der 2. Hälfte des 3. Jahrhunderts hergestellt worden sein, Serie A (Tk 307-309) stammt aus stilistischen Gründen noch aus der 1. Hälfte des 3. Jahrhunderts und Serie C (Tk 317-321 a-h) aus der Zeit um 200 v. Chr. Eine Datierung der Statuetten aus Demetrias ins 3. Jahrhundert wird gestützt durch einen stilistischen Vergleich mit den Figuren aus den alexandrinischen Nekropolen von Sciatbi (325-240 v. Chr.) und Hadra (280-180 v. Chr.). Sie lässt sich darüber hinaus gut mit dem historischen Kontext vereinbaren: Demetrias wurde 293 v. Chr. von Demetrios Poliorketes als Militär- und Verwaltungsstützpunkt auf thessalischem Gebiet gegründet und war zeitweilig Residenz, bevor die Stadt und das Umland ab 196 v. Chr. unter dem Druck der Römer wieder thessalisch wurden. Das Auftreten von Statuetten mit makedonischer Kausia beschränkt sich demnach auf die Zeit der makedonischen Herrschaft.

Aus Kassandreia, das 316 v. Chr. von Kassander auf dem Gebiet des früheren Poteidaia gegründet wurde, stammt ein Chlamydephoros (Tk 334 [o. Abb.]). Dargestellt ist eine junge,

\footnotetext{
${ }^{447}$ Vgl. Hornung-Bertemes, Demetrias, $187 \mathrm{f}$.

${ }^{448}$ Vgl. Hornung-Bertemes, Demetrias, 188.

${ }^{449}$ Vgl. Hornung-Bertemes, Demetrias, 186, 201 („Konkordanzliste“ zwischen den Inventarnummern des Museums Volos etc. und dem - nicht publizierten - Bearbeitungskatalog), 203 f. Abb. 2-4, 205 Abb. 5 (Säulendiagramm). Es lässt sich jeweils nicht oder nur teilweise nachvollziehen, ob bzw. in welchem Umfang die genannten Statuetten mit denjenigen bei Arvanitopoulos, Demetrias, 46 ff. Abb. 52 ff. identisch sind.

${ }^{450}$ Als „Typen“ bezeichnet K. Hornung-Bertemes Gruppen von Figuren, die sich aufgrund einer „stilistischen Typologie“ (Hornung-Bertemes, Demetrias, 188) auf eine gemeinsame Form (bzw. Patrize/Matrize) zurückführen lassen. Diese „Typen“ sollte man jedoch besser als Serien bezeichnen, wie sie selbst anmerkt (Hornung-Bertemes, Demetrias, 191 Anm. 42). - Das Ziel des Aufsatzes beschränkt sich weitgehend darauf, Fragen in Zusammenhang mit dem Produktionsprozess (z.B. „Produktionsfiliation“) zu klären. Andere Fragestellungen werden nicht angegangen bzw. wird ihre Beantwortbarkeit verneint („Die Funde aus Demetrias ermöglichen es aber derzeit nicht, den Kreis der Weihenden und die Bedeutung dieses Ritus näher einzugrenzen.“ Hornung-Bertemes, Demetrias, 182). Die Materialgrundlage wird in so eingeschränkter Form dargestellt, dass Personen, die nicht ausschließlich an produktionstechnischen Problemen interessiert sind, sie nicht verwerten können. Statt der Veröffentlichung einer Konkordanz zwischen dem Inventarbuch des Museums Volos und dem nicht publizierten Bearbeitungskatalog sowie einer Tabelle, aus der die Form der Brennlöcher hervorgeht (Diese Tabelle wird im Text nirgendwo erwähnt!), wäre es wünschenswert gewesen, eine Konkordanz/Tabelle zu publizieren, aus der zu entnehmen ist, welche bei K. Hornung-Bertemes besprochenen Statuetten schon bei A. Arvanitopoulos bzw. V. Milojcic veröffentlicht wurden, und zu jedem einzelnen Exemplar Angaben zu Inventarnummer, Typus, Serie, genauem Fundort etc. zu machen.
} 
männliche Person in Chlamys, Chiton und Kausia. Der rechte Arm hängt nicht am Körper herab, wie beim Normaltypus üblich, sondern ist leicht angewinkelt und teilweise ins Gewand gehüllt. Mit dem linken Arm stützt sich die Figur auf einen Baumstumpf. Die linke Hand wird unter der Chlamys vor das Kinn geführt. Der Kopf ist nach vorne geneigt.

Die Statuette wurde als Streufund ${ }^{451}$ in der Nähe eines durch seine Klinenausstattung bekannten makedonischen Grabes ${ }^{452}$ gefunden. Sie lässt sich anhand stilistischer Merkmale, der Langhaarfrisur, der an den spätklassischen „Epheben-Soldaten“-Typus erinnernden relativ kurzen Chlamys und des Fundkontextes in das späte 4. Jahrhundert v. Chr. datieren.

Die geringe Anzahl von Terrakotten aus Kassandreia dürfte einerseits auf den Stand der Forschung zurückzuführen sein und andererseits darauf, dass Kassander nur bis 298/7 v. Chr. herrschte und die Stadt danach im Gegensatz zu anderen Gründungen hellenistischer Könige wie Demetrias oder gar Alexandria oder Seleukia am Tigris von nur noch regionaler Bedeutung war.

Aus der Stadt Thessaloniki sind keine Terrakottafiguren mit Kausia bekannt, die eindeutig den Nekropolen der Stadt entstammen. Dies ist bemerkenswert, da Terrakotten in Thessaloniki durchaus in Gebrauch waren und die bisher dort gefundenen Statuetten auch publiziert sind. ${ }^{453}$ Thessaloniki ist damit die einzige neugegründete, makedonische Königsresidenz, in der sich keine koroplastischen Wiedergaben der makedonischen Kopfbedeckung fanden und sich dies nicht von vornherein mit dem mangelhaften Forschungsstand erklären lässt. ${ }^{45}$ Möglicherweise handelt es sich dennoch um einen Zufall der Überlieferung. Im ca. 20-30 km westlich von Thessaloniki gelegenen Gephyra wurden in einer Nekropole vier stehende Chlamydephoroi mit Kausia bzw. Fragmente von solchen (Tk 330-333, vgl. Taf. 24 Abb. 8789) gefunden, die aufgrund von Ton und Stil einer Werkstatt in Thessaloniki zugewiesen werden. ${ }^{455}$

Im Museum von Thessaloniki befinden sich zwei Statuetten von Chlamydephoren vom Normaltypus ohne Kopf und damit auch ohne erhaltene Kausia. ${ }^{456}$ Die Vergleichsstücke aus dem Bereich der nördlichen Ägäis (z.B. Demetrias, Samothrake) zeigen, dass solche Statuetten in dieser Region in der Regel mit Kausia zu ergänzen sind. Der Fundort dieser Figuren ist unbekannt, Thessaloniki, der Aufbewahrungsort, liegt jedoch nahe. Auch zwei Figuren (Tk 460,

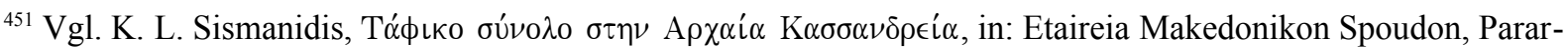
tema Makedonikon 6 (Mneme Manole Andronikou) (1997) 313. 320 Abb. 34

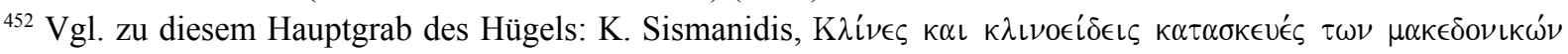
$\tau \alpha \dot{\phi} \omega \nu$ (1997). Die Bestattung ist antik gestört.

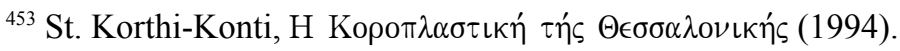

${ }^{454}$ Auf einen mangelhaften Forschungsstand ist wahrscheinlich das Fehlen von Terrakotten mit Kausia z.B. in Lysimacheia oder Antiocheia am Orontes zurückzuführen. In hellenistische Residenzen, deren koroplastisches Materials in ausreichendem Maße bearbeitet bzw. publiziert ist, kann regelmäßig ein gehäuftes Auftreten von Statuetten mit Kausia beobachtet werden (vgl. z.B. Alexandria, Demetrias, Seleukia/Tigris).

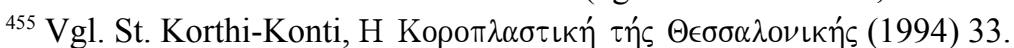

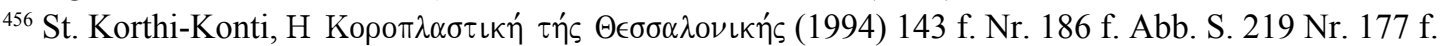


ohne Fundort) in der Sammlung A. Phostiropoulos (Thessaloniki) mit Kausia in Chiton und zurückgeschlagener Chlamys (?) könnten aus der Region stammen.

Dennoch ist von einem gehäuften Auftreten von koroplastischen Wiedergaben von Kausiaträgern in Thessaloniki derzeit nicht auszugehen. Dies könnte darauf zurückzuführen sein, dass es hier am Rande des makedonischen Kernlandes keinen Grund gab, die makedonische Identität besonders zu betonen. In sonst vergleichbaren Städten (z.B. Alexandria, Seleukia/Tigris, Demetrias) sah dies anders aus. Dort lebte die makedonische Bevölkerung inmitten fremder, teilweise feindlich gesinnter, Volksgruppen (Ägypter, Orientalen, Thessaler). Ein engerer Zusammenschluss der Makedonen und eine verstärkte Zurschaustellung der Identität durch das Tragen und auch die bildliche Wiedergabe der typisch makedonischen Bekleidung könnte die Folge gewesen sein.

Die Terrakotten im Museum von Thessaloniki werden anhand des Stiles ins 1. Jahrhundert v. Chr. bzw. die Zeit um Christi Geburt datiert. ${ }^{457}$ Da jedoch die Oberfläche der Statuetten stark verrieben ist, erscheint mir eine Beurteilung des Stiles problematisch. Der Typus, die Langhaarfrisur und die historischen Rahmenbedingungen weisen eher ins 3. Jahrhundert v. Chr., wie Vergleiche mit den Verhältnissen z.B. in Demetras, Alexandria oder Samothrake zeigen.

\section{Zusammenfassung}

Wie in den weiter entfernt liegenden Königsstädten Alexandria oder Seleukia am Tigris treten Chlamydephoren-Statuetten mit Kausia auch in Demetrias gehäuft auf. Entscheidend für das Vorhandensein solcher Terrakotten sind demnach nicht die Entfernung oder Nähe zum makedonischen Mutterland, sondern die Existenz bestimmter Personengruppen oder Institutionen, mit denen in allen Königsstädten zu rechnen ist.

Im Gegensatz zu den Städten im Orient und in Ägypten erscheinen auf dem Balkan nur Chlamydephorentypen, während Darstellungen von Reitern, Soldaten und hockenden Knaben fehlen. Dies ist, wie zu zeigen sein wird, darauf zurückzuführen, dass die in den neuen Reichen vorhandenen regionalen Einflüsse und Sonderentwicklungen in Nordgriechenland keine Rolle spielen.

Auf chronologischem Gebiet ist Demetrias mit Alexandria vergleichbar (Zusammenfallen des Endes der Verwendung von Terrakotten mit Kausia und der makedonischen bzw. ptolemäischen Herrschaft). Anders sehen die Verhältnisse in Seleukia am Tigris aus, wo koroplastische Darstellungen das politische Ende des Seleukidenreiches überleben.

Das zahlenmäßig geringe Auftreten von Terrakotten in Thessaloniki und Kassandreia ist vermutlich teilweise auf den Forschungs- bzw. Publikationsstand zurückzuführen, im Falle Kassandreias auch auf die geringe Bedeutung der Stadt. Das Beispiel Amphipolis, einer Stadt, die vergleichbar weit von Makedonien entfernt liegt und ebenfalls Verwaltungsaufgaben (Reichsprägestätte) erfüllte, zeigt, dass die Nähe zu Makedonien nicht zu einem Fehlen von Terrakotten führen muss.

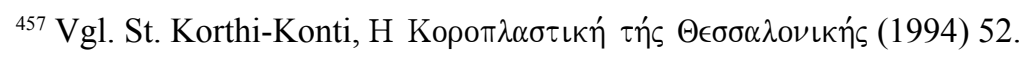




\subsubsection{Griechische Poleis auf der Krim / Bosporanisches Reich}

Die Griechenstädte an der nördlichen Küste des Schwarzen Meeres standen in engem wirtschaftlichen und kulturellen Kontakt zu den Städten und Reichen der östlichen Mittelmeerwelt. Im Gegensatz zu den bisher genannten Regionen war dieses Gebiet jedoch nie von Makedonien abhängig.

Die elf koroplastischen Darstellungen von Kausiaträgern stammen aus Pantikapaion/Kertsch (Tk 335-342), aus Chersonesos/Sewastopol (Tk 343) und aus Phanagoria bzw. von der Tamanhalbinsel (Tk 344-345). Es handelt sich um einen sitzenden Chlamydephoros (ohne Chiton) (Tk 335, vgl. Taf. 23 Abb. 83), einen reitenden nackten (?) Knaben mit Kausia (Tk 343 [o. Abb.]), einen hockenden Knaben (,temple boy“) in Chlamys und Kausia (ohne Chiton) auf hoher Rundbasis (Tk 336, Taf. 35 Abb. 137), fünf Eros-und-Psyche-Gruppen ${ }^{458}$ (Tk 337 340, 344, Taf. 39 Abb. 149-151), einen auf einem Delphin reitenden Knaben (in Chlamys und Kausia, ohne Chiton) mit Leier (Tk 341 [o. Abb.]), einen laufenden Knaben (in Mantel und Kausia, ohne Chiton) mit Hund (Tk 342 [o. Abb.]) sowie einen mit einer Gans kämpfenden Eros (Tk 345 [o. Abb.]).

Die einzelnen Statuetten werden in die Zeit vom 3. Jahrhundert v.Chr. bis zum 1. Jahrhundert n.Chr. datiert. ${ }^{459}$ Als Fundorte werden teilweise Nekropolen angegeben.

Die im Kernverbreitungsgebiet der Kausia übliche Kombination dieser Kopfbedeckung mit Chlamys und Chiton (vollbekleideter Chlamydephoros vom „Normaltypus“) findet sich auf der Krim und der Tamanhalbinsel überhaupt nicht. Das Fundmaterial wird dominiert von Eroten und nackten Knaben. Ein ähnliches Themen- und Typenspektrum ist auch in anderen Regionen, die nie unter makedonischer Kontrolle standen (Süditalien, Sizilien), festzustellen.

In wieweit diese Übereinstimmung zwischen den Funden von der Krim und denen aus dem westlichen Mittelmeergebiet auf das Fehlen der makedonischen Herrschaft und mit ihr verbundener Einrichtungen auf religiösem, politischem oder gesellschaftlichen Gebiet (z.B. Herrscherkult, Gymnasion/Ephebie als politisch relevante Institutionen, Militärkolonien) zusammenhängt, lässt sich nicht eindeutig klären. Es ist auch denkbar, dass bestimmte Kulte (z.B. der des Eros) sowohl auf der Krim als auch im Westen von besonderer Bedeutung waren und dass das Auftreten der betreffenden Statuetten vom Vorhandensein dieser Kulte abhängig war.

\subsubsection{Zusammenfassung: Terrakotten mit Kausia auf der Balkanhalbinsel}

Auf dem Balkan lassen sich vier unterschiedliche Gruppen von Fundorten herausarbeiten:

\footnotetext{
${ }^{458}$ Die Eroten werden bis auf die Kausia und teilweise einen zurückgeschlagenen Mantel weitgehend nackt dargestellt (ohne Chiton). Sie tragen durchweg Kausia. Die Psychen sind teils weitgehend nackt, teils bekleidet (Chiton, Mantel; z.B. Tk 339). Vereinzelt trägt auch Psyche die Kausia (Tk 338).

${ }^{459}$ Tk 335: 3. Jh. v. Chr.; Tk 343: 2. Jh. v. Chr.; Tk 337, 342: 2.-1. Jh. v. Chr.; Tk 339-340, 344-345: 1. Jh. v. Chr.; Tk 336: späthellenistisch; Tk 341: 1. Jh. v.- 1. Jh. n. Chr.
} 
1. Die königlichen Neugründungen: In diesen entsprechen Typenspektrum (d.h. in erster Linie Chlamydephoren) und Häufigkeit solcher Darstellungen denen in den großen königlichen Neugründungen im Nahen Osten und in Ägypten, wie auch den dortigen kleineren Militärund Siedlerkolonien.

2. Die Städte der Krim und der Tamanhalbinsel (Bosporanisches Reich), in denen Kausiadarstellungen in der Koroplastik nur vereinzelt auftreten und zwar in der Regel nicht in Verbindung mit denjenigen Typen, die im makedonisierten Bereich üblich sind (Chlamydephoren, Reiter, Soldaten), sondern mit solchen, die auch in anderen Gebieten, die nie unter makedonischer Herrschaft standen (Italien), Verwendung fanden (z.B. Eroten).

3. Griechische Poleis, die im Zuge der makedonischen Expansion seit Philipp II. unter direkte (Nordgriechenland) oder indirekte (Korinthischer Bund) makedonische Verwaltung gerieten. Je nach Zeitpunkt, Dauer und Form der makedonischen Herrschaft variieren Zahl und Typenspektrum leicht. Gemeinsam ist den Statuetten mit Kausia aus diesen Städten, dass sie mehr oder weniger selten erscheinen und dass das Typenspektrum nicht so verengt ist wie in den makedonischen Königsstädten und Siedlerkolonien (fast ausschließlich stehende Chlamydephoren vom „Normaltypus“). Stattdessen werden ähnliche Typen (z.B. schreitende Chlamydephoren, „Ephebensoldaten“, sitzende Chlamydephoren ohne Untergewand) verwendet, die in der Region ursprünglich nicht mit der Kausia kombiniert wurden - vielleicht zur Deckung des Bedarfes einer makedonischen Minderheit (z.B. Militär- und Verwaltungspersonal).

Übereinstimmungen zwischen den frühen attisch-böotischen Chlamydephoren mit Kausia und den in den hellenistischen Großreichen verwendeten Statuetten sind darauf zurückzuführen, dass attisch-böotische Werkstätten und/oder Handwerker in spätklassisch-frühhellenistischer Zeit durch Export von Statuetten oder von Formen oder durch auswandernde Koroplasten das Typenspektrum in den Diadochenreichen maßgeblich beeinflussten und dort die vorgegebenen Typen in den folgenden Jahrhunderten rezipiert und reproduziert wurden.

4. Makedonien in den Grenzen von 359 v.Chr. Dort erscheinen Terrakotten nur sehr seltenund ohne Bindung an den üblichen Typenkanon.

Auf der Balkanhalbinsel sind auf der einen Seite große Unterschiede in Bezug auf die Häufigkeit von koroplastischen Kausiadarstellungen und das Typenspektrum zu beobachten. Auf der anderen Seite lassen sich die verschiedenen Unterregionen gut mit den unterschiedlichen Regionen der hellenistischen Welt vergleichen: Häufigkeit und Typenspektrum der Krim-Region entsprechen denen in Italien, Demetrias ist mit Alexandria oder Nordwestkleinasien zu vergleichen und die griechischen Poleis sind es ansatzweise mit Orten an der Küste Phöniziens (s.u.).

Einen Sonderfall stellt Makedonien selbst dar. Hier war zwar die makedonische Herrschaft sehr direkt und es lebten hier in ausreichender Zahl Makedonen. Es handelte sich jedoch nicht um eine Fremdherrschaft und es fehlte die fremde Umgebung, in der und gegenüber deren 
Bevölkerung die makedonischen Siedler und Soldaten sich durch Zurschaustellung der eigenen Kleidung kenntlich machen oder abgrenzen konnten.

Die Folge ist, dass die Verhältnisse in Makedonien am ehesten mit denen in solchen Regionen zu vergleichen sind, in denen es ebenfalls keine makedonische Fremdherrschaft gab (Italien und Krim).

Demnach ist nicht die Nähe zu Makedonien für die Häufigkeit von koroplastischen Darstellungen mit Kausia und das in Verbindung mit der Kausia auftretende Typenspektrum verantwortlich. Vielmehr scheinen die Form der Abhängigkeit von Makedonien und die damit verbundene Zahl der Makedonen bzw. sich makedonisch gebenden Personen entscheidend gewesen sein.

\subsubsection{Westliches Mittelmeer}

Terrakottastatuetten mit Kausia sind im Westen relativ selten. ${ }^{460}$ Das Typenspektrum unterscheidet sich stark von dem im ostmediterranen Raum üblichen.

\subsubsection{Chlamydephoroi}

Die im östlichen Mittelmeerbecken und bis nach Mesopotamien hinein weit verbreiteten Chlamydephorentypen finden sich im Westen nur vereinzelt.

Die einzige Statuette eines sitzenden Chlamydephoren in Chlamys, Chiton und Kausia, die sich in Italien fand, stammt aus Capua (Tk 353, vgl. Taf. 23 Abb. 84) und wird in die 1. Hälfte des 3. Jahrhunderts v. Chr. datiert.

Auf Lipari wurde das Oberkörperfragment eines stehenden vollbekleideten Chlamydephoren gefunden. ${ }^{461}$ Dieser gehört jedoch der Variante an, die die Chlamys vor den unteren Teil des Gesichtes gezogen zeigt (Tk 368, vgl. Taf. 25 Abb. 90-93). Es lässt sich aufgrund historischer Überlegungen in die Zeit vor 252 v. Chr. datieren, wozu auch die Langhaarfrisur passt. Ein weiterer stehender Chlamydephoros aus „Italien“ (Tk 346 [o. Abb.]) kombiniert, soweit dies beim schlechten Erhaltungszustand erkennbar ist, den Typus des stehenden Chlamydephoren (mit nicht vor das Gesicht gezogener Chlamys) mit dem Typus Epheben-Soldat. Der linke Arm liegt unter der langen Chlamys vor der Brust, der Mantel verhüllt jedoch nur die linke, obere Körperhälfte.

Im Bereich des Kybele-Attis-Heiligtums auf dem Palatin in Rom wurde das Oberkörperfragment einer Chlamydephoren-Statuette mit Kausia und zurückgeschlagener Chlamys gefunden (Tk 348, Taf. 37 Abb. 145), die kein Untergewand trägt und entsprechend entblößt wirkt. Das Heiligtum der Kybele wurde um 191 v. Chr. eingerichtet, die Langhaarfrisur der Terrakotte orientiert sich noch an Vorbildern des 3. Jahrhunderts v. Chr.

\footnotetext{
${ }^{460}$ Aus Italien stammen 25 Exemplare (Tk 346-369), aus den französischen Alpen eines (Tk 370).

${ }^{461}$ L. B. Brea, Menandro e il teatro greco nelle terracotte liparesi (1981) 108 (E 110) spricht die Figur aufgrund der langen Haare als Frau an und bringt sie mit den Hierodulen von Paphos in Verbindung.
} 
Aus Paestum/Poseidonia stammt die Statuette eines an einen Baumstamm gelehnten Chlamydephoros mit Kausia, aber ohne Chiton (Tk 358, Taf. 37 Abb. 143). Die Figur wird ins 4.-3. Jahrhundert v.Chr. datiert. Vertreter des gleichen Typus (ohne Kausia) wurden als Grabbeigaben verwendet. ${ }^{462}$

\subsubsection{Soldaten}

Das Oberkörperfragment einer Tonfigur aus Tarent (Tk 359, Taf. 29 Abb. 108) zeigt einen dickbäuchigen Mann in Chiton, Chlamys und Kausia, der ein in der Scheide befindliches Schwert in der linken Hand am Körper hält. Das Schwert kennzeichnet die Statuette als Soldaten, die Dickbäuchigkeit deutet darauf hin, dass es sich um einen Schauspieler handelt. $\mathrm{Ob}$ dieser wie der Haupttypus der ptolemäischen Terrakottasoldaten (Tk 3-8, 54-57, 99-100, 110 112, 126, vgl. Taf. 28 Abb. 102-105) keine Maske trägt, ist unklar. Er weist zumindest eine ausgeprägte Mimik auf. Von den ptolemäischen Soldatenfiguren unterscheidet er sich jedoch dadurch, dass er statt einer kurzen zurückgeschlagenen eine lange den Körper verhüllende Chlamys trägt. Während demnach der Soldat aus Tarent von der Masse der koroplastischen Soldatendarstellungen aus Ägypten abweicht, stimmt die Gewandgestaltung des tarentiner Terrakottasoldaten mit der einer nur sechs Zentimeter hoher Steatitstatuette aus Koptos in Kairo (P 2) und einer heute verschollenen, vermutlich aus dem Faijum stammende Terrakotte (Tk 113) überein. Diese halten jedoch kein Schwert, was diesen Nebentypus mit dem ptolemäischen Haupttypus verbindet, der mit Schwert (z.B. Tk 3), mit Beutel (z.B. Tk 54) oder ohne Attribut ${ }^{463}$ (z.B. Tk 57) auftritt. Da die Kausia als militärische Kopfbedeckung in erster Linie im makedonisierten Osten üblich war und die nächsten ikonographischen Parallelen in ägyptisch-ptolemäischen Ton- und Steatitfiguren zu finden sind, ist anzunehmen, dass entweder der koroplastische Typus oder der Theatercharakter aus dem ostmediterranen Bereich, am ehesten aus Ägypten, übernommen wurde oder von dort beeinflusst ist. Der historische Kontext legt eine Datierung in (früh-) hellenistische Zeit nahe.

Eine männliche Statuette mit auf der rechten Schulter zusammengehaltener Chlamys, Kausia und bärtiger Theatermaske (Tk 369, Taf. 40 Abb. 155) aus Lipari wird von L. B. Brea ${ }^{464}$ als Darstellung eines Sklaven der Neuen Komödie in Reisebekleidung gedeutet. In Anlehnung an die Soldatendarstellungen aus Tarent (Tk 359), der Kyrenaika (Tk 125) und Ägypten (z.B. Tk 109) halte ich eine Deutung als Soldatencharakter für wahrscheinlicher, eine Einordnung als Sklave ist aber nicht auszuschließen. Die Figur wird stratigraphisch in die Zeit vor 252 v. Chr. datiert.

\footnotetext{
${ }^{462}$ Vgl. Poseidonia e i Lucani (Hrsgg.: M. Cipriani, F. Longo), Ausstellungskatalog Paestum 1996, 240 Nr. 176.13

${ }^{463}$ Es ist nicht eindeutig, dass es Soldaten ohne Attribut gibt. Die meisten Figuren scheinen einen Gegenstand in der linken Hand zu halten, Details sind oft nicht mehr erkennbar, ursprünglich vorhandene Attribute können abgerieben sein.

${ }^{464}$ L. B. Brea a.a.O. 205.
} 


\subsubsection{Reiter}

In Voiron im Tal der Isère in den französischen Alpen wurde eine Terrakottafigur vom Typus „Reiter über Gegner““ ausgegraben (Tk 370, vgl. Taf. 30-31 Abb. 113, 118). Alle weiteren 28 Exemplare dieses Typus stammen aus dem ptolemäischen Ägypten (Tk 9-20, 62-64, 95-96, 97a/b, 102a/b, 106-107, 114-116, 118-119). Da sich die Statuette aus Voiron weder typologisch noch handwerklich von den ptolemäischen Reitern unterscheidet, wird auch sie ursprünglich aus Ägypten in den Alpenraum gelangt sein. Sie ist wie die anderen Vertreter dieses Typus ins späte 4. bzw. 3. Jahrhundert v.Chr. zu datieren.

Wie die Figur in die Alpen gelangte, lässt sich nicht mehr eindeutig rekonstruieren. Denkbar ist, dass gallische Söldner, die nachweisbar auch im Dienste frühptolemäischer Könige standen, ${ }^{465}$ die Statuette mit nach Hause brachten. Es ist versucht worden, die ptolemäischen Reiter mit den gallo-römischen Jupiter-Giganten-Darstellungen (bzw. entsprechenden Vorgängerkulten) in Verbindung zu bringen. ${ }^{466}$ Auch wenn eine direkte Beeinflussung der kaiserzeitlichen Monumente durch die frühhellenistischen Terrakotten unwahrscheinlich ist, verbirgt sich hinter ihnen doch ein ähnlicher Gedanke: Der siegreiche Götterkönig/Gottkönig reitet einen (mit ihm verwandten) Gott/Gegner nieder. Dies könnte den „Export“ der Terrakotte nach Gallien gefördert haben.

\subsubsection{Manteljünglinge mit Syrinx}

Manteljünglinge mit Syrinx fanden sich in Rom (Tk 349-352, Taf. 37 Abb. 146) und Capua (Tk 357, Taf. 37 Abb. 144). Die Statuetten aus Rom stammen (wie der entblößte Chlamydephoros [Tk 348]) aus dem Kybele-Heiligtum auf dem Palatin und werden entsprechend in die Zeit nach 191 v. Chr. datiert. Es handelt sich überwiegend um Oberkörperfragmente, nur Tk 349 ist noch bis zu den Unterschenkeln erhalten. Dargestellt sind jeweils Jugendliche mit Kausia und am Rücken herabhängendem Mantel. Ein Untergewand fehlt, die Körper sind entsprechend weitgehend entblößt. Tk 349 scheint den nackten Bauch betont nach vorne zu schieben. Die Jünglinge halten mit der rechten Hand eine Syrinx vor der Brust. Der Fundort (Kybele-Attis-Heiligtum) und die Syrinx legen nahe, dass Attis oder ein Verehrer des Gottes dargestellt wird. Im Kybele-Heiligtum auf dem Palatin fanden sich auch „Attis“-Statuetten ohne Kopfbedeckung bzw. mit phrygischer Mütze. ${ }^{467}$ Da die in Rom lebenden Attis-Verehrer überwiegend aus den Ostprovinzen stammten, ${ }^{468}$ ist es möglich, dass die Attis-Statuetten vorzugsweise von aus Makedonien oder makedonisierten Regionen des Orients stammenden Personen geweiht wurden. Vielleicht wurde die Kausia im Westen aber auch nur als eine „orien-

\footnotetext{
${ }^{465}$ Vgl. Pausanias $1,7,2$.

${ }^{466}$ Vgl. F. Benoit, Mars et Mercure - Nouvelles Recherches sur l'interpretation gauloise des divinités romaines, Publications des annales de la faculté des Lettres, Aix-en-Provence, N.S. 25 (1959) 37 .- M. Mackintosh, The Divine Rider in the Art of the Western Roman Empire, BAR Intern. Series 607 (1995) $22 \mathrm{f}$.

${ }^{467}$ Vgl. M. J. Vermaseren, Corpus Cultus Cybelae Attidisque III. Italia-Latium (1977) Taf. 36 f. $47 \mathrm{ff}$.

${ }^{468} \mathrm{Vgl}$. K. Schillinger, Untersuchungen zur Entwicklung des Magna Mater-Kultes im Westen des römischen Kaiserreichs (1979) 289 .- G. Sanders, Kybele und Attis, in: Die Orientalischen Religionen im Römerreich, OrRR (Hrsg.: M. J. Vermaseren) (1981) 275 ff. 279 ff.
} 
talische" Kopfbedeckung unter anderen angesehen und war in römischen Augen genauso zur Charakterisierung des Attis geeignet, wie die phrygische Mütze.

Eine vermutlich aus Capua stammende Figur (Tk 357) unterscheidet sich von den römischen Statuetten dadurch, dass der Jüngling die Syrinx an den Mund geführt hat. Sie wird ebenfalls ins 2. Jahrhundert v. Chr. datiert.

\subsubsection{Eros und Eros-und-Psyche}

Durch Flügel eindeutig als Eroten identifizierbare Terrakotten mit Kausia fanden sich in Tarent (Tk 360, Taf. 37 Abb. 142), Ruvo (Tk 363) und Centuripe (Tk 367). Die Eroten aus Tarent und Ruvo sind neben der Kausia mit einer Chlamys bekleidet, der Eros aus Centuripe mit einem nicht eindeutig bestimmbaren Mantel. Alle Figuren tragen kein Untergewand und bei allen ist der Mantel auf den Rücken zurückgeschlagen, die Vorderseite des Körpers einschließlich der Genitalien ist weitgehend entblößt. Die Statuetten werden durchweg in frühhellenistische Zeit datiert.

Neben den durch Flügel als Eroten gekennzeichneten Terrakotten sei auf die oben schon beschriebenen Chlamydephoren ohne Chiton (Tk 348, 358, Taf. 37 Abb. 143, 145) verwiesen, deren Ikonographie weitgehend der der Eroten entspricht. Mit den Eroten vergleichbar ist auch ein an einen Pfeiler gelehnter Knabe (Tk 364 [o. Abb.]) mit Kausia und herabgerutschtem Gewand, der entsprechend ebenfalls weitgehend nackt wirkt.

Aus Capua stammen drei Gruppen (Tk 354-356, Taf. 39 Abb. 152-153), die jeweils einen jungen Mann in Chlamys, ${ }^{469}$ Chiton und Kausia zeigen, der von einer jungen Frau umarmt wird. Flügel sind nicht vorhanden, wie bei Beispielen aus anderen Regionen (Tk $337 \mathrm{f}$. von der Krim); vielleicht handelt es sich dennoch um Eros und Psyche, zumindest um ein erotisches Thema (Soldat und Hetäre?). Stil und Langhaarfrisuren deuten ins 4.-3. Jahrhundert v. Chr.

\subsubsection{Frauen}

Aus Tarent stammen eine Frau (Tk 361) und eine Mänade (Tk 362) mit Kausia (Taf. 38 Abb. 147-148). Es handelt sich um die mit einer Ausnahme ${ }^{470}$ einzigen mir bekannten Darstellungen weiblicher Personen mit Kausia. ${ }^{471}$ Die stehende Frau (Tk 361) ist bekleidet mit einem hochgegürtetem Chiton, einem Mantel, der um die Unterarme geschlungen ist und am Rücken herabfällt, sowie einer Kausia. Die Mänade (Tk 362) trägt einen Chiton, der links von der Schulter gerutscht ist und die Brust frei gibt, einem um den Unterkörper geschlungenen Mantel und eine Kausia. Sie lehnt sich im dem rechten Unterarm auf einen Pfeiler und hält in der linken Hand ein Gefäß (Situla), im rechten Arm eine lange Fackel. Das Fell eines Rehes (?)

\footnotetext{
${ }^{469}$ Tk 355 und Tk 356 zeigen einen Chlamydephoros in kurzem Chiton und zurückgeschlagener Chlamys (= Typus Epheben-Soldat), Tk 356 einen Chlamydephoros in bodenlanger Chlamys.

${ }^{470}$ Tk 338 (Krim) zeigt eine Psyche, die wie der zur betreffenden Gruppe gehörende Eros eine Kausia trägt.

${ }^{471}$ In der Literatur werden teilweise langhaarige Chlamydephoroi als Frauen oder Mädchen bezeichnet. Vgl. L.

B. Brea a.a.O. 108. E 110 .- Pingiatoglou, Benaki, Nr. 357. 380.
} 
ist über die rechte Schulter geworfen und diagonal über den Oberkörper zur linken Hüfte geführt.

Die Statuetten werden ins 3. bzw. 2 Jahrhundert datiert und wurden in Gräbern ${ }^{472}$ gefunden. Das Motiv (Mänade, Nymphe) gehört in den dionysischen Bereich. ${ }^{473}$ Dionysisches findet sich sowohl in männlichen als auch weiblichen Bestattungen. Die Herkunft der weiblichen Figurentypen ist vermutlich im weiblichen Votivwesen zu suchen. ${ }^{474}$

Die Kombination von Frauenstatuetten mit der Kausia ist einzigartig und lässt sich vielleicht damit begründen, dass diese Kopfbedeckung im Westen real nicht oder nur selten getragen wurde.

\subsubsection{Köpfe}

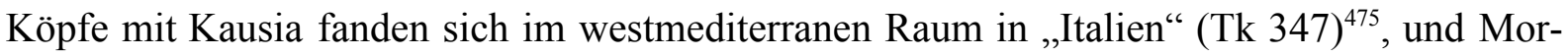
gantina (TK 365-366) ${ }^{476}$.

\subsubsection{Zusammenfassung}

Koroplastische Wiedergaben der Kausia sind im Westen selten. Treten sie auf, dann meist nicht in Kombination mit den im Osten üblichen Typen (besonders den Chlamydephoroi) und Trachtbestandteilen (Chlamys). Stattdessen erscheint die Kausia größtenteils in Verbindung mit anderen, in Italien beliebten Typen (Eroten, Manteljünglingen), die sonst mit Petasos, Kranz oder ohne Kopfbedeckung dargestellt werden.

Die überwiegend von den ostmediterranen Kleidungs- und Darstellungskonventionen losgelöste Kombination der Kausia mit Statuettentypen, die im Osten nicht mit dieser verbunden wurden, erklärt sich möglicherweise damit, dass die Kausia im Westen real nur selten und von anderen als den im ostmediterranen Bereich üblichen Personengruppen getragen wurde. Als exotische Kopfbedeckung konnte sie daher relativ frei mit beliebten westlichen Typen verbunden wurde.

Die Statuetten aus den Griechenstädten Unteritaliens werden in die Zeit vom 4.-2. Jahrhundert v. Chr. mit Schwerpunkt im 4.-3. Jahrhundert datiert. Dies entspricht der Blütezeit der Diadochenreiche und wohl auch der Zeit ihres größten Einflusses auf die westgriechische Kultur. Das weitgehende Fehlen von Terrakotten mit Kausia in der Zeit nach 200 v. Chr. kann aber auch mit veränderten Kultpraktiken zusammenhängen. So scheinen z.B. die Weihungen von

\footnotetext{
${ }^{472} \mathrm{Zu}$ Tk 361 liegen keine weiteren Angaben zum Fundkontext vor. Zu Tk 362 vgl. D. Graepler, Tonfiguren im Grab (1997) 261 Grab 46: Mehrfachbestattung (ein Kind und Frauen?), diverse Beifunde (Terrakotten, Keramik, Fingerringe).

${ }^{473}$ D. Graepler, Tonfiguren im Grab(1997) $205 \mathrm{ff}$.

${ }^{474}$ Vgl. D. Graepler, Kunstgenuß im Jenseits? Zur Funktion und Bedeutung hellenistischer Terrakotten als Grabbeigabe, in: Bürgerwelten (Ausstellungskatalog Berlin 1994) 53.

${ }^{475}$ Der langhaarige Kopf im Louvre wird aufgrund des Stiles ins 3. Jh. v. Chr. datiert.

${ }^{476}$ Die Statuetten aus Morgantina lassen sich aus stratigraphischen Gründen in die Zeit vor 211 v. Chr. datieren. Hierfür sprechen auch Stil und Langhaarfrisur. Tk 365 stammt aus einem Heiligtum vielleicht der Persephone. Vgl. M. Bell, Morgantina Studies I. The Terracottas (1981) 252 ff.
} 
Terrakotten in kleinere Heiligtümer der Demeter und Kore weitgehend eingestellt worden zu sein. ${ }^{477}$

Eindeutig in die Zeit nach 200 v. Chr. lassen sich nur die Figuren aus Rom datieren. Diese sind jedoch am ehesten mit einer ostmediterranen Bevölkerungsgruppe in Rom zu verbinden. Dies unterscheidet sie von den Statuetten aus den Griechenstädten Unteritaliens und Siziliens.

\subsubsection{Zypern}

Auf Zypern wurden seit alters verschiedene Kopfbedeckungen getragen. Diese werden auch in der Koroplastik wiedergegeben. Es handelt sich meist um Darstellungen von Reitern oder Wagenlenkern. Die betreffenden Figuren wurden in großer Zahl in zypriotische Heiligtümer geweiht. ${ }^{478}$ Einige dieser Kopfbedeckungen gleichen im Aussehen der Kausia weitestgehend. Da entsprechende Statuetten seit archaischer Zeit ${ }^{479}$ nachweisbar sind, kann es sich bei diesen Mützen jedoch nicht um makedonische Kausien handeln. Es muss demnach auf Zypern eine regionale, mit der Kausia nicht identische, aber sehr ähnliche Kopfbedeckung gegeben haben. Da Zypern in hellenistischer Zeit als Teil des Alexanderreiches und seiner Nachfolgestaaten zum potentiellen Verbreitungsgebiet der makedonischen Kausia gehörte, stellt sich die Frage, ob die bildlichen Wiedergaben von kausiaähnlichen Mützen aus hellenistisch-römischer Zeit auf der Insel mit der Kausia oder einer zyprischen Kopfbedeckung in Verbindung zu bringen sind.

Diese Frage ist derzeit nicht eindeutig zu beantworten, da beispielsweise nicht bekannt ist, ob die betreffenden Statuetten von einheimischen „Zyprioten“ oder zugewanderten „Makedonen“ geweiht wurden oder es zu einem Verschmelzen beiden Mützen gekommen ist. Im Rahmen dieser Arbeit werden als bildliche Wiedergaben makedonischer Kausien nur solche Darstellungen von der Kausia gleichenden Kopfbedeckungen angesprochen, die typolo-

\footnotetext{
${ }^{477}$ Vgl. V. Hinz, Der Kult von Demeter und Kore auf Sizilien und in der Magna Graecia, Palilia 4 (1998) $231 \mathrm{f}$.

${ }^{478}$ Vgl. zum Apollon-Heiligtum von Kourion beispielsweise J. H. Young/S. H. Young, Terracottafigurines from Kourion in Cyprus (1955) 86, 89 Taf. 38 Mold 3B3 (=Nr. 1889-1905); 95, 97. Taf. 39 Mold 6B (= Nr. 2061-70); 102 Taf. 32 Mold 11A (= Nr. 2168-81); 117 Taf. 42 Mold 26 (= Nr. 2450-54); 117 f. Taf. 42 Mold 27 (= Nr. 2458-63); 118 f. Taf. 42 Mold 28B (= Nr. 2470-2510); 121 Taf. 44 Mold 31A (= Nr. 2565-89 ?); 121 Taf. 36 Mold 30 Nr. 2536; 121 f. Taf. 56 Mold 31 (= Nr. 2565-94 ?); 122 f. Taf. 43 Mold 32B (= Nr. 2655-2690-27062713 ?); 124 Taf. 43 Mold 33A(= Nr. 2732-35); 123 Pl. 36 Nr. 2622 (= Mold 32A), 2735 (= Mold 32A); 126 Taf. 36 Nr. 2770 (= Mold 34A); 125 Taf. 43 Mold 33C1 (= Nr. 2756 ff.?); 125 Taf. 43 Mold 33C2 (=Nr. 2760-69); 126 f. Taf. 44 Mold 35 (=2796-99, 2803 ?); 127 Taf. 44 Mold 36 (=2810-13); 127 Taf. 44 Mold 37 (= Nr. 281418); 128 Taf. 36 Mold 38 (= Nr. 2843); 131 Taf. 45 Mold 44 (= Nr. 2882-86); 134 f. Taf. 37 Nr. 2905; 142 Taf. 52 Mold 49 (= Nr. 2959-61); 143 Taf. 52 Mold 51 (= Nr. 2966f); 144 Taf. 52 Mold 54A (= Nr. 2974-79); 145 Taf. 50 Mold 54B2 (= Nr. 2990); 146 Taf. 51 Mold 54B2 Nr. 2996; 136 Taf. 46 Nr. 2915, 2918; 137 Taf. 48 Nr. 2934. und N. A. Winter, The terracottas, in: D. Buitron-Oliver, The Sanctuary of Apollo Hylates at Kourion. Excavations in the Archaic Precinct, SIMA 109 (1996) 89 ff. 100 ff. 104 ff. (headdresses) 135 f. und zum Aphrodite-Adonis-Heiligtum von Amathous J. H. Young/S. H. Young, Terracottafigurines from Kourion in Cyprus (1955) 163 Taf. 62 Nr. 3021, 3016.

${ }^{479}$ Vgl. z.B. die archaischen Tonfiguren aus Agia Irini in E. Sjöqvist, Swedisch Cyprus Expedition II (1935) Nr. 259 S. 683 Taf. 229; Nr. 1219 S. 716 Taf. 231; Nr. 1796 S. 741 Taf. 213 sowie A. Caubert,Das Ende der Archaik und die klassische Epoche, in: Aphrodites Schwestern und das christliche Zypern, Ausstellungskatalog Bremen 1987, 83 (Quadriga-Wagenlenker wie auch später im hellenistischen Kourion üblich).
} 
gisch mit solchen Typen (Chlamydephoren, hockende Knaben) zu vergleichen sind, die auch außerhalb Zyperns in Verbindung mit der Kausia erscheinen, und die möglichst auch handwerklich in spätklassisch-griechischer Tradition stehen. Auf diesem Wege wird eine möglicherweise mehrer hundert Exemplare umfassende Gruppe von Terrakotten hellenistisch-römischer Zeit mit kausiaähnlicher Kopfbedeckung nicht zu den Darstellungen der makedonischen Kausia gezählt. ${ }^{480}$ Denn diese Statuetten stehen sowohl typologisch (Wagenlenker, einzeln gearbeitete Reiter) als auch handwerklich (handgeformte Figuren, denen von griechischen Statuetten abgeformte Gesichter aufgestempelt wurden) in einheimischer, vorhellenistischer Tradition.

\subsubsection{Statuetten aus Ton}

Typologisch und handwerklich eindeutig in spätklassisch-griechischer Tradition stehen nur fünf der auf Zypern gefundenen Terrakotten. Zu diesen gehören ein stehender Chlamydephoros in Chlamys, Chiton und Kausia (Tk 378, vgl. Taf. 24 Abb. 87-89) aus Kition (Larnaka), ein „Ephebensoldat“ (vgl. Taf. 27 Abb. 98-101) aus Cythrea (Tk 374) sowie zwei weitere „Ephebensoldaten“, von denen nur bekannt ist, dass sie aus „Zypern“ (Tk 371-372) stammen. Ein Köpfchen (Tk 375) fand sich in der Anfang des 2. Jahrhunderts verfüllten Kanalisation des Aphrodite- (Adonis-) Heiligtums von Amathous. Es handelt sich um eine der wenigen Statuetten, für die die Verwendung (Votiv) und ein terminus ante quem gesichert sind. Runde Gesichtsformen und Locken deuten auf eine Entstehung noch im 3. Jahrhundert hin.

\footnotetext{
${ }^{480} \mathrm{~J}$. H. Young/S. H. Young, Terracottafigurines from Kourion in Cyprus (1955) nennen 16 Statuetten mit Kausia (Nr. 2355, 2374, 2402, 2593, 2594, 2647, 2648, 2649, 2961-65, 2967, 2978, 2996) .- N. Winter, SIMA 109, 1996, 89 ff. bezeichnet die Kopfbedeckungen von sechs Statuetten (Nr. 988, 1927-30, 1941-42) als „,causia or beret“" (= headdress 32) und von drei weiteren Figuren (Nr. 1390, 1392, 1606) als ,causia with headband“ (= headdress 34). Zusammen ergibt dies bis zu 25 Terrakotten mit Kausia (alles Reiter oder Wagenlenker, Ende 4. Jh. v.Chr. bis 1. Jh. n.Chr.). Da sich die erwähnten Katalognummern keiner Abbildung zuweisen lassen, ist eine Überprüfung der Benennungen nicht möglich. - Unter den wenigen in Verbindung mit der Katalognummer abgebildeten Exemplaren befinden sich einige, bei deren Kopfbedeckungen es sich um kausiaähnliche Mützen handelt, die aber von den Bearbeitern nicht als „,causia[i]“ benannt werden (vgl. z.B. J. H. Young/S. H. Young aa.O. Nr. 2934 [low tiara], 2990 [flat cap], 3016 [flat cap and fillet] und N. Winter a.a.O. Nr. 469 und 486 [douple turban]). Die Anzahl der Terrakotten, die von oben genannten Autoren als mit „low tiara“, „flat cap“, ,double turban or beret-like cap" usw. versehen bezeichnet wird, geht in die Hunderte. - Young/Young und Winter bilden den größten Teil der Statuetten unter alleiniger Nennung der Mold-Nummer ab, ohne dass die Möglichkeit bestände, diese mit einer Katalognummer zu verbinden. Unter diesen befinden sich viele, die der Kausia sehr (J. H. Young/S. H. Young a.a.O. Taf. 32 Mold 11A.- N. Winter a.a.O. Taf. 19 Abb. 28CA1. 29D. 33H3; Taf. 21 Abb. 44P1. 45PP3. 46Q1 ff.; Taf. 22 Abb. 47QQ2. 48T2) oder relativ ähnlich sind (J. H. Young/S. H. Young a.a.O. Taf. 36 Nr. 2843. 2622. 2770. 2536. 2725; Taf. 37 Nr. 2905; Taf. 38 Mold 3B3; Taf. 39 Mold 6B; Taf. 42 Mold 26. 27. 28B; Taf. 43 Mold 32B. 33A. 33C1. 33C2; Taf. 44 Mold 31A. 35-37; Taf. 45 Mold 44; Taf. 46 Nr. 2915. 2918; Taf. 51 Nr. 1996; Taf. 52 Mold 54A. 51. 49; Taf. 56 Mold 1 .- N.Winter a.a.O. Taf. 19 Abb. 25AA; Taf. 21 Abb. 43; Taf. 22 Abb. 52; Taf. 26 Abb. 87f; Taf. 29 Abb. 123. 125). Die Publikationen sind jedoch einseitig auf die Identifizierung und Bearbeitung der Gesichtsstempel (,molds“) ausgerichtet. Die Abbildungen sind daher meist jeweils nur mit der Nummer des Stempels gekennzeichnet. Da sich hinter einzelnen Stempeln Dutzende von Statuetten mit unterschiedlichsten Kopfbedeckungen verbergen können, ist die Verbindung der abgebildeten Exemplare mit einzelnen Katalognummern nicht möglich. Die Bezeichnungen der Autoren für bestimmte Kopfbedeckungen sind hierdurch nicht nachprüfbar.
} 


\section{Deutung}

Die wenigen handwerklich (Form) und thematisch (Chlamydephoros) griechischen Terrakotten mit Kausia dürften wie vergleichbare Stücke aus Ägypten von Makedonen oder makedonisch geprägten Personen geweiht worden sein. Dass sie u.a. aus Kition und Amathous, den nach Salamis und Paphos wichtigsten ptolemäischen Verwaltungszentren der Insel, stammen, bestätigt dies.

\subsubsection{Statuetten aus Kalkstein}

Eine Besonderheit Zyperns sind knapp unterlebensgroße Knabenstatuetten aus Kalkstein. Sie lassen sich in zwei Gruppen einteilen:

Die erste zeigt hockende, männliche Kinder in Chiton und Kausia, die meist mit einem Vogel spielend dargestellt sind (Taf. 35 Abb. 138-139), die so genannten, ,temple boys ${ }^{\text {‘481 }}$. Gefunden wurden sie in einem Heiligtum in Kourion (P 5), in Nikosia (Heiligtum?, P 6), im ApollonHeiligtum von Voni (P 7) sowie an anderen nicht näher bekannten Orten Zyperns (P 8-9). Aus Golgoi stammt das Oberkörperfragment (P 10) eines Knaben im Chiton, das aufgrund der Kleidung am ehesten hockend zu ergänzen ist. ${ }^{482}$

Die zweite Gruppe bilden stehende Figuren von Jugendlichen oder jungen Männern in Chlamys, Chiton und Kausia. Die Statuen stammen aus dem Apollon-Heiligtum von Idalion (P 1112, Taf. 27 Abb. 100-101).

Darüber hinaus gibt es eine Reihe von männlichen Köpfen mit Kausia, die Personen zeigen, deren Alter schwer bestimmbar ist. ${ }^{483}$ Diese dürften sich zu ,temple boys“ oder Chlamydephoroi ergänzen lassen. Als Fundorte werden das Heiligtum der Mutter der Götter in Tamassos (P 13-14), das Heiligtum des Apollon in Idalion (P 15-17), Golgoi ${ }^{484}$ (P 18-30), Agios Phokas (P 31) und nicht näher bekannte Orte auf Zypern (P 32-34) genannt.

Soweit genauere Angaben zur Datierung gemacht werden, wird eine zeitliche Einordnung der Statuetten und Köpfe in das späte 4. und das 3. Jahrhundert v.Chr. vorgenommen.

Alle Statuen und Köpfe, zu denen ausreichende Informationen zum Fundort vorliegen, stammen aus Heiligtümern.

\footnotetext{
${ }^{481}$ Hockende Knaben mit Kausia sind in der Gruppe der „temple boys“ eine Ausnahme. Die Masse der „temple boys" trägt keine Kopfbedeckung, teilweise werden sie auch mehr oder weniger nackt dargestellt. Vgl. C. Beer, Temple Boys (1994).

${ }^{482}$ Vgl. A. Hermary, Catalogue des Antiquités de Chypre. Sculptures (1989) $72 \mathrm{ff}$.

${ }^{483}$ Die Köpfe wirken oft relativ alterslos. A. Hermary, Catalogue des Antiquités de Chypre. Sculptures (1989) 236 ff. spricht sie bezeichnenderweise nur als „têtes..." bzw. „personnages masculin“ an, und verzichtet auf die bei ihm sonst in der Überschrift übliche Altersbestimmung (z.B. ,têtes d'enfants couronnées“ [a.a.O. 194 ff.]). Die zu den Köpfen aus Golgoi potentiell zugehörigen Körperfragmente werden im Gegenzug als „enfants et jeunes adolescents“ oder „adultes“ bezeichnet (a.a.O. 275 ff., 271 ff.).

${ }^{484}$ Zur möglichen Ergänzung der Köpfe aus Golgoi vgl. das ebenfalls aus Golgoi stammende Fragment (ohne Kopf) eines stehenden Chlamydephoros (mit Ente?) im Louvre (MA 2812): A. Hermary, Catalogue des Antiquités de Chypre. Sculptures (1989) 276 Nr. 561.
} 


\section{Deutung}

Die Rückseiten der Kalksteinvotive sind oft nicht oder nur teilweise ausgearbeitet, und viele Figuren sind so flach gearbeitet, dass sie fast als Reliefs bezeichnet werden können. Es handelt sich um regionale Arbeiten, die aber, wie qualitätvollere Werke aus Zypern und dem benachbarten Phönizien zeigen, ${ }^{485}$ dennoch in griechischer Handwerkstradition stehen.

Typologisch vergleichbar sind die hockenden „temple boys“ (P 5-9, 10 [?]) [86 $^{486}$ it entsprechenden (Horus-) Knaben aus Ägypten (Tk 25-27, 65, 117; vgl. auch Tk 336 aus Pantikapaion/Krim). Die stehenden Chlamydephoren (P 11-12) lassen sich problemlos in die für die hellenistischen Terrakotten entwickelte Typologie einordnen. P 12 entspricht dem „Typus stehender Chlamydephoros“, P 11 dem „Typus Epheben-Soldat“.

Da alle Kalksteinstatuetten, zu denen nähere Angaben zum Fundort vorliegen, aus Heiligtümern stammen, ist davor auszugehen, dass sie eine Funktion als Votiv besaßen. Ähnlich wie im Fall der in Heiligtümern gefundenen koroplastischen Chlamydephoroi handelt es sich, soweit bekannt, auch bei denjenigen Gottheiten, denen die Kalksteinfiguren geweiht wurden, um Muttergöttinnen (Meter-Hera-Astarte, Aphrodite[?]) oder um deren göttlichen Söhne (Apollon). Insbesondere die hockenden ,temple boys“ wurden früher mit der auf Zypern vorkommenden Tempelprostitution in Verbindung gebracht. ${ }^{487}$ In neuerer Zeit werden sie - ähnlich wie Darstellungen jugendlicher Personen mit Votivcharakter allgemein - meist als Danksagungen z.B. für die Geburt eines Kindes oder den Schutz des Kindes in einem gefährdeten Lebensalter sowie in Zusammenhang mit Übergangsriten gedeutet. ${ }^{488}$

Die Kalkstein-Chlamydephoren zeigen nicht nur die Kausia, sondern übernehmen bis in Details hinein Merkmale der koroplastischen Chlamydephoren-Typen. Es ist daher ebenfalls an eine Weihung der Figuren durch „Makedonen“ zu denken, vielleicht auch an eine Verbindung mit hinter den Chlamydephoroi stehenden Themen (z.B. Ephebie $)^{489}$.

\subsubsection{Vorderer Orient}

Aus dem Vorderen Orient (Syrien, Libanon, Zweistromland, Susiane, Insel Failaka) stammen 187 Tonfiguren mit Kausia (Tk 379-452). ${ }^{490}$ Von diesen sind jedoch in 66 Fällen ( 35\%) nur die Köpfe erhalten, bei weiteren rund 50 Exemplaren nur der Kopf mit Teilen des Oberkörpers, was eine Zuordnung zu einzelnen Themen oder Typen erschwert bzw. unmöglich macht.

\footnotetext{
${ }^{485}$ Vgl. z.B. einen hockenden Knaben (4. Jh. v.Chr.) aus dem Eschmun-Tempel (Sidon) in Beirut (A. Parrot/M. H. Chéhab/S. Moscati, Die Phönizier [1977] 123 Abb. 132).

${ }^{486}$ Entsprechende Statuen sind auf Zypern seit dem 5. Jh. nachweisbar (C. Beer, Temple Boys [1994] z.B. 14 f. Nr. 2 ff.). Ähnliche Figuren finden sich vereinzelt auch in Phönizien.

${ }^{487}$ E. Sjöqvist, A Cypriote Temple Attendant, AJA 59, 1955, 46.

${ }^{488}$ Vgl. die Diskussion bei A. Hermary, Catalogue des Antiquités de Chypre. Sculptures (1989) 69 (mit älterer Literatur). Vgl. auch R. Stucky, Die Skulpturen aus dem Eschmun-Heiligtum bei Sidon (1993) 35-39, der bei der Interpretation in erster Linie vom Charakter des dort verehrten Heilgottes ausgeht und nur am Rande erwähnt, dass auch in Sidon der Übergang von einem Lebensabschnitt zum anderen eine Rolle gespielt haben könnte.

${ }^{489}$ Zur Deutung der Statuetten vgl. unten die Kapitel zum kulturellen Umfeld koroplastischer Typen.

${ }^{490}$ Hierbei sind die 19 Exemplare mitgezählt, die vermutlich eine der makedonischen Kausia gleichende orientalische Mütze zeigen (*Tk 381a-382g, 385a-386b).
} 
Bei den in ausreichendem Umfang erhaltenen Terrakotten und Fragmenten von Terrakotten mit makedonischer Kausia (zusammen 102 Exemplare) handelt es sich in 97\% der Fälle um Reiter ( $73 \%$ ) und Chlamydephoroi ( $25 \%)$. Andere Themen (zwei sitzende Knaben und ein Paar) erscheinen nur ausnahmsweise. ${ }^{491}$

\subsubsection{Chlamydephoroi}

Statuetten sitzender Chlamydephoroi sind im Vorderen Orient nicht nachweisbar. Für stehende Chlamydephoroi des Normaltypus (vgl. Taf. 24 Abb. 87-89) im ostmediterranen Sinne, wie sie sich z.B. in Ägypten und im Bereich des Ägäis häufig finden, gibt es im Vorderen Orient nur zwei Beispiele. ${ }^{492}$ Sie stammen aus Babylon (Tk 423) und Uruk (Tk 436).

Von den sechs Vertretern des Typus „Epheben-Soldat““ (Taf. 27 Abb. 99) stammen vier aus Kharayeb (Tk 380 a- d) und zwei formgleiche Exemplare aus Uruk (Tk 437 a-b).

Der in der gesamten hellenistischen Welt relativ seltene Typus ${ }^{493}$ zeigt stehende, junge Männer, bekleidet mit Kausia, in der Taille gegürtetem Chiton und auf der rechten Schulter zusammengesteckter Chlamys. Die Chlamys gibt die rechte untere Hälfte des Körpers bzw. des Chitons frei und reicht nur bis oberhalb der Knie. Sie wirkt nicht so betont verhüllend, wie die Chlamyden der Statuetten vom mediterranen Chlamydephoren-Normaltypus. Die Armhaltung variiert, meist ist ein Arm in die Hüfte gestemmt, der andere hängt locker am Körper herab. ${ }^{494}$ Die Stücke aus Uruk sind - wie fast alle Terrakottafiguren aus Mesopotamien - nur allgemein in seleukidisch-parthische Zeit zu datieren. Die lineare Gestaltung der Statuetten macht eine regionale Werkstatt wahrscheinlich. Die Tonfiguren aus Kharayeb sind aufgrund des Stiles entweder als spätklassisch-frühhellenistisch ${ }^{495}$ oder als klassizistisch ${ }^{496}$ verstanden worden. Die handwerklich sehr qualitätvolle Arbeit könnte auf einen Export (z.B. aus dem griechischen Mutterland) hindeuten.

Der Typus stammt aus dem spätklassischen Athen. ${ }^{497}$ Alle Statuetten werden, abgesehen von klassizistischen Stücken, in den Übergang vom 4. zum 3. Jahrhundert v. Chr. datiert. Ort und

\footnotetext{
${ }^{491}$ Tk 379-452 zeigen: 66 Köpfe, 74 Reiter (-fragmente), 25 Chlamydephoren (-fragmente), zwei sitzende Knaben mit Hahn bzw. Trauben, ein Paar und 19 Darstellungen mit phönizischer Mütze.

${ }^{492}$ Ein drittes Beispiel ist vielleicht Tk 400 aus Jebel Khalid. Es handelt sich um das Fragment einer männlichen Figur, das wahrscheinlich einen Kopf mit Kausia (?) und die Schulter mit rechts zusammengesteckter Chlamys zeigt. Die Statuette ist auch als Frau mit Stephane gedeutet worden (vgl. P. J. Connor, Terracottas from Seleucid Jebel Khalid, MeditArch 7, 1994, 78 f. Taf. 4,3).

${ }^{493}$ Die wenigen weiteren Vertreter dieses Typus stammen aus Xanthos (Tk 175), Limyra (Tk 179), Böotien (Tk 292-293) und Zypern (Tk 371-372, 374).

${ }^{494}$ Bei den Epheben-Soldaten aus Kharayeb und Uruk ist jeweils der linke Arm in die Hüfte gestemmt, bei denen aus Xanthos und Böotien der rechte. Die Hände werden bei den Exemplaren aus Xanthos und Böotien wie bei den Chlamydephoroi vom Normaltypus durch Greifen oder Einwickeln in das Gewand ruhiggestellt.

${ }^{495}$ G. Schneider-Herrmann, in: Alessandria e il mondo ellenistico-romano (FS A. Adriani) (1984) 303: 3. Jh. v. Chr. .- J. P. Uhlenbrock, in: The Coroplast's Art(FS D. Burr-Thompson) (1990) 116: Anfang 3. Jh. v. Chr.

${ }^{496}$ Chéhab, Kharayeb, 158: 100 v. Chr.

${ }^{497}$ Vgl. Epheben-Soldaten aus dem spätklassischen Athen (R. Higgins, Tanagra and the Figurines [1986] 149 Abb. 180 f.).
} 
Zeitpunkt der Entstehung und das Aussehen des Typus verweisen auf die attische Ephebie in ihrer paramilitärisch durchorganisierten Form der Zeit kurz nach etwa 336 v. Chr. Dies macht eine Abhängigkeit des „Epheben-Soldaten“-Typus von der attischen Ephebie wahrscheinlich.

Eine Variante des Chlamydephoren-Themas bildet das Oberkörperfragment (Tk 407 [o. Abb.]) einer Figur, die sich mit dem linken Ellenbogen auf einen Pfeiler lehnt und dabei den Kopf mit der Hand stützt (Denkerpose). Die Statuette stammt aus Seleukia am Tigris und wird stratigraphisch ins 1.-2. Jahrhundert n. Chr. datiert.

Oberkörperfragmente von Chlamydephoroi stammen aus Jebel Khalid (am Euphrat) und Seleukia am Tigris. Das Exemplar aus Jebel Khalid (Tk 400 [o. Abb.]) lässt sich aufgrund des sehr fragmentarischen Zustandes keinem Typus zuordnen. Von den 12 Figuren aus Seleukia sind neun (Tk 406 a-i [o. Abb.]) mit einiger Sicherheit zu stehenden Chlamydephoroi des mediterranen Normaltypus' und drei (Tk 408 a-c [o. Abb.]) vielleicht zu „Epheben-Soldaten“ zu rekonstruieren. Datiert werden die Statuetten aus Seleukia aus Gründen der Stratigraphie ins 1.-2. Jahrhundert n. Chr.

\subsubsection{Reiter}

Die Reiterfiguren aus dem Vorderen Orient lassen sich in drei Gruppen einteilen: Statuetten, die sowohl handwerklich (Herstellung aus der Form) als auch typologisch mediterranen ${ }^{498}$ Vorbildern folgen, Terrakotten, die handwerklich (Handformung) und typologisch ganz in orientalischer ${ }^{499}$ Tradition stehen sowie mediterran-orientalischen Mischformen.

\section{a) Mediterrane Reiter-Typen}

Nur eine Statuette aus dem Orient lässt sich mit einiger Sicherheit einem mediterranen Typus zuweisen. Es handelt sich um eine Figur vom Typus „Reiter ohne Gegner“ (vgl. Taf. 30 Abb. 111-112) aus Ibn Hani (Tk 392). Der Ort war im 3. Jahrhundert v. Chr. ein ptolemäischer Militärstützpunkt und hatte die Aufgabe, den Zugang zur nahegelegenen seleukidischen Hafenstadt Laodikeia (Lattakia) an der syrischen Küste zu kontrollieren. ${ }^{500}$ Die Terrakotte ist wohl mit den hier stationierten ptolemäischen Truppen in Verbindung zu bringen. Historischer $\mathrm{Zu}-$ sammenhang, Stilvergleich und die Langhaarfrisur des Reiters ergeben eine Datierung der Statuette ins 3. Jahrhundert v. Chr.

Aus dem seleukidischen Laodikeia am Libanon (Tell Nebi Mend) ist das Fragment einer Reiterstatuette erhalten (Tk 390 [o. Abb.]). Es zeigt nur noch den zur Seite blickenden Kopf (mit Kausia und Langhaarfrisur) und die Schultern des Reiters sowie Kopf und Hals des Pferdes. Der Reiter wird im Vergleich zum Pferd sehr klein wiedergegeben. Eine verbindliche Zuord-

\footnotetext{
498 „Mediterran“ meint hier: griechisch-mutterländisch, griechisch-kleinasiatisch, ptolemäisch-ägyptisch.

499 „Orientalisch“ meint in persisch-mesopotamischer Tradition stehend.

${ }^{500}$ Vgl. G. Hölbl, Geschichte des Ptolemäerreiches (1994) 291 Anm. 90.
} 
nung zu einem bestimmten Typus ist infolge des fragmentarischen Zustandes nicht möglich. Eine enge Anlehnung an mediterrane Typen („Reiter über Gegner“?) ist jedoch sehr wahrscheinlich. Stil und Frisur deuten wiederum auf das 3. Jahrhundert v. Chr.

Drei Reiterfragmente stammen aus Tell Halaf(Tk 394-396, Taf. 32 Abb. 121). Erhalten ist jeweils nur der Kopf (mit Kausia), der Schulterbereich und teils die Ansätze der Arme. Oberkörper und Kopf sind zur Seite gedreht, so dass die Figuren zur Seite blicken. Orientalische Einflüsse sind nicht erkennbar. Es spricht nichts gegen eine Rekonstruktion der Statuetten als Vertreter des Typus „Reiter ohne Gegner“501, da die erhaltenen Reste mit diesem übereinstimmen und verschiedene Varianten dieses Typus (ohne Kausia) in Tell Halaf nachweisbar sind $^{502}$

In Babylon wurde eine vollständig erhaltene Reiterterrakotte gefunden (Tk 424 [o. Abb.]). Sie zeigt einen Reiter in Chlamys, Chiton, Stiefeln und Kausia auf einem springenden Pferd. Der Reiter schmiegt seinen Körper eng an den Hals des Pferdes. Handwerkliche Ausführung und Stil entsprechen griechisch-mutterländischen Statuetten. Das Motiv (springendes bzw. galoppierendes Pferd) ähnelt dem ptolemäischen Typus „Reiter über Gegner/Schild“, doch fehlt hier der Gegner. Ebenfalls nicht mit mediterranen Darstellungen vergleichbar ist die hohe, ovale Basis, aus der das Pferd erwächst.

\section{b) Mediterran-orientalische Mischformen}

Eine Statuette aus Tell Halaf zeigt einen Reiter mit Kausia und vermutlich Chlamys (Tk 393, Taf. 32 Abb. 119). Der Mann blickt wie die ptolemäischen Vergleichsstücke vom Typus „Reiter ohne/über Gegner“ (Tk 9 ff., 62 ff. u.ö.) nach rechts. Während die Gestaltung der Reiters und auch die Technik (Herstellung mit Hilfe von Formen) griechischen Vorbildern folgen, erinnert die summarische Gestaltung des Rumpfes und der Beine des Pferdes sehr an handgeformte südmesopotamische Figuren (vgl. Tk 432 f., 445 f., 448 ff., Taf. 33 Abb. 125-130). Anatomische Details des Pferdekörpers wurden stark vernachlässigt, auch die für ptolemäische Reiterfiguren typische Standplatte fehlt - wie bei den handgeformten Pferden des Orients. In Tell Halaf wurden auch Statuetten gefunden, die weitgehend identische Pferde, jedoch mit orientalisch gekleideten Reitern, zeigen. Auch dies spricht für Querverbindungen zu östlichen Traditionen. ${ }^{503}$ Die Terrakotte wird in hellenistisch-parthische Zeit datiert.

Eine ebenfalls aus der Form stammende Tonfigur aus Seleukia am Tigris bietet einen geradeaus blickenden, den Oberkörper leicht nach rechts drehenden Reiter in Chlamys, Chiton (?)

\footnotetext{
${ }^{501}$ Tk 394-95 werden auch von B. Hrouda, Tell Halaf 4. Die Kleinfunde aus historischer Zeit (1962) 24 Nr. 151 f. als Reiterfragmente angesprochen. Tk 396 deutet Hrouda als Fragment eines Tänzers (ähnlich Tk 385-386 aus Kharayeb). Vgl. B. Hrouda, a.a.O. 22 Nr. 109. Es spricht jedoch nichts gegen eine Ergänzung auch von Tk 396 als Reiter (Vgl. auch das Reiterfragment [mit linken ausgestrecktem Arm über dem eindeutig erkennbaren Pferdekopf] aus Jebel Khalid [P. J. Connor, Terracottas fromSeleucid Jebel Khalid, MeditArch 7, 1994, Taf. 7, 3] mit gleicher Armhaltung.).

${ }^{502}$ Vgl. B. Hrouda, Tell Halaf 4. Die Kleinfunde aus historischer Zeit (1962) Nr. 142 Taf. 17, Nr. 143, 144, 147 Taf. 18.

${ }^{503}$ Vgl. B. Hrouda, Tell Halaf 4. Die Kleinfunde (1962) 24 Nr. 147 Taf. 18.
} 
und Kausia (Tk 409, Taf. 32 Abb. 120). Reiter mit Blickrichtung nach vorne finden sich zwar vereinzelt auch im Mittelmeerraum ${ }^{504}$, die Masse $^{505}$ blickt jedoch, wie auch alle kausiatragenden, ptolemäischen Reiterfiguren, zur Seite und dreht den Oberkörper entsprechend. Im Gegensatz hierzu sitzen die vollständig handgeformten Reiter (z.B. Tk 448 ff.) sowie die handgeformten Statuetten mit aufgestempelten Gesicht (z.B. Tk 425 f.) aus dem Orient gerade mit Blick voraus auf dem Pferd. Die anatomischen Details des Pferdes der Terrakotte aus Seleukia sind besser herausgearbeitet als bei der vorher besprochenen Statuette aus Tell Halaf. Dennoch erinnert die unbeweglich wirkende Gesamtkonzeption noch an die handgeformten Pferde des Orients. Ob eine Standplatte vorhanden war, lässt sich nicht mehr klären, da der untere Teil der Beine fehlt. Datiert wird die Statuette ins 1.-3. Jahrhundert n. Chr.

\section{Fragmente}

Acht Fragmente (Tk 410a-411d [o.Abb.]) aus Seleukia am Tigris zeigen männliche Figuren in Chlamys und Kausia. Erhalten sind jeweils nur die Oberkörper. Die Statuetten erscheinen auf den ersten Blick wie frontal stehende junge Männer. Die Abdrücke von Pferdemähnen auf den Brustkörben verraten jedoch, dass es sich um Reiter handeln muss. Die Terrakotten sind aus der Form gearbeitet. Die Ausrichtung der Reiter nach vorne geht wahrscheinlich auf östlichen Einfluss zurück. Datiert werden die Fragmente auf stratigraphischer Grundlage in die Zeit von 150 v. Chr. bis an den Anfang des 3. Jahrhunderts n. Chr., d.h. in die parthische Epoche.

Aus Babylon stammen fünf Oberkörperfragmente (Tk 425a-426, Taf. 32 Abb. 123-124), aus Uruk ein weiteres (Tk 440 [o. Abb.]), die sich anhand der Abdrücke von Pferdemähnen zu Reitern ergänzen lassen. An Bekleidung ist nur die Kausia erkennbar. Die Körper sind handgeformt und wirken brettartig, die Gesichter sind aufgestempelt. ${ }^{506}$ Diese orientalisch-griechische Mischtechnik findet sich auch auf Zypern mit seiner ebenfalls multiethnischen bzw. multikulturellen Bevölkerung.

\section{c) Handgeformte orientalische Reiter-Typen}

Vollständig handgeformte Reiterstatuetten ohne Gesichtsstempel, d.h. ganz orientalischen Handwerkstraditionen folgende Terrakotten, finden sich nur im südlichen Zweistromland (Nippur, Tello, Uruk) und der östlich angrenzenden Susiane (Susa, Masjid-i Solaiman) sowie auf der Insel Ikaros (Failaka) vor der kuwaitischen Küste.

Es handelt sich jeweils um handgeformte Reiter auf handgeformten Pferden (Taf. 33 Abb. 125-130). Gesichtszüge sind in sehr grober Form teilweise angedeutet. Das einzig erkennbare

\footnotetext{
${ }^{504}$ Vgl. Winter, Typen II, 298.

${ }^{505} \mathrm{Vgl}$. Winter, Typen II, $299 \mathrm{ff}$.

${ }^{506}$ Der Körper ist nicht weiter untergliedert, auch Ansätze von Armen finden sich nicht. Eine Ausnahme bildet Tk 426 aus Babylon: Hier befinden sich am handgeformten Körper mit Gesichtsstempel ebenfalls handgeformte Arme. Dies erinnert an die vollständig handgeformten, komplett erhaltenen Reiter aus Nippur (Tk 430a-c) und Uruk (Tk 442a-443), die jedoch keine Gesichtsstempel aufweisen.
} 
Kleidungsstück ist eine barettartige Kopfbedeckung, die, da Reiter mit solchen Mützen erst in seleukidischer Zeit nachweisbar sind, als Kausia gedeutet wird. ${ }^{507}$

Diese Reiterstatuetten lassen sich in vier Typen untergliedern: Reiter ohne Attribut, Reiter mit Rundschild, Reiter auf Doppelpferd ( $(\mu \phi \iota \pi \pi \circ \varsigma)$ und Reiter auf Doppelpferd mit Göttin.

Die Scheidung verschiedener Werkstattkreise ist in gewissem Umfang möglich.

\section{Reiter ohne Attribut}

Es handelt sich bei diesem Typus um handgeformte Statuetten eines Reiters auf einem Pferd. Abgesehen von der Kausia sind keine Attribute vorhanden (Taf. 33 Abb. 125-126). Entsprechende Figuren fanden sich in Nippur (3 Exemplare, Tk 430a-c), Tello (2 Expl., Tk 432-433), Uruk (5 Expl., Tk 438a-d -439), Ikaros (21 Expl., Tk 452a-u), Susa (2 Expl., Tk 445a-b) sowie Masjid-i Solaiman (2 Expl., Tk 448 a-b).

\section{Reiter mit Rundschild}

Die Vertreter dieses Typus unterscheiden sich von den oben genannten Reitern nur durch den Rundschild ${ }^{508}$ am linken Arm (Taf. 33 Abb. 127). Der Rundschild wurde von iranischen Reitervölkern nicht verwendet, sondern erst in hellenistischer Zeit in Mesopotamien eingeführt. ${ }^{509}$ Er kennzeichnet den Reiter als seleukidischen Kavalleristen. ${ }^{510}$ Die Statuetten stammen aus Susa (1 Exemplar, Tk 446) und Masjid-i Solaiman (3 Expl., Tk 449a-c).

\footnotetext{
${ }^{507}$ Ursprünglich wurde die Kopfbedeckung als orientalischer Priesterhut (,priest‘s hat“) gedeutet (E. D. van Buren, Clay Figurines of Babylonia and Assyria [1930] 165 f. Nr. 799 Taf. 45, 217 = Tk 430a-c). Im gleichen Jahr (1930) kam die Deutung als Kausia („Causia“) auf (L. Legrain, Terracottas from Nippur [1930] 32 Taf. 50 Nr. 263, $264=$ Tk 430a-c), die sich seitdem bis in die jüngsten Publikationen hinein gehalten hat (vgl. M.-Th. Barrelet, Figurines et Reliefs en Terrecuite de la Mesopotamie antique I [= Institut Français d'Archéologie de Berouth. Bibliothèque archéologique et historique 85] [1968] 158 Nr. 55 Taf. 5 ; R. Ghirshman, Terrasses Sacrées de Bard-è Nechandeh et Masjid-i Solaiman [= MDAI 45] [1976] 79 ff.; H. E. Mathiesen, Ikaros - The Hellenistic Settlement I. The Terracotta Figurines [1982] 22 ff. Nr. 25 ff.; Nadja Wrede, Katalog der Terrakotten der archäologischen Oberflächenuntersuchung [Survey] des Stadtgebietes von Uruk [Uruk 35-37], BaM 21, 1990, 257 Nr. 69 Taf. 20). Vereinzelt wurde sie auch als Petasos bezeichnet (H. de Genouillac, Fouilles de Telloh II [1936] 56 Nr. TG4083). Der summarische Ausarbeitung und das teilweise recht unterschiedliche Aussehen (Die Kopfbedeckung einiger Exemplare [z.B. Tk 430a-c aus Nippur und Tk 432 aus Tello] ähnelt eher einem Trichter und wird wohl in erster Linie in Anlehnung an eindeutigere Stücke als Kausia bezeichnet.) werden eine absolut sichere Identifizierung als Kausia immer unmöglich machen. Die Benennung der barettartigen Mütze als Kausia erscheint mir jedoch als die wahrscheinlichste. Insbesondere die Kopfbedeckungen der - sämtlich aus einer Werkstatt stammenden - Reiter aus Susa (Tk 445a-447), Masjid-i Solaiman (Tk 448a-451d) und Ikaros (Tk 452a-u) dürften aufgrund der großen Ähnlichkeit mit der Kausia, der Kombination mit dem Rundschild (vgl. nachfolgende Anm.) und auch aufgrund der historischen Rahmenbedingungen relativ sicher als Kausia zu bezeichnen sein. Diese Statuetten bilden die Grundlage der Interpretation der Bedeutung und Funktion der orientalischen Reiter.

${ }^{508}$ Der militärische Kontext widerspricht einer Benennung der Kopfbedeckung als Priesterhut.

${ }^{509}$ Vgl. R. Ghirshman, Iran - Parther und Sasaniden (1962) 104.

${ }^{510}$ Der Schild könnte ursprünglich durch Bemalung eindeutig als „makedonischer“ Schild kenntlich gemacht gewesen sein.
} 


\section{Reiter auf Doppelpferd}

Diese Figuren unterscheiden sich vom Typus „Reiter ohne Attribut“ nur durch das Reittier. Es handelt sich um ein Pferd mit zwei Hälsen und zwei Köpfen, aber - soweit dies erkennbar ist anscheinend mit nur einem Körper und vier Beinen (Taf. 33 Abb. 128). Der Reiter sitzt entweder auf zwei Pferden gleichzeitig, deren Körper und Beine aufgrund der summarischen Darstellungsweise nicht zu unterscheiden sind, oder reitet ein doppelköpfiges Wesen. Gefunden wurden die Statuetten in Masjid-i Solaiman (2 Exemplare, Tk 450a-b).

\section{Reiter mit Doppelpferd und nackter Göttin}

Die Statuetten dieses Typus unterscheiden sich von den „Reitern auf Doppelpferd“ durch eine nackte, weibliche Figur, die zwischen den zwei Pferdehälsen angebracht ist (Taf. 33 Abb. 129-130). Vertreter dieses Typus stammen aus Susa (1 Fragment, Tk 447) und Masjid-i Solaiman (4 Exemplare, Tk 451a-d).

\section{Fragmente}

Oberkörperfragmente von relativ ähnlichen, handgeformten Reitern, die sich keinem Typus mehr zuordnen lassen, wurden in Seleukia am Tigris (1 Exemplar, Tk 422), Tello (2 Expl., Tk 434, 435 [?]) sowie Uruk (6 Expl., Tk 441a-443) $)^{511}$ gefunden.

\section{Der Werkstattkreis der handgeformten orientalischen Reiter-Typen}

Die Reiterfiguren aus Susa (4 Exemplare, Tk 445a-447), Masjid-i Solaiman (11 Expl., Tk 448a-451d), und Ikaros (21 Expl., Tk 452a-u) und vielleicht auch diejenigen aus Tello (2 Expl., Tk 432-433) stimmen im Gesamterscheinungsbild und diversen Details soweit überein, wie dies bei handgeformten Terrakotten der Fall sein kann. Die Herkunft aus einer Werkstatt und ein relativ enger zeitlicher Zusammenhang sind daher sehr wahrscheinlich. ${ }^{512}$ Die Verteilung der Typen spricht für Susa als Produktionsort: Nur hier sind alle vier Typen vertreten. Im relativ nahen Masjid-i Solaiman finden sich noch drei Typen (Doppelreiter mit Göttin, Reiter mit Schild, Reiter ohne Attribut), an den weiter entfernten Fundorten (Ikaros, Tello) nur noch die einfachen Reiter ohne Attribut ${ }^{513}$.

Die Reiterfiguren aus Seleukia/Tigris, Nippur, Uruk und teilweise Tello weisen Übereinstimmungen in einzelnen Details sowohl innerhalb des Fundzusammenhanges als auch im überregionalen Vergleich auf. Die Unterschiede überwiegen jedoch, so dass dort von verschiedenen Werkstätten und/oder einem weiteren zeitlichen Rahmen auszugehen ist.

\footnotetext{
${ }^{511}$ Die Exemplare aus Uruk sind stark fragmentiert (Tk 441a-b: Köpfe) oder weichen typologisch stark ab (Tk 442a-443: Reiter?).

${ }^{512}$ Eine Werkstatt mit Sitz in Susa nimmt auch H. E. Mathiesen, Ikaros - The Hellenistic Settlement I. The Terracotta Figurines (1982) 72 für die Reiter aus Susa, Masjid-i Solaiman und Ikaros an.

${ }^{513}$ Bei den einfachen Reitern ohne Attribut ist zu überlegen, ob diese nicht ursprünglich Schilde trugen, die im Laufe der Zeit abgefallen sind. Auch bei den Doppelreitern ohne Göttin kann nicht ausgeschlossen werden, dass zumindest einige Statuetten eine heute verlorene Göttin aufwiesen.
} 


\section{Datierung}

Die handgeformten Reiterstatuetten werden meist nur allgemein in seleukidisch-parthische Zeit (3. Jahrhundert v. Chr. bis Anfang 3. Jahrhundert n. Chr.) datiert

Genauere Angaben liegen nur zu den Statuetten aus Ikaros (Tk 452a-u) und Masjid-i Solaiman (Tk 448a-451d) vor. Eine der Reiterfiguren aus Ikaros lässt sich aus Gründen der Stratigraphie dem Anfang des 2. Jahrhunderts v. Chr. zuordnen. ${ }^{514}$ Die Reiter aus Masjid-i Solaiman werden aus historischen und stratigraphischen Überlegungen in seleukidische Zeit, das ist in der betreffenden Region der Zeitraum von etwa 300-140 v. Chr., datiert. ${ }^{515}$ Die Datierungsansätze der werkstattgleichen Figuren aus Ikaros und Masjid-i Solaiman überschneiden sich im Bereich der 1. Hälfte des 2. Jahrhunderts v. Chr. Dies führt zu einer zeitlichen Einordnung der ganzen Werkstatt und damit aller Reiter aus Ikaros, Masjid-i Solaiman und Susa sowie wahrscheinlich auch der oben genannten Figuren aus Tello zwischen 200 und 140 v. Chr.

\subsubsection{Ausnahmen}

Abgesehen von den Köpfen lassen sich nur drei Statuetten mit Kausia keinem der sonst auch im Orient vorherrschenden Themen (Reiter, Chlamydephoroi) zuordnen. Von diesen entfallen zwei Figuren auf Kharayeb (Tk 383-384) und eine Statuette auf Nippur (Tk 431).

Zwei Tonfiguren aus Kharayeb (Tk 383-384, Taf. 36 Abb. 140-141) sind jeweils von der Taille an aufwärts erhalten. Der rechte Arm fehlt in beiden Fällen. Die Knaben sind mit Kausia und Chiton bekleidet. Der Chiton ist jeweils von der rechten Schulter herabgerutscht. Der linke Arm ist angewinkelt, die Hand kommt etwa vor dem Zwerchfell zu Liegen und hält eine Traube bzw. einen Hahn (?). Vergleichbar sind die beiden Figuren mit einer Statuette aus Tanagra im Louvre ${ }^{516}$. Sie trägt statt der Kausia einen Kranz mit Blättern und Beeren und darüber eine Wulstbinde und hält einen Beutel. Die Körperhaltung und der von der Schulter herabgerutschte Chiton stimmen bei allen drei Exemplaren überein. ${ }^{517}$ Auch die Haargestaltung (in die Stirn gekämmte Strähnen) einer der beiden Terrakotten (Tk 384 [sowie einiger Köpfe, Tk 388]) lässt sich gut mit der tanagräischen Figur vergleichen. Der Knabe im Louvre ist vollständig erhalten: Er sitzt auf einem würfelförmigen, oben profilierten Quader, zu seiner linken Seite liegt eine Theatermaske der Neuen Komödie. In Anlehnung daran könnte es sich beim Würfel um den Ausschnitt einer Sitzreihe im Theater handeln. Zumindest Tk 384 dürfte entsprechend der Statuette im Louvre zu ergänzen sein. Bei Tk 383 ist die Körperhaltung leicht abgewandelt. Die halbmondförmige Bruchstelle unterhalb des rechten Ellenbogens sowie vielleicht auch ein Bruch im Bereich der linken Hüfte weisen jedoch ebenfalls auf eine Sitzfi-

\footnotetext{
${ }^{514}$ Vgl. H. E. Mathiesen, Ikaros I (1982) 73.

515 Vgl. R. Ghirshman, Terrasses Sacrées de Bard-è Néchandeh et Masjid-i Solaiman, MDAI 45 (1976) 79 ff., 179 ff. (R. Ghirshman datierte 14 Jahre vorher die werkstattgleichen Reiter aus Susa noch ins 1.-3. Jh. n. Chr. [ders., Iran - Parther und Sasaniden [1962] 104]).

${ }^{516}$ Louvre, MNB 442, aus Tanagra, Höhe: $12 \mathrm{~cm}, 250-200$ v. Chr.; vgl. R. Higgins, Tanagra and the Figurines (1986) 155 Abb. 190.

${ }^{517}$ Tk 384 weicht leicht ab: Der Kopf ist nicht nach links unten geneigt, der Oberkörper wirkt aufrechter.
} 
gur hin. Sowohl die Theatermaske als auch der Theater (?)- Sitz, Kranz und Trauben weisen in den dionysischen Bereich. Die Figur im Louvre wird von R. Higgins stilistisch in die 2. Hälfte des 3. Jahrhundert v. Chr. datiert. Die Statuetten aus Kharayeb dürften ähnlich zu datieren sein.

Aus Nippur stammt die Darstellung eines Paares (Tk 431, vgl. Taf. 39 Abb. 154). Die Frau trägt einen Chiton und einen über den Kopf gezogenen Mantel, der Mann Chiton (?), Himation und auf dem Kopf vermutlich eine Kausia. Er legt seinen rechten Arm um die Schulter der Frau. Diese lehnt ihren Kopf leicht an den des Mannes. Der Stil und die Langhaarfrisur (des Mannes) deuten auf eine Datierung in die seleukidische Zeit.

Die nächst vergleichbaren Statuetten von Liebespaaren finden sich an den entgegengesetzten Enden der hellenistischen Welt. Es handelt sich um Paare aus Süditalien (Tk 354-356) bei denen der männliche Partner als Chlamydephoros dargestellt ist und um weitgehend nackte Paare von der Krim (Tk 338-340, 346), die durch entsprechende Flügel eindeutig als Eros und Psyche gekennzeichnet sind. Die abweichende Ikonographie der Gruppe aus Nippur, insbesondere die Verschleierung der Frau, weist auf einen Heiratsritus hin. Möglicherweise ist die Terrakotte mit dem im Zweistromland wichtigen Kult der Heiligen Hochzeit in Verbindung zu bringen. ${ }^{518}$

\subsubsection{Köpfe}

Aus dem Orient stammen 76 Terrakotta-Köpfe mit Kausia. ${ }^{519}$ Sie wurden in Umm el-Amad (Tk 379; 1 Exemplar), Kharayeb (Tk 387a-389; 11 Expl.), Laodikeia am Libanon (Tk 391; 1 Expl.), Tell Halaf (Tk 397-399i; 14 Expl.), Jebel Khalid (Tk 401-405; 5 Expl.), Seleukia am Tigris (Tk 412-421c; 40 Expl.), Babylon (Tk 427-429, 3 Expl.) und Uruk (Tk 444; 1 Expl.) ${ }^{520}$ gefunden. Alle sind nach griechischer Handwerkstradition aus der Form gearbeitet. ${ }^{521}$ Neben den genannten Tonköpfen fand sich in Seleukia am Tigris auch ein knapp $4 \mathrm{~cm}$ hohes, nicht sehr qualitätvolles Alabasterköpfchen mit Kausia (P 35). Bis auf eine Ausnahme (Tk 405) zeigen die Köpfe männliche, unbärtige Gesichter. Eine Zuweisung zu einzelnen Typen ist wiederum nicht möglich.

Eine Besonderheit stellt der Kopf aus Jebel Khalid (Tk 405, Taf. 40 Abb. 157) dar. Er weist einen langen, unten rechteckig begrenzten Bart auf. Es wird hier eine makedonische Kopfbe-

\footnotetext{
${ }^{518}$ Vgl. E. Klengel-Brandt, Die hellenistische Kultur in Babylon: das Zeugnis der Terrakotten, in: Arabia Antiqua (Hrsgg.: A. Invernizzi, J.-F. Salles) (Serie Orientale Roma 70, 2) (1993) 195.

${ }^{519}$ Die Anzahl der Köpfe (ca. 45\%) wie auch der sehr fragmentarisch erhaltenen Figuren ist im Orient extrem hoch. Dies ist in erster Linie darauf zurückzuführen, dass die Funde aus dieser Region meist aus wissenschaftlichen (zudem meist nicht klassisch-[kunst-] archäologischen) Grabungen stammen. Im Gegensatz hierzu gelangte z.B. das Material aus Kleinasien größtenteils über den „Kunsthandel“ in die Sammlungen. Im Kunsthandel werden jedoch meist ansehnliche, d.h. vollständige, Stücke angeboten.

${ }^{520}$ Tk 444 (Kopf und Schulteransatz) wird von Ch. Ziegler, Die Terrakotten von Warka, ADFGUW 6 (1962) 119 Nr. 798 Abb. 452 als Frau mit runder, flacher Kopfbedeckung gedeutet.

${ }^{521}$ Nicht aufgeführt sind hier die Köpfe handgeformter Reiterstatuetten (Tk 442, 443, 452a-u [teilweise]) aus dem südlichen Zweistromland (Uruk, Ikaros). Diese lassen sich trotz ihres fragmentarischen Zustandes eindeutig mit den Reitern verbinden und werden an entsprechender Stelle behandelt.
} 
deckung mit einer orientalischen Haar- bzw. Barttracht verbunden. Eine Identifizierung (makedonisierter Orientale, orientalisierter Makedone) ist u.a. infolge des fragmentarischen $\mathrm{Zu}$ standes nicht möglich.

\subsubsection{Zusammenfassung}

Während die Statuetten des phönizisch-libanesischen Raumes (Kharayeb, Ibn Hani, Laodikeia am Libanon) ganz dem im Mittelmeerraum üblichen Spektrum folgen (überwiegend Chlamydephorentypen, teils ,ptolemäische“ Reiter, alle aus der Form gearbeitet) finden sich am äußersten südöstlichen Rand (Susa, Tello, Ikaros, Masjid-i Solaiman) des Verbreitungsgebietes ausschließlich Reiterfiguren in orientalischer Handwerkstradition (handgeformt). Dazwischen erstreckt sich vom Nordirak (Jebel Khalid, Tell Halaf) bis ins südliche Mesopotamien (Seleukia/Tigris, Babylon, Nippur, Uruk) eine Übergangszone in der von Norden nach Süden der orientalische Einfluss zunimmt. Klare Abgrenzungen sind innerhalb dieses Bereiches auf Grund der diversen Mischformen, des oft stark fragmentierten Fundmaterials und der an vielen Orten nur geringen Funddichte nicht möglich.

Eine Sonderstellung nimmt Seleukia ein. Aus dieser Stadt stammen 55 Terrakotten mit Kausia. Die Stadt am Tigris gehört damit zusammen mit Alexandria (56 Exemplare), Demetrias (mindestens 50 Exemplare) und Samothrake (mehr als 80 Exemplare) zu den zahlenmäßig bedeutendsten Fundorten. Die Statuetten verteilen sich etwa je zur Hälfte auf Chlamydephorenund Reitertypen.

Überwiegend griechisch-mediterran geprägt - wenn auch eindeutig aus einheimischer Produktion - sind die Chlamydephoroi (Tk 406a-408c). Handgeformte orientalische Reiter sind in Seleukia nur in einem Fall nachweisbar (Tk 422). Sich eindeutig an westliche, insbesondere ptolemäische Typen anlehnende Reiter finden sich nicht. Die Reiter (Tk 409-411d) werden stattdessen gerade sitzend und nach vorne schauend dargestellt, während die ptolemäischen Reiter regelmäßig den Oberkörper zur rechten Seite wenden. Das Pferd (nur in einem Fall erhalten; Tk 409) erinnert, obwohl es aus der Form stammt, an handgeformte orientalische Vorbilder. Es hat den Anschein, dass orientalische (d.h. ursprünglich handgeformte) Reiter mit Hilfe griechischer Handwerkstechnik (Form) an einen neuen Geschmack oder ein neues Publikum angepasst wurden.

Seleukia am Tigris ist nicht nur die einzige Stadt im Orient, die ein ausgewogenes Verhältnis von Chlamydephoren und Reitern aufweist, Seleukia ist auch die einzige Stadt des Orients, in der in nennenswertem Umfang eine Sonder- oder Weiterentwicklung stattfand, die sowohl griechische als auch orientalische Traditionen aufnahm.

\subsubsection{Zusammenfassung: Verbreitung von Statuetten mit Kausia}

Die Materialvorstellung schließt mit einer zusammenfassenden Auswertung der Ergebnisse des im Vorfeld nach Regionen getrennt untersuchten Materials. 
Vorweg wird in einem kurzen Exkurs am Beispiel der Chlamydephoren-Statuetten das Verbreitungsgebiet von Figuren, die sowohl mit Kausia als auch mit andern Kopfbedeckungen auftreten können, ermittelt. Ein Ziel dieses Exkurses ist es, zu überprüfen, ob und in welchem Umfang Unregelmäßigkeiten der Verbreitung von Terrakotten mit Kausia Rückschlüsse auf die Verbreitung, Verwendung und Funktion von Darstellungen von Personen mit dieser Kopfbedeckung zulassen oder ob entsprechende Unterschiede vielmehr im Kontext der zugehörigen Typen zu interpretieren sind.

\subsubsection{Verbreitung von Statuetten ohne Kausia am Beispiel der Chlamydephoren}

Alle hier bearbeiteten Typen von Terrakottastatuetten erscheinen in der antiken Koroplastik auch ohne Kopfbedeckung bzw. mit anderen wie dem Petasos, Pilos, Helm oder Kranz. Die Untersuchung der teils abweichenden Verbreitungsgebiete typengleicher Statuetten mit und ohne Kausia hat zum Ziel, die Bedeutung von Figuren mit Kausia einschätzen zu können und Hinweise zur Deutung dieser Darstellungen und ihrer Funktion zu erhalten.

Eine vollständige Erfassung und Bearbeitung sämtlicher koroplastischer Darstellungen von Knaben und jungen Männer hellenistisch-römisch-parthischer Zeit würde jedoch den Rahmen dieser Arbeit sprengen. Andererseits hätte eine regionale oder chronologische Verengung des Untersuchungsgebietes zwar eine Verringerung der Materialmenge zur Folge. Regionale und zeitliche Unterschiede, die im Rahmen dieser Untersuchung von besonderer Bedeutung sind, wären dann aber nicht mehr interpretierbar.

Auf Grund der großen Zahl von Terrakotten ohne Kausia wird im Rahmen dieser Untersuchung nur eine Auswahl von Tonfiguren herangezogen, jedoch eine, die den gesamten Bereich zwischen Italien und Mesopotamien während der hier relevanten Zeiten abdeckt, darunter sowohl Kerngebiete der Verbreitung von Statuetten mit Kausia, als auch solche, in denen sich koroplastische Wiedergaben dieser Kopfbedeckung nur selten finden. Als Materialgrundlage dienen die in einer Reihe von einschlägigen Überblickswerken ${ }^{522}$, Museumskatalogen ${ }^{523}$ sowie Grabungspublikationen ${ }^{524}$ veröffentlichten Exemplare. Diese dürften ein halbwegs repräsentatives Bild des bekannten Gesamtbestandes liefern.

Weiterhin ziehe ich als Vergleichsmaterial nicht Vertreter aller jemals mit der Kausia kombinierten Typen von Terrakottastatuetten heran, sondern beschränke mich auf die mit Abstand

\footnotetext{
${ }^{522}$ Winter, Typen II .- R.A. Higgins, Greek Terracottas (1967) .- J.P. Uhlenbrock, Greek Terracottas of the Hellenistic World, in: The Coroplast's Art (FS D. Burr-Thompson) (1990).

${ }^{523}$ Bayer-Niemeier, Frankfurt .- (Mollard-) Besques Paris II-IV .- Breccia, Alexandria II 1/2 .- Dunand, Paris .Fischer, Slg. Sieglin/Schreiber .- Leyenaar-Plaisier, Leiden .- Pingiatoglou, Benaki .- Schürmann, Karlsruhe .Weber, Berlin.

${ }^{524}$ M. Bell, Morgantina Studies I. The Terracottas (1981) .- Breccia, Sciatbi .- Burr-Thompson, Troy .- Chéhab, Kharayeb .- Graepler, Tarent .- Ingen, Seleukia .- Laumonier, Delos XIII. Les figurines de terre cuite (1957) .-

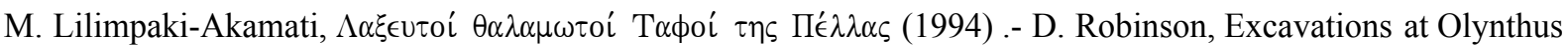
IV. The Terracottas (1931) .- ders., Excavations at Olynthus VII. The Terracottas (1933) .- ders., Excavations at Olynthus XIV. The Terracottas (1952) .- B. Schmaltz, Terrakotten aus dem Kabirenheiligtum bei Theben (1974) .- E. Töpperwein, Terrakotten von Pergamon (PF 3) (1976) .- H. Thompson, D. B. Thompson, S. Rotroff, Hellenistic Pottery and Terracottas (1987) (= Reprints aus Hesperia 3, 21, 23, 26, 28, 31, 34, 35, 1934-1966) .- u.a.
} 
größte Gruppe unter diesen, die Chlamydephoroi, und innerhalb dieser auf die „Normaltypen“6525.

Als problematisch erwies sich im Verlauf der Materialerfassung, dass Statuetten, die exakt typengleich sind mit solchen, die häufig mit Kausia dargestellt werden, sich vorzugsweise in einem begrenzten geographischen Raum finden (Athen/Böotien, nordwestliches Kleinasien, Ägypten). Verlässt man diese ostmediterrane Kernzone, erweitert bzw. verändert sich das Typenspektrum. In Italien beispielsweise treten zwar Chlamydephoroi vom Normaltypus (in Chlamys und Chiton) nur selten auf, dafür erscheinen dort Knaben und junge Männer, die nur einen Mantel tragen, jedoch kein Untergewand, in großer Zahl. Diese lassen die verschiedensten Kopfbedeckungen, darunter vereinzelt auch die Kausia, erkennen. ${ }^{526}$ Die Statuetten weichen typologisch von den Chlamydephoroi ab. ${ }^{527}$ Sie sind in diesem Sinne nicht mit den Figuren in Chlamys, Chiton und Kausia vergleichbar. Andererseits erfüllen sie im westmediterranen Bereich möglicherweise die gleiche Funktion wie die Chlamydephoroi im Osten.

Verunklärend wirkt auch, dass Köpfe wesentlich häufiger ,gefunden“, inventarisiert und publiziert werden als die zugehörigen Körper, die gerne „übersehen“ werden. Während Köpfe mit Kausia zum Nachweis dieser Kopfbedeckung ausreichen (und zudem oft mit großer Wahrscheinlichkeit zu Chlamydephoroi ergänzt werden können $)^{528}$, lassen sich jugendliche Männerköpfe mit Petasos, Kranz oder ohne Kopfbedeckung nicht als Vergleichsmaterial heranziehen. Denn diese sind auf Basis des derzeitigen Forschungsstandes nicht mit ausreichender Sicherheit mit einem bestimmten Typus in Verbindung zu bringen.

Aus oben genannten Gründen ergibt sich, dass ein Vergleich absoluter Zahlen nicht möglich ist und die Ergebnisse dieses Exkurses mit verschiedenen Unsicherheiten behaftet sind. Dennoch geben sie Annäherungswerte und Trends wieder, die ausreichen, einige grundlegende Fragen zu beantworten.

In einigen Gebieten der hellenistischen Welt kommen die gesuchten Chlamydephoren-Typen nicht oder nur selten vor. Hierzu gehören u.a. Italien, Makedonien und das dorische Griechenland. Entsprechend finden sich in diesen Regionen Statuetten vom Typus Chlamydephoros weder mit noch ohne Kausia in nennenswerter Anzahl. Einzelne Funktionen der Chlamydephorenstatuetten könnten in diesen Gegenden von verwandten Typen (in Italien beispielsweise von den „Eroten“) übernommen worden sein.

In jenen Gegenden, in denen Terrakotten des Typus „Chlamydephoros“ gehäuft auftreten (Attika/Böotien, Nordwestkleinasien, Mesopotamien, Ägypten sowie einzelnen Inseln [z.B. Sa-

\footnotetext{
${ }^{525}$ Das sind stehende oder auf einem Felsen sitzende, jüngere, männliche Personen in Chiton und Chlamys.

${ }^{526}$ Vgl. Winter, Typen II, 252-54 und Tk 357 f.

527 Wird ein Vergleich mit den Göttern angestellt, entspricht ihr Aussehen nicht dem des Hermes, sondern des Eros.

${ }^{528}$ In bestimmten Regionen (z.B. Samothrake) kommt die Kausia nur in Verbindung mit Chlamydephorentypen vor, wie vollständig erhaltene Figuren zeigen. Köpfe mit Kausia können daher mit einiger Sicherheit zu Chlamydephoroi ergänzt werden. Im Falle der Kopffragmente ohne Kausia ist dieses Verfahren nicht einsetzbar, da Köpfe ohne Kausia bei verschiedenen Typen auftreten.
} 
mothrake] und Orten [z.B. Demetrias] entlang der Küste des östlichen Mittelmeeres), lassen sich Gebiete, in denen Statuetten mit Kausia überwiegen, und solche, in denen die Kausia nur sehr selten erscheint, relativ scharf von einander trennen.

In Attika/Böotien ${ }^{529}$, einem Hauptverbreitungsgebiet solcher Statuetten und vermutlich auch der Ursprungsregion des Typus', erscheinen fast ausschließlich Figuren mit Petasos oder Kranz bzw. ohne Kopfbedeckung.

Im Gegenzug erscheinen in anderen Gegenden ( $̈$ gypten ${ }^{530}$, Mesopotamien $^{531}$, Samothrake $^{532}$ ) Chlamydephoren fast ausschließlich mit Kausia.

Einen Grenzbereich stellt das nordwestliche Kleinasien dar. Aus der Troas ${ }^{533}$ stammen fast nur Statuetten mit Kausia, in Myrina ${ }^{534}$ überwiegen solche mit anderen Kopfbedeckungen bzw. ohne Kopfbedeckung und in dem der kleinasiatischen Küste vorgelagerten Lesbos ${ }^{535}$ erscheinen sowohl Figuren mit als auch ohne Kausia. Problematisch ist in dieser Region die oft nicht eindeutig geklärte Herkunft von Terrakotten mit Fundortbezeichnungen wie „südliche Aiolis“ und ,ionische Küste“ oder auch „Myrina“ und „Smyrna“.

Sowohl der Typus (Junge/junger Mann in Chlamys und Chiton) als auch das vermutete Thema der Darstellung (Ephebie) stammen aus dem spätklassischen Athen. ${ }^{536}$ Dieses war zwar im entsprechenden Zeitraum meist politisch von Makedonien abhängig, bewahrte aber seine kulturelle Eigenständigkeit und nahm seinerseits insbesondere in frühhellenistischer Zeit Einfluss auf die Kunst und Kultur anderer Regionen. Die Folge war, dass Chlamysträger hier weiterhin mit zentralgriechischer Kopfbedeckung (Petasos) bzw. Kranz oder barhäuptig wiedergegeben wurden. $^{537}$

Im Gegensatz hierzu tritt in Gebieten, die von Makedonen erobert und/oder in nennenswerter Anzahl besiedelt worden sind (z.B. Ägypten, Demetrias, Teile Kleinasiens [Troas], Mesopotamien), der Typus regelmäßig in Kombination mit der Kausia auf. Griechische (nichtmakedonische) Siedler, die in großer Zahl an der Besiedlung Ägyptens und des Orients beteiligt waren, hinterließen im Rahmen der koroplastischen Chlamydephorendarstellungen fast keine Spuren. Dies könnte darauf zurückgeführt werden, dass der Typus auch in Griechenland nur in einer eng begrenzten Region (Attika/Böotien) Verwendung fand oder dass sich die Grie-

\footnotetext{
${ }^{529}$ Vgl. Winter, Typen II, 237; 238, 1-8; 240, 1-2, 6-8; 256, 1-5, 7; 257, 1-8 .- Leyenaar-Plaisier, Leiden III, Taf. 38 .- Besques, Paris III, Taf. 38-43.

${ }^{530} \mathrm{Vgl}$. Tk $1 \mathrm{ff}$.

${ }^{531} \mathrm{Vgl}$. Tk 406 ff. (Seleukia/Tigris).

${ }^{532} \mathrm{Vgl}$. Tk $201 \mathrm{ff}$.

${ }^{533} \mathrm{Vgl}$. Tk 132 ff.

${ }^{534}$ Mit Petasos etc.: Winter, Typen II, 241, 1, 3,-5, 7 .- Besques, Paris II, Taf. 143-48, 154-55 .- Leyenaar-Plaisier, Leiden III, 105-6. Mit Kausia: Tk 157 ff.

${ }^{535}$ Vgl. Tk 180 ff. bzw. A. Archontidou-Argiri, ADelt 43 B`2, 1988, Taf. 278.

${ }^{536}$ Vgl. R. Higgins, Tanagra and the Figurines (1986) 148 ff. Abb. 179 ff. und 150 ff. Abb. 186 ff. .- Vgl. zur Interpretation u. das Kapitel zur kulturellen Umwelt koroplastischer Typen.

${ }^{537}$ Entsprechendes gilt vielleicht auch für schon lange hellenisierte Gebiete im nordwestlichen Kleinasien (z.B. um Myrina, gegenüber der Ägäisküste Attikas und Böotiens).
} 
chen im Orient ebenfalls mit Kausia, d.h. wie Makedonen und damit Angehörige der politisch dominierende Volksgruppe, wiedergeben ließen.

Regionen, die weder attisch noch makedonisch geprägt, erobert oder besiedelt waren, weisen weder Kausiadarstellungen noch entsprechende Typen von Tonfiguren ohne Kausia in nennenswertem Umfang auf (z.B. Unteritalien/Sizilien, Südgriechenland).

Makedonien (in den Grenzen von 359 v.Ch.) stellt einen Sonderfall dar. Koroplastische Darstellungen waren auch hier von einer gewissen Bedeutung, wie einzelne Fundkomplexe zeigen. Es ist daher bemerkenswert, dass sich unter den z.B. in der Nekropole von Pella in dreistelliger Zahl gefundenen Tonfiguren kein einziger Chlamydephoros mit oder ohne Kausia findet. Dies könnte darauf zurückzuführen sein, dass im alten makedonischen Stammesgebiet weder Athens politisch-organisatorischer Einfluss (und hiermit verbundene koroplastische Typen) von Bedeutung war noch innerhalb Makedoniens die Notwendigkeit bestand, sich durch das Tragen der Kausia von anderen Bevölkerungsgruppen abzusetzen. Möglich ist jedoch auch, dass die Bestattungssitten und die religiösen Praktiken in Makedonien anderen Traditionen folgten und dort z.B. andere Typen von Tonfiguren oder nicht-koroplastische Beigaben und Votive die Funktion der Chlamydephoren-Statuetten übernahmen.

Sind Chlamydephoren-Typen in bestimmten Gegenden weder mit noch ohne Kausia in nennenswerter Zahl nachweisbar, so ist allein hieraus nur der Schluss zulässig, dass dort entweder Tonfiguren allgemein oder koroplastische Chlamydephoroi keine Rolle spielten.

Die reale Verbreitung und Bedeutung der Kausia in der betreffenden Region ist hiervon vorerst unberührt. Aussagen über diese sind nur möglich, wenn weitere Informationen vorliegen. So deuten für Italien und Südgriechenland der geringe kulturelle und/oder politische Einfluss Makedoniens sowie das weitgehende Fehlen von Kausiadarstellungen in anderen Gattungen darauf hin, dass hier nicht nur koroplastischen Wiedergaben von Chlamysträgern, sondern auch die reale Kausia von geringer Bedeutung waren. Für Makedonien hingegen zeigen Wiedergaben der Kausia in anderen Gattungen ${ }^{538}$ sowie schriftliche Quellen ${ }^{539}$, dass die Kausia sowohl real getragen, als auch in bestimmten Bereichen dargestellt wurde.

Außerhalb des attisch-böotischen Raumes treten Chlamydephoren-Statuetten fast ausschließlich in Verbindung mit der Kausia auf. Sieht man demnach von den Beispielen aus Mittelgriechenland ab, die einen Sonderfall darstellen, da sie für das vorhellenistische Vorbild der hellenistisch-makedonischen Chlamydephoren stehen, handelt es sich bei den ChlamydephorenStatuetten nicht um allgemein verbreitete Typen, die in unterschiedlichen Regionen mit regional unterschiedlichen Kopfbedeckungen versehen werden konnten. Stattdessen bedingen sich Chlamydephoren-Typen und koroplastische Darstellungen der Kausia weitgehend. Diese Zusammengehörigkeit ist bei der Untersuchung der Ikonographie ${ }^{540}$ der Statuetten zu beachten, bei der der Ausgangspunkt der Untersuchung letztlich nicht die Kausia zu sein hat, sondern

\footnotetext{
${ }^{538} \mathrm{Vgl}$. Re 2, Ma 5 f., Nu 6 ff., Ka 3.

${ }^{539}$ Anth. Pal. 4, 335 (Q 1) .- Eustathios, Kommentar zu Ilias B 461 (255, 1) (Q 5a) .- Herodian, 4, 8, 1-2 (Q 7b) .Polyainos, 5, 44, 4-5 (Q 15) .- Pollux, Onomastikon 10, 162 (Q 17) .- u.ö.

${ }^{540}$ Auf die Ikonographie der Statuetten und deren kulturelles Umfeld gehe ich unten ausführlich ein.
} 
die Ikonographie der Gesamtdarstellung. Der Beitrag der Kausia zur Bedeutung und Funktion der Statuetten ist erst in einen zweiten Schritt zu klären.

\subsubsection{Das Gesamtverbreitungsgebiet von Statuetten mit Kausia}

Grundsätzlich deckt sich das Verbreitungsgebiet kleinplastischer Statuetten mit Kausia (Karte 3) in etwa mit dem Gebiet des Alexanderreiches bzw. der Diadochenreiche. Eine Ausnahme bildet die Region östlich der Susiane, in der keine Figuren nachweisbar sind. Da jedoch die Kausia, wie die Münzprägung belegt, auch im äußersten Osten des Alexanderreiches bekannt war (Karte 1), kann das Fehlen von Terrakotten mit Kausia im Mittleren Osten auch eine Folge z.B. des unzureichenden Standes der Forschung, der unter Umständen geringeren Zahl von dort produzierten Tonfiguren oder abweichender Kultpraktiken und Bestattungssitten sein.

Außerhalb des Alexander- und der Diadochenreiche finden sich Tonfiguren mit Kausia vereinzelt auf der Krim und in Italien und Sizilien. Das Typenspektrum der kausiatragenden Terrakotten in diesen Regionen (Eroten, Frauen u.a.) weicht stark von dem der makedonisch beherrschten Gebiete (Chlamydephoren, Reiter u.a.) ab.

Die auf dem Gebiet des Alexanderreiches gefundenen Terrakotten mit Kausia geben überwiegend Chlamydephoren wieder. Während auf der Balkanhalbinsel und in Kleinasien fast ausschließlich die verschiedenen Typen und Varianten von Chlamydephoren (stehend, sitzend, angelehnt, schreitend, vereinzelt mit Attributen [Syrinx/Lagobolon, Herme], „Ephebensoldaten“) zu beobachten sind, wird das Spektrum in Ägypten und im Orient (Zypern, Syrien, Mesopotamien) durch teils in lokaler Tradition stehende, teils Sonderentwicklungen darstellende Typen und Themen von meist nur regionaler Bedeutung ergänzt. Diese können in den entsprechenden Gebieten zahlenmäßig überwiegen. Es handelt sich in Ägypten um Statuetten von Reitern (ohne Gegner, über Gegner/über Schild), Soldaten und seltener von hockenden Knaben (Harpokrates?). Im Osten treten neben den Chlamydephoren in erster Linie Reiter (ohne Gegner) in Erscheinung, deren Ikonographie im südlichen Mesopotamien und der Susiane in starkem Maße von lokalen Traditionen ${ }^{541}$ beeinflusst wird (Reiter mit und ohne Rundschild, sog. Amphippoi mit und ohne Göttin) (vgl. Karten 5-7).

Regionsübergreifend ist zu beobachten, dass der Typen- bzw. Variantenreichtum von bestimmten, von der Entfernung einer Region zu Makedonien relativ unabhängigen Faktoren beeinflusst wird: Das Typenspektrum ist am stärksten eingeschränkt (z.B. fast ausschließlich stehende Chlamydephoren vom Normaltypus) in Ortschaften, in denen Makedonen (bzw. „Hellenen“) die Bevölkerungsmehrheit innerhalb eines nicht-makedonischen Umlandes bilden (z.B. Königsstädte [Demetrias, Alexandria], Kleruchen-/Katoikensiedlungen). In Orten mit nicht-makedonischer Bevölkerungsmehrheit und makedonischer Minderheit (z.B. griechischen Poleis mit makedonischer Garnison) werden auch regional vorhandene Statuettentypen

\footnotetext{
${ }^{541}$ Lokale Traditionen schlagen sich vereinzelt auch im handwerklichen Bereich nieder. In der Regel werden die Statuetten - wie in Griechenland üblich - mit Hilfe von Formen hergestellt, Details und Attribute (einschließlich der Kausia) können nachgearbeitet bzw. nachträglich hinzugefügt sein. Abweichend hiervon treten im Osten (insbesondere im südlichen Mesopotamien und der Susiane) ohne Form von Hand gefertigte Tonfiguren auf.
} 
mit Kausia versehen, die den in den makedonischen Siedlungskolonien verwendeten ähneln, jedoch nicht vollständig mit diesen übereinstimmen. Die Folge ist ein größerer Reichtum an Untertypen und Varianten in diesen Gebieten. Es bleiben diejenigen Regionen, in denen entweder zwar Makedonen leben, aber das nicht-makedonische Umland fehlt (Makedonien in den Grenzen von 359 v.Chr.) oder in denen nur eine kleine, herrschaftspolitisch unbedeutende Gruppe von Makedonen innerhalb einer nicht-makedonischen Bevölkerung lebt (Krim, Italien). In solchen Gebieten treten Terrakotten mit Kausia selten und ohne Bindung an bestimmte Typen auf. Typenspektrum und Variationsbreite sind demnach auch abhängig von demographischen Gegebenheiten und der Form der makedonischen Herrschaftsausübung.

Das Auftreten von Terrakotten mit Kausia fällt zeitlich durchweg mit dem Beginn der makedonischen Einflussnahme - in der Regel der Eroberung des betreffenden Gebietes durch Philipp oder Alexander - zusammen. Das Ende der Produktion dieser Statuetten orientiert sich teils ebenfalls an den politischen Grenzen. So stimmen in Griechenland (insbesondere Demetrias) und Ägypten das Auslaufen von Wiedergaben der Kausia in der Koroplastik und das Ende der makedonischen Reiche bzw. der Beginn der römischen Herrschaft weitgehend überein. In anderen Regionen dagegen hält die Verwendung von Tonfiguren mit Kausia bis weit in die römische Kaiserzeit (Kleinasien) bzw. die Partherzeit (Mesopotamien) hinein an.

\subsection{Fundorte und Fundkontexte von Statuetten}

Als Fundorte der hier behandelten Statuetten werden meist nur Städte, teils auch nur Regionen genannt. Hinweise auf den genauen Fundort innerhalb einer Stadt (z.B. eine bestimmte Nekropole oder ein Heiligtum) sind selten. Detaillierte Angaben zum Fundkontext oder zu Beifunden finden sich noch seltener.

Dennoch soll versucht werden, die potentiellen Fundorte innerhalb und außerhalb der Siedlungen näher einzugrenzen und aus diesen, wie auch aus den wenigen näher bekannten Kontexten, auf Art und Anlass der Verwendung sowie den Kreis der Verwender Rückschlüsse zu ziehen.

Eine Durchsicht des Materials ergibt, dass als Fundorte Nekropolen, Heiligtümer sowie sonstige Siedlungsareale genannt werden. Die Funde der drei genannten Bereiche werden nachfolgend sowohl im Überblick und soweit möglich auch im Detail besprochen.

\subsubsection{Funde aus Nekropolen}

Tonfiguren mit Kausia fanden sich in den Nekropolen von Alexandria (Tk 39-41, 47-49, 51 52, 58-60, 92-94), Myrina (Tk 157-163), Limyra (Tk 177), Mytilene (Tk 180-82, 184), Pella (Tk 186-187), Pydna (Tk 188), Amphipolis (Tk 190-200 [?]), Samothrake Tk 201, 202-239 [?], 246-249), Chalkis (Tk 301), Thessaloniki (Tk 330-333), Kassandreia (Tk 334), Tarent (Tk 361-362), Lipari (Tk 368-369) und Nippur (Tk 430-431 [?]) (vgl. Karte 8). 
Meist beschränken sich die Angaben jedoch auf die Nennung des Namens der Nekropole bzw. des Ortes. Dies trifft für folgende Katalognummern zu: Tk 39-40, 46, 58-60 (AlexandriaSciatbi), Tk 41, 48-49, 92-93 (Alexandria-Hadra), Tk 51 (Alexandria-Sciatbi/Hadra), Tk 52 (Alexandria-Ibrahimieh), Tk 62 (Alexandria-Schukafa), Tk 94 (Alexandria-Ras el Soda), Tk 157-163 (Myrina), Tk 177-178 (Limyra), Tk 189-200 (Amphipolis), Tk 330-333 (Thessaloniki-Gephyra), Tk 334 (Kassandreia), Tk 361-362 (Tarent), Tk 368-369 (Lipari) und vielleicht Tk 430a-431 (Nippur).

Nähere Angaben zum Fundkontext sind selten. Zudem sind diese oft unvollständig und unsystematisch aufgenommen sowie in einer Form publiziert, die eine Überprüfung der Befunde nicht zulässt. Entsprechend müssen viele Fragen offen bleiben.

Zu nur einer der aus Alexandria stammenden Terrakotten mit Kausia ist Näheres zum Fundzusammenhang bekannt. ${ }^{542}$ Es handelt sich um die Statuette eines stehenden Chlamydephoros (Tk 47) aus der Hadra-Nekropole (el Manara, Grab 29). Die Figur fand sich zusammen mit der eines Mädchens im Chiton sowie einer kleinen Amphore, einem zweihenkeligen Schälchen und einem Alabastron. Es handelt sich nicht um eine Loculus-Bestattung, wie sie in el Manara häufig vorkommt, sondern um die Bestattung in einer Grube (fossa).

Die vier koroplastischen Chlamydephoren mit Kausia aus Mytilene (Tk 180-182, 184) wurden zusammen mit sechs ähnlichen, teilweise formgleichen Figuren ohne Kopfbedeckung bzw. mit Petasos, 147 Astragalen, acht Ohranhängern aus Gold, einem goldenen Kranz, einigen Fingerringen, 62 vergoldeten Perlen, einem mit einem orphischen Text beschrifteten Goldblech, Golddraht, weiteren metallenen Kleinteilen, einem bronzenen Weinblatt, einem Spiegel, einer Lampe und fünf Münzen in zwölf Gräbern eines Gräberfeldes gefunden. Eine Zuordnung der Beigaben zu einzelnen Gräbern ist auf Basis des das Material nach Gattungen ordnenden Grabungsvorberichtes ${ }^{543}$ nicht möglich. Gesicherte Aussagen zu Fundvergesellschaftungen und zur Person der Verstorbenen und eine daraus ableitbare Deutung der Terrakotten sind daher nicht möglich.

Aus zwei Gräbern in der Nähe von Pella stammen koroplastische Darstellungen der Kausia. In Kammergrab $\Theta{ }^{544}$ fanden sich auf der Nordkline (gegenüber dem Eingang; auf der Ostund Westseite befinden sich ebenfalls Klinen) fünf Terrakotten, die auf Ziegenböcken reitende Knaben mit Kausia und Chlamys darstellen (Tk 186a-e). Auf der betreffenden Kline wurden neben den Knabenstatuetten mit Kausia verschiedene keramische Gefäße (Skypoi, Unguentarien, Amphoren, Pyxiden), Lampen, weitere Tonfiguren (Pädagoge mit Schützling, Junge auf Hahn reitend, Krieger mit keltischem Schild, Widder, Junge mit Gans, Paare; meist jeweils

\footnotetext{
${ }^{542} \mathrm{Vgl}$. Adriani, Annuaire III, 14 Nr. 29 Taf. 5,1 und 6,2.

${ }^{543}$ Vgl. A. Archontidou-Argyri, ADelt 43 B'2, 1988, 459 Abb. 9-10 Taf. 277 ff.

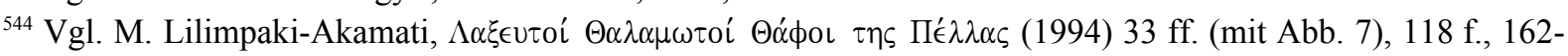
172 Nr. 193-249 Taf. 24-27.
} 
mehrere Exemplare), goldene Blätter eines Kranzes, verschiedene bronzene Kleinteile sowie ein Paar goldener Ohrringe gefunden.

Die West- und die Ost-Kline waren wesentlich schlichter ausgestattet. Auf ihnen befanden sich in erster Linie keramische Gefäße. Eine Strigilis lag auf der West-Kline, eine weitere auf dem Boden der Kammer.

Zum Alter und Geschlecht der auf der Nord-Kline bestatteten Person lässt sich Folgendes sagen: Infolge der räumlichen Verteilung der Beigaben auf der Kline handelt es sich um ein Kind. ${ }^{545}$ Die Ohrringe weisen auf eine weibliche Bestattung. Andererseits zeigen die Terrakotten durchweg männliche Personen und Themen, obwohl Frauenstatuetten im koroplastischen Material der Gräber von Pella überwiegen. Die auf dem Boden des Grabes gefundene Strigilis könnte zur Nord-Kline gehören, was ebenfalls auf eine männliche Bestattung hinweisen würde. Zusammengefasst heißt dies, dass das Geschlecht des Kindes eher weiblich, aber nicht eindeutig zu bestimmen ist.

Im Zugang (Dromos) eines Grabes ${ }^{546}$ auf dem Grundstück Zotakis fand sich ebenfalls ein auf einem Ziegenbock reitender Junge in Chlamys und Kausia (Tk 187). Es handelt sich um ein Doppelkammergrab mit mehreren Bestattungen. In beiden Kammern fand sich eine größere Anzahl von Skyphoi, Unguentarien, Amphoren, Pyxiden und Lampen. In der ersten Kammer wurden zudem ein Tintenfass, eine Strigilis und Terrakotten - meist weibliche Figuren, aber auch ein Widderträger (als „Hermes“ bezeichnet) in Chlamys - entdeckt. Die zweite Kammer bot als Besonderheiten goldenen Schmuck sowie Tonfiguren (Frauen und Eroten). Im Dromos lagen neben Tk 187 verschiedene andere Tonfiguren (Frauen, Eros, Schauspieler, Pädagoge). Es ergibt sich hieraus, dass in dem Doppelkammergrab mindestens ein Mann (Strigilis) und mindestens eine Frau (Schmuck) bestattet worden sind. In die gleiche Richtung deuten auch die Terrakotten, die sowohl männliche als auch weibliche Themen abdecken. Zu welcher Bestattung der Ziegenbockreiter mit Chlamys und die anderen Tonfiguren aus dem Dromos gehören, bleibt unklar.

Ein sehr qualitätvoller stehender Chlamydephoros, der sich das Gewand vor das Kinn zieht (Tk 188), wurde in einem Grab der Südnekropole von Pydna entdeckt. Die Statuette soll zusammen mit weiteren Terrakotten und anderen Gegenständen aus einem kleinen Kistengrab stammen, dessen geringe Größe auf die Beisetzung eines Kindes hindeutet. ${ }^{547}$

Aus den Nekropolen von Samothrake stammen 47 Terrakottafiguren mit Kausia (Tk 201247). Davon entfallen vier auf die H-Nekropole (Tk 244-247), vier auf die West-Nekropole (Tk 240-243) und 39 auf die Südnekropole (Tk 201-239).

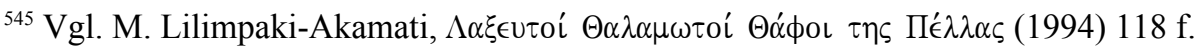

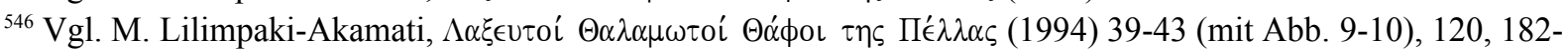
212 Nr. 302-421 Taf. 36-45.

${ }^{547}$ Nach freundlicher Auskunft des Ausgräbers (M. Besios, Thessaloniki) und des Museums in Pydna.
} 
H-Nekropole: Pithos-Grab H 17 enthielt die Knochen eines etwa zehnjährigen Kindes, drei Terrakottastatuetten mit Kausia vom „Typus stehender Chlamydephoros“ (Tk 244-246; 300275 v.Chr.) sowie einen vergoldeten Bronzekranz und mehrere Gefäße. Neben dem Pithos standen zwei Kochgefäße. Im Umkreis des Grabes fanden sich zwei fragmentierte Miniaturschälchen, zwei Kantharoi (einer fragmentiert), ein fragmentierter „Feeder“ und ein Teller sowie das Oberkörperfragment eines stehenden Chlamydephoros, der ebenfalls die Kausia trägt $(\text { Tk 247) })^{548}$. Diese Funde könnten von einem mit Grab H 17 in Verbindung stehenden Bestattungsritual herrühren.

West-Nekropole: Die Statuetten aus der West-Nekropole (Tk 240-243; ca. 300 v.Chr.) sind wesentlich älter als die umliegenden Gräber (z.B. Kammergrab W 12: um Christi Geburt). Die Figuren stehen in keinem Zusammenhang mit dem später an dieser Stelle gelegenen Bestattungsplatz. Sie gehören vermutlich zu einer älteren Kultanlage und werden entsprechend im nachfolgenden Kapitel („Funde aus Heiligtümern“) beschrieben.

Süd-Nekropole: Die Süd-Nekropole liegt auf einer Hügelkuppe südwestlich des Propylons des Heiligtums der Großen Götter bzw. der Straße von der Stadt zum Heiligtum. Der begrenzte Platz wurde im Laufe der Jahrhunderte immer wieder für Bestattungen genutzt. Dies führte zur Störung der hier interessierenden frühhellenistischen (Pithos- und Ziegel-) Gräber durch spätere Beisetzungen.

Von den 39 Terrakottastatuetten mit Kausia (Tk 201-239) wurden von E. Dusenbery nur vier Exemplare bestimmten Gräbern zugeordnet: Tk 201 (sitzender Chlamydephoros) dem Grab S 125, die Köpfe Tk 202-203 Grab S 130 und Kopf Tk 204 Grab S 131. Es kann jedoch nur die Zugehörigkeit des sitzenden Chlamydephoren aus Grab S 125 zum Fundkontext als relativ gesichert gelten. Die mit Dachziegeln abgedeckte Bestattung S 125 beinhaltete neben Tk 201 nur ein Unguentarium und die Knochen eines Kindes.

Die Köpfe aus den Gräbern 130-131 stammen aus den möglicherweise nachträglichen Erdverfüllungen der Pithoi. Dass die Beifunde aus Grab S 130 ins 4. Jahrhundert v.Chr. und früher datiert werden, die Terrakotten Tk 202-203 jedoch ins 3. Jahrhundert v.Chr., spricht gegen einen Zusammenhang. Für Grab S 131 wird die Zugehörigkeit von der Bearbeiterin des Fundmaterials selbst angezweifelt und ein späteres Einsickern aus dem Bereich eines nahegelegenen Terrakottadeposits vermutet. ${ }^{549}$

Das erwähnte Terrakottadeposit der Südnekropole (=TCDS) befindet sich in der Nähe der Gräber 125, 130 und 131. Das genaue räumliche Verhältnis zwischen Deposit und Gräbern lässt sich mangels Plänen und Schnittzeichnungen nicht ermitteln. Der Terrakottahort besteht

\footnotetext{
${ }^{548}$ Das Fragment wurde erstmals 1956 (BCH, Chronique, 80, 1956, 321 Abb. 7) veröffentlicht und damals noch der später von E.B. Dusenbery als H 20 bezeichneten Bestattung zugewiesen (Vgl. Dusenbery, Samothrake, 463 f., H20-1-4). In der Gesamtpublikation der Funde aus Samothrake wird das Stück jetzt dem Umfeld von Grab 17 zugerechnet (Dusenbery, Samothrake, 461, H17-I).

${ }^{549} \mathrm{Vgl}$. Dusenbery, Samothrake, 200.
} 
aus 30 Statuetten $^{550}$, unter denen sich 13 Figuren mit Kausia befinden (Tk 205-217: ein relativ vollständiger stehender Chlamydephoros sowie zwölf teilweise formgleiche Oberkörper- bzw. Kopffragmente). E.B. Dusenbery deutet den Fund einerseits als Rest eines Bestattungsrituales $^{551}$ in Zusammenhang mit Grab S 130 (zwei jugendliche Bestattungen unbekannten Geschlechtes, Befund gestört), andererseits spricht sie die Terrakotten als Votive ${ }^{52}$ aus einem Schrein vielleicht chthonischer Gottheiten an.

In der Süd-Nekropole wurden darüber hinaus weitere 22 Statuetten mit Kausia gefunden. Sie tragen in E.B. Dusenberys Katalog XS- (= irgendwo aus der Süd-Nekropole) -Nummern. Ihr genauer Fundort ist nicht bekannt. Es handelt sich um zwei fragmentierte stehende Chlamydephoroi (Tk 218-219) sowie 20 teilweise formgleiche Köpfchen (Tk 220-239).

Zusammenfassend lässt sich zu den Tonfiguren aus der Süd-Nekropole sagen, dass nur für den sitzenden Chlamydephoros (Tk 201) ein sepulkraler Zusammenhang nachweisbar ist. Die 38 übrigen Statuetten lassen sich aufgrund antiker Störungen und/oder moderner Grabungsund Publikationsmethoden weder bestimmten Gräbern zuordnen, noch ist eindeutig zu sagen, ob sie mit religiösen oder sepulkralen Handlungen in Verbindung zu bringen sind.

Auf sämtliche in den Nekropolen von Samothrake gefunden Terrakottastatuetten mit Kausia bezogen bedeutet dies, dass sich nur die drei in Grab 17 der H-Nekropole gefundenen stehenden Chlamydephoroi (Tk 244-246) und das aus dem Umkreis von H 17 stammende Fragment eines stehenden Chlamydephoren (Tk 247) sowie der sitzende Chlamydephoros (Tk 201) aus Grab 125 der Süd-Nekropole eindeutig bestimmten Bestattungen zuweisen lassen. Alle anderen 42 Statuetten entziehen sich infolge der oben genannten Gründe einer weiteren Interpretation.

Ein schreitender Chlamydephoros (Tk 301) wird Grab 4 der Nekropole von Chalkis auf Euböa zugeordnet. Das Grab misst nur 85 x $41 \mathrm{~cm}$ und ist entsprechend als Kinderbestattung anzusprechen. Im Grab selbst fanden sich ein bronzener Kranz sowie ein Armband. Die Chlamydephoren-Statuette wurde zusammen mit einer weiteren Terrakotte (nackter Knabe) und Keramik (schwarze Schale, Unguentarium) nicht im Grab selbst, sondern in der Umgebung gefunden. In nächster Umgebung liegen jedoch auch die Gräber 1, 3 und 5. ${ }^{553}$ Die Zuordnung erscheint daher als unsicher.

Sollte die Statuette zur Bestattung 4 gehört haben, könnte sie, da sie nicht direkt aus dem Grab stammt, eher im Kult am Grab statt als Beigabe gedient haben. Die Alterstufe der dargestellten Person (Knabe) und das des oder der Bestatteten (Kind) stimmen überein. Das Vor-

\footnotetext{
${ }^{550}$ Dusenbery, Samothrake, 847 ff.: 14 Gruppen, die eine stehende Frau und ein Mädchen zeigen, eine betende Frau, ein weiblicher Kopf und eine Ringergruppe.

${ }^{551} \mathrm{Vgl}$. Dusenbery, Samothrake, $844 \mathrm{f}$.

${ }^{552} \mathrm{Vgl}$. Dusenbery, Samothrake, $844 \mathrm{f}$.

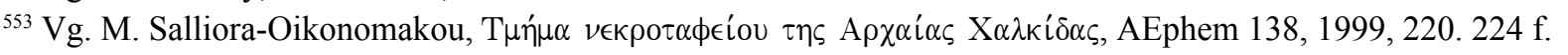


kommen einer Kausiadarstellung auf Euböa könnte mit der Existenz einer makedonischen Garnison in der Stadt erklärt werden.

Aus einen Halbkammergrab bei Tarent stammt die besprochene Darstellung einer Mänade (Tk 362). ${ }^{554}$ Zum Grabinventar gehören verschiedene Gefäße (Askos, Oinochoe, Schälchen, Alabastron, zwei Teller, Situla, Schale mit hohem Fuß, Unguentarien und ein sog. Baby-Feeder), zwei Fingerringe und weitere Terrakotten (15 weibliche Figuren, je ein Vogel, ein Nymphaeum und ein Altar sowie über 50 Fragmente). Aufgrund der Beigaben soll es sich um die Beisetzung einer Frau und eines Kindes handeln. ${ }^{555}$

\subsubsection{Zusammenfassung}

Eine Reihe von Statuetten, für die über die reine Ortsnennung hinausgehende Angaben zum Fundort bekannt sind, stammt aus Nekropolen. Die genannten Städte verteilen sich relativ gleichmäßig über das Gesamtverbreitungsgebiet der Tonfiguren mit Kausia (vgl. Karten 3 und 8).

Es lassen sich fast alle Typen von Statuetten, die in Kombination mit der Kausia auftreten können, nachweisen. So finden sich verschiedene Chlamydephoren-- ${ }^{556}$ und Reitertypen ${ }^{557}$ in oder in der Nähe der Gräber, sowie diverse Ausnahmen (Ziegenreiter ${ }^{58}$, Manteljünglinge[?] $]^{559}$, Frau/Mänade ${ }^{560}$, bärtiger Schauspieler ${ }^{561}, \mathrm{Paar}^{562}$ ).

Nur für die „Reiter über Gegner“ und die Soldaten-Statuetten ist eine Verwendung im sepulkralen Bereich bisher nicht bekannt. Dies ist einerseits darauf zurückzuführen, dass für diese Typen keine näheren Angaben zum Fundort vorliegen, andererseits ist aber auch eine ausschließlich sakrale Funktion möglich.

\footnotetext{
${ }^{554}$ Vgl. D. Graepler, Tonfiguren im Grab (1997) 206. 261 Grab 46 Nr. 12.

${ }^{555}$ Vgl. D. Graepler, Tonfiguren im Grab (1997) 176 mit Anm. 222; 238 mit Anm. 301; 240 mit Anm. 314; 261 Grab 46 Nr. 12.

${ }^{556}$ Sitzende Chlamydephoren (Normaltypus) zeigen: Tk 39-41 (Alexandria), Tk 201 (Samothrake). Sitzende Chlamydephoren mit Herme vgl.: Tk 180-182 (Mytilene [Tk 181-182 ziehen zusätzlich die Chlamys vor den unteren Teil des Gesichts]). Sitzende Chlamydephoren in Denkerpose: Tk 189 (Amphipolis, Nekropole?). Sitzende Chlamydephoren ohne Untergewand: Tk 190-196 (Amphipolis, Nekropole?). -- Stehende Chlamydephoren (Normaltypus) vgl.: Tk 46-49, 51-52 (Alexandria), Tk 157 (Myrina), Tk 202-239. (Samothrake, sepulkrale Verwendung?), Tk 244-247 (Samothrake), Tk 330 (Thessaloniki-Gephyra). Stehende Chlamydephoren, die die Chlamys vor den unteren Teil des Gesichtes ziehen, zeigen: Tk 158-159 (Myrina), Tk 184 (Mytilene), Tk 188 (Pydna), Tk 197-198 (Amphipolis, Nekropole?), Tk 334 (Kassandreia, an Pfeiler gelehnt), Tk 368 (Lipari). Einen schreitende Chlamydephoren zeigt: Tk 301 (Chalkis). - Die Oberkörperfragmente und Köpfe Tk 92-94 (Alexandria), Tk 160-163 (Myrina), Tk 177 (Limyra), Tk 238-239 (Samothrake, sepulkrale Verwendung?) und Tk 332-333 (Thessaloniki-Gephyra) dürften größtenteils zu Chlamydephoren zu ergänzen sein.

${ }^{557}$ „Reiter ohne Gegner“ zeigen: Tk 58-60 (Alexandria-Sciatbi). Drei handgeformte orientalische Reiter (Tk 430a-c) stammen vermutlich aus einer Nekropole bei Nippur.

${ }^{558}$ Tk 186-187 (Pella).

${ }^{559}$ Tk 199-200 (Amphipolis, Nekropole?).

${ }^{560}$ Tk 361-362 (Tarent).

${ }^{561}$ Tk 369: Sklave oder Variante des Soldaten-Typus? (Lipari).

${ }^{562}$ Tk 431 (Nippur).
} 
Diese Tonfiguren könnten einerseits die Funktion einer Beigabe gehabt haben, die der verstorbenen Person selbst mit ins Grab gegeben wurde, oder sie könnten eine Funktion während des Bestattungsrituales außerhalb des Grabes oder nach der eigentlichen Beisetzung (z.B. anlässlich von Gedenkfeiern) besessen haben. Ein Großteil der oben näher beschriebenen Befunde wurde jedoch entweder gestört vorgefunden oder nicht in ausreichender Form publiziert. Daher lässt sich in den meisten Fällen nicht mehr eindeutig bestimmen, ob Statuetten, die im Umfeld der eigentlichen Bestattung gefunden wurden, sich ursprünglich als Beigaben im Grab (bzw. auf der Kline/in der Urne) befanden und nachträglich verlagert wurden, oder ob sie eine Funktion außerhalb des Grabes im Ritual besaßen. Entsprechend kann die Funktion der Figuren innerhalb des sepulkralen Bereiches derzeit nur auf der Basis einer extrem geringen Zahl von Terrakotten näher umschrieben werden.

Als Beigaben lassen sich nur die fünf Ziegenreiter (Tk 186a-e) von der Kline eines Kammergrabes bei Pella bezeichnen, sowie aus den Nekropolen von Samothrake ein sitzender Chlamydephoros (Tk 201) aus dem Ziegelgrab S 125 der Südnekropole und drei stehende Chlamydephoren (Tk 244-246) aus Pithosgrab 17 der H-Nekropole sowie vielleicht die Mänade (Tk 362) aus Tarent.

Um Überreste von Bestattungsritualen außerhalb des Grabes - z.B. von Opfern oder in Zusammenhang mit Mahlzeiten im Rahmen der Bestattung oder in einem bestimmten zeitlichen Abstand von dieser - handelt es sich vielleicht bei dem Ziegenreiter aus dem Dromos eines Grabes bei Pella (Tk 187) und dem Chlamydephoros (Tk 247) aus der H-Nekropole von Samothrake.

Demnach wurden Terrakotten mit Kausia sowohl als Beigaben im Grab als auch im Rahmen ritueller Handlungen am Grab verwendet. Problematisch ist jedoch nicht nur die zahlenmäßig sehr geringe Materialgrundlage, sondern auch, dass es bei den meisten Figuren, zu denen Informationen zur Funktion vorliegen, um Statuetten handelt, die nicht als repräsentativ für die große Mehrzahl der Terrakotten mit Kausia angesehen werden können. So handelt es sich bei den auf Ziegenböcken reitenden Knaben, die in Pella sowohl innerhalb als auch außerhalb der Kammergräber gefunden wurden, um die einzigen Vertreter dieses Typus, die mit Kausia wiedergegeben werden. Die Mänade aus Tarent und eine ebenfalls aus Tarent stammende Frauenstatuette bieten die beiden einzigen Wiedergaben weiblicher Personen mit Kausia. Italien ist zudem ein Randgebiet der Verbreitung von Kausiadarstellungen, und die eindeutige Identifizierung der makedonischen Kausia wird hier durch das Vorhandensein einer sehr ähnlichen, regionalen Kopfbedeckung erschwert. Letztlich bleiben als Beispiele für die Funktion von Tonfiguren mit Kausia sowohl im als auch am Grab nur die Statuetten aus den Nekropolen von Samothrake. Bei diesen handelt es sich um Chlamydephoren, d.h. die zahlenmäßig umfangreichste Gruppe unter den koroplastischen Darstellungen mit Kausia. Sie stammen aus dem Kerngebiet der Verbreitung dieser Statuetten und werden in hellenistische Zeit datiert. Gerade die genaue Fundsituation der meisten samothrakischen Terrakotten ist jedoch problematisch. 
Angaben zu Alter und Geschlecht der in Verbindung mit kausiatragenden Terrakotten beigesetzten Personen sind ebenfalls nur in sehr eingeschränkter Form möglich. Die Terrakotten aus Mytilene (Tk 180-182, 184) lassen sich nur einer Gruppe von Gräbern, nicht aber einem Einzelgrab zuordnen. Ebenfalls nicht eindeutig zuordnen lassen sich die in Zusammenhang mit Mehrfachbestattungen gefundenen Figuren aus Pella (Grab auf Grundstück Zotakis) und Tarent. Tk 187 (Pella) fand sich im Dromos. In der zugehörigen Kammer sind sowohl männliche als auch weibliche Personen beigesetzt worden. Nur unsicher ist Tk 301 (Chalkis) einer Kinderbestattung zuzuordnen. Tk 362 (Tarent) stammt aus einem Halbkammergrab, in dem eine Frau und ein Kind beigesetzt waren. Der Chlamydephoros (Tk 47) aus Alexandria fand sich zusammen mit einer Mädchenstatuette und Keramik (Miniaturkrater, Schälchen, Unguentarium) in einem Graben (fossa), der als Einzelbestattung angesprochen wurde. Sollte es sich um eine solche handeln, ${ }^{563}$ würde dies gegen einen Zusammenhang zwischen dem Geschlecht der bestatteten Person und dem der dargestellten Personen sprechen. In Samothrake (Tk 201, 244-246) ist aufgrund von Knochenfunden eine Altersbestimmung möglich: Es handelt sich bei den in Grab S 125 und H 17 Beigesetzten jeweils um etwa zehnjährige Kinder. Eine vom koroplastischen Material unabhängige Geschlechtsbestimmung ist mangels eindeutiger Beifunde nicht möglich. In Pella (Grab $\Theta$, Nord-Kline, Tk 186a-e) handelt es sich aufgrund der Verteilung der Funde auf der Kline um ein Kind und wegen des mitgefundenen Schmuckes vielleicht um ein Mädchen. Die Größe eines Kistengrabes in Pydna (Tk 188) deutet ebenfalls auf eine Kinderbestattung hin.

Zusammengenommen bedeutet dies, dass in keinem einzigen Fall nachgewiesen werden kann, dass kausiatragende Terrakotten einem Knaben oder einem jungen Mann mit ins Grab gegeben wurden. In Samothrake fanden sich in zwei Fällen Wiedergaben jugendlicher Chlamydephoren in Gräbern von Kindern unbekannten Geschlechts. Gleiches gilt für den Chlamydephoros aus dem kleinen Kistengrab in Pydna (Tk 188). Eine Mänade mit Kausia (Tk 362) stammt aus einem Grab in dem auch eine Frau ihre letzte Ruhe fand. Fünf auf Ziegenböcken reitende Knaben mit Kausia (Tk 186a-e, Pella) wurden auf der Grabkline vermutlich eines Mädchens entdeckt.

Die vordergründig nahe liegende Vermutung, dass sich Alter, Geschlecht, soziale Stellung oder andere persönliche Merkmale der oder des Verstorbenen in den mitgegebenen koroplastischen Darstellungen spiegeln, lässt sich demnach weder bestätigen noch verwerfen. Es sei aber noch einmal darauf hingewiesen, dass die Materialgrundlage - nur drei Befunde - zu klein ist, um zu verbindlichen Aussagen zu gelangen, selbst wenn deren Aussage einheitlich gewesen wäre. Weiter sei nochmals angemerkt, dass zu den beiden Hauptgruppen, den Chlamydephoren und den Reitern, praktisch keine Angaben vorliegen; gleiches gilt für Kernregionen wie Ägypten und Mesopotamien. Dass auf einem Ziegenbock reitende Knaben sich in ei-

\footnotetext{
${ }^{563}$ Es liegen keine Angaben zum Umfang der Fossa oder zu Knochenfunden vor. So ist nicht auszuschließen, dass es sich um eine Mehrfachbestattung, die Reste eines Bestattungsrituals oder einen gestörten Befund handelt.
} 
nem Mädchengrab finden, besagt letztlich nichts über die Funktion von Chlamydephoren-Statuetten. Denn die Funktion und der Kreis der Verwender solcher Statuetten sind weniger vom Vorhandensein der Kausia als vielmehr vom Typus bzw. dem dahinter stehenden Thema abhängig. Dieses könnte im Fall der Ziegenreiter der dionysische Bereich sein. Darstellungen aus dem dionysischen Bereich kommen jedoch sowohl in weiblichen als auch in männlichen Gräbern vor. ${ }^{564}$ In Samothrake ist eine von den koroplastischen Beigaben unabhängige Geschlechtsbestimmung zwar nicht möglich, es gibt jedoch auch keine Hinweise auf Mädchen. Dass alle Terrakotten junge, männliche Chlamydephoren zeigen, deren Vorhandensein in einem Mädchengrab nur mit einer weitgehende Willkürlichkeit der Beigabensitten zu erklären wäre, spricht jedoch eher für männliche Bestattungen. Dass zudem das Alter der dargestellten Personen (Knabe/Jugendlicher) ${ }^{565}$ in etwa mit dem der in den Gräbern S 125 und H 17 bestatteten Personen ( $\sim 10$ Jahre) übereinstimmt, ermöglicht es, in den Terrakotten mit einiger Sicherheit Darstellungen des Toten oder eines Vertreters seiner Altersklasse zu sehen.

Interessant wäre auch zu untersuchen, ob es Unterschiede z.B. typologischer Art zwischen den als Beigaben und den außerhalb oder oberhalb des eigentlichen Grabes bei rituellen Handlungen verwendeten Terrakotten gibt, sowie ob sich hinter diesen verschiedene Personengruppen, z.B. die Bestatteten und die Bestattenden, verbergen. Auch hierfür reicht die Materialbasis nicht aus.

Letztlich lässt sich demnach nur sagen, dass Tonfiguren mit Kausia in weiten Teilen der hellenistischen Welt in relativ großer Zahl eine Funktion im sepulkralen Bereich hatten, dass sie wahrscheinlich Funktionen sowohl als Beigabe im Grab als auch im Ritus am Grab erfüllen konnten und dass eine gewisse Wahrscheinlichkeit besteht, dass Figuren, die des Öfteren in Kindergräbern gefunden wurden, einen thematischen Zusammenhang zur bestatteten Person aufweisen.

\subsubsection{Funde aus Heiligtümern}

Tonfiguren mit Kausia fanden sich in Heiligtümern folgender Orte: Troja (Tk 135, 139-142), Xanthos (Tk 175), Samothrake (Tk 201-239 [?], 242-245, 250x-283x), Delos (Tk 302), Demetrias (Tk 307-308, 316a-r [?], 318-319, 319a-h [?], 322-326e, 327-329a-j [?]), Rom (Tk 348-352), Morgantina (Tk 365), Amathous (Tk 375), Umm el-Amad (Tk 379), Kharayeb (Tk 380a-b, 383-384, 387a-389), Masjid-i Solaiman (Tk 448a-451d) und Ikaros (Tk 452a-u).

$\mathrm{Zu}$ nennen ist darüber hinaus eine Reihe kleinformatiger Figuren aus Kalkstein, die sich in verschiedenen Heiligtümern der Insel Zypern fanden: P 5 (Kourion, Heiligtum), P 6 (Nikosia, Heiligtum?), P 7 (Voni, Apollon-Heiligtum), P 11-12 (Idalion, Apollon-Heiligtum), P 13-14

\footnotetext{
${ }^{564}$ Vgl. D. Graepler, Tonfiguren im Grab (1997) 212.

${ }^{565}$ Vgl. Dusenbery, Samothrake, 457, H17-2-3, 866, H17-1-3. Die Terrakotten werden teils als „,boy“ teils als „youth“ bezeichnet. Das Alter der Dargestellten lässt sich nicht näher bestimmen.
} 
(Tamassos, Heiligtum der Mutter der Götter/Astarte). Vermutlich ebenfalls aus einem Heiligtum stammen die Statuetten aus Golgoi (P 10, 18-30).

Entsprechende Statuetten erfüllen demnach rund ums Mittelmeer sowie in Mesopotamien eine Funktion im Heiligtum (Karte 8). Das Verbreitungsgebiet der Figuren aus Heiligtümern ist, ähnlich wie jenes der Statuetten aus Nekropolen, weitgehend identisch mit dem Gesamtverbreitungsgebiet von Statuetten mit Kausia. Nur aus Ägypten stammen scheinbar keine Figuren, die in Heiligtümern gefunden worden sind. Dies dürfte jedoch darauf zurückzuführen sein, dass die genaue Herkunft vieler in dieser Region gefundener Statuetten unbekannt ist. ${ }^{566}$ Ähnlich wie im Falle der Funde aus den Nekropolen liegen auch zu denjenigen aus den Heiligtümern nur selten detaillierte Angaben zum Fundkontext vor. Im Falle der Terrakotten aus dem sepulkralen Bereich führte dies dazu, dass sich nur in sehr eingeschränktem Umfang weitere Schlüsse ziehen ließen, da dort die Bezugnahme auf eine einzelne Bestattung und damit eine einzelne Person wichtig ist. Bei den in Heiligtümern gefundenen Tonfiguren verhält sich dies teilweise anders. Auch dort wäre es zwar interessant, wenn sich aus dem Fundkontext ablesen ließe, welche Personengruppen zu welchem Anlass welche Statuetten im Heiligtum niedergelegt hätten. In gewissem Umfang lassen sich entsprechende Angaben jedoch erschließen, wenn bekannt ist, welcher Gottheit das Heiligtum geweiht war und welche Bevölkerungsteile diese üblicherweise in welcher Form verehrten.

In Troja wurde das Oberkörperfragment (Tk 135) eines stehenden Chlamydephoros, der sich die Chlamys vor den unteren Bereich des Gesichtes zieht, im Temenos einer unbekannten Gottheit nahe dem Altar gefunden. Vier Köpfchen (Tk 139-142) stammen aus dem Bereich unterhalb des Kybele-Heiligtumes, von wo aus sie wahrscheinlich den Hang herabgerutscht sind. Einer der Köpfe (Tk 139) zeigt wiederum einen Chlamydephoren, der sich das Gewand vor das Gesicht zieht.

Im Letoon von Xanthos wurde die Statuette eines „Ephebensoldaten“ (Tk 175) gefunden. Da eine Inschrift ${ }^{567}$ aus dem Letoon von Xanthos es Soldaten verbietet, den Temenos in militärischer (?) Ausrüstung (einschließlich der Kausia) zu betreten, können zu den Verehrern der Göttin kausiatragende Soldaten gehört haben.

Von den auf Samothrake entdeckten Terrakotten mit Kausia wurden bisher (mindestens) 81 Exemplare (Tk 201-281x) veröffentlicht. Vier bzw. fünf Statuetten (Tk 201, 244-248, 247 [?]) lassen sich sicher mit Bestattungen in Verbindung bringen. Weitere 38 bzw. 39 Figuren stammen aus dem Bereich der Nekropolen, zu ihrer genauen Verwendung oder Deutung (Grabbeigabe, Bestandteil des Bestattungsrituals oder Votiv) lässt sich aufgrund antiker Störungen der Befunde bzw. unzureichender Grabungs- und Publikationenmethoden nichts sagen.

\footnotetext{
${ }^{566}$ Aus Heiligtümern stammen vermutlich die ptolemäischen „Reiter über Gegner“. Vgl. die Diskussion unten in Kapitel „Reiter über Gegner/Schild“.

${ }^{567} \mathrm{Chr}$. Le Roy, Un règlement religieux au Létôon du Xanthos, RA, 1986, 279 ff. (= Q 20).
} 
Einem oder mehreren Heiligtümern werden die Terrakotten aus der späteren Westnekropole (Tk 240-243) ${ }^{568}$, aus dem Vorhof des Propylons zum Heiligtum der Großen Götter (Tk 248 $\mathrm{x})^{569}$ sowie aus dem unteren Bereich des Abhanges zwischen der Stadtmauer und dem Heiligtum der Großen Götter (Tk 249-281 x) (570 $^{570}$ ueschrieben.

Allen genannten Figuren ist gemeinsam, dass sie aus den östlichen und südlichen Randgebieten des Heiligtums der Großen Götter stammen, jedoch nicht mit diesem in Verbindung zu bringen sind. ${ }^{571}$ Aus den Fundorten und den Beifunden ergibt sich, dass die Statuetten einem oder mehren am Hang gelegenen Heiligtümern zuzuordnen sind und wahrscheinlich der Demeter oder einer vergleichbaren Gottheit geweiht waren. ${ }^{572}$

In Delos fand sich am Hang unterhalb eines Kabirion bzw. Samothrakeion genannten Heiligtumes das Oberkörperfragment (Tk 302) eines vermutlich stehenden Chlamydephoren.

Die Statuetten aus Demetrias stammen u.a. aus verschiedenen Heiligtümern der Stadt. Ein großer Teil (Tk 307, 318-319 und vermutlich auch Tk 316 a-r, 321 a-f und 327-329 sowie vielleicht Tk 311-13) ${ }^{573}$ wurden im Heiligtum der Pasikrata gefunden. Eine Göttin welchen Charakters sich hinter diesem Namen verbirgt, ist umstritten. Es könnte sich um eine Form

\footnotetext{
${ }^{568}$ Vgl. Dusenbery, Samothrake, 495 ff.: Fragmente von mindestens vier stehenden Chlamydephoroi mit Kausia. Beifunde: Statuetten bekleideter Frauen, Steinchen, Holzkohle, angeschmolzenes Unguentarium.

${ }^{569}$ Vgl. J.R. McCredie, Preliminary Report, Hesperia 34, 1965, 120 f. Taf. 38c: Abgebildet ist ein Kopf mit Kausia, es soll sich aber nur um ein Beispiel von vielen handeln. Beifunde: u.a. Hydrophoroi.

${ }^{570}$ Dort wurden 12 Köpfe bzw. Oberkörperfragmente von Chlamydephoroi mit Kausia und vor das Kinn gezogener Chlamys sowie 19 weitere Köpfe (mit Chlamys, aber ohne vor das Gesicht/Kinn gezogener Chlamys) gefunden. Diese werden heute im Louvre aufbewahrt und wurden bisher aufgrund des Tones, des Stiles und von Überlegungen zu den mutmaßlichen Ausgräbern der „Aiolis“ zugeordnet (Besques, Paris III, 114 ff.). Die Figuren gehören einem größeren Fundkomplex an, dem darüber hinaus koroplastische Darstellungen von 16 weiblichen Personen (darunter Tänzerinnen und eine Kitharödin), fünf Knaben (darunter ein auf einem Widder reitender Junge), vier Schauspielern und acht Tieren (Böcke, Pferde, Vögel) angehören (Vgl. Besques, Paris III, $114 \mathrm{ff}$. D740-816.). Die Zuweisung dieser Statuetten nach Samothrake durch E.B. Dusenbery beruht darauf, dass einige der Exemplare im Louvre aus der gleichen Form stammen wie auf Samothrake gefundene Statuetten, für die aufgrund der einfachen Qualität regionale Produktion angenommen wird (Vgl. bei Besques, Paris III, D793-5 [= Louvre Ca 4547, CA 4559, CA 4548] [= Tk 277-279] mit den Vertretern des ,samothracian type I“ nach Dusenbery, Samothrake 867 ff. [= Tk 202, 205-210, 218-221, 247] und das Frauenköpfchen Besques, Paris III, D750 mit Dusenbery, Samothrake, 906, XS-310.). Die Tonfiguren im Louvre wurden vermutlich 1866 von G. Deville und E. Coquart bei Grabungen am südöstlichen Rand des Heiligtums der Großen Götter, d.h. im Bereich des Abhanges zwischen der Stadt und dem Heiligtum bzw. Propylon, entdeckt (Vgl. J.R. McCredie, Hesperia 34, 1965, 121 und Dusenbery, Samothrake, 867 f. Anm. 14.).

${ }^{571}$ Die Fundlage legt es nahe, dass sie den Hang hinabgespült wurden. Im Heiligtum der Großen Götter sollen nur wenige - bisher unveröffentlichte - Terrakotten gefunden worden sein (Dusenbery, Samothrake, 863 Anm. 14). Tonfiguren waren demnach keine typische Weihgabe in diesem Heiligtum.

${ }^{572}$ Vgl. D. Burr-Thompson, Troy, 84 ff. .- J.R. McCredie, Hesperia 34, 1965, 120 f. .- Besques, Paris III, 114 f. .Dusenbery, Samothrake, 496.

${ }^{573}$ Arvanitopoulos, Demetrias, 46 gibt als Fundort aller von ihm publizierten Terrakotten das Pasikrata-Heiligtum an. Laut Hornung-Bertemes, Demetrias, 186 findet sich ein entsprechender Hinweis im Inventarbuch des Museums von Volos jedoch nur in fünf Fällen. - Ich vermute, dass es sich dabei um die bei K. Hornung-Bertemes genannten Nummern TK 24-28 (= meine Tk 307, 318-319) handelt. Eindeutig ist dies nicht.
} 
der Aphrodite ${ }^{574}$ oder der Artemis ${ }^{575}$ handeln. Bei den geweihten Tonfiguren handelt es sich hauptsächlich um stehende Chlamydephoren vom Normaltypus (Tk 311-313, 316a-r, 321a-h, 329 [?]). Es erscheint aber auch ein Vertreter des „Typus stehender Chlamydephoros mit vor das Kinn gezogener Chlamys“ (Tk 310). Vermutlich stammen auch ein weitgehend nackter Manteljüngling mit Kausia (Tk 327) sowie ein schreitender Junge ohne Untergewand mit zurückgeschlagener Chlamys und Kausia (Tk 328) aus dem Pasikrata-Heiligtum.

Aus einer als Bothros bzw. Favissa bezeichneten Opfergrube auf Höhe 35 (innerhalb der Mauern am östlichen Rand der Stadt) stammen sechs stehende Chlamydephoren (u.a. Tk 308), davon vier mit vor den unteren Teil des Gesichtes gezogener Chlamys. ${ }^{576}$ Weiter fanden sich hier mindestens vier stehende Chlamydephoren mit Syrinx (Tk 322-323, 326a-e[?]), mit Lagobolon (Tk 324, 326 a-e[?]) oder Syrinx und Lagobolon (Tk 325, 326 a-e[?]) in der rechten Hand. Der Bothros gehört zu einem Heiligtum, das aufgrund einer in der Nähe gefundenen Inschrift und der sonstigen koroplastischen Opfergaben (meist Statuetten von Frauen mit Tieren) mit Demeter in Verbindung gebracht wird. ${ }^{577}$

In Rom wurden in dem 191 v.Chr. eingerichteten Heiligtum der Kybele und des Attis auf dem Palatin fünf Statuetten bzw. Fragmente von Statuetten mit Kausia gefunden. Sie zeigen einen Chlamydephoros (Tk 348), bekleidet nur mit Kausia und zurückgeschlagener Chlamys, und vier Manteljünglinge (Tk 349-352), die jeweils eine Syrinx in der rechten Hand halten. Allen fünf Statuetten ist gemeinsam, dass die Dargestellten keine Untergewänder tragen und ihre Mäntel so zurückschlagen, dass ihre Körper weitgehend entblößt sind. Teilweise schieben sie die nackten Unterkörper betont nach vorne. Im selben Heiligtum wurden auch typologisch vergleichbare Figuren mit phrygischer Mütze bzw. ohne Kopfbedeckung entdeckt. ${ }^{578}$ Aufgrund des Fundortes, der Bekleidung der Tonfiguren und des Attributes (Syrinx) ist davon auszugehen, dass es sich um Wiedergaben des Attis (oder seiner Anhänger) handelt. Dieser konnte in Rom anscheinend unterschiedslos mit phrygischer Mütze oder Kausia dargestellt werden. Zurückzuführen ist dies vielleicht darauf, dass aus römischer Sicht die makedonische Kausia wie die phrygische Mütze aus dem Osten kam und dass sie sich zwischenzeitlich auch in Kleinasien, der Heimat der Kybele und des Attis, infolge der makedonischen Kolonisationstätigkeit, großer Beliebtheit erfreute. Bei den Verehrern des Attis handelte es sich in Rom, nach Aussage epigraphischer Quellen, in erster Linie um aus dem hellenistischen Osten des Reiches stammende Sklaven und Freigelassene. ${ }^{579} \mathrm{Zu}$ den Gebieten, die die Römer in den

\footnotetext{
${ }^{574} \mathrm{Vgl}$. A. Arvanitopoulos, Prakt 1920, $22 \mathrm{ff}$.

${ }^{575}$ F. Stählin, E. Meyer, A. Heidner, Pagasai und Demetrias (1934) 188 mit Anm. 2: Artemis als Weggottheit (Enodia), vielleicht in Verbindung mit Hermes (Enodios).

${ }^{576}$ Es handelt sich um zwei Figuren vom „Typus A nach Hornung-Bertemes“ (= Normaltypus) und vier Exemplare vom „Typus B nach Hornung-Bertemes“ (= mit teils verhülltem Gesicht). Vgl. K. Hornung-Bertemes, Demetrias, 186 f. 205 Abb. 5 (Säulendiagramm).

${ }^{577}$ Vgl. Hornung-Bertemes, Demetrias, 187 mit Anm. 30-31.

${ }^{578}$ Vgl. M. J. Vermaseren, Corpus Cultus Cybelae Attidisque III. Italia-Latium (1977) Taf. 36 f. 47 ff.

${ }^{579} \mathrm{Vgl}$. K. Schillinger, Untersuchungen zur Entwicklung des Magna Mater-Kultes im Westen des römischen Kaiserreichs (1979) 289 .- G. Sanders, Kybele und Attis, in: Die Orientalischen Religionen im Römerreich, OrRR
} 
zwei Jahrhunderten vor Christi Geburt eroberten und aus denen eine große Anzahl von Gefangenen in die Hauptstadt gelangte, gehörte auch der Großteil jener Gebiete, in den Makedonen und makedonisierte Bevölkerungsgruppen lebten (Makedonien, Griechenland, Kleinasien, Syrien, schließlich Ägypten) und in denen sowohl die Kausia selbst als auch Statuetten mit dieser Kopfbedeckung verbreitet waren. Es ist anzunehmen, dass Personen aus den der römischen Expansion zum Opfer gefallenen makedonisch-hellenistischen Reichen die Kausia bzw. die Verwendung von Statuetten mit Kausia im Kybele-Kult in Rom einführten.

Ein Köpfchen (Tk 365) mit Langhaarfrisur und Kausia, das sich stratigraphisch in die Zeit vor 211 v.Chr. datieren lässt, stammt aus dem sog. „North Sanctuary Annex“6580 der sizilischen Stadt Morgantina. Wie die übrigen im Heiligtum gefundenen Terrakotten - es handelt überwiegend um weibliche Gottheiten (meist Persephone), Frauen, Kinder und Eroten, Theatercharaktere sowie vereinzelt männliche Gottheiten (Hades), Tiere, Früchte u.a. - zeigen, handelt es sich vermutlich wie beim „North Sanctuary“ um ein Heiligtum der Persephone und verwandter Gottheiten.

Aus der zu Anfang des 2. Jahrhunderts v.Chr. verfüllten Kanalisation des Aphrodite-(Adonis)Heiligtumes auf der Akropolis der zyprischen Stadt Amathous wurde ein Terrakotta-Köpfchen mit Kausia (Tk 375) geborgen.

In verschiedenen Heiligtümern der Insel Zypern wurden zudem Kalksteinstatuen stehender oder hockender Knaben und jugendlicher Männer (sog. temple-boys) gefunden:

Eine Kalksteinstatuette (P 5), die einen hockenden Knaben (mit Ente) in Chiton und Kausia zeigt, wurde in einem Tempel in Kourion entdeckt. Figuren des gleichen Typus fanden sich auch in Nikosia (P 6; nahe einem Heiligtum ergraben) und in Voni (P 7) im Temenos des Apollon. ${ }^{581}$

Zwei Kalksteinstatuetten, die stehende (junge?) männliche Personen in Chlamys, Chiton und Kausia wiedergeben, stammen aus dem Apollon-Heiligtum von Idalion (P 11-12). Der Typus entspricht weitgehend dem des in der Koroplastik häufig vorkommenden „stehenden Chlamydephoren“. Teilweise kann ein Attribut hinzugefügt werden (P 11; mit Apfel [?] in der linken Hand). Ebenfalls in Idalion wurden mehrere Kalksteinköpfe mit Kausia entdeckt (P 15-17).

\footnotetext{
(Hrsg.: M. J. Vermaseren) (1981) 275 ff. 279 ff.

${ }^{580}$ Der Begriff „Annex“ ist irreführend, da es sich nicht um ein Nebengebäude des „North Sanctuary“ handelt, sondern um einen eigenständigen, durch eine Straße vom „North Sanctuary“ getrennten Komplex. Die Beziehung der beiden Heiligtümer zueinander ist ungeklärt, entsprechende Doppelkomplexe sind jedoch mehrfach belegt (Vgl. M. Bell, Morgantina Studies I. The Terracottas [1981] 252 ff.).

${ }^{581}$ Weitere Statuetten von hockenden Knaben aus Zypern, zu denen keine näheren Angaben zum Fundort vorliegen, dürften ebenfalls als Votive in Heiligtümern gedient haben (P 8-9; vgl. auch P10 [Oberkörperfragment eines Knaben mit Kausia und Chiton aus Golgoi]). Vgl. auch die Köpfe mit Kausia aus Zypern ohne nähere Fundortangabe (P 33-34).
} 
Entsprechende Köpfe sind auch in einem Votivdepot im Heiligtum der Mutter der Götter (,Meter“, „Hera“, „Astarte“) in Tamassos (P 13-14) entdeckt worden.

Eine Reihe von Kalksteinköpfen im Louvre, die 1865 von E. Duthoit zutage gefördert wurden, stammt von einem Ruinenfeld in der Nähe des Dorfes Athienou (zwischen Nikosia und Larnaka). Hierbei handelt es sich vermutlich um das antike Golgoi. ${ }^{582}$ Nach den literarischen Quellen befand sich dort das älteste Aphrodite-Heiligtum Zyperns. ${ }^{583}$ Die archäologische Hinterlassenschaft deutet zudem auf ein Apollon-Heiligtum hin. ${ }^{584}$ Es spricht einiges dafür, dass die Köpfe (wie auch das Oberkörperfragment P 10 [Knabe in Chiton und Kausia] und eine Chlamydephoren-Statuette [fragmentiert, ohne Kopf] ${ }^{585}$ ) aus einem dieser Heiligtümer stammen.

Im sog. Osttempel von Umm el-Amad (ca. $12 \mathrm{~km}$ südlich von Tyros, $2 \mathrm{~km}$ von Iskenderoun/Alexandrou Skene entfernt) wurde ein Kopf mit Kausia (Tk 379) entdeckt. Das Heiligtum, in dem sich persische, kleinasiatische, phönizische und ägyptische Elemente verbinden, ist vermutlich der Göttin Astarte zuzuordnen. ${ }^{586}$

In einer Grube (Favissa) in einem Heiligtum bei Kharayeb (bei Sidon) wurden mehr als 1100 Tonfiguren bzw. Fragmente von Tonfiguren gefunden. Von diesen trugen 18 die Kausia ${ }^{587}$ als Kopfbedeckung (Tk 380a-d, 383-384, 387a-389). Es handelt sich um vier „Ephebensoldaten“ (Tk 380a-d), zwei (sitzende?) Jugendliche mit einem Vogel und/oder Weintrauben (Tk 383384), sowie zwölf Köpfe mit Kausia (Tk 387a -389). Der Name der hier verehrten Gottheit ist nicht bekannt. Bruchstückhaft erhaltene Inschriften sind in phönizischer Schrift verfasst, nennen jedoch keine Namen. ${ }^{588}$ Das koroplastische Material weist überwiegend griechische sowie ptolemäisch-ägyptische Themen und Typen auf, in geringerem Umfang auch orientalische. Häufig wiederkehrende Darstellungen deuten an, dass in Kharayeb eine Muttergöttin zusammen mit einem jungen männlichen Gott und vielleicht einer jungen Göttin verehrt wurde. ${ }^{589}$

\footnotetext{
${ }^{582}$ Vgl. RE VII (1912) 1579 ff. s.v. Golgoi (Oberhummer) .- O. Masson, Kypriaka. IX. Recherches sur les Antiquités du Golgoi, BCH 95, 1971, 305 ff. (307 ff.).

${ }^{583}$ Vgl. RE VII (1912) 1579 s.v. Golgoi (Oberhummer) mit Verweis auf insbesondere Pausanias 7, 5, 2.

${ }^{584}$ Vgl. RE VII (1912) 1580 s.v. Golgoi (Oberhummer).

${ }^{585}$ A. Hermary, Catalogue des Antiquités de Chypre. Sculptures (1989) 276 Nr. 561.

${ }^{586}$ M. Dunand - R. Duru, Oumm el-‘Amed (1962) 233.

${ }^{587}$ Bei den Kopfbedeckungen einiger insgesamt orientalisch gekleideter Statuetten (Chéhab, Kharayeb, 35 f. Taf. 36, 3. 37,1-3; 59 Taf. 69, 4-5) handelt es sich wahrscheinlich um eine der makedonischen Kausia ähnliche phönizisch-punische Kopfbedeckung.

${ }^{588}$ M. Chéhab, Les terres cuites de Kharayeb, BMusBeyr 10/11, 1951/52, 77.

${ }^{589}$ Unter den rund 1100 Terrakotten aus Kharayeb befinden sich auch mindestens 160 Darstellungen von Göttern. Die größte Gruppe unter diesen bilden Wiedergaben jugendlicher männlicher Götter (25 x Harpokrates, 24 x Dionysos [und Satyr/Silen], 16 x Eros [teils mit Psyche], 11 x Hermes, 6 x Herakles), gefolgt von mütterlichen Göttinnen (14 x „Déesse-Mère“ [Unter diesem Begriff fasst M. Chéhab Darstellungen orientalischer Göttinnen wie Astarte, aber auch der Isis lactans und stehender Frauen mit Kind auf dem Arm zusammen.], 9 x Demeter [und Kore], 2 x Baubo) und seltener jungen Göttinnen ( 9 x Kore [und Demeter], 5 x Aphrodite, 2 x Artemis). Die Zahlen sind der bei M. Chéhab, Les terres cuites de Kharayeb, BMusBeyr 10/11, 1951/52, 132 abgedruckten Tabelle entnommen. Diese stimmen nur teilweise mit den im „Index des noms propres“ (S. XXI-XXII des Tafel-
} 
Im Kult spielten Musik und Tanz eine Rolle. Bei einem Großteil derjenigen Statuetten, die nicht eindeutig als Götter zu identifizieren sind, handelt es sich um junge Personen beiderlei Geschlechts, die tanzen, musizieren etc. ${ }^{590}$ Kindliche und jugendliche Personen beiderlei Geschlechts nahmen daran teil. Unter den Statuetten sind die verschiedenen Altersklassen vertreten: (Klein-) Kinder (Jungen/Mädchen), Schüler/Schülerinnen, Epheben, junge Männer/Frauen. ${ }^{591}$ Die Besucher des Heiligtums brachten landwirtschaftliche Produkte (hauptsächlich Federvieh und Weintrauben sowie Ziegen/Schafe) dar. ${ }^{592}$

Im „Großen Tempel“ von Masjid-i Solaiman (Iran) wurden elf handgeformte Reiterstatuetten mit Kausia ausgegraben. Es sind alle vier Untertypen vertreten: Reiter mit Kausia (Tk 448ab), Reiter mit Kausia und Rundschild (Tk 449a-c), Doppelreiter ( $\propto \mu ф\llcorner\pi \pi \circ \varsigma)$ mit Kausia (Tk 450a-b) sowie Doppelreiter mit Kausia und Göttin zwischen den Pferdehälsen (Tk 451a-d). Das Heiligtum ist, wie unten ausgeführt wird, vermutlich mit der elymäischen Göttin Azara zu verbinden, die meist mit der griechischen Artemis gleichgesetzt wird. ${ }^{593}$

Von den 21 in Ikaros auf der Insel Failaka vor der Küste Kuwaits gefundenen handgeformten Reiterstatuetten mit Kausia (Tk 452a-u) stammt eine aus dem sog. Tempel B und eine weitere aus dem Bereich der Altäre vor den Tempeln A und B. Beide Tempel sind vermutlich zwei Ausformungen der Artemis (teils in Verbindung mit Apollon und seleukidischen Königen) geweiht gewesen, der hier in erster Linie interessierende Tempel B am ehesten der Artemis Tauropolos. ${ }^{594}$ Deren Heiligtum umfasste auch ein Orakel. ${ }^{595}$ Die Artemis Tauropolos geht wahr-

bandes) gegebenen Angaben überein (Beide Verzeichnisse sind unvollständig und weichen in der Benennung teilweise voneinander ab: So fehlt in der Tabelle z.B. die Inventarnummern Kh. 31 [Muttergöttin], während im „Index“ die in der Tabelle als „Astarte“ geführte Statuette Kh. 7 als „Muttergöttin“ geführt wird.). Zudem werden unter den Götterdarstellungen nur Statuetten aufgeführt, die aufgrund von Attributen o.ä. eindeutig Gottheiten zeigen. Nicht mitgezählt sind z.B. die vielen Frauen- und Mädchenfiguren, hinter denen sich ebenfalls Darstellungen der Demeter oder Kore verbergen könnten. -- M. Chéhab a.a.O. 132. 143 ff. vermutet ein Heiligtum der Demeter und Kore, des Dionysos und/oder der Aphrodite und des Eros sowie einen den Mysterien von Eleusis vergleichbaren Kult.

${ }^{590}$ M. Chéhab, Les terres cuites de Kharayeb, BMusBeyr 10/11, 1951/52, 35 ff. (Kh. 260 ff.) Taf. 36-46.

${ }^{591}$ Vgl. M. Chéhab a.a.O. z.B. auf S. XII ff. (Tafelband): enfant/fillette, écolier/écolière, ephèbe, jeune homme/femme.

${ }^{592}$ M. Chéhab, Les terres cuites de Kharayeb, BMusBeyr 10/11, 1951/52 Taf. 26. 50-58. 61-62.

${ }^{593} \mathrm{Vgl}$. Strabon 16,1,18 und unten Kapitel „Die koroplastischen Typen und ihr kulturelles Umfeld: Handgeformte Reiter aus dem Orient". Aus dem nahegelegenen Susa stammen Reiterstatuetten, die in der gleichen Werkstatt gearbeitet wurden wie die Figuren aus Masjid-i Solaiman und Ikaros. Für diese Statuetten liegen keine näheren Angaben zum Fundort vor, es biete sich jedoch an, diese ebenfalls mit einem Heiligtum in Verbindung zu bringen - in diesem Fall mit einem der Artemis-Nanai.

${ }^{594} \mathrm{Zu}$ der von mir vorgenommenen Zuordnung des Tempels A an Artemis Soteira (und Apollon sowie Angehörige der seleukidischen Herrscherfamilie) und des Tempels B an Artemis Tauropolos vgl. unten das Kapitel „Handgeformte Reiter aus dem Orient“. K. Jeppesen, Ikaros III -The Sacred Enclosure in the Early Hellenistic Period. With an appendix on epigraphic finds (1989) $78 \mathrm{f}$. sieht in Tempel A ein Heiligtum des Apollon (und des Seleukos/Antiochos) und in Tempel B eines der Artemis Soteira (und der Stratonike). Das Heiligtum der Artemis Tauropolos lokalisiert er außerhalb der Stadt. Gemeinsam ist jedoch beiden Deutungen, dass in Tempel B eine „Artemis“" verehrt wurde. 
scheinlich - wie die bei in Masjid-i Solaiman verehrte Artemis-Azara - auf eine vorhellenistische Gottheit zurück. ${ }^{596}$

\subsubsection{Zusammenfassung}

Kausiatragende Terrakotta- und Steinfiguren werden vielfach als Votive in Heiligtümer geweiht. Dabei fällt auf, dass diese Statuetten trotz des weiten geographischen Rahmens regelmäßig in Heiligtümern von Muttergöttinnen gefunden worden sind. Im Westen (dies meint in diesem Fall den Raum von Italien bis Kleinasien) werden Kybele (Troja, Rom), Leto (Xanthos) und Demeter (Samothrake, Demetrias) genannt. Im Osten (Zypern/Phönizien bis Iran) treten neben Muttergöttinnen (Meter in Tamassos, Demeter [?] in Kharayeb) teils Göttinnen auf, die auf den ersten Blick eher jugendlich erscheinen, wie Aphrodite (Amathous, Umm elAmad [?], Kharayeb [?]) und Artemis (Masjid-i Solaiman, Ikaros). Bei näherem Hinsehen verbergen sich jedoch hinter deren griechischen Bezeichnungen einheimische mütterliche Göttinnen wie Astarte (Zypern, Phönizien), Azara (Masjid-i Solaiman) und Nana (Susa). ${ }^{597}$ Gemeinsam ist diesen Müttern naturgemäß, dass sie göttliche Kinder zur Welt brachten. Diese wurden meist zusammen mit der Mutter verehrt bzw. spielten in deren Kult eine Rolle. In der Praxis sind meist außer der Mutter auch eine Tochter und/oder ein Sohn (der teils auch als Liebhaber der Mutter auftreten konnte) im gleichen Heiligtum verehrt worden, wodurch ein Bezug gerade zu jüngeren Personen hergestellt wird. Nicht zufällig wurden die wenigen Statuetten mit Kausia, die nicht explizit aus Heiligtümern von Müttergöttinnen stammen, in solchen entdeckt, die ihren Kindern zugeschrieben werden: Apollon (Idalion und Kourion [?]) sowie in Kombination mit der jeweiligen Mutter Attis (Rom), Adonis (Amathous) und Kore (Kharayeb[?]).

Abgesehen von der ähnlichen „Familien“-Struktur verbindet diese Zweier- bzw. Dreiergruppen von Gottheiten untereinander, dass sie für die Fruchtbarkeit zuständig sind - und zwar nicht nur für die der Tiere und Pflanzen, sondern auch die der Menschen. Diese Zuständigkeit endet nicht mit der Zeugung oder Aussaat, sondern reicht bis zur Ernte. Übertragen auf den Menschen heißt dies, dass die Göttin und ihre Kinder die Entwicklung eines Kindes bis zum Erreichen des Erwachsenenalters überwachen. Dies umfasst nicht nur die körperliche Entwicklung, sondern auch die geistige sowie die hiermit eng verbundene Einordnung in die Gesellschaft.

\footnotetext{
${ }^{595}$ Strabon, Geographie 16, 3, 2 berichtet von einem Heiligtum des Apollon und einem Orakel der Tauropolos aus Ikaros. Die Nachricht geht vermutlich über Eratosthenes auf Androsthenes, der die Strecke 324 v.Chr. absegelte, zurück.

${ }^{596}$ Eine mit Artemis gleichgesetzte orientalische Göttin, der Ziegen und Hirsche heilig waren, ist die einzige nachweisbar schon in vorhellenistischer Zeit auf Ikaros/Failaka verehrte Gottheit (Arrian, Anabasis 7, 20, 3). Vermutlich sind die Kultnamen Tauropolos und Soteira in hellenistischer Zeit auf diese Göttin übertragen worden. Als Tauropolos wurde Artemis auch auf der Ägäisinsel Ikaros verehrt. „Soteira“ erinnert an den Beinamen seleukidischer Könige (Soter) und ist wie Apollon (Stammvater der Seleukiden) mit seleukidischem Einfluss in Verbindung zu bringen (Vgl. K. Jeppesen, Ikaros III [1989] 76 ff.).

${ }^{597}$ Vg. G. LeRider, Suse sous les Séleucides et les Parthes, MDAI/MMAI 38 (1965) $287 \mathrm{ff}$.
} 
Typisch für diese Kulte ist auch der mysterienartige Charakter, der Eintritts- und Übergangsriten nach sich zog. Diese Riten markierten formal nur die Aufnahme in die Kultgemeinschaft oder den Aufstieg in dieser. Bei der engen Verzahnung von Religion und Staat (bzw. Polis, Stamm o.ä.) dürfte zeitlich und inhaltlich parallel hiermit auch ein Wechsel im gesellschaftlichen Status verbunden gewesen sein. ${ }^{598}$

Das auf den ersten Blick überraschende Ergebnis, dass sich Ton- und Steinstatuetten, die junge männliche Personen darstellen, vorzugsweise in Heiligtümern älterer weiblicher Gottheiten finden, lässt sich demnach damit erklären, dass diese Göttinnen u.a. für die Erziehung der Kinder, Jugendlichen und jungen Erwachsenen zuständig waren und für ihre Eingliederung in die Gesellschaft. Entsprechende Einschnitte im Leben der Heranwachsenden - z.B. die Einschreibung in die Bürgerliste, der Eintritt in die im Gymnasion aktiven Gruppen der Paides, Epheboi und Neoi oder die endgültige Aufnahme in den Bürgerverband - wurden regelmäßig von kultischen Handlungen wie Opfern und Weihungen begleitet. Bei solchen Anlässen können Statuetten als Votive ins Heiligtum einer entsprechenden Gottheit gelangt sein. Auch wenn sich auf der Grundlage des überlieferten Materials nicht beweisen lässt, wer welche Figur weihte, ist es durchaus denkbar, dass ein junger Mensch (oder die Verwandten oder Bekannten für ihn) eine Statuette ins Heiligtum weihte, die den Weihenden in seinem derzeitigen, vorangegangenen oder beginnenden Alter und Status zeigt und die z.B. den Dank für einen erfolgreich abgeschlossenen Abschnitt des Lebens zum Ausdruck bringen soll oder die Bitte um den guter Übergang in einen neuen Lebensabschnitt.

\subsubsection{Funde aus Siedlungen}

In Siedlungen können Terrakotten mit Kausia nur selten und unsicher nachgewiesen werden. Im ägyptischen Athribis wurden etwa $50 \mathrm{~cm}$ unterhalb eines in frühptolemäischer Zeit erbauten Bades zwei Reiterstatuetten (Tk 106-107; ,Typus Reiter über Gegner“) entdeckt. Sie befanden sich zusammen mit einer Tonfigur der Pseudo-Baubo in einem überbauten Brennofen. Für das Oberkörperfragment eines Chlamydephoren aus Limyra (Tk 176) ist als Fundort „Hangterrassen“ angegeben. Auf diesen Hangterrassen befanden sich sowohl Wohngegenden als auch Kultnischen.

Aus einer Werkstatt in Odessos (Varna) am Schwarzen Meer stammt ein schreitender Chlamydephoros (Tk 282).

In einer Ecke der Südstoa der Agora von Korinth fanden sich in einem „Deposit“ zwei Reiterstatuetten (Tk 305-306), die vermutlich Kausia tragen. Der Fund besteht überwiegend aus Terrakottastatuetten und Terrakottareliefs. Dargestellt werden neben Reitern die Teilnehmer eines Bankettes, Stelen, auf denen ein Helm liegt und an denen sich eine Schlange hochschlängelt, Frauen mit Opfergaben in der Hand sowie Votivschilde mit Kranz. Während das

\footnotetext{
${ }^{598}$ Vgl. den sowohl religiösen als auch politischen Kontext z.B. des Apaturia-Festes oder den bei uns noch heute mit einem - wenn auch mittlerweile freiwilligen - Gottesdienst beginnenden Ersten Schultag.
} 
koroplastische Material auf einen Heroenkult hindeutet, sprechen u.a. der Fundort (Markthalle) und das Vorhandensein von 45 Bronzemünzen für das Depot eines Votivhändlers.99

Aus der Fundamentierung des sog. Anaktoron von Demetrias, eines Gebäudes, das wahrscheinlich Teil der makedonischen Königsresidenz war, stammt ein stehender Chlamydepho$\operatorname{ros}(\mathrm{Tk} 314)$.

Ein kausiatragender Kopf kam in einer hauptsächlich aus Siedlungsschutt bestehenden Auffüllung am Westhügel von Morgantina zu Tage (Tk 366). Es soll sich dabei um Material aus dem privat-häuslichen (,,domestic“) Bereich handeln. ${ }^{600}$ Die dort gefundenen Terrakotten - es sind neben Köpfen hauptsächlich Göttinnen (Artemis, Aphrodite, Persephone), Götter (Pan, Eros), (dionysische) Theaterfiguren und (Opfer-) Tiere - verweisen jedoch eher auf den religiösen Bereich.

Im syrischen Tell Halaf wurde eine Reiterstatuette (Tk 393) an der westlichen Stadtmauer gefunden sowie ein Kopf (Tk 397) im Wohnpalast.

Aus Wohngebieten Seleukias am Tigris stammen Statuetten von Chlamydephoren und Reitern (Tk 406a-411d, 413a-421c). Sie scheinen zumindest teilweise in Lehmziegeln verbacken als Baumaterial wieder verwendet worden zu sein. Ihre Erstverwendung ist unklar.

In Ikaros fanden sich handgeformte Reiterfiguren mit Kausia (Tk 452a-u) außer im Heiligtum auch in Wohngegenden und in Befestigungstürmen. Genauere Angaben liegen nicht vor.

Zusammengefasst heißt dies, dass Terrakotten in zwei Fällen in Werkstätten gefunden wurden (Athribis, Odessos) und in einem Fall in einem vermutlichen Händlerdepot (Korinth). In allen anderen Fällen ist die Verwendung letztlich ungewiss: Die entsprechenden Figuren wurden in Zweitverwendung gefunden (z.B. zur Magerung von Lehmziegeln in Seleukia) oder in Fundament- oder Auffüllschichten (Demetrias, Morgantina). Meist ist jedoch zum genauen Fundort und Fundkontext zu wenig bekannt. Denn allgemeine Fundortangaben wie „Siedlungsareal“ oder „Befestigung“ belegen keine private Nutzung der Figuren in einem nicht-sepulkralen und nicht-religiösem Sinne. Rein profane Stadtteile gibt es nicht, da auch außerhalb von größeren Heiligtümern mit sakralen Bereichen zu rechnen ist. So sind z.B. Hermen an Straßenkreuzungen und im Gymnasion zu finden. Sie boten die Möglichkeit zur Niederlegung von Votiven. Weiter ist von häuslichen Kulten auszugehen, und insbesondere an gefährdeten Stellen der Stadtbefestigung, wie an Türmen und Toren, dürften sich die Schreine von Schutzgöttern befunden haben. Auf einen religiösen Zusammenhang weisen auch die Beifunde der Statuetten hin, bei denen es sich meist um Darstellungen von Gottheiten handelt (z.B. in Morgantina, Korinth).

\footnotetext{
${ }^{599}$ Vgl. G. Davidson, A Hellenistic Deposit at Corinth, Hesperia 11, 1942, $126 \mathrm{f}$.

${ }^{600}$ So M. Bell, Morgantina Studies I. The Terracottas (1981) $242 \mathrm{f}$.
} 
Ich halte deshalb die Verwendung von Statuetten mit Kausia im Haus zu ausschließlich dekorativen Zwecken ${ }^{601}$ oder eine Verwendung als Spielzeug ${ }^{602}$ für unwahrscheinlich. Eine solche Nutzung lässt sich für keine einzige Figur, die eine Kausia trägt, nachweisen.

\subsubsection{Zusammenfassung}

Kleinformatige Statuetten mit Kausia stammen, gemessen an der Zahl der Fundorte, etwa je zur Hälfte aus Nekropolen ${ }^{603}$ und Heiligtümern ${ }^{604}$. Diese Fundorte verteilen sich relativ gleichmäßig über das Gesamtverbreitungsgebiet der Statuetten mit Kausia (vgl. Karten 3 und 8). Abweichungen wie das Fehlen von Funden aus ägyptischen Heiligtümern oder nahöstlichen Nekropolen liegen vermutlich im unzureichenden Forschungstand oder unterschiedlichen religiösen und sepulkralen Praktiken begründet.

Sowohl die verschiedenen Typen und Varianten von Chlamydephoren-Statuetten als auch unterschiedliche Reitertypen finden sich sowohl in Nekropolen als auch in Heiligtümern. Eine Bindung einzelner Typen an einen bestimmten Ort der Niederlegung ist demnach nicht festzustellen. Unregelmäßigkeiten sind hier einerseits wiederum mit dem ungleichmäßigen Forschungs- und Publikationsstand zu erklären und andererseits auf regionale Besonderheiten zurückzuführen. So dürften insbesondere einige Gruppen von Statuetten („Reiter über Gegner“, Soldaten, [koroplastische] hockende Knaben), die in Ägypten häufig mit Kausia kombiniert wurden und sich derzeit weder in Nekropolen noch in Heiligtümern nachweisen lassen, dennoch von solchen Fundorten stammen.

Eine Verbindung zwischen den als Grabbeigabe oder im Grabkult verwendeten Statuetten und dem oder der Verstorbenen oder den Trauernden in dem Sinne, dass z.B. die Chlamydephoren-Figuren für den Verstorbenen stehen oder auf seine Stellung im Leben verweisen, ist auf Grundlage des unzureichenden Materials letztlich weder zu beweisen noch zu widerlegen.

\footnotetext{
${ }^{601}$ Gegen eine Verwendung in Privathäusern spricht auch, dass fast alle aus solchen Häusern stammenden Terrakotten in unzerstörtem Zustand Höhen zwischen 20 und $50 \mathrm{~cm}$ aufweisen (Vgl. Th. Wiegand - H. Schrader, Priene. Ergebnisse der Ausgrabungen und Untersuchungen in den Jahren 1895-98 [1904] 330 ff.), während Terrakottastatuetten mit Kausia fast ausnahmslos nur ca. 6 bis $15 \mathrm{~cm}$ messen, wie auch diejenigen Votivstatuetten aus z.B. dem Demeter Heiligtum von Priene (Th. Wiegand - H. Schrader a.a.O. 157 ff.). - Zur Funktion und Bedeutung von Terrakotten (ohne Kausia) im Haus (beispielsweise Andron) vgl. L. Giuliani, Die seligen Krüppel, AA $1987,712 \mathrm{ff}$.

${ }^{602}$ Entsprechende Überlegungen entbehren in Bezug auf die hier behandelten Terrakotten jeder Grundlage, da diese keinerlei Hinweise in dieser Richtung bieten (wie z.B. bewegliche Glieder oder Ösen zur Anbringung von Marionettenfäden) und sich auch anders sinnvoll deuten lassen. - Demosthenes, IV, 26 belegt zwar, dass auf der Athener Agora Statuetten von Taxiarchen und Phylarchen verkauft wurden, es lässt sich aus dem Text jedoch nicht entnehmen, dass diese als Spielzeug Verwendung fanden, wie D. Burr-Thompson, Troy III (1963) 55 Anm. 144 und J. H. Vince, Demosthenes I (1970) 82 Anm. a behaupten.

${ }^{603}$ Alexandria, Myrina, Mytilene, Limyra, Pella, Pydna, Amphipolis, Samothrake, Chalkis, Kassandreia, Thessaloniki, Tarent, Lipari.

${ }^{604}$ Troja, Xanthos, Samothrake, Delos, Demetrias, Rom, Morgantina, Zypern (Amathous, Kourion, Nikosia, Voni, Idalion, Tamassos, [Golgoi?]), Oummel-‘Amed, Kharayeb, Masjid-i Solaiman, Ikaros.
} 
Statuetten mit Kausia spielten nur im Kult einer Gruppe relativ homogener Gottheiten eine Rolle. Dies deutet an, dass die betreffenden Figuren gezielt verwendet wurden und mit bestimmten Personengruppen und Riten zu verbinden sind.

\section{Exkurs: Nicht-koroplastische Wiedergaben aus Nekropolen und Heiligtümern}

Nicht nur die kleinformatigen Statuetten aus Stein und gebranntem Ton stammen, soweit sich dies nachweisen lässt, ganz überwiegend aus Nekropolen und Heiligtümern, auch ein Teil der nichtkoroplastischen Wiedergaben, die schon im Rahmen der „szenischen Darstellungen der Kausia" näher besprochen wurden, findet sich auf Grabmonumenten und Weihungen.

So sind dem sepulkralen Bereich zuzuordnen: ein Grabrelief (Re 2) aus Vergina (um 350-325 v. Chr.), mehrere bemalte Grabstelen (Ma 1-3) aus Alexandria (Ende 4.- 3. Jh. v.Chr.), die bemalten Fassaden der makedonischen Gräber in Vergina (Ma 5; „Philippsgrab“, um 300 v.Chr.) und Agios Athanasios (Ma 6, um 300 v.Chr.), die Malerei im Dromos des Grabes von Kasanlak (Ma 7, um 300 v.Chr.), ein bemalter Architrav im Peristyl des Grabes Nr. 1 der MustafaPascha-Nekropole in Alexandria (Ma 4, Anfang 3. Jh. v.Chr.) und drei bemalte Grabstelen aus Demetrias (Ma 8-10, 3. Jh. v.Chr.).

Dargestellt sind jeweils stehende Chlamydephoroi (Re 2, Ma 1, 5-9, [10, liegend?]) oder Reiter (Ma 2-4) in Chlamys, Chiton und Kausia. Sowohl die einen als auch die anderen können bewaffnet sein (Ma 1-7 [davon Ma 5 mit Jagdspeeren]).

Dem sakralen Bereich entstammen: zwei Strategen-Reliefs aus Mesambria (Re 3 [200-50 v.Chr.], Re 4 [um 100 v.Chr.]) sowie vielleicht das Löwenjagdrelief auf einer Rundbasis aus Messene (Re 5, um 300 v.Chr.).

Wiedergegeben sind wiederum stehende Chlamydephoroi (Re 3-4) und ein reitender Chlamydephoros $(\operatorname{Re} 5)$.

\subsection{Die koroplastischen Typen und ihr kulturelles Umfeld}

Nachdem zuerst die geographische Verbreitung der einzelnen Typen geklärt worden ist und danach anhand regelmäßig wiederkehrender Fundkontexte innerhalb und außerhalb der Städte (Nekropolen und Heiligtümer) die Art der Verwendung (Beigabe, Opfer, Weihung) erschlossen wurde, soll in einem weiteren Schritt eine Deutung der Darstellung versucht werden. Nach einer Untersuchung der Ikonographie kann auch das kulturelle Umfeld der wiedergegebenen Personen zur Klärung der Funktion der Statuetten herangezogen werden. Schließlich sind die Ergebnisse der Untersuchungen zur Verbreitung, Verwendung, Ikonographie und zum kulturellen Kontext zu verbinden, um die Symbolik und Funktion der Statuetten zu ergründen. 


\subsubsection{Einschränkende Vorbemerkung}

In den nachfolgenden Abschnitten wird der Versuch unternommen, die in der Koroplastik mit einer Kausia dargestellten Personen mit möglichst genau definierten Gruppen und Institutionen in Beziehung zu bringen.

Dies widerspricht in gewissem Sinne der nachfolgend ${ }^{605}$ erwähnten Annahme, nach der die Kausia von allen „Makedonen“ bei allen im Freien stattfindenden Aktivitäten getragen werden konnte. Und es ist daher zu fragen, warum es sich bei den dargestellten Personen nicht einfach um (junge) Makedonen in ihrer zu verschiedensten Anlässen getragenen Alltagskleidung handelt.

Dem widerspricht jedoch, dass es zumindest in der Antike in aller Regel nicht um eine rein dekorative Darstellung des Alltags ging und dass Attribute - und hierzu gehört auch die Kausia - in bildlichen Darstellungen nicht willkürlich verwendet wurden.

Für eine gezielte Verwendung der Kausia im Rahmen koroplastischer Darstellungen spricht die Seltenheit solcher Darstellungen in Makedonien, obwohl die Kausia dort sicher zur Alltagskleidung gehörte. Gegen eine Betonung ausschließlich der Zugehörigkeit zur Gruppe der Makedonen wiederum spricht, dass nicht alle realistischen Darstellungen männlicher Personen aus makedonisch geprägten Gebieten die Kausia tragen bzw. viele potentiell darstellbare Personengruppen in der Koroplastik überhaupt nicht dargestellt wurden. Hinzu kommen die einleitend ${ }^{606}$ geäußerten grundsätzlichen Zweifel am neuzeitlich geprägten Denken in nationalen Kategorien.

Im Gegenzug werden bestimmte Personen (Chlamydephoren, Reiter) in bestimmten Regionen sehr regelmäßig mit der Kausia wiedergegeben. Hierfür muss es Gründe geben. Die von mir nachfolgend angestellten Überlegungen lassen sich nicht eindeutig nachweisen. Sie scheinen mir jedoch sowohl im Ausschlussverfahren als auch auf Grund von Indizien am besten belegt zu sein.

Vergleichbar ist das Phänomen vielleicht mit der Darstellung des attischen Bürgers im Himation. Dieses Gewand erscheint als Regelbekleidung auf den Grabstelen attischer Bürger. ${ }^{607}$ Körperliche Arbeit dürfte im Himation jedoch weitgehend unmöglich gewesen sein. Das Himation kann demnach als Alltagsgewand nur von der begrenzten Gruppe von Oberschichtangehörigen getragen worden sein. Hinzu kommen Vertreter bestimmter „Berufe“ (Redner, Lehrer, Philosophen), die oft ebenfalls dieser Schicht angehört haben dürften. Die Masse der Bürger (z.B. die Handwerker ${ }^{608}$ ) wird das Himation nur zu bestimmten Anlässen (Versammlungen auf der Agora/im Theater, Tempelbesuch) getragen haben - vergleichbar einem neuzeitlichen Sonntagsanzug. Wenn demnach Sokrates immer im Himation dargestellt wird, heißt dies nicht, dass er im Alltag als Steinmetz dieses Gewand trug, sondern dass er das Himation zu

\footnotetext{
${ }^{605}$ Vgl. das Kap. „Literarische und archäologische Quellen im Vergleich - eine Zusammenfassung“.

${ }^{606} \mathrm{Vgl}$. oben den „Exkurs: Die Kausia als ,nationales Symbol““.

${ }^{607}$ Vgl. z.B. J. Bergemann, Demos und Thanatos (1997).

${ }^{608}$ Zur Bekleidung der körperlich arbeitenden Bevölkerung vgl. z.B. A. Pekridou-Gorecki, Mode im antiken Griechenland (1989) 87.
} 
bestimmten politischen, religiösen und kulturellen Anlässen auf der Agora, im Theater, im Heiligtum oder im Gymnasion trug oder zu besonderen privaten Einladungen (Symposion). Immer im Himation dargestellt wurde er, da er als politisch aktiver Bürger und als Philosoph wahrgenommen werden wollte oder andere ihn so sehen wollten und sollten.

In diesem Sinne ist auch bei den Chlamydephoren mit Kausia nicht zu fragen, wer zum einen oder anderen Anlass grundsätzlich Chlamys und Kausia tragen konnte - dies wären dann alle (jungen) Männer aus „makedonisch“ geprägten Bevölkerungsgruppen, sondern was mit der regelmäßigen bildlichen Wiedergabe in dieser Bekleidung ausgesagt werden sollte.

\subsubsection{Chlamydephoroi: Paides, Epheboi und Neoi und das Gymnasion ${ }^{609}$}

Diese Statuetten zeigen Knaben, Jugendliche und (junge) Männer in Chlamys, Chiton und Kausia. Sie sind stehend oder auf einem Felsen sitzend dargestellt (Taf. 23-27 Abb. 83-101). In der Literatur werden sie meist einfach als Knaben, Jugendliche oder junge Männer bezeichnet. ${ }^{610}$ Wird eine nähere Bestimmung vorgenommen, spricht man sie als Epheben an. ${ }^{611}$ Auffallend ist, dass dies hauptsächlich beim Typus Epheben-Soldat (Taf. 27 Abb. 98-101) der Fall ist. ${ }^{612}$ Das dürfte darauf zurückzuführen sein, dass dieser Typus junge Männer darstellt, die am ehesten dem Bild des spätklassisch-frühhellenistischen attischen Epheben entsprechen, der ein Alter von 18-20 Jahren aufwies. Die übrigen Terrakotten geben in der Mehrzahl Personen wieder, die jünger erscheinen und deshalb mit dem, was von der attischen Ephebie bekannt ist, nicht vereinbar sind. Gerade die attische Ephebie stellt jedoch einen Sonderfall dar. In Ägypten sahen die Verhältnisse sicher anders aus und in Kleinasien und dem Orient vermutlich auch.

Um zu klären, ob die für einen Teil der Statuetten vorgeschlagene Bezeichnung als Epheben zutrifft und ob diese auch auf die übrigen Chlamydephoren übertragen werden kann oder diese Statuetten anders zu deuten sind, gehe ich in den folgenden Abschnitten kurz auf die Ephebie und die hinter ihr stehende Örtlichkeit, das Gymnasion, ein. Weiter beschäftige ich mich mit der Bedeutung des angenommenen kulturellen Kontextes der Terrakotten (Ephebie, Gymnasion) innerhalb der hellenistischen Gesellschaft.

\footnotetext{
${ }^{609}$ Zum gesamten Themenbereich vgl. jetzt die einzelnen Aufsätze in D.Kah/P.Scholz(Hrsg.), Das hellenistische Gymnasion (Wissenskultur und gesellschaftlicher Wanel 8), Symposion Frankfurt 2001 (2004).

${ }^{610}$ Vgl. z.B. Breccia, Alexandria II 1, 39 Nr. 133 (und öfter) .- Fischer, Slg. Sieglin/Schreiber, 160 Nr. 196 (und öfter) .- Adriani, Annuaire III, 14 Nr. 29 .- Leyenaar-Plaisier, Leiden, 433 Nr. 1206 .- Burr-Thompson, Troy, 86 Nr. 52 ff. .- E. Paul, Antike Welt in Ton (o.J., spätestens 1968) 84 Nr. 194 .- Mollard-Besques, Paris II, 130 Myr 291 .- u.v.a.m.

${ }^{611}$ Dies beruht darauf, dass das Aussehen attischer Epheben bekannt ist: Sie sind 18-19 Jahre alt (Aristoteles, Ath. pol. 42) und tragen Chlamys und Petasos (Pollux 10, 164). Entsprechend aussehende Terrakotten sind als Epheben angesprochen worden (R. Higgins, Tanagra and the Figurines [1986] 148 f. Abb. 179 ff.) und auf diese lassen sich die hier zu besprechenden Statuetten zurückführen.

${ }^{612}$ Chéhab, Kharayeb, 65 (Tk 380a-d) .- J. P. Uhlenbrock, in: The Coroplast's Art, FS D. Burr-Thompson (1990) 116 Nr. 9 (Tk 292).
} 
Anschließend wird zunächst auf die primäre Funktion der Statuetten, d.h. die Art der praktischen Verwendung dieser Darstellungen eingegangen. Es folgt eine Erörterung des symbolischen Gehaltes der Figuren und ihrer Funktion in der Gesellschaft.

\subsubsection{Die Ephebie in Athen}

Die Anfänge der Ephebie ${ }^{613}$ in Athen sind dunkel. Entstanden vermutlich schon im 5. Jahrhundert ${ }^{614}$, ist sie seit etwa 370 v. Chr. indirekt ${ }^{615}$ und seit den 330er Jahren in straff organisierter Form nachweisbar. In diesen Jahren trat ein auf Antrag des Epikrates erlassenes Gesetz in Kraft, ${ }^{616}$ das ihre Durchführung verbindlich regelte. ${ }^{617}$ Sie stellt sich als eine Art von Wehrpflicht dar. Die volljährig, d.h. 18 Jahre alt werdenden Männer wurden für zwei Jahre eingezogen. Sie erhielten Sold (vier Obolen täglich) und eine Uniform (Chlamys und Petasos). ${ }^{618}$ Das erste Jahr spielte sich in den Kasernen des Piräus ab, das zweite in den attischen Landgebieten und Grenzfestungen. Nach Ableistung des ersten Jahres bekamen die Epheben im Theater vor versammeltem Volk Schild und Speer verliehen, und sie leisteten vermutlich bei dieser Gelegenheit den Eid. ${ }^{619}$ Am Ende ihrer Dienstzeit wurden die Epheben in die Bürgerschaft übernommen, nachdem schon vorher ihr Anrecht hierauf im Rahmen der Dokimasie überprüft worden war. ${ }^{620}$ Neben militärischen und sportlichen Übungen hat die Ausbildung schon in dieser frühen Zeit eine Einführung in die Sitten und Gebräuche mit dem Ziel der Vorbereitung auf die Ausübung der bürgerlichen Rechte und Pflichten beinhaltet. Aufgabe der reformierten Ephebie war es, sowohl die militärische Schlagkraft zu stärken als auch den inneren Zusammenhalt der demokratischen Polis. Die Ephebie passte sich hiermit gut in das

\footnotetext{
${ }^{613}$ Vgl. allg. RE V (1905) 2737 ff. s.v. $\dot{\epsilon} \phi \eta \beta i ́ \alpha$ (Thalheim) .- Marrou, Erziehung 204-7 .- Nilsson, Schule, 17 ff. .Zur Entstehung der attischen Ephebie und ihrer spätklassischen Form siehe jetzt: L. Burckhardt, Bürger und Soldaten. Aspekte der politischen und militärischen Rolle athenischer Bürger im Kriegswesen des 4. Jahrhunderts v.Chr., Historia Einzelschriften 101 (1996) 26-75.

${ }^{614}$ Marrou, Erziehung, 90 f. Anm. 3; 204 ff. .- Burckhardt, Bürger und Soldaten, 30 ff.

${ }^{615}$ Aischines (Kata Timarchou 43; Peri Parapresbeias 167) erwähnt, dass er als junger Mann zwei Jahre Militär-

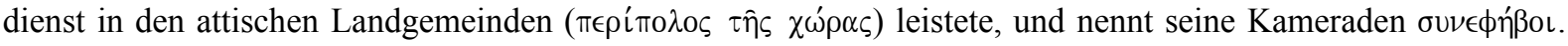
D.h., Grundelemente und Bezeichnung sind älter als die lykurgische Reform der Ephebie. - Zu weiteren Hinweisen auf eine ephebieähnliche Einrichtung in der antiken Literatur vgl. Burckhardt, Bürger und Soldaten, 30. 32.

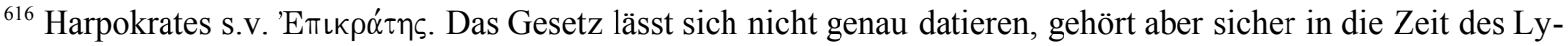
kurg (vgl. Burckhardt, Bürger und Soldaten, 31). Die Ephebiereform schlägt sich u.a. in der zeitgenössischen Literatur (Lykurg, Leokr. 76 f., Aristoteles, Ath. pol. 4; vgl. Burckhardt a.a.O. 29. 34) sowie dem Aufkommen der Ephebeninschriften (vgl. Burckhardt a.a.O. 29. 63 ff.) nieder.

${ }^{617} \mathrm{Vgl}$. Aristoteles, Ath. pol. 42.

${ }^{618}$ Pollux 10, 164 .- Philostrat, vit. soph. 2, 1, 550.

${ }^{619} \mathrm{Ob}$ Waffenübergabe und Eid gleichzeitig im Theater stattfanden, ist umstritten. Der Eid wurde möglicherweise auch im Heiligtum der Aglauros abgelegt (Diskussion vgl. Burckhardt, Bürger und Soldaten, 58 .- B. HintzenBohlen, Die Kulturpolitik des Eubulos und des Lykurg [1997] 118).

${ }^{620}$ Genau genommen bildet das Ausscheiden aus dem Ephebencorps nur den Endpunkt einer mehrjährigen Übergangsphase. In die Listen der Phratrien werden die jungen Athener schon mit ca. 16 Jahren eingeschrieben, in die Demenlisten mit 18 Jahren (Dokimasie). Sie gehören der Bürgerschaft also schon seit Jahren an, wenn ihnen mit 20 Jahren die Wahrnehmung der meisten bürgerlichen Rechte und Pflichten gestattet wird (vgl. Burckhardt, Bürger und Soldaten, 53 ff.).
} 
Gesamtkonzept der Politik des Lykurg nach der verlorenen Schlacht von Chaironeia (338 v.Chr.) ein. ${ }^{621}$

Schon wenige Jahre nach Einführung der Ephebie in der oben geschilderten Weise änderten sich die außenpolitischen Rahmenbedingungen derart, dass das Bürgerheer und die darauf vorbereitende Ephebie zunehmend unbedeutender wurden. Dem passte sich die Ephebie an. ${ }^{622}$ $\mathrm{Ab}$ 305/4 wurde sie einjährig und freiwillig. Die Führungsstruktur änderte sich. Die Anzahl der „Fächer“ und der „Lehrer“ und deren Rangfolge wandelten sich. Der militärisch-sportliche Teil trat zunehmend zurück, während literarisch-rhetorisch-philosophische Disziplinen an Bedeutung gewannen. Die Zahl der Epheben pro Jahrgang sank von 500-600623 im Jahre 334/3 auf nur noch $23 \mathrm{im}$ Jahre 244/3. Sie muss im 2. Jahrhundert v.Chr. wieder angestiegen sein und hat sich bei rund 100-250 eingependelt. Seit 119/8 v.Chr. wurden auch Nicht-Athener aufgenommen. Die Ephebie hatte sich von einer Wehrpflichtigenorganisation zu einer Einrichtung zur Vermittlung von Allgemeinbildung an junge Männer höherer Schichten entwickelt. Sie ist in Athen bis 262/3 oder 266/7 n.Chr. nachweisbar.

\subsubsection{Erziehung und Ephebie in hellenistischer Zeit}

Die Ephebie ist in über 100 Städten rund ums Mittel- und Schwarze Meer und weit nach Vorderasien hinein nachweisbar. ${ }^{624}$ Sie kann in hellenistischer Zeit als allgemein verbreitet angesehen werden und dies nicht nur in den Poleis, sondern im hellenistischen Osten und in Ägypten gerade auch in den griechischen und makedonischen Siedlungen ohne Polisstatus und entsprechende Institutionen. ${ }^{625}$

Infolge der äußersten Vielfalt regional und zeitlich verschiedener Regelungen ist es schwierig, ein allgemein verbindliches Bild der Ephebie in hellenistischer Zeit zu zeichnen. Versucht man es dennoch, ergibt sich folgendes: Die Ephebie ist Teil eines Erziehungssystems, das drei

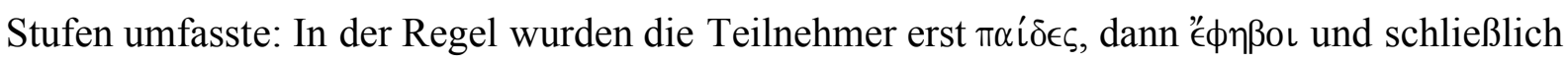
véol genannt. ${ }^{626}$ Die Aktivitäten aller drei Gruppen fanden in einem gemeinsamen oder nach Altersgruppen getrennt in mehreren Gymnasien statt. Der Unterricht umfasste militärische Übungen, Sport, Musik und literarisch-rhetorisch-philosophische Fächer (von Lesen und Schreiben bis Philosophie). Die Gewichtung der Fächer konnte regional und zeitlich stark schwanken und war an das Alter der Teilnehmer angepasst. In eine Art Elementarschule traten die Kinder ( $\pi \alpha i \delta \epsilon \varsigma)$ mit vielleicht sieben $J_{a h r e n}^{627}$ ein. Dieser Teil der Ausbildung war staat-

\footnotetext{
${ }^{621}$ Vgl. Burckhardt, Bürger und Soldaten, 30 mit Anm. 16, 52 .- B. Hintzen-Bohlen, Die Kulturpolitik des Eubulos und des Lykurg (1997) $117 \mathrm{f}$.

${ }^{622}$ Vgl. zum Folgenden: Marrou, Erziehung 207-212.

${ }^{623}$ Zur Errechnung der Gesamtzahl der Epheben in spätklassischer Zeit und damit verbundener Probleme vgl. Burckhardt, Bürger und Soldaten, $36 \mathrm{ff}$.

${ }^{624}$ So schon RE V (1905) 2742 ff. s.v. '́ $\phi \eta \beta^{\prime} \alpha$ (Oehler). Die Zahl der zu nennenden Orte dürfte in den letzten 100 Jahren gestiegen sein.

${ }^{625}$ Vgl. M. Rostovtzeff, Die hellenistische Welt. Gesellschaft und Wirtschaft II (1955) 838 ff.

${ }^{626}$ Nilsson, Schule, 34 ff.

${ }^{627}$ Marrou, Erziehung, 198. 229 .- M. Hadas, Hellenistische Kultur (1981 [engl. Erstausg. 1959]) 78.
} 
lich weniger streng geregelt als die Ephebie und vermutlich teilweise noch privat organisiert wie in vorhellenistischer Zeit. In der Phase vor dem Übertritt in die Ephebie konnten die Paides als Mellepheben ${ }^{628}$ oder Parepheben ${ }^{629}$ bezeichnet werden. Die Aufnahme in die Ephebie fand in Athen (in spätklassischer Zeit) mit 18 Jahren $^{630}$, im ptolemäisch-römischen Ägypten mit 14 Jahren $^{631}$ statt. Zu welchem Zeitpunkt der Eintritt in der übrigen hellenistischen Welt erfolgte, ist unklar bzw. umstritten. Der Hauptstrom der Forschung geht von einer weitgehenden Angleichung an attische Verhältnisse aus. ${ }^{632}$

Nach Abschluss der Ephebie werden die jungen Erwachsenen Neoi genannt. Sie nutzen wohl auf weitgehend freiwilliger Basis - weiter das Gymnasion.

\subsubsection{Das Gymnasion}

Das Gymnasion ${ }^{633}$ hellenistischer Zeit bestand im Kern aus einem viereckigen von Peristylen umgebenen Platz (Palästra ${ }^{634}$, d.h. Ringplatz). An die Säulenhallen schlossen sich an einer oder mehreren Seiten verschiedene Räumlichkeiten an, an zentraler Stelle das Ephebeion, in dem die Versammlungen und der Unterricht der Epheben stattfanden. Außerhalb des Hofes lagen ein Stadion und gegebenenfalls weitere Anlagen. ${ }^{635}$

In klassischer Zeit befanden sich die Gymnasien außerhalb der Städte, wie dies noch bei den beiden bekanntesten Gymnasien, der Akademie und dem Lykeion, festzustellen ist. ${ }^{636} \mathrm{Im}$ ausgehenden vierten und im dritten Jahrhundert wurden sie besonders bei neugegründeten Städten wie Alexandria in der Stadtmitte errichtet, dort wo man in früherer Zeit die Agora angelegt hätte. ${ }^{637}$ Seit dem zweiten Jahrhundert war das Bild weniger eindeutig. Die Gymnasien lagen teilweise am Stadtrand, teilweise gab es mehrere an verschiedenen Punkten der Stadt.

Das Gymnasion besaß auch einen sakralen Bereich. ${ }^{638}$ Götter des Gymnasiums und der Ephebie waren meist Hermes, Herakles oder Eros ${ }^{639}$ aber auch andere. Ihnen zu Ehren fanden Feste mit Opfern, Agonen etc. statt. Man errichtete im Gymnasion Altäre und Götterstatuen (insbe-

\footnotetext{
${ }^{628}$ RE XV (1931) 557 f. s.v. $\mu \in \lambda \lambda \dot{\epsilon} \phi \eta \beta o \varsigma$ (Poland) .- Nilsson, Schule, 37.

${ }^{629}$ RE V (1905) 2744 s.v. $€ \phi \eta ß i ́ \alpha$ (Oehler).

${ }^{630}$ Aristoteles, Ath. pol. 42.

${ }^{631}$ Marrou, Erziehung, 198.

${ }^{632}$ Vgl. z.B. Marrou, Erziehung, 198 f. Gegen eine Orientierung am attischen Vorbild spricht, dass sich die Ephebie in Athen in frühhellenistischer Zeit in einem äußerst schlechten Zustand befand und sich erst zu einem Zeitpunkt wieder fingt, zu dem das hellenistische Erziehungssystem schon in voller Blüte stand.

${ }^{633}$ Vgl. allg.: RE VII (1912) 2004 ff. s.v. Gymnasium (Oehler) .- J. Delorme, Gymnasion (1960) .- Vitruv 5,11,1.

${ }^{634}$ Die Begriffe „Palästra“ und „Gymnasion“ werden in der Antike teilweise synonym verwendet. Vgl. B.

Rückert, Die Hermen im öffentlichen und privaten Leben der Griechen (1998) 112 f. 126 f. 133 ff. 136 ff.

${ }^{635}$ Marrou, Erziehung, 247 f. .- Nilsson, Schule, 30.

${ }^{636}$ H. von Hesberg, Das griechische Gymnasion im 2. Jh. v.Chr. in: Stadtbild und Bürgerbild im Hellenismus, Kolloquium München 1993, Hrsgg. von M. Wörrle und P. Zanker (1995) 14 f.

${ }^{637}$ Hesberg, Gymnasion, $16 \mathrm{f}$.

${ }^{638}$ RE VII (1912) 2022 f. s.v. Gymnasium (Oehler) .- Nilsson, Schule, 62 f. 86.- Hesberg, Gymnasion, 21.

${ }^{639} \mathrm{Vgl}$. B. Rückert, Die Hermen im öffentlichen und privaten Leben der Griechen (1998) 114.
} 
sondere Hermen) und stellte oder hing Votive auf. ${ }^{640}$ Auch profane Statuenaufstellungen waren möglich. ${ }^{641}$

\subsubsection{Bedeutung von Ephebie und Gymnasion in hellenistischer Zeit}

Die Bedeutung von Gymnasion und Ephebie nahm in nachklassischer Zeit besonders in den neu hellenisierten Gebieten stark zu. Diese Einrichtungen dienten hier sowohl der Erziehung der Jugend als auch der Herausbildung einer einheitlichen hellenistischen Kultur. Dies hatte nicht nur die Stärkung des Gemeinschaftsgefühls der Siedler und eine Abgrenzung gegen Einflüsse von außen zur Folge, sondern wirkte gleichzeitig nach außen hellenisierend auf die umwohnende, barbarische Bevölkerung. ${ }^{642}$

In Gebieten Asiens und Ägyptens, in denen die griechisch-makedonische Bevölkerung in ländlichen Ansiedlungen bzw. in Poleis, die über keine entsprechenden Institutionen verfügten, wohnten, übernahm das Gymnasion in großem Umfang politische Funktionen. ${ }^{643}$ Dies lässt sich aufgrund der Überlieferungssituation besonders an den Verhältnissen in Ägypten zeigen. ${ }^{644}$ Der Gymnasiarch, der ursprünglich nur die inneren Angelegenheiten des Gymnasions ordnete, wurde eponymer Beamter der Stadt. Er und die ihm nachgeordneten Personen übernahmen Aufgaben, die im klassischen Griechenland die städtischen Magistrate erfüllten. ${ }^{645}$ Die Aufnahme in die Bürgerschaft war spätestens in römischer Zeit abhängig von der Zugehörigkeit zum Gymnasion. Ins Gymnasion konnte wiederum nur derjenige eintreten, des-

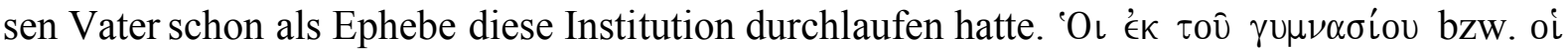

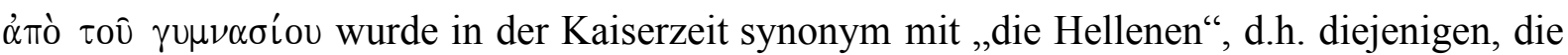
der privilegierten Bürgerschicht angehörten. ${ }^{646}$

Das Gymnasion bildete schon immer auch eine Kultgemeinschaft. Ob es in hellenistischer Zeit auf religiösem Gebiet an Bedeutung gewann, ist nicht eindeutig zu sagen. Dafür spricht jedoch, dass Politik und Religion in der Antike nicht trennbar sind und das Gymnasion politisch an Bedeutung gewann. ${ }^{647}$ Auffallend ist, dass die Epheben in massivem Umfang mit reli-

\footnotetext{
${ }^{640}$ Marrou, Erziehung, 251 .- Nilsson, Schule, 55 .- Hesberg, Gymnasion, $21 \mathrm{f}$.

${ }^{641}$ Hesberg, Gymnasion, 22.

${ }^{642}$ Nilsson, Schule, 83 ff. .- M. Hadas, Hellenistische Kultur (1981) 38. 52. 73.

${ }^{643} \mathrm{Vgl}$. M. Rostovtzeff, Die hellenistische Welt. Gesellschaft und Wirtschaft II (1955) 840 ff.

${ }^{644} \mathrm{Zu}$ den Verhältnissen im Seleukidenreich liegen weit weniger Informationen vor. Dieses führt auch hier zur Vernachlässigung dieser Gebietes. Da sich in den hellenisierten Regionen des Ostens sowohl Institutionen wie die Ephebie (Athenaios 5, 194 f ) und das Gymnasion (RE VII [1912] 2005 ff. s.v. Gymnasium [Oehler]) als auch Terrakotten mit Kausia (z.B. 54 Exemplare in Seleukia/Tigris [Tk 406 ff.]) finden, ist im Zweifelsfall von einer ähnlichen Lage auszugehen wie in Ägypten. Dies ergibt sich auch z.B. aus der Einrichtung eines Gymnasions im Rahmen der (Neu-) Gründung Jerusalems als Polis im seleukidischen Reich (1. Mak. 1, 15). Vgl. zum Gymnasion im Seleukidenreich M. Rostovtzeff, Die hellenistische Welt. Gesellschaft und Wirtschaft II (1955) $841 \mathrm{f}$.

${ }^{645}$ Marrou, Erziehung, 217 .- Nilsson, Schule, $85 \mathrm{ff}$.

${ }^{646}$ Marrou, Erziehung, 215 f. .- M. Rostovtzeff, Die hellenistische Welt. Gesellschaft und Wirtschaft II (1955) 480 .- M. Hadas, Hellenistische Kultur (1981) 81.

${ }^{647}$ Dies spiegelt sich u.a. darin, dass der Herrscherkult auch im Gymnasion ausgeübt wurde. Vgl. RE VII (1912) 2023 s.v. Gymnasion (Oehler) .- Nilsson, Schule, 87 .- H. Kyrieleis, Bildnisse der Ptolemäer (1975) 145 f.
} 
giösen Handlungen beschäftigt waren ${ }^{648}$ und zwar weit über das hinaus, was man als „Einführung in Sitten und Gebräuche" bezeichnen könnte. Sie stellten unter anderem die für den Kult wichtigen Chöre. ${ }^{649}$ Die Epheben scheinen im kultischen Bereich geradezu in Vertretung der Bürgerschaft aufgetreten zu sein.

In Folge der immens gestiegenen kulturellen, politischen und religiösen Bedeutung des Gymnasions ist es verständlich, dass dieses in die Stadt hineingeholt wird, den Platz der Agora einnehmen kann und dieser nach Architektur und Ausstattung weitgehend angeglichen wird.

\subsubsection{Zum Begriff „Ephebe“6}

Der Begriff „Ephebe“ (bzw. „Ephebie“ etc.) besaß schon in der Antike zwei Bedeutungen. ${ }^{650}$ Gemeint sein konnte einerseits der Jugendliche oder junge Mann, der einer verpflichtenden, von der Polis straff organisierten Organisation, wie z. B. der vom Verfasser der Athenaion Politeia ${ }^{651}$ beschriebenen attischen Ephebie, angehörte. Das Alter der Mitglieder war vom Staat vorgegeben und orientierte sich an der Zielrichtung der Organisation. Diese war im spätklassischen Athen vornehmlich militärisch ausgerichtet, und entsprechend lag das Eintrittsalter bei 18 Jahren.

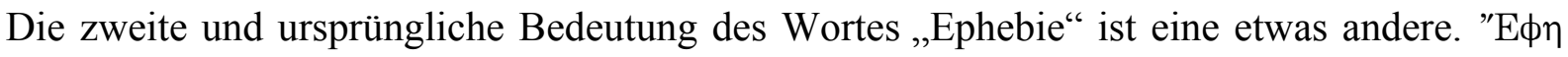
ßos bezeichnet eigentlich denjenigen, der die $\eta^{\prime} \beta \eta$ (Hebe = Pubertät, Mannbarkeit) erreicht hat. ${ }^{652}$ Als Zeitpunkt wird in den antiken Quellen meist das 14. oder 16. Lebensjahr angenommen. Als Ephebe kann in diesem Sinne der Jugendliche bezeichnet werden, der die Pubertät

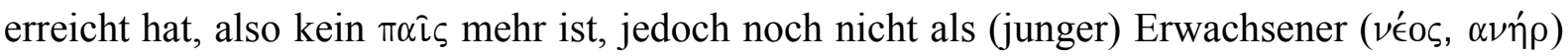
gezählt wird, d.h. der 14/16 - 18/20 jährige. Hinweise auf ein solches Verständnis des Begriffes „Ephebe“ finden sich sowohl im klassischen als auch im nachklassischen Athen als auch in anderen Teilen der griechischsprachigen Welt: die Einschreibung in die Demenliste erfolgte im spätklassischen Athen zwar erst im Alter von 18 Jahren, wahrgenommen werden konnten die Bürgerrechte sogar erst mit 20 Jahren nach Ableistung des Ephebendienstes. Die Einschreibung in die Listen der Phratrien und damit die Aufnahme in die Bürgerschaft fand jedoch schon im Alter von 16 Jahren statt. Als in nachklassischer Zeit die militärische Komponente der attischen Ephebie zunehmend an Bedeutung verlor, sank auch das Eintrittsalter der Epheben. Auch im ptolemäischen Ägypten orientierte sich die Ephebie offenbar an der Pubertät: Das Eintrittsalter lag bei 14 Jahren.

\footnotetext{
${ }^{648}$ Nilsson, Schule, $67 \mathrm{ff}$.

${ }^{649}$ Nilsson, Schule, $70 \mathrm{ff}$.

${ }^{650}$ So schon L. Grassberger, Erziehung und Unterricht im klassischen Altertum. III. Theil: Die Ephebenbildung (1881) $17 \mathrm{ff}$.

${ }^{651} \mathrm{Vgl}$. Aristoteles, Ath. pol. 42.

${ }^{652}$ Die Quellen werden diskutiert u.a. bei L. Grassberger, Erziehung und Unterricht im klassischen Altertum. III. Theil: Die Ephebenbildung (1881) 17 ff. und Ch. Pélékidis, Histoire de l'Éphebie attique (1962) 55 ff.
} 
Die Mehrdeutigkeit des Ephebenbegriffes hat schon in (spät-) antiker Zeit für Verwirrung ${ }^{653}$ gesorgt und in der modernen Forschung zu Meinungsverschiedenheiten ${ }^{654}$ geführt. Einträglicher ist es, ihn in seiner Zweideutigkeit zu akzeptieren und gegebenenfalls nach geographischen und zeitlichen Gesichtspunkten zu differenzieren.

\subsubsection{Zur Benennung der Chlamydephorenstatuetten}

Das Aussehen attischer Epheben ist bekannt: Sie trugen Chlamys und Petasos und befanden sich während der Ableistung ihres Dienstes im 18. - 19. Lebensjahr. ${ }^{655}$ Entsprechend wurden Statuetten junger Männer in Chlamys und Petasos, soweit sie aus dem attisch-böotischen Raum und spätklassisch-frühhellenistischer Zeit stammen, als Epheben gedeutet. ${ }^{656}$

Diese Terrakottafiguren gehören verschiedenen Typen sitzender und stehender Chlamydephoren an. Für alle der von mir gesammelten Typen hellenistischer sitzender und stehender Chlamydephoren mit Kausia lassen sich Vorbilder mit Petasos im spätklassischen, griechischen Mutterland finden. ${ }^{657}$ In der Literatur werden von den Terrakotten mit Kausia jedoch nur wenige als Epheben bezeichnet. ${ }^{658}$ Dies liegt nicht daran, dass sie die Kausia tragen, denn diese Kopfbedeckung kann in diesem Zusammenhang als makedonische Entsprechung zum Petasos mit gleicher Funktion und gleicher Nutzergruppe angesehen werden, sondern, dass die meisten Terrakotten mit Kausia Personen darstellen, die jünger sind oder jünger erscheinen. Die wenigen als Epheben angesprochenen Statuetten zeigen denn auch junge Männer.

Betrachtet man die kausiatragenden Terrakottastatuetten genauer, stellt man fest, dass sich wenige eindeutig als (Klein-) Kinder identifizieren lassen (vielleicht z.B. Tk 152). Die Mehrzahl der Dargestellten ließe sich auch als Jugendliche benennen (z.B. Tk 40-53, 128-129, 132, 135-136, 199, 207-212, 286, 289, 297-299, 304, 309-325), wobei die Frage, ob es sich eher um zwölf- bis dreizehnjährige oder um vierzehn- bis fünfzehnjährige oder noch ältere Perso-

\footnotetext{
${ }^{653}$ Vgl. L. Grassberger, Erziehung und Unterricht im klassischen Altertum. III. Theil: Die Ephebenbildung (1881) $17 \mathrm{ff}$.

${ }^{654}$ Vgl. z.B. Marrou, Erziehung, 198, der sich stark an der attischen Ephebie orientiert, und Nilsson, Schule, 35 ff., der unter Ephebie den Zeitraum von der Pubertät bis zur Volljährigkeit versteht und in dieser Institution das mehrjährige Kernstück einer umfassenden Erziehung sieht (Vgl. hierzu jedoch die Rezension von L. Illig, Gymnasium 65, 1958, 569-71.).

${ }^{655}$ Pollux 10, 164 .- Aristoteles, Ath. pol. 42.

${ }^{656}$ R. Higgins, Tanagra and the Figurines (1986) 148 Abb. 179-181 .- P. Zanker, Die Maske des Sokrates (1995)

91 f. Abb. 51 f.

${ }^{657}$ Zum „Typus sitzender Chlamydephoros“vgl. Winter, Typen II, 256 Nr. 6 .- zum „Typus sitzender Chlamydephoros (Variante Denkerpose)“ vgl. Winter, Typen II, 258 Nr. 2 .- zum „Typus sitzender Chlamydephoros (Variante mit Herme)“ vgl. Winter, Typen II, 257 Nr. 2; 256 Nr. 3 (aus Tanagra, formgleich mit Tk 182-183) .- zum „Typus sitzender Chlamydephoros, entblößt“ vgl. Winter, Typen II, 259 Nr. 9 -- zum „Typus stehender Chlamydephoros“ vgl. R. Higgins, Tanagra and the Figurines (1986) 148 Abb. 179 .- zum „Typus EphebenSoldat" vgl. R. Higgins a.a.O. 148 f. Abb. 180 f. .- Der Gestus der vor das Kinn gezogenen Chlamys erscheint schon bei den frühen Exemplaren aus Athen/Böotien (Tk 294-296) und Lesbos (Tk 182-184, teilweise formgleich mit Winter, Typen II, 256 Nr. 3 [ausTanagra]).

${ }^{658}$ Chéhab, Kharayeb, 65 (= Tk 382a-d) .- G. Schneider-Herrmann in: Alessandria e il mondo ellenistico-romano. FS A. Adriani (1984) 304 Taf. 55, 1.2 (= Tk 382, 298) .- A. Archontidou-Argyri, ADelt 43 B'2, 1988, 459 (= Tk 180-182, 184) .- J. P. Uhlenbrock in: The Coroplast's Art. FS D. Burr-Thompson (1990) 116 (= Tk 292).
} 
nen handelt, in der Regel nicht beantwortbar ist. Somit kann nicht gesagt werden, ob z.B. die ptolemäischen Figuren speziell die 14 jährigen Epheben Ägyptens meinen oder auch die Jahrgänge darüber und darunter. Auch scheinbar kindliche Formen (rundes Gesicht, längere Locken) sollten weniger zur Feststellung des Alters der dargestellten Person denn zur Datierung (ca. 330-200 v.Chr.) herangezogen werden. Entsprechende Statuette erscheinen über Jahrhunderte und große Entfernungen hinweg in Nekropolen sowie Heiligtümern immer derselben Gottheiten. An der Funktion und der Art der Verwendung scheint sich nichts zu verändern. Es gibt daher keinen Grund anzunehmen, dass die sonst typengleichen Figuren im 4. Jahrhundert v.Chr. und dann wieder ab dem 2. Jahrhundert v.Chr. ältere (kurzhaarige) Jugendliche, im 3. Jahrhundert dagegen jüngere (langhaarige) Knaben darstellen. ${ }^{659}$

Besonders die kaiserzeitlichen Figuren (z.B. Tk 150-154, 172) sind weitgehend alterslos dargestellt und nur in Anlehnung an ihre hellenistischen Vorgänger deutbar.

Auf der anderen Seite lässt sich der Zeitpunkt der Ableistung des Ephebendienstes nur ungenau abgrenzen: Eine zweijährige Dienstzeit im Alter von 18-19 Jahren ist nur für Athen und auch dort nur für die spätklassische und frühhellenistische Zeit nachweisbar. ${ }^{660}$ In Ägypten betrug die Dauer ein Jahr, und die Epheben befanden sich im 14. Lebensjahr. Die Einschreibung in die Ephebenliste war sogar schon im Alter von einem Jahr möglich. ${ }^{661}$ Im Rest der griechisch sprechenden Welt dauerte die Ephebenzeit zwischen einem und drei Jahren und fand zwischen dem 15. und 20. Lebensjahr statt. ${ }^{662}$

Auch die Kleidung der Epheben ist weder für diese erfunden worden noch wurde sie ausschließlich von ihnen getragen. Petasos/Kausia und Chlamys galten auch in vorhellenistischer Zeit als die typische Bekleidung von Reisenden und Kriegern ${ }^{663}$ und werden dies auch geblieben sein. Aus praktischen Grünen wurden diese Kleidungsstücke als Uniform der Epheben übernommen. ${ }^{664}$ Es ist anzunehmen, dass zumindest die sportlich-aktiven Besucher des Gymnasions aus praktischen Gründen ähnlich gekleidet waren. Die Neoi hatten wohl keinen Grund Chlamys und Petasos/Kausia abzulegen, die sie als ehemalige Epheben und damit Angehörige der Bürgerschaft ${ }^{665}$ kennzeichneten. Für die Paides als (vielleicht schon vorsorglich in die Ephebenlisten eingeschriebene) Anwärter auf die Ephebie dürfte ähnliches gegolten haben.

\footnotetext{
${ }^{659}$ Gegen eine solche Deutung spricht auch, dass es Gruppen gibt, die einen älteren (langhaarigen, pausbäckigen) Jugendlichen zeigen, der einen kleinen Jungen (mit Kurzhaarfrisur) auf den Schultern trägt (Taf. 22 Abb. 82; vgl. Chéhab, Kharayeb, 34 Nr. 234-241 Taf. 35 ).

${ }^{660}$ RE V (1905) 2738 s.v. $€ \phi \eta \beta i ́ \alpha$ (Thalheim).

${ }^{661}$ Marrou, Erziehung, $215 \mathrm{f}$.

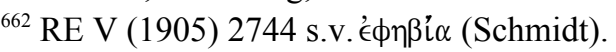

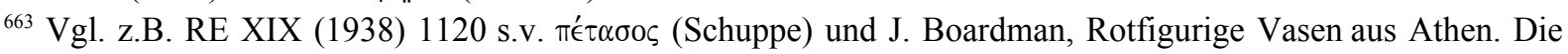
klassische Zeit (1991) Abb. 269.

${ }^{664}$ Vgl. Pollux 10, 164 .- Philostrat, vit. soph. 2, 1, 550.

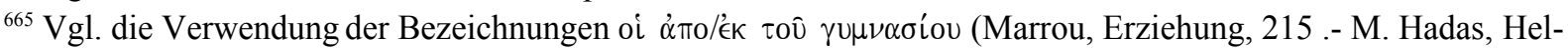
lenistische Kultur [1981] 81).
} 
Entscheidend ist, dass es sich bei den Dargestellten um Teilnehmer an den Aktivitäten im Gymnasion handelt, ${ }^{666}$ ob es nun demnächst in die Ephebie übertretende Paides oder Epheben oder Neoi, d.h. gewesene Epheben, sind.

\subsubsection{Zu einzelnen Chlamydephoren-Typen}

Allen sitzenden Typen ist gemeinsam, dass die Chlamydephoren auf unregelmäßig geformten Felsen sitzen. Felsen deuten eine naturbelassene Umgebung an, und diese lässt sich schwer mit dem innerstädtischen Gymnasion verbinden. Das im Zentrum der Stadt gelegene Gymnasion ist jedoch eine Erscheinung des Hellenismus, und besonders der neugegründeten Städte Ägyptens und Asiens. Der Typus des sitzenden Chlamydephoren stammt aus dem klassischen Athen ${ }^{667}$, und die Gymnasien Athens lagen vor der Stadt in natürlicher Umgebung. ${ }^{668}$ Dieser Zustand könnte in hellenistischer Zeit weiterhin dargestellt worden sein, auch wenn er nur noch teilweise der Realität entsprach. Für eine Lokalisierung des Felsensitzes im Gymnasion sprechen auch noch andere Details. Aus allen Felsen der mytilenischen ${ }^{669}$ Variante des „Typus sitzender Chlamydephoros" erwachsen Hermen (Tk 180-182). Hermes und Herakles waren die Götter des Gymnasions ${ }^{670}$ und der Ephebie und Hermen ein bevorzugter Ausstattungsgegenstand in Gymnasien ${ }^{671}$. Ein sitzender Chlamydephoros aus Ägypten hält eine Strigilis (Tk 1). Dies ist besonders sinnvoll, wenn die Szene ins Gymnasion gehört. ${ }^{672}$

Zum Gymnasion und den hier in unbekleideten Zustand stattfindenden sportlichen Aktivitäten passt auch, dass ein Teil der sitzenden Chlamydephoren-Figuren nur mit Kausia und zurückgeschlagener Chlamys aber ohne Chiton, d.h. weitgehend nackt, dargestellt ist. ${ }^{673}$

Relativ selten erscheint der „Typus Epheben-Soldat“. Die attischen Exemplare (mit Petasos), auf die dieser Typus zurückgeführt werden kann, zeigen den Chlamydephoren teilweise mit Speer und Brustpanzer, ${ }^{674}$ was eine Deutung dieser Statuetten als Epheben in ihrer ursprünglichen militärischen Funktion nahe legt. Hiermit stimmt überein, dass der Typus fast aus-

\footnotetext{
${ }^{666}$ Hierauf deuten neben den genannten eher allgemeinen Überlegungen zum Kreis der Träger von Kausia und Chlamys noch verschiedene Details (insbesondere die Strigilis) hin, auf die ich im Anschluss an diesen Abschnitt bei der Deutung einzelner Typen und Varianten zurückkommen werde.

${ }^{667}$ Vgl. z.B. Winter, Typen II, 256 Nr. 1-2, 6-7; 257 Nr. 1-4, 8 .- R. Higgins, Tanagra and the Figurines (1986) 66 Abb. 65 und 152 Abb. $186 \mathrm{f}$.

${ }^{668} \mathrm{Vgl}$. Hesberg, Gymnasion, 14.

${ }^{669}$ Die mytilenischen Stücke sind teilweise formgleich mit solchen aus Tanagra (vgl. Tk 182-183 mit Winter, Typen II, 256 Nr. 3). Es dürften also nicht nur der Ursprung des Typus, sondern auch der Herstellungsort im attischböotischen Raum zu suchen sein.

${ }^{670}$ Beliebt waren auch die Musen (und Apollon Musagetes). Vereinzelt kommen andere Götter und Heroen vor. Vgl. RE VII (1912) 2022 f. s.v. Gymnasium (Oehler) .- Nilsson, Schule, 62 f. 86.

${ }^{671}$ Vgl. J. Audiat, Le Gymnase de Délos et l'Inventaire de Kallistratos, BCH 54, 1930, 97 f. (Inventar des Kallistratos, Z. 146 f.) .- Hesberg, Gymnasion, 21.

${ }^{672}$ Auch Hermes, die beliebteste Gymnasionsgottheit, konnte auf einem Felsen ausruhend dargestellt werden (z.B. LIMC V [1990] Hermes 961) wie auch Sportler (z.B.: Faustkämpfer in Rom, Thermenmuseum 1055).

${ }^{673}$ Hier können jedoch auch gemeingriechische Darstellungskonventionen eine Rolle spielen.

${ }^{674}$ R. Higgins, Tanagra and the Figurines (1986) 149 Abb. 180.
} 
schließlich in der Spätklassik und im Frühhellenismus erscheint, also zu einer Zeit, in der die Ephebie noch militärische Bedeutung besaß.

Beim weitaus größten Teil sowohl der stehenden als auch der sitzenden Chlamydephoren ist der Körper in eine relativ lange Chlamys gehüllt. Der linke Arm befindet sich unter der Chlamys und ist stark angewinkelt, die Hand liegt auf dem oberen Brustbein. Der rechte Arm hängt am Körper herab und ist samt Hand ins Gewand gehüllt. Der Chiton ist (im Gegensatz zu dem der „Epheben-Soldaten“) weitgehend unsichtbar.

Der Gestus der verhüllten Hände und eng am Körper anliegenden Arme wird von B. Fehro75 anhand von Statuen attischer Bürger im Himation gedeutet. Dies geschieht in Anlehnung an eine Rede des Aischines ${ }^{676}$, in der dieser eine entsprechende Haltung gemäß dem Vorbild Solons und anderer als für den vor der Volksversammlung Redenden angemessen und als ein Zeichen der Sophrosyne des Dargestellten anspricht.

Auf die Chlamydephoroi übertragen könnte es sich um Darstellungen von Schülern als Teilnehmern oder Absolventen des im Gymnasion stattfindenden Unterrichts handeln. Dieser dürfte die Einübung entsprechender Gesten im Rahmen beispielsweise der rhetorischen Ausbildung umfasst haben.

In einem allgemeineren Sinne erlernte der Ephebe hier die dem Bürger angemessene formale Zurückhaltung (Sophrosyne).

Eine Variante dieses Typus kommt hauptsächlich in der Troas (Tk 135-137b, 139) und auf Samothrake (Tk 238, 240-241, 243, 249-260) vom dritten bis zum ersten Jahrhundert v. Chr. vor, ist jedoch auf frühhellenistische, attische Vorbilder(Tk 294-297) zurückführbar. Der Chlamydephoros verhüllt mit der Chlamys den unteren Teil des Gesichts, was das Reden unmöglich macht und so die Deutung als Redner ausschließt. D. Burr-Thompson ${ }^{677}$ deutet diesen Gestus

\footnotetext{
${ }^{675}$ B. Fehr, Verhaltensweisen und Bewegungsideale (1979) 18 mit Anm. 102; 58 mit Anm. 410.

${ }^{676}$ Aischines 1, 25 f. ; vgl. auch Xen. Lak. pol. 3, 4 .- Aristot. Ath. pol. 28 .- Demosth. 19, 251. 255 .- Plut. Phokion 4 .- Plut. Nikias 8, 3.

${ }^{677}$ Burr-Thompson, Troy, 84 unter Hinweis auf (Kult-) Tänzerinnen und V.von Gonzenbach, Untersuchungen zu den Knabenweihen im Isiskult der römischen Kaiserzeit (1957) 24 ff., die vermutet, dass die Griechen das harpokratische Daumenlutschen als Schweigegestus missdeutet haben könnten, und auf das Schweigegebot in griechischen Mysterienkulten verweist. Hierzu: F. Cumont, The Bacchic Inscription in the Metropolitan Museum, AJA 37, 1933, 262 f. (dort auch antike Quellen genannt). - Vgl. zu den Chlamydephoren mit vor das Kinn bzw. den unteren Teil des Gesichtes gezogener Chlamys auch „schwebende Eroten“ (Winter, Typen II, 327 Nr. 2, 3, 7; 328 Nr. 6, 8; 329 Nr. 1; 331 Nr. 7, 8) bzw. „Graberoen“ (U. Mrogenda, Die Terrakotten von Myrina [1996] Taf. 2 Nr. 98,7 ff; Taf. 6 Nr. 114,3 ff.). Dass „Graberoten“ ausschließlich in Myrina vorkommen (U. Mrogenda a.a.O. 129) trifft nicht zu. Die Variante mit verhülltem Kinn findet sich auch in Pitane (Winter, Typen II, 327 Nr. 2), diejenige mit unverhülltem Gesicht auch in der Troas (Winter, Typen II, 327 Nr. 1). Das Verbreitungsgebiet ist also identisch mit dem Hauptverbreitungsgebiet der Chlamydephoren mit verhülltem Gesicht in Kleinasien. Wie bei den Chlamydephoren kommt auch bei den „Graberoten“ die unverhüllte Variante öfter vor als die verhüllte. Die Deutung der „Graberoten“ (sie tragen nie die typische Ephebenbekleidung Kausia/Chlamys) ist unklar (Eroten oder Eidola der toten Seelen). Die religiöse Deutung des Gestus der vor das Gesicht gezogenen Chlamys ist sowohl auf Chlamydephoren/Epheben als auch auf schwebende „Graberoten“ o.ä. sinnvoll anwendbar, eine weitergehende Bedeutung beider Themen muss nicht übereinstimmen. - A. Conze, AvP I 2 (1930) 236 Nr. 43 deutete
} 
als Hinweis auf die vor dem Opfer gebotene Stille. Der Chlamydephoros wird hier demnach als Teilnehmer an einer religiösen Handlung im Heiligtum (gemeint sein kann eines der großen Heiligtümer, aber auch eine Herme im Gymnasion) oder am Grab dargestellt.

Nur vereinzelt erscheint ein sitzender Ephebe, der das Kinn mit dem Arm stützt (Denkerpose) ${ }^{678}$. Diese Pose lässt sich sinnvoll mit denjenigen Fächern des Unterrichts im Gymnasion verbinden, die zur Nachdenklichkeit auffordern (z.B. Philosophie).

Zusammenfassend kann zu den oben beschriebenen Typen folgendes sagen werden: Aufgrund der Kleidung sind die wiedergegebenen Personen als Chlamydephoren zu bezeichnen. Ambiente und Attribute (Felsensitz, Herme, Strigilis) deuten überwiegend auf das Gymnasion als Aufenthaltsort. Gesten und Bekleidung bzw. Nicht-Bekleidung lassen sich durchweg mit den verschiedenen Aspekten der Ephebie und des Gymnasions (Sport, Militär, Religion und Erziehung [Sophrosyne, Rhetorik, Philosophie]) verbinden. Es kann sich daher jeweils um Darstellungen von Kindern, Jugendlichen und jungen Erwachsenen handeln, die als Paides, Epheben und Neoi gezeigt werden.

\subsubsection{Zur primär-synchronen Funktion von Chlamydephoren-Statuetten}

Nur auf Umwegen und, soweit eindeutige Beweise fehlen, auch nur versuchsweise kann ermittelt werden, welche Personengruppen die Chlamydephoren-Statuetten wo und in welchem Zusammenhang verwendet haben. Die Grundlage für die Beantwortung entsprechender Fragen bilden wieder die Ikonographie der Figuren (mit ihren Bezügen zu Ephebie und Gymnasion), die Fundorte sowie externe Informationen z.B. zu den Aktivitäten von Jugendlichen oder zur Funktion des Gymnasions.

Alle Terrakotten, zu denen nähere Angaben zum Fundort vorliegen, stammen entweder aus Gräbern oder aus Heiligtümern.

Anhand der unzureichend beobachteten bzw. publizierten Fundumstände der Terrakotten mit Kausia ist, wie erwähnt, derzeit nicht zu beweisen, dass ein direkter Zusammenhang zwischen dem Alter und Geschlecht der Bestatteten und den ihnen mitgegebenen Beigaben bestand. Die Ergebnisse der Auswertung der Grabbeigaben aus den Nekropolen von Tarent ${ }^{679}$ machen dies jedoch wahrscheinlich. Entsprechend wäre es denkbar, dass es sich bei den Toten um Epheben, ehemalige Epheben (Neoi) oder Kinder (Paides), die es einmal werden sollten, handelt. Dies ist jedoch nicht in dem Sinne zu verstehen, dass männlichen Toten nur Darstellungen männlicher Personen mit ins Grab gegeben wurden und Frauen nur Frauenfiguren. ${ }^{600}$ Viel-

die Geste an einem Kalksteinkopf als ,winterlich“.

${ }^{678}$ Vgl. P. Zanker, Die Maske des Sokrates (1995) $91 \mathrm{f}$.

${ }^{679}$ Vgl. D. Graepler, Kunstgenuß im Jenseits? Zur Funktion und Bedeutung hellenistischer Terrakotten als Grabbeigabe. in: Bürgerwelten (Ausstellungskatalog Berlin) (1994) 47 ff. .- D. Graepler, Tonfiguren im Grab (1997) $201 \mathrm{ff}$.

${ }^{680} \mathrm{Zu}$ diesem Schluss könnte das bei D. Graepler, Kunstgenuß im Jenseits? Zur Funktion und Bedeutung hellenistischer Terrakotten als Grabbeigabe. in: Bürgerwelten (Ausstellungskatalog Berlin) (1994) 49 gebrachte Bei- 
mehr gibt es Themen, die Bezug entweder zur männlichen oder zur weiblichen Lebenswelt oder zu beiden Sphären nehmen. ${ }^{681}$ Darstellungen dieser Themen finden sich dann in den entsprechenden Gräbern. „Männliche“ Themen müssen aber nicht unbedingt durch bildliche Wiedergaben männlicher Personen repräsentiert werden, während Themen, die auch in der weiblichen Lebenswelt relevant sind, auch in Form männlicher Personen dargestellt werden können. Sind demnach die Chlamydephoren-Figuren vordergründig als Darstellungen junger männlicher Personen anzusprechen, ist das Thema - die Eingliederung in die Gesellschaft dennoch nicht unbedingt männlich. In einer Gesellschaft, die sowohl auf die Eingliederung der Jungen als auch der Mädchen in die Gesellschaft Wert legt, wäre entsprechend auch die Beigabe einer männlichen Chlamydephoren-Statuette in ein Mädchengrab sinnvoll. In einem ähnlichen Sinne wären auch Darstellungen von Chlamydephoren im Grab einer Mutter, die der Gesellschaft Kinder geschenkt und so zum Fortbestand des Gemeinwesens beigetragen hat, möglich und angebracht.

Diejenigen Heiligtümer, in denen Tonfiguren mit Kausia gefunden wurden, sind ganz überwiegend solche weiblicher Gottheiten. ${ }^{682}$ Nimmt man einen Zusammenhang zwischen den Darstellungen und den sie Weihenden an, müsste es sich auch bei diesen um Jungen und junge Männer handeln. Warum sollten Darstellungen junger Männer von diesen (bzw. stellvertretend von deren Eltern) fast ausschließlich an Göttinnen geweiht worden sein? Auf den ersten Blick verwundert dies. Es lässt sich jedoch einerseits nachweisen, dass auch männliche, kausiatragende Militärangehörige Heiligtümer weiblicher Gottheiten besuchten, in denen Terrakotten mit Kausia gefunden wurden, ${ }^{683}$ und andererseits wurde in diesen Heiligtümern meist nicht nur eine einzelne Göttin verehrt. In der Regel handelt es sich um ein Paar bestehend aus einer dominierenden (Mutter-) Göttin und ihrem männlichen Kultpartner (z.B. die zyprische Aphrodite-Astarte und Herakles-Melkart) oder um ein Trio aus Mutter, Tochter und Sohn (z.B. Leto, Artemis und Apollon). Gerade diese Gottheiten spielen häufig eine Rolle in der Erziehung der Heranwachsenden und in ihrer Eingliederung in die Gesellschaft. In Verbin-

spiel aus der Anthologia Palatina (VI, 280) verleiten: Eine Kore bringt eine Kore(-nstatuette) der (Göttin) Kore dar. - Als Gegenbeispiel ließe sich das Grab des Phrygerkönigs Midas anführen, auf dessen Grab eine bronzene Kore gelegen haben soll (Platon, Phaidros 264 C). Auch diese Kore wird einen Bezug zum König gehabt haben (vielleicht im Sinne der Darstellung von adeliger Lebensführung und Reichtum), dennoch weichen das Geschlecht des Midas und der Kore voneinander ab.

${ }^{681}$ Vgl. D. Graepler, Kunstgenuß im Jenseits? Zur Funktion und Bedeutung hellenistischer Terrakotten als Grabbeigabe. in: Bürgerwelten (Ausstellungskatalog Berlin) (1994) 48 ff. .- D. Graepler, Tonfiguren im Grab (1997) $205 \mathrm{ff}$.

${ }^{682}$ Das Vorherrschen weiblicher Gottheiten lässt sich nicht allein damit erklären, dass die ausreichend beobachteten Funde größtenteils aus dem kleinasiatischen und vorderorientalischen Raum stammen und dort Göttinnen das religiöse Leben dominierten. Auch im Osten gab es junge männliche Götter, in deren Heiligtümer man Statuetten junger Männer gezielt hätte weihen können.

${ }^{683}$ Vgl. zum Verbot des Betretens des Letoons von Xanthos mit Kausia: Chr. Le Roy, Un règlement religieux au Létôon du Xanthos, RA, 1986, 279 ff. .- M. J. Mellink, AJA 92, 1988, 119 f. Abb. 17 (S. 116) .- Text der Inschrift: Q 20. 
dung mit dieser fanden Übergangsriten ${ }^{64}$ statt. Es ist denkbar, dass junge Menschen Abbilder ihrer selbst im Rahmen dieser Übergangsriten weihten.

Neben den Heiligtümern im engeren Sinn bietet sich als Ort entsprechender Weihungen das Gymnasion an. Hier spielte sich nicht nur ein bedeutender Teil des Lebens der Paides, Epheben und Neoi ab, sondern hier waren auch entsprechende Kulte (Hermes, Herakles u.a.) angesiedelt. Nachweisbar sind Weihungen von Terrakotten mit Kausia in Gymnasionsheiligtümer bisher nicht, was jedoch in Anbetracht der schlechten Forschungs- und Publikationslage nur von geringem Aussagewert ist.

Nähert man sich dem Problem von der anderen Seite und fragt, ob und in welchen Zusammenhängen z.B. Epheben - sei es im spätklassisch-attisch-militärischen Sinne oder im Sinne von Jugendlichen zwischen Pubertät und Volljährigkeit - die beschriebenen Tonfiguren geweiht haben können, finden sich in den literarischen und epigraphischen Quellen durchaus Anhaltspunkte. Greift man aufgrund der Quellenlage die spätklassischen attischen Epheben heraus, ergeben sich als geeignete Termine u.a. der Eintritt in den Ephebendienst, Eidesablegung und Waffenvergabe sowie das Ende des Ephebendienstes an. Wie alle wichtigen Ereignisse im politischen und gesellschaftlichen Bereich werden auch diese mit religiösen Handlungen wie Weihungen verbunden gewesen sein. Gleiches gilt für die Agone der Epheben.

Aber auch vor Eintritt in die institutionalisierte Ephebie boten sich für die jungen Athener solche Anlässe. Zu nennen ist z.B. ein Apaturia ${ }^{685}$ genanntes Fest: Der dritte und letzte Tag dieser

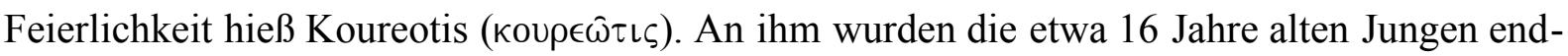
gültig in die Phratrielisten eingeschrieben. Weiter fanden Opferungen und eine in Zusammen-

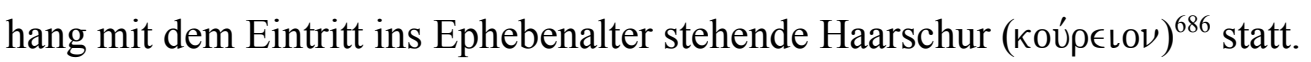

\footnotetext{
${ }^{684} \mathrm{Zu}$ Initiations- und Übergangsriten vgl. P. Vídal-Naquet, Der schwarze Jäger (1989) 105 ff. und R. Zoepffel, Geschlechtsreife und Legitimation zur Zeugung, in: Geschlechtsreife und Legitimation zur Zeugung im Alten Griechenland (Hrsg. von E.W. Müller), Veröffentlichungen des Institutes für Historische Antropologie 3 (1985) 319-402. Zu Leto, Apollon und Artemis als Initiationsgottheiten vgl. z.B. W. Burkert, Greek Cult (1985) 144 f., $151 \mathrm{f.}, 261 \mathrm{ff}$.

${ }^{685}$ Vgl. RE I (1894) 2672 ff. s.v. Apaturia (Toepffer) .- E. Samter, Familienfeste der Griechen und Römer (1901) 70 f. .- L. Deubner, Attische Feste (1932) 232 ff. .- M.P. Nilsson, Cults, Myths, Oracles, and Politics in Ancient Greece (1951) $150 \mathrm{ff}$. .- S.G. Cole, The social function of Rituals of Maturation: The Koureion und the Arkteia, ZPE 55, 1984, 233 ff. .- R. Zoepffel, Geschlechtsreife und Legitimation zur Zeugung, in: Geschlechtsreife und Legitimation zur Zeugung im Alten Griechenland (Hrsg. von E.W. Müller), Veröffentlichungen des Institutes für Historische Antropologie 3 (1985) 319-402. Die Apaturien sind nicht nur in Athen, sondern mit wenigen Ausnahmen in allen ionischen Städten nachweisbar. In anderen griechischen Landschaften erscheinen ähnliche Feste unter anderen Namen (im westgriechischen und dorischen Bereich meist Apella/Apellaia) bzw. können durch entsprechende Monatsnamen (z.B. Phratrios in der Aiolis) erschlossen werden.

${ }^{686}$ Rituelles Haarescheren am Übergang von der Kindheit zum Erwachsenenalter ist in der griechischen Welt und darüber hinaus (z.B. Ägypten) weit verbreitet (L. Grassberger, Erziehung und Unterricht im klassischen Altertum. III. Theil: Die Ephebenbildung [1881] 36 ff. .- E. Samter, Familienfeste der Griechen und Römer [1901] 71 ff. .- M.P. Nilsson, Geschichte der griechischen Religion I, HAW 5.2.1 [1941] 137). Dies bedeutet jedoch nicht, dass die Epheben die gesamte Dienstzeit über kurzgeschorene Haare trugen (wie Th. Schäfer, Andres Agathoi [1997] 153 Anm. 20 andeutet). Sie konnten ihr Haar wieder nachwachsen lassen (L. Grassberger a.a.O. 42). Entsprechend ist die bei einigen Chlamydephoren-Statuetten zu beobachtende Langhaarigkeit kein Beleg dafür, dass es sich nicht um Epheben handeln kann (Im Übrigen könnte der Zustand vor Eintritt in die Ephebie dargestellt sein.). Vielmehr deutet das zeitlich begrenzte Auftreten dieser Haartracht auf einen Frisurentyp hin. Dass diese Haarmode erstmals in der frühellenistischen Epoche nachweisbar ist, könnte auf eine Anlehnung an die Frisur
} 
Eine solche Einschreibung fand vorher schon einmal im Alter von drei bis vier Jahren ${ }^{687}$ im Rahmen des Choenfestes ${ }^{688}$ am zweiten Tag der dem Dionysos gewidmeten Anthesterien ${ }^{689}$ statt. Diesem Akt wiederum ging ein $\mu \in \hat{\imath} o \nu$ genanntes Opfer voran, das wie das koúp€เov an der Koureotis stattfand und dem Zweck diente, den Phratriegenossen die Geburt des zukünftigen Mitbürgers anzuzeigen. ${ }^{690}$

Die jungen Athener wurden jedoch nicht nur in die Listen der Phratrien eingetragen, sondern auch in die der Demen. Dies geschah im Alter von etwa 18 Jahren (Dokimasie). ${ }^{691}$

Aber auch andere Feste, die nicht direkt mit der Ephebie oder der Einführung in die Phratrien oder Demen in Verbindung standen, boten den Kindern und Jugendlichen die Gelegenheit, sich am religiösen und damit gesellschaftlichen Leben der Polis zu beteiligen: So opferten attische Epheben beispielsweise nachweisbar an einem „Galaxia“ genannten Fest zu Ehren der Göttermutter. ${ }^{692}$

\subsubsection{Die Soldaten und das Theater}

\subsubsection{Benennung}

$\mathrm{Zu}$ Beginn des 20. Jahrhunderts benannte W. Weber ${ }^{693}$ drei in Berlin befindliche Statuetten (Tk 3-4, 109, Taf. 28-29 Abb. 105, 102, 107), die dickbäuchige, männliche Personen in Chiton, Chlamys und Kausia zeigen, als makedonische Soldaten und brachte sie mit einem entsprechenden Charakter der Neuen Komödie in Verbindung. Diese Deutung setzte sich jedoch nicht durch. Die Soldaten wurden in den folgenden Jahrzehnten als dickbäuchige Kaufleute ${ }^{694}$, dickbäuchige Kinder mit Matrosenmütze ${ }^{695}$, Makedonen ${ }^{696}$ oder makedonische Knaben ${ }^{697}$ bezeichnet.

Interpretationen dieser Art sind einerseits darauf zurückzuführen, dass die Kausia teils nicht als solche erkannt wurde, und andererseits in besonderem Maße darauf, dass im Rahmen von Museumspublikationen immer nur einzelne Exemplare besprochen werden. Betrachtet man

\footnotetext{
Alexanders hindeuten bzw. ließe sich die Frisur Alexanders auch als typische Haarmode der Zeit deuten. - Das dem коúpєı $\nu$ vergleichbare Opfer für die Aufnahme der jungen Frauen in die Phratrie des Ehemannes heißt $\gamma \alpha \mu$ $\eta \lambda i \alpha$. Es wurde ebenfalls an der Koureotis vom Ehemann dargebracht (L. Deubner, Attische Feste [1932] 232234).

${ }^{687}$ L. Deubner, Attische Feste (1932) 115. 116 mit Anm.9.

${ }^{688}$ L. Deubner, Attische Feste (1932) $93.96 \mathrm{ff}$.

${ }^{689}$ L. Deubner, Attische Feste (1932) 93 ff.

${ }^{690}$ L. Deubner, Attische Feste (1932) 232-234.

${ }^{691}$ Burckhardt, Bürger und Soldaten, $53 \mathrm{ff}$.

${ }^{692}$ L. Deubner, Attische Feste (1932) 216.

${ }^{693}$ Weber, Berlin, 201 f.; diese Deutung wurde auch von E. Bayer-Niemeier, Frankfurt, 68 Nr. 24-26 im Jahre 1988 wiederaufgenommen.

${ }^{694}$ R. Pagenstecher, AA 1918, Sp. 124 Nr. 16.

${ }^{695}$ Breccia, Alexandria II 2, 43 Nr. 237.

${ }^{696}$ G. A. S. Snijder, Algemeene Gids (1937) 46 Nr. 388 .- Dunand, Paris, 212 Nr. 571 f.

${ }^{697}$ W. D. van Wijngaarden, De Grieks-egyptische Terrakotta's in het Rijksmuseum van Oudheden (1958) $19 \mathrm{Nr}$. 58 .- Fischer, Slg. Sieglin/Schreiber, $161 \mathrm{f}$.
} 
die Soldaten dagegen als Gruppe, ergibt sich folgendes Bild: Aufgrund der Kleidung, insbesondere der Kausia, lassen sich die Dargestellten der makedonischen Bevölkerungsschicht zuweisen. Zwei der Statuetten tragen einen Bart (Tk 109, 125, Taf. 29 Abb. 107, 106), es handelt sich also um Erwachsene. Dickbäuchigkeit und allgemein gedrungen-rundliche Körperformen deuten entsprechend nicht kindliche Proportionen, sondern Wohlgenährtheit bzw. Übergewicht an und bedürfen einer anderen Interpretation. Den Schlüssel hierzu bietet eine verlorene Wandmalerei aus der Casa della Fontana grande in Pompeii (Ma 12, Taf. 13 Abb. 54). Sie ist auf drei Zeichnungen überliefert. Dargestellt ist jeweils ein Mann mit Kausia, Chlamys und Chiton, der in der rechten Hand eine Lanze hält, eine Theatermaske trägt und von weiteren Schauspielern und sonstigen Bühnenpersonal umgeben ist. ${ }^{698}$ Es handelt sich demnach um einen Schauspieler in der Rolle eines Soldaten. ${ }^{699}$ Auf der Grundlage dieses Bildes hat M. Bieber ${ }^{700}$ den frühhellenistischen Soldaten aus der Kyrenaika (Tk 125) identifiziert, nachdem schon W. Weber ${ }^{701}$ das Wandgemälde zur Deutung der Terrakotten in Berlin herangezogen hatte. Dickbäuchigkeit und die teilweise zu beobachtende Waffenlosigkeit ${ }^{702}$ einiger Terrakottastatuetten sind dadurch zu erklären, dass der Soldat der Komödie weniger durch seine kriegerischen Fähigkeiten, denn durch seinen Reichtum ${ }^{703}$ und die Möglichkeit, sich und seinem aus Parasiten und Hetären bestehenden Gefolge ein Leben in Wohlstand zu ermöglichen, charakterisiert wird. ${ }^{704}$

Problematisch ist die Verbindung der Statuetten mit einem Charakter speziell der Neuen Komödie: ${ }^{705}$ Die hohe Zeit der neuen Komödie war das ausgehende vierte und beginnende dritte Jahrhundert. ${ }^{706}$ Die Terrakotten lassen sich jedoch mit Ausnahme des Exemplars aus der Kyre-

\footnotetext{
${ }^{698}$ Die gesamte Szene ist abgebildet in A. Mau, Pompeji (1908) 584 Abb. 307, die drei überlieferten Zeichnungen des Soldaten in C. Robert, Die Masken der neueren attischen Komoedie, 25. HallWPr, 1911, Abb. 7-9.

${ }^{699}$ Terrakotten, die durch dicke Bäuche und Masken als Darstellungen von Schauspielern insbesondere der Komödie gekennzeichnet sind, sich jedoch nicht eindeutig mit dem Soldaten-Charakter in Verbindung bringen lassen, treten vereinzelt auch in anderen Regionen der hellenistischen Welt auf: Vgl. Tk 371 (aus Lipari, Chlamydephoros mit bärtiger Maske und Kausia; nach L. B. Brea, Menandro e il teatro greco nelle terracotte liparesi [1981] 205 Abb. 341 ein Slave), Tk 304 (aus Delos [?], Kopf mit bärtiger Maske und Kausia; nach A. Laumonier, Delos XXIII [1956] 264 Nr. 1229 Taf. 93 ein Sklave [?]), Tk 457 (ohne Fundort in New York, mit bärtiger Maske, Kausia und kurzer Chlamys; nach B.M. Kingsley ein Soldaten-Schauspieler (B.M. Kingsley, The „Chitrali“. A Macedonian Import to the West, Afghanistan Journal 8, 1981, 91 Abb. 2 bzw. ein Silen/Schauspieler (dies., Alexander's Kausia and Macedonian Tradition, ClAnt 10, 1991, 64 mit Abb. 10 ein Soldat oder Silen).

${ }^{700}$ M. Bieber, AJA 60, 1956, 171 f. .- M. Bieber, History of Greek and Roman Theater (1961 [1. Aufl. 1939]) 99. Schon H. Walters, Catalogue of the Terracotta's in the British Museum (1903) 286. C827 hat die Statuette aus der Kyrenaika als ,actor“ bezeichnet.

${ }^{701}$ Weber, Berlin, 202 Anm. 3. Dass die Soldaten Tk 3 und Tk 109 (beide in Berlin) Schwerter halten könnten bzw. einen Schwertriemen (Tk 109) aufweisen, hat Weber nicht bemerkt.

${ }^{702}$ Aufgrund der schlechten Qualität bzw. des schlechten Erhaltungszustandes ist in der Regel schwer zu erkennen, ob und wenn ja welches Attribut die Soldatenfiguren aufweisen. In der linken Hand kann ein kugelförmiger Gegenstand erscheinen, der als Geldbeutel (Tk 54, 56 [?], 111-112 [?]) gedeutet wird, oder ein länglicher, bei dem es sich um ein Schwert (Tk 3, 8, 109 [?], 110 [?]) handeln kann.

${ }^{703}$ Einige Soldatenfiguren tragen einen (Geld-?) Beutel (Tk 54, 56 [?], 111-112 [?]).

${ }^{704}$ Vgl. z.B. den Polemon in Menander, Perikeiromene oder den Pyrgopolynikes in Plautus, Miles gloriosus.

${ }^{705}$ So Weber, Berlin, 201 f. .- M. Bieber, History of the Greek and Roman Theater (1961) 99.

${ }^{706}$ Zur Neuen Komödie vgl. RE XI (1921) 1207 ff. s.v. Komödie (Korte) .- Kleines Wörterbuch des Hellenismus (1988) 136 ff. s.v. Drama III 2. Neue Komödie (Mehrlein).
} 
naika am ehesten ins zweite bis erste Jahrhundert datieren. Die Schauspieler der Komödie traten mit Theatermasken auf, wie dies auch auf dem Wandbild aus Pompeii zu sehen ist. Sämtliche Soldatenstatuetten erscheinen ohne Maske. Ausgangspunkt der Neuen Komödie war Athen. Von dort aus verbreitete sie sich über die gesamte griechisch sprechende Welt. Die Terrakotten vom „Typus Soldat“ finden sich dagegen ausschließlich in Ägypten (einschließlich der Kyrenaika). Beseitigen lassen sich diese Widersprüche, wenn man die Soldaten nicht mit der Neuen Komödie, sondern mit dem Mimos ${ }^{707}$ in Verbindung bringt. Dieser löste die Komödie ab und hielt sich bis in spätantike Zeit. Die Schauspieler traten ohne Masken auf. Texte von wirklich aufgeführten Stücken sind nicht überliefert, vermutlich gab es vollständig ausformulierte Dialoge auch nie, sondern es wurde improvisiert. Aus erhaltenen Fragmenten des Kunstmimos lässt sich jedoch erschließen, dass die Charaktere der Neuen Komödie übernommen wurden. Themen des Mimos waren Alltagsprobleme, die von Schauspielern, die in Alltagskleidung auftraten, auf sehr derbe Weise dargestellt wurden. Es ist denkbar, dass die Hauptthemen dieser volksnahen Stücke regional variierten und dass der Charakter des Soldaten in makedonischer Kleidung sich entsprechend seiner Bedeutung in der ptolemäischen Gesellschaft in Ägypten wesentlich größerer Bedeutung erfreute als zum Beispiel in Athen.

Zusammenfassend lässt sich sagen, dass die Vertreter des „Typus Soldat“ einen Schauspieler des Mimos (in seiner ägyptischen Variante) zeigen, der einen makedonischen Soldaten spielt.

\subsubsection{Bedeutung von Heer und Theater}

Die Soldaten-Schauspieler weisen Bezüge einerseits zum Heer und andererseits zum Theater auf. Der symbolische Gehalt und die Funktion der Statuetten sind vor dem Hintergrund dieser beiden Institutionen zu sehen.

Die Heere der hellenistischen Reiche bildeten die maßgebliche Stütze der Macht der Könige. Sie verteidigten die äußeren Grenzen und sorgten für den Bestand der politischen und sozialen Ordnung im Innern. Die Armee förderte jedoch auch die Integration der aus allen Teilen der Mittelmmeerwelt und des Orients stammenden Soldaten. Diese verschmolzen während ihres Dienstes weitgehend unabhängig davon, ob sie aus Makedonien, den angrenzenden Gebieten des Balkans, der griechischsprachigen Welt, Kleinasien, Persien oder Ägypten stammten, zu den „Hellenen“708, der staatstragende Gruppe der Bevölkerung der hellenistischen Reiche.

Das Theater der spät- und nachklassischen Zeit wird oft als Ort reiner Unterhaltung angesehen. ${ }^{709}$ Dies trifft nur in eingeschränktem Umfang zu. Das spätklassisch-hellenistische Theater

\footnotetext{
${ }^{707}$ Zum Mimos vgl. M. Bieber, Die Denkmäler zum Theaterwesen im Altertum (1920) 175 ff. .- RE XV (1932) 1727-64 s.v. Mimos (Wüst) .- H. Wiemken, Der griechische Mimos (1972) .- Kleines Wörterbuch des Hellenismus (1988) 141 ff. s.v. Drama V. Mimos (Mehrlein).

${ }^{708} \mathrm{Zu}$ den „Hellenes“ vgl. oben das Kapitel „Die ,Makedones“ - eine ,ethnische“ Gruppe“ und dort insbesondere die Verweise auf D.J. Thompson, Hellenistic Hellenes. The Case of Ptolemaic Egypt, in: I. Malkin (Hrsg.), Ancient Perceptions of Greek Identity, Center of Hellenic Studies colloquia 5 (2001) $301 \mathrm{ff}$.

${ }^{709}$ So z.B. F. Kolb, Polis und Theater, in: Das griechische Drama (Hrsg. von G.A. Seeck) (1979) 517, der von einer „Loslösung der Drameninhalte von der Polis“, einer Entwicklung vom „kultischen Ritual zum Unterhaltungsstück“ und dem Theater ,,als Mittel der Unterhaltung“ spricht. Grundlage dieser Deutung ist vielleicht die
} 
hatte zwar wie die meisten politisch und religiös bedeutsamen Veranstaltungen neben religiösen und politischen Aspekten auch eine unterhaltsame Komponente. Dies gilt jedoch ebenso für das Theater der vorausgegangenen Epochen. Was den Wandel (in Form und Inhalt) betrifft, so war dieser erst in zweiter Linie einer des Theaters. Zuerst änderten sich die politischen und gesellschaftlichen Rahmenbedingungen: In Athen konnte es nach dem verlorenen Peloponnesischen Krieg, dem Verlust der Seeherrschaft und dem Aufstieg der Diadochenreiche nicht mehr um die Darstellung attischer Großmachtpolitik bzw. daraus resultierender innenpolitischer Folgen und Ziele gehen. Athen sank zu einer Mittelmacht ab, die Voraussetzungen der Politik wie auch die Wünsche und Ängste der Bürger änderten sich. Das Theater folgt diesem Wandel. ${ }^{710}$ Gerade hierin ist ein Zeichen der festen Verwurzelung in einer lebendigen, sich weiterentwickelnden Gesellschaft zu sehen. Im Gegenteil wäre gerade ein Festhalten an alten Formen und Inhalten ${ }^{711}$ unter veränderten politischen und gesellschaftlichen Bedingungen ein Hinweis auf die Loslösung eines jetzt apolitischen Theaters von der Polis gewesen. ${ }^{712}$

Funktion und Bedeutung des Theaters entsprechen in leicht abgeschwächter Form der des Gymnasions. ${ }^{713}$ Das Theater gehörte, wie das Gymnasion, zur Grundausstattung einer hellenistischen Stadt. ${ }^{714}$ Es diente der Erziehung der Jugend und vielleicht auch der Hellenisierung der umwohnenden, nicht griechischen Bevölkerung. Im Theater versammelte und feierte ${ }^{715}$ sich die Gemeinschaft. Wie jede griechische Gemeinschaftseinrichtung besaß auch das Theater eine religiöse Komponente, die im wiederum gemeinschaftsstiftenden Vollzug des (Dionysos-) Kultes bestand..$^{716}$

vermeintliche Ähnlichkeit spätklassisch-hellenistischer Stücke mit dem modernen Schauspiel, und eine Übertragung ihres teils apolitischen Charakters auf antike Verhältnisse. Kolb betont aber zugleich, dass „die Verbindung des Theaters mit Polis und Religion in der griechischen Welt erhalten“ blieb und „das Theater zu einem charakteristischen Bestandteil der hellenistischen Polis und wichtigen Faktor im Hellenisierungsprozess" werden konnte (Kolb a.a.O. 517).

${ }^{710}$ Vgl. K. Treu, Zur Wirkungsgeschichte in der Antike, in: Die griechische Tragödie in ihrer gesellschaftlichen Funktion (Hrsg.: H. Kuch), Veröffentlichungen des Zentralinstituts für Alte Geschichte und Archäologie der Akademie der Wissenschaften der DDR 11 (1983) 201-216, der auch in den „ständigen Umbauten“ einen Beleg dafür sieht, dass „,das Theater eine lebendige Äußerung des gesellschaftlichen Lebens blieb und dessen Wandlungen mitmachte“ (Treu a.a.O. 206). Die Neuere Komödie und Menander könnten als „,nach Form und Inhalt“ in der Tradition „des Euripides“ stehend betrachtet werden. Sie würde ein Höchstmaß an „Lebensechtheit“ aufweisen (Treu a.a.O. 207). Auch die niederen Formen des Theaters zeigten bis in die Spätantike „Lebenskraft“ (Treu a.a.O. 214).

${ }^{711}$ Das überwiegend mythologische Gewand der Älteren Tragödie und teilweise auch der Älteren Komödie ist Folge der Herkunft des Theaters aus dem religiösen Bereich. Das Eindringen alltäglich-zeitgenössischer Menschen beginnt schon in klassischer Zeit (Euripides) und ist an sich kein Hinweis auf Entpolitisierung o.ä.

${ }^{712}$ Dem widerspricht auch die Wiederaufführung einzelner Werke der Klassiker im Vorfeld spätklassisch-hellenistischer Theateragone nicht, da sie nicht den Kern der Veranstaltung ausmachten. Der sehr fragmentarische Überlieferungszustand der spät- und nachklassischen Theaterstücke spiegelt nicht ihre politisch-gesellschaftliche Bedeutung für die Zeitgenossen, sondern die anders begründeten Vorlieben nachfolgender Epochen.

${ }^{713}$ Vgl. M. Hadas, Hellenistische Kultur (1981) 52 f.

${ }^{714}$ Pausanias 10, 4, 1.

${ }^{715}$ A. Chaniotis, Sich selbst feiern? Städtische Feste des Hellenismus im Spannungsfeld von Religion und Politik, in: Stadtbild und Bürgerbild. Kolloquium München 1993. M. Wörle - P. Zanker (Hrsgg.) (1995) 147 ff. 
Die Wirkung des Heeres und des Theaters in der Gesellschaft der hellenistischen Reiche ist demnach der des Gymnasions vergleichbar.

\subsubsection{Die Reiter und der (Herrscher-) Kult}

In diesem Kapitel wird zunächst auf die ptolemäischen Reitertypen („Reiter ohne Gegner“, „Reiter über Gegner“, „Reiter über Schild“) eingegangen. Hierunter verstehe ich diejenigen Typen, die sich fast ausschließlich im ptolemäisch-ägyptischen Kernland, den ptolemäischen Außenbesitzungen und Gebieten im ptolemäischen Einflussbereich finden. Im Anschluss werden die handgeformten Reiterstatuetten aus dem südlichen - damals seleukidischen - Zweistromland besprochen. Die unterschiedlichen Reitertypen des nordsyrisch-nordmesopotamischen Bereiches sind teils analog zu den ptolemäischen Reitern ohne Gegner, teils analog zu den südmesopotamischen Reitern zu deuten, teils stehen sie in anderen regionalen und/oder persischen Traditionen ${ }^{717}$. Über die genannten Beispiele hinaus erscheinen Reiterstatuetten mit Kausia in der hellenistisch-parthisch-römischen Welt nur äußerst selten (Tk 343 [Chersones/Sewastopol]).

Abschließend wird auf die Symbolik und Funktion sowohl der ptolemäischen als auch der orientalisch-seleukidischen Reitertypen eingegangen.

\subsubsection{1 „Reiter ohne Gegner“6}

Bei den Reitern ohne Gegner (Taf. 30 Abb. 111-112) handelt es sich - wie bei allen Reiterstatuetten aus dem ptolemäischen Bereich - letztlich um reitende Chlamydephoren: Wie diese tragen sie neben einem Untergewand (Chiton) und den nur selten erkennbaren Stiefeln eine Chlamys und eine Kopfbedeckung. Wie die stehenden und sitzenden Chlamydephoren aus Ägypten weisen auch die Reiter aus dem ptolemäischen Raum - und aus diesem stammen fast alle Reiter aus dem mediterranen Bereich - als Kopfbedeckung die Kausia auf. Diese kennzeichnet die Reiter als Makedonen bzw. als in einem makedonischen Kontext befindlich.

In den reitenden Chlamydephoren, die keine weiteren Attribute aufweisen („Typus Reiter ohne Gegner" $)^{718}$, sind analog zu den stehenden Chlamydephoren junge ${ }^{719}$ „Makedonen“ zu

\footnotetext{
${ }^{716}$ Zum sowohl architektonischen als auch funktionalen Zusammenhang von Orchestra und Agora und damit Theater (und Dionysoskult) und Politik seit frühgriechischer Zeit vgl. F. Kolb, Polis und Theater, in: Das griechische Drama (Hrsg.: G.A. Seeck) (1979) 504 ff. .- ders., Agora und Theater, Volks- und Festversammlung, AF 9 (1981).

${ }^{717}$ Vgl. oben das Kap. „Mediterran-orientalische Mischformen“.

${ }^{718}$ Es handelt sich um Tk 58-61 (Alexandria/Sciatbi), Tk 105 (Athribis), Tk 394 (aus der ptolemäischen Garnison beim modernen Ibn Hani nahe dem seleukidischen Laodikeia am Meer/Syrien) sowie Tk 138 (Troas), Tk 185 (Lesbos?), Tk 307-308 (Korinth). Die Troas, Lesbos und Korinth gehörten zur nicht direkt zum Ptolemäerreich, lagen jedoch zur betreffenden Zeit (Mitte 3. Jh. v.Chr.) im ptolemäischen Einflussbereich, worin die im ägäischen Raum untypische Darstellung von Reitern mit Kausia begründet sein könnte.

${ }^{719}$ Lockenfrisur und rundliches Gesicht der „Reiter ohne Gegner“ sind ebenfalls mit denen der gleichzeitigen alexandrinischen Chlamydephoren vergleichbar. Ähnliche Locken und Gesichtsformen erscheinen aufgrund geringer zeitlicher oder regionaler Differenzen in teils leicht veränderter Form auch bei den Reitern über Gegner bzw. Schild, die aufgrund des Gegners bzw. des den Gegner symbolisierenden Schildes eindeutig im Kampf dar-
} 
sehen. Da die Ausbildung im Rahmen der Ephebie auch das Reiten umfasste, ${ }^{720}$ kann es sich um Wiedergaben reitenden Epheben handeln, aber auch um die Darstellungen ptolemäischer Kavalleristen. Dem muss nicht widersprechen, dass die „Reiter ohne Gegner“ unbewaffnet wiedergegeben werden und daher nicht eindeutig als Soldaten identifizierbar sind. Denn auch die auf alexandrinischen Grabstelen (Ma 1-2, Taf. 13 Abb. 53, Taf. 11 Abb. 50) gezeigten Soldaten können als Chlamydephoren dargestellt werden und sind als Militärs nur aufgrund der von einem Diener getragenen Ausrüstung erkennbar.

Die Darstellung als Reiter beinhaltet darüber hinaus einen Hinweis auf die gehobene soziale Stellung der wiedergegebenen Person. Denn der Dienst in der ptolemäischen Reiterei hatte die Zuteilung eines im Vergleich zu den Fußtruppen größeren Landloses und einen zugehörigen gesellschaftlichen Status zur Folge. ${ }^{721}$

Vertreter des „Typus Reiter ohne Gegner“ wurden wie auch solche stehender und sitzender Chlamydephoren-Typen in Gräbern ${ }^{722}$ gefunden, was für eine ähnliche Bedeutung und Funktion sprechen könnte.

\subsubsection{2 „Reiter über Gegner/Schild“}

Bei den übrigen ptolemäischen Reitertypen („Reiter über Gegner“/,Reiter über Schild“, Taf. 30-31 Abb. 111-114, 118) ${ }^{723}$ weisen die Reiter selbst ebenfalls keine Attribute auf. Da diese Reiter jedoch mit den Gegnern bzw. den für diese stehenden Schilden eine Gruppe bilden, bieten sich neue Deutungsansätze. Das Niederreiten des Knienden kann nur als Tötung verstanden werden. Es handelt sich jedoch nicht um die Wiedergabe einer realistischen Kampfhandlung, denn der Reiter ist unbewaffnet. Gegen eine Kampfhandlung sprechen auch die

gestellt sind. Dies weist darauf hin, dass es sich auch bei den frühen Reitern ohne Gegner/Schild um Krieger handeln kann und Haartracht und ähnliches nicht das kindlich-jugendliche Alter des Dargestellten wiedergeben, sondern die bei jungen Männern bis zum Ende des dritten Jahrhunderts und dann wieder seit etwa Mitte des ersten Jahrhunderts vor Christus übliche Haarmode. Vgl. hierzu die schon in Verbindung mit den Chlamydephoren beobachtete Entwicklung der Frisuren von lockig-lang (4. - 3. Jh. v.Chr.) über kurz (2. -1. Jh. v.Chr.) zu lockiglang-,,dädalisch“ (1. Jh. v. - 2. Jh. n. Chr.). Vgl. Taf. 22 Abb. 81.

${ }^{720}$ Reitübungen gehörten zur attischen Ephebie (RE V [1905] 2739 s.v. ${ }^{\prime} \phi \eta \beta i ́ \alpha$ [Thalheim] .- G.R. Bugh, The Horsemen of Athens [1988] 184 ff. .- Th. Schäfer, Andres Agathoi [1997] 153 f.). Da die ptolemäische Armee zu einem Drittel aus der Kavallerie bestand (Athenaios 5, 203 a) und die Ephebie auf den Militärdienst vorbereitete, ist davon auszugehen, dass auch die ptolemäischen Epheben das Reiten lernten.

${ }^{721}$ Die Größe der Landlose schwankte im ptolemäischen Ägypten von Gau zu Gau. Reiter erhielten in der Regel 100 oder 80 Aruren $\left(1\right.$ Arure $\left.\sim 2756 \mathrm{~m}^{2}\right)$, einfache Soldaten 40 oder 30 Aruren. Im 2. Jh. v.Chr. wurden an (ägyptischstämmige?) „Machimoi“ auch wesentlich kleinere Kleroi vergeben (7/5 Aruren). Vgl. F. Uebel, Die Kleruchen Ägyptens unter den ersten sechs Ptolemäern, AbhBerlin (Klasse f. Sprache, Literatur u. Kunst), 1968/3, 32 ff. 378 ff. Auch im Seleukidenreich waren die Landlose der Reiter größer als die der Fußsoldaten (RE

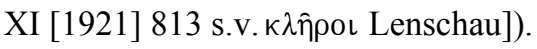

722 „Reiter ohne Gegner“ in Gräbern: Tk 58-60 (Sciatbi-Nekropole).

${ }^{723}$ Die „Reiter über Gegner“ stammen aus „Ägypten“ (Tk 9-20), Alexandria (Tk 62-64), Sais (Tk 95-96), Thmuis (Tk 97 a-b), Naukratis (Tk 102a-b), Athribis (Tk 106-107), Kom-el-Ahdar (bei Bubastis?) (Tk 118-119) und dem Faijum (Tk 114-116). Das einzige Exemplar dieses Typus, das nicht in Ägypten gefunden wurde, stammt aus Voiron (Tk 372) in den französischen Alpen und ist vielleicht als Mitbringsel eines in ptolemäischen Diensten stehenden gallischen Söldners zu verstehen. - Sämtliche Vertreter des „Typus Reiter über Schild“ (Tk 21-24) wurden in „Ägypten“ entdeckt. 
Körperhaltung und das Verhalten des Knienden. Obwohl er vornüber zu kippen droht, stützt er sich nicht mit den Händen ab. Er versucht aber auch nicht, den von hinten angreifenden Reiter abzuwehren und sich z.B. durch Anheben der Arme vor den Hufen des Pferdes zu schützen. Die Arme werden stattdessen eng am Körper anliegend gezeigt. Die Handgelenke scheinen die Unterschenkel bzw. Fußgelenke zu berühren. Stricke oder Ketten sind nicht zu erkennen, können jedoch einst in Malerei angegeben gewesen sein. Eine Fesselung der Hände an die Füße würde die Körperhaltung sowie die Passivität des Knienden erklären. Es handelt sich weniger um einen Kampf, als um eine Hinrichtung oder Opferung. Aber auch eine solche Handlung geben die Statuetten nicht in realistischer Weise wieder. Es ist daher von einem symbolischen Gehalt auszugehen. Da es für Darstellungen dieser Art keine griechischen Vorbilder gibt und mit einer Ausnahme alle Vertreter dieser Typen auf dem Gebiet des ptolemäischen Reiches gefundenen wurden, ist eine Entstehung des Motivs in Ägypten und ein Bezug zu Ägypten anzunehmen.

Ein sehr ähnliches Darstellungsschema findet sich auf ägyptischen Reliefs seit den Anfängen der dortigen Kultur immer wieder. ${ }^{724}$ Es zeigt jeweils den stehenden Pharao und vor diesem einen geschlagenen Feind. Dieser kniet mit vom Pharao abgewandtem Gesicht und auf dem Rücken zusammengebundenen Händen. Der Pharao hält mit der einen Hand eine Lanze, mit der er auf den Gefangenen einsticht, und in der anderen Hand das Ende des Seiles, an dessen anderem Ende sich der Gefesselte befindet. Entsprechende ägyptische Reliefs unterscheiden sich von den hellenistischen Terrakotten im Stil, in der Kleidung und im Vorhandensein von Bewaffnung ${ }^{725}$ sowie in der Art der Fortbewegung. ${ }^{726}$ Die Unterschiede sind in abweichenden Darstellungstraditionen und -konventionen begründet. Das eigentliche Schema ist jedoch identisch (Taf. 31 Abb. 115-117).

\footnotetext{
${ }^{724}$ Eines der frühesten Beispiele ist z.B. zu sehen auf der „Palette des Narmer“ aus der Zeit der 0. Dynastie (um 3100 v.Chr.) in Kairo, Ägyptisches Museum, JE 32169 (CG 14716), aus Hierakonpolis. Abgebildet u.a. in: E. Hornung, Der Eine und die Vielen (1971) 97 Abb. 9 .- R. Schulz - M. Seidel (Hrsgg.), Ägypten - Die Welt der Pharaonen (1997) 29 Abb. 39. Vergleichbare Darstellungen finden sich durch die Jahrtausende immer wieder.

${ }^{725}$ Der markanteste Unterschied zwischen den rein ägyptischen Darstellungen des Pharaos und den ptolemäischen Reitern besteht in der Waffenlosigkeit der Reiter, mit der die Mühelosigkeit des Sieges ausgedrückt wird. Die altäyptischen Pharaonen werden zwar immer mit der Lanze wiedergegeben, mit der sie ihre Opfer niederstechen. Die Mühelosigkeit des Sieges bzw. der Tötung wird jedoch auch in den altägyptischen Darstellungen zum Ausdruck gebracht: Der Pharao erscheint weitgehend bewegungslos, der Gegner kniet und wehrt sich nicht. Sollte dagegen der dem Sieg vorausgehende Kampf gezeigt werden, wurde der Pharao bewegt dargestellt, der Gegner in Abwehrhaltung. (Vgl. z.B. ein Etikettentäfelchen aus der Zeit 1. Dynastie, um 2900 v.Chr., in London, The British Museum, EA 55586, aus Abydos. Abgebildet in: R. Schulz/M. Seidel [Hrsgg.], Ägypten - Die Welt der Pharaonen [1997] 34 Abb. 50).

${ }^{726}$ Die Reiterei war im Alten Ägypten mit Ausnahme von Perioden der Fremdherrschaft (Hyksos- und Perserzeit) nur von untergeordneter Bedeutung (Vgl. S. Lewis, The Iconography of the Coptic Horseman in Byzantine Egypt, JARCE 10, 1973, 32 ff.). Der Pharao wurde daher gemäß der landestypischen Kampfesweise als Infanterist oder Wagenkämpfer wiedergegeben. Das Heer Alexanders dagegen bestand zu 10-15\% aus Reiterei (Vgl. P. A. Brunt, Alexander's Macedonian Cavalry, JHS 83, 1963, 23 ff. [Tabellen S. 39, 46].), die ptolemäische Armee zu einem Drittel (Athenaios 5, 203a). Gestellt wurde die Kavallerie meist von Angehörigen der Oberschicht. Die Wiedergabe als Reiter war demnach einem makedonischen bzw. ptolemäischen König angemessen (Vgl. A. Stewart, Faces of Power - Alexander's Image and Hellenistic Politics [1993] Abb. 21. 25 ff. 52 .- H. Kyrieleis, Bildnisse der Ptolemäer [1975] Taf. 10,1 [Ptolemaios II.]).
} 
Genutzt wird dieses Schema einerseits zur Darstellung des Sieges des Pharaos über seine Feinde und andererseits zur Wiedergabe des Sieges des Gottes Horus über seinen Widersacher Seth, wobei der Pharao nach ägyptischen Vorstellungen als irdisches Abbild des Gottes anzusehen ist. Entsprechende Darstellungen in rein ägyptischem Stil finden sich auch in hellenistischer Zeit, in der die Ptolemäerkönige die Stelle der Pharaonen einnehmen. ${ }^{727}$

Es handelt sich bei den Terrakotten vom „Typus Reiter über Gegner“ daher mit einiger Sicherheit entweder um die teilgräzisierte Fassung der Darstellung des Sieges des ägyptischen Gottkönigs über seine irdischen ${ }^{728}$ und göttlichen Gegner ${ }^{729}$ oder umgekehrt um die Einbindung ägyptischer Schemata in die Ikonographie einer griechischen Reiterstatuette. Da unbekannt ist, ob die Terrakotten in einer ägyptischen oder einer griechischen Werkstatt entstanden oder etwa in einer ägyptischen Werkstatt für Kleruchen gemacht wurden, kann derzeit nicht entschieden werden, welche Seite bei der anderen Anleihen machte. Eindeutig ist, dass Übernahmen stattfanden: Griechisch bzw. hellenistisch-makedonisch-ptolemäisch sind jeweils die Kleidung sowie das Reiten bzw. die Wiedergabe des Herrschers zu Pferde. ${ }^{730}$ Ägyptisch sind

\footnotetext{
${ }^{727}$ Vgl. z.B. das Relief auf dem Gedenkstein von al-Nibeira (Taf. 31 Abb. 115) mit dem Priesterdekret von Memphis (Text auch auf dem Stein von Rosette wiedergegeben) aus dem Jahr 195 v.Chr. (Ptolemaios IV.). Zu sehen sind (v.l.n.r.) acht ägyptische Gottheiten, ihnen gegenüber der Pharao Ptolemaios (in ägyptischer Tracht, mit Doppelkrone), der auf eine vor ihm kniende gefesselte Person einsticht (G. Roeder, Die ägyptische Religion in Texten und Bildern. Bd. 3: Kulte, Orakel und Naturverehrung im alten Ägypten [1960] 167 ff. Taf. 11). - Oder die unter Ptolemaios X. (um 100 v.Chr.) entstandenen Darstellungen auf der Innenwand des westlichen Armes der Umfassungsmauer des ptolemäischen Neubaus des Tempels von Edfu. Eines der Bilder (Taf. 31 Abb. 116) zeigt (v.l.n.r.) den Pharao Ptolemaios (in ägyptischer Kleidung und mit ägyptischer Krone), der mit der Lanze einer kleinen Person in den Rücken sticht, die gefesselt vor ihm kniet. Ihm gegenüber steht der falkenköpfige Horus (mit ägyptischer Doppelkrone), der mit einer Lanze auf ein kleines Nilpferd (Seth) einsticht. Hinter ihm ist die Göttin Isis zu sehen (G. Roeder, Die ägyptische Religion in Texten und Bildern. 2. Mythen und Legenden um ägyptische Gottheiten und Pharaonen [1960] 145 Abb. 28).

${ }^{728}$ Es ist versucht worden, die knienden Gefangenen als Gallier (A. J. Reinach, Les Galates dans l'Art Alexandrin, MontPiot 18, 1910, 103 mit Anm. 1) oder Afrikaner (Fischer, Slg. Sieglin/Schreiber, 387 Nr. 995 f.) zu identifizieren.

${ }^{729}$ Eine Zwischenstufe - nicht im chronologischen Sinne, sondern im Sinne einer geringeren Gräzisierung - stellt eine Wiedergabe Ptolemaios IV. auf einem Gedenkstein in Kairo, Ägyptisches Museum Nr. C.G. 31088 dar (Taf. 31 Abb. 117). Der König wird auf einem springenden Pferd gezeigt und sticht mit einer langen Lanze auf einen (weggebrochenen) Gegner ein. Die Darstellung des Herrschers auf dem Pferd entspricht griechischer Tradition, der Stil, die Tracht (einschl. Krone) und die Beschriftung (Hieroglyphen) sind ägyptisch gehalten (K. Parlasca, Pseudokoptische „Reiterheilige“, in: G. Koch [Hrsg.], Studien zur spätantiken und frühchristlichen Kunst und Kultur des Orients, Göttinger Orientforschungen II 6 [1982] 23 [mit Anm. 3] Taf. 11, 2 .- H. P. Laubscher, Ptolemäische Reiterbilder, AM 106, 1991, 226 ff.).

${ }^{730}$ Auf die Möglichkeit des Einflusses verschiedener griechischer Reiter- und Heroenkulte (z.B. Dioskuren) sowie reitender Götter (z.B. Eros: Besques, Paris IV-II, Taf. 7. D 4201 ff.) und insbesondere der im thrakisch-danubischen Raum weit verbreiteten Kulte reitender Gottheiten (z.B. Heron: Breccia, Alexandria I, 110 ff. Taf. 54) auf die Ikonographie der Reiterstatuetten und des Horus als Reiter allgemein gehe ich hier nicht weiter ein. Vgl. hierzu z.B. S. Lewis, The Iconography of the Coptic Horseman in Byzantine Egypt, JARCE 10, 1973, 27 ff. .- K. Parlasca, Pseudokoptische „Reiterheilige“, in: G. Koch (Hrsg.), Studien zur spätantiken und frühchristlichen Kunst und Kultur des Orients, Göttinger Orientforschungen II 6 (1982) 19 ff. .- E. Bayer-Niemeier, Harpokrates zu Pferde und andere Reiterdarstellungen des hellenistisch-römischen Ägyptens, StädelJb N.F. 10, 1985, 27 ff. .Fischer, Slg. Sieglin/Schreiber, Nr. 624-29. Eine solche Einflussnahme ist sehr wahrscheinlich, widerspricht meiner Deutung jedoch nicht.
} 
der kniende Gegner ${ }^{731}$ und die Gesamtbedeutung der Gruppe. Eine Neuschöpfung ${ }^{732}$ der Alexanderzeit oder der frühptolemäischen Zeit, die altägyptisches Gedankengut durch griechische Stilmittel zum Ausdruck bringt, ist möglicherweise die Darstellung des mühelosen Sieges durch Weglassen der Waffen. ${ }^{733}$

Es lässt sich demnach die Übernahme formaler Elemente aus dem jeweils anderen Kulturkreis beobachten. Die Übernahme auch der Inhalte muss nicht mit dieser einhergegangen sein. Für die Verständlichkeit des Inhaltes („Der König siegt über die realen Gegner wie der Gott über die mythischen Feinde.") durch Angehörige beider Kulturen spricht jedoch, dass sich ähnliche Phänomene sowohl in überwiegend ägyptisch als auch in überwiegend griechisch gehaltenen Beispielen wahrscheinlich machen lassen.

Der „Typus Reiter über Gegner“ umfasst grundsätzlich die Darstellung sowohl des Königsgottes Horus als auch des Pharaos bzw. Königs, da dieser nach ägyptischer Vorstellung als irdische Ausprägung des Gottes aufzufassen ist. Dennoch besteht die Möglichkeit, den einen oder den anderen Aspekt stärker zu betonen. So existieren Terrakotten aber auch Reliefs hellenistischer bis spätantiker Zeit, die den Reiter durch entsprechende Attribute oder die Wiedergabe mit Falkenkopf eindeutig als Horus bzw. Harpokrates (= Horus als Kind) kennzeichnen. ${ }^{734}$ Dass bei den kausiatragenden Reitern auf solche Hinweise verzichtet wird, deutet auf

\footnotetext{
${ }^{731}$ Bei den „Reitern über Schild“ ist der kniende Gegner durch einen Schild ersetzt. Die Darstellung ist in diesem Sinne in stärkerem Umfang gräzisiert. Die Gesamtdeutung bleibt jedoch identisch. Hierauf deutet auch hin, dass in der Koroplastik vereinzelt Wiedergaben des reitenden Horus (eindeutig gekennzeichnet z.B. durch Topf unter dem Arm, Finger am Mund und ägyptische Krone) erscheinen, die diesen über einen Schild hinwegsprengend zeigen (Breccia, Alexandria II 2, 29 Nr. 123 Taf. 13,52 .- Besques, Paris IV-II, 107 Taf. 66 b), sowie dass (die von der Ikonographie Alexanders beeinflussten) Darstellungen koptischer Reiterheiliger als Gegner oder Beute wahlweise Menschen, Tiere oder Schilde bieten (S. Lewis, The Iconography of the Coptic Horseman in Byzantine Egypt, JARCE 10, 1973, 55 f. Abb. [im Tafelteil] 1-16 [Schilde s. Abb. 1-2, 14]).

${ }^{732}$ Neuschöpfungen im Sinne von Darstellungen, die sich nicht direkt auf ein griechisches oder altägyptisches Vorbild zurückführen lassen, sind in der ptolemäerzeitlichen Kleinplastik öfter zu beobachten. Vgl. zu (in den kultischen Bereich gehörenden) Zwergenstatuetten und Harpokratesfigürchen mit überdimensionalem Phallos J. Fischer, Der Zwerg, der Phallos und Harpokrates, in: H. Felber - S. Fisterer-Haas (Hrsgg.), Ägypter - Griechen Römer. Begegnungen der Kulturen, Kanobos 1 (1999) 31 f. 35.37 f. und zu den sog. ,ptolemäischen Ringergruppen“ die Anm. am Ende dieses Kapitels.

${ }^{733}$ Schon das Reiterstandbild für Alexander als Ktistes (Stadtgründer) von Alexandria zeigte den Herrscher ohne Angriffswaffen und nur teilweise mit Defensivwaffen (Brustpanzer, Beinschienen, aber ohne Helm) ausgestattet. Dies ist auch darauf zurückzuführen, dass Alexander nicht als militärischer Eroberer, sondern als ziviler Stadtgründer dargestellt wird, wurde aber - schon oder noch - in der Spätantike damit in Verbindung gebracht, dass Alexander einen Helm nicht nötig habe (Ps.-Libanios = Nikolaos Rhetor, Progymnasmata 27, 3; vgl. A. Stewart, Faces of Power [1993] 397 ff. [Text und Übersetzung]). - Weitgehend unbewaffnet reiten noch die (ikonographisch von Alexander abhängigen) koptischen Reiterheiligen in die Schlacht bzw. zur Jagd (S. Lewis, The Iconography of the Coptic Horseman in Byzantine Egypt, JARCE 10, 1973, 30. 34. 51).

${ }^{734}$ Terrakottastatuetten des Horus/Harpokrates zu Pferde mit ägyptischer Krone, Finger im Mund o.ä. finden sich in großer Zahl in den einschlägigen Terrakottakatalogen (z.B. Fischer, Slg. Sieglin/Schreiber, Taf. Nr. 624 ff. 65 ff.). Darstellungen auf Steinschälchen, im Relief und in Form eines steinernen Fenstergitters (Horos [mit Falkenkopf] reitet über ein Krokodil und sticht dieses mit der Lanze nieder) sowie seltenere koroplastische Typen sind zusammengestellt bei S. Lewis, The Iconography of the Coptic Horseman in Byzantine Egypt, JARCE 10, 1973, 27-63 Abb. 32 ff. und K. Parlasca, Pseudokoptische „Reiterheilige“, in: G. Koch (Hrsg.), Studien zur spätantiken und frühchristlichen Kunst und Kultur des Orients, Göttinger Orientforschungen II 6 (1982) 19-27 Taf. 10 ff. -An dieser Stelle sei angemerkt, dass Darstellungen reitender ägyptischer Gottheiten von der Forschung bisher in
} 
eine Betonung des irdischen Aspektes hin. Dass der irdische König nicht klar als solcher gekennzeichnet wird, kann darauf zurückgeführt werden, dass die Gruppe für den Zeitgenossen auch so eindeutig identifizierbar war. ${ }^{735}$ Es besteht auch die Möglichkeit, dass z.B. ein um die Kausia gewundenes Diadem, das den König eindeutig gekennzeichnet hätte, heute nicht mehr vorhanden ist, ursprünglich jedoch in Malerei angegeben war. In zwei Fällen ${ }^{736}$ lassen sich rote Farbspuren auf der Kausia beobachten. Diese können als Reste einer purpurnen Farbgebung verstanden werden, wie sie für die Kausia des Herrschers zu erwarten ist. Da sich jedoch bei 90\% der Terrakotten vom „Typus Reiter über Gegner“ die ursprüngliche Farbgebung nicht mehr ermitteln lässt und rote Farbe vereinzelt auch an den Kausien stehender und sitzender Chlamydephoren ${ }^{737}$ zu beobachten ist, obwohl es sich bei diesen sicher nicht um Darstellungen von Königen handelt, muss die Rotfärbung der Reiterkausien nicht zwangsläufig mit der purpurfarbenen Tracht der Könige in Verbindung stehen.

Bei der Kleidung des Reiters handelt es sich um die eines Makedonen, und sie ist vollständig. Weder wird diese durch ägyptische oder griechische Elemente (z.B. den Petasos) noch durch das Weglassen einzelner Kleidungsstücke verunklärt. Hieraus kann geschlossen werden, dass es von Bedeutung gewesen ist, dass es sich bei dem dargestellten Herrscher um einen Make-

aller Regel in späthellenistische bis spätantike Zeit datiert werden - und dies mit einem deutlichen Schwerpunkt in der Spätantike (A.M. Jones, The Equestrian Motive in the Coptic Textiles [1974] 62 .- F. Dunand, Religion Populaire en Egypt romaine. Les terres cuites isiaques du Musée du Caire, Etudes préliminiaire aux religions orientales dans l'empire romaine 76 [1979] 81). Gleiches galt bisher auch für die Statuetten vom „Typus Reiter über Gegner/Schild“ und dies wurde u.a. mit Überlegungen zum Stil begründet (E. Bayer-Niemeier, Harpokrates zu Pferde und andere Reiterdarstellungen des hellenistisch-römischen Ägyptens, StädelJb N.F. 10, 1985, 36). Gegen solche Fehldatierungen, die zu einer Einordnung der Objekte in einen unzutreffenden politischen, gesellschaftlichen und religiösen Kontext führten, wandte sich schon K. Parlasca (K. Parlasca, Pseudokoptische „Reiterheilige“, in: G. Koch [Hrsg.], Studien zur spätantiken und frühchristlichen Kunst und Kultur des Orients, Göttinger Orientforschungen II 6 [1982] 19-27) und datierte z.B. das Fenstergitter (Louvre X 5130; reitender Horus über Krokodil) in die mittlere Kaiserzeit statt ins 4.-6. Jh. n.Chr., ohne sich hiermit durchsetzen zu können (anders wieder E. Bayer-Niemeier a.a.O. 37). Die stratigraphisch abgesicherte Datierung der „Reiter über Gegner“ ins 4./3. Jh. v.Chr. statt ins 3./4. Jh. n.Chr. belegt, wenn die Deutung als Gottkönig/Königsgott zutrifft, die Existenz von Darstellungen reitender Götter in Ägypten seit frühhellenistischer Zeit und stützt die auch den ikonographischen Kontext einbeziehenden Frühdatierungen Parlascas. Sie wirft aber auch ein ungünstiges Bild auf eine Art und Weise der Datierung, die stilistische Merkmale nicht nur zur relativen Datierung nutzt, sondern anhand des Stils absolut und auch gegen den politischen, gesellschaftlichen und politischen Kontext datieren möchte.

${ }^{735}$ Für den modernen Betrachter sind zur Identifizierung einer aus dem Kontext gerissenen Darstellung meist Attribute o.ä. erforderlich. Der antike Betrachter kann die notwendigen Informationen auch aus dem Aufstellungskontext gezogen haben.

${ }^{736}$ Eine rote Kausia weisen die „Reiter über Gegner“ Tk 12 (aus „Ägypten“, in Tübingen) und Tk 102a-b (Naukratis) auf.

${ }^{737}$ Rote Kausien finden sich auch in Verbindung mit den Chlamydephoren Tk 46 (Alexandria/Sciatbi, ,rosa“), Tk 123 (Kyrenaika), Tk 145 („,südliche Aiolis“) und Tk 353 (Rom, mit Syrinx). Die Kausia einer Frauenstatuette aus Tarent (Tk 363) ist magentafarben. Zwei Köpfchen aus der „südlichen Aiolis“ (Tk 151) bzw. von der ,,ionischen Küste“ (Tk 169) weisen ebenfalls rote Kausien auf. Diese Figuren sind gemäß den in der Region üblichen Typen mit großer Wahrscheinlichkeit ebenfalls zu Chlamydephoren zu ergänzen. 
donen handelt. ${ }^{738}$ In Frage kommen der Makedonenkönig Alexander III. (der Große) sowie die Angehörigen der ebenfalls aus Makedonien stammenden Ptolemäerdynastie.

Die Betonung des Makedonischen legt nahe, dass auch die Verwender „Makedonen“ bzw. „Hellenen“ waren. Ob dagegen auch Teile der ägyptischstämmigen Bevölkerung zum Kreis der Verwender der Statuetten gehörten, ist schwer zu sagen. Für diese Möglichkeit spricht die Mischung ägyptischer und griechisch-makedonischer Elemente im Typus der „Reiter über Gegner“7739, aber auch, dass es auch auf anderen Gebieten zu einer gewissen Angleichung zumindest der oberen Schichten der beiden Volksgruppen kam. So nahmen Ägypter neben ihrem ägyptischen Namen auch noch einen makedonischen oder griechischen an, ${ }^{740}$ wurden seit Ptolemaios V. ins ptolemäische Heer aufgenommen und erlangten so den Status von Kleruchen, ${ }^{741}$ während andererseits Makedonen in bestimmte Priesterkollegien aufgenommen wurden und an in ägyptischer Tradition stehenden und zahlenmäßig von Ägyptern dominierten Priestersynoden teilnahmen.

Grundsätzlich könnte die Art der Verwendung der Terrakotten aus dem Fundort und der Ikonographie zu erschließen sein. Genaue Fundortangaben liegen jedoch zu keiner der Statuetten vom „Typus Reiter über Gegner/Schild“ vor. Da in den zeitgleichen Nekropolen von Alexandria Vertreter des „Typus Reiter ohne Gegner“ sowie sitzende und stehende ChlamydephorenTypen zutage traten, jedoch keine „Reiter über Gegner/Schild“, fanden diese vermutlich keine Verwendung im Grabkult oder als Grabbeigabe. Als mögliche Fundorte bleiben demnach Heiligtümer und „Siedlungsgebiete“ ${ }^{\text {“742 }}$. In den kultischen Bereich weisen auch die engen ikonographischen Beziehungen, die die Wiedergaben des Herrschers, der den besiegten Gegner niederreitet, mit denen des Gottes Horus, der Seth tötet, verbinden. Schließlich sind auch die makedonisch-ptolemäischen Könige Ägyptens Pharaonen und damit Vertreter des Königsgottes auf Erden. Als Götter mit eigenem Kult wurden Alexander und Angehörige der ptolemäischen Königsfamilie spätestens nach ihrem Tode verehrt. ${ }^{743}$

\footnotetext{
${ }^{738} \mathrm{Im}$ Gegenzug war es auch möglich, einen aus Makedonien stammenden Herrscher als Ägypter erscheinen zu lassen. Vgl. das den ptolemäischen König in ägyptischer Kleidung darstellende, ganz im ägyptischen Stil gehaltene Relief auf dem Gedenkstein von al-Nibeira mit dem Dekret der in altägyptischer Tradition stehenden und von ägyptischstämmigen Personen dominierten Priestersynode von Memphis aus dem Jahr 195 v.Chr. (Ptolemaios IV.). Vgl. G. Roeder, Die ägyptische Religion in Texten und Bildern 3. Kulte, Orakel und Naturverehrung im alten Ägypten (1960) 167 ff. Taf. 11.

${ }^{739}$ Es sei in diesem Zusammenhang darauf hingewiesen, dass sich ein griechischer Einfluss auf ägyptische religiöse Darstellungen schon seit dem 6./5. Jahrhundert v.Chr. bemerken lässt (J. Fischer, Der Zwerg, der Phallos und Harpokrates, in: H. Felber - S. Pfisterer-Haas [Hrsgg.], Ägypter-Griechen-Römer, Kanobos 1 [1999] 38). Dieser Trend dürfte sich nach der Einbeziehung Ägyptens in das Alexanderreich verstärkt haben.

${ }^{740}$ Vgl. R. Scholl, Identitäten und Multikulturalität. Das Zeitalter der Griechen in Ägypten, in: H. Felber - S. Pfisterer-Haas (Hrsgg.), Ägypter-Griechen-Römer, Kanobos 1 (1999) 125 ff.

${ }^{741}$ Vgl. RE XI (1921) 16 s.v. Katoikoi (Oertel).

${ }^{742}$ Wie oben im Kapitel „Funde aus Siedlungen“ dargelegt wurde, ist bei Statuetten aus Siedlungsgebieten ebenfalls oft mit einer religiösen Bedeutung und Funktion zu rechnen - insbesondere wenn auch die Ikonographie in diese Richtung weist.

${ }^{743}$ Vgl. G. Hölbl, Geschichte des Ptolemäerreiches (1994) 69 ff. 141 ff. 228 ff.
} 
Die Funktion der „Reiter über Gegner/Schild“ kann darin bestanden haben, als Votiv zu dienen. Orte der Niederlegung könnten neben speziell für den Herrscherkult ${ }^{744}$ errichteten Heiligtümern solche von eng mit dem Königtum verbundenen Göttern (Horus, Osiris, Ptah) gewesen sein sowie die große Zahl von Heiligtümern, in denen die Angehörigen der Herrscherdynastie zusammen mit den jeweiligen ägyptischen Gottheiten verehrt wurden. ${ }^{75}$ Orte der Ausübung des Königskultes waren aber auch die Gymnasien. ${ }^{76}$ Außerhalb der öffentlichen Heiligtümer kommt zudem eine kultbildähnliche Funktion im häuslichen Herrscherkult in Frage. Die Aufstellung von Herrscherbildnissen in privaten Hausschreinen wurde durch ägyptische Priestersynoden ausdrücklich begrüßt. ${ }^{747}$

Welcher König erstmals im Schema „Reiter über Gegner“ dargestellt wurde, ist abhängig von der Datierung der frühesten Terrakotten dieses Typus. Eine Datierung dieser Statuetten auf stratigraphischer Grundlage ist jedoch nur in einem Fall möglich. Es handelt sich um die Figuren Tk 106-107 aus dem Ofen eines Koroplasten in Athribis, der in einem Handwerkerviertel entdeckt wurde, das unter einer frühptolemäischen Badeanlage lag, die bis zur Zeit Ptolemaios IV. bestand. Der Ausgräber K. Mysliwiec bringt das Handwerkerviertel mit einer Ansiedlung von Soldaten des Alexanderfeldzuges in Verbindung. ${ }^{78}$ Der wiedergegebene Herrscher könnte demnach Alexander der Große sein. Andererseits ist unklar, wann das Handwerkerviertel durch die Badeanlage überbaut wurde. Gesichert ist nur, dass diese zu Beginn des 2. Jahrhunderts zerstört wurde. Es ist demnach möglich, dass das Bad nicht schon Ende des 4. Jahrhunderts entstand, sondern erst im Laufe des 3. Jahrhunderts v.Chr. Die Reiterdarstellungen könnten sich entsprechend nicht nur auf Alexander, sondern auch auf einen der ersten drei bis vier Ptolemäerkönige beziehen. Die sehr traditionell-konservativen Grundstrukturen so-

\footnotetext{
${ }^{744}$ Auf die unterschiedlichen Formen und Ursprünge der Verehrung Alexanders und der Ptolemäer (städtische Kulte für Alexander und Ptolemaios I. als Stadtgründer [Ktistes] von Alexandria und Ptolemais; Alexander und die Angehörigen des ptolemäischen Herrscherhauses als Reichsgötter mit teils unterschiedlichen Formen der Verehrung zu Lebzeiten und nach dem Tode) gehe ich nicht näher ein (Vgl. hierzu z.B. G. Hölbl, Geschichte des Ptolemäerreiches [1994] 85 ff.), da es derzeit nicht möglich ist, die Reiterstatuetten verbindlich und ausschließlich mit einem bestimmten Kult oder Herrscher zu verbinden, wenn man davon absieht, dass die weite Streuung der Funde einen auf die Stadtgründerkulte in Alexandria und Ptolemais beschränkte Verwendung der Figuren ausschließt.

${ }^{745}$ So berichtet das Priesteredikt von Memphis aus dem Jahr 195 v.Chr. von Statuengruppen bestehend aus den Bildnissen der Stadtgottheit und des Königs in den Vorhöfen der Tempel, Königsstatuen, die in einem Schrein zusammen mit den Statuen anderer Götter im Allerheiligsten des Heiligtums aufbewahrt werden, sowie Prozessionen, Opfern und Priestern (Stein von Rosette, Zeile 6-14; vgl. G. Roeder, Die ägyptische Religion in Texten und Bildern 3. Kulte, Orakel und Naturverehrung im alten Ägypten [1960] 184 ff.). Ähnliches ist auch dem Kanopos-Edikt (von 238 v.Chr.) ab Zeile 12 ff. zu entnehmen (Vgl. G. Roeder, Die ägyptische Religion in Texten und Bildern 3. Kulte, Orakel und Naturverehrung im alten Ägypten [1960] 156 ff.). Zum Unterschied zwischen dem Statuen- bzw. Festkult für lebende Könige und dem eigentlichen Götterkult vgl. G. Hölbl, Geschichte des Ptolemäerreiches (1994) $80 \mathrm{f}$.

${ }^{746}$ H. Kyrieleis, Bildnisse der Ptolemäer (1975) $145 \mathrm{f}$.

${ }^{747}$ Vgl. Edikt der Priestersynode von Memphis (Rosetta-Stein) Z. 13 f. (G. Roeder, Die ägyptische Religion in Texten und Bildern 3. Kulte, Orakel und Naturverehrung im alten Ägypten [1960] 189).

${ }^{748} \mathrm{~K}$. Mysliwiec, Fruchtbarkeitskult und erotische Kunst im ptolemäischen Athribis (Unterägypten), in: H. Felber - S. Pfisterer-Haas (Hrsgg.), Ägypter-Griechen-Römer, Kanobos 1 (1999) 79 .- K. Mysliwiec - Moattameda Bakr Said, Polish-Egyptian Excavations at Tell Atrib in 1994-1995, EtTrav 17, 1999, 191.
} 
wohl der ägyptischen Religion als auch des ptolemäischen Herrscherbildnisses machen es zudem wahrscheinlich, dass ein für Alexander oder einen der ersten Ptolemäerkönige entwickeltes Schema auch von den nachfolgenden Herrschern der Ptolemäerdynastie weiter genutzt wurde.

Hinweise auf den Kreis der Verwender können die Kleidung des Reiters, der Stil der Darstellung sowie das Verbreitungsgebiet der Statuetten liefern. Die Bekleidung ist „makedonisch“ und der Stil ist griechisch. Das Verbreitungsgebiet ist beschränkt auf Alexandria, die Stadt des Königs und der Zentralverwaltung, sowie das Delta (Sais, Thmuis, Naukratis, Athribis, Komel-Ahdar [bei Bubastis?]) und das Faijum, d.h. diejenigen Regionen Unterägyptens, in denen der Großteil der makedonisch-griechischen Bevölkerung lebte. Aus Mittel- und Oberägypten dagegen, die stärker ägyptisch geprägt blieben, sind derzeit keine Statuetten vom „Typus Reiter über Gegner“ bekannt. Ähnlich wie bei denjenigen Statuetten, die Chlamydephoren zeigen, sind als Verwender daher am ehesten die Bewohner der überwiegend griechisch-makedonisch geprägten Stadt Alexandria sowie die makedonischstämmigen oder makedonisierten Militärsiedler (Kleruchen/Katoiken) der ländlichen Gebiete des Deltas und des Faijums zu vermuten.

Die in Athribis entdeckten Statuetten wurden dort auch produziert. ${ }^{749}$ Dies schließt Alexandria als zentralen Produktionsort aller Terrakotten vom „Typus Reiter über Gegner“ aus. Es gibt jedoch keine Hinweise darauf, dass Athribis ${ }^{750}$ ein solcher Zentralort der koroplastischen Produktion gewesen wäre. Entsprechend ist von einer Produktion bzw. Imitation an verschiedenen Orten auszugehen. Die großen Ähnlichkeiten der Reiterstatuetten sowohl im Aussehen als auch in den Abmessungen legen jedoch die Existenz eines gemeinsamen Urbildes nahe. Als Ort der Entstehung dieser Vorlage kommt in erster Linie Alexandria in Frage: Die Stadt war kulturelles und künstlerisches Zentrum des ptolemäischen Ägypten. Hier residierte der königliche Hof, in dessen Umfeld am ehesten mit der Konzeption von Statuetten für den Herrscherkult zu rechnen ist. Beim Vorbild könnte es sich von Anfang an um eine kleinplastische Statuette gehandelt haben, nach der Tonfiguren hergestellt und regional imitiert wurden. Möglich

\footnotetext{
${ }^{749}$ K. Mysliwiec - Moattameda Bakr Said, Polish-Egyptian Excavations at Tell Atrib in 1994-1995, EtTrav 17, 1999, 218.

${ }^{750}$ Einerseits kann Athribis nicht völlig als Entstehungsort des „Typus Reiter über Gegner“ ausgeschlossen werden, da einige Grundvoraussetzungen erfüllt werden: In Athribis lassen sich koroplastische Werkstätten, angesiedelte Soldaten des Alexanderheeres als potentielle Verwender (K. Mysliwiec, Fruchtbarkeitskult und erotische Kunst im ptolemäischen Athribis [Unterägypten], in: H. Felber - S. Pfisterer-Haas [Hrsgg.], Ägypter-GriechenRömer, Kanobos 1 [1999] 79) sowie die Verehrung der Götter Horus und Osiris (B. George, Ptolemaios II und Arsinoe II vor den Göttern von Athribis, MedelhavsMusB 17, 1982, 12 ff.) nachweisen. Andererseits werden diese Voraussetzungen auch von anderen Orten erfüllt. Die überregionale Verbreitung der „Reiter über Gegner“ spricht gegen Athribis. Eine 1988 veröffentlichte Untersuchung (P. Ballet, Terres cuites d'Alexandrie et de la Chôra. Essai d'etude comparative de quelques ateliers. Thèmes et techniques, in: Commerce et artisanat dans 1 'Alexandrie hellénistique et romainè, BCH Suppl. 33 [Actes du Colloque d'Athenes 1988] [1998] 217-243), die die erst später entdeckten Funde von Athribis noch nicht berücksichtigt, deutet an, dass in erster Linie die in Alexandria geschaffenen Typen von überregionaler Bedeutung waren, während die regionalen Sondertypen auch nur regional und temporär Verbreitung fanden.
} 
ist aber auch, dass dem kleinplastischen Modell ein großplastisches, nicht erhaltenes Reiterstandbild ${ }^{751}$ zugrunde lag. ${ }^{752}$

In einem zeitgleich zu dieser Arbeit entstandenen Aufsatz schlägt Jutta Fischer, die die „Reiter über Gegner" ähnlich deutet wie der Verfasser,jetzt vor, den Typus auf ein großplastisches Siegesdenkmal zurückzuführen, dass Ptolemaios I. anlässlich des Sieges in der Schlacht von Gaza (312) hätte errichten lassen können. ${ }^{753}$

\subsubsection{Handgeformte Reiter aus dem Orient}

Die genauen Fundorte der meisten Reiterstatuetten sind nur unzulänglich bekannt. Die Figuren aus Seleukia, Tello, Uruk und Susa lassen sich nur allgemein einem Ort zuweisen. Die Terrakotten aus Nippur stammen aus Gräbern erwachsener Personen, was eine Deutung als Spielzeug ausschließt. Solange die Funktion und Bedeutung von Grabbeigaben umstritten sind, ist eine weitergehende Interpretation problematisch. Die Fundorte der Reiter aus Ikaros

\footnotetext{
${ }^{751}$ Zwei Reiterstandbilder Alexanders, die den König in der Schlacht am Granikos (geschaffen von Lysipp; aufgestellt ursprünglich in Dion, später in Rom) und als Stadtgründer von Alexandria wiedergeben, sind literarisch bzw. in kleinplastischen Repliken überliefert (Vgl. A. Stewart, Faces of Power [1993] 123 ff. 243 ff. 388 ff. [literarische Quellen zu Alexander in Dion/Rom], 397 ff. [literarische Quelle zu Alexander in Alexandria].). Beide weichen in der Kleidung, Bewaffnung und Körperhaltung von den Reitern über Gegner ab. Insbesondere fehlt jeweils der Gegner. Dies schließt jedoch nicht aus, dass es sich bei den Statuetten vom „Typus Reiter über Gegner/Schild“ um kleinplastische Repliken eines literarisch nicht überlieferten Monumentes handelt. - Ein solches Vorbild könnte seine Spuren in den allerdings kaiserzeitlichen Bekrönungen der Jupiter-Giganten-Säulen hinterlassen haben (Vgl. M. Mackintosh, The Divine Rider in the Art of the Western Roman Empire, BAR Intern. Series 607 [1995] 22 f.). Spätantike Herrscherdarstellungen auf Münzen und Kontorniaten zeigen teils den Kaiser (z.B. auf einem Aureus des Lucius Verus [165 n.Chr.] oder einem Antonian des Probus [276-282 n.Chr.]: auf der Rückseite reitet jeweils der Kaiser einen Gegner nieder - im Falle des Probus ist der Kaiser unbewaffnet, der kniende Barbar gefesselt [Spätantike und frühes Christentum, Ausstellungskatalog Frankfurt/M. 1983-84 [1983] 657 ff. Nr. 234-235]), teils Alexander (z.B. auf einem Kontorniaten [um 356-394 n.Chr.] mit Alexander im Profil nach rechts auf der Vorderseite und auf der Rückseite der Legende „ALEXANDER MAGNUS MACEDON“ und einer Darstellung Alexanders zu Pferde nach links, der mit der Lanze einen knienden Gegner niedersticht [Spätantike und frühes Christentum [Ausstellungskatalog Frankfurt/M. 1983/84] [1983] 594 Nr. 189]) als „Reiter über Gegner“. Entsprechende Darstellungen müssen jedoch nicht zwangsläufig auf ein frühhellenistisches Alexander-Monument zurückgeführt werden, sondern können auch durch andere Traditionsstränge beeinflusst sein (z.B. die thrakisch-danubischen Reiterheroen: vgl. Z. Gočeva/M. Oppermann u.a. [ Hrsg.: M. J. Vermaseren], Corpus Cultus Equitis Thraci, CCET I-V [1979-82] .- D. Tudor [Hrsg.: M. J. Vermaseren], Corpus Monumentorum Religionis Equitum Danuvinorum, CMRED I-II [1969-76]).

${ }^{752}$ Ein ebenfalls pharaonisches Triumphalschema in griechischer Umwandlung zeigen die ptolemäischen Ringer-

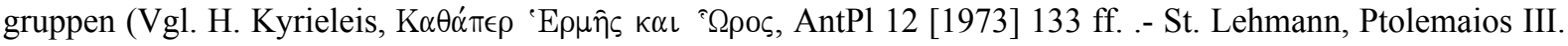
Euergetes - Hermes Enagonios als Pentathlos und Pankratiast, in: K. Gschwantler, A. Bernhard-Walcher [Hrsgg.], Griechische und römische Statuetten und Großbronzen [Akten... Wien 1986] [1988] 290 f. .- H. J. Thissen, Studien zum Raphia-Edikt [1966] 11 ff. .- H. P. Laubscher, AntK 30 [1987] 131 f.). Diese zeigen einen „Ringer“, der seinen Gegner mit Leichtigkeit besiegt, wie Ptolemaios (II.?) die Gallier (?) besiegt, wie Horus über Seth siegt, und erweitern die Darstellung um Anspielungen auf den König, der wie Thot/Hermes für Recht und Gerechtigkeit sorgt.

${ }^{753}$ J. Fischer, Ein triumphierender Makedonenreiter - Zeugnis eines ptolemäischen Siegesdenkmals?, StädelJb 19, 2004, 492f. Vgl. C. Maderna, Zum Feindbild der Ptolemäer, in: Ägypten Griechenland Rom. Abwehr und Berührung, Ausstellung Städelsches Kunstinstitut und Städtische Gallerie Frankfurt, 2005/06, 258-266, 584f. Nr. 157.
} 
verteilen sich über das ganze Stadtgebiet (Siedlungsareal, Befestigungsanlagen, Tempel) und bieten deshalb keinen klaren Anhaltspunkt für die Deutung.

Den Schlüssel für die Verwendung und Deutung der Reiterterrakotten liefern die Figuren aus Masjid-i Solaiman (Taf. 33 Abb. 125, 127-130). Sie stammen alle eindeutig aus einem Heiligtum, es handelt sich demnach um Votive. Die nackte weibliche Person, die einige der Doppelpferde zwischen den Hälsen tragen, dürfte die Gottheit darstellen, der die Figuren geweiht waren. Es ist anzunehmen, dass es sich auch bei denjenigen Reiterfiguren, die keine Göttin tragen, aber ebenfalls aus dem Heiligtum stammen, um Votive für die gleiche Göttin handelt. Aufgrund der Kausia und des Schildes sieht R. Ghirshman ${ }^{754}$ in den Weihenden griechischmakedonische Kavalleristen, die in der Gegend zur Sicherung der Straße vom Persischen Golf nach Gabai (Isfahan) angesiedelt worden seien. Diese hätten in einer orientalischen nackten Göttin die griechische Athena Hippia erkannt und dieser die Reiter geweiht. In den Reitervotiven würden sich der Kultname (Hippia), die Funktion der Göttin (Schützerin der Pferde und Reiter) und der Beruf der Weihenden (Kavalleristen) spiegeln. ${ }^{755}$

Die Statuetten aus Susa (u.a. mit nackter Göttin zwischen den Pferdeköpfen) dürften, auch wenn keine genauen Angaben zum Fundort vorliegen, einer vergleichbaren Gottheit geweiht gewesen sein.

Die Reiter aus Ikaros/Failaka stammen, wie schon erwähnt, sowohl aus Heiligtümern als auch aus Siedlungsarealen und den Befestigungsanlagen. Die Verwendung der Statuetten aus dem heiligen Bezirk ist unbestritten. Die weite Streuung der übrigen Figuren täuscht darüber hinweg, dass sich auch im Bereich der Wohnhäuser und der Stadtbefestigung (insbesondere in der Nähe von Toren und Türmen) Kultnischen u. ä. befunden haben werden und deshalb nichts gegen eine Verwendung sämtlicher Reiterterrakotten im sakralen Bereich spricht. ${ }^{756}$ Mit Athena Hippia lassen sich die Reiter aus Ikaros jedoch nicht verbinden, da hier, soweit die literarischen und epigraphischen Quellen Aussagen zulassen, nur Artemis Tauropolos, Artemis Soteira und Apollon sowie - vielleicht in Verbindung mit Apollon und Artemis Soteira Mitglieder der seleukidischen Herrscherfamilie (Seuleukos I., Antiochos I. Soter, Stratonike) verehrt wurden. ${ }^{757}$

K. Jeppesen, der Bearbeiter der literarisch-epigraphischen Quellen und der architektonischen Reste der beiden Tempel von Ikaros, lokalisiert den Kult des Apollon (und des Seleukos/Antiochos) im größeren Tempel A (ca. 260 v. Chr.), den Kult der Artemis Soteira (und der Stratonike) im kleineren Tempel B (ca. 240 v. Chr.) und das Orakelheiligtum der Artemis Tauro-

\footnotetext{
${ }^{754}$ Vgl. R. Ghirshman, Terrasses Sacrées de Bard-è Néchandeh et Masjid-i Solaiman, MDAI 45 (1976) 80.

${ }^{755}$ Der Befund ist vielleicht etwas zu wörtlich überinterpretiert.

${ }^{756}$ Zur Existenz von Hauskulten vgl. J. B. Connelly, The terracotta figurines. Greek types and cult, in: Failaka. Fouilles françaises 1986-88, Travaux de la Maison de l'Orient 18 (1990) 217.

${ }^{757} \mathrm{~K}$. Jeppesen, Ikaros III -The Sacred Enclosure in the Early Hellenistic Period. With an appendix on epigraphic finds (1989) 76 ff. In einer frühhellenistischen Inschrift werden darüber hinaus noch Zeus Soter und Poseidon (in Verbindung mit Artemis Soteira) erwähnt (S. Sherwin-White/A. Kuhrt, From Samarkhand to Sardis [1993] 168 Taf. 11).
} 
polos irgendwo außerhalb der Stadt. Archäologische Belege für diese Zuweisungen gibt er nicht. $^{758}$

Die Terrakotten aus Ikaros lassen sich in drei Hauptgruppen scheiden: Reiter, nackte Göttinnen und Boote. ${ }^{759}$ H. E. Mathiesen ordnet diese nur allgemein einem Sonnengott (Reiter), einer Fruchtbarkeitsgöttin (nackte Frau) und einer Mondgöttin (Boote) zu. ${ }^{760}$ Auf die in Ikaros nachweisbaren Gottheiten übertragen bedeutet dies, dass die Reiter dem Apollon und die nackten Göttinnen sowie die Boote den beiden mit Artemis benannten Göttinnen geweiht wurden. Dies hätte jedoch zur Folge, dass die Reiter, die in Masjid-i Solaiman und wahrscheinlich auch Susa einer Göttin („Athena Hippia“) gestiftet wurden, in Ikaros dem Kult eines männlichen Gottes (Apollon) zugeordnet sind. Identische Figuren wären also ganz unterschiedlichen Gottheiten geweiht worden.

Untersucht man die Verteilung der Terrakotten auf die einzelnen Heiligtümer, ergibt sich ein neues Bild: Die Boote, Symbole einer Mondgöttin, fanden sich ausschließlich in Tempel A, der bisher mit Apollon (und Seleukos/Antiochos) in Verbindung gebracht wurde. Die mit einem Sonnengott oder „Athena Hippia“ verknüpften Reiterstatuetten stammen aus Tempel B (bisher Artemis Soteira und Stratonike zugeschrieben). Die nackten Frauen (Fruchtbarkeitsgöttin) sind in beiden Tempeln nachweisbar. Daraus ergibt sich: Beide Tempel waren weiblichen Gottheiten geweiht (Artemis Soteira und Artemis Tauropolos) ${ }^{761}$. Apollon wurde in Tempel A und B nicht oder nur in Kombination mit Artemis in einem der beiden dieser Göttin geweihten Tempel verehrt. Die Angehörigen des seleukidischen Herrscherhauses könnten ebenfalls zusammen mit Artemis, aufgrund des Kultnamens wohl der Artemis Soteira, verehrt worden sein. Theoretisch ist die Verehrung von Artemis Soteira, ihrem Bruder Apollon (dem mythischen Begründer der Seleukidendynastie), Seleukos I./Antiochos I. Soter und Stratonike in einem der beiden Tempel möglich. Wegen seiner Ausmaße und der ungewöhnlichen Form und Größe der Kultbildbasis ${ }^{762}$ ist Tempel A als Heiligtum einer Gruppe von Gottheiten besser geeignet. Tempel B bliebe als Heiligtum der Artemis Tauropolos. Die Reiterfiguren sind demnach Votive wahrscheinlich für Artemis Tauropolos, zumindestaber einer „Artemis“.

In Susa wurden - wie in allen bedeutenderen Städten des Seleukidenreiches - die Dynastiegottheiten Apollon und Artemis verehrt. Hauptgöttin des Ortes war jedoch die ursprünglich

\footnotetext{
${ }^{758}$ K. Jeppesen, Ikaros III -The Sacred Enclosure in the Early Hellenistic Period. With an appendix on epigraphic finds (1989) $78 \mathrm{f}$.

${ }^{759}$ Vgl. die Tabelle in: H. E. Mathiesen, Ikaros I. The Terracotta. Figurines (1982) 89 ff. Kat. Nr. 1-62.

${ }^{760}$ H. E. Mathiesen, Ikaros I (1982) $74 \mathrm{f}$.

${ }^{761}$ Eine mit der griechischen Artemis gleichgesetzte orientalische Göttin ist die einzige nachweisbar schon in vorhellenistischer Zeit auf Ikaros/Failaka verehrte Gottheit (Arrian, Anabasis 7, 20, 3). Vermutlich sind die Kultnamen Tauropolos und Soteira in hellenistischer Zeit auf diese Göttin übertragen worden. Als Tauropolos wurde Artemis auch auf der Ägäisinsel Ikaros verehrt. Soteira erinnert an den Beinamen seleukidischer Könige (Soter) und ist wie Apollon (der Stammvater der Seleukiden) mit seleukidischem Einfluss in Verbindung zu bringen (Vgl. K. Jeppesen, Ikaros III [1989] 76 ff.).

${ }^{762}$ Vom Kultbild sind keine Reste erhalten. Form und Höhe der Basis sprechen gegen ein stehendes Götterbild. K. Jeppesen, Ikaros III (1989) 53. 62 Abb. 84 ff. nimmt eine Sitzstatue (vergleichbar der Demeter von Knidos) oder wahrscheinlicher eine hölzerne Quadriga, in deren Wagen mehrere Figuren hätten stehen können, an.
} 
aus Uruk entführte Nanai, die nach und nach immer stärker mit Artemis gleichgesetzt wurde. Auf Münzen erscheint zudem vereinzelt das Bild der Athena ${ }^{763}$.

Die Elymaier, auf deren Gebiet das Heiligtum von Masjid-i Solaiman vermutlich lag, verehrten in erster Linie Athena und Artemis. Die „Artemis“ der Elymaier geht auf eine einheimische Göttin namens Azara ${ }^{764}$ zurück.

Es ist also sowohl für Susa als auch für Masjid-i Solaiman der Kult der Athena und der Artemis nachweisbar, wobei die mit Artemis gleichgesetzte Göttin (Nanai, Azara) die jeweils ältere und bedeutendere gewesen sein dürfte.

Eine Weihung der Statuetten in Susa und Masjid-i Solaiman an Athena ist nicht auszuschlieBen. ${ }^{765}$ Wahrscheinlicher ist eine Weihung der Reiter an Artemis. Hierfür spricht einerseits die größere Bedeutung der Göttin und die Möglichkeit, sie auf eine orientalische „Vorgängerin“ zurückzuführen, ${ }^{766}$ und andererseits, dass Athena in Ikaros nicht verehrt wurde. Mit großer Wahrscheinlichkeit wurden daher alle Reiterstatuetten aus Ikaros, Susa und Masjid-i Solaiman einer Göttin geweiht, in der die Griechen Artemis erkannten.

Wem die handgeformten Reiter aus Uruk, Tello und Nippur sowie die teils griechisch, teils orientalisch beeinflussten Terrakotten aus Babylon und Seleukia/Tigris geweiht waren, lässt sich aufgrund mangelnder Informationen zum genauen Fundort nicht sagen. In allen diesen Städten Babyloniens gab es jedoch Heiligtümer einer der Artemis-Nanai-Azara vergleichbaren Göttin.

Da die Reiterstatuetten nicht die Gottheit zeigen, der sie geweiht wurden, ist es nahe liegend, in ihnen Abbilder der sie Weihenden zu sehen. Die Kausia kennzeichnet die Reiter als „Makedonen“. Der Rundschild, den einige der Reiter tragen, verweist die Figuren in einen militärischen Kontext. Bei den Dargestellten handelt es sich demnach am ehesten um seleukidische Kavalleristen.

R. Ghirshman ${ }^{767}$ verbindet die Figuren vom Typus Doppelreiter mit einer bestimmten Reitereinheit, den Amphippoi ( $\left.\alpha_{\alpha}^{\prime} \phi \iota \pi \pi \circ\right)^{768}$. Diese waren eine leichtbewaffnete Reitertruppe, in der jeder Reiter zwecks Erhöhung der Mobilität über zwei Pferde verfügte.

\footnotetext{
${ }^{763}$ Vgl. G. LeRider, Suse sous les Séleucides et les Parthes, MDAI/MMAI 38 (1965) $287 \mathrm{ff}$.

${ }^{764}$ Strabon $16,1,18$.

${ }^{765}$ Zumal die Möglichkeit besteht, dass sehr ähnliche orientalische Gottheiten an verschiedenen Orten mit verschiedenen griechischen Göttinnen und Göttern identifiziert wurden.

${ }^{766}$ Die vorhellenistische, in hellenistischer Zeit auch im Orient überholte Handwerkstradition der handgeformten Terrakotten ließe sich dann mit einer entsprechenden Tradition des Kultbetriebes verbinden.

${ }^{767}$ R. Ghirshman, Terrasses Sacrées de Bard-è Néchandeh et Masjid-i Solaiman, MDAI 45 (1976) $79 \mathrm{f}$.

${ }^{768}$ Im Heer des Antigonos Monophthalmos kämpften 317/6 v. Chr. Amphippoi gegen Eumenes von Kardia (Diodor 19, 29, 2). Ähnliche Einheiten gab es auch in anderen hellenistischen Heeren (vgl. z.B. Livius 35, 28, 8: Tarentiner).
} 
Die Stationierung makedonischer Reiterei in der Gegend um Susa ${ }^{769}$ und Masjid-i Solaiman erscheint sinnvoll. Sowohl die Hauptstraße von Babylon über Susa nach Persepolis führte durch diese Region als auch die Verkehrswege zwischen dem Mündungsgebiet von Euphrat und Tigris und dem iranischen Hochland. Seit Anfang des 2. Jahrhunderts v. Chr. war die Susiane Grenzprovinz zum Partherreich.

Ikaros ${ }^{770}$ war seleukidische Grenzfestung. Der Stützpunkt diente jedoch in erster Linie zum Schutz der Seewege entlang der Küste des Persischen Golfes sowie als Zollstation. Deshalb und aufgrund der geringen Größe der Insel (ca. 5x11,5 km) erscheint die Stationierung von Kavallerie unwahrscheinlich. Zumindest auf Failaka dürften zu den Spendern der Statuetten auch Fuß- bzw. Seesoldaten gehört haben. Möglicherweise wurde ein alter orientalischer Votivtypus übernommen und nur durch die Aktualisierung der Kopfbedeckung an die neuen Verwender angepasst. ${ }^{711}$ Die Fußsoldaten hätten dann ein Schema übernommen, das auf sie nur begrenzt zutraf.

In Susa und Ikaros und vermutlich auch in anderen Orte Mesopotamiens und der Susiane sind diejenigen Personen, die Terrakotten mit Kausia weihten, mit einiger Sicherheit die ,makedonischen“" Militärkolonisten ${ }^{772}$, die hier zur Kontrolle der Grenzen und der Verkehrswege angesiedelt worden waren. Im ptolemäischen Ägypten und vielleicht auch bestimmten Gebieten in Westkleinasien und Syrien sahen die Verhältnisse ähnlich aus. Während aber die im Mittelmeerraum geweihten Statuetten (Reiter, Chlamydephoroi) mit Hilfe westlicher Handwerkstechniken (Form) produziert wurden und das Typenspektrum zumindest teilweise (Chlamydephoroi) westlichen Ursprungs war, weihten im Zweistromland aus dem Westen stammende Soldaten Figuren, die in östlicher Handwerkstradition stehen und an ursprünglich orientalische Gottheiten gegeben wurden.

\footnotetext{
${ }^{769}$ Schon Alexander der Große stationierte in Susa, wo Teile des persischen Staatsschatzes gelagert wurden, mehrere tausend Soldaten (Quintius Curtius 5, 2, 16 f.). In hellenistischer Zeit wurde Susa in Seleukia am Eulaios umbenannt. Es sind makedonische Eigen-, Orts- und Monatsnamen nachweisbar. Möglicherweise gab es in

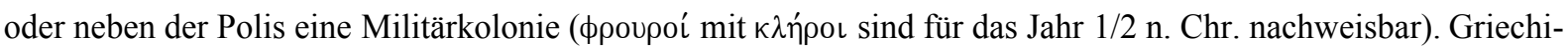
sche Beamtentitel (Archon, Gymnasiarch) blieben bis mindestens ins 1. Jahrhundert n. Chr. in Gebrauch (vgl. G. LeRider, Suse sous les Séleucides et les Parthes, MDAI/MMAI 38 [1965] 280-87). Von einer griechisch-makedonischen Kolonie bei Susa gehen auch S. Sherwin-White/A. Kuhrt, From Samarkhand to Sardis (1993) 158. 179 aus.

${ }^{770} \mathrm{Zu}$ Ikaros als seleukidischer Garnison vgl. S. Sherwin-White/A. Kuhrt, From Samarkhand to Sardis (1993) 168. 173.

${ }^{771}$ In Tell Halaf z. B. fanden sich neben Reitern mit Kausia (Tk 395) sonst weitgehend identische Reiterstatuetten in orientalischer Kleidung (B. Hrouda, Tell Halaf 4. Die Kleinfunde [1962] Taf. 18 Nr. 144-47).

${ }^{772} \mathrm{Zu}$ den Militärkolonisten in Susa vgl. die Anm. oben. Zu den Verhältnissen in Ikaros vgl. K. Jeppesen, Ikaros III. The Sacred Enclosure in the Early Hellenistic Period. With an appendix on epigraphical finds (1989) $82 \mathrm{ff} .:$ In einer im Einzelnen umstrittenen Inschrift aus dem Heiligtum von Ikaros werden gymnische Agone (Zeile 18 f.), Katoikoi oder Katoikiai (Z. 22) und Kleroi (Z. 40), vielleicht auch Neoi (Z. 18) genannt. Die gleichen Begriffe erscheinen auch in Zusammenhang mit makedonischen Militärkolonien in Ägypten und Kleinasien.
} 


\section{Unterschiedliche Häufigkeit von Darstellungen in einzelnen Regionen und Gattungen}

\subsection{Die Verbreitung in den einzelnen Regionen}

In den nachfolgenden Kapiteln werden - nach Regionen geordnet - knappe Abrisse der gattungsübergreifenden Verbreitung von bildlichen Wiedergaben der Kausia geboten. Die Deutung bestimmter Phänomene wurde in der Regel in den vorhergehenden Abschnitten näher erläutert und wird daher nur kurz angefügt.

\subsection{1 Ägypten}

Ägypten ist eines der Hauptverbreitungsgebiete von Statuetten mit Kausia (Tk 1-126, P 2-3). In geringerem Umfang finden sich bildliche Wiedergaben dieser Kopfbedeckung in der großformatigen Rundplastik (P 1), in der Malerei (Ma 1-4) und auf Kameen (Ka 1-2) und Siegeln (Si 1-4). Darstellungen im Relief und auf Münzen fehlen (vgl. Karten 1-3, 5).

In Ägypten (insbesondere in Alexandria, im Nildelta und im Faijumbecken) ließen sich in hellenistischer Zeit eine nennenswerte Anzahl von makedonischen oder makedonisierten (Militär-) Siedlern nieder.

Neben den mit diesen makedonischen Siedlern und ihren Interessen zu verbindenden Terrakotten und Grabstelen kommen in geringem Umfang Siegelabdrücke sowie Kameen und ein rundplastisches Herrscherporträt vor. Diese Darstellungen entstammen dem herrschaftlichen Bereich und dienen in erster Linie der Repräsentation des Königs.

Die „Region Ägypten“ umfasst die afrikanischen Besitzungen der Ptolemäer. Zusätzlich gehörten zum ptolemäischen Reich bzw. dessen Einflussgebiet insbesondere in der Mitte des 3. Jahrhunderts verschiedene Städte und kleinere Gebiete entlang der Küsten der Levante und Kleinasiens sowie im Bereich der Ägäis. Auch Zypern war bis zur Mitte des 1. Jahrhunderts v.Chr. Teil des Ptolemäerreiches. Die Terrakotten und Münzen dieses Bereiches werden teilweise ebenfalls mit ptolemäischem Militär- und Verwaltungspersonal bzw. Münzmeistern zu verbinden sein. Eine eindeutige Zuweisung der Terrakotten ist in der Regel nicht möglich, da sich einerseits die Grenzen des ptolemäischen Einflusses ständig änderten und andererseits die Datierung der Figuren zu ungenau ist.

Schließlich ist auf Wiedergaben der Kausia zu verweisen, die außerhalb des ptolemäischen Machtbereiches gefunden wurden, aber dennoch Rückschlüsse auf die Verhältnisse in Ägypten zulassen wie die in Kallipolis entdeckten Siegelabdrücke mit Bildnissen ptolemäischer Herrscher oder Darstellungen in der Malerei und im Mosaik aus Pompeii und Umgebung, die vielleicht auf alexandrinische Vorbilder zurückgehen. 


\subsubsection{Kleinasien}

In Kleinasien erscheint die Kausia als Kopfbedeckung von Terrakotten (Tk 127-185) sowie als „Beutewaffe“ auf einem Relief aus Pergamon (Re 1) (vgl. Karten1-3, 5).

Wie in Ägypten ist die weitgehende Beschränkung auf die Koroplastik und innerhalb dieser auf bestimmte Typen (Chlamydephoren) kennzeichnend für Gebiete, in denen makedonische (Militär-) Siedler in Orten ohne Polisstatus lebten.

\subsubsection{Balkanhalbinsel}

\section{Makedonien (in den Grenzen von 359 v.Chr.)}

Im makedonischen Kerngebiet kommen Kausia-Darstellungen einerseits in fast allen Gattungen vor, andererseits jedoch immer nur in geringer Anzahl (Tk 186-187, Re 2, Ma 5-6 und indirekt Nu 6-10 und Ka 3) (vgl. Karten 1-3, 5, 7).

In Makedonien gab es keine neuangesiedelten Militärkolonisten, die sich in einer fremden Umgebung von der nicht-makedonischen Bevölkerung abgrenzen wollten und in gleicher Weise zur Organisation ihres Gemeinschaftslebens auf die polisähnlichen Strukturen des Gymnasions angewiesen waren wie die Neusiedler. Entsprechend fehlt auch eine größere Gruppe typologisch homogener Terrakotten, die die Kausia aufweisen. Die in den in verschiedenen anderen Gattung vereinzelt auftretenden Darstellungen der Kausia sind in erster Linie als Abbildungen der in Makedonien real getragenen Kleidung zu verstehen.

\section{Nordgriechische Poleis (von Philipp II. zwischen 359 und 340 v.Chr. erobert)}

In den früh von Philipp II. dem makedonischen Königreich in relativ enger Form angeschlossenen griechischen Poleis finden sich Darstellungen der Kausia in größerer Zahl in der Koroplastik (Tk 188-283) sowie vielleicht einmal in der Rundplastik (P 4).

Unter der Regierung Philipp II. entwickelte sich Makedonien vom Stammeskönigtum mit eher regionaler Bedeutung zur Vormacht Griechenlands und der südlichen Balkanhalbinsel, die sich anschickte es mit dem Perserreich aufzunehmen.

Die Makedonen erweiterten ihr Gebiet nach Norden (Paionien), Süden (Thessalien) und insbesondere nach Osten (Nordküste von Ägäis und Propontis, thrakisches Hinterland). Im Zuge dieser Expansionspolitik kam auch eine Reihe griechischer Poleis, aus denen Darstellungen der Kausia bekannt sind, unter makedonische Herrschaft: Pydna (seit 357 v. Chr. makedonisch), Amphipolis (357) sowie die Inseln Thasos und Samothrake (340/39). In den betreffenden Städten hielt sich makedonisches Militär- und Verwaltungspersonal in wiederum nichtmakedonischer Umgebung auf. Deren Situation ist mit der der Siedler in den Diadochenreichen vergleichbar. Auch hier werden eine Abgrenzung gegenüber der einheimischen, in diesem Fall griechischen Bevölkerung und bestimmte Organisationsformen (Gymnasion?) die Verwendung von Chlamydephoren mit Kausia hervorgerufen haben. Die genannten Poleis lie- 
gen zudem sehr nahe am makedonischen Mutterland. Dies hat vermutlich den Zuzug ziviler Auswanderer aus den ländlichen Gebieten Makedoniens gefördert.

\section{Stammesgebiete}

In den illyrisch-thrakischen Stammesgebieten erscheint die Kausia im numismatischen Bereich (Nu 1-5) und in der Malerei (Ma 7).

Die betreffenden Gebiete sind teilweise von Makedonien abhängig (Paionien seit 358 v.Chr., Thrakien seit 343/2 v.Chr.), teilweise liegen sie am Rande des makedonischen Machtbereiches (das Reich des Genthios, das spätere Koinon der Labeaten an der illyrischen Küste). Das Vorkommen der Kausia in diesen Gebieten ist dennoch wahrscheinlich weniger auf makedonischen Einfluss, als auf die Existenz einer kausiaähnlichen Kopfbedeckung auch in den nördlich an Makedonien grenzenden Regionen zurückzuführen. Für einen Großraum MakedonienIllyrien-Thrakien als Ursprungsgebiet der Kausia spricht auch, dass sich die Beispiele aus Illyrien und Thrakien ähnlich denen aus Makedonien auf verschiedene Gattungen verteilen und insbesondere solche aus dem Bereich der Koroplastik fehlen.

\section{Griechische Poleis am Schwarzen Meer unter makedonischer Kontrolle}

Aus griechischen Poleis an der Westküste des Schwarzen Meeres stammen die Tonfiguren Tk 282-288 und die Reliefdarstellungen Re 3-4.

Die betreffenden Städte (Mesambria, Odessos, Kallatis) gehörten seit 343/2 v.Chr. zur makedonischen Strategie Thrakien, die neben Stammesgebieten auch eine Reihe griechischer Poleis am Schwarzen Meer umfasste. Wiedergaben der Kausia können eine Folge der makedonischen Herrschaft und der Anwesenheit von Makedonen (z.B. Garnisonssoldaten) sein, es ist aber auch ein Einsickern der Kausia aus dem thrakischen Hinterland möglich, in dem die Kausia vermutlich ebenfalls verbreitet war.

\section{Griechische Poleis im „Korinthischen Bund““}

In den Städten des Korinthischen Bundes finden sich Darstellungen der Kausia vereinzelt in der Koroplastik (Tk 289-305), im Relief (Re 5) und auf dort gefundenen Siegelabdrücken (Si 5-9).

Die Mehrheit der Terrakotten stammen aus Städten (Chalkis, Athen, Korinth), in denen makedonische Garnisonen lagen, deren Soldaten bzw. deren Umfeld als Verwender der Statuetten in Frage kommen. Die Basis mit dem Löwenjagdrelief aus Messene wurde in einer Stadt gefunden, die das Fortbestehen ihrer Unabhängigkeit von Sparta auch Makedonien verdankte. Die Häufung von Siegelabdrücken im Archiv der Stadt Kallipolis ist eine Folge der zufällig günstigen Überlieferungsbedingungen und des sehr ungleichmäßigen Publikationsstandes im Bereich der Sphragistik. Siegelabdrücke mit Darstellungen hellenistischer Könige mit Kausia werden sich in Folge des politischen und wirtschaftlichen Gewichtes der Diadochenreiche in den Archiven der meisten Städte der hellenistischen Welt befunden haben. 


\section{Königliche Neugründungen}

Wiedergaben der Kausia finden sich in den königlich-makedonischen Städteneugründungen auf dem Balkan in der Koroplastik (Tk 307-334) und vereinzelt auf bemalten Grabstelen (Ma 8-10).

Auch in diesen Städten dient die Kausia der Unterscheidung der makedonischen oder makedonisierten Neusiedler von der nicht-makedonischen Umgebung (vgl. Alexandria „bei“ Ägypten, Seleukia am Tigris). Die vermehrte Darstellung von Chlamydephoren-Typen in der Koroplastik und auf bemalten Grabstelen entspricht der Bedeutung des Gymnasion in diesen Städten.

\section{Griechische Poleis auf der Krim / Bosporanisches Reich}

In den Städten des Bosporanischen Reiches wurden vereinzelt Terrakotten mit Kausia (Tk 335-345) entdeckt.

Die Griechenstädte der Krim und der angrenzenden Gebiete waren niemals von Makedonien abhängig, sondern autonom bzw. im Bosporanischen Reich zusammengeschlossen. Dennoch wurden auch aus dieser Gegend bildliche Wiedergaben der makedonischen Kausia gefunden.

Das Typenspektrum der Terrakotten mit Kausia aus dieser Region entspricht jedoch eher dem der westgriechischen Gebiete. Es werden regional vorherrschende Typen vereinzelt mit der Kausia verbunden, ohne dass Rücksicht auf die gesellschaftliche Bedeutung der Kausia in den makedonisierten Gebieten und ihre dort bestehende Bindung an bestimmte Typen genommen würde.

\section{Zusammenfassung: Balkanhalbinsel}

Auf der Balkanhalbinsel erscheinen bildliche Wiedergaben der Kausia in der Koroplastik (Tk 186-347), der Rundplastik (P 4), auf Reliefs (Re 2-5), in der Malerei (Ma 5-10), der Numismatik (Nu 1-7) und Sphragistik (Si 5-9) sowie auf einer Kamee (Ka 3) (vgl. Karten1-3, 5, 7). Die relativ gleichmäßige Verteilung auf die verschiedenen Gattungen auf dem Balkan als Großregion verdeckt, dass einzelne Gattungen und Typen jeweils in bestimmten Unterregionen vorherrschen bzw. fehlen. Die Region bietet ein verkleinertes Abbild der hellenistischen Welt.

\subsubsection{Westliches Mittelmeer}

Vereinzelt finden sich bildliche Wiedergaben der Kausia auch im westmediterranen Bereich. Es handelt sich um zwei Wandmalereien und ein Mosaik aus Pompeii und Umgebung (Ma 1112, Mo 1) sowie Terrakotten aus Italien (einschließlich Sizilien) und den französischen Alpen (Tk 346-370) (vgl. Karten1-3, 7).

Bei den Terrakotten handelt es sich bis auf Ausnahmen um Exemplare, die lokal vorherrschende Typen von Statuetten mit der Kausia als modischer Kopfbedeckung verbinden, ohne 
Rücksicht auf die gesellschaftliche Funktion der Kausia im ostmediterranen Raum zu nehmen.

Die Darstellungen in anderen Gattungen zeigen überwiegend Kopien nach östlichen Vorbildern. ${ }^{773}$

\subsubsection{Zypern}

Auf Zypern erscheinen Darstellungen der makedonischen Kausia in der Koroplastik (Tk 371372, 374-375, 378), der Rundplastik (P 5-34), auf Münzen (Nu 14-24) und auf Siegeln (Si $10-$ 15) (vgl. Karten 1-3, 5). ${ }^{774}$

In hellenistischer Zeit gehörte die Insel, abgesehen von kurzen Unterbrechungen, zum Ptolemäerreich. ${ }^{775}$ Verwaltungshauptstadt war anfangs Salamis. Nachdem die Ptolemäer im 5. Syrischen Krieg weite Teile ihrer asiatischen Besitzungen einschließlich Koilesyriens verloren hatten, stieg die Bedeutung Zyperns innerhalb des Ptolemäischen Reiches. Die Folge war u.a. die Verlegung des Verwaltungszentrums in das sowohl Alexandria als auch der Ägäis näher gelegene Nea Paphos (ab 192/1 v.Chr.). ${ }^{776}$ Verbunden mit der ptolemäischen Herrschaft war eine Bereicherung der Bevölkerung durch ptolemäische Verwaltungsbeamte sowie Militärangehörige. ${ }^{777}$ Diese dürften teilweise makedonischer Herkunft gewesen sein. Die hellenistischen Neu- bzw. Wiedergründungen hießen allesamt Arsinoe und waren von eher geringer Bedeutung und vorwiegend mit einheimischer Bevölkerung besiedelt. ${ }^{778}$

Eine Veränderung der Bevölkerungsstruktur durch makedonisch-griechische Neubesiedlung ist abgesehen von dem oben erwähnten Herrschaftspersonal nicht erkennbar.

Diejenigen Städte Zyperns, die sich mit Kausiadarstellungen in Verbindung bringen lassen, können in zwei Gruppen geteilt werden. Einerseits sind die Orte zu nennen, die eine Funktion in der ptolemäischen Verwaltung innehatten und in denen mit der Anwesenheit von ptolemäisch-makedonischen Verwaltungs- und Militärpersonal zu rechnen ist. Dies sind die Residenz

\footnotetext{
${ }^{773}$ Vgl. zur Kausia auf Zypern unten Kap. 4.1 (Zypern).

${ }^{774}$ Hinzu kommen Wiedergaben einer regionalen, zyprisch-phönizischen Kopfbedeckung, die der makedonischen Kausia weitgehend gleicht (*Tk 373, 376x-377x). Zu diesen phönizisch-zyprischen Kopfbedeckungen vgl. unten „Exkurs: Eine kausiaähnliche Mütze im zypriotisch-phönizisch-punischen Raum“.

${ }^{775}$ Vgl. allg. RE XII (1925) 103 ff. s.v. Kypros (Oberhummer).

${ }^{776}$ G. Hölbl, Geschichte des Ptolemäerreiches (1994) 126.

777 Die beiden höchsten Beamten waren der Stratege und der Oikonomos. Die Strategen waren teils makedonischer teils griechischer Herkunft, zu den Oikonomoi liegen keine Angaben vor (R. S. Bagnall, The Administration of the Ptolemaic Possessions outside Egypt [1976] 40 ff. 253 ff.). Unter den 69 namentlich bekannten ptolemäischen Garnisonssoldaten (Vgl. R. S. Bagnal a.a.O. 263 ff.) finden sich keine Makedonen im engeren Sinne, wenn man von insgesamt vier Männern aus Alexandria, Antiochia und Lysimacheia, hinter denen sich solche verbergen könnten, absieht. Als Ethnika werden neben diesen drei Städten genannt: Persien, Kalymnos, Andros, Arkadien, Kardia, Aspendos, Kyrene, Kreta, Byzanz, Thessalien, Naxos, Amphipolis, Antandros, Xanthos, Arados, Euhesperia, Mytilene, Kadyana, Limyra, Myra, Patara, Tlos, Karystos, Thrakien, Sidon, Babylon, Libyen, Illyrien, Milet, Stratonikeia, Athen, Tarsos, Ephesos, Magnesia und Hypaipa.

${ }^{778}$ G. M. Cohen, The Hellenistic Settlement in Europe, the islands, and in Asia Minor (1995) 134-6: ArsinoeMarion, Arsinoe bei Alt-Paphos, Arsinoe bei Salamis.
} 
des Strategen, d.h. Salamis bis 192/1 v. Chr., danach Nea Paphos, sowie die Münzprägestät$\operatorname{ten}^{779}$ Salamis, Nea Paphos und Kition. Andererseits gibt es die übrigen Ortschaften, in denen von geringer ptolemäisch-makedonischer Beeinflussung auszugehen ist.

Das Fundmaterial lässt sich bezeichnenderweise ebenfalls in zwei Gruppen einteilen. Die mit Verwaltung und Herrschaft zu verbindenden Münzen und Siegel stammen aus Salamis, Kition und Nea Paphos, was angesichts der Funktion dieser Städte nicht verwundert. Die kausiatragenden Votivfiguren aus Kalkstein und Terrakotta wurden im Gegensatz hierzu nicht in den Zentren $^{780}$, sondern den eher traditionell gebundenen Gebieten ${ }^{781}$ einschließlich des gebirgigen Inselinneren gefunden. Hier ist wohl in erster Linie mit einheimischen, gerade in religiösen Belangen nur oberflächlich von hellenistischen Phänomenen beeinflussten Besuchern der alten Heiligtümer zu rechnen und nur in geringem Umfang mit griechisch-makedonischen Einwanderern.

\subsubsection{Orient}

Im Vorderen und Mittleren Osten (ohne Kleinasien) finden sich bildliche Wiedergaben der Kausia in folgenden Gattungen: Koroplastik (Tk 379-380b, 383-384, 387a-452), Rundplastik (P 35), Numismatik (Nu 26-36 sowie Nu 25 [Tonmodell einer Münze?]) und Sphragistik (Si 16-20) (vgl. Karten 1-3, 5).

Der Orient lässt sich in drei größere Regionen (Levante, Mesopotamien, Baktrien) aufteilen, die teils weiter untergliedert werden können.

Aus dem phönizisch-syrischen Raum stammen die Terrakotten Tk 379-380b, 383-384, 387a405. In Mesopotamien und den südlich und südöstlich angrenzenden Regionen (Insel Failaka, Susiane) erscheinen Wiedergaben der Kausia in Verbindung mit Tonfiguren (Tk 406-452) und einmal in der kleinformatigen Rundplastik (P 35) sowie auf einer „Tonmünze“ (Nu 25) und Siegelabdrücken (Si 16-20). In Baktrien und den indo-griechischen Reichen kommen Kausiadarstellungen ausschließlich auf Münzen ( $\mathrm{Nu} 26-36)$ vor.

Baktrien und die indo-griechischen Reiche stellen, sowohl was das Fundmaterial betrifft (ausschließlich Münzen) als auch aufgrund ihrer Rolle als Außenposten der hellenistischen Kultur, einen Sonderfall dar. Die Terrakotten aus Mesopotamien sind wie im Westen jeweils mit großen städtischen Neugründungen, Militärkolonien und/oder Garnisonen zu verbinden und weisen ein entsprechendes Typenspektrum auf. Sie können insbesondere im handwerklichen Bereich einheimische Traditionen aufnehmen. Im phönizisch-syrischen Küstenbereich vermischen sich verschiedenen Einflusszonen (u.a. ptolemäische Garnisonen, seleukidische Sied-

\footnotetext{
${ }^{779}$ Amathous diente nur 170-68 v. Chr. als Ersatzprägestätte für Paphos vielleicht infolge kriegerischer Ereignisse im Verlauf des 6. Syrischen Krieges (O. Mørkholm/A. Kromann, Chiron 14, 1984, 152).

${ }^{780}$ Ausnahmen bilden Tk 378 aus Kition und Tk 375 aus Amathous.

${ }^{781}$ Vgl. Tk 374 (Cythrea), P 5 (Kourion), P 6 (Nikosia), P 7 (Voni), P 10, 18-30 (Golgoi), P 11-12, 15-17 (Idalion), P 13-14 (Tamassos), P 31 Agios Phokas (nahe Kythrea/Vouni). Nur allg. „Zypern“ zuordnen lassen sich Tk 371-374 und $\mathrm{P}$ 8-9, 32-34.
} 
lungskolonien). Zusätzlich ist in Phönizien von einer einheimischen kausiaähnlichen Kopfbedeckung auszugehen.

\subsubsection{Exkurs: Eine kausiaähnliche Mütze im zypriotisch-phönizisch- punischen Raum}

Im Aussehen mit der makedonischen Kausia identische Kopfbedeckungen erfreuen sich, wie schon erwähnt, auch in anderen Regionen und in anderen Epochen einer gewissen Beliebtheit (beispielsweise im prähistorisch-antiken Italien oder im modernen Afghanistan/Pakistan). Verwechslungen sind jedoch auf Grund des räumlichen oder zeitlichen Abstands vom Hauptverbreitungsgebiet der Kausia in der Regel ausgeschlossen. ${ }^{782}$

Eine Ausnahme bilden Phönizien, die Insel Zypern mit ihrer teils griechisch, teils phönizisch geprägten Kultur sowie die phönizisch-punischen Koloniestädte im Westen, in dieser Arbeit vertreten durch Sulcis auf Sardinien. In diesem Bereich waren im Altertum das Tragen von Kopfbedeckungen und auch die Darstellung mit diesen üblich. Unter diesen findet sich auch eine Mütze, die sich in bildlichen Wiedergaben im Aussehen nicht von der makedonischen Kausia unterscheiden lässt. Da diese Kopfbedeckung jedoch zumindest auf Zypern seit spätestens der archaischen Zeit nachzuweisen ist, kann es sich nicht um die makedonische Kausia handeln. Diese Mütze erscheint auch im benachbarten Phönizien und im punischen Bereich. Der gemeinsame Nenner dieser Gebiete ist in ihrer Zugehörigkeit zum phönizischen Kulturkreis zu sehen ist. Es handelt sich daher wahrscheinlich um eine gemein-phönizische Kopfbedeckung. Phönizien und Zypern gehörten jedoch in hellenistischer Zeit als Teil des Alexanderreiches und seiner Nachfolgestaaten zum potentiellen Verbreitungsgebiet der makedonischen Kausia. Es stellt sich daher die Frage, ob bildliche Wiedergaben von kausiaähnlichen Mützen aus hellenistisch-römischer Zeit in diesem Bereich mit der Kausia oder einer phönizischen Kopfbedeckung in Verbindung zu bringen sind.

Diese Frage ist derzeit nicht eindeutig zu beantworten, da beispielsweise nicht bekannt ist, ob die betreffenden Statuetten von einheimischen Phöniziern oder Zyprioten oder zugewanderten „Makedonen“ geweiht wurden oder es zu einem Verschmelzen beiden Mützen gekommen ist. Als phönizische Mützen werden hier versuchsweise solche Kopfbedeckungen angesprochen, die im Rahmen von Darstellungen erscheinen, die weitere Beziehungen zu phönizischen Kultur aufweisen. $\mathrm{Zu}$ nennen sind die Kombination mit anderen phönizischen Trachtelementen oder die Herstellung in einheimischer Handwerkstradition (handgeformte Terrakotten).

Die gleichzeitige Existenz der makedonischen Kausia und einer äußerlich identischen zyprisch-phönizisch-punischen Mütze in den hier angesprochenen Regionen kann die Akzeptanz und Verwendung dieser Kopfbedeckungen beeinflusst haben oder zu Mischformen und inhaltlichen Überschneidungen geführt haben. Näheres lässt sich auf Grund der schlechten Quellenlage jedoch nicht feststellen.

\footnotetext{
${ }^{782}$ Zum Problem kausiaähnlicher antiker Kopfbedeckungen auf den Balkan bzw. einer allgemeinen Verbreitung der dann nicht nur „,makedonischen“ Kausia auch bei den Illyrern, Paionen und Thrakern vgl. oben.
} 


\subsubsection{Zypern}

Auf Zypern wurden in der Antike verschiedene Kopfbedeckungen getragen und u.a. auch in der Koroplastik wiedergegeben. Es handelt sich meist um Darstellungen von Reitern oder Wagenlenkern. Einige dieser Kopfbedeckungen gleichen im Aussehen der Kausia weitgehend. Da entsprechende Statuetten seit archaischer Zeit ${ }^{783}$ nachweisbar sind, ist eine Identifizierung dieser Mützen mit den makedonischen Kausien auszuschließen.

Handgeformte zypriotische Tonfiguren mit kausiaähnlicher Mütze der Zeit vom Ende des 4. Jahrhunderts bis um Christi Geburt stammen fast ausschließlich aus dem Apollon-Heiligtum von Kourion (*Tk 377 x), einige auch aus dem Aphrodite-Adonis-Heiligtum von Amathous (*Tk 376 x). Die Tonfiguren stehen sowohl typologisch (Wagenlenker, einzeln gearbeitete Reiter) als auch handwerklich (handgeformte Figuren, denen von griechischen Statuetten abgeformte Gesichter aufgestempelt wurden) in einheimischer, vorhellenistischer Tradition. Die Anzahl der Statuetten lässt sich infolge der nur auf die Identifizierung und Bearbeitung der Gesichtsstempel („molds“) ausgerichteten Publikationsweise derzeit nicht näher bestimmen. Es handelt sich wahrscheinlich um eine zwei- bis dreistellige Zahl. ${ }^{784}$

Auf Zypern lassen sich seit dem ausgehenden 2. Jahrtausend drei Volksgruppen nachweisen: die Griechen in Salamis, Kourion, Paphos, Marion, Soloi, Lapethos, Golgoi, Idalion, Tamassos, Ledra und Chytroi, die Phönizier in Kition sowie teilweise in Idalion, Tamassos, Marion

\footnotetext{
${ }^{783}$ Vgl. z.B. die archaischen Tonfiguren aus Agia Irini in E. Sjöqvist, Swedisch Cyprus Expedition II (1935) Nr. 259 S. 683 Taf. 229; Nr. 1219 S. 716 Taf. 231; Nr. 1796 S. 741 Taf. 213 sowie A. Caubert,Das Ende der Archaik und die klassische Epoche, in: Aphrodites Schwestern und das christliche Zypern, Ausstellungskatalog Bremen 1987, 83 (Quadriga-Wagenlenker wie auch später im hellenistischen Kourion üblich).

${ }^{784} \mathrm{~J}$. H. Young/S. H. Young, Terracottafigurines from Kourion in Cyprus (1955) nennen 16 Statuetten mit Kausia (Nr. 2355, 2374, 2402, 2593, 2594, 2647, 2648, 2649, 2961-65, 2967, 2978, 2996) .- N. Winter, SIMA 109, 1996, 89 ff. bezeichnet die Kopfbedeckungen von sechs Statuetten (Nr. 988, 1927-30, 1941-42) als „,causia or beret“" (= headdress 32) und von drei weiteren Figuren (Nr. 1390, 1392, 1606) als ,causia with headband“ (= headdress 34). Zusammen ergibt dies bis zu 25 Terrakotten mit kausiähnlicher Kopfbedeckung (alles Reiter oder Wagenlenker, Ende 4. Jh. v.Chr. bis 1. Jh. n.Chr.). Da sich die erwähnten Katalognummern keiner Abbildung zuweisen lassen, ist eine Überprüfung der Benennungen nicht möglich. - Unter den wenigen in Verbindung mit der Katalognummer abgebildeten Exemplaren befinden sich einige, bei deren Kopfbedeckungen es sich um kausiaähnliche Mützen handelt, die aber von den Bearbeitern nicht als „causia[i]“ benannt werden (vgl. z.B. J. H. Young/S. H. Young a.a.O. Nr. 2934 [low tiara], 2990 [flat cap], 3016 [flat cap and fillet] und N. Winter a.a.O. Nr. 469 und 486 [douple turban]). Die Anzahl der Terrakotten, die von oben genannten Autoren als mit „low tiara“, „flat cap“, „double turban or beret-like cap“ usw. versehen bezeichnet wird, geht in die Hunderte. Young/Young und Winter bilden den größter Teil der Statuetten unter alleiniger Nennung der Mold-Nummer ab, ohne dass die Möglichkeit bestände, diese mit einer Katalognummer zu verbinden. Unter diesen befinden sich viele, die der Kausia sehr (J. H. Young/S. H. Young a.a.O. Taf. 32 Mold 11A.- N. Winter a.a.O. Taf. 19 Abb. 28CA1. 29D. 33H3; Taf. 21 Abb. 44P1. 45PP3. 46Q1 ff.; Taf. 22 Abb. 47QQ2. 48T2) oder relativ ähnlich sind (J. H. Young/S. H. Young a.a.O. Taf. 36 Nr. 2843. 2622. 2770. 2536.2725; Taf. 37 Nr. 2905; Taf. 38 Mold 3B3; Taf. 39 Mold 6B; Taf. 42 Mold 26. 27. 28B; Taf. 43 Mold 32B. 33A. 33C1. 33C2; Taf. 44 Mold 31A. 35-37; Taf. 45 Mold 44; Taf. 46 Nr. 2915. 2918; Taf. 51 Nr. 1996; Taf. 52 Mold 54A. 51. 49; Taf. 56 Mold 1 .- N. Winter a.a.O. Taf. 19 Abb. 25AA; Taf. 21 Abb. 43; Taf. 22 Abb. 52; Taf. 26 Abb. 87f; Taf. 29 Abb. 123. 125). Die Publikationen sind jedoch einseitig auf die Identifizierung und Bearbeitung der Gesichtsstempel (,molds“) ausgerichtet. Die Abbildungen sind daher meist jeweils nur mit der Nummer des Stempels gekennzeichnet. Da sich hinter einzelnen Stempeln Dutzende von Statuetten mit unterschiedlichsten Kopfbedeckungen verbergen können, ist die Verbindung der abgebildeten Exemplare mit einzelner Katalognummer nicht möglich. Die Bezeichnungen der Autoren für bestimmte Kopfbedeckungen sind hierdurch nicht nachprüfbar.
} 
und Lapethos und die „Urbevölkerung“, die so genannten Eteozyprer ${ }^{785}$, in Amathous sowie vereinzelt in Golgoi und Alt-Paphos. ${ }^{786}$ Auf der gesamten Insel ist mit unterschiedlich starker Durchmischung der Bevölkerung sowie gegenseitiger kultureller Beeinflussung zu rechnen. Ethnische Konflikte sind nicht nachweisbar. ${ }^{787}$

Die kausiaähnlichen zyprischen Mützen wären demnach dem griechischen bzw. eteozyprischen Bevölkerungsteil (Kourion, Amathous) zuzuweisen. Auf Grund einerseits der in der Forschung angenommenen Durchmischung und der gegenseitigen kulturellen Beeinflussung und andererseits der vermutlich lückenhaften Quellenlage muss dieses Ergebnis nicht repräsentativ sein.

\subsubsection{Phönizien}

Aus einem Heiligtum bei Kharayeb (nahe Sidon) stammen 15 Tonfiguren (*Tk 381a-382g Taf. 19 Abb. 72), die junge stehende Männer zeigen, die eine der Kausia gleichende Kopfbedeckung, einen langen Chiton und einen über die linke Schulter geworfenen schmalen (Stoff-?) Streifen tragen. Bei diesem handelt es sich wahrscheinlich um einen orientalischen (Gebets-) Mantel (hebr.: Tallit), ${ }^{788}$ wie er auch auf der Priesterstele aus Umm el-Amad ${ }^{789}$ (* Re 6, Taf. 20 Abb. 74) und den Grabstelen aus der punisch-sardischen Stadt Sulcis (*Re 7-9, Taf. 20 Abb. 75-76) zu beobachten ist. Zumindest Chiton und Tallit stellen demnach eine regelmäBig in phönizischen Gebieten wiederkehrende Tracht dar.

Vier weitere Figuren aus Kharayeb (*Tk 385-386, Taf. 19 Abb. 73) zeigen eine tanzende männliche Person. Diese ist mit einer kausiaähnlichen Mütze ${ }^{790}$ und Mantel bekleidet. Die Statuette steht auf dem rechten Bein, das linke ist abgespreizt. Der Mantel wird mit beiden Händen (der linke Arm ist weit ausgestreckt) angehoben, so dass die Genitalien zu sehen sind. Tanz und Entblößung würden im griechischen Kontext in den dionysischen oder aphrodisischen Bereich weisen. In Kharayeb wurden ebenfalls Terrakottafiguren von tanzenden Mäd-

\footnotetext{
${ }^{785}$ Die Existenz einer eteozyprischen Bevölkerungsgruppe ist in der neueren Forschung umstritten. Vgl. A. Mehl, Griechen und Phöniker im hellenistischen Zypern - ein Nationalitätenproblem?, in: B. Funck (Hrsg.), Hellenismus. Beiträge zur Erforschung von Akkulturation und politischer Ordnung in den Staaten des hellenistischen Zeitalters (Akten des Internationalen Hellenismus Kolloquiums, 9.-14. März 1994 in Berlin) (1996) 374 mit Anm. 4.

${ }^{786}$ J. Seibert, Zur Bevölkerungsstruktur Zyperns, AncSoc 7, 1976, 1-28.

${ }^{787}$ A. Mehl, Griechen und Phöniker in hellenistischer Zeit - ein Nationalitätenproblem, in: B. Funck (Hrsg.), Hellenismus. Beiträge zur Erforschung von Akkulturation und politischer Ordnung in den Staaten des hellenistischen Zeitalters (Akten des Internationalen Hellenismus Kolloquiums, 9.-14. März 1994 in Berlin) (1996) 377414 (bes. 406).

${ }^{788}$ So A. Parrot/M. Chéhab/S. Moscati, Die Phönizier (1977) 118, die den Gebetsmantel jedoch als „Tefillin“ (Gebetsriemen) bezeichnen. - Chéhab, Kharayeb, 59 erwähnt einen Hinweis von J. Charbonneux, nach dem es sich auch um einen in Syrien üblichen lang gestreckten Geldbeutel („Kamar“) handeln könnte.

${ }^{789}$ In Umm el-Amed wurde auch ein Terrakottakopf mit Kausia (Tk 381) gefunden, dessen Deutung entsprechend unklar ist.

${ }^{790}$ Die Kopfbedeckung ist nicht eindeutig zu erkennen. Der Hinterkopf wird vom Mantel bedeckt. Es könnte sich auch um eine Wulstbinde oder ähnliches handeln.
} 
chen, die den Körper nicht entblößen, gefunden. Die Statuetten, deren Gewandgestaltung vergleichbar ist, werden ins 3. - 2. Jahrhundert v. Chr. datiert. ${ }^{791}$

\subsubsection{Punisch-Sardinien}

Aus der punischen Stadt Sulcis auf Sardinien stammen Grabreliefs (*Re 7-9, Taf. 20 Abb. 7576) aus dem 2.-1. Jahrhundert v. Chr., die Männer in Chiton, Tallit (Mantel) und kausiaartiger Mütze zeigen. Diese halten ein Tanit-Symbol in ihrer rechten Hand. Sie werden demnach nach Fundort, Kleidung und Attribut als Phönizier gekennzeichnet. Dies deutet, wie ähnliche Erscheinungen auf dem teilweise phönizisch bevölkerten Zypern, darauf hin, dass es an der Levante eine regionale Kopfbedeckung gab, die optisch nicht von der makedonischen Kausia zu unterscheiden ist.

\subsection{Die Kausia in unterschiedlichen Bildgattungen}

\subsection{1 (Rund-) Plastik}

Rundplastische, steinerne Darstellungen der Kausia sind selten (vgl. Karte 2). Aus einigen Regionen sind keine Beispiele bekannt (Kleinasien, Westen). In den meisten anderen Regionen erscheinen sie selten (Ägypten [3x], Mesopotamien [1x], Nordgriechenland [1x?]). Nur Zypern weist mit 29 Exemplaren eine größere Anzahl auf. Abgesehen von wenigen Ausnahmen $^{792}$ sind sie kleinformatig. ${ }^{793}$ Gemeinsam ist den meisten Darstellungen (P 1, 5-34), dass sie von nicht-griechischen Traditionen und Darstellungskonventionen beeinflusst sind. ${ }^{794}$ Viele steinerne Wiedergaben sind mit ähnlichen Darstellungen in der Koroplastik durch Übereinstimmungen in der Typologie und Thematik ${ }^{795}$ sowie der Verwendung als Votiv ${ }^{96}$ verbunden.

\subsubsection{Relief}

Auch im Relief sind bildliche Wiedergaben der Kausia selten (vgl. Karte 2). Im Gegensatz zu den rundplastischen Darstellungen verteilen sich die Reliefs jedoch gleichmäßiger (Griechen-

\footnotetext{
${ }^{791}$ A. Parrot/M. Chéhab/S. Moscati, Die Phönizier (1977) 122 Abb. 130 f.

${ }^{792}$ Lebensgroß sind das Porträt Ptolemaios XV. (P 1)und der Kopf aus Thasos (P 5, mit Kausia?).

${ }^{793}$ Von den zyprischen Votivfiguren (P 5-34) erreichen die hockenden Knaben zwischen 16 und 30,6 cm, die stehenden Chlamydephoren 14,4 bis 52,5 cm und die Kopffragmente 4,5 bis 14,8 cm. Die Köpfchen aus Memphis (P 3) und Seleukia/T. (P 35) messen 3 bzw. 3,9 cm. Der dickbäuchige Chlamydephoros/Soldat (P 2) erreicht insgesamt nur $6 \mathrm{~cm}$.

${ }^{794}$ P 1 (Porträt Ptolemaios XV.) folgt teils ägyptisch-pharaonischen Vorbildern, P 5-34 stehen in der Tradition zyprischen Votivstatuetten.

${ }^{795}$ P 2 (dickbäuchiger Chlamydephoros/Soldat) entspricht weitgehend den Terrakotten Tk 108 und 351. Hockende Knaben (P 5-9, sog. „temple boys“) erscheinen auch in der Koroplastik (Vgl. z.B. Winter, Typen II, 266, 268 f.). Mit P 11 (Chlamydephoros/“Ephebensoldat") und P 12 (Chlamydephoros, stehend) vergleichbare Statuetten erscheinen zu Hunderten in der Koroplastik.

${ }^{796}$ Sämtliche rundplastischen Wiedergaben, deren Fundorte in ausreichendem Maße bekannt sind, stammen aus Heiligtümern (P 5, 6 [?], 7, 11-14, 15-17 [?]; alle aus Zypern).
} 
land, Makedonien, Schwarzmeerküste, Kleinasien) über das Gesamtverbreitungsgebiet. Die breite Streuung deutet an, dass ein Bezug zu den Zentren der makedonischen Siedlungstätigkeit nicht besteht. Es werden jeweils Hinweise zu Einzelaspekten gegeben: So bietet das Relief aus Pergamon (Re 1) einen der archäologischen Belege für eine militärische Nutzung, wie sie in der literarischen Überlieferung im Vordergrund steht. Das Grabrelief aus Vergina $(\operatorname{Re} 2)$ zeigt eine der frühesten Wiedergaben der Kausia und kann als Indiz für die makedonische Herkunft der Kopfbedeckung verstanden werden. Bei den Strategenreliefs aus Mesambria (Re 3-4) ist unklar, ob die dargestellte „Kausia“ aus Makedonien oder dem benachbarten Thrakien eingeführt wurde (Re 3-4). In der Reliefbasis aus Messene ( $\operatorname{Re} 5)$ ist in erster Linie ein Beitrag zur Ikonographie des Krateros und der Löwenjagd zu sehen.

\subsubsection{Malerei und Mosaik}

Im Gegensatz zu den Darstellungen in der Rundplastik und im Relief stammen die bildlichen Wiedergaben der Kausia in der Flächenkunst (Malerei, Mosaik) in erster Linie aus denjenigen Gebieten, die auch von „Makedonen“ bewohnt wurden. Dies sind einerseits die neugegründeten Städte Alexandria (Ma 1-4) und Demetrias (Ma 8-10) und andererseits Makedonien selbst (Ma 5-6). Bei den Beispielen aus Italien handelt es sich zumindest beim Alexandermosaik (Mo 1) und wohl auch bei der Makedonia aus der Villa von Boscoreale (Ma 11) um Importstücke aus hellenistischen Königsresidenzen bzw. die Kopien entsprechender Vorbilder. Da Darstellungen von Soldaten-Schauspielern mit Kausia sonst in erster Linie aus dem ptolemäischen Ägypten bekannt sind, ist vielleicht auch die Theaterszene aus Pompeii (Ma 12) von dort entlehnt. Das Grabmal von Kasanlak (Ma 7) verweist wiederum auf eine thrakische Variante der Kausia. Die geographische Verbreitung von Kausiadarstellungen in der Flächenkunst entspricht demnach ansatzweise derjenigen der koroplastischen Wiedergaben (vgl. Karte 2 und 3).

Die Thematik ist abhängig von den Auftraggebern: Oberschichtspezifische Themen (Krieg, Herrschaft, Jagd, Gelage) finden sich in den großen Gräbern (Ma 5-7) und den mit Palästen (Ma 11, Mo 1) in Verbindung gebrachten Darstellungen. Die einfacheren Grabstelen (Ma 1-3) wie auch die Theaterszene (Ma 12) zeigen Makedonen als Chlamydephoroi in militärischem Kontext. Nur die Stelen aus Demetrias (Ma 8-10) folgen teils Traditionen, die dem attischen Bürgerideal verhaftet sind, das durch die Verbindung mit der Kausia (und der Chlamys) makedonisiert wird.

Abgesehen von den im Westen gefundenen Darstellungen gehören alle Beispiele dem sepulkralen Bereich (Ma 1-10) an.

\subsubsection{Münzen}

Darstellungen der Kausia erscheinen auf Münzen aus Paionien, Illyrien und Amphipolis (makedonische Reichsprägung), aus dem ptolemäischen Zypern, vielleicht aus Seleukia am Tigris 
(Tonmodell), aus Baktrien und Indien und auf römischen Prägungen der späten Republik und der Kaiserzeit. Der zeitliche Rahmen reicht vom späten 4. Jahrhundert v.Chr. bis ins 2. Jahrhundert n.Chr. Die breite geographische und chronologische Streuung täuscht jedoch.

Die Münzbilder lassen sich in drei nach Ikonographie und Funktion klar getrennte Gruppen aufteilen (vgl. Karte 4): Die erste Gruppe besteht aus Münzen, die auf der Vorderseite das Porträt des Herrschers mit Kausia diadematophoros zeigen. Sämtliche ${ }^{797}$ Beispiele stammen aus Baktrien und den indo-griechischen Reichen (Nu 26-36). Der Hinweis auf die Nachfolge in der Herrschaft Alexanders und die makedonische Militärtradition war vielleicht gerade für die Könige dieser Reiche am Ende der hellenistischen Welt, die ihr Königtum nur indirekt über die Seleukiden von dem Alexanders ableiten konnten und meist keine Makedonen waren, von besonderer Wichtigkeit. Alle anderen Diadochenkönige nahmen, obwohl sie ihre Herrschaft direkt auf Alexander zurückführen konnten und aus Makedonien stammten, in der Selbstdarstellung zumindest in der Münzprägung keinen Bezug auf die Kausia.

Die zweite Gruppe zeigt ebenfalls nicht die einfache Kausia, sondern die mit dem Diadem umwundene. Die entsprechenden Emissionen wurden im späten 4. Jahrhunderts in der makedonischen Reichsmünzstätte von Amphipolis (Nu 6-7) sowie im 2. Jahrhundert v.Chr. in ptolemäischen Münzstätten auf Zypern (Nu 14-24) geprägt. Diese zeigen auf der Rückseite jeweils die Kausia diadematophoros als kleines Beizeichen. Hinter den Darstellungen eines Symbols des makedonischen Königtums verbirg sich wahrscheinlich die Demonstration des Nahverhältnisses von Münzprägebeamten zum Herrscher.

Die dritte Gruppe ist weniger homogen. Gemeinsam ist den betreffenden Münzen jedoch, dass die Kausia kein Diadem aufweist und entsprechend auch kein Bezug auf einen Herrscher genommen wird. Die Kausia erscheint stattdessen als Kopfbedeckung eines Gottes (Nu 4-5 [Labeaten/Illyrien] mit dem Porträt des Gottes Redon), von Personifikationen (Nu 8-12 [Rom] mit einer weiblichen Macedonia) sowie vermutlich in Zusammenhang mit einem Heroenkult (Nu 1-3 [Paionien] Gegner eines Reiterheroen). Die mit Kausia dargestellten Personen sind demnach dem irrealen, meist mehr oder weniger religiösen Bereich entnommen. Gemeinsam ist diesen Prägungen auch, dass sie im Ursprungsgebiet der Kausia (Makedonien und nördlich angrenzende Stammesgebiete) geschlagen wurden bzw. (im Fall der römischen Personifikationsmünzen) auf dieses verweisen.

Kausien können im numismatischen Bereich demnach drei Funktionen erfüllen: Herrschaftssicherung durch Verweis auf Alexander und die makedonische Militärtradition, Demonstration der Nähe zur Macht sowie die Symbolisierung einer Region bzw. eines Stammes durch die Darstellung einer Person oder eines Gottes mit der landestypischen Kopfbedeckung. Mit diesen funktionsbedingten Gruppen stimmen drei geographische Bereiche (Baktrien/Indien, östliches Mittelmeer, Balkanhalbinsel) überein.

\footnotetext{
${ }^{797}$ Eine Ausnahme bildet das in Seleukia am Tigris gefundene Tonmodell einer Münze (Nu 25). Bei dieser „Münze“ handelt es sich jedoch möglicherweise um eine Nachahmung der baktrischen Prägungen.
} 


\subsubsection{Kameen}

Hellenistische Könige trugen nach Aussage der literarischen Quellen regelmäßig die Kausia. In den bildlichen Wiedergaben ist dies die Ausnahme. Dies scheint einerseits gattungsbedingt zu sein, andererseits lässt sich fragen, ob es nicht in Einzelfällen bestimmte Gründe für die Darstellung des Königs mit Kausia gab. Die Deutung der Kameen wird durch die nicht ganz geklärte Identifizierung der wiedergegebenen Könige erschwert. Es handelt sich aber möglicherweise jeweils um einen der letzten Vertreter des ptolemäischen bzw. antigonidischen Königshauses (Ka 1-2: Ptolemaios VIII.-XII.; Ka 3: Philipp V./Perseus). Diese gerieten zunehmend mit Rom in Konflikt bzw. standen im Krieg mit den Römern. Eine solche Krisensituation könnte der Anlass gewesen sein, an das makedonische Nationalgefühl und den AlexanderMythos zu erinnern.

Die Kausia war als maßgeblicher Bestandteil der makedonischen Kleidung sowie als Mütze der hellenistischen Könige seit Alexander geeignet, beides zu leisten.

\subsubsection{Siegel (-abdrücke)}

Siegel - genauer Siegelabdrücke - mit Kausiadarstellungen wurden in Kallipolis (Aitolien), Nea Paphos (Zypern), Edfu (Oberägypten) und in Seleukia am Tigris gefunden. Es werden jeweils männliche Köpfe im Profil wiedergegeben, die als Kopfbedeckung eine Kausia tragen. Dokumente - sowohl öffentliche als auch private - sind in der Antike regelmäßig versiegelt und archiviert worden. ${ }^{798}$ Archive gab es in den Hauptstädten (z.B. Seleukia/Tigris) und Verwaltungszentren (z.B. Nea Paphos), aber auch in kleineren Orten (Kallipolis) und in Heiligtümern (Edfu/Philae [?]) und vermutlich auch im privaten Bereich. ${ }^{799}$ Die Anzahl der Siegelabdrücke muss unermesslich groß gewesen sein, ${ }^{800}$ erhalten blieb nur ein verschwindend geringer Teil. Dies ist darauf zurückzuführen, dass die Bullen (bullae) genannten Tonkugeln, in die die Siegel eingedrückt wurden, ungebrannt blieben und sich nur unter besonderen Bedingungen erhielten. Diese besonderen Bedingungen sind das heiße, trockene Klima Ägyptens oder ein Brand im Archiv, der die Bullen gehärtet, gleichzeitig aber die Papyri zerstört hat. Letzteres trifft auf die hier besprochenen Siegelabdrücke zu. Von den relativ wenigen erhaltenen

\footnotetext{
${ }^{798}$ Zur Praxis der Versiegelung von Dokumenten finden sich diverse Aufsätze in: Archives et Sceaux du monde hellenistique, BCH Suppl. 29 (Hrsgg.: M.-F. Boussac, A. Invernizzi) (Symposium Turin 1993) (1996). Vgl. dort u.a.: K. Vandorpe, Seals in and on the Papyri of Greco-Roman and Byzantine Egypt, 231 ff. Taf. 45 ff. und D. Berges, Der Fundkomplex griechischer Siegelabdrücke aus Karthago, 327 ff. Taf. 67 ff.

${ }^{799}$ Einen Überblick zum Gebrauch von Siegeln und über die wichtigsten Fundkomplexe bietet jetzt: D. Plantzos, Hellenistic Engraved Gems (1999) 18-34 (Seals and Seal Usage in Antiquity). Vgl. jetzt auch die Bemerkungen bei H.Kyrieleis, ders., Ägyptische Bildelemente auf Siegelabdrücken aus Nea Paphos (Zypern), StädelJb 19, 2004, 114f.

${ }^{800}$ So gehören z.B. zum Fund von Nea Paphos etwa 11000 Bullen mit je mehreren Abdrücken, darunter 1200, die Porträts zeigen (H. Kyrieleis, Ptolemäische Porträts auf Siegelabdrücken aus Nea Paphos [Zypern], in: Archives et Sceaux du monde hellenistique, BCH Suppl. 29 [Hrsgg.: M.-F. Boussac, A. Invernizzi] [Symposium Turin 1993] [1996] 315 ff.). Im „Stadtarchiv“ von Seleukia am Tigris wurden ca. 30000 Tonbullen gefunden (EAA V 2. Suppl. 1974-94 [1997] 210 ff. 212 s.v. Seleucia sull Tigri [A. Invernizzi]). Publiziert sind von diesen jeweils nur rund ein Dutzend.
} 
Abdrücken ist wiederum nur ein sehr geringer Teil publiziert. In angemessener Weise veröffentlicht sind von den hier relevanten Funden nur die Siegelabdrücke aus Kallipolis. ${ }^{801}$ Das übrige Material ist nur in minimalem Umfang in Form von Vorberichten bekannt gemacht worden. Solange die abschließenden Veröffentlichungen ${ }^{802}$ nicht vorliegen, sind die nachfolgend angestellten Deutungen, die aufgrund der beschriebenen Ausgangslage verhältnismäßig allgemein bleiben, unter entsprechendem Vorbehalt zu sehen.

Die Kausia wird auf Siegeln überwiegend in Verbindung mit den Porträts hellenistischer Könige ${ }^{803}$ wiedergegeben. Als Herrscherporträts werden hier Bildnisse angesprochen, die durch Diadem und/oder göttliche Attribute gekennzeichnet sind oder eindeutig anhand der Ähnlichkeit mit bekannten Bildnissen (z.B. auf Münzen) identifizierbar sind. Die übrigen Siegel werden als solche angesprochen, die Privatpersonen ${ }^{804}$ zeigen. In gewissem Umfang können sich auch hinter diesen Herrscherbildnisse verbergen, insbesondere wenn die Siegel nur teilweise abgedrückt sind und Hinweise auf Königsdarstellungen (z.B. Diadem [-enden]) auf diesem Weg verloren gegangen sind.

Das Material deckt den gesamten Zeitraum des Hellenismus - im politischen Sinne - ab, wobei es zu regionalen Verschiebungen kommt. Die letzten Siegel, die Personen mit Kausia zeigen, werden jeweils in die Zeit kurz vor der Eroberung des entsprechenden Gebietes durch die Parther bzw. Römer datiert.

Mit der Kausia als Kopfbedeckung werden Ptolemäer und Seleukiden dargestellt sowie vielleicht der Usurpator Timarchos und baktrische Könige. Das Fehlen weiterer Dynastien, z.B. der Antigoniden und der Attaliden, kann eine Folge der schlechten Erhaltungsbedingungen oder des mangelhaften Publikationsstandes sein. Ptolemäische Könige sind überrepräsentiert. Dies dürfte jedoch einerseits auf die Lage von zwei der vier Fundorte im ptolemäischen Bereich (Edfu, Nea Paphos) und andererseits auf den fortgeschrittenen Stand der Erforschung des ptolemäischen Porträts ${ }^{805}$ zurückzuführen sein. Zeitlich verteilen sich die Siegelbildnisse mit Kausia relativ gleichmäßig auf die gesamte hellenistische Zeit, beginnend mit Ptolemaios I. (posthum) bzw. Ptolemaios III. und Antiochos III. und endend mit Ptolemaios XV. Kaisarion. Berücksichtigt man, dass die Erforschung hellenistischer Siegelabdrücke noch ganz am Anfang steht, lässt sich vermuten, dass Vertreter aller großen hellenistischen Dynastien während der gesamten Zeit des Bestehens dieser Herrscherhäuser mit der Kausia dargestellt wurden. Dieses entspricht einer realistischen Wiedergabe der Bekleidung hellenistischer Könige, wie sie literarisch überliefert ist.

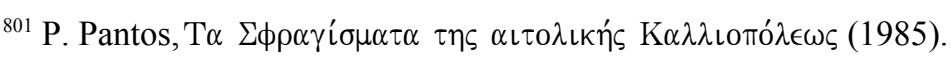

${ }^{802}$ Die Siegelabdrücke aus Nea Paphos, Edfu und Seleukia/Tigris werden seit längerem von H. Kyrieleis, D. Plantzos und A. Invernizzi bearbeitet.

${ }^{803}$ Ptolemaios I. (Si 1), Ptolemaios III. (Si 5), Ptolemaios IV. (Si 6), Ptolemaios X. (Si 10-12), Ptolemaios XV. (Si 13-14), unbestimmte Ptolemäer (Si 2-4, 15), Antiochos III. (Si 7), Demetrios II. (Si 16) sowie möglicherweise Timarchos (Si 17, 19-20) oder baktrische Könige (Si 17, 19-20).

${ }^{804}$ Si 18 (Seleukia/Tigris) und vielleicht Si 8-9 (Kallipolis), Si 17, 19-20 (Seleukia/Tigris).

${ }^{805}$ z.B. H. Kyrieleis, Bildnisse der Ptolemäer, AF 2 (1975).
} 
Dargestellt wurden Herrscher mit dieser Kopfbedeckung in anderen Gattungen jedoch nur in Ausnahmefällen. Entsprechende bildliche Wiedergaben bleiben weitgehend auf die Gattung der Siegel (-abdrücke) begrenzt. In anderen Gattungen (Münzen, Großplastik) erscheint das Herrscherporträt fast ausschließlich ohne die Kausia. ${ }^{806}$ Es galten in den zuletzt genannten Gattungen demnach sich nur begrenzt an der Realität orientierende, die Variationsmöglichkeiten stark einschränkende Darstellungskonventionen.

Entsprechend kann das verstärkte Vorkommen von Wiedergaben, die den König mit der Kausia zeigen, auf Siegeln dadurch begünstigt worden sein, dass in dieser Gattung die Verwendung von Attributen in geringerem Maße Einschränkungen unterlag. Dennoch wurden diese auch in dieser Gattung nicht willkürlich verwendet und es ging nicht allein um die Darstellung der realen Alltagskleidung des Herrschers. Denn auch auf Siegeln erscheinen Gegenstände, die nur symbolisch verstanden werden können. ${ }^{807}$ Darstellungen der Kausia müssen einen symbolischen Gehalt gehabt haben, wie er auch in der Art und Weise angedeutet wird, in der Wiedergaben der Kausia in anderen Gattungen verwendet wurden. Die Kausia diente dort einerseits der Demonstration der Zugehörigkeit zur gesellschaftlich und politisch führenden Gruppe der Makedonen ${ }^{808}$ und andererseits der der Alexandernachfolge meist im Rahmen der Herrschaftsausübung. ${ }^{809}$ Teilweise überschneiden sich die symbolischen Bedeutungen (Makedonien und siegreiche Alexandernachfolge). Oft wird nicht zu trennen sein, worauf in erster Linie Bezug genommen wird. In welchem Sinne die Kausia auf den Siegeln als Symbol Verwendung fand, ist nur hypothetisch zu beantworteten, solange unklar ist, wer mit diesen siegelte bzw. wer für die Gestaltung der Siegel verantwortlich war. Dass nur der König mit seinem Porträt siegelte, ist unwahrscheinlich, da entsprechende Abdrücke sich relativ weiter Verbreitung erfreuen. Unklar bleibt, ob diese Siegel nur von königlichen Beamten oder auch von Amtsträgern im weiteren Sinne oder auch von Privatpersonen, die hiermit eine besondere Beziehung zum Herrscher zum Ausdruck bringen wollten, genutzt werden konnten. Unklar ist auch, ob die Inhaber der Siegel diese weitgehend frei gestalten konnten oder ob vom König und seinem Beraterkreis bestimmte Porträttypen und Attribute vorgegeben wurden, wie dies für die großplastischen Porträts und die Münzbildnisse wahrscheinlich ist.

Spielt man die verschiedenen Möglichkeiten durch, ergibt sich folgendes: Ein Bezug auf die Zugehörigkeit zur Gruppe der Makedonen ist möglich. Die Ptolemäerkönige und auch die Seleukiden stammten aus Makedonien, und dies könnte durch das Tragen der Kausia betont worden sein. Es stellt sich jedoch die Frage, was hierdurch bewirkt werden sollte. Eine Beto-

\footnotetext{
${ }^{806}$ Vgl. z.B. H. Kyrieleis, Bildnisse der Ptolemäer, AF 2 (1975) und R. Fleischer, Studien zur seleukidischen Kunst 1. Herrscherbildnisse (1991).

${ }^{807}$ Vgl. z.B. Ptolemäerkönig mit Strahlen (H. Kyrieleis, Ptolemäische Porträts auf Siegelabdrücken aus Nea Paphos [Zypern], in: Archives et Sceaux du monde hellenistique, BCH Suppl. 29 [Hrsgg.: M.-F. Boussac, A. Invernizzi] [Symposium Turin 1993] [1996] 315 ff Taf. 57 Abb. 4 u. re.) oder Ptolemaios XV. mit Hermesstab (H. Kyrieleis a.a.O. Taf. 55 Abb. $2=\mathrm{Si} 14$ ).

${ }^{808}$ So im Fall der tönernen Chlamydephoroi mit Kausia (siehe oben).

${ }^{809}$ Vgl. die Darstellungen auf baktrischen Münzen.
} 
nung dieser allgemein bekannten Tatsache ist nur sinnvoll, wenn sie angezweifelt wird oder wenn ihre Zurschaustellung Vorteile durch Abgrenzung von potentiellen Konkurrenten bringt. Dies scheint aber weder im Falle der Ptolemäer noch des Antiochos III. relevant gewesen zu sein. Sind die Siegel nicht das Ergebnis der königlichen Propaganda, sondern von Dritten gestaltet worden, könnten sie deren Wünsche und Bedürfnisse spiegeln. Hierzu könnte es gehört haben, die gemeinsame makedonische Herkunft sowohl der Könige als auch eines Teiles der Untergebenen bzw. von Teilen der Bevölkerung der hellenistischen Reiche zu demonstrieren. Dies hätte einen Beitrag zur Stärkung des Gemeinschaftsgefühls zwischen dem makedonischen König und den betreffenden Bevölkerungsgruppen sowie innerhalb der Makedonen bzw. „Hellenen“ insgesamt leisten können. Die Darstellung eines Nahverhältnisses zum Herrscher verbesserte darüber hinaus die Stellung der Makedonen und „Hellenen“ gegenüber der nachgeordneten einheimischen Bevölkerung.

Aber auch die Symbolisierung der Alexandernachfolge ist möglich. In diesem Fall wäre das Siegelbildnis vergleichbar dem Münzporträt als Mittel der Herrscherpropaganda zu verstehen. Denkbar ist sowohl die Kopierung offizieller Vorlagen als auch die indirekte Beeinflussung durch allgemein verbreitete Gedanken zur Herrschaftskonzeption. Alle Könige, die mit Kausia dargestellt wurden und sicher zu identifizieren sind, hätten - wenn auch unterschiedliche Gründe gehabt, ihre Herrschaft als eine in der Nachfolge Alexanders stehende auszugeben: Ptolemaios I. gehört noch zum Kreis der Generale Alexanders, trat die Herrschaft über Ägypten als direkter Nachfolger Alexanders an und strebte vielleicht ursprünglich noch die Nachfolge als König im gesamten Alexanderreich an. Antiochos III. kam der Wiederaufrichtung der Gesamtherrschaft über das ehemalige Alexanderreich näher als alle anderen hellenistischen Könige. Demetrios II. eroberte Seleukia am Tigris von den Parthern zurück und konnte sich wie Alexanders als Besieger der Perser sehen. Sein Beiname „Nikator“ spielt vielleicht auf die eng mit Alexander verbundene Sieghaftigkeit an. Für Ptolemaios X. Alexander macht schon die Wahl des Beinamens eine Anlehnung an Alexander den Großen wahrscheinlich. Die Kinder Kleopatras VII. wurden im Kampf gegen Rom von ihrer Mutter gezielt als letzte Nachfolger Alexanders des Großen aufgebaut. Kleopatras Sohn von Antonius hieß Alexander, dieser und sein jüngerer Bruder Ptolemaios Philadephos traten in Tiara und Kitaris bzw. Kausia, Chlamys und Krepides auf, worin die königliche Kleidung der Perser und die der auf Alexander folgenden Könige gesehen wurde. Für den ältesten Sohn der Kleopatra, Caesars Sohn Ptolemaios XV. Kaisarion, ist ebenfalls eine Anlehnung an Alexander den Großen anzunehmen. Die Darstellung des letzten ptolemäischen Königs mit Kausia ist in diesem Sinne zu interpretieren.

Ähnlich wie auf den Münzen baktrischer Könige und (anti-) seleukidischer Usurpatoren kann demnach auf ptolemäischen und seleukidischen Siegeln der König mit Kausia dargestellt worden sein, um die Nachfolge in der Herrschaft Alexanders des Großen zu symbolisieren. Während aber der Verweis auf die Alexandernachfolge auf den genannten Münzen zumindest unabhängig von einer makedonischen Herkunft der Dargestellten erscheint und wahrscheinlich 
teilweise sogar zum Aushebeln legitimer makedonisch-seleukidischer Ansprüche genutzt wurde, ist im Falle der Siegel ein Hinweis sowohl auf Makedonien als auch auf Alexander im jeweils oben beschriebenen Sinne möglich.

\subsection{Zusammenfassung der Besonderheiten in Regionen und Gattungen}

\subsubsection{Besonderheiten der Symbolik und Funktion in einzelnen Regionen}

Darstellungen der Kausia verweisen in allen Regionen auf Makedonen oder einen Einfluss Makedoniens. Darüber hinaus kann die Kausia in bestimmten Regionen eine tiefer greifende Symbolik und diachron-soziale Funktionen besitzen. Es handelt sich hierbei in der Regel um solche Regionen, die unter Alexander erobert wurden und in denen Makedonen in der Folgezeit (vorwiegend als Minderheit) neben alteingesessenen ethnischen Gruppen lebten. Makedonen stellten in diesen Regionen meist die Könige und dominierten den Staatsapparat (Verwaltung, Militär), woraus ihnen weitere Vorteile erwuchsen, so die Möglichkeit der Nutzung landwirtschaftlich interessanter Flächen und die Ansiedlung in neugegründeten Städten. Die Kausia hatte in diesen Gebieten die (unten) beschriebene identitätsstiftende und solidaritätsfördernde sowie die Herrschaft legitimierende Wirkung. Sie diente der Festigung der politischen Ordnung und trug somit zur Sicherung der Interessen der makedonischen Minderheit bei.

In Regionen, in denen die Makedonen nicht eine Minderheit bildeten, die über eine Mehrheit herrschte, spielte die oben genannte Symbolik und Funktion eine weit geringere Rolle. So dürfte die Kausia im makedonischen Kernland allgemein verbreitet gewesen sein, wurde hier jedoch nur relativ selten bildlich wiedergegeben. Die wenigen Darstellungen verteilen sich zudem auf die verschiedensten Gattungen, Themen und Typen. Die aus Makedonien stammenden Darstellungen von Personen, die die Kausia tragen, sind daher als Reflexe der dort üblichen Alltagskleidung zu verstehen, ohne dass eine tiefere Symbolik oder Funktion erkennbar wäre.

In Regionen, in denen Makedonen nur vereinzelt auftraten und keine politische Oberherrschaft ausübten (Italien, Krim), wird die Kausia ebenfalls nur selten und ohne Bindung an bestimmte Themen und Typen dargestellt. Bei den dargestellten Personen könnte es sich um einzelne dort lebende Makedonen handeln. Möglich ist aber auch die Verwendung der Kausia als einem modischen Kleidungsstück der Zeit durch Einheimische. Hierfür spricht insbesondere, dass in Süditalien vereinzelt auch Frauen mit der Kausia wiedergegeben werden können, während in Makedonien und in den Nachfolgestaaten des Alexanderreiches ausschließlich Männer die Kausia tragen. 


\subsubsection{Besonderheiten der Symbolik und Funktion in einzelnen Gattungen}

Die Symbolik und Funktion der Darstellung einer Person mit Kausia wird durch die Wahl einer bestimmten Gattung als Medium nicht oder nur indirekt beeinflusst.

Eine bestimmte Symbolik kann in der Regel Darstellungen aus unterschiedlichen Gattungen innewohnen, wie auch bestimmte diachrone Funktionen von verschiedenen Gattungen wahrgenommen werden können. So finden sich bildliche Wiedergaben, die einen Hinweis auf die Herrschaft in der Nachfolge des Makedonenkönigs Alexander zeigen und diese legitimieren sollen, in rundplastischen Arbeiten, auf Münzen, Siegeln und Kameen sowie in der Malerei.

Die Wahl der Gattung wird letztlich nur durch die Zugriffsmöglichkeiten der unterschiedlichen Bevölkerungsgruppen auf die einzelnen Medien beschränkt. So hat auf die Münzprägung in erster Linie der Herrscher und sein Umfeld Einfluss, während großformatige Darstellungen (Wandmalerei, Mosaik, Großplastik) entsprechende finanzielle Mittel voraussetzen und die preisgünstigen Terrakotten auch den unteren Schichten der Bevölkerung zur Verfügung stehen. 


\section{Die Kausia als Kopfbedeckung bestimmter Personengruppen}

\subsection{Vorbemerkung und Forschungsgeschichte}

Bevor ich anhand der bildlichen Wiedergaben und der schriftlichen Erwähnungen der Kausia den Kreis derjenigen Personen, die diese Kopfbedeckung trugen, bestimme, möchte ich kurz auf einige in der Forschung diskutierte Interpretationen der Kausia einerseits als einer kultischen Kopfbedeckung und andererseits als Mütze eng begrenzter Personengruppen (z.B. Soldaten, Herrscher, Pagen) hinweisen.

\subsubsection{Die Kausia: eine kultische Kopfbedeckung ?}

Diejenigen Wiedergaben der Kausia, insbesondere Terrakotten mit Kausia, die aus religiösen Kontexten stammen, wurden regelmäßig in Heiligtümern weiblicher Gottheiten gefunden, wie die oben gegebene Übersicht deutlich gemacht hat. Dies hat immer wieder Anlass zu Vermutungen über eine mögliche Verbindung zwischen den entsprechenden Kulten und der Kausia bzw. denjenigen Personen, die die Kausia trugen, gegeben.

Mitte der 50er Jahre untersuchte E. Sjöqvist ${ }^{810}$ im Rahmen der Publikation des sog. StanfordKopfes (P 33) auch eine Reihe von bildlichen Wiedergaben einer flachen Mütze aus Zypern. Es handelte sich um Tonfiguren archaischer bis hellenistischer Zeit und um stehende oder hockende Knabenstatuetten (,temple boys“) hellenistischer Zeit aus Sandstein. Soweit bekannt, stammen die Figuren überwiegend aus „Aphrodite“-Heiligtümern. Sjöqvist schloss auf der genannten Grundlage, dass die flache Mütze nicht die makedonische Kausia zeigt, sondern eine regionale zypriotische Kopfbedeckung. ${ }^{811}$ Infolge des Fundortes deutete er die Statuetten als Darstellungen kindlicher Tempeldiener, vielleicht männlicher Tempelprostituierter, und die Mütze als kultische Kopfbedeckung dieser Personengruppe. ${ }^{812}$

Die Publikation der Terrakotten aus Troja durch D. Burr-Thompson ${ }^{813}$ im Jahre 1963 führte zu einer erneuten Beschäftigung mit dem Thema. Materialbasis waren einerseits die kausiatragenden Tonfiguren aus Troja, die größtenteils unterhalb des Kybele-Heiligtums gefunden wurden, andererseits eine Anzahl von Vergleichsstücken ${ }^{814}$ aus Gebieten rund ums Mittelmeer. D. Burr-Thompson kam zu dem Ergebnis, dass es sich aufgrund der räumlichen Verbreitung und der (hellenistischen) Zeitstellung eindeutig um Wiedergaben der Kausia handeln müsse,

\footnotetext{
${ }^{810}$ E. Sjöqvist, A Cypriote Temple Attendant, AJA 59, 1955, 45 ff. Taf.31.

${ }^{811}$ Vgl. E. Sjöqvist, A Cypriote Temple Attendant, AJA 59, 1955, 45.

${ }^{812}$ Vgl. E. Sjöqvist, A Cypriote Temple Attendant, AJA 59, 1955, 46.

${ }^{813}$ D. Burr-Thompson, Troy III. The Terracotta Figurines of the Hellenistic Period (1963).

${ }^{814}$ Vgl. Burr-Thompson, Troy, 54 f. mit Anm. 143-151.
} 
die sich im Zuge der makedonischen Expansion über weite Teile der Mittelmeerwelt und des Vorderen Orients verbreitet habe. ${ }^{815}$

Weiter ging Dorothy Burr-Thompson davon aus, dass es sich bei den Figuren um Votive und bei den dargestellten jugendlichen, männlichen Personen um Verehrer (votaries) handelt. Insbesondere in den Figuren, die sich die Chlamys vor den unteren Bereich des Gesichtes ziehen (z.B. Tk 130, 133) und damit ihrer Meinung nach rituelle Stille andeuten, sah sie Anhänger einer Gottheit. Unter diesen können sich auch Tempeldiener befunden haben und diese könnten mit Kausia wiedergegeben worden sein. Eine kultische Bedeutung der Kausia sei hieraus jedoch nicht abzuleiten, wie diverse Darstellungen sowohl in der Koroplastik als auch in anderen Gattungen belegen, die eindeutig nicht in einem religiösen Zusammenhang zu sehen sind. ${ }^{816}$

In jüngster Zeit bezog sich E. Dusenbery ${ }^{817}$ im Rahmen einer Deutung der Terrakottastatuetten mit Kausia aus den Nekropolen von Samothrake wieder auf die Thesen von E. Sjöqvist und angeblich auch auf D. Burr-Thompson. ${ }^{818}$

E. Dusenbery will in den Mützen - wie die gesamte moderne Terrakottenforschung - Kausien erkennen, versucht dann jedoch einen möglichst engen Bezug zwischen den mit Kausia dargestellten Personen und dem Kultpersonal des Heiligtum der Großen Götter von Samothrake oder den Kindern dieser Kultdiener herzustellen. ${ }^{819}$ Belegen lässt sich dies jedoch auf Grundlage der Terrakotten aus Samothrake nicht. So bietet E.B. Dusenbery sowohl was die Verwendung $^{820}$ als auch was die dargestellte Personengruppe ${ }^{821}$ betrifft jeweils mehrere Deutungen an.

Die genannten Deutungen beruhen jeweils auf der Interpretation einer begrenzten Anzahl von Darstellungen eines einzelnen Fundortes. Auf eine systematische Untersuchung des Gesamtverbreitungsgebietes solcher Statuetten, die unterschiedlichen Arten der Verwendung im Kult und am Grab und insbesondere auf eine vom Fundort unabhängige Klärung der Ikonographie wird weitgehend verzichtet. Stattdessen werden Nachrichten, die zum am Fundort ausgeübten Kult vorhanden sind, direkt mit der Kausia bzw. den sie tragenden Personen verbunden. Daraus ergeben sich Deutungen, die auf der einen Seite selbst für den Ausgangsort nicht zutreffend sind - die Kausia ist auch auf Zypern keine kultische Kopfbedeckung - und bei der Übertragung auf andere Orte (z.B. Samothrake) zunehmend problematischer werden oder auf der anderen Seite sehr allgemein gehalten sind. So ist die Überlegung, dass es sich bei den in ein Heiligtum geweihten Darstellungen von Personen, die nicht eindeutig als göttlich gekennzeichnet sind, um bildliche Wiedergaben der Weihenden handeln könnte, möglicherweise

\footnotetext{
${ }^{815}$ Vgl. Burr-Thompson, Troy, 54 f. 85.

${ }^{816} \mathrm{Vgl}$. Burr-Thompson, Troy, $84 \mathrm{ff}$.

${ }^{817}$ E. B. Dusenbery, Samothrace 11 - The Necropoleis (1998).

${ }^{818} \mathrm{Vgl}$. Dusenbery, Samothrake, $863 \mathrm{f}$.

${ }^{819}$ Dusenbery, Samothrake, 845. 863.

${ }^{820}$ Dusenbery, Samothrake, 844 f. (Opfer an Toten oder Gott der Unterwelt beim Bestattungsritual oder Votiv im Schrein). 845 (Votiv im Heiligtum chthonischen Göttin [Demeter]).

${ }^{821}$ Dusenbery, Samothrake, 864 (einfache makedonische Knaben/Jugendliche oder Eingeweihte).
} 
richtig. Es bleibt jedoch zu fragen, wer die Weihenden waren, warum sie sich in entsprechender Weise darstellen ließen und was der Anlass zur Weihung gewesen sein könnte.

\subsubsection{Die Kausia: eine Kopfbedeckung ausschließlich derbasilikoi paides?}

Im Mittelpunkt der Erforschung der Kausia standen in den letzten rund 20 Jahren Bemühungen, den Kreis derjenigen Personen, die diese Kopfbedeckung trugen, näher einzugrenzen: Es ist insbesondere versucht worden, die Kausia als Kopfbedeckung bestimmter Gruppen zu definieren. So wurden die hellenistischen Herrscher, die Soldaten ${ }^{822}$ und die „königlichen Pagen“" ( $\beta \alpha \sigma \iota \lambda \iota \kappa o \grave{~} \pi \alpha \hat{\imath} \delta \epsilon \varsigma)^{823}$ vorgeschlagen.

Dies ist nicht zulässig, wie die Zusammenstellung der literarischen und archäologischen Quellen zur Kausia zeigt. Bevor ich zusammenfassend auf die in den Schriftquellen sowie den bildlichen Wiedergaben auftretenden Personengruppen eingehe, möchte ich diejenigen Ansätze, die die genannte Einengung des Kreises der Träger der Kausia begründen und die für den derzeitigen Stand der Forschung stehen, benennen und hinterfragen.

Die Anzahl der herangezogenen Darstellungen der Kausia ist bisher jeweils sehr gering gewesen. Ältere Arbeiten gingen meist von einzelnen Objekten aus, um die eine begrenzte Zahl von Vergleichsbeispielen gruppiert wurde. ${ }^{824}$ Die neueren Aufsätze ${ }^{825}$ basieren durchweg auf dem bei P. Dintsis ${ }^{826}$ gegebenen Katalog und erweitern diesen jeweils nur um wenige Exemplare. Obwohl Dintsis' Katalog nur 20 bildliche Wiedergaben der Kausia aufweist, wird seine Zusammenstellung als vollständig angesprochen. ${ }^{827}$ Sie enthält zudem Beispiele, bei denen es

\footnotetext{
${ }^{822} \mathrm{Vgl}$. A. M. Prestianni-Giallombardo, Un copricapo dell' equipaggiamento militare macedone: la kausia, NumAntCl 22, 1993, 61 ff. .- Saatsoglou-Paliadeli, Costume, 137 ff. .- P. Dintsis sah in der Kausia noch einerseits einen Ausrüstungsgegenstand der makedonischer Soldaten (Dintsis, Helme, 189-195), andererseits aber auch die Kopfbedeckung der Könige und der Makedonen allgemein (Dintsis, Helme, 186 ff.) und vereinzelt auch Angehöriger andere Volksgruppen (Dintsis, Helme, 188). -- P. Dintsis hat zudem vorgeschlagen, die Kausia mit bestimmten Teilen des makedonischen Heeres zu verbinden (Dintsis, Helme, 192 f.). Da jedoch entsprechende Angaben weder den literarischen noch den archäologischen Quellen zu entnehmen sind und überdies umstritten ist, welche Einheiten des makedonischen Heeres als leicht bzw. schwer bewaffnet anzusprechen sind (Vgl. die Diskussion bei Dintsis, Helme, 192 ff. mit Anm. 68-75 [mit älterer Literatur].), bleiben solche Vermutungen spekulativ.

${ }^{823}$ Ch. Saatsoglou-Paliadeli (Saatsoglou-Paliadeli, Costume, 135 ff. 139 f. 142.) hat versucht nachzuweisen, dass die Kausia abgesehen vom König nur von der eng begrenzten Gruppe der königlichen Pagen getragen wurde. Vgl. A.M. Prestianni-Giallombardo, Un Copricapo dell' equipaggiamento militare macedone: la kausia, NumAntCl 22, 1993, 84, die neben den Soldaten und den Königen die Philoi des König als Träger der Kausia sieht. ${ }^{824}$ Vgl. z.B. E. Sjöqvist, A Cypriot Temple Attendant, AJA 59, 1955, 47 Nr. 13-17 .- D. Burr-Thompson, Troy, $84 \mathrm{ff}$.

${ }^{825}$ A.M. Prestianni-Giallombardo, Un Copricapo dell' equipaggiamento militare macedone: la kausia, NumAntCl 22, 1993, 61 ff. .- Ch. Saatsoglou-Paliadeli, Aspects of the Ancient Macedonian Costume, JHS 113, 1993, 122 ff. .- B.M. Kingsley, Alexander's Kausia and Macedonian Tradition, ClAnt 10, 1991, 59 ff.

${ }^{826}$ P. Dintsis, Hellenistische Helme (1986) 304-312 Nr. 281-301.

${ }^{827}$ Saatsoglou-Paliadeli, Costume, 122 f. Vgl. A. M. Prestianni-Giallombardo, Un copricapo dell' equipaggiamento militare macedone: la kausia, NumAntCl 22, 1993, 61 und B.M. Kingsley, Alexander's Kausia and Macedonian Tradition, ClAnt 10, 1991,59.
} 
sich nicht um Kausien handelt. ${ }^{828}$ Weiter ist Dintsis' Katalog nicht repräsentativ für das Gesamtmaterial, sondern orientiert sich am Thema seiner Arbeit („Hellenistische Helme“) und führt entsprechend vorzugsweise Beispiele aus dem militärischen Bereich auf.

Im Falle der Schriftquellen verhält es sich ähnlich. Es wird jeweils nur eine Auswahl der Erwähnungen der Kausia in der antiken Literatur bearbeitet. Innerhalb dieser Auswahl werden meist - passend zur archäologischen Materialbasis bzw. zu Fragestellung - bestimmte Texte stark betont. ${ }^{829}$ Teils werden auch Texte genutzt, deren Bezug zur Kausia unklar oder nicht gegeben ist. So wird in allen neueren Artikeln mit einer Passage aus Plautus' Trinummus argumentiert, aus der angeblich die Pilzförmigkeit der Kausia hervorgeht. Plautus (Trinummus 851) bzw. Philemon, auf dessen griechische Vorlage die römische Version zurückgeht, schreibt dort: Pol hic quidem fungino generest: capite se totum tegit. - „Dieser hier gehört gewiss zur Pilzfamilie: durch den Kopf wird er ganz bedeckt.“ Abgesehen davon das hier zunächst der Kopf und nicht unbedingt die Kopfbedeckung beschrieben wird, erwähnt Plautus weder die Kausia noch findet sich ein Hinweis auf Makedonien. Der nachfolgende - üblicherweise nicht zitierte - Vers beschreibt die betreffende Person ${ }^{830}$ dagegen als in illyrischer Kleidung auftretend: Hilurica facies videtur hominis, eo ornatu advenit. - „Das Aussehen des Mannes scheint illyrisch zu sein, in dieser Ausstattung kommt er daher." Sollte demnach im Trinummus eine Kopfbedeckung beschrieben worden sein, dann eine illyrische Mütze, die nicht zwangsläufig mit der makedonischen Kausia identisch sein muss.

Nachdem P. Dintsis und A.M. Prestianni-Giallombardo die Gruppe der Träger der Kausia entsprechend der oben beschriebenen Quellenauswahl zunächst auf Militärangehörige sowie die Könige und Personen aus deren näheren Umfeld beschränkt hatten, verengte Ch. SaatsoglouPaliadeli den Kreis weiter. Dies geschah jedoch weniger aufgrund einer erweiterten Materialbasis als vielmehr durch die stärkere Betonung einzelner Quellen. Denn Ch. Saatsoglou-Paliadeli erweiterte die Gruppe der bildlichen Wiedergaben der Kausia nicht nur um das sog. Phil-

\footnotetext{
${ }^{828}$ Nicht um Kausien handelt es sich bei folgenden Exemplaren: Dintsis, Helme, 304 ff. Nr. 281 (Tetradrachmen Philipps II.), Nr. 282 (Grabrelief Aiane) und Nr. 294 (Büste des Euthydemos I. von Baktrien [es könnte sich bestenfalls um die umgedeutete bzw. missverstandene Kopie eines Originals mit Kausia handeln]). Nr. 300 (Meleager und Atalante auf Wandgemälde aus der Casa del Centauro in Pompeii im Nationalmuseum Neapel) gehört zu den von mir nicht bearbeiteten Darstellungen aus dem Westen, bei den unklar ist, ob die makedonische Kausia oder eine im Aussehen vergleichbare italische Kopfbedeckung wiedergegeben ist.

${ }^{829}$ So beruht die Interpretation Ch. Saatsoglou-Paliadelis (Saatsoglou-Paliadeli, Costume, 127. 136) in erster Linie auf der vermeintlichen Beschreibung der Kausia bei Plautus als pilzförmig (Plautus, Trinummus 851; das Zitat wird nachfolgend näher besprochen). Eine andere Textstelle, die die Kausia als flach (oder breit ?) bezeichnet

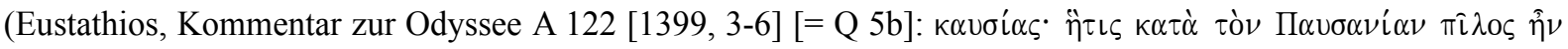
$\pi \lambda \alpha \tau$ ćc. - „Die Kausia war nach Pausanias eine flache/breite Filzmütze.“) und die Ch. Saatsoglou-Paliadeli bekannt ist (Saatsoglou-Paliadeli, Costume, 127), spielt dagegen im Rahmen der Deutung keine Rolle, da sie ihrer Interpretation widersprechen würde.

${ }^{830}$ Bei der betreffenden Person handelt es sich um einen Athener, der angeblich gerade aus Seleukia (am Tigris?) nach Athen gereist ist und daher als Ausländer verkleidet auftritt. Plautus, Trinummus 771: Is homo exornetur graphice in peregrinum modum; quasi ad adulescentem a patre ex Seleucia veniat, ... - „Dieser Mann wird fein ausgestattet auf ausländische Art; gleichsam als käme er zum jungen Mann vom Vater aus Seleukia,...“
} 
ippsgrab bei Vergina, sondern ging bei der Auswertung des Materials in erster Linie von diesem Monument aus.

Die Kernaussage des Aufsatzes von Ch. Saatsoglou-Paliadeli ${ }^{831}$ besagt, dass die Kausia zumindest ursprünglich ausschließlich vom König selbst und der eng begrenzten Gruppe der königlichen Pagen $(\beta \alpha \sigma \iota \lambda \iota \kappa o \grave{~} \pi \alpha \imath \hat{\imath} \delta \varsigma)^{832}$, die sich aus den jugendlichen Angehörigen des makedonischen Adels rekrutierten und den König begleiteten, getragen wurde. Als Träger der Kausia kommen entsprechend nur der König, die Pagen und die ehemaligen Pagen, das sind insbesondere die Generäle Alexanders, in Frage.

Als Ausgangspunkte dienen ihr einerseits diejenigen Schriftquellen, die den König und sein Umfeld als Träger der Kausia nennen, und die oben zitierte Textstelle aus dem Trinummus des Plautus ${ }^{833}$ und andererseits der Fries auf der Fassade des so genannten Philippsgrabes (Ma 5) bei Vergina. 834

Auf Grundlage des Plautus-Zitates erkennt Ch. Saatsoglou-Paliadeli auf dem Fries am Philippsgrab nur in einem Teil der dort dargestellten Kopfbedeckungen Kausien: ${ }^{835}$ So identifiziert sie zwar die Mützen zweier Jäger als Kausien, nicht jedoch die im Aussehen leicht variierende Kopfbedeckung eines Netzträgers. Da die zwei Jäger zwar mit Kopfbedeckung, Chlamys

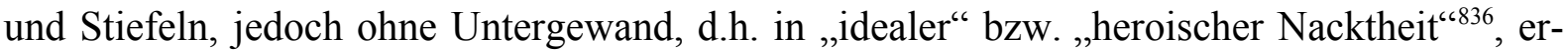
scheinen, das Grab von Ch. Saatsoglou-Paliadeli als solches des Makedonenkönigs Philipp II. angesprochen und die Malerei als „Hofkunst“6837 bezeichnet wird, möchte sie in den nur teilweise bekleideten Teilnehmern der Jagdgesellschaft den König bzw. Angehörige des königlichen Gefolges sehen. ${ }^{838}$ Da die Kopfbedeckung des makedonischen Königs und der ihn begleitenden Pagen nach Aussage der Schriftquellen die Kausia ist, ${ }^{839}$ bezeichnet sie als Kausien wiederum nur die Kopfbedeckungen der zwei teilweise bekleideten Jäger. ${ }^{840}$ In der Folge spricht sie allen nicht vom makedonischen König und den Paides getragenen barettähnlichen Kopfbedeckungen die Zugehörigkeit zur Gruppe der Kausien ab. ${ }^{841}$

Entsprechend kann sie in der flachen Mütze des ebenfalls auf dem Fries des „Philippsgrabes“ dargestellten Netzträgers ${ }^{842}$, den sie aufgrund seiner vollständigen Bekleidung (Mütze, Fellumhang, Stiefel sowie Chiton) und der von ihm ausgeübten Tätigkeit als Mann geringeren

\footnotetext{
${ }^{831}$ Saatsoglou-Paliadeli, Costume, 135 ff. 139 f. 142.

${ }^{832}$ Vgl. zu den „Pagen“ RE III (1897) 97 s.v. B $\alpha \sigma \iota \lambda \iota \kappa o i ̀ ~ \pi \alpha \iota \hat{\delta} \delta \varsigma$ (Droysen) .- H. Berve, Das Alexanderreich auf prosopographischer Grundlage I (1926) $37 \mathrm{ff}$.

${ }^{833}$ Saatsoglou-Paliadeli, Costume, 127. 136.

${ }^{834}$ Saatsoglou-Paliadeli, Costume, 135.

${ }^{835}$ Saatsoglou-Paliadeli, Costume, $135 \mathrm{f}$.

${ }^{836}$ Vgl. N. Himmelmann, Ideale Nacktheit in der griechischen Kunst (1990) 53 mit Rez. T. Hölscher, Gnomon 65, 1993, 519-28 .- Th. Schäfer, Andres Agathoi (1997) 38 ff. 147 ff. 149 ff. 158 ff.

${ }^{837}$ Saatsoglou-Paliadeli, Costume, 137: ,court art“".

${ }^{838}$ Saatsoglou-Paliadeli, Costume, $135 \mathrm{f}$.

${ }^{839}$ Saatsoglou-Paliadeli, Costume, 137 ff. bes. 139. 142.

${ }^{840}$ Saatsoglou-Paliadeli, Costume, 135 f. 137.

${ }^{841}$ Saatsoglou-Paliadeli, Costume, 135. 142.

${ }^{842}$ Der Netzträger ist noch schlechter erhalten als die Jäger. Auf den publizierte Photos ist nicht einmal eindeutig zu erkennen, ob es sich um Kausia oder Petasos handelt (Vgl. M. Andronicos, ebenda 100 f.).
} 
Ranges interpretiert, sowie in den Kopfbedeckungen Hunderter von Terrakottastatuetten ${ }^{843}$ nur eine mit der Kausia nicht identische Form des Baretts ausmachen. ${ }^{844}$

Als Beispiele für die Pagen-Kausia des 4. Jahrhunderts nennt sie neben den beiden Jägern vom Fries des „Philippsgrabes“ (Ma 5) ${ }^{845}$ ausschließlich den mutmaßlichen Ptolemaios bzw. Seleukos vom Alexandermosaik (Mo 1). ${ }^{846}$

Da sich diese Verengung des Kreises der Kausiaträger weder mit den literarischen noch mit den archäologischen Quellen vereinbaren lässt, geht Ch. Saatsoglou-Paliadeli einerseits davon aus, dass sich die Kausia schon ab Ende des 4. Jahrhunderts inflationär auch außerhalb des eng begrenzten Kreises der Pagen verbreitete und es sich andererseits bei den meisten barettartigen Mützen nicht um Kausien, sondern um andere Kopfbedeckungen handelt.

Dem ist Folgendes entgegen zu halten: Da das von Ch. Saatsoglou-Paliadeli ${ }^{847}$ zur Identifizierung der Kausia herangezogene Plautus-Zitat (Trinummus 851) sich nicht eindeutig auf die Kausia bezieht, kann es nicht zur Bestimmung der Form der makedonischen Kausia herangezogen werden. ${ }^{848}$ Die Beschreibung der Kausia als flacher Mütze durch Eustathios ${ }^{849}$ widerspricht der Aussage des Plautus zudem und erweitert das Spektrum möglicher Formen der Kausia zumindest.

Auf dem Jagdfries des sog. Philippsgrabes können - unabhängig davon, ob es sich um das Grab Philipps II. oder eines etwa eine Generation jüngeren Angehörigen der makedonischen

\footnotetext{
${ }^{843}$ Auf welche Terrakotten Ch. Saatsoglou-Paliadeli sich bezieht, ist nicht ganz klar. Aus Anmerkungen und Anspielungen ist zu entnehmen, dass ihr die bei Burr-Thompson, Troy, Taf. 16 (Troja), Taf. 56 (Troas, Alexandria, Kleinasien, Böotien) genannten und ein Teil der Figuren aus Alexandria (?) bekannt sind. Diese weisen alle Varianten der makedonischen Kausia auf. Auch das für die Pagen-Kausia geforderte Aussehen kommt vor (z.B. Tk 133). Weiter scheint sie die zypriotischen Statuetten zu kennen (Vgl. z.B. E. Sjöqvist, A Cypriot Temple Attendant, AJA 59, 1955, 47 Nr. 13-17.). Sie stammen größtenteils aus vorhellenistischer Zeit und zeigen zumindest teilweise eine von der makedonischen Kausia unabhängige, kausiaähnliche, zyprische Kopfbedeckung.

${ }^{844}$ Saatsoglou-Paliadeli, Costume, 135.

${ }^{845}$ Den Fries vom so genannten Philippsgrab bildet Ch. Saatsoglou-Paliadeli, Costume, Taf. 3 b nur nach der Rekonstruktionszeichnung von G. Miltsakakis ab. Auf Abbildungen des Originals sind Details nur schwer zu erkennen (Vgl. M. Andronicos, Vergina. The Royal Tombs [1984] 100 ff.). Die Datierung und die Zuweisung des Grabes an Philipp II. sind zudem nicht gesichert. Ich tendiere zu einer Datierung frühestens in die Zeit um 320300 v.Chr. (Vgl. oben die Besprechung der Rundbasis aus Messene, des „Philippsgrabes“ und der Kraterosgruppe in Delphi.). Es handelt sich demnach nicht um das Grab Philipps II. und muss sich grundsätzlich auch nicht um die letzte Ruhestätte eines anderen Königs handeln.

${ }^{846}$ Das Alexandermosaik zeigt sie nur in Umzeichnung (Saatsoglou-Paliadeli, Costume, 136 Abb. 4). Die Kausia ist zu etwa $90 \%$ ergänzt.

${ }^{847}$ Saatsoglou-Paliadeli, Costume, 136; die anderen von ihr genannten Quellen (S. 127) spielen im Rahmen ihrer Interpretation keine nennenswerte Rolle.

${ }^{848}$ Selbst wenn Plautus, Trinummus 851 auf die Kausia zu beziehen wäre, ließe sich hierin kein Hinweis auf eine ausschließliche Verwendung durch den König und die Pagen ableiten. Auch eine Identifizierung einer bestimmten Form von Kausia ist mit Hilfe der Textstelle nicht möglich, da die gegebene Beschreibung (,pilzförmig“) interpretationsbedürftig ist, was sich unter anderem darin niederschlägt, dass Dintsis, Helme, $185 \mathrm{f}$. auf Basis dieser Quelle eine Scheidung der Kausia in pilzförmig (im Sinne von flach) und konisch vornimmt, während es sich bei den konischen Kausien nach Saatsoglou-Paliadeli, Costume, 132 um Helme handelt.

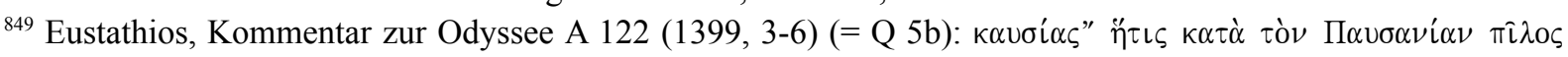

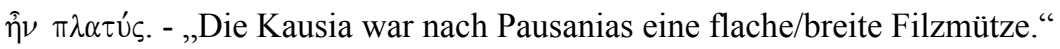


Oberschicht handelt - Personen aus dem Umfeld des makedonischen Königshauses und damit potentiell „Pagen“ dargestellt worden sein. Während dies jedoch einerseits grundsätzlich nicht ausschließt, dass die Kausia in Makedonien allgemein verbreitet war, sprechen andererseits sowohl die literarischen wie auch die archäologischen Quellen für eine weite Verbreitung der Kausia:

Schon die Aussagen derjenigen Schriftquellen ${ }^{850}$, die sich noch auf das 4. Jahrhundert v.Chr., d.h. die Zeit, zu der die Kausia angeblich nur von den Königen und ihren Pagen getragen wurde, beziehen, sind nicht eindeutig. Krateros und Kallas könnten als Angehörige des makedonischen Adels ursprünglich zu den Pagen gehört haben, nachweisbar ist dies nicht. ${ }^{851}$ Für die dem Kallas (bzw. Memnon) untergeordneten Offiziere ist dies unwahrscheinlich. Onesikritos von Astypalaia, der als Philosoph und Steuermann am Alexanderzug teilnahm, gehörte als Grieche kaum zum Pagenkorps. ${ }^{852}$ 321/20 verschenkt Eumenes von Kardia an 1000 Soldaten purpurne Kausien und Chlamyden. ${ }^{853}$ Abgesehen davon, dass die Kausia spätestens zu diesem frühen Zeitpunkt durch größere Teile des Heeres verwendet wurde, scheint die Betonung auf „purpurn“ zu liegen. ${ }^{854}$ Dem entspricht, dass das Geschenk als königlich bezeichnet wird. Dass die Soldaten vorher keine andersfarbigen Kausien und Chlamyden besaßen, wird nicht gesagt und ist insbesondere für die Chlamyden weitgehend auszuschließen.

Im archäologischen Material findet sich schon sehr früh auf der einen Seite die von Ch. Saatsoglou-Paliadeli für die Pagen reservierte Form auch auf bildlichen Wiedergaben von Personen, die nicht der Königsfamilie oder dem Pagencorps angehören, während andererseits Herrscher und Pagen mit flachem „Unterschicht-Barett“ dargestellt werden: Eine Grabstele (Re 2) aus Vergina (um 350-25 v. Chr.?) zeigt die „Pagen-Kausia“. Die Stele ist jedoch so einfach gehalten, dass es sich bei dem Bestatteten kaum um eine Person aus dem Umfeld des Königs gehandelt haben dürfte. Die „Pagen-Kausia“ tragen auch Terrakotten unterschiedli-

\footnotetext{
${ }^{850}$ Die entsprechenden Quellen sind: Plutarch, Eumenes 6, 1 (Q 14c) zu Krateros .- Polyainos 5, 44, 5 (Q 15) zu Kalas/Memnon .- Onesikritos, FGrHist 134, 17 A (= Strabon 15, 1, 64) (Q 10) zu Onesikritos (Bei Plutarch, Alexander 65 werden im Rahmen der Geschichte um Onesikritos Chlamys und Kausia nicht erwähnt, dafür wird dieser aufgefordert, auch noch das Untergewand [Chiton] auszuziehen.) .- Plutarch, Eumenes 8, 7 (Q 14d) zu Eumenes von Kardia. Sie finden sich zusammengestellt bei E. A. Fredricksmeyer, Alexander the Great and the Macedonian Kausia, TransactAmPhilAss 116, 1986, 219 ff.

${ }^{851}$ In den entsprechenden RE-Artikeln und in Berves Prosopographie finden sich keine Hinweise auf eine Zugehörigkeit zu den $\beta \alpha \sigma \iota \lambda \iota \kappa o i ~ \pi \alpha \imath \delta \delta \epsilon \zeta$ (RE Supp. IV [1924] 1038 ff. s.v. Krateros [1a] [Geyer] .- RE Suppl. IV [1924] 854 f. s.v. Kalas [1] [Berve] .- H. Berve, Das Alexanderreich auf prosopographischer Grundlage II [1926] 220 ff. Nr. 446 [Krateros]. 188 Nr. 397 [Kalas]). - Auch N.G.L. Hammond/G.T. Griffith, A History of Macedonia II (1979) 401 f. mit Anm. 3 erwähnen nicht, wie Saatsoglou-Paliadeli, Costume, 139 mit Anm. 182 behauptet, dass Krateros Page gewesen sei.

${ }^{852}$ Auch RE XVIII (1942) 460 ff. s.v. Onesikritos (H. Strasburger) und H. Berve, Das Alexanderreich auf prosopographischer Grundlage II (1926) 288 ff. Nr. 583 erwähnen die Zugehörigkeit zum Pagenkorps nicht.

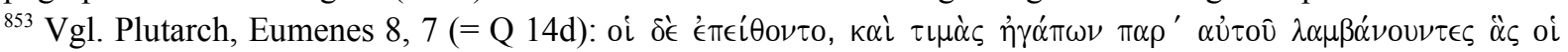

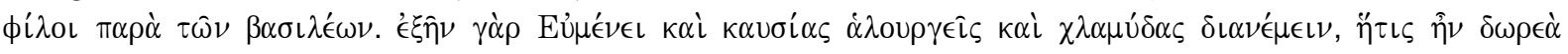

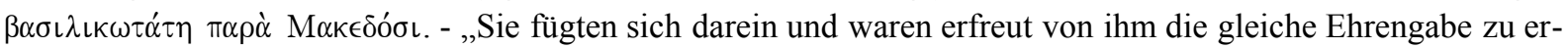
halten wie die Freunde (Philoi) von den Königen. Denn Eumenes [von Kardia] hatte das Recht, auch purpurne Kausien und Chlamyden zu verleihen, die höchste Königsgabe bei den Makedonen.“

${ }^{854}$ So auch B.M. Kingsley, Alexander's Kausia and Macedonian Tradition, ClAnt 10, 1991, 70.
} 
cher Typen (Chlamydephoren, Reiter, Soldaten) aus Ägypten (z.B. Tk 7, 40, 43, 58) und Kleinasien (Tk 133, 148, 153, 157), die ins späte 4. und 3. Jahrhundert datiert werden können. Die Basis mit dem Löwenjagdrelief aus Messene (Re 5; Ende 4. Jh. v.Chr.) zeigt dagegen vermutlich den mutmaßlichen ehemaligen Pagen Krateros, jedoch mit einer flachen Kausia, wie sie nach Ch. Saatsoglou-Paliadeli von den Nicht-Pagen getragen wurde.

Die Königsbildnisse auf Münzen und Siegelabdrücken stellen die Herrscher sowohl mit flacher (Nu 26 ff.; Si 2, 7) als auch mit konischer Kausia (Nu 35; Si 10) dar. Da diese Zeugnisse sich im ptolemäischen, seleukidischen und griechisch-mutterländischen Bereich finden und sich teils noch ins frühe 3. Jahrhundert v.Chr. datieren lassen, hätten sich also Vertreter aller großen hellenistischen Dynastien seit frühester Zeit regelmäßig versehentlich mit dem Barett der Unterschicht statt der Kausia darstellen lassen, so man Ch. Saatsoglou-Paliadeli folgt.

Die Ergebnisse der Arbeiten P. Dintsis', A. M. Prestianni-Giallombardos und Ch. SaatsoglouPaliadelis umschreiben letztlich nicht den Kreis derjenigen Personen näher, die die Kausia trugen oder mit dieser dargestellt wurden, sondern die betreffenden Resultate spiegeln die begrenzte archäologische Materialbasis (hauptsächlich Darstellungen aus dem militärischen Bereich, erweitert um das „Philippsgrab“) sowie die Aussagen der Schriftquellen, die sich aufgrund von in bestimmten literarischen Gattungen wirkenden Konventionen überwiegend mit bestimmten Themen (politische [Königs-] Geschichte, Kriege) beschäftigen. ${ }^{855}$ Die begrenzten thematischen Schwerpunkte der schriftlichen Überlieferung beeinflussten wiederum die angeführten Fragestellungen und führten zu einer sich am vermeintlichen Schwerpunkt der sowohl archäologischen als auch literarischen Überlieferung orientierenden Auswahl von Quellen innerhalb des ohnehin begrenzten Materials und zu deren Überinterpretation in der oben beschriebenen Form.

\footnotetext{
${ }^{855}$ Bei den entsprechenden literarischen Quellen im Allgemeinen und insbesondere denen, die die Zeit Philipps und Alexanders behandeln, handelt es sich ganz überwiegend um historiographische Werke und (Herrscher-) Biographien. Da dort fast nur Könige und Personen aus ihrem Umfeld beschrieben werden, kann die Kausia dort auch nur von solchen Personen getragen werden. Die Quellenlage lässt eher Aussagen darüber zu, welche Personengruppen üblicherweise im Rahmen der Geschichtsschreibung erwähnt wurden denn über den Kreis der Kausiaträger. -- Vereinfacht ausgedrückt ist ein Großteil der antiken Literatur von Angehörigen der Oberschicht mit oberschicht-typischen Vorurteilen für Angehörige der Oberschicht über Angehörige der Oberschicht oder Angehörige der Oberschicht interessierende Themen geschrieben, was entsprechende Verengungen und Brechungen der Realität zur Folge hat. Vgl. zum Umgang mit Quellen E. Flaig, Den Kaiser herausfordern (1992) 14 ff.
} 


\subsection{Personengruppen mit Kausia in den literarischen Quellen}

\subsubsection{Die Könige und ihr Umfeld}

Die Kausia wird in antiken Quellen als die Kopfbedeckung der makedonischen bzw. der auf Alexander folgenden Könige bezeichnet (Q 5b, 14a, 7a ${ }^{856}$ Namentlich genannt werden Alexander der Große (Q 2, 4) ${ }^{857}$, Demetrios Poliorketes (Q 3, 14b) ${ }^{858}$, Antigonos Gonatas (Q 19) ${ }^{859}$, der dem toten Pyrrhos seine eigene Kausia aufsetzt, schließlich Ptolemaios Philadelphos (Q $14 a)^{860}$, der Sohn der Kleopatra und des Markus Antonius, sowie der römische Kaiser Caracalla (Q 7b) ${ }^{861}$, der die Kausia in Anlehnung an Alexander während einer Makedonienreise trug. Wird die Kausia der genannten Könige näher beschrieben, ist sie purpurfarben (Q 3, 14d $)^{862}$ und mit einem Diadem (Q 2, 4, 5b, 7a, 14a 3, 14b) ${ }^{863}$ umwunden. Neben den Herrschern selbst werden aus dem Umfeld des Königs sowohl Gruppen von Personen als auch einzelne Männer mit der Kausia beschrieben: Die Kausia wird als passendes Geschenk des Herrschers an die „Freunde“ des Königs (oi фí̀

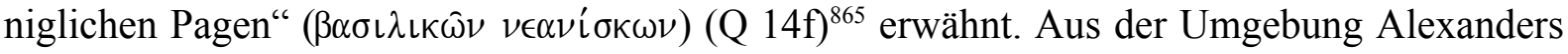
werden namentlich Krateros (Q 14c) ${ }^{866}$ und Onesikritos (Q 10) $)^{867}$ genannt.

\subsubsection{Feldherren und Soldaten}

Polyainos berichtet von Memnon von Rhodos, der im Auftrag des Perserkönigs die mit Philipp II. verbündeten Griechenstädte in Kleinasien zurückerobern sollte, dass dieser sich 336

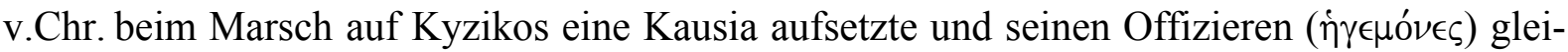

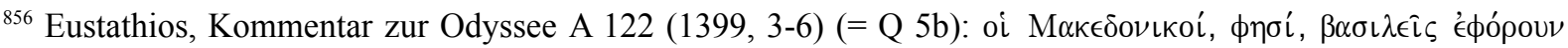

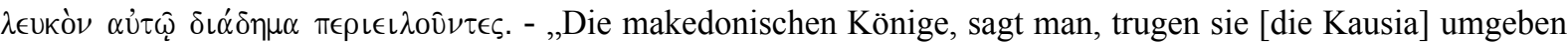

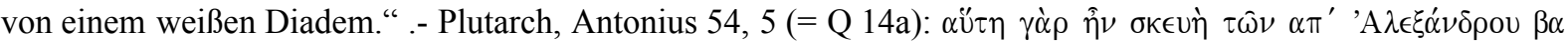
$\sigma \iota \lambda^{\prime} \epsilon \nu, \ldots$ - „Denn dies war die Kleidung der auf Alexander folgenden Könige,...“. Von Antigonos Monophthalmos wird berichtet, dass er statt Kausia diadematophoros und Zepter in Anlehnung an Dionysos Kranz und Thyrsos trug (Herodian, 1, 3, 3) (= Q 7a).

${ }^{857}$ Vgl. Aristobulos, FGrHist 139, 55 (= Arrian, Anabasis 7, 22, 2) (= Q 2) und Ephippos, FGrHist 126, 5 (= Athenaios 12, 537 e) (= Q 4).

${ }^{858}$ Duris, Frgt. 14 (= Athenaios 12, 535 f. = Q 3) .- Plutarch, Demetrios 41, 6 (= Q 14b).

${ }^{859}$ Valerius Maximus, Facta et dicta memorabilia 5, 1, ext. 4 (= Q 19).

${ }^{860}$ Plutarch, Antonius 54, 5 (= Q 14a).

${ }^{861}$ Herodian, 4, 8, 1-2. (= Q 7b).

${ }^{862}$ Duris, Frgt. 14 (= Athenaios 12, 535f.) (= Q 3) und Plutarch, Eumenes 8, 7 (= Q 14d) verwenden den Begriff

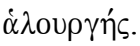

${ }^{863}$ Vgl. zur Kausia diadematophoros: Aristobul, FGrHist 139, 55 (= Arrian, Anabasis 7, 22, 2) (= Q 2), Ephippos, FGrHist 126, 5 (= Athenaios 12, 537e) $(=\mathrm{Q} 4)$, Eustathios, in Od. 1399, 3 (nach Pausanias) (= Q 5b), Herodian 1, 3, $3(=\mathrm{Q}$ 7a) und Plutarch, Antonius 54, $5(=\mathrm{Q}$ 14a) verwenden die Begriffe $\delta\llcorner\alpha \dot{\delta} \eta \mu \alpha$ bzw. $\delta\llcorner\alpha \delta \eta \mu \alpha \tau o \phi o ́ p o s . ~ D e m e t r i o s$ Poliorketes umwand die Kausia stattdessen doppelt mit der Mitra. Vgl. Duris, Frgt.

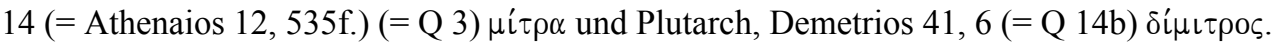

${ }^{864}$ Plutarch, Eumenes 8, 7 (= Q 14d). Es handelt sich in diesem Fall um purpurfarbene Kausien.

${ }^{865}$ Plutarch, Moralia 760 B (= Q 14 f).

${ }^{866}$ Plutarch, Eumenes 6, 1 (= Q 14c).

${ }^{867}$ Onesikritos, FGrHist 134, 17 A (= Strabo 15, 1, 64) (= Q 10).
} 
ches befahl (Q 15) ${ }^{868}$. Das Ziel dieser Verkleidung war es, dass die Kyzikener ihn und seine Unterfeldherren für die Führung des erwarteten Entsatzheeres unter dem Makedonen Kallas hielten. Demnach kann die Kausia als typisch für makedonische Feldherren und Offiziere angesehen werden. Der zweite namentlich bekannte makedonische Feldherr, der nachweisbar die Kausia trug, ist Krateros (Q 14c $)^{869}$. Aber auch Dorimachos, der im späten 3. Jahrhundert v.Chr. als Stratege des Aitolischen Bundes gegen Makedonien kämpfte, wird als Träger der Kausia erwähnt (Q 16) $)^{870}$.

Weiter sind die oben aufgezählten Herrscher in der Regel als Feldherren anzusprechen: In dieser Funktion treten die Könige meist in den Quellen auf, und auf dem Oberbefehl über das Heer beruhte letztlich ihre Macht.

Neben Feldherren und Offizieren nennen die schriftlichen Quellen vereinzelt auch einfachere Soldaten: 321/0 v.Chr. vergab Eumenes von Kardia an 1000 Soldaten des makedonischen Heeres - purpurne - Chlamyden und Kausien (Q 14d) ${ }^{871}$. Für die allgemeine Verbreitung einfacher Kausien im Heer spricht, dass Demetrios Poliorketes, als er 288 v.Chr. unerkannt aus dem Lager der Makedonen entkommen wollte, sich mit einer schlichten Chlamys sowie einer ebensolchen Kausia bekleidete $(\mathrm{Q} 14 \mathrm{e})^{872}$. In militärischen Zusammenhängen erscheint die Kausia auch bei Antipatros (Q 1) ${ }^{873}$, der die Kausia als „Helm“ (кópuৎ) bezeichnet, der die Perser und Thraker unterwarf, und in einer Inschrift aus dem Letoon von Xanthos (Q 20) ${ }^{874}$, wo sie unter denjenigen (militärischen?) Ausrüstungsgegenständen (ő $\lambda \lambda^{\circ} \nu$ ), die nicht mit in das Heiligtum hineingenommen werden durften, aufgezählt wird.

Von den epirotischen Molossern wird berichtet, dass sie nach der Eroberung eines Heiligtumes auf der Insel Kephallenia dem dortigen Kultbild der Artemis eine Kausia aufsetzten (Q $6)^{875}$. Dies spricht für eine Verwendung der Kausia auch durch die Bewohner der nördlich und östlich an Makedonien angrenzenden Völkerschaften und deren Krieger. ${ }^{876}$

\footnotetext{
${ }^{868}$ Polyainos, Strategemata 5, 44, 5 (= Q 15).

${ }^{869}$ Plutarch, Eumenes 6, 1 (= Q 14c).

${ }^{870}$ Polybios, 4, 4, 5 (= Q 16).

${ }^{871}$ Plutarch, Eumenes 8, 7 (= Q 14d).

${ }^{872}$ Plutarch, Pyrrhos 11, 6 (= Q 14e).

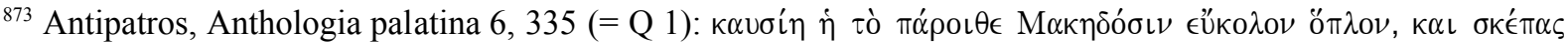

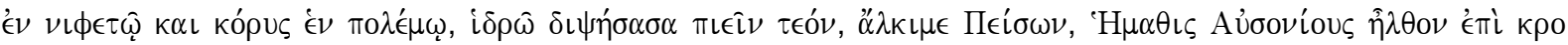

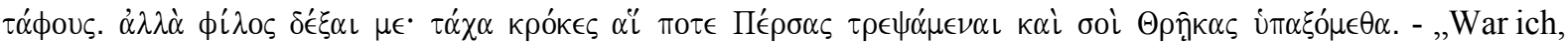
die Kausia, einst Makedonen guter/leichter Ausrüstungsgegenstand, während des Schneiens ein Hut, während des Krieges ein Helm, heute komme ich zu dir aus Emathia, tapferer [C. Calpurnius] Piso, dir vom ausonischen Haupt durstig zu schlürfen den Schweiß. Darum empfang mich als Freund. Hat dieses Gewebe die Perser einst geschlagen, sie macht dir auch die Thraker zum Knecht."

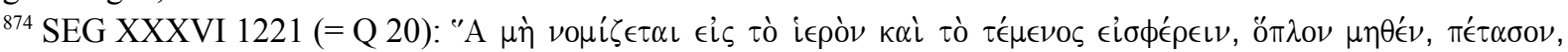

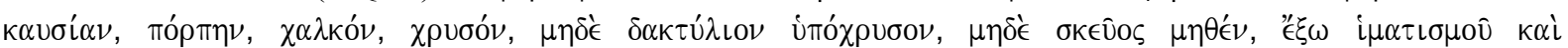

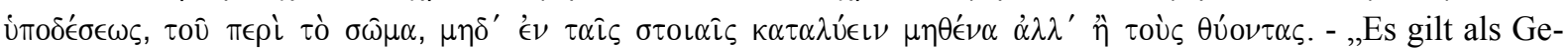
setz, diese Dinge nicht in das Heiligtum und den heiligen Bezirk hineinzubringen: nicht eine Waffe, einen Petasos, eine Kausia, eine Spange, Bronze, Gold, auch nicht einen goldhaltigen Fingerring, noch auch Bekleidung, außer Bekleidung und Schuhwerk, die (sich) auf dem Körper (befinden), auch nicht beim Rasten in den Wandelhallen, niemand außer den Opfernden.“

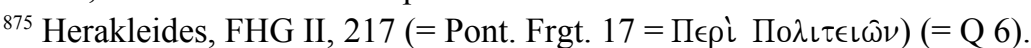

${ }^{876}$ Vgl. die Darstellungen der Kausia aus Illyrien (Nu 4-5), Paionien (Nu 1-3) und Thrakien (Ma 7).
} 


\subsubsection{Zivilisten}

Plautus (Q 13b $)^{877}$ beschreibt einen vermeintlichen Sklavenhändler als Träger der Kausia. Verantwortlich hierfür ist jedoch nicht der Beruf des Mannes, sondern dessen Herkunft aus Seleukia am Tigris. ${ }^{878}$

Die Kausia tragen bei Plautus (Q 13a) ${ }^{879}$ zudem ein attischer Schiffsherr sowie die Fischer von Ephesos. Bei der betreffenden Seemannsmütze handelt es sich möglicherweise jedoch nicht um die „makedonische“ Kausia, sondern um eine im Aussehen weitgehend identische Kopfbedeckung, die anscheinend bei verschiedenen seefahrenden Völkern der Mittelmeerwelt verbreitet war. $^{880}$

Der Grieche Onesikritos nahm als Steuermann am Alexanderzug teil und wurde als Gesandter zu den indischen Gymnosophisten geschickt. Bei dieser Gelegenheit trug er Kausia, Chlamys und Chiton (Q 10) ${ }^{881}$. Ob diese Bekleidung als die eines Angehörigen des Alexanderheeres, eines Seemannes oder als Zivilkleidung zu verstehen ist, bleibt unklar.

Philon (Q 11) ${ }^{882}$ berichtet, dass das Leder der Kausia geeignet war mit unsichtbarer Tinte beschrieben zu werden. Auf diesem Wege sollten geheime Botschaften in belagerte Städte geschmuggelt werden. Da die Geheimkuriere kaum als „Uniformierte“ zu denken sind, kann vermutet werden, dass es sich bei der Kausia um eine relativ unauffällige, weil allgemein verbreitete Kopfbedeckung handelte.

Ein Papyros aus dem Archiv des Zenon von Kaunos in Philadelpia (Ägypten) berichtet von Männern, die in Schaffell-Kausien nach Memphis geschickt werden (oder in Memphis solche Kausien kaufen sollen?) (Q 21) ${ }^{883}$. Diese Nachricht, der kein Hinweis auf eine spezielle Verwendung beispielsweise im militärischen Bereich zu entnehmen ist, deutet, wie auch andere, allerdings meist späte Quellen, die die Kausia allgemein als makedonische Kopfbedeckung bezeichnen (Q 1, 5a, 17, 20) $)^{884}$, auf eine weite, über einzelne Standes- oder Berufsgruppen hinausreichende Nutzung der Kausia in Makedonien und den Diadochenreichen hin.

\footnotetext{
${ }^{877}$ Plautus, Persa 155 (I, 3) (= Q 13b).

${ }^{878}$ Der gleiche Mann wird später mit der Tiara beschrieben (Plautus, Persa 463 [IV, 2]). Entscheidend ist demnach die Herkunft aus dem persisch-seleukidischen Bereich.

${ }^{879}$ Plautus, Miles gloriosus 1178-1181 (IV, 4) (= Q 13a).

${ }^{880}$ Vgl. z.B. die Kopfbedeckung des illyrischen Meeresgottes Redon (Nu 4-5) oder des auf einem Mosaik vom Forum Romanum in einer maritimen Szene wiedergegebenen Mannes (E. Wuescher-Becchi, Petasus e Causia, BullCom 32, 1904, 94 Abb. 1).

${ }^{881}$ Onesikritos, FGrHist 134, 17 A (= Strabo $\left.15,1,64\right)(=$ Q 10).

${ }^{882}$ Philon von Byzanz, Mechanike Syntaxis VII. VIII. (IV, 77 f.; p. 102) (= Q 11).

${ }^{883}$ Zenon Papyrus Kairo 59633 (= Q 21).

${ }^{884}$ Eustathios, Kommentar zu Ilias B $461(255,1)$ (= Q 5 a) (nach Antipatros, Q 1) .- Pollux, Onomastikon 10, 162 (= Q 17) (nach Menander). Aus der Inschrift aus dem Letoon von Xanthos (= Q 20) geht nicht eindeutig hervor, ob die Kausia als militärischer Ausrüstungsgegenstand (ö $\pi \lambda \nu \nu=$ Waffe ?) zu verstehen ist oder wie verschie-

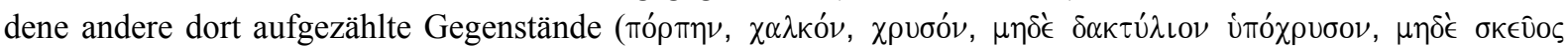

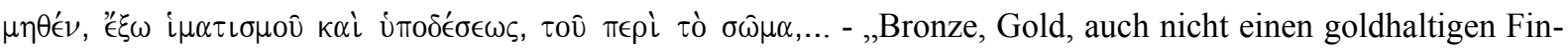
gerring, noch auch Bekleidung, außer Bekleidung und Schuhwerk, die (sich) auf dem Körper (befinden),...") auch dem zivilen Bereich zugerechnet werden kann.
} 
Martial (Q 8) ${ }^{885}$ schließlich berichtet, dass die causea im 1. Jahrhundert n.Chr. von Besuchern des Pompeius-Theaters in Rom (als Sonnenhut) getragen wurde. Inwieweit es sich hierbei um die makedonische Kausia im engeren Sinne handelt oder um eine italische Variante oder die erwähnte Seemannsmütze, bleibt wiederum unklar.

\subsubsection{Zusammenfassung}

Die Kausia konnte demnach von den Königen Makedoniens und der Diadochenreiche sowie von Personen aus dem Umkreis des Herrschers, u.a. den „Freunden“ und den „Pagen“, weiter von Feldherren, Unterführern und einfachen Soldaten, und schließlich allgemein von den Bewohnern Makedoniens und der neuen hellenistischen Reiche, darunter z.B. Sklavenhändlern, getragen werden.

Die genannten Personengruppen lassen sich einerseits dem herrschaftlich-miltärischen Bereich (Könige, Feldherren, Soldaten) und andererseits dem zivilen Bereich zuordnen. Dieser Aufteilung entspricht tendenziell die Verteilung auf bestimmte literarische Gattungen: Die Nachrichten über Herrscher und militärische Aktionen entstammen in der Regel historischen bzw. biographischen Werken. ${ }^{886}$ Im Mittelpunkt dieser Schriften steht die „politische“ Geschichte, d.h. eine Geschichte von Königen und Kriegen. Bei den dort beschriebenen Personen handelt es sich entsprechend um Herrscher und Soldaten. Im Gegenzug stammen die wenigen konkreten Angaben zur Verwendung im zivilen Bereich den Komödien des Plautus bzw. denen seiner griechischen Vorbilder ${ }^{887}$ Hiermit stimmt überein, dass die Komödie sich den Themen des Alltags widmete. Einer weiteren Gruppe, die Werke unterschiedlicher Art (z.B. Epigramm, Brief, Lexikon $)^{888}$ enthält, sind differierende, oft allgemeine Angaben zu entnehmen. In den Hinweisen, die sich den antiken Schriften entnehmen lassen, spiegeln sich demnach zunächst die thematischen Schwerpunkte bestimmter literarischer Gattungen bzw. diejenigen Bereiche des Lebens, die in der Literatur überhaupt Beachtung fanden. Die Schriftquellen geben entsprechend nur einen Ausschnitt der realen Verbreitung der Kausia wieder. Da dennoch eine verhältnismäßig große Zahl unterschiedlicher Bevölkerungsgruppen mit der Kausia beschrieben und die Kausia teils ohne einschränkende Bemerkung allgemein als Kopfbedeckung der Makedonen bezeichnet wird und keiner Quelle die Begrenzung auf eine bestimmte Gruppe zu entnehmen ist, kann davon ausgegangen werden, dass die Kausia von weiten Teilen der Bevölkerung Makedoniens und des makedonischen bzw. „hellenischen“ Bevölkerungsteils der neuen hellenistischen Reiche getragen wurde.

\footnotetext{
${ }^{885}$ Martial, Epigramm 14, 29 (= Q 8).

${ }^{886}$ Q 2 (Aristobul [Arrian]), Q 3 (Duris [nach Athenaios]), Q 4 (Ephippos [nach Athenaios]), Q 7 (Herodian), Q 10 (Onesikritos [nach Strabo]), Q 14a-f (Plutarch), Q 15 (Polyainos), Q 16 (Polybios), Q 19 (Valerius Maximus). ${ }^{887}$ Q 13 a (Plautus [nach Alexis von Thurioi ?]), Q 13b (Plautus). Vgl. Q 9 (Menander), Q 17 (Pollux [nach Menander]).

${ }^{888}$ Q 1 (Antipatros), Q 5 (Eustathios), Q 8 (Martial), Q 11 (Philon), Q 12 (Photios), Q 17 (Pollux [nach Menander]), Q 18a/b (Suda [nach Antipatros/Photios]), Q 20 (Inschrift Xanthos), Q 21 (Zenon-Papyros).
} 


\subsection{Personengruppen mit Kausia in den archäologischen Quellen}

\subsubsection{Könige und ihr Umfeld}

Mit der Kausia als Kopfbedeckung wurden nachweisbar Angehörige des ptolemäischen und des seleukidischen Herrscherhauses dargestellt sowie baktrische und indo-griechische Könige. Im Falle der in Makedonien selbst herrschenden Dynastien der Argeaden und später der Antigoniden ist dies bisher nicht in eindeutiger Weise zu belegen. Es besteht einerseits die Möglichkeit, dass die in Makedonien regierenden Herrscher nie mit der Kausia dargestellt wurden, da in einer Region, in der die große Mehrheit der Bevölkerung makedonisch war, eine gezielte Zurschaustellung der Herkunft nicht notwendig war. Andererseits könnten sich unter den nicht eindeutig identifizierbaren Porträts von Personen, die eine Kausia diadematophoros tragen, auch Bildnisse argidischer und antigonidischer Könige verbergen.

Neben den Wiedergaben von Personen mit der Kausia diadematophoros, die in der Regel den König zeigen dürften, werden im Rahmen von Darstellungen königlicher oder adeliger Jagdgesellschaften Personen abgebildet, die eine einfache Kausia tragen und sowohl Angehörige der Oberschicht als auch einfache Jagdhelfer zeigen.

Schließlich sei auf die Terrakottafiguren, die einen Reiter zeigen, der über einen am Boden hockenden, gefesselten Gegner hinwegprescht, hingewiesen. Die Reitergruppen zeigen wahrscheinlich Alexander oder den ptolemäischen König, der wie die Pharaonen über seine Gegner siegt, wie dies schon der Gott Horus im mythologischen Zusammenhang tat.

\subsubsection{Soldaten}

Makedonische bzw. ptolemäische Fußsoldaten finden sich in gemalter Form auf dem Grabmal von Agios Athanasios (Makedonien) sowie in den Nekropolen Alexandrias.

Eine Kausia ist neben anderen militärischen Ausrüstungsgegenständen auf einem Fries aus Pergamon wiedergegeben, der Beutewaffen zeigt.

Auf einem Wandgemälde in Pompeii ist eine Theaterszene zu sehen, in der ein Schauspieler mit einem Speer und der Kausia auftritt. Einen entsprechenden Charakter zeigen auch die dickbäuchigen, teils mit einem Schwert bewaffneten Ton- und vereinzelt Stein- Statuetten aus dem ptolemäischen Ägypten, die ebenfalls die Kausia tragen.

Als junge Soldaten oder Epheben im Sinne von Angehörigen einer Wehrpflichtorganisation können vielleicht auch die Chlamydephoren-Statuetten gedeutet werden, die sich an vielen Orten rund um das östliche Mittelmeer sowie im Vorderen Orient finden.

Seleukidische Kavalleristen geben die teils mit einem Rundschild ausgestatteten Terrakottastatuetten aus dem südlichen Mesopotamien wieder, die ebenfalls einen Reiter mit der Kausia zeigen. Ein ptolemäischer Reitersoldat erscheint auf einer Grabstele aus Alexandria. Die im Rahmen der Herrscherdarstellungen erwähnten Terrakotten, die einen Kausiaträger zeigen, der einen Gegner bzw. einen für diesen stehenden Schild niederreitet, können auch als An- 
spielung auf die ptolemäische Kavallerie verstanden werden. Dies gilt allgemein für die hellenistisch-ptolemäischen Reiterstatuetten, die eine Kausia aufweisen, auch wenn diese nicht direkt in einem militärischen Kontext dargestellt werden. Denn deren Bekleidung (Kausia, Chlamys, Chiton) legt eine Deutung als Soldaten, als Epheben, d.h. Angehörigen einer paramilitärischen auch auf den Dienst im ptolemäischen Heer vorbereitende Institution, oder als makedonischen Militärkolonisten (Kleruchen/Katoiken) nahe.

Krieger, die eine Kausia tragen, werden auf paionischen Münzen und im thrakischen Grab bei Kasanlak dargestellt. Dies spricht für eine Verwendung einer Form der Kausia auch durch die meist leichtbewaffneten Soldaten der nördlich und östlich an Makedonien angrenzenden Völker.

\subsubsection{Bürger und Epheben}

Darstellungen makedonischer Bürger im Sinne von Personen, die nicht als Könige oder Mitglieder der Oberschicht und nicht als Militärangehörige gekennzeichnet sind, werden auf Grabstelen aus Vergina und Demetrias wiedergegeben. Diese entstanden unter attischem Einfluss und variieren die in Athen üblichen Bürgerdarstellungen (in Himation und barhäuptig), indem die betreffenden Personen bei Beibehaltung des Stand- bzw. Sitzmotives in Kausia, Chlamys und Chiton gezeigt werden.

Als einfacher Makedone ist der Netzträger in Chiton, Fellumhang und Kausia auf dem Fries des sog. Philippsgrabs zu deuten.

Bei den Weihreliefs der am Schwarzen Meer gelegenen Polis Mesambria, die sowohl die Strategen, die dem militärischen Bereich zuzuordnen sind, aber auch den zivilen Schreiber der Boule mit Kausia und Chlamys darstellen, ist wiederum unklar, ob die Verwendung der Kausia auf makedonischen Einfluss zurückzuführen ist oder den der thrakischen Bewohner des Hinterlandes der Stadt.

Die schon im Rahmen der Soldatendarstellungen angesprochenen Tonstatuetten unbewaffneter stehender, sitzender oder reitender Jugendlicher und junger Männer in Chlamys, Chiton und, soweit erkennbar, Krepides sowie Kausia können einerseits als Epheben (im Sinne von Wehrpflichtigen), Soldaten (auf dem Marsch) oder Militärkolonisten gedeutet werden. Andererseits kann die Bekleidung der beschriebenen Personen jedoch auch als die für die Besucher des Gymnasions typische Zivilkleidung angesprochen werden. Bei den Dargestellten handelte es sich in diesem Fall um Angehörige der verschiedenen im Gymnasion lernenden und trainierenden Altersklassen (Paides, Epheboi, Neoi). Deren Ausbildung umfasste auf der einen Seite militärische Übungen, auf der anderen Seite aber auch die Vermittlung der kulturellen Grundlagen, auf denen die Gesellschaft der hellenistischen Staaten beruhte und deren Beherrschung die Voraussetzung für die Zugehörigkeit zur maßgeblichen gesellschaftlichen und letztlich staatstragenden Gruppe der Bevölkerung war. 


\subsubsection{Zusammenfassung}

Mit der Kausia diadematophoros dargestellt wurden demnach ptolemäische und seleukidische Könige sowie Könige aus den baktrischen und indo-griechischen Reichen und möglicherweise auch Argeaden und Antigoniden. Mit der einfachen Kausia wiedergegeben wurden der Oberschicht angehörende Teilnehmer königlicher oder adeliger Jagdgesellschaften, makedonische Soldaten aus den Machtbereichen der Antigoniden, Seleukiden und Ptolemäer, die zivilen Bewohner der Städte im makedonischen Kernland (Vergina) wie auch der neugegründeten Königsstädte (Demetrias), schließlich einfache Jagdhelfer und in großem Umfang die Chlamydephoren, hinter denen sich wahrscheinlich die meist jugendlichen oder jungen Besucher der Gymnasien verbergen, die hier ihre Ausbildung auf sowohl militärischem als auch staatsbürgerlichem und kulturellem Gebiet erhielten.

\subsection{Literarische und archäologische Quellen im Vergleich - eine Zusammenfassung}

Die literarischen und die archäologischen Quellen unterscheiden sich in zwei Aspekten grundsätzlich:

1. Während die Schriftquellen berichten, welche Personen die Kausia in der Realität trugen, zeigt das archäologische Material, wer mit der Kausia dargestellt wurde bzw. sich mit dieser darstellen ließ. Hiermit ist im gewissen Umfang ein Unterschied der funktionalen Ebenen verbunden. Im realen Leben wird der Grund für das Aufsetzen einer Kausia zunächst darin bestanden haben, sich während des Aufenthaltes unter freiem Himmel vor äußeren Einflüssen (Hitze, Kälte, Feuchtigkeit) zu schützen. Teils erst in zweiter Linie werden die mit der Kausia verbundene Symbolik und damit einhergehende Funktionen im gesellschaftlichen Bereich eine Rolle gespielt haben. Im Falle der Kausia-Darstellungen ist das Verhältnis umgekehrt. Auch den bildlichen Wiedergaben kann oft die primär-synchrone Funktion der Kausia im wirklichen Leben entnommen werden, der Grund für die Herstellung und Verwendung einer bestimmten Darstellung wird jedoch in der Regel in deren Symbolgehalt und einer sekundären diachronen Funktion in der Gesellschaft zu suchen sein.

2. Der Blickwinkel ist ein unterschiedlicher: In den literarischen Quellen berichten Historiker, Dichter und andere Schriftsteller, d.h. Dritte, über diejenigen Personen, die die Kausia trugen. Bei den Darstellungen dagegen handelt es sich in der Regel um Objekte, die von den Dargestellten selbst in Auftrag gegeben oder verwendet oder von Personen aus dem Umfeld des Dargestellten ausgesucht wurden. Im Gegensatz zu den Schriftquellen stellen die bildlichen Darstellungen demnach in einem weiteren Sinne Selbstzeugnisse von Kausiaträgern dar. Gemeinsam ist den literarischen und den archäologischen Quellen, dass sie den Kreis derjenigen Personen und Personengruppen, die in der Realität die Kausia trugen, verengt wiedergeben. Denn die Literaten berichten nur über Themen, die sie oder ihre Leser- bzw. Hörerschaft interessieren. Sowohl die Schriftsteller als auch ein Großteil ihrer Leser stehen zudem nicht 
für die Gesamtbevölkerung, sondern entstammen vorzugsweise den gehobenen Schichten bzw. der städtischen Bevölkerung. Angehörige der Unterschicht dürften sich nur unter den Zuschauern der Komödien in großer Zahl befunden haben. Entsprechend werden hauptsächlich Personen, die im Rahmen dieser Interessengebiete eine Rolle spielen, als Träger der Kausia beschrieben. Bildliche Darstellungen der Kausia wiederum bleiben auf thematische Bereiche beschränkt, die im gesellschaftlichen Leben von Bedeutung waren. Im Rahmen dieser Themen entwickelte sich deren Symbolik und konnte diese eine Funktion in der Gesellschaft ausüben. Im Gegensatz zu den literarischen Quellen repräsentieren die archäologische Objekte bzw. einzelne Bildgattungen unter diesen die Interessen sowohl der Oberschicht (z.B. die Münz- und Siegelbildnisse) als auch der mittleren und unteren Schichten (z.B. die Terrakotten).

Obwohl die antiken Schriften die reale Kausia und deren reale Träger beschreiben, während die archäologischen Relikte Darstellungen bieten, die mit der Realität übereinstimmen können, aber nicht müssen, obwohl es sich einerseits um Beschreibungen durch Dritte handelt und andererseits um Selbstzeugnisse und obwohl die Interessengebiete der Schöpfer und Nutzer der einzelnen Quellenarten und die Funktionen der Quellen sich unterscheiden, sind diejenigen Personengruppen, die in den literarischen und in den archäologischen Quellen die Kausia tragen bzw. mit dieser dargestellt werden, weitgehend identisch: Es handelt sich um den Herrscher und Personen aus seiner Umgebung, um Militärangehörige sowie um Zivilpersonen unterschiedlicher Altersgruppen und Berufe. Die trotz unterschiedlicher Realitätsebenen, Blickwinkel und Interessengebiete große Übereinstimmung der Aussagen der literarischen und archäologischen Zeugnisse, sowie die Tatsache, dass letztlich alle wichtigen Gruppen der makedonischen Bevölkerung in einer oder mehreren Quellenarten mit der Kausia in Verbindung gebracht werden, deuten darauf hin, dass jeder Makedone die Kausia bei fast allen im Freien stattfindenden Aktivitäten tragen ${ }^{889}$ und sich mit dieser darstellen lassen konnte und durfte.

\footnotetext{
${ }^{889}$ Die Kausia als real getragene Kopfbedeckung ist bezüglich ihrer primären Funktion (Wetterschutz) und ihrer allgemeinen Verbreitung unter den Makedonen dem Petasos der Griechen vergleichbar.
} 


\section{Symbolik und Funktion}

\subsection{Symbolik und Funktion in szenischen Darstellungen}

\subsubsection{Symbolik und Funktion der Kausia im herrschaftlichen Bereich}

\subsubsection{Herrscher mit Kausia diadematophoros}

Die Kausia kennzeichnet eine Verbindung ihres Trägers zu Makedonien. Handelt es sich um die mit dem Diadem umwundene Kausia, wird die sie tragende Person zusätzlich als Herrscher gekennzeichnet. Die Kausia diadematophoros symbolisiert demnach den „makedonischen König“. Dieser ist jedoch weder als „König von Makedonien“ noch als „König makedonischer Herkunft“ zu verstehen, da die betreffenden Herrscher überwiegend nicht über Makedonien herrschten und teils auch nicht aus Makedonien stammten. Die Gemeinsamkeit der betreffenden Könige liegt vielmehr in der Nachfolge in der Herrschaft Alexanders des Großen, der als Makedone die Kausia trug und diese als Herrscher eines über Makedonien hinausgreifenden Großreiches mit dem Diadem verband. Entsprechend wird die Kausia von Plutarch als „die Bekleidung der auf Alexander folgenden Könige ${ }^{6890}$ bezeichnet.

Die Funktion der Darstellung des Herrschers mit der Kausia im Allgemeinen und der Kausia diadematophoros im Besonderen ist eine zweifache. Die Kausia ist einerseits ein Symbol der gemeinsamen Grundlage, auf der sowohl die Herrschaft des Königs als auch die Vorrechte derjenigen Makedonen, die mit diesem zusammen auf den unterschiedlichen Ebenen in Militär und Verwaltung die Diadochenreiche regierten, beruhte. Die makedonische Kausia steht für die auf die Eroberung durch einen makedonischen König und ein makedonisches Heer zurückgehenden Ansprüche, kennzeichnet die Teilhaber als Angehörige einer Gruppe, dient der Solidarität innerhalb der Gruppe und der Abgrenzung gegen andere und festigt so diese Gruppe und ihre gemeinsamen Interessen.

Mit dem Tragen der Kausia diadematophoros erscheint andererseits der König als in der Nachfolge Alexanders des Großen regierend. So wird in der königlichen Propaganda die Kausia gleichzeitig als Symbol makedonischer Traditionen und der Alexandernachfolge genutzt. Eine solche Aussage kann auf die eigene Bevölkerung oder Gruppen innerhalb dieser abzielen, aber auch auf sowohl freundlich als auch feindlich gesinnte Nachbarstaaten oder bestimmte Kräfte innerhalb dieser. Bei diesem auswärtigen Publikum kann es sich sowohl um ein ebenfalls in makedonischer Tradition stehendes handeln, aber auch um ein anderes z.B. indisches oder römisches. Die diachrone Funktion der Kausia diadematophoros besteht letztlich

\footnotetext{
${ }^{890}$ Plutarch, Antonius 54, 4 (Q 14a).
} 
darin, den in der Tradition Alexanders stehenden ,personal-victorialen“691 Herrschaftsstil der Diadochen nach innen und außen zu demonstrieren und zu legitimieren.

\subsubsection{Die isolierte Kausia diadematophoros}

Die isolierte Kausia diadematophoros steht ebenfalls für die Gruppe der Makedonen und die Herrschaft in der Nachfolge Alexanders. Darstellungen der isolierten Kausia diadematophoros wurden - obwohl Zeichen des Königtums in der Nachfolge Alexanders - vermutlich von Personen verwendet, die nicht zu den Nachfolgern Alexanders gehörten. Die Gründe sind unklar, und so ist nur zu vermuten, dass sie auf der diachron-funktionalen Ebene der Solidarisierung innerhalb der Gruppe und der Legitimierung sowohl der Ansprüche der gesamten Gruppe als auch der des Königs diente.

\subsubsection{Königliche Jagdgesellschaften: Herrscher mit einfacher Kausia?}

Nur auf zwei überlieferten Monumenten (Relief aus Messene, Fries in Vergina) werden Jäger mit Kausia gezeigt. Von den insgesamt drei Jagdszenen (zwei Löwenjagden und eine Bärenjagd) gehen jedoch die zwei Löwenjagden vermutlich auf ein gemeinsames Vorbild (KraterosMonument in Delphi) zurück.

Die Kausia hat in den genannten Jagdszenen eine primär-synchrone Funktion als Wetterschutz und sie kennzeichnet die sie tragenden Personen als Makedonen.

Darüber hinaus besitzt die Kausia in den dargestellten Szenen jedoch keinen tiefgreifenderen Symbolcharakter und weist keine weiteren Funktionen auf. Denn obwohl es sich bei den betreffenden Personen vermutlich überwiegend um Herrscher und Männer aus deren nächsten Umfeld handelt, fehlt der Bezug zum herrschaftlichen Bereich weitgehend. Weder erscheint die mit dem Diadem umwundene Kausia, noch ist dem szenischen Kontext oder den Aufstellungs- bzw. Herstellungsgründen ein Hinweis auf einen bestimmten Machtanspruch zu entnehmen. Auch die Fundorte (Vergina, Messene und - als Aufstellungsort des vermutlichen Urbildes - Delphi) sprechen gegen eine weitere Funktion der Wiedergabe der betreffenden Personen mit der Kausia. Vergina liegt in Makedonien. Hier ist weder eine Legitimation des Königtums durch dasjenige Alexanders erforderlich, ${ }^{892}$ noch herrschte in Makedonien eine auf inneren Zusammenhalt und Abgrenzung gegen andere angewiesene makedonische Minderheit über eine nicht-makedonische Bevölkerungsmehrheit. Messene und Delphi liegen zwar außerhalb Makedoniens, jedoch in einer Region, in der weder mit einer größeren Gruppe makedonischer (Militär-) Siedler zu rechnen ist, die die griechische Bevölkerung kontrollierten, noch standen diese Orte unter direkter Königsherrschaft. Es fehlen demnach die Empfänger potentieller Botschaften. ${ }^{893}$

\footnotetext{
${ }^{891}$ H.-J. Gehrke, Geschichte des Hellenismus ${ }^{2}$ (1995) 166.

${ }^{892}$ Vgl. zur späten Einführung des Diadems als Kennzeichen der hellenistischen Königsherrschaft in Makedonien selbst die im Detail teils widersprüchlichen Angaben bei H.-W. Ritter, Diadem und Königsherrschaft (1965) $33 \mathrm{f} .155 \mathrm{f}$.
} 
Insbesondere im Fall der vollständig bekleideten Personen bieten die Jagdszenen demnach in erster Linie ein Abbild der realen makedonischen Alltags- bzw. Jagdbekleidung. In Einzelfällen (z.B. in Kombination mit Nacktheit) kann die Kausia eine symbolische Bedeutung aufweisen.

\subsubsection{Symbolik und Funktion der Kausia im militärischen Bereich}

Die Kausia als regionale Kopfbedeckung kann auf der synchron-funktionalen Ebene Soldaten aus entsprechenden Regionen (Makedonien, Thrakien, Illyrien) kennzeichnen. Insbesondere außerhalb des balkanischen Ursprungsgebietes kann die Kausia z.B. im ptolemäischen Ägypten als Erkennungszeichen der dort stationierten „makedonischen“ Truppen angesehen werden. Als Symbol Makedoniens kann sie der Abgrenzung dieser Verbände nach außen und der Solidarität innerhalb der Gruppe gedient haben. Da jedoch innerhalb der hier behandelten Gattungen Soldaten nur in Einzelfällen mit der Kausia wiedergegeben werden, sollten der Symbolcharakter und die diachrone Funktion dieser Darstellungen nicht überbetont werden.

Anders verhält es sich bei einigen Gruppen von Soldatendarstellungen aus dem koroplastischen Bereich, auf die oben im Rahmen der Bearbeitung der Weihungen und Grabbeigaben eingegangen wurde. Bestimmte Typen dieser Statuetten treten insbesondere im ptolemäischen Ägypten und im seleukidischen Mesopotamien regelmäßig in Kombination mit der Kausia auf. Da die Makedonen in diesen Regionen Minderheiten bildeten, die zur Durchsetzung ihrer Interessen auf die Wahrung der Gruppensolidarität sowie einer Abgrenzung gegenüber der beherrschten Bevölkerungsmehrheit angewiesen waren, ist eine Symbolik und diachron-soziale Funktion der Soldaten-Figuren in diesem Sinne wahrscheinlich.

Die Symbolik und die Funktion sind im Einzelfall je nach Thema (Reiter, dickbäuchige Theatersoldaten) im Spannungsfeld von Heer und Gymnasion bzw. Theater sowie in Verbindung mit dem Kult näher zu beschreiben.

\subsubsection{Symbolik und Funktion der Kausia im bürgerlichen Bereich}

Darstellungen von Bürgern und bürgerlichen Beamten, die die Kausia tragen, sind unter den szenischen Darstellungen selten. Die wenigen Beispiele verteilen sich zudem auf verschiedene Regionen und Gattungen. Inwieweit die Kausia in den betreffenden Fällen einen Symbolgehalt oder eine Funktion besitzt, die über die Kennzeichnung der dargestellten Personen als Makedonen hinausgeht, ist daher meist im Einzelfall zu prüfen.

Die Kausia auf einem Grabrelief aus Vergina wird, da sie aus Makedonien selbst stammt und die Makedonen dort keine Minderheit bildeten, die sich zusammenschließen oder gegen andere abgrenzen musste, um ihre Interessen zu wahren, keinen weiteren Symbolgehalt gehabt haben.

\footnotetext{
${ }^{893}$ Eine Voraussetzung für die Funktion eines Kleidungsstückes innerhalb eines Kommunikationsprozesses ist das Vorhandensein eines „Senders“ und eines „Empfängers“ (Vgl. Schubert, Kleidung, 47 ff. und L. Schneider/B. Fehr/K.-H. Meyer, Zeichen - Kommunikation - Interaktion, Hephaistos 1, 1979, 20).
} 
Die Grabstelen aus Demetrias, einer makedonischen Neugründung auf thessalisch-griechischen Gebiet, könnten als Kennzeichen einer Gruppe, die wenn auch in der Nähe so doch auBerhalb Makedoniens, Siedlungsrechte auf Kosten der alteingesessenen Bevölkerung für sich in Anspruch nahm, gesehen werden und der Solidarisierung innerhalb der Gruppe und der Abgrenzung gegen die Umwohner gedient haben. Da Personen mit Kausia jedoch nur auf wenigen Grabstelen aus Demetrias erscheinen, sollte diese diachron-soziale Funktion wiederum nicht überbewertet werden.

Eine Deutung der kausiatragenden Beamten (Strategen und Ratsschreiber) auf den Weihreliefs von Mesambria ist nicht möglich, da nicht eindeutig zu klären ist, ob das Erscheinen dieser Kopfbedeckung in der westpontischen Griechenstadt auf makedonischen oder thrakischen Einfluss zurückzuführen ist.

Auch die Deutung der Siegelabdrücke und des thasischen Porträts ist mit Unsicherheiten behaftet, da in der Regel nicht zweifelsfrei entschieden werden kann, ob es sich um Privatporträts handelt oder um Wiedergaben von Personifikationen oder Herrschern. Für eine Deutung der Darstellungen von Privatpersonen wären zudem nähere Angaben (z.B. zum Beruf und zur Herkunft) der betreffenden Personen notwendig. Allgemein kann nur vermutet werden, dass sich diese Personen durch die Wiedergabe mit der Kausia anderen Makedonen oder auch Dritten als Makedonen zu erkennen geben wollten und sich hierdurch bestimmte Vorteile, die sich aus ihrem Status oder ihrer Gruppenzugehörigkeit ergaben, versprachen.

Im bürgerlichen Bereich spielt die Kausia als Gruppensymbol mit entsprechender Funktion (Solidarität im Innern, Abgrenzung gegen andere und daraus folgend Festigung der Gruppe und Sicherung von Vorrechten) im Rahmen der szenischen Darstellungen keine hervorragende Rolle. Im Gegensatz hierzu bilden die Wiedergaben von bürgerlichen Personen, die die Kausia tragen, unter den Grab- und Votivstatuetten, auf die unter näher eingegangen wird, die Mehrheit.

\subsubsection{Symbolik und Funktion der Kausia von Personifikationen}

Bei der Interpretation der Symbolik und Funktion der Kausia als Kopfbedeckung von Personifikationen Makedoniens ist zwischen Darstellungen zu unterscheiden, die von Römern für ein meist römisches Publikum geschaffen wurden, und solchen, die in einem makedonisch-hellenistischen Kontext zu verstehen sind.

Die Ausstattung von Personifikationen Makedoniens mit der Kausia diente im römischen Bereich ausschließlich der Erkennbarkeit durch römische Betrachter.

Das einzige Beispiel einer Personifikation Makedoniens aus dem hellenistischen Bereich kann wiederum der Legitimierung (königlicher) Machtansprüche oder der Stärkung der Gruppensolidarität und der Abgrenzung gegen andere Gruppen und deren Ansprüche gedient haben. So kann eine Darstellung in Boscoreale, die auf ein ostmediterranes Vorbild zurückgeht, als Personifikation der Herrschaft in der Nachfolge des Makedonenkönigs Alexander gedeutet werden und der Begründung entsprechender Herrschaftsansprüche gedient haben. Da jedoch die 
Herkunft des Urbildes und der zugehörige historische Kontext umstritten sind, ist eine nähere Bestimmung dieser Ansprüche nicht möglich.

Die Interpretation von Siegelbildnissen mit Kausia, hinter denen sich neben Darstellungen von Herrschern und Privatpersonen auch solche der Personifikation Makedoniens verbergen könnten, ist aufgrund der Unsicherheit solche Zuweisungen bzw. des unbekannten Kontextes nicht möglich.

\subsection{Symbolik und Funktion der Statuetten in Kult und Gesellschaft}

\subsubsection{Die koroplastischen Typen und Themen}

\subsubsection{Die Reiter: Könige, Soldaten und Epheben?}

Die Reiterstatuetten besaßen, wie aus vereinzelt beobachteten Fundkontexten hervorgeht, sowohl in Ägypten als auch in Mesopotamien primär-synchrone Funktionen entweder im sepulkralen oder sakralen Bereich. ${ }^{894}$

Die Reiter sind - soweit erkennbar - mit Chlamys und Kausia bekleidet. Sie können daher als berittene Makedonen gedeutet werden. Innerhalb der Makedonen kommen infolge der Bekleidung (Chlamys, Kausia) sowie der teilweise vorhandenen Bezüge zum militärischen Bereich (Schild, Gegner) und möglicher Anleihen aus der Herrscher- bzw. Götterikonographie insbesondere drei Untergruppen in Frage: reitende Besucher des Gymnasions bzw. Gymnasionsnutzer bei der Reitübung (z.B. Epheben), reitende Soldaten sowie siegreiche Könige bzw. Königsgötter. Es wird demnach verwiesen auf die Übergangszone zwischen dem zivilen und dem militärischen Bereich (Ephebie/Gymnasion), auf den rein militärischen Bereich und das Königtum mit Verweisen auf militärische und religiöse Aspekte. Gemeinsam ist diesen drei Themen nicht nur der durch die Kausia vorgegebene makedonische Kontext, sondern auch der Bezug zum militärischen Bereich: Denn diesem gehören nicht nur die Kavalleristen an, sondern auch die Epheben als Anwärter auf den Dienst in der Armee - reitende Epheben und reitende Soldaten stehen letztlich für zwei Altersklassen innerhalb einer Personengruppe - und auch die ptolemäischen Herrscher, deren Macht maßgeblich auf ihrer Befehlsgewalt beruht und die letztlich als siegreiche Feldherren erscheinen.

Die konkrete Zuweisung einzelner Typen von Reiter-Statuetten zu den genannten Personengruppen ist abhängig von der Bestimmung des Lebensalters der dargestellten Personen (Jugendlicher oder Erwachsener), der Deutung bestimmter ikonographischer Besonderheiten (Bewaffnung, Gegner) und den regional variierenden Rahmenbedingungen. Da eine eindeutige Bestimmung des Lebensalters in der Regel nicht möglich ist, alle drei Personengruppen und die zugehörigen Typen letztlich unabhängig davon, ob sie mit oder ohne Bewaffnung

\footnotetext{
${ }^{894}$ Vgl. z.B. die „Reiter ohne Gegner“ aus der alexandrinischen Sciatbi-Nekropole (Tk 58-60) oder die orientalischen handgeformten Reiter aus dem Heiligtum von Masjid-i Solaiman (Tk 448a - 451d).
} 
oder einen Gegner dargestellt werden, Verbindungen zum militärischen Bereich aufweisen und ein Einfluss der Herrscher- und Götterikonographie auf bestimmte Statuetten zwar wahrscheinlich ist, nicht aber bewiesen werden kann, ist die nachfolgend gegebene Zuweisung der Statuetten zu einzelnen Personengruppen mit Unsicherheiten behaftet.

Die „Reiter ohne Gegner“ aus dem ptolemäischen bzw. mediterranen Raum zeigen, da teilweise jugendliche Gesichtszüge festzustellen sind und eine Bewaffnung fehlt, wahrscheinlich reitende Epheben und Neoi, möglich ist aber auch die Darstellung von Kavalleristen, die außerhalb der Schlacht ihre Waffen nicht (persönlich) mit sich führen mussten. Die Reiter aus dem Orient, insbesondere die handgeformten Reiter, die teils Rundschilde tragen, geben wahrscheinlich (seleukidische) Kavalleristen wieder. Hierfür sprechen auch die Fundorte dieser Figuren, die oft an militärisch relevanten Stellen liegen (z.B. Ikaros und Masjid-i Solaiman), und die persische Tradition, in der solche reitenden Soldaten stehen. Die ptolemäischen „Reiter über Gegner bzw. Schild“" stehen einerseits eindeutig in einem militärischen Zusammenhang und weisen andererseits Bezüge zur Ikonographie der altägyptischen Pharaonen und Königsgötter auf. Sollten diese Bezüge in hellenistischer Zeit im Falle der betreffenden Terrakotten noch in der alten Weise verwendet worden sein, müssten in den Reitern nicht nur siegreiche ptolemäische Kavalleristen gesehen werden, sondern der vergöttlichte König bzw. ein Königsgott.

Diese Feinheiten können jedoch im Rahmen der Bestimmung der Symbolik und diachron-sozialen Funktionen der Reiterstatuetten in gewissem Umfang vernachlässigt werden, da es sich bei der mit den Statuetten zu verbindenden Personengruppe immer um die makedonisch-hellenische Minderheit der Diadochenreiche handelt. Die einzelnen Typen stehen jeweils für bestimmte Institutionen, die eine wichtige Rolle im Leben dieser Gruppe spielten: Gymnasion und Ephebie, Heer und Kavallerie, (gottähnliches) Königtum.

Die diachrone Funktion der Statuetten ist immer eine identitätsstiftende und solidaritätsfördernde, im Falle der potentiellen Königsdarstellungen verweist sie zusätzlich auf die Herrschaft in der Nachfolge Alexanders und der Pharaonen und wirkt legitimierend. Die NutznieBer der Festigung der bestehenden Ordnung sind jeweils die „Makedonen“ bzw. „Hellenen“, seien es die makedonischen Diadochenkönige oder ihre Landsleute im Militär, der Reichsund Kommunalverwaltung oder in wirtschaftliche Schlüsselpositionen.

\subsubsection{Die Theater-Soldaten}

Für die Verwendung der Soldatenfiguren gibt es keine direkten Hinweise. Da aber nichts auf eine andersartige Nutzung hinweist, gehe ich bei diesen analog zu den Chlamydephorenstatuetten von einer Verwendung im sepulkralen und sakralen Bereich aus. Hierauf deutet auch die Verwendung anderer Schauspielerfiguren in diesen Bereichen hin. ${ }^{895}$

\footnotetext{
${ }^{895}$ Vgl. z.B. zu Schauspielerterrakotten in Gräbern: Myrina Gräber Nr. 99, 114 (U. Mrogenda, Die Terrakottafiguren von Myrina [1996] 40 Tab. 1).
} 
Während es im Falle der Chlamydephoren-Statuetten wahrscheinlich ist, dass sie diejenigen Personen zeigen, die diese weihten oder in deren Namen sie geweiht oder denen solche Figuren mit ins Grab gegeben wurden, ist dies im Falle der Soldaten-Schauspieler weitgehend auszuschließen. Es kann sich bei den Verwendern nicht nur um Schauspieler gehandelt haben, da hierfür die Zahl der Schauspielerterrakotten (auch anderer Typen) zu groß ist. Gegen eine strikte Begrenzung auf Militärangehörige spricht, dass nicht reale Soldaten dargestellt sind, sondern ein Charakter des Mimos.

Die Deutung der Symbolik und der Funktion der Statuetten hat daher von der nächst höheren Ebene, dem Theater und dem Heer, auszugehen. Wie die Chlamydephoren für das Gymnasion und die mit diesem verbundenen Aufgaben und Personengruppen stehen, sind die Schauspieler-Statuetten mit dem Theater zu verbinden. Die Gruppe der im Theater Versammelten ist im Idealfall weitgehend identisch mit dem Demos der klassischen Polis bzw. vergleichbaren Gruppen in den hellenistischen Siedlungen. In der Beigabe solcher Statuetten ins Grab oder ihrer Weihung ${ }^{86}$ drückt sich wiederum ein Bekenntnis zur zugehörigen Gemeinschaft aus.

Innerhalb der Schauspieler-Figuren bilden die Soldaten eine Untergruppe. Diese stehen, wenn auch in karikierender Form, für die Makedonen im ptolemäischen Heer. Die makedonischen Soldaten stellten als Nachfahren des Alexanderheeres die Kerntruppe des Ptolemäerreiches. Ähnlich wie die Militärkolonisten in anderen Diadochenreichen besaßen sie bestimmte Gruppeninteressen, die gegen andere Gruppen - insbesondere die ägyptische Bevölkerungsmehrheit - zu verteidigen waren. Im Rahmen der Wahrung dieser Interessen könnten Weihungen und Grabbeigaben, die sich auf diese Gruppe bezogen und denen eine identitätsstiftende und gemeinschaftsfördernde Symbolik und diachron-soziale Funktion innewohnte, von makedonischen Armeeangehörigen und Personen aus deren Umfeld bevorzugt genutzt worden sein.

\subsubsection{Chlamydephoren: Paides, Epheben, Neoi und Soldaten?}

Bei den dargestellten Personen handelt es sich um Jugendliche und junge Männer. Diese tragen die insbesondere für das Gymnasion typische Bekleidung (Chlamys und Kopfbedeckung) und werden durch die Kausia als Makedonen gekennzeichnet. Die Dargestellten können entsprechend als jugendliche, makedonische Besucher des Gymnasions (Paides, Epheboi, Neoi) gedeutet werden. Hierfür spricht auch, dass diese Figuren größtenteils aus Regionen außerhalb Makedoniens stammen, in denen es in hellenistischer Zeit zu verstärkter militärischer und ziviler Siedlungstätigkeit durch „Makedonen“ bzw. „Hellenen“ kam. Zumindest in Ägypten nutzten diese Kolonisten (Kleruchen, Katoiken) in Siedlungen, die meist keinen Polisstatus besaßen, ersatzweise die Organisationsstrukturen des Gymnasions im Rahmen der kommunalen Selbstverwaltung. Das Gymnasion bildete den Mittelpunkt des gesellschaftlichen Lebens und diente der Erziehung der Jugend und ihrer Eingliederung in die Gemeinschaft.

\footnotetext{
${ }^{896}$ Eng mit dem Theater verbunden ist der Dionysos-Kult. Es muss sich bei den Schauspieler-Statuetten dennoch nicht durchweg um Weihungen an Dionysos handeln, da die Bedeutung und Funktion des Theaters sich auf das gesamte Gemeinwesen bezogen und entsprechende Weihungen im Kult aller eng mit der Polis (oder einer ähnlich strukturierten Siedlung) verbundenen Götter sinnvoll wären.
} 
Auf die Bedeutung der Erziehung und eine Funktion im Rahmen der Eingliederung der Jugend in die Gesellschaft weisen auch die Fundkontexte hin: Die betreffenden Statuetten wurden oft in Heiligtümern gefunden, in denen Gottheiten verehrt wurden, die für die Erziehung und Eingliederung der Jugendlichen zuständig waren. In diesen Heiligtümern fanden Riten statt, die geeignet waren, den Übergang von einem Lebensabschnitt zum anderen und die fortschreitende Eingliederung von Jugendlichen in die Gesellschaft auf religiöser Ebene zu begleiten, und die die Möglichkeit boten, Votivstatuetten niederzulegen.

Auf der synchron-funktionalen Ebene stehen die Chlamydephoren-Statuetten demnach für junge männliche „Makedonen“, die im Gymnasion trainierten bzw. dienten, und fanden als Votiv oder Grabbeigabe Verwendung, um den Status der dargestellten Person zu dokumentieren.

Auf einer anderen Ebene symbolisieren die Figuren die Institution (das Gymnasion), die hinter diesen steht, und die Aufgaben, die das Gymnasion erfüllte (Erziehung, Eingliederung in die Gemeinschaft). Die Statuetten stehen letztlich für die Aufnahme in die Gesellschaft und damit die Erneuerung und den Fortbestand der Gesellschaft. Entsprechend besteht auch die Funktion nicht nur darin, den Status einer bestimmten Person oder den Vollzug eines bestimmten Ritus bildlich festzuhalten. Die Personen, die sich entsprechend wiedergeben ließen, die diese Darstellungen weihten oder im Grab niederlegten oder die die Verwendung dieser Statuetten zuließen, akzeptierten den Status und den Aufstieg der als Chlamydephoros dargestellten Person in der Gesellschaft und schließlich den Aufbau der Gesellschaft insgesamt und so auch die Vorrechte bestimmter Gruppe innerhalb dieser gesellschaftlichen Ordnung.

Die kausiatragenden Chlamydephoren stehen letztlich für die führende Gruppe unter den verschiedenen Gruppierungen, aus denen sich die Gesellschaften des Alexanderreiches und seiner Nachfolgestaaten zusammensetzten. Die Statuetten dienten auf der diachronen Ebene wie entsprechende Darstellungen aus dem szenischen Bereich - der Identifizierung mit der eigenen Gruppe, der Solidarisierung innerhalb der Gruppe, der Abgrenzung der Gruppe gegen andere und der Anerkennung als Gruppe (mit bestimmten Rechten) durch andere. Die diachron-soziale Funktion bestand demnach in der Stärkung der führenden Gruppe der hellenistischen Gesellschaft und der Festigung der Gesamtgesellschaft.

\subsubsection{Primär-synchrone Funktionen}

Terrakotten mit Kausia werden in der Regel - wie die allgemeine Verbreitung solcher Statuetten sowie diejenigen Gebiete mit hoher Fundkonzentration zeigen - von „Makedonen“, insbesondere den Bewohnern der großen Königsstädte, der Militärkolonien und der Garnisonen verwendet. Orte der Verwendung sind einerseits Nekropolen und andererseits Heiligtümer (insbesondere von Muttergottheiten und ihren Kindern). Hieraus ergeben sich die Arten der Verwendung: Im sepulkralen Bereich ist ein Einsatz entweder als Beigabe oder im oberirdischen Grabkult möglich, auf sakralem Gebiet dienten die Statuetten als Weihgeschenke. Die Ikonographie bezieht sich bezeichnenderweise weder auf das Jenseits noch die Götter, son- 
dern ist bis auf Ausnahmen dem profanen Sektor entnommen. Die Chlamydephorenstatuetten zeigen Jungen und junge Männer in derjenigen Kleidung, die im Gymnasion üblich war. Es handelt sich demnach bei den Dargestellten um Angehörige der dort übenden Gruppen der Paides, Epheben und Neoi. Hinter den Darstellungen von makedonischen Soldaten verbirgt sich der entsprechende Charakter des volkstümlichen hellenistischen Theaters. Die einfachen Reiterdarstellungen geben letztlich Chlamydephoren zu Pferde wieder, hier kommen neben reitenden Epheben und Neoi Angehörige der makedonischen bzw. ptolemäischen oder seleukidischen Kavallerie in Frage. Nur die hockenden Knaben und wahrscheinlich die Vertreter des Typus „Reiter über Gegner/Schild“ weisen ikonographische Bezüge zur verehrten Gottheit auf. Die „Reiter über Gegner/Schild“ zeigen den gottähnlichen König und Pharao in Angleichung an den Königsgott Horus, die Ikonographie der hockenden Knaben orientiert sich an der des Harpokrates. Entsprechend verweisen auch die sich hinter diesen Themen verbergenden Kontexte in erster Linie in den gesellschaftlichen Bereich: Die Chlamydephoren deuten auf das Gymnasion und die Ephebie hin, Institutionen, die einerseits der Erziehung und andererseits der Eingliederung in den Bürgerverband dienten. Die Soldaten weisen auf die Bedeutung des Heeres in der (ptolemäischen) Gesellschaft hin sowie auf das Theater, das auch in hellenistischer Zeit noch seine Rolle spielte, z.B. als Spiegel der Gesellschaft und ihrer Probleme oder als Ort der Meinungsbildung und der Hellenisierung. Hinter den Reiterstatuetten (ohne Gegner) verbergen sich wieder Gymnasion und Ephebie oder die Kavallerie als vornehmster Teil des Heeres. Das Thema der „Reiter über Gegner/Schild“ ist zwar das des Kultes des Königs (-gottes), dieser Kult ist jedoch in noch stärkerem Sinne, als dies bei der allgemein engen Bindung von Religion und Gesellschaft in alten Kulturen der Fall ist, vorwiegend als herrschaftspolitisches Phänomen zu sehen. Eine gesellschaftliche Relevanz ist aus der Ikonographie der hockenden Knaben nicht zu erschließen, eine solche ergibt sich jedoch bei der Betrachtung möglicher konkreter Anlässe, da es sich bei diesen vermutlich um ähnliche handelt wie bei den Chlamydephoren.

$\mathrm{Zu}$ welchen Anlässen Terrakotten mit Kausia einer Gottheit geweiht wurden, ist nicht direkt überliefert, lässt sich jedoch mit einer gewissen Wahrscheinlichkeit aus dem Charakter der jeweiligen Heiligtümer bzw. der dort verehrten Gottheiten, der Ikonographie der Figuren sowie dem gesellschaftlichen Kontext des dargestellten Themas erschließen. Im Falle der Chlamydephoren ergibt sich aus dem Aufgabenbereich der verehrten Gottheiten (Erziehung, Eingliederung in die Gesellschaft) und dem oft initiatorischen Charakter des Kultes dieser Gottheiten sowie aus dem kulturellen Hintergrund der Ikonographie (Gymnasion, Ephebie), der wiederum in den Bereich der Erziehung und Eingliederung in die Gesellschaft verweist, eine Weihung anlässlich eines im Rahmen der Erziehung und der Eingliederung in die Gesellschaft relevanten Ereignisses. Solche Ereignisse gab es im Leben eines jungen Makedonen eine ganze Reihe (von der Anerkennung des Kleinkindes durch den Vater vor den Mitbürgern und die Einschreibung in die Bürgerlisten, die Aufnahme in die verschiedenen Abteilungen des Gymnasions [Paides, Epheboi, Neoi] und den Abschluss der betreffenden Lebensabschnitte bis zur 
endgültigen Aufnahme in den Bürgerverband). Diese Einschnitte im Leben dürften jeweils mit Kulthandlungen, in deren Verlauf es zu Weihungen kam, verbunden gewesen sein. Parallel zum Aufstieg in der Gesellschaft bzw. zur Eingliederung in diese ist vielleicht von entsprechenden Schritten auf dem Weg zur vollständigen Aufnahme in den Kultverband auszugehen, die mit initiatorischen Riten verbunden waren. Bei vergleichbaren Anlässen können auch die hockenden Knaben sowie die reitenden Chlamydephoren geweiht worden sein. Die Soldatenfiguren sind als Schauspielerdarstellungen Dionysos, dem Gott des Theaters, zuzuordnen. Das Theater erfüllte in der Gesellschaft eine ähnliche Funktion wie das Gymnasion, und Dionysos ist nicht nur wie die in Verbindung mit den Chlamydephoren genannten Götter ein Gott der Initiation, sondern wie das Theater eng mit dem Politischen verbunden. Die Soldaten könnten Dionysos, aber auch anderen die Polis repräsentierenden Gottheiten geweiht worden sein. Die „Reiter über Gegner/Schild“ gehören in den Bereich des Herrscherkultes und sind, wie ebenfalls schon näher dargelegt, entweder anlässlich zugehöriger Feste geweiht worden oder spielten eine Rolle als Ersatzkultbild im privaten Kult. Wie schon die Weihungen von Chlamydephoren-Statuetten waren auch die von Reiterfiguren weniger auf der Erfüllung privater religiöser Bedürfnisse ausgerichtet, sondern hatten vielmehr einen Bezug zur Gesellschaft, in diesem Fall zum realen König als führender Persönlichkeit der eigenen Gemeinschaft.

\subsubsection{Symbolik und diachron-soziale Funktionen}

Auf der Grundlage der oben zusammengefassten Ergebnisse sowie einiger allgemeiner Vorüberlegungen lässt sich jetzt die Frage nach der Symbolik und Funktion der Statuetten stellen. In einem Heiligtum gefundene Terrakotten erfüllen eine Aufgabe im religiösen Bereich. Diese Antwort ist zwar sicherlich zutreffend, sie ist jedoch weitgehend inhaltslos, solange der Charakter der betreffenden Religion nicht näher umrissen ist. Denn der Charakter einer Religionsform bzw. die Aufgabe, die diese Religion im Leben der Menschen erfüllt, ist letztlich auch verantwortlich für die Funktion, die Weihungen in ihr ausüben. Grundsätzlich bestehen zwei Möglichkeiten: Die Religion kann als eine weitgehend private und persönliche Sache angesehen werden, deren Ausübung in erster Linie der Verfolgung individueller Wünsche und Ziele gilt. Dies ist die Art und Weise, in der Religion in den meisten Ländern des christlichen Abendlandes seit der formalen Trennung von Staat und Religion, die meist im Verlauf des 20. Jahrhunderts erfolgte, heute von der Mehrheit der Bevölkerung praktiziert wird. Die Religion kann aber auch als eine hauptsächlich die Gemeinschaft betreffende Angelegenheit gesehen werden, deren Ausübung in starkem Maße auf die Befriedigung gemeinsamer Bedürfnisse und die Verfolgung gemeinsamer Interessen gerichtet ist. Eine solche Religion ist auf das engste verbunden mit einer Gemeinschaft, die im Falle der „Makedonen“ weitgehend identisch ist mit der staatstragende Gruppe, die letztlich für den „Staat“ insgesamt stehen kann. Dieser tritt im klassischen Griechenland meist in Form der Polis auf. In den hellenistischen Reichen kann der Staat einerseits auch durch den König repräsentiert werden, während andererseits auf lokaler Ebene teils Siedlungen erscheinen, die vom klassischen Vorbild abwei- 
chende politische und urbanistische Strukturen aufweisen und dennoch ähnliche Funktionen erfüllen.

Welcher dieser Religionsauffassungen die in einem Heiligtum gefundenen Weihungen zugewiesen werden, scheint derzeit weitgehend davon abhängig zu sein, in welcher Weise an das Material herangegangen bzw. in welcher Weise dieses durchdrungen wird. Geht man von einem einzelnen Heiligtum oder einer relativ willkürlichen Auswahl von Heiligtümern aus und stellt fest, dass in Heiligtümer Gegenstände verschiedenster Art geweiht werden konnten und sich z.B. unter den koroplastischen Votiven Dutzende von Themen und Typen inje dutzendfacher Ausführung finden, kann dies dazu verleiten, eine private Religionsauffassung der Weihenden zu vermuten. Denn scheinbar weihten viele verschiedene Personen in verschiedene Heiligtümer die verschiedensten Dinge entsprechend ihren unterschiedlichen individuellen Wünschen. Dieser Schluss ist falsch. Denn immer, wenn ein Weihgeschenk in gleicher oder ähnlicher Form mehrfach in einem Heiligtum anzutreffen ist, handelt es sich um den Bestandteil einer Gruppe von Weihungen. Eine solche Gruppe von Weihgeschenken ist - das zeigen zumindest die Ergebnisse der Untersuchung der Gruppen der Chlamydephoren-, Soldatenund Reiter-Statuetten - mit einer bestimmten Gruppe von Weihenden zu verbinden. Die Vielfalt unterschiedlicher Weihgeschenke ist demnach in der Regel nicht auf die unterschiedlichen Wünsche und Bedürfnisse von Einzelindividuen zurückzuführen, sondern auf die Nutzung eines Heiligtums durch verschiedene Gruppen. Diese Gruppen haben bestimmte Gruppeninteressen, die für die Auswahl eines bestimmten von der Gruppe regelmäßig verwendeten Weihgeschenks verantwortlich sind. Dieses Gruppeninteresse kann privater Natur sein, es kann aber auch ein auf die Gemeinschaft bezogenes sein.

Die Klärung der Bedeutung, Symbolik und Funktion bestimmter Gruppen von Weihgeschenken darf daher nicht vom Fundbestand einzelner Heiligtümer ausgehen, will sie nicht zu Ergebnissen gelangen, die letztlich weder regional noch allgemein zutreffen. Denn solche Ergebnisse würden auf der Übertragung einer Mischung von mehr oder weniger willkürlich überlieferten Einzelinformationen zu regionalen Begebenheiten und oft eher allgemeinen Angaben zu den jeweiligen Gottheiten beruhen.

Die Deutung der Symbolik und Funktion von Weihgeschenken hat statt dessen von einzelnen Typen bzw. Gruppen von Typen auszugehen. Anhand der überregionalen Verbreitung dieser Typen, ihrer Verteilung auf Heiligtümer ähnlich strukturierter Gottheiten, ihrer Ikonographie und des kulturellen Gesamtkontextes, dem diese zuzuordnen sind, muss versucht werden, die sich hinter der jeweiligen Gruppe von Weihungen verbergende Personengruppe zu ermitteln. Deren Gruppeninteresse ${ }^{897}$, das sich auch in der Ikonographie der Weihgeschenke und in der Auswahl bestimmter Heiligtümer und Gottheiten spiegeln dürfte, ist letztlich verantwortlich für die Weihung eines bestimmten Gegenstandes. Das Gruppeninteresse bietet auch den Schlüssel zur Bestimmung der Funktion einer Weihung im Kult. Handelt es sich um einen

\footnotetext{
${ }^{897}$ Zur engen Bindung von Konnotationen und Subcodes im Rahmen von Zeichen- und Kommunikationstheorien vgl. L. Schneider, B. Fehr, K.-H. Meyer, Zeichen - Kommunikation - Interaktion, Hephaistos 1, 1979, 21 f.
} 
Kult bzw. einen Ritus innerhalb dieses Kultes mit eher gesellschaftspolitischer als privater Ausrichtung - dies ist wiederum dem Gruppeninteresse und der Ikonographie zu entnehmen ist aus dem Gruppeninteresse infolge der engen Bindung von Kult und Gesellschaft auch die Funktion des Weihgeschenkes in der Gesellschaft abzuleiten.

Wendet man diese Methode auf die verschiedenen Gruppen von Terrakotten mit Kausia an, ergibt sich folgendes Bild: Sämtliche Typen von Terrakotten mit Kausia lassen sich aufgrund des Gesamtverbreitungsgebietes und der Ikonographie (u.a. der Darstellung der Kausia) mit der Gruppe der außerhalb des eigentlichen Makedoniens in fremder Umgebung in neugegründeten Ortschaften unterschiedlicher Größe (Königsstädte, Militärkolonien/Katoikiai) oder Garnisonen lebenden „makedonischen“ (Militär-) Siedler verbinden. Aufgrund ihrer Ikonographie und des zugehörigen kulturellen Kontextes sowie der teilweise auf bestimmte Regionen beschränkten Verbreitung einiger Typen ist es möglich, bestimmte Typen auf begrenzte Gruppen innerhalb der makedonischen Bevölkerung zu beziehen.

So wurden Chlamydephoren-Statuetten wahrscheinlich im Rahmen von Kulthandlungen geweiht, an denen die im Gymnasion übenden Gruppen der Paides, Epheboi und Neoi beteiligt waren. Die ptolemäischen Reiter (ohne Gegner) sind entweder als Kavalleristen zu deuten oder als reitende Chlamydephoren ebenfalls mit Epheben oder Neoi, deren Ausbildung auch den militärischen Bereich einschloss, in Verbindung zu bringen. Die handgeformten orientalischen Reiter stellen mit einiger Sicherheit bestimmte Verbände der seleukidischen Kavallerie dar. Die Ikonographie der ptolemäischen „Reiter über Gegner/Schild“ liefert keinen Hinweis auf die Verwender, da vermutlich der König bzw. Königsgott gezeigt wird. Die Verteilung der Fundorte innerhalb Ägyptens deutet jedoch auf Angehörige des Alexanderheeres bzw. „Makedonen“, die als Kleruchen/Katoiken den Kern des ptolemäischen Heeres bildeten, als die Weihenden hin. $\mathrm{Zu}$ den ptolemäischen Soldaten-Figuren liegen in keinem Fall Angaben zum Fundkontext vor, was die Deutung erschwert. Die Ikonographie deutet wiederum auf den militärischen Bereich. Da es sich um Schauspielerdarstellungen handelt, ist im Theater der kulturelle Kontext zu sehen. Sollte es sich auch bei diesen Terrakotten um Weihgeschenke handeln, bietet sich einerseits eine Weihung an Dionysos, den Gott des Theaters, dargebracht von Theaterbesuchern (vornehmlich vielleicht aus dem Umfeld des Militärs), an. Andererseits kommen aufgrund der auch weiter zu fassenden politischen Bedeutung des Theaters auch weitere eng mit der politischen Gemeinschaft verbundene Gottheiten in Frage. Als Anlässe der Weihung der Chlamydephoren-Figuren konnten Riten in Verbindung mit der Aufnahme in eine Körperschaft der Bürgerschaft bzw. dem Aufstiegs in dieser wahrscheinlich gemacht werden. Die Statuetten vom Typus „Reiter über Gegner/Schild“ dienten vermutlich als Weihgeschenke oder Ersatzkultbilder im Herrscherkult.

Vernachlässigt man diejenigen Personengruppen, bei denen eine über die Bestimmung der makedonischen „Nationalität“ hinausgehende Eingrenzung infolge unzureichender Angaben zum Fundort oder zum kulturellen Umfeld der Statuetten nur relativ unverbindlich möglich 
ist, bleiben zwei Gruppen: Personen, die die Chlamydephoren weihten, und solche, die die „Reiter über Gegner/Schild“ verwendeten.

Diejenigen Personen, die eine Chlamydephoren-Figur in ein Heiligtum gaben, weihten Statuetten, deren Ikonographie weder einen Hinweis auf die verehrte Gottheit enthält, noch versucht, die wiedergegebene Person zum Beispiel durch Beigabe von Attributen oder persönlichen Merkmalen in einer individuellen Weise darzustellen. Stattdessen werden insbesondere in den Zentren der Verbreitung von Terrakotten mit Kausia in stereotyper Weise Chlamydephoren vom Normaltypus geweiht. Es liegt nahe, dass nicht das Individuum oder die Gottheit dargestellt werden sollte, sondern die Betonung auf dem Gemeinsamen lag, d.h. der Kleidung bestehend aus Chlamys und Kausia. Diese Kleidung ist die der „makedonischen“ Paides, Epheben und Neoi. Diese wiederum stehen für das Gymnasion und Einrichtungen wie die Ephebie. Die Absolvierung dieser Institutionen wird spätestens in römischer Zeit die Voraussetzung für die Zuerkennung des Bürgerrechtes. Parallel zur Aufnahme in die einzelnen Unterabteilungen des Gymnasions erfolgte die Eingliederung in die Gesellschaft sowie in mit der politischen Gemeinschaft weitgehend identische Kultgemeinschaften. Die Terrakotten illustrieren diesen Prozess der schrittweisen Eingliederung in die politische und kultische Gemeinschaft, von der letztlich der Erhalt der Gruppe in der Zukunft abhängt. Die Funktion der Statuetten besteht darin, diesen Prozess öffentlich sichtbar zu machen und quasi zu besiegeln. Das Ziel dieser Form der kollektiven Selbstdarstellung ist es, die Aufnahme in die eigene Gemeinschaft zu beschreiben, sich damit auch gegen andere abzugrenzen und auf diesem Wege die eigene Gemeinschaft zu festigen. Der Ritus der Weihung von Chlamydephoren-Statuetten durch die Träger von Chlamys und Kausia bzw. durch deren Freunde und Verwandte ist demnach - wenn man davon absieht, dass die Zugehörigkeit zu einer Gruppe auch dem einzelnen Individuum dient - ausgerichtet auf die Gemeinschaft.

Ähnlich verhält es sich auch mit den „Reitern über Gegner/Schild“. Unabhängig davon, ob diese in die großen öffentlichen Heiligtümer geweiht wurden oder im Hauskult Verwendung fanden, bezogen sie sich auf den Herrscher, der Leitsymbol sowohl des Gesamtstaates als auch der „,makedonischen“ Bevölkerungsgruppe innerhalb dieser Staaten war. In der Teilnahme am Herrscherkult drückten sich Loyalität zu König und Staat aus, aber auch der Anspruch, selbst der staatstragenden Gruppe anzugehören. Der Herrscherkult und die in diesem verwendeten Statuetten sind demnach ebenfalls auf die Gesellschaft ausgerichtet.

Im Falle der Grabfunde ist eine Verbindung bestimmter Gruppen von Statuetten mit bestimmten Personengruppen auf der Grundlage des derzeit publizierten Materials nicht möglich, da die Fundkontexte der Terrakotten in aller Regel nicht mit ausreichender Genauigkeit beobachtet und veröffentlicht wurden. Die wenigen scheinbar aussagekräftigen Beispiele bieten ein widersprüchliches Bild, es handelt sich zudem meist um regionale Besonderheiten oder typologisch abweichende Wiedergaben. Es ist demnach zur Zeit auf archäologischer Grundlage weder zu beweisen noch zu widerlegen, dass z.B. Darstellungen von Chlamydephoren nur jungen männlichen Makedonen mit ins Grab gegeben wurden oder von solchen im oberirdi- 
schen Grabkult genutzt wurden, um zu zeigen, dass die betreffenden Personen z.B. Ephebenstatus besaßen und sich auf dem Weg der Eingliederung in die Gesellschaft befanden bzw. diese angestrebt hätten, wenn sie nicht frühzeitig verstorben wären. Da jedoch die oben genannten Vorüberlegungen zur Deutung der Statuetten aus Heiligtümer weitgehend auf diejenigen aus Nekropolen zu übertragen sind und es sich sowohl beim Grab- als auch beim Götterkult um ein im weiteren Sinne religiöses Phänomen mit jeweils enger Rückbindung an die Gesellschaft handelt, gehe ich davon aus, dass bei den aus dem sepulkralen Bereich stammenden Figuren mit großer Wahrscheinlichkeit mit ähnlichen Mechanismen und Motiven zu rechnen ist. Auch die im oder am Grab aufgestellten Chlamydephoren sind daher weniger als Zeichen individueller Beigabenpraxis oder individuellen Grabkultes zu sehen, sondern verweisen wiederum auf den Status in der Gesellschaft und die Zugehörigkeit zu einer Gruppe.

Die Funktion der Weihungen ist in der Festigung der Gemeinschaft durch eine gemeinschaftsbezogene (Selbst-) Darstellung zu sehen. Die Kleidung und der kulturelle Kontext verweisen auf den Ort (Gymnasion) und die Institution (u.a. Ephebie) der Sozialisation. Die für die Niederlegung der Statuetten gewählten Heiligtümer sind solche, in denen parallel zur Eingliederung in die politische Gemeinschaft eine Aufnahme in die eng mit dieser verbundene Kultgemeinde stattfand. In der Weihung eines Abbildes des eigenen Status bzw. in der Mitgabe eines Abbildes des Status des Toten ins Grab spiegelt sich die Anerkennung der eigenen (sozialen) Stellung bzw. der des Verstorbenen durch die Hinterbliebenen. Die unbewusste ${ }^{898}$ Darstellung dieser Akzeptanz dient der Stabilisierung der wiedergegebenen sozialen Wirklichkeit und stärkt so die Gemeinschaft.

Grundsätzlich sind entsprechende Darstellungen auch ohne die Kausia in dieser Weise zu deuten. Die Kausia bewirkt jedoch eine auch ethnische ${ }^{899}$ Abgrenzung gegenüber anderen Gruppen und beschreibt den Kreis der Angehörigen der eigenen Gruppe entsprechend präziser und enger. Hierin ist eine zusätzliche Festigung der Gemeinschaft zu sehen.

Die Symbolik und Funktion der allermeisten Statuetten, die die Kausia tragen, ist letztlich weitgehend identisch: Sie stehen für die „Makedonen“ bzw. "Hellenen“ in den Diadochenreichen, die dort meist als Minderheit umgeben von einer Überzahl von Menschen anderer ethnischer Herkunft siedelten. Diese „Makedonen“ und „Hellenen“ traten als Militärkolonisten und Garnisonssoldaten auf, nahmen auf verschiedenen Ebenen Aufgaben in der Verwaltung wahr und stellten die Könige. „Makedonen“ und „Hellenen“ wurden aber auch in der Landwirtschaft, im Handel und im Handwerk tätig. Die Voraussetzung für die verstärkte Zuwanderung aus dem makedonisch-griechischen Raum waren die Eroberung der betreffenden Gebiete durch das Alexanderheer und der Fortbestand einer politischen und gesellschaftlichen Ord-

\footnotetext{
${ }^{898}$ Vgl. zum „Problem der Bewußtheit“ L. Schneider, B. Fehr, K.-H. Meyer, Zeichen - Kommunikation - Interaktion, Hephaistos 1, 1979, 23.

${ }^{899}$ „Ethnisch“ im Sinne der oben diskutierten Überlegungen zur Zusammensetzung der „Makedonen“ und „Hellenen“. Vgl. Kap. „Die ,Makedones“ - eine ,ethnische“ Gruppe?“.
} 
nung, die es den Neusiedler erlaubte, den genannten Aktivitäten möglichst ungehindert nachzugehen.

Statuetten, die Personen wiedergeben, die die Kausia tragen, kennzeichnen diese jedoch nicht nur als „Makedonen“ bzw. „Hellenen“, sie verweisen in der Regel auch auf diejenigen Institutionen, die maßgeblich zum Erhalt der politischen Ordnung beitragen: Gymnasion und Ephebie, das Theater, das Heer und das Königtum. Diese Einrichtungen waren einerseits zuständig für die Erziehung der Jugend und die Schaffung und Bewahrung eines gemeinsamen kulturellen Kontextes und sicherten so die Ordnung innerhalb der makedonischen Bevölkerungsgruppe (Gymnasion/Ephebie, Theater). Andererseits standen sie für die Herrschaft über die nichtmakedonische Bevölkerungsmehrheit und für den Schutz vor äußeren Feinden (Gymnasion/Ephebie [als Wehrpflichtorganisation], Heer, König). Diese Einrichtungen wurden durch die identitätsstiftende und solidaritätsfördernde Wirkung der Statuetten gefestigt, die somit der Aufrechterhaltung der gesamten gesellschaftlichen und politischen Ordnung dienten. 


\section{Zusammenfassung}

\subsection{Die Kausia als Realie}

Die Kausia ist eine dem Barett ähnliche Mütze aus Stoff und/oder Leder. Sie stammt aus Makedonien und verbreitete sich nach der Eroberung des Perserreiches (einschließlich Ägyptens) durch Alexander den Großen und der daraus resultierenden gewachsenen Bedeutung Makedoniens seit dieser Zeit in den Ländern rund um das östliche Mittelmeer und das Schwarze Meer sowie im Orient bis nach Afghanistan und zum Indus. Schwerpunkte der Verbreitung von Darstellungen der Kausia sind Gebiete, in den es zur Ansiedlung von „makedonischen“ bzw. „hellenischen“ Militär- und Verwaltungspersonal kam (Kleinasien, Ägypten, Mesopotamien, Baktrien, einzelne Orte im Bereich der Ägäis). In diesen Gebieten wird die Kausia auch zur realen Kleidung der dort wohnenden Makedonen und „Hellenen“ gehört haben. ${ }^{900}$

Die Kausia wurde von Königen und Soldaten getragen, konnte aber auch im zivilen und privaten Bereich aufgesetzt werden. Sie ist das makedonische Gegenstück zum griechischen Petasos mit einem entsprechenden Verwendungsspektrum.

\subsection{Primär-synchrone Funktionen der Kausia als realem Bestandteil der makedonischen Kleidung}

Die Kausia war zunächst geeignet gegen widrige Witterungseinflüsse verschiedenster Art, so beispielsweise gegen übermäßige Wärme, Kälte oder Feuchtigkeit, zu schützen. Sie konnte daher bei im Freien ausgeübten Aktivitäten, etwa auf der Jagd, während eines Feldzuges oder beim Besuch eines Theaters oder Gymnasions, getragen werden.

Die Kausia war darüber hinaus zumindest ursprünglich die typische Kopfbedeckung einer bestimmten Region bzw. einer bestimmten Volksgruppe, nämlich der Makedonen (und vermutlich auch angrenzender Völker). Sie kann infolgedessen als Erkennungszeichen dieser Gruppe angesehen werden. Dies dürfte insbesondere außerhalb Makedoniens von Interesse gewesen sein, denn nur in Regionen, in denen nicht ohnehin (fast) jeder Makedone war, konnte es von Nutzen sein, dass sich die Angehörigen einer Minderheit gegenseitig erkannten oder von der Masse der Bevölkerung als Angehörige einer Volksgruppe erkannt wurden, die unter Umständen bestimmte Rechte besaß.

Von Bedeutung ist hierbei, dass es sich bei den Makedonen nicht um irgendeinen Volksstamm handelte, sondern um denjenigen, der weite Teile der damaligen Welt unterworfen hatte und

\footnotetext{
${ }^{900}$ Das Hauptverbreitungsgebiet bildlicher Wiedergaben der Kausia dürfte in etwa identisch sein mit demjenigen Gebiet, in dem außerhalb Makedoniens mit größeren Gruppen von Makedonen zu rechnen ist.
} 
dessen Vertreter für Jahrhunderte diese Welt beherrschen sollten. Entsprechend war auch die Kausia nicht eine Kopfbedeckung unter anderen, sondern die derjenigen Bevölkerungsgruppe, die auf verschiedenen Ebenen einen Führungsanspruch erhob und die später um die „Hellenen" erweitert wurde bzw. mit diesen verschmolz. Die Kausia konnte daher nicht nur Symbol Makedoniens sein, sondern auch für die Vorherrschaft der „Makedonen“ und „Hellenen“ stehen.

\subsection{Symbolik und diachron-soziale Funktion der Kausia als Realie und in bildlichen Wiedergaben}

Neben der allgemeinen Feststellung, dass die Kausia dem Schutz vor Witterungseinflüssen diente und einen Makedonen kennzeichnen konnte, lässt sich in den meisten Fällen näher definieren, welchen symbolischen Gehalt und welche Funktion die bildliche Wiedergabe einer Kausia im Rahmen einer bestimmten Darstellung und letztlich auch die Kausia selbst besaß. Auch kann das Gewicht, das der Symbolgehalt der Kausia innerhalb eines größeren Zusammenhanges einnahm, näher bestimmt werden.

Damit von einem gesteigerten symbolischen Aussagewert der Kausia ausgegangen werden kann, müssen in der Regel zwei Voraussetzungen erfüllt sein. Erstens kann die Kausia nur dann als vestimentäres Zeichen innerhalb eines Kommunikationsprozesses dienen, wenn auBer einem „Sender“ (dem Träger der Kausia) auch ein „Empfänger“ existiert. ${ }^{901}$ Es müssen sich also in einer Region beispielsweise weitere Angehörige der makedonischen Minderheit aufhalten, die ein Interesse daran haben, einander zu erkennen, um die gemeinsamen Belange der Gruppe besser durchsetzen zu können, oder es muss eine Bevölkerungsgruppe vorhanden sein, der gegenüber Herrschaftsansprüche vertreten werden können. Zweitens kann die Kausia nur dann als Gruppenkennzeichen gewertet werden, wenn sie mit einer gewissen Regelmäßigkeit von weiten Teilen der Gruppe getragen wird bzw. diese sich regelmäßig mit dieser wiedergeben lassen. Treffen eine oder beide Voraussetzungen nicht $\mathrm{zu}$, ist zu prüfen, ob es sich nicht eher um eine Darstellung des Alltags handelt. Dieser Fall ist bei den vereinzelten bildlichen Wiedergaben der Kausia aus Makedonien überwiegend anzunehmen, da in dieser Region eine nicht-makedonische Bevölkerungsmehrheit, gegenüber der sich profiliert werden könnte, bzw. unterworfene Völker, denen gegenüber der Herrschaftsanspruch auf diesem Wege zu verdeutlichen wäre, fehlen. Es besteht auch die Möglichkeit, dass die Kausia weniger als Element der makedonischen Kleidung, denn als eines der Mode ${ }^{902}$ der Zeit auftritt, wie dies im Falle der in Süditalien und auf der Krim vereinzelt auftretenden Terrakotta-Statuetten mit Kausia zutreffen könnte. Auch dort fehlen diejenigen Gruppen, denen gegenüber Ansprüche

\footnotetext{
${ }^{901}$ Vgl. Schubert, Kleidung, 47 ff. .- L. Schneider, B. Fehr, K.-H. Meyer, Zeichen - Kommunikation - Interaktion, Hephaistos 1, 1979, 20

${ }^{902}$ Vgl. I. Petrascheck-Heim, Die Sprache der Kleidung. Wesen und Wandel von Tracht, Mode, Kostümund Uniform (2. neubearb. Aufl. 1988) $102 \mathrm{ff}$.
} 
durchgesetzt werden könnten. In Darstellungen, in denen die Kausia eher zufällig in Alltagsszenen erscheint oder als modisches Element auftritt und eine gezielte Ausrichtung auf eine Empfängergruppe nicht erkennbar ist, kann daher von einem stark verringerten Gewicht des Symbolgehaltes ausgegangen werden.

Im Gegenzug kann in denjenigen Fällen, in denen Sender und Empfänger näher bestimmt werden können, auch die symbolische Aussage genauer umrissen und ein besonderes Gewicht dieser Aussage festgestellt werden.

Die Kausia steht für Makedonien und die makedonische Herrschaft. Auf welchem dieser Aspekte der Schwerpunkt der Aussage liegt, ist vom jeweiligen Kontext abhängig. Ähnliches gilt für die exakte Funktion, die die Kausia innerhalb dieses Kontextes als Zeichen erfüllt.

Einfluss auf die Symbolik und Funktion einer bildlichen Wiedergabe der Kausia (und ähnlich der Kausia selbst) können der politische, soziale und kulturelle Kontext der Darstellung, die politische Struktur und die ethnische Zusammensetzung der Bevölkerung des Gebietes sowie die Funktion der betreffenden Gattung haben.

So verweisen bildliche Wiedergaben aus dem herrschaftlichen Bereich (beispielsweise der König mit Kausia diadematophoros) auf den Machtanspruch eines makedonischen Königs, die Nachfolge in der Herrschaft Alexanders des Großen und mit diesem verbundene Eigenschaften wie die der Fähigkeit zum Siegen. Die isolierte Darstellung der Kausia diadematophoros erweitert diese Aussagen möglicherweise um den Hinweis auf die göttliche Verehrung des Königs oder seiner Vorfahren und einen damit zusammenhängenden Herrscherkult. Dagegen weisen die Wiedergaben aus dem bürgerlichen Bereich (z.B. Epheben, Bürger oder Beamte mit Kausia) auf den gesellschaftlichen oder rechtlichen Status der makedonischen Bewohner und die hiervon abhängenden Vorrechte dieser Gruppe im Heer und in der Verwaltung der Diadochenreiche hin sowie auf das Recht zur Beteiligung an der kommunalen Selbstverwaltung im Rahmen polisähnlich strukturierter Einrichtungen wie des Gymnasions. Die Beispiele aus dem militärischen Bereich vereinen den Hinweis auf die makedonische Königsherrschaft, die letztlich militärisch begründet war, und die Vorrechte, die die mit der Umsetzung dieser Macht betrauten Soldaten besaßen. Durch die häufige und weitreichende Verbreitung der Kausia als Symbol Makedoniens und des makedonischen Königtums konnte diese zur Kennzeichnung von Personifikationen Makedoniens herangezogen werden. Dies geschah sowohl durch Makedonen als auch durch die Römer.

Die aus dem Fundort und dem Fundkontext erschließbare Funktion bestimmter bildlicher Wiedergaben (z.B. jugendlicher Chlamydephoren oder reitender Chlamydephoren mit Kausia) als Weihung oder Grabbeigabe bzw. im Grabkult lässt unter Berücksichtigung des gesellschaftlichen, kulturellen und religiösen Umfeldes Rückschlüsse auf die Selbstdarstellung von Makedonen im Rahmen bestimmter Kulte und Riten und vor dem Hintergrund bestimmter gesellschaftlicher Einrichtungen zu. Die Art der Selbstdarstellung verweist wiederum auf die oben genannte Symbolik (makedonische Königsherrschaft und makedonischer Bürgerstatus mit jeweils zugehörigen Ansprüchen und Vorrechten). 
Die Häufigkeit von Kausiadarstellungen sowie bestimmter Gattungen und Themen in einzelnen Regionen ist in starkem Maße abhängig von der ethnischen Zusammensetzung und dem Anteil der Makedonen an der Bevölkerung, der Art der makedonischer Herrschaft und der Siedlungsweise und den damit einhergehenden Strukturen der (kommunal-) politischen Selbstverwaltung der dort lebenden Makedonen, aber auch der Größe und Oberflächenstruktur des Landes und der daran angepassten Gliederung des Heeres in Infanterie und Kavallerie sowie der Entfernung einer Region zum Zentrum der hellenistischen Welt und der im Falle einer Randlage möglichen Nachbarschaft zu nicht-griechisch-hellenistischen Völkern. Gehäuft treten Wiedergaben der Kausia in Gebieten außerhalb Makedoniens, aber innerhalb der Diadochenreiche und innerhalb dieser in den Zentren makedonischer ziviler oder militärischer Siedlungstätigkeit (beispielsweise in königlichen Neugründungen, makedonischen Militärkolonien und Städten mit makedonischer Garnison) auf. Die Breite des Spektrums der Gattungen ist wie das Vorhandensein typologischer und thematischer Schwerpunkte von den regionalen Besonderheiten abhängig. Es kann zu beträchtlichen Unterschieden in der Themenwahl selbst innerhalb einer Gattung kommen. So ist im Falle der Tonfiguren die Herstellung von fast ausschließlich Chlamydephoren-Statuetten in Kleinasien, von Chlamydephoren-, Reiterund Soldaten-Figuren in Ägypten und von ausschließlich Reiterstatuetten im südlichen Mesopotamien zu beobachten. Möglich sind aber auch große Ähnlichkeiten über weite Strecken hinweg, wie im Falle der königliche Städtegründungen Demetrias (Thessalien), Alexandria (Ägypten) und Seleukia am Tigris (Mesopotamien). Die Häufigkeit bestimmter Gattungen und Themen lässt im jeweiligen Kontext wiederum Rückschlüsse auf das Selbstverständnis der betreffenden Gruppe makedonischer Siedler oder Soldaten, bestimmte gesellschaftliche und kultische Einrichtungen und die zugehörige Symbolik und Funktion zu.

Ähnlich kann aus der Gattung, die zur Wiedergabe eines Themas herangezogen wird, auf die Funktion der Wiedergabe und die als Sender und Empfänger einer symbolischen Aussage in Frage kommenden Personengruppen geschlossen werden. So gibt es ortsfeste Darstellungen (z.B. Grabstelen), die sich in der Regel an ein lokales Publikum gerichtet haben werden, Edelmetall-Prägungen, die im grenzüberschreitenden Gebrauch waren, oder Werke von unterschiedlichem Wert, wie die Grabmalerei in (königlichen) Grabhügeln oder preiswerte Tonfiguren, die Rückschlüsse auf den Reichtum und die soziale Stellung der Person, die sich eine entsprechende Darstellung leisten konnte, zulassen.

Zusammenfassend kann festgestellt werden, dass die Kausia - abgesehen von denjenigen relativ seltenen Fällen, in denen sie nur als modisches Element genutzt wird - in der Regel neben einer praktischen Bestimmung als Wetterschutz auch den Charakter eines vestimentären Zeichens besitzt. Nur so ist zu erklären, dass sich die Kausia gegenüber dem Petasos als Kopfbedeckung der „Hellenen“ durchsetzten konnte. Als ein solches Zeichen verweist sie einerseits auf die Herrschaft in der Nachfolge des Makedonenkönigs Alexander und andererseits auf die „Makedonen“ bzw. „Hellenen“ als einer Gruppe, die insbesondere in denjenigen Gebieten der 
Diadochenreiche, die außerhalb des makedonischen Kernlandes lagen, in verschiedenen Bereichen (Militär, Reichsverwaltung, Kommunalverwaltung) bestimmte (Vor-) Rechte besaß. Diese zwei Möglichkeiten des symbolischen Gehaltes können sich mit unterschiedlicher Gewichtung überlagern.

Diejenigen Darstellungen, die in erster Linie auf das makedonische Königtum verweisen, richten sich nicht an die wiedergegebene Person (dies ist meist der König), sondern je nach Kontext entweder an die Bewohner des eigenen Reiches oder an die Nachbarn. Entsprechende Darstellungen dienen der Begründung und Stützung des Herrschaftsanspruches.

Dagegen richten sich diejenigen Wiedergaben, die auf den Makedonenstatus der dargestellten Person verweisen, in erster Linie an die Gruppe, zu der die dargestellten Personen gehören, selbst. In deren Kleidung drückt sich ihre personale und soziale Identität aus. ${ }^{903}$ Die Kausia kann, wenn sie von allen Mitgliedern einer Gruppe getragen wird, als ein Symbol der gesellschaftlichen Identifikation dienen. ${ }^{904}$ Sie spiegelt das Bedürfnis nach Zugehörigkeit zu einer bestimmten Gruppe und einem festen Platz in der Gesellschaft. Die Beachtung von Kleidungsnormen steht auch für die Anerkennung politischer, sozialer und kultureller Normen. ${ }^{905}$ Die Kausia ist zu guter Letzt das Symbol der Solidarität ${ }^{906}$ einer Gruppe, nämlich der Makedonen, wobei unter den „Makedonen“ in den neuen Reichen meist die „Hellenen“ zu verstehen sind. Diese Gruppensolidarität stärkt die Gemeinschaft und ist - insbesondere in einer fremden Umgebung - die Voraussetzung sowohl der Durchsetzung gemeinsamer Interessen als auch der Ziele einzelner Mitglieder der Gruppe.

Die Funktion der symbolischen Nutzung der Kausia einerseits durch hellenistische Könige und andererseits durch makedonische (Militär-) Siedler ist im gewissen Sinne dieselbe: In beiden Fällen geht es um die Durchsetzung bestimmter Ansprüche, sei es um solche, die in der Nachfolge in der Herrschaft Alexanders begründet sind, oder um solche, die schon den Soldaten und Veteranen Alexanders zustanden. Das Symbol dieser Ansprüche war die Kausia als der gemeinsamen Kopfbedeckung Alexanders und seiner Soldaten.

Mit dem Ende der Durchsetzbarkeit solcher Ansprüche in Folge der Eroberung der betreffenden Regionen (im Westen durch die Römer und im Osten zunächst durch die Parther und später durch die Sassaniden) verschwanden auch die Darstellungen der Kausia weitgehend. Während die Herstellung bildlicher Wiedergaben der Kausia in einem herrschaftlichen oder militärischen Kontext meist schlagartig abbricht, können solche aus dem bürgerlichen Bereich entsprechend der langsameren Veränderung des gesellschaftlichen Kontextes noch jahrhundertelang weiterproduziert werden. Auch die Darstellungen der Personifikation Makedoniens erle-

\footnotetext{
${ }^{903}$ Vgl. Schubert, Kleidung, 63.

${ }^{904}$ Vgl. B. Jacobs, Kleidung als Symbol. Das Beispiel der Altgläubigen Südsibiriens im 19. und beginnenden 20. Jahrhundert, Kölner ethnologische Studien 2 (1992) 17 .- Schubert, Kleidung, 65.

${ }^{905}$ Vgl. B. Jacobs, Kleidung als Symbol. Das Beispiel der Altgläubigen Südsibiriens im 19. und beginnenden 20. Jahrhundert, Kölner ethnologische Studien 21 (1992) 17.

${ }^{906}$ Vg. B. Jacobs, Kleidung als Symbol. Das Beispiel der Altgläubigen Südsibiriens im 19. und beginnenden 20. Jahrhundert, Kölner ethnologische Studien 21 (1992) 17 .- Schubert, Kleidung, 65.
} 
ben eine späte Nachblüte. Sie werden dann jedoch durch Römer oder in einem römischen Kontext verwendet und dienen in erster Linie der Erkennbarkeit solchen Darstellungen, während ihre tiefere Symbolik und deren Funktion verloren gegangen sind.

Der Symbolik und Funktion der bildlichen Wiedergaben der Kausia vergleichbar dürfte das Tragen der realen Kausia gewesen sein. Dies trifft insbesondere dann zu, wenn es sich beim Träger um den König handelte oder wenn ein einfacher „Makedone“ bzw. „Hellene“ die Kausia in einem Kontext trug, der ebenfalls für den Zusammenhalt der „Makedonen“ untereinander oder ihre Aufgabe in der Gesellschaft stand, so für Gymnasionsnutzer oder Soldaten. Das Verschwinden der Kausia als realem Kleidungsstück war wiederum die Folge des Endes derjenigen Institutionen - insbesondere des hellenistischen Königtums, der Heere der Diadochenreiche und des Gymnasions, in denen die Kausia eine Funktion als Symbol besaß.

Die primär-synchrone Funktion der Kausia als Realie bestand in der eines Witterungsschutzes und - insbesondere außerhalb Makedoniens - in der Kennzeichnung eines „Makedonen“ bzw. „Hellenen“.

In hellenistischer Zeit wurde die Kausia zu einem Symbol einerseits der makedonisch-hellenischen Bevölkerung der Diadochenreiche und andererseits der Königsherrschaft in der Nachfolge Alexanders. Im Rahmen der symbolischen Nutzung ging die Kausia eine enge Verbindung mit anderen Einrichtungen und Symbolen ein, die für ähnliche Inhalte standen (Gymnasion, Diadem).

Die diachron-soziale Funktion fast aller bildlichen Wiedergaben dieser Kopfbedeckung und teils auch der real getragenen Kausia zielte entweder der Stärkung der Identität und der Solidarität innerhalb der Gruppe der „Makedonen“ bzw. „Hellenen“ oder der Legitimierung der (Königs-) Herrschaft und gegebenenfalls einer Kombination aus beiden ab. Die Festigung der Stellung der „Hellenen“ und der des Königtums als zweier Säulen der hellenistischen Gesellschaft trugen so zur Sicherung des Fortbestandes dieser Gesellschaft und der zugehörigen Staatswesen bei. 


\section{Katalog}

Der Katalog dient dem Nachweis der Existenz der jeweiligen Exemplare. Eine umfassende Beschreibung, Bibliographie oder ähnliches zu einzelnen Darstellungen wird nicht angestrebt. Es werden daher, neben einer Literaturangabe, nur die Grunddaten genannt. Den angeführten Literaturhinweisen sind Orte, Maße und Datierungen entnommen, und über diese lassen sich Abbildungen und gegebenenfalls weitere Publikationen ermitteln.

Mit Sternchen (*) versehene Angaben - insbesondere zur Datierung und zum Fundort - stammen vom Verfasser. Sie werden in der Regel oben im Text oder unter der Rubrik „Bemerk:“ begründet.

Ein Sternchen $(*)$ vor einer Katalognummer (z.B. *Tk....) deutet an, dass es sich mit großer Wahrscheinlichkeit nicht um eine Darstellung der makedonischen Kausia handelt, sondern um die einer ähnlichen phönizisch-zyprischen Kopfbedeckung.

Im Katalog werden neben den im Abkürzungsverzeichnis genannten zusätzlich folgende Abkürzungen verwendet:
A. Anfang
AO: $\quad$ Aufbewahrungsort
B: $\quad$ Breite in $\mathrm{cm}$
Bemerk: $\quad$ Bemerkung
D: $\quad$ Datierung
Dm: $\quad$ Durchmesser
FO: $\quad$ Fundort
FS Festschrift
Gw: Gewicht:
E. Ende
Ka Kamee
H. Hälfte
$\mathrm{H}: \quad$ Höhe in $\mathrm{cm}(\mathrm{x}$ Breite $\mathrm{x}$ Tiefe)
Hlgt. Heiligtum
hell. hellenistisch
Lit: $\quad$ Literatur
M. Mitte
M: $\quad$ Material (wird meist nicht angegeben) 


$\begin{array}{ll}\mathrm{Ma} & \text { Malerei } \\ \mathrm{Mo} & \text { Mosaik } \\ \mathrm{Nu} & \text { Münze } \\ \mathrm{P} & \text { Plastik } \\ \mathrm{PO}: & \text { Prägeort } \\ \mathrm{Re} & \text { Relief } \\ \mathrm{Si} & \text { Siegel(-abdruck) } \\ \mathrm{T}: & \text { Tiefe in cm } \\ \mathrm{Tk} & \text { Terrakotte }\end{array}$

Eine Katalognummer steht in der Regel für ein Exemplar. Umfasst eine Nummer mehrere Exemplare, ist dies angegeben. Hinter den 569 Katalognummern verbergen sich rund 740 Darstellungen.

Der Katalog ist geordnet nach Gattungen (Plastik, Relief, Malerei, Mosaik, Münzen, Kameen, Siegel, Terrakotten), innerhalb dieser nach Regionen (Ägypten, Kleinasien, Balkan, Westen, Zypern, Orient, „ohne Fundort“), innerhalb dieser nach Orten bzw. Landschaften. Die Terrakottastatuetten sind zudem nach Typen (Chlamydephoroi, Soldaten, Reiter, Ausnahmen, Köpfe) untergliedert. 


\section{Rundplastik}

\section{Ägypten}

P 1 Porträt des Ptolemaios' XV. Kaisarion? (Abb. 5)

mit Kausia diadematophoros, daran Uräus-Schlange

FO: Faijum

AO: New York (Harmon Fine Arts/Leonard Stern) zeitweilig ausgestellt in New York (Metropolitan Museum, L 1992.3)

H: 23

M: Kalkstein

D: 1. Jh. vor Chr. / 50-30 vor Chr.

Lit: R. S. Bianchi, Alexander the Great as a Kausia Diadematophoros from Egypt, in: The Intellectual Heritage of Egypt, Studia aegyptiaca 14 (FS Lásló Kakosy) (1992) 69-75 Taf. 3-4 .- B. V. Bothmer Hellenistic Elements in Egyptian Sculpture of the Ptolemaic Period, in: Alexandria and Alexandrianism (Symposium Malibu 1993) (1996) 220 Abb. 17 .- J.A. Josephson, Egyptian Royal Sculpture of the Late Period. 400-246 B.C. (1997) 19-21 .- G. Grimm, Alexandria. Die erste Königsstadt der hellenistischen Welt (1998) 143 Abb. 131

P 2 Soldat (Variante) (Abb. 110)

(Chlamydephoros mit Kausia, stehend, dickbäuchig/gedrungen)

FO: Koptos ? (dort gekauft)

AO: Kairo (Museum, 27504)

H: 6

M: Steatit

D: hell.*

Lit: M.C.C. Edgar, Catalogue Général des Antiquités Égyptiennes du Musée du Caire. Greek Sculpture (1903) 72 f. Taf. 11
Bemerk: Gleicher Typus wie Tk 113 (aus Faijum?) und Tk 359 (Tarent).

\section{P 3 Köpfchen mit Kausia}

FO: Memphis/Mit Rahineh (Kom el arbain)

AO: Kairo (Museum, 27505)

H: 2

M: gelber Kalkstein

D: hell.*

Lit: M.C.C. Edgar, Catalogue Général des Antiquités Égyptiennes du Musée du Caire. Greek Sculpture (1903) 73 Taf. 11

\section{Griechenland}

P 4 Kopf, unfertig, mit Kausia ? (Abb. 66)

FO: Thasos (Agora, hinter der Grundmauer der NPortikus)

AO: ? (Inv. 1011)

H: 29

D: -

Lit: J. Pouilloux (u.a.), Chronique des fouilles en 1951. Thasos, BCH 76, 1952, 269 Abb. 63 f. (S. 265)

\section{Zypern}

P 5 Junge, hockend, in Chiton, mit Ente (Abb. 139)

FO: Kourion (Tempel)

AO: New York (Metropolitan Museum, $74.51 .2750)$

H: $30,6 \times 26 \times 10$

M: Kalkstein

D: E. 4. - A. 3. Jh. vor Chr.

Lit: C. Beer, Temple Boys. A Study of Cypriot Votiv Sculpture, 1. Catalogue, SIMA 113 (1994) 57 Nr. 192 Taf. $112.113 \mathrm{a}+\mathrm{b}$

P 6 Junge, hockend, in Chiton FO: Nikosia 
AO: Nikosia (Cyprus Museum, CS 2650/2)

H: $21,5 \times 12 \times 2,5$

M: Kalkstein

D: E. 4. - A. 3. Jh. vor Chr.

Lit: C. Beer, Temple Boys. A Study of Cypriot Votiv Sculpture, SIMA 113 (1994) 13 f. Nr. 1 Taf. 134 d. $135 \mathrm{c}$

P 7 Junge, hockend, in Chiton, mit Vogel (Abb. 138)

FO: Voni, Apollon-Temenos (Grabung Ohnefalsch-Richter 1883)

AO: Nikosia (Cyprus Museum, E 191)

H: $20 \times 16 \times 6,5$

M: Kalkstein

D: E. 4. - A. 3. Jh. vor Chr.

Lit: C. Beer, Temple Boys. A Study of Cypriot Votiv Sculpture, 1. Catalogue, SIMA 113 (1994) 33 Nr. 90 Taf. 140 a-d

P 8 Junge, hockend, in Chiton

FO: Zypern

AO: Nikosia (Cyprus Museum, E 124)

H: 16 x 3,8

M: Kalkstein

D: hell.

Lit: C. Beer, Temple Boys. A Study of Cypriot Votiv Sculpture, 1. Catalogue, SIMA 113 (1994) 83 Taf. 151 a-d

P 9 Junge, hockend, in Chiton, mit Vogel

FO: Zypern

AO: Nikosia (Cyprus Museum, E 128)

H: $24 \times 16 \times 7$

M: Kalkstein

D: $325-300$ vor Chr.

Lit: C. Beer, Temple Boys. A Study of Cypriot Votiv Sculpture, 1. Catalogue, SIMA 113 (1994) 32 Nr. 85 Taf. 138 a-d
P 10 Oberkörperfrgt. (Kopf bis Brustkorb)

Junge, hockend (oder stehend?), in Chiton

FO: Golgoi

AO: Paris (Louvre, AM 3387)

H: $22,5 \times 16,5 \times 8,4$

M: Kalkstein

D: E. 4. Jh. vor Chr.?

Lit: H. Hermary, Catalogue des Antiquités de Cyphre. Sculptures (Musée du Louvre) (1989) 236 Nr. 477

P 11 Epheben-Soldat (Abb. 101)

(Chlamydephoros, stehend, mit Apfel)

FO: Idalion, Apollon-Heiligtum

AO: London (Brit. Mus., C 199)

H: 52,5

M: Kalkstein

D: 4./3. Jh. vor Chr.?*

Lit: F. N. Pryce, Catalogue of the Sculpture in the British Museum I 2 (1930) 80 f. Abb. 130 .- R. Senff, Das Apollonheiligtum von Idalion, SIMA 94 (1993) 57 f. Taf. 40 a-c

P 12 Chlamydephoros, stehend (Abb. 100)

FO: Idalion, Apollon-Heiligtum

AO: London (Brit. Mus., C 202)

H: 14,4

M: Kalkstein

D: 3. Jh. vor Chr.?

Lit: R. Senff, Das Apollonheiligtum von Idalion, SIMA 94 (1993) 57 f. Taf. 40 d-g

P 13 Kopf

FO: Tamassos, Heiligtum der Mutter der Götter (Areal TA III)

AO: ? (Inv.Nr. 864/1976)

$\mathrm{H}: 4,5$

M: Kalkstein

D: hell.?* 
Lit: H.-G. Buchholz, Tamassos, Zypern, 1974-76 -

3. Bericht, AA 1978, 155 ff. 226 f. Abb. 67 b

P 14 Kopf

FO: Tamassos, Heiligtum der Mutter der Götter

(Votivdepot)

AO: -

$\mathrm{H}:-$

M: Kalkstein

D: hell.

Lit: H.-G. Buchholz, Tamassos, Zypern, 1970-72 -

1. Bericht, AA 1973, 295 ff. 246 f. (mit Anm. 109) Abb. 46 (S. 343)

P 15 Kopf

FO: Idalion, Apollon-Heiligtum

AO: London (Brit. Mus., C 200)

H: 14,8

M: Kalkstein

D: 3. Jh. vor Chr.?

Lit: F. N. Pryce, Catalogue of the Sculpture in the British Museum I 2 (1930) 80 f. Abb. 131 .- R. Senff, Das Apollonheiligtum von Idalion, SIMA 94 (1993) 57 f. Taf. 40 h-j

P 16 Kopf

FO: Idalion

AO: Paris (Louvre, MN 1632)

H: $10,5 \times 7,7 \times 7$

M: Kalkstein

D: E. 4. - A. 3. Jh. vor Chr.

Lit: H. Hermary, Catalogue des Antiquités de Cyphre. Sculptures (Musée du Louvre) (1989) 241 Nr. 486

P 17 Kopf

FO: Idalion

AO: Paris (Louvre, AM 3397)

H: 9, x 7,5 x 8,5

M: Kalkstein
D: 3. Jh. vor Chr.

Lit: H. Hermary, Catalogue des Antiquités de Cyphre. Sculptures (Musée du Louvre) (1989) 241 Nr. 487

P 18 Kopf

FO: Golgoi

AO: Paris (Louvre, AM 3274)

H: $9,7 \times 8,9 \times 8$

M: Kalkstein

D: E. 4. Jh. vor Chr.

Lit: H. Hermary, Catalogue des Antiquités de Cyphre. Sculptures (Musée du Louvre) (1989) 236 Nr. 476

P 19 Kopf

FO: Golgoi

AO: Paris (Louvre, AM 3398)

H: $13 \times 10,2 \times 12$

M: Kalkstein

D: E. 4. Jh. vor Chr.

Lit: H. Hermary, Catalogue des Antiquités de Cyphre. Sculptures (Musée du Louvre) (1989) 237 Nr. 478

P 20 Kopf

FO: Golgoi

AO: Paris (Louvre, AM 3399)

H: $10 \times 8,4 \times 7,8$

M: Kalkstein

D: E. 4. Jh. vor Chr.

Lit: H. Hermary, Catalogue des Antiquités de Cyphre. Sculptures (Musée du Louvre) (1989) 237 Nr. 479

\section{P 21 Kopf}

FO: Golgoi

AO: Paris (Louvre, AM 3401)

$\mathrm{H}: 11 \times 9,5 \times 10,5$

M: Kalkstein 
D: E. 4. Jh. vor Chr.

Lit: H. Hermary, Catalogue des Antiquités de Cyphre. Sculptures (Musée du Louvre) (1989) 238 Nr. 480

P 22 Kopf

FO: Golgoi

AO: Paris (Louvre, AM 3842)

H: $10,5 \times 10,3 \times 9,6$

M: Kalkstein

D: E. 4. Jh. vor Chr.

Lit: H. Hermary, Catalogue des Antiquités de Cyphre. Sculptures (Musée du Louvre) (1989) 238 Nr. 481

P 23 Kopf (mit Kausia oder Kranz?)

FO: Golgoi

AO: Paris (Louvre, AM 3259)

H: 9 × 7,5 × 312

M: Kalkstein

D: E. 4. Jh. oder A. 3. Jh. vor Chr.

Lit: H. Hermary, Catalogue des Antiquités de Cyphre. Sculptures (Musée du Louvre) (1989) 239 Nr. 482

\section{P 24 Kopf}

FO: Golgoi

AO: Paris (Louvre, AM 3396)

H: $9,8 \times 8,6 \times 7,6$

M: Kalkstein

D: E. 4. Jh. - A. 3. Jh. vor Chr.

Lit: H. Hermary, Catalogue des Antiquités de Cyphre. Sculptures (Musée du Louvre) (1989) 239 Nr. 483

\section{P 25 Kopf}

FO: Golgoi

AO: Paris (Louvre, AM 3400)

$\mathrm{H}: 11,2 \times 9,5 \times 9,3$

M: Kalkstein
D: E. 4. Jh. - A. 3. Jh. vor Chr.

Lit: H. Hermary, Catalogue des Antiquités de Cyphre. Sculptures (Musée du Louvre) (1989) 240 Nr. 484

P 26 Kopf

FO: Golgoi

AO: Paris (Louvre, AM 3404)

$\mathrm{H}: 12,1 \times 9,8 \times 10,5$

M: Kalkstein

D: E. 4. Jh. - A. 3. Jh. vor Chr.

Lit: H. Hermary, Catalogue des Antiquités de Cyphre. Sculptures (Musée du Louvre) (1989) $240 \mathrm{Nr} .485$

\section{P 27 Kopf}

FO: Golgoi

AO: Paris (Louvre, AM 3402)

H: $7,8 \times 6,4 \times 6,2$

M: Kalkstein

D: 3. Jh. vor Chr.

Lit: H. Hermary, Catalogue des Antiquités de Cyphre. Sculptures (Musée du Louvre) (1989) 242 Nr. 488

P 28 Kopf

FO: Golgoi

AO: Paris (Louvre, AM 3403)

H: $9,8 \times 8,7 \times 8$

M: Kalkstein

D: 3. Jh. vor Chr.

Lit: H. Hermary, Catalogue des Antiquités de Cyphre. Sculptures (Musée du Louvre) (1989) 242 Nr. 489

\section{P 29 Kopf}

FO: Golgoi

AO: Paris (Louvre, AM 3405)

H: $9,8 \times 7,6 \times 6,8$

M: Kalkstein 
D: 3. Jh. vor Chr.

Lit: H. Hermary, Catalogue des Antiquités de Cyphre. Sculptures (Musée du Louvre) (1989) 243 Nr. 490

P 30 Kopf

FO: Golgoi

AO: Paris (Louvre, AM 3406)

$\mathrm{H}: 8,3 \times 6 \times 6,4$

M: Kalkstein

D: 3. Jh. vor Chr.

Lit: H. Hermary, Catalogue des Antiquités de Cyphre. Sculptures (Musée du Louvre) (1989) 243 Nr. 491

P 31 Kopf

FO: Agios Phokas (nahe Kythrea/Vouni)

AO: Stockholm (Medelhavsmuseet MMAcc. 620)

$\mathrm{H}: 6,5$

M: Kalkstein

D: hell.

Lit: C. Beer, A „Temple Boy“ and a Head with cap from Cyprus, MedelhavsMusB 13, 1978, 41 ff. Abb. 4-6

\section{P 32 Kopf}

FO: Zypern

AO: London (Brit. Mus., C 201)

H: 9,8

M: Kalkstein

D: frühhellenistisch ?*

Lit: F. N. Pryce, Catalogue of the Sculpture in the British Museum I 2 (1930) 80 f. Abb. 131

P 33 Kopf

FO: Zypern

AO: Princeton (NY) (CH.W. Stanfort, 1954 aus Kunsthandel New York)

$\mathrm{H}: 10,1$

M: Kalkstein
D: 1. H. 3. Jh. vor Chr.

Lit: E. Sjöqvist, A Cypriote Temple Attendant, AJA 59, 1955, 45, Taf. 31 Abb. 1-3

P 34 Kopf

FO: Zypern

AO: Nikosia (Cyprus Museum, Inv.Nr. 1961/VIII$17 / 40)$

$\mathrm{H}: 12$

M: Kalkstein

D: 3. Jh. vor Chr.

Lit: V. Karageorghis, Chronique de Fouilles à Cyphre en 1961, BCH 1962, 349 Nr. 3 Abb. 28 ab .- C. Beer, MedelhavsMusB 13, 1978, 43 (Abb.)

\section{Seleukia am Tigris}

P 35 Kopf mit Kausia (?)

FO: Seleukia

AO: Michigan (Uni., Mus. of Class. Arch., M16104)

H: 3,9

M: Alabaster

D: ? (Oberflächenfund)

Lit: Ingen, Seleukia, 363 Nr. 1702 Taf. 93, 674

\section{Relief}

\section{Kleinasien}

Re 1 Fries mit Darstellungen militärischer Ausrüstungsgegenstände (Abb. 56)

FO: Pergamon (Athena-Heiligtum, Nordhalle, Waffenfries)

AO: Berlin (Pergamon Museum)

H: -

D: 183 vor Chr. (?) / 197-159 vor Chr. (Eumenes II.)

Lit: Dintsis, Helme, 309 Taf. 83, 1 


\section{Makedonien}

Re 2 Grabrelief, stehender Chlamydephoros (re.) mit Kausia reicht sitzender Frau (li.) die Hand, dazwischen stehender Knabe (Abb. 62)

FO: Vergina

AO: -

H: -

D: $350-25$ vor Chr.

Lit: Saatsoglou-Paliadeli, Costume, 135 Taf. 3 a

\section{Schwarzes Meer}

Re 3 Strategenrelief (Abb. 65)

6 Strategen und 1 Grammateus (jeweils in Chlamys, Chiton und Kausia) sowie kindliche Beifiguren opfern Widder am Altar/Sarkophag des Heroen Sozipolis, Beischriften

FO: Mesambria (in Stadtmauer [um 50 v. Chr.] verbaut)

AO: -

H: $100 \times 47 \times 10$

D: 2.- M. 1. Jh. vor Chr. / A. 2. Jh. vor Chr.*

Lit: I. Venedikov, Troisreliefs surprenants de Mesambria, in: V. Velkov (Hrsg.), Nessèbre 2 (1980) 81-95 Abb. 3 .- V. Velkov, MesambriaPontica, in; W. Schuller (Hrsg.), Die bulgarische Schwarzmeerküste im Altertum, Xenia 16 (1985) 29 ff. Abb.S. 47 .- M. Alexandrescu Vianu, L'Iconographie des reliefs aux stratèges de Mesambria, in: Studii Classici (FS Pippidi) (1986) 99- 107 Abb. 2

Re 4 Strategenrelief (2 Frgte., angeblich zusammengehörig)

6 Strategen und 1 Grammateus (jeweils in Chlamys, Chiton und Kausia) sowie kindliche Beifiguren opfern Widder am Altar/Sarkophag des Heroen Sozipolis (nur 1 Stratege und Grammateus erhalten), Beischriften

FO: Mesambria (in Stadtmauer [um 50 v. Chr.] verbaut)

AO: -
H: 103 (= Frgte. zusammen) x 45 x 10

D: um $100 \mathrm{v}$.

Lit: I. Venedikov, Troisreliefs surprenants de Mesambria, in: V. Velkov (Hrsg.), Nessèbre 2 (1980) 81-95 Abb. 4-5 .- V. Velkov, Mesambria Pontica, in; W. Schuller (Hrsg.), Die bulgarische Schwarzmeerküste im Altertum, Xenia 16 (1985) 29 ff. .M. Alexandrescu Vianu, L'Iconographie des reliefs aux stratèges de Mesambria, in: Studii Classici (FS Pippidi) (1986) 99- 107 Abb. 3

\section{Griechenland}

Re 5 Rundbasis mit Löwenjagdrelief

2 Jäger mit Hunden jagen Löwen, Reiter (Krateros?) mit Chlamys, Chiton und Kausia (?; Kopfbedeckung stark bestoßen) (Abb. 43. 45)

FO: Messene

AO: Paris (Louvre)

$\mathrm{H}:-$

D: E. 4. Jh. vor Chr.

Lit: P. Perdrizet, Venatio Alexandri, JHS 19, 1899, 273 ff. Taf. 11, 1 .- A. Borbein, Die griechische Statue des 4. Jahrhunderts v.Chr. Formanalytische Untersuchungen zur Kunst der Nachklassik, JdI 88, 1973, 92 Abb. 92 .- V. von Graeve, Der Alexandersarkophag und seine Werkstatt, IstForsch 28 (1970) 69 .- T. Hölscher, Griechische Historienreliefs des 5. und 4. Jahrhunderts v. Chr. (1973) 183 f. Taf. 15, 3 .- Dintsis, Helme, 306 Nr. 285

\section{Phönizien (einschl. Kolonien)}

*Re 6 Stele des Baalschamar (Abb. 74)

Mann nach li., stehend, in langem Chiton, Gebetsmantel/Tallit (?) und Kausia, re. Hand erhoben (zum Gebet?), in li. Hand Pyxis (?)

darüber: Flügelsonne mit Uräen darunter: phönizische Inschrift: Für Baalschamar, den Chef der Pförtner (rab scha'arîm), den Sohn des Abdosir, durch seinen Sohn Abdosir, den Chef der Pförtner, errichtete Grabstele. 
FO: Umm el-Amad (15 km südl. von Tyros, 2 km südlich von Iskandaroun/Alexandrou Skene)

AO: Beirut

H: 117

M: Sandstein

D: 2. Jh. vor Chr.

Lit: M. Dunand - R. Duru, Oumm el-'Amed (1962) 194 ff. Nr. 16 Taf. 88 bis, 1 .- A. Parrot M. Chéhab, S. Moscati, Die Phönizier (Universum der Kunst) (1977) 118 Abb. 123

Bemerk: Vgl. Tk 379 (Kopf mit Kausia) aus Umm el-Amad, Osttempel.

*Re 7 Votivstele

Mann, stehend, in langem Chiton, Gebetsmantel/Tallit (?) und Kausia, in der re. Hand Tanit-Zeichen

(in Tempelarchitektur: Anten, Architrav, Giebel)

FO: Sulcis (Sardinien)

AO: Sant' Antioco (Museo Communale, 101003)

H: $24,2 \times 17,3 \times 5,5$

M: Tuff

D: 4.-2. Jh. vor Chr.

Lit: S. Moscati, Stelae, in: The Phoenicians, Ausstellungskatalog Venedig 1988, S. 304 ff. Abb.S. 320, S. 672 Nr. 519

*Re 8 Votivstele (Abb. 78)

Mann, stehend, in langem Chiton, Gebetsmantel/Tallit (?) und Kausia, in der re. Hand Tanit-Zeichen

(in Tempelarchitektur: Säulen, Architrav, Giebel mit Blüte)

FO: Sulcis (Sardinien)

AO: Cagliari (Museo Archeologico Nazionale)

H: 12,6 x 12,3

M: Tuff

D: 3. Jh. vor Chr.
Lit: S. Moscati, Stelae, in: The Phoenicians, Ausstellungskatalog Venedig 1988, S. 304 ff. Abb.S. 321

*Re 9 Votivstele (Abb. 75)

Mann, stehend, in langem Chiton, Gebetsmantel/Tallit (?) und Kausia, in der re. Hand Tanit-Zeichen

(in Tempelarchitektur: Anten, Architrav, Giebel) FO: Sulcis (Sardinien)

AO: Sant ${ }^{`}$ Antioco (Museo Communale)

H: $45,5 \times 33,5$

M: Tuff/Sandstein

D: 3.-2. Jh. vor Chr.

Lit: S. Moscati, Stelae, in: The Phoenicians, Ausstellungskatalog Venedig 1988, S. 304 ff. Abb.S. 324; S. 672 Nr. 520

\section{Malerei}

\section{Ägypten}

Ma 1 Grabstele, bemalt (Abb. 53)

Chlamydephoros mit Kausia, stehend, zu seiner Rechten kleiner Diener mit Speeren

FO: Alexandria

AO: Paris (Louvre MA 3632, früher MNC 825)

H: 58,5 (x 29 x 9)

D: 1. H. 3. Jh. vor Chr.

Lit: A. Rouveret, Un Exemple de diffusion des techniques, in: L'Italie méridionale et les premières expériences de la peinture hellenistique, Collection de l'école française de Rome 244 (Actes... Rome 18.02.1994) (1998) 181 Abb. 1 a-b .- A. Rouveret/Ph. Walter, Les stèles Alexandrines du Musée du Louvre: Apport des analyses techniques a l'histoire de la couleur dans la 
peinture hellenistique, RA 1998, 216-221 mit Abb. 1

Ma 2 Grabstele: Nıк $\alpha \omega \rho$ M $\alpha \kappa \epsilon \ldots\llcorner о$ (Abb. 50) bemalt: Reiter in Chlamys und Kausia nach re.; kleiner Diener mit Speeren li. dahinter, hält sich am Schwanz des Pferdes fest

FO: Alexandria, Hadra Nekropole, Cimentière el Manara

AO: Alexandria (Museum)

H: -

D: M. 3. Jh. vor Chr.

Lit: P. Brown, Ptolemaic Paintings and Mosaics and the Alexandrinian Style (1957) 28 Nr. 26 Taf. 19,1-2 .- Dintsis, Helme, 308 Nr. 291 Taf. 81, 1 .Saatsoglou-Paliadeli, Costume, 130. 132

\section{Ma 3 Grabstele, bemalt (Abb. 51)}

Reiter in Chlamys und Kausia mit Speer auf sich aufbäumendem Pferd, nach re.

kleiner Diener (li.) reicht ihm Helm

FO: Alexandria, Hadra Nekropole

AO: Alexandria (Inv.Nr. Nr. 22116)

H: 35 (x 25)

D: E. 4. Jh. vor Chr.

Lit: P. Brown, Ptolemaic Paintings and Mosaics and the Alexandrinian Style (1957) 24 f. Nr. 16 Taf. 10 .- Dintsis, Helme, 308 Nr. 290 Taf. 82, 1 .Saatsoglou-Paliadeli, Costume, 130

Ma 4 Grab, Malerei auf Architrav (Abb. 52)

3 Reiter in Rüstungen nach re. reitend, mit Phialen in der re. Hand spendend - zwischen den Reitern 2 stehende Frauen, ebenfalls mit Phialen opfernd, zwischen mittlerem Reiter und li. Frau Altar Kopfbedeckungen der Reiter von li. nach. re: Kausia (?), Petasos, Helm

FO: Alexandria, Mustafa Pascha Nekropole, Grab 1

AO: in situ
H: 60 (x 167)

D: A. 3. Jh. vor Chr.

Lit: P. Brown, Ptolemaic Paintings and Mosaics and the Alexandrinian Style (1957) 52 f. Nr. 34 Taf. 24, 1 .- Dintsis, Helme, 307 Nr. 289 Taf. 82,6 .- Saatsoglou-Paliadeli, Costume, 130 .- N. Secunda, Seleucid and Ptolemaic Reformed Armies 168-145 B.C., Bd. 2: The Ptolemaic Army (1995) Abb. 198 f.

\section{Makedonien}

Ma 5 Grab, Malerei auf Architrav (Abb. 44. 46) Jagdfries: u.a.: Löwenjagd: fünf Jäger; darunter 2 Personen mit Chlamys, ohne Chiton, Krepides und Kausia und Lanze; Bärenjagd: re. daneben: 1 Netzträger mit Chiton, Krepides, Fellumhang und Kausia

FO: Vergina („Philippsgrab“)

AO: in situ

$\mathrm{H}:-$

D: 4./3. Jh. vor Chr.*

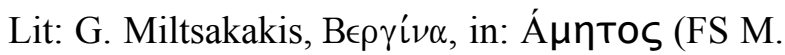
Andronikos) (1987) S. XXIII (Abb.) .- PrestianniGiallombardo, Kausia, 61 ff. Taf. II, 7. Taf. III, 8, 9

Ma 6 makedonisches Grab bei Agios Athanasios, Malerei auf der Fassade (Abb. 48. 49)

Architrav: Symposion (Mitte) zu dem von re. und li. Personen ziehen, diese teilweise in Chlamys, Chiton, Krepides und Kausia, mit Speer

Wand re. und li. neben Eingang: lebensgroße Wächterfiguren in Chlamys, Chiton, Krepides und Kausia, auf Sarissen gestützt, darüber hängen Schilde an der Wand

FO: Agios Athanasios (15 km nordöstlich von Thessaloniki)

AO: in situ

H: -

D: E. 4. Jh. vor Chr. 
Lit: A. Panagiotarea in: $H$ KAOHMEPINH (05.02.1995) 1 (mit Abb.) .- M. Tsimbidou-Avloniti, Chronique, BCH 120, 1996, 1245 f. Fig. 17276 .- dies., AErgMak 10A, 1996, 427-442 Abb. 110 (dort weitere Publikationen angekündigt auf S. 432 Anm. 19) .- dies., Revealing a painted Macedonian tomb near Thessaloniki, in: A. Pontrandolfo (Hrsg.), La pittura parietale in Macedonia e Magna Grecia (Atti... Salerno-Paestum 1996) (2002) 37-43 Taf. 6-7

\section{Thrakien}

Ma 7 Grab, Malerei im Dromos zwischen Eingang und Hauptkammer, Ostfries (Abb. 61. 79)

Schlachtenfries: Krieger in Chlamys und Kausia mit Krummsäbel, Speeren und länglichem Schild FO: Kasanlak

AO: in situ

$\mathrm{H}:-$

D: E. 4. - A. 3. Jh. vor Chr.

Lit: C. Verdiani, Original Hellenistic Paintings in a Thracian Tomb, AJA 49, 1945, 402-415 Abb. 3

.- L. Shivkova, Das Grabmal von Kasanlak (1973) 55 Abb. 14 .- Dintsis, Helme, 306 Nr. 286 Taf. 83, 3

\section{Hellenistische Königsstädte}

Ma 8 Grabstele des Herodot und der Peneis (Abb. 63)

stehender Mann in Chlamys, Chiton und Kausia reicht sitzender Frau die Hand (Dexiosis) (v.l.n.r.) FO: Demetrias

AO: Volos (Museum Inv.L 29)

$\mathrm{H}:-$

D: 2. H. 3. Jh. vor Chr. terminus post/ante quem: 293-194/1 vor Chr.

Lit: Arvanitopoulos, Demetrias, 17 Abb. 10 .- V. von Graeve, Die bemalten Stelen von Demetrias, in: La Thessalie, Collection de la Maison de 1`Orient Méditerranéen 6, Série Archeologique 5
(Actes... Lyon 1975) (1979) 117. 137 Taf. 6, 1 .V. von Graeve/F. Preusser, Zur Technik griechischer Malerei auf Marmor, JdI 96, 1981, 133 (Abb. 14 f.) 135 (Abb. 16f.) 141 (Farbabb. 2) .- B. Helly, Stèles Funéraires de Démétrias: ...Chrono-

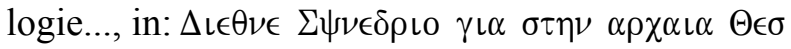
$\sigma \alpha \lambda \iota \alpha$ (FS Theochari) (1992) 349 ff. Taf. 79

Ma 9 Grabstele

sitzende Frau reicht stehendem Mann in Chlamys, Chiton und Kausia die Hand, stehender Knabe (v.l.n.r.)

FO: Demetrias

AO: Volos (Museum Inv.L 46 / Code 50)

$\mathrm{H}:-$

D: 2. H.- E. 3. Jh. vor terminus post/ante quem: 293-194/1 vor Lit: V. von Graeve, Die bemalten Stelen von Demetrias, in: La Thessalie, Collection de la Maison de 1‘Orient Méditerranéen 6, Série Archeologique 5 (Actes... Lyon 1975) (1979) 116. 137 Taf. 6,2

Ma 10 Grabstele (Frgt.) (Abb. 64)

sitzender bzw. liegender Mann mit Kausia (?), in der Hand Gefäß

FO: Demetrias

AO: Volos (Museum Inv.L 44 / Code 48)

H: -

D: terminus post/ante quem: 293-194/1 vor Chr.

Lit: V. von Graeve, Die bemalten Stelen von Demetrias, in: La Thessalie, Collection de la Maison de 1'Orient Méditerranéen 6, Série Archeologique 5 (Actes... Lyon 1975) (1979) 132 Taf. 1, 1-3

\section{Westen}

Ma 11 Wandmalerei (Abb. 67)

weibliche Personifikationen von Makedonia und Asia, sich an Meerenge gegenüber sitzend; Make- 
donia in Chiton, Mantel und Kausia diadematophoros (?), mit makedonischem Schild und Sarisse

FO: Pompeii/Boscoreale, Villa des Fannius Synistor, Festsaal, Westwand

AO: Neapel (Nationalmuseum, Inv. 906)

H: $201 \times 3,24$

D: 40 vor Chr., nach Original des 3. Jh. vor Chr. Lit: Dintsis, Helme, 307 Nr. 287 Taf. 80, 4.- M. Pfrommer, Göttliche Fürsten in Boscoreale, 12. MarbWPr, 1992, 38 ff. .- G. Grimm, Alexandria. Die erste Königsstadt der hellenistischen Welt (1998) 137 ff. Abb. 127 g .- K. Fittschen (Vortrag Göttingen 15.06.1999) lehnt Verbindung zu Ptolemaios III. und 3. Syrischen Krieg bzw. Kleopatra VII. ab.

Ma 12 Wandmalerei, Theaterszene (Abb. 54)

Soldat mit bärtiger Maske, in langärmeligem Chiton, Chlamys (?) und Kausia mit Speer/Lanze

FO: Pompeii, Casa della Fontana grande

AO: verloren

H: -

D: 69-79 nach Chr.

Lit: J. Overbeck - A. Mau, Pompeji (1884) 584 Abb. 307 .- Dintsis, Helme, 312 Nr. 301

\section{Mosaik}

\section{Westen}

Mo 1 Alexandermosaik (Abb. 55)

„Krateros“ mit Kausia (?) und Chlamys (li. neben dem rechen Unterarm Alexanders, nur Schulter, Kinn, Mund, Nase Stirn und Ansatz der Kopfbedeckung erhalten)

FO: Pompeii, Casa del Fauno

AO: Neapel (Nationalmuseum, Inv.Nr. 10020)
H: -

D: Mitte - 2. H. 2. Jh. vor Chr.

nach ostmediterranem Original des 4.-2. Jh. vor Chr.

Lit: Dintsis, Helme, 305 f. Nr. 284 Taf. 3, 2. Taf. 83, 2 .- T. Hölscher, griechische Historienbilder des 4. und 5. Jahrhunderts v.Chr. (1973) 122-169 (Alexandermosaik) 135 f. (Mann mit Kausia) .M. Donderer, Das pompejanische Alexandermosa ik - Ein östliches Importstück, in: Das antike Rom und der Osten (FS Parlasca) (1990) 19 ff. .- M. Pfrommer, Untersuchungen zur Chronologie und Komposition des Alexandermosaiks auf antiquarischer Grundlage, Aegyptiaca Treverensia 8 (1998) $101 \mathrm{ff} .159$ f. 215 ff.

\section{Münzen}

\section{Paionien}

Nu 1 Tetradrachme König Patraos'(Abb. 57)

VS: Kopf nach re. (Gott ?)

RS: ПATPAOY, Reiter (-heros?) mit Lanze, Helm und Brustpanzer reitet Fußsoldaten mit Speer, makedonischem Schild und meist Kausia sowie kurzem Chiton und meist Hosen nieder PO: Paionien

Gw: ca. 12,1-12, 9 g (chalkidischer Münzfuß) M: AR

D: $331-15$ vor Chr.

Lit: H. Gaebler, Die antiken Münzen von Makedonia und Paionia (Die Antiken Münzen NordGriechenlands III, 2) (1935) 201 f. Taf. 37, 15 .Dintsis, Helme, 305 Nr. 283 Taf. 82, 2 .- Prestianni Giallombardo, Kausia, 61 ff. Taf. 2, 3 .- K. Liampi, Der makedonische Schild (1998) 134 M 83 Taf. 28 
$\mathrm{Nu} 2$ Tetradrachme König Patraos'(Abb. 58)

VS: Kopf nach re., mit Strophion (Gott ?)

RS: ПАТРAOY, Reiter (-heros?) mit Lanze, Helm und Brustpanzer reitet Fußsoldaten mit Speer, makedonischem Schild und meist Kausia sowie kurzem Chiton und meist Hosen nieder

PO: Paionien

Gw: ca. 12,1-12, 9 g (chalkidischer Münzfuß)

M: AR

D: $331-15$ vor Chr.

Lit: H. Gaebler, Die antiken Münzen von Makedonia und Paionia (Die Antiken Münzen NordGriechenlands III, 2) (1935) 202 Taf. 37, 16 .Dintsis, Helme, 305 Nr. 283 Taf. 82, 2 .- Prestianni Giallombardo, Kausia, 61 ff. Taf. 2, 3 .- K. Liampi, Der makedonische Schild (1998) $134 \mathrm{M}$ 84

Nu 3 Tetradrachme König Patraos'(Abb. 59)

VS: Kopf nach re., mit Lorbeerkranz (Apollon ?)

RS: ПАТРАOY, Reiter (-heros?) mit Lanze, Helm und Brustpanzer reitet Fußsoldaten mit Speer, makedonischem Schild und meist Kausia sowie kurzem Chiton und meist Hosen nieder

PO: Paionien

Gw: ca. 12,1-12, 9 g (chalkidischer Münzfuß)

M: AR

D: $331-15$ vor Chr.

Lit: H. Gaebler, Die antiken Münzen von Makedonia und Paionia (Die Antiken Münzen NordGriechenlands III, 2) (1935) 202 Taf. 37, 17 f. .Dintsis, Helme, 305 Nr. 283 Taf. 82, 2 .- Prestianni Giallombardo, Kausia, 61 ff. Taf. 2, 3 .- K. Liampi, Der makedonische Schild (1998) $134 \mathrm{M}$ 85-87 Taf. 28

\section{Illyrien}

$\mathrm{Nu} 4$ Münze des Königs Genthios (Abb. 77)

VS: Kopf mit Kausia (?) nach re. (Gott Redon)
RS: ГEN@IOY (?), darüber: Schiff (Liburne/Lembe)

PO: Illyrien (Shkodra, Lissos ?)

Dm: 1,7-1,8

M: AE

D: $181-168$ vor Chr.

Lit: Dintsis, Helme, 311 Nr. 297 Taf. 82, 5 .- Albanien. Schätze aus dem Land der Skipetaren, Ausstellungskatalog Hildesheim 1988, 271 Nr. $137 \mathrm{a}, \mathrm{b}$

Nu 5 Münze des Labeaten-Koinons (Abb. 78)

VS: Kopf mit Kausia (?) nach re. (Gott Redon)

RS: $\quad$ ABEATQN (?), darunter: Schiff (Liburne/Lembe), Delphin

PO: Illyrien (Shkodra, Lissos ?)

Dm: 2

M: AE

D: $168-147$ vor Chr.

Lit: Dintsis, Helme, 311 Nr. 297 Taf. 82, 5 .- Albanien. Schätze aus dem Land der Skipetaren, Ausstellungskatalog Hildesheim 1988, 274 Nr. 140

\section{Makedonische Reichsprägestätte Amphi- polis}

Nu 6a Tetradrachme Philipps III. (Abb. 31)

VS: bärtiger Kopf mit Lorbeerkranz nach re. (Zeus ?)

RS: ФІАІППОY, Reiter mit Palmzweig nach re., Beizeichen Kausia diadematophoros

PO: Amphipolis

Gw: ca. 13,1-14,6

M: AR

D: 323/2-316/5 vor Chr.

Lit: G. Le Rider, Le Monnayage d'Argent et d'Or de Philippe II. - Frappé en Macédoinie de 359 á 294 (1977) 122 Taf. 44 Nr. 29-33 .- Prestianni Giallombardo, Kausia, 61 ff. Taf. 2, 6 
Nu 6 b 1/5 Tetradrachme Philipps III. (Abb. 32)

VS: unbärtiger Kopf mit Strophion nach re.

RS: ФI $\Lambda$ IППОY, Reiter nach re., Beizeichen Kausia diadematophoros

PO: Amphipolis

Gw: ca. 2,36-2,55

M: AR

D: 323/2-316/5 vor Chr.

Lit: G. Le Rider, Le Monnayage d'Argent et d'Or de Philippe II. - Frappé en Macédoinie de 359 á 294 (1977) 122 Taf. 44 Nr. 34-35; Taf. 45 Nr. 1-4

$\mathrm{Nu} 7$ Stater Philipps III. (Abb. 33)

VS: Kopf mit Lorbeerkranz nach re. (Apollon ?)

RS: ФІАІППОY, Biga nach re., Beizeichen Kausia diadematophoros

PO: Amphipolis

Gw: ca. 8,5-8,6

M: AV

D: $323 / 2-316 / 5$ vor Chr.

Lit: G. Le Rider, Le Monnayage d'Argent et d'Or de Philippe II. - Frappé en Macédoinie de 359 á 294 (1977) 226 Nr. 242 ff. Taf. 81 .- Prestianni Giallombardo, Kausia, 61 ff. Taf. 2, 5

\section{Römische Prägungen}

$\mathrm{Nu} 8$ Denar des Ädilen Cn. Plancius (Abb. 68)

VS: CN:PLANCIVS:AED:CVR:S:C, weiblicher Kopf nach re. mit Kausia (Macedonia)

RS: Köcher, Bogen, kretische Ziege

PO: Rom

Gw: -

M: AR

D: $55 / 54$ vor $\mathrm{Chr}$.

Lit: M. H. Crawford, Roman Republican Coinage (2 Bde.) (1974) 455 Nr. 432 Taf. 52, 8

$\mathrm{Nu} 9$ Denar des Prokonsuls C. Antonius (Abb. 69)
VS: C:ANTONIVS:M:F:PRO:COS, Büste mit Kausia nach re. (Macedonia)

RS: PONTIFEX, Opfergeräte

PO: auf dem Marsch von Rom nach Makedonien

Gw: $3,95 \mathrm{~g} \quad$ Dm: 1,8

M: AR

D: $44 / 43$ vor Chr.

Lit: M. H. Crawford, Roman Republican Coinage (2 Bde.) (1974) 496 Nr. 484 Taf. 57, 25 .- Dintsis, Helme, 311f. Nr. 299 Taf. 82, 3

$\mathrm{Nu} 10$ As oder Dupondius des Hadrian (Abb. 70) VS: HADRIANUS AUG COS III PP, Hadrianporträt nach re.

RS: ADVENTUI AUG MACEDONIAE SC, stehender Togatus, Altar, stehende, opfernde Frau (Macedonia) in kurzem Chiton und Kausia, mit Patera in der re. und Palmzweig in der li. Hand (v.l.n.r.)

PO: Rom

Gw: $11,86 / 9,8 \mathrm{~g} \quad$ Dm: 2,7

M: AE

D: 119-137 nach Chr.

Lit: H. Mattingly, Coins of the Roman Empire in The British Museum III (1936) 494 Nr. 1662, 1663 Taf. 91, 15 .- J. Ostrowski, Les Personifications des Provinces dans 1'Art Romain (1990) $184 \mathrm{f}$.

$\mathrm{Nu} 11$ As oder Dupondius des Hadrian

VS: HADRIANUS AUG COS III PP, Hadrianporträt nach re.

RS: RESTITUTORI MACEDONIAE SC, stehender Togatus, Altar, stehende, opfernde Frau (Macedonia) in kurzem Chiton und Kausia, mit Patera in der re. und Palmzweig in der li. Hand (v.l.n.r.) PO: Rom

Gw: $10,14 \mathrm{~g}$ Dm: 1,7

M: AE

D: 119-137 nach Chr. 
Lit: H. Mattingly, Coins of the Roman Empire in The British Museum III (1936) 524 Nr. 1826A (ohne Abb.) .- J. Ostrowski, Les Personifications des Provinces dans l'Art Romain (1990) 184 f.

Nu 12 Sesterz des Hadrian (Abb. 71)

VS: HADRIANUS AUG COS III PP, Hadrianporträt nach re.

RS: RESTITUTORI MACEDONIAE SC, Togatus (re.) reicht kniender Frau (Macedonia mit Kausia) die Hand

PO: Rom

Gw: $22,47 \mathrm{~g}$ Dm: 3,2

M: AE

D: 119-137 nach Chr.

Lit: H. Mattingly, Coins of the Roman Empire in The British Museum III (1936) 524 Nr. 1826 Taf. 97, 3 .- J. Ostrowski, Les Personifications des Provinces dans l'Art Romain (1990) 184 f.

$\mathrm{Nu} 13$ Denar des Hadrian

VS: HADRIANUS AUG COS III PP, Hadrianporträt nach re.

RS: RESTITUTORI MACEDONIAE, Togatus (li.) reicht kniender Frau mit Kausia (Macedonia) die Hand

PO: Rom

Gw: $2,48 \mathrm{~g} \quad$ Dm: 1,9

M: AR

D: 119-137 nach Chr.

Lit: H. Mattingly, Coins of the Roman Empire in The British Museum III (1936) 352 Nr. 891 Taf. 64, 10 .- J. Ostrowski, Les Personifications des Provinces dans l'Art Romain (1990) 184 f.

\section{Zypern}

Nu 14 Tetradrachme Ptolemaios' V. Epiphanes (Abb. 35)

VS: Porträt Ptolemaios' I. nach re.
RS: ПTO $\Lambda$ EMAIOY BA $\Sigma I \Lambda E \Omega \Sigma$, Adler auf Blitzbündel, Beizeichen: Kausia diadematophoros, Dioskurenkappen, $\operatorname{LK} \Delta / \Sigma \mathrm{A}$

PO: Salamis

Gw: 13,9-14,25

$\mathrm{M}: \mathrm{AR}$

D: $182 / 1$ vor Chr.

Lit: O. Mørkholm †/A. Kromann, The Ptolemaic Silver Coinage on Cyprus 192/1-164/3 B.C., Chiron 14, 1984, 156 Taf. 1 (A5-16)

$\mathrm{Nu} 15$ Tetradrachme Ptolemaios' VI. Philometor (Abb. 36)

VS: Porträt Ptolemaios' I. nach re.

RS: ПTO $\Lambda$ EMAIOY BA $\Sigma I \Lambda E \Omega \Sigma$, Adler auf Blitzbündel, Beizeichen: Kausia diadematophoros, Dioskurenkappen, LB / $\Sigma$ A

PO: Salamis

Gw: $14,2-14,3$

M: AR

D: $180 / 79$ vor Chr.

Lit: O. Mørkholm †/A. Kromann, The Ptolemaic Silver Coinage on Cyprus 192/1-164/3 B.C., Chiron 14, 1984, 156 Taf. 1 (A5-18/20)

Nu 16 Tetradrachme Ptolemaios' VI. Philometor VS: Porträt Ptolemaios' I. nach re.

RS: ПTO $\Lambda$ EMAIOY BA $\Sigma I \Lambda E \Omega \Sigma$, Adler auf Blitzbündel, Beizeichen: Kausia diadematophoros, Dioskurenkappen, L $\Delta / \Sigma \mathrm{A}$

PO: Salamis

Gw: $\sim 14,2$

M: AR

D: $178 / 77$ vor Chr.

Lit: O. Mørkholm †/A. Kromann, The Ptolemaic Silver Coinage on Cyprus 192/1-164/3 B.C., Chiron 14, 1984, 156 Taf. 2 (A6-21)

Nu 17 Tetradrachme Ptolemaios' VI. Philometor VS: Porträt Ptolemaios' I. nach re. 
RS: ПTO $\Lambda$ EMAIOY BA $\Sigma I \Lambda E \Omega \Sigma$, Adler auf Blitzbündel, Beizeichen: Kausia diadematophoros, Dioskurenkappen, LE / $\mathrm{AA}$

PO: Salamis

Gw: $13,5-14,2$

M: AR

D: $177 / 76$ vor Chr.

Lit: O. Mørkholm $\uparrow /$ A. Kromann, The Ptolemaic Silver Coinage on Cyprus 192/1-164/3 B.C., Chiron 14, 1984, 157 Taf. 2 (A7-27)

$\mathrm{Nu} 18$ Tetradrachme Ptolemaios' VI. Philometor VS: Porträt Ptolemaios' I. nach re.

RS: ПTO $\Lambda$ EMAIOY BA $\Sigma I \Lambda E \Omega \Sigma$, Adler auf Blitzbündel, Beizeichen: Kausia diadematophoros, Dioskurenkappen, LF / (teilweise) $\Sigma$ A

PO: Salamis

Gw: 13,5-14,2

M: AR

D: $176 / 75$ vor Chr.

Lit: O. Mørkholm †/A. Kromann, The Ptolemaic Silver Coinage on Cyprus 192/1-164/3 B.C., Chiron 14, 1984, 157 Taf. 2 (A7-37, A8-39, A9-46)

Nu 19 Tetradrachme Ptolemaios' VI. Philometor (Abb. 37)

VS: Porträt Ptolemaios' I. nach re.

RS: ПTO $\Lambda$ EMAIOY BA $\Sigma I \Lambda E \Omega \Sigma$, Adler auf Blitzbündel, Beizeichen: Kausia diadematophoros, Dioskurenkappen, LZ / ¿A

PO: Salamis

Gw: $\sim 14,0$

M: AR

D: $175 / 74$ vor Chr.

Lit: R. Stuart Poole. BMC. The Greek Coins. The Ptolemies. The Kings of Egypt (1883) 70 Nr.20 Taf. 16,4 .- O. Mørkholm †/A. Kromann, The Ptolemaic Silver Coinage on Cyprus 192/1-164/3
B.C., Chiron 14, 1984, 157 Taf. 2 (A9-48, A1052)

Bemerk: Die Zuweisung und Datierung der zyprischen Münzen folgt Mørkholm $\uparrow /$ Kromann. R. S. Poole datiert die Prägungen rund 20 Jahre früher (z.B. Nu 19: 200/199 v.Chr. [Ptolemaios V. Epiphanes]).

Nu 20 Tetradrachme Ptolemaios' VI. Philometor (Abb. 38)

VS: Porträt Ptolemaios' I. nach re.

RS: ПTO $\Lambda$ EMAIOY BA $\Sigma I \Lambda E \Omega \Sigma$, Adler auf Blitzbündel, Beizeichen: Kausia diadematophoros, $\mathrm{L} \Lambda \mathrm{B} / \Sigma \mathrm{A}$

PO: Salamis

Gw: 14,1

$\mathrm{M}: \mathrm{AR}$

D: $150 / 49$ vor Chr.

Lit: I. Nicolaou/O. Mørkholm, Paphos I. A Ptolemaic Coin Hoard (1976) 30 Nr. 28 Taf. 2

Nu 21 Tetradrachme Ptolemaios' VIII. Euergetes II. (Abb. 41)

VS: Porträt Ptolemaios' I. nach re.

RS: ПTO $\Lambda$ EMAIOY BA $\Sigma I \Lambda E \Omega \Sigma$, Adler auf Blitzbündel, Beizeichen: Kausia diadematophoros, $\mathrm{LM} \Theta / \Sigma \mathrm{A}$

PO: Salamis

Gw: 13,8-14,2

M: AR

D: $122 / 21$ vor Chr.

Lit: I. Nicolaou/O. Mørkholm, Paphos I. A Ptolemaic Coin Hoard (1976) 34 Nr. 202 ff., 213 ff., $216 \mathrm{ff}$. Taf. 5

Nu 22 Tetradrachme Ptolemaios' VI. Philometor (Abb. 39-40)

VS: Porträt Ptolemaios' I. nach re. 
RS: ПTO $\Lambda$ EMAIOY BA $\Sigma I \Lambda E \Omega \Sigma$, Adler auf Blitzbündel, Beizeichen: Kausia diadematophoros, $\mathrm{L} \Lambda \mathrm{B} / \mathrm{KI}$

PO: Kition

Gw: $13,9-14,2$

M: AR

D: $150 / 49$ vor Chr.

Lit: R. Stuart Poole, BMC. The Greek Coins. The Ptolemies. The Kings of Egypt (1883) 91 Nr. 38 Taf. 21,7; 92 Nr. 42 Taf. 21, 9 .- I. Nicolaou/O. Mørkholm,Paphos I. A Ptolemaic Coin Hoard (1976) 52 Nr. 13 f. Taf. 8

Bermerk: Die Zuweisung und Datierung folgt Nicolaou/Mørkholm. R. S. Poole sprach sich für Ptolemaios VIII. Euergetes II. und 139/138 bzw. 150/149 v.Chr. aus.

Nu 23 Tetradrachme Ptolemaios' VIII. Euergetes II. (Abb. 42)

VS: Porträt Ptolemaios' I. nach re.

RS: ПTO $\Lambda$ EMAIOY BA $\Sigma \mathrm{I} \Lambda \mathrm{E} \Omega \Sigma$, Adler auf Blitzbündel, Beizeichen: Kausia diadematophoros, $\mathrm{LM} \Theta$ / KI

PO: Kition

$\mathrm{Gw}: \sim 13,8-14,2$

M: AR

D: $122 / 21$ vor Chr.

Lit: I. Nicolaou/O. Mørkholm, Paphos I. A Ptolemaic Coin Hoard (1976) 56 Nr. 217, 233, 235 Taf. 11

Nu 24 Didrachme Ptolemaios' IV. ff. (?) (Abb. 34)

VS: Porträt Ptolemaios' IV. nach re.; mit Efeukranz und Thyrsos (?) als Dionysos (?)

RS: ПTO $\Lambda$ EMAIOY BA $\Sigma \mathrm{I} \Lambda \mathrm{E} \Omega \Sigma$, Adler auf Blitzbündel, Beizeichen: Kausia diadematophoros

PO: Zypern

Gw: 5,9-6,7

M: AR
D: -

Lit: R. Stuart Poole, BMC. The Greek Coins. The Ptolemies. The Kings of Egypt (1883) 99 Nr. 135 f. Taf. 24,3

\section{Seleukia am Tigris}

Nu 25 Tonmodell einer Münze (?) des Timarchos(?) oder Alexander Balas (?) (Abb. 18)

VS: Porträt nach re., mit Kausia diadematophoros RS: stehende, nackte, männliche Stützfigur, vierzeilige Beischrift unleserlich FO: Seleukia

AO: -

Dm: 3,2

M: Ton

D: $162-160$ vor Chr. ?(Timarchos ?)

Lit: R. H. McDowell, Stamped and Inscribed Objects from Seleukia on the Tigris (1935) 217-20. 249 f. Taf. 6 Nr. 115 f.

\section{Baktrien / Indien}

Nu 26 Tetradrachme des Antimachos I. von Baktrien (einschl. Paropamisade und Arachosien)

VS: Porträt Antimachos' I. nach re., mit Kausia diadematophoros (Abb. 25)

RS: ANTIMAXOY BAII $A E \Omega \Sigma$ OEOY, Poseidon, stehend, mit Dreizack

PO: Baktrien

Gw: 16,2-17 g (attische Tetradrachme)

M: AR

D: $185-170$ vor Chr.

Lit: R. Curiel, G. Fussman, Le Trésor Monétaire de Qunduz, Mémoires de la Délégation Archéologique Française en Afghanistan 20 (1965) 20 f. Taf. 7 f. Nr. 87-98 .- Dintsis, Helme, 310, Nr. 295 Taf. 80, 5 .- O. Bopearachchi, Monnaies gréco-bactriennes et indo-greques. Catalogue raisonné (Bibliotèque nationale) (1991) 183 ff. Taf. 9 f. Série 1 Nr. 1-8 
Bemerk: Das Beizeichen auf der Rückseite ist mit dem einiger Prägungen des Apollodotos I. (180160 v.Chr.), die ebenfalls den König mit Kausia zeigen, identisch (vgl. Bopearachchi, a.a.O. Taf. 11 Série $1, A=\mathrm{Nu} 30)$.

Nu 27 Drachme des Antimachos I. von Baktrien (einschl. Paropamisade und Arachosien)

VS: Porträt Antimachos I. nach re., mit Kausia diadematophoros

RS: ANTIMAXOY BAII $\Lambda \mathrm{E} \Omega \Sigma$, Poseidon, stehend, mit Dreizack

PO: Baktrien

Gw: 3,66-3,97 g (attische Drachme)

M: AR

D: $185-170$ vor $\mathrm{Chr}$.

Lit: P. Bernard, Fouilles d'Aï Khanoum 4, Mémoires de la Délégation Archéologique Française en Afghanistan 28 (1985) 143 Nr. 9 Taf. 12; 150 Nr. 7 Taf. 10 .- O. Bopearachchi, Monnaies gréco-bactriennes et indo-greques. Catalogue raisonné (Bibliotèque nationale) (1991) 183 ff. Taf. 10 Série 2 Nr. 9-10

Nu 28 Hemidrachme/Diobole (?) des Antimachos I. von Baktrien (einschl. Paropamisade und Arachosien)

VS: Porträt Antimachos' I. nach re., mit Kausia diadematophoros

RS: ANTIMAXOY BAII $\Lambda$ E $\Omega \Sigma$, Poseidon, stehend, mit Dreizack

PO: Baktrien

Gw: 1,31 g

$\mathrm{M}: \mathrm{AR}$

D: $185-170$ vor $\mathrm{Chr}$.

Lit: P. Bernard, Fouilles d'Aï Khanoum 4, Mémoires de la Délégation Archéologique Française en Afghanistan 28 (1985) 143 Nr. 11 Taf. 12 .- O. Bopearachchi, Monnaies grécobactriennes et indo-greques. Catalogue raisonné
(Bibliotèque nationale) (1991) 183 ff. Taf. 10 Série 3 Nr. A

$\mathrm{Nu} 29$ Obole des Antimachos I. von Baktrien (einschl. Paropamisade und Arachosien)

VS: Porträt Antimachos' I. nach re., mit Kausia diadematophoros

RS: ANTIMAXOY BALI $\Lambda E \Omega \Sigma$, Poseidon, stehend, mit Dreizack

PO: Baktrien

Gw: 0,57-0,68 g Dm: 1,2 (attische Obole)

$\mathrm{M}: \mathrm{AR}$

D: $185-170$ vor Chr.

Lit: P. Bernard, Fouilles d'Aï Khanoum 4, Mémoires de la Délégation Archéologique Française en Afghanistan 28 (1985) 143 Nr. 10 Taf. 12; 62 Nr. 163 Taf. 7 .- O. Bopearachchi, Monnaies gréco-bactriennes et indo-greques. Catalogue raisonné (Bibliotèque nationale) (1991) 183 ff. Taf. 10 Série 4 Nr. 11-12

Nu 30 Tetradrachme des Apollodotos I. (Paropamisade, Arachosien, Gandhara, Punjab) (Abb. 26)

VS: Porträt Apollodotos' I. nach re., mit Kausia diadematophoros

RS: $\mathrm{A} \Pi \Lambda \Lambda \mathrm{O} \Delta \mathrm{OTOY}$ BA $\Sigma \mathrm{I} \Lambda \mathrm{E} \Omega \Sigma$, Athena, thronend

PO: Baktrien/Indien

Gw: (attische Tetradrachme)

M: AR

D: $180-160$ vor Chr.

Lit: O. Bopearachchi, Monnaies gréco-bactriennes et indo-greques. Catalogue raisonné (Bibliotèque nationale) (1991) 188 Taf. 11 Série1 Nr. A

Bemerk: Das Beizeichen auf der Rückseite ist mit dem einiger Prägungen des Antimachos I. (185170 v.Chr.), die ebenfalls den König mit Kausia zeigen, identisch (vgl. Bopearachchi, a.a.O. Taf. 9 Série 1, 1 = Nu 26). 
Nu 31 Münze des Lysias Aniketos

(Paropamisade und Arachosien) (Abb. 27)

VS: Porträt Lysias' nach re., mit Kausia diadematophoros

griechische Legende: BA II $\Lambda \mathrm{E} \Omega \Sigma$ ANIKHTOY $\Lambda$ Y $\Sigma I O Y$

RS: Herakles, stehend, sich mit der Rechten bekränzend, in der li. Hand Keule, Palmwedel, Löwenfell

indische (kharoshthi) Legende: Maharajasa apadihatasa Lisikasa/Lisiasa

PO: -

Gw: 2,19 g (,indische Drachme“)

M: AR

D: $120-110$ vor Chr.

Lit: O. Bopearachchi, Monnaies gréco-bactriennes et indo-greques. Catalogue raisonné (Bibliotèque nationale) (1991) 269 Taf. 38 Série 7 Nr. 19

Nu 32 Tetradrachme des Antialkidas I. Nikephoros (Paropamisade und Arachosien) (Abb. 28)

VS: Porträt Antialkidas' I. nach re., mit Kausia diadematophoros

RS: BA $\Sigma \Lambda \Lambda E \Omega \Sigma$ NIKHФOPOY ANTIA $\Lambda$ KI $\Delta \mathrm{OY}$, Zeus, thronend, hält Nike, Elefant

PO: -

Gw: 16,07-16,72 g (attische Tetradrachme)

M: AR

D: $115-95$ vor Chr.

Lit: O. Bopearachchi, Monnaies gréco-bactriennes et indo-greques. Catalogue raisonné (Bibliotèque nationale) (1991) 271 ff. Taf. 39 Série 4 Nr. C .R. Curiel, G. Fussman, Le Trésor Monétaire de Qunduz, Mémoires de la Délégation Archéologique Française en Afghanistan 20 (1965) 46 Taf. 51. Nr. 617 f.
Nu 33 Drachme des Antialkidas I. Nikephoros (Paropamisade und Arachosien)

VS: Porträt Antialkidas' I. nach re., mit Kausia diadematophoros

RS: BA $\Sigma I \Lambda E \Omega \Sigma$ NIKHФOPOY ANTIA $\Lambda$ KI $\Delta O Y$, Zeus, thronend, hält Nike, Elefant

PO: -

Gw: 4,07 g Dm: 1,8-2,0 (attische Drachme) M: AR

D: $115-95$ vor Chr.

Lit: O. Bopearachchi, Monnaies gréco-bactriennes et indo-greques. Catalogue raisonné (Bibliotèque nationale) (1991) 271 ff. Taf. 39 Série 5 Nr. 3-4

Nu 34 Münze des Antialkidas I. Nikephoros (Paropamisade und Arachosien)

VS: Porträt Antialkidas' I. nach re., mit Kausia diadematophoros

griechische Legende: BA $\Sigma \mathrm{I} \Lambda \mathrm{E} \Omega \Sigma$ NIKHФOPOY ANTIA $\Lambda$ KI $\Delta O Y$

RS: Zeus, thronend, hält Nike, Elefant indische (kharoshthi) Legende: Maharajasa jayadharasa Amtialkidasa

PO: -

Gw: 1,97-2,44 g; Dm: 1,5-1,7 (,indische Drach$m e^{\text {") }}$

M: AR

D: $115-95$ vor Chr.

Lit: M. Mitchiner, Indo-Greek and Indo-Scythian Coinage 2 (1975) 150 Type 277-278 (Type 278 mit abweichender Legende: BASILEWS NIHTOU) .- O. Bopearachchi, Monnaies grécobactriennes et indo-greques. Catalogue raisonné (Bibliotèque nationale) (1991) $271 \mathrm{ff.} 276 \mathrm{f}$. Taf. 40 f. Série 13 Nr. 27-51

Nu 35 Münze des Demetrios III. Aniketos (Gandhara) (Abb. 29)

VS: Porträt Demetrios' III. nach re., mit Kausia diadematophoros 
griechische Legende: BA II $\Lambda \mathrm{E} \Omega \Sigma$ ANIKHTOY $\triangle$ HMHTPIOY

RS: Zeus, stehend, mit Blitz und Zepter

indische (kharoshthi) Legende: Maharajasa aparajitasa Dimetriyasa

PO: -

Gw: $\sim 8,5 \mathrm{~g}$ (,indische Tetradrachme“)

M: AR

D: 100 vor Chr.

Lit: G. Jenkins, Ancient Greek Coins (1972) Nr. 618f. .- Dintsis, Helme, 310 Nr. 296 Taf. 80, 6 .M. Mitchiner, Indo-Greek and Indo-Scythian Coinage 1 (1975) 61 type 111 (dort Demetrios I. [ 200 v.Chr.] zugeschrieben) .- O. Bopearachchi, Monnaies gréco-bactriennes et indo-greques. Catalogue raisonné (Bibliotèque nationale) (1991) 287 Serie 1 Taf. 43 Série 1 Nr. E .- SaatsoglouPaliadeli, Costume, 132 mit Anm. 113

Nu 36 Münze des Amyntas (Gandhara) (Abb. 30)

VS: Porträt Amyntas' nach re., mit Kausia diadematophoros

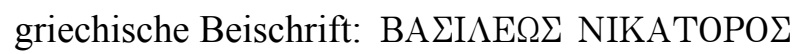
AMYNTOY

RS: Zeus, thronend, hält Nike

indische (kharoshthi) Legende: Maharajasa jayadharasa Amitasa

PO: -

Gw: $2,1-2,44 \mathrm{~g} \quad$ Dm: $1,8 \quad$,indische

Drachme“)

M: AR

D: $95-90$ vor $\mathrm{Chr}$.

Lit: O. Bopearachchi, Monnaies gréco-bactriennes et indo-greques. Catalogue raisonné (Bibliotèque nationale) (1991) 301 Taf. 47 Série 7 Nr. 3-6

\section{Kameen}

\section{Ägypten}

Ka 1 Porträt nach re., Ptolemaios VIII.-XII.(?) ptolemäischer König mit Kausia diadematophoros, Panzer und Chlamys (Abb. 12)

FO: -

AO: London (Brit.Mus., 3824)

H: $25 \times 18$

M: Glas

D: ca. $120-80$ vor Chr.

Lit: D. Plantzos, Ptolemaic Cameos of the 2nd and 1st Centuries B.C., OJA 15, 1996, 39-61 (39. 41. 43f.) Nr. A4 .- ders., Hellenistic Engraved Gems (1999) 101 f. Taf. 87, 2

Bemerk: Am wahrscheinlichsten ist eine Identifizierung mit Ptolemaios IX. Soter II. (116-107 / 88-81 v. Chr.) oder Ptolemaios X. Alexander (107-88 v. Chr.). Vgl. D. Plantzos, Ptolemaic Cameos of the 2nd and 1st Centuries B.C., OJA 15, 1996, 44.

Ka 2 Porträt nach re., Ptolemaios VIII.-XII.(?) ptolemäischer König (?) mit Kausia diadematophoros (?), Panzer und Chlamys

FO: Herculaneum (alexandrinische Werkstatt?)

AO: Neapel (Museo Nazionale, 155881)

H: $26 \times 20$

M: Glas

D: ca. $120-80$ vor Chr.

Lit: D. Plantzos, Ptolemaic Cameos of the 2nd and 1st Centuries B.C., OJA 15, 1996, 39-61 (39. 41. 43 f.) Abb. 5 (S. 42) Nr. A5

Bemerk: Sehr ähnlich Ka 1. Wenn Diadem vorhanden, gleicher König.

\section{Makedonien}

Ka 3 Porträtbüste, Philipp V. (?)(Abb. 4) 
Büste nach links mit Kausia diadematophoros, Kausia verziert mit Kentauromachie, Aegis, Lanze in der Rechten

FO: -

AO: Paris (Cabinet des Medailles, Inv.Nr. A.10666)

H: 6,7 x 4,8

M: Karneol

D: E. 3. - A. 2. Jh. vor Chr.

Lit: G. Richter The Engraved Gems of the Greeks, Etruscians and Romans I (1968) 154 Nr. 608 .Dintsis, Helme, 309 Nr. 292 Taf. 81, 3 .- Saatsoglou-Paliadeli, Costume, 132 .- D. Svenson, Darstellungen hellenistischer Könige mit Götterat tributen (1995) 323 A2.20 Taf 5 .- B. M.-L. Vollenweider, Camées et intailles I. Les Portraits grecs du Cabinet des médailles. Catalogue raisonné (1995) Tafelband S. 93 Nr. 201 (Textband S. 184)

\section{Siegel (-Abdrücke)}

\section{Ägypten}

Si 1 Porträt nach re., Ptolemaios I. Soter (posthum) (Abb. 6)

mit Kausia diadematophoros und Chlamys

FO: Edfu (Philae, Tempelarchiv ?)

AO: Amsterdam (Allard Pierson Museum)

$\mathrm{H}:$ -

D: 205-31 vor Chr.

Lit: D. Plantzos, Female Portait Types from the Edfu Hoard of Clay Seal Impressions, in: Archivi e Sigilli nel mondo ellenistico, BCH Suppl. 29 (Symposion Turin 1993) (1996) 307 ff. Nr. 1 Taf. 48

Si 2 Porträt nach re., ptolemäischer König mit Kausia diadematophoros und Chlamys FO: Edfu (Philae, Tempelarchiv ?)

AO: Toronto (Royal Ontario Museum, 906.12.68)

$\mathrm{H}: 1,4 \times 1,1$

D: 205-31 vor Chr.

Lit: J. G. Milne, Ptolemaic Seal Impressions, JHS 36, 1916, 91 Nr. 65 Taf. 4 .- D. Plantzos, Female Portait Types from the Edfu Hoard of Clay Seal Impressions, in: Archivi e Sigilli nel mondo ellenistico, BCH Suppl. 29 (Symposion Turin 1993) (1996) $307 \mathrm{ff}$.

Si 3 Porträt nach re., ptolemäischer König mit Kausia diadematophoros und Chlamys FO: Edfu (Philae, Tempelarchiv ?)

AO: Toronto (Royal Ontario Museum, 906.12.66)

H: $1,6 \times 1,2$

D: 205-31 vor Chr.

Lit: J. G. Milne, Ptolemaic Seal Impressions, JHS 36, 1916, 91 Nr. 63 Taf. 4 .- D. Plantzos, Female Portait Types from the Edfu Hoard of Clay Seal Impressions, in: Archivi e Sigilli nel mondo ellenistico, BCH Suppl. 29 (Symposion Turin 1993) (1996) $307 \mathrm{ff}$.

Si 4 Porträt nach re., ptolemäischer König

mit Kausia diadematophoros, Strahlen um Kausia?, Aigis

FO: Edfu (Philae, Tempelarchiv ?)

AO: Toronto (Royal Ontario Museum, 906.12.67)

H: $1,5 \times 1,2$

D: 205-31 vor Chr.

Lit: J. G. Milne, Ptolemaic Seal Impressions, JHS 36, 1916, 91 Nr. 64 Taf. 4 .- D. Plantzos, Female Portait Types from the Edfu Hoard of Clay Seal Impressions, in: Archivi e Sigilli nel mondo ellenistico, BCH Suppl. 29 (Symposion Turin 1993) (1996) 307 ff. 


\section{Griechenland}

Si 5 Porträt nach re., Ptolemaios III. Euergetes mit Kausia diadematophoros (Abb. 7)

FO: Kallipolis/Aitolien (Haus V, „Archivhaus“)

AO: ? (M $\Delta$ 14468, 14470, 14475, 14476, 14477 , 14479)

$\mathrm{H}: 2,05 \mathrm{x} 1,65(\mathrm{M} \Delta \mathrm{14468)}$

D: 246-21 vor Chr.

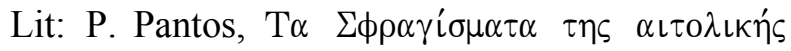
K $\alpha \lambda \lambda$ เото́ $\lambda \epsilon \omega \varsigma$ (1985) 258 ff. Nr. 258 Taf. 35 .- R.

Fleischer, in: Archivi e Sigilli nel mondo ellenistico, BCH Suppl. 29 (Symposion Turin 1993) (1996) 321 ff. Taf. 64 Abb. 11

Si 6 Porträt nach re., Ptolemaios IV. Philopator mit Kausia diademtophoros (Abb. 8)

FO: Kallipolis/Aitolien (Haus V, „Archivhaus“) AO: ? (M $\Delta 14473,14474)$

$\mathrm{H}: 1,55 \times 1,3 / 1,4 \times 1,4$

D: 221-205 vor Chr.

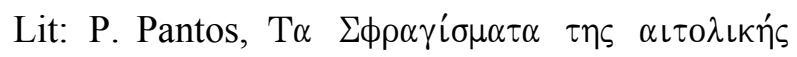

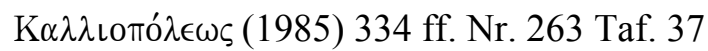

Si 7 Porträt nach re., Antiochos III. (?)

mit Kausia und Diadem (?) (Abb. 16 a-c)

FO: Kallipolis/Aitolien (Haus V, „Archivhaus“)

AO: ? (M $\Delta 14480,14481)$

H: $1,2 \times 1,5 / 1,6 \times 1,5$

D: 223-187 vor Chr. (?)

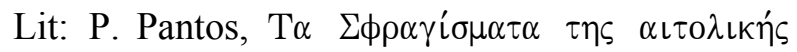
K $\alpha \lambda \lambda\left\llcorner\right.$ เó́ $\epsilon_{\omega \varsigma}$ (1985) 336 ff. Nr. 283 Taf. 41 .ders., in: Archivi e Sigilli nel mondo ellenistico, BCH Suppl. 29 (Symposion Turin 1993) (1996) 189 Taf. 38,4

Si 8 Porträt nach re., König oder Privatperson?

mit Kausia und Diadem (?) (Abb. 21)

FO: Kallipolis/Aitolien (Haus V, „Archivhaus“)

AO: ? (M $\Delta$ 14464, 14469, 14471, 14472, 14482)
H: $1,8 \times 1,7(\mathrm{M} \Delta 14464)$

D: ca. $230-150$ vor Chr.

Lit: P. Themelis, Ausgrabungen in Kallipolis 1977-78, AAA 12/2, 1979, 245- 79 Abb. 24 .- P.

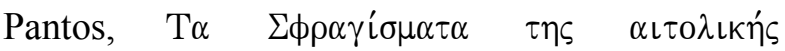
K $\alpha \lambda \lambda$ เото́ $\lambda \epsilon \omega \varsigma$ (1985) 401 ff. Nr. 307 Taf. 45 .ders., in: Archivi e Sigilli nel mondo ellenistico, BCH Suppl. 29 (Symposion Turin 1993) (1996) 189 Taf. 38 Abb. 5

Bemerk: Die Datierung ist die des Gesamtfundes (P. Pantos). Die Datierung bei P. Themelis (vor 279 v. Chr.) ist überholt.

Si 9 Porträt nach re., Privatperson (?) mit Kausia (ohne Diadem?) (Abb. 24)

FO: Kallipolis/Aitolien (Haus V, „Archivhaus“)

AO: ? $(\mathrm{M} \Delta$ 14529)

$\mathrm{H}: 1,4 \times 1,05$

D: ca. $230-150$ vor Chr.

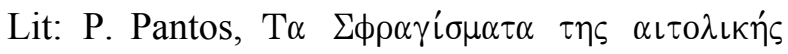
K $\alpha \lambda \lambda$ เопо́ $\lambda \epsilon \omega \varsigma$ (1985) 404 f. Nr. 308 Taf. 46

\section{Zypern}

Si 10 Porträt nach re., Ptolemaios X. Alexander I. (?) mit Kausia diadematophoros, Stern auf Kausia (Abb. 9)

FO: Nea Paphos, Archiv (unter dem Fußbodenmosaik im Haus des Dionysos)

AO: Nikosia (Cyprus Museum)

$\mathrm{H}:-$

D: 110/09 - 107/6-88 vor Chr. (Ptolemaios X. König in Zypern/in Ägypten und Zypern)

145-15 vor Chr. (Archiv insgesamt: Ptolemaios VIII.- Kleopatra VII./Augustus; 15 v. Chr.: Erdbeben)

Lit: H. Kyrieleis, Ptolemäische Porträts auf Siegelabdrücken aus Nea Paphos (Zypern), in: Archivi e Sigilli nel mondo ellenistico, BCH Suppl. 29 (Symposion Turin 1993) (1996) 315 ff. 319 Taf. 59 Abb. 6 (oben li.) 
Si 11 Porträt nach re., Ptolemaios X. Alexander I. (?) mit Kausia diadematophoros

Isis-Komposit-Symbol (Sonnenscheibe zwischen geschwungenen Kuhhörnern und zwei aufrechte Federn) auf der Seite der Kausia, 2 Sterne über Kausia/Stirn (Abb. 10)

FO: Nea Paphos, Archiv (unter dem Fußbodenmosaik im Haus des Dionysos)

AO: Nikosia (Cyprus Museum)

H: -

D: 110/09-107/6-88 vor Chr. (Ptolemaios X. König in Zypern/in Ägypten und Zypern)

145-15 vor Chr. (Archiv insgesamt: Ptolemaios VIII.- Kleopatra VII./Augustus; 15 v. Chr.: Erdbeben)

Lit: H. Kyrieleis, Ptolemäische Porträts auf Siegelabdrücken aus Nea Paphos (Zypern), in: Archivi e Sigilli nel mondo ellenistico, BCH Suppl. 29 (Symposion Turin 1993) (1996) 315 ff. 319 Taf. 60 Abb. 7

Si 12 Porträt nach re., Ptolemaios X. Alexander I. (?) mit Kausia diadematophoros (Abb. 11)

FO: Nea Paphos, Archiv (unter dem Fußbodenmosaik im Haus des Dionysos)

AO: Nikosia (Cyprus Museum)

H: -

D: 110/09 - 107/6-88 vor (Ptolemaios X. König in Zypern/in Ägypten und Zypern)

145-15 vor Chr. (Archiv insgesamt: Ptolemaios VIII.- Kleopatra VII./Augustus; 15 v. Chr.: Erdbeben)

Lit: H. Kyrieleis, Ptolemäische Porträts auf Siegelabdrücken aus Nea Paphos (Zypern), in: Archivi e Sigilli nel mondo ellenistico, BCH Suppl. 29 (Symposion Turin 1993) (1996) 315 ff. 319 Taf. 59 Abb. 6 (unten re.) .- ders., Ägyptische Bildelemente auf Siegelabdrücken aus Nea Paphos (Zypern), in: StädelJb 19, 2004, 111ff. Abb. 11
Si 13 Porträt nach li., Ptolemaios XV. Kaisarion mit Kausia diadematophoros (Abb. 14)

FO: Nea Paphos, Archiv (unter dem Fußbodenmosaik im Haus des Dionysos)

AO: Nikosia (Cyprus Museum)

H: -

D: 44-33 vor Chr. (Ptolemaios XV. Kaisarion)

145-15 vor Chr. (Archiv insgesamt: Ptolemaios VIII.- Kleopatra VII./Augustus; 15 v. Chr.: Erdbeben)

Lit: H. Kyrieleis, Bildnisse des Kaisarion. Zu den Siegelabdrücken aus Nea Paphos, in: Akten des XIII. Internationalen Kongresses für Klassische Archäologie (Berlin 1988) (1990) 457 f. Taf. 67 c

Si 14 Porträt, bärtig, nach re., Ptolemaios XV. Kaisarion mit Kerykeion über Schulter (Abb. 15) mit Kausia diadematophoros, ägyptischer AtefKrone am Diadem über Stirn (Abb. 15)

FO: Nea Paphos, Archiv (unter dem Fußbodenmosaik im Haus des Dionysos)

AO: Nikosia (Cyprus Museum)

$\mathrm{H}:-$

D: 44-33 vor Chr. (Ptolemaios XV. Kaisarion)

145-15 vor Chr. (Archiv insgesamt: Ptolemaios VIII.- Kleopatra VII./Augustus; 15 v. Chr.: Erdbeben)

Lit: H. Kyrieleis, Bildnisse des Kaisarion. Zu den Siegelabdrücken aus Nea Paphos, in: Akten des XIII. Internationalen Kongresses für Klassische Archäologie (Berlin 1988) (1990) 457 f. Taf. 67 e .- ders.; Ptolemäische Porträts auf Siegelabdrücken aus Nea Paphos (Zypern), in: Archivi e Sigilli nel mondo ellenistico, BCH Suppl. 29 (Symposion Turin 1993) (1996) 315 ff. 318 Taf. 55 Abb. 2.- ders., Ägyptische Bildelemente auf Siegelabdrücken aus Nea Paphos (Zypern), in: StädelJb 19, 2004,111 Abb. 8 
Si 15 Porträt nach li., ptolemäischer König (?) (Abb. 13)

mit Kausia, Stern auf Kausia; Diadem (-enden) nicht erkennbar, da Abdruck fragmentiert

FO: Nea Paphos, Archiv (unter dem Fußbodenmosaik im Haus des Dionysos)

AO: Nikosia (Cyprus Museum)

$\mathrm{H}$ :

D: $145-15$ vor Chr. (Archiv insgesamt: Ptolemaios VIII.- Kleopatra VII./Augustus; 15 v. Chr.: Erdbeben)

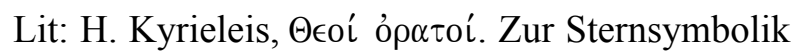
hellenistischer Herrscher-bildnisse, in: Studien zur Klassischen Archäologie, Saarbrücker Studien zur Archäologie und Alten Geschichte 1 (FS F. Hiller) (1986) 55 ff. Abb. 6

\section{Seleukia am Tigris}

Si 16 Porträt nach re., Demetrios II. Nikator mit Kausia diadematophoros, bärtig (Abb. 17) FO: Seleukia/Tigris

AO: Bagdad (Archäologisches Museum, S 7.4058)

H: 2 x 2,7

D: 129 - 125 vor Chr. (Demetrios II.)

Lit: La Terra tra i due fiumi, Mostra... Firenze 1986, 176 Nr. 104 .- Prestianni Giallombardo, Kausia, 61 ff. Taf. 3, 12 .- R. Fleischer, Portraits of Hellenistic Rulers on bullae, in: Archivi e Sigit li nel mondo ellenistico, BCH Suppl. 29 (Symposion Turin 1993) (1996) 323 Taf. 64, 8

Si 17 Porträt nach re. (nur Mund, Nase, Stirn und Ansatz der Kopfbedeckung abgedrückt) mit Kausia (?); Diadem nicht erkennbar, da Abdruck fragmentiert (Abb. 22)

FO: Seleukia/Tigris (Archiv)

AO: Bagdad (Archäologisches Museum, S 7.2055)

H: $1,8 \times 1,25$
D: 250-150 vor Chr. / seleukidisch-parthisch*

Lit: La Terra tra i due fiume, Mostra... Firenze 1986, 92 f. 125 Nr. 106 Abb.S. 176

Si 18 Porträt nach re., mit Kausia (ohne Diadem) (Abb. 23)

FO: Seleukia / Tigris (Archiv)

AO: Bagdad (Archäologisches Museum, S 8.89)

H: $1,5 \times 2,1 \times 1,15$

D: 250 - 150 vor Chr. / seleukidisch-parthisch*

Lit: La Terra tra i due fiumi, Mostra... Firenze 1986, 92 f. 125 Abb. 109 (S. 178)

Si 19 Porträt nach li., Timarchos (?) mit Kausia, Diademenden nicht erkennbar (Siegel nicht vollständig abgedrückt?) (Abb. 19)

FO: Seleukia, Archiv A (great house, level III = equivalent to level IV, room $141 \mathrm{sub}$ )

AO: ? (Bulla Nr. AIc[24], Impression IA30/1)

H: $2,1 \times 2,4$

D: 162-160 vor Chr. (?) (Timarchos ?)

295/80-141/25 v.Chr. (Archiv A: Seleukos I. - Demetrios II.)

Lit: R. H. McDowell, Stamped and Inscribed Objects from Seleucia on the Tigris (1935) $46 \mathrm{f}$. Taf. 1, 10, S. 11 ff. S. 214 ff.

Si 20 Porträt nach re.

mit Kausia (?) (Abb. 20)

FO: Seleukia (Archiv B)

AO: ? (Bulla Nr. AIIa (29))

$\mathrm{H}:-$

D: $188-153 / 2$ vor Chr. (Archiv B)

Lit: R. H. McDowell, Stamped and Inscribed Objects from Seleucia on the Tigris (1935) $67 \mathrm{f}$. Taf. 2, 28, S. 11 ff. S. 214 ff. 


\section{Terrakotten}

\section{Ägypten (einschließlich Kyrenaika)}

\section{Ägypten (allg.)}

Tk 1 Chlamydephoros, sitzend, entblößt, mit Strigilis in re. Hand (Abb. 84)

FO: Ägypten (gekauft in Kairo)

AO: Gent

H: 10

D: 3. Jh.vor Chr.*

Lit: P. Graindor, Terres Cuites de 1' Égypte grécoromaine (1939) $134 \mathrm{Nr} .52$ Taf. 19

Tk 2 Chlamydephoros, stehend, auf Pfeiler gestützt

FO: Unterägypten

AO: Kairo (Slg. Fouquet)

H: 10,5

D: ,praxitelisch“

Lit: P. Perdrizet, Les Terres Cuites greques d 'Égypte de Collection Fouquet (1921) 18 Nr. 73 Taf. 80

Tk 3 Soldat (Abb. 106)

FO: Ägypten (in Kairo gekauft)

AO: Berlin (9130)

$\mathrm{H}: 8,8$

D: hell.*

Lit: Weber, Berlin, 202 Nr. 340 Taf. 32

Tk 4 Soldat (Abb. 103)

FO: Ägypten

AO: Berlin (6735)

H: 9,5

D: hell.*

Lit: Weber, Berlin, 201 f. und 202 Nr. 339 Taf. 32

Tk 5 Soldat

FO: Ägypten
AO: Alexandria (8032)

H: 8

D: hell.*

Lit: Breccia, Alexandria II 2, 43 Nr. 237 Taf. 77, 403

Tk 6 Soldat

FO: Ägypten

AO: Kopenhagen (Ny Carlsberg Glyptotek, AE.I.NACH 449 = E 661; Inv.Nr. 333 zz)

H: 8,9

D: E. 2. - 1. Jh. vor Chr. / hell.*

Lit: M. Fjeldhagen, Graeco-roman Terracottas from Egypt. Catalogue Ny Carlsberg Glyptotek (1995) 132 Nr. 115

Tk 7 Soldat (Abb. 104)

FO: Ägypten ?

AO: Leiden (Rijksmuseum [aus Slg. Maria Cimba ], Inv.Nr. C. I. 629)

H: 9,5

D: (spät-) hell.*

Lit: Wijngaarden, Leiden, 58 Taf. 14

Tk 8 Soldat

FO: -

AO: Göttingen (Archäologisches Institut, TK 46)

H: 10,3

D: hell.*

Lit: unpubliziert

Tk 9 Reiter über Gegner

FO: Ägypten

AO: Alexandria (20486)

H: 10-11

D: 4./3. Jh. vor Chr.*

Lit: Breccia, Alexandria II 2, 28 Nr. 121 Taf. 13, 49

Bemerk: Breccia verwendet die Inv.Nr. 20486 auch für Tk 62. 
Lit: Besques, Paris VI-II, 121 D 4520 Taf. 76 b, d

Tk 10 Reiter über Gegner

FO: Ägypten (Alexandria ?)

AO: Amsterdam (Arch. Mus. der Uni., 7164)

H: 11,5

D: 4./3. Jh. vor Chr.*

Lit: G. A. S. Snijder, Allard-Pierson-Museum Amsterdam - Algemeen Gids (1937) 46 Nr. 389

Taf. 23

Tk 11 Reiter über Gegner (ohne Kopf)

FO: Ägypten

AO: Tübingen (S/13 2736 [ehemals Slg. Sieglin])

H: 11,9

D: 1.-2. Jh. nach Chr. / 4./3. Jh. vor*

Lit: Fischer, Slg. Sieglin/Schreiber, 387 Nr. 995

Taf. 107

Tk 12 Reiter über Gegner

FO: Ägypten

AO: Tübingen (5015/25 [ehemals Slg. Sieglin])

$\mathrm{H}: 12,5$

D: 1.-2. Jh. nach Chr. / 4./3. Jh. vor*

Lit: Fischer, Slg. Sieglin/Schreiber, 387 Nr. 996

Taf. 107. (Vgl. unpublizierte Reiter in London, Brit. Mus., Inv.Nr. 1933 7-12 1).

Tk 13 Reiter über Gegner (Frgt.)

FO: Ägypten

AO: Dresden (2600.C.405)

H: 4,8 (Frgt.)

D: 1./2. Jh. nach Chr. / 4./3. Jh. vor Chr.*

Lit: Fischer, Slg. Sieglin/Schreiber, 387 Nr. 997 (o. Abb.)

Tk 14 Reiter über Gegner (Abb. 117)

FO: Ägypten

AO: Paris (Louvre, CA 6024, Coll.Fouquet)

H: 12

D: späthellenistisch / 4./3. Jh. vor Chr.*
Tk 15 Reiter über Gegner

FO: Ägypten (gek. Clot-bey, 1852)

AO: Paris (Louvre, MN 1433)

H: 8

D: späthellenistisch / 4./3. Jh. vor Chr.*

Lit: Besques, Paris VI-II, 121 D 4521 Taf. 76 f

Tk 16 Reiter über Gegner (Abb. 114)

FO: Ägypten

AO: Hamburg (Museum für Kunst und Gewerbe, Inv.Nr. 1989.615)

H: 11,8

D: 4./3. Jh. vor Chr.*

Lit: Götter, Gräber und Grotesken, Ausst.-Kat. Hamburg (1991) 83 Nr. 94 .- C.Maderna, Zum Feindbild der Ptolemäer, in: Ägypten Griechenland Rom. Abwehr und Berührung, Ausstellung Städelsches Kunstinstitut und Städtische Gallerie Frankfurt, 2005/06, 258-266, 584f. Nr. 157

Tk 17 Reiter über Gegner

FO: Ägypten

AO: Paris (Louvre, E 20831, früher Musée Guinet)

H: 11,4

D: römisch / 4./3. Jh. vor Chr.*

Lit: Dunand, Paris, 214 f. Nr. 581

Tk 18 Reiter über Gegner

FO: Ägypten

AO: Kopenhagen (Ny Carlsberg Glyptotek, AE.I.N 491 = E 653; Inv.Nr. 331 qq)

H: 12,2

D: 1. - 4. Jh. nach Chr. / 4./3. Jh. vor Chr.*

Lit: M. Fjeldhagen, Graeco-roman Terracottas from Egypt. Catalogue Ny Carlsberg Glyptotek (1995) 131 Nr. 114 
Tk 19 Reiter über Gegner (ohne Kopf)

FO: Ägypten

AO: Alexandria (22912)

$\mathrm{H}: 10-11$

D: 4./3. Jh. vor Chr.*

Lit: Breccia, Alexandria II 2, 28 Nr. 121 Taf. 13, 48

Tk 20 Reiter über Gegner (ohne Kopf)

FO: Ägypten (in Kairo gekauft)

AO: Berlin (9244)

H: 12,5

D: 4./3. Jh. vor Chr.*

Lit: Weber, Berlin, 200 Nr. 337 Taf. 31

Tk 21 Reiter über Schild (Abb. 115)

FO: Ägypten (in Kairo erworben)

AO: Frankfurt/M. (Liebieghaus, Inv.Nr. 2400.1757)

H: $13,7 \quad$ B: $11 \quad$ T: 3,6

D: 1. H. 4. Jh. nach Chr. / späthell.*

Lit: Bayer-Niemeier, Frankfurt, 223 Nr. 513 Taf.

91,4

Tk 22 Reiter über Schild (ohne Kopf)

FO: Ägypten

AO: Karlsruhe (Badisches Landesmuseum, H 791; 1897 aus Slg. Reinhardt)

H: 22,3

D: 3. Jh. nach Chr. / hell.?*

Lit: Schürmann, Karlsruhe, 304 Nr. 1143 Taf. 190

Tk 23 Reiter über Schild (ohne Kopf)

FO: Ägypten

AO: Alexandria (22911)

H: -

D: hell.?*

Lit: Breccia, Alexandria II 2, 28 Nr. 122 Taf. 13, 50
Tk 24 Reiter über Schild (ohne Kopf)

FO: (Unter-) Ägypten

AO: Karlsruhe (Badisches Landesmuseum, H 775

a; 1897 aus Slg. Reinhardt)

H: 11,3

D: 3. Jh. nach Chr. / hell.*

Lit: Schürmann, Karlsruhe, 303 f. Nr. 1142 Taf. 189

Tk 25 Harpokrates (Knabe, hockend, mit überdimensionalem Phallos im li. Arm, Chlamys über die Schultern zurückgeschlagen) (Abb. 133)

FO: Ägypten

AO: Paris (Louvre, E 20900 bis [früher Musée Guinet])

H: 7,5

D: hellenistisch?

Lit: Dunand, Paris, 213 Nr. 578

Tk 26 Harpokrates (Knabe, hockend, mit überdimensionalem Phallos im li. Arm, Chlamys über die Schultern zurückgeschlagen) (Abb. 130)

FO: Ägypten ? (in Berlin gekauft)

AO: Berlin (10146)

$\mathrm{H}: 7,5$

D: hell.*

Lit: Weber, Berlin, 105 mit Abb. 65 Nr. 149 Taf. 14

Bemerk: Formgleich mit Tk 117 (Faijum?, 3. Jh. vor Chr.).

Tk 27 Harpokrates (Knabe, hockend mit 2 (?) großen Phalloi in den Armen) (Abb. 131)

FO: Ägypten

AO: Bonn (Akadem. Kunstmuseum, D 71)

H: 6,95

D: 3. Jh. vor Chr.?

Lit: St. Schmidt, Katalog der ptolemäischen und kaiserzeitlichen Objekte aus Ägypten im Akade- 
mischen Kunstmuseum Bonn (1997) 104 Nr. 132 Taf. 45

Tk 28 Knabe mit überdimensionalem Phallos, wie Füllhorn im li. Arm haltend, in re. Hand Scha le, am Rücken herabgerutschter Mantel, ohne Chiton (Abb. 135)

FO: Ägypten (in Kairo gekauft)

AO: Gent?

H: 12,5

D: hell.*

Lit: P. Graindor, Terres Cuites de 1'Égypte grécoromaine (1939) 75 f. Nr. 6 Taf. 5

Tk 29 Kopf

FO: Ägypten

AO: Paris (Louvre, AF 8323)

H: 3,7

D: hellenistisch?

Lit: Dunand, Paris, 213 Nr. 577

Tk 30 Kopf

FO: Ägypten

AO: Paris (Louvre, AF 8322)

H: 3,2

D: hellenistisch ?

Lit: Dunand, Paris, 213 Nr. 576

Tk 31 Kopf

FO: Ägypten

AO: Paris (Louvre, AF 8321)

H: 5,3 (!)

D: hellenistisch ?

Lit: Dunand, Paris, 213 Nr. 575

Tk 32 Kopf

FO: Ägypten

AO: Athen (Museum Benaki, Ap.eup. 21540)

H: 3,5

D: hell.?*
Lit : Pingiatoglou, Benaki, 134 und 144 Nr. 304

Tk 33 Kopf

FO: Ägypten

AO: Athen (Museum Benaki, Ap.єup. 12602)

H: 3

D: ?

Lit: Pingiatoglou, Benaki, 154 und 164 Nr. 380

Tk 34 Kopf

FO: Ägypten

AO: Hamburg (Museum für Kunst und Gewerbe, 1989.1110)

H: 3

D: ?

Lit: Götter, Gräber und Grotesken (Ausst.-Kat. Hamburg) (1991) 82 Nr. 88

Tk 35 Kopf

FO: Ägypten

AO: Athen (Museum Benaki, Ap.єup. 22908)

H: 3,8

D: A. 2. Jh. vor Chr.

Lit: Pingiatoglou, Benaki, 162 Nr. 373

Tk 36 Oberkörperfragment (Chlamydephoros) FO: Ägypten

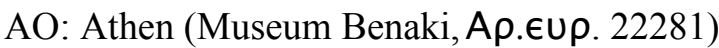

H: 4,9

D: ?

Lit: Pingiatoglou, Benaki, 154 und 156 Nr. 352

Tk 37 Kopf

FO: Ägypten

AO: Kopenhagen (Ny Carlsberg Glyptotek, AE.I.N 1693)

H: 4

D: hell. 
Lit: M. Fjeldhagen, Graeco-roman Terracottas from Egypt. Catalog Ny Carlsberg Glyptotek (1995) 144 Nr. 128

Tk 38 Kopf

FO: Ägypten (dort gekauft)

AO: Budapest (Museum, SZM52.748)

H: 3

D: frühes 2. Jh. vor Chr.

Lit: L. Török, Hellenistic and Roman Terracottas from Egypt, Biblioteca Archaeologica 15, Monumenta antiquitates extra Hungaria reperta 4 (1995) 146 f. Nr. 219 Taf. 117

\section{Alexandria}

Tk 39 Chlamydephoros, sitzend (Abb. 85)

FO: Alexandria, Sciatbi

AO: Alexandria (18922)

H: 13

D: $325-240$ vor Chr.*

Lit: Breccia, Sciatbi, 145 Nr. 466 Taf. 72,219 .Breccia, Alexandria II 1, 39 Nr. 133, Taf. 50,6

Bemerk: Die Datierung der Terrakotten aus den Nekropolen Sciatbi (325-240 vor Chr.) und Hadra (280-180 vor Chr.) folgt: W. D. E. Coulson, Chatby reconsidered, JEA 73, 1987, 234 ff. .- Fischer, Slg. Sieglin/Schreiber, 38 f.

Tk 40 Chlamydephoros, sitzend

FO: Alexandria, Sciatbi

AO: Alexandria (16312)

$\mathrm{H}: 13$ (?)

D: $325-240$ vor Chr.*

Lit: Breccia, Alexandria II 1, 39 Nr. 133 Taf. 44,4

Bemerk: Vgl. Tk 39.

Tk 41 Chlamydephoros, sitzend

FO: Alexandria, Hadra

AO: Alexandria (9460)

H: 12
D: $280-180$ vor Chr.*

Lit: Breccia, Alexandria II 1, 39 Nr. 134 Taf. 15,7

Bemerk: Vgl. Tk 39.

Tk 42 Chlamydephoros, sitzend

FO: Alexandria, Hadra ?*

AO: Athen (Museum Benaki, Ap.єup. 23841)

H: 11,5

D: Anfang 2. Jh. vor Chr. / 280-180 vor Chr.*

Lit: Pingiatoglou, Benaki, 154 und 158 Nr. 357

Bemerk: Vgl. zum FO: formgleich mit Tk 39; zur

Datierung: Tk 39; S. Pingiatoglou (a. O.) hält die

Statuette - wie alle langhaarigen Chlamydephoroi

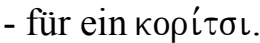

Tk 43 Chlamydephoros, sitzend

FO: Alexandria

AO: ? (Slg. Sieglin/Schreiber ?)

H: 11,5

D: 3. Jh. vor Chr.*

Lit: J. Vogt, Expedition Ernst von Sieglin II 2 (1924) 170 Nr. 4 Taf. 79

Tk 44 Chlamydephoros, sitzend

FO: Alexandria ?*

AO: Kairo (26760)

H: D: 3. Jh. vor Chr.*

Lit: unpubliziert

Bemerk: Die Statuette mit der nächst folgenden Kairener Inventarnummer (Kairo $26761=$ Tk 61) ist formgleich mit einer Terrakotte aus Alexandria / Sciatbi (Tk 59, Reiter ohne Gegner).

Tk 45 Chlamydephoros, sitzend FO: unbekannt, Alexandria?

AO: Marseille (Musée, Inv. 2631)

H: 12,4

D: 3. Jh. vor Chr.

Lit: La gloire d'Alexandrie, Ausstellungskatalog Paris 1999, 117 Abb. 76 
Tk 46 Chlamydephoros, stehend (Abb. 81 b. 88)

FO: Alexandria, Sciatbi

AO: Alexandria (18920)

H: 15

D: $280-240$ vor Chr.*

Lit: Breccia, Sciatbi, 145 Nr. 463 Taf. 72, 217

Bemerk: Zur Datierung von Sciatbi und Hadra vgl. Tk 39; formgleich mit Tk 47 aus Hadra.

Tk 47 Chlamydephoros, stehend (Abb. 88)

FO: Alexandria, Hadra (el Manara, Grab 29)

AO: Alexandria (Musée Gréco-romaine, Inv. Nr. 25711)

H: 15,7

D: $280-240$ vor Chr.*

Lit: Adriani, Annuaire III, 14 Nr. 29 Taf. 5,1 und 6,2 .- La gloire d'Alexandrie, Ausstellungskatalog Paris 1998, 108 Nr. 70 (P. Pelletier-Hornby/P. Bał let)

Bemerk: Datierung vgl. Tk 39; formgleich mit Tk 46 aus Sciatbi.

Tk 48 Chlamydephoros, stehend

FO: Alexandria, Hadra

AO: Alexandria (9217)

H: 14,5

D: $280-180$ vor Chr.*

Lit: Breccia, Alexandria II 1, 37 Nr. 108 Taf. 14,1

Bemerk: Vgl. Tk 39.

Tk 49 Chlamydephoros, stehend

FO: Alexandria, Hadra

AO: Alexandria (Musée Gréco-romaine, Inv.Nr. 21446)

H: 16

D: $280-180$ vor Chr.*

Lit: Breccia, Alexandria II 1, 37 Nr. 109 Taf. 14,3

.- R. Higgins, Greek Terracottas (1967) 131 f. Nr.

$62 \mathrm{~B}$
Tk 50 Chlamydephoros, stehend

FO: Alexandria (?)

AO: Dresden (2600.C.14, aus Slg. Sieglin/Schreiber)

H: 12,2

D: 2. H. 3. Jh. vor Chr.

Lit: J. Vogt, Expedition Ernst von Sieglin II 2 (1924) 65 und 170 Taf. 79,6 .- Fischer, Slg. Sieglin/Schreiber, 160 Nr. 196 Taf. 17

Tk 51 Chlamydephoros, stehend FO: Alexandria, Sciatbi oder Hadra

AO: Alexandria (18919)

H: -

D: $320-180$ vor Chr.*

Lit: Breccia, Alexandria II 1, 37 Nr. 109, Taf. 53,20

Bemerk: Vgl. Tk 39.

Tk 52 Chlamydephoros, stehend FO: Alexandria, Ibrahimieh AO: Alexandria (Museum Inv. 15682)

H: -

D: tanagräisch / 3. Jh. vor Chr.*

Lit: D. Kassab Tezgör, Tanagréennes d'Alexandrie, in: Commerce et Artisant dans l'Alexandrie hellénistique et romainè, $\mathrm{BCH}$ Suppl. 33 (Actes du Colloque d'Athènes 1988) (1998) 204 f. Abb. 1 a-b.

Tk 53 Chlamydephoros, stehend

FO: Alexandria ?*

AO: Kairo

H: -

D: um 200 vor Chr.*

Lit: unpubliziert

Tk 54 Soldat (Abb. 105) 
FO: Alexandria (?)

AO: Tübingen (5062/25; aus Slg. Schreiber)

$\mathrm{H}: 8,8 \quad$ B: $3,1 \quad \mathrm{~T}: 2,9$

D: 2.-1. Jh. vor Chr. / hell.*

Lit: Fischer, Slg. Sieglin/Schreiber, 162 Nr. 200

Taf. 17

Tk 55 Soldat

FO: alexandrinisch (?)

AO: Amsterdam (Arch. Mus. der Uni., 7165)

$\mathrm{H}: 8$

D: hell.*

Lit: G. A. S. Snijder, Allard-Pierson Museum Algemeen Gids (1937) Nr. 388 Taf. 23

Tk 56 Soldat

FO: Alexandria (oder Unterägypten ?)

AO: Rostock (Universität, NACH 603; ex Slg. Herold?)

$\mathrm{H}: 12,2$

D: hell.*

Lit: R. Pagenstecher, Neuerwerbungen der archäologischen Sammlung der Universität Rostock, AA, 1918, Sp. 124 Nr. 16 mit Abb. 11 (Sp. 122)

\section{Tk 57 Soldat}

FO: Alexandria (?)

AO: Tübingen (5009/25, aus Slg. Schreiber)

H: 9 B: $3,1 \quad$ T: 3,5

D: 2. H. 2. Jh. vor Chr. / hell.*

Lit: Fischer, Slg. Sieglin/Schreiber, 161 f. Nr. 199

Taf. 17

Tk 58 Reiter ohne Gegner (Abb. 112)

FO: Alexandria, Sciatbi

AO: Alexandria (10615)

H: 14,3

D: $320-240$ vor Chr.*

Lit: Breccia, Sciatbi, 150 Nr. 483 Taf. 73,224 .Breccia, Alexandria II 1, 40 Nr. 141 Taf. 39,1
Bemerk: Datierung vgl. Tk 39.

Tk 59 Reiter ohne Gegner

FO: Alexandria, Sciatbi

AO: Alexandria (9218)

H: 15,4

D: $325-240$ vor Chr.*

Lit: Breccia, Alexandria II 1, 40 Nr. 141 (Anm.) Taf. 40, 6

Bemerk: Formgleich mit Tk 60 (Alexandria, Sciatbi) und Tk 61 (Alexandria?, in Kairo).

Tk 60 Reiter ohne Gegner (ohne Kopf) FO: Alexandria, Sciatbi

AO: Alexandria (9220)

H: 13 (ohne Kopf)

D: 325-240 vor Chr.*

Lit: Breccia, Alexandria II 1, 40 Nr. 141 (Anm.) Taf. 39, 3

Bemerk: Formgleich mit Tk 59 (Alexandria, Sciatbi) und Tk 61 (Alexandria?, in Kairo).

Tk 61 Reiter ohne Gegner (Abb. 113)

FO: Alexandria?

AO: Kairo (Ägyptisches Museum, 26761)

H: 15,4

D: $325-240$ vor Chr.*

Lit: La gloire d'Alexandrie, Ausstellungskatalog Paris 1998, 106 Nr. 68 (P. Pelletier-Hornby/P. Bat let)

Bemerk: Formgleich mit Tk 59 (Alexandria, Sciatbi) und Tk 60 (Alexandria, Sciatbi).

Tk 62 Reiter über Gegner

FO: Alexandria, Schukafa („Montes testacei“)

AO: Alexandria (20486)

H: 10

D: 4./3. Jh. vor Chr.*

Lit: Breccia, Alexandria II 1, 63 Nr. 341 Taf 39, 5 
Bemerk: Breccia verwendet die Inv.Nr. 20486 auch für Tk 9.

Tk 63 Reiter über Gegner

FO: Alexandria

AO: Çanakkale (Slg. Calvert)

H: 11,5

D: hellenistisch ?

Lit: A. Reinach, Les Galates dans 1'Art Alexandrin, MontPiot 18, 1910, 103 Abb. 30 und 104 Anm. 1

Tk 64 Reiter über Gegner

FO: Alexandria (?)

AO: Karlsruhe (Badisches Landesmuseum, B 616; 1853 aus Slg. Palin)

H: $8,3 \quad$ B: 9,6

D: 3. Jh. nach Chr. / 4./3. Jh. vor Chr.*

Lit: Schürmann, Karlsruhe, 304 Nr. 1144 Taf. 190

Tk 65 Knabe, hockend (Abb. 134)

ohne Attribut oder mit Tier im re. Arm (?)

FO: Alexandria

AO: Alexandria (7560)

H: -

D: hell.*

Lit: Breccia, Alexandria II 1, Taf. 44, 4 (im Text nicht erwähnt)

Tk 66 Kopf

FO: Alexandria (?)

AO: Dresden (2600.C.32)

H: $3,8 \quad$ B: $2,8 \quad$ T: 2,5

D: 1. H. 3. Jh. vor Chr.

Lit: Fischer, Slg. Sieglin/Schreiber, 163 Nr. 204

Taf. 18

Tk 67 Kopf

FO: Alexandria (?)

AO: Dresden (2600.C.28)
H: $4 \quad$ B: $2,9 \quad$ T: 2,8

D: späthellenistisch ?

Lit: Fischer, Slg. Sieglin/Schreiber, 165 Nr. 219

Taf. 18

Tk 68 Kopf

FO: Alexandria

AO: Tübingen (5089/25, aus Slg. Schreiber)

H: $3,2 \quad$ B: $2,4 \quad$ T: 2,5

D: 1. Jh. vor?

Lit: Fischer, Slg. Sieglin/Schreiber, 166 Nr. 220

Taf. 18

Tk 69 Kopf

FO: Alexandria (?)

AO: Dresden (2600.C.34)

$\begin{array}{lll}\text { H: } 3,9 & \text { B: } 2,7 & \text { T. } 2,4\end{array}$

D. hellenistisch ?

Lit: Fischer, Slg. Sieglin/Schreiber, 166 Nr. 221

Taf. 18

Tk 70 Kopf

FO: Alexandria (?)

AO: Dresden (2600.C.30)

H: $3,4 \quad$ B: $2,8 \quad$ T: 2,2

D: E. 3. Jh. vor

Lit: Fischer, Slg. Sieglin/Schreiber, 163 Nr. 208

(o. Abb.)

Tk 71 Kopf

FO: Alexandria (?)

AO: Dresden (2600.C.33)

H: $3,6 \quad$ B: $2,7 \quad$ T: 2,4

D: E. 3. Jh. vor Chr.

Lit: Fischer, Slg. Sieglin/Schreiber, 164 Nr. 210 (o. Abb.)

Tk 72 Kopf

FO: Alexandria (?)

AO: Dresden (2600.C.26) 
H: $3 \quad$ B: $2,2 \quad$ T: 2,3

D: 2. Jh. vor Chr.

Lit: Fischer, Slg. Sieglin/Schreiber, 164 Nr. 212 (o. Abb.)

Tk 73 Kopf

FO: Alexandria (?)

AO: Dresden (2600.C.23)

H: 2,2 B: $2 \quad$ T: 2

D: auf Typus des 2. Jh. vor Chr. zurückgehend, wohl kaiserzeitlich

Lit: Fischer, Slg. Sieglin/Schreiber, 164 Nr. 213 (o. Abb.)

Tk 74 Kopf

FO: Alexandria (?)

AO: Dresden (2600.C.19)

H: $3,1 \quad$ B: $2,7 \quad$ T: 2,5

D: A./M. 3. Jh. vor Chr.

Lit: Fischer, Slg. Sieglin/Schreiber; 162 Nr. 202 (o. Abb.)

Tk 75 Kopf

FO: Alexandria (?)

AO: Dresden (2600.C.25)

H: $3,2 \quad$ B: $2,7 \quad$ T: 2,4

D: A./M. 3. Jh. vor Chr.

Lit: Fischer, Slg. Sieglin/Schreiber, 163 Nr. 203 (o. Abb.)

Tk 76 Kopf

FO: Alexandria (?)

AO: Leipzig (o. Nr., alte Verz. Nr. 96)

H: $5 \quad$ B: 3,1 T: 2,6

D: A./M. 3. Jh. vor Chr.

Lit: Fischer, Slg. Sieglin/Schreiber, 163 Nr. 205 (o. Abb.)

Tk 77 Kopf

FO: Alexandria (?)

AO: Dresden (2600.C.17)
H: $3,5 \quad$ B: $2,8 \quad$ T: 2,6

D: E. 3. Jh. vor Chr.

Lit: Fischer, Slg. Sieglin/Schreiber, 163 Nr. 206 (o. Abb.)

Tk 78 Oberkörperfragment

(Chlamydephoros, sitzend/stehend ?)

FO: Alexandria (?)

AO: Dresden (2600.C.37)

H: $7 \quad$ B: 3,5 T: 3,2

D: M.-2. H. 2. Jh. vor Chr.

Lit: Fischer, Slg. Sieglin/Schreiber, 161 Nr. 198 Taf. 17

Tk 79 Oberkörperfragment

(Chlamydephoros, sitzend/stehend ?)

FO: Alexandria (?)

AO: Dresden (2600.C.15)

H: 4,8 B: 2,1 (Kopf) T: 2,4 (Kopf)

D: 2. Jh. vor Chr.

Lit: Fischer, Slg. Sieglin/Schreiber, 161 Nr. 197

Taf. 17

Tk 80 Kopf

FO: Alexandria (?)

AO: Dresden (2600. C.18)

H: $2,6 \quad$ B: $2,4 \quad$ T: 2,5

D: 2. Jh. vor Chr.

Lit: Fischer, Slg. Sieglin/Schreiber, 164 Nr. 211

Taf. 18

Tk 81 Kopf

FO: Alexandria (?)

AO: Dresden (2600.C.20; aus Slg. Herold)

H: $3,9 \quad$ B: $6 \quad$ T: 2,2

D: 1. H. 2. Jh. vor Chr.

Lit: Fischer, Slg. Sieglin/Schreiber, 164 Nr. 214

Taf. 18 
Tk 82 Kopf

FO: Alexandria (?)

AO: Dresden (2600.C.22; aus Slg. Herold)

H: $3,5 \quad$ B: $2,8 \quad$ T: 2,3

D: Ende 3. Jh. vor Chr.

Lit: Fischer, Slg. Sieglin/Schreiber, 163 Nr. 203

Taf. 18

Tk 83 Kopf

FO: Alexandria (?)

AO: Dresden (2600.C.31)

H: 3,6 B: $2,7 \quad$ T: 2,5

D: 2. H. 3. Jh. vor Chr.

Lit: Fischer, Slg. Sieglin/Schreiber, 164 Nr. 209

Taf. 18

Tk 84 Kopf (mit Kausia ?)

FO: Alexandria (?)

AO: Dresden (2600.C.35)

$\mathrm{H}: 3,5 \quad$ B: $2,6 \quad \mathrm{~T}: 2,3$

D: 2. H. 3. Jh. vor Chr.

Lit: Fischer, Slg. Sieglin/Schreiber, 166 Nr. 222

Taf. 18

Tk 85 Kopf

FO: Alexandria (?)

AO: Dresden (2600.C.24)

$\mathrm{H}: 2,7 \quad$ B. $2,2 \quad \mathrm{~T}: 2$

D: 1. Jh. vor Chr.

Lit: Fischer, Slg. Sieglin/Schreiber, 165 Nr. 217 (o. Abb.)

Tk 86 Kopf

FO: Alexandria (?)

AO: Dresden (2600.C.27)

$\mathrm{H}: 3,1 \quad$ B: $2,2 \quad \mathrm{~T}: 2$

D: 1. Jh. vor Chr.

Lit: Fischer, Slg. Sieglin/Schreiber, 165 Nr. 218 (o. Abb.)
Tk 87 Kopf

FO: Alexandria (?)

AO: Dresden (2600.C.36)

H: $3,5 \quad$ B: $2,9 \quad$ T: 2,9

D: 2. H. 3. Jh. vor Chr.

Lit: Fischer, Slg. Sieglin/Schreiber, 166 Nr. 233 (o. Abb.)

Tk 88 Kopf

FO: Alexandria (?)

AO: Dresden (2600.C.29)

H: $3,4 \quad$ B: $3 \quad$ T: 3,1

D: 3. Jh. vor Chr. / kaiserzeitlich wiederholt?

Lit: Fischer, Slg. Sieglin/Schreiber, 165 Nr. 215

Taf. 18

Tk 89 Kopf

FO: Alexandria (?)

AO: Dresden (2600.C.21)

H: $3,4 \quad$ B: $2,5 \quad$ T: 2,1

D: 1. Jh. vor Chr. ?

Lit: Fischer, Slg. Sieglin/Schreiber, 165 Nr. 216

Taf. 18

Tk 90 Kopf

FO: Alexandria (?)

AO: Dresden (2600.C.16)

$\mathrm{H}: 3,4 \quad$ B: $2,6 \quad$ T: 2,5

D: A. - M. 3. Jh. vor Chr.

Lit: Fischer, Slg. Sieglin/Schreiber, 162 Nr. 201

Taf. 17

Tk 91 Kopf

FO: Alexandria

AO: Athen (Museum Benaki, Ap.єup. 22906)

H: 3,2

D: M. 1. Jh. nach Chr. (Pingiatoglou)

oder 3. Jh. vor Chr. (Burr-Thompson)

Lit: Pingiatoglou, Benaki, 13. 154. 162. Nr. 372 .-

Burr-Thompson, Troy, 54 Taf. 61,6 
Tk 92 Kopf (mit Kausia oder Federkrone ?)

FO: Alexandria, Hadra

AO: Alexandria (9863)

H: 3,5

D: $280-180$ vor Chr.*

Lit: Breccia, Alexandria II 1, 61 Nr. 326 Taf. 53, 16

Bemerk: Datierung s. Tk 39. Die Kopfbedeckung wird von Breccia (a.a.O.) als Federkrone bezeichnet; vgl. zwei ähnliche Stücke aus Athen (Agora) und in Paris (Coll. Camille Lecuyer): Stella Miller, AJA 43, 1974, 194 ff. (240 f.), Taf. 37 Nr. 88. Taf. 40 Nr. 97.

Tk 93 Kopf

FO: Alexandria, Hadra

AO: Alexandria (22566)

H: -

D: $280-180$ vor Chr.*

Lit: Breccia, Alexandria II 1, 37 Nr. 109 Taf. 53, 11

Bemerk: Datierung vgl. Tk 39.

Tk 94 Oberkörperfragment (Chlamydephoros, sitzend/stehend ?)

FO: Alexandria, Ras el Soda

AO: Alexandria (Musée Gréco-romaine, 25976)

H: 5,5

D: 2. H. 3. Jh. vor Chr. (Himmelmann)

Lit: Adriani, Annuaire III, 36 Taf. 17, 3 .- N. Himmelmann, Alexandria und der Realismus in der griechischen Kunst (1983) 50

\section{Saïs}

Tk 95 Reiter über Gegner

FO: Saïs (Sa-el-Hagar)

AO: Paris (Coll. Fouquet)

H: 11,7

D: 4./3. Jh. vor Chr.*
Lit: P. Perdrizet, Negotium perambulans in tenbris, Étude de demonologie gréco-orientale, Publications de la Faculté des lettres de 1'Université de Strasbourg 6 (1922) 10 Abb. 4

Tk 96 Reiter über Gegner (ohne Kopf)

FO: Saïs (Sa-el-Hagar)

AO: Tübingen

$\mathrm{H}:-$

D: 4./3. Jh. vor Chr.*

Lit: F. Beniot, Mars et Mercure (1959) Taf. 2, 1

\section{Thmuis}

Tk 97 a/b Reiter über Gegner (2 Exemplare)

FO: Thmuis (Tell Roba)

AO: -

$\mathrm{H}:-$

D: 4./3. Jh. vor Chr.*

Lit: Breccia, Alexandria II 1, 63 Nr. 341 (ohne Abb.)

\section{Tanis}

Tk 98 Oberkörperfragment

(Chlamydephoros, sitzend?)

FO: Tanis

AO: Paris (Louvre, E 16143 [Monet [1938] Inv. Nr. MMVd 75])

H: 6,7

D: hellenistisch ?

Lit: Dunand, Paris, 213 Nr. 573

Tk 99 Soldat

FO: Tanis

AO: Paris (Louvre, E15000 [früher Inv.Nr. Monet MMVd 76])

H: 7 (ohne Beine)

D: hellenistisch ?

Lit: Dunand, Paris, 212 Nr. 571

Tk 100 Soldat 
FO: Tanis

AO: Paris (Louvre, E 16139 [Inv.Nr. Monet MMVd 77])

H: 8,6 (ohne Beine)

D: hellenistisch?

Lit: Dunand, Paris, 212 Nr. 572

Tk 101 Kopf

FO: Tanis

AO: Paris (Louvre, AF 8320 [Inv.Nr. Monet MMVd 115])

$\mathrm{H}: 3,3$

D: hellenistisch ?

Lit: Dunand, Paris, 213 Nr. 574

\section{Naukratis}

Tk 102a/b Reiter über Gegner (2 Exemplare) FO: Naukratis

AO: -

$\mathrm{H}: 11,5$

D: hellenistisch ? / 4./3. Jh. vor Chr.*

Lit: A. Reinach, Les Galates dans 1'Art Alexandrin, MontPiot 18, 1910, 103 Abb. 30 und 104 mit Anm. 1

Tk 103 Kopf

FO: Naukratis?

AO: Leiden (ohne Inv.Nr.)

$\mathrm{H}: 3,2$

D: 3. Jh. vor Chr.

Lit: Leyenaar-Plaisier, Leiden, 528 Nr. 1538 Taf. 198

\section{Athribis (Delta)}

Tk 104 Oberkörperfragment (Chlamydephoros)

FO: Athribis (Tell Atrib)

AO: ? (TA 92/24)

$\mathrm{H}: 5$

D: frühes 2. Jh. vor Chr.
Lit: K. Mysliwiec/S. Abu Senna, Polish-Egyptian Excavation at Tell Atrib in 1991-1193, EtTrav 17, 1995, 220 Abb. 19

Tk 105 Reiter ohne Gegner

FO: Athribis (Tell Atrib)

AO: -

H: -

D: 3. Jh. vor Chr. (Kontext)

Lit: K. Mysliwiec/H. Szymanska, Les terres cuites de Tell Atrib. Rapport preliminaire, ChrEg 67, 1992, 127 Abb. 8 (S. 125)

Bemerk: Zwei weitere Köpfe mit Kausia werden im Text erwähnt (K. Mysliwiec/H. Szymanska, a.a.O. 127).

Tk 106 Reiter über Gegner FO: Athribis (Tell Atrib, square FFF, Room 241; $50 \mathrm{~cm}$ unter dem Niveau des frühptol. Bades)

AO: ? (TA 95/92)

H: 7,5 (ohne Pferdebeine)

D: spätes 4. Jh. vor Chr.

Lit: K. Mysliwiec/M. Bakr Said, Polish-Egyptian Excavation at Tell Atrib in 1994-1995, EtTrav 18, 1999, 179-219 (bes. 218) Abb. 26 a-b

Bemerk: Die Datierung ist stratigraphisch gesichert und wird hier zur Datierung des gesamten Typus herangezogen (sonst meist in tetrachische Zeit datiert).

Tk 107 Reiter über Gegner

FO: Athribis (Tell Atrib, square FFF, Room 241; $50 \mathrm{~cm}$ unter dem Niveau des frühptol. Bades)

AO: ? (TA 95/98)

$\mathrm{H}: 12,5$

D: spätes 4. Jh. vor Chr.

Lit: K. Mysliwiec/M. Bakr Said, Polish-Egyptian Excavation at Tell Atrib in 1994-1995, EtTrav 18, 1999, 179219 (bes. 218) Abb. 26 c-d 
Bemerk: Die Datierung ist stratigraphisch gesichert und wird hier zur Datierung des gesamten Typus herangezogen (sonst meist in tetrachische Zeit datiert).

\section{Memphis}

Tk 108 Kopf

FO: Memphis (Mit Rahineh)

AO: -

H: ca. 3,7

D: hell.*

Lit: W. M. Flinders Petrie (u.a.), Meydum and Memphis III (= Brit. School of Archeology in Egypt and Egypt Research Account 16, 1910) 46 Taf. 43,148

\section{Faijum}

Tk 109 Soldat, bärtig, schreitend (Abb. 107)

mit Schwert (?) und Schwertband (?)

FO: Faijum ? (in Kairo gekauft)

AO: Berlin

H: 6,2

D: hell.*

Lit: Weber, Berlin, 202 Nr. 341 Taf. 32

Tk 110 Soldat

FO: Faijum

AO: Frankfurt/M. (Liebieghaus, Inv. 2400.1291)

H: $10,9 \quad$ B: $4,4 \quad$ T: 3,7

D: hell.*

Lit: Bayer-Niemeier, Frankfurt, 68 Nr. 25 Taf. 4,2

\section{Tk 111 Soldat}

FO: Faijum ?

AO: Frankfurt/M. (Liebieghaus, Inv. 2400.1292)
H: 9,15
B: $3,3 \quad$ T: 2,8
D: hell.*

Lit: Bayer-Niemeier, Frankfurt, 68 Nr. 26 Taf. 4,3

Tk 112 Soldat
FO: Faijum ?

AO: Frankfurt/M. (Liebieghaus, Nr. 2400.1290)

H: 8 B: $3,5 \quad$ T: 3,1

D: 2. / 1. Jh. vor Chr.

Lit: Bayer-Niemeier, Frankfurt, 68 Nr. 24 Taf. 4,1

Tk 113 Soldat (Variante)(Abb. 109)

FO: Faijum ?

AO: Frankfurt (1915 im Liebieghaus, aus Slg. Kaufmann, heute verschollen)

$\mathrm{H}:-$

D: hell.*

Lit: C. M. Kaufmann, Graeco-Ägyptische Koroplastik (1915) Taf. 46 Nr. 391 (nicht im Text erwähnt?)

Bemerk: Gleicher Typus wie P 2 (Steatit-Statuette, $6 \mathrm{~cm}$, aus Koptos?) und Tk 359 (Tarent).

Tk 114 Reiter über Gegner

FO: Faijum ?

AO: Frankfurt/M. (Liebieghaus, Inv. 2400.1032)

H: 9,6 B: 8,5 T: 3,8 (ohne Pferdebeine)

D: A. 4. Jh. nach Chr. / 4./3. Jh. vor Chr.*

Lit: Bayer-Niemeier, Frankfurt, 223 f. Nr. 514 Taf. 90,3

Tk 115 Reiter über Gegner

FO: Faijum ?

AO: Berlin (9133)

H: 12,5 oder 12,75 (H. Philipp)

D: 300 nach Chr. (H. Philipp) / 4./3. Jh. vor Chr.* Lit: Weber, Berlin, 200 Nr. 336 Taf. 31.- H. Philipp, Terrakotten aus Ägypten im Ägyptischen Mut seum Berlin (1972) 31 Nr. 43 Abb. 38

Tk 116 Reiter über Gegner FO: Faijum ?

AO: Frankfurt/M. (Liebieghaus, Inv. 2400.1036)

H: $8,9 \quad$ B: $11,3 \quad$ T: 3,7

D: A. 4. Jh. nach Chr. / 4./3. Jh. vor Chr.* 
Lit: Bayer-Niemeier, Frankfurt, 224 Nr. 515 Taf. 90,5

Tk 117 Harpokrates (Knabe, hockend, mit überdimensionalem Phallos im li. Arm, Chlamys über die Schultern zurückgeschlagen) (Abb. 132)

FO. Faijum?

AO: Frankfurt (Liebieghaus, Inv. 2400.1304)

H: $7 \quad$ B: 3,5 T: 4,8

D: 3. Jh. vor Chr.

Lit: Bayer-Niemeier, Frankfurt, 206 Nr. 456 Taf. 83

Bemerk: Formgleich mit Tk 26.

\section{Kom-el-Ahdar (bei Bubastis?)}

Tk 118 Reiter über Gegner

FO: Kom-el-Ahdar

AO: Alexandria (21432)

$\mathrm{H}:-$

D: 4./3. Jh. vor Chr.*

Lit: Breccia, Alexandria II 1, 63 Nr. 341 (ohne Abb.)

Tk 119 Reiter über Gegner

FO: Kom-el-Ahdar

AO: Alexandria (21433)

$\mathrm{H}$ :

D: 4./3. Jh. vor Chr.*

Lit: Breccia, Alexandria II 1, 63 Nr. 341 (ohne Abb.)

\section{Apollinopolis magna / Edfu}

Tk 120 Kopf

FO: Apollinopolis magna/Edfu, kôm central

AO: ? (Inv. 559)

H: 5,7

D: römisch (1. Jh. nach Chr.) / hell.*

Lit: K. Michalowski (u.a.), Tell Edfou 1938 (= Fouilles franco-polonaises, Rapport II) (1938) 116

Nr. 559 Taf. 37, 20
Bemerk: Von K. Michalowski als ,tête de femme coiffée du velum" bezeichnet.

Tk 121 a-f Köpfe (6 Exemplare ?)

FO: Apollinopolis magna/Edfu, kôm central

AO: ? (Inv. 369, 374, 376, 377, 379, 380)

H: 5,$2 ; 6,1 ; 4,5 ; 4,4 ; 4,8 ; 5$

D: römisch (1. Jh. nach Chr.) / hell.*

Lit: K. Michalowski (u.a.), Tell Edfou 1939 (= Fouilles franco-polonaises, Rapport III) (1950) 212 f. Taf. XXVII, 9, 11, 12, 14, 15, 19

Bemerk: Die Köpfe werden von K. Michalowski als „tête de femme coiffée du velum“ bezeichnet. Die Qualität der Abbildungen ist sehr schlecht. Bei den meisten Exemplaren wird es sich jedoch um männliche Köpfe mit Kausia handeln.

\section{Kyrenaika}

Tk 122 Chlamydephoros, sitzend

FO: Kyrenaika

AO: Paris (Louvre, N 4539 [früher MN 624], Bourville, gek. 1850)

H: 12

D: 1. H. 3. Jh. vor Chr.

Lit: Besques, Paris IV-II, 66 D 4354 Taf. 34 a .Tanagra. Mythe et archeólogie, Ausstellung Paris/Montreal 2003/04, 270f. Nr. 212 (330-200 v.Chr.)

Tk 123 Chlamydephoros, stehend, Kinn verhüllend

FO: Kyrenaika

AO: Paris (Louvre, N 4348 [früher NM 643], Bourville, gek. 1850)

H: 9

D: 1. H. 3. Jh. vor Chr.

Lit: Winter, Typen II, 239 Nr. 5; Besques, Paris IV-II, 65 D 4348 Taf. 33 a

Tk 124 Oberkörperfragment 
(Chlamydephoros, stehend ?)

FO: Kyrenaika

AO: Paris (Louvre, CA 7169 [früher 9810790

AGER, ancient founds])

$\mathrm{H}: 5$

D: 3. Jh. vor Chr.

Lit: Besques, Paris IV-II, 66.D 4352 Taf. 33 e

Tk 125 Soldat, bärtig (Abb. 106)

FO: Kyrenaika

AO: London (British Museum, C827)

H: 5 in = ca. $12,6 \mathrm{~cm}$ (untere Hälfte der Beine fehlt)

D: A. 3. Jh. vor Chr.

Lit: H. Walters, Catalogue of the Terracottas in the British Museum (1903) 286 C827 .- M. Bieber, The History of the Greek and Roman Theater (1961) 99 Abb. 370 .- Dintsis, Helme, 307 Nr. 288 Taf. 81,4

Tk 126 Soldat

FO: Kyrenaika

AO: Paris (Louvre, N $4767=$ Mn 66; gek. 1850)

$\mathrm{H}: 11,5$

D: A. 3. Jh. vor Chr.

Lit: Besques, Paris IV-II, 71 D4378 Taf. 38 c

\section{Kleinasien (einschl. Lesbos)}

\section{Kleinasien allg.}

Tk 127 Chlamydephoros, stehend

FO: Kleinasien ? (gekauft 1890 in Paris)

AO: Frederikssund/Schweden (Willumsen Museum)

$\mathrm{H}: 16,7$

D: 2. Jh. vor Chr. ?

Lit: P. Guldagar Bilde, L. Krogh (Hrsgg.), Tanagra. J. F. Willumsen og hans antiksamling, Ausstellungskatalog 1996/1997, 121 Nr. 34
Tk 128 Chlamydephoros, stehend

FO: Kleinasien ?

AO: Leipzig (Archäologisches Institut, T 2188)

$\mathrm{H}: 14,5$

D: frühhellenistisch

Lit: E. Paul, Antike Welt in Ton (o. J.) 84 Nr. 194, Taf. 52

Bemerk: Formgleich mit Tk 129. Vgl. Datierungen.

Tk 129 Chlamydephoros, stehend

FO: Kleinasien

AO: Brunswick (Bowdoin College, Walter Art Museum 08.14)

$\mathrm{H}:-$

D: 1. Jh. vor Chr.

Lit: Burr-Thompson, Troy, 86 Taf. $61 \mathrm{c}$

Bemerk: Formgleich mit Tk 128. Vgl. Datierungen.

Tk 130 Oberkörperfragment (Chlamydephoros)

FO: Kleinasien? Smyrna?

AO: Detmold (Lippisches Landesmuseum)

$\mathrm{H}: 5,7$

D: 3./2. Jh. vor Chr.

Lit: U. Mrogenda, Die figürlichen Terrakotten im Lippischen Landesmuseum Detmold, Boreas 14/15, 1991/92, 258 f. Nr. 36

Tk 131 Oberkörperfragment

(Chlamydephoros, stehend)

FO: Kleinasien

AO: Paris (Louvre, CA 3731)

H: 5,8

D. späthellenistisch

Lit: Besques, Paris III-I, 131. D 880 Taf. 162 d

\section{Troas}

Tk 132 Chlamydephoros, stehend (Abb. 81c. 89) 
FO: Troja

AO: Çanakkale (Museum, Slg. Calvert)

H: -

D: hell.*

Lit: Burr-Thompson, Troy, 86 Taf. 56 e

Tk 133 Chlamydephoros, stehend

FO: Troas

AO: Çanakkale (Museum, Slg. Calvert)

H: 8

D: hell.*

Lit: Winter, Typen II, 239 Nr. 2 .- Burr-

Thompson, Troy, 86 Taf. 56 a

Tk 134 Oberkörperfragment (Chlamydephoros, stehend)

FO: Troja

AO: -

H: ca. 7-8 (Frgt.)

D: hell.*

Lit: unpubliziert

Foto: DAI Athen, Dörpfeld Neg. Nr. Troja 639

Tk 135 Oberkörperfragment (Chlamydephoros, stehend, Kinn verhüllend)

FO: Troja (nahe Heiligtum)

AO: Troja (36-541)

H: 7,8

D: spätes 2. Jh. vor Chr.

(terminus ante quem 22 vor Chr.[?])

Lit: Burr-Thompson, Troy, 53. 86. Nr. 52 Taf. 56

Tk 136 Oberkörperfragment (Chlamydephoros, stehend, Kinn verhüllend) (Abb. 93)

FO: Troja (Context: squares Z-A 4-5[gestört])

AO: Troja (36-569)

H: 6,1

D: 1. Jh. vor Chr.

Lit: Burr-Thompson, Troy, 53 ff. 86 Nr. 53 Taf. 56
Tk 137 a/b Chlamydephoroi, stehend, Kinn verhüllend ( 2 Exemplare)

FO: Troas?

AO: Çanakkale (Museum, Slg. Calvert)

H: 13

D: 2. - 1. Jh. vor Chr.

Lit: Winter, Typen II, 239 Nr. 3 .- Burr-Thompson, Troy, 55 Anm. 150

Tk 138 Reiter ohne Gegner

FO: Troas

AO: Çanakkale (Museum, Slg. Calvert)

H: 13

D: 3. Jh. vor Chr.* (?)

Lit: Winter, Typen 301, 1

Tk 139 Kopf (Kinn verhüllend?)

FO: Troja (unterhalb des Kybele Heiligtums)

AO: Troja (32-496)

H: 2,5

D: 1. Jh. vor Chr.

(terminus ante quem 85 vor $\mathrm{Chr}$. [?])

Lit: Burr-Thompson, Troy, 53 ff. 86 Nr. 54 Taf. 16

Tk 140 Kopf

FO: Troja (unterhalb des Kybele Heiligtums)

AO: Troja (32-226)

H: 3,2

D: spätes 3. Jh. vor Chr.

(terminus ante quem 85 vor $\mathrm{Chr}$.[?])

Lit: Burr-Thompson, Troy, 53 ff. 86 Nr. 55 Taf. 16

Tk 141 Kopf

FO: Troja (unterhalb des Kybele Heiligtums)

AO: Troja (32-498)

H: 3

D: Typus: frühes 2. Jh. vor Chr.; hergestellt: 1. Jh. vor Chr.

Lit: Burr-Thompson, Troy, 53 ff. 86 Nr. 56 Taf. 16 
Tk 142 Kopf

FO: Troja (unterhalb des Kybele Heiligtums)

AO: Troja (32-245)

H: 3,2

D: spätes 1 . Jh. vor Chr. oder terminus ante quem 85 vor Chr. ?

Lit: Burr-Thompson, Troy, 53 ff. 86 Nr. 57, Taf. 16

\section{Pergamon}

Tk 143 Kopf

FO: Pergamon (oder Umgebung von Pergamon)

AO: Bergama (Museum, T 242)

$\mathrm{H}: 2$

D: 2. Jh. vor Chr. / 3. Jh. vor Chr.*

Lit: E. Töpperwein, Terrakotten aus Pergamon

(PF 3) (1976) 125. 237 Nr. 529 Taf. 76

\section{Südliche Aiolis}

Tk 144 Chlamydephoros, stehend

FO: südliche Aiolis

AO: Leiden (Lka 949, gek. 1887 in Smyrna)

H: 12,9

D: 1. Jh. vor Chr.

Lit: Leyenaar-Plaisier, Leiden, 405 Nr. 1123 Taf. 145

Tk 145 Oberkörperfragment

(Chlamydephoros, stehend)

FO: südliche Aiolis

AO: Leiden (Lka 172, gek. 1886 in Smyrna)

H: 6

D: 1. Jh. vor Chr.

Lit: Leyenaar-Plaisier, Leiden, 406 Nr. 1124 Taf. 146

Tk 146 Oberkörperfragment

(Chlamydephoros, stehend)

FO: südliche Aiolis

AO: Leiden (Lka 496, gek. 1887 in Smyrna)
$\mathrm{H}: 6,1$

D: 1. Jh. vor Chr.

Lit: Leyenaar-Plaisier, Leiden, 406 Nr. 1126 Taf. 146

Tk 147 Oberkörperfragment

(Chlamydephoros, stehend)

FO: südl. Aiolis

AO: Leiden (LKA 339, gek. 1886 in Smyrna)

H: 5,7

D: 1. H. 1. Jh. vor Chr.

Lit: Leyenaar-Plaisier, Leiden, 406 Nr. 1125 Taf. 146

Tk 148 Oberkörperfragment

(Chlamydephoros, stehend)

FO: südl. Aiolis

AO: Leiden (LKA 495, gek. 1887 in Smyrna)

H: 7,1

D: 1. Jh. vor Chr.

Lit: Leyenaar-Plaisier, Leiden, 406 f. Nr. 1127

Taf. 146

Tk 149 Oberkörperfragment

(Chlamydephoros, stehend)

FO: südl. Aiolis

AO: Leiden (LKA 498, gek. 1887 in Smyrna)

H: 5,6

D: 1. Jh. vor Chr.

Lit: Leyenaar-Plaisier, Leiden, 407 Nr. 1128 (o. Abb.)

Tk 150 Oberkörperfragment

(Chlamydephoros, stehend)

FO: südl. Aiolis

AO: Leiden (LKA 181, gek. 1889 in Smyrna)

H: 5,5

D: 1. H. 1. Jh. nach Chr.

Lit: Leyenaar-Plaisier, Leiden, 407 Nr. 1129 Taf. 146 
Tk 151 Oberkörperfragment

(Chlamydephoros, stehend)

FO: südl. Aiolis

AO: Leiden (LKA 500, gek. 1887 in Smyrna)

H: 6

D: 1. H. 1. Jh. nach Chr.

Lit: Leyenaar-Plaisier, Leiden, 407 Nr. 1130 (o. Abb.)

Tk 152 Oberkörperfragment

(Chlamydephoros, stehend)

FO: südl. Aiolis

AO: Leiden (LKA 499, gek. 1887 in Smyrna)

$\mathrm{H}: 7$

D: E. 1. - 2. Jh. nach Chr.

Lit: Leyenaar-Plaisier, Leiden, 408 Nr. 1132 Taf. 146

Tk 153 Oberkörperfragment

(Chlamydephoros, stehend)

FO: südl. Aiolis

AO: Leiden (LKA 170, gek. 1886 in Smyrna)

H: 9

D: E. 1. - A. 2. Jh. nach Chr.

Lit: Leyenaar-Plaisier, Leiden, 407 f. Nr. 1131

Taf. 146

Tk 154 Oberkörperfragment (Abb. 81d. 88ff.)

(Chlamydephoros, stehend)

FO: südl. Aiolis

AO: Leiden (LKA 494, gek. 1887 in Smyrna)

H: 9,9

D: 2. Jh. nach Chr.

Lit: Leyenaar-Plaisier, Leiden, 408 Nr. 1133 Taf. 146

Tk 155 Kopf

FO: südl. Aiolis

AO: Leiden (LKA 343, gek. 1886 in Smyrna)
H: 3,9

D: 1. H. 1. Jh. vor Chr.

Lit: Leyenaar-Plaisier, Leiden, 409 Nr. 1137 Taf.

147

Tk 156 Kopf

FO: südl. Aiolis

AO: Leiden (LKA 694, gek. 1887 in Smyrna)

H: 4,2

D: E. 1. - A. 2. Jh. nach Chr.

Lit: Leyenaar-Plaisier, Leiden, 409 Nr. 1138 Taf. 147

\section{Myrina}

Tk 157 Oberkörperfragment

(Chlamydephoros, stehend)

FO: Myrina

AO: Paris (Louvre, Myrina 1458)

H: 8,7

D: M. 1. Jh. vor Chr.

Lit: Mollard-Besques, Paris II, 137. Myrina 1458

Taf. 168 b

Tk 158 Clamydephoros, stehend, Kinn verhüllend FO: Myrina

AO: Paris (Louvre, Myr 291 [früher Inv.Nr. 46 ?])

H: 11,75

D: 3.-2. Jh. vor Chr.*

Lit: Mollard-Besques, Paris II, 130. Myr 291 Taf. $155 \mathrm{f}$ (E. 2. Jh. v.Chr.) .- Tanagra. Mythe et archeólogie, Ausstellung Paris/Montreal 2003/04, 253 Nr. 193 (325-200 v.Chr.)

Bemerk: Formgleich mit Tk 159 ?

Tk 159 Clamydephoros, stehend, Kinn verhüllend FO: Myrina

AO: Dresden (Albertinum, Z.V. 735)

H: 12,6

D: 3./2. Jh. vor Chr.*

Lit: Winter, Typen II, 239 Nr. 4 b 
Tk 160 Kopf

FO: Myrina

AO: Paris (Louvre, Myrina 1585)

H: 3

D: E. 3. Jh. vor Chr.

Lit: Mollard-Besques, Paris II, 191. Myrina 1585

Taf. 226)

Tk 161 Kopf

FO: Myrina

AO: Paris (Louvre, Myrina 1584)

H: 3,1

D: 1. Jh. vor Chr.

Lit: Mollard-Besques, Paris II, 191. Myrina 1584

Taf. 226

Tk 162 Kopf

FO: Myrina

AO: Leiden (LKA 341, gek. 1886 in Smyrna)

H: 3,1

D: 1. H. 1. Jh. nach Chr.

Lit: Leyenaar-Plaisier, Leiden, 348 f. Nr. 945 Taf. 125

Tk 163 Kopf

FO: Myrina

AO: Leiden (LKA 340, gek. 1886 in Smyrna)

H: 3.3

D: 2. H. 1. Jh. nach Chr.

Lit: Leyenaar-Plaisier, Leiden, 349 Nr. 955 Taf. 125

\section{Kyme}

Tk 164 Chlamydephoros, stehend

FO: Kyme (Kleinasien)

AO: Paris (Collection Gréau)

H: 14,4

D: 1./2. Jh. nach Chr.*

\section{Larisa am Hermos}

Tk 165 Affe (?) mit Schwert, Rundschild und Kausia

FO: Larisa

AO: -

H: 5,5

D: vor 300 vor Chr. (stratigraphisch)

Lit: J. Boehlau, K. Schefold (Hrsgg.), Larisa am Hermos. Die Ergebnisse der Ausgrabungen 190234. Band 3: Die Kleinfunde (1942) 44 Taf. 9, 16

\section{Ionische Küste}

Tk 166 Chlamydephoros, sitzend, „Denker“ (Abb. 86)

FO: ionische Küste (Smyrna ?)

AO: Leiden (SvL 394, gek. 1880 in Smyrna)

H: 8,1 (Frgt. ohne Füße)

D: E. 4. - A. 3. Jh. vor Chr.

Lit: Leyenaar-Plaisier, Leiden, 433 Nr. 1206 Taf. 158

Tk 167 Oberkörperfragment

(Chlamydephoros, stehend)

FO: ion. Küste

AO: Leiden (LKA 171, gek. 1886 in Smyrna)

H: 8

D: 2. Jh. vor Chr. ?

Lit: Leyenaar-Plaisier, Leiden, 433 Nr. 1207 Taf. 158

Tk 168 Oberkörperfragment

(Chlamydephoros, stehend)

FO: ionische Küste

AO: Leiden (LKA 497, gek. 1887 in Smyrna)

H: 5,7

D: 1. H. 1. Jh. nach Chr.

Lit: Leyenaar-Plaisier, Leiden, 423 Nr. 1208 Taf. 158 
Lit: Besques, Paris III-I, 131. D 879 Taf. 162 b,e

Tk 169 Kopf

FO: ionische Küste (gek. in Smyrna 1882)

AO: Leiden (SNs. 209)

H: 2,9

D: 1. H. 1. Jh. nach Chr.

Lit: Leyenaar-Plaisier, Leiden, 484 f. Nr. 1388

Taf. 178

Tk 170 Kopf

FO: ionische Küste (gek. in Smyrna 1886)

AO: Leiden (LKA 342)

H: 2,6

D: späthell.

Lit: Leyenaar-Plaisier, Leiden, 484 Nr. 1387 Taf. 178

Tk 171 Kopf

FO: ionische Küste (gek. in Smyrna 1887)

AO: Leiden (LKA 764)

H: 2,3

D: hell.

Lit: Leyenaar-Plaisier, Leiden, 484 Nr. 1386 Taf. 178

\section{Smyrna}

Tk 172 Chlamydephoros, stehend

FO: ionische Küste / Smyrna ?

AO: Leiden (SvL 393, Geschenk A.O. von Lennep, Smyrna 1880)

H: 11,4 (Frgt. ohne Füße)

D: severisch

Lit: Leyenaar-Plaisier, Leiden, 434 Nr. 1209 Taf. 158

Tk 173 Chlamydephoros, stehend

FO: Smyrna

AO: Paris (Louvre, CA 2345)

H: 13

D: späthellenistisch
Tk 174 Chlamydephoros, stehend

FO: Smyrna

AO: Paris (Louvre, CA 1534)

H: 12

D: späthellenistisch

Lit: Besques, Paris III-I, 165. D 1133 Taf. 229 c,f

\section{Xanthos}

Tk 175 Epheben-Soldat

FO: Xanthos (Letoon)

AO: verschollen? (nicht in Antalya)

$\mathrm{H}:-$

D: frühhellenistisch ?*

(terminus ante quem 98-102 nach Chr.)

Lit: M. J. Mellink, AJA 92, 1988, 119 f. Abb. 17

(S. 116)

Bemerk: Die Beifunde entstammen dem 6.-1. Jh. v. Chr.

\section{Limyra}

Tk 176 Oberkörperfragment

(Chlamydephoros, stehend?)

FO: Limyra (Hangterrassen)

AO: ? (Inv.Nr. Li 74/K8)

H: 5,9 B: 4,4 (Gesicht: 1,4)

D: hellenistisch

Lit: K. Zhuber-Okrog, Terrakotten aus Limyra, ÖJh 60, 1990, Beibl. 118. Tk 54 Abb. 32 (Sp. 113 f.)

Tk 177 Kopf

FO: Limyra (Nekropole II, Terrasse vor den Gräbern des Tebursseli und des Pizzi))

AO: ? (Inv.Nr. Li 71/T15)

H: 2

D: E. 4. Jh. vor Chr.

(terminus post quem $330 / 20$ vor) 
Lit: E. Specht, Die Felsgräber des Tebursseli und des Pizzi in der Nekropole II von Limyra, ÖJh 58, 1988, Beibl. 139 Nr. 12 Abb. 37 c (Sp. 130)

Tk 178 Kopf

FO: Limyra (Nekropole V)

AO: ? (Inv.Nr. Li 87/KF112)

H: 3,6 B: 2,8 (Gesicht: 1,6)

D: späthellenistisch

Lit: K. Zhuber-Okrog, Terrakotten aus Limyra, ÖJh 60, 1990, Beibl. 117 f. Tk 55 Abb. 33

\section{Lykien / Pamphylien}

Tk 179 Epheben-Soldat

FO: Lykien/Pamphylien?

AO: Antalya (Museum)

$\mathrm{H}:$ -

D: frühhellenistisch ?*

Lit: unpubliziert

\section{Mytilene (Lesbos)}

Tk 180 Chlamydephoros, sitzend (mit Herme)

FO: Mytilene (Nekropole Odos Venizelou)

AO: ? (BE 8406 ?)

H: ca. 14

D: um 250 vor Chr.

Lit: A. Archontidou-Argyri, ADelt 43 B'2, 1988, 459 Abb. 9-10 Taf. 277 ff.

Tk 181 Chlamydephoros, sitzend, Kinn verhüllend? (mit Herme)

FO: Mytilene (Nekropole Odos Venizelou)

AO: ? (BE 8407 ?)

H: ca. 12-13

D: um 250 vor Chr.

Lit: A. Archontidou-Argyri, ADelt 43 B'2, 1988, 459 Abb. 9-10 Taf. 277 ff.

Tk 182 Chlamydephoros, sitzend, Kinn verhüllend (mit Herme) (Abb. 87)
FO: Mytilene (Nekropole Odos Venizelou)

AO: ? (BE 8408 ?)

H: ca. 14

D: um 250 vor Chr.

Lit: A. Archontidou-Argyri, ADelt 43 B'2, 1988, 459 Abb. 9-10 Taf. 277 ff.

Bemerk: Formgleich mit Tk 183 und Winter, Typen II, 256 Nr. 3 (aus Tanagra, ohne Kausia).

Tk 183 Chlamydephoros, sitzend, Kinn verhüllend (Herme abgebrochen) (Abb. 87)

FO: Lesbos* ?

AO: England (Slg. S. Matanos, privat)

H: 12

D: 330-200 / um 250 vor Chr.*

Lit: Ancient Live in Miniature - An Exhibition of Classical Terracottas from Private Collections in England, Birmingham 1968, 28 Nr. 90 Taf. 15 Bemerk: Formgleich mit Tk 182 und Winter, Typen II, 256 Nr. 3 (aus Tanagra, ohne Kausia.)

Tk 184 Chlamydephoros, stehend, Kinn verhüllend

FO: Mytilene (Nekropole Odos Venizelou)

AO: ? (BE 8405 ?)

H: ca. 13

D: um 250 vor Chr.

Lit: A. Archontidou-Argyri, ADelt 43 B'2, 1988, 459 Abb. 9-10 Taf. 277 ff.

Tk 185 Reiter ohne Gegner

FO: Lesbos*?

AO: Leipzig (Archäologisches Institut, T 1028; Geschenk Warren [1901] aus Slg. auf Lesbos)

H: 10,3

D: 2. Jh. vor Chr. / 3./2. Jh. vor Chr.*

Lit: S. Fisterer-Haas, Antike Terrakotten (1996) 48 Nr. 34 (mit Farbabb.)

Bemerk: Vgl. zu FO und Datierung den Haupttext. 
Griechenland, Makedonien und Schwarzes

Meer

Makedonien (in den Grenzen von 359 v.

Chr.)

Pella

Tk 186a-e Junge auf Ziegenbock (Abb 158)

in Chiton und Chlamys

(5 Exemplare aus gleicher Form)

FO: Pella (Grab $\Theta$, Ostkline)

AO: Pella (Museum, Inv.Nr. Be 1978/108-112)

H: 11

D: M. 2. Jh. vor Chr.

Lit: M. Lilimpaki-Akamati, $\Lambda \alpha \xi \in$ €voí $\Theta \alpha \lambda \alpha \mu \omega \tau o$ í

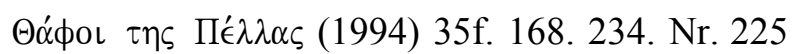

Taf. 27

Tk 187 Junge (in Chiton, Chlamys) auf Ziegenbock

FO: Pella (Grab auf Grundstück Zotaki, Dromos)

AO: Pella (Museum, Inv.Nr. Be 1976/206)

$\mathrm{H}: 8,5$

D: $225-200$ vor $\mathrm{Chr}$.

Lit: M. Lilimpaki-Akamati, $\Lambda \alpha \xi \in$ €voí $\Theta \alpha \lambda \alpha \mu \omega \tau o i ́$

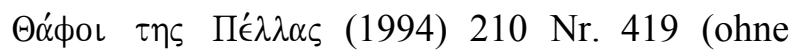
Abb.)

Griechische Poleis (seit Philipp II. [359-336 v. Chr.] makedonisch)

\section{Pydna}

Tk 188 Chlamydephoros, stehend, Kinn verhüllend (Abb. 90)

FO: Pydna (Südnekropole)

AO: Dion (Museum)

H: -

D: E. 4. Jh. vor Chr.

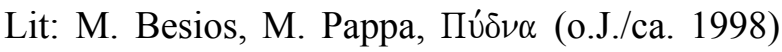
94f. (nur Abb., ohne Text)

Bemerk: Formgleich mit Tk 294-295 (aus Böotien/Attika).

\section{Amphipolis}

Tk 189 Chlamydephoros, sitzend, Denkerpose FO: Amphipolis (Grab)

AO: -

$\mathrm{H}:-$

D: hell.

Lit: D. Lazaridis, Ergon 1959, 38 Abb. 38 (S. 40)

Tk 190 Chlamydephoros, sitzend, entblößt

FO: Amphipolis (Neohori)

AO: Belgrad (Nationalmuseum, 557/1 [alte Nr. 1728])

H: 11,3

D: 2. - 1. Jh. vor Chr.

Lit: M. Velickovic, Catalogue des Terres Cuites grecques et romaines (1957) 104 Nr. 57 Taf. 19

Bemerk: Formgleich mit Tk 191?

Tk 191 Chlamydephoros, sitzend, entblößt

FO: Amphipolis (Neohori)

AO: Kavalla (Museum)

$\mathrm{H}:-$

D: 2. - 1. Jh. vor Chr.*?

Lit: unpubliziert

Bemerk: Formgleich mit Tk 190?

Tk 192 Chlamydephoros, sitzend, entblößt

FO: Amphipolis (Neohori)

AO: Belgrad (Nationalmuseum, Inv.Nr. 554/1 [alte Nr. 1726])

H: 11,6

D: 2. - 1. Jh. vor Chr.

Lit: M. Velickovic, Catalogue des Terres Cuites grecques et romaines (1957) $103 \mathrm{Nr}$. 54. Taf. 19 
Tk 193 Chlamydephoros, sitzend, entblößt

FO: Amphipolis (Neohori)

AO: Belgrad (Nationalmuseum, Inv.Nr. 555/1

[alte Nr. 1729])

H: 10,6

D: 2. - 1. Jh. vor Chr.

Lit: M. Velickovic, Catalogue des Terres Cuites grecques et romaines (1957) $103 \mathrm{Nr} .55$ Taf. 19

Tk 194 Chlamydephoros, sitzend, entblößt

FO: Amphipolis (Neohori)

AO: Belgrad (Nationalmuseum, Inv.Nr. 556/1

[alte Nr. 1727])

H: 10,8

D: 2. - 1. Jh. vor Chr.

Lit: M. Velickovic, Catalogue des Terres Cuites grecques et romaines (1957) $103 \mathrm{Nr}$. 56 Taf. 19

Tk 195 Chlamydephoros, sitzend, entblößt

FO: Amphipolis (Neohori)

AO: Kavalla (Museum 430e/1482p)

H: -

D: 2. - 1. Jh. vor Chr.*

Lit: unpubliziert

Bemerk: Formgleich mit Tk 192-193.

Tk 196 Chlamydephoros, sitzend, entblößt

FO: Amphipolis

AO: Kavalla (Museum)

H: -

D: hell.*

Lit: unpubliziert

Tk 197 Chlamydephoros, stehend, Kinn verhüllend (Abb. 91)

FO: Amphipolis

AO: Belgrad (Nationalmuseum, Inv.Nr. 558/1

[alte Nr. 1744])

H: 10,4

D: 2. - 1. Jh. vor Chr. / 3./2.Jh. vor Chr.*
Lit: M. Velickovic, Catalogue des Terres Cuites grecques et romaines (1957) 104 f. Nr. 58 Taf. 20

Tk 198a-b Chlamydephoroi, stehend, Kinn verhüllend (2 Exemplare)

FO: Amphipolis

AO: -

H: ca. 13

D: hell.*

Lit: P. Perdizet, BCH 21, 1897, 513 Nr.C

Bemerk: Ähnlich Tk 197.

Tk 199 Manteljüngling (Chlamys?), ohne Chiton/entblößt

FO: Amphipolis

AO: Kavalla (Museum, 346 E)

$\mathrm{H}:-$

D: hell.*

Lit: unpubliziert

Tk 200 Jüngling

(Mantel am Rücken herab gerutscht/entblößt)

FO: Amphipolis (Nekropole)

AO: Kavalla (Museum)

$\mathrm{H}:-$

D: hell.*

Lit: unpubliziert

\section{Samothrake}

\section{Samothrake, Südnekropole}

Tk 201 Chlamydephoros, sitzend

FO: Samothrake, Südnekropole S125

AO: ? (Inv. 57.802, S125-2)

H: 9,9

D: 300 vor Chr.

Lit: Dusenbery, Samothrake, 190. 865 S125-2

Tk 202 Chlamydephoros, stehend „samothracian type I“ (Kopffrgt.) 
FO: Samothrake, Südnekropole S130

AO: ? (Inv. 57.305, S130-24)

$\mathrm{H}: 3$

D: 3. Jh. vor Chr. bzw. 275-50 vor Chr.

Lit: Dusenbery, Samothrake, 200 ff. 204 f. 869 S130-24

Tk 203 Chlamydephoros, stehend „samothracian type II“ (Kopffrgt.)

FO: Samothrake, Südnekropole S130

AO: ? (Inv. 60. 37, S130-25)

H: 3,1

D: 3. Jh. vor Chr. bzw. 275-50 vor Chr.

Lit: Dusenbery, Samothrake, 200 ff. 205. 871

S130-25

Tk 204 Chlamydephoros, stehend „samothracian type III“ (Kopffrgt.)

FO: Samothrake, Südnekropole S131

AO: ? (Inv. 57.507, S131-3)

$\mathrm{H}: 3,7$

D: $275-50$ vor Chr.

Lit: Dusenbery, Samothrake, 208 ff. 873 S131-3

Tk 205 Chlamydephoros, stehend „samothracian type I“

FO: Samothrake, Südnekropole, Terrakottadeposit AO: ? (Inv. 57.609, TCDS-16)

H: 16,4

D: $300-275$ vor Chr.

Lit: Dusenbery, Samothrake, 268, 847 ff. (852 f. 867 f. 870) TCDS-16-21

Tk 206 Chlamydephoros, stehend „samothracian type I“ (Kopf)

FO: Samothrake, Südnekropole, Terrakottadeposit AO: ? (Inv. 57.304, TCDS-17)

H: 5,3

D: $300-275$ vor Chr.
Lit: Dusenbery, Samothrake, 268, 847 ff. (852 f. 867 f. 870) TCDS-16-21

Tk 207 Chlamydephoros, stehend „samothracian type I“ (Kopf)

FO: Samothrake, Südnekropole, Terrakottadeposit AO: ? (Inv. 60.258, TCDS-18)

H: 4,2

D: $300-275$ vor Chr.

Lit: Dusenbery, Samothrake, 268, 847 ff. (852 f. 867 f. 870) TCDS-16-21

Tk 208 Chlamydephoros, stehend „samothracian type I“ (Kopf)

FO: Samothrake, Südnekropole, Terrakottadeposit AO: ? (Inv. 60.257, TCDS-19)

H: 5,15

D: $300-275$ vor Chr.

Lit: Dusenbery, Samothrake, 268, 847 ff. (852 f. 867 f. 870) TCDS-16-21

Tk 209 Chlamydephoros, stehend „samothracian type I“ (Kopf)

FO: Samothrake, Südnekropole, Terrakottadeposit AO: ? (Inv. 57.392A, TCDS-20)

$\mathrm{H}: 4,8$

D: $300-275$ vor Chr.

Lit: Dusenbery, Samothrake, 268, 847 ff. (852 f. 867 f. 870) TCDS-16-21

Tk 210 Chlamydephoros, stehend „samothracian type I“ (Unterkörperfrgt.)

FO: Samothrake, Südnekropole, Terrakottadeposit AO: ? (Inv. 60.261B, TCDS-21)

H: 6,7

D: $300-275$ vor Chr.

Lit: Dusenbery, Samothrake, 268, 847 ff. (852 f. 867 f. 870) TCDS-16-21

Tk 212 Chlamydephoros, stehend 
„samothracian type II“ (Kopf)

FO: Samothrake, Südnekropole, Terrakottadeposit

AO: ? (Inv. 60.262, TCDS-23)

H: 4,6

D: $300-275$ vor Chr.

Lit: Dusenbery, Samothrake, 853 TCDS-23

Tk 212 Chlamydephoros, stehend „samothracian type III“ (Kopf)

FO: Samothrake, Südnekropole, Terrakottadeposit

AO: ? (Inv. 57.309, TCDS-24)

H: 3,35

D: $300-275$ vor Chr.

Lit: Dusenbery, Samothrake, 853f. TCDS-24

Tk 213 Chlamydephoros, stehend „samothracian type III“ (Kopf)

FO: Samothrake, Südnekropole, Terrakottadeposit AO: ? (Inv. 57.506, TCDS-25)

H: 3,66

D: $300-275$ vor Chr.

Lit: Dusenbery, Samothrake, 853 f. TCDS-25

Tk 214 Chlamydephoros, stehend „samothracian type III“ (Kopf)

FO: Samothrake, Südnekropole, Terrakottadeposit AO: ? (Inv. 60.271 TCDS-26)

H: 3,6

D: $300-275$ vor Chr.

Lit: Dusenbery, Samothrake, 853 f. TCDS-26

Tk 215 Chlamydephoros, stehend „samothracian type III“ (Kopf)

FO: Samothrake, Südnekropole, Terrakottadeposit AO: ? (Inv. 57.392C, TCDS-27)

H: 3,15

D: $300-275$ vor Chr.

Lit: Dusenbery, Samothrake, 853 f. TCDS-27 „samothracian type III“ (Kopf)

FO: Samothrake, Südnekropole, Terrakottadeposit AO: ? (Inv. 60.270, TCDS-28)

H: 3,1

D: $300-275$ vor Chr.

Lit: Dusenbery, Samothrake, 853 f. TCDS-28

Tk 217 Chlamydephoros, stehend „samothracian type III“ (Kopf)

FO: Samothrake, Südnekropole, Terrakottadeposit AO: ? (Inv. 57.74, TCDS-29)

$\mathrm{H}: 3,7$

D: $300-275$ vor Chr.

Lit: Dusenbery, Samothrake, 853 f. TCDS-29

Tk 218 Chlamydephoros, stehend „samothracian type I“ (Unterkörperfrgt.)

FO: Samothrake, Südnekropole XS

AO: ? (Inv. 64.SN.171, XS253)

H: 8

D: ca. 275 vor Chr.

Lit: Dusenbery, Samothrake, 869 f. XS253

Tk 219 Chlamydephoros, stehend „samothracian type I“ (Oberkörperfrgt.)

FO: Samothrake, Südnekropole XS

AO: ? (Inv. 57.476, XS254)

H: 10,2

D: ca. 275 vor Chr.

Lit: Dusenbery, Samothrake, 869 f. XS254

Tk 220 Chlamydephoros, stehend „samothracian type I“ (Kopf)

FO: Samothrake, Südnekropole XS

AO: ? (Inv. 57.504, XS255)

H: 3,7

D: ca. 275 vor Chr.

Lit: Dusenbery, Samothrake, 869 f. XS255

Tk 221 Chlamydephoros, stehend 
„samothracian type I“ (Kopf)

FO: Samothrake, Südnekropole XS

AO: ? (Inv. 57.442, XS256)

H: 4,6

D: ca. 275 vor Chr.

Lit: Dusenbery, Samothrake, 869 f. XS256

Tk 222 Chlamydephoros, stehend „samothracian type II“ (Kopf)

FO: Samothrake, Südnekropole XS

AO: ? (Inv. 64.SN.184, XS257)

H: 5,6

D: ca. 275 vor Chr.

Lit: Dusenbery, Samothrake, 871 XS257

Tk 223 Chlamydephoros, stehend „samothracian type III“ (Kopf)

FO: Samothrake, Südnekropole XS

AO: ? (Inv. 57.505, XS259)

H: 4

D: ca. 275 vor Chr.

Lit: Dusenbery, Samothrake, 872 ff. XS259

Tk 224 Chlamydephoros, stehend „samothracian type III“ (Kopf)

FO: Samothrake, Südnekropole XS

AO: ? (Inv. 57.365C, XS260)

H: 3,2

D: ca. 275 vor Chr.

Lit: Dusenbery, Samothrake, 872 ff. XS260

Tk 225 Chlamydephoros, stehend „samothracian type III“ (Kopf)

FO: Samothrake, Südnekropole XS

AO: ? (Inv. 57.492, XS261)

H: 3,3

D: ca. 275 vor Chr.

Lit: Dusenbery, Samothrake, 872 ff. XS261

Tk 226 Chlamydephoros, stehend „samothracian type III“ (Kopf)

FO: Samothrake, Südnekropole XS

AO: ? (Inv. 57.508, XS262)

H: 3,1

D: ca. 275 vor Chr.

Lit: Dusenbery, Samothrake, 872 ff. XS262

Tk 227 Chlamydephoros, stehend „samothracian type III“ (Kopf)

FO: Samothrake, Südnekropole XS

AO:? (Inv. 60.274, XS263)

H: 3

D: ca. 275 vor Chr.

Lit: Dusenbery, Samothrake, 872 ff. XS263

Tk 228 Chlamydephoros, stehend „samothracian type III“ (Kopf)

FO: Samothrake, Südnekropole XS

AO: ? (Inv. 60.272, XS264)

H: 2,3

D: ca. 275 vor Chr.

Lit: Dusenbery, Samothrake, 872 ff. XS264

Tk 229 Chlamydephoros, stehend „samothracian type III“ (Kopf)

FO: Samothrake, Südnekropole XS

AO: ? (Inv. 60.273, XS265)

H: 3,1

D: ca. 275 vor Chr.

Lit: Dusenbery, Samothrake, 872 ff. XS224

Tk 230 Chlamydephoros, stehend „samothracian type III“ (Kopf)

FO: Samothrake, Südnekropole XS

AO: ? (Inv. 57.502, XS266)

H: 3,4

D: ca. 275 vor Chr.

Lit: Dusenbery, Samothrake, 872 ff. XS266

Tk 231 Chlamydephoros, stehend 
„samothracian type III“ (Kopf)

FO: Samothrake, Südnekropole XS

AO: ? Inv. 64.SN:288, XS267)

$\mathrm{H}$ :

D: ca. 275 vor Chr.

Lit: Dusenbery, Samothrake, 872 ff. XS267

Tk 232 Chlamydephoros, stehend „samothracian type IV“ (Kopf)

FO: Samothrake, Südnekropole XS

AO: ? (Inv. 57.384, XS268)

H: 2,9

D: vielleicht 3. Jh. vor Chr.

Lit: Dusenbery, Samothrake, 874 f. XS268

Tk 233 Chlamydephoros, stehend „samothracian type IV“ (Kopf)

FO: Samothrake, Südnekropole XS

AO: ? (Inv. 63.SN.259, XS269)

H: 3,1

D: vielleicht 3. Jh. vor Chr.

Lit: Dusenbery, Samothrake, 874 f. XS269

Tk 234 Chlamydephoros, stehend „samothracian type IV“ (Kopf)

FO: Samothrake, Südnekropole XS

AO: ? (ohne Inv. Nr., XS270)

H: 2,8

D: vielleicht 3. Jh. vor Chr.

Lit: Dusenbery, Samothrake, 874 f. XS 270

Tk 235 Chlamydephoros, stehend „samothracian type IV“ (Kopf)

FO: Samothrake, Südnekropole XS

AO: ? (Inv. 60.263, XS271)

H: 3,5

D: vielleicht 3. Jh. vor Chr.

Lit: Dusenbery, Samothrake, 874 f. XS271

Tk 236 Chlamydephoros, stehend „samothracian type IV“ (Kopf)

FO: Samothrake, Südnekropole XS

AO: ? (Inv. 63.SN.759, XS272)

H: 2,7

D: vielleicht 3. Jh. vor Chr.

Lit: Dusenbery, Samothrake, 874 f. XS272

Tk 237 Chlamydephoros, stehend „samothracian type IV“ (Kopf)

FO: Samothrake, Südnekropole XS

AO: ? (Inv. 60.265, XS273)

H: 2,5

D: vielleicht 3. Jh. vor Chr.

Lit: Dusenbery, Samothrake, 874 f. XS273

Tk 238 Kopf (Chlamydephoros ?)

FO: Samothrake, Südnekropole XS

AO: ? (Inv. 57.477, XS 274)

$\mathrm{H}: 2,7$

D: 3. Jh. vor Chr. ?

Lit: Dusenbery, Samothrake, 875 f. XS274

Tk 239 Kopf (Chlamydephoros ?)

FO: Samothrake, Südnekropole XS

AO: ? (Inv. 64.SN.060, XS275)

H: 3,5

D: 3. Jh. vor Chr. ?

Lit: Dusenbery, Samothrake, 876 XS275

\section{Samothrake, spätere Westnekropole}

Tk 240 Chlamydephoros, stehend, Kinn verhüllend/Hand am Kinn

FO: Samothrake, Deposit auf dem Gebiet der späteren Westnekropole

AO: ? (Inv. WT-1; WTD-1)

H: 11,4

D: $300-275$ vor $\mathrm{Chr}$.

Lit: Dusenbery, Samothrake, 495 WTD-1

Bemerk: Formgleich mit Tk 241. 
Tk 241 Chlamydephoros, stehend (ohne Kopf)

FO: Samothrake, Deposit auf dem Gebiet der späteren Westnekropole

AO: ? (Inv. WT-2; WTD-2)

H: 9,9

D: $300-275$ vor Chr.

Lit: Dusenbery, Samothrake, 495 WTD-2

Bemerk: Formgleich mit Tk 240.

Tk 242 Chlamydephoros, stehend (ohne Kopf, mit Kausia?)

„samothracian type I“"?

FO: Samothrake, Deposit auf dem Gebiet der späteren Westnekropole

AO: ? (Inv. WT-6, WTD-5)

H: 14,4 (ohne Kopf)

D: $300-275$ vor Chr.

Lit: Dusenbery, Samothrake, 495 ff. 497 ff. WTD5

Tk 243 Chlamydephoros, stehend (2 Frgte.)

FO: Samothrake, Deposit auf dem Gebiet der späteren Westnekropole

AO: ? (Inv. WT-5, WTD-4)

H: 5,9 und 8,5 (zwei Frgte., angeblich zusammengehörend)

D: $300-275$ vor Chr.

Lit: Dusenbery, Samothrake, 495 ff. WTD-4

\section{Samothrake, H -Nekropole}

Tk 244 Chlamydephoros, stehend

FO: Samothrake, H - Nekropole, Kindergrab H17 AO: ? (Inv. 55.85B, H17-3)

H: 12,9

D: $300-275$ vor Chr.

Lit: Chronique des Fouilles en 1955 - Macedoine orientale, Thrace, Samothrace (o. Verf.), BCH 80, 1956, 325 Abb. 6 (S. 321) .- Dusenbery, Samothrake, 457 ff (459) 866 H17-2-4
Tk 245 Chlamydephoros, stehend

FO: Samothrake, H - Nekropole, Kindergrab H17

AO: ? (Inv. 55.85C, H17-4)

H: 12,9

D: $300-275$ vor $\mathrm{Chr}$.

Lit: Dusenbery, Samothrake, 457 ff (459) 866 H17-2-4 .- Vgl. auch: Chronique des Fouilles en 1955 - Macedoine orientale, Thrace, Samothrace (o. Verf.), BCH 80, 1956, 325 Abb. 6 (S. 321).

Tk 246 Chlamydephoros, stehend FO: Samothrake, H - Nekropole, Kindergrab H17 AO: ? (Inv. 55.85A, H17-2)

H: 12,9

D: $300-275$ vor Chr.

Lit: Chronique des Fouilles en 1955 - Macedoine orientale, Thrace, Samothrace (o. Verf.), BCH 80, 1956, 325 Abb. 6 (S. 321) .- Dusenbery, Samothrake, 457 ff (459) 866 H17-2-4

Tk 247 Chlamydephoros, stehend „samothracian type I“ (Oberkörperfrgt.)

FO: Samothrake, H - Nekropole (außerhalb von Grab H17)

AO: ? (Inv. 55.100, H17 I)

H: 5

D: $300-275$ vor $\mathrm{Chr}$.

Lit: Dusenbery, Samothrake, 461 H17 I

\section{Samothrake, unterer Hangbereich zwischen Stadt und Heiligtum}

Tk 248 x mehrere Köpfe

(Chlamydephoroi, stehend?)

FO: Samothrake, östlich des Vorhofes des Propylons, vom Hang zwischen Stadt und Heiligtum der Großen Götter herabgerutscht

AO: ? (Inv. 63. 267D)

$\mathrm{H}:-$

D: hell.* 
Lit: J. R. McCredie, Hesperia 34, 1965, 120 f. Taf. $38 \mathrm{c}$

Tk 249 Kopf, Kinn verhüllend (Chlamydephoros) FO: Samothrake

AO: Paris (Louvre, CA 4562)

H: 6

D: hellenistisch

Lit: Besques, Paris III-I, 117. D 756 Taf. 144

Bemerk: Von S. Besques ursprünglich der Aiolis zugewiesen.

Tk 250 Oberkörperfragment, Kinn verhüllend (Chlamydephoros)

FO: Samothrake

AO: Paris (Louvre, CA 4562)

H: 7.1

D: M. 2. Jh. vor Chr.

Lit: Besques, Paris III-I, 117. D 757 Taf. 144 h

Bemerk: Von S. Besques ursprünglich der Aiolis zugewiesen.

Tk 251 Kopf, Kinn verhüllend (Chlamydephoros) FO: Samothrake

AO: Paris (Louvre, CA 4561)

H: 5

D: 1. H. 2. Jh. vor Chr.

Lit: Besques, Paris III-I, 117.D 758 Taf. 144 g

Bemerk: Von S. Besques ursprünglich der Aiolis zugewiesen.

Tk 252 Kopf, Kinn verhüllend (Chlamydephoros)

FO: Samothrake

AO: Paris (Louvre, CA 4567 bis)

H: 4,2

D: 2. H. 2. Jh. vor Chr.

Lit: Besques, Paris III-I, 117. D 760 Taf. 145 a

Bemerk: Von S. Besques ursprünglich der Aiolis zugewiesen.
Tk 253 Kopf, Kinn verhüllend (Chlamydephoros)

FO: Samothrake

AO: Paris (Louvre, CA 4567)

H: 4,2

D: M. 2. Jh. vor Chr.

Lit: Besques, Paris III-I, 117.D 759 Taf. 144 j

Bemerk: Von S. Besques ursprünglich der Aiolis zugewiesen.

Tk 254 Kopf, Kinn verhüllend (Chlamydephoros) FO: Samothrake

AO: Paris (Louvre, CA 4575)

H: 3,1

D: A. 2. Jh. vor Chr.

Lit: Besques, Paris III-I, 118.D 772 Taf. 146 d

Bemerk: Von S. Besques ursprünglich der Aiolis zugewiesen.

Tk 255 Kopf, Kinn verhüllend (Chlamydephoros) FO: Samothrake

AO: Paris (Louvre, CA 4584)

H: 4

D: hell.*

Lit: Besques, Paris III-I, 118. D 773 Taf. 146 f

Bemerk: Von S. Besques ursprünglich der Aiolis zugewiesen.

Tk 256 Kopf, Kinn verhüllend (Chlamydephoros) FO: Samothrake

AO: Paris (Louvre, CA 4573)

H: 3,8

D: hell.*

Lit: Besques, Paris III-I, 118. D 774 Taf. 146 g

Bemerk: Von S. Besques ursprünglich der Aiolis zugewiesen.

Tk 257 Kopf, Kinn verhüllend (Chlamydephoros) FO: Samothrake

AO: Paris (Louvre, CA 4582) 
H: 4,1

D: hell.*

Lit: Besques, Paris III-I, 118 D 775 (o. Abb.)

Bemerk: Von S. Besques ursprünglich der Aiolis zugewiesen.

Tk 258 Kopf, Kinn verhüllend (Chlamydephoros) (Abb. 92)

FO: Samothrake

AO: Paris (Louvre, CA 4564)

H: 4,2

D: hell.*

Lit: Besques, Paris III-I, 119 D 776 Taf. 146 h

Bemerk: Von S. Besques ursprünglich der Aiolis zugewiesen.

Tk 259 Kopf, Kinn verhüllend (Chlamydephoros)

FO: Samothrake

AO: Paris (Louvre, CA 4883)

H: 4,2

D: hell.*

Lit: Besques, Paris III-I, 119 D 777 (o. Abb.)

Bemerk: Von S. Besques ursprünglich der Aiolis zugewiesen.

TK 260 Kopf, Kinn verhüllend (Chlamydephoros) FO: Samothrake

AO: Paris (Louvre, CA 4576)

H: 3,2

D: A. 2. Jh. vor Chr.

Lit: Besques, Paris III-I, 119.D 778 Taf. 146 i

Bemerk: Von S. Besques ursprünglich der Aiolis zugewiesen.

Tk 261 Kopf (Chlamydephoros)

FO: Samothrake

AO: Paris (Louvre, CA 4567 ter)

H: 4,1

D: M. 2. Jh. vor Chr.

Lit: Besques, Paris III-I, 117.D 761 Taf. 145 c
Bemerk: Von S. Besques ursprünglich der Aiolis zugewiesen.

Tk 262 Kopf (Chlamydephoros)

FO: Samothrake

AO: Paris (Louvre, CA 4570)

$\mathrm{H}: 3,5$

D: A. 2. Jh. vor Chr. / 3./2. Jh. vor Chr.*

Lit: Besques, Paris III-I, 118. D 771 Taf. 146 e

Bemerk: Von S. Besques ursprünglich der Aiolis zugewiesen.

Tk 263 Kopf (Chlamydephoros)

FO: Aiolis

AO: Paris (Louvre, CA 4578)

H: 3,5

D: E. 3. Jh. vor Chr. / 3./2. Jh. vor Chr.* Lit: Besques, Paris III-I, 119. D 779 Taf. 147 a

Bemerk: Von S. Besques ursprünglich der Aiolis zugewiesen.

TK 264 Kopf (Chlamydephoros)

FO: Samothrake

AO: Paris (Louvre, CA 4565)

H: 3,5

D: hell.*

Lit: Besques, Paris III-I, 119. D 780 Taf. 147 b

Bemerk: Von S. Besques ursprünglich der Aiolis zugewiesen.

Tk 265 Kopf

FO: Samothrake

AO: Paris (Louvre, CA 4558)

H: 4

D: hell.*

Lit: Besques, Paris III-I, 119.D 781 Taf. 147 c

Bemerk: Von S. Besques ursprünglich der Aiolis zugewiesen.

Tk 266 Kopf 
FO: Samothrake

AO: Paris (Louvre, CA 4569)

$\mathrm{H}: 4$

D: hell.*

Lit: Besques, Paris III-I, 119.D 782 Taf. 147 d

Bemerk: Von S. Besques ursprünglich der Aiolis zugewiesen.

Tk 267 Kopf

FO: Samothrake

AO: Paris (Louvre, CA 4601)

H: 2

D: hell.*

Lit: Besques, Paris III-I, 119.D 783 (o. Abb.)

Bemerk: Von S. Besques ursprünglich der Aiolis zugewiesen.

Tk 268 Kopf

FO: Samothrake

AO: Paris (Louvre, CA 4572)

H: 3,6

D: 2. H. 2. Jh. vor Chr.

Lit: Besques, Paris III-I, 119.D 784 Taf. 147 f

Bemerk: Von S. Besques ursprünglich der Aiolis zugewiesen.

Tk 269 Kopf

FO: Samothrake

AO: Paris (Louvre, CA 4571)

H: 3,5

D: 2. H. 2. Jh. vor Chr.

Lit: Besques, Paris III-I, 119.D 785 Taf. 147 e

Bemerk: Von S. Besques ursprünglich der Aiolis zugewiesen.

Tk 270 Kopf

FO: Samothrake

AO: Paris (Louvre, CA 4574)

H: 3,8

D: 2. H 2. Jh. vor Chr.
Lit: Besques, Paris III-I, 119.D 786 Taf. 147 g

Bemerk: Von S. Besques ursprünglich der Aiolis zugewiesen.

Tk 271 Kopf

FO: Samothrake

AO: Paris (Louvre, CA 4586)

$\mathrm{H}: 3,5$

D: 2. H. 2. Jh. vor Chr.

Lit: Besques, Paris III-I, 119.D 787 Taf. 147 h

Bemerk: Von S. Besques ursprünglich der Aiolis zugewiesen.

Tk 272 Kopf

FO: Samothrake

AO: Paris (Louvre, CA 4587)

$\mathrm{H}: 3,2$

D: A. 1. Jh. vor

Lit: Besques, Paris III-I, 119.D 788 Taf. 147 i

Bemerk: Von S. Besques ursprünglich der Aiolis zugewiesen.

Tk 273 Kopf

FO: Samothrake

AO: Paris (Louvre, CA 4585)

$\mathrm{H}: 3,5$

D: 2. H. 2. Jh. vor Chr.

Lit: Besques, Paris III-I, 119.D 789 Taf. 147 j

Bemerk: Von S. Besques ursprünglich der Aiolis zugewiesen.

Tk 274 Kopf

FO: Samothrake

AO: Paris (Louvre, CA 4560)

H: 3,7

D: A. 2. Jh. vor Chr.

Lit: Besques, Paris III-I, 120. D 790 Taf. 148 b

Bemerk: Von S. Besques ursprünglich der Aiolis zugewiesen. 
Tk 275 Kopf

FO: Samothrake

AO: Paris (Louvre, CA 4577)

H: 2,2

D: 1. H. 2. Jh. vor Chr.

Lit: Besques, Paris III-I, 120. D 791 Taf. 148 a

Bemerk: Von S. Besques ursprünglich der Aiolis zugewiesen.

Tk 276 Kopf

FO: Samothrake

AO: Paris (Louvre, CA 4579)

$\mathrm{H}: 3,5$

D: -

Lit: Besques, Paris III- I, 120. D 792 Taf. 148 c

Bemerk: Von S. Besques ursprünglich der Aiolis zugewiesen.

Tk 277 Kopf (Chlamydephoros, stehend)

„samothracian type I“

FO: Samothrake

AO: Paris (Louvre, CA 4547)

H: 5,2

D: A. 2. Jh. vor Chr. (Besques) / A. 3. Jh. vor Chr.

(Dusenbery)

Lit: Besques, Paris III-I, 120. D 793 Taf. 148 e

Bemerk: Von S. Besques ursprünglich der Aiolis zugewiesen. Vgl. zum „samothracian type I“ z.B. Tk 198.

Tk 278 Kopf (Chlamydephoros, stehend)

„samothracian type I“

FO: Samothrake

AO: Paris (Louvre, CA 4559)

H: 5,9

D: A. 2. Jh. vor Chr. (Besques) / A. 3. Jh. vor Chr.

(Dusenbery)

Lit: Besques, Paris III-I, 120. D 794 Taf. 148 d
Bemerk: Von S. Besques ursprünglich der Aiolis zugewiesen. Vgl. zum „samothracian type I“ z.B. Tk 205.

Tk 279 Kopf (Chlamydephoros, stehend)

„samothracian type I“"

FO: Samothrake

AO: Paris (Louvre, CA 4548)

H: 5,5

D: A. 2. Jh. vor Chr. (Besques) / A. 3. Jh. vor Chr. (Dusenbery)

Lit: Besques, Paris III-I, 120. D 795 Taf. 148 f

Bemerk: Von S. Besques ursprünglich der Aiolis zugewiesen. Vgl. zum „samothracian type I“ z.B. Tk 205

Tk 280 Kopf

FO: Samothrake

AO: Paris (Louvre, CA 4600)

H: 2,1

D: A. 2. Jh. vor Chr.

Lit: Besques, Paris III-I, 121. D 804 Taf. 1481

Bemerk: Von S. Besques ursprünglich der Aiolis zugewiesen.

Tk 281 x mindestens sieben Körperfragmente von Chlamydephoroi (jeweils ohne Kopf mit Kausia?)

FO: Samothrake

AO: Paris (Louvre, CA 4526, 4530, 4528, 4529, 4539, 4534, 4531)

H: -

D: hell.*

Lit: Besques, Paris III-I, 117 f. D 762, 763, 764, 765, 766, 769, 770 Taf. 145-146 
Griechische Poleis am westlichen Schwarzen Meer

\section{Odessos/Varna (Bulgarien)}

Tk 282 Chlamydephoros, schreitend (Abb. 97)

FO: Odessos/Varna (Werkstatt)

AO: Varna (Historical Museum, Arch. Dep. Nr. II 305)

H: 14,5

D: 2. Jh. vor Chr. / 3./2. Jh. vor Chr.*

Lit: S. Dremisizova, Anticni terakoti ot Bulgaria (1971) 66. 121 Nr. 83

Bemerk: Von S. Dremisizova als „Orator“ bezeichnet.

\section{Kallatis/Mangalia (Rumänien)}

Tk 283 Chlamydephoros, sitzend, Denkerpose

FO: Kallatis

AO: Bukarest (Slg. Dr. H. Slobozianu)

H: 7

D: hell.*

Lit: Canarache, Kallatis, 150 Nr. 208

Tk 284 Epheben-Soldat

FO: Kallatis

AO: Konstanza (Archäologisches Museum, Slg.

M. Mirea, Inv. 5342)

H: 24

D: E. 4. Jh. vor Chr.

Lit: V. Canarache, Kallatis, 129 Nr. 177

Bemerk: Formgleich mit Tk 292 (aus „Böotien, in Boston).

Tk 285 Chlamydephoros, stehend

FO: Kallatis

AO: Bukarest (Slg. Dr. H. Slobozianu)

H: 10 (Frgt., Unterschenkel fehlen)

D: 3./2. Jh. vor Chr.?*

Lit: Canarache, Kallatis, 149 Nr. 206
Tk 286 Oberkörperfragment

(Chlamydephoros, stehend?)

FO: Kallatis

AO: Bukarest (Slg. Prof. M. Herovanu)

H: 7

D: 3./2. Jh. vor Chr.?*

Lit: Canarache, Kallatis, 149 Nr. 207

TK 287 Kopf (mit Kausia?)

FO: Kallatis

AO: Konstanza (Archäologisches Museum, Inv. 15720)

H: 3

D: hell.?*

Lit: Canarache, Kallatis, 151 Nr. 210

TK 288 Kopf

FO: Kallatis

AO: Konstanza (Archäologisches Museum, Inv. 15719)

H: 3

D:3. Jh. vor Chr.?*

Lit: Canarache, Kallatis, 151 Nr. 211

Griechische Poleis (seit Chaironeia [338 v.

Chr.] unter makedonischer Kontrolle)

\section{Attika / Böotien}

Tk 289 Chlamydephoros, sitzend, entblößt

FO: Böotien (?)

AO: Leiden (Inv. I 1931/6.5.)

H: 20,4

D: E. 4.-A. 3. Jh. vor Chr.

Lit: Leyenaar-Plaisier, Leiden, 110 Nr. 222 Taf. 38

Tk 290 Chlamydephoros, sitzend, entblößt

FO: Tanagra

AO: Paris (Collection E. Piot 360) 
H: ca. 13

D: 4./3. Jh. vor Chr.*

Lit: Winter, Typen II, 259 Nr. 8

Bemerk: Zwei weitere oder ähnliche Exemplare in Athen und Würzburg, vgl. Winter, Typen II, 259 Nr. 8.

Tk 291 Form (Vorder- und Rückseite) für Chlamydephoros, sitzend, mit Chiton und Kausia

FO: Böotien/Tanagra

AO: Paris (Louvre, CA 631 (1894), D221)

$\mathrm{H}: 12$

M: gelbliche, leicht gebrannte Erde

D: A. 3. Jh. vor Chr.

Lit: Besques, Paris III-I,2 ; 40 Taf. 49 D221 .- Tanagra. Mythe et archeólogie, Ausstellung Paris/Montreal 2003/04, 175 Nr. 117

Tk 292 Epheben-Soldat (Abb. 98)

FO: Böotien

AO: Boston (MFA, 01.7807 [1910])

$\mathrm{H}: 23,3$

D: A. 3. Jh. vor Chr.

Lit: J. P. Uhlenbrock in: The Coroplast's Art. FS D. Burr-Thompson (1990) 116 Nr. 9

Bemerk: Formgleich mit Tk 284 (aus Kallatis, E. 4. Jh. vor Chr.).

Tk 293 Epheben-Soldat

FO: Böotien (?)

AO: München (Slg. Loeb)

$\mathrm{H}: 30,7$

D: E. 4. Jh. vor Chr.

Lit: J. Sieveking, Die Terrakotten der Sammlung Loeb, Bd. II. (1916) 1 Taf. 65

Bemerk: Kopf und Körper zusammengehörig?

Tk 294 Chlamydephoros, stehend, Kinn verhüllend

FO: (?) (Ton attisch)
AO: London (British Museum, Reg. no. 1906.1019.1)

H: 15,5

D: 340/30-250 vor Chr. / E. 4. Jh. vor Chr.*

Lit: R. Higgins, Greek Terracottas (1967) 100 Nr. 41 D .- Tanagra. Mythe et archeólogie, Ausstellung Paris/Montreal 2003/04, 223 Nr.162

Bemerk: Formgleich mit Tk 295 (aus Böotien/Attika, in New York) und Tk 188 (FO: Pydna).

Tk 295 Chlamydephoros, stehend, Kinn verhüllend

FO: böotisch ? (in Athen gekauft !)

AO: New York (Metropolitan Museum of Art, Acc. Nr. 06.1064)

H: 15,8

D: frühes 3. Jh. vor Chr. / E. 4. Jh. vor Chr.*

Lit: H. Rühfel, Das Kind in der griechischen Kunst (1984) 204 (mit Anm. 57). 205 (Abb.)

Bemerk: Formgleich mit Tk 294 (aus Böotien/Attika, in London) und Tk 188 (FO: Pydna).

Tk 296 Chlamydephoros, stehend, Kinn verhüllend

FO: Athen (?)

AO: Athen (Paul and Alexandra Canellopoulos Museum, 1234)

H: -

D: 3. Jh. vor Chr. / 4./3. Jh. vor Chr.*

Lit: M. Bouskari, The Paul and Alexandra Canellopoulos Museum (1985) 86. 89 (Abb.)

Tk 297 Chlamydephoros, stehend FO: Athen (Akropolis Museum, E 247)

$\mathrm{H}:$

D: 4./3. Jh. vor Chr.*

Lit: Burr-Thompson, Troy, 54 Anm. 143 (o. Abb.) Bemerk: D. Burr-Thompson (a.a.O.) verweist zu Aussehen und Datierung auf ein ähnliches Exemplar ohne Kausia aus Halae. Vgl. dazu: H. Gold- 
mann, F. Jones, Terracottas from the Necropolis of Halae, Hesperia 11, 1942, 365 ff. Taf. 24.V-j-g

Tk 298 Chlamydephoros, stehend, mit linkem Arm auf Säule gelehnt

FO: Böotien

AO: München (Slg. Loeb)

H: 21,5

D: 4./3. Jh. vor Chr.*

Lit: J. Sieveking, Die Terrakotten der Sammlung Loeb, Bd. II (1916) 1 Taf. 66

Tk 299 Junge, stehend, entblößt (Mantel über Schultern herabgerutscht), mit Kausia (?)

FO: Böotien ?

AO: Paris (Louvre, D 173)

H: 12

D: 1. H. 3. Jh. vor Chr.

Lit: Besques, Paris III-I, 32. D 173 Taf. 39f.

Tk 300 Junge, stehend, entblößt (Himation hinten über die Schultern herabfallend), Theatermaske in der rechten Hand, Kausia (?)

FO: böotisch

AO: Paris (Louvre, MNB 608 (1874), D 174)

H: 11

D: 1. H. 3. Jh. vor Chr.

Lit: Winter, Typen II, 288 Nr. 9.- Besques, Paris III-I, 32. D 174 Taf. 39 e

Bemerk: Identisch mit Athen, Kunsthandel, 1875

(vgl. Winter, Typen II, 288 Nr. 9) ?

\section{Chalkis (Euboia)}

Tk 301 Chlamydephoros, schreitend FO: Chalkis (Archaia Chalkis, Nekropole, Grab 4) AO: ? ( $\alpha \rho . \in \cup \rho .5718)$

H: 14,5

D: $250-200$ vor Chr. (?)
Lit: $\quad$ M. Salliora-Oikonomakou, T $\mu \eta \dot{\mu} \mu \alpha$

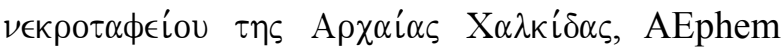
138, 1999, 219-239 bes. 224 f. Abb. 4

\section{Delos}

Tk 302 Oberkörperfragment

(Chlamydephoros, stehend?)

FO: Delos (östlich vom Kabirion)

AO: ? (A 2317)

$\mathrm{H}: 4,5$

D: 1.-2. Jh. nach Chr.?*

Lit: A. Laumonier, Delos XXIII (1956) 178 Nr. 591 Taf. 58

Bemerk: Zur Datierung vgl. Tk 152 ff. (,südliche Aiolis").

Tk 303 Kopf (Chlamydephoros ?)

FO: Delos

AO: ? (A 3741)

$\mathrm{H}: 3,3$

D: 1.-2. Jh. nach Chr.?*

Lit: A. Laumonier, Delos XXIII (1956) 218 Nr. 876 Taf. 77

Bemerk: Zur Datierung vgl. Tk 152 ff. (,südliche Aiolis“).

Tk 304 Kopf, bärtig (Abb. 156)

FO: ? (Delos ?)

AO: Mykonos (Museum, A 3701)

H: 3

D: -

Lit: A. Laumonier, Delos XXIII (1956) 264 Nr. 1229 Taf. 93

\section{Korinth}

Tk 305 Reiter ohne Gegner (mit Kausia?)

FO: Korinth, Deposit VI (Agora, Südstoa)

AO: Korinth (Museum)

H: 7,7 (ohne Pferdebeine)

D: ca. 250-220 vor Chr. 
Lit: G. Davidson, A Hellenistic Deposit at Corinth, Hesperia 11, 1942, 105 ff. Abb. 3. 12 .- R. Higgins, Tanagra und the Figurines (1967) 104 Nr./Taf. 47 D

Tk 306 Reiter ohne Gegner (ohne Kopf)

FO: Korinth, Deposit VI (Agora, Südstoa)

AO: Korinth (Museum)

H: 8,2 (ohne Kopf des Reiters)

D: ca. 250-220 vor Chr.

Lit: G. Davidson, A Hellenistic Deposit at Corinth, Hesperia 11, 1942, 105 ff. Abb. 3. 12 .- R. Higgins, Tanagra und the Figurines (1967) 104 Nr./Taf. 47 E

\section{Königlich-makedonische Stadtgründungen in Nordgriechenland}

\section{Demetrias}

Tk 307 Chlamydephoros, stehend, Kinn verhüllend

„Typus A nach K. Hornung-Bertemes“

FO: Demetrias, Pasikrata-Heiligtum

AO: Volos (M 2014)

H: ca. 15,5

D: 1. H. 3. Jh. vor Chr.

Lit: Arvanitopoulos, Demetrias, 46 Abb. 53 (1. Reihe, 4. von links) .- Hornung-Bertemes, Demetrias, $182 \mathrm{ff}$. Abb. 2 li.

Tk 308 Chlamydephoros, stehend, Kinn verhüllend

„Typus A nach K. Hornung-Bertemes“

FO: Demetrias, Höhe 35, Bothros/Favissa (Demeter-Heiligtum?)

AO: Volos (Depot der dt. Grabung 4/19/20/21)

H: ca. 15,8

D: 1. H. 3. Jh. vor Chr.
Lit: Hornung-Bertemes, Demetrias, 182 ff. Abb. 2 (Mitte)

Bemerk: Vom gleichen Fundort stammen insgesamt sechs Chlamydephoren, davon zwei vom „Typus A“ und vier vom „Typus B“ (Vgl. Hornung-Bertemes, Demetrias, 186 f. 205 Abb. 5 [Säulendiagramm].).

Tk 309 Chlamydephoros, stehend, Kinn verhüllend

„Typus A nach K. Hornung-Bertemes“

FO: Demetrias, „Agria“ (südl. von Goritza)

AO: Volos (M 5680 VI)

H: ca. 15,5

D: 1. H. 3. Jh. vor Chr.

Lit: Hornung-Bertemes, Demetrias, 182 ff. Abb. 2 (re.)

Tk 310 Chlamydephoros, stehend „Typus B nach K. Hornung-Bertemes“

FO: Demetrias

AO: Volos (M 2018)

H: ca. 13,8

D: 2. H. 3. Jh. vor Chr.

Lit: Hornung-Bertemes, Demetrias, 182 ff. Abb. 3

Tk 311 Chlamydephoros, stehend „Typus B nach K. Hornung-Bertemes“

FO: Demetrias

AO: Volos (M 5678 XXXIX)

H: ca. 14,2

D: 2. H. 3. Jh. vor Chr.

Lit: Hornung-Bertemes, Demetrias, 182 ff. Abb. 3 (2. v. li.)

Tk 312 Chlamydephoros, stehend „Typus B nach K. Hornung-Bertemes“

FO: Demetrias

AO: Volos (M 5678 XXXVIII) 
H: ca. 14

D: 2. H. 3. Jh. vor Chr.

Lit: Hornung-Bertemes, Demetrias, 182 ff. Abb. 3

(3. v. 1i.)

Tk 313 Chlamydephoros, stehend „Typus B nach K. Hornung-Bertemes“،

FO: Demetrias

AO: Volos (M 5678 XL)

H: ca. 14,2

D: 2. H. 3. Jh. vor Chr.

Lit: Hornung-Bertemes, Demetrias, 182 ff. Abb. 3 (re.)

Tk 314 Körperfragment

(Chlamydephoros, stehend) „Typus B nach K. Hornung-Bertemes“،

FO: Demetrias, aus Fundamentierung des Anaktorons (= makedonischer Königspalast?)

AO: Volos

H: ca. 5,5 (Frgt.)

D: 2. H. 3. Jh. vor Chr.

Lit: Hornung-Bertemes, Demetrias, 182 ff. Abb. 1

Tk 315 Chlamydephoros, stehend „Typus B nach K. Hornung-Bertemes“

FO: Demetrias

AO: Volos

$\mathrm{H}:-$

D: 2. H. 3. Jh. vor Chr.

Lit: G. Hourmouziadis (u.a.), Magnesia (1982) 90 Abb. 59

Bemerk: Vielleicht identisch mit Tk 310.

Tk 316a-r 18 Statuetten vom Typus Chlamydephoros, stehend

„Typus B nach K. Hornung-Bertemes“

FO: Demetrias (Pasikrata-Heiligtum?)

AO: Volos

$\mathrm{H}:-$
D: 2. H. 3. Jh. vor Chr.

Lit: Arvanitopoulos, Demetrias, 46 Abb. 52 (3. Reihe, 15. von links) Abb. 53 (2. Reihe, 1.-5. v. 1.; 3. Reihe, 1.-5, 7.-17) Abb. 54

Bemerk: Die Statuetten sind nur in einer Größe von ca. $1 \mathrm{~cm}$ abgebildet. Details sind nicht erkennbar.

Tk 317 Chlamydephoros, stehend „Typus C nach K. Hornung-Bertemes“

FO: Demetrias

AO: Volos (M 2016)

H: ca. 16,5

D: um 200 vor Chr.

Lit: Hornung-Bertemes, Demetrias, 182 ff. Abb. 4

Tk 318 Chlamydephoros, stehend „Typus C nach K. Hornung-Bertemes“ FO: Demetrias, Pasikrata-Heiligtum

AO: Volos (M 2022)

H: ca. 16,2

D: um 200 vor Chr.

Lit: Hornung-Bertemes, Demetrias, 182 ff. Abb. 4

Tk 319 Chlamydephoros, stehend „Typus C nach K. Hornung-Bertemes“

FO: Demetrias, Pasikrata-Heiligtum

AO: Volos (M 2013)

H: ca. 15,6

D: um 200 vor

Lit: Hornung-Bertemes, Demetrias, 182 ff. Abb. 4

Tk 320 Chlamydephoros, stehend „Typus C nach K. Hornung-Bertemes“

FO: Demetrias

AO: Volos (Museum)

$\mathrm{H}:-$

D: um 200 vor

Lit: G. Hourmouziadis (u.a.), Magnesia (1982) 90 Abb. 59 
Tk 321a-h acht Statuetten vom Typus Chlamydephoros, stehend

„Typus C nach K. Hornung-Bertemes“

FO: Demetrias (Pasikrata-Heiligtum?)

AO: Volos

H: -

D: um 200 vor Chr.

Lit: Arvanitopoulos, Demetrias, 46 Abb. 52 (3. Reihe, 2., 5., 16. v. li.) Abb. 53 (1. Reihe, 5. v. 1i.; 3. Reihe, 1.-4. v. li.)

Bemerk: Weitere 10 Figuren (Arvanitopoulos, Demetrias, 46 Abb. 53 [1. Reihe, 3., 6.-14. v. li.]) gehören ebenfalls dem „Typus $\mathrm{C}$ nach Hornung-Bertemes" an. Auf Grund der schlechten Abbildungsqualität und der geringen Größe der Abbildungen (ca. $1 \mathrm{~cm}$ ) lässt sich nicht entscheiden, ob diese Kausia tragen.

Tk 322 Chlamydephoros, stehend, mit Syrinx in re. Hand (?)

FO: Demetrias, Höhe 35, Bothros/Favissa (Demeter-Heiligtum?)

AO: -

H: ca. 16

D: hell. / 3./2. Jh. vor Chr.*

Lit: V. Milojcic, Bericht über die deutschen archäologischen Ausgrabungen in Thessalien, ADelt 28B`2, 1973, 347 f. Taf. 309c .- J.-P. Michaud, Chronique, BCH 97, 1973, 335 Abb. 176 f. (S.338)

Tk 323 Chlamydephoros, stehend, mit Syrinx in re. Hand (Abb. 94)

FO: Demetrias, Höhe 35, Bothros/Favissa (Demeter-Heiligtum?)

AO: -

H: ca. 17

D: 2. H. 3. Jh. vor Chr. / 3.-2. Jh. vor Chr.*
Lit: V. Milojcic, Bericht über die deutschen archäologischen Ausgrabungen in Thessalien, ADelt 28B'2, 1973, 347 f. Taf. 309c .- J.-P. Michaud, Chronique, BCH 97, 1973, 335 Abb. 178 (S. 338)

Tk 324 Chlamydephoros, stehend, mit Wurfholz in re. Hand (Abb. 94)

FO: Demetrias, Höhe 35, Bothros/Favissa (Demeter-Heiligtum?)

AO: -

H: -

D: 3.-2. Jh. vor Chr.*

Lit: V. Milojcic, Bericht über die deutschen archäologischen Ausgrabungen in Thessalien, ADelt 28B`2, 1973, 347 f. Taf. 309c .- J.-P. Michaud, Chronique, BCH 97, 1973, 335 Abb. 176 (S.338)

Bemerk: Bei der Abb. handelt es sich um ein Grabungsfoto mit mehreren, sehr klein abgebildeten Figuren in Fundlage/teilweise von Erde bedeckt.

Tk 325 Oberkörperfragment (ohne Kopf)

Chlamydephoros, stehend, mit Syrinx (?) und Wurfholz in re. Hand (Abb. 96)

FO: Demetrias, Höhe 35, Bothros/Favissa (Demeter-Heiligtum?)

AO: -

$\mathrm{H}:-$

D: 3.-2. Jh. vor*

Lit: V. Milojcic, Bericht über die deutschen archäologischen Ausgrabungen in Thessalien, ADelt 28B'2, 1973, 347 f. Taf. 309c .- J.-P. Michaud, Chronique, BCH 97, 1973, 335 Abb. 176 (S.338)

Bemerk: Bei der Abb. handelt es sich um ein Grabungsfoto mit mehreren, sehr klein abgebildeten Figuren in Fundlage/teilweise von Erde bedeckt. 
Tk 326a-e (?) ca. fünf Fragmente von Chlamydephoroi (teils mit Syrinx oder Lagobolon?)

FO: Demetrias, Höhe 35, Bothros/Favissa (Demeter-Heiligtum?)

AO: -

$\mathrm{H}:-$

D: 3.-2. Jh. vor Chr.*

Lit: V. Milojcic, Bericht über die deutschen archäologischen Ausgrabungen in Thessalien, ADelt 28B`2, 1973, 347 f. Taf. 309c .- J.-P. Michaud, Chronique, BCH 97, 1973, 335 Abb. 176 (S.338)

Bemerk: Bei der Abb. handelt es sich um ein Grabungsfoto mit mehreren, sehr klein abgebildeten Figuren in Fundlage/teilweise von Erde bedeckt. Zwei der mindestens fünf Statuetten könnten identisch sein mit Tk 322 und 323.

Tk 327 Knabe in Mantel (Chlamys?) am Rücken herabhängend, ohne Chiton

FO: Demetrias (Pasikrata-Heiligtum?)

AO: Volos

H: -

D: 4./3. Jh. vor Chr.

Lit: A. S. Arvanitopoulos, Prakt 1912, 204 Abb. 16 .- Arvanitopoulos, Demetrias, 46 Abb. 53 (2. Reihe, 6. von links)

Bemerk: Die Statuetten sind nur in einer Größe von ca. $1 \mathrm{~cm}$ abgebildet. Details sind nicht erkennbar.

Tk 328 Chlamydephoros, schreitend,

Chlamys über Schultern zurückgeschlagen, ohne Chiton

FO: Demetrias (Pasikrata-Heiligtum?)

AO: Volos (Museum)

$\mathrm{H}:-$

D: 4.-2. Jh. vor Chr.*
Lit: Arvanitopoulos, Demetrias, 46 Abb. 52 (3. Reihe, 6. von links) $=47$ Abb. 55 b (2. Reihe, 5. v. 1.)

Bemerk: Die Statuetten sind nur in einer Größe von ca. $1 \mathrm{~cm}$ abgebildet. Details sind nicht erkennbar.

Tk 329a-j zehn Fragmente von Chlamydephoroi

FO: Demetrias (Pasikrata-Heiligtum?)

AO: Volos (Museum)

$\mathrm{H}:-$

D: 4.-2. Jh. vor Chr.*

Lit: Arvanitopoulos, Demetrias, 46 Abb. 52 (3. Reihe, 9. v. li.; 4. Reihe, 2.-4., 9.-10., 12., 14.-15., 18. v. 1.)

Bemerk: Die Statuetten sind nur in einer Größe von ca. $1 \mathrm{~cm}$ abgebildet. Details sind nicht erkennbar.

\section{Thessaloniki-Gephyra}

Tk 330 Chlamydephoros, stehend FO: Gephyra (20 km westl. v. Thessaloniki), Grab AO: Thessaloniki (M $\Theta$ 1639)

H: 15,6

D: um Chr. Geb. / 3.-1. Jh. vor Chr.*

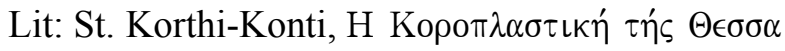

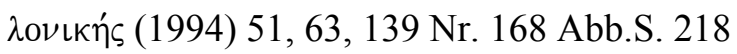

Bemerk: Ton aus Thessaloniki (St. Korthi-Konti ebenda)

Tk 331 Chlamydephoros, stehend (ohne Kopf, Kausia?)

FO: Gephyra (20 km westl. v. Thessaloniki),Grab

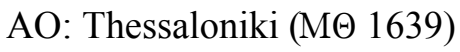

H: 12,5 (ohne Kopf)

D: um Chr. Geb. / 3.-1. Jh. vor Chr.*

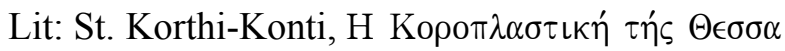

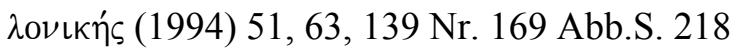


Bemerk: Ton aus Thessaloniki (St. Korthi-Konti ebenda) .- St. Korthi-Konti bildet S. 219 Nr. 177178 (= Katalog-Nr. 186-87?) zwei weitere Chlamydephoroi ohne Kopf ab (FO: unbekannt; AO:

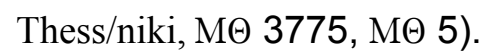

Tk 332 Oberkörperfragment (Chlamydephoros)

FO: Gephyra (20 km westl. v. Thessaloniki), Grab AO: Thessaloniki (M@ 1641)

H: 9

D: um Chr. Geb. / 3.-2. Jh. vor Chr.*

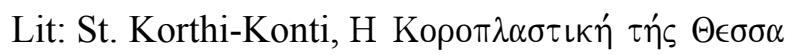

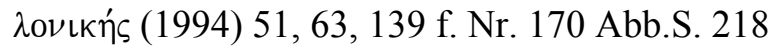

Bemerk: Ton aus Thessaloniki (St. Korthi-Konti ebenda)

Tk 333 Oberkörperfragment (Chlamydephoros)

FO: Gephyra (20 km westl. v. Thessaloniki), Grab

AO: Thessaloniki (M@ 1642)

H: 7,5

D: um Chr. Geb. / 3.-2. Jh. vor Chr.*

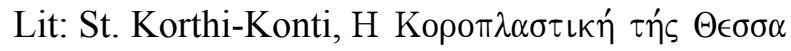

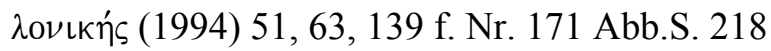

Bemerk: Ton aus Thessaloniki (St. Korthi-Konti ebenda)

\section{Kassandreia / Poteidaia}

Tk 334 Chlamydephoros, Kinn verhüllend (?), Kopf geneigt, auf Felsenpfeiler gelehnt

FO: Kassandreia (nahe makedonischem Grab)

AO: Thessaloniki (Museum, Saal 9, Vitrine 29,

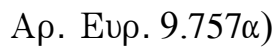

H: 14

D: E. 4. Jh. vor Chr.

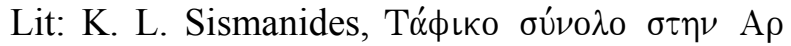
$\chi \alpha i \alpha$ K $\alpha \sigma \sigma \alpha \alpha \nu \delta \rho \in i \alpha$, in: Etaireia Makedonikon Spoudon, Parartema Makedonikon 6 (Mneme Manole Andronikou) (1997) 313. 320 Abb. 34

\section{Bosporanisches Reich}

\section{Pantikapaion / Kertsch (Krim)}

Tk 335 Chlamydephoros, sitzend, entblößt

FO: Pantikapaion (Mithridatesberg)

AO: St. Petersburg (Ermitage, Kertschsaal 908 B)

H: 12-13

D: 3. Jh. vor Chr.

Lit: Winter, Typen II, 259, 10 .- Swod Archeologi ceskij Istocinkow (SAI), Archeologia SSSR, G 111, Terrakotorye statuétki IV: Pridonje i Tamanskij Polystrov (1974) 26 Nr. 57 Taf. 26, 2

Tk 336 Knabe, hockend, in Chlamys, ohne Chiton, auf hoher Rundbasis (Abb. 137)

FO: Pantikapaion

AO: Paris (Louvre, CA 2294 [1920], D322)

H: 13

D: späthellenistisch

Lit: Besques, Paris III-I, 2, 58 Taf. 69, d D322

Tk 337 Eros (mit Kausia) und Psyche (Abb. 149) sich küssend, beide weitgehend nackt und mit Flügeln

FO: Pantikapaion

AO: -

H: 13,1

D: 2.-1. Jh. vor Chr.

Lit: Swod Archeologiceskij Istocinkow (SAI), Archeologia SSSR, G 1-11, Terrakotorye statuétki III: Pantikapei (1974) 30 Nr. 147 Taf. 33, 1

Tk 338 Eros und Psyche (Abb. 1509

sich küssend, beide mit Kausia und Flügeln (Oberkörperfrgt.)

FO: Myrmekon (bei Pantikapaion/Kertsch)

AO: -

H: 6,5

D: 1. Jh. vor Chr. 
Lit: Swod Archeologiceskij Istocinkow (SAI), Archeologia SSSR, G 1-11, Terrakotorye statuétki I/II: Schwarzmeerküste (1970) 99 Nr. 28 Taf. 45, 4

Tk 339 Paar ohne Flügel (Abb. 151)

beide mit Kausia (?), Mann (Eros?) nackt, Frau (Psyche?) bekleidet

FO: Kertsch

AO: Odessa (Museum)

H: 12,3

D: 1. Jh. vor Chr.

Lit: Winter, Typen II, 228, 7 .- Swod Archeologiceskij Istocinkow (SAI), Archeologia SSSR, G 111, Terrakotorye statuétki IV: Pridonje i Tamanskij Polystrov (1974) 48 Nr. 28 Taf. 54, 3

Bemerk: Formgleich mit Tk 340 (Frgt.).

Tk 340 Fragment (formgleich mit Tk 339: „Eros“ nackt, „Psyche“ bekleidet) eines Paars ohne Flügel mit Kausia (?),

FO: Pantikapaion

AO: Odessa (Museum)

H: 12-13

D: 1. Jh. vor Chr.

Lit: Swod Archeologiceskij Istocinkow (SAI), Archeologia SSSR, G 1-11, Terrakotorye statuétki IV: Pridonje i Tamanskij Polystrov (1974) 29 Nr. 92 Taf. 32,6

Tk 341 Knabe mit zurückgeschlagener Chlamys, ohne Chiton, mit Leier, im Damensitz auf Delphin reitend

FO: Pantikapaion

AO: Odessa (Museum)

H: 15

D: 1. Jh. vor Chr. - 1. Jh. nach Chr.

Lit: Winter, Typen II, 311, 6 .- Swod Archeologiceskij Istocinkow (SAI), Archeologia SSSR, G 1-
11, Terrakotorye statuétki III: Pantikapei (1974) 29 Nr. 138 Taf. 31, 4

Tk 342 Knabe in Chlamys, ohne Chiton, nach links laufend, ihm nach ein Hund

FO: Pantikapaion (Mithridatesberg, Katakombe)

AO: St. Petersburg (Ermitage, Kertschsaal 866 B)

H: 8,5

D: 2.-1. Jh. vor Chr.

Lit: Winter, Typen II, 259 Nr. 10 .- Swod Archeologiceskij Istocinkow (SAI), Archeologia SSSR, G 1-11, Terrakotorye statuétki III: Pantikapei (1974) 32 Nr. 171 Taf. 38, 4

\section{Chersonesos / Sewastopol (Krim)}

Tk 343 Reiter ohne Gegner

FO: Chersonesos

AO: -

$\mathrm{H}: 13-14$

D: 2. Jh. vor Chr.

Lit: Swod Archeologiceskij Istocinkow (SAI), Archeologia SSSR, G 1-11, Terrakotvrye statuétki I/II: Schwarzmeerküste (1970) 76 Nr. 48 Taf. 16, 1

\section{Phanagoria (Tamanhalbinsel)}

Tk 344 Paar (Eros und Psyche ?), sich küssend, ohne Flügel und weitgehend unbekleidet, linke Person mit Kausia (?)

FO: Tamanhalbinsel

AO: St. Petersburg (Ermitage, Kertschsaal 882B)

H: 20 / 10 ?

D: 1. Jh. vor Chr.

Lit: Winter, Typen II, 228, 2c .- Swod Archeologiceskij Istocinkow (SAI), Archeologia SSSR, G 1-11, Terrakotvrye statuétki IV: Pridonje i Tamanskij Polystrov (1974) 28f.Nr. 90 Taf. 32, 4

Tk 345 nackter Eros (Flügel) mit Gans/Schwan (?) spielend, mit Kausia (?) 
FO: Phanagoria

AO: -

$\mathrm{H}: 7$

D: 1. Jh. vor Chr.

Lit: Swod Archeologiceskij Istocinkow (SAI), Archeologia SSSR, G 1-11, Terrakotvrye statuétki IV: Pridonje i Tamanskij Polystrov (1974) $28 \mathrm{Nr}$. 84 Taf. 31,4

\section{Westen}

\section{Süditalien allg.}

Tk 346 Chlamydephoros, stehend, Epheben-Soldat

FO: Italien / „westgriechisch“

AO: Karlsruhe (Badisches Landesmuseum, B 395 [1835 erworben])

$\mathrm{H}: 10,5$

D: 1. Jh. vor Chr. ?

Lit: Schürmann, Karlsruhe, 224 Nr. 816 Taf. 138

Tk 347 Kopf

FO: Süditalien

AO: Paris (Louvre, CA 3999)

$\mathrm{H}: 3$

D: 3. Jh. vor Chr.

Lit: Besques, Paris IV-I, 122.D 3999 Taf. 118 i

\section{Rom}

Tk 348 Chlamydephoros, stehend, entblößt (Frgt.) (Abb. 145)

FO: Rom, Palatin, Kybele-Attis-Heiligtum

AO: Rom (Antiquarium, Inv. 9187)

H: 8,6 (ohne Beine)

D: hell. (terminus post quem: 191 vor Chr.)

Lit: M. J. Vermaseren, Corpus Cultus Cybelae Attidisque, CCCA III. Italia-Latium (1977) 14 Nr. 36 Taf. 37
Tk 349 Chlamydephoros (?), stehend, entblößt, mit Syrinx in re. Hand (Abb. 146)

FO: Rom, Palatin, Kybele-Attis-Heiligtum

AO: Rom (Antiquarium, Inv. 9186)

H: 13,7 (ohne Füße)

D: hell. (terminus post quem: 191 vor Chr.)

Lit: M. J. Vermaseren, Corpus Cultus Cybelae Attidisque, CCCA III. Italia-Latium (1977) $14 \mathrm{Nr}$. 35 Taf. 36

Tk 350 Chlamydephoros (?), stehend, entblößt, mit Syrinx in re. Hand (Oberkörperfrgt.)

FO: Rom, Palatin, Kybele-Attis-Heiligtum

AO: Rom (Antiquarium, Inv. 9207)

H: 9 (Frgt.)

D: hell. (terminus post quem: 191 vor Chr.)

Lit: M. J. Vermaseren, Corpus Cultus Cybelae Attidisque, CCCA III. Italia-Latium (1977) 18 Nr.

56 Taf. 47

Tk 351 Chlamydephoros (?), stehend, entblößt, mit Syrinx in re. Hand (Oberkörperfrgt.)

FO: Rom, Palatin, Kybele-Attis-Heiligtum

AO: Rom (Antiquarium, Inv. 9210)

H: 7 (Frgt.)

D: hell. (terminus post quem: 191 vor Chr.)

Lit: M. J. Vermaseren, Corpus Cultus Cybelae Attidisque, CCCA III. Italia-Latium (1977) 14 Nr. 36 Taf. 37

Tk 352 Chlamydephoros (?), entblößt, mit Syrinx in re. Hand (Oberkörperfrgt.)

FO: Rom, Palatin, Kybele-Attis-Heiligtum

AO: Rom (Palatinmuseum, Magazin, Grabung Boni)

$\mathrm{H}$ :

D: hell. (terminus post quem: 191 vor Chr.)

Lit: M. J. Vermaseren, Corpus Cultus Cybelae Attidisque, CCCA III. Italia-Latium (1977) $11 \mathrm{Nr}$. 13 Taf. 24 


\section{Capua}

Tk 353 Chlamydephoros, sitzend

FO: Capua

AO: Paris (Louvre, CA 6592, aus Coll.

Campana?)

H: 4,7

D: 1. h. 3. Jh. vor Chr.

Lit: Besques, Paris IV-I, 63 Taf. 54, d D 3640

Tk 354 Paar sich umarmend (Eros und Psyche ohne Flügel/Soldat und Hetäre?), Mann im „Typus Epheben-Soldat“

FO: Capua

AO: Berlin (Antiquarium, 7360)

H: 14,5

D: 3. Jh. vor Chr.?*

Lit: Winter, Typen II, 230, 10

Bemerk: Formgleich mit Tk 355.

Tk 355 Paar sich umarmend (Abb. 153)

Eros und Psyche ohne Flügel? Soldat und Hetäre?

Mann im „Typus Epheben-Soldat“

FO: unbekannt / Capua*

AO: Madrid (Slg. Salamanca, 3362)

H: 14

D: hellenistisch / 3. Jh. vor Chr.?*

Lit: A. Laumonier, Catalogue de Terres Cuites du Musée Archeologique de Madrid (1921) 166 Nr. 785 Taf. 85,1

Bemerk: Formgleich mit Tk 354 (aus Capua).

Tk 356 Paar (sich umarmend) (Abb. 152)

Mann im Typus Chlamydephoros, stehend

FO: unbekannt / Capua ?*

AO: Madrid (Slg. Salamanca, 3361)

H: 16

D: hellenistisch / 3. Jh. vor Chr.?*

Lit: A. Laumonier, Catalogue de Terres Cuites du Musée Archeologique de Madrid (1921) 166 Nr.

786 Taf. 85,3
Bemerk: „FO: Capua?*“, da wie Tk 355 (Capua) aus Slg. Salamanca und da Typus Paar sonst nur selten vorkommt (vgl. Tk 431: Paar, „Eros“ im Typus Chlamydephoros [aus Nippur in Mesopotamien]; weitgehend nackte Eros-und-Psyche-Paare finden sich im Bereich des Bosporanischen Reiches: Tk 338-340 [Pantikapaion], Tk 344 [Tamanhalbinsel]).

Tk 357 Knabe im Mantel (herabhängend am Rücken), entblößt, auf Syrinx spielend (Abb. 144) FO: Capua (?)

AO: Paris (Louvre, Cp. $4684=$ Coll. Campana 222)

H: 11,2

D. 2. Jh. vor Chr.

Lit: Winter, Typen II, 289, 12 .- Besques, Paris IVI, 61 Taf. 52, f D 3629

\section{Poseidonia / Paestum}

Tk 358 Knabe in Chlamys, entblößt, rechts hinter diesem ein Baumstumpf (Abb. 143)

FO: Poseidonia/Paestum

AO: ? (Inv. 134753)

H: 11

D: E. 4.- A. 3. Jh. vor Chr.

Lit: M. Cipriani/F. Longo (Hrsgg.), Poseidonia e i Lucani (Ausstellungskatalog Paestum) (1996) 240 Nr. 176.13

\section{Tarent}

Tk 359 Soldat, Chlamys nicht zurückgeschlagen, Schwert in der li. Hand (Abb. 108)

FO: Tarent

AO: Paris (Louvre, MNB 2720; gek. von de Witte, Grabung Lenornant, 1880)

H: 8,7 (Frgt. ohne Beine)

D: hell.

Lit: Besques, Paris IV-I, 75 Taf. 68, e D 3715

Bemerk: Vgl. zum Typus Tk 113 und P 2. 
Tk 360 Eros mit Flügeln, stehend/schreitend, in langer Chlamys, entblößt (Abb. 142)

FO: Tarent?

AO: England (J. Bomford, privat)

H: 12,7

D: 3. Jh. vor Chr.

Lit: Ancient Live in Miniature - An Exhibition of Classical Terracottas from Private Collections in England, Birmingham 1968, 34 Nr. 128. Taf. 33

Bemerk: Formgleich mit Tk 363 (Ruvo)?

Tk 361 Frau (Abb. 148)

in Chiton, Himation (am Rücken herabhängend)

FO: Tarent (Grab)

AO: New York (Metropolitan Museum, 11.212.16

[Rogers Fund 1911])

H: 27

D: M. 3. Jh. vor Chr.

Lit: J. P. Uhlenbrock, The Coroplast and his Craft, in: The Coroplast's Art (FS D. Burr-Thompson) (1990) 154 Nr. 41 (mit Abb.) und S. 19 (Farbtaf. 4)

\section{Tk 362 Mänade (Abb. 147)}

mit Fackel (re.) und Situla (li.), Rehfell (?) diagonal über rechte Schulter gelegt, in Chiton und auf die Hüfte herabgerutschtem Himation, li. Brust entblößt, mit dem re. Arm auf Pfeiler gelehnt, auf (moderner?) Rundbasis

FO: Tarent (Contrada Corvisea, Proprieta Marina Militae, Grab 22 [1930], TP 11726)

AO: Tarent (Inv. 20093)

$\mathrm{H}$ :

D: 2. Jh. vor Chr.? (Phase D)

Lit: D. Graepler, Tonfiguren im Grab. Fundkontexte hellenistischer Terrakotten aus der Nekropole von Tarent (1997) 261 Grab 46 Abb. 94

Bemerk: Aus Halbkammergrab, Mehrfachbestattung: ein Kind? und zwei Frauen?

\section{Ruvo}

Tk 363 Eros mit Flügeln, stehend, in langer Chlamys, entblößt

FO: Ruvo

AO: London (British Museum, WT 372)

H: 9,5

D: 3. Jh. vor Chr.*

Lit: Winter, Typen II, 250 Nr. 7

Bemerk: Formgleich mit Tk 360 (Tarent ?)?

\section{Sizilien allg.}

Tk 364 Junge an Pfeiler gelehnt, entblößt (Mantel weitgehend herabgerutscht) (Kausia?)

FO: Sizilien

AO: Wien (Antikencabinet, 257)

H: 13

D: hell.*

Lit: Winter, Typen II, 253 Nr. 7

\section{Morgantina}

Tk 365 Kopf

FO: Morgantina (North Sanctuary Annex, Raum 10)

AO: ? (59-844)

H: 4,6

D: spätes 3. Jh. vor Chr.

(terminus ante quem 211 vor Chr.)

Lit: M. Bell, Morgantina Studies I. The Terracottas (1981) 209. 242. 253. Nr. 703 Taf. 113

Tk 366 Kopf

FO: Morgantina

AO: ? (60-1294)

H: 4,4

D: 3. Jh. vor Chr. (Kontext 4. -1. Jh. vor Chr.)

Lit: M. Bell, Morgantina Studies I (1981) 209. 242. Nr. 702 Taf. 113

Centuripe 
Tk 367 Eros, stehend, fast nackt

FO: Centuripe

AO: Syrakus (Archäologisches Museum, Slg.

Mammana)

H: -

D: frühhellenistisch ?

Lit: G. Libertini, Centuripe (1926) 104 Taf. 24,3

\section{Lipari}

Tk 368 Chlamydephoros, stehend, Kinn verhüllend (Oberkörperfrgt.)

FO: Lipari (Nekropole, Schnitt XVII)

AO: Lipari (Museo Eoliano, 3471)

H: 4,3

D: terminus ante quem 252 vor $\mathrm{Chr}$.

Lit: L. B. Brea, Menadro e il teatro greco nelle terrakotte liparesi (1981) 108 E110 Abb. 179 a

Tk 369 Schauspieler mit bärtiger Maske, stehend, in Chlamys (Abb. 155)

FO: Lipari (Nekropole, Schnitt XXXI)

AO: Lipari (Museo Eoliano, 10.582)

H: 10,1

D: terminus ante quem 252 vor Chr.

Lit: L. B. Brea, Menandro e il teatro greco nelle terracotte liparesi (1981) 205 Abb. 341 und Farbtaf. nach S. 144

\section{Voiron/Isère (französische Alpen)}

Tk 370 Reiter über Gegner

FO: Voiron

AO: ? (Musée des Ant. Nat., Nr. 13453)

H: -

D: 4./3. Jh. vor Chr.*

Lit: F. Benoit, Mars et Mercure. Nouvelles Recherches sur 1'interpretation gauloise des divinités romaines, Publications des annales de la faculté des Lettres, Aix-en-Provence, N.S. 25 (1959) 37 Taf. 2, 2 .- M. Mackintosh, The Divine
Rider in the Art of the Western Roman Empire, BAR Intern. Series 607 (1995) 22 f. 97 Abb. 32

\section{Zypern}

\section{Zypern allg.}

Tk 371 Epheben-Soldat

FO: Zypern

AO: Paris (Cabinet des Médailles, 173)

H: 17,5

D: E. 4. Jh. vor Chr.*

Lit: Winter, Typen II, 238, 9a (vgl. Tanagra. Mythe et archeólogie, Ausstellung Paris/Montreal 2003/04, 267 Nr. 207 [FO: Limasol/Polis tis Chrysochou, 3. Jh. v.Chr., Louvre MNB 18])

Tk 372 Epheben-Soldat

FO: Zypern

AO: Paris (Louvre)

H: 17,5

D: E. 4. Jh. vor Chr.*

Lit: Winter, Typen II, 238, 9b (vgl. Tanagra. Mythe et archeólogie, Ausstellung Paris/Montreal 2003/04, 267 Nr. 207 [FO: Limasol/Polis tis Chrysochou, 3. Jh. v.Chr., Louvre MNB 18])

*Tk 373 Reiter, handgeformt, Kinn aufgestempelt (Frgt.)

FO: Zypern

AO: -

Abstand von Auge zu Auge: 1,4

D: -

Lit. J. H. Young/S. H. Young, Terracottafigurines from Kourion in Cyprus (1955) 164 Taf. 67 Nr. 3030

\section{Cythrea}

Tk 374 Chlamydephoros/Epheben-Soldat FO: Cythrea 
AO: New York (Metropolitan Museum)

H: 18

D: E. 4. Jh. vor Chr.*

Lit: Winter, Typen II, 238 c

\section{Amathous}

Tk 375 Kopf

FO: Amathous (Aphrodite- [Adonis-] Heiligtum, Kanalisation)

AO: Amathous (MY 263)

$\mathrm{H}: 3,5$

D: E. 3. Jh. - A. 2. Jh. vor Chr.

Lit: A. Queyrel, Amathonte IV, Les Figurines Hellenistiques de Terre Cuites (1988) 209.234 Nr. 979 Taf. 82

*Tk 376 x Reiter, handgeformt, Kinn aufgestempelt (Frgt.); zwei oder mehr Exemplare

FO: Amathous

AO: -

Abstand von Auge zu Auge: 1-1,5

D: -

Lit. J. H. Young/S. H. Young, Terracottafigurines from Kourion in Cyprus (1955) 163 Taf. 62 Nr. 3021,3016

\section{Kourion}

*Tk 377 x Reiter und Wagenlenker, handgeformt, Gesichter aufgestempelt; diverse (ca. 100?) Exemplare

FO: Kourion (Votivgrube außerhalb des ApollonHylates-Heiligtum)

AO: -

$\mathrm{H}:$ -

D: E. 4. -1. Jh. vor Chr.

Lit: J. H. Young/S. H. Young, Terracottafigurines from Kourion in Cyprus (1955) 86, 89 Taf. 38 Mold 3B3 (= Nr. 1889-1905); 95, 97. Taf. 39 Mold 6B (= Nr. 2061-70); 102 Taf. 32 Mold 11A (=Nr. 2168-81); 117 Taf. 42 Mold 26 (=Nr. 2450-
54); 117 f. Taf. 42 Mold 27 (=Nr. 2458-63); 118 f. Taf. 42 Mold 28B (= Nr. 2470-2510); 121 Taf. 44 Mold 31A (=Nr. 2565-89 ?); 121 Taf. 36 Mold 30 Nr. 2536; 121 f. Taf. 56 Mold 31 (= Nr. 256594 ?); 122 f. Taf. 43 Mold 32B (= Nr. 2655-26902706-2713 ?); 124 Taf. 43 Mold 33A(= Nr. 273235); 123 Pl. 36 Nr. 2622 (= Mold 32A), 2735 (= Mold 32A); 126 Taf. 36 Nr. 2770 (= Mold 34A); 125 Taf. 43 Mold 33C1 (= Nr. 2756 ff.?); 125 Taf. 43 Mold 33C2 (=Nr. 2760-69); 126 f. Taf. 44 Mold 35 (=2796-99, 2803 ?); 127 Taf. 44 Mold 36 (=2810-13); 127 Taf. 44 Mold 37 (= Nr. 281418); 128 Taf. 36 Mold 38 (=Nr. 2843); 131 Taf. 45 Mold 44 (= Nr. 2882-86); 134 f. Taf. 37 Nr. 2905; 142 Taf. 52 Mold 49 (= Nr. 2959-61); 143 Taf. 52 Mold 51 (=Nr. 2966f.); 144 Taf. 52 Mold 54A (= Nr. 2974-79); 145 Taf. 50 Mold 54B2 (= Nr. 2990); 146 Taf. 51 Mold 54B2 Nr. 2996; 136 Taf. 46 Nr. 2915, 2918; 137 Taf. 48 Nr. 2934. .N. A. Winter, The terracottas, in: D. Buitron-Oliver, The Sanctuary of Apollo Hylates at Kourion. Excavations in the Archaic Precinct, SIMA 109 (1996) 89 ff. 100 ff. 104 ff. (headdresses) 135 f.

Bemerk: Eine Zuordnung der Katalognummern zu den „Molds“ sowie zu den Abbildungen ist sowohl bei J. H. Young/S. H. Young als auch bei N. A. Winter nicht bzw. nur in Einzelfällen möglich. Eine Überprüfung der Angaben zur Kopfbedeckung (causia, flat cap, round cap, flat cap and fillet, cap and wreath, pointed brim hat, two-rowed wreath, pilos, low/high tiara, mitra etc.) sowie die Feststellung der Gesamtzahl werden hierdurch unmöglich gemacht.

\section{Kition / Larnaka}

TK 378 Chlamydephoros, stehend (Kausia ?)

FO: Kition / Larnaka

AO: New York (Metropolitan Museum)

H: 13,5

D: - 


\section{Phönizien / Syrien}

\section{Umm el-Amad}

Tk 379 Kopf

FO: Umm el-Amad, Ost-Tempel

AO: -

H: ca. 5

D: hell.?

Lit: M. Dunand, R. Duru, Oumm el- JAmed - Un ville de l'Epoque hellénistique aux Échelles de Tyr, Études et Documents d'Archéologie 4 (1962) 219 Taf. 69, 4 (ohne Text?)

Bemerk: Vgl. *Re 6 (Stele des Baalschamar) aus Umm el-Amad.

\section{Kharayeb}

Tk 380 a-d Epheben-Soldaten (Abb. 81a. 99) (4 Exemplare: davon 3 ohne Kopf, 2 ohne Unterschenkel)

FO: Kharayeb

AO: Beirut (Museum, Inv.Nr. 912-15)

H: 15,7 / 19,8 / 16,4 / 19,5

D: 100 vor Chr. (Chéhab)

3. Jh. vor Chr. (?) (Schneider-Herrmann)

\section{4./3. Jh. vor Chr.*}

Lit: Chéhab, Kharayeb, 65, 112, 158 Nr. 912-15

Taf. 73, 3 .- G. Schneider-Herrmann in: Alessandria e il mondo ellenistico-romano (FS A. Adriani) (1984) 303 Taf 55, 2

*Tk 381a-h Jüngling, stehend in Mantel

(8 Frgte., davon 6 ohne Kopf) (Abb. 72)

FO: Kharayeb (Favissa)

AO: $\quad($ Kh 783-91)

H: 10,3 - 17,2 (Frgte.)

D: -

Lit: Chéhab, Kharayeb, 59 Taf. 69, 5
*Tk 382a-g Jünglinge, stehend im Mantel (Chlamys?)

(7 Exemplare, davon 6 Frgte. ohne Kopf)

FO: Kharayeb (Favissa)

AO: $\quad(\mathrm{Kh} 776-82)$

H: 12,2

D: -

Lit: Chéhab, Kharayeb, 59 Taf. 69, 4

Tk 383 Oberkörperfragment (Junge in Chiton, mit Hahn?) (Abb. 140)

FO: Kharayeb (Favissa)

AO: Beirut ? (Kh 535)

H: 10,2

D: -

Lit: Chéhab, Kharayeb, 47 Taf. 55, 2

Tk 384 Oberkörperfragment (Junge in Chiton, mit Hahn und/oder Trauben?) (Abb. 141)

FO: Kharayeb (Favissa)

AO: Beirut ? (Kh 536)

H: 8,2

D: -

Lit: Chéhab, Kharayeb, 47 Taf. 54

*Tk 385a-b Manteltänzer, die Genitalien entblößend (mit Kausia?) (Abb. 73)

(2 Exemplare [eines ohne Kopf])

FO: Kharayeb (Favissa)

AO: Beirut (Kh -275 -275b [?])

H: 9,4 / ?

D: 3. - 2. Jh. vor Chr.

Lit: Chéhab, Kharayeb, 35 f. Taf. 36, 3.37, 3

Bemerk: Zur Datierung vgl. A. Parrot, M. Chéhab, S. Moscati, Die Phönizier (1977) 122 Abb. 130 f.

*Tk 386a-b Manteltänzer, die Genitalien entblößend (mit Kausia?)

(2 Exemplare) 
FO: Kharayeb (Favissa)

AO: Beirut ? (Kh 273-274)

H: 10,2 / 10,3 (ohne Unterschenkel)

D: 3. - 2. Jh. vor Chr.

Lit: Chéhab, Kharayeb, 35 f. Taf. 37, 1-2

Bemerk: Zur Datierung vgl. A. Parrot, M. Chéhab, S. Moscati, Die Phönizier (1977) 122 Abb. 130 f.

Tk 387a-c Köpfe (3 Exemplare)

FO: Kharayeb

AO: Beirut ? (Kh 1059-61)

H: 5,1 / 5,1 / 4,5

D:4./3. Jh. vor Chr.*

Lit: Chéhab, Kharayeb, 74 Taf. 90, 2

Tk 388a-h Köpfe (8 Exemplare)

FO: Kharayeb

AO: Beirut? (Kh 1062-69)

H: 6 / 7 / 4,8 / 4,8 / 4,6 / 4,6 / 4,8 / 4,8

D: -

Lit: Chéhab, Kharayeb, 74 Taf. 90, 1

Tk 389 Kopf

FO: Kharayeb

AO: Beirut? (Kh 1078)

H: 4,4

D: -

Lit: Chéhab, Kharayeb, 74 Taf. 90, 3

\section{Laodikeia am Libanon}

Tk 390 Reiter (ohne Gegner?)

(Frgt.: Kopf und Schultern des Reiters, Pferdekopf)

FO: Laodikeia am Libanon

AO: -

H: -

D: seleukidisch

Lit: M. Pézard, Qadesh - Mission Archéologique a Tell Nebi Mend 1921-22, Biblotheque Archéologique et Historique 15 (1931) 16 Taf. $20 \mathrm{~d}$
Tk 391 Reiter (?) (ohne Gegner?)

(Frgt.: Kopf und Schultern eines Reiters)

FO: Laodikeia am Libanon

AO: -

$\mathrm{H}:-$

D: seleukidisch

Lit: M. Pézard, Qadesh - Mission Archéologique a Tell Nebi Mend 1921-22, Biblotheque Archéologique et Historique 15 (1931) 16 Taf. 20, 1 a

\section{Ibn Hani}

Tk 392 Reiter ohne Gegner

FO: Ibn Hani (Zone F)

AO: -

H: ca. 12,4

D: hell.? / M. 3. Jh. vor Chr.*

Lit: A. Bounni, J. Lagarce, N. Saliby, Rapport préliminaire sur la première campagne de fouilles (1975) a Ibn Hani (Syrie), Syria 7, 1976, 233 ff. (256 f. m. Anm. 4, 1-3) Abb. 30, 1 (S. 279)

\section{Tell Halaf (Nordirak)}

Tk 393 Reiter ohne Gegner (Abb. 119)

(mediterran-orientalischer Typus)

FO: Tell Halaf (westl. Stadtmauer)

AO: Berlin (V. A. 12751)

H: 11

D: hellenistisch-parthisch

Lit: B. Hrouda, Tell Halaf 4. Die Kleinfunde aus historischer Zeit (1962) 15 f. 24 Nr. 144 Taf. 18

Tk 394 Reiter - Fragment (Abb. 121)

FO: Tell Halaf

AO: früher Berlin (Tell Halaf Museum, T.H. 4084)

H: 5,6 (Kopf und Schultern)

D: -

Lit: B. Hrouda, Tell Halaf 4. Die Kleinfunde (1962) 1625 Nr. 152 Taf. 19 
Tk 395 Reiter - Fragment

FO: Tell Halaf

AO: früher Berlin (Tell Halaf Museum, T.H. 4085)

H: 6 (Kopf und Schultern)

D: -

Lit: B. Hrouda, Tell Halaf 4. Die Kleinfunde (1962) 1625 Nr. 151 Taf. 19

Tk 396 Fragment eines Manteltänzers oder eines Reiters?

FO: Tell Halaf

AO: früher Berlin (Tell Halaf Museum, T.H. 4098)

H: 6,2 (Kopf und Schultern)

D: 4./3. Jh. vor Chr.

Lit: B. Hrouda, Tell Halaf 4. Die Kleinfunde (1962) 1322 Nr. 109 Taf. 14

Bemerk: Vgl. Manteltänzer Kharayeb (*Tk 385 f.) oder Reiter (z.B. Tk 393 aus Tell Halaf, Tk 9 ff. aus Ägypten).

Tk 397 Kopf

FO: Tell Halaf

AO: früher Berlin (V.A. 12754)

H: 5,2

D: hellenistisch - parthisch

Lit: B. Hrouda, Tell Halaf 4. Die Kleinfunde (1962) 1624 Nr. 149 Taf. 19

Tk 398 Kopf

FO: Tell Halaf

AO: Berlin (FU, Institut f. Alte Geschichte)

H: 5

D: -

Lit: B. Hrouda, Tell Halaf 4. Die Kleinfunde (1962) 1624 Nr. 150 Taf. 19

Tk 399a-i Köpfe (11 Exemplare)
FO: Tell Halaf

AO: Berlin

$\mathrm{H}:-$

D: -

Lit: B. Hrouda, Tell Halaf 4. Die Kleinfunde (1962) 1625 Nr. 155-65 (ohne Abb.)

\section{Jebel Khalid}

Tk 400 Oberkörperfragment (Chlamydephoros [?] mit Kausia [?])

FO: Jebel Khalid

AO: ? (Inv. 89.599)

H: 6,7

D: seleukidisch

Lit: P. J. Connor, Terracottas from Seleucid Jebel Khalid, MeditArch 7, 1994, 78 f. Taf. 4, 3

Bemerk: Von P. J. Connor als Frau mit Stephane beschrieben.

Tk 401 Kopf mit Kausia (?)

FO: Jebel Khalid

AO: ? (Inv. 88.282)

H: 4,8

D: seleukidisch

Lit: P. J. Connor, Terracottas from Seleucid Jebel Khalid, MeditArch 7, 1994, 78 f. Taf. 4, 2

Bemerk: Von P. J. Connor als Frau mit Stephane beschrieben.

Tk 402 Kopf mit Kausia (?)

FO: Jebel Khalid

AO: ? (Inv. 90.102)

H: 2,2

D: seleukidisch

Lit: P. J. Connor, Terracottas from Seleucid Jebel Khalid, MeditArch 7, 1994, 78 f. Taf. 4, 1

Bemerk: Von P. J. Connor als Frau mit Stephane beschrieben.

Tk 403 Kopf mit Kausia (?) 
FO: Jebel Khalid

AO:? (Inv. 89.155)

H: 2,7

D: seleukidisch

Lit: P. J. Connor, Terracottas from Seleucid Jebel Khalid, MeditArch 7, 1994, 78 f. Taf. 4, 1

Bemerk: Von P. J. Connor als Frau mit Stephane beschrieben.

Tk 404 Kopf mit Kausia (?)

FO: Jebel Khalid

AO: ? (Inv. 90.410)

H: 3,2

D: seleukidisch

Lit: P. J. Connor, Terracottas from Seleucid Jebel Khalid, MeditArch 7, 1994, 78 f. Taf. 4, 1

Bemerk: Von P. J. Connor als Frau mit Stephane beschrieben.

Tk 405 bärtiger Kopf mit Kausia (Abb. 157)

FO: Jebel Khalid

AO: (Inv. 89.137)

H: 4,7

D: seleukidisch

Lit: P. J. Connor, Terracottas from Seleucid Jebel Khalid, MeditArch 7, 1994, 78 f. Taf. 4, 3

\section{Mesopotamien}

\section{Seleukia am Tigris}

Tk 406a-i Chlamydephoroi (?)

(9 Oberkörperfragmente)

FO: Seleukia

AO: Michigan (University, Museum of Classical Archeology) und Bagdad (Iraq Museum): M 15338, M 14369, B 5228, M 16312, M 15327, B 4945, M 14693, M 14063

$\mathrm{H}: 4,1$ (=B 5228)

D: stratigraph.: a-b: 1-200 nach Chr. c-d: 1-200 nach Chr.

e: 200 nach Chr. und später

f-i: Oberflächenfunde

Lit: Ingen, Seleukia, 281 Nr. 1196 a-i Taf. 67, 488

.- Zur Datierung vgl. K. Karvonen-Kaunas, The Seleucid and Parthian Terracotta Figurines from Babylon (1995) 37 Anm. 109 (mit Verweis auf A. Invernizzi, Mesopotamia 5-6, 1970-71, 33 ff.).

Tk 407 Chlamydephoros, stehend, mit li. Arm auf Pfeiler gestützt, Denkerpose

FO: Seleukia

AO: Michigan (University, Museum of Classical Archeology 16451)

H: 7

D: stratigraph.: 1-200 nach Chr.

Lit: Ingen, Seleukia, 101 Nr. 214 Taf. 16, 110 .Zur Datierung vgl. K. Karvonen-Kaunas, The Seleucid and Parthian Terracotta Figurines from Babylon (1995) 37 Anm. 109 (mit Verweis auf A. In vernizzi, Mesopotamia 5-6, 1970-71, 33 ff.).

Tk 408a-c Chlamydephoros, stehend

(3 Oberkörperfragmente)

FO: Seleukia

AO: Michigan (University, Museum of Classical Archeology) und Bagdad (Iraq Museum): M 16385, B 4438, B 3651

H: 5,8 / 6,9 / 9

D: stratigraph.: a: 1-200 nach Chr.

b: 200 nach Chr. und später

c: Oberflächenfund

Lit: Ingen, Seleukia, 117 Nr. 299 a-c Taf. 21, 141 .- Zur Datierung vgl. K. Karvonen-Kaunas, The Seleucid and Parthian Terracotta Figurines from Babylon (1995) 37 Anm. 109 (mit Verweis auf A. Invernizzi, Mesopotamia 5-6, 1970-71, 33 ff.).

Tk 409 Reiter ohne Gegner (Abb. 120) (mediterran-orientalischer Typus) 
FO: Seleukia

AO: Bagdad (Iraq Museum, 17082*)

H: -

D: stratigraph.: 1-200 nach Chr. und später

Lit: Ingen, Seleukia, 153 Nr. 475 Taf. 34, 244 .-

Zur Datierung vgl. K. Karvonen-Kaunas, The Seleucid and Parthian Terracotta Figurines from Babylon (1995) 37 Anm. 109 (mit Verweis auf A. In vernizzi, Mesopotamia 5-6, 1970-71, 33 ff.).

Tk 410a-d Chlamydephoroi, stehend

(4 Oberkörperfragmente) (Abb. 122)

FO: Seleukia

AO: Michigan (University, Museum of Classical Archeology 15099, 15105, 15106, 16487)

H: 6,1 / 6,8 7 7,2 / 6,8

D: stratigraph.: 150 - 1 vor Chr.

150 - 1 vor Chr.

1-200 nach Chr.

200 nach Chr. und später

Lit: Ingen, Seleukia, 117 Nr. 301 a-d Taf. 21, 142

.- Zur Datierung vgl. K. Karvonen-Kaunas, The Seleucid and Parthian Terracotta Figurines from Babylon (1995) 37 Anm. 109 (mit Verweis auf A. Invernizzi, Mesopotamia 5-6, 1970-71, 33 ff.).

Tk 411a-d Reiter (4 Oberkörperfragmente)

FO: Seleukia

AO: Michigan (Uni., Mus. of Cl. Arch., 15114, $15184,15181,15101)$

H: 8,5 / 6 / 8,1 / 7

D: stratigraph.: a: 1-200 nach Chr.

b: 200 nach Chr. und später c-d: ( ? )

Lit: Ingen, Seleukia, 144 Nr. 432 a-d Taf. 30, 218

.- Zur Datierung vgl. K. Karvonen-Kaunas, The Seleucid and Parthian Terracotta Figurines from Babylon (1995) 37 Anm. 109 (mit Verweis auf A. Invernizzi, Mesopotamia 5-6, 1970-71, 33 ff.).
Tk 412 Kopf

FO: Seleukia

AO: Bagdad (Iraq Museum, 102201)

$\mathrm{H}: 4,4$

D: parthisch (nach 140 nach Chr.)

Lit: La Terra tra i due fiumi (Ausstellungskatalog Florenz 1986) 130. 186 Nr./Abb. 143

Tk 413a-n Köpfe (14 Exemplare) FO: Seleukia

AO: Michigan (University, Mus. of Class. Arch., 15344, 15318, 14083, 15352, 16455, 15297, 15351, 15289, 15291, 15306, 14880, 15824, $15298,15339)$

$\mathrm{H}: 3,2$

D: stratigraph.: a-g: 1-200 nach Chr.

h-k: 200 nach Chr. und später 1-m: ( ?)

Lit: Ingen, Seleukia, 279 ff. Nr. 1192-1200 Taf. 67, 487-489 .- Zur Datierung vgl. K. KarvonenKaunas, The Seleucid and Parthian Terracotta Figurines from Babylon (1995) 37 Anm. 109 (mit Verweis auf A. Invernizzi, Mesopotamia 5-6, 1970-71, 33 ff.).

Tk 414a-c Köpfe

(mit Knopfohrringen und Kausia ?) (3 Exemplare) FO: Seleukia

AO: Michigan (University, Museum of Classical Archeology, 14599, 14633, 14410)

H: 4,3 / 4,2 / 5,4

D: stratigraph.: a: 1-200 nach Chr. b-c: (?)

Lit: Ingen, Seleukia, 280 Nr. 1193 a-c (ohne Abb.) .- Zur Datierung vgl. K. Karvonen-Kaunas, The Seleucid and Parthian Terracotta Figurines from Babylon (1995) 37 Anm. 109 (mit Verweis auf A. Invernizzi, Mesopotamia 5-6, 1970-71, 33 ff.).

\section{Tk 415a-d Köpfe}


(mit Knopfohrringen und Kausia ?)(4 Exemplare) FO: Seleukia

AO: Michigan (University, Museum of Classical Archeology) und Bagdad (Iraq Museum): M 15361, M 14417, B 4623, M 15313

$\mathrm{H}: 4,4$ / 4,2 / 4,4 / 3,6

D: stratigraph.: a-c: 1-200 nach Chr.

$$
\mathrm{d}:(?)
$$

Lit: Ingen, Seleukia, 280 Nr. 1194 (ohne Abb.) .Zur Datierung vgl. K. Karvonen-Kaunas, The Seleucid and Parthian Terracotta Figurines from Babylon (1995) 37 Anm. 109 (mit Verweis auf A. In vernizzi, Mesopotamia 5-6, 1970-71, 33 ff.).

Tk 416 Kopf (mit Kausia ?)

FO: Seleukia

AO: Michigan (Uni., Mus. of Class. Arch., 15337)

$\mathrm{H}: 3,7$

D: 200 nach Chr. und später ?

Lit: Ingen, Seleukia, 280 Nr. 1195 (ohne Abb.) .Zur Datierung vgl. K. Karvonen-Kaunas, The Seleucid and Parthian Terracotta Figurines from Babylon (1995) 37 Anm. 109 (mit Verweis auf A. In vernizzi, Mesopotamia 5-6, 1970-71, 33 ff.).

\section{Tk 417 Kopf}

FO: Seleukia

AO: Michigan (Uni., Mus. of Class. Arch., 16544)

$\mathrm{H}: 3,5$

D: stratigraph.: 1-200 nach Chr.

Lit: Ingen, Seleukia, 281 Nr. 1197 (ohne Abb.) .Zur Datierung vgl. K. Karvonen-Kaunas, The Seleucid and Parthian Terracotta Figurines from Babylon (1995) 37 Anm. 109 (mit Verweis auf A. In vernizzi, Mesopotamia 5-6, 1970-71, 33 ff.).

Tk 418a-b Köpfe (2 Exemplare)

FO: Seleukia

AO: Bagdad (Iraq Museum, 17390*, 17337*)

H: -
D: stratigraph.: 1-200 nach Chr.

Lit: Ingen, Seleukia, 281 Nr. 1200 (ohne Abb.) .Zur Datierung vgl. K. Karvonen-Kaunas, The Seleucid and Parthian Terracotta Figurines from Babylon (1995) 37 Anm. 109 (mit Verweis auf A. In vernizzi, Mesopotamia 5-6, 1970-71, 33 ff.).

Tk 419 Kopf im Profil nach links

FO: Seleukia

AO: Michigan (Uni., Mus. of Class. Arch., 14656)

H: 3,8

D: stratigraph.: 1-200 nach Chr.

Lit: Ingen, Seleukia, 281 Nr. 1199 (ohne Abb.) .Zur Datierung vgl. K. Karvonen-Kaunas, The Seleucid and Parthian Terracotta Figurines from Babylon (1995) 37 Anm. 109 (mit Verweis auf A. In vernizzi, Mesopotamia 5-6, 1970-71, 33 ff.).

Tk 420 Kopf

FO: Seleukia

AO: Michigan (Uni., Mus. of Class. Arch., 14099)

$\mathrm{H}: 3,7$

D: 4./3. Jh. vor Chr.*

Lit: Ingen, Seleukia, 281 Nr. 1198 Taf. 67, 489 .Zur Datierung vgl. K. Karvonen-Kaunas, The Seleucid and Parthian Terracotta Figurines from Babylon (1995) 37 Anm. 109 (mit Verweis auf A. In vernizzi, Mesopotamia 5-6, 1970-71, 33 ff.).

Tk 421a-c Köpfe (3 Exemplare)

FO: Seleukia

AO: Toledo (Museum of Art, 29.101), Michigan (Univ., Mus. of Class. Arch., 15787), Bagdad (Iraq Museum, reg. 6383A)

H: 3,9 / 3,0 / 3,8

D: stratigraph.: b: 1-200 nach Chr. stilistisch: 2. Jh. nach Chr.* Lit: Ingen, Seleukia, 264 Nr. 1091,1092 a-b Taf. 63, 457 f. .- Zur Datierung vgl. K. Karvonen-Kaunas, The Seleucid and Parthian Terracotta Figuri- 
nes from Babylon (1995) 37 Anm. 109 (mit Verweis auf A. Invernizzi, Mesopotamia 5-6, 197071, 33 ff.).

Bemerk: Nach van Ingen handelt es sich um Frauenköpfe mit Turban.

Tk 422 Reiter (o. Pferd), handgeformt, mit Kausia ?

FO: Seleukia (TT 4, Oberfläche)

AO: Michigan (Uni., Mus. of Class. Arch., 15594)

H: 5,2

D: seleukidisch-parthisch

Lit: Ingen, Seleukia, 145 Nr. 434 Taf. 30, 219

\section{Babylon}

Tk 423 Chlamydephoros, stehend (Frgt.)

FO: Babylon

AO: London (Brit. Mus., 80-6-17-1705)

$\mathrm{H}: 10,2$ (ohne Unterschenkel)

D: seleukidisch-parthisch / 4./3. Jh. vor Chr.?*

Lit: K. Karvonen-Kaunas, The Seleucid and Parthian Terracotta Figurines from Babylon (in the Iraq Museum, The British Museum and the Louvre), Monografie di Mesopotamia 4 (Diss. Helsinki) (1995) 166 Nr. 381 Taf. 61

Tk 424 Reiter ohne Gegner (babylonische Variante)

FO: Babylon

AO: Bagdad (Iraq Museum, 93463)

H: 16,3

D: parthisch / 3. Jh. vor Chr.?*

Lit: K. Karvonen-Kaunas, The Seleucid and Parthian Terracotta Figurines from Babylon (in the Iraq Museum, The British Museum and the Louvre), Monografie di Mesopotamia 4 (Diss. Helsinki) (1995) 38 f. (mit Anm. 114) 93 f. 169 Nr. 406 Taf. 63
Tk 425a-d Reiter, handgeformt, Gesichter gestempelt (Abb. 123)

(4 Oberkörperfrgte.)

FO: Babylon

AO: $\quad$ London (Brit. Mus., 80-11-12-1927, 81-428-957, Sp.38+)

Bagdad (Iraq Museum, 63724)

H: ca. 5-7 (Oberkörperfrgt.)

D: parthisch / 4./3. Jh. vor Chr.?*

Lit: K. Karvonen-Kaunas, The Seleucid and Parthian Terracotta Figurines from Babylon (in the Iraq Museum, The British Museum and the Louvre), Monografie di Mesopotamia 4 (Diss. Helsinki) (1995) 38 f. 175 Nr. 462-465 Taf. 66 (außer 465)

Tk 426 Reiter, handgeformt, Gesicht gestempelt (Frgt.) (Abb. 124)

FO: Babylon

AO: Bagdad (Iraq Museum, 93202)

H: 5,5 x 3,9 (Oberkörperfrgt.)

D: parthisch / 4./3. Jh. vor Chr.?*

Lit: K. Karvonen-Kaunas, The Seleucid and Parthian Terracotta Figurines from Babylon (in the Iraq Museum, The British Museum and the Louvre), Monografie di Mesopotamia 4 (Diss. Helsinki) (1995) 38 f. 177 Nr. 478 Taf. 67

Tk 427 Kopf

FO: Babylon

AO: London (Brit. Mus., 80-6-17-1728)

H: 3 x 3,5

D: parthisch / 3. Jh. vor Chr.?*

Lit: K. Karvonen-Kaunas, The Seleucid and Parthian Terracotta Figurines from Babylon (in the Iraq Museum, The British Museum and the Louvre), Monografie di Mesopotamia 4 (Diss. Helsinki) (1995) 38 f. 190 Nr. 595 Taf. 78 
FO: Babylon

AO: London (Brit. Mus., 80-6-17-1705)

$\mathrm{H}: 3,3 \times 3$

D: parthisch / 4./3. Jh. vor Chr.?*

Lit: K. Karvonen-Kaunas, The Seleucid and Parthian Terracotta Figurines from Babylon (in the Iraq Museum, The British Museum and the Louvre), Monografie di Mesopotamia 4 (Diss. Helsinki) (1995) 38 f. 190 Nr. 596 Taf. 78

Tk 429 Kopf

FO: Babylon

AO: London (Brit. Mus., 80-6-17-1720)

$\mathrm{H}: 4,5 \times 3$

D: parthisch / 4./3. Jh. vor Chr.?*

Lit: K. Karvonen-Kaunas, The Seleucid and Parthian Terracotta Figurines from Babylon (in the Iraq Museum, The British Museum and the Louvre), Monografie di Mesopotamia 4 (Diss. Helsinki) (1995) 38 f. 190 Nr. 597 Taf. 78

\section{Nippur}

Tk 430a-c Reiter, handgeformt

(3 Exemplare)

FO: Nippur (Grab ?)

AO: Philadelphia/Penn. (Uni.-Mus., CBS 15486, CBS 15480)

H $10,8 \times 10,8 / 12,7 \times 11$

D: hell. (Legrain) 100 vor Chr. - 100 nach Chr. (Buren)

Lit: L. Legrain, Terracottas from Nippur (1930) 32 Taf. 50 Nr. 263, 264 .-E. D. van Buren, Clay Figurines of Babylonia and Assyria (1930) 165f. Nr. 799 Taf. 45,217

Bemerk: L. Legrain deutet die Kopfbedeckung als „causia“, E. D. van Buren als „priest's hat“.

Tk 431 Paar, sich umarmend, Mann mit Chiton, Himation und Kausia? (Abb. 154)

FO: Nippur (Grab ?)
AO: Philadelphia/Penn. (Uni.-Mus., CBS 9449)

H 13

D: hell.

Lit: L. Legrain, Terracottas from Nippur (1930) 21

Taf. 24 Nr. 127

Bemerk: L. Legrain deutet die Kopfbedeckung als „flat turban“.

Tello (Sirpoula, Lagash, in Chaldäa, bei Nasrieh)

Tk 432 Reiter, handgeformt

FO: Tello

AO: -

$\mathrm{H}: 12$

D: 200-140 vor Chr.*

Lit: G. Cros, Nouvelles Fouilles de Tello (Mission française de Chaldée) (1910) 301 Abb. 15

Tk 433 Reiter, handgeformt (Frgt.)

FO: Tello

AO: -

H: -

D: époque grecque / 200-140 vor Chr.*

Lit: H. de Genouillac, Fouilles de Telloh II (1936)

56 TG 782 Taf. 126, 4

Bemerk: Werkstattgleich mit Tk 445-447 (Susa), Tk 448-451 (Masjid-i Solaiman) und Ikaros (Tk 452)?*

Tk 434 Reiter, handgeformt (Frgt.)

FO: Tello

AO: -

$\mathrm{H}:-$

D: époque araméenne

Lit: H. de Genouillac, Fouilles de Telloh II (1936)

56 TG 4083 Taf. 126, 2

Tk 435 Reiter, handgeformt

FO: Tello (= Girsu?)

AO: - 
H: $5,7 \times 2,6$

D: 539 vor Chr. - 224 nach Chr.

Lit: M.-Th. Barrelet, Figurines et Reliefs en Terre cuite de la Mesopotamie antique 1, Institut Français d'Archeologie de Beyrouth. Bibliothèque archéologique et historique 85 (1968) 158 Nr. 55 Taf. 5

\section{Uruk (Warka)}

Tk 436 Chlamydephoros, stehend (Frgt.)

FO: Uruk (W 16247a/K XVII, im seleukidischen Lehmziegelschutt)

AO: Berlin (VA12275)

H: 10

D: seleukidisch

Lit: Ch. Ziegler, Die Terrakotten von Warka, ADFGUW 6 (1962) 102 Nr. 684 Abb. 364

Bemerk: Von Ch. Ziegler als Frau mit diademartigen Kopfschmuck gedeutet.

Tk 437a-b Epheben-Soldaten

(2 Exemplare, davon 1 Frgt.)

FO: Uruk (W 15918 / Oberflächenfund T VIII; W 24327 / S10c4)

AO: Berlin (VA 14620)

H: 17,8 / 6,4 (Frgt.)

D: seleukidisch-parthisch

Lit: Ch. Ziegler, Die Terrakotten von Warka (1962) 122 Nr. 819 Abb. 472 .- A. Invernizzi, Problemi di coroplastica tardo-mesepotamica III. La cultura di Uruk, Mesopotamia 5/6, 1970-71, 325 ff. Abb. 79 .- N. Wrede, BaM 21, 1990, 259 Nr. 74 Taf. 21

Tk 438a-d Reiter, handgeformt

(4 Exemplare)

FO: Uruk (Survey: Q9e5, R4a5, R8d1, T14a1)

AO: -

$\mathrm{H}: 10,9$ (= R8d1)

D: seleukidisch-parthisch
Lit: Nadja Wrede, Katalog der Terrakotten der archäologischen Oberflächenuntersuchung (Survey) des Stadtgebietes von Uruk, BaM 21, 1990, 257 Nr. 70 Taf. 20 (= R8d1)

Tk 439 Reiter, handgeformt (Frgt.)

FO: Uruk (Survey: Q10e3)

AO: -

H: 6,8 (Frgt.)

D: seleukidisch-parthisch

Lit: Nadja Wrede, Katalog der Terrakotten der archäologischen Oberflächenuntersuchung (Survey) des Stadtgebietes von Uruk, BaM 21, 1990, 257 Nr. 71 Taf. 20

Tk 440 Reiter, handgeformt, Gesicht gestempelt (Frgt.)

FO: Uruk (W 8257/Stadtgebiet)

AO: Berlin (VA 12162)

H: 7

D: seleukidisch-parthisch

Lit: Ch. Ziegler, Die Terrakotten von Warka (1962) 129 Nr. 873 Abb. 504

Tk 441a-b Reiter, handgeformt, mit Kausia ? (Frgt.) (2 Exemplare)

FO: Uruk (W 1599a/Stadtgebiet, W13596a)

AO: Berlin (VA 11900, 11899)

H: 4,1 / 5,2

D: seleukidisch-parthisch

Lit: Ch. Ziegler, Die Terrakotten von Warka (1962) 133 Nr. 902 f. Abb. 524 f.

Tk 442a-c Reiter, handgeformt (Frgte.)

(3 Exemplare)

FO: Uruk (Survey: P8d1, H17d5, K19b4)

AO: ? (Inv. W 24330 / - / - )

H: 7,3

D: seleukidisch-parthisch 
Lit: Nadja Wrede, Katalog der Terrakotten der archäologischen Oberflächenuntersuchung (Survey) des Stadtgebietes von Uruk, BaM 21, 1990, 257 Nr. 69 Taf. 20

Tk 443 Reiter, handgeformt (Frgt.)

FO: Uruk (Oa XV 5: Schnittsteg über dem Hof des Stampflehmgebäudes aus den jüngeren Schichten)

AO: Bagdad (W 21754)

H: 4,5

D: ,altbabylonisch oder älter?“

1. Jahrtausend vor Chr.* (Fundkontext)

Lit: H. J. Lenzen, XXIV. vorläufiger Bericht über die von dem DAI und der DOG aus Mitteln der DFG unternommenen Ausgrabungen in UrukWarka (Winter 1965/66) (1968) 11 f. 28 (W21754) Taf. 22c

Tk 444 Kopf (mit Schulteransatz)

FO: Uruk (W 1872/Stadtgebiet, angeblich südl. vom Südbau)

AO: Berlin (VA 12163)

H: 5,8

D: seleukidisch-parthisch

Lit: Ch. Ziegler, Die Terrakotten von Warka (1962) 119 Nr. 798 Abb. 452

\section{Susa}

Tk 445a-b Reiter, handgeformt

(2 Exemplare)

FO: Susa

AO: Teheran (Archäologisches Museum)

H: ca. 10-12

D: 1. - 3. Jh. nach Chr. / 200 - 140. vor Chr.*

Lit: R. Ghirshman, Iran - Parther und Sasaniden (1962) 104 Abb. 118

Bemerk: Gleiche Werkstatt wie Tk 448 ff. (Masjid-i Solaiman) und Tk 452 (Ikaros).
Tk 446 Reiter, handgeformt, mit Rundschild FO: Susa

AO: Teheran (Archäologisches Museum)

H: ca. 10-12

D: 1. - 3. Jh. nach Chr. / 200-140 vor Chr.*

Lit: R. Ghirshman, Iran - Parther und Sasaniden (1962) 104 Abb. 118

Bemerk: Gleiche Werkstatt wie Tk 448 ff. (Masjid-i Solaiman) und Tk 452 (Ikaros).

Tk 447 Amphippos mit Göttin (Frgt.)

FO: Susa

AO: -

$\mathrm{H}:-$

D: $200-140$ vor Chr.*

Lit: Fouilles de Suse, 1933-39, MDAI-Mission de Susiane 29, 1943, 42 Abb. 36

Bemerk: Gleiche Werkstatt wie Tk 448 ff. (Masjid-i Solaiman) und Tk 452 (Ikaros).

\section{Masjid-i Solaiman}

Tk 448a-b Reiter, handgeformt (Abb. 125)

(2 Exemplare)

FO: Masjid-i Solaiman (Großer Tempel)

AO: ? (G.MIS 622 / ohne Nr.)

H: 16,5

D: $300-140$ vor / 200-140 vor Chr.*

Lit: R. Ghirshman, Terrasse Sacrés de Bard-è Nechandeh et Masjid-i Solaiman, MDAI 45 (1976) 79 ff. Taf.CXII, 2, 3 Taf. 44 Taf. CXIII, 1 Bemerk: Gleiche Werkstatt wie Tk 445 ff. (Susa) und Tk 452 (Ikaros).

Tk 449a-c Reiter, handgeformt (Abb. 126) mit Rundschild (3 Exemplare)

FO: Masjid-i Solaiman (Großer Tempel)

AO: ? (G.MIS 456 / 623 / ?)

H: 17 / 15,5 / ?

D: $300-140$ vor Chr. / 200-140 vor Chr.* 
Lit: R. Ghirshman, Terrasse Sacrés de Bard-è Nechandeh et Masjid-i Solaiman, MDAI 45 (1976) 79 ff. Taf. CXII, 2 Taf. 44

Bemerk: Gleiche Werkstatt wie Tk 445 ff. (Susa) und Tk 452 (Ikaros).

Tk 450a-b Amphippoi, handgeformt

(2 Exemplare) (Abb. 127)

FO: Masjid-i Solaiman (Großer Tempel)

AO: ? (G.MIS 457 / 449)

$\mathrm{H}: 16,5$ / 16

D: $300-140$ vor / 200-140 vor Chr.*

Lit: R. Ghirshman, Terrasse Sacrés de Bard-è Nechandeh et Masjid-i Solaiman, MDAI 45 (1976) 79 ff. Taf. CXII, 2 Taf. 44

Bemerk: Gleiche Werkstatt wie Tk 445 ff. (Susa) und Tk 452 (Ikaros).

Tk 451a-d Amphippoi, handgeformt mit Göttin (4 Exemplare) (Abb. 128. 130) FO: Masjid-i Solaiman (Großer Tempel) AO: ? (G.MIS 525 / 621 / 512 / 452)

H: 22,5 / 17 / 17 / 11 (Frgt.)

D: 300-140 vor Chr. / 200-140 vor Chr.*

Lit: R. Ghirshman, Terrasse Sacrés de Bard-è Nechandeh et Masjid-i Solaiman, MDAI 45 (1976) 79 ff. Taf. CXI, 1-3. CXII, 1 Taf. 44

Bemerk: Gleiche Werkstatt wie Tk 445 ff. (Susa) und Tk 452 (Ikaros).

\section{Ikaros / Failaka}

Tk 452a-u Reiter, handgeformt

21 Exemplare ? (Frgte.) (Abb. 129)

FO: Ikaros (Siedlungsbereich, Befestigungsanlagen, Heiligtümer)

AO: Kuwait (Nationalmuseum) und Failaka (Ausstellung)

H: ca. 12 (ergänzt)

D: hellenistisch? ein Exemplar (Nr. 29) stratigraphisch datiert auf: Anfang 2. Jh. vor Chr.

200-140 vor Chr.*

Lit: H. E. Mathiesen, Ikaros - The Hellenistic Settlement. Vol. 1 The Terracotta Figurines (1982) 22 ff. Nr. 25 ff. Abb. 6 ff.

Bemerk: Gleiche Werkstatt wie Tk 445 ff. (Susa) und Tk 448 ff. (Masjid-i Solaiman).

\section{Ohne Fundort}

\section{Amsterdam}

Tk 453 Kopf, handgeformt? (mit Kausia?)

FO: unbekannt, Ägypten ?

AO: Amsterdam (Privatslg.)

H: 9,5

D: ptolemäisch

Lit. B. V. Bothmer, Hellenistic Elements in Egyptian Sculpture of the Ptolemaic Period, in: Alexandria and Alexandrianism (Symposion Malibu 1993) (1996) 219 Abb. 16

\section{Hannover}

Tk 454 Chlamydephoros, stehend FO: (Griechenland ?)

AO: Hannover (Kestner Museum, 1927,161 [aus Privatbesitz Dr. Lederer, Berlin])

H: 16,1

D: 2. Jh. vor Chr.

Lit: U. Liebmann, Griechische Terrakotten, Bronzen, Skulpturen (1975) 91. T97

\section{Leiden}

Tk 455 Chlamydephoros, sitzend, Denkerpose FO: unbekannt

AO: Leiden (Slg. C.W. Lunsingh Scheurleer, Inv.Nr. 65)

H: 10,5 
D: 4. Jh. vor Chr.

Lit: G. Schneider-Herrmann, Eine niederländische Studiensammlung antiker Kunst, 1974, 13 Nr. 16 Taf. 7 Abb. 16

Bemerk: Kopf zugehörig?

\section{Madrid}

Tk 456 Reiter ohne Gegner

FO: unbekannt

AO: Madrid (Arch. Mus., Slg. Salamanca 3400)

H: 9,5

D: ,style romain“ / 3. Jh. vor Chr.*

Lit: A. Laumonier, Catalogue de terre cuites du Musée Archéologique de Madrid (1921) 178 Nr. 834 Taf. 93, 2

\section{New York}

Tk 457 Schauspieler (Silen/Soldat?), mit Theatermaske und kurzer Chlamys, dickbäuchig

FO: unbekannt

AO: New York (Metropolitan Museum of Art, Inv. 07.286.27)

H: -

D: -

Lit: B.M. Kingsley, The „Chitrali“. A Macedonian Import to the West, Afghanistan Journal, 8, 1981, 91 Abb. 2 .- dies., Alexander's Kausia and Macedonian Tradition, ClAnt 10, 1991, 64 mit Abb. 10. Bemerk: B.M. Kingsley spricht die Statuette zunächst als ,actor dressed as a comic Macedonian soldier“ (1981), später als „fat old Silenos and/or actor" (1991) an.

\section{Paris}

Tk 458 Chlamydephoros, stehend

FO: unbekannt (Nordgriechenland?)

AO: Paris (Louvre, S 3360)

H: 8,5

D: -
Lit: Besques, Paris III-I, 358. D 3088 Taf. 196 a

Tk 459 Chlamydephoros, stehend FO: unbekannt / Westkleinasien ?*

AO: Paris (Louvre, S 3762 [5])

H: 12,7

D: 1. Jh. vor Chr. / 1. - 2. Jh. nach Chr.*

Lit: Besques, Paris III-I, 358. D 3087 Taf. 196 c

\section{Thessaloniki}

Tk 460 a-b Chlamydephoroi, stehend, Epheben-Soldaten?

(2 Exemplare)

FO: unbekannt

AO: Thessaloniki (Slg. A. Phostiropoulou, 71-72)

H: 11 / 18

D: hell.

Lit: Ph. Petsas, Makedonika 14, 1974, 344 ff. Taf. $41 \mathrm{~b}$ 


\section{Literaturverzeichnis}

Angegeben wird ausschließlich die in den Anmerkungen erwähnte Literatur. Lexikonartikel (RE, LIMC) werden nur in Auswahl genannt. Ausschließlich im Katalog erwähnte Werke werdennicht aufgeführt.

\section{A}

Alessandro Magno. Storia e mito (Ausstellungskatalog Rom 1995/96) (1995)

Alexandria and Alexandrianism (Symposium, Malibu, 22-25.04.1993) (1996)

A. Adriani, Annuaire du Musée Gréco-Romaine 1940-50, 1952

Albanien. Schätze aus dem Land der Skipetaren (Ausstellungskatalog Hildesheim 1988) (1988)

B. Andreae, Antike Bildmosaiken (2003)

B. Andreae, Seleukos Nikator als Pezhétairos im Alexandermosaik, RM 111, 2004, 69-82

M. Andronicos, Vergina. The Royal Tombs and the Ancient City (1984)

A. Arvanitopoulos, Prakt 1912, 204 ff.

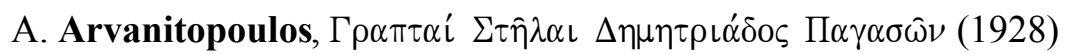

J. Audiat, Le Gymnase de Délos et l'Inventaire de Kallistratos, BCH 54, 1930, 97 f.

\section{B}

E. Babelon, Catalogue des Camées antiques et modernes de la Bibliothèque Nationale (1897)

E. Badian, The Deification of Alexander the Great, in FS C. Edson (1981) 27-71

R. S. Bagnall, The Administration of the Ptolemaic Possessions outside Egypt (1976)

P. Ballet, Terres cuites d'Alexandrie et de la Chôra. Essai d'etude comparative de quelques atelliers. Thèmes et techniques, in: Commerce et artisanat dans 1'Alexandrie hellénistique et romainè, BCH Suppl. 33 (Actes du Colloque d'Athenes 1988) (1998)

M.-Th. Barrelet, Figurines et Reliefs en Terrecuite de la Mesopotamie antique 1, Institut Français d'Archéologie de Berouth. Bibliothèque archéologique et historique 85 (1968)

E. Bayer-Niemeier, Harpokrates zu Pferde und andere Reiterdarstellungen des hellenistisch-römischen Ägyptens, StädelJb N.F. 10, 1985, 27 ff.

E. Bayer-Niemeier, Griechisch-römische Terrakotten. Bildwerke der Sammlung Kaufmann 1. LiebieghausMuseum Alter Plastik. Frankfurt am Main (1988)

C. Beer, Temple Boys (1994)

M. Bell, Morgantina Studies I. The Terracottas (1981)

F. Benoit, Mars et Mercure - Nouvelles Recherches sur l'interpretation gauloise des divinités romaines, Publications des annales de la faculté des Lettres, Aix-en-Provence, N.S. 25 (1959) 37

J. Bergemann, Demos und Thanatos (1997) 
D. Berges, Der Fundkomplex griechischer Siegelabdrücke aus Karthago, in: M.-F. Boussac, A. Invernizzi (Hrsgg.), Archives et Sceaux du monde hellenistique, BCH Suppl. 29 (Symposium Turin 1993) (1996) 327 ff.

M. Bergmann, Die Strahlen der Herrscher (1998)

H. Berve, Das Alexanderreich auf prosopographischer Grundlage I (1926)

H. Berve, Das Alexanderreich auf prosopographischer Grundlage II (1926)

S. Mollard-Besques, Musée National du Louvre. Catalogue raisonnée des figurines et reliefs en terre-cuite grecs, étrusques et romaines II. Myrina (1963)

S. Besques, Musée National du Louvre. Catalogue raisonnée des figurines et reliefs en terre-cuite grecs, étrusques et romaines III. Epoques hellénistique et romaine. Grèce et Asie Mineure (1972)

S. Besques, Musée National du Louvre. Catalogue raisonnée des figurines et reliefs en terre-cuite grecs, étrusques et romaines IV-I. Epoques hellénistique et romaine. Italie méredionale - Sicile - Sardaigne (1986)

S. Besques, Musée National du Louvre. Catalogue raisonnée des figurines et reliefs en terre-cuite grecs, étrusques et romaines IV-II. Epoques hellénistique et romaine. Cyrénaique, Égypte ptolémaique et romaine, Afrique du Nord et Proche Orient (1992)

R. S. Bianchi, Alexander the Great as a Kausia Diadematophoros from Egypt, in: The Intellectual Heritage of Egypt, Studia Aegytiaca 14 (FS Lásló Kakosy) (1992) 69-75

M. Bieber, Die Denkmäler zum Theaterwesen im Altertum (1920)

M. Bieber, Griechische Kleidung (1928).

M. Bieber, AJA 60, 1956, $171 \mathrm{f}$.

M. Bieber, History of Greek and Roman Theater (1961 [1.Aufl. 1939])

H. Biesantz, Die thessalischen Grabreliefs (1965)

P. Bilde, T. Engberg-Pedersen, L. Hannestad (Hrsgg.), Ethnicity in Hellenistic Egypt, Studies in Hellenistic Civilisation 3 (1992)

BMC, Greek Coins. The Seleucid Kings of Syria (1878)

BMC, Greek Coins. The Ptolemies (1883)

J. Boardman, Rotfigurige Vasen aus Athen. Die klassische Zeit (1991)

J. Boehlau, K. Schefold (Hrsgg.), Larisa am Hermos (Die Ergebnisse der Ausgrabungen 1902-34) 3. Die Kleinfunde (1942)

G. Böth, Kleidungsforschung, in: R.W. Brednich, Grundriß der Volkskunde. Eine Einführung in die Forschungsfelder der Europäischen Ethnologie ${ }^{3}$ (2001)

P. G. Bogatyrev, Funkcie kroja na Moravskom Slovensku (1937). (Engl. Fassung: P. G. Bogatyrev, The funktion of Folk Costume in Moravian Slovacia, Approaches to Semiotics 5 [1971])

L. Bonfante, Etruscan Dress (1975)

O. Bopeorachchi, Monnaies gréco-bactriennes et indo-grecques (1991)

B.v. Bothmer, Hellenistic Elements in Egyptian Sculpture of the Ptolemaic Period, in: Alexandria and Alexandrianism ( Symposium Malibu 1993) (1996) $220 \mathrm{f}$.

A. K. Bowman, Egypt after the Pharaohs (1989)

H. Brandenburg, Studien zur Mitra (1966)

L. B. Brea, Menandro e il teatro greco nelle terracotte liparesi (1981) 
E. Breccia, La necropoli di Sciatbi (1912)

E. Breccia, Terrecotte figurate greche e greco-egizie del Museo di Alessandria. Monuments de 1'Égypte gréco-romaine II 1 (1930)

E. Breccia, Terrecotte figurate greche e greco-egizie del Museo di Alessandria. Monuments de 1'Égypte gréco-romaine II 2 (1934)

B. R. Brown, Ptolemaic Paintings and Mosaics and The Alexandrian Style (1957)

P. A. Brunt, Alexander's Macedonian Cavalry, JHS 83, 1963, 23 ff.

G. R. Bugh, The Horsemen of Athens (1988)

L. Burckhardt, Bürger und Soldaten. Aspekte der politischen und militärischen Rolle athenischer Bürger im Kriegswesen des 4. Jahrhunderts v.Chr., Historia Einzelschriften 101 (1996)

E. D. van Buren, Clay Figurines of Babylonia and Assyria (1930)

W. Burkert, Greek Cult (1985)

D. Burr-Thompson, Troy III. The Terracotta Figurines of the Hellenistic Period (1963)

D. Burr-Thompson, The Origin of the Tanagras, AJA 70, 1966, $51 \mathrm{ff}$.

C

G. Camporeale, in: Die Etrusker und Europa (Ausst.-Kat. Berlin 1993) $81 \mathrm{f}$.

V.Caranache, Masken und Tanagra-Figuren aus Werkstätten von Callatis-Mangalia (1969)

A. Caubert, Das Ende der Archaik und die klassische Epoche, in: Aphrodites Schwestern und das christliche Zypern (Ausstellungskatalog Bremen) (1987)

A. Chaniotis, Sich selbst feiern? Städtische Feste des Hellenismus im Spannungsfeld von Religion und Politik, in: M. Wörle - P. Zanker (Hrsgg.), Stadtbild und Bürgerbild im Hellenismus (Kolloquium München 1993) (1995) $147 \mathrm{ff}$.

M. Chéhab, Les terres cuites de Kharayeb, BMusBeyr 10/11, 1951/52

M. Christofani, I Bronzi degli Etruschi (1985)

G. W. Clarke, Jebel Khalid on the Euphrates. The Acropolis Buildings, MeditArch 7, 1994, 75

G. M. Cohen, Katoikiai, Katoikoi and the Macedonians in Asia Minor, AncSoc 22, 1991, 41-50

G. M. Cohen, The Hellenistic Settlement in Europe, the islands, and in Asia Minor, Hellenistic Culture and Society 17 (1995)

S.G. Cole, The social Function of Rituals of Maturation: The Koureion und the Arkteia, ZPE 55, 1984, 233 ff.

J. B. Connelly, Hellenistic Alexandria, in: J. P. Uhlenbrock (Hrsg.), The Coroplast's Art (FS D. Burr Thompson) (1990) $89 \mathrm{ff}$.

J. B. Connelly, The terracotta figurines. Greek types and cult, in: Failaka. Fouilles françaises 1986-88, Travaux de la Maison de l'Orient 18 (1990) 217

P. J. Connor, Terracottas from Seleucid Jebel Khalid, MeditArch 7, 1994, 78 f.

A. Conze, AvP I 2 (1930)

W. D. E. Coulson, Chatby reconsidered, JEA 73, 1987, 234-236

F. Courby, FdD II. La terrasse du temple (1927)

F. Cumont, The Bacchic Inscription in the Metropolitan Museum, AJA 37, 1933, 262 f. 
G. Davidson, A Hellenistic Deposit at Corinth, Hesperia 11, 1942, 111

N. Davis/C. M. Kraay, The Hellenistic Kingdoms. Portrait Coins and History (1973)

D. Delia, „All Army Boots and Uniforms?“ Ethnicity in Ptolemaic Egypt, in: Alexandria and Alexandrianism (Symposium Malibu 1993) (1996) $41 \mathrm{ff} .45$

P. Delev, Bevölkerung und Siedlungssystem an der bulgarischen Schwarzmeerküste, in: W. Schuller (Hrsg.), Die bulgarische Schwarzmeerküste im Altertum, Xenia 16 (1985) 17

J. Delorme, Gymnasion (1960)

L. Deubner, Attische Feste (1932)

P. Dintsis, Hellenistische Helme (1986)

M. Donderer, Das pompejanische Alexandermosaik - Ein östliches Importstück, in: Das antike Rom und der Osten (FS Parlasca) (1990) 19 ff.

S. Dremisizova, Anticni Terakoti ot Bulgaria (1971)

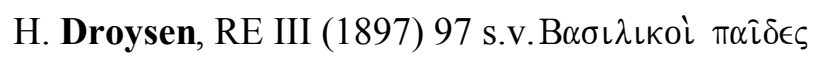

S. Düll, Die Götterkulte Nordmakedoniens (1977)

F. Dunand, Religion Populaire en Egypt romaine. Les terres cuites isiaques du Musée du Caire, Etudes préliminiaire aux religions orientales dans l'empire romaine 76 (1979)

F. Dunand, Terres cuites gréco-romaine d'Égypte. Musée du Louvre, Département des Antiquites Égytiennes (1990)

M. Dunand - R. Duru, Oumm el-‘Amed (1962)

E. B. Dusenbery, Samothrace - The Necropoleis, Samothrace 11 (Hrsgg.: K. Lehmann/Ph. Williams Lehmann) (1998)

$\mathbf{E}$

V.Ehrenberg, Der Staat der Griechen² (1965)

$\mathbf{F}$

B. Fehr, Verhaltensweisen und Bewegungsideale (1979)

A. Ferri, Il Museo Archeologico di Bologna (1974)

J. Fischer, Griechisch-römische Terrakotten aus Ägypten. Die Sammlungen Sieglin und Schreiber. DresdenLeipzig-Stuttgart-Tübingen (1994)

J. Fischer, Der Zwerg, der Phallos und Harpokrates, in: H. Felber - S. Fisterer-Haas (Hrsgg.), Ägypter Griechen - Römer. Begegnungen der Kulturen, Kanobos 1 (1999) 31 ff.

J. Fischer, Ein triumphierender Makedonenreiter. Zeugnis eines ptolemäischen Siegesdenkmals?, in: P.C.Bol - G.Kaminski - C.Maderna (Hrsg.), Fremdheit - Eigenheit. Ägypten, Griechenland und Rom. Austausch und Verständnis, StädelJb 19, 2004, 487-498

S. Fisterer-Haas, Antike Terrakotten (1996)

M. Fjeldhagen, Graeco-roman Terracottas from Egypt. Ny Carlsberg Glyptotek (1995)

E. Flaig, Den Kaiser herausfordern (1992) 
R. Fleischer, Studien zur seleukidischen Kunst 1. Herrscherbildnisse (1991)

P. M. Fraser, Ptolemaic Alexandria (1972)

E. A. Fredricksmeyer, Alexander the Great and the Macedonian Kausia, TAPhA 116, 1986, $215 \mathrm{ff}$.

W. Fuchs, Die Skulptur der Griechen (1993)

\section{G}

H. Gabelmann, Antike Audienz- und Tribunalszenen (1984)

H. Gaebler, Die antiken Münzen von Makedonia und Paionia (Die antiken Münzen Nord-Griechenlands III

2) (1935)

H.-J. Gehrke, Geschichte des Hellenismus², Oldenbourg Grundriß der Geschichte 1A (1995)

H. de Genouillac, Fouilles de Telloh II (1936)

B. George, Ptolemaios II und Arsinoe II vor den Göttern von Athribis, MedelhavsMusB 17, 1982, 12 ff.

R. Ghirshman, Iran - Parther und Sasaniden (1962)

R. Ghirshman, Terrasses Sacrées de Bard-è Nechandeh et Masjid-i Solaiman, MDAI 45 (1976)

L. Giuliani, Die seligen Krüppel, AA 1987, 701-721

H. R. Goette, Studien zu römischen Togadarstellungen (1990)

V. von Gonzenbach, Untersuchungen zu den Knabenweihen im Isiskult der römischen Kaiserzeit (1957)

K. Goudriaan, Ethnicity in Ptolemaic Egypt, Dutch Monographs on Ancient History and Archaeology 5 (1988)

D. Graepler, Kunstgenuß im Jenseits? Zur Funktion und Bedeutung hellenistischer Terrakotten als Grabbeigabe, in: Bürgerwelten (Ausstellungskatalog Berlin) (1994) 53

D. Graepler, Tonfiguren im Grab (1997)

V. von Graeve, Die bemalten Grabstelen von Demetrias, in: La Thessalie, Collection de la Maison de l’Orient Méditerranéen 6, Série Archeologique 5 (Actes Lyon) (1979) 113

L. Grassberger, Erziehung und Unterricht im klassischen Altertum. III. Theil: Die Ephebenbildung (1881)

G. Grimm, Alexandria. Die erste Königsstadt der hellenistischen Welt (1998)

\section{H}

Ch. Habicht. Gottmenschentum und griechische Städte ${ }^{2}$, Zetemata 14 (1977)

M. Hadas, Hellenistische Kultur (1981 [engl. 1959])

M. Hain, Das Lebensbild eines oberhessischen Trachtendorfes. Von bäuerlicher Tracht und Gemeinschaft, Forschungen zur deutschen Volkskunde 1 (1936)

N. G. L. Hammond - G. T. Griffith, A History of Macedonia II (1979)

M. B. Hatzopoulos, Macedonian Institutions under the Kings, Meletemata 22 (1996)

F. Heckmann, Ethnische Minderheiten, Volk und Nation. Soziologie inter-ethnischer Beziehungen (1992)

U. Heimberg, Was bedeutet „Romanisierung“"?, AntW 29, 1998, 20 ff.

Hellenismus. Beiträge zur Erforschung von Akkulturation und politischer Ordnung in den Staaten des hellenistischen Zeitalters (Akten des Internationalen Hellenismus Kolloquiums, 9.-14. März 1994 in Berlin, Hrsg von B. Funck) (1996)

A. Hermary, Catalogue des Antiquités de Chypre. Sculptures (1989) 
H. von Hesberg, Das griechische Gymnasion im 2. Jh. v.Chr. in: M. Wörrle und P. Zanker (Hrsgg.), Stadtbild und Bürgerbild im Hellenismus (Kolloquium München 1993) (1995)

L. Heuzey, Daremberg-Saglio I, 2 (1896) 975 f. s.v. Causia

L. Heuzey, Histoire de la costume antique (1922)

R.A. Higgins, Greek Terracottas (1967)

R. A. Higgins, Tanagra and the Figurines (1986)

$\mathrm{Ph}$. Hill, The Temples and Statues of Apollo in Rom, NumChron 2, 1962, $135 \mathrm{f}$.

K.-H. Hillmann, Wörterbuch der Soziologie (1994) 13 s.v. Akkulturation

N. Himmelmann, Ideale Nacktheit in der griechischen Kunst (1990)

N. Himmelmann, Spendende Götter, in: Minima archaeologia (1996) 54-61

B. Hintzen-Bohlen, Die Kulturpolitik des Eubulos und des Lykurg (1997)

V.Hinz, Der Kult von Demeter und Kore auf Sizilien und in der Magna Graecia, Palilia 4 (1998)

R. F. Hoddinott, Bulgaria in Antiquity (1975)

G. Hölbl, Geschichte des Ptolemäerreiches (1994)

T. Hölscher, Historienbilder des 4. - 5. Jh. v. Chr.(1973)

O. Hoffmann, Die Makedonen (1906)

F. L. Hol, Alexander the Great and Bactria, Mnemosyne Suppl.104 (1988)

E. Honigmann, RE 2. Reihe III (1929) 2152 f. s.v. Stasanor

G. v. Horn, Eine minoische Bronze in Leiden, JdI 30, 1915, 65 ff.

E. Hornung, Der Eine und die Vielen (1971)

K. Hornung-Bertemes, Die „Kausia“-Darstellungen aus Demetrias, in: A. Muller (Hrsg.), Le moulage en terre cuite dans l'antiquité: creation et production dérivée, fabrication et diffusion (Kolloquium Lille 1995) (1997/99) 181-206

A. Houghton, Timarchus as King in Babylonia, RevNum 21, 1979, 214

A. Houghton, Coins of the Seleucid Empire from the Collection of Arthur Houghton (1983)

B. Hrouda, Tell Halaf 4. Die Kleinfunde aus historischer Zeit (1962)

\section{I}

L. Illig, Rezension zu Marrou, Gymnasium 65, 1958, 569-571

W. van Ingen, Figurines from Seleucia on the Tigris (1939)

A. Invernizzi, in: La terra tra i due fiumi (Ausstellungskatalog Florenz 1986) $125 \mathrm{Nr} 104 \mathrm{ff}$.

A. Invernizzi, Arte seleucide in Mesopotamia, in: Akten des XIII. Internationalen Kongresses für Klassische Archäologie (Berlin 1988) (1990) 20

$\mathbf{J}$

B. Jacobs, Kleidung als Symbol. Das Beispiel der Altgläubigen Südsibiriens im 19. und beginnenden 20. Jahrhundert, Kölner ethnologische Studien 21 (1992)

K. Jeppesen, Ikaros III -The Sacred Enclosure in the Early Hellenistic Period. With an appendix on epigraphic finds (1989)

A. M. Jones, The Equestrian Motive in the Coptic Textiles (1974) 
S. Jones, The Archaeology of Ethnicity (1997)

J. A. Josephson, Egyptian Royal Sculpture of the Late Period.400-246 B.C. (1997) 19-21

P. Jouguet, Inscriptions greques d’Égypte, BCH 20, 1896, 194

$\mathbf{K}$

A. Kähler, Der große Fies von Pergamon (1948)

D. Kah/P. Scholz (Hrsg.), Das hellenistische Gymnasion (Wissenskultur und gesellschaftlicher Wanel 8) (2004)

K. Karttunen, India and the Hellenistic World, Studia Orientalia 83 (1997)

K. Karvonen-Kaunas, The Seleucid and Parthian Terracotta Figurines from Babylon (1995)

B. M. Kingsley, The Cap that Survived Alexander, AJA 85, 1981, 39-46

B. M. Kingsley, The „Chitrali“. A Macedonian Import to the West, Afghanistan Journal 8, 1981, 90-93

B. M. Kingsley, The Kausia Diadematophoros, AJA 88, 1984, 66 ff.

B. M. Kingsley $\dagger$, Alexander's Kausia and Macedonian Tradition, ClAnt 10, 1991, 59-76

E. Klengel-Brandt, Die hellenistische Kultur in Babylon: das Zeugnis der Terrakotten, in: Arabia Antiqua, Serie Orientale Roma 70, 2 (Hrsg. v. A. Invernizzi, J.-F. Salles) (1993) 195

A. Kneppe, Timarchos von Milet - ein Usurpator im Seleukidenreich, in: Migratio et commutatio (FS T. Pekáry) (1989) 37 ff.

L. Koenen, Eine agonistische Inschrift aus Ägypten und frühptolemäische Königsfeste, Beiträge zur Klassischen Philologie 56 (1977)

F. Kolb, Polis und Theater, in: Das griechische Drama (Hrsg. von G.A. Seeck) (1979) 517

F. Kolb, Agora und Theater, Volks- und Festversammlung, AF 9 (1981).

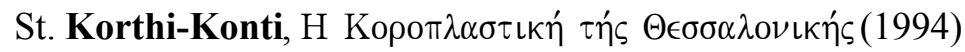

A. Krug, Binden in der griechischen Kunst (1968)

H. Kyrieleis, Der Kameo Gonzaga, BJB 171, 1971, 166 f.

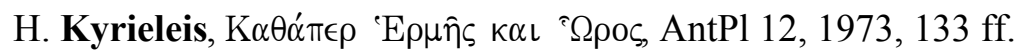

H. Kyrieleis, Die Porträtmünzen Ptolemaios` V., JdI 88, 1973, 215 ff.

H. Kyrieleis, Bildnisse der Ptolemäer, AF 2 (1975)

H. Kyrieleis, Bildnisse des Kaisarion. Zu den Siegelabdrücken aus Nea Paphos, in: Akten des XIII. Internationalen Kongresses für Klassische Archäologie (Berlin 1988) (1990) 457 f.

H. Kyrieleis, Ptolemäische Porträts auf Siegelabrücken aus Nea Paphos (Zypern), in: Archives et Sceaux du monde hellenistique, BCH Suppl. 29 (Symposium Turin 1993) (Hrsg. v. M.-F. Boussac, A. Invernizzi) (1996) $315 \mathrm{ff}$.

H. Kyrieleis, Ägyptische Bildelemente auf Siegelabdrücken aus Nea Paphos (Zypern), in: P.C.Bol- G.Kaminski - C.Maderna (Hrsg.), Fremdheit - Eigenheit. Ägypten, Griechenland und Rom. Austausch und Verständnis, StädelJb 19, 2004, 109-116

$\mathbf{L}$

F. Lammert, RE 2. Reihe I,2 (1920) 2515 ff. s.v. Sarisse

F. Lammert, RE XIX (1938) 403-406 s.v. Peltastai 
H. P. Laubscher, AntK 30, 1987, 131 f.

H. P. Laubscher, Ptolemäische Reiterbilder, AM 106, 1991, 223-238

A. Laumonier, Delos XIII. Les figurines de terre cuite (1957)

L. Legrain, Terracottas from Nippur (1930)

St. Lehmann, Ptolemaios III. Euergetes - Hermes Enagonios als Pentathlos und Pankratiast, in: K. Gschwantler, A. Bernhard-Walcher (Hrsgg.), Griechische und römische Statuetten und Großbronzen (Akten... Wien 1986) (1988) $290 \mathrm{f}$.

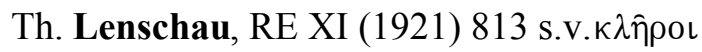

G. LeRider, Suse sous les Séleucides et les Parthes, MDAI/MMAI 38 (1965)

G. LeRider, Le Monnayage d'Argent et d'Or de Philippe II. - Frappé en Macédoinie de 359 á 294 (1977)

Chr. Le Roy, Un règlement religieux au Létôon du Xanthos, RA, 1986, 279 ff.

N. Lewis, Greeks in Ptolemaic Egypt (1986)

S. Lewis, The Iconography of the Coptic Horseman in Byzantine Egypt, JARCE 10, 1973, $32 \mathrm{ff}$.

P. G. Leyenaar-Plaisier, Les terres cuites gréques et romaines I-III. Catalogue de la Collection du Musée National des Antiquites a Leiden (1979)

K. Liampi, Der makedonische Schild (1998)

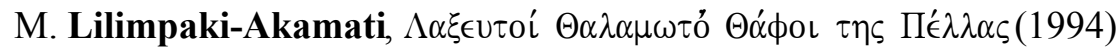

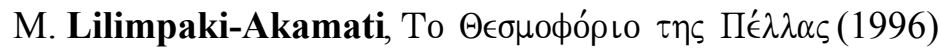

G. Lilliu, Scultura Sardegna Nuragica (1966) 51.266. 268

M

M. Mackintosh, The Divine Rider in the Art of the Western Roman Empire, BAR Intern.Series 607 (1995) C. Maderna, Zum Feindbild der Ptolemäer, in: Ägypten Griechenland Rom. Abwehr und Berührung, Ausstellung Städelsches Kunstinstitut und Städtische Gallerie Frankfurt, 2005/06, 258-266, 584f.Nr. 157

I. Malkin (Hrsg.), Ancient Perceptions of Greek Identity, Center of Hellenic Studies colloquia 5 (2001)

H. I. Marrou, Geschichte der Erziehung im Klassischen Altertum (1977 [= Taschenbuchauflage nach der 7. Aufl.]; franz. Erstaufl. 1948)

O. Masson, Kypriaka. IX. Recherches sur les Antiquités du Golgoi, BCH 95, 1971, 305 ff.

H. E. Mathiesen, Ikaros - The Hellenistic Settlement I. The Terracotta Figurines (1982)

A. Mau, RE V (1903) 303 s.v. Diadema

A. Mau, Pompeji (1908)

J. R. McCredie, Preliminary Report, Hesperia 34, 1965, 120 f.

R.H. McDowell, Stamped and Inscribed Objects from Seleucia on the Tigris (1935)

A. Mehl, Erziehung zum Hellenen. Erziehung zum Weltbürger. Bemerkungen zum Gymnasion im hellenisti schen Osten, Nikephoros 5, 1992, 65

A. Mehl, Griechen und Phöniker im hellenistischen Zypern - ein Nationalitätenproblem?, in: B. Funck (Hrsg.), Hellenismus. Beiträge zur Erforschung von Akkulturation und politischer Ordnung in den Staaten des hellenistischen Zeitalters (Akten des Internationalen Hellenismus Kolloquiums, 9.-14. März 1994 in Ber lin) (1996) 374

J.-P. Michaud, Chronique, BCH 97, 1973, 335 ff. 
V. Milojcic, Bericht über die deutschen archäologischen Ausgrabungen in Thessalien, ADelt 28B`2, 1973, $347 \mathrm{f}$.

V. Milojcic, BCH 97, 1973, 338

V. Milojcic, D. Theocharis (Hrsgg.), Demetrias III, BAM, 19 (1980)

M. Mitchiner, Indo-Greek and Indo-Scytian Coinage 1-3 (1975)

O. Mørkholm, Sculpture and Coins: The Portrait of Alexander Balas of Syria, NumAntCl 10, 1981, $235 \mathrm{ff}$.

O. Mørkholm/A. Kromann, The Ptolemaic Silver Coinage on Cyprus 192/1-164/3 B.C., Chiron 14, 1984, $150 \mathrm{ff}$.

S. Mollard-Besques, Musée National du Louvre. Catalogue raisonnée des figurines et reliefs en terre-cuite grecs, étrusques et romaines II. Myrina (1963)

P. Moreno, Scultura ellenistica I (1994)

P. Moreno, Elementi di pittura ellenistica, in: L'Italie méridionale et lespremières expériences de la peinture hellenistique, Collection de l'école française de Rome 244 (Actes...Rome 18.02.1994) (1998) 19 ff.

U. Mrogenda, Die Terrakotten von Myrina (1996)

K. Mysliwiec, Fruchtbarkeitskult und erotische Kunst im ptolemäischen Athribis (Unterägypten), in: H. Felber - S. Pfisterer-Haas (Hrsgg.), Ägypter-Griechen-Römer, Kanobos 1 (1999) 79

K. Mysliwiec - Moattameda Bakr Said, Polish-Egyptian Excavations at Tell Atrib in 1994-1995, EtTrav 17, 1999, 191

\section{$\mathbf{N}$}

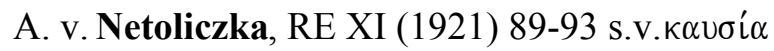

E. Newell, The Seleucid Mint of Antioch (1917 [Nachdruck 1978])

M. P. Nilsson, Geschichte der griechischen Religion 1, HAW 5.2. 1. (1941)

M. P. Nilsson, Cults, Myths, Oracles, and Politics in Ancient Greece (1951)

M. P. Nilsson, Die hellenistische Schule (1955)

M. P. Nilsson, The Minoan-Mycenaean Religion and ist Survivals in Greek Religion (1955)

\section{$\mathbf{O}$}

E. Oberhummer, RE VII (1912) 1579 ff. s.v. Golgoi

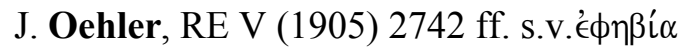

J. Oehler, RE VII (1912) 2004 ff. s.v. Gymnasium

J. Overbeck, A. Mau, Pompeji (1884)

\section{$\mathbf{P}$}

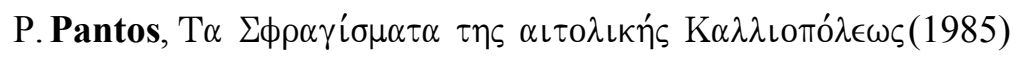

P. Pantos, in: Archivi e Sigilli nel mondo ellenistico, BCH Suppl. 29 (Symposium Turin 1993) (1996) 184194

P.Paris, Daremberg-Saglio IV 1 (o.J./vermutlich zw. 1899 und 1912) 421 s.v.đé $\tau \alpha \sigma o \varsigma$ 
K. Parlasca, Pseudokoptische „Reiterheilige“, in: G. Koch (Hrsg.), Studien zur spätantiken und frühchristlichen Kunst und Kultur des Orients, Göttinger Orientforschungen II 6 (1982) 19 ff.
A. Parrot, M. Chéhab, S. Moscati, Die Phönizier (1977)
E. Paul, Tanagrafiguren (1962)
E. Paul, Antike Welt in Ton (o. J. [um 1958, spätestens 1968])

A. Pekridou-Gorecki, Mode im antiken Griechenland (1989)

Ch. Pélékidis, Histoire de l'Éphebie attique (1962)

I. Petrascheck-Heim, Die Sprache der Kleidung. Wesen und Wandel von Tracht, Mode, Kostüm und Uniform (1988 [2. neubearb. Aufl.])

M. Pfrommer, Göttliche Fürsten in Boscoreale, 12. MWPr (1992)

M. Pfrommer, Untersuchungen zur Chronologie und Komposition des Alexandermosaiks auf antiquarischer Grundlage (1998)

H. Philipp, Terrakotten aus Ägypten im Ägyptischen Museum Berlin (1972)

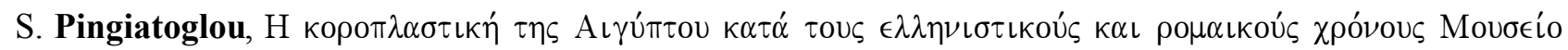

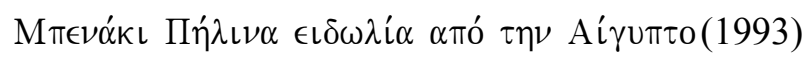

D. Plantzos, Female portrait types from the Edfu hoard of clay seal impressions, in: Archivi e Sigilli nel mondo ellenistico, BCH Suppl. 29 (Symposion Turin 1993) (1996) 307 ff.

D. Plantzos, Ptolemaic Cameos of the 2nd and 1st Centuries B.C., OJA 15, 1996, 44

D. Plantzos, Hellenistic Engraved Gems (1999)

F. Poland, RE XV (1931) 557 f. s.v. $\mu \epsilon \lambda \lambda^{\prime} \phi \eta \beta O \varsigma$

W. Posch, Baktrien zwischen Griechen und Kuschan (1995)

Poseidonia e i Luccani (Ausstellungskatalog Paestum 1996, Hrsgg.: M. Cipriani, F. Longo) (1996)

A.M. Prestianni-Giallombardo, Recenti testimonianze iconografiche sulla kausia in Macedonia e la datazione del fregio della caccia della II tomba reale di Vergina, DialHistAnc 17, 1991, 257-304

A.M. Prestianni-Giallombardo, Un Copricapo dell' equipaggiamento militare macedone: la kausia, $\mathrm{Nu}-$ mAntCl 22, 1993, 61 ff.

$\mathbf{R}$

W. Radt, Pergamon (1988)

A. Reinach, Les Galates dans l'Art Alexandrin, MontPiot 18, 1910, 103 f.

G. M. A. Richter, The Portraits of the Greeks III (1965)

H.-W. Ritter, Diadem und Königsherrschaft (1965)

H. W. Ritter, Zum so genannten Diadem des Philippsgrabes, AA 1984, 105-111

C. Robert, Die Masken der neueren attischen Komoedie, 25.HallWPr (1911)

D. Robinson, Excavations at Olynthus IV. The Terracottas (1931)

D. Robinson., Excavations at Olynthus VII. The Terracottas (1933)

D. Robinson, Excavations at Olynthus XIV.The Terracottas (1952)

G. Roeder, Die ägyptische Religion in Texten und Bildern 2. Mythen und Legenden um ägyptische Gottheiten und Pharaonen (1960) 
G. Roeder, Die ägyptische Religion in Texten und Bildern 3. Kulte, Orakel und Naturverehrung im alten Ägypten (1960)

M. Rostovtzeff, Die hellenistische Welt. Gesellschaft und Wirtschaft II (1955)

B. Rückert, Die Hermen im öffentlichen und privaten Leben der Griechen (1998)

S

Ch. Saatsoglou-Paliadeli, Aspects of the Ancient Macedonian Costume, JHS 113, 1993, $122 \mathrm{ff}$.

G. Sanders, Kybele und Attis, in: Die Orientalischen Religionen im Römerreich, OrRR (Hrsg. M. J. Vermaseren) (1981)

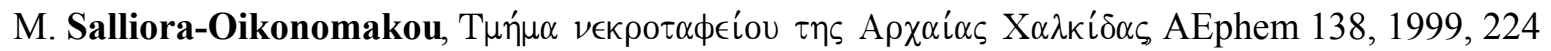

E. Samter, Familienfeste der Griechen und Römer (1901)

Th. Schäfer, Imperii Insignia. Zur Repräsentation römischer Magistrate (1989)

Th. Schäfer, Andres Agathoi (1997)

K. Schillinger, Untersuchungen zur Entwicklung des Magna Mater-Kultes im Westen des römischen Kaiser reichs (1979) 289

B. Schmaltz, Terrakotten aus dem Kabirenheiligtum bei Theben (1974)

J. Schmidt, RE V (1905) 2744 s.v.é $\phi \eta \beta i ́ \alpha$

C. Schneider, Kulturgeschichte des Hellenismus II (1969) 32

L. Schneider, B. Fehr, K.-H. Meyer, Zeichen - Kommunikation - Interaktion, Hephaistos 1, 1979, 7 ff.

G. Schneider-Herrmann, in: Alessandria e il mondo ellenistico-romano (FS A. Adriani) (1984) 303

V. v.Schoeffer, RE III (1897) 80 f. s.v. Basileus (1)

A. Scholl, Die attischen Bildfeldstelen des 4. Jhs. v.Chr. (1996)

R. Scholl, Identitäten und Multikulturalität. Das Zeitalter der Griechen in Ägypten, in: H. Felber - S. Pfisterer-Haas (Hrsgg.), Ägypter-Griechen-Römer, Kanobos 1 (1999) 125 ff.

B. Scholz, Untersuchungen zur Tracht der römischen matrona (1992)

G. Schubert, Kleidung als Zeichen. Kopfbedeckungen im Donau-Balkanraum, Balkanologische Veröffentli chungen 20 (1993 [= Habilitationsschrift, FU Berlin, 1991])

W. Schürmann, Katalog der antiken Terrakotten im badischen Landesmuseum Karlsruhe (1989)

R. Schulz - M. Seidel (Hrsgg.), Ägypten - Die Welt der Pharaonen (1997)

E. Schuppe, RE XIX (1938) 1121 s.v. $\pi^{\prime} \epsilon \alpha \sigma o \varsigma$

N. Secunda, Seleucid and Ptolemaic Reformed Armies 168-145 B.C. II. The Ptolemaic Army (1995)

J. Seibert, Zur Bevölkerungsstruktur Zyperns, AncSoc 7, 1976, 1-28

S. Sherwin-White, A. Kuhrt, From Samarkhand to Sardis (1993)

E. Simon, LIMC II (1985) 378 f. s.v. Apollon/Apollo Nr. 53 f.

E. Simon, LIMC VIII Suppl. (1997) 1130 s.v. Silenoi Nr. 216

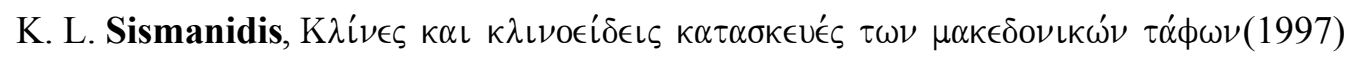

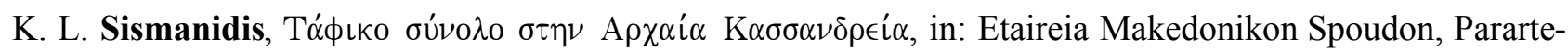
ma Makedonikon 6 (Mneme Manole Andronikou) (1997)

E. Sjöqvist, The Swedish Cyprus Expedition II (1935)

E. Sjöqvist, A Cypriot Temple Atttendant, AJA 59, 1955, 47 
R. R. R. Smith, Hellenistic Royal Portraits (1988)

G. A. S. Snijder, Algemeene Gids (1937)

A. Spycket, Les figurines de Suse, MDAI 52 (1992)

Stadtbild und Bürgerbild im Hellenismus (Kolloquium München 1993, Hrsgg. von M. Wörrle und P. Zanker) (1995)

F. Stählin, E. Meyer, A. Heidner, Pagasai und Demetrias (1934)

A. Stewart, Faces of Power - Alexander's Image and Hellenistic Politics (1993)

A. Stamatiou, Alexander the Great as a Lion Hunter, in: Praktika tou XII Diethnous synedriou klasikes archaiologias 2 (Athen 1983) (1988) $209 \mathrm{ff}$.

D. Stollberg, Wahrnehmen und Annehmen. Seelsorge in Theorie und Praxis (1978)

D. Svenson, Darstellungen hellenistischer Könige mit Götterattributen, Archäologische Studien 10 (1995)

$\mathbf{T}$

F. B. Tarbell, The Form of the Chlamys, ChPh 1, 1906, 283-89

W. W.Tarn, The Greeks in Bactria and India (1951)

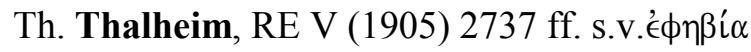

P. Themelis, Ausgrabungen in Kallipolis 1977-78, AAA 12/2, 1979, 245-279

H. J. Thissen, Studien zum Raphia-Edikt (1966) 11 ff.

D.J. Thompson, Language and Literacy in Early Ptolemaic Egypt, in: P. Bilde, T. Engberg-Pedersen, L. Hannestad (Hrsgg.), Ethnicity in Hellenistic Egypt, Studies in Hellenistic Civilisation 3 (1992) 48

D.J. Thompson, Hellenistic Hellenes. The Case of Ptolemaic Egypt, in: I. Malkin (Hrsg.), Ancient Perceptions of Greek Identity, Center of Hellenic Studies colloquia 5 (2001) $301 \mathrm{ff}$.

H. Thompson, D. B. Thompson, S. Rotroff, Hellenistic Pottery and Terracottas (1987) (= Reprints aus Hes peria 3, 21, 23, 26, 28, 31, 34, 35, 1934-1966)

J. Toepffer, RE I (1894) 2672 ff. s.v. Apaturia

E. Töpperwein, Terrakotten von Pergamon, PF 3 (1976)

K. Treu, Zur Wirkungsgeschichte in der Antike, in: H. Kuch (Hrsg.), Die griechische Tragödie in ihrer gesellschaftlichen Funktion, Veröffentlichungen des Zentralinstituts für Alte Geschichte und Archäologie der Akademie der Wissenschaften der DDR 11 (1983) 201-216

M. Tsimbidou-Avloniti AErgMak 10A, 1996, 427-442

$\mathbf{U}$

F. Uebel, Die Kleruchen Ägyptens unter den ersten sechs Ptolemäern, AbhBerlin (Klasse für Sprache, Literatur und Kunst) 3/1968

J. P. Uhlenbrock, Greek Terracottas of the Hellenistic World, in: The Coroplast's Art (FS D. BurrThompson) (1990) 116

V

E. D. van Buren, Clay Figurines of Babylonia and Assyria (1930) 
W. van Ingen, Figurines from Seleucia on the Tigris (1939)

K. Vandorpe, Seals in and on the Papyri of Greco-Roman and Byzantine Egypt, in: Archives et Sceaux du monde hellenistique, BCH Suppl. 29 (Symposium Turin 1993) (Hrsgg.: M.-F. Boussac, A. Invernizzi) (1996) $231 \mathrm{ff}$.

V. Velkov, Mesambria Pontica, in: W. Schuller (Hrsg.), Die bulgarische Schwarzmeerküste im Altertum, Xenia, 16 (1985) $30 \mathrm{ff}$.

M. J. Vermaseren, Corpus Cultus Cybelae Attidisque III. Italia-Latium (1977)

P. Vídal-Naquet, Der schwarze Jäger (1989)

M.-L. Vollenweider, Camées et intailles I. Les Portraits grecs du Cabinet des médailles. Catalogue raisonné (1995)

\section{W}

F. W.Walbank, Die hellenistische Welt (1983)

G. Walser, Die Völkerschaften auf den Reliefs von Persepolis, TeherF 2 (1966), $33 \mathrm{ff}$.

H. Walters, Catalogue of the Terracotta's in the British Museum (1903)

W. Weber, Die ägyptisch-griechischen Terrakotten. Königliche Museen zu Berlin. Mitteilungen aus der Ägyptischen Sammlung II (1914)

T. B. L. Webster, Greek Dramatic Monuments from the Athenian Agora and Pnyx, Hesperia 29, 1960, 263

ff. Taf. 66

F. H. Weisbach, Die Keilinschriften der Achämeniden (1911)

Th. Wiegand - H. Schrader, Priene. Ergebnisse der Ausgrabungen und Untersuchungen in den Jahren 189598 (1904)

H. Wiemken, Der griechische Mimos (1972)

W. D. van Wijngaarden, De Grieks-egyptische Terracotta's in het Rijksmuseum van Oudheden te Leiden (1958)

U. v. Wilamowitz-Moellendorff, Zwei Gedichte aus der Zeit Euergetes II., ArchPF 1, 1901, 119 ff.

E. Will, Histoire politique du monde hellénistique (1979)

H. Willrich, RE V (1905) 714 f. s.v. Diodotos (7)

H. Willlrich, RE VI (1909) 1503 f. s.v. Euthydemos (9)

F. Winter, Die Typen der figürlichen Terrakotten II, in: R. Kekulévon Stradonitz (Hrsg.), Die antiken Terrakotten III. (1903)

N. Winter, The Terracottas, in: D. Buitron-Oliver (Hrsg.), The Sanctuary of Apollon Hylates at Kourion, SIMA 109 (1996) 89 ff.

C. Wolters, Die Anthemien-Ornamente der Grabstelen von Demetrias (Diss. Heidelberg 1969/70)

N. Wrede, Katalog der Terrakotten der archäologischen Oberflächenuntersuchung (Survey) des Stadtgebietes von Uruk (Uruk 35-37), BaM 21, 1990, 257

E. Wuescher-Becchi, Petasus e Causia, BullCom 32, 1904, 93-110

E. Wüst, RE XV (1932) 1727-64 s.v. Mimos 
J.H. Young- S.H. Young Terracotta Figurines from Kourion in Cyprus (1955)

$\mathbf{Z}$

P.Zanker, Die Maske des Sokrates (1995)

R. Zoepffel, Geschlechtsreife und Legitimation zur Zeugung, in: Geschlechtsreife und Legitimation zur Zeut gung im Alten Griechenland, Veröffentlichungen des Institutes für Historische Antropologie 3 (Hrsg. von E.W. Müller) (1985)

Ch. Ziegler, Die Terrakotten von Warka, ADFGUW 6 (1962) 


\section{Abbildungsnachweis}

Alle im Nachweis nicht genannten Zeichnungen stammen vom Verfasser.

Abb. 1: taz 12.09.2001 (Foto: Thomas Grapka)

Abb. 2: nach B.M. Kingsley, AJA 85, 1981, 39 Abb. 1: Making of a chitrali

Abb. 16 c: P. Pantos, in: Archivi e Sigilli nel mondo ellenistico, BCH Suppl. 29 (Symposion Turin 1993)

(1996) 189 Taf. 38, 4 (Zeichnung E. Marziliano-Mori nach Nr. 283M $\Delta$ 24481)

Abb. 44: M. Andronicos, Vergina.The Royal Tombs and the Ancient City (1984) 103 Abb. 59 re.

Abb. 47: F. Courby, FdD II.La terrasse du temple (1927) Abb. 191 (nach S. 240)

Abb. 50: P. Brown, Ptolemaic Paintings and Mosaics and the Alexandrinian Style (1957) Nr. 16 Taf. 19, 2

Abb. 54: J. Overbeck - A. Mau, Pompeji (1884) 584 Abb. 307

Abb. 63: V. von Graeve, F. Preusser, Zur Technik griechischer Malerei auf Marmor, JdI 96, 1981, 135 Abb. 17

Abb. 64: V. von Graeve, Die bemalten Stelen von Demetrias, in: La Thessalie, Collection de la Maison de 1‘Orient Méditerranéen 6, Série Archeologique 5 (Actes Lyon 1975) (1979) 132 Taf. 1, 3

Abb. 116:G. Roeder, Die ägyptische Religion in Texten und Bildern 2. Mythen und Legenden um ägyptische Gottheiten und Pharaonen [1960] 145 Abb. 28 
Tafeln 
Tafel 1

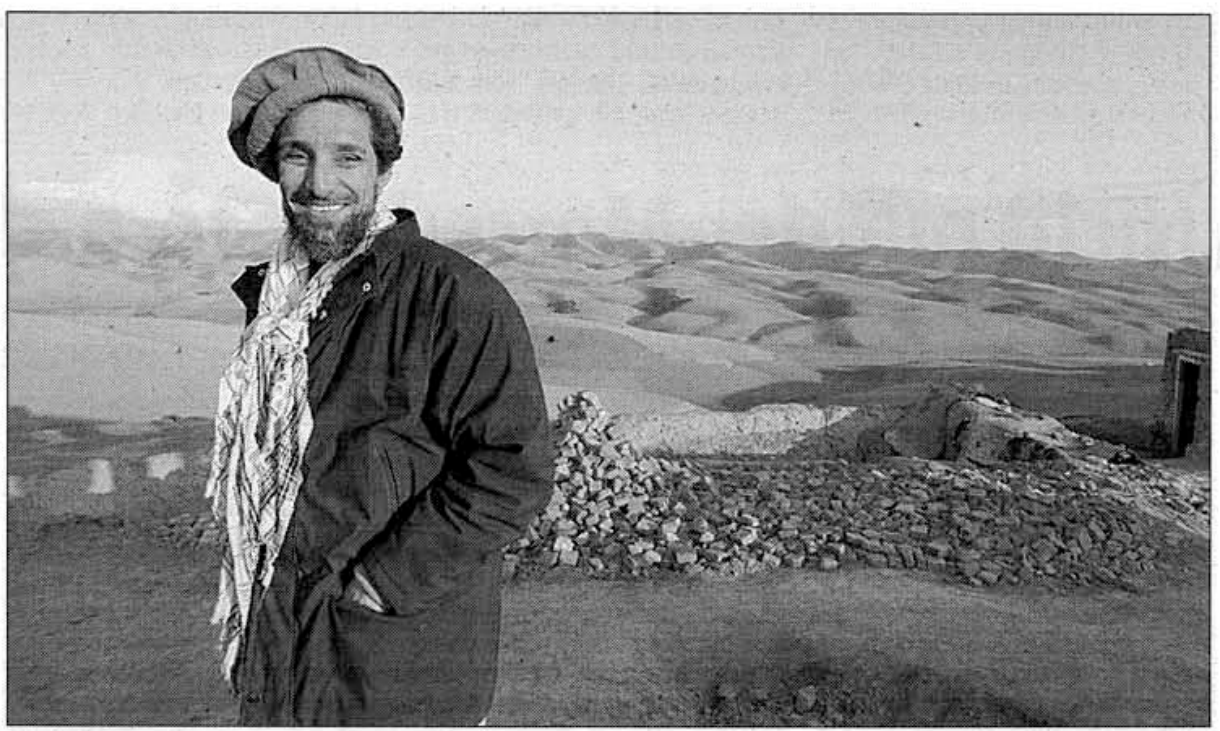

Abb. 1: Ahmad Schah Massud mit afghanisch-pakistanischer Chitrali (taz, 12.09.2001)
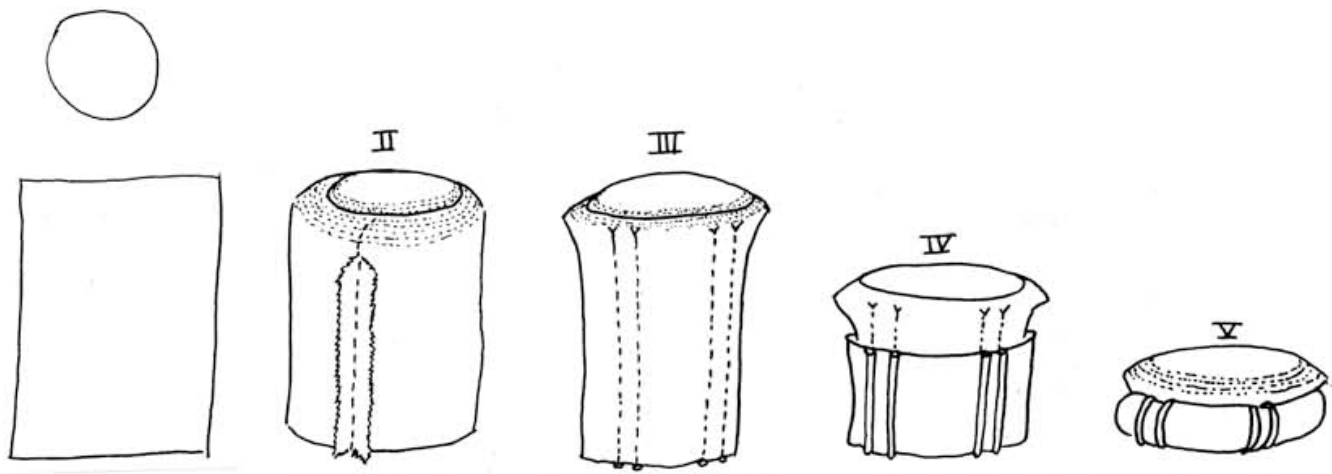

Abb.: 2 Schnittmuster der Kausia nach dem Vorbild der Chitrali (nach B.M. Kingsley)
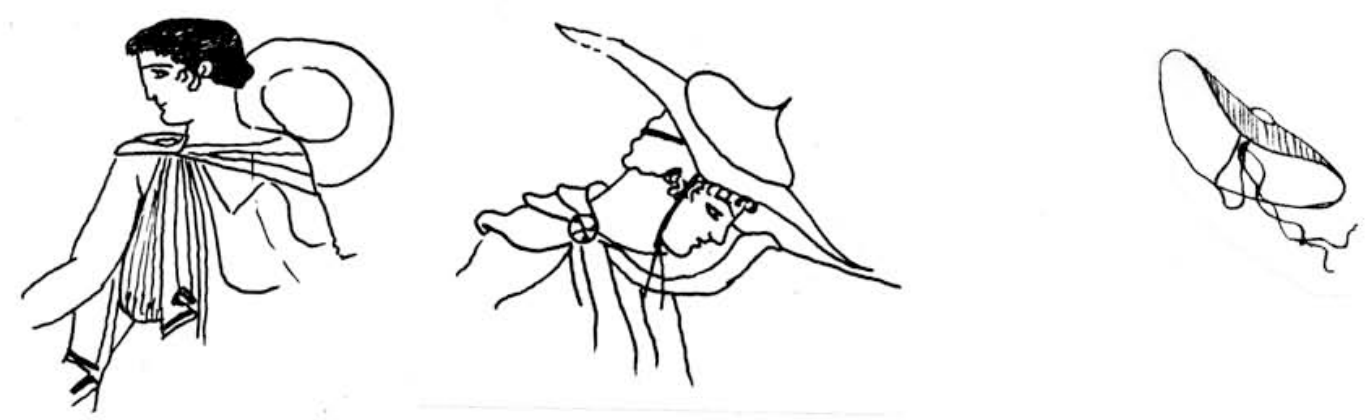

Abb. 3 a-c: Petasos

Petasos auf attischen Vasen (ARV² 599,6; 336,16)

Pella, Mosaik des Gnosis 
Tafel 2

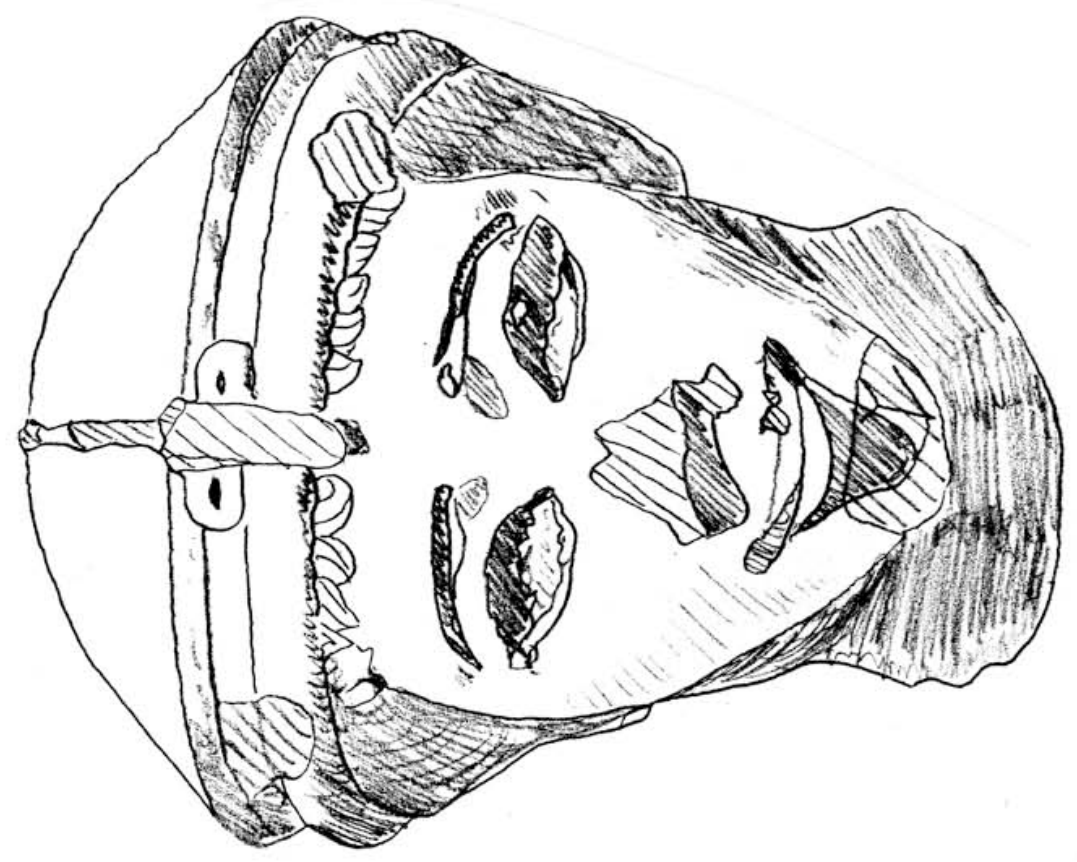

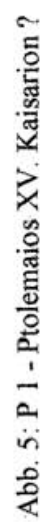

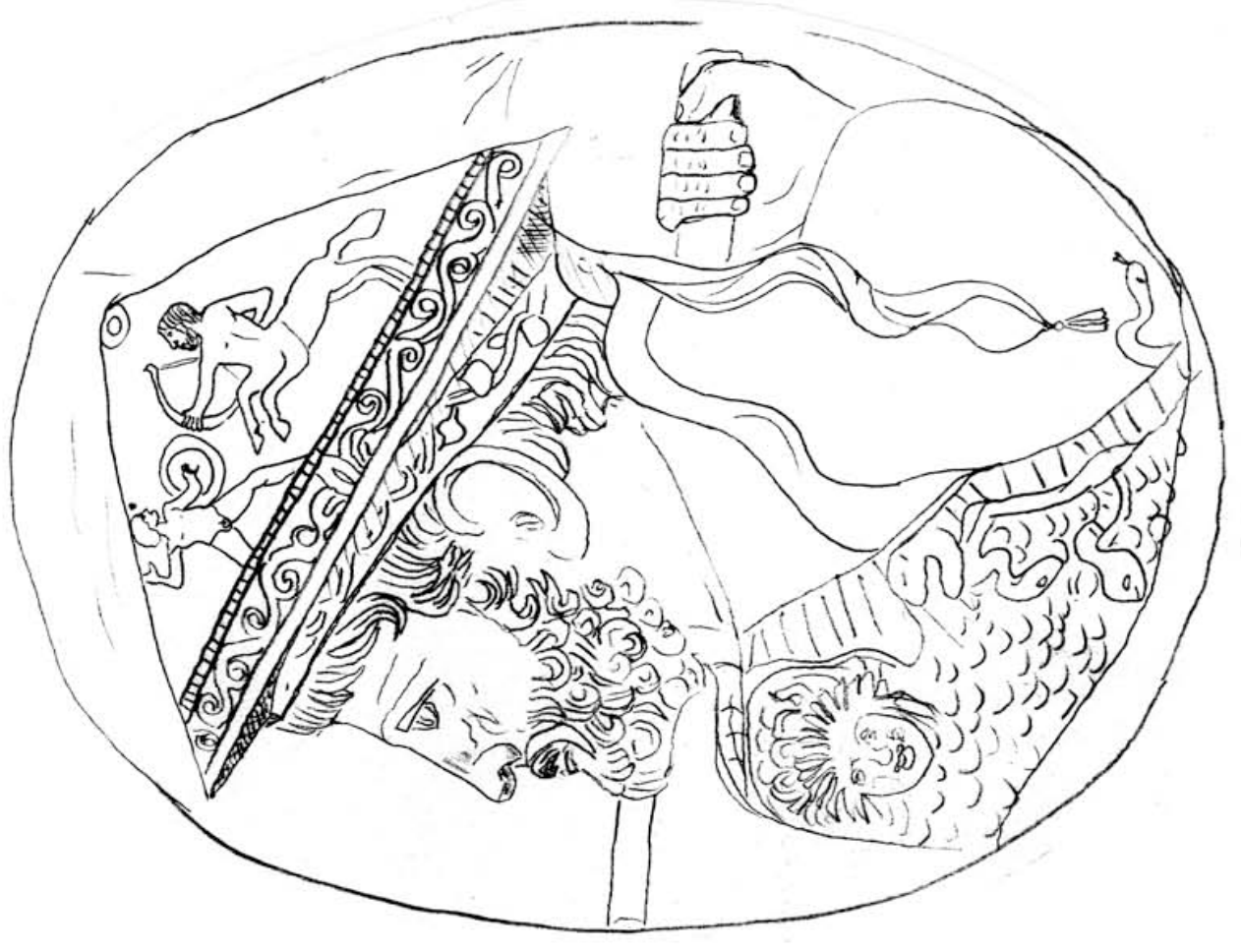

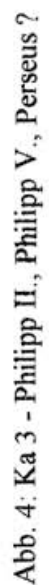


Tafel 3
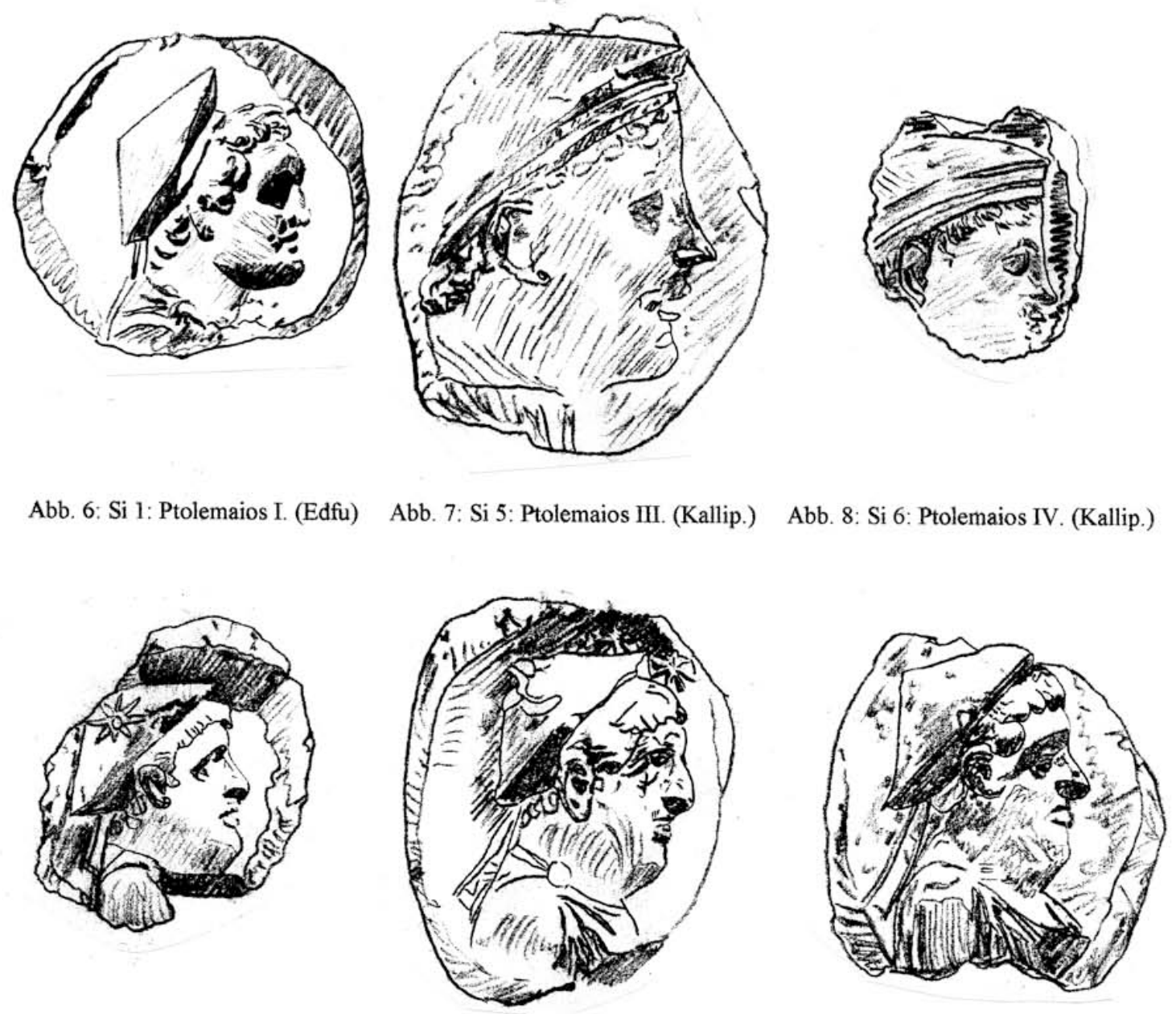

Abb. 9-11: Si 10-12: Ptolemaios X. Alexander I. (?) (Nea Paphos)

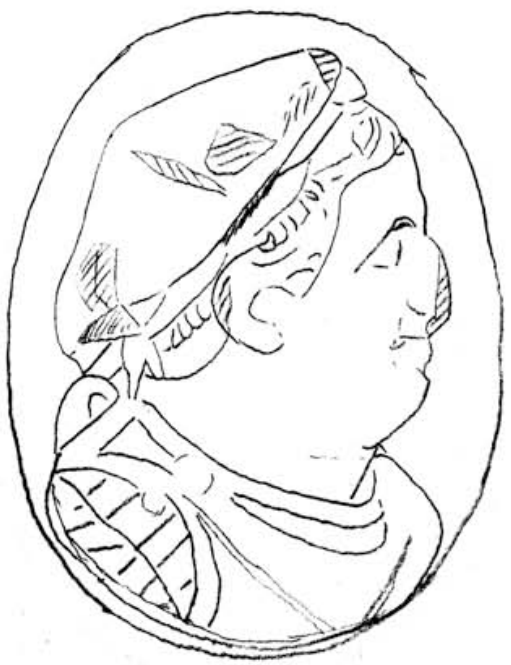

Abb. 12: Ka 1: Ptolemaios VIII- XII.

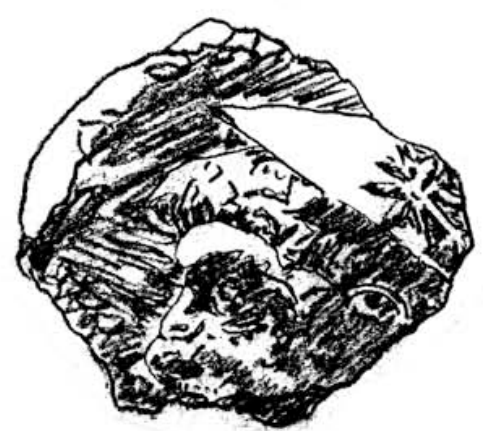

Abb. 13: Si 15: ptolemäischer König (Nea Paphos) 

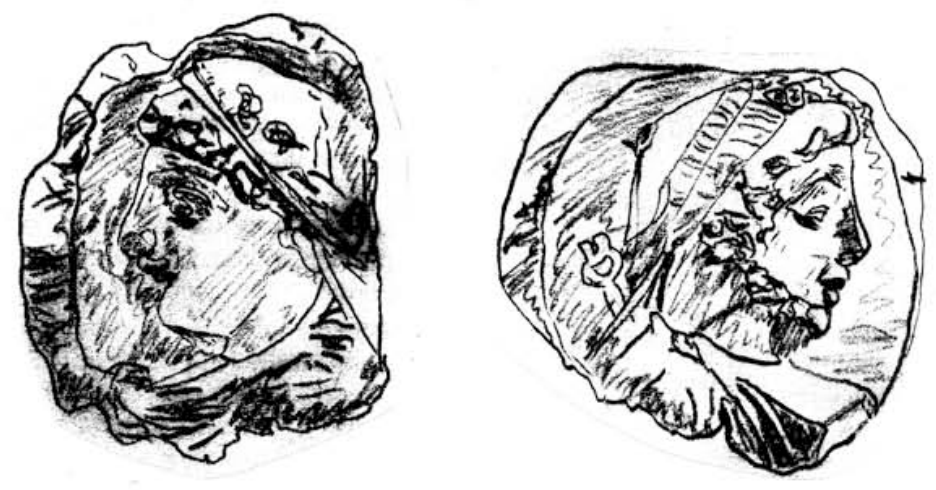

Abb. 14-15: Si 13-14: Ptolemaios XV. Kaisarion (Nea Paphos)
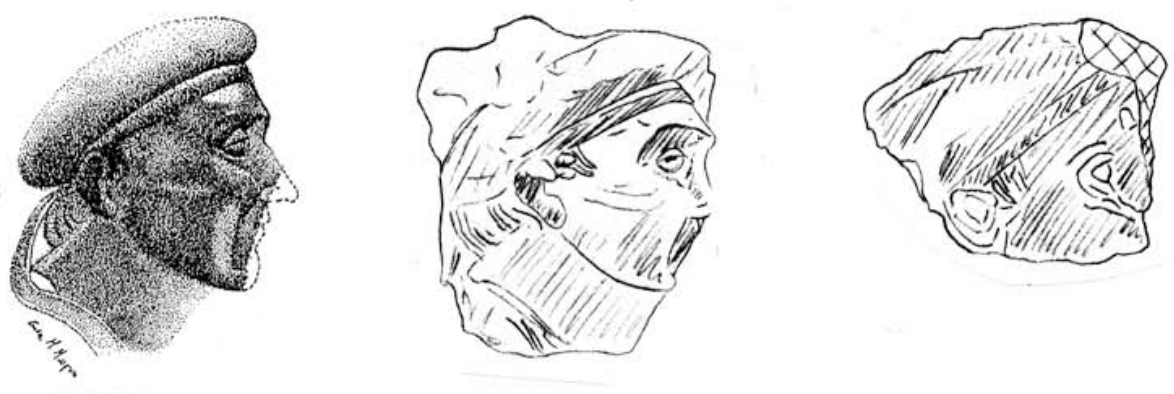

Abb. 16 a-c: Si 7: Antiochos III. (Kallipolis)

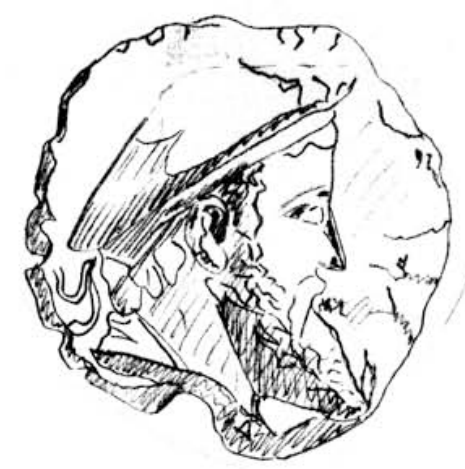

Abb. 17: Si 16: Demetrios II. (Seleukia) 
Tafel 5
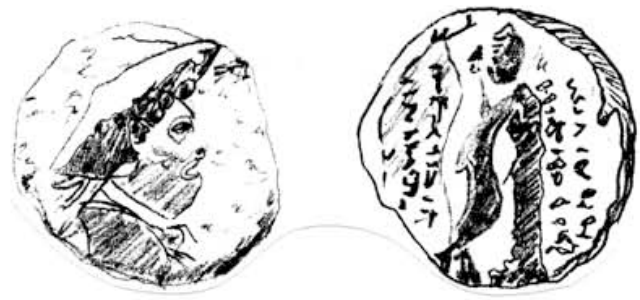

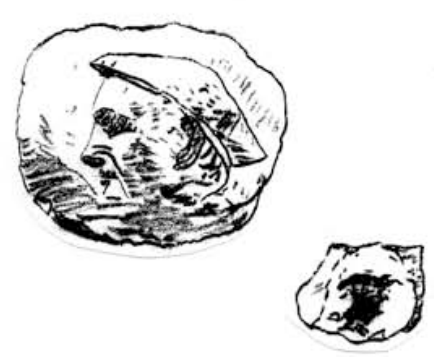

Abb. 19-20: Si 19-20: „Timarchos“/seleuk. Kge. ? (Seleukia)

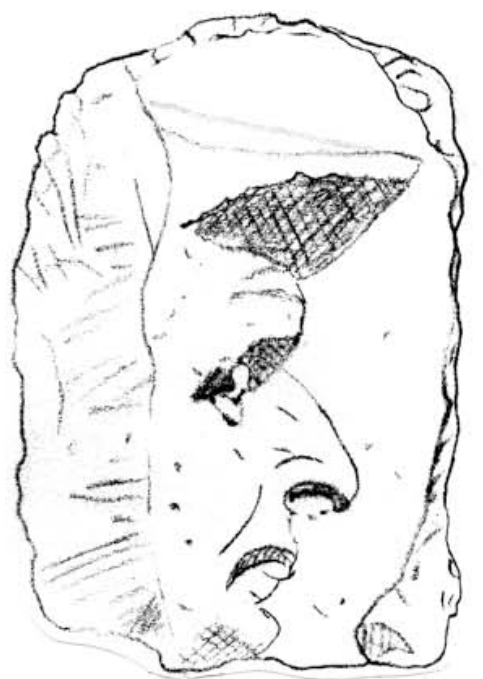

Abb. 22: Si 17: seleuk. Kg. (?) mit Kausia/ Helm (?) (Seleukia)

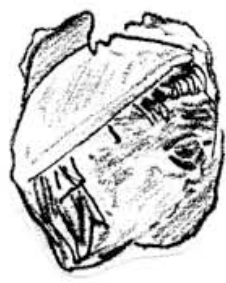

Abb. 24: Si 9: Privatperson (?) (Kallipolis) 
Tafel 6

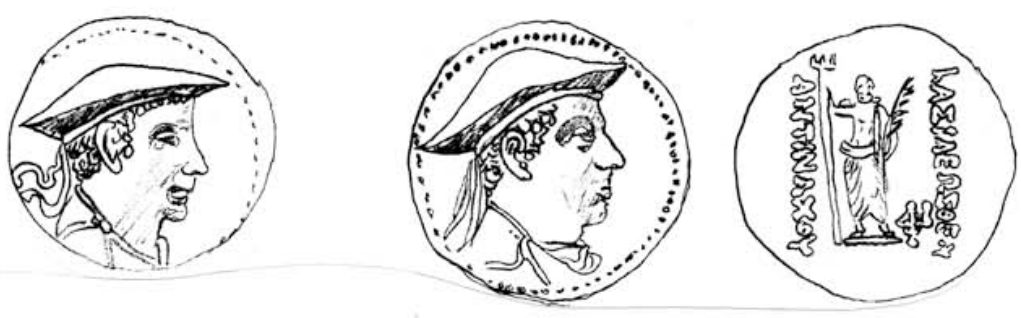

Abb. 25: Nu 26: Antimachos I. (attische Tetradrachme)
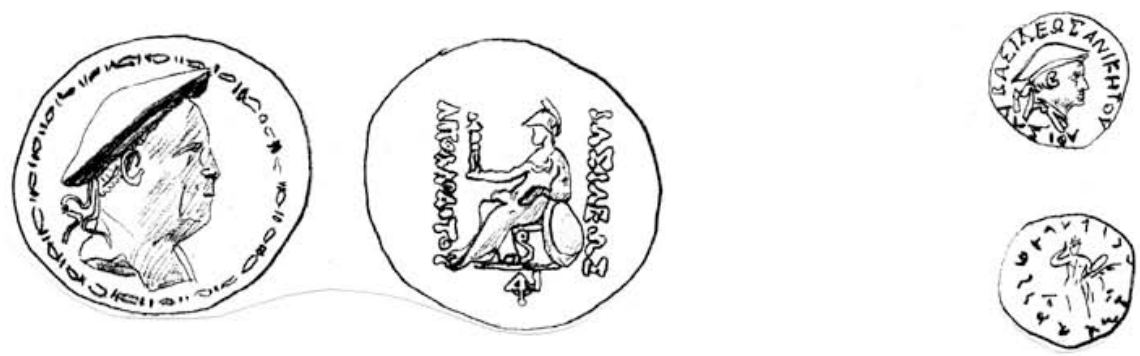

Abb. 26: Nu 30: Apollodotos I. (att. Tdr.)

Abb. 27: Nu 31: Lysias Aniketos (indische „Drachme)

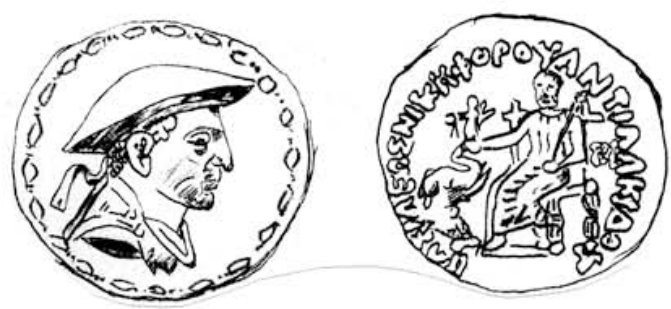

Abb. 28: Nu 32: Antialkidas I. Nikephoros (attische Tetradrachme)
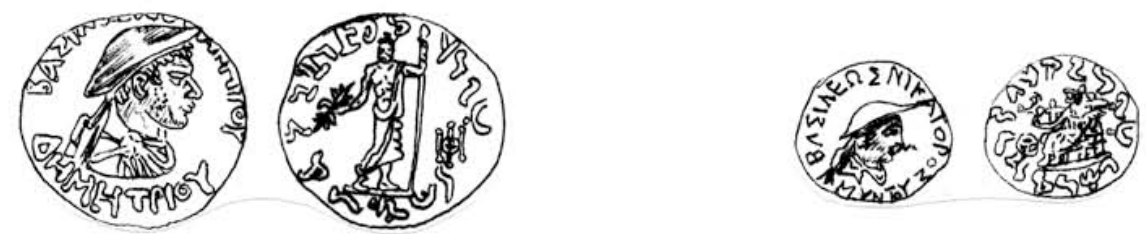

Abb. 29: Nu 35: Demetrios III. Aniketos (,ind. Tdr.")

Abb. 30: Nu 36: Amyntas Nikator (ind. „Drachme“) 

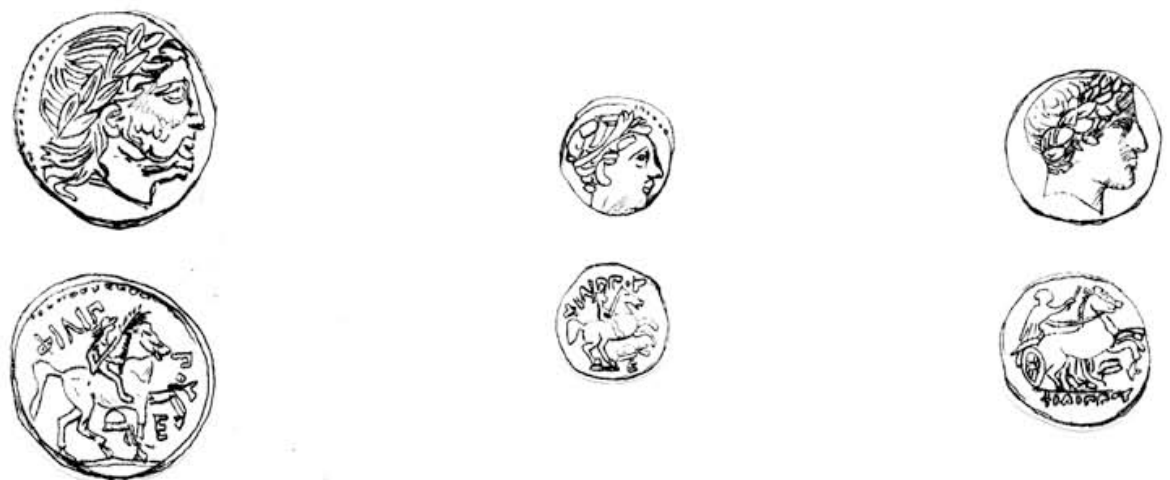

Abb. 31-33: Nu 6 a, 6 b, 7: Philipp III. (Tetradrachme, 1/5 Tetradrachme, Stater; Amphipolis)
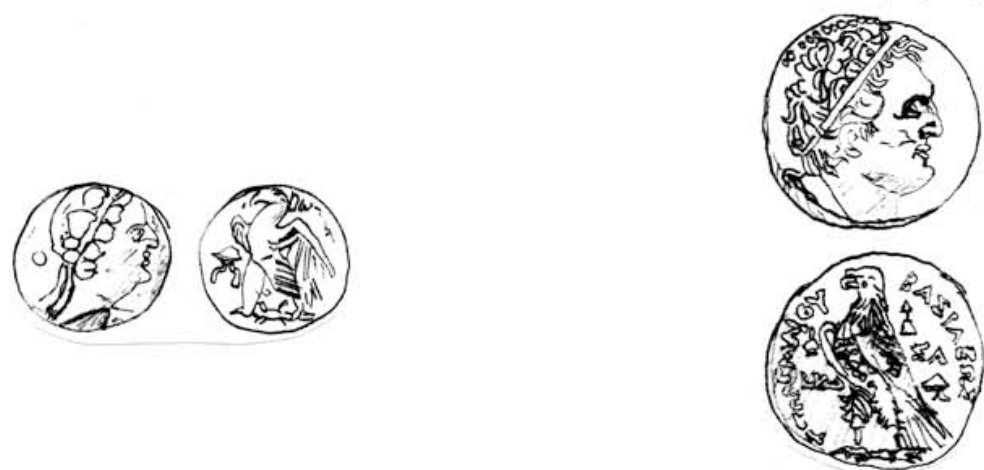

Abb. 34: Nu 24: Ptolemaios IV. (ff. ?) (Didr., Zypern)
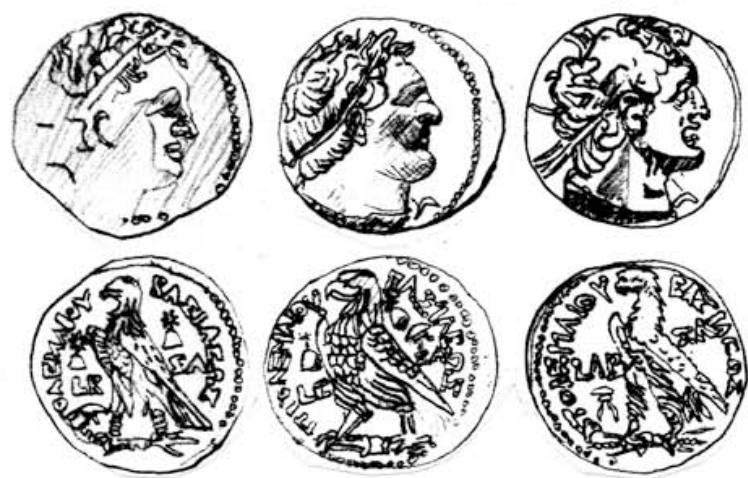

Abb. 36-38: Nu 15, 19, 20: Ptolemaios VI. (Tdr., Salamis)
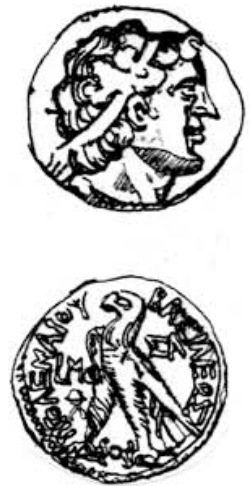

Abb. 41: Nu 21: Ptolemaios VIII. (Tdr., Salamis)
Abb. 35: Nu 14: Ptolemaios V. (Tdr., Salamis)
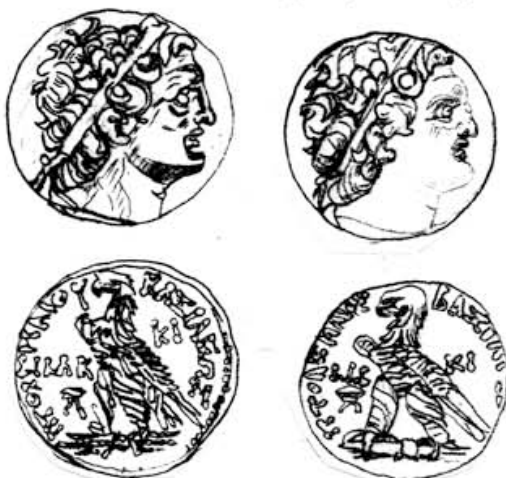

Abb. 39-40: Nu 22/22: Ptolemaios VI. (Tdr., Kition)
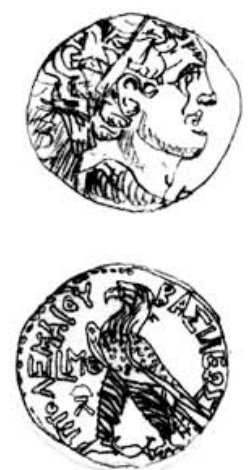

Abb. 42: Nu 23: Ptolemaios VIII. (Tdr., Kition) 
Tafel 8

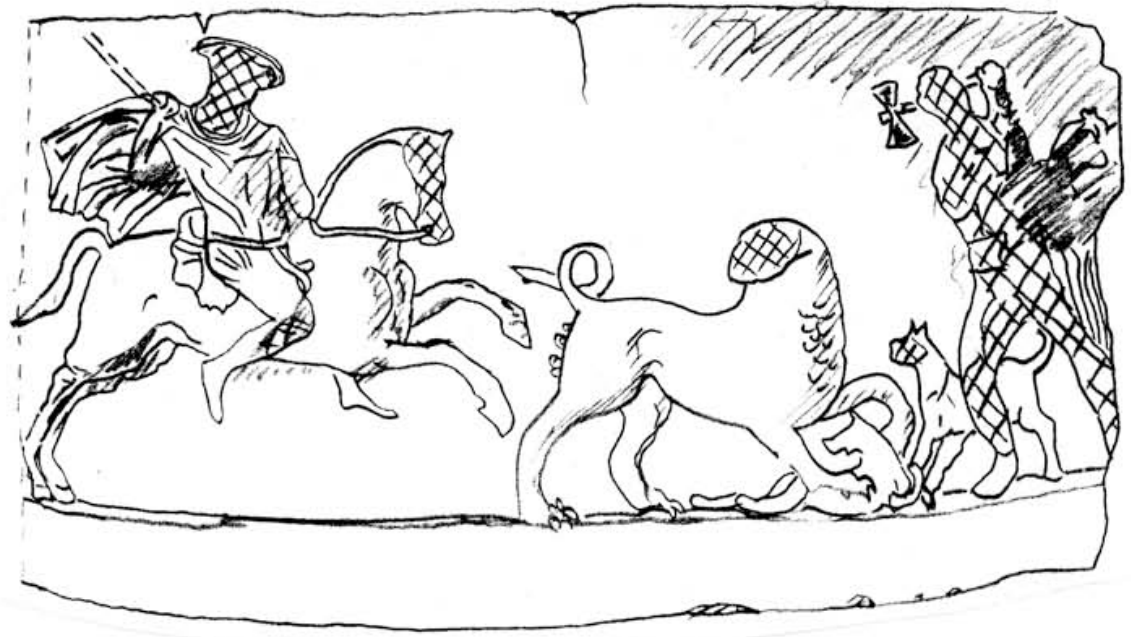

Abb. 43: Re 5: Messene, Rundbasis

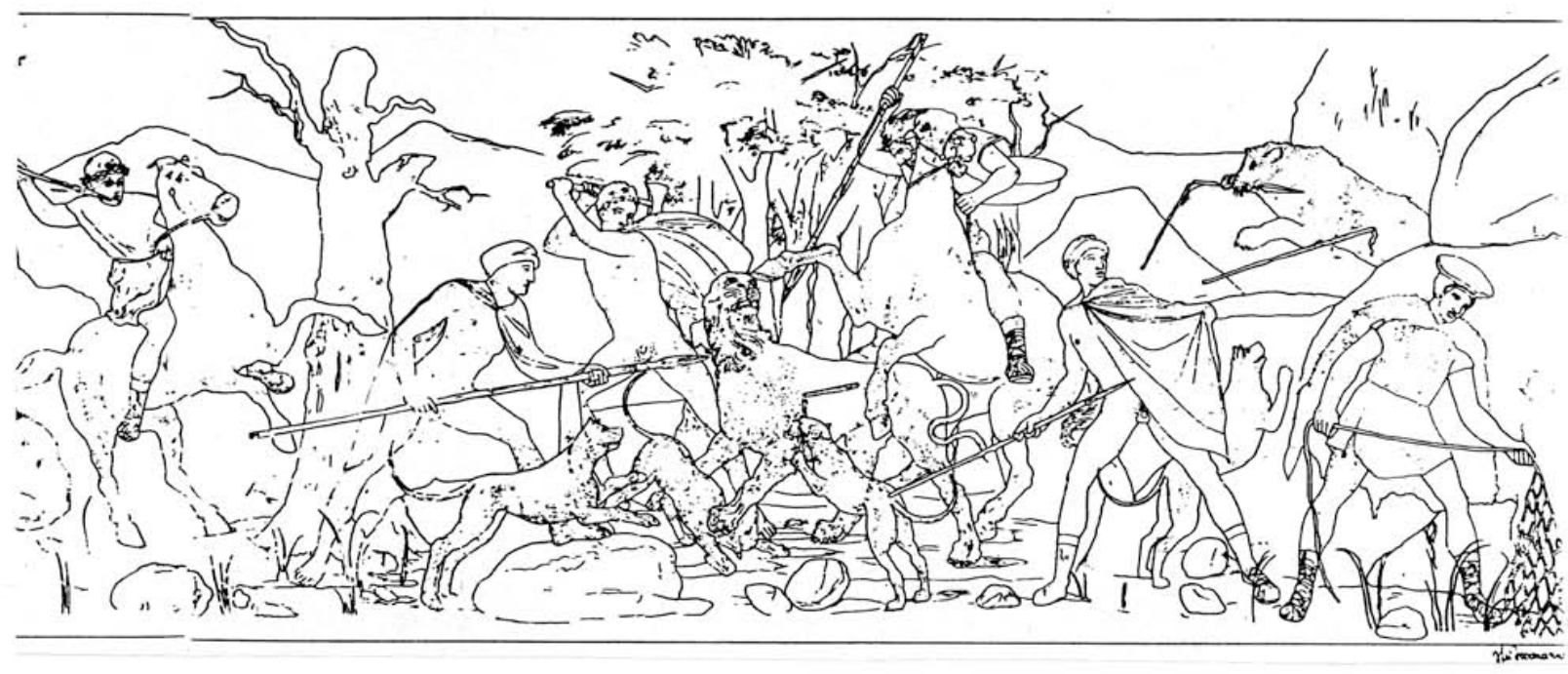

Abb. 44: Ma 5: Vergina, Fries des „Philippsgrabes“ (rechte Hälfte) 


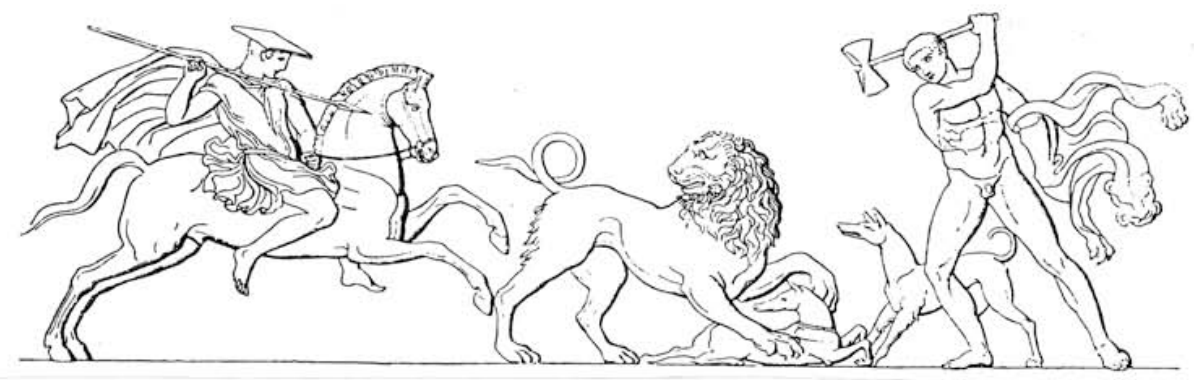

Abb. 45: Re 5: Messene, Rundbasis (Zeichnung v. Stackelberg)

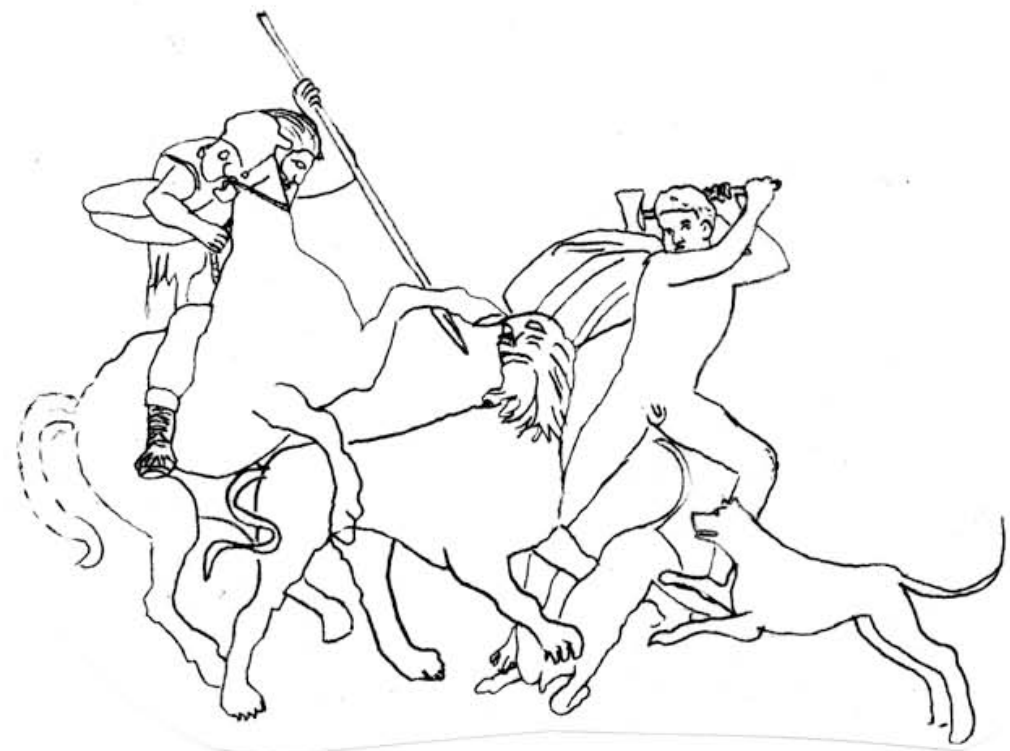

Abb. 46: Ma 5: Vergina, Fries des „Philippsgrabes“ (Löwenjagd) - Figuren in Auswahl und seitenverkehrt -

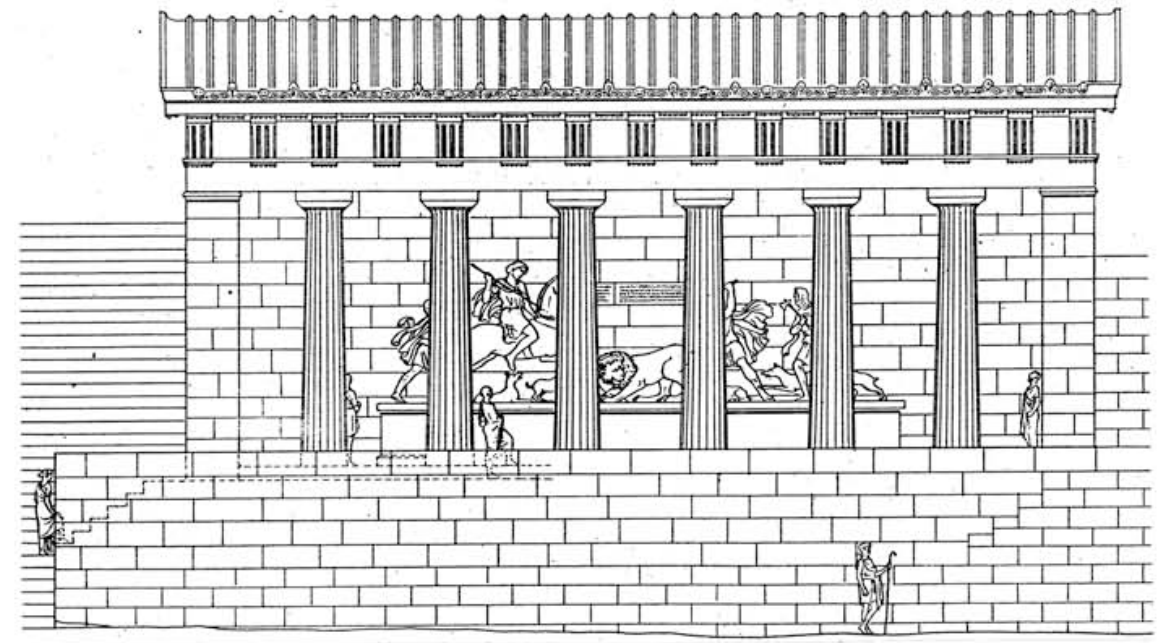

Abb. 47: Delphi, Rekonstruktion des Krateros-Monumentes 
Tafel 10

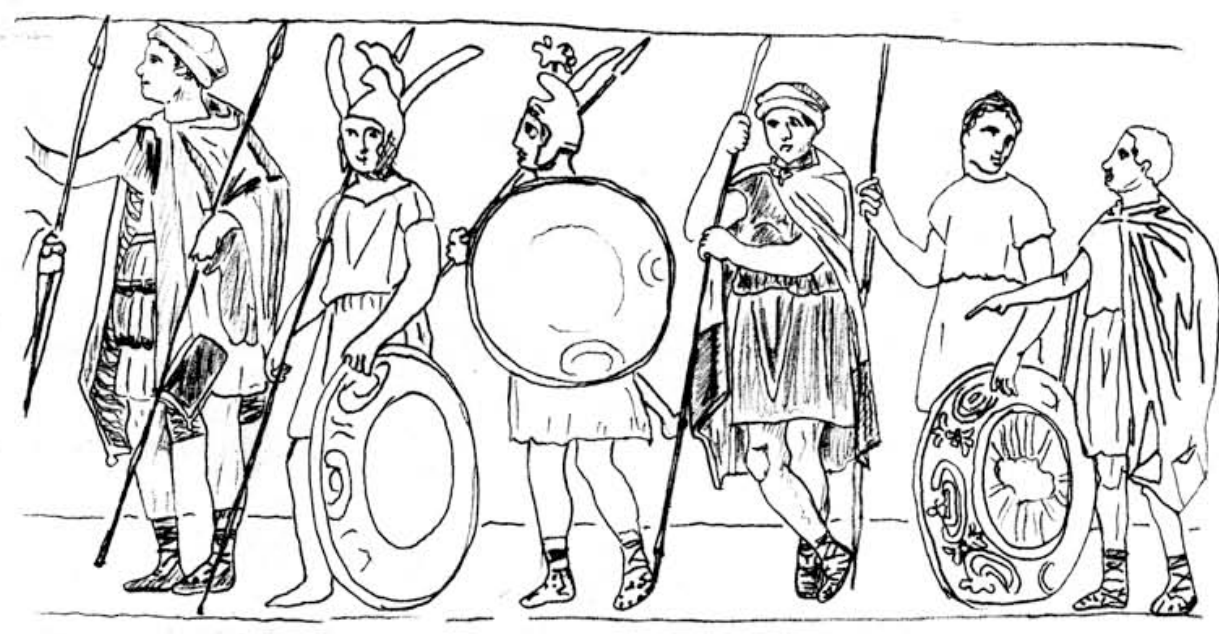

Abb. 48: Ma 6: Ag. Athanasios, makedonisches Grab, rechtes Ende des Frieses

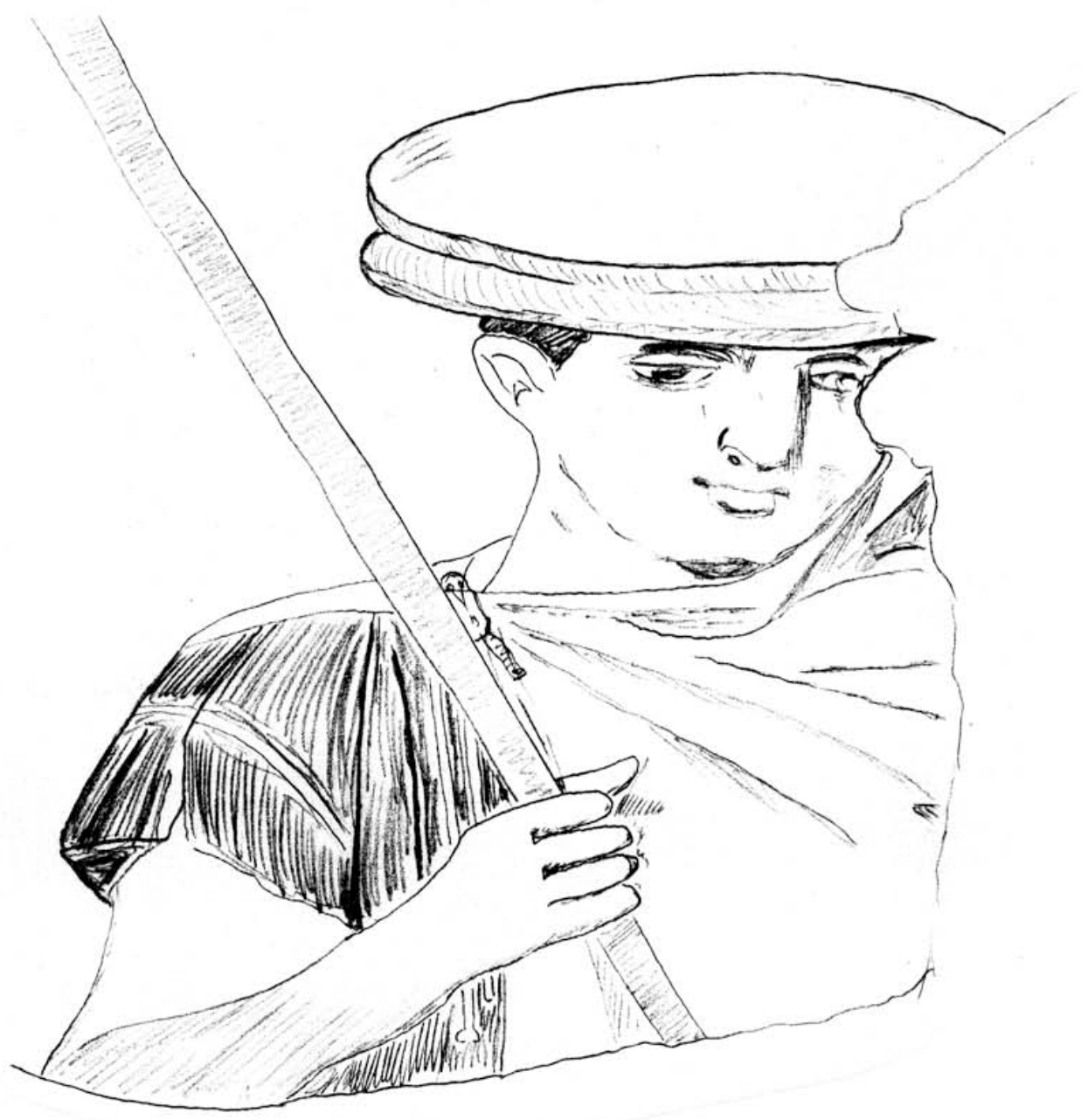

Abb. 49: Ma 6: Ag. Athanasios, makedonisches Grab, Fassade rechts der Tür 
Tafel 11

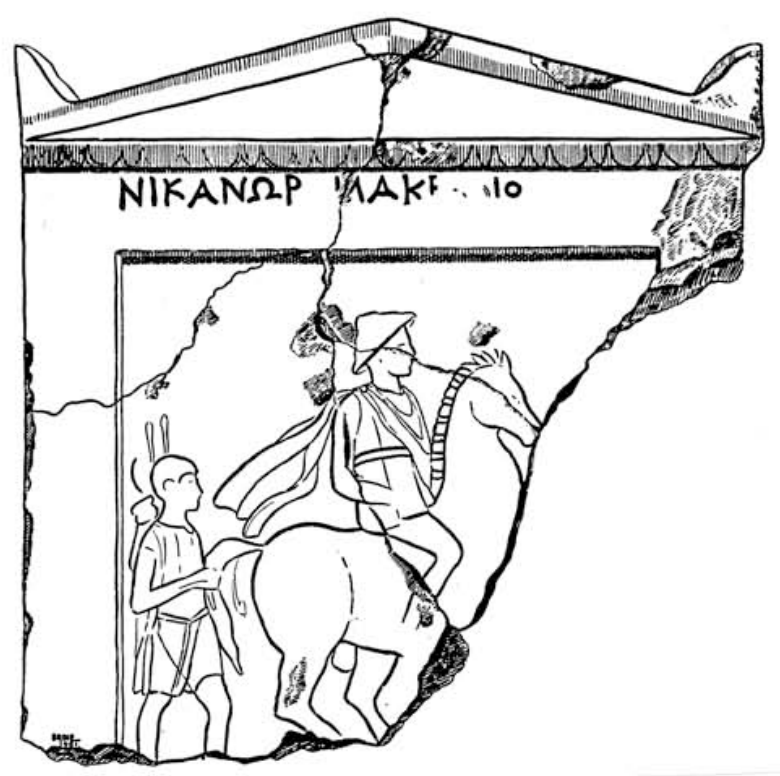

Abb. 50: Ma 2: Alexandria, Hadra-Nekropole, Grabstele des Nikanor

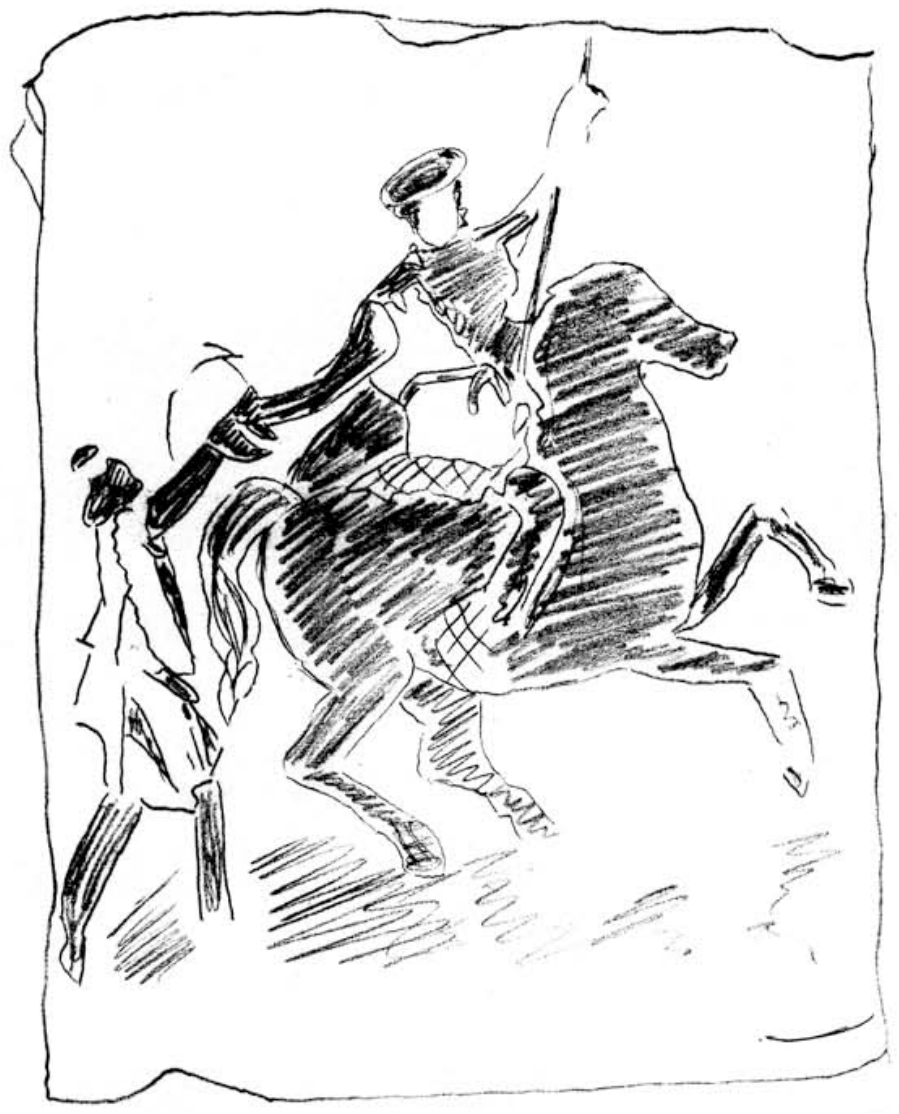

Abb. 51: Ma 3: Alexandria, Hadra-Nekropole, Grabstele 
Tafel 12

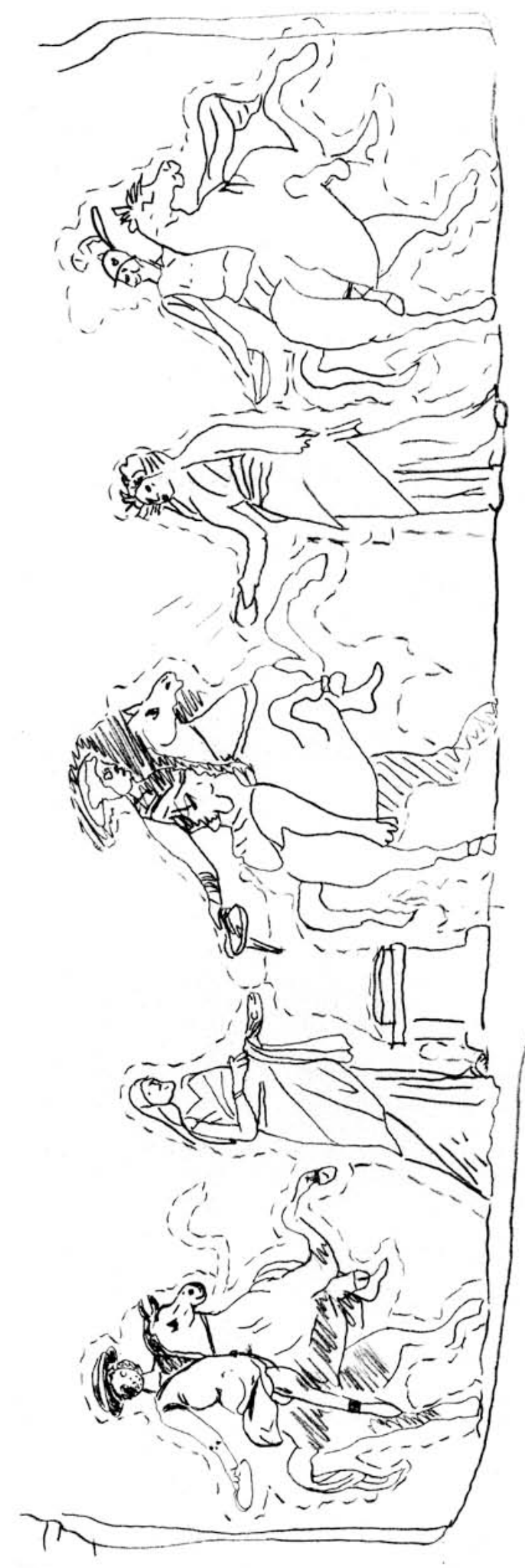

है 
Tafel 13

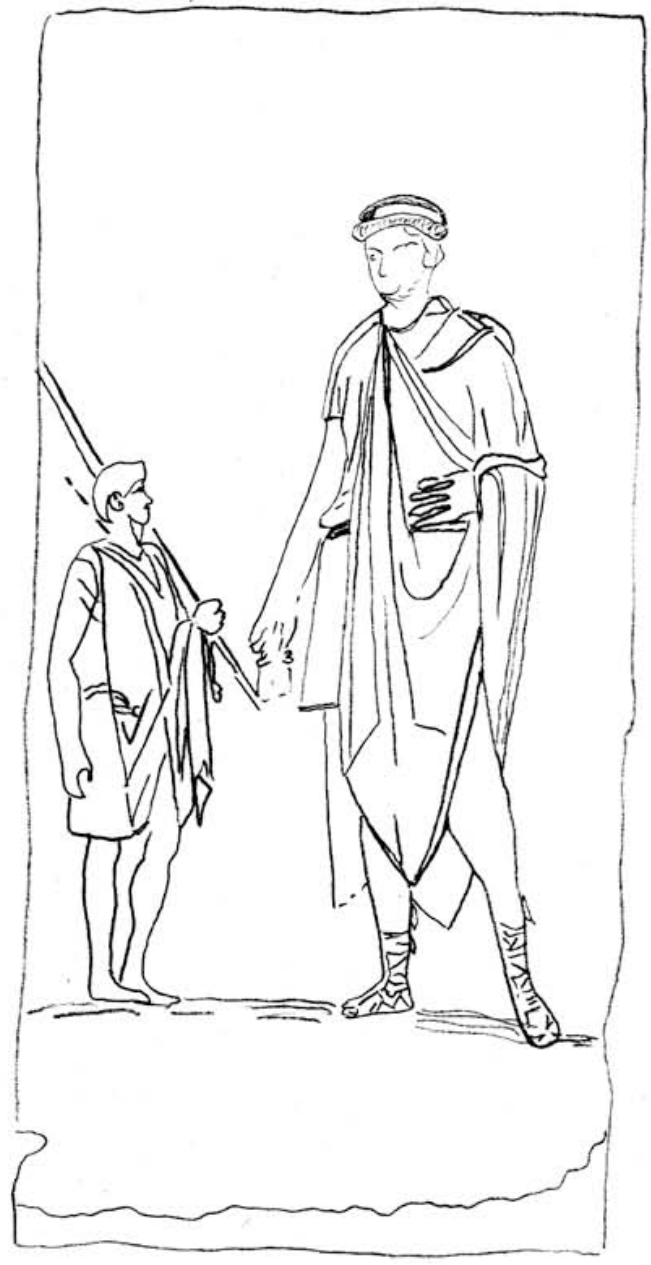

Abb. 53: Ma 1: Alexandria, Grabstele

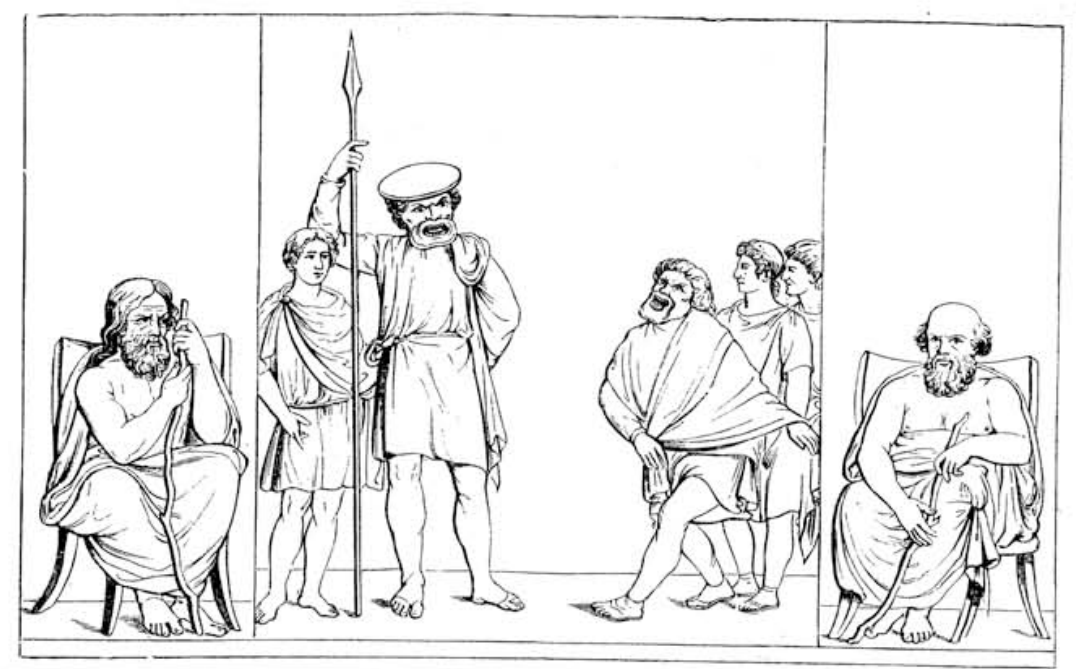

Abb. 54: Ma 12: Pompeii, Casa della Fontana grande, Wandmalerei 
Tafel 14

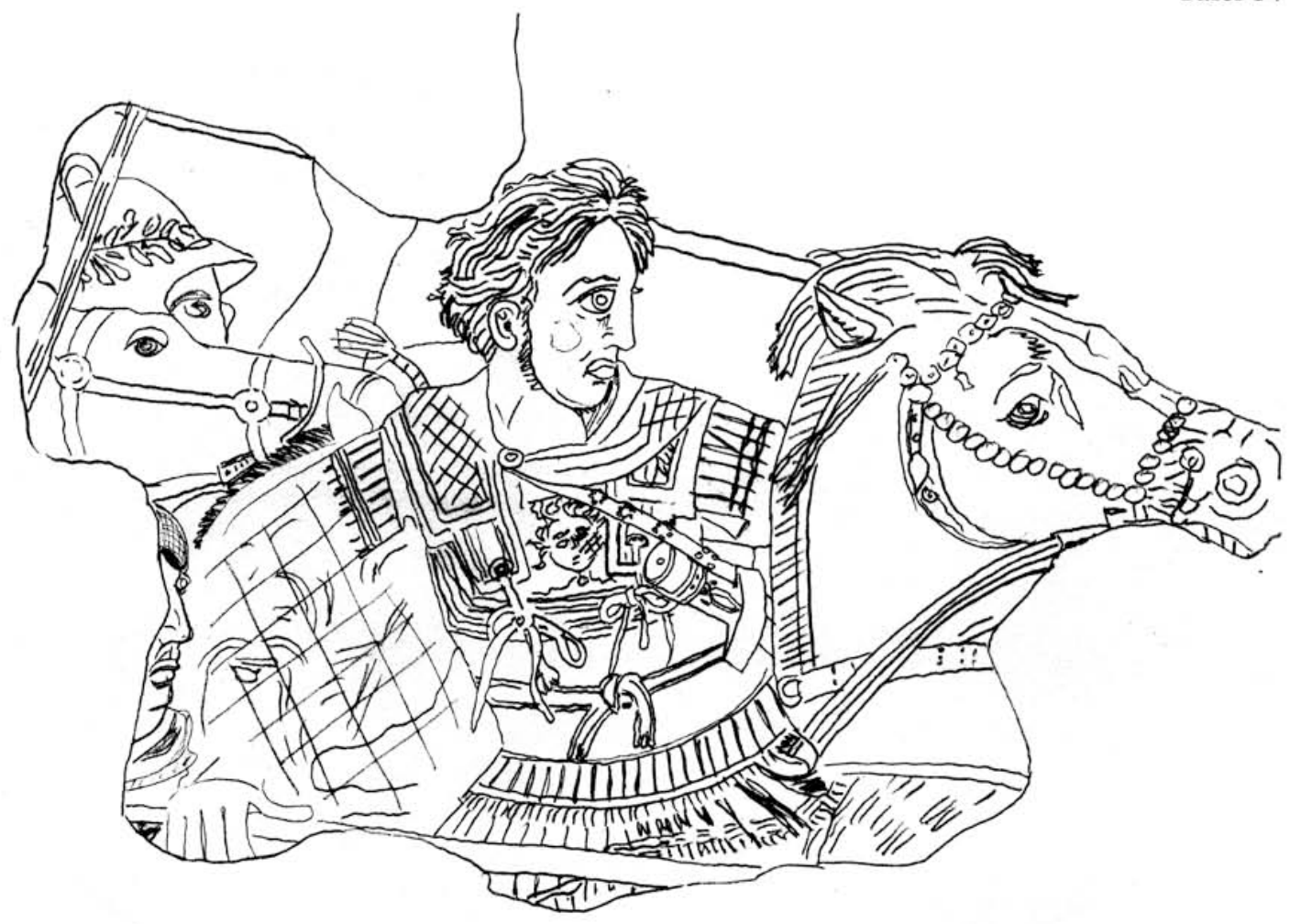

Abb. 55: Mo 1: Pompeii, Casa del Fauno, Alexandermosaik (Ausschnitt)

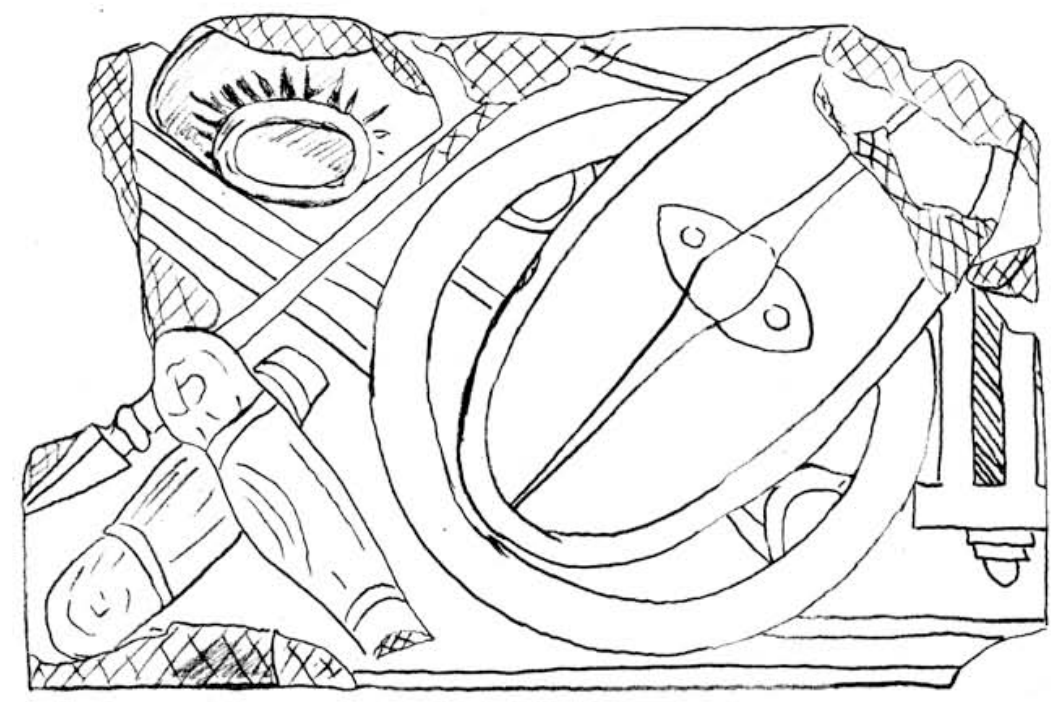

Abb. 56: Re 1: Pergamon, Athena-Polias-Heiligtum, Nordhalle, Waffenfries (Ausschnitt) 
Tafel 15
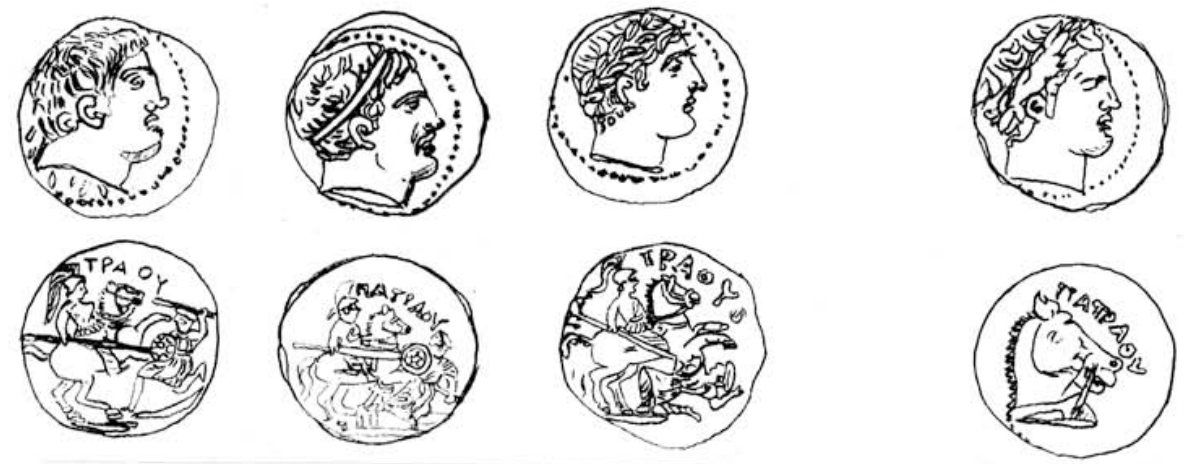

Abb. 57-60: Nu 1-3, ohne Kat.-Nr.: Patraos von Paionien (Tetradrachmen)

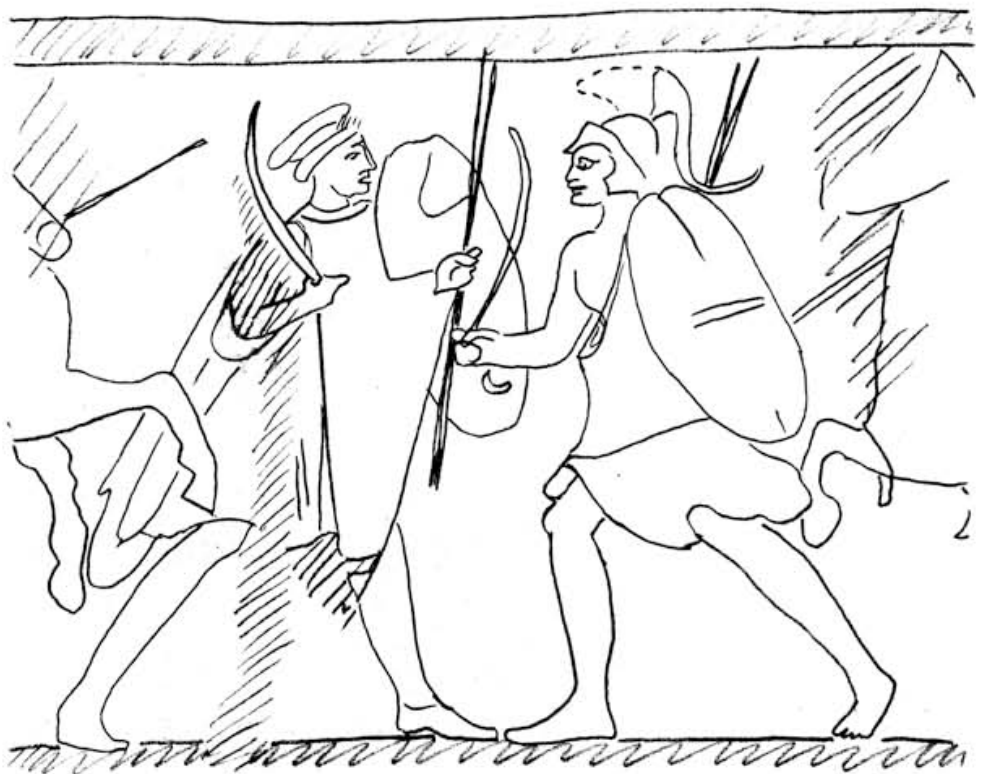

Abb. 61: Ma 7: Kasanlak, Grabmal, Malerei im Dromos zwischen Eingang und Hauptkammer, Ostfries 
Tafel 16

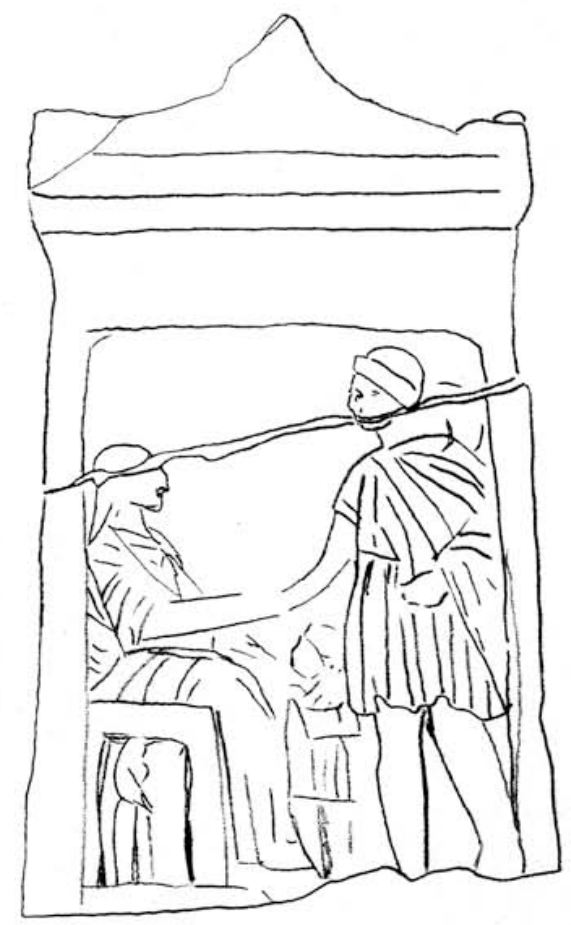

Abb. 62: Re 2: Vergina, Grabstele
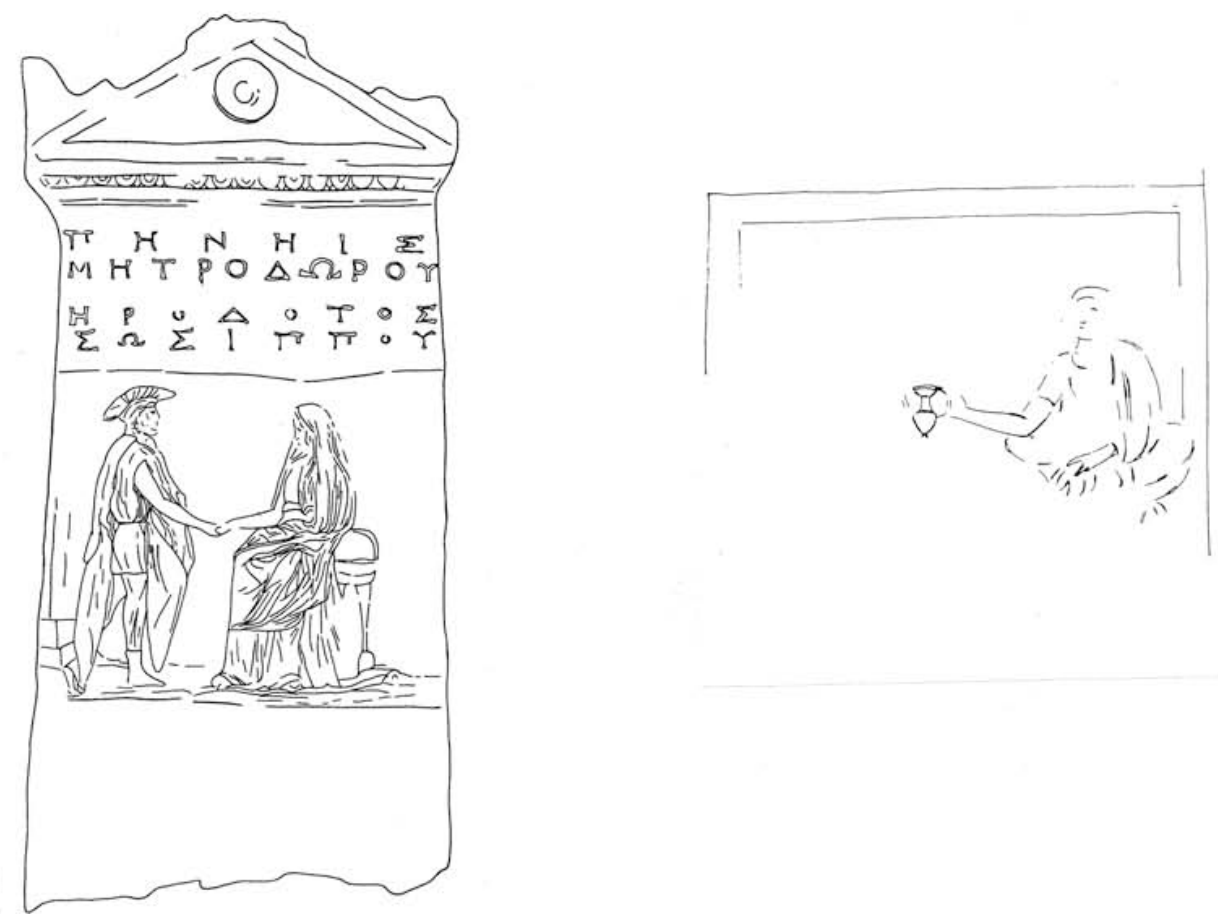

Abb. 63: Ma 8: Demetrias, Grabstele (Herodot und Peneis) Abb. 64: Ma 10: Demetrias, Grabstele (Fragment) 


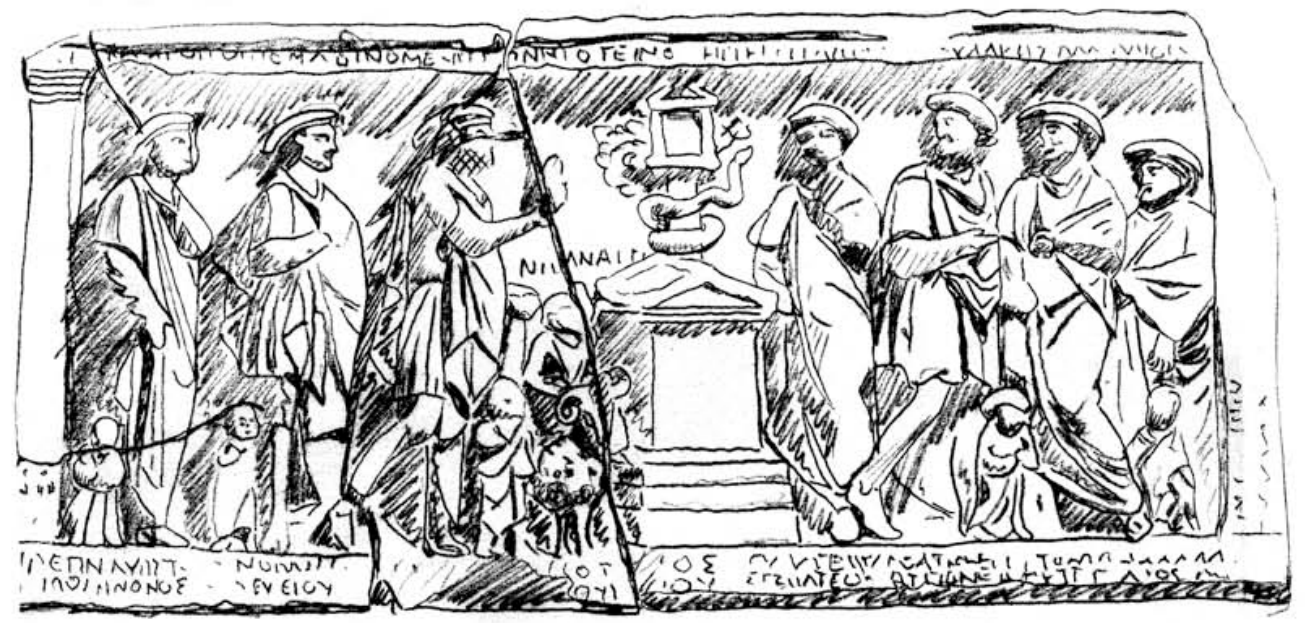

Abb. 65: Re 3: Mesambria, Strategenrelief
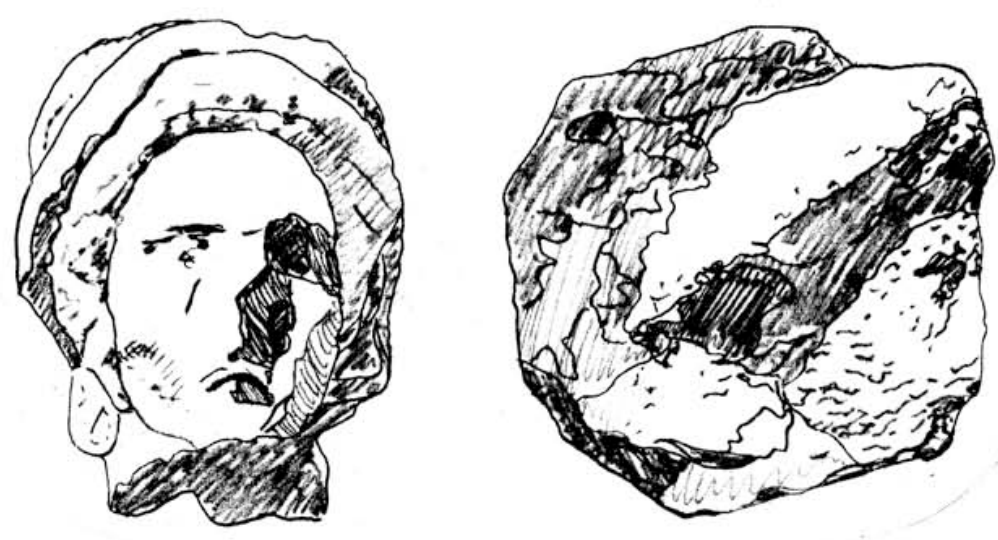

Abb. 66: P 4: Thasos, Agora (hinter der Grundmauer der N-Portikus), unfertiges Porträt 
Tafel 18

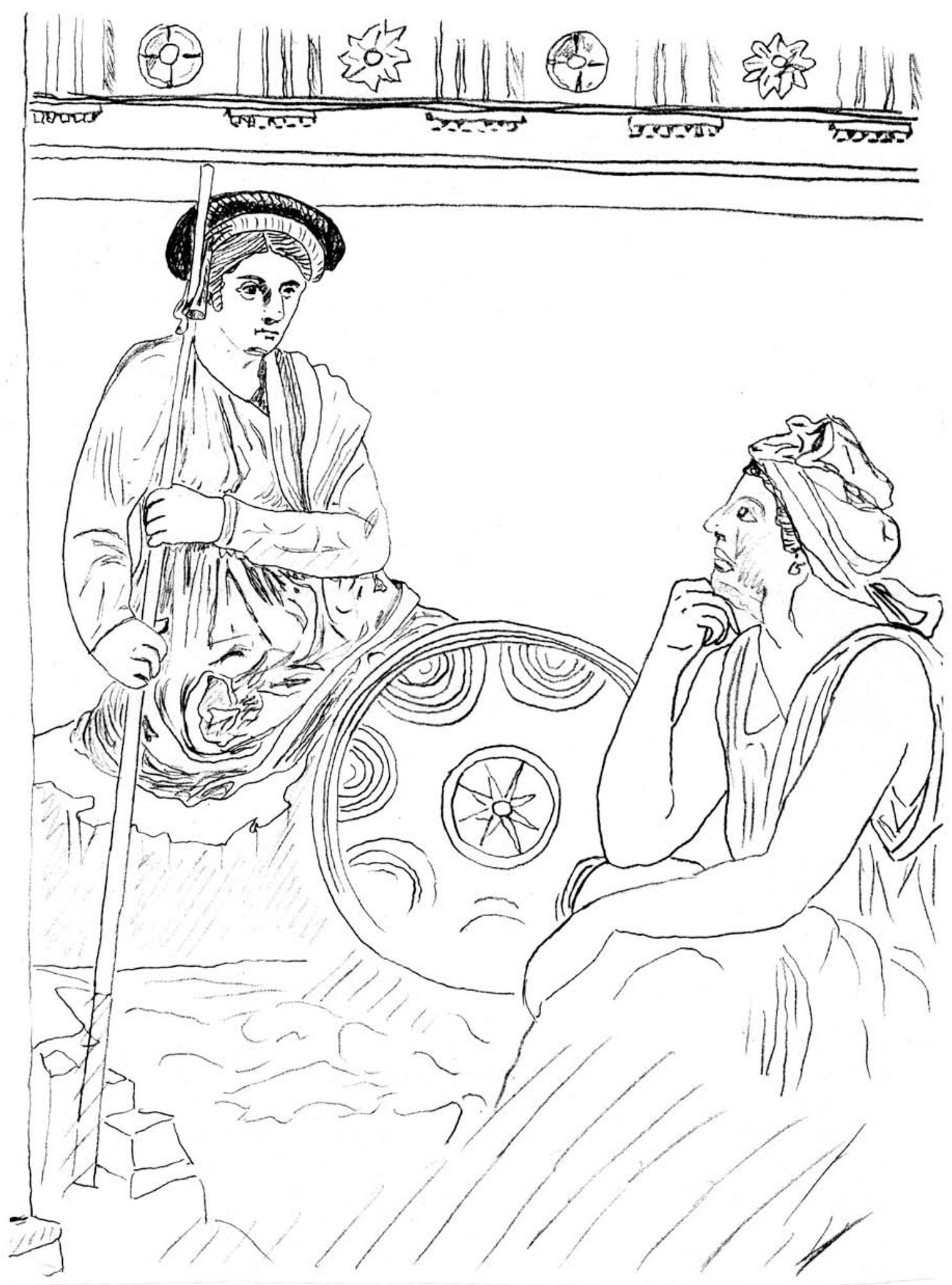

Abb. 67: Ma 11: Pompeii / Boscoreale, Villa des Fannius Synistor, Festsaal, Westwand 
Tafel 19
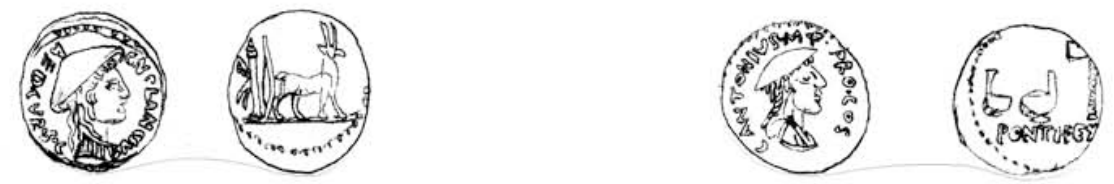

Abb. 68-69: Nu 8-9: Denare des Cn. Plancius und des C. Antonius
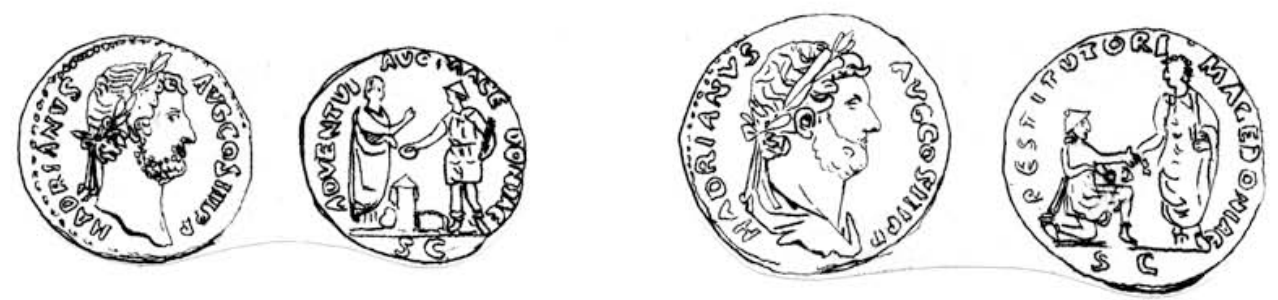

Abb. 70-71: Nu 10, 12: As oder Dupondius und Sesterz der Hadrian

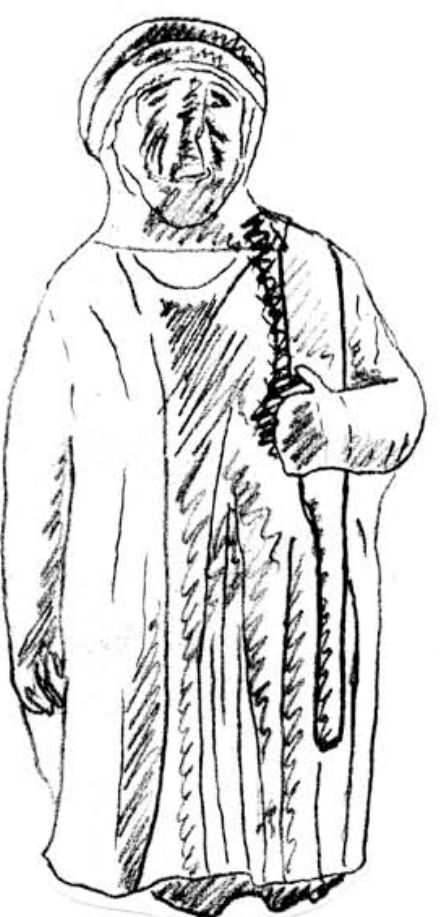

Abb. 72-73: Phönizier:

*Tk 381: Kharayeb

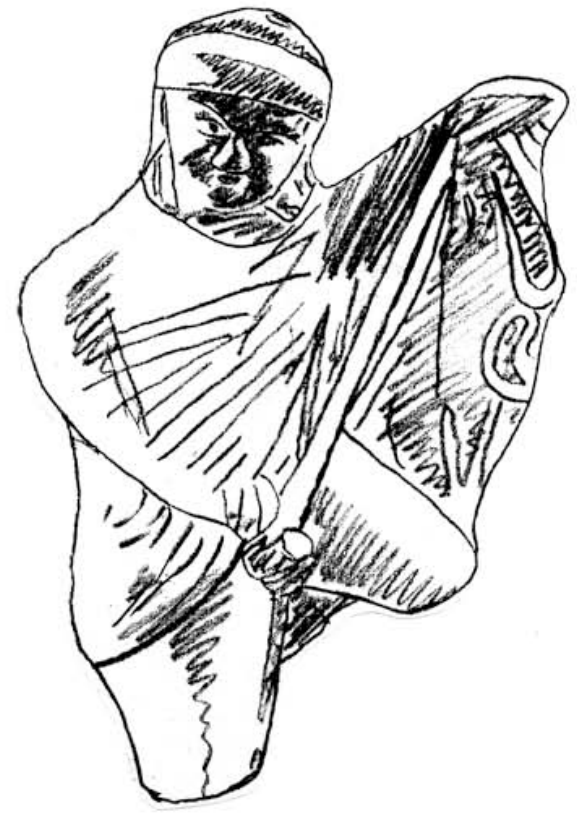

*Tk 385: Mantel-Tänzer, Kharayeb, 3./2. Jh. vor Chr. 


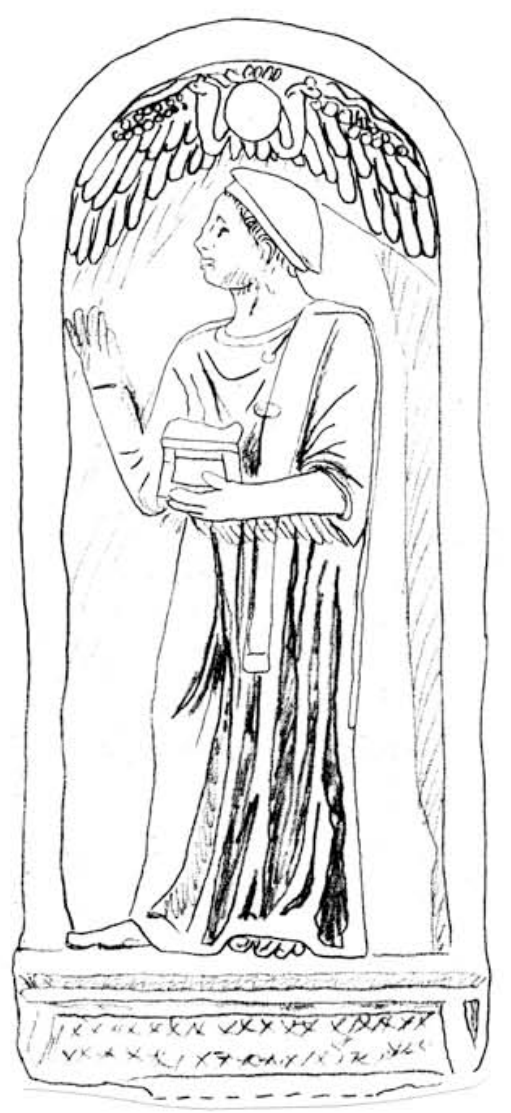

Tafel 20

Abb. 74: Phönizier: *Re 6: Umm el-Amad (Tyros), Stele des Baalschamar

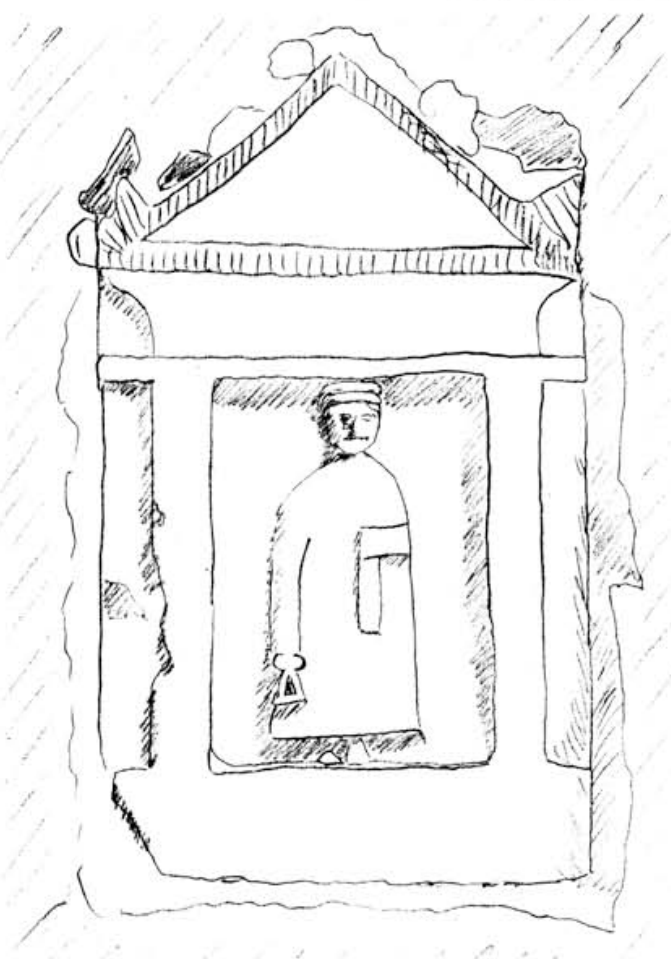

Abb. 75-76: sardisch-phönzische Votivstelen: *Re 9: Sulcis

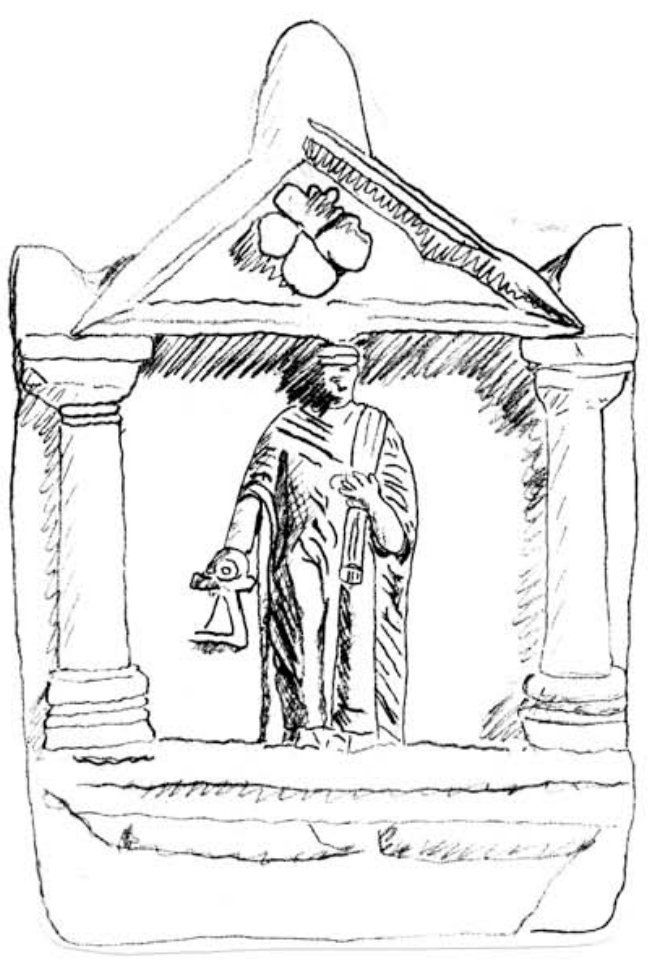

${ }^{*} \operatorname{Re} 8$ : Sulcis 

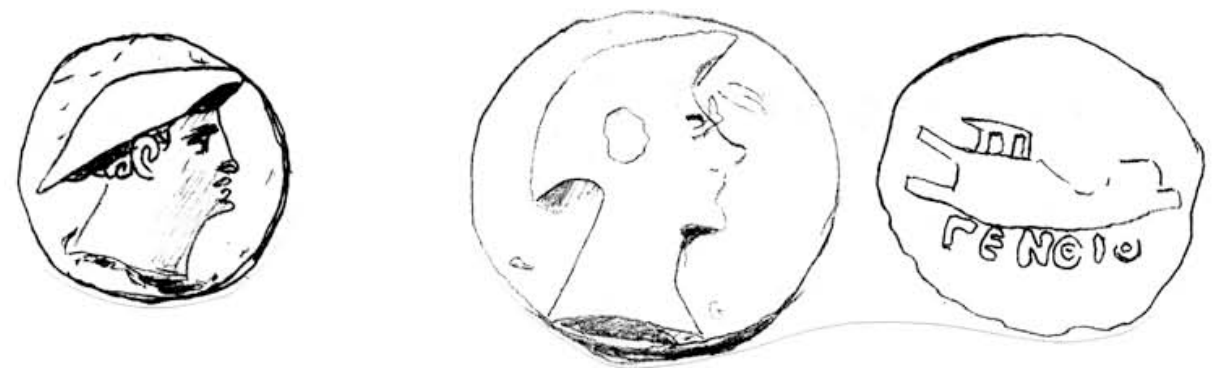

Abb. 77: Nu 4/4: Bronzemünzen des illyrischen Königs Genthios

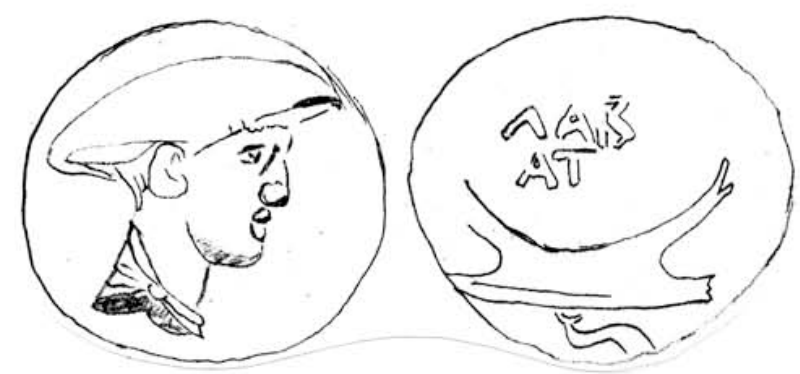

Abb. 78: Nu 5: Bronzemünze des Koinons der Labeaten (Illyrien, Shkodra/Lissos)
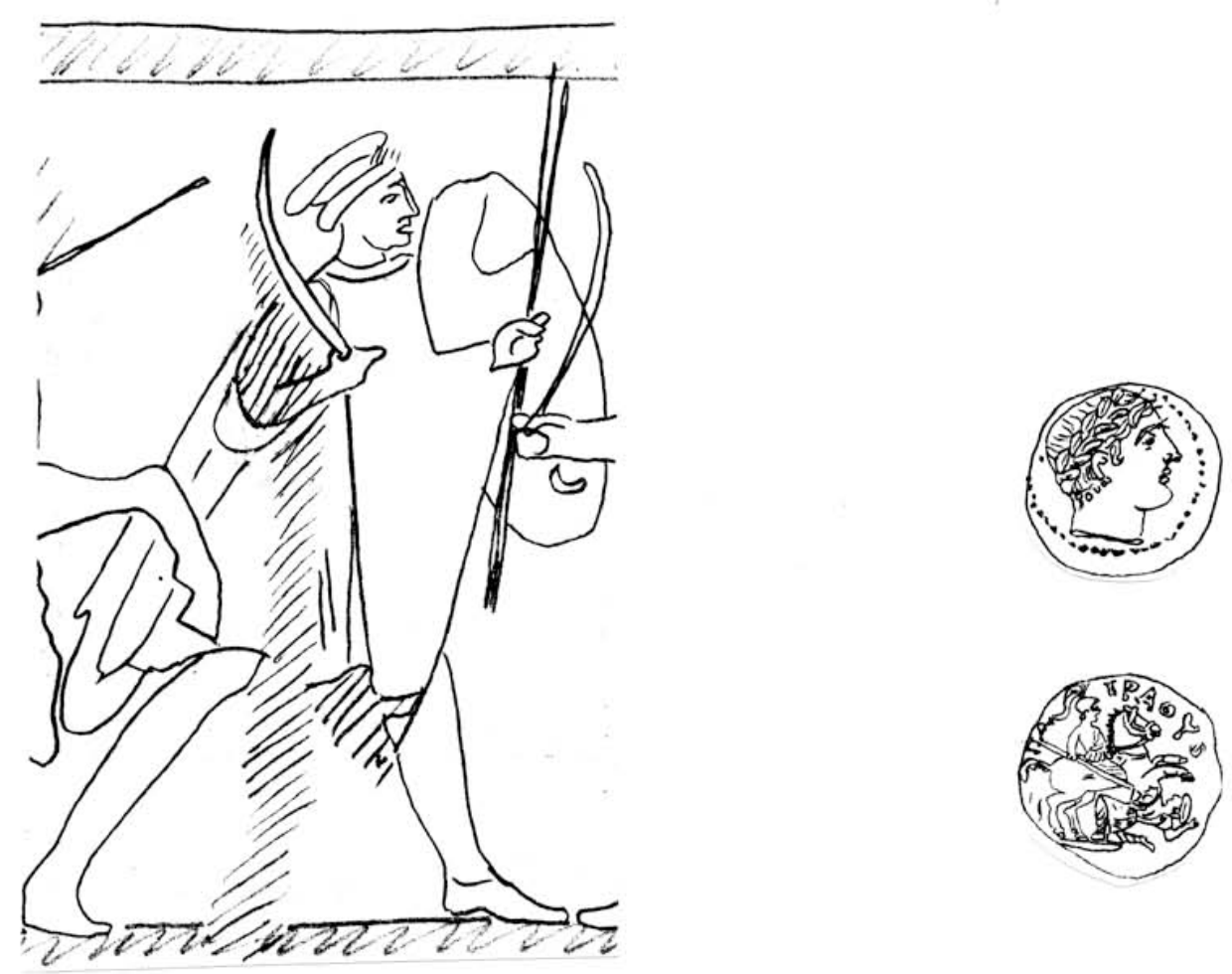

Abb. 79: Ma 7: Kasanlak, Grabmal, Malerei im Dromos 

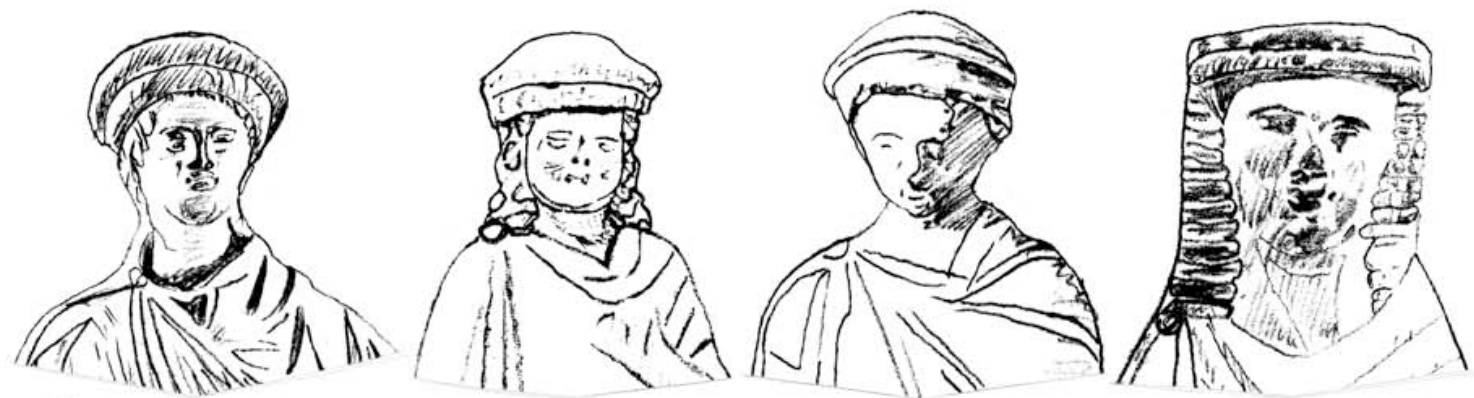

Abb. 81: Köpfe der Statuetten Tk 380 (Kharayeb), Tk 46 (Alexandria), Tk 132 (Troja), Tk 154 („südliche Aiolis“):

4./3. Jh. vor Chr. 280-240 vor $\mathrm{Chr}$.

2.-1. Jh. vor Chr. (?)

2. Jh. nach $\mathrm{Chr}$.

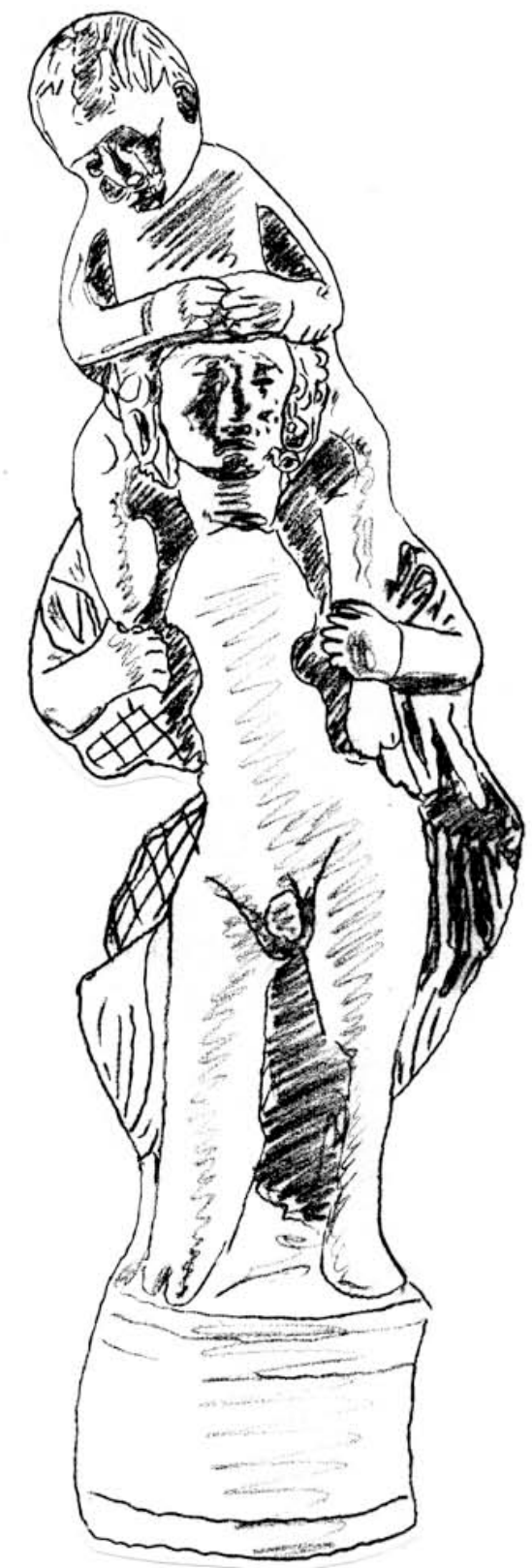

Abb. 82: Kurzhaariger Knabe auf Schultern von langhaarigem Jugendlichen (Kharayeb [bei Sidon], 4./3. Jh. v. Chr.) 
Tafel 23

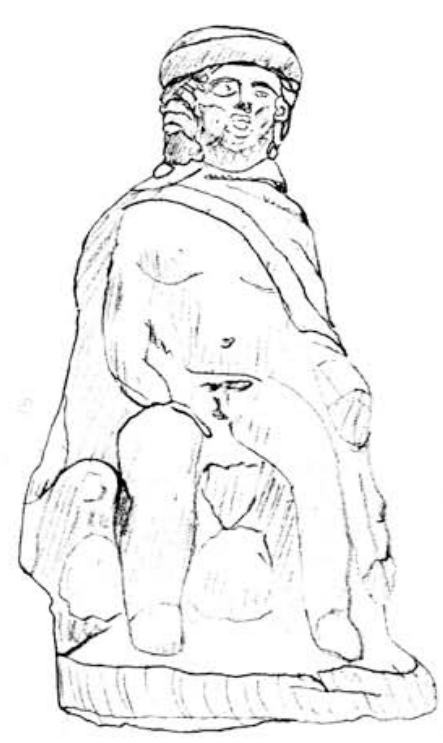

Abb. 84-85: sitzende Chlamydephoroi:

Tk 1: ohne Chiton (Ägypten, 3. Jh. vor Chr.)

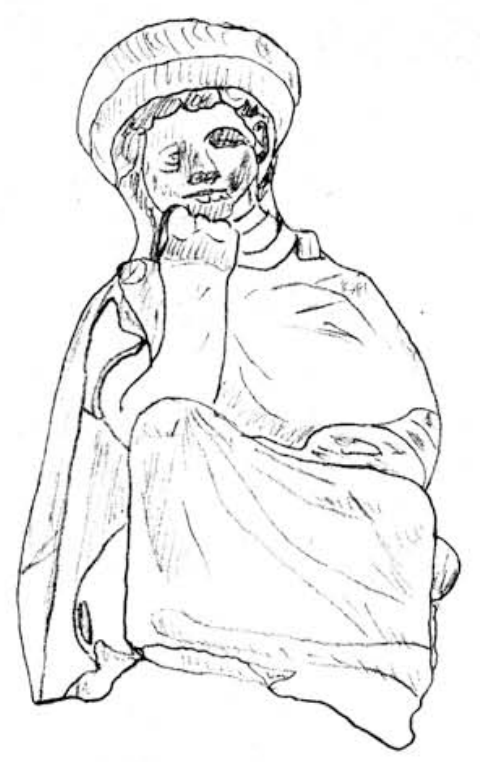

Abb. 86-87: sitzende Chlamydephoroi:

Tk 166: „Denker“ (Ionien/Smyrna, 4./3. Jh. v. Chr.)

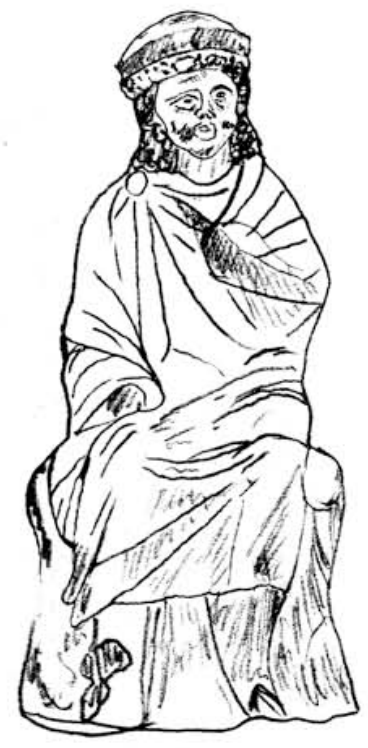

Tk 39: Normaltypus (Alexandria/Sciatbi, 325-240 v.Chr.)

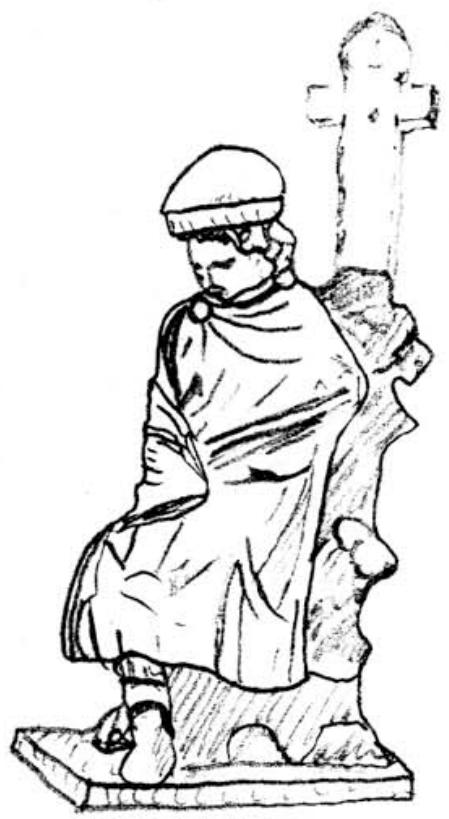

Tk 183/182: mit Herme (Mytilene, 250 v.Chr.) 
Tafel 24

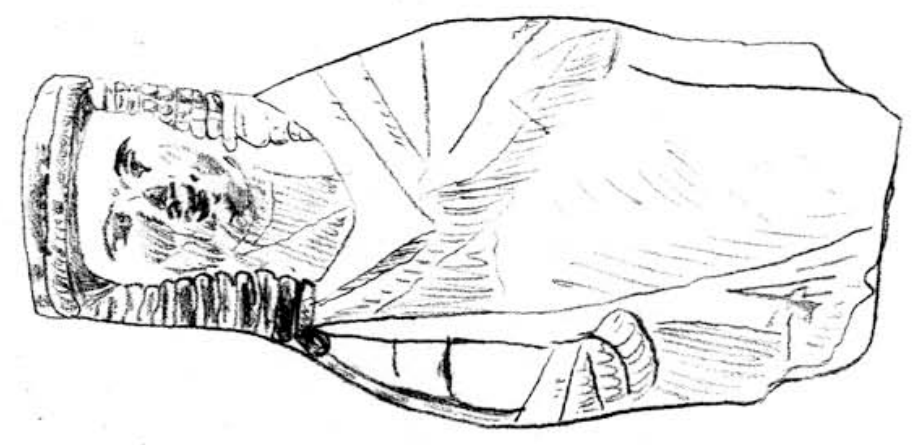

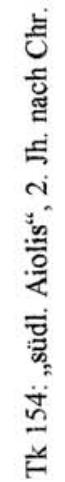

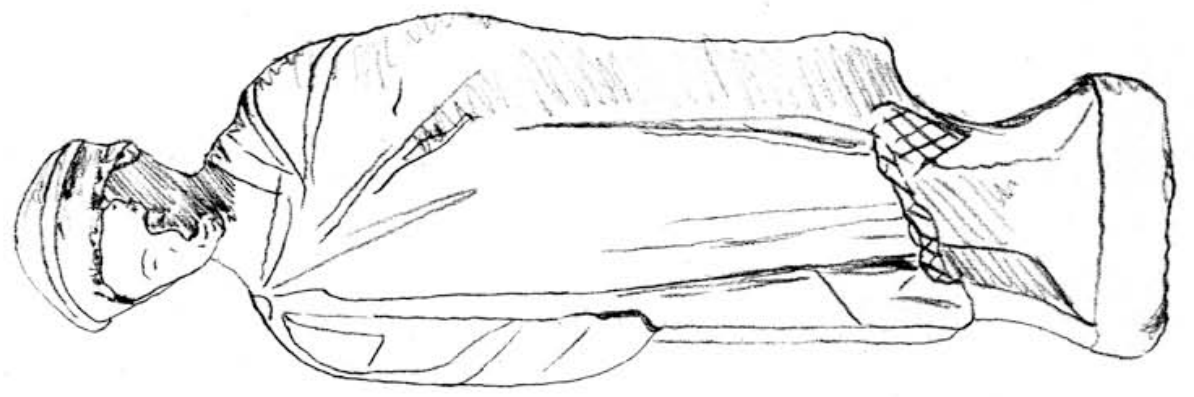

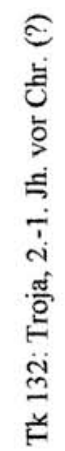

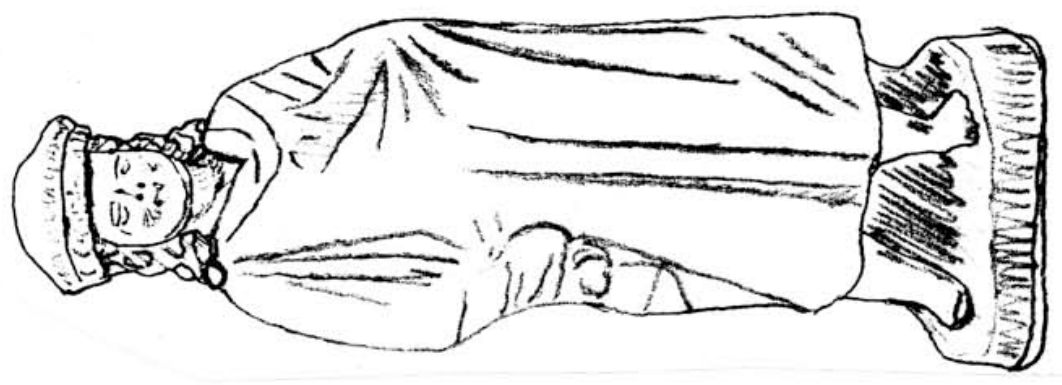

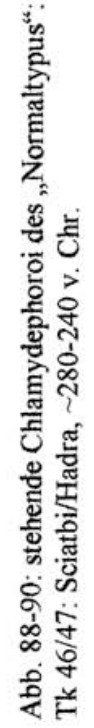




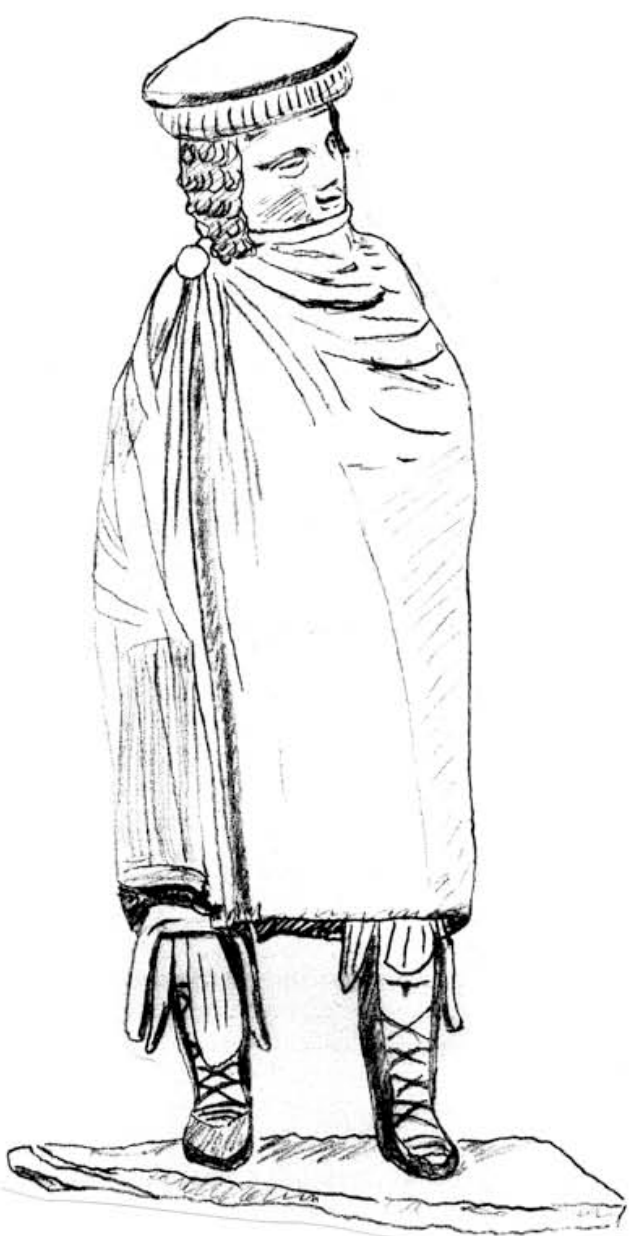

Abb. 90-91: stehende Chlamydephoroi, Kinn verhüllend: Tk 188: Pydna, E. 4. Jh. v. Chr.

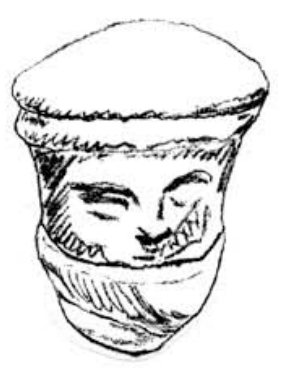

Tk 197: Amphipolis, 3./2. Jh. v. Chr.

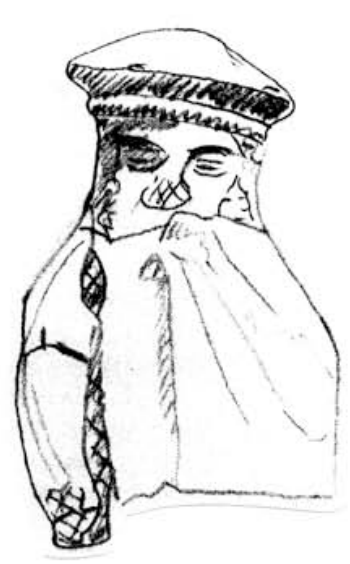

Tk 136: Troja, 1. Jh. v. Chr
Abb. 92-93: stehende Chlamydephoroi, Kinn verhüllend: Tk 258: Samothrake, 2. Jh. v.Chr. (?)

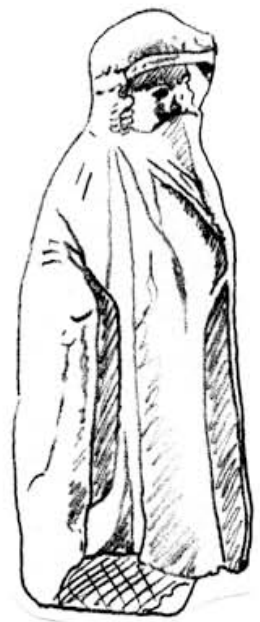


Tafel 26
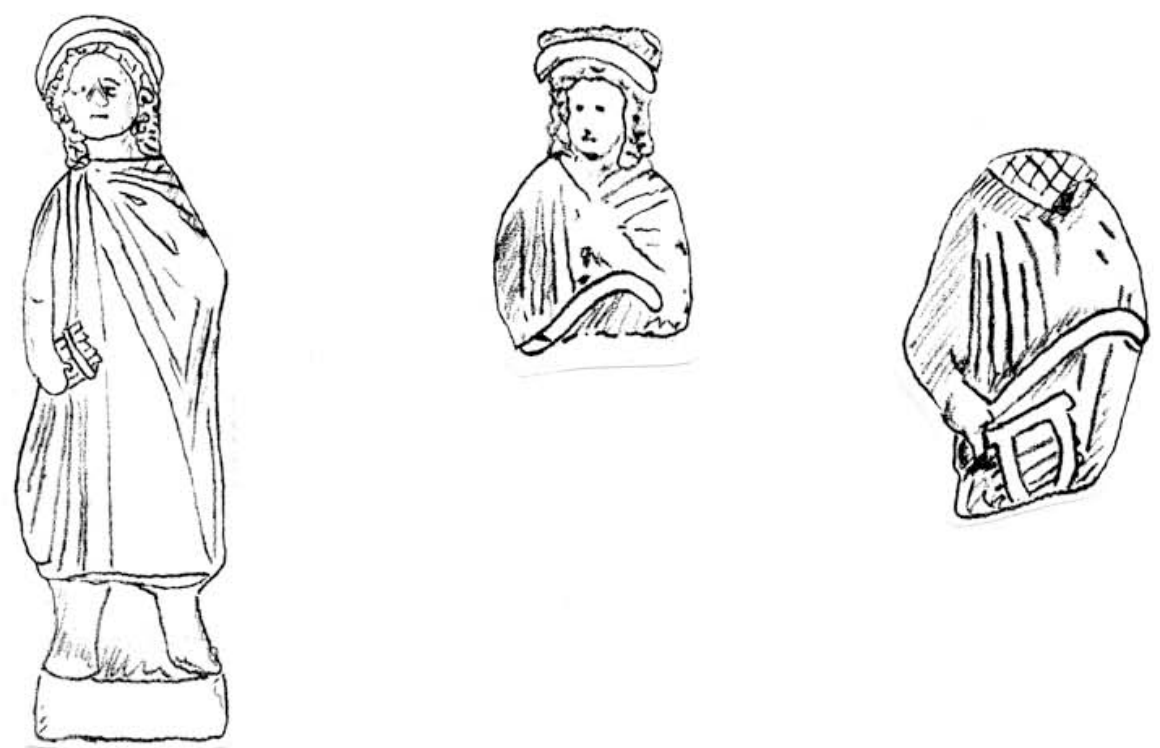

Abb. 94-96: stehende Chlamydephoroi mit Syrinx und/oder Lagobolon: Tk 323-325: Demetrias, 3.-2. Jh. vor Chr.

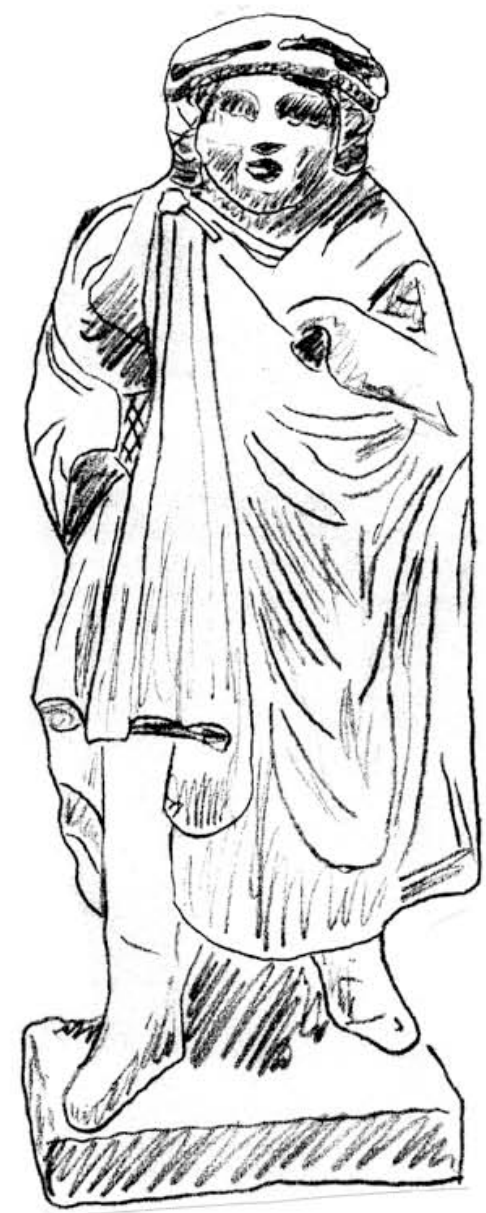

Abb. 97: schreitender Chlamydephoros: Tk 282: Odessos (Varna), 3./2. Jh. vor Chr 
Tafel 27

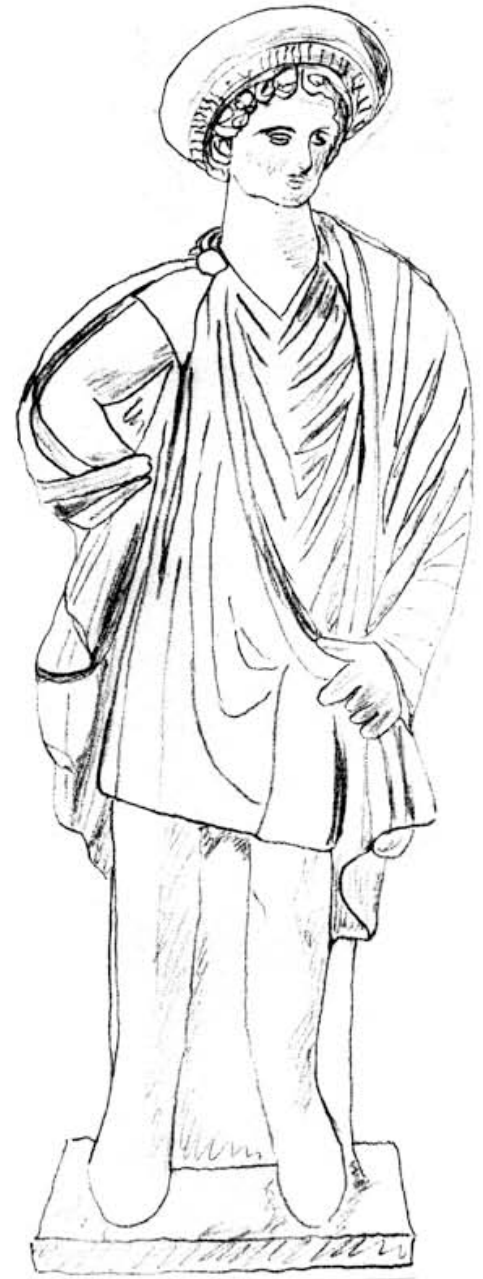

Abb. 98-99: Epheben-Soldaten (Terrakotten): Tk 292: „Böotien", 4./3. Jh. vor Chr.

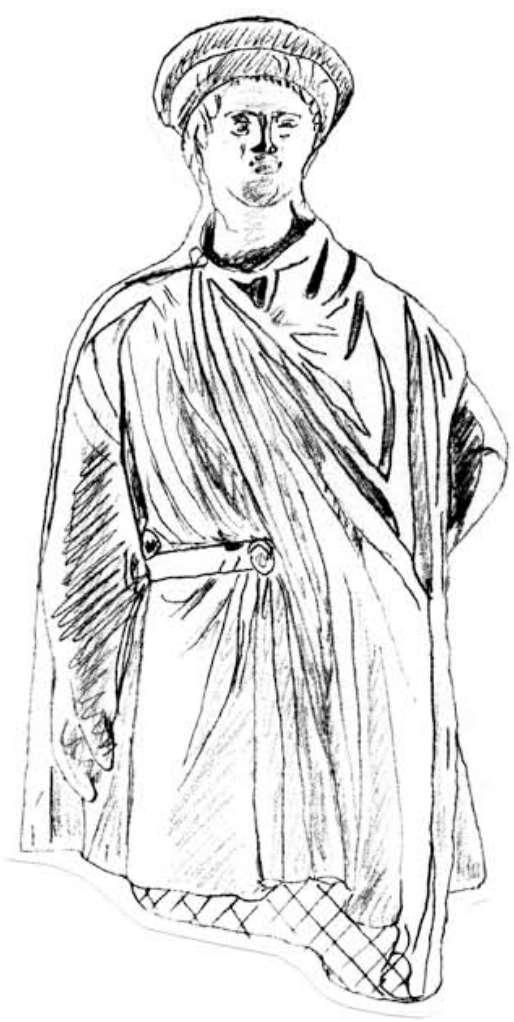

Tk 380: Kharayeb (bei Sidon), 4./3. Jh. vor Chr.
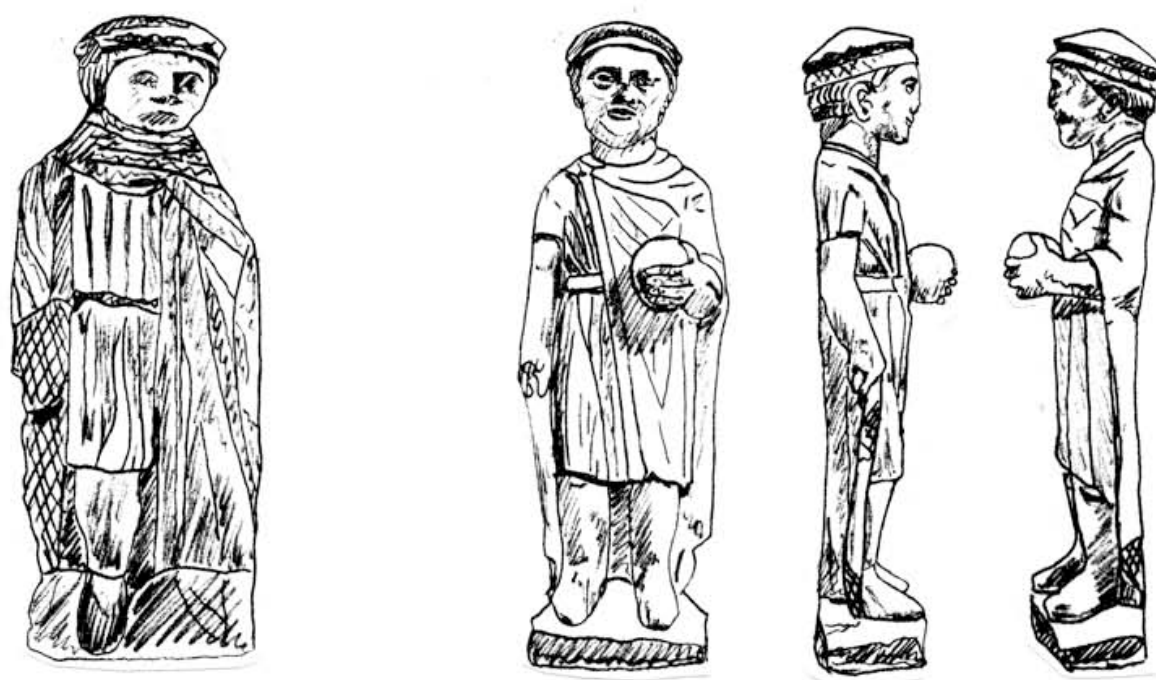

Abb. 100-101 a-c: Kalksteinstatuetten (Typus Epheben-Soldat) aus Idalion/Zypern (Apollon-Heiligtum) P 12: 3. Jh. vor Chr. P 11: 4./3. Jh. vor Chr 
Tafel 28

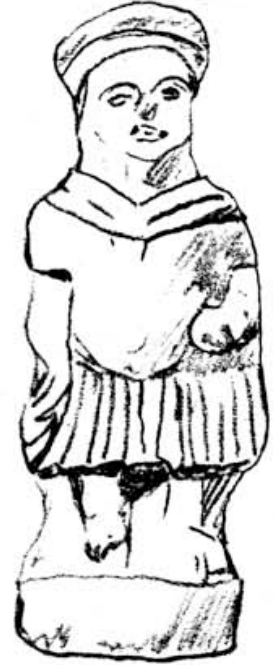

Abb. 103- 104: Soldaten („Normaltypus")

Tk 4: Ägypten, hellenistisch

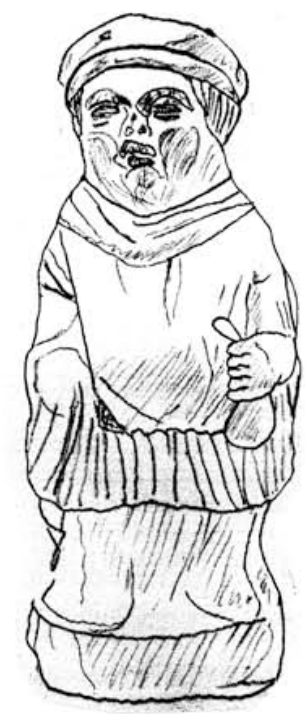

Abb. 105- 106: Soldaten:

Tk 54: mit Beutel, Alexandria, hellenistisch

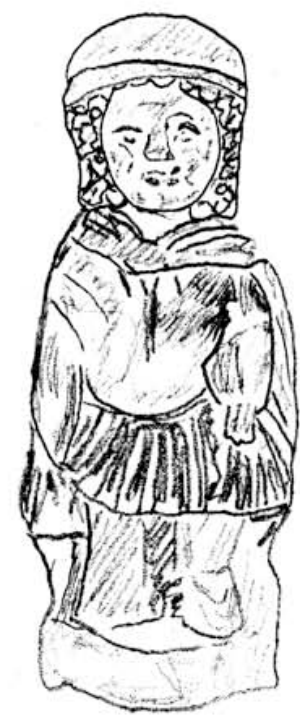

Tk 7: Ägypten, (spät-) hellenistisch

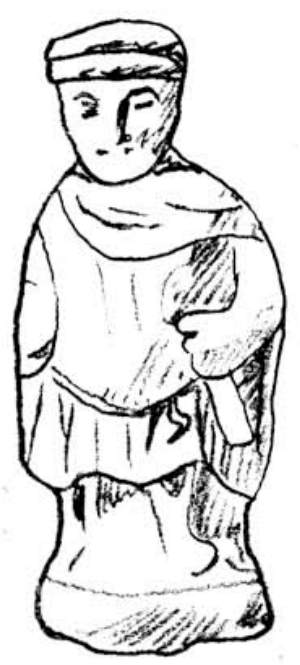

Tk 3: mit Schwert, Ägypten, hellenistisch 


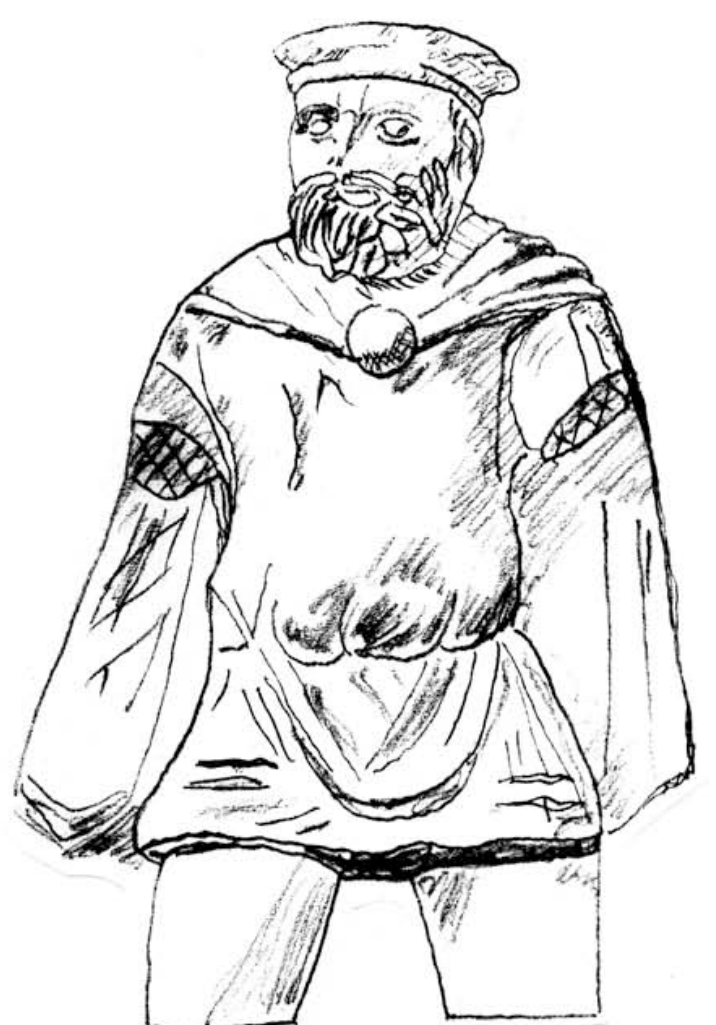

Abb. 106-107: Soldaten, bärtig:

Tk 125: Kyrenaika, A. 3. Jh. vor Chr.

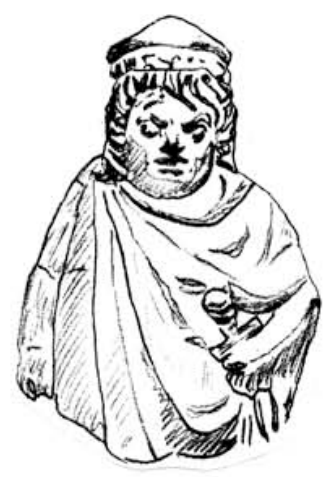

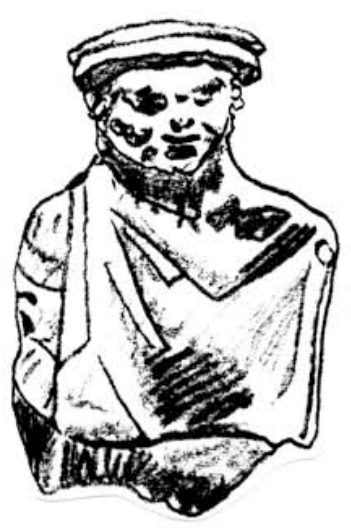

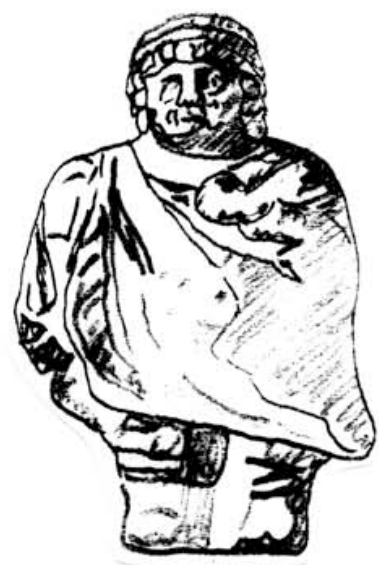

Abb. 108-110: Varianten des Soldat- Typus:

Tk 359: Tarent, hellenistisch Tk 113: Faijum (?), hellenistisch

P 2 (Steatit): Koptos (?), hellenistisch 
Tafel 30
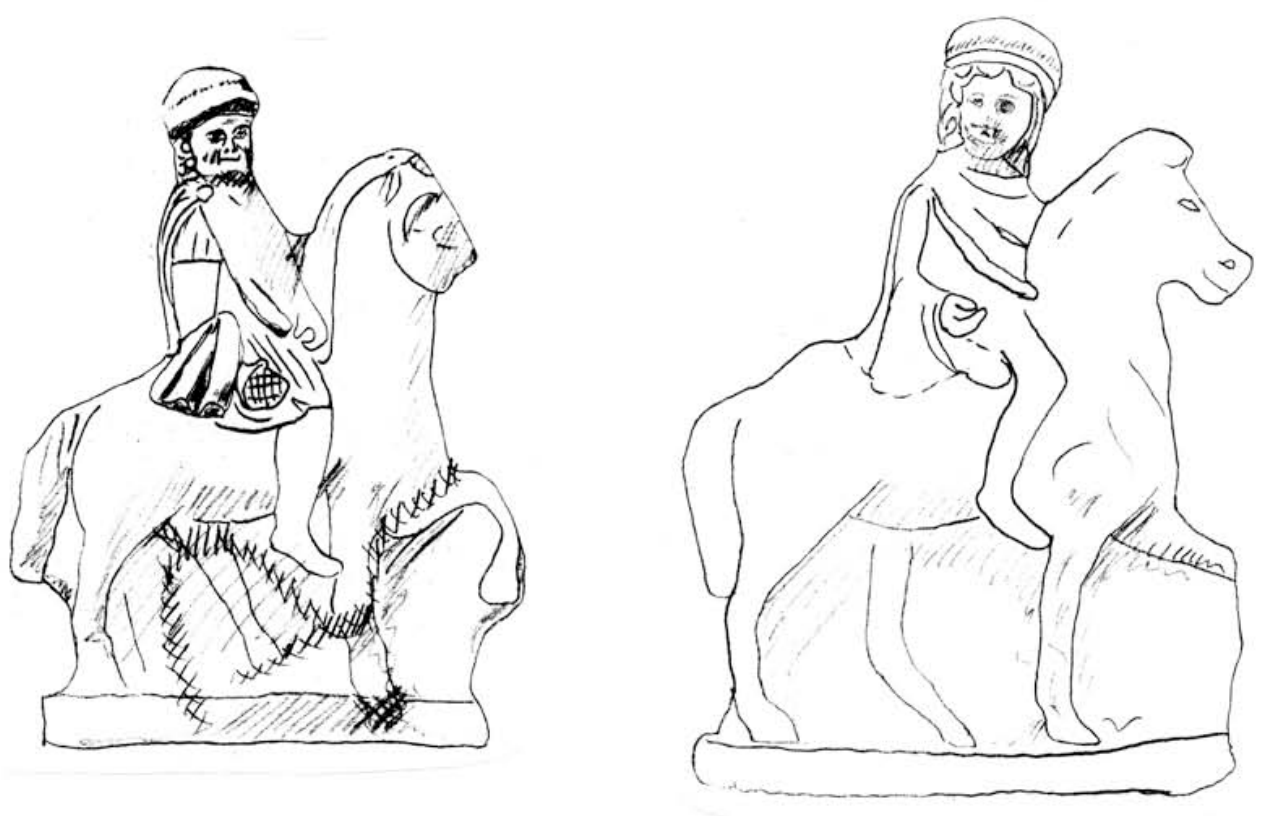

Abb. 112-113: Typus „Reiter ohne Gegner“.
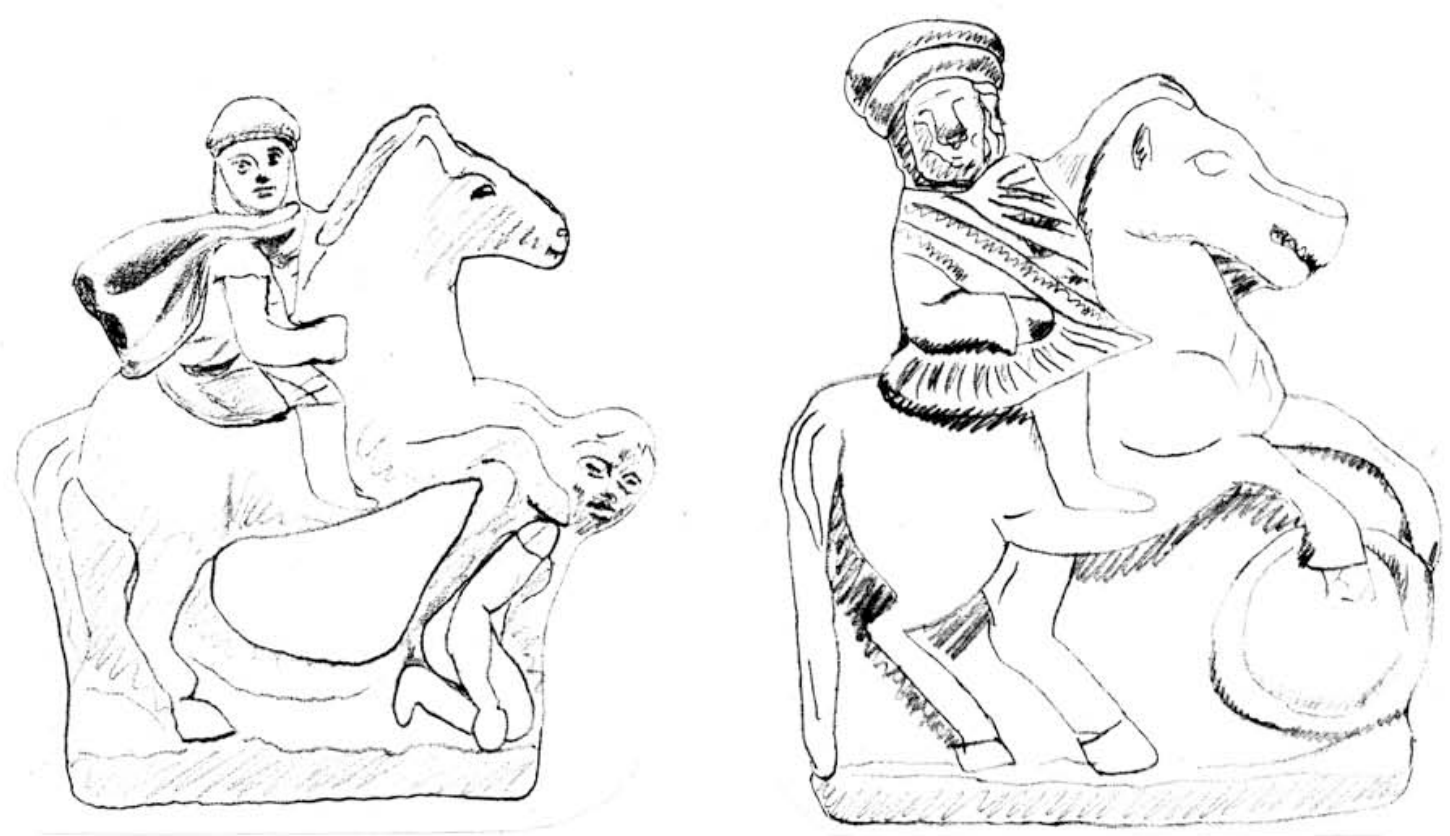

Abb. 114-115: Typus „Reiter über Gegner" bzw. „Reiter über Schild“:

Tk 16: Ägypten, 4./3. Jh. vor Chr.

Tk 21: Ägypten, (spät-) hellenistisch 


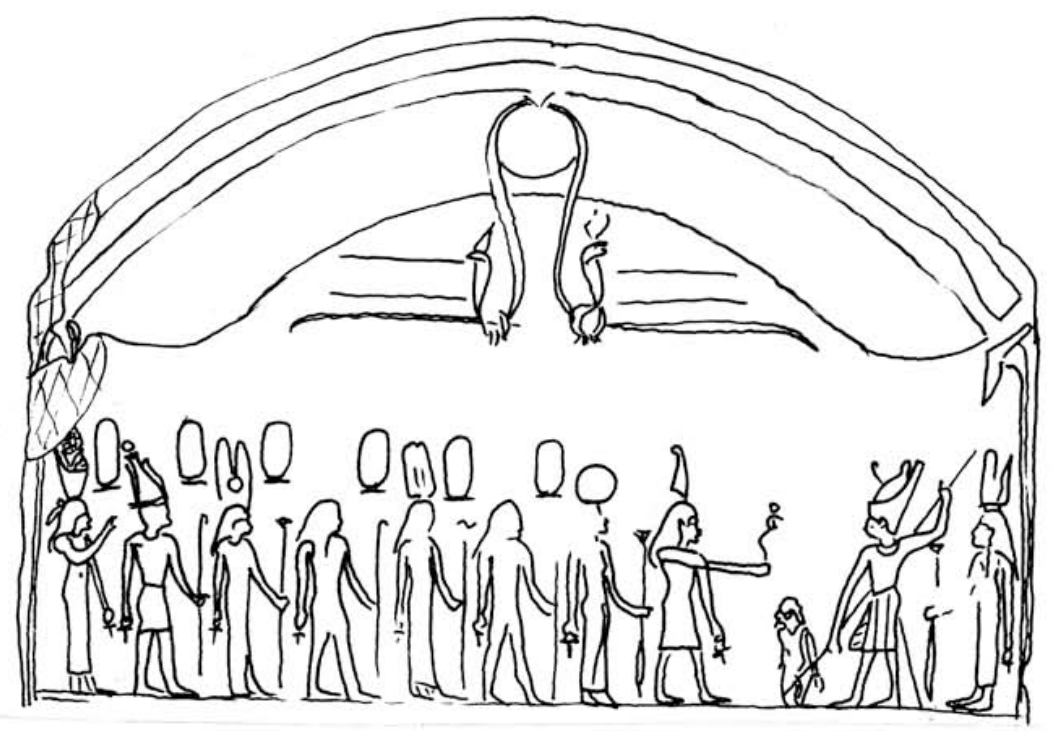

Tafel 31

Abb. 116 a:Stein von al-Nibeira mit Priesteredikt von Memphis, Kairo 22188, Ptolemaios IV.

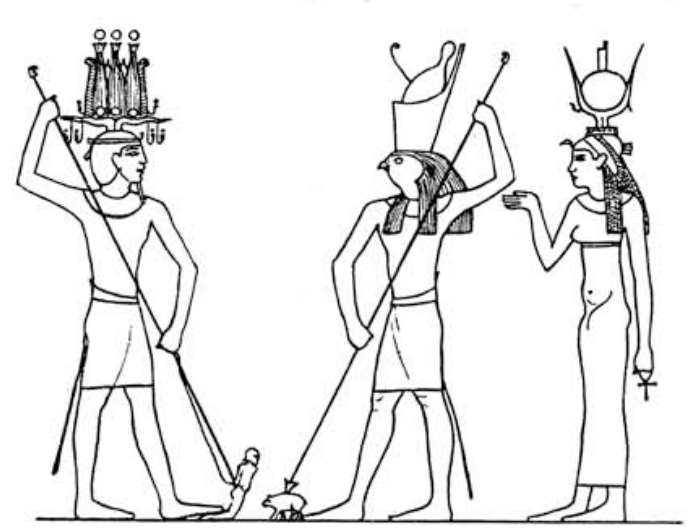

Abb. 116 b: Edfu, Tempel, Ptolemaios X., Horos, Isis

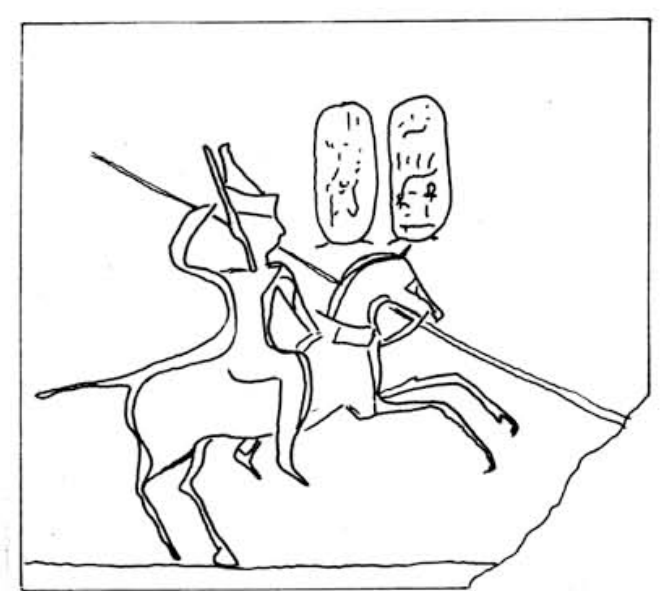

Abb. 116 c:Gedenkstein, Kairo 31088, Ptolemaios IV.
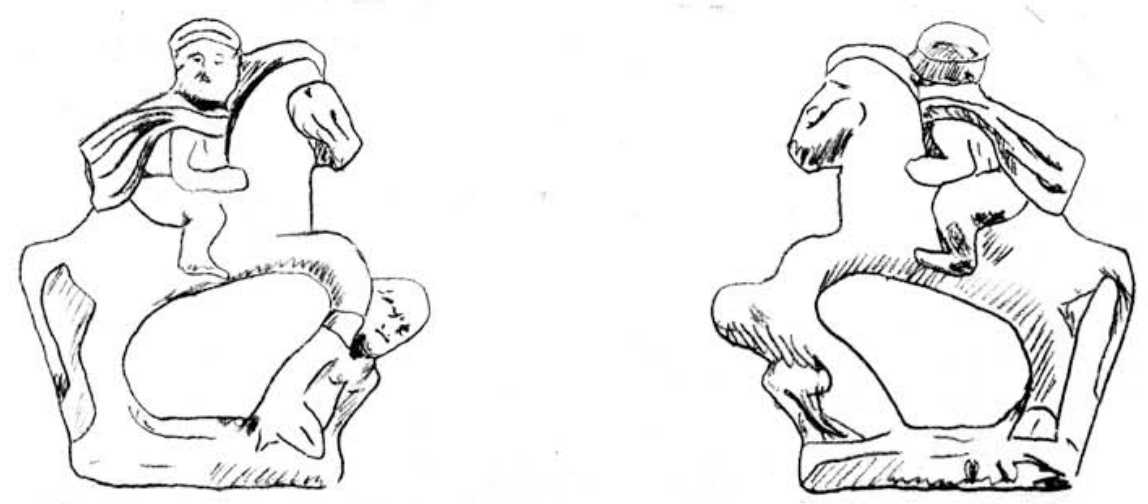

Abb. 117: Typus „Reiter über Gegner“: Tk 14: Ägypten, 4./3. Jh. vor Chr. 

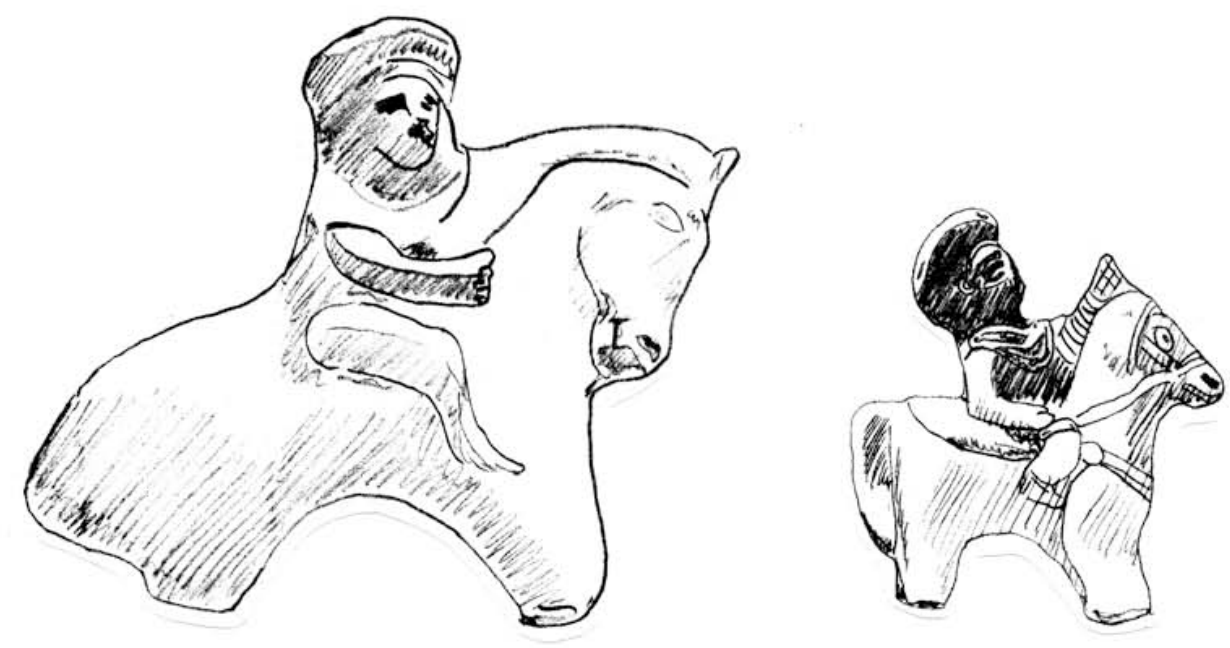

Abb. 119-120: Reiter (mediterran-orientalische Mischtypen):

Tk 393: Tell Halaf (N-Irak), hell.-parthisch

Tk 409: Seleukia, 1-200 n. Chr. oder später
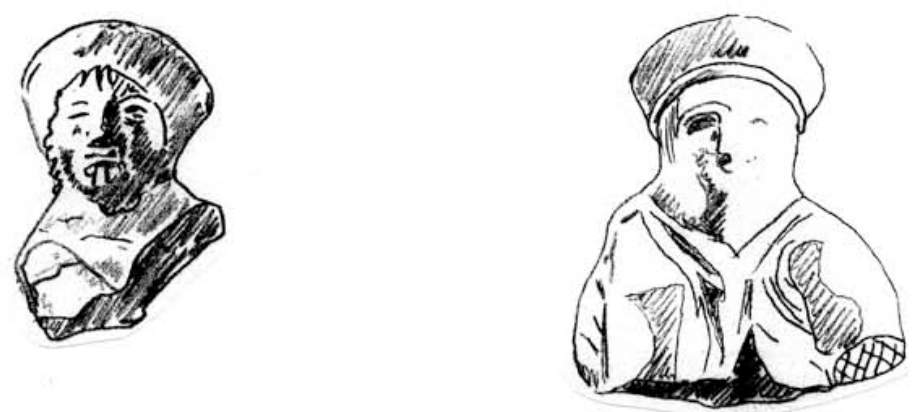

Abb. 121-122: Reiter (mediterran-orientalische Mischtypen):

Tk 394: Tell Halaf, hellenistisch-parthisch ?

Tk 410: Seleukia, 150 v.Chr. - 200 n. Chr. oder später
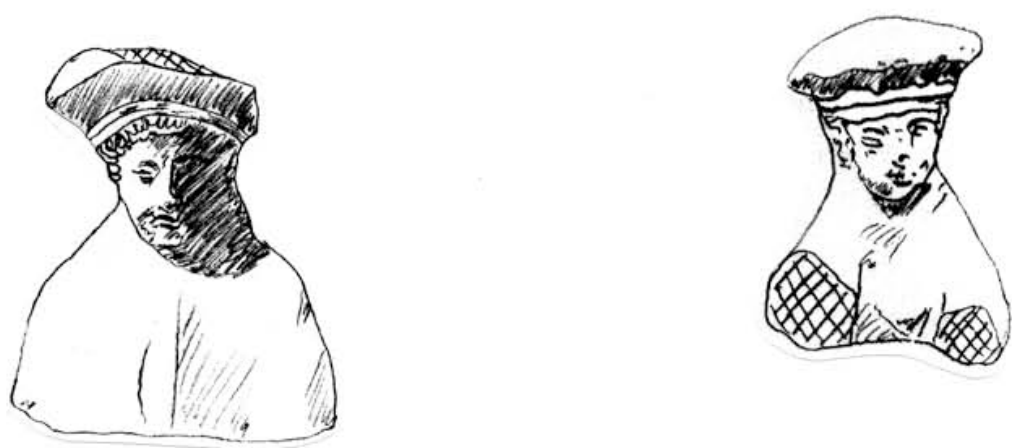

Abb. 123-124: Reiter (mediterran-orientalische Mischtypen):

Tk 425: Babylon, parthisch / 4./3. Jh. vor Chr.?

Tk 426: Babylon, parthisch / 4./3. Jh. vor Chr? 
Tafel 33

Abb. 125-130: Handgeformte Reiter aus Süd-Mesopotamien (einschl. Susiane und Ikaros) (200-140 vor Chr.):

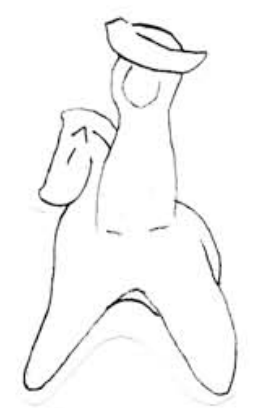

Tk 448: Masjid-i Solaiman, Reiter

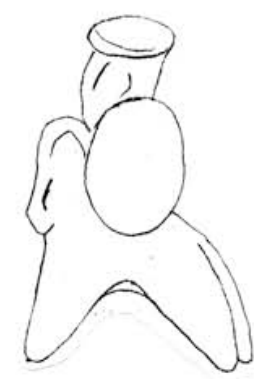

Tk 449: Masjid-i Solaiman, Reiter mit Rundschild

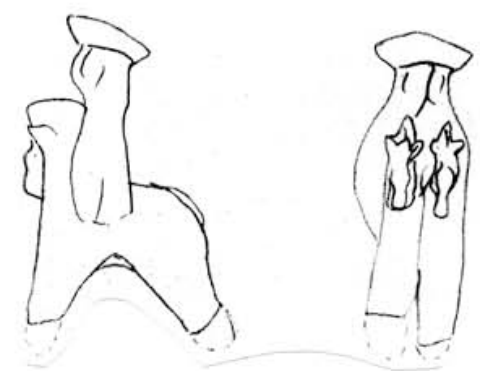

Tk 450: Masjid-i Solaiman, Doppelreiter (Amphippos)

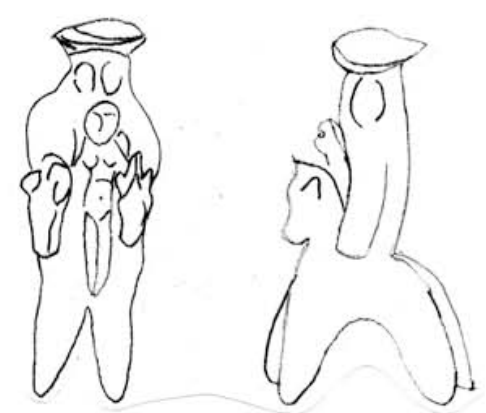

Tk 451: Masjid-i Solaiman, Amphippos mit Göttin

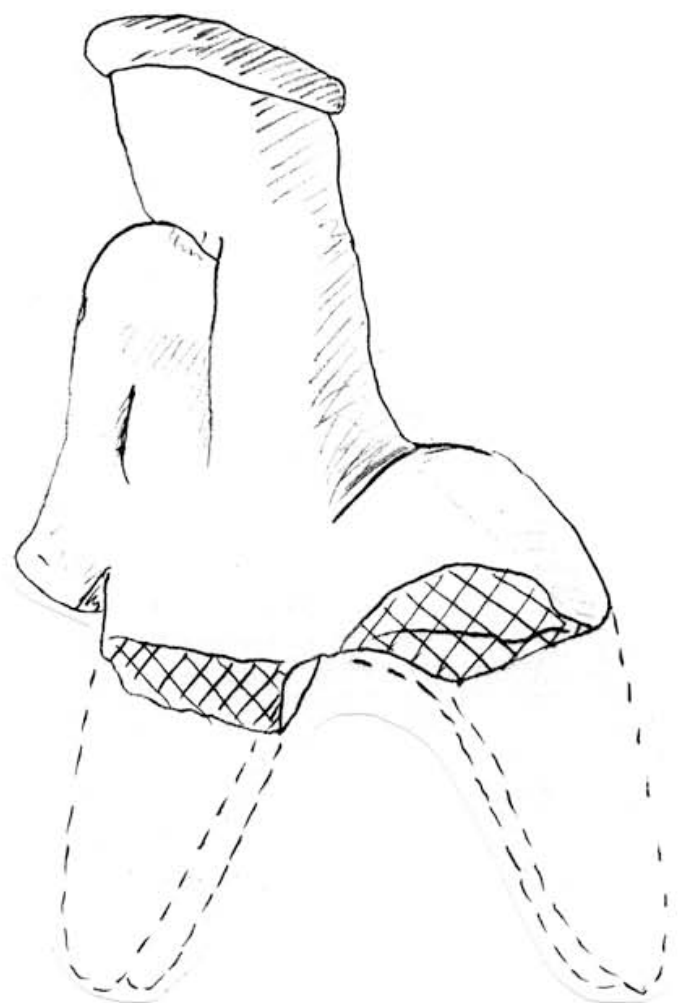

Tk 452: Ikaros, Reiter

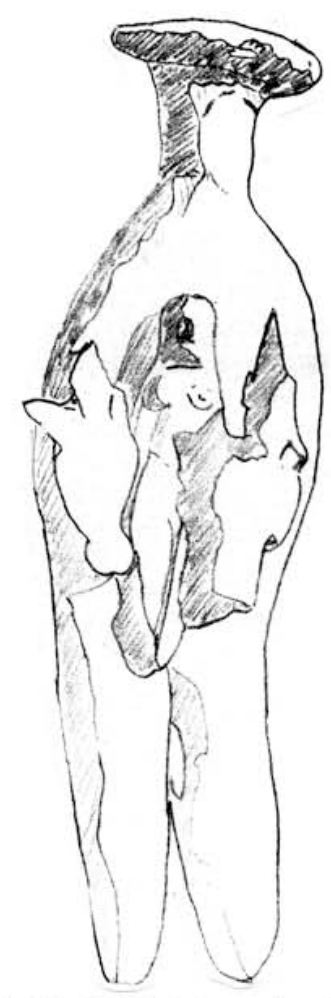

Tk 451: Masjid-i Solaiman, Amphippos mit Göttin 

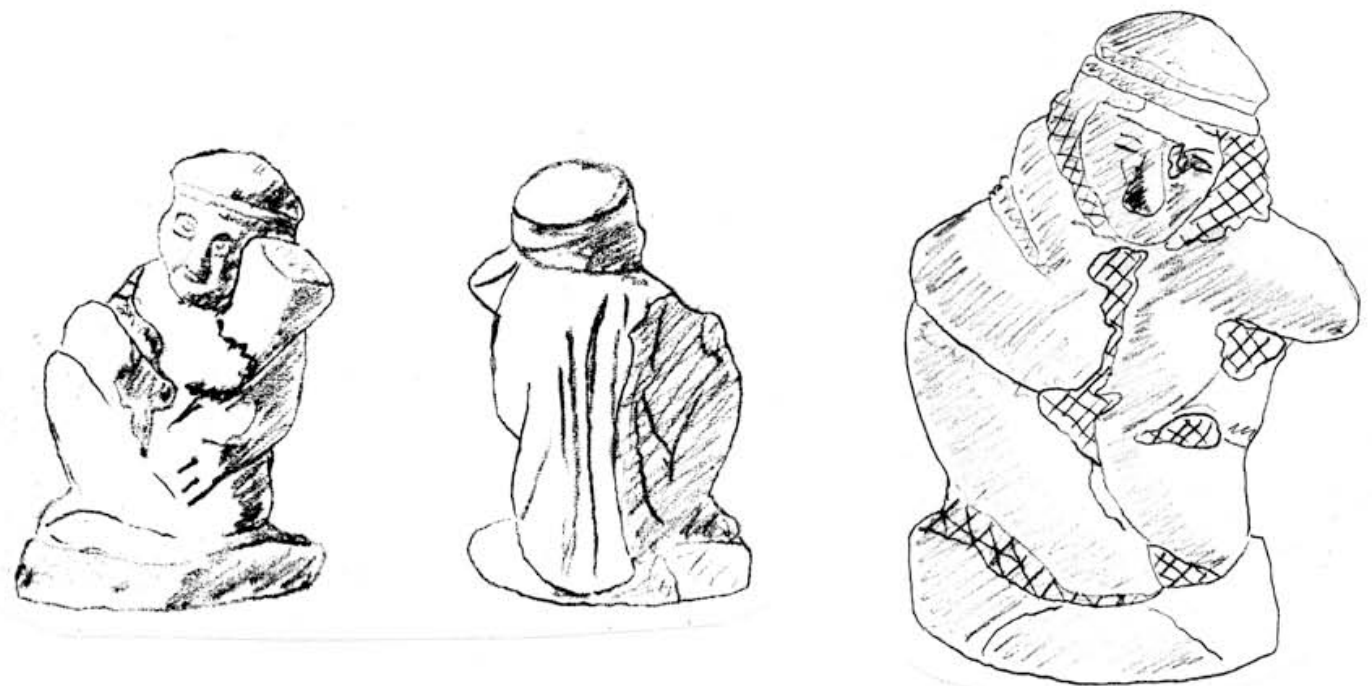

Abb. 130 a/b-131: Hockende Knaben (Harpokrates?) in zurückgeschlagener Chlamys mit Phallos oder Rhyton:
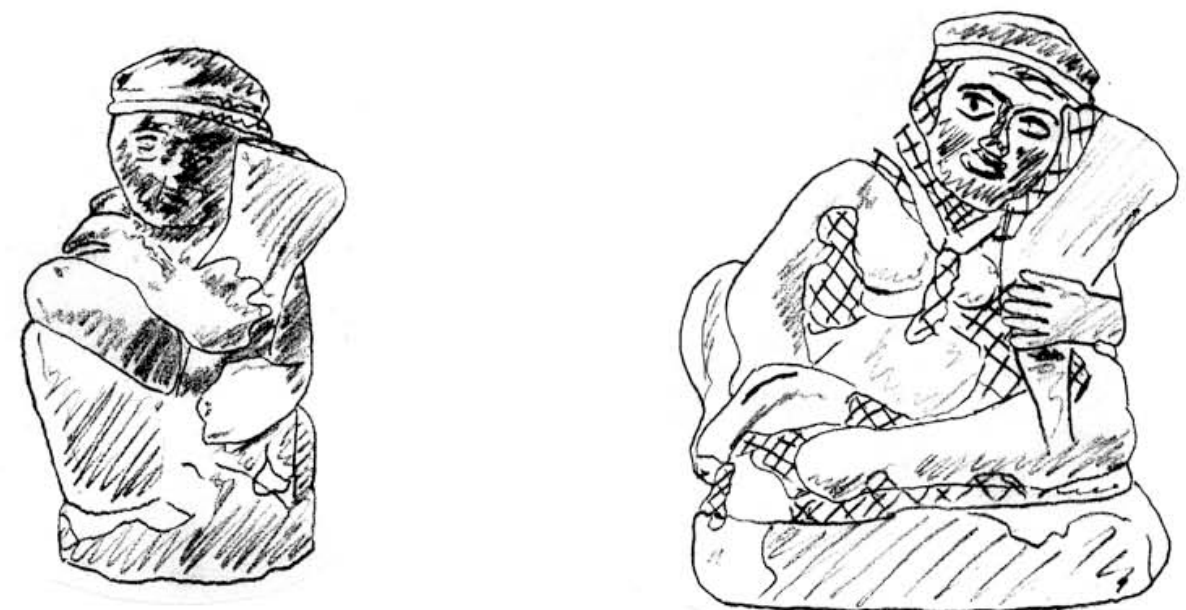

Abb. 132-133: Hockende Knaben (Harpokrates?) in zurückgeschlagener Chlamys mit Phallos oder Rhyton: Tk 117: Ägypten/Fayum (?), 3. Jh. v. Chr. Tk 25: Ägypten, hellenistisch?
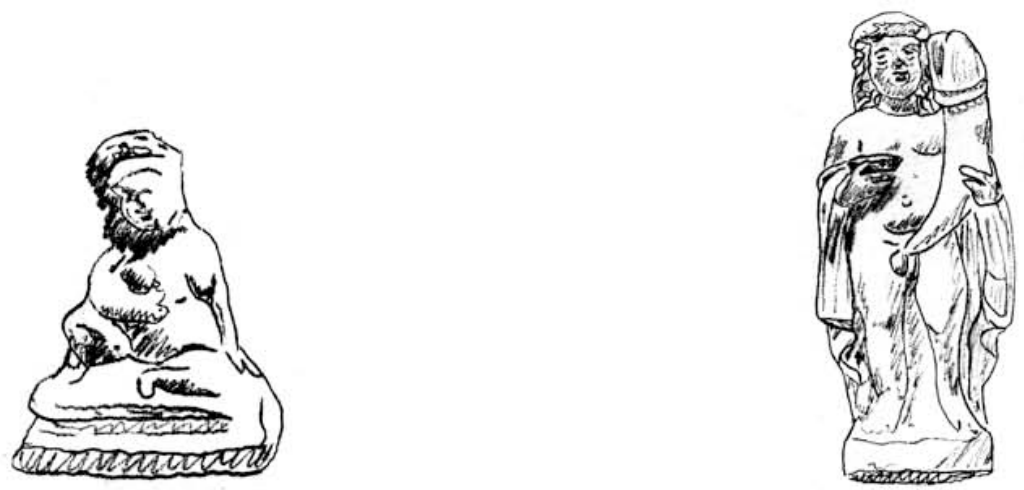

Abb. 134-135: Varianten: hockender Knabe ohne Attribut (?); stehender Knabe mit Phallos und Schale Tk 65: Alexandria, hellenistisch Tk 28: Ägypten, hellenistisch 


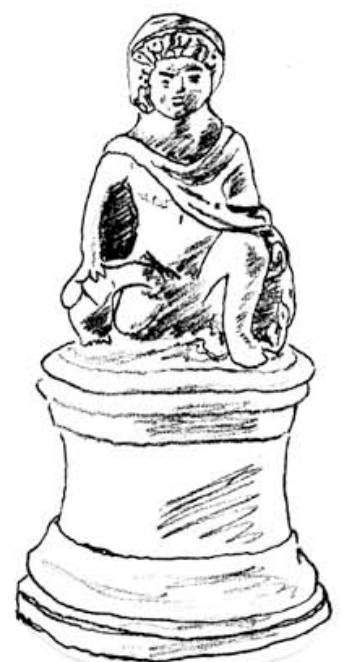

Abb. 137: Hockender Knabe in Chlamys mit Ente/Gans: Tk 336: Pantikapaion, späthellenistisch
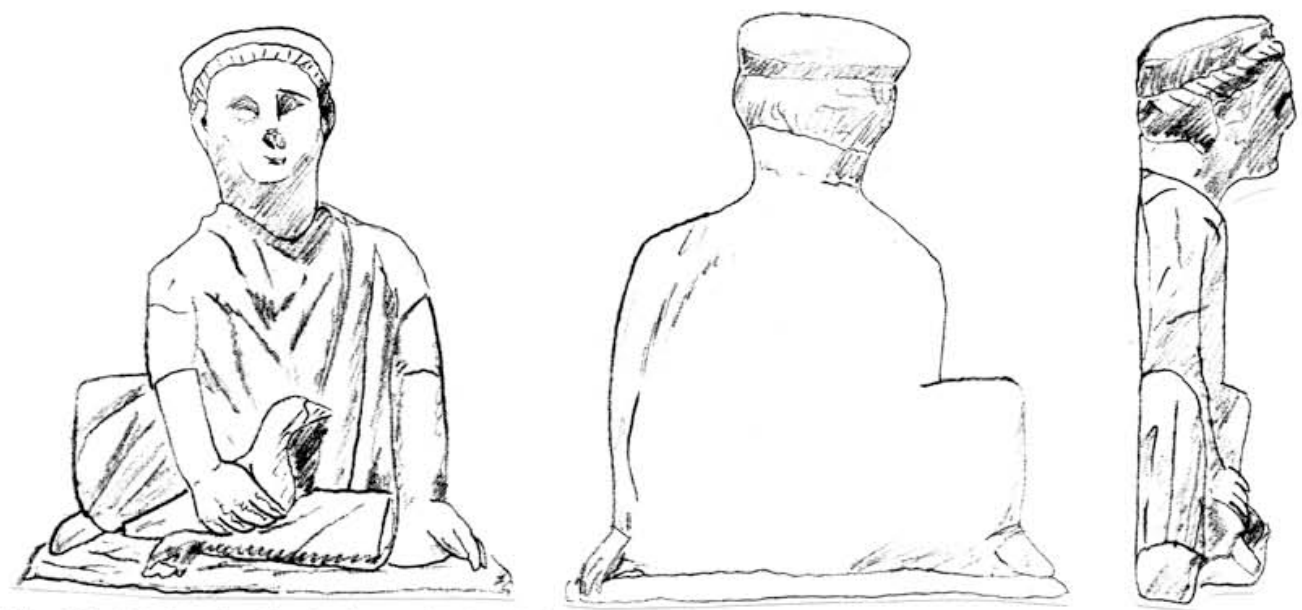

Abb. 138: Hockender Knabe (,temple boy") in Chiton mit Vogel:

P 7 (Kalkstein): Voni (Zypern), Apollon-Temenos, E. 4./ A. 3. Jh. vor Chr.
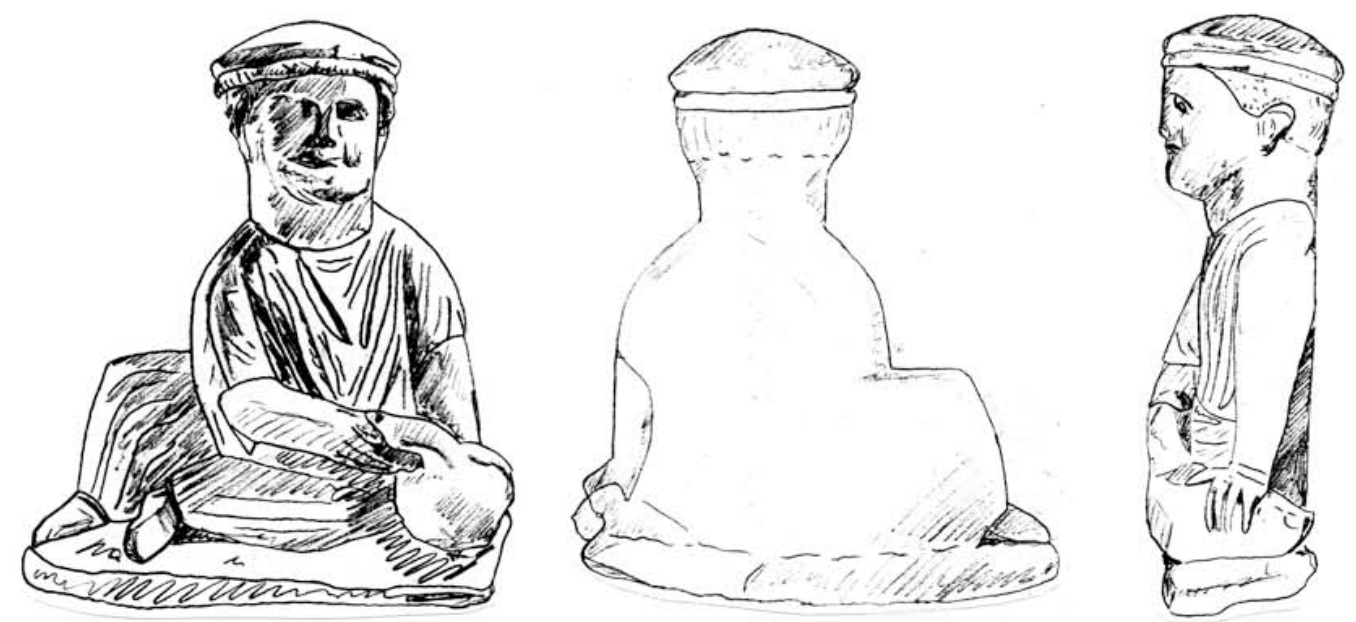

Abb. 139: Hockender Knabe (,temple boy“) in Chiton mit Gans:

P 5 (Kalkstein): Kourion (Zypern), Heiligtum, E. 4./ A. 3. Jh. vor Chr. 


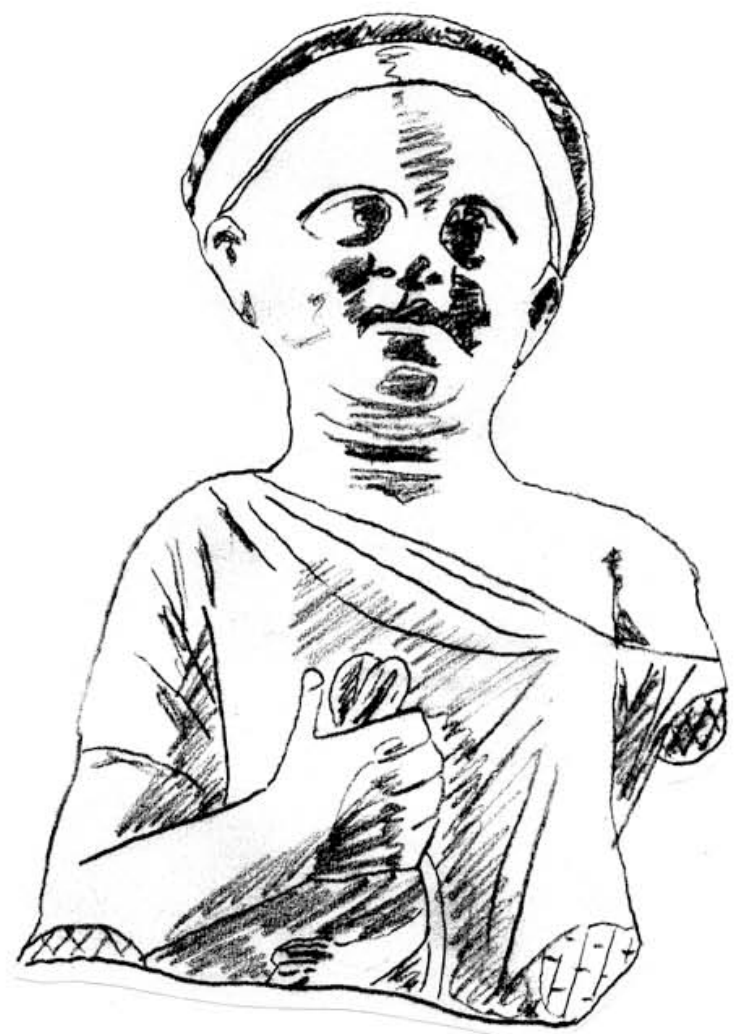

Tafel 36

Abb. 140: Sitzender (?) Knabe (Frgt.) in Chiton, mit Hahn: Tk 383: Kharayeb (bei Sidon), hellenistisch ?

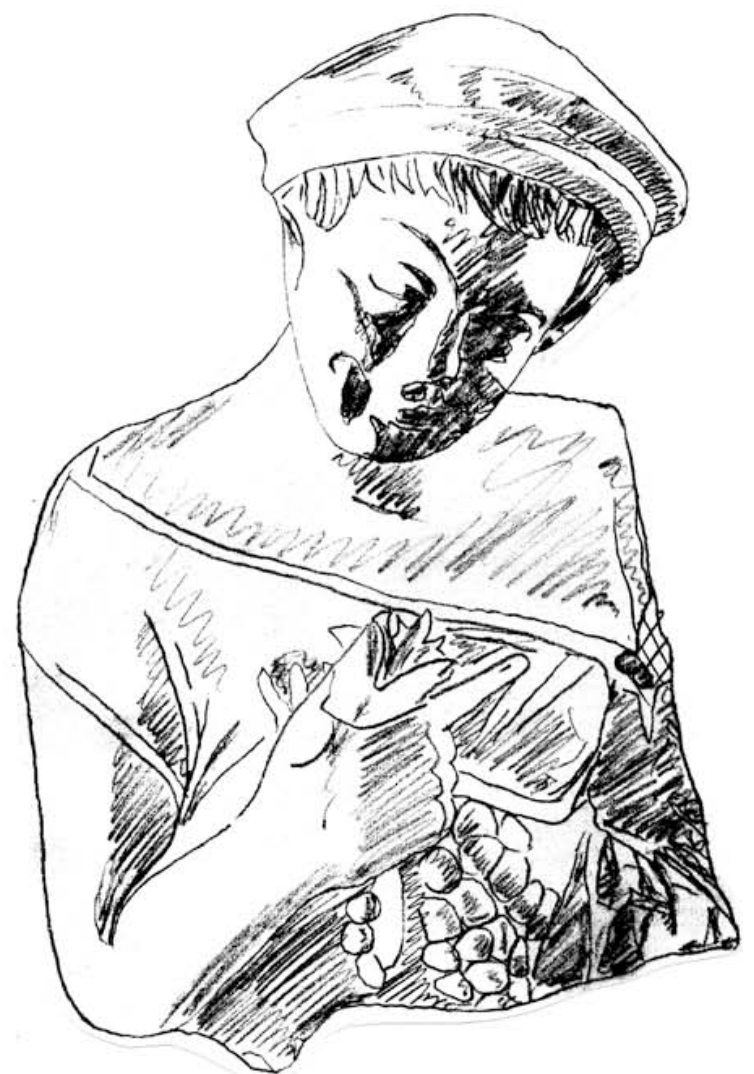

Abb. 141 Sitzender (?) Knabe (Frgt.) in Chiton, mit Hahn/Trauben (?): Tk 384: Kharayeb (bei Sidon), hellenistisch ? 
Tafel 37
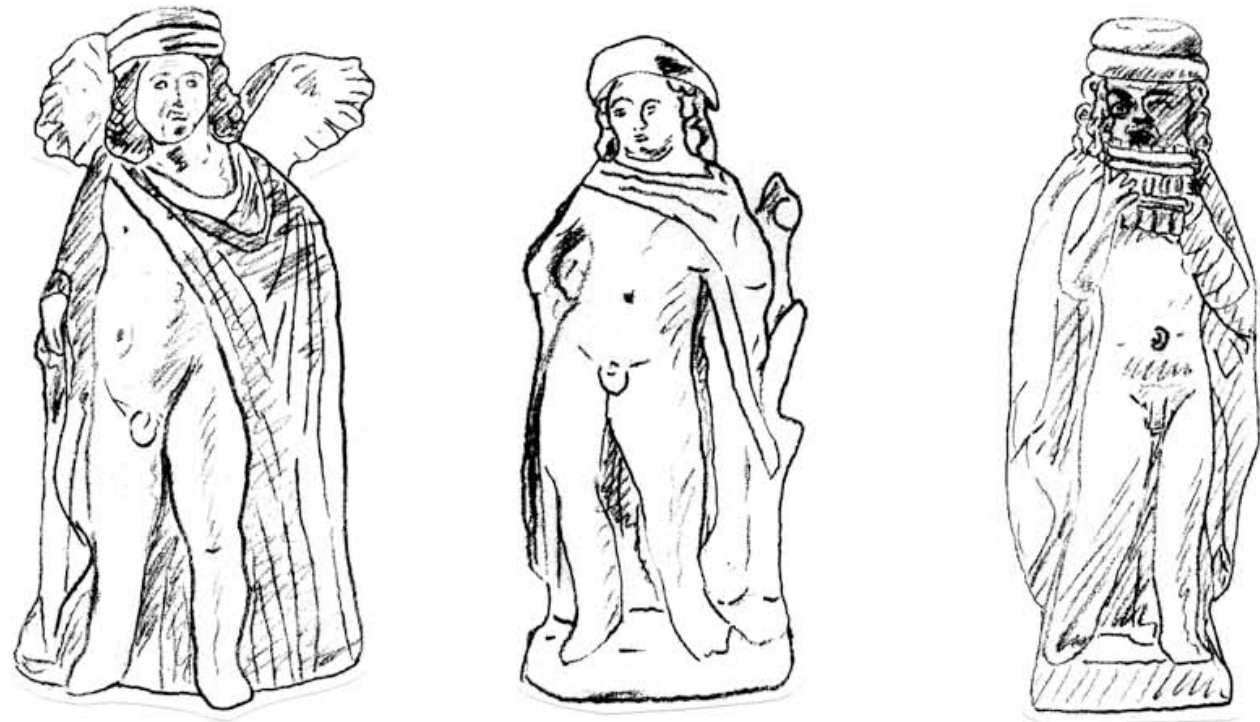

Abb. 142-144: Eroten bzw. Jugendliche im Mantel (ohne Chiton):

Tk 360: Flügel, Tarent, 3. Jh. v.Chr.

Tk 358: Paestum, 4./3. Jh. v.Chr.

Tk 357: Syrinx, Capua, 2. Jh. v.Chr.
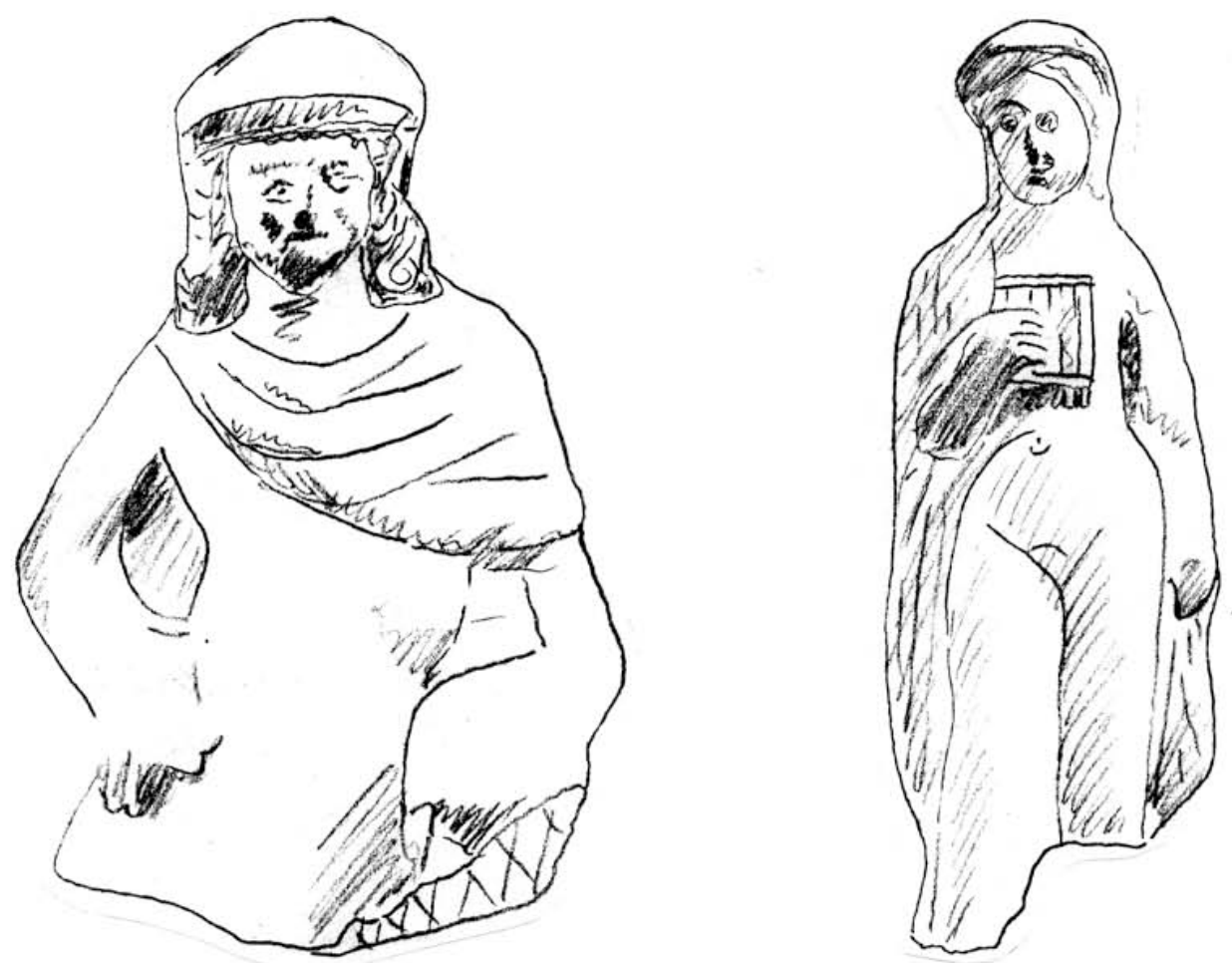

Abb. 145-146: Jugendliche (teils mit Syrinx) in zurückgeschlagener Chlamys, ohne Chiton: Tk 348-349: Rom, Palatin, Attis-Kybele-Heiligtum, nach 191 v. Chr. 
Tafel 38
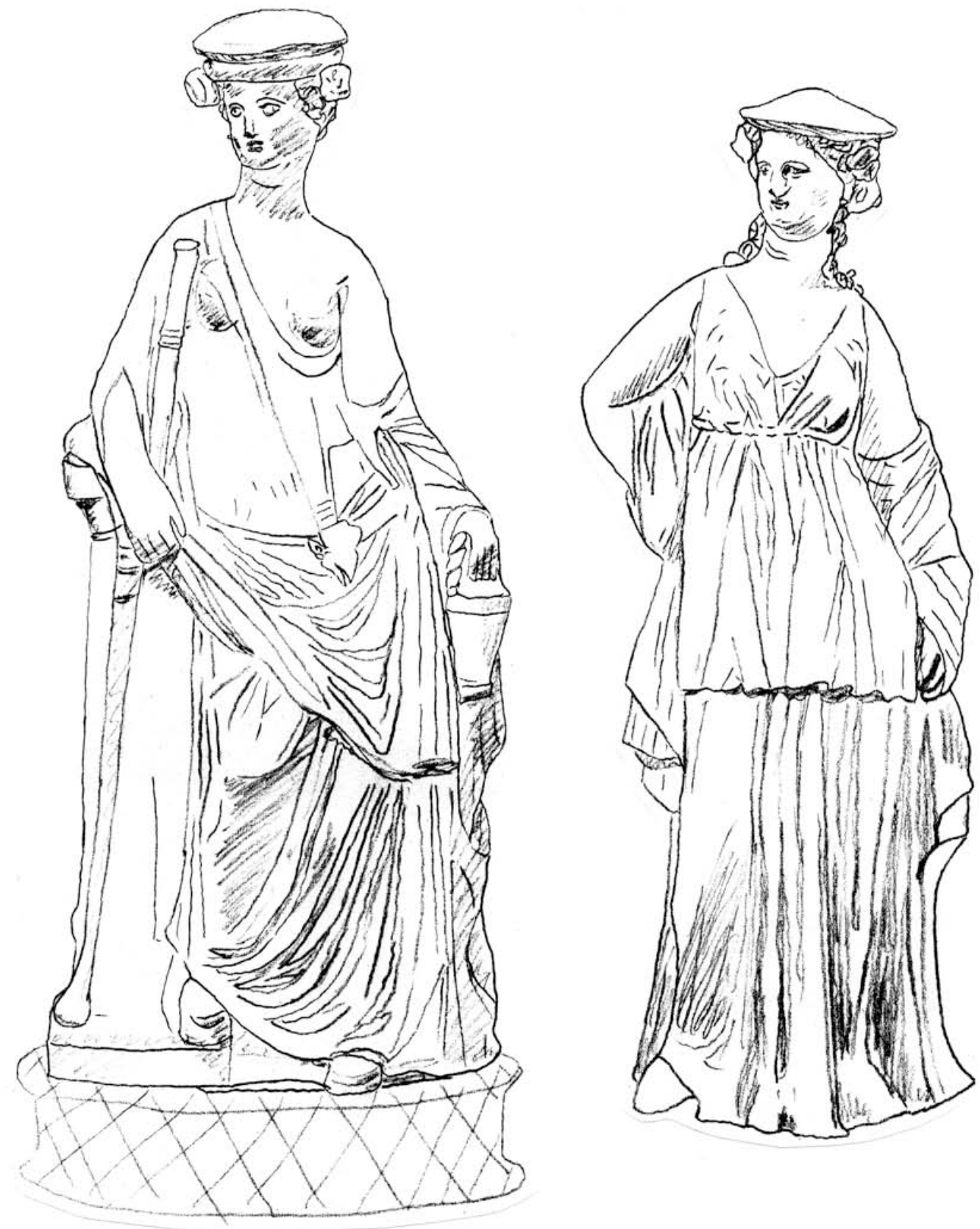

Abb. 147-148:

Tk 362: Mänade (Fackel, Situla, Fell), Tarent, 2. Jh. v.Chr. Tk 361: Frau, Tarent, M. 3. Jh. v. Chr. 

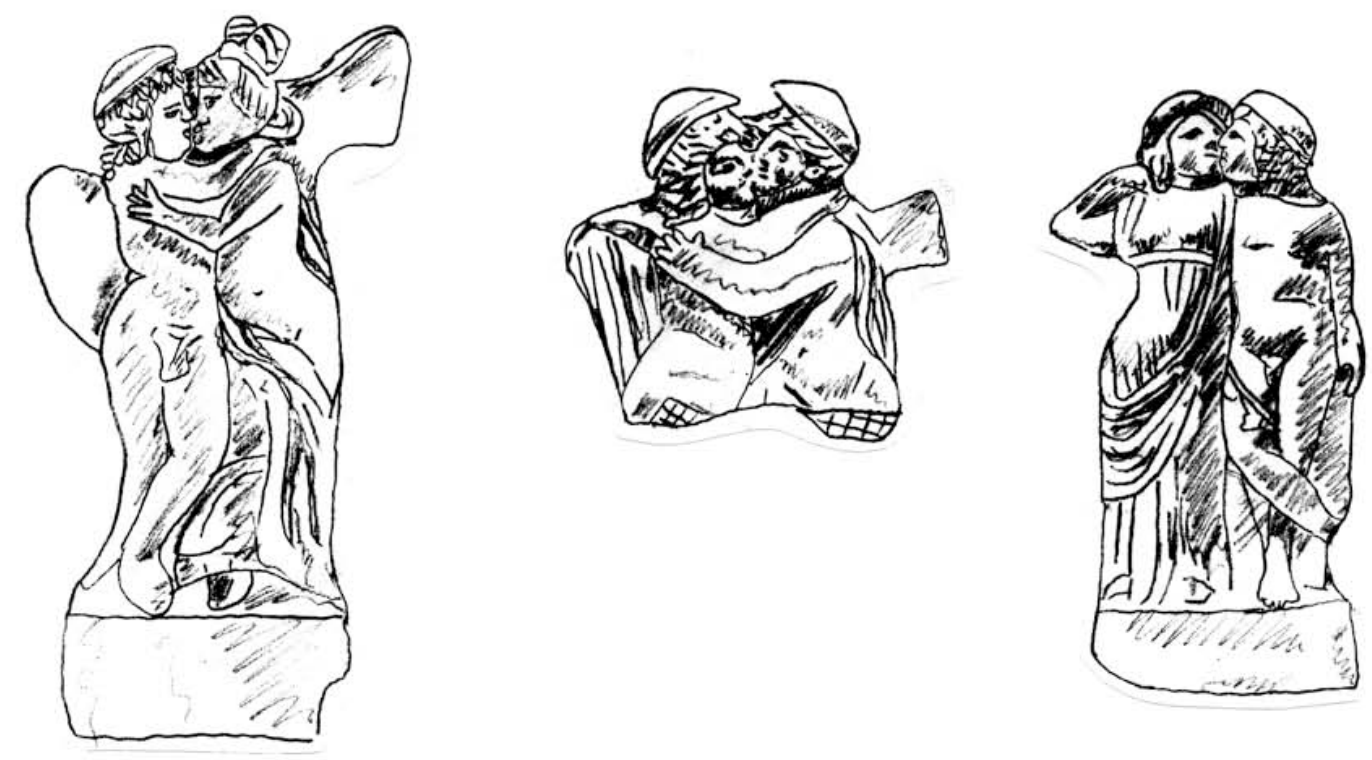

Abb. 149-151: Paare: Eros (immer mit Kausia) und Psyche (teils mit Kausia) : Pantikapaion, 1. Jh. vor Chr.

Tk 337: beide Flügel, nackt Tk 338: beide Flügel, Kausia, nackt

Tk 339: ohne Flügel, Frau in Chiton
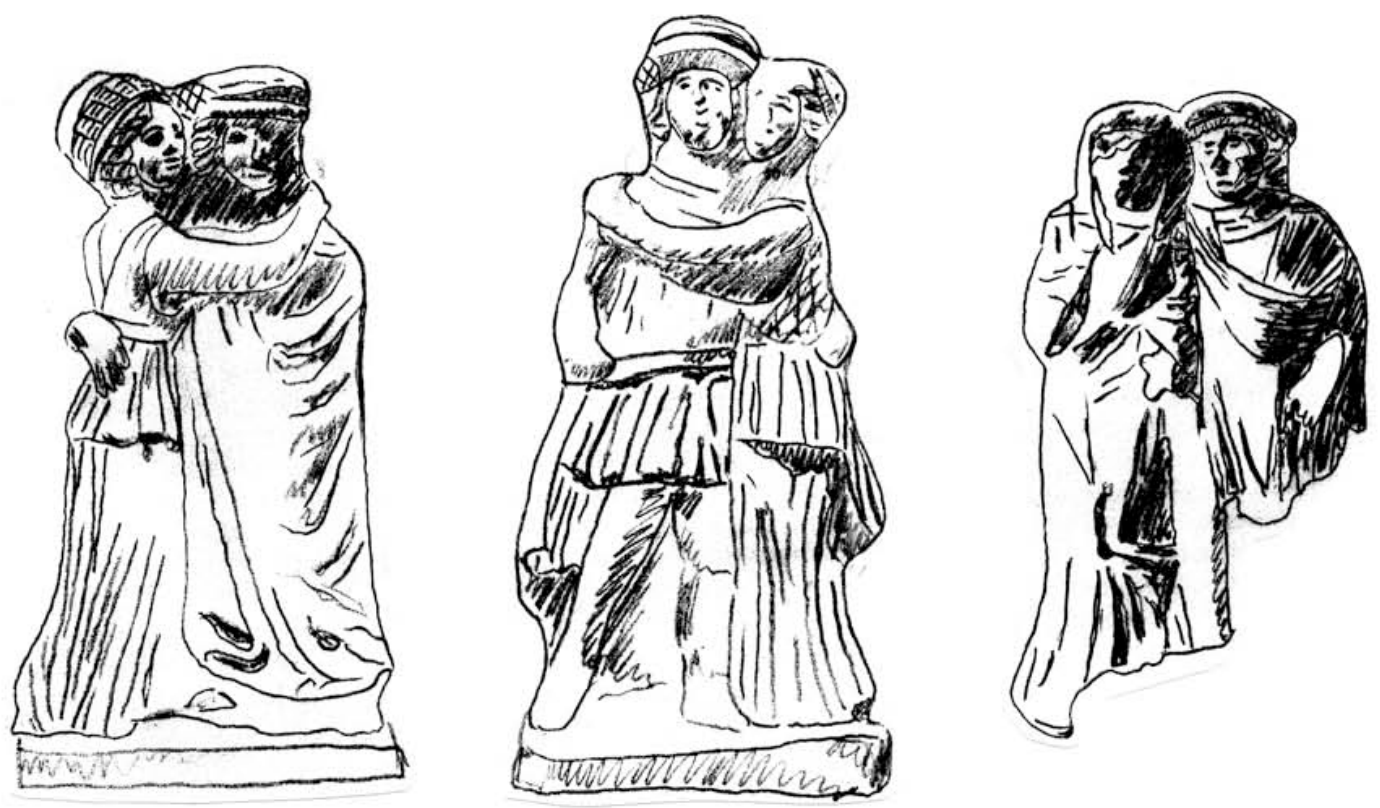

Abb. 152-154: Paare: Mann (Chlamydephoros, Epheben-Soldat, Manteljüngling) jeweils mit Kausia
Tk 356: Capua (?), 3. Jh. v.Chr. (?)
Tk 355: Capua (?), 3. Jh. v.Chr. (?)
Tk 431: Nippur, hell. 

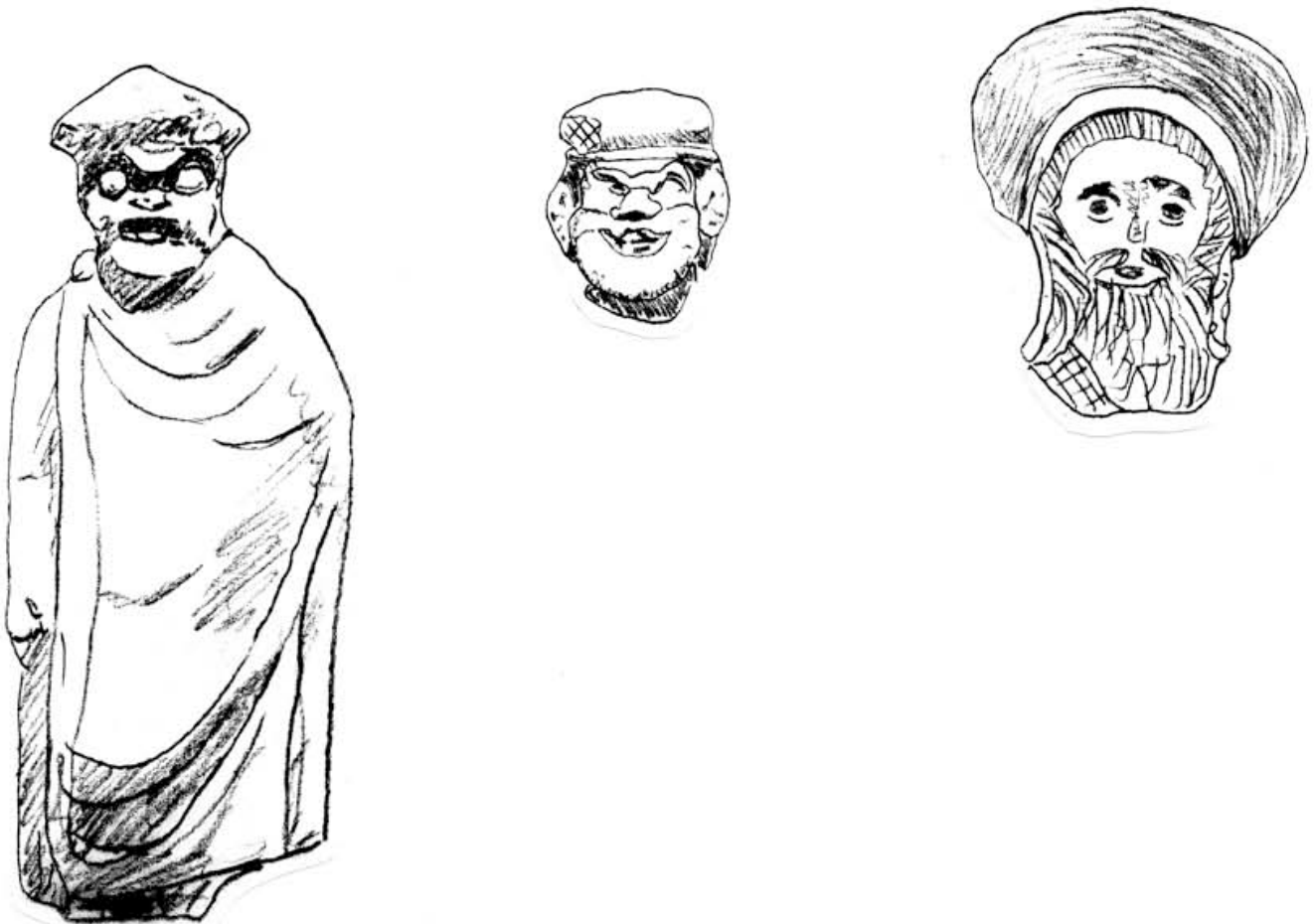

Abb. 155-157: Sonderfälle: Sklave oder Soldat, Kopf mit Bart (Maske?), Kopf mit orientalischem Bart
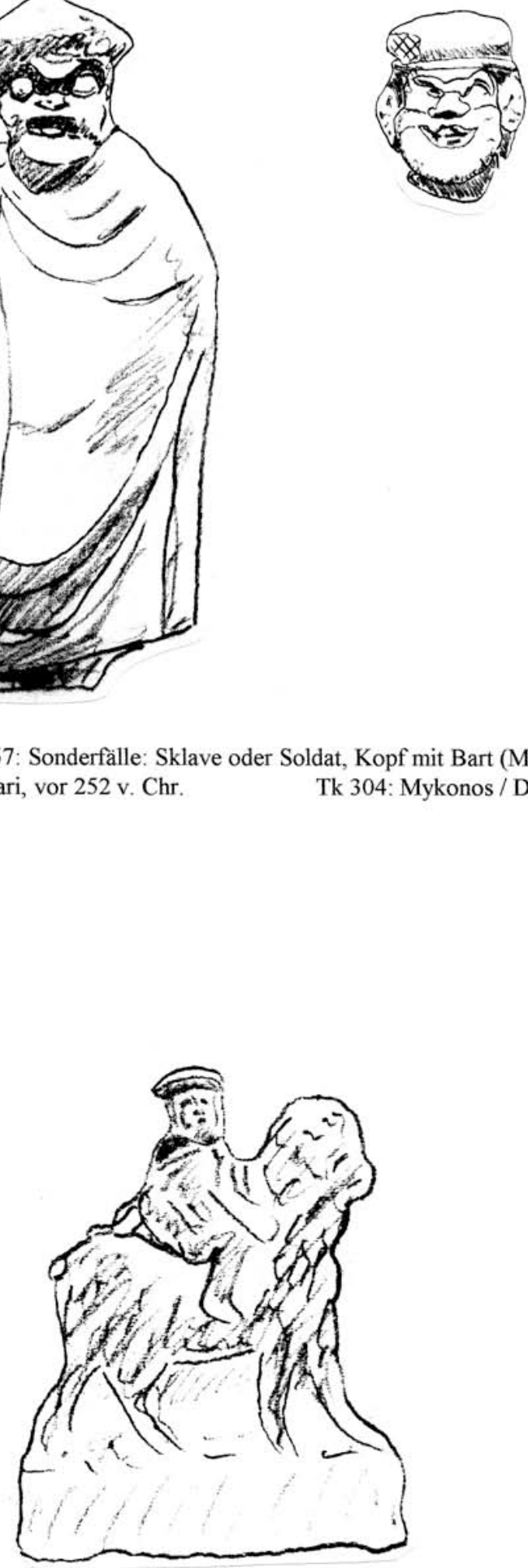

Abb. 158: Sonderfall: Tk 186: Ziegenreiter, Pella, M. 2. Jh. vor Chr. 


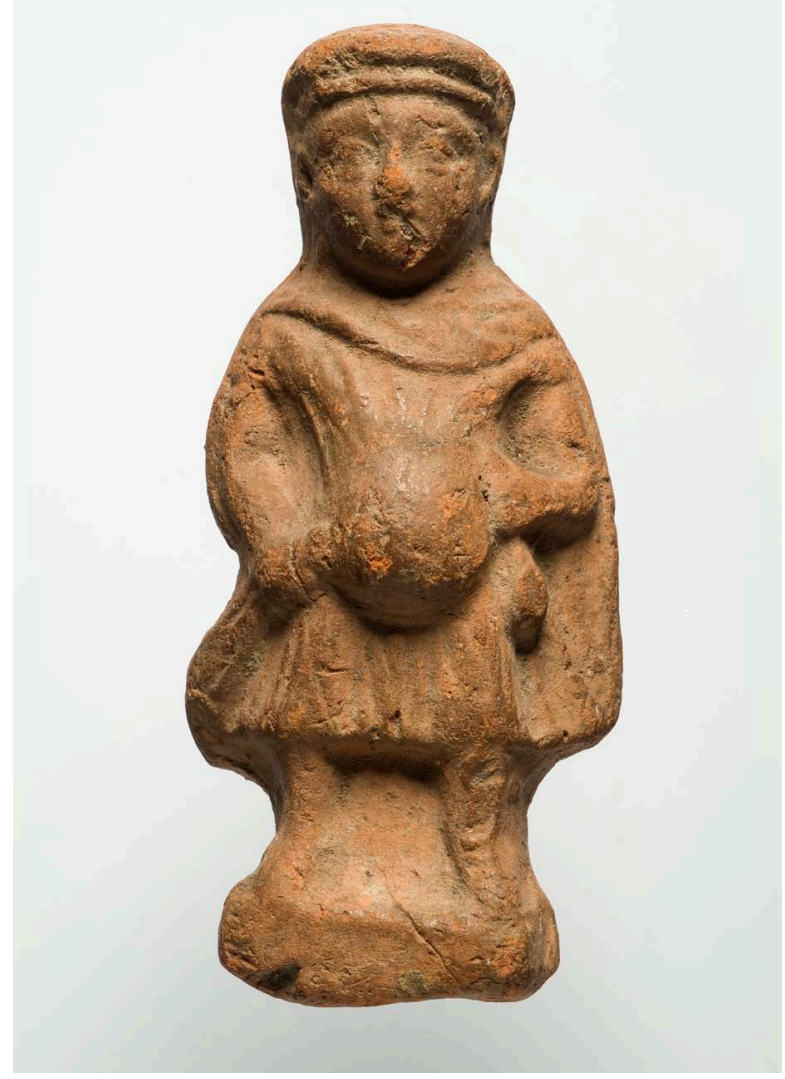

(a)

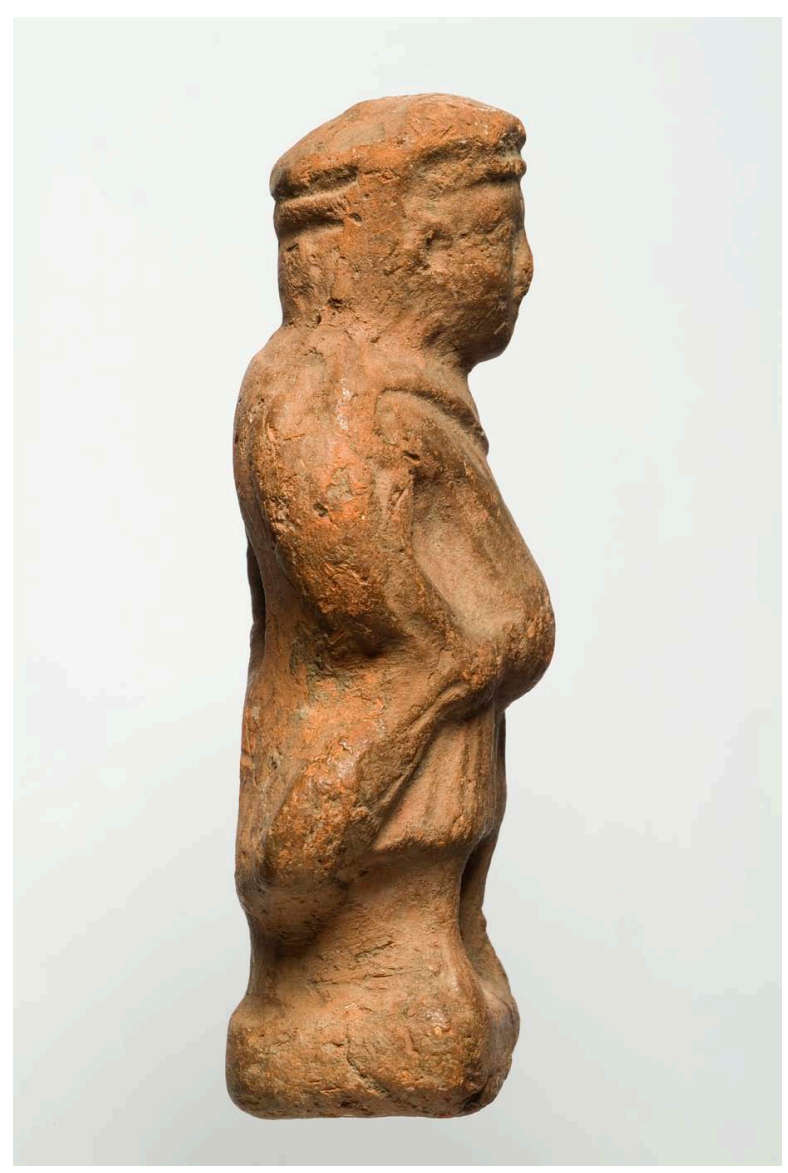

(c)

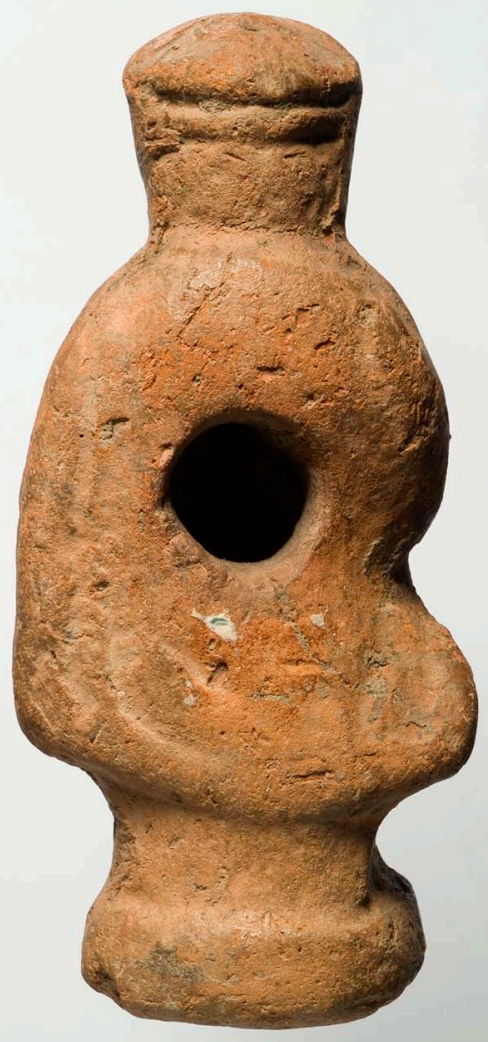

(b)

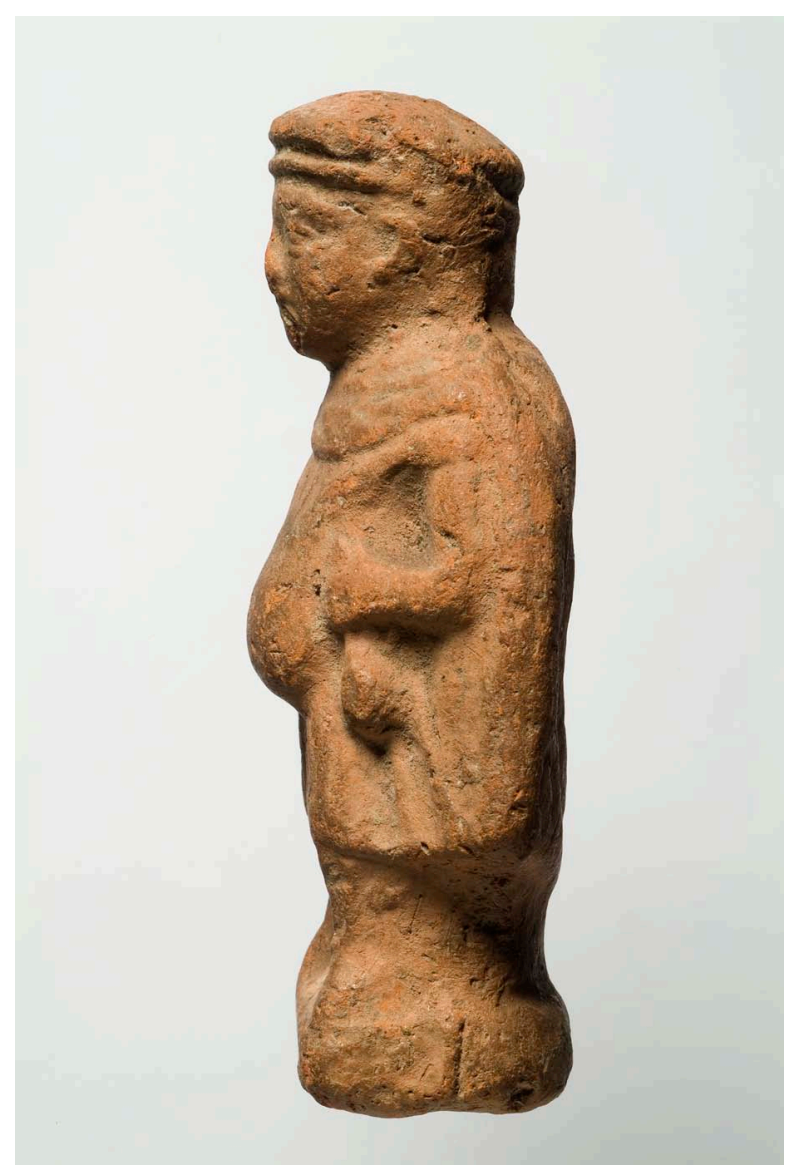

(d)

Tk 8: Soldat Göttingen (TK 46): (a) von vorne; (b) von hinten; (c) von rechts; (d) von links (Fotos: Stephan Eckardt, Göttingen). 